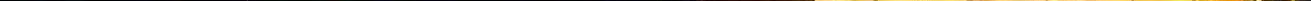


No. $23-d .1 \%$
GLASGOW

UNIVERSITY

L I B R A R Y.

WALKER-ARNOTT COLLECTION. 


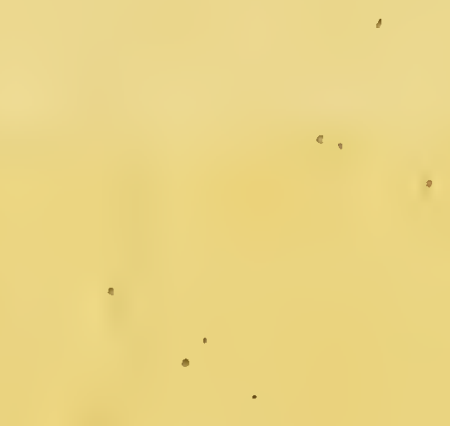





\section{BOTANIQUE MÉDICALE,}

O U

\section{HISTOIRE NATURELLE ET MÉDICALE}

DES REDICAMENS, DES POISONSTT DES ALIMENS,

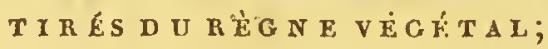

\section{par Achille Richard,}

Docteur en Médecine, Démonstrateur de Botanique à la Faculté de Médecine de Paris; Professeur suppléant à la Faculté des sciences; Membre de la Société Philomatique et de la Société d'Histoire Naturelle de Paris; Correspondant de la Société Linnéenne de Bordeaux, de la Société des Curieux de la Nature de Bonn, etc.
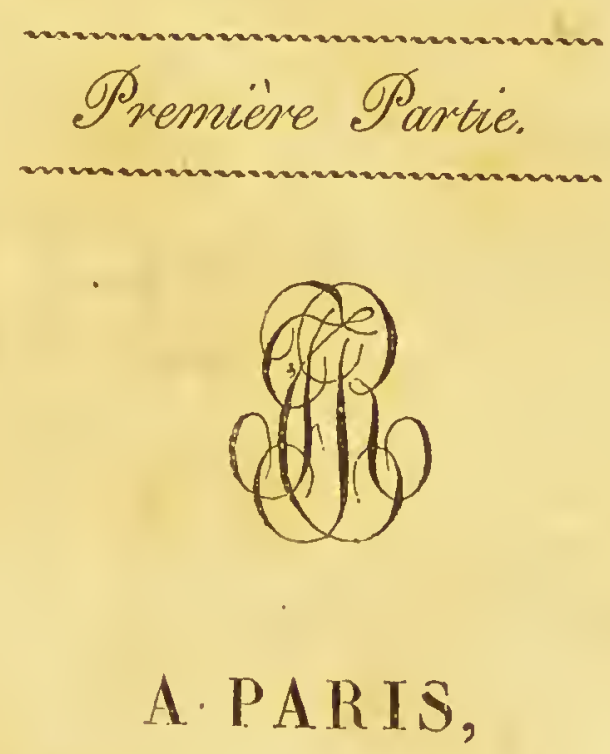

CHEZ BÉCHET JEUNE, LIBRAIRE,

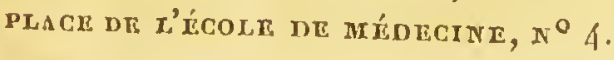

I 823 . 


\section{A MESSIEURS}

\section{DE JUSSIEU ET DESFONTAINES,}

GHEValieas de La LÉgion d'HoNTeur,

MEMBAES DE L'ACADÉMIE ROYALE DES SCIENCES DE L'INSTITUT, PROFESSEURS DE BOTANIQUE AU JAMDIN DU ROI, ETC.

Coomme une faiblo maryes te la reconnuis. sance do louteur.

bochille Roichard. 



\section{PRÉ F A CE.}

Le but que nous nous sommes proposé d'atteindre dạs cet ouvrage nous paraît suffisamment indiqué par le titre de вotanique mépicale que nous lui avonș donné. Faire comnaître les caractères de tous les végétaux, tant indigènes qu'exotiques, qui sont employés en Europe à titre de inédicamens, d'alimens ou.de poisons; énumérer les propriétés médicales, hygiéniques ou vénéneusẹs de ces différens agens, les circonstances où leur emploi est indiqué, les doses auxquelles on les administre, les préparations qu'on leur fait subir, tels sont les objets dont traite le livre que nous offrons aujourd'hui au public. Il forme la seconde partie du cours de Botanique médicale, que nous faisons. depuis cinq années auprès de la Faculté de Médecine de Paris.

Destinant spécialement cet ouvrage à ceux qui se livrent à l'étude ou à la pratique de l'art de guérir, nous avons cru devoir en élaguer les détails botaniques trop minutieıx, nécessaires dans les ouvrages destinés à faire connaitre dẹ faits nouveaux ou à éclairer quelque point de doctrine fondarnentale, mais superflus lorsqu'il s'agit seulement 
de tracer avec exactitude et fidélité la physionomie propre à un petit nombre de végétaux déjà connus. Nous nous sommes donc efforcés de mettre dans nos descriptions la plus grande simplicité. Mais cependant il nous a été impossible de ne pas employer une foule de mots substantifs et adjectifs, qui, ayant une acception propre et technique dans le langage botanique, pourraient arrêter ceux qui n'auraient point étudié préalablement les principes généraux de la science. Aussi la lecture de cet ouvrage ne pourra-t-elle être véritablement profitable qu'à ceux qui l'auront fait précéder de l'étude des élémens de la botanique générale, et de la physiologie végétale.

Dans l'exposition méthodique des objets dont nous traitons, nous avons adopté l'ordre des fa'milles naturelles, comme étant à la fois le plus satisfaisant pour l'esprit, et le plus propre à généraliser les idées. En effet, nous verrons que les végétaux qui se trouvent rapprochés et réunis par l'analogie de leurs formes extérieures et de leur structure interne, jouissent généralement de propriétés médicales analogues et quelquefois entièrement semblables. Cette classification offrira donc les plus grands avantages pour opérer la substitution de certains végétaux exotiques, ou de quelques autres qui, bien qu'indigènes, seraient difficiles à se procurer, C'est ainsi que toutes les Malvacées 
étant émollientes, toutes les Crucifères âcres et stimulantes, toutes les Gentianées amères et toniques, toutes les Labiées aromatiques, toutes les Apocynées âcres, laiteuses et irritantes, le médecin pourra sans nul inconvénient employer indistinctement chacune des plantes qui entrent dans ces familles; mais il remarquera aussi que certains groupes, quoique souvent composés de végétaux dont l'organisation est analogue, offrent des diffé. rences extrêmement tranchées dans les propriétés médicales dont ils sont doués. Il apprendra ainsi que dans ces familles, chaque végétal ayant sur l'économie animale un mode d'action différent à un autre, aucun d'eux ne pourra servir de succédané. Mais, il faut en convenir, le nombre des ordres naturels où l'on observe ces anomalies est incomparablement plus petit que celui où existe la loi de' l'analogie entre les caractères botaniques et les propriétés médicales. Les végétaux seront donc, dans cet ouvrage, disposés par groupes ou familles naturelles, et ces familles seront arrangées en classes d'après une méthode artificielle, dont les caractères seront spécialement tirés de l'adhérence ou de la non adhérence de l'ovaire avec le tube du calice. Dans l'introduction de cet ouvrage, nous ferons connaitre avec plus de détails cette classification, déjà employée par quelques auteurs. 
Exposons maintenant la marche que nous avons suivie dans l'exécution de notre plan. Après avoir trạcé d'une manière générale les caractères botaniques propres à une famille naturelle de plantes, et avoir indiqué en quoi elle se rapproche et en quoi elle se distingue de celles qui l'avoisinent, nous donnons successivement les caractères génériques et la description de toutes les plantes de cette fạmille qui nous intéressent, comme médicament, comme poison, ou enfin comme aliment. Aux noms français et latin de chaque espèce nous ajoutons en général : $I^{\circ}$ la citation d'une figure, choisie autant que possible dans l'ouvrage de Bulliard ou celui de Blackwell; $2^{\circ}$ la partie de la plante qui est employée; $3^{\circ}$ le nom latin pharmaceutique; $4^{\circ}$ enfin; nous citons ses noms vulgaires les plus répandus.

Quant à la description des espèces, nous avons, autant que possible, cherché à la faire très-complète, sans cependant répéter le caractère général que nous avons tracé en décrivant le genre.Lorsque nous décrivons plusieurs espèces d'un même genre, nous donnons en général plus d'extension à la description de la première de ces espèces; et dans celle des suivantes, nous faisons seulement ressortir les différences qui les distingueut de la première déjà décrite. Par ce moyen nous avons évité de grossir inutilement le volume de cet ouvrage. 
Chaque description est terminée par l'indication du pays, des localités dans lesquels croît chaque végétal, et de l'époque où on voit ses fleurs s'épanouir et ses fruits parvenir à leur parfaite maturité.

La description des caractères de familles, des genres et des espèces, constitue la partie botanique de l'ouvrage. Nous y avons mis un soin tout particulier. Toutes nos descriptions ont été faites d'après nature et non copiées dans d'autres livres, ainsi qu'on l'a fait trop souvent pour les ouvrages de ce genre. Toutes les espèces qui croissent en France, ont été décrites sur des individus frais et vivans. La description des plantes exotiques a été tracée soit d'après des individus cultivés dans les jardins, soit d'après des échantillons secs, que nous possédons pour la plus grande partie dans notre propre herbier. Quant au caractère des genres et des familles, nous avons tâché d'y mettre toute l'exactitude et la précision possibles; et les personnes qui les compareront avec ceux qui ont été donnés par les autres botanistes, s'apercevront facilement des changemens que nous $y$ avous faits pour les rendre plus exacts et plus précis.

La description de chaque plante est suivie d'un article où nous la considérons sous le rapport médical. Nons commençons par décrire la partie de cette plante qui est employée en médecine telle qu'elle nous est livrée par le commerce. Ainsi, 
après avoir décrit le cannellier, nous faisons connaître les différentes sortes de cannelle, leurs caractères distinctifs et leur analyse chimique. Nous suivons la même marche pour tous les autres médicamens, en sorte que leur histoire naturelle se trouve également traitée dans cet ouvrage. Les propriétés médicales de chaque plante sont exposées dans l'ordre suivant. Nous indiquons : $I^{\circ}$ l'action immédiate que chaque substance exerce sur l'économic animale; $2^{\circ}$ les changemens que cette action détermine dans les différens organes et les fonctions qui en dépendent; $3^{\circ}$ les circonstances où l'emploi de ce médicament a été conseillé. Nous terminons en faisant connaître les préparations qu'on lui a fait subir pour faciliter son administration et les doses auxquelles on les prescrit.

Cette partie, la plus importante de l'ouvrage, est aussi celle qui nous a présenté les plus grandes difficultés. L'anatomie pathologique, en nous faisant mieux connaître les causes et la nature d'un grand nombre de maladies, a fait voir combien étaient vaines 'et ridicules les propriétés médicales attribuées à un grand nombre de végétaux. Lorsque l'on parcourt la plupart des ouvrages qui traitent des vertus des plantes, on est frappé, en voyant. les merveilleuses propriétés attribuces à plusieurs d'entre elles dans le traitement des maladies les 
plus rebelles, qu'un si grand inombre d'altérations graves résistent aux méthodes curatives les mieux combinées. Que de plantes inertes auxquelles on attribue des propriétés extraordinaires! Peut-on ne pas sourire lorsque l'on voit certains auteurs vanter, avec une sorte d'enthousiasme, l'efficacité des fleurs de bleuet dans le traitement des fièvres intermittentes, et les sommités de galiet comme une sorte de spécifique contre l'épilepsie? Si nous n'avons pas toujours pu bannir de cette partie de notre ouvrage les propriétés qui nous paraissaient peu d'accord avec la nature des altérations organiques contre lesquelles on les employait, nous avons cependant diminué de beaucoup la liste des maladies que chaque médicament devait vaincre; et ceux qui compareront cette partie de notre livre avec celle des autres ouvrages analogues, s'apercevront des efforts que nous avons faits pour la mettre plus en harmonie avec les progrès des autres sciences médicales. Peut-être, dans un ouvrage de ce genre, devrait-on se borner à indiquer l'action immédiate des médicamens et les effets secondaires qu’ils déterminent, sans parler de leurs propriétés curatives, qui sont aussi variables que les causes nombreuses qui peuvent occasioner les maladies.

Nous ne saurions terminer cette Préface sans témoigner ici combien nous a été utile l'excellent ouvrage de M. De Candolle sur les propriétés mé- 
xiv PRÉEACE.

dicales des plantes. Il nous a été fort souvent impossible de ne pas suivre cet auteur ingénieux dans les détails qu'il donne sur certaines familles exotiques; nous ne pouvions au reste puiser à une meilleure source. 


\section{INTRODUCTION.}

La Botanique, considérée dans son ensemble, est una science immense, puisqu'elle embrasse non-sculcment la connaissance des caractères de tous les végétaux qui couvrent la surface de la terre, mais encore celle de leur structure, deleurs fonctions, et cnfin deleurs usages dans les arts et l'ćconomie domestique. Près dc quarante mille végétaux ont déjà été découvcrts par les voyageurs infatigables qui ont pénétré dans prcsque toutcs les contrées du globe. Si toutes ces plantes intéressent également le naturaliste, comme servant à ćtablir les différens degrés de l'échelle dcs êtrcs organisés, leur importance relative est loin d'êtrc la même, surtout lorsqu'on les considère sous le point de vue de leur utilité particulière. Les dimensions du volume, l'élégance des parties ne sont point toujours un indice certain de l'intérêt que doit nous inspirer un végétal. La pomme de terrc, le blé, le seigle, ct en général toutes lcs Céréales sont des plantes hcrbacées, qui s'élèvent à peinc de quelques picds au-dessus de la surface du sol; leur's formes ni leur port n'ont ricn de remarquable, surtout si on les comparc à ceux du marronier d'Inde, du platane et de quelques autres arbres qui font l'ornement dc nos parcs et de nos jardins. Mais comparez ces différcns végétaux par rapport à leur utilité et aux avantagcs que l'hommc peut retircr de leur culture, et vous verrcz si l'élćgancc des formcs, si la beautć du feuillage, la grandeur et l'éclat des fleurs sont toujours l'apanage des vé-
gétaux utiles. 
Parmi ce grand nombre de végétaux déjà connus, les uns méritent de fixer notre attention à cause des produits qu'lls fournissent aux arts industriels, les autres parce qu'ils peuvent être naturalisés avec avantage dans nos forêts; ceux-ci nous intéressent par la beauté, l'élégance et la suavité de leurs fleurs, ceux-là enfin parce qu'ils peuvent être employés pour nourrir l'homme ou le soulager dans les maladies auxquelles il est souvent en proie. Ce sont de ces derniers seulement dont nous nous oceuperons dans cet ouvrage. Ce sont eux en effet qu'il est utile, indispensable mêmé que le médecin connaisse. Nous y joindrons l'histoire des plantes vénéneuses, qui intéressent doublement le médecin, soit par les aecidens graves et souvent mortels qu'elles peuvent oeeasioner, soit parce que, sagement administrés, la plupart des poisons végétaux deviennent entre les mains du praticien habile lés ressources les plus puissantes de la thérapeutique.

Nous ne reproduirons pas iei les motifs qui nous ont engagé à préférer la méthode des familles naturelles aux systèmes de Tournefort ou de Linnæus, dans l'exposition des earactères propres aux différens végétaux, dont nous allońs exposer les caractères et l'histoire. Ces motifs ont été suffisamment développés dans la préfaee de cet ouvrage. Mais tout en adoptant la classification du savant auteur du Genera plantarum, nous nous éloignerons de lui dans quelques points pour la eoordination des familles en elasses. Ne devant nous occuper dans cet ouvrage que des plantes employées eomme médicamens, comme alimens ou comme poisons, nous serons obligés de passer sous silenee un assez grand nombre de familles, qui ne nous offriraient aucun intérêt sous l'un de ces rap)ports. Ce molif a dû nous engager à modifier la classification des familles naturelles des plantes, telle qu'elle a été présentée par M. de Jussieu, et telle que nous l'avons 
exposée nous-même dans nos Élémens de Botanique et de Physiologie végétalc ${ }^{\mathrm{I}}$.

Une des plus grandes difficultés attachées à la clàssification de M. de Jussieu, est sans contredit l'insertion relative des étamines employée comme base des différentes classcs. Les caractèrcs que l'on en tire sont, nous sommes bien loin de le eontester, les plus solides et les plus invariables; mais l'extrêmc diffieulté que les commenȩans éprouvent pour déterıniner le mode et la nature de l'insertion, et la dissidenee d'opinion qui existe eneore, cntre un grand noinbrc de botanistes, pour fixer les limites des trois espèces d'insertion généralement admiscs, nous ont engagé à chèreher dans d'autres considérations les nouvelles bases de notre classification. Or, après l'insertion relative des étamịnes, nous ne connaissons point de caraetères plus fixè, plus généraux, que ceux que l'on peut tirer de la considération de l'ovaire lorsqu'il est infèrc, c'est-à-dire soudć par tous lcs points de sa surface externe avee la base du caliec, ou quarid il est supère, ou libre au fond dela fleur. Disposées d'après ee earactère, les familles conscrvent également leurs rapports et leurs affinités mutuclles.

Cependant nous sommes loin d'ignorer que ce principe, quoique général, soit sujet à quclques aberrations qui semblent au premier eoup d'œil en détruire l'aniformité, et que plusieurs familles extrêmement naturelles réunisscnt des genres à ovaire infèrc et,à ovaire libre. Mais nous ferons remarquer aussi que les observations plus précises de quelques botanistes modernes et lès cliangcmens qu'elles ont néeessairement anenés dans la classifieation, ont considérablement diminuéle nombre de ces exceptions. C'est ainsi, pour n'en citer qu'un exemple, que la fanille des Narcisses, telle qu'clle

* Seeonde édition. Chez Béchet jeune, librairc. 
avait été limitée par M. de Jussieu dans son Genera plan. tarum, comprenait des genres à ovaire infère et d'autres à ovaire supère; mais ces 'genres ont été distribués en deux ordres différens par l'illustre Robert Brown; qui en a formé la famille des Hémérocallidées, contenant les genres dont l'ovaire est libre, et la famille des Amaryllidées, où se trouvent réunis les.genres dont l'ovaire est adhérent avec le calice. Nous pourrions faire les mêmes observations sur les familles des Amentacées, des Bruyères et quelques autres, dont les genres, mieux étudiés et mieux connus dans leur organisation intérieure, sont devenus les types de plusieurs familles nouvelles.

L'ovaịre libre ou soudé avec la base du calice, nous servira donc à former nos classes dans chacune des grandes divisions précédemment établies par M. de Jussieu, et nous arriverons au tableau suivant, dont nous allons donner une explication détaillée dans cette introduction.

I. ACOTYLÉDONS.

ACOTYLÉdonir. Tre classe.

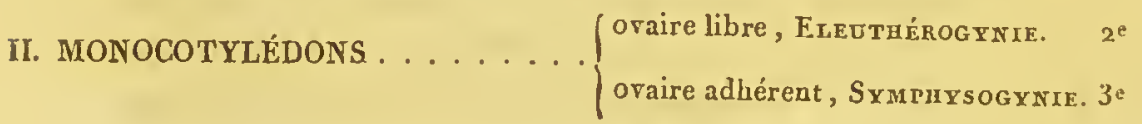

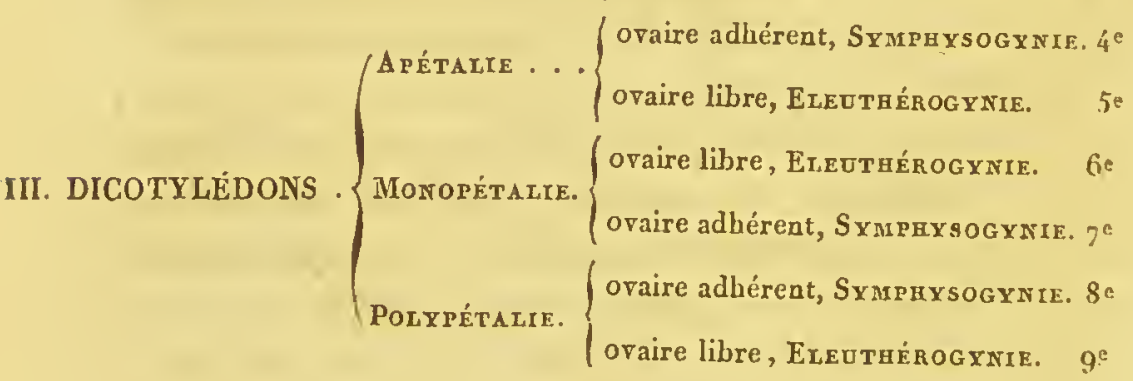

On voit, d'après le tableau quii précède, qu'à l'exemple de M. de Jussieu, nous divisons le règne végétal en trois embranchemens principaux, d'après la structure de l'enbryon; savoir: les Acotylídons, qui sont dépourvus d'embryon; les Monocotruídons, qui offrent un embryon à un seul cotylédon, et enfin les Digotýḱdons, qui cọ̣- 
prennent tous les végétaux, dont la graine développe deux feuilles séminales à l'époque de la germination. La structure de l'embryon n'est pas le seul caractère qui distingue ces trois divisions primordiales du règne végétal : il s'y réunit plusieurs autres signes qui facilitent la distinction des végétaux qui appartiennent à chacune d'elles; et comme il est essentiel de bien connaître dabord ces trois groupes primitifs, nous allons en exposer les caractères avec quelques détails.

\section{DES PLANTES AGOTYLÉDONÉES.}

Cette première division du règne végétal comprend toutes les plantes dépourvues d'organes sexuels apparens, de fleurs et par conséquent de graines et d'embryons. Linnæus les a désignées sous le nom de Cryptogames, par opposition au nom de Phanérogames ou Phénogames, donné aux végétaux dont les sexes sont apparens et visibles à l'extérieur. MI. de Jussieu, fondant leur caractère distinctif sur leur privation de cotylédons et d'embryon, les a nommées Acotylédons; mon père les appelait Arhizes, par opposition aux noms d'Endorhizes et d'Exorhizes, qu'il domnait aux plantes phanérogames; enfin M. de Candolle, considérant qu'un grand nombre d'entre ces plantes sont dépourvues de vaisseaux et entièrement formées de tissu cellulaire, leur à imposé la dénomination de végétaux cellulaires.

Ce groupe, où l'on voit l'organisation s'élever graduellement de l'état le plus simple à une complication progressivement croissante, renferme plusieurs familles distinctes, par la forme, la disposition et la structure des différens organes qui les composent.

Aucune des plantes qui appartiennent aux familles rangées dans cette première division n'offie d'organes semblables aux étamines ni aux pistils des végétaux em- 
bryonés ou phanérogames. Plusicurs dc ces familles ont été placées, par des auteurs fort célèbrcs, parmi les plantes pourvues d'embryon; mais nous ne saurions partager eette opinion, quoiquc présentée par des botanistes dont la réputation est bien capable de l'étayer. Il est impossible de voir, dans les organes de la reproduetion de ces plantes, rien d'analogue, ni pour la structure, ni pour les usages, avec ccux des plantes phanérogames; et le corps que l'on rcgarde ehez elles commc l'cmbryon, cn est, selon nous, tout-à-fait différent. Le caractère d'un embryon dans les êtres organisés, et particulièrcment dans les végćtaux, est d'offrir en raccourci toutes les parties dont l'être doit ètre composé lors de son entier dćveloppement. Ainsi dans les animaux le fotus, qui est l'analogue de l'embryon végétal, offre une tête, un tronc, des membrcs, en un mot toutes lcs parties dont l'animal adulte se composcra; de même l'embryon d'un liaricot, d'une courge, offre, à l'état rudimeniaire, une racine (radicule), une tige (tigelle), des feuillcs (gemmule et corps cotylédonaire). Par l'aetc de la germination (analoguc dans scs effets au commencement de la vie extra-utérine du foetus ) toutcs ees parties, d'abord préexistantes, se développent, acquièrent plus dc force, plus d'extension, se modifient suivant la vie nouvclle qu'clles vont parcourir. Mais la germination nc crée ancunc de ccs parties, qui existaient avant l'influenee qu'elle excree sur elles.

Voyons maintcnant ee qui a lieu lors du développement d'un de ces prétendus embryons d'une fougèrc ou d'une presle. Si on l'cxamine dans l'état de repos, on n'y trouve aucune trace des parties qui doivent sc montrer plus 'tard; rien qui annonce lcs rudimens d'une raeine, d'unc tige, etc. : e'est une masse homogènc de tissu cellnlairc. Détachć de l'ètre sur lequel il s'esti développé, ce corps 
va en reproduire un tout-à-fait semblable. Le point par lequel il touche à la terre s'allongcrä, s'y enfoncera, et deviendra la racine; le point diamétrálement opposé formera la tige, et bientôt un nouvel être se montrera. Mais parcc quc ce corpss sc sera transformé en un végétal semblable en tout à celui dont il s'est détaché, doiton le considérer comme un embryon? Non sans doute; car, $I^{\alpha}$ il n'y a pas d'embryon, de foetus sans fécondation: or dans ces plantes point d'organes fécondans, point d'organes fécondés; $2^{\circ}$ le foetus ou embryon est un être órganisé, offrant à l'état rudimentaire les organes dont l'être adulte se composera : ici rien d'analogue.

Dans les végétaux pourvus d'embryon, d'autres corps accomplissent les mêmes fins, sans être de la même nature. Ainsiles bourgeons forment en quelque sorte chaque année autant d'êtres nouveaux. Les bulbilles qui se dévcloppent sur ccrtains Monocotylédons, détachés de la plante-mère, forment dè nouvcllcs plantes parfaitement semblables. Or s'cst-il trouvé des botanistes qui aient donné à ces corps le nom d'embryons, et qui les aient regardés comme parfaitement semblables à ceux qui sont produits par l'actc de la fécondation? Coupez par morceaux un polype, une astérie, et chacune de ses pièces va devenir un nouvel animal. Dans quelqucs genres même il se détache naturcllement du corps de ces animaux, à certaines époques, des portions d'euxmêmes, qui se développcnt, et reproduiscnt de nouvcaux êtrcs. Aucun zoologistc, quc je sache, n'a donné le nom de foctus, à ces corps, à ces portions d'individus.

Il résultc des faits cxposés précédcmment, que, dans les plantes incmbryonées, il n'y a point d'organcs scxuels, point de graines ni d'embryon; quc ces plantes se rcproduisent au moyen de petits corps particuliers nommés sporules ou gongyles, analogues aux gemmes, aux bulbilles de ccrtains végétanx embryonés, ou aux 
portions qui se détachent du corps de plusieurs animaux d'un ordre inférieur.

I.e but de cet ouvrage, dans lequel nous ne devons faire connaître que les êtres utiles à l'homme ou préjudiciables à son existence, ne nous a pas permis de donner des détails sur toutes les familles des plantes cryptogames, nous avons dû nous restreindre à celles qui renferment des médicamens, deśs alimens ou des poisons. Cette observation générale s'appliquue également à toutes les autres clásses du règne végétal. Nous nous contenterons d'indiquer, à la suite des familles dont nous traiterons ici, celles dont quelque individu a autrefois été employé par les médecins $\mathrm{r}$.

DES PLANTES COTYLÉDONÉES.

Toutes les plantes pourvues de fleurs visibles, d'organes sexuels ápparens, c'est-à-dire d'étamines et dè pistils, et se reproduisant au moyen de graines ou d'embryons, appartiennent à cette seconde division du règne végétal. Ce groupe de végétaux est incomparablement plus considérable en espèces que le précédent. Les plantes qu'il renferme présentent une organisation plus compliquée, un ensemble de parties plus complet. Outre le tissu cellulaire, qui compose exclusivement les premiers de ces végétanx, on trouve içi des vaisseaux dè différente nature, diversement groupés et disposés, servant principalement - au mouvement des fluides, à leur ascension, à leur répartition dans toutes les parties du végétal.

Lie caractère distinctif des végétaux phànérogames consiste danš leur reproduction pair embryons, c'est-à-

' Voyez, pour de plus grands détails sur l'organisation des plantes cryptogames, dans mes Élémens de Botanique, le chapitre qui traité de l'organisation des plantes agames. 
"dire au moyen de corps organisés, offrant en quelque sorte en miniature tous les organes qui doivent constituer le végétal adulte, ct les développant successivement par l'acte de la germination.

C'est du nombre des cotylédons ou lobes séminaux que présente l'embryon au moment de la germination; que $M^{r}$. A: L. de Jussieu a tiré les caractères des deux grandés sections qu'il a établics parmi les végétaux embryonés. En effet il les divise cn Monocotylédons, ou ceux qui n'ont qu'un seul cotylédon à l'embryon, et en Dicotylédons, ou ceux qui en offrent deux.

\section{S I. Plantes Monocotylédonées.}

Ëlles présentent les caractères suivans :

Embryon ayant le corps cotylédonaire simple et indivis; la gemmule renfermée le plus souvent dans l'intérieur du cotylédon unique; la radicule intérieurc, c'est-àdire enveloppée de toutes parts dans un prolongement de la substance de l'embryon, qui lui forme une sorte d'étui, 'qu'elle doit percer pour pouvoir se développer à l'extérieur, et se changer en racine. Tels sont les caractères essentiels, ceux qui sont tirés des organes fondamentaux. Mais ils sont accompagnés par d'autres signes beaucoup plus faciles à saisir, que l'on observc dans les organes extérieurs, et qui, au défaut des premiers, pourraient seuls servir à distinguer les végétaux de cette division. Ainsi dans les monocotylédons, les fibres sont toujours longitudinales; lcs nervures des feuilles sont simples, parallèles. Mais c'cst principalement la structure du tronc qui fait la distinction de ces deux groupes. Dans les monocotylédons il est presquc toujours simple, cylindrique, couronné par un bouquet de feuillcs terminales. Son intérieur, au lieu de présenter, comme dans les dicotybédons, des couches concentriques d'écorce, d'aubier, 
de bois et un étui, central pour la moelle, n'offre qu'une substance spongieuse, médullaire, dans laquelle sont disséminés des faisceaux irréguliers de fibres longitudinales, et point d'écorce distincte des autres parties.

Le port particulier des plantes de ces denx groupes fournit encore des caractères utiles pour établir leur distinction; mais l'habitudc seule peut donner une idée de ces caractères, et la langue n'a pas d'expressions propres à les faire connaître. Ainsi celui qui aura examiné soigneusement la forme générale des Graminées, des Joncs, des Liliacées, des Orchidées, etc., sentira sûrement le lien qui unit entre elles ces différentes familles, et saura reconnaître, dans les végétaux analogues, ces traits généraux de ressemblance qui existent dans toutes les plantes monocotylédonées.

Les familles qui appartiennent à cette première subdivision des végétaux embryonés sont plus nombreuses que celles des inembryonés, quoique moins considérables elles - mêmes que celles qui ont été établies parmi les dicotylédons. Voicìla manière dont nous avons classé celles de ces familles dont nous traitons dans cet ouvrage. Nous en formons deux groupes. Le premier comprend les familles de plantes monocotylédonées dont l'ovaire est libre. Il forme la seconde classe de notre système. Nous le subdivisons en deux sections, suivant que lc calice manque ou est remplacé par des écailles, suivant qu'il existe et qu'il est coloré et pétaloïde. Le second groupe, qui constitue notre troisième classe, se compose des familles, moins nombreuses que celles de la classc prćcédente, qui offrent un ovaire infère et adhćrent avec la base du calice.

\section{§II. Plantes Dicotylédonées.}

I, caractèrc essentiel des végétaux de cette seconde 
division consiste, comme celui de la première, dans la structure de leur embryon. En effet, à l'époque de la germination, la radicule, qui est nue et extérieure, s'allonge, et devient la racine; le corps cotylédonaire est formé de deux lobes séminaux opposés, entre lesquels est située la gemmule.

Les autres signes tirés des organes de la végétation, ne distinguent pas moins les Dicotylédons des Monocotylédons, que ceux fournis par l'organisation de l'embryon. Si vous coupez transversalement le tronc d'un arbre dicotylédon, par exemple, d'un peuplier, d'un chêne, vous verrez son centre occupé par un canal rempli de moelle (canal médullaire); entre ce canal et l'écorce, des couches concentriques de bois emboîtées les unes dans les autres, et dont les plus intérieures plus foncées, d'une texture plus ferme et plus compacte, constituent le bois proprement dit, tandis que les plus extérieures, d'un tissu moins dense, moins serré, d'une couleur plus pâle, forment l'aubier ou faux bois ; enfin, tout-à-fait en dehors, se trouve une écorce bien conformée. Si l'on rapproche cette structure intérieure de celle des végétaux monocotylédonés, il sera faoile de saisir les différences qui établissent le caractère distinctif de ces deux groupes de végétaux pourvus d'embryon.

Comme les Dicotylédons comprennent un nombre beaucoup plus considérable de végétaux que les deux divisions précédentes, il était indispensable, afin d'en faciliter la classification et la recherche, d'y multiplier le nombre des sections et des classes. C'est dans les enveloppes florales que M. de Jussieu a cherché les bases des divisions primaires à établir dans les dicotylédonés. Ainsi, tantôt le périanthe est nul ou simple, c'est - à - dire qu’il n'existe qu'une seule enveloppe florale autour des organes sexuels, ou que ces organes sont tout-ì-fait nus. Tantôt: au contraire, le périanthe est double, et l'on trouve en 
dehors du pistil et des étamines deux enveloppes propres INTRODUCTION.

à les protéger. On appelle Apítalés ou sans pétales, les végétaux qui, n'ayant point d'enveloppe florale, ou n'en offrant qu'une seule, sont dépourvus de corolle, et $\mathrm{P}_{\mathrm{E}}$ TALÉS, ceux qui ont à la fois une corolle et un calice. On a ensuite partagé les végétaux pétalés en deux autres sections, suivant que la corolle est monopétale ou polypétale. Par ce moyen, on est arrivé à trois sections primaires dans les dicotylédonés, savoir:

io Dicotylédonés Apétalie;

$2^{\circ}$

$3^{\circ}$

Monopétalie;

Chacune de ces sections a ensuite été divisée en classes, suivant que l'ovaire est libre, c'est-à-dire sans adhérence avec le calice, et suivant au contraire qu'il est infère ou soudé avec 'cet organe.

En subdivisant ainsi chacune de ces trois sections en deux groupes, on obtient six classes parmi les plantes dicotylédonées, qui, réunies aux tròis déjạ̀ établies pour les acotylédonés et les monocotylédonés, constituent neufclasses principales dans lesquelles nons répartissons les différens végétaux dont nous devons traiter dans cet ouvrage. Le nombre des classes pourrait d'abord paraître peu considérable, lorsque l'on réfléchit que plus on multiplie les divisions dans un système quelconque, plus on facilite la recherche des différens objets qui y sont classés. Mais comme chacune d'elles a ensuite été divisée en plusieurs groupcs ou paragraphes, lorsque le nombre des famillcs qu'elle renferme l'a permis, nous croyons que ce reproche ne nous sera point adressé. D'ailleurs nous ne sanrions trop répéter qu'en n'adoptant pas entièrement la classification de M. de Jussieu, notre intention n'a point été d'en créer une nonvclle qui fût applicable à tont le rçgne végétal, mais senlement de modifier la premic̀re, de manière à la rendre plus 
commode et plus facile pour l'arrangement des végétaux qui font l'objet de ce livre.

Nous avons cru nécessaire de donner un nom substantif à chacune des neuf classes que nous avons établies. Ce travail, quoique fort simple en apparence, nous a cependant offert de très - grandes difficultés. En effet les caractères des classes n'étant tirés que de deux considérations, l'ovaire libre et l'ovaire adhérent, il nous a été impossible de trouver pour chacune d'elles un nom propre qui lui fût particulier. Cependant nous avons cherché à remédier autant que possible à cet inconvénient, en employant deux noms, dont le second, tịré de l'ovaire libre ou adhérent, devra toujours être considéré plus spécialement conme celui de la classé.

Ainsi la première classe qui comprend toutes les familles de plantes acotylédonées porte le nom d'Acotylédonie. La seconde classe, qui renferme les familles monocotylédonées, dont l'ovaire est libre, s'appellera Mono-Eleuthérogynie. Nous appellerons Mono-Symphysogrnie la troisième classe dans laquelle nous rangeons les familles Monocotylédonées, dont l'ovaire est adhérent.

Quant aux six classes formées parmi les Dicotylédons, le premier des deux noms de chaque classe sera tiré $d u$ périanthe, et le second de l'ovaire; et nous dirons pour la quatrième classe où nous plaçons toutes les plantes dicotylédonées apétales, dont l'ovaire est adhérent, Apétalie symphysogrnie; Apétalie èlenthérogynie, pour la cinquiènı classe; Monopétalie éleuthérogynie, pour la sixième; Monopétalic symphysogynie, pour la septième; Polypétalie symphysogynic, pour la huitième; et enfin Polypétalie éleuthérogynie, pour la
neuvième et dennière classe.

Nous ne présentons ces noms qu'avec une sorte de doute, et seulement comme un essai, Quels qu'ils soient, 
nous les croyons utiles, comme évitant l'emploi d'une périphrase indispensable pour exprimer le caractère de chaque classe. Mais ceux qui réfléchiront aux difficultés que nous avions à vaincre, nous sauront peut-être quelque gré des efforts que nous avons faits pour les surmonter. 


\section{BOTANIQUE MÉDICALE.}

\section{PLANTES ACOTYLÉDONEES.}

PREMIERE GLASSE.

\section{A CO'TYLÉDONIE.}

PREMIERE FAMILLE.

\section{A L G U ES. $-A L G \not E$.}

LEs algues sont des plantes d'une organisation extrêmement simple, qui se présentent sous la forme de filamens déliés eomme des eheveux, de lames minces, entières ou lobées, dont la substanee paraît homogène dans tous ses points, ou simplement traversée par des filamens vaseulaires. Les fructifications, quand elles existent, sont renfermées soit dans l'intérieur même de la plante, soit dans des espèces de eonceptaeles partieuliers en forme de tubercules plus ou moins allongés.

Cette famille se compose de plantes qui vivent sur la surface de la terre humide, ou qui flottent sur l'eau douce ou salée, ce qui les a fait partager en deux sections, $I^{\circ}$ les Conferves ou eelles qui végètent dans les eaux douces; $2^{\circ}$ les Thalassiophytes, qui vivent à la surface des eaux salées.

C'est parmi les algues que l'on tronve les végétaux de l'organisation la moins compliquée, puisque quelques-unes consistent uniquement en des filamens capil- 
laires; et c'est également dans cette famille que l'on observe les points de contact les plus marqués entre les végétaux et les animaux. En effet, les oscillatoires et les conjuguées appartiennent, suivant quelques-uns, aux végétaux, suivant d'autres au contraire elles doivent être considérées comme des animaux. Un fait non moins digne de remarque, c'est que l'on voit quelquefois, comme semblent le démontrer les observations du professeur Agardh, de petits animaux infusoires se transformer en algues, tandis que d'un autre côté des algues se sont converties en animaux.

Une autre considération cependant ferait rapprocher davantage les champignons des animaux. D'après les analyses chimiques des algues, elles ne renferment point de matières animalisées, tandis qu'il y en a au moins trois bien caractérisées qui constituent les champigons.

Parmi toutes les plantes de cette famille, une seule est employée en médecine, c'est la mousse de Corse ou helminthocorton, dont voici la description :

VAREG velMifuge. Fucus helminthocorlos, D. C. fl. fr.

Nom pharmaceutique : Helminthocorton; noms vulgaires: mousse de Corse ou helminthocorton. Partie usitće: toute la plante.

Ce varec forme des touffes extrêmement serrées, dont les ramifieations sont entrelacćes les unes dans les autres, et se tiennent accrochées an moycn de petits crampons, dont les tiges sont armées; ccs tiges sont grèles et cylindriques, terminćes par quelques petits rameaux redressćs et crochus : les fruetifieations sont des tubereulcs situćs sur les côtés des rameaux et sessiles. La consistance de cette plante est eartilagineuse : sa couleur est variable; il est tantôt jaunâtre, tantôt d'un rouge plus ou moins intense. Ce varec eroit sur les côtes de la Méditerrance et de l'île de Corse. 
Propriétés et usages. Les recherches de M. de Candolle, ont prouvé que la inousse de Corse du eommeree n'est point un inédieament homogène, formé par une seule plante, mais qu'au contraire c'est un mélange de différentes espèees de varecs, de céramions et de corallines. Cependant, comme le varee vermifuge y prédomine, on rapporte en général la mousse de Corse à cette plante.

La mousse de Corse a une odeur saunâtre et désagl'éable, analogue : à eelle des éponges fraîches : a propriété vermifuge est en grande réputation, et c'est un des inédicamens que l'on cmploie le plus fréquemment pour corxbattre les vers, surtout chez les enfans : on l'administre en décoction, en poudle, ete. Sa dose est d'un à 'six gros.

P'lusieurs autenrs ont recommandé les cendres de virec, et entre autres celles du varec vésiculeux, contre le léveloppement du corps thyroïde, désignć sous le nom ie goïtre. M. le docteur Coindet, de Genève, s'est assuré, pardes ex̌périences multipliées, que cette singulière proprití de ees cendres pour dissoudre le goître, était due à l’ocle qu'elles contiennent, commc on sait, à l'ćlat d'hydriodat de potasse. II a ensuite employé l'iode sous différentes formo, è paraît en avoir reliré du suceès dans le traitement du gî̂tre. Cependant deś accidens graves ont.quelquefois a ecomjagné l'emploi de ce nouveau médieament. C'ćtait d'abord ei dissolution dans l'aleohol qu'il l'administrait; mais il paraît que, d'après les reeherches jharmaceutiques de IMM. Dumas et Le Royer, il a abandonné ce mode de préparation, tan à eause dàc la transformation rapide de l'iode en aeide lidriodique, que par la trop dangereusc action de eette sibstnce sur le eanal digestif. C'est pourquoi on emploie maintenart les hydriodales avec plus de succès. Ou administre l'iod, dins plusienr's autres maladies, telle's que les affeetions scrophleuses, la leucorrhée, ctc. Mais l'expériencc n’a point encle entièsement confirmé les succès annonećs par quelques ateurs.

Les algues ne renferment aueune plan' vćnćneuse; elles sont toutes formécs en grande partic deinucilage, d'albu- 
mine ct de matière colorante; aussi plusieurs espèces, surtout parmi les ulves, sont-elles employées comme alinens dans quelques contrées maritimes. Mr. Gaultier de Claubry, qui a donnć l'analise de six espèces de fucus (F. sarcharinus, f. digitatus, f. vesiculosus, f. serratus, f. siliquosus et f. flum.), y a observé en outre, ainsi que M. Vauquelin, de la mannite et un grand nombre de sels, parmi lesquels prédomine l'hydriodate de potasse, dont nous venons de signaler l'énergique propriété. (Ann. de chimie, t. $9^{3}$, p. $7^{5}$.)

DEUXI主ME TAMILLT.

\section{CHAMPIGNONS . $-F U N G I$.}

Li forme, la consistance, la couleur des champignous, sont ixtrêmement variables. Tantôt ce sont de simples tuberc $l$ les à peine perćeptibles; tantôt des frlamens déliés; d'utres fois ils ont la forme de branches de corail, de paraols bombés ou concaves en dessus et recouverts en dessois de lames perpendiculaires rayonnantes, de tubes, de pores, de stries, etc. Celte partie supérieure porte le non de chapeau, et le pied qui la soutient celui de stipe ou jédicule. Quelquefois le champignon tout entier est carhé avant son développement dans une espèce de bourie, qui se rompt irrégulièrement, et'qu'on appelle volva. Issez fréquemment la face inférieure du chapeau est recuverte d'une membrane qui s'attache à sa circonférerce, et qui, loorsqu'elle vient à se rompré, forme autour lu stipe une sorte de collier on d'anneau. découpé.

- Il existe 'm tris-grand nombre d'ouvrages sur les champignons; Tes plus utilesì consulter sont les suivans: Paulet, Traité des champignons, a vo. in $4^{\circ}$; Paris, 1793. Bulliard, Histoire des champiguous de la Frace, 4 vol. in- $4^{0}$; Paris, fig. col. Persoon., Synopsis fungorum, in- $\delta$ " ${ }_{x}$ ottingue, $180 \mathrm{x}$. Id. Traité des champignons comestibles, in- $8^{\circ}$; fig. ol.; Paris, $18 \times 8$. Orfiln, Leçons de médccine légale, in-8n, fig. $0_{.}$; Paris, i 821 . 
Les sporules ou organes de la reproduetion dans les chiampignons sont plicés, soit à l'intérieur de leur substarice, soit à leur extérieur, étendus, sous forme de poussì̀re, sur ünè lame qui porté le' nom d'hymeniüm.

Les champignons croissent en généial dans les lieux un peu humides et ombragés; tantôt à terre, tantôt sur le tronc d'autres végétaux ou sur des matières animales. en état de'déeomposition. Presque jamais lcur substance n'est verte à l'intérieur, caractère qui les distingue spécialement des algues, dans lesquelles eette eouleur est presque générale.

Les champignons nous intéressent à plus d'un titre: $\mathrm{I}^{\circ}$ Un grand nombre d'entre eux sérvent d'aliment à l'homme $; 2^{\circ}$ plúsieurs sont des poisons subtils; $3^{\circ}$ quelques-uns sont émployés comme médieamens. Mais pour faire d'une manière complète l'hisstoire de cette famille, il faudrait entrer dans des détails que la nature et le but de cet ouvrage ne comportent point. Cependant nous allons faire connaitrè les caractères dès genres principaux et deș espèces qu'il est plùs important de distinguer, soit à cause de leurs qualités nuisibles, soit au contraire sous le rapport de leur utilité.

$$
\text { A GÁRIC. - A GARICUS. }
$$

Champignons charnus, à chapcàu garni à sa facc infërieure. de feuillets rayonnans, ordinairement simples; pédicule dépourvu de bourse ou volva.

Cc genre, excessivemént nombreux en espèces, a été partngé en plusicurs groupes.

I0 Pédicule central pourvu d'un collicr.

Agaric conestinít: Agaricus campestris L. Bull. Champ.

$$
\text { t.: } 134 \text {. }
$$

Nom vulgaire : champignon de couche.

C'est l'espèce dont on fait le plus souvent usage, au moins à Paris; c'est la sculc qu'il y soit permis de vendre dans 
Ies marchés. Il est d'abord arrondi; en forme de boulc : son pédicule est liaut d'un à dcux pouces, plein intérieurement: son chapeau est convexe, lisse, glabre, garni en dessous de feuillets, d'une couleur rosée, un peu tcrne, qui devienncnt noirâtres en vieillissant $:$ sa couleur génćrale est blanche un peu brunâtre. Il croît naturellement șur les pe- ' louses sèches et exposées au solcil. On lobtient ćgalement de culture au moycn de couehes de fumier, sur lesquelles on a projeté du blanc de champignion.

Son odeur ct sa saveur sont fort agréables. On en fait une grande consommation à Paris.

Il faut bien se garder de confondre cette "espèce avee l'amanite vénéneuse, qui lui ressemble beaucoup pour le port. ( . nyez plus loin sa deseription, pag. 26.)

L'agaric boule de neige (Bul. t. 514), n'ẹst qu'une variété de l'agaric comestible, et on le mange comme lui.

Agaric Élevé. Agaricus procerus. Pers. Syn. fung. 256. Ag. colubrinus. Bull. t. 78 et 583.

Noms vulgaires : couleurrée, coulemelle, cormelle, parasol, poturon, boutarot, vertet, etc.

Cettc espèce est la plus élevée du genre agaric : son stipe est haut de huit à douze pouces, il 'est bulbcux à sa base creux à soll centre, _ct recouveat d'écailles brunâtres. Le chapeau est de couleur 'bistre, chargć d'éciilles imbriquées; ses feuillets sont blancs et forment un bourrelet au sommet du pédieule : La largeur du chapeau cst de dix à donze pouces. Il croít en automne sur les pelonses découvertcs.

La chair de son chapeau est tendrc ct d'un goût agréable. On le mange dans beaucoup de provinces de la Francc. On doit rejeter lc pédicule qui est dur ct coriace.

Agaric añonaine. Agaricus anmularius. Bull., 1.540. Orf. med. leg. \%. $19, f$. 1.

Nom vulgaire : téte de Méduse. Pavist.

Ce champignon vicn! par groupes composés quelquefois. 
de quarante à cinquantc individus, et se développe, soit à terre, soit sur les vieilles souches. Sa couleur est fauve roussâtre. Son stipe est charnu, cylindrique, haut de trois à quatre pouces, ćcailleux dans sa partie supérieure, où se trouve un collet annulaire redressé et coneave. Le chapeau est convexc mamelonné à son centrc, un peu écailleux, large d'environ trois pouces: Les lames sont inégales, d'abord blanches, puis un peu brunàtres. On le trouve en automne dans les bois.

Cette espèce est très-vénćneuse.

$2^{\circ}$ Pédicule central, point de collier.

Agaric mousseron. Agaricus mousseron. Bull., t. I 42.

Sa couleur génćrale est d'un blanc sale, tirant quelquefois sur le gris. Son pédicule est épais, long d'un pouce à un pouce et demi, un peu enfoncé dans la terre. Son chapeau est trèsconvexe, presque globuleux, glabre, un peu onduleux sur les bords: les lames sont blanches, serrées, étroites. La substance du mousseron est blanche, charnue, cassante; son odeur est très-agréable. Celte espèce est du petit nombre de celles qui paraissent, dès le printemps, sur les pelouses sèches et la lisièrc des bols.

On en fait un grand usage comme aliment, ainsi que du mousseron blanc (ag. albellus DC.) que l'on connaît sous le nom de champignon muscat, à cause de son odeur musquée, qu'il couserve lorsqu'il est désséché. Cette dernière espèce paraît être la plus agréable, et la plus estimée.

Agaric oreiluette. Agaricus auricula. DG. fl. fr. 6 p. 48 .

Le pédicule de 'ce champign̈on' est court, plein, blanchâtre, cylindrique; son chapeau est rarement bien arrondi, d'un. gris plus ou moins foncé et, roulé sur ses bords; ses feuillets sont blancs, décurrens șur le pédicule.

Cc champignon a un bon goût, se dessèche aisément ct ne se pèle pas; il est commun cn automne sur les pclouses aux environs d'Orléans, ou on le mange avee confiance. DC. 
Agaric nit moux. Agaricus aquifolii. Pers. ch. com., p. 206.

Noms vulgaires: oreille de houx, grande girolle.

Il est d'un jaune clair. Son pédicule a quatre ou cinq pouces de hauteur; il est un peu aplati et très-épais. Le chapeau larśe de trois à quatre pouccs cst lisse et glabre; ses feuillets sort blanchâtres. Il eroît en automne sous les buissons de houx, (Ilex aquifolium), sa chair est fine et dćlicatc, sa saveur parfumée et agrćable; en un mot, e'est suivant MM. Paulet et Persoon un de nos meilleurs ehampignons.

Aganuc de L'ouivier. Agaricus olearius. DC. fl. fr. 6 ,

$$
\text { p. } 44 \text {. }
$$

Nom vulgaire : oreille de l'olivier.

La couleur de celte espèce, est rousse-dorée, très-vive; il naît souvent par touffes sur les racines de l'olivier et de quelques autres arbres: son pédicule est court, un peu courbé, ordinaircment attaché sur l'un des côtés du cliapeau, et fort rarẹment dans son eentre; ses lames sont déeurrentes, sa ehair cst dure el filandreuse.

Il est très-important de bien reeonnaîre ce champignon, qui cst fort vénéneux. Il croît dans les provinces méridionalcs de Ja France.

Agaric faux-mousserion. Agaricus pseudo-mousseron. Bull., t. 326 . Agaricus tortilis DC. f. fr.

Noms vulgaires : mousseron godaille ou de Dieppe, mousseron pied dur ou d'automne.

Sa couleur est d'un jaune pâlc tirant sur le roux. Son pédicule est trçş-grẻ̉lc, un peu fusiforme; son chapeau eonvexc, mamclonnć au ccntrc, large d'un pouce cldenni à dcux pouces. Sa chair est assez dure, mais savourcusc et d'une odeur agréable. Il croit à la fin de l'été daus les pâturages et les cndroits déeouverts des bois.

Il se eonserve bien, et est fort agréable lorsqu'il cst euit. 
Agaric buulavt. Agaricus urens. Bull. t. 528 , f. i. Ord. méd. lég. t. r 8 , f. r.

Ce champignon cst d'un jaunc sale; son pédicule cst long de cinq à six pouces, eylindrique, glabre, strié el un pen velu à sa base; son chapeau, d'abord convexe, sc creuse et finit par circ légèrement concave; il est large dc deux pouees, ses lames ou feuillcts sont inégaux, d'une eouleur Jrune. Cette espèce croît dans les bois humides et principalement sur les fenilles mortes.

Sa saveur est âere et brủlanie. Il est cssentiellement vénéneux.

$3^{\circ}$ Agarics à sucs laiteux. (Lactankes.)

Les espèees de cette seetion sont remarquables par le suc laiteux qu'elles renferment, et qui s'en écoule, lorsqu'on entame lenr substanee. Ce sue a une saveur âere, poivrée et irès-forte. Ces ehampignons sont en général plus ou moins suspects el désagrćables : eependant plúsieurs espèees alimentaires appartiennent à eette seetion.

Agiric décicieux. Agaricus deliciosus. L. Schoff. t. 2.

I) eroít en touffes, surtout dans les forêts de sapins du nord de l'Europc; son pédicule est long de deux à trois pouees, ćpais, charnu, jaune. Le ehapeau, d'abord jaune, devient fauve ou rougeâtre; il est légc̀rement eoneave et marqué assez souvent de zônes jaunâtres. Les̀ lames sont d'une couleur plus pâle que le elrapeau, et inégales. Le sue est d'un rouge de brique, plus ou moins intense. Le goût de ce ehampignon eșt âere et assez désagréable. La cuisson le fait disparaître en grande partic; cependant il ne nous paraît pas mériter l'épitlète de délicicux, quoi‘qu'il ne soit pas malfaisant.

On mange de même les variélés de l'agr. acris, figurées par linlliard. †. 538 ct t. 588 , çuoique leur sue soit éggalcment âcre: el poivré. 
Agaric meuntrier. Agaricus necator. Bull.t. 529, f. 2 , et t. I4. Orfi. méd. lég. t. I9, f. 3. A. torminosus. Schœffer, fung. t. I 2.

Noms vulgaircs : morton, raffoult, mouton zoné.

Ce champignon est d'un brun roux; son pédicule est cylindrique, long dc deuxà trois pouccs; son chapeau cst convexe, un peu enfoncć vers son centre, marqué quelquefois de zones concentriques, ct r'ecouvcrt de petites pellicules écailleuscs, inégales, d'une couleur plus foncée, qui ne s'observent que dans les jcunes individus. Scs bords sont roulés en dessous; ses feuillets sont inćgaux. Il est commun à la fin de l'été dans les bois. Le suc qui découle des entamures que l'on fait à sa substancc est âcre, caustique, blanc, quelquefois légèrement jaune.

On doit se défier de cc champignon qu'un grand nombre d'auteurs regardent comme très-vénéncux, tandis que d'autres, etj M. Paulet en particulier, prétendent quiil ne produit point d'accidens. La prudence exige dc s'en abstenir soigneusement.

Agaric caustique. Agaricus prrogalus. Bull. t. 529 , f. I. Orf. méd. lég., t. r 8, f. 2.

Sa conleur est d'un rouge assez vif; son pédicule est jaunâtre, plein, haut d'un à deux pouces, cylindrique; son chitpeau est convexe, un peu concavc au ccntre, souvent rayé de zones concentriques d'une couleur plus foncéc; scs fcuillets adhércns au pédicule sont inégaux et rougeâtres. Il cst asscz commun dans les bois. Son suc est jaunâtre, très-caustique.

Cette cspècc est vćnéneuse.

$4^{\circ}$ Pédicule latéral.

Agaric styptique. Agaricus.stypticus. Bull. t. x40 et 557 , f. I. Orf. méd. lég. t. I 8, f. 4 ; t. 19, f. 2.

Celtc cspèce est d'une coulcur jaunc camnclle plus ou moins foncéc; sou pédiculc est plein, conique, latćral, long de huit à 
dix lignes; son chapeau est hémisphérique, ressemblant en quelque sorte "à une oreille d'homme; son grand diamètre est d'environ un pouce; ses feuillets son égaux entre eux, se détachant facilement de lá chair du chapeau; il végète sur les vieux troncs d'arbres, les souches coupées à fleur de terre. Sa saveur cst âcre et astringcnte.

On doit le rejeter, car il est vénćncux.

\section{AMI A N ITE. $-A M A N I T A$. Pers.}

Ce genre diffère de l'agaric, par la présencc d'une boursc ou volva, qui enveloppc le champignon en partie ou en totalité avant son developpement, et par son pćdicule, presque toujours bulbeux à sa base.

Amanite orotge. Amanita amrantiaca. Pers. ch. com., p. I74, t. I. Agaricus aurantiacus. Bull. t. I 20.

Noms vulgaires : oronge, jaserand, dorade, jaune d'œuf, cadran, elc.'

L'oronge paraît d'abord sous la forme et avee l'apparence d'un auf : en cffet son volva est blanc et la recouvrc cn totalitć; mais il se sćpare ensuite cn plusicurs lobes pour laisser sortir le champignon. Celui-ci est d'une couleur rouge-orangé fort éclatante; son pédicule est plein, cylindrique, jaune avec un collet membraneux et pcndant; le chapcau est convexe, large de quatre à cinq pouces, glabre, lisse, strić et souvent incisé sur son bord; ses lames sont jaunes, épaisses et inćgales.

Ce champignon croît dans lcs bois, surtout dans les provinces méridionales. Il n'est pas rare en automne aux environs de Paris. C'est un champignon délicieux, dont on fait un gi’and usage dans les provinces où il croît. Les Romains l'cstimaient beaucoup et le désignaicnt sous les noms de fungorum princeps Boletus.

Il cst cssentiel de nic pas confondle l'oronge vraie que nous venons de décrire, avec la fiusse oronge qui est fort dangereusc, et qui lui ressemble beaucoup. 
Amante fausse ononge. Ainanita muscuria. Pers. Agaricus muscarius. L. Ag. pseudo-aurantiacus. Bull. t. I22. Orf. méd. lég. t. 14, f. I.

Noms vulgaires : agaric aux mousses, fausse oronge.

La fausse oronge ressemble absolument pour le port et la contleur à l'oronge vraie, dont elle diffère par lcs earactèr'es suivans: son volva est incomplet, c'est-à-dire qu'il nc recouvre pas la tolilitć du chapcau; celui-ci, lorsqu'il cst dévcloppé, est tacheté dc plaques jaunâtres et irrégulières (nommées verrues); son pćdiculc et ses lames sont blanches et non jaunes.

C'cst malheureusement une des espèces les plus répandues dans nos bois pendant l'automne. Elle est très-vénéneuse.

Amanite vénéneuse. Amanita venenosa. Pers. ch. com., p. 178. t. 2. Agaricus bulbosus. Auct.

Sons ce nom, M. Persoon a réuni, à l'excmple de Bulliard, plusieurs espèces de ehampignons distinguées par les auteurs sous les noms d'agaric bulbeux, printanier, ete. Cette espèce comprend trois variétćs principales, savoir :

$I^{\circ}$ L'amanite bulbcuse blanche ou oronge ciguë blanche dc Paulęt (agricus bulbosus vernus. Bull. t. 18o.) Elle es! blanche dans toutes scs parties;

$2^{\circ}$ L'amanite sulfurinc ou oronge ciguë jaunâtre de Paulet (amanita citrina Pers.) Bull., t. 577, f. 9. La couleur du chapean de cettc variélé èst d'un jaunc eitron, ainsi quc l'anneau; lc pédiculc cst long de trois à quatrc pouccs; le elıapcau cst tacheté de verrues bruncs. Elle est eommunc dans les bois sombres et humides;

$3^{\circ}$ L'amanite verdatre ou oronge ciguë verte de Paulct (amanita viridis. Pers. $\Lambda$ garicus bulbosus. Bull. $t .108 \mathrm{dt}$ 577, f. D.)

Son chapeau cst ordinairement lisse et sans verrues, if est d'un vert plus on moins foncé. Celtc varićté, plus grande que les deux autres, a une saveur el unc odemr plis naraséabondes et plus fortes. On lit trouve en aniomne dans ie: bois ombragris. 
Cc champignon ct scs varićtés sont une des espèccs les plus dangereuscs de toute cette famille, à cause dc sa ressemblance avec le champignon de couche; c'est même celle qui a donné lieu arı méprises les plus frćquentes et les plus funestes. Mais on évitcra facilcment cette erreur en songeant que le champignon de couche n'a ni bulbe, ni volva à la base de son pédicule, quc ses lames sont toujours rosâtres $\mathrm{et}$ jamais blanches, ct qu'enfin son chapeau ne porte point dc verrues.

Ananite a tète lisse. Amanita leucocephala. Pers, ch. com. 183. Agar. leucoceph. DG. fl. fr. 6. p. 53.

L'amanite à tćte lissc, dit M. de Candolle, est entièrement blanche, mème dans un âge avancé. Son odeur est agréable, sa chair ferme, sa superficie sèche et chagrince, son pédicule épais vers la base; son chapcau a 7 à 8 pouces de diamètre, ses feuillets sont nombreux, non adhérens au pédicule qui est dépourvu dc collier ; son volva est grand. On lá vond au marché de Montpellier.

Cette espc̀ce, qui est comestible, ne peut être confondue avec la précédente, parcc qu'clle manque de collier.

C'cst encore au genre Amanite, que l'on doit rapportcr plusieurs cspcces encorc mal connues, et qui n’ont été indiquées que par M. Paulet, sous le nom générique d'Hypophyllum; tels sont :

$1^{D}$ L'oronge croix de Malte. Hypophyllum crux melitensis. Paulet. Orfil. méd. lég. $t .16, f .1$, dont le chapeau se fend en plusieurs lobes rayonnans;

$2^{\circ} L^{\prime}$ oronge souris. Hyp. anguincum. Paulet, Orf., l. c. t. $16, f .2$;

$3^{\circ}$ L'oronge peaucière de Picardie. Hyp. pellitum. Paulet. ov. l. c., t. $16, f .3$;

$4^{\circ}$ L'oronge dartrcuse. Hyp. maculatum. Paulet, Orf, l. ¿. 1. $16, \int .4$;

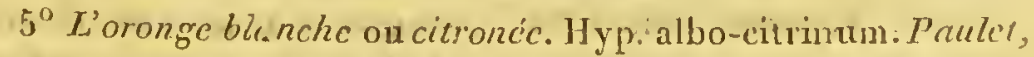
Orf., l. c., t. 17, f. 1;

$6^{\circ}$ L'oronge th pointes de trois quarts. Hyp. tricupidaltum. Paulet, Orf., l. c. t. 17, r. 2; 
$7^{\circ}$ L'oronge a rape. Hyp. rapula. Paulet, Orfila, l. $c$. t. $17, f .3$.

Ces différentes espèces de $M$. Paulet nous paraissent pour la plupart de simples variétćs de l'amanite vćnéneuse. Toutes au rcste sont comme elle délétères, et ont donné lieu à des accidens plus ou moins grayes. Voyez, pour de plus grands détails sur ces espèces, les Planches de champignons le M. Paulct, et les Leçons de médecine légale du professeur Orfila.

\section{BOLET. - BOLETUS.}

Champignons clarnus ou coriaces, avec ou sans pédicule, dont le chapeau cst garni à sa face inférieure de tubes serrćs et perpendiculaires, ou de pores.

Il est important dc noter qu'aueune des éspèces de ce genre n’est véritablement, vériéneuse.

$x^{0}$ Pédicule central; tubes adhérens entre eux et au chapeau.

Bolet comistible. Boletus edulis. Bull. t. 494.

Noms vulgaires : cepe, girole, bruguet, bolé, porchin potiron, etc.

Sa teinte générale est d'un jaune grisâtre terne ; son pédicule est haut de quatrc à cinq pouces, épais, charnu; renflé à sa basc et comme réticulé à sa surfacc; son chapeau égalcment épais et charnu est d'un jaune un pcu brunâtre, son diamètre est de cinq à huit pouces; ses tubes d'abord blancs, prement ensuite une teinte jaunâtre, sa chair est blanehe et ne changc pas de couleur quand on la casse. Cette espéce cst cxtrêmement commune dans les bois depuis la fin de l'été jusqu'cn automne. Sa savcur a quelque analogie avee celle de la noisctte et son goùt est fort agréablc. On le mange eru ou cuit, ct apprèté de différentes manièrcs.

Les autres bolets cumestibles de cette section sont le bolet bronzé. (B. æreus. Bull. t. 385), designé sous les nons de cepc noir, de champignon à téte noire. Le bolet blenc ou potiron blanc (B. albus. Pers). Le bolet orangé ou fonge oronge de Paulet. (B. anrantiacus. Bull, , t. 489 , f. 2.) Le bolet rude (B. asper. 
Pers.), et enfin toutes les espèees qui sont eharnues, et ne ehangent point de eouleur lorsqu'on les entame.

\section{$2^{\circ}$ Pédicule nul.}

Les espèes de eette seetion sont en général d'une substanee plus ou moins sèehe et eoriaee, et ne sont point employées eomme alimens.

Bolet ou mécteze. Boletus laricis. Bull. t. 296. Bol. purgans. Pers.

Nom pharm. : agaricus; nom vulgaire: agaric blanc; partie employée : toute la plante.

Ce bolet' est, à sa surfaée extérieure, d’un blanc sàlế; sa forme est à peu près eelle d'un sabot de eheval; il 'est semi-cireulaire et attaehé par un de ses eôtés; sa elıair èst blanehe, eoriaee et épaisse; sa pellicule supérieure est brünâtre et marquée de quelques zones eoneentriques; ses tủbes sont jaınâtres et très-serrés. Il eroît sur le tronc des mélèzes en Asie, 'dans l'Europe méridionale et dans les Alpes.

Celui du eommeree est blane, léger, poreux, dépouillé de sa pellieule supérieur̦e. C'eșt un violent purgatif drastique, en général peu employé aujourd'hui, surtout en Franee.

Bolet anadouvien. Boletus igniarius, Sowerb. fung. t. i3r. (non Bull.) $B$. iinguilatus. Bull. t. 401 , et เ. $49 \mathrm{r}$, f. 2 .

Nom pharm.: agaricus chirargorim; noms vulgaires: agaric, agaric de chêne, amadousiér, cte.

Sa couleur est d'ún blane ferrugincux; sa forme est la mène que eelle de l'espéce jréeédente; sa chair est d'abord molasse et filandreuse; mais elle itequiert bientôt la dureté du bois; ses tubes sont très-sérrés et bruns. Il vicrít eómmunément sur le trone du chênc, du pommier, ete.

C'est avee cè eliampignon eneorc jeune, coupé par tranélies, ’ trempé dans úne solution de nitrate de potasse, séelié êt. battu convenablement, que se préparc l'ainadou ou ağaric, si fréquemment employé dans la ehirurgie et l'économie do. mestique. 


\section{MÉRULE $\rightarrow$ MERULIUS.}

Champignons charnus dont lc chapcau est infundibuliforme, ct garni en dessous de plis ćtroits, ramifiés et veineux. (Pers.)

\section{Mínule chanterelue. Merulius cantharellus. Bull. t. 505.}

\section{Agar. cantharellus. L.}

Noms vulgaires : girolle ordinaire, cheville, jaunelet, moussetine, cassine, etc.

Cette espèce, exlrêmement commune dans tous nos bois, se monlrc, pendant l'ćtç. Sa belle couleur jaune orangée, sa forme en entonnoir, son pédicule court, la font facilement reconnailre: sa chair a une saveur agrćable, mais un peu poivrće surlout quand on la mangc crue.

On en fait unc très-grande consommalion dans les licux où ellc croît.

\section{CLAVAIRE.-CLAVARIA.}

Champignons charnus, ayant la forme dune massue, ou plus sonvent de branches de corail ramifiécs.

Gravalíe coralloïne. Clavaria corallö̈des. L. Bull.t. 2 I 2.

Noins vulgaires : barbe de chèvre, gallinète, mainotte, espi-

$$
\text { gnette, poule, buisson, clc. }
$$

Sa couleur est ordinairement x'osûtre ou d'un jaune orangé ; ellc est cepcndant quelqucfois blanchc. Elle forme des touffes plus ou moins scrrées, branchues, charnues, hautes de trois it quatre pouccs, qui naissent à terre en aulomnc sous les bois ombragés. Leur chair cst blanche, cassante, un peu corince, mais asscz nourrissantc.

On mange encorc plusieurs autrcs clavaircs. Aucunc cspice de cc genre n’est vénéncusc.

$$
\text { MORILLE. - MORCHELLA. Pers. }
$$

Champignous claumus, sans volva, dont lc chapenu, plus 
ou moins globuleux, est recouvert supérieurement de larges alvéoles, ayant les bords membraneux et persistans.

Morilue ordinarne. Morchella esculenta. Pers. syn. fung. 6r8. Phallus esculentus. L. Bull. t. 2 r 8.

Ce petit ehampignon est très-commun au printemps et en ćté dans les endroits déeouverts des bois ealerires, surlout: dans les places où l'on a brûlé du eharbon. Son pédiculè est. creux, lisse, de eouleur blanehe; son ehapeau est presque;globuleux, alvéolé, grisàtre.

On fait une très-grande consommation des morilles, soit fraîches, soit séehées et conservées pour l'hiver.

\section{HELVELIE. - HELVELLA.}

Champignons dont le ehapeau membraneux et lisse, est ribaitu des deux eôtés, libre ou attaché au pédicule, qui est solide et souvent diversement sillonné et lacuneux.

Henvelue comestinle. Helvella esculenta. Pers. champ. com., t: 4, f. $\mathbf{i}-5$.

Le pédieule de eetle helvelle est plein, haut d'un à deux pouces, d'un brun rougeâtre; son chạpeau, d'une forme irrégulière, est rouge, inégal, mamelonné et eomme cérébriforme. Elle eroît dans les bois montueux. "Toutes les helvelles, ainsi que les grandes pezizes, peuvent servir d'aliment, car elles sont toutes de la même nature que les morilles." Pers.

$$
\text { TRUFEE. - TUBER. }
$$

Champignons eliarnus, irrégulièrcment arrondis, dontl'in-léricur est marbré on veiné.

'l'rufes norre. Tuber cibarium. Bull. t. 556. Iycoperdon. iuber. $\mathrm{T}$.

La truffe met ordinairement me année pour aequérir toui son développement. $\Lambda u$ printemps elle, se préscnte sous la forme d'un pelit tubercule arrondi, pisiforme rougeâtre; au 
comineneement de l'été elle est plus grosse, et blanehe intérieúrement, elle eonstitue alors la truffe blanche, qui est un peu indigeste et sans parfum. A la fin de l'automne et au eommeneement de l'hiver, sa surface est moire, ehagrince, sa ehair est brune, marbrée, très-odorante.

Les truffes se rencontrent partieulièrement dans les régions méridionales. En Franee, les plus estimées sont eelles du Périgord. C'est un mets fort recherelié.

'Cónsidèrations générales sur' les champignons vénéneux.

$\Lambda$ près avoîr déerit les espèees prineipales de ehampignons, il nous reste à faire eonnaitre s'il existe quelques moyens de distinguer, au premier eoup d'œil, la nature dangereuse d'un champignon. Celte partie essentielle de leur étude est eelle sur laquelle on possède le moins de notions préeises. En effet il $n^{\prime} y$ a point de caraelèrres invariables, propres à faire connaítre cette distinction. Voiei cependạnt ee que l'on a remarqué de plus eonstant à eet éģard.

En 'général, il faut rejeter les ehampignons dont l'odeur et le goût sont désagréables; ,eeux dont la chair est molasse et aqueuse; eeux qui eroissent dans les lieux ombragés et trop humides, qui se gâtent' ávee facilité; 'ceux dont le goût est amer, astringent ou trop poivré; eeux qui ehangent de eouleur quand"on lès "entame. Une teinte rouge, brillante, est assez souvent'l"indice de qualités délétères, eomme on l'observe dans la fausse oronge ct plusieurs autres espèees dangereuses; eependant l'oronge vraie, qui offre eette eoloration est une des espèees les plus saines. Les espèees même auxquelles on n'a pas reeonnu de propriétés malfaisantes, doivent être reeueillies avant leur entier développement, ear plus tard elles perdent de leurs qualités.

L'analise ehimique, en isolant les prineipes immédiats des ehampignons, n'a pu jeter.aucun jour sur leurs proprićtés. MM. Boullon-Lagrange, Yauquelin et surtout Mr. Braeonot de Nancy, ont fait des reeherches qui n'ont abouti qu'à la connaissanee de quelcques substances sans qualités appaientes, ou sur lesquelles les physiologistes ne se sont pas eneore exercés. Telle est la fingine (Brae.), substanee analogue à la fibre 
végétale quant à l'inertie de ses propriétés, mais entièrement diffćrente en ce qu'elle donne à la distillation tous les produits des matières animales. Tels sont aussi : un acide particulier (acide fungique, Braconot), uni le plus souvent à la potasse; deux matières animalisées, l'ìnc soluble dans l'alcohol (osmazome) l'autre peu connue et insoluble dans ce fluide; du sucrc , de l’adipocire, de l'huile, etc. M. Vaququelin a analisé quatre agarics: Agaricus campestris, A. bulbosus, A. théogalus, $\Lambda$. muscarius; et y a rencontrć à peu près tous les principes que nous venons d'énoncer et qui constituent chimiquement le Boletus Juglandis, selon M. Braconot. Le Peziza nigra a fourni en outre, à celui-ci, de la bassorine, de la gomme ct de l'acide fungique libre en partie. (Ann. de chimie. t. 79 ct 87 .)

Il serait à désirer que ces analises fussent reprises par les chimistes et physiologistes qui se sont déjả occupćs de recherches sur les principes actifs dcs végétaux, afin de constater d'une manière certaine les effets de ceux des champignons sur l'économie animalc.

D’après unc foule d'cxpériences, il a ćté reconnu que, le premier soin à remplir dans les accidens occasionćs par lcs champignons vénéneux, est de les chasser le plus promptement possible hors du canal alimentaire. Pour cela, on doit commencer par administrcr un vomitif, ou mieux encore un ćméto-cathartique, lorsque les accidens n'ont pas encore paru, ou sont peu intenscs : ces accidens nc sc montrent fréquemment que huit, douze ou même vingt-quatre heures aprćs l'introduction des champignons vénéneux dans l'estomac. Lorsque l'on a ainsi évacuć tout ce qui reste dı poison, on donne au malade une potion fortement ćthćrće. Le médecin devra ensuite surveiller la marche des symptômes qui se développeront. Si des douleurs vives se font sentir dans l'abdomen, et annoncerit une inflummation dc quelquc partic du canal alimentaire, on aura recours aux ćmolliens, aux mucilaginenx. Si au contrairc lcs accidens se concentrcnt vers la têtc, 'qu'il y ait délire, agitation, ctc., les révulsifs, tcls quc les sinapismes,
les vésicatoires sont indiquès. 


\section{LICHENEES. - LICHENERE.}

Les lichens se présentent sous la forme de croûtes membraneuses, simples ou lobées, de feuilles, de tiges plus ou moins rameuses, quelquefois d'une simple poussière. Leur consistance est ordinairement sèche et co' riace; leur couleur varie beaucoup. Les fruetifications sont renfermées dans des réceptaeles en forme d'écussons on de tubercules, situés sur la face supérieure ou sur les bords de ceux qui sont aplatis, ou à l'extrémité des ramificatious, dans ceux qui sont dendroïdes, c'està-dire rạmifiés à la manière des arbres.

Ces plantes végètent, soit sur le tronc des arbres, soit sur les mur's, les rochers, ou, même sur la terre. En général, leur durée n'est pas bien déterminée; ils vivent ordinairement plus d'une année.

Les différens genres de cette famille sont désignéz dans les ouvrages de Linnæus sous le nom générique do lichen. M. de Jussieu a vait plaeé ce genre parmi les algues; mais aujourd'hui que l'organisation de ees plantes est beaucoup mieux connue, on a trouvé des earactères suffisans pour partager le genre lichen de Linnæus en un grand nombre de genres qui constituent une famille tout-ì-fait distincte. Parni toutes les espèees de cette famille il n'en existe qu'une senle qui soit pour nous d'un grand intérêt, et dont nous allons donner la deseriptio II : c'est le lichen d' Islande.

Liamen d'Isuande. Cetraria Islandica. Achar meth. lich., p. 293. Lichen Islundicus. L. Phgscia. Islandica. DG. f. $\mathrm{fr}$.

Noms pharm.: Lichen Islandicus. Partic usitée: toute la plante. Ce lichen est foliacé, d'une consislance sèche et comme car- 
tilagineuse, formant des touffes serrées, composées de plusieurs ramifications dressćes et entrelacées. Il est d'un rouge foncé à sa base, d'un gris blanchâtre à la partie supérieure; sa hauteur est de trois à quatre pouces. Il offre quelquefois des cils sur les bords de ses déeoupnres. Les fructificalions sont des' espèces d'écussons situés obliquement sur lc bord des feuilles, et d'unc couleur pourpre foncée.

Il croit sur la terre, les rochers des montagnes, 'dans les Vosges, les $\Lambda$ lpes, en Islande, etc.

Propriétés et usagres. Depuis une quinzaine d'années, l'usage de ce inédieament s'est singulièrcment répandu. Le lichen d'Islande a une saveur légèrement amère, qui disparaît en fràtie lorsqu'on l'a mis préalablement macérer dans l'cau. Il eonticnt 20 à $25 \mathrm{p}$. roo d'une substancc coagulable, analogue à la gélatine, suivant M. Berzćlins, et à la gomme, selon d'autres 'chimistes. C'est cette subslance qui le rend fort nourrissant, et qui le fait servir d'aliment en Islande. Les habilans de cette ile, après l'avoir privé en parlie de son anertume, par des lavages répétćs, le réduisent en farine, et en forment des espèces de pâtes on de bouillies, en le faisant cuire avec du lait.

Mais on conçoit que l'amertume qui reste opiniâtrément dans ces préparations de lichen, ne doit pas leur donner un goût très-agréable. MM. Westring et Berzélins ont done cherclté a les en priver entièrcment, et ils y ont réussi par le prócédé suivant : sur 5 oo grammes de lichen moulu, on verse $12 \mathrm{ki}$. ligrammes d'une solutiou aqqueuse de 32 grammes d'un sonscarbonate alcalin; on abandome le mélange à lni-même pendant vingt-quatre heures, on dicante, on fait macérer de nouveau dans de l'eau pendant le même espace de temps, et l'on fait séches: ( Ann. de chimie, t. yo, p. 316.) On obtient par cé procédé simple une pâte entièrement privée d'amertume et très-nourrissante.

On emploic ce médicament dans les différentes affections do la poitrine, dans les catarrhes ehroniques, l'hémoptysie, cte.; en général il calme la toux, et facilite l'expectoration. Il peut également ćtre avantageux dans la dyssenterie, dans la diarrhée chronique, etc. C'est principalement en décoction qu'or 
l'administre. On fait bouillir deux onees de lichen dans trois livres d'eau, que l'on fait réduire d'un tiers. On peut couper eette boisson avec moitié de lait de vache. On prépare encore des tablettes, une pâte, inne gelée de lichen d'Islande : on a même fait un chocolat au lichen; en un mot ee médicament peut être pris sous toutes les formes.

Lc liehen d'Islande est, de toules les plantes de eette famille, la seule qui soit encore fréquemment usitće; quelques autres, autrefois fort en vogue, sont aujourd'hui tombées dans l'oubli. Nous allons les mentionner iei, parce qu'au défaut du lichen d'Islande elles pourraient être employées à sa place. Tels sont:

$x^{0}$ Le lichen pulmonaire, ou la pulmonaire de chêne (lichen pulmonarius, L. Lobaria pulmonaria, DC. fl. fr.), qui croit sur le tronc des vieux arbres, et forme des expansious cartilagineuses, lobćes, relevćes de lignes saillạntes qui s'entrecroisent ; sa couleur est roussâtre : il est commun en France;

$2^{\circ}$ Le liehen aphtheux (L. aphthiosus, L. Peltigera aphthosa; DC. fl. fr. ) qui se trouve sur la terre sous forme d'expansions d'un vert grisâtre.

$3^{\circ}$ Le lichen pyxidé ( L. pyxidatus, L. Bcemyces pyxidatus, A.ch. ) qui a la forme"de petits entonnoirs allongés, quelquefois superposćs les uns sur les autrcs.

Ces différentes espèces, et plusicurs autres, ont quelque analogie dans leur mode d'action avec le lichen d'Islandc; mais elles sont un peu âcres ct astringentes, ct contiennent moins de féeule. Cependant en les lavant et les laissant macérer dans l'eau bouillante, on pourrait les priver dc leurs principes âcres et astringens, et remplacer par eux l'usage du lichen d'Islande.

L'orseille, qui fournit une eouleur violette on purpurine fort'employće dans l'art de la teinture, cst un lichen qui portc le nom de Roccella tinctoria, DC. fl. fr. Il eroit abondamment sur les côtes des îles Canaries et de la France. 
QUATRIÈME FAMILLE.

FOUĠंES. - FILICES.

Les fougères sont des plantes ordinairement herbacées, à tiges souterraines, rampantes et vivaces, que l'on regarde communément comme les racines. Leurs feuilles sont alternes, roulées en volute ou en crosse avant leur entier développement; elles sont simples, pinnatifides ou décomposées : les organes de la fructification occupent la face inférieure des feuilles, ou constituent des espèces de grappes ou d'épis terminaux : ces organés consistent dans de petites sporules, analngues aux graines, contenues dans des espèces de capsules, "en forme d'écailles, entourées quelquefois d'un bourrelet élastique, s'ouvrant par une fente transversale, ou se déchirant irrégulièrement. Ces capsules sont regardées par Hedwig comme des fleurs femelles, tandis qu'il appelle fleurs mâles, de petits filamens renflés qu'on observe sur les nervures des frondes avant leur déroulernent.

\section{POLYPODE. - POLYPODIU.M. Swartz.}

Sporules réunies en groupes arrondis, nues, sans anneaux et sans eapsules.

Polyode commun. Polypodium vulgare. L. Sp. i 554. Bull. t. rgr.

Nom pharm. : Polypodium. Nom vulg. : Polypode de chéne. Partie usitée : la racine.

La souche de celtc plante est lorizontale, épaisse, charnue, blanchâtre à l'intérieur, brunc et écailleuse à l'extćrieur. Scs fcuilles sont longues de huil à douze pouees, pétiolées, ovales, lancéolécs, profondément pinnalifides; les découpurcs sont enticres, lancćolées, parallèles, et diminuent de longueur et de largeur cn s'approehant du sommet. Les fruetifications form- 
ment des groupes arrondis, disposés longitudinalement sur lea. denx côtés de la nervure que présente chaque division.

Le polypode eroît stur les vienx murs, dans les dicombres, etc.

Proprićtés et usages. La racine du polypode a une saveur donce et sucrée : elle est fort peu employće, paree que ses proprićtćs sont presque nulles. Réduile en poudre, on l'emploie soit comme absorbant, à l'extérieur, soit pour recouvtir des pilules.

\section{Polypode calaguala. Pol.jpodiun calaguala. Ruiz.}

Nom pharm. : Radix calarualre. Nom vulg.: Calaguala, Calahuala

Cette fougire off'c une souche ou racine horizontale rampante flexueuse, de la grosseur du doigt, écaillense, donnant naissance à plusieurs fibrilles grĉles et rameuses, et a des feuilles alternes, entières, lanećolées, étroites, longues de huit à douze pouces, ayant les bords réfléchis en dessous et portées sur des pétioles de denx à trois pouces de longueur. Les feuilles prćsentent à leur fice inférieure des sporules réunies en petits groupes arrondis et disposés en quinquonce.

La calaguala croît dans les régions montisuses du royaume

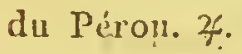

La description que nous venons de donner de cette plante est bien différente de celle qui est rapportéc par la plupart des auleurs, qui regardent la racine de la calaguala comme provenant de l'aspidium coriaceum de Swartz. Mais nous nous sommes eonformés à l'opinion de Ruiz, qui dans son mémoire sur la véritable raeine de la calaguala donne la figure et la descripution de la fougere dont la racine porte ce non.

Propricitćs ct usages. La racine de ealaguala, telle qu'elic nous est livićc par le commerce, est d'une saveur huilçuse et désagrénble. Don Hijpolyte Ruiz est le premier yui ait appelé l'altention des niédecins enropéens sur' ses propriétés médieales. Mais il paraît que son usage était depuis fort long-iemps connu des praticiens du Nonvean-Monde. On l'a surtout beareonp vanté commo un médicanent excitant, ayant une action spéciale sur le système exhalant. Aussi l'a-t-on prineipalemcnt 
préconisć comme sudorifique dans le traitement du rhumatisıne chronique et de la syphilis constitutionnelle. Mais quelques cssais tentés en Francic n'ont point justilié les éloges qui lui ont été prodigués par plusieurs médeeins espagnols. Peut-être serait-il naturcl d'attribuer la diffćrence des résultats que l'on a oblenus, à la différence des racines que l'on a employées sous le nom de calaguala. Car il est certain que eelles de plusieurs fongères sont désignées sous ee nom dans le commeree, puisque la plante déerite et figurće par M. Ruiz, s’éloigne entièrement de celle de Cavanilles et de Swartz. Mais comme nous nc manquons pas de médicamcns sudorifiques, ntême parmi les indigènes, on peut sans beaucoup d'inconvéniens, négliger l'emploi de la racine de ealaguala.

\section{NEPHRODE. - NEPHRODIUM.}

$S_{i}$ ’rules disposćes en points arrondis, épars, recouverts d'un tégument ombiliquć, atlaché par le eentre seulement, et libre dans toute sa eirconférence.

NépHrode fougìre Male. Nephrodium filix mas. Rich. cat. hort. med. Polypodium filix mas. L. Sp. 155 I. Búll. t. 183 .

Nom pharm. : Filix mas. Partie usitée : la racine.

Sa raeine est une souche souterraine, horizontale, de la grosseur du pouce, noueuse, brune et éeailleuse a l'extérieur, blanchâtre en dedans. Ses feuilles sont grandes, hautes d'environ deux pieds, pćliolées, ovales, lancéolćes, pinnées : lès pinnules sont trés-longues, rapprochées les unes des autres; chaeunc d'elles cst profondément pinnatifide, à divisions dentées, obtuses, confluentes par la base et inclinées vers le sommet de la pinnule. Les pétioles sont eourts, d'un brun foncé et lout couverts d'ceailles minees et brunes; les fruciifieations sout rćniformes, arrondies, ombiliquécs à leur centre, et s'ouvrent daus toute lcur eirconférence.

La forigere mâle crnit dans les lieux ombragés, dans les bois un peu humilcs, aux environs de Paris. $y$

propriciés el "suges. La racine de fougcire mále a une odent 
assez désagréable, une saveur amère et un peu astringente. On l'employait autrefois comme apéritivc; mais aujourd'hui on restreint scs usagcs à expulser les vers du canal alimentaire. Sous ce dernier rapport elle est encore fort souvent mise cn usagc, particulicrement pour le traitement du teenia on ver solitaire. On administre cette racine à la dose d'une once à une once et demie en décoction, dans seize onces d'eau; ou sa poudre, à la dose de deux gros, ou une demi-once étendue dans de la tisane ou du vin, et répétée plusicurs fois de suite.

On met rarement ce remède seul en usage pour l'cxpulsion du tænia; on y associe ordinairement les purgatifs drastiques, le mercure doux ou l'ćther.

$$
\text { DO RADILLE. - ASPLENIUM. L. J. }
$$

Fructifications disposées par plaques allongées, éparses, recouvertes d'un tégumcnt écaillenx qui part latéralement d'une nervure secondaire, et s'ouvre d'un seul côté de dcdans cn dehors.

Doradille rue des murailles. Asplenium ruta mutaria. L. Sp. I54ז. Bull. t. I $9^{5}$.

Nom pharm. : ruta muraria. Nom vulg. : sauve-rie, rue des murailles. Partie usitée: les feuilles.

Cette petite fougère croît par touffes serrées, liautes dc deux à trois pouees, dans les fentes des rochers, des vieillcs murailles. Ses pétioles sont bruns, simples et nus dans leur moitié inférieure, ramifiés ct décomposés supérieuremcnt ct portant de petitcs folioles irrégulièrcinent arrondies, un pcu épaisses, coriaces, glabrcs, que l'on a comparées à eelics de la rue officinalc; ccs folioles sont courtcs, obtuses, irrégulic̀rcment dentécs: les fructifications sc montrent d'abord sous lit forme de deux on trois lignes étroites à la facc inféricurc de chaque foliole, qui bicntôt, par le dévcloppement de ccs lignucs, cn cst presque cntičrement rccouvertc.

I a rue des inurailles cst très-communc aux cnvirous dc Paris et dans presque toutc la France. 2 
Doradiule polxtric. Aspleniumtrichomanes. L. Sp. 1540. Bull.t. I 85 .

Nom pharm. : Trichomanes. Nom vulg. : Polytric des boutiques. Partie usitée : les feuilles.

Cette espèce est également en touffes serrćes, un peu plus grandes que celles de la rue des murailles : ses feuilles longues de six à huit pouces, sont portćes sur un pétiole grêle, d'un brun foncć; elles sont simplement pinnées; les folioles sont sessiles, arrondies, irrégulièrement dentelées, petites; eelles qui occupent la partie inférieure sont anguleuses, presque triangulaires. Les fructifications constituent cinq ou six petites lignes à la face inférieure de chaque foliole, qui s'élargissent insensiblement.

Cette petite fougère est fort commune dans les fentes de rochers un peu ombragćs et humides, ainsi que dans les vieux murs. $F$

Propriétés et usages. Les fenilles de ces deux fougères, ainsi que celles de la doradille noire ou capillaire noire (aspl. adianthum nigrum. L. ), sont ordinairement mćlangées ensemble dans les pharmacies et souvcnt substitućes au vćritable capillaire, c'est-à-dire à celui de Montpellier et du Canada. Cette substitution n'a d'autrcs inconvéniens que le peu d'arôme de ces espèces; arôme qui est plus développé et très-agrćable daus le vrai capillaire. Du restc ces plantes peuvent être employées dans les mèmes circonstances, car elles sont ćgalement un peu mucilagineusès ct légc̀rement astringentes. Les médecins en font aujourd'hui perx d'usage, tandis qu'autrefois la rue des murailles était regardée comme une sorte de panacée.

\section{ADIANTHE. - ADIANTHUM. L. J.}

Capsules réunies en ligne interrompue sur le bord des feuilles roulé en dessous, qui leur sert de tégument et s'ouvrc de dedans en dehors. 
Adiantie captciare de Montpelrerer. Adianthum capillus veneris. L. Sp. 1558. Bull. herb. t. 247.

Nom pharm.: Adianthum capillus veneris, partie usitie : les feuilles.

Nous trouvons dans celte plante une souche vivace, des feuilles toutes radicales, péliolćes, longues de six à dix potzces, décomposćes en un grand nombre de folioles cunéïformes, minces, très-glabres, incisćes sur leur bord supérieur, dont les divisions sont ronlées en dessous pour envclopper les sporules ct former autant dc petits paquets séparés.

Le capillaire de Montpellier, croît dans les lieux hnmides, sur le bord des fontaines, dans les puits des provinces méridionales de la France. $z$

Usages et propriétés. Son odcur et sa saveur sont légc̀rement aromatiques et agrćables: il est un peu mucilagineux. On l'emploie principalement en infusion dans les affections catarrhales peu intenses. Lc sirop de capillaire sc fait en versant du sirop simple et bonillant sur des feuillss de capillaire.

Ie capillaire du Canada ( $\Lambda$ dianth. pedatum, L.), dont les feuillessont plus grandes, les pétioles plus longs et ramifiés seu. lement à leur sommet, de manière que toutes leurs branchcs partent en divergeaut du même point, cst employé aux mémes usag̉es que le prćcédent, ct mélangé aveclui dans le commerce.

Il cst plus cstimé que le précédent ct cst originaire de l'Amérique septentrionale. $z$

$$
\text { OSMONDE. - OSMUNDA. L.J. }
$$

Capsules arrondics, pédiccllécs, à rine seule loge, s'ourrant en deux valves, disposées en grappc terminale, on rapprochées sur le dos des feuilles.

Osmonde moxare. Osmunda regalis. L. Sp. i 52 r. Lamk.

$$
\text { IIl. t. } 865, \text { f. } 2 \text {. }
$$

Noms vulgnires : fougère royale, fougere flcurie. Partic usitéc: la racine.

La racine de celle foucerc cst rampante, composie de 
fibres allongées, d'un brun foncé. Ses feuilles sont toutes radicales, fort grandes, hautes de trois à quatre pieds, bipinnćes, à dívisions opposées: les foliolcs sont ovales, obtuses, comme tronquées à lcur base, marquées sur leur face inférieure de nervures asscz apparentes; elles sont tout-à-fait glabres. La grappe sst terminale à la partie supérieure des feuilles, aux dćpens de laquellc elle semble formée; cllc est rameuse, d'une couleur fauve, quand les capsules sont mûrcs.

L'osmonde se plait dans les lieux marćcageux et lourbcux : ellc vient en rouffes serrées auprès des buissons à Miontmorency, St-Léger, etc. etc. $\Varangle$

Proprictés et usagres. La racinc de fougère royale a èté employéc autrefois contre un grand nombre dc maladies, mais plus particulic̀rement contre les scrofules et le rachitis. M. le docteur Aubcrt, de Genève, a rapporté, dans le journàl général de mćdecine de 1813 , plusicurs oljscrvations de gnérison d'affeetion rachilique par l'usage de l'extrait de fougère royale, à la dose de trois à quatre gros par jour. Cependant ce médicament est presque cntičrement abandonné par les praticiens.

Nous nous sommes contenté de décrire quelques-unes des fougères dont l'usage avait ćté introduit dans la médecine par les praticiens ancicns. Nous avons cru inutile d'en faire connaitre un plus grand nombre, parce qn'aucunc de celles que nous avons onnises à dessein, nc prćsente d'intérùt pour la thérapeutique; nous allons simplement mentionner ici celles qui ont joui de quelque rćputation:

$1^{\circ} \mathrm{La}$ racine de la fougère femelle (aspidium fulix famina, Swartz), jouit à peu prés des mèınes propriétés que cellc de fougère mâle, quoiqu'ì un degré plus faible. On peut en dire autant de la racine de pteris aquilina.

$2^{0}$ Les feuilics de scolopendre ou langue de cerf, (scolopendrium nffecinarum, Willd), ont étć rccommandées dans l'obstruction des viscères abdomiuanx.

$3^{\circ}$ ll cn est de même du cétérnch (ceterach officinarum), dont l's fcuilles élaient réputées propres à combattre l'astlumc, les affections catarrhales, etc.

Aujuurd'hui ces médicamens sont tomliés dans un oubli mérité. 
Propriétés inédicales et usages des fougères. Les plantes de cette famille ne prćsentent rien de bien remarquable, lorsque l'on considère les avantages que l'homme en retire. En effct lcs propriétés dont elles sont douées, n'ont rien de saillant. Les feuilles d'un grand nombre de fougères sont mucilagincuscs, légèrement. aromatiques et astringentes, ct employées comme béchiques; telles sont principalement les espèces dćsignées sous le nom de capillaires. Quant aux raeines, c'est-àdire aux, tiges souterraines, que l'on regarde communément comme des racines, clles ont, dans un très-grand nombre d'espèees, une saveur amère, acerbe, plus ou moins âcre et sont placées parmi les médcamens anthclmintiques. La racinc de polypode de chêne offre au contraire unesaveur sucrée assez agréable.

Il n'y a pas, dans celte famille, de plantes vénéneuses.

Outre les familles dont nous venons de tracer les caraetères et l'histoire, plusieurs autrcs, appartenant aussi à la première classe,conticnnent quelqucs végétaux qui ont jouiautrefois d'une cerlaine réputation; mais commeiils ne sont plus employés aujourd'hui, nous n'avons pas cru devoir grossir inutilement ce volume en les dćcrivant avec détail; nous nous contenterons donc de les mentionner rapidement. Voyez, pour de plus grands délails sur les plantes eryptogames; dans mes Élémens de botanique, le ehapitre qui traite de l'organisation desplantes agames.

$x^{\circ}$ Les Hypoxylées: Ce sont de petits êtres qui tiennent le milieu entre les lichens et les champignons parasites. Aucun d'eux n'a de propriétés connues.

$2^{0}$ Les Hépatiques. Elles ont en général le port des mousses. Elles ne sont plus cmployćes. La marchantia polymorpha ćtait. regardée par les anciens comme propre à combattre les maladies du foie; de là son nom vulgaire d'hépatique.

$3^{\circ}$ Les Mousses. Cette famille, fort nombrcuse cn espèces, est Irès-distincle des autres par son organisation. Le polytric commun (polyt. commune L). était enployć autrefois commc béchique et sudorifique.

$4^{\circ}$ Les.Lycopodiacées : Sont intermédiaires cntrc les mousses ct les fougères. Il s'éehrappe de leurs capsulcs une poudre sans odeur, très-fine ctlégc̀re, que l'on emploic commc absorbante à l'cxtćricur, sürtout pour recouvrir les cxcoriations qui se for- 
ment dans différentes parties du corps des nouveaux-nés. Cette poudre s'enflamme et brûle avec tant de rapidité, qu'elle ne peut communiquer le feu aux objets environnans.

$5^{\circ}$ Les Équisétacées ou Presles. Toutes sont plus ou moins astringentes; quelques-unes ont été employées comme diurétiques. Une espèce, l'equisetum hyemale, recouverte d'aspérités rudes et fines, sert à polir les bois, et à rendre aux ustensiles de métal leur poli et leur éclat. 


\title{
PLANTES MONOCOTYLÉDONEES.
}

\author{
DEUXIÈME CLASSE.
}

\section{MONO-ÉLEUTHÉROGYNIE.}

\section{\$I. Fleurs nues ou simplement ens'eloppées d'écailles.}

\author{
CINQUIÉ ME FAMILLE.
}

\section{AROIDÉES. - $A R O I D E A$.}

Les fleurs sont tantôt hermaphrodites, tantôt unisexuées, portées sur un spaclice, dont les fleurs mâles et les fleurs femellessont quelquefois mélangées, d'autres fois au contraire éloignées, les mâles oecupant la partie supérieure, les femelles garnissant la partie inférieure; tantôt ee spadice est enveloppé dans une spathe monophylle, d'antres fois il en est dépourvu. Ces fleurs sont quelquefois nues et sans enveloppes florales, d'autres fois elles offrent un ealice divisé, surtout celles qui sont hermaphrodites. Le nombre des étamines est variable; le pistil se eompose d'un ovaire à une seule loge, rarement à trois loges, eouronné par un stigmate glanduleux. Les fruits sont ordinairement de petites baies à une ou plusiemrs graines.

Les Aroïlées sont des plantes sans tige, ayant des feuilles engaînantes, des racines souvent tubéreuses et charnues.

$$
\begin{aligned}
& \text { I }^{\circ} \text { Spadice garni d'une spathe. } \\
& \text { GOUET }-A R U M . \text { L. J. }
\end{aligned}
$$

Spathe convolutéc, rouléc en cornet, pelu ouverte; spadicc claviforme, nu à sa partic supérieure, couvert inférieurement de fleurs femelles, qui consistent on un pistil nu; dans le mi- 
lieu, d'étamines qui constituent autant de fleurs mâles. Lo fruit est une baie globuleuse, pisiforme, renfermant une graine.

Godet ondinark. Arum vulgare. Lamk. Arum maculatum. L. Sp. 25. Bull. t. 1370.

Nom pharm. : radix ari vulgaris. Nom vulgairc : pied de veau. Partie usitée : la racine.

Racine vivace formée d'un tubercule charnu, arrondi, blanchâlre, de la grosscur d'une petite noix, garni de fibres radicalés à sa partie inférieure.

Fcuilles glabres, toutes ladicales, au nombre de trois à quatre, partant du, collet de la raciue, aecompagnées d'unc ou deux grandes ćeailles foliacées, minces, membraneuses ct dimitransparentes. Ces feuilles, portíes sur des pélioles de,six à huit pouces de longueur, cylindriques, angulcux, largement dilatés el nembraneux à leur base, sont sagittées, aiguës, sinucuses, cntières, vcrtes et luisantes en dcssus, quelquefois tachelćes de noir.

Flcurs disposées en spadice pédnnculé; pédoncule de qualre à cinq pouces de lauteur, sirić, cylindrique, rougeâtre.

Spathe monopliylle trés-grandc, en cornet allongé et aigu; un peu ovö̈de à sa parlie iuférieure, offrant au-dessus un rélrécissement, puis inscnsiblement ouverte; d'un ver't pâlc, bordée de pourpre. Spadice allonģé, cn massue à sa partic supćrieure, qui est nue.

Flcurs fcmellcs, environ trentc, ocenpant la partie inférieure du spadice, calice et corolle nuls. Ovaire libre, sessile, ovoïde glabre, jaune; à une scule loge, qui conticnt trois a quatre ovules dressés. Stigmale scssile couronnant eliaquie ovaire, formé de petits grains glanduleux allongés.

Fleurs inâles, monandres, en grand nombre, rínies audessus des fleurs femclles. Aux pistils succèdent aulant de petiles baies rougeâlıes de la grosscur d'un pois, formant une sorte d'épi rlense, la parlie supéricure du spadice ćlant lombée.

Le gonet croit dans les licux ombragés et lumides; il est 
commun aux environs de Paris, où il fleurit dès le mois de inars. $z$

Propriétés et usages. La l'acine d'Arum est charnue et presque entièrement formće d'amidon; elle contient cu outre un suc àcre et laiteux, extrêmement caustique et brûlant, quand la racine est fraîche. Ce suc lui donne une propriété purgative très-intense; mais on en fait aujourd'hui fort peu usage, à cause de sa trop grande âcreté. Cependant, comme cette âcreté se dćtruit par la torréfaction et la fermentation, on s'est quelquefois servi de cette racine, privée de son suc caustique, pour rémćdier à la disette du pain, et servir d'aliment.

La racine d'arum est un des ingrédiens de l'opiat mésentérique et de la poudre d'arum composée.

$2^{\circ}$ Spadice nu et sans spathe à sa base.

ACORE. - ACORUS. L. J.

Spadice cylindrique, tout couvert de fleurs hermaphrodites très-serrées. Chacunè d'elles sc compose d'un calice à six divisions; de six étamines un peu plus longues que le calice; d'un ovaire à trois loges, surmonté d'un stigmate très-petit. Le fruit est une capsule triangulaire à trois loges.

Acore aromatiQue. Acortus calamus. L. Sp. 462 . Blackw. herb. t. 466.

Nom pharm. : Calamus aromaticus. Nom vulgaire : Acore vrai. Partie usiléc: la racine.

L'acorc offrc une racine vivace, rampantc, liorizontalc, de la grosseur du doigt, présentant des nœuds de distance en distance, et donnant naissancc à des fibres radicales très-nombreuses et à une touffc de fcuillcs élröitcs cnsiformes, glabres, striées, engainantcs à leur base, longucs de dcux à trois pieds.

La tigc est drcssée, très-simplc, comprimćc ct ensiforme comme les feuilles, un pcu plus longuc qu'clles; s'ouvrant a sa partie moyenne snr l'un de ses côtés, pour laisser sortir un spadice scssile, de la grosscur du doigt, long de deux à Irois 
pouces, et colvert de fleurs hermaphrodites. Ces flcurs sont tyès-serrćes les unes contre les autres. Le fruit est une pelite capsule triangulaire a trois loges, entource par le calice qui est persistant.

Celtc plantc croît sur le bord des fossćs et des étangs, dans les Vosges, l'Alsace, la Normanủie, etc. $\not 2$

Propriétés et usages. Sa racine est aujourd'hui répandue dans le commerce sous le nom de calamus aromaticus. Son olleur est agréable, sa saveur aromalique et comme camplirée. Elle renferme, d'après l'aralise de M. Tromsdorff, une huile volalile, le la résine, une malic̀re extraclive, de la gommc et de l'inuline. Cette racine doit être placée parmi les substances stimulanies: on l'administre en poudre à la dose d'un scrupule à un ǵros, ou en infusion dans du vin. On en fait rarement usage.

Propriètés médicales et usages des Aroüdées.

Dans celte famille de plantes, comme au resté dans presque toutes les autres familles monocotylédonćcs, ce sont les racines senles qui offrent del'intćrêt, sous le rapport de leurs propriétés médicales ou des usages économiques auxquels on peut les employer. Ainsi dans le plus grand nombre des Aroïdéeș, les racincs sont tuberculeuses, charnues, remplies de fécule, et peuvcnt, quand on les a privées lu șuc âcre ct caustique qui s'y trouve mélangé, servir efficacement à la nourriturc de l'homme. C'esı cc que l'on remarquc très-bien dans lẹs racines d'arum esculentum, a. colocasia, a. arisarum, etc. Cc principc âcrc étant Irès-volalil et solublc dans l'eau, on parvient à en priver ces racines, soit par la dessication, soit par la torréfaction, soit enfin par des lávages fićquemınent répétés.

Ce suc caustique rerd suspectes dans leur usage plusieurs plantcs de cette famille.

SIXI Ė I FA II ILE.

\section{PIPÉRINÉES. - PIPERINEAE.}

Cette famille est uniquement formée de l'ancien genre piper de linnæus, dont les auteurs de la flore du Pérou 
ont fait deux genres, savoir : le véritable piper contenant les espèces-fvutiqueuses et portant trois étamines, et le genre peperomia, qui comprend toutes celles qui sont herbacées et n'ont que deux étamines.

$\mathrm{Du}$ reste on conçoit que les caractères de la famille doivent être les mêmes que ceux du genre unique (Piper L.) qui la constitue.

Les Pipérinées sont une de ces familles sur lesquelles tous les botanistes ne sont pas encore réunis d'opinion. M. de Jussieu, dans son Genera, place le genre piper parmi les Urticées; mais cependant il en indique l'affinité avec les Aroidées (pag. 25, in obs.) Depuis cette époque, la plupart des botanistes ont imité M. de Jussieu, en rejetant les poivres parmi les Dicotylédones, et en les rapprochant des Urticées. Mon père et M. Kunth, jeune et déjà célèbre botaniste, qui rédige la Flore équinoxiale ${ }^{I}$ de MM. de Humboldt et Bonpland, en ont fait une famille nouvelle, qu'ils ont placée parmi les Monocutylédons, à côté des Aroïdées. En effet tous les caractères intéricurs, le port, la struçture des différentes parties rapprochent les Pipérinées des calamus et autres genres de la famille des Aroïdées, dont il est impossible de les éloigner, sans méconnaître les affinités les plus naturelles.

\section{POIVRIFR-PIPER.}

Fleurs aues, disposées en spadice eylindrique, sans involucre : chaque fleur se compose d'un ovaire uniloculaire, monosperme, terminé par un stigmate tri ou quadriparti : de 3 étamines, aecompagnées quelquefois d'éeailles irrégulières. Le fruit est une baie monosperme coriace et presque sèche. La tige est sous-frutescente.

= Nova genera et speeies plantarum americanarum, eto. 
Poivarer noin. Pipernigrum. L. Sp. r5g. Blackw., t. 348.

Nom pharm. : Fructus piperis nigri. Partie usitée: les fruits.

Cet arbrissean sarmenteux porte des feuilles alternes, ovales, acuminées, glabres, entières, courtement pétiolées, longues de trois à cinc poirces, larges d'environ deux pouees. Ses fleurs forment des chatons grêles et pendans, lonģs de quatre à cinq ponecs extraaxillaires : elles sont petites, verdâtres, sessiles, herınaphrodites; il leur suceède des fruits globuleux, pisiformes, rougeâtres, un peu charnus à l'extérieur, contenant intérieurement une seule graine.

Le poivrier croît dans l'Inde; on le eultive partieulièrement dans les îles de Jaya, Bornéo, Malaea et Sumatra. Le fruit entier, quand il est desséché, est noirâtre, ridó à sa surface, et porte le nom de poivre noir. Dépouillée de son périearpe, la ģraine, qui est jaunâtre et moins âcre, est désignnée sous le nom de poive blanc.

Propriétés et uisages. I,es usages économiques du poivre, comme condiment, sont trop eonnus pour que nous les rappellions ici. On sait que, mélangé avec modération daus les alimens, il excite les forces digestives de l'estomae, et favorise la digestion de substancesque, sans lui, eet organe ne pourrait supporter. Son usage convient partieuliérement aux personnes grasses, molles et lymphátiques. Oir doit surtout le mêler aux alimens tirés du règne végétal; tels que les choux, les narets, etc.

Le poivre est moins fréquemment employé comme médicament. Son odeur aromatiçue et piquanle, son goût âcre, brûlant, poivré, le placent au rang des médicamens.exeitaus les plus énergiques. On en a recommandé l'usagge dans les fières intermittentes, dans l'anorhexie, et plusieurs autres maladies. On a également vanté ses vertus cmménagogue, dinrétique, etc.; mais dans ee eas il ne doit èłre adıninistré que quand la suppression des règles ou de l'nl'ine dépend d'une faiblesse loeale ou générale; dans le cas contraire il aggraverait la maladie, loin d'y porter remède.

Il entre dans un très-grand nombre de préparations 
pharmaceutiques, telles que la thériaque, le mithridate, ete.

On peut donner le poivre en poudre, depuis cinq jusqu’à vingt-eincl grains; en infusion, dans du vin blane, un gros pour une livre de viu, ete.

M. Pelletier vient de soumettre le poivre noir à une nouvelle analise, surtout pour s'assurer des résultats de M. OErsted, qui a annoncé (Jour. de pł̌ysiq. : févicier $\mathbf{x}_{2} \mathrm{I}$ ), avoir découvert dans ces fruits une nouvelle base salifiable, à laquéllé lë poivre devrait sa saveur et ses propriétés. Mais le chimiste de Paris est loin d'être arrivé aux mêmes résultáts. M. Pelletier a rctiré du poivre noir une substance cristalline, mais eettè substanee est tout-á-fait insipide, et ne peut en aucune manière se combiner avec les acides. C'est un principe immédiat nouveau que M. Pelletier propose d'appeler Piperin. La savér du poivre est due à une huile particulière peú volatile. Dú reste l'analise de $\mathbf{M}$. Pelletier s'accorde parfaitement areć celle des Cubèbes, qui a été faite antérieurement par \$L. Vauquelin.

Poivrier cubèbs. Piper cubeba. L. Suppl. go.

Nom plsarm. : Piper caudatum. Noin vulg.: Cubébe :poivre d queue. Partie usitée: les fruits.

Cette espèce est également sarmentéuse et glabre dans toutes ses parties : sa tige est flexueuse et articulée : ses feuilles sont pétiolées, ovales, oblungues, quelquefois laneéolées, entiéres cl eoriaces; elles sont un peu inćquilatérales. Les fleurs constituant des épis allongés et pendans sont longuement pédicellées, caractçe qui, les distinguant très-bien de l'espèce précédente, leur a valu le nóm vulgaire de poive à queuc (Pipér caudatum ). Les fruits sont pisiformes, noirâtres, ridés, portés sur lcur pédoncule.

Le eubìbe eroit dans l'Inde, à Java, en Guince, etc.

Propriétés et usages. Ce n'est que depuis un très-petil nombre d'années que les'fruits du cubèbe sont sortis de l'oubli auquel leurs qualités, moins énergiques que celles du poivre noir, semblaient les avoir eondamnés. Ils jouissent en effet à peil pres de la même saveur ét de la même odeur que le pré- 
cédent, quoiqu’à un degré plus faible. Cependant ils doivent également être regardés comme essentiellement stimulans. On concevra d'après cela assez difficilement l'usage auquel on les emploic aujourd'hui, et les succès que l'on obtient de leur administration. On combat maintenant avee la poudre du poivre cubèbe les blénorrhagies urétrales même les plus intenses, et par ce moyen on arrête, dit-on, presque instantanément les accidens inflammatoires. C'est en Angleterre que cette nouvelle méthode de traiter la blénorrhagie a étẻ d'abord mise en pratique. Elle a ensuite été imitée en France par plusieurs grand praticiens, parmi lesquels nous citerons $\mathbf{M}$. Cullerier à Piris, et M. le professeur Delpech à Montpellier, qui paraissent en avoir égaleinent obtenu des suceès. Pour produire eet effet, on emploie la poudre de Cubèbe à la dose d'un gros et demi, répétée trois fois dans les vingt-quatre heures. Il est rare que l'on soit obligé d'aller au delà.

"ivi. Vauquelin a soumis les eubèbes à une analise qui n’a rien fourni de bien intéressant; voici ses résultats : $x^{\circ}$ Une huile volatile presque concrète; $2^{\circ}$ une résine semblable à celle du baume de Copahu; $3^{\circ}$ une petite quantité d'une autre résine colorée; $4^{\circ}$ une matière gommeuse colorée; $5^{\circ}$ un principé cxiractif analogue à celui qui se trouve dans les plantes légumineuses; $6^{\circ}$ quelques substances salines.

\section{Propriétés médicales, et usages des l'ipérinées.}

Cette famille doit être rangée parmi celles où les propriétés, médieales présentent l'uniformité la plus grande. En effet, les différentes parties de ees plantes possèdent, à un degré plus ou moins prononé, cette saveur âcre et brûlante si développée dans les fruits de plusieurs espèees, telles que les $P$. nigrum, $P$. cubcba et $P$. betel. Aussi dans les pays où croissent naturellement les espèces de poivriers, emploie-t-on indifféremuent les espices indigènes pour remplacer les exotiques.

ll n'existe pas de plantes vénéneuses dans la fanilles des. Pipórimies. 
SEPTIEME FAMILLE.

\section{CYPERACÉES. - CYPERACEA.}

\section{Cyperoideæ J.}

Les fleurs sont hermaphrodites ou unisexuées, tantôt monoïques, tantôt dioïques, disposées en épis ou chatons: les enveloppes florales consistent daus une simple écaille; les écailles inférieures sont souvent vides, par l'avortement des fleurs; les étamines sont au nombre de trois; le pistil se compose d'un ovaire à une seule loge et à une seule graine, surmonté d'un style qui se termine par deux on trois stigmates; autour de la base de l'ovaire on trouve quelquefois des soies plus ou moins nombreuses, qui prennent un accroissement très-grand dans le genre eriophorum; d'autrefois c'est un urcéole membraneux monophylle qui enveloppe la presque totalité de l'ovaire.

Le fruit est un petit akène de forme variable. Les tiges ou chatumes des Cypéracées sont le plus souvent dépourvues de nouds, et présentent fréquemment des angles; leurs feuilles sont engaînantes, et leurs gaines ne sont point fendues.

$I^{0}$ Fleurs hermaphrodites.

\section{SOUCHET. $-C Y P E R U S . \mathrm{L} . J$.}

Fleurs hermaphrodites, disposées en épillets allongés; les écailles sont distiques et imbriquées sur les côtés d'un axe commun. Les fruits ne sont point accompagnés de soies à leur base.

Souchet Long. Cyperus longus. Lin. Sp. $67^{\circ}$

Nom pharm. : Radix cyperi longi. Parlic usitée : la racine.

Sa racine est brunàtre, rampant obliquement sous la terre ; sa saveur est aromatique, piquante, et offre quelque analogie 
avec celle du gingembre; son odeur est aromatique et assez agréable; sa tige est triangulaire nue, haute d'environ deux pieds; toutes ses feuilles sont radicales, assez longues, lancéolées, aiguës et carénées sur leuir dos, un peu rudes sur les bords. Les épillets sont portés sur des pédicelles ramifiés, inégaux, disposés en ombelle à la partie supérieure de la tige; ces épillets sont roussâtres, allongés, très-étroits, presque linéaires et pointus à leurs dcux extrémités.

Cette plante croît sur le bord des ruịsseaux. Elle fleurit en été. $\mathcal{F}$

Propriétés et usages. Sa racine est connue sous le. nom de souchet ou souchet odorant. Elle est légèrement excitante; on a long-temps vanté ses vertus emménagogues et stomachiques. Elle est aujourd'hui fort peu employće.

On peut en dire autant de la racine de souchet rond (cyperus rotundus), qui est tubéreuse, arrondie, d'une saveur amère et comme résineuse, et qui n'est plus usitće.

Lcs tuberculcs du souchet comestible (C. esculentus), sont charnus, ont une saveur sucrée et agréable, et sont mangés en Espagne, en Italie, en Egypte, elc. On en fait, dans quelques contrées, une sorte d'orgeat en les broyant dans de l'cau avec du sucre.

Ces trois espèces croissent également en France.

$2^{\circ}$ Fleurs unisexuées.

\section{A ICH E. $-C A R E X . \mathrm{L} . \mathrm{J}$.}

Flcurs monoïques dans un même épi ou dans deux épis distincts ou chatons écailleux : fleur's mâles ayant trois étamines : fleurs femelles présentant un ovaire ordinairement triangulaire, entièrement enveloppć dans un urcéolc ouvert au sommet :style simple, terminé par trois ou senlement deux stigmates. Le fruit est un akène enveloppé dans son urcéole.

Le chaume est très-souvent triangulaire. 
Laichis des sibles. Carex arenaria L. Sp. 1381. Schkw. Car., n. 8, t. B.

Nom pharm. : radix caricis. Nom vulg. : Salscparcille d'Allemagne. Partie usitée: la racine ou souche soutcraine.

Cette petite plante cst remarquable par la longueur de sa racine, qui est une souelic liorizontale, rampante sous la terre, grossc comme une plume à ćcrire, noneuse el enveloppéc des débris des feuilles desséclices et devenues brunâtres; les rameaux sont redressés, triangulaires, hauts de cinq à six poueec, assez-nombreux, rudes sur les angles; les feuilles sont engầnantes, ćtroites, aiguës, très-rudes au toucker. Les fleurs sont roussâtres, disposées cn un épi composć đe cinq a six épillets ovoïdes, allongés; les épillets inférieurs sont formés de fleurs femelles, lcs supérieurs de fleurs mâles et·femelles entremêlécs. Les ćcailles sont ovales lancéolćes, très-aiguc̈s, plus longucs que les fruits, qui sont triangulaires el terminés par deux petites.pointes.

Cette espèce eroit dans les iicux sablonneux aux environs de Paris, a Mortefontaine, et sur'les bords de la mer. On la plante dans les lieux sablonneux et sur les dunes pour arrêter et fixer en quelque sorte lc terrain. 2

Propriétés et usages. Ses racines ont une saveur légèrement aromalique, qui a quclque analogie arec eelle de la salsepareille. $\Lambda$ ussi l'a-t-on proposće comme suecćdanée indigène de cettc racine, et est-elle connue sous le nom vulgaire de salseparcille d'Allemagne. Merz, qui a ćcril une disscrtation sur les cspèces de carex quc l'on peut substitucr à la salsepareille, vante singulièrement les effets de celte plante dans le traitement des maladies vénériennes.

Plusieurs autres espèces, à racines longues ct rampantes, jouissent dcs mềnes propriétés.

\section{Propriétés incidicáles: et üsages des'Cypéraciées.}

Les Cypéracćes présentent fort peu d'intérêt, considérúes sons le point dc vuc de lenrs propriétés médicales. Ce sont presque toutes des plantcs herbacćes insipides et inodorcs. Il n'y a 
guère quc les racines de cerlaines espéces de laiches et de souchets qui soient douées de quuelque vertu excitante, à cause de leur odeur aromatique et de lenr saveur plus ou moins piquante. Encore ces médicamens sont-ils presque inusilés par les praticiens modernes.

H U.ITI I I E F MITII.

\section{GRA MINÉES. - GRAMINEAE.}

Les Graminées, l'une des familles 'les plus naturelles du règne végétal, présenteut une organisation tellement particulière, 'qu’il est impossible de néeonnaître l'af. finité des genres qui la composent. Leurs fleurs sont, 'à proprenient parler, nues, e'est-à-dire eomposées des seuls organes șexuels, sans ealice ni corolle; 'de simples écailles tiennent lieu de ces enveloppes. La disposition régulière de ees écailles leur a fait donner des noms partieuliers; ainsi l'on nomme glume I les deux éeailles qui forment ehaque fleur; tantôt cette glunie est bivalve, quelquefois elle n'est eomposée que d'une seule valve ou écaille; les fleurs des Graminées sont le plus souvent hermaphrodites, quelquefois elles sont unisexuées, monoïques, ou diö̈ques, ou polygames : les fleurs hermaphrodites sont composées' d'un pistil formé d'un ovaire uniloculaire, monosperne, surmonté d'un ou deux styles et le plus souvent de deux stigmates birbus ot glanduleux; le nombre des itamines est ordinairenuent de trois, cependant il. y a des Grami-

- Tous les auteurs ne sont pas d'aceord sur les noms à donner aux écailles florales des Graminées. Linnæus noinmait glume ou calice ce que nous appelons lépicène; eorolle ce que nous nommons glume, et neetairc ce qui est désigné sous le nom de glumclle. Jussieu au contraire appelle caliee ee que Linnæus nommait eorolle; Beauvois clonne le nom de bale à la lépicène, et le nom de glumes à. chacune de ses valves; celuide'stragule à notre glime, qui est la corollc de Linmaxis et le calice cle Jussieu. 
nées à une, à deux, à six et à un grand nombre d'étamines; à la base de l'ovaire se trouvent une ou deux petites paléoles (qui manquent quelquefois); elles constituent la glumelle. Ces fleurs sont le plus souvent rassemblées plusieurs ensemble sur un axe commun; et forment de petits épis qui portent le nom d'épillets (spiculae). A la base de ehaque épillet, on trouve deux éeailles vides, sans organes sexuels, constituant la lépicène; quelquèfois il n'y a qu'une valve ou écaille à la lépicène, qui est alors univalve. Les épillets sont tantôt réunis en un épi serré et simple, d'autres fois eet épi est rameux; enfin ils constituent fréquemment une pañieule.

Le fruit est une cariopse ou un akène; l'embryon est endospermique, extraire et basilaire; l'endosperme est farineux; l'embryon est plus ou moins dur.

La tige des Graminées porte le nom de chaume; elle est ordinairement ereuse et marquée de nœuds de distanee en distanee; les feuilles sont alternes et engaînantes; leur gaine est fendue longitudinalement; au point de réunion de la gaine, que l'on peut regarder comme une sorte de pétiole, et de la base de la feuille, est une petite languctte désignée sous le nom de ligule.

$\mathbf{x}^{0}$ Fleurs hermaphrodites, à trois étamines.

\section{A. Fleurs en épis.}

\section{FROMENT. - TRITICUM. L. J.}

Épillets solitaires sur chaque dent de l'axe, qu'ils regardent par leur partie latérale; lépicène bivalve, contenant de trois à dix fleur's; valves navieulaires, terminées par une soie et ćehancrées au sommet; glume formée de deux paillettes dont l'inférieure est également terminéc par une soie (quelquefois toutes les éeailles sont muliques, c'est-à-dirc sans soie ni arète). Style biparli; deux stigmates plumeux. Le fruit est une cariopse ovoïde, marquée d'un sillon longitudinal, souvent enveloppéc dans la glume. 
Fronent cultivé: Triticum sativum. Lamk, enc. 2.p. 554 . $T$. cestivum et $T$. hybernum. L.

Chaumes dressés, simples, hauts de einq à oix pieds, glauques, noueux, glabres, porlant des feuilles alternes, engaînantes, linéaires, glabres, molles et d'une couleur verte un peu glauque.

Fleurs disposées en épi serré, à l'extrémité de la tige. Axe commun, simple, flexueux et denté, denls alternes, un épillet multiflore à elıque dent. Chaque épillet se compose d'une lépicène bivalve égale, contenant ordinairement trois à quatre fleurs. Ces valves sont ćgales, carénées, comme tronquées à leur sommct.

Chaque fleur a une glume composée de deux paillettes mutiques, emboîtćes l'une dans l'autre, navieulaires; l'extćrieur'e est plus grande cue l'intérieure qu'elle recouvre. La glumelle se eompose de deux palćoles arrondies, velıes, situées du eôté externe.

Le fruit est ovoïde, jaunâtre, marqué d'un sillon longitudinal; il est tantôt glabre, tantôt velu, sclon les varićtés, qui sont fort nombreuses, tant sous le rapport de la couleur et de la grosseur'du fruit, que pour la forme des ćcailles florales, qui sont tantôt mutiques, tantôt aristées, ete.

On ignore la patrie du blé, de même au reste que celle de la plupart des autres cérćales qui sont eultivćes depuis longtemps. Quelques auteurs la placent dans la Perse, et je serais d'autant plus porté à adopter cette opinion, que j'ai trouvé dans les plantes recueillies en Perse par And. Michaux, des ćchantillons de eette plante, qui par leur port, leur forme générale, semblent annoneer des individus sauvages et noncultivćs. Cependant, comme aucune note ne les aceompagne, je suis loin de donner cette assertion eommc positive.

Froprićtés et usagres du froment ou blé. La farine du froment fait la base d'un des alimens les plus sains, les plus nourxissans, du pain de froment. Lorsqu'il est bien préparé, ce pain est blanc, d'unc odeur faible, inais agréable, d'une saveur douee, légèrement suerée. Il est un de ceux que l'estomac digère le plus facilement. $\Lambda$ ussi convient-il beaucoup plus aux lıa- 
GRAMINÉES.

bitans des villes, dont l'estomac cst en gínéral plus faible, qu'aux gens des campagnes, chez lesquels l'habitude du travail, l'excrcice journalier, l'exposition au grand air excitent et développent d'une manière remarquable les forces digestives.

Le son, ou l'enveloppe exlérieure din fruit, que l'on sćpare de la farine, sert à la nourriture des bestiaux ct à la préparation de décoctions, dont on fait des lavemens acloucissans.

La mie du pain cuite dans l'eau, dans du lait ou de la décoction dc guimanve, formc des cataplasmes émolliens, que l'on cst obligé de rcnouveler fréquemment, parce qu'elle s'aigrit très-promplement.

Plusieurs autres espèces de froment sont cultivécs en grand dans différcntes provinces de la Francc; tels sont le froment à épi rameux ou blé de miracle ( $T$. composilum); Ic froment à grain dur ( $T$. clurum. Desf. ); l'épautre ( $T$. spella. ); le froment locular ou petitc épautre ( $T$. monococcum), cullivé dạns le midi de la France, et avec les graines duquel on fait sui tout de la bierre et du gruau.

C'est au,gluten contenu dans la farine de froment que celle-ci doit principalement ses propriétés alimentaires. Il est d'autant plus abondant, selon .M. Iavy, que le blé provient d'une contréc plus méridionale. M. Proust en a retiré 12 p. Ioo de la farine qu'il a analisée, et $M$. Vogel jusqu’à 24 p. 100 ; mais il faut obscrver que celui-ci n’était pas desséché. Le blé contient en outre de 68 à 74 j). 100 d'amidon, et 10 à 12 d'extrait gommeux sucrú. Toutes ces substances sont nutrịtives; mais le gluten, comme malière végéto-animale, et par consćqucnt plus assimiluble aux principes animaux quc les autres, constitue par sou abondance la bonne qualité de la farine; cc que lęs boulangers savent fort bicn: plus la pâte cst tirante, diseut ills, et meillcur doit êtrc le pain.

Froment ranpant. Triticum repens. L. Sp. 128 . Schreb. gram. t. 26.

Nom pharm. : radix tritici. Nom vulgaire : chicndent des buiztiques. Partie usiteic: la racine.

C'eltc plante est vivace; sẹs racincs, longues, xampanics, s'élendent ct se propagent arce unc rapidité rqui fair quclęuc- 
lois le désespoir du cultivatcur. Ces raeines, on tiges souterraines, sont blanches, grêles, eylindriques, nòueuses. Léur's liges, droites, hautes d'environ deux pieds, portent des feuilles molles, vertes, légèremient vèlues en dessus. L'épi est allongé, comprimé, longr de trois ponees ou à pcu près; les épillcts sont distiques sans arètes et renferment ordinaircment de quatré à cinq flenrs; les valves sont aiguës à lcur sommet.

Cette plante eroit en abondance dans les lieux incultes, lé long des haies, des vieux inurs. $₹$

Propriétés et usag'es. Ce sont ses raeines que l'on vend soùs le nom de chiendent. Lcur décoction est très-fréqueminent mis̀e en usage. Elle est un peu mucilagineusc, et contient qúelques prineipes salins, đui la rendent légèrement raffraíchissante ét diurétique.

Un'e seconde espčce de chichrlent beaucoüp möins employée, est fournie par une autre Gráminée, nommée, pied de poule (eynodon daetylon. Rich. ou Panicum dactylon L.)

$$
\text { IVRAIE-LOLIUM. L.J. }
$$

Cé genre diffère du froment par la posilion de ses épillets, qui regardent l'axe par une de leur's faees, et non par un de Icứrs côtés, et par sù lépicène, qui est quelquefois à une seulé valve.

\section{Iyraie enivrante. Lolium temulentum. L. Sp. 122.}

\section{Bull. t. 107.}

Racine annuelle, capillaire, surmontće d'un chaumè dicssé, haut d'rin,à deux pieds, offrant quelques noèds. Feuilles engainantes, très-longues, plarics, asseź larges, un peu rudes au ioucher; gainc fendue, offrant à son orifice une mcmbrane ironquéc.

Fleurs disposécs cn épi distique à la partic supérieurc du chaume : épillets alternes sessiles, coinprimés d'avant en arrière.

Lépicène bivalve parallc̀le à l'axe, renfcrmnant six fleurs, qui constituent un épillet allongé et eomprimé; valves inégales; l'externe de la longeur de l'ćpillct, lancéolée, aiguë, striće longitudinalcment, l'interne pliss petitc, ayaut à peu près le tiers de la hauteur de l'épillet, minee et scarieusc. Dans chaque 
fleur la glume est bivalve; les valves sont à peu près égales; l'extérieure, un peu plus grande, ovale, striée, presqu'obtuse, est terminée par une arète assez longue, droite, subulée et un peu scabre, qui est insérée au-dessous de son sommet. Le fruit est allongé, petit. Cette plante est commune dans les ehamps. $\odot$.

Proprićtés et usages. L'ivraie est une plante déjà connue par les auteurs de l'antiquité, et désignée comme un des végétaux les plus nuisibles aux moissons et à l'homme. Mais ces assertions nous paraissent exagérées, et ont besoin d'étre réduites à leur juste valeur. Les fruits de l'ivraie paraissent contenir un prineipe vireux et délćtère, qui a souvent occasioné des accidens graves, lorsque les graines de cette plante se sont trouvées mélangées avee le blé ou le seigle. Mais cependant ces aceidens n'ont jamais été jusqu'à produire la mort. Quelques expćriences plus récentes sembleraient même n’attribuer à l'ivraie aucune propriété délétère, opinion que cependant nous sommes loin de partager.

Parmentier a donné le moyen de faire perdre aux graines d'ivraie leur âcreté. Il suffit de les sćcher au four avant de les réduire en farine. Le pain que l'on prépare alors avee elles, n'est plus malsain, surtout quand on le mange lorsqu'il est bien refroidi.

$$
\text { SEIGLE. - SECALE. }
$$

Épillets solitaires sur chaque dent de l'axe, biflores; lépicène à deux valves lancẻolćes; glume à deux paillettes, dont l'inférieure est terminée par une soie; la supérieure est mutique. Les deux styles sont extrêmement eourts, les deux stigmates sont plumenx : la eariopse est enveloppée dans la glume et marquée d'un sillon.

Seigue cultivé. Secale cereale. L. Sp. 124. Lamk. Ill. t. 49 .

Racine eapillaire annuelle. Chaume herbacé, noueux, glabre inférieurement, lisse, de quatre à six pieds de hauteur. Feuilles altérnes engainantes.

Fleurs bermaphrodites disposćes en un épi allongé, simple, barbu. Lépicène bivalve, bifore, attachice à chacun des erans 
du rachis. Valves ćtroites, lancéolées, aiguës, rudes, 'plus, courtes que la glume.

Glume bivalve; valve extérieure plus grande, comme elı nacelle, couverte sur son angle externe de poils cour!s et très-rudes, terminée à son soinmet par un aréte filiformc, longue, droile et très-rudc; valve intérieure un peu plus courte, muliquc, assez molle, allongée, obtuse, concave.

Le fruit est une cáriopse ovoïde allorgée, marquée d'un sillon longitudinal.

Cette graminée est originaire de l'Asie mineure; on la cultive aujourd'hui en Europe, dans les contríes froides et les terrains maigres. (-).

Propriétés et usages. Le pain fabriqué avec sa farine est un peu dense, gras, d'une couleur brune; son goût est agréable; il est fort nourrisant, un peu rafraîchissant. Quand on inchle ensemble les farines de froment et de seiglc, on obtient un pain plus substantiel et encore plus nourrissant.

On fait avec la farine de seigle des cataplasmes résolutifs.

Plusieurs graminées, le seigle surtout, sont sujettes à présenter, à la place de leur grain, une excroissance noirâtrc, allongée, plus longue que les écailles florales, recourbsé en crochet, et que l'on désigne sous le nom d'ergot; dc là le nom de seigle ergoté donnć à leurs grains, lorsqu'ils offrent ce phénomène. Jusqu'á présent l'on avait attribué cette transformation à une maladie qui dénaturail la substance intćrieure de la graine du seigle. M. de Candolle, au contraire, regarde cette végétalion comme une espc̀ce particulière de champignon, auquel il donne le nom de sclerotium clavus.

Quoi qu'il en soit de ces deux opinions sur la nature de l'ergot des Graminées, il est certain qu'il donne lieu à des aecidens extrèmement gravcs, lorsqu'il se trouve mćlangé, cn quantité notable, dans les farines de seiglc ou de froment : ces accidens sont des vertiges, des ćtourdissemens, la gangrène des extrémilés, et mème la mort.

Malgrć cette action délélc̀re, l'on a essayé l'emploi dc l'ergot à l'intérieur. Quelques pratieiens l'ont préconisé commc possédant la vertu d'excitcr les contractions de l'utérus, et comme propre à activer le travail dc l'accouchement, lorsqu'il 
est lent et diffieile à cause de la faiblesse de cet organe. Mais les essais tent'́s ì cet égard n'ont point justifié eelte propriété.

Le seigle ergoté, analisé par M. Vauquelin, ( $A n n$. de Chimie et de Physique, t. 3, pag. 337 ) lui a présenté pour sıbs tanees immédiates: ${ }^{\circ}$ Deux niatières coloranles, l'une jaune fauve et soluble dans l'aleohol, l'autre violette, analogue à l'or. seille, mais insoluble dans l'alcoho!, et pouvant être employée dans la teinture. $2^{\circ}$ Une matière huileuse, doueeảtre et trèsabondante. $3^{\circ} \mathrm{Un}$ aeide indéterminé (probablement de l'aeide phosphorique.) $4^{\circ}$ De l'ammoniaque libre. $5^{\circ} \mathrm{Et}$ une subsianee végéto-animale très-abondante et trc̀s-disposée à la putréfaction, par conséquent, ni amidon, ni sucre, ni mueilage, ni albumine, matière dont est presque entièrement eomposée la färine de seigle à l'état oiddinaire.

\section{ORGE. - HORDEUM. L. J.}

Trois épillets uniflores à chaque dent de l'axe; lépieène bivalve, valves laneéolées, aiguës; glume bivalve , pailieite inférieure terminée par une soie, la supérieure entière; style biparli, stigmates glanduleux et poilus; eariopse sillonnée, enveloppée dans la glume.

Orge cultrvé. Hordeum vulgare. L. Sp. I 25. Blackw. herb. t. 423 .

Racine annuelle capillaire. Chaume haut d'environ quatre à cinq pieds, cylindrique, giabre, un pen glauque, fistuleux et noueux. Fenilles alternes engaînantes à ehaque nœud de la tige, planes, laneéolées, très-aiguës, un peu rndes an toueher, glabres.

Fleurs en épi dense et serré à l'extrémité de la lige. $\boldsymbol{\Lambda}$ xe commun, denté, à dents alternes; trois fleurs sessiles à chaque dent. Chaque fleur présente une lépicène composèe de deux valves linćaires, aiguës, glauques, finissant en une soie trèsfine. Glumc à deux paillettes; l'extérieurc plus griande embrasse l'interne dans presque tout son contour; elle se terminc à son sommet par ane soie très-Iongue, aplatie, effilće, roide, présentant sur ses deux bords de petites pointes rodressées, trèsrudes. L'intérieure ëst ovale, airguè, creusée extérieurement d'une large gouttière, qui receoit le côté de la fleur voisine. 
玉e fruit, qui est la scule partic usitée, est oroüde, jaunàtre, commetronqué à son sommet, marqué d'un sillon longitudinal.

Proprietés et usages. L'orge est originaire, à ce que l'on soupconne, dé la Sicile; il mérite à plus d'ún titre notre attention : $1^{\circ}$ commc aliment, $2^{\circ}$ comme médieament.

Comme aliment, l'orge fait la base de la nourriture du panvre, dans les pays du Nord, où le frornent ne peut réussir. Le pain préparé avec sa farine est plus lourd, plus grossier, beaueoup moins nourrissant que le pain de seigle, et à plus forte raison que le pain de froment. Il est, dit-on, rafraichissant.

La bierre, celte boisson fermentée qui remplace le vin dans toute l'Europe septentrionale, est faite avee l'orge et le houblon.

Comme médieament, l'orgc bouilli dans l'eau, forme une tisane à la fois rafraichissante et légèremeut nourrisante. On se sert plus particulièrement pour eette préparation de l'orge mondé ou de l'orge perlé, c'est-ì-dire des grains privés de leur enveloppe et plus ou' moins arrondis.

Selon M. Proust, la composition approximative de la farine d'orge est celle-ei : Résine jaunc I, extrait gommeux sucré 9 , gluten 3 , amidon 32 , hordeïn 55 . Cette dernière substance est placée par M. Thénard parmi les principes immédials clouteux; c'est elle qui nuit le plus à la bonté de la farine d'orge; qui d'ailleur's serait très - alimentaire, vu la grrande quantité d'extrait gommeux suerć relativement aux autres matières.

\section{B. Fleurs en panicule. \\ AVOINE-AVENA. L. J.}

Les valves de la lépiec̀ne, qui renferme de deux à sept neưrs, sont membrancuses, plus longues que les fleurs; la glume est. à deux pailleltes, dont l'inférieure offre une arête croclue ct tordue, qui part du milieu de son dos.

Avorne cultivie. - Averia sativa. I. Sp. x 8 . Blackw. t. 1322.

Raeinc annuelle, eapillaire, donnant naissance a deschutu- 
mes hauts $\mathrm{dc}$ deux à trois pieds, portant à chaque noud des feuilles linéaires aiguës.

Fleurs disposées en panicule lâehe, un peu pendante. Pédoneulcs scmi-verticillćs, portant un ou deux ćpillets triflores; la troisième fleur est stérile et rudimentaire. Lćpicc̀ne bivalve biflore, valves égales ; mutiques, laneéolćes, très-aiguës, carênées, glabres. Glume à deux valves; l'extérieurc plus grande, lancéolće, trc̀s-aiguë, terminće par deux pointes, ehargće de longs poils bruns et soyeux, offrant sur le milieu de son dos une arĉte roide; eette valve est effilée, deux fois plus longué que la fleur, embrassant presque entièrcment la valve interne, qui est plane et glabre.

Le fruit est allongé, aigu, brunâtre, enveloppé dans la glume.

Propriétés et usages. L'avoine n'est point seulement l'aliment principal de nos chevaux; les gens de la campagne, dans certaines provinees de l'Oucst, s'en nourrissent prcsque exelusivcment. Le gruau d'aroine se prépare en enlevant l'écoree extérieure des grains, et en les concassant grossièrement. Cctte préparation cst fort usitée; on cn fait, par la déeoction, des tisanes adorcissantes, dont on recommande l'emploi dans les rhumcs, les maladies de poitrine, etc. On peut faire cuirc. le gruau dans du lait ou du bouillon gras; il est fort nourrissant.

On doit à MMM. Davy et Vogel l'analise de la farine d'avoine. Leurs rćsultats sont assez différens, puisque le premier y a trorrvé 6 p. roo de gluten, landis quc M. Vogel ne le signale pas comme un des principes constiluans de celte graine. Indépendamment de la fécule, du sucrc el du mucilage, l'avoine renferme aussi une huile grasse ct un principc amer que M.Vogel n'a pu isoler du sucre.

$$
\text { ROSEAU. - ARUNDO. L.J. }
$$

Épillets solitaires, multiflores; lépicc̀ne à deux valvcs aiguës, glumc à deux palćoles eouvertes ă Jcur base d'mne touffc de poils persistans. 
Rosenu a quenouilles. - Arundo Donax. L. Sp. 120.

Nom pharm. : Radix donacis. Nom vulgaire : Canne de Provence.

Cette bellc graminée a une racine vivaec; ses tiges sont droites, hautes de huit à dix pieds, ligneuses, ereuses intérieurement', et séparées de distanee en distance par des nouds pleins; ses feuilles sont larges d'environ deux pouees; longues de deux pieds, un peu rudes au toneher; sa pańienle est très-grande, très-rameuse, terminale et un peu dense; la lépicène est triflore; la glume est de la longueur de la lépieène.

Cette plante eroit abondaument dans le midi de la Franee, où on la cultive sur la lisière des champs. Elle fleurit en septembre et en oetobre. 2

Propriétés médicales et usages. La racine est la seule partic nsitée en unédecine; elle est douce et sucrée. Sa déeoction est légèrement diurétique et porte à la pean. Elle jouit d'une fort grande réputation parmi les femmes du peuple qui l'einploient comme antilaiteuse après l'aecouehement.

La raeine du roseau à balais (A. phragmites L.) possède les mêmes propriétés et s'emploie aux mêmes usages. Elle a aussi été vantée comme possédant des propriétés, antisyphilitiques, et à eet égard on a mème prétendu qu'elle faisait la base dı fameux Rob de Laffecteur. Mais il n'est guère probable qu'une raeine aussi insignifiante puisse produire les effets, sans doute exagérés, qu'on attribue à celte préparation.

\section{GAN'NE A SUCRE. - SACCHARUM.L.J.}

Épillets paueiflores géminés; l'un sessile, l'autre pédoneulé, tous deux hermaphrodites; lépieène bivalve, environnée de poils persistans; glume à une seule paléole.

Ganne a sucre officinale. Saccharum officinamu. L. hort. cliff. 26 .

La canne à sucre est une des plus belles et des plus grancles espèees de toute la famille des graminées. Sa raeine est vivaec; 
ses liges sont droiles, alteignant dix et douze pieds de hauteur, cylindriques, pleines intérieurement et comme charnues, striécs cans leur longueur, ayant les entre-nœuds rapprochés et un peu renflés; elles portent des feuilles engainantes, planes, aiguës au sommet, longues au moins de deux à trois pieds, larges de deux pouces, un peu rudes au toucher, rapprochées les unes des autres. Les flcurs forment une panicule terminale très-grande, éfalée, ayant une forme presque pyramidale. Les épillels sont triflores. Les valves de la lépieène sont marquées d'une nervure longitudinale, peu apparente, rarement de deux, et convertes de longs poils soyeux.

La canne à sucre est originaire de l'Inde, d'où elle a ensuite été transportée et naturalisée dins le nouvean Monde. Le fáncux uavigatcur français de Bougainville, dans son voyage autour du monde, a transporté d'Otaïti dans les Antilles une variété très-renarqiuable, plus grande, plus robuste, résistant micux au froid, donnant une plus grande quantitć de sucre, ct qu'il serait faeile de naturaliser et de ezlliver en grand dans l'Europe méridionale. 2

Usages et propriétés. C'est des tiges de cette Graminée que l'on retire la plus grande partie du suere consommé en Europe. Le sue abondant qu'elles renferment, exprimé au moyen de presses très-fortes, cuit jusçu'à consistance de sirop épais ct ensuile abandonné à lui-mème, se cristallise confusćment et se prend en masse irrégulièrc. C'est dans cet état de cassonade qu'on le transporte en Europe, où, par des procétlés divers il est purifié ou raffiné avce soin et. qu'on lui domne la forme de pains coniques.

Le sucre est einployé à tant d'usages différens dans l'économie donestique, il joue un si grand ròle dans une foule de préparations pharmaceutiques, qu'il doit ćtre compté parmi les substanees exotiqques les plus indispensables. Il est vrai que li découverte du sucre de betterave diminıe singulièrement l'importance du sucre de canne; néanmoins cette substance n'en reste pas moins un des prodnils les plus précienx de nos colonies.

I.e suere n’est presque jamais employé scul comple médicament; on uc le mel gurre en usrige que comme condinrent, 
et sous ee rapport son emploi est immense. Celle substance est fort nourrissante, surtont avant son raffinage, ear les nègres employés à son extraetion en font leur seul aliment, et ils sont: en général très-forts et très-vigourcux.

la canne à suere nous intéresse eneore par un autre de scs produits; c'est le rhum, on cau-de-vie de sucre, que l'on obtient en soumeltant à la fermentation spiritueuse les éeumes relirées lors de la euite du snere.

$2^{\circ}$ Fleurs herınaphrodites à six étamines.

$$
\text { RIZ. - ORYZA. L. J. }
$$

lipillets uniflores; lépicène à deux valves très-pelites, linéair'és; glume à deux paillelles eomprimées, striées l'inférieure; plus grande en forme de nacelle earénée, terminée à son sommel par une soie qui manque quelquefois. Six étamines.

\section{Riz cultrvé. Oryza sativa. L. Sp.}

Chaume droil et dressé, haut de trois à quatre pieds, eylindrique, glabre, présentant trois ou quatre nouds.

Feuilles linéaires, lancéolées, aiguës, souvent longues de donze à dix-huit pouees, glabres, denticulées et très-rudes sur les bords; gaîne profondément fendue; ligule membraneuse dressée eontre le elıame, minee, glabre, biparlie. $\Lambda$ la base de la feuille, au point ou les deux bords se eonfondent avee la gaîne, on tronve, de ehaque côté, nn petit appendice falciforme, offrant à son bord inférieur une rangée de eils longs et soyenx.

Tleurs disposées en une panicule terninale, plus ou moins élalée. Épillels uniflores: lépiè̀ne bivalve, velue et très-petile; glune, également à deux pailleltes, trois à quatre fois plus longue; valve externe, en forme de earène très-saillante, marquée de eôtes longitudinales, et lerminée à son sommet par nne arćte courte el droile; la valve inlerne est plus allongcét, 110ins saillante.

Proprićlés et usages. Lete giz est originaire de l'Inde, on le culive dans les provinces méridionales de l'Europe, en Ilalie, en lisplagne, elc. Il aime les licux humides el marécigeux. Colmi. 
de l'Ainérique septentrionale, surtout de la Caroline, est trèsestimé. Le riz sert d’aliment dans au moins la moitié du globe; il est très-nourrissant et très-sain.

En médecine, on emploie sa décoetion, qui est adoueissante; surtout à eause de la fécule qu'elle eontient. On l'administre contre la diarthée. Elle ne renferme point de prineipe astringent comme le pensaient les aneiens.

Le riz, d'après IM. Vauquelin, diffère essentiellement des autres graines eéréales, en ce qu'il ne contient que des traces a peine pereeptibles de gluten et de phosphate de ehaux; ainsi le mode suivant lequel le riz nourrit doit être différent de eelui du froment. M. Vauquelin n'a pu également y déeouvrir la matière suerée que MM. Vogel et Beaumont y ont trouvée. Si eette matière n'existait effectivement pas, il resterait à expliquer eomment il se fait qu'on puisse en retirer de l'eau-devie par la fermentation.

$3^{\circ}$ Fleurs monoïques.

$$
\text { MA I S. - ZEA. L. J. }
$$

Fleurs mâles en panieule terminale ayant la lépicène biflore ; Jes fleurs femelles, en gros épis axillaires, ont la lépièene uniflore, par avortement, bivalve; la glume et la glumelle à deux écáilles ; l'ovaire terminé par un seul sligmate plumeux et filiforme long de huit à dix pouces. Les fruits sont gros, irrégulièrement arrondis, disposés par séries longitudinales, et comme incrustés dans l'axe eharnu de l'épi.

\section{Maïs cultrvé. Zea maïs. L. Sp. 133.}

Nom vnlgaire: Blé de Turquie.

Chaume haut de six à huit pieds, rameux, glabre, cylindrique. Feuilles alternes, engainantes, longues de deux pieds et plus, larges d'environ deux à trois pouees. Flenrs monoïques dans des épis séparés. Fleurs mâles oceupant la partie supéricure de la plante, où elles constitucnt une très-grande panicule rameuse, formée par la réunion d'un grand nombre d'épis recourbés à leur partie supérieure. L'axe de ees épis est long de huit à dix poues, flexucux, pubeseent. On trouve 
à chaque dent de l'axe deux ćpillets biflores, dont l'un est sessile, l'autre pédonculé.

Lépicène bivalve, biflore; yalves un peu inégales, l'extćrieure plus grande, plus pubescente que l'intérieure; toutes deux carênées. Gluıne égalcment bivalvc. Paillettes trçs-minces, membraneuses et transparentes. Les étamines, au nombre dẹ trois, sont pendantes.

Fleurs femelles situćes au-dessous ḍes mâles, aux aisșclles des feuilles. Elles sont réunies par lignes longitudinales sur une sorte d'axe charnu, conoïde. Cet assemblage ou capitule'allongé de fleurs est cnveloppé d'un grand nombre de feuilles vaginantes qui sc développent trís-tard.

Chaque ćpillet est biflore, mais l'unc des deux fleurs arorte constamment et est rudimentaire; la lépicène est à deux valves arrondies obtuses plus courtes que l'ovaire; la glume offre deux paillettes plus petites que la lépicène.

Ovairc ovoide, glabre. Style court, glabrc, stigmate filiforme, plumeux, très-mou, long de huit à dix pouces; la réunion déc ces stigmates forme une barbe épaisse, molle et charnuc, qui pend par-dessus la partie supérieurc de la gaînç foliacće qui entoure l'assemblage des fleurs.

Le fruit est irrćgulièrement arrondi, comprimé yers sa base; c'est un des plus gros de toute la famille.

Le maïs paraît originaire del' $\Lambda$ mérique méridionale. Au moins est-il certain que les Europćens l'y trouvèrent lors de la conquête du nouveau Monde.

Proprićtés médicales et usages. Le maïs cst cultivé dans toutẹ les provinces méridionales de la France, où il est connu sous les noms de blé de Turquie, blé d'Tnde, blé de Guinée; gros millet des Indes.

La farine que l'on retire de cette grainc a une conlcur jaunâtre. On ne l'cmploic pas pour fairc du pain, parce qu'elle est peu susceptible de lever; mais on en fait des bouillies, des gâteaux, qui sont fort nourrissans et d'un goût agrćable. Dans plusicurs provinces du midi de l'Europe, tontc la classe indigente se nourrit de la farinc de blé de Turquic.

Fille scrt égalcment à nourrir et à cngraisser les volailles. 
Prapriétés médicales et usages des plantes de la famille des Graminées.

La famille des Graminées doil être placée au jiremier rang, sous le rapport des services qu'elle rend à l'humanilć. En effet presque tous les peuples eivilisés du glohe, trouvent dans le fruit de ees plantes la base prineipale de leur alimentation. Le pain, eet aliment sain et nourrissant par exeellenee, est fait, comme tout le monde le sait, avee la farine retirée des différentes Graniriées. Dans l'Europe, l'Afrique septentrionale, e'est le blë ou froment qui sert spéeialementà la nourriture de l'hommc; tandis que dans l'Inde, unc partie de l'Afrique et de l'Amćrique on n'emploie ciuc le riz ou le mais.

Ce n'est point seulement à l'homme que les Graminées fournissent sa prineipale nourriture: le eheval, le bœuf, le mouton, etc., trouvent dans son herbe fraîche ou séchée le meilleur des fourrages; et les fruits de l'orge et de l'avoine sont pour le cheval une nourriture qui ranime ses forees et excite son ardeur.

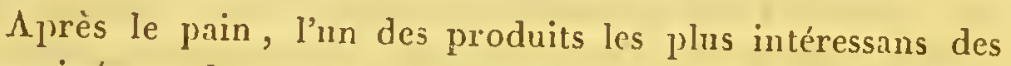
Graminées est le suere de eanne, que l'on retire par expression des tiges du saccharum officinarum. Personne n'ignore son usage dans l'économie domestique et les arts. Ce principe sucré existe également, mais en bien moins grande quantitć, dans le ehaume de plusieur's autres pliantes de la même famille, telles que le sorghum saccharatum, le zea mais, atc.

On serait tenté de eroire que e'est sur' l'existence de ee prineipe sueré qu'est fondée l'extraetion de l'alcohol dans un grand nombrc de graines eéréales, car on sait que c'est une branehe d'industrie eonsidérable dans le Nord. Cependant l'analise ehimique n'a pu y faire aperecroir que des quantitćs Irès-faibles de suere et liors de toute proportion arec celles d'alcolıol obtenı. Il parait donc très-probable que les autres prineipes immćdiats, ct sur'out l'amidon, subissent une transformation partieulière pendautl'acte de la fermentation, et produisent aussi de l'ean-de-vie. $\Lambda$ u reste les belles expérienees de M. Théodore de Saussure sur la transformation directe de l'umilon en suere ne laissent plus de donte à cet égard. On 
sait aussi gue les grains germés (l’orge, flar exemple,) contiennent plus de sucre qu'arparavant; pourquoi donc, la fermentation ne donnerait-elle pas des produits analogues?

Considérće sous le point de vue de ses propriétés médicales, la famille des Graminées n'offre point un aussi grand intérêt. En effet, les tiges et les racines de toutes les espèees sont plus ou moins douces et sucrées; eelles de chiendent et de canne dc Provcnce sont un peu excitantes, la première est diurétique, la sceonde diaplıorćtique.

Les fruits dépouillés de leurs enveloppes, et principalement eeux d'orge, de rì, d'avoine, ete., servent à faire des dćcoctions qui sont adoucissantes ct alimentaires.

L'ivraic seulc fait exception à cette uniformité dans les propriétés médicales des eérćales. Quoique plisieurs auteurs aient absolument nić ses proprićtés malfaisantès, il est cependant manifeste que ses graines, moulues avec eelles du froment, ont communiqué au pain des qualités malsaines, et oecasioné des vertiges, des ćtourdissemens et d'autres aceidens plus ou moins graves.

\section{§II. Fleurs munies d'un calice pétaloüde.}

A. Plısieurs pistils ou plusieurs stigmates dans une même fleur.

NEUVI它 M E F MILLE.

ALISMACÉES. - ALISMACEAE.

Le calice est à six divisions plus ou moins étalées, dont trois intérienres sont colorées et pétalöldes. Les étamines sont le plus souvent au nombre de six, quelquefois en plus grand nombre, insérées à la base des divisions calycinales. Les pistils sont nombreux; l'ovaire est uniloculaire, contenant un ou deux ovules; le style et le stigmate sont simples. Les fruits sont des capsules ordinairement monospernes indéhiscentes. L'embryon, dépourvu d'endosperme, est recourbé en forme de fer a cheval.

Ies Alismacécs, formées seulement des gemres alis- 
ma, damasonium et sagittaria, ont quelque analogie de port avec les Renonculacées, dont elles diffèrent par tous les autres caractères. Ce sont des plantes herbacées, vivant dans l'eau ou sur le bord des étangs, ayant des feuilles alternes et engaînantes, des fleurs hermaphrodites, rarement unisexuées (sagittaria).

M. de Jussieu, dans son Genera plantarum, avait placé ces genres dans la famille polymorphe des Joncs, dont ils diffèrent essentiellement.

\section{FLUT'EAU. - ALI SMA, J,}

Calice étalé, à six divisious, trois extćrieures calyeinales et persistantes, trois intérieures pétalö̈des, eolorées et eaduques; ordinairement six élamines; pistils très-nombreux; eapsules monospermes, rarement dispermes, indéhiseentes. Fleurs hermaphrodites.

Futteau a feulles de plantain. Alisma plantago. L. Sp. 489, fl. dan. t. 56 г.

Nom vulgaire : plantain d'eau.

Une raeine vivaee, formée d'une touffe de fibrilles blanchâtres, donne naissanee à une lige haute de deux à trois pieds, dressée, nuc, cylindrique, glabre, simplc inférieurement, divisće à sa parie supérieure en ramcaux verticillés, dont l'enscmble constitue une sorte de panieule dressée et pyramidale : les feuilles sont toutes radicales longuement pétiolées et engaînantes à leur base, ovales, aiguës, glabres, entières et un peu eordiformes. Les fleurs sont assez petiles, de couleur rose pâle, très-nombreuses. Les capsules, au nombre de quinze à vingt, sont un peu eomprimées et restent incléliscentes.

Le plantain d'call eroit en abondance sur le bord des ćtangs ct des ruisseaux, aux environș de Paris, oì il fleurit en juin et juillet. $\mathcal{F}$

Propriétés medicales et usages. On a réeemment vanté la poudre de sa raeine comme un remède infaillible eontre la rage. On en preserivait l'usage à la dose d'un demi-gros à un gros, soit infusée dans du vin, soit amalgaméc avec un sirop 
et sous forme de bols. Mais ce remèdé a été fort raremcnt: essayć en Francc, et l'on manque d'observations précises qui constatent positivement son efficacité. La rage est une maladie si terrible, qu'il ne faudrait essayer ce nouveau remède qu'après avoir employé la eautérisation, dont les bons effets sont mieux connus.

Les autres plantes de cette famille n'ont aucune propriété remarquable.

DIXI Ė E FAMILLE.

\section{GOLCHICÉES. - COLCHICEAE.}

Périanthe eoloré pétalö̈le, à six divisions, formant quelquefois un tube à la base. Six étamiries attachées au périanthe, opposées à ses divisions, ayant les anthères introrses; style trifide, ou trois styles distinets; trois stigmates. Ovaire à trois eôtes saillantes et à trois loges, ou trois ovaires uniloeulaires; ovules nombreux, attaehés à l'angle rentrant des loges. Capsule triloculaire, souvent tripartie à son sommet, souvrant en trois valves; graines pourvues d'un endosperme charnu.

Les Colehieées sont des plantes herbạeées, à feuilles alternes, à racine, souvent bulbifère.

Elles se distinguent des Liliaeées par un style triparti, souvent trois styles distinets et trois stigmates, par leurs étamines opposées aux divisions dú périantle, par la déhiscence de leurs capsules, dont les valves n'entraînent point avec elles les eloisons.

GOLCHIQUE.-COLCHICUM. L. J.

Le ealiee est infundibuliforme, longuement tubuleux à sa base; son limbe eampanulć est à six divisions profondes; les étamines sont insérécs au sommet du tube; l'ovairc est tiifide; chaeune de ses divisions est terminée par un long style, qui déborde le tube. La capsule est ovoïde et il trois loges. Les graines sont arillées.

Les flurs partent immédiatement d'un bulbe solidc, sins ètre portées sur un pédaneulc; clles naissent avant les feuilles. 
Corcinque d'a utomne. Colchicum anumnale. L. Sp. 485. Bull. t. ry.

Noms vulgaires: tue-ehien, safran bittard, veilleuse, veilloule. Partie usitée : les bulbes.

Son bulbe est solide et charnu. Il s'en forme chaque année un nouveau, à la partie latérale el inférieure du précédent, cn sorle que la plante tend à s'enfoneer de plus en plus dans lar terre. Les fleurs sont très-grandes, purpurines rosées, el paraissent an mois de septembre, long-temps avant les feuilles; elles sortent au nombre de cinq à six de la terre. Leur tube est extrêmeinent long (8 à I 2 pouees), leur limbc est eampanulées à six divisions profondes; les étamines et les styles sont saillans hors din tube; les feuilles ne se montrcnt qu'en hiver, après la chute des fleurs; elles forment unc touffe dressće : ellcs sont lanećolées, obtuses, luisantes, et terminées infírieurement par une gainc qui embrasse la tige, laquelle est fort courte. La capsule est ovoïde, allongće, glabre, trifide à son sommct, marquée de trois sillons profonds.

Lc eolehique d'automne est trés-commun dans les prés liuinides, aux environs de Paris. $\%$

Proprićtés et usages. - Les bubles solides du eolchique, outre la fécule qui en forme la base, renferment un principe âcre, stimulant, essentiellement vénćneux, que MM. Pelletier et Caventou ont reeoniu être de natúre particulière, anologne aux substanees alkalines végétales, el qu'ils ont nommé vératrine, paree qu'ils l'ont également rencontré dans les veratrum. C'est à eé prineipe nouveau, très-délétère, que l'on doit attribuer les propriétćs ćnergiques des bulbes di colelıique et lcur aetion dangcreuse sur l'éeonomie animale. En effet ces bulbes agissent à la manière des médieamcns drastiques les plus riolciss, et peuvent oeeasioncr une foule d'aecidcns graves, telles que des eoliques, des superpurgations, l'inflammation du canal alimentaire et nnême la mor't.

Cependant Stoerck, qui a fait des expériences si multiplices sur la eiguë, l'aconil, la jusquirme, et cen géuéral toutes lis plantes vireuscs, a elerchí à utiliscr l'aetivité et l'énergie des bulbes de colchiquc. Ses cxpériences l'ont amené à recomnatre 
dins cettc substance un médicament diurétique Irès-puissant, dont les effets sont souvent suivis de succès, dans le traitement des hydropisies dites passives, dont la cause cst due à l'altćra. iion de qualque viscère de l'abdomen. Les préparations dont il faisait le plus souvent usagc sont loxymel de colchique et l'extrait de ces bulbes. Mais en France, ce médicament est à peinc employé.

\section{VERATRE-VERATRUM. L. J.}

Calice étalé, à six divisions glanduleuscs à la basc; étamines dressées, attachées à la base des divisions; trois pistils disłincts au centre de la fleur, trois caspules allongćes uniloculaires; flcurs polygames disposées en panicule.

Vératre blanc. Veratrum album. L. Sp. i 476. Bull. t. 155 .

Partie usitée : la racine. Nom pharm.: helleborus albus. Noms vulgaires : hellébore blanc, varaire, etc.

Sa racine est pivotante, tuberculcuse, charnue, allongée, de la grosscur du pouce, recouverte d'un grand nombre cle fibrilles grisâtres. La tiģc est dresséc, glabre, striée, hautc de. deux pieds, terminće par une panicule de fleurs verdàtrcs. Ses feuilles sont sessilcs, amplexicaules, ovales, aiguës, entièrcs, marquécs de plis longitudinaux. Cette plante croît dans lcs pâturages ćlevés de l’Auvcrgnc, dn Dauphinć, du Jura, de la Provence, des $\Lambda$ lpcs, etc. $\dddot{\psi}$

Propriétés et usages. Sa racine, réduite en poudre; est un mćdicament drastique des plus violens. On l'cmployait autrefois a la dose de quatre à huit grains, dans les hydropisies, la manie, etc. On ne la met plus en usage aujourd'lui.

Veratre sfivadutu. Veratrim sabadilla. Retz. Obs. bot.

$$
\text { p. } 29 \text {. }
$$

Partie usitée : les fruits. Nom pharm.: sabadilli seme'n. Ifoms vulgaires: Cevadille, Cebadille, poudre de capurin.

Sa tigc est terıniuće par des fleurs disposécs en épi, un pen penchées et dirigées d'un seul côté; d'unc couleur pourple usiratre. Filles sonf hermaplarorlites, formées d'un calice à 
six sépales ovales, dont trois sont cxtérieurs; de six étamines insérées à la base du calice, supportées par des filets plus larges vers la partie inférieure, et dc trois pistils a styles très-courts, dont les stigmates sont simples. Les capsules sont an nombre de trois, oblongues et déhiscentes intérieurement, renfermant deux à trois graines oblongucs et tronqućes à leur sommet. Les flcurs sont quclquefois mâles par avortement de l'ovaire, dont on aperçoit Ic rudiment.

Cette plante est originaire du Mexique. 2

Propriétés et usages. Ce sont les capsules avec leurs graines que l'on met en usage. Elles sont globuleuses, rougeàtres, à trois loges minces, dont chacune renferme deux graines noirâtres, allongées, angulcuscs.

La Cédaville est un médicament dangereux, dont quelques praticicns prudens proscrivent l'tisagc intcrne. En cffet il est douć d'une âcreté violcnte quile rend presque cathéréliquc. Cependant plusieurs auteurs l'ont administrć à l'intérieur pour combattre lc tania. Sclımuker en portc même la dose jusqu'à demi-gros en poudre.

Mais aujourd'hui on emploic fort pen cc médicancnt, et quand on le met en usage, c'est seulement à l'cxtćricur, pour dćtruire les poux qui pullulcnt en trop grande abondance dans ccrtaines parties. Encore a-t-on vu cctte application cxtcrne de la cévadille sur la têtc, produirc des vcrtigcs, des convulsions et même la mort.

C'est dans la graine du veratrum sabadilla que MM. Pelletier et Caventou ont d'abord rencontré la basé salifiable végétalc, à laquelle ils ont donnć le noin dc Vératrine. Dcpuis ils l'ont retrouvée dans la racine de l'ellćbore blane (vératr. allumm) et dans le bulbe du colchique d'automne. (Voycz plus lıaut.) Nous ajouterons a ce que nous avons dit de l'action de ce nouveau principe sur l'ćconomie animale, qu'il donne la mort à la dose de quclques grains, et qu'il irrite principalement les inembranes muqueuses, puisqu'unc quantité extrèmemcnt faible, portéc dans les narincs, a produit lc plus violent éternument. Ce principe ne sature les acides qu'imparfaitement; c'est-àdire qu'il forme avec cenx-ei des sels tonjour's aeides, et ne rougit pas par l'aeidc nitrique concentré, earaetère que pré- 
seritent les autres alcalis végćtaux, exeepté la delphine et la picrotoxine.

Proprićtćs et usages des plantes de láfamille des Colchicées.

Les genres qui appartienncnt à eette famille avaient été placés M. de Jussieu dans la famille des Joucs. Mais leurs earactères partieuliers, la pluralitć des pistils, la strueture du fruit, ont été suffisans pour en former une famillc nouvelle. Ces caractères, qui ont engagé lcs botanistes à retirer les Colehicées des Joncs, se trouvent encore forlifiés par les propriétés âeres dont ces plantes sont douées, proprićtés qui n'existent pas dans les véritables Joncées. Les plantes de. la famille des Colchicées renferment un principe âcrc, très-vénéncux (vératrine), auquel elles doivcnt toute leur action violente sur l'ćconomie animale. On doit sc défier des plantes qui appartiennent à cette famille.

ONZI E M L FAM I L L E.

$$
\text { PAL MIERS. - PALM } E \text {. }
$$

La famille des Palmiers est une de celles qui renferment les arbres les plus grands et les fruits les plus utiles à l'homme, surtouit pour les habitans des régions équatoriales. Ses caractères botaniques sunt les suivans : Le calice. est double et persistant, à six divisions, dont trois extérieures beaucoup plus petites. Les étamines, au nombre de six, (rarement plus ou moins). Les pistils libres et supérieurs. Les ovaires, au nombre de trois dans chaque fleur : deux avortent souvent; en sorte qu'il n'y. a qu'un seul fruit. Celui-ci est extrêmement variable dans les différens genres : ainsi dans le dattier c'est une drupe; e'est une noix dans le cocotier, etc.

Les Palmiers sont tous des arbres ou des arbustes à tronc droit cylindrique, souvent indivis, formé de fibrés longitudinales. Leurs feuilles, qui sont grandes, en forme de palmes ou d'éventail, sont rassemblées en un faisceau au sommet de la tige, qui porte le nom de 
stipe. Ils sont tous originaires des contrées chaudes du nouveau et de l'ancien continent, à l'exception du palmier éven tail(chamærops humilis) qui croît natureliement sur les côtes européennes du bassin de la Méditerranée.

\section{AT I I R. - P H OE NIX. L. J.}

Les fleurs sont unisexuces et dioïques; elles forment un régime (sortc de panicule) rameux, qui sort d'une spatle coriace, fendue d'un seul côté. Le calice est double; l'extéricur très-petit. Les flcur's mâles on t six étamines; les fleur's fernellcs ont trois ovaires terminés par un style en forme de erochet. Le fruit est simple, unique (par l'avortement presque constant de deux ovaires), charnu et renfermant une graine allongće très-dlure, mar'quée d'un sillon longitudinal.

\section{Datrier cultivé. Phoenix dactylifera. L. Sp. Del. Egyp. t. 62 .}

Partie usitée : les fruits. Nom pliarnn. : clactyli fructus.

Le dattier est un grand et bel arbre dont le trone simple et eylindrique, quelquefois plus renflé vers son milieu, s'élère sans aucune ramification à cinquante ou soixante pieds. Ses feuilles, qui sont extrêmement grandes, engainantes à leur base, pinnćes, sont rassemblées en bouquets au sonunet $d u$ stipe. Les fleurs mâles et les fleur's fentelles sont portées sur des pieds distinets, ct constituent aux aisselles des feuilles de longs régimes rameux, qui sortent d'une grande spathe coriace, monophylle, fenduc latéralement d'un seul côté. Les fruits sont ovoïdes allongés, de la grosseur et à peu près de la longueur du poucc. Ils sont eharnus et sucrés : on leur donne le nom de clattes.

Le datlier croît naturellement en Égryłe, daus l'Inde. Oı lc cultive dans toulcs les régions chrandes clu globe. Il végète assez bicn en plein air dans le miali de la Franec : connme à T'oulon, à Hières, ct dans le glofe de Gẻnes, à Nice, et sur-tout à la Bordiglicra, où il ch cxiste unc plantation superbe; mais ses fruits n'y mûrisscut jamais parfaitement.

Propriétés et usages des dattes. L'es fruits du dattier, parvenus à leur maturité, sout formés d'une ehair sucrée, un peu 
ferme, el d'une amande très-dure. On nous les aprorte en France, après les avoir desséehés au soleil. Dans cet état, leur goût est fort agréable, et ils sont très-nourrissans. Une grande partie des peuplades de l'Afrique et de l'Inde s'en nourrissent presque exelusivement. La plus grande partie des dattes qu'on importe en Europe proviennent du Levant. On les emploie à faire des tisanes adoucissantes et pectorales, soit en les faisant bouillir scules dans de l'eau, après les avoir privées de leur graine, soit en les mélangeant avee les figues, les jujubes et les raisins sees. On obtient alors une tisane douce el suçée que l'on reeommande spéeialement dans les irritations des or *. ganes de la respiration.

Usages et propriétés des Palmiers. Outre le dalticr fiue. nous venons de décrire, cette famille renferme eneore plusieurs autres arbres fort intéressans par les serviees qu'ils rendent à l'humanité.

Les cocos ou fruits du eoeotier (cocos nucifera), les fruils de l'areca, de l'ćlais fournissent aux habitans des pays ou croissent ces précieux végétaux une nourriture aussi saine qu'agréable. Le bourgeon nón eneore développé, qui termine le stipe du ehou palmiste (areca oleracea) est un aliment non moins sain et non moins abondant. On le mange ordinairement eru. Sa saveur est à peu près eelle de l'artichaul.

La féeule amilacée connue sous le nom de sagou paraît être retirée de différentes espèces de Palmiers, cntre autres du sagus farinifera et du phanix farinifera; ainsi que d'un autre arbre de la famille des Cyeadées, le cycas revoluta. C'est une sorte d'exsudation, qui sort du tronc à ecrtaines époques, et qui s'y conerète sous la forme de petites gouttelettes arrondies et solides, presque uniqueinent eomposées d’amidon à l'état de pureté.

Suivant Bergius, les Indiens, après avoir préparé la féeule des sagoutiers, comme nous le faisons pour eelle de la pomme de terre, e'est-à-dire en eoupant lon gitudinalement le tronc ds? ees arbres, râpant et lavant à l'eau froide eette rîpure pul peuse, en font une pâte qu'ils forcent à passer à traver's un erible, et l'ayant ainsi granulé, la forit sécher d'abord au soleil puis à la ehaleur d'un feu très-modéré. De eette manière ils 
ohlicnnent d'un seul arbre jusqu'à deux cents kilogrammes d?e sagor.

B. Un seul pistil dans chaque fleur.

กOUZISM E FA MIILE.

\section{ASPARAGINÉES - ASPARAGINEAE.}

\section{Asparagorum pars. Juss.}

Le calice est coloré pétalö̈le, formé de quatre à six sépalcs, quelquefois soudés par leur basc; les étamines soht en nombre égal à cclui des sépales et attachécs vers leur partie inférieure : l'ovaire est libre et non adhérent, it trois $\operatorname{loges}$, dont ehacunc conticnt un à trois ovules : le stylc est simple ou trifide; le stigmatc est trilobć. Le fruit est une haie globuleuse, renfermant un petit nombre de graincs.

La tige est herbacée ou sarmenteuse; les feuilles sont alternes, quelquefois cngaînantcs à leur base; les fleurs diversement disposées. La racine est fibrcusc; jamais bulbifère.

A l'exemple du célèbre $\mathrm{R}$. Brown, nous n'aurions pas balancé à réunir la plupart des genres de la famille des Asparaginées à ovaire libre, avee les véritables Liliacées, si le port des plantes de ees doux fanilles n'offrait autant de différence. Voici leurs caractères distinctifs : dans les Asparaginécs, le fruit eśt une baie; c'est ordinairement unc capsule dans les Liliacées; dans ces dernières; la racine est bulbifère; elle cst au eontraire fibreuse dans les Asparaginécs.

* Fleurs hermaphrodites.

ASPERGE. - ASPARAGUS. I. J.

Calice tubuleux, subeampanulé, formé de six sépales soudiés par leur base; six étamines courtes; baic globuleuse à trois loges, renfermant chaeune deux graines. 
Asperge orficinale. Asparagus officinalis. L. Sp. 448. Blackw. t. 332 .

La racine cst une souche rampante, écaillcuse, cylindracćc, ramcuse, cliarnuc, vivace, de la grosseur du poucc, donnant naissance á un grand nombre de fibrcs allongées, simples, charnues, cylindriques, grosscs'eomme unc plume à écrirc. La tige est dressée, cylindrique, glabre, rameuse à sa partie supérieure; les feuilles sont fasciculées, sélaeécs, dressécs, subulées, molles, partant de l'aisselle d'une écaille; les flẹu's sont d'un jaune verdâtre, pctites, jortćes sur des pédiccllcs grêles, pendans, articulés vers leur milieu. Ces fleurs sont unisexuées, et je les ai presque constamment trourćes dioïques, c'cst-à-dire uniquement mâles ou femelles sur un mĉme. individu : le calice est en cloche allongée, à șix divisions obtuses, disposées sur deux rangs. Dans les fleur's mâlcs on observe six élamines incluses, attacliées vers le tiers inférieur du calicc : au centre de la fleur est un pistil avorté. Les flcurs femelles se composent d'un ovaire à trois loges qui renferment chacune deux ovules; le slyle cst trigone, terminé par trois stignates. Lcs fruits sont de petites baies pisiforines, rouges, renfermant de trois à six graines.

L’asperge croît dans les lieux cultivés aux cnvirons de Paris; on la cultive dans les jardins potagers. $\underset{F}{ }$

Propriétés et usages. Les jeunes pousses ou turions qui s'élèvent chaque annéc des racines de l'asperge sont un aliment sain et d'une digestion très-facilc. La.rapidité avcc laquelle les asperges communiquent à l'urine une odeur forte et désagréable, prouve l'action qu'elles excrcent sur l'apparcil urinairc. Les racincs, conployécs comıne médicaınens, sont mucilagineuses, un peu amc̀res. Elles étaicnt jadis comptécs parmi les cinq racines apéritises. On les cmploie fréquemment comme diurétiques ct apćritives, quoique ces propriétés puissent icur
ítre contestées.

En analisant le suc de l'aspcrge, MRI. Vanquelin ct Robiruet ont trouvé un principc immédiat nouvcau, cristallisable, d'une savcur fraîche et légèrement nauséabonde, cxeilant la sécrétion de la salive, et que ces habiles chimistes one 
nommé Asparagine. Cette substanee, dont lcs propriétés sont presque nulles, est placéc parmi les principes immédiats végéto-animaux, parce qu'elle produit un peu d'ammoniaque en se décomposant.

MUGUET. - CONVALLARIA. Roth.

Caliee ureéolé, globuleux, à six petites dents roulées en dchors, baie globuleuse, à trois loges monospermes.

Muguẹt de mar. Convallaria maialis. L. Sp. 45 r, Bull.

$$
\text { t. } 2 \text { I9. }
$$

Sa racine est vivace, allongée, noueuse, donnant naissanee à un grand nombre dc fibrilles blanchâtres.

La hampe cst drcssée, latérale, haute de deux à trois pouces, un peu penchée à sa partie supérieure, triangulaire, la faee qui regarde du eôté des feuillcs étant plus large et plus plane.

Les feuilles, au nombre de deux ou trois, partent immédiatement de la racine. Elles s'engainent les unes dans les autres à leur base par leurs pétioles, qui sont mcmbraneux; elles sont élliptiques, aiguës, entières, glabres, marquées de veines longitudinales peu apparentes.

Les fleurs sont blanehcs et petites, disposées an nombre de quatre à six en un épi unilatéral, à l'extrémité de la hampe; elles sont pendantes, et portées sur des pédicelles de quatre à cinq lignes, situés à l'aisselle d'une braetée trèscourte.

Le calice est monosépale, globulcux ct urcéolé, à six divisions pcu profondes, roulécs en dehors. I.es six étamines sont très-courtes; le pistil cst à peu près de la longueur du calice.

Lc fruit est une petite baic pisiformc, rougeâtre.

Lc muguet: croît au printemps dans les bois ombragés : il fleurit en mai. $₹$

Propriétés ct usages. L'odenr agréable, mais vive des flcur's dc muguct, semble annonecr en clles un prineipe actif, enpable d'cxcrcer quelque action sur le systèmc ncrveux. Aussi l'eau distillćc, dc ecs fleurs aujourd'hui peu employéc, l'était - elle beancoup autrcfois comme untispasmodique. 
La raeine et les fleurs, réduites en poudre, sont sternutatoires; e'est le seul usage auquel on les fasse servir aujourd'hui.

La raeine du sceau de Salomon (polygonatum vulgare, Déf.) est légèrement astringente; on n'en fait aujourd'hui aucune espèee d'usage en médecine, quoiqu'elle ait été employée aulrefois.

** Fleurs unisexuées.

\section{SMILAX. $-S M I L A X$.}

Fleurs dioïques, ealice à six divisions; fleurs mâles eomposées de six étamines; fleurs femelles d'un ovaire à trois loges monospermes, portant un style eourt, terminé par trois stig. mates; baie arrondie, à trois graines ou à une seule par ạvortement, enveloppée par le caliẹ.

Tige ordinairement fruteseente; pétioles souvent roulés en tire-bourre.

\section{Sinilax salsepareille. Smilax salsaparilla. L. Sp.}

Partic usitée : la racine. Nom pharm. : radix salsaparilla. Nom vulgaire: salsepareille.

Cet arbuste sarmenteux et grimpant, est très-glabre dans toutes ses parties. Sa raeine est eomposée d'un très-grand nombre de' fibres simples très-longues, eylindriques, d'un gris eendré. Sa tige est artieulée, rameuse, garnie de distanee en distanee d'aiguillons reeourbés; ses feuilles sont alternes, pétiolées, coriaees, eordiformes, aiguës, cntières, très-glabres, marquées de trois à einq nervures longitudinales, et son t munies à leur base de deux vrilles tordues en spirale. Les fleurs forment de petites ombelles simples, qui sont portées sur un pédoneule eommun, plus long que les pétioles. Ces fleurs sont verdâtres, dioïques, pédieellées, les fruits sont de petites baies globuleuses, rougeâtres, qui renferment d'une à trois graines.

La salsepareille est originaire du nouveau continent de l' $\Lambda$ incrique. Elle eroìt natnrellement au Pérou, au Mexique et clans d'autres parties de l'Amérique méridionale. On l'a en quelIue sorie naturalisce dans différentes eolonies, et en partieulierà l'lle de Franee. 24

Propriétés el usages. Lat grande réputation dont jouissent. 
les racines de salsepareille semblerait un pen usurpée à eclui qui reehcreherait avec soin les principes qu'elle renferme, ct lès plénomc̀res auxquels son administration donnc lieu. Sa saveur est mucilagineuse et un peu amère; son odeur cst nullc. Elle est en grande partie composéc de fécule amilacée et de fibre vćgétale. Plnsieurs auteurs, et entre autres, Cullen, regardent la salseparcille comme une substance fort insignifiante, déponrvue d'aucune action réelle, tandis que d'autres au con-. traire la vantent eomme un médicamcnt sudorifique et diurćtique dcs plus efficaees. On l'emploie fréquemment dans les maladies syphilitiques, surtout en l'assoeiant au gayae et an sassafras. La dose de la salsepareille est de dcux à trois onces pour trois livres d'eau, que l'on fait bouillir jusqu'à réduetion d'un tiers. C'cst un des principaux ingrédiens du sirop de Cuisinier et du rob de Laffeeteur.

La SQUiNe est la racine d'une autre espèce de ce genre, le Smilax china L., qui croît en Chine et aux grandes Indes. Cette racine est noueuse, de la grossenr dn poing, d'un brun rougeâtrc; sa saveur cst fade et eomme farineuse. Elle est principalement forméc d'amidon, de gommc et d'une matièrc colorante rougeâtre soluble daus l'eau. On l'emploie dans les mêmes cireonstances que la salsepareille.

$$
\text { FRAGON. - RUSCUS. L. J. }
$$

Les fleurs sont ordinairement dioïques, le ealice est à six divisions; les trois étamines sont monadelphes, et leurs filets réunis constituent un urcéole globuleux couronné par les anthères; l'ovaire est à une seule loge, qui renferme deux graines; il est aminei à son sommet, terminé par une stigmatc triangulairc : le fruit est une petite baie monosperme.

Fragon a feullles piguantes. Ruscus aculeatus. L. Sp. I 474 . Bull. t. 243.

Partie usitéc: la racince. Nom pharm. : rusci radix. Noms vulg. :

Petit houx, housson, buis piquant, myrte épincux etc.

Une souche horizontale, rampante, dc la grosseur du pctit doight, donne naissance à un grand nombre de fibres grêles, blanelıes, perpendiculaires, et pousse une tige frutesecnte, dressée, rameusc, forme, hautc d'u: à denx pieds: la base de 
chaque rameau est aceomplagnée d'une petile stipule laneéolée, très-aiguë. Les feuilles sont alternes, très-rapprochées, eoriaees, sessiles, ovales, aiguës, piquantes, entières; une petite stipule aecompagne la base de ehacune d'clles. Les fleurs sont très-petites, dioïques, solitaires, naissant sur le milierı de la nervure médiane de la face supérieure des feuilles : elles sont d'abord renfermées dans une petite spathe nembraneuse. Le ealice, dans les fleurs mâles et les fleurs femelles, est étalć, à six sépales, dont trois extérieurs plus grands. Le fruit est une petite baie pisiforme d'un rouge vif, renfermant une ou deux graines très-blanehes.

Le petit houx eroit dans les bois un peu eouveris aux environs de Paris, dans la forêt de Saint-Germain et ailleurs. Il fleurit en mars et avril. $2 f$

Propriétés et usages. La racine de petit houx était'une des cinq racines apéritives majeures des aneiennes pharmaeopées. Elle est un peu mueilagineuse, d'une saveur amère, et mème un peu âere. On en fait grand usage en décoetion comme apéritive et diurétique. Elle est un des ingrédiens du sirop des cinq raeines.

\section{Propriétés médicales et usages des Asparaginées.}

Les plantes de eețte fumille offrent une uniformité assez rẹinarquable dans les propriétés dont elles sont douées, ct quoique ees propriétés soient peu intenses, eependant les $\Lambda$ sparaginées nous intéressent à plus d'un tilre. Les jeunes porsses l'un grand nomibre, surtout dans le genre asperge, sont employćes eomme aliment. Mais ce sont surtout les ráeines qui sont doućes de propriétés médieinales, et sous ee rapport, une analogic frappante existe parmi ellcs. $\Lambda$ insi elles sont toules plus or moins mueilagineuses, formées en grande partie d'amidon, de gomme, et paraissent exereer une aetion légèrement excitante sur les organes sćeréteurs de l'urine; e'est ce que l'on obscrve, par exemple, dans les raeines d'asperge, de fragon, ete. La salsepareille, la squine, agissent de plus eomne diaphorétiques; mais elles ne possc̀dent cetre qualité qu'it un faible degré.

Il n’y a point de plantes véućncuses parmi les $\Lambda$ spraraginćcs. 


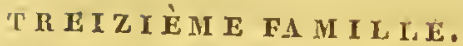

\section{I L I A CÉES. - LILIACE E.}

Lilia et Asphodeli. Jrsss.

- Lc calice est coloré, pétaloïde, formé de six sépales quelqucfois soudés par leur base et constituant un calice monosépale. Le.pistil est libre et supèrc : l'ovaire, de forme variée, offre trois logcs, renfermant ordinairement plusieurs ovules attachés sur deux rangées à l'angle rentrant de chaque loge. Le style, qui manque quelquefois, cst simple et terminé par un stigmate ordinairement trilobé. Le fruit est une capsule triloculaire, à trois valves: les graines sont nombreuses.

La racine est souvent bulbifère, rarement fibrcuse. La tige est herbacée, les feuilles alternes, quelquefois verticillées.

Nous rćunissons ici la famillc des Lis et des Asphodc̀les de M. de Jussieu, dont lcs genres ne nous ont point offert de caractères assez tranchés, pour former dcux ordres distincts.

$$
\text { LIS. - LI LIU M. L. J. }
$$

Calice campanulé, hexasépalc, régulier, sépalcs marqués cn dedans d'un sillon glanduleux : étamines plus courtes que le pistil. Style simple, terminé par un stigmatc trigone : capsule triloculaire, renfermant un grand nombre de graines aplaties.

Racinc bulbifèrc; bulbc écailleux.

Lrs buanc. Lilium candidum. L. Sp. 433.

Son bulbe est arrondi, formé d'ćcaillcs charnues imbriquécs, dont quelques-uncs des plus cxtéricures s'allongent en feuilles à leur sommet.

Ia tige est simple ct dressée, glabre, cylindrique, feuillue, hautc d'cnviron deux picds. Les feuilles sont éparses, scssiles, lancćolécs, aiģuëe, gुlabres, d'un vert clair. Les flcurs sont 
blanches, très - grandes, répandaut une odeur très-forte et agréable; elles forment une sorte d'épi à la partie supérieure de la tige, et sont portées sur des pédoneules d'un pouee de longueur, dressés, un peu striés. Les six étamines sont plus courtes que le style, qui est terminé par un stigmate à trois lobes obtus. Le fruit est une eapsule triloculaire, obovoïde'et à six angles.

Le lis est eultivé dans tous les jardins, à eause de la beauté et de l'odeur suave de ses fleurs. $F$

Propriétés et usages. On ne fait plus maintenant usage dans la thérapeutique que des bulbes ou ognons de lis. Ils sont formés d'éeailles imbriquées, épaisses, eharnues, remplies d'une grande quantité de mueilage et d'amidon, auxquels se joint unc petite quantité d'un prineipe âere. On prépare avee ees bulbes, euits sous les eendres, des cataplasmes" légèrement exeitans, dont on fait un fréquent usage pour aecélérer la suppuration, dans les abcès sous-eutanés.

Quant à l'eau distillée de fleurs de lis, vantée comme antipasmodique, et à l'huile dans laquelle on faisait maeérer ees fleurs, on ne les emploie plus aujourd'hui.

$$
\text { AIL. - }-A L L I U M \text {. L. J. }
$$

Fleurs disposées en ombelle, enveloppées dans une spathe a vant leur développement, laquelle est formée de deux éeailles sèehes et membraneuses. Caliee eampanulé, formé de six sépales distinets; filamens des étamines sonvent trifurqués au sommet.

Raeine bulbifćre; bulbe à tuniques, simple ou eomposé.

all commun. Allium sativum. L. Sp. 425.

Nòm vulg. : Ail, ail cultivé.

Le bulbe de eette plante est eomposé de plusieurs antres petits bulbes ovoïdes, rapprochés, réunis, etenveloppés dans des membranes minees, blanehâtres, qui leur' sont eommunes. Ces petits bulbes sont vulgairement désignés sous le nom de gousses d'ail. La tige est haute d'un pied et demi, eylindrique, glabre, portant des feuilles engainintes, planes, laneéolées, étroites, allongées. L'ombelle est terminale, eomposée de fleurs blanehes p'́doneulées, entremêlées de bulbilles charnus et écailleux. 
L'ail croit naturellement en Italie, en Sieile, ct dans les provinees méridionales de la France: on le cultive dans'les jardins potagers.

Propriétés et usages. Les bulbes de l'ail eultivé ont une odeur forte et piquante, une saveur âcre et brûlante, principalement due à une huile volatile très-odorante, de couleur jaune. Ils contiennent de plus de l'albumine, du soufre, une matière suerée et un peu de féeule.

L'ail est une substanee très-stimulante. Dans l'éeonomie domestiugue on l'emploie comme assaisonnement. Les habitans des contrćes méridionales en font une grande consommalion, surtout en Provenee et en Espagne. L'ail est ćgaIement employé comme médieament. Quelques pratieiens en ont vanté l'usage dans les rétentions d'urine, surtout celles qui dépendent de l'atonie de la vessie; mais e'est prineipalement comme vermifuge qu'il est plus fréquemment inis en usage. On administre quelques gouttes du sue expriné de ses bulbes sur un moreeau de sucre, ou bien on les mélange crus ou cuits avee les alimens. lion.

$\Lambda$ ppliqué sur la peau, I'ail peut en oeeasioner la rubéfac-

$$
\text { Air poireau. Allium porrum. L. Sp. }
$$

Nom vulgaire: Poireau.

La raeine est fibrease; les feuilles sont planes, un peu eanaliculćes, allongées, aiguës, longues d'un pied et plus, engainantcs, serrées lcs unes eontre les autres, et eharnues à leur base, de manicrc à représenter un bulbe blane, ovö̈de, allongé jeu renflé, dont toutes les tuniques sc sont changées en ferilles ţui environnent étroitement lì tige simple, eylindrique haute de trois a quatre pieds; l'ombelle est globulcuse, composéc le fleurs petites et rougeâlr'es.

Celle plante est cultivée dans les jardins polagers; elle esl moins âerc que l'ail ct l'ognnon ordinaire. Kille est plus mueilagineuse; son usagc est très-favoralle aux persouncs iffeetćcs de eatarrhe chronique de la vessie. 
Ail ognon. Allium cepa. L. Sp.

Nom vulgaire: Ognon des cuisines.

Son bulbe est arrondi, ventru, quelquefois ovoïde, allongé, d'une grosseur très-variable, composé de tuniques épaisscs, charnues, distinctes, et recourert extérieurement de membranes sèches, minces, searieuses, d'un jaune doré, ou blanches. Sa hampe est nue, eylindrique, haute d'environ deux pieds, ereuse intćrieurement et plus rcnflée vers sa partie moyenne; sés feuilles sont également creuses, eylindriques, terminées en pointe à leur sommet, et un peu plus eourtes que la hampe. Ses fleurs blanehâtres forment un eapitule ovoïdc. Elles sont fort nombreuses et peu ouvertes.

On cultive abondamment cette plante pour rceucillir son bulbe, fort usité dans les préparations eulinaires. Lorsqu’il est cru, il a une odeur forle, piquantc, une saveur âerc et un peu sucrée; il perd cette âeretć par la cuisson, et il est alors assez nourrissant; mais en général difficile à digérer, et donnant souvent des rapports désagréables et nidoreux.

Lcs bulbes d'ognons sont composćs, d'après les expérienees de Fourcroy et dc Mi. Vauquelin : $x^{\circ}$ d'une huile blanche, âcrc, rolatile, tenant en dissolution dı soufre, qui la rend fétide; $2^{0}$ d'une matière végéto-animale analogue au gluten, et suseeptible de se concréter par la ehaleur; $3^{\circ}$ de beaucoup de suere ineristallisable; $4^{\circ}$ d'une grande quantité de mucilage semblable à la gomme arabique; $5^{\circ}$ d'aeide phosphoriçue tant libre que combiné à la chaux, d'acide aećtique et d'un peu de eitrate caleaire; $6^{\circ}$ ct de fibre végétale.

C'est à l'huile volatilc que l'ognon doit sa propriété irritante que la cuisson lıi enlève presque entièrement. Le principe gommeux-sueré y est alors si abondant, qu'on s'en sert souvent comme d'un cxeellent topique ćmollient et résolutif. Cependant il n'a pu éprouver de fermentation vineuse lorsqu'oß l'a soumis à unc température de i 8 à 20 degrés. Le sucre avait bien disparu, mais il parait qu'au lien de se transformer en aleohol, comme cela arrive ordinairement, ses prineipes s'ćtaient convertis en acirle aećtique et cn mannitc, substanec qui, comme nous le verrons par la suile, constitue la majeure partic 
de la manne. Nous observerons d'une manière générale que lous les bulbes de Liliaeées eontiennent du mucilage presque identique avee la gomme arabique. Il est surtout très-abondant dans eeux de la scilla nutans, DC. Hyacinthus non scriptus, L., plante qui est assez eommune dans les bois des environs de Paris.

Propriétés médicales du genre AIL en général. Il est peu de genres, non-seulement dans. eelte famille, mais eneore dans tout le règne végétal, où les propriétés médieales offrent plus d'ensemble et d'analogie que parmi les aulx. Toutes les espèees en effet ont des bulbes eharnus qui eontiennent, outre du mueilage et de la féeule, une huile volatile très-âere, piquante, qui leur donne des propriétés slimulantes fort remarquables. Ces propriétés existent non-seulement dans les bulbes, mais eneore dans les feuilles, qui offrent et la même odeur et la mème saveur.

Indépendamment des trois espèees dont nous avons donné la deseription, plusieurs autres sont également employées dans les préparations eulinaires. Telles sont l'éehalotte (Allium ascalonicum), la eivette (A. schoenoprasum), la roeambolle (A. scorocloprasum), ete. Toutes jouissent des mêmes propriétés et ne diffèrent que par quelque nuanee dausla saveur.

\section{SCILLE. - SCILLA. L. J.}

Caliee pétaloïde formé de six sépales étalés, un peu réunis par la base; étamines à filets simples, style terminé par un stigmate légèrement trilobé.

Raeine bulbifère : bulbe à tuniques.

Scilue orficinale. Scilla maritima. L. Sp. 440, Blackw. t. 59 r.

Nom pharm.:': Scillce vel squillae radix. Partie nsitée: les écailles du bulbe.

Le bulbe de la seille est ovoïde arrondi, de la grosseur des deux poings, formé intérieurement de tuniques eharnues et blanches, recouvert extéricurenient de membranes minees d'une couleur brune foncée.Les feuilles sont radicales, lisses, luisantes, d'in vert 
foneé, ovales, laneéolées, aiguës, un peu onduleuses. La hampe, qui pousse toujours avant les feuilles, est droite, élanée, simple, haute de deux à trois pieds, couverte dans sa moitié supérieure de fleurs blanehes, pédoneulées, formant un long épi terminal; ehaque fleur est aeeompagnée d'une braetée linéaire aiguë, à peu près de la longueur du pédoneule.

Le ealiee est pétaloïde, à six divisions très -profondes presque étalées. Les étamines, à peu près de la longueur du ealiee, sont insérées à sa base interne; les filets sont planes, et subulés. L'ovaire est surmonté d'un style simple, que termine un stigmate très-petit, obseurément trilobé. La eapsule est'trigone, à trois loges, et s'ouvre en trois valves.

La seille offieinale ou maritime eroits sur les bords sablonneux de l'Oeéan et de la Méditerranće. Je l'ai cueillie aux environs de Grasse et de Niee. Elle fleurit en août. $\underset{f}{ }$

Propriétés et 'usages. On n'emploie que les éeailles du bulbe, lorsqu'elles ont été préalablement desséehées; on les désignue alors eommunément sous le nom de squames de scille. Leur saveur-est âcre et amère, leur odeur est presque nulle. M. Vogel a trouvé dans ces éeailles $I^{\circ}$ un prineipe partieulier trèsamer, soluble daus l'eau et dans l'aleohol, qui parait être le prineipe aetif et auquel il a donné le nom de scillitine; $2^{\circ}$ dé la gomme; $3^{\circ}$ du tannin; $4^{\circ}$ du eitrate de ehaux; $5^{\circ}$ de lit malière sucrée; $6^{\circ}$ de la fibre ligneuse; $7^{\circ}$ enfin un prineipe âcre qu'il n'a pu isoler.

La seille est un médieament indigèue des plus préeieux. Son anertume et surtout son prineipe âere indiquent sa plaee parmi les médiearaens touiques et stimulans. Elle porte spéeialement son aetion sur deux organes en partieulier, savoir les poumons et les reins. Aussi l'emploie-t-on surtout eomme expectorante et cliurétique. Mais pour être effieaee, elle ne doit être administrée que quanizles organes avee lesquels elle est inise en eontaet ont besoin d'être exeités; dans le eas eontraire, clle aggraverait les aceidens. Ainsi, dans les eatarrhes pulmonaires chroniques, surtout ehez les vieillards, la seille, faeilite l'expeetoration. De mème on ne devra la mettre en usage comme diurétique, que dans les leueophlegmasies, les hydropisies
passives, ele. 
On administre la scille en poudre sous la forme de pilules ou de bols, depuis deux jusqu’à donze grains; le vin, le vinaigre ct l'oximel scillitiques sont les préparations les plus usitćes.

\section{ALOĖs. - ALOE. L.J.}

Calice cylindracé, à six divisions profondes, six étamincs attachées à la base du ealice, style court, terminé par un stigmate trilobé.

Les aloès sont dcs plantes à racines vivaccs cı fibreuses, à fevilles trc̀s-épaisses et sueculentes, ct dont lcs fleur's sont disposécs en épi.

Aloes perfolix. Aloe perfoliata. Lamk. Dict. I. p. 88.

Partie usitée : le suc épaissi. Noms pharm.: Aloe socotrina. All. hepatica. Al. caballina.

Sa racine est fibrensc. Ses feuilles, rasscmblées en rosctte a la basc de la tigc, sont épaisses, charnues, allongćcs, aiguës, longues de huit à dix pouces, larg̉es de trois à quatre, dentelées sur les bords; clles sont amplexicaulcs, et d'nne couleur verte glauqué; parscmées de quelques verrucs blanchâtres et épincuses. La hampe cst haute d'environ dcux picds, rceouverte d'éeailles dressées: aiguës, les fleurs sont rouges, pendantes à l'époque de la floraison, dressées avant lcur épanouisscment ct forment un épi allongé : ccs fleurs sont tubuleuscs; Ics étamines sont un pcu plus longues que le calice; la capsule est ovoïde, allongée, à trois loges, marquće de trois sillons longitudininx.

Cette plante, originairc d'Afrique, a cusnitc été transportéc en Amérique et en Asie, où cllc rénssit parfaitement. 2

Aloès en Épr. Aloe spicata. L. Suppl. 205.

Cette cspèce, très-rapprochée de la préeédente, a ćgalcment ses fleurs cn épi: mais clles sont eampanulécs et non tubrleuscs; les fenilles sont planes, moins épaisses, ct dentécs. Elle est du restc fort mal eonnue quant à ses autres caracteres botaniques.

Elle croît au eap de Bome-Espérance. 2 f 
Proprictés méclicales et usages. Ce sont ces dcux plantcs, et probablement quelqucs autres cspèccs voisines du même genrc, qui fournissent le médicament connu sous le nom d'Aloès. C'est une substance extracto-résineuse, solide, en masses plus ou moins considérables. Elle offre trois variétés principales, qui portent les noms d'Aloès sucotrin, aloès hépatique ct aloès caballin.

- ${ }^{\circ}$ L'aloés sucotrin ou socotrin est la plus pure de ces trois varićlés. Il vient du cap de Bonnc-Espérancc et de la Jamaïque. Il est en masses, d'un brun foncé, d'une odeur aromatique e.t agréable, d'une saveur amère; sa cassurc est résineuse et brillante; sa poudre est d'un beau jaune doré. MM. BouillonLagrange et Vogel l'ont trouvé composć d'extractif 68 , de résine 32 part. Il se dissout en partie dans l'eau froide et en totalité dans l'eau bouillante. $\mathrm{A}$ cetle cspècc parait appartenir l'aloès lucicle, répandu dcpuis quelques années dans le commercc.

$2^{\circ}$ L'aloés hépatique, ainsi nommé à cause de sa couleur rouge foncée, assez analoguc à celle du foie, contient :quelques matières étrangères. Il est moins pur, ct formé d'extractif 52 ; de résine $l_{i} 2$, et de matière albumineuse 6 ; son odeur est forte, assez désagréable; sa savenr amère; sa poudre d'un jaune rougeâtre. Il n'est soluble en tolalité ni dans l'eau froide ni dans l'eau liouillante.

$3^{\circ}$ Enfin, l'aloès caballin, le moins estimé, le plus impur, employé seulement dans la médccine vétćrinaire, est presque noir, ct contient, outre les principes des dcux autres variẻtés, du sable et unc grande quantité de matières ćtranigères;

L'aloès est un médicament tonique, dont l'action se porte spécialement sur les organes de la digestion : donné à pctitcs doscs, il stimule l'estomac, ct facilite la digestion. Si cettc ciose est portée à huit ou dix grains, cette action s'étcnd aux inteslins, et parait en quelque sorte se concentrcr vers lcur pariie inférieure; l'aloès cst alors un purgatif tonique.

Si l'on continue quclque tcmps l'usage de l'aloc̀s, il détermine vers le rectum une fluxion sanguine; lcs vaisscaux héinorrhoïdaux se gonflent, sc distendent, et le rectum devient les siege d'unc irritation intense. Les praticiens mettent a profit ce mode d'action de l'aloès, ct l'administrcut sonvent: 
pour produire une révulsion ehez les sujets menaećs de congestion cérébrale. On le donne également eomme emménagoguc, dans l'aménorrhće; nais il est plus sage de n'y point avoir reeours dans eette maladie.

Les préparations dans lesquelles entre l'aloès sont trop nombreuses pour pouvoir les rapporter iei. Sa dose est de deux à quatre grains, comme tonique; de six à douze grains, comme purgatif.

Son usage, trop long-temps prolongé, surtout lorsqu'on l'administre à des doses élevées, peut oeeasioner à la longue des aeeidens graves.

Propriétés et usages des Liliacées. Si nous en exeeptons le genre aloès, ee sont prineipalement les bulbes, dans les plantes de cette famille, qui eontiennent les prineipes les plus aetifs : ainsi eeux de l'ail, de l'ognon, de là seille sont les organes que la matière médieale ou l'éeonomie domestique réelament. Mais dans les aloès, au eontraire, ee sont les feuilles qui recèlent les prineipes véritablement médieamenteux. Cependant si l'on réfléehit un instant que les bulbes ne sont que des bourgeons dont les feuilles ne se sont pas développées, et sont restées à l'état d'éeailles, on verra alors l'analogie parfaite qui existe entre les feuilles de l'aloès et les bulbes des autres Liliaeées, et eette anomalie apparente disparaîtra entièrement.

Deux prineipes se reneontrent dans les bulbes des Liliacées, savoir, l'amidon et une substanee amère à laquelle se joiut quelquefois un autre prineipe âere et volatile. Lorsque la première de ees,substanees est prédominante, ees bulbes pentvent servir d'aliment, eomme on le remarque, par exemple, dans l'oguon, le poireau, l'ail, ete. Si au eontraire le prineipe amer est très-abondant, ils agissent alors, et sont employés eomme médieamens; c'est ee qui a lieu pour la seille et les aloès, qui produisent des effets sinon parfaitement semblables, au inoins très-analogues; en sorte que la loi de l'malogie est conservée dans celle famille sous le rapport de ses proprićtés unédieales.

Le prineipe âere qui existe dans plusieurs Liliacées pent en rendre l'usage dangerenx. Cependant ancune des plantes de celte famille n'est véribableneut véníncuse. 
QUATORZILA F FA M ILLE.

\section{NYMPHÉACÉES 1. - NYMPHEACE ZE.}

I.e périanthe est coloré, pétaloïle, formé d'un grand nombre de folioles, disposées sur plusieurs rangées et souvent insérées, ainsi que les étamines, sur. la partie inférieure des parois de l'ovaire; les plus extérieures de ces folioles semblent constituer un calice, tandis que les intérieures formeraient une corolle. Les étamines sont fort nombreuses; les anthères sont tournées vers le centre de la fleur. L'ovaire est simple, recouvert dans sa presque totalité par les folioles du périanthe et par les étamines; il est globuleux, à plusieurs loges qui contiennent chacune un grand nombre d'ovules; le stigmate est rayonnant, pelté, sessile. Le fruit est globuleux, ressemblant pour l'extérieur à une capsule de pavot, indéhiscent, charnu à son intérieur; partagé en un grand nombire de loges, renfermant des graines éparses dans une pulpe charnue.

Les Nymphéacées sont toutes des plantes vivaces qui végètent au milieu des eaux douces.

\section{NÉNUPHAR. - NYMPHAEA. L. J.}

Périanthe formé d'un'grand nombre de sépales, dont les plus extéricurs constituent une sorte de calice et les plus intérieurs une corolle polypćtale. Les étamines sont nombrcuses, attachées, ainsi que les sépales, sur les parois de l'ovaire, qui est globuleux, à plusieurs loges, ct surmonté d'un stigmate pècté, divisé en lobes rayonnans et glanduleux en dessus. Le fruil cst charnu intéricurement, surmonté par le stigmatc persistant.

- Ce n'est point ici le lieu de discuter la place que doit occuper cette famille dans la série naturelle. Plusieúrs botanistes, s'appuyant sur des ressemblances extérieures, plutòt que sur la struct ure interne des Nymphéacées, les rangent parmi les Dicotylédons, entre les Renonculacées et les Papavéracées. 
Nénuphar blanc. Nymphcea alba. L. Sp. 729 . Al. dan. t. 602 .

Non pharm. : Nymphace albae radix. Partie usitée : la racine.

La raeine est une souche charnue, jaunâtre, rameuse, de la grosseur du bras, reeouverte d'éeailles écartées, donnant naissance à un grand nombre de fibres capillaires. Les feuilles sont nageantes à la surfaee de l'eau et portées sur des pétioles d'autant plus longs, que le niveau de l'cau est plus élevé; elles sont cordiformes, obtuses, très-grandes et giabres. Les fleurs sont solitaircs, blanches, fort grandes, élevées à la surface de l'eau sur des pédoncules semblables aux pétioles : le calice est formé de quatre sépales : la corolle sc compose d'un très-grand noinbre de pétales disposés sur plusieurs rangées : ces pćtales sont insćrés sur toute la surface externe et inférieure de l'ovaire. Le fruit est pomiforme, et ressemble assez, pour la grosseur et la forme, à une capsule de pavot.

Le nćnuphar blanc est sans eontredit la plus belle de toutes les plantes aquatiqucs de l'Europe; ellc se trouve abondamment en V'rance, à la surface des étangs et des rivières. Ses fleurs s'épanouissent en juin ct juillet. $\nsucc$

Propriétés et usages. La souche eharnue du nénuphar blane, que l'on désigne communément sous lc nom dc racine, est presque entièrement composée de fécule amilacée, unie à un principe un peu âcre et narcotique. Ellc n'est plus usitće de nos jours. Quelques autenrs, entre autres Dutharding, prétendent avoir arrêté des fièvres intermittentcs; en appliquant des tranches ćpaisses de celtc racinc fraiehc sur la planlc des pieds. Quant aux fleur's, elles sont légèrement aromatiques, et paráissent possédcr' une vertu narcotique et sédative, qui portc spécialement son aetion sur les organes de la génération. Aussi sont-elles placécs parmi les remèdes antiaphrodisilques. C'est avec ees fleurs que se prépare le sirop de n'mphaca.

Le nénuphar jaune (Nympleara luter. L.), qui constitue un genre nouveau, désigné par Salisbury, sons le nom de Nuphar, jouil des mèmes propriétés, et s'cmploie dans les mênes cireonslances. Il est anssi très-commun aux environs de Paris. 7 
TROISIÈ ME CLASSE.

\title{
MONO-SYMPHYSOGYNIE.
}

\author{
QUINZIEME FAMILLE。
}

DIOSGORÉES. - DIOSCOREAE.

Les fleurs sont dioïques : le calice est adhérent avec l'ovaire, à six divisions profondes : les fleurs mâles offrent six étamines attachées à la base des divisions du calice; les fleurs femelles ont un ovaire infère, à trois loges, qui contiennent chacune un, deux ou trois ovules: le style est profondément trifide; chaque division est terminée par un stigmate simple ou bifide.

Le fruit est une capsule ou une baie quelquefois à une seule loge, par l'avortement de deux des loges; les graines sont planes.

Les Dioscorées sont des plantes volubiles à feuilles alternes, rarement opposées, ayant les fleurs petites et ordinairement disposées en épis.

Ciette famille, établie par M. R. Brown, comprend les genres de la famille des Asparaginées qui ont l'ovaire infère.

$$
\text { TAMINIER. - TAMUS. L. }
$$

Fleurs diö̈ques; calice campanulé, à six divisions très-profondes; fleurs mâles à six étamines plus courtes que le calice; fleurs femelles ayant l'ovaire allongé et infère; un style triparti, dont chaque division est terminée par un sligmate bifide. Le fruit est une baic ovoïde à trois loges.

'Íminier commun. Tamus communis. L. Sp. 68o. Lamk. Ill. t. $8 \mathrm{r}$.

Noms vulgaires : Sceau de la Vierge, sceau de Notre-Dame, vigne noire, etc.

Racine tuberculeuse, charnue, à peu près de la gros- 
seur du poing, noirâtre cul dcliors, blanchâtre en dedans. Tiges grểles, volubiles, grimpantes, ramcuses, longues de huit à dix pieds et plus, se tordant et s'élevant sur les arbres roisins; elles portent des feuilles alternes pétiolécs, cordiforunes, tcrminées en pointe, molles, glabrcs, très-luisantes en dessus. Les fleurs sont dioïques, petites, verdâtres, formant des espćces de grappes grêles ct axillaires; les baies sont ovoïdes, rougeâtres, couronnées par le calicc, à trois loges', qui contiennent chacune de deux à trois graines.

Le taminicr est commun dans les bois, les haies, où il grimpe en s'entortillant autour des corps voisins. Il fleurit en mai et juin. $\%$

Propriétés et usages. Sa racine est presque entièrement formée d'amidon auquel se joint un principe âcre et amer. Elle est aujourd'hui à peine employée, encore ne l'est-elle que par les gens de la campagne. Elle a beaucoup d'analogie dans ses propriétćs avec la racine de bryone, c'est-à-dire qu'elle est purgative. Quelques axateurs prétendent qu'appliquée extérieurement, elle calme les doulcurs arthritiques. Mais anjourd'hui on n'cn fait plus usage.

Cette grande quantité d'amidon qui existe dans la racine du taminier, la rend propre à devenir alimentaire, lorsqu'on l’a privée du principe âcre et ancr qu'elle contient. C'est même sous ce rapport seulement que nous avons cru devoir en placer la description dans cet ouvrage, n'igṇorant pas son inutilité dans la thérapeutị̣ue.

Cette proprićté nutritive se retrouve au plus haut degrć dans un genre plus intéressant de cette famille, cclui des ignames (Dioscorea), dont les racines, grosscs, épaisses, charnues, servent d'aliment dans l'Inde, dans nne partie de l'Amérique, et dans la plupart des îles du grand Ocćan anstral.

SEIZIÈ II FAM ILLE.

\section{BROMELLAGÉES - BROMELIACEA.}

Le calice est à six divịsions plus on moins profondes, adhérent par sa base avec l'ovaire, qui est infère : de ces six divisions, trois sont souvent plus grandes : il y a six 
étamines insérées au calice, ou quelquefois à un disque épigyne glandalenx, qui couronne le sommet de l'ovaire. Lestỳle est simple, surmonté d'un stigmate trifide. Le fruit est une capsule ou une baie à trois loges, renfermant plusieurs graines.

Dans les Broméliacées, les fleurs sont souvent en épis serrés, quelquefois en panicule ou en corymbe : les feuilles sont ordinairement radicales et engainantes à leur base.

\section{ANANAS.-BRO'MELIA.L.J.}

Calice double; l'extérieur tubuleux, trifide; l'intérieur colorć, pétaloïde, à trois divisions plus longues que les extćrieures, onguiculées et glanduleuses à leur base. Baie polysperme.

\section{Ananas conestibue. Bromelia ananas. L. Sp. Blackw.} t. 567 .

La racine de l'ananas est composće de fibres allongées, cylindriques; elle pousse une touffe de feuilles roides, dressćes, très-aiguës, d'un vert glauque; longues de deux à trois pieds, creusées en gouttière, lárges de deux à trois pouces, et bordées de pointes roides et épineuses: Du milieu de ces feuilles s'élc̀vc une hampe cylindrique, : épaisse, feuillée, haute d'environ un pied, portant un épi densc, ovoïde, de fleur's violâtres, lequel est'surmonté d'unc couronne de feuilles analogues à cellcs qui partent de la racine. Ces fleurs sont sessiles sur un axe épaissi et charnu; lcur ovaire, qui est infère, est à demi enfoncé dans la substance de cet axe. Après la floraison, le calice tombe en partie, l'ovairc reste niché dans l'axe florifère, qui acçuiert plus de développcment, devient charnu et succulent. Les ovaires, qui sont très-serrćs lcs uns contre les autres, finissent par sc souder de manicre à donner à cet assemblage composé l'aspect d'ún cône de pin. La' couronne de feuillcs persiste sur le fruit, qui devicnt d'une bellc couleur jaune dorée.

L'ananas est originairc de l'Amérique inéridionale; il croit 
également aux Indes et en $\Lambda$ frique. On le cultive en Europe, dans des serres très-chaudes.

Propriétés et "usages. Nous donnons ici la description de l'ananas, non pas qu'il serve de médicament-dans aucune partie du globe, mais seulement parce que ses fruits sont des plus délicats et des pliss recherchés, même pour les tables les plus soinptrueuses.

Cependant il parait que ceux que nous obtenons en France par la culture sont loín de pouvoir être comparés pour la finesse du goût, la délicatesse du parfum à ccux qu'on cullive dans les Indes. L'ananas est, au récit de tous les voyageurs, le meilleur de tous les fruits connus. On retire, par expression, de ses fruits, un suc que l'on fait fermenter, et qui forme une liqueur alcoholique très-forte. Elle est, dit-on, cxcitante et diurétique.

DIX-SEPTIÉ ME FA MI ILIE.

\section{AMAR YLLIDÉES. - AMARYLLIDEAE.}

Les fleurs sont ordinairement enveloppées avant leur épanouissement, dans des spathes membraneuses et sèches. Chacune d'elles se compose d'un calice pétaloïdc monosépale, soudé par sa base avec l'ovaire, qui est infère; lc limbe offre six divisionș; la gorge du calice est quelquefois garnie d'un nectairc pétaloïde concave, d'unc seule piècc, plus ou moins profondément divisé. Les étamines sont au nombre de six; l'ovaire infère est à trois loges pluriovulées; le style porte un stigmate quelquefois trilobé. Le fruit est une capsule à trois loges, souvrant en trois valves.

La racine est ordinairement bulbifère; quelquefois fibreuse; les feuilles sont toutes radicales.

Nous ne comprenons ici, sous le nom d'Amaryllidées, que les genres de la seconde section des Narcisses da M, de Jussiẹ. 


\section{NARCISSE. - NARCISSUS. L. J.}

Spathe monophylle, fcnduc latćralement, contenant une ou plusieurs fleurs; calice lubuleux; limbe à six divisions égales et étalćes; nectaire en godet, campanulé, monoplıylle, pétaloïde, entier ou divisé; ćtamines incluses; stigmatc légèrement trifide.

Racine bulbifère; fleurs jauncs ou blanehcs.

NarcISSE Des pRÉs. Narcissus pseudo-narcissus. I. Sp. / 1 4, Orf. méd. lég. t. 2.

Nom vulgaire: Porillon, Narcisse sausage, ctc.

Le bulbe de cettc plante cst arrondi, formé d'ćcailles très-scrrées; ses feuilles sont allongées, étroites, aplaties, obtuscs, un peu plus courtes quc la hampe. Celle-ci est longue d'environ un pied, très-comprimée, glauque ainsi quc les feuilles; terminée par uneseuleflcur; grande, jaune, un pcu penchée, odorante, qui sort d'runc spathe scarieuse, fendue longitudinalement d'nn seul côtć. Le limbe du calice est à six divisions ovales aiguës ; lc nectaire est très-grand; campaniformc, allongć, jaune; son bord est frangé ct comme glandileux.

Le narcisse des prés croît dans les lieux humides, les. bois ombragés. Il cst assez commun aux environs de Paris. Il flenrit à la fin de mars ou au commencement d'avril. $\&$

Propriétés médicales et usages. On fait usage des fleurs. Elles sont regardćes avcc quelquc raison comme antispasmodiques. MM. Dufresnoy et Deslonchamps les ont données avec quelque succés dans l'ćpilepsic ct surlout la coqueluche : c'est cn effet pour combattre cette affection qu'on einploic le plus souvent le narcisse des prés. On administre son infusion, son sirop, ou énfin son cxtrait, à des doses variées sc̀lon l'âge du malade ct l'intensité de la maladic. L'cfficacité de celte plante n'cst point aussi bicn prouvćc dans la dysscnteric ct les fières intermittentes, quoique quclques arteurs prétcndent avoir reliré des succès de son administratiou. L'cxtrait cst. la préparation la plus active. M. Orfila le regarde commc un poison irritant susceptible d'occasioner la mort dans l'espace 
de quel(pues heures, lorsqu'il est cmployć à la dose de deux à trois gros (Voy. Orfla, Leçons de Mćd. lég. p. 187).

Propriétés médicales et usages des Amaryllidées.

Les plantes de cette famille nous intéressent moins sous le rapport de leurs proprićtćs médicales qu'à cause dı grand nombre d'espèces qui sont cultivćes dans nos parterres; nos serres, et qui en font l'ornement. I Les différentes espèces du genre narcisse, du genre Crinum, Pancratium, etc., sont fort recherchées des amateur's de belles fleurs.

Lc point le plus remarquablc de l'histoire médicale des plantes de cette famille, c'est quc leurs bulbes sont plus ou moins âcres, ct possèdent une vertu émétique très-prononcée. Cette propriété existe dans le narcisse des prés, le narcisse odorant, le pancratium maritimum, lc perce-neige et plusieurs autres plantes de cetle famille. Du reste, les Amaryllidées, considérées dans leur ensemble, ne présentent rien de remarquable, sous le point de vue de leur's propriétés médicales.

DIX-HUDTIEM FA M ILLE.

\section{IRIDÉES. -IRIDERE.}

Les fleurs sont d'abord renfermées dans une spathe. L'ovaire est infère; le calice est pétaloïde, tubuleux à sa b ase; le limbe est à six clivisions, souvent irrégulières; les étamines sont au noinbre de trois, libres et distinctes, tantôt soudées par leurs filets et monadelphes. Le style est simple ou trifide; chacune de ses divisions est ter* minée par unstigmate le plus souvent planc et pétaloïde. Lefruit est une capsule à trois loges renfermant un grand nombre de graines disposées sur deux rangées longitudinales, et souvrant en trois loges.

La racine est bulbifère ou rampante. Les bulbes sont solides et charıus. La liampe est tantôt nue, tantôt couverte de feuilles. 


\section{R IS. - IR I S. L. J.}

Calice tubuleux à la base, limbe partagé en six segmens, dont trois dressés et trois alternes a vec ceux-ci ct réfléchis : trois étamines opposées aux divisionz réfléchies du calice : style simple à sa base, divisé supérieureuent en trois lanières pétaloïdes, recourbées en voûtc, stigmatifères et recouvrant les trois ćtamines. Capsule trigone, triloculaire, trivalve, renfermant des graines planes ou arrondies.

Racine charnue, rampante.

Iris des marais. Iris pseudo-aconus. L. Sp. 56, Bull. t. 137 .

Nom pharm. : Acori palustris radix. Partie usitée : la racine.

La racinc de celte plante forme une souche charnue, située horizontalement sous la terre. Sa tige 'est dressće, un peu comprimée, lisse, glabre et glauquc, haute d'environ deux pieds, offrant dcs noeuds très-écartés à l'attache de chacune des feuilles qu'clle porte. Les feuilles sont ensiformes allongćes, aiguës, entic̀res, amplexicaules. Les fleurs jaunes, grandes, au nombre de quatre à cinq à la partie supćrieure de la tige. Chacune d'elles est pćdonculée et environnée d'une spathe foliacée, verdâtre.

Le limbe du calice est à six divisions; trois très-petites et dressées, plus intérieures, égalcs entre elles : trois plus grandes, alternant avec celles-ci, ct recourbées en bas; elles sont ovales, allongées, obtuses, non barbues sur leur milieu.

Lcs étamines sont siluées sous les trois divisions pćtaloïdes du style, qui à sa base est distinct du tube ducalice, et non soudé avec lui.

Le fruit est une capsufe obovoüde, obtuse, à trois côtes; ellc est triloculaire, trivalvc et renferme dans chaque loge un grand nombre dc graines, disposées irrégulic̀remcnt sur deux rangées longitudinales.

Cctte espèce croît abondamment sur les bords des ruisseaux aux environs de Paris. Elle fleurit en mài et juin. $₹$

Proprićtés et usages. Comme toutes les autres espèces du 
même genre, sa souche ou tige souterraine cst remplie d'un sue âcre, qui jouit d'une vertu émétique et purgative. Mais elle u'est plus employéc par les médeeins. Scs graines lorréfiées ont une savcur amèrc, une odeur assez aromatique, aussi les a-l-on proposćes, ainsi que bearcoup d'autres graines, eomme un suceédané indigène du café.

Iris D'Allemagne. Iris Germanica. L.Sp. 55 , Bull, t. I 4 I.

Nom pharm. : Iridis nostratis radix.

Cette espèee, que'l'on eultive dans lous les jardins, se distingue de la prćcédente par ses fleur's plus grandes, d'un beau bleu indigo, par les divisions intérieurcs de son ealice beaueoup plus larges, et par la rangée longitudinale de poils glandulenx que l'on observe au inilieu de scs divisions externes. Elle est eommune en France, dans les lieux stériles, les déeombres, sur les vieux murs. Elle fleurit en mai et juin. $₹$

Propriétés et usages. La souehe horizontale et charnue que l'on regarde communćment eomme la racine, et qui n'est qu'une tige souterraine, contient un sue âere et caustique, qui irrite for'cment l'estomae et le eanal alimentaire. C'est un émétique et un drastique assez violent, dont les médecins aneiens ont rccommandé l'usage dans l'hydropisie. Aujourd'hui ce remède n'est plus mis en usage, cxecpté par les gens de la eampagne, qui l'emploient eneore pour se purger.

Iris de Florence. Iris Florentina. L. Sp. 55, Bull: t. 4 r 4.

Nom pharm. : Iridis forentina radix.

L'iris de Florence est très-voisinc de la précédente; clle n'en diffère que par les earaelères suivans: Ses fleurs sont constamment blanehes, scssiles; le tube du ealiec est plus eourl. Sa raeine, surtout lorscu'ellc cst sèelıe, est plıs odorante. Ellc croît eommunément en Italie; on l'a également. trouvée en Provence. Je l'ai recucillic aux cnvirons de Niee el de Toulon. 2

Propriété; et usnges. Fort peu usitée aujourd'Ini, si ec n'cs। dans la parfumeric, el pour aromatiser diverses priparations pharmaceuliques; auxquelles elle communique unc odeur de 
violette très-prononeée. $\Lambda$ utrefois on administrait eette racine sèche et réduite en poudre, à la dose de dix à vingt grains, dans les rhumes, les eatarrhes pulmonaires ehroniques, etc. On l'a également recommandíc dans les affections asthmatiques.

On emploie cncore aujourd'hui la raciue d'iris de Florenee pour faire des pois à cautère;leur âcretć qui n'est point totaleunent dissipée par la dessication, les rond très-propres à entretenir dans la plaie une irritation convenable à l'effet qu'on se propose d'obtenir.

\section{SAFRAN. - CROCUS. L.J.}

Calice pélaloïde, à tube très-long et grêle, à limbe à six divisions presque égales, dressćes, les trois extérieures portant à leur base les étarnines. Le style, simple inférieurement, est partagé à sa partie supérieure en trois Janières roulées en cornet et terminées ehacune par un siggmate erćnelé. La capsule est petite, globuleuse, à trois Inges, et renferme quelques graines globuleuses.

La racine est surmontée d'un bulbe solide, dćprimć.

Safran curtivé. Crocus sativus. L. Sp. 5o. Red. Lil. t. $x 73$.

Nom pharm. : Crocus. Partie usitée : les stigmates.

Le bulbe du safran est arrondi, dćprimé, charnu et blane dans son intérieur, recouvert extérieurement de débris de tuniqques sèches et brunes. Ses feuilles sont dressćes, étroiles, à bords réfléchis, vertes et lisses cn dessus, blanehes en dessous. Les fleurs, au nombre d'une à trois, sortent du milieu de ees feuilles; elles sont grandes, radicales, violettes, marquées de veines rouges ou purpurines. Le style, d'abord simple, est partagé supérienrcment en trois lanières très-longues, un peu roulćes et crénelées à leur sommet, d'une eouleur jaune foneć; elles corstituent Jes sliginates.

Le safran est originaire d'Orient. Il est enllivé en grand dans différentes provinces de la France, surtout dans le Gatinois. Il fleurit en sentembrc el octobre. $\not$

Proprićtés médicales et usages. La substancc répandue dans le commerce sous le nom de safian dru Gatimois, n'est que la 
partie supérieure du style et les stigmatcs du crocus sativus, et peut-ètre de quelcues autres espèees confondıres et cullivécs avec lui.

Le safran est d'une couleur jaune rougeâtre, d'une odeur forte, assez agréable, d'une saveur un peu amère et piquante. D'après l'analise de MM. Bouillon-Lagrange et Vogel, il eontient une matière colorante particulière; susceptible de prendre différentes nuances de bleu et de vert par l'action des acides et des alcalis; ils la nomment Polychroïte. Cette matière est soluble dans l'eau et dans l'alcohol.

Le safran doit être placé parmi les médicamens stimulans et antispasmodiques. $\Lambda$ petite dose, il excite les différentes fonctions, tandis qu'il en pervertit la marche quand il est administré à des doses un peu eonsidérables, telles que deux à quatre seruprules. Il. détermine alor's tous les symptômes et tous les accidens de l'ivresse; une eongestion cérébrale plus ou moins for ie, le délire, etc.

Il entre dans une foule de préparations pharmaceutiques, notamment dans le laudanum de Sydenhan, l'élixir de Garus, et plusieurs autres.

On emploie le safran daus les arts, à cause de son principe eolorant.

Propriétés médicales et usages des plantes de la famille des Iridées.

De toules les Iridées, il n'y a guère que dans le genre Crocus que les stigmates soient odorans, et jouissent d'une propriété excitante aussi manifeste que celle du safran. Mais une partie qui offre dans toutes ees plantes ine analogie frappante sous le rapport dé ses proprićtés, c'est la racine; en effet elle est toujours charnue, et conlient, outre la féeule, qui en forme. la majeure partic, un principe irritant et âcre qui la rend prop̣re à déterminer des phélomènes très-marqués dans les organes avee lesquels on la met en contaet.

In général, celte fanille ne renferme point de végétaux vénéneux. 
A MOMÉES. - A MOMEAE.

Fleurs solitaires, en épi ou en grappe, renfermées dans des spathes avant leur développensent. Calice coloré, pétaloïde, tubuleux à sa base : limbe double; l'extérieur à trois divisions, l'intérieur également à trois divisions irrégulières et comme bilabiées; deux divisions plus petites formant la lèvre supérieure; une seule constituant la lèvre inférieure, qui est souvent trilobée. Une seule étamine épigyne, dont le filet est quelquefois dilaté et pétaloïde, d'autre fois sondé en partie avec le style; tandis que l'anthère est souvent séparée en deux parties distinctes. L'ovaire est à trois loges; le style est grêle, le stigmate est terminal et concave. Le fruit est une capsule trilocnlaire, trivalve, rarement une baie, renfermant plusieur's graines:

Les Amomées sont des plantes aronsatiques, d'un port particulier, ayant des racines vivaces, tuberculeuses et des fleurs souvent d'une couleur fort éclatante.

\section{AMOME. - $A M O M U M$. L.}

Calice double; l'extérieur cylindrique, inégal; l'intéricur à rois divisions. L'anthère est double; le filet est pétaloïde, et trilobé à son sommet.

Les fleurss sont disposées en épi ou en grappe.

Amone en grappe. Amomum racemosum. Lamk. dict. I, p. x 34. Illust. t. 2, f. 2. A. cardamomum. L. A. grana paradisi. Id.

Noms jharm. : Cardamomum minus, medium et majus. Grana paradisi. Nomsjulgaires: Amone, Cardamone, ou Grains de paradis, Maniguruete.

I.'obscurité profonde qui règne sur ces différentes plantes, 
ne nous permet point de juger si e'est avee raison que dans l'Encyclopédie méth. ( 1, 1. 134), M. de La Marck réunit sous le nom d'Amone en grappe les espèces désignées sous les noms de Cardamomes et de Graines de paradis. Voiei, d'après le savant auteur dı dietionnaire de botanique de l'Encyclopédie, la description de l'anome en grappe:

Racine longue, traçante, un peı épaisse, noueuse, blanchâtre et garnie de beaueoup de fibres latérales. Tiges feuillées, droites, hautes de huit à douze pieds. Feuilles alternes, étroites, lancéolées, engaînantes à leur base, longues d'environ un pied, larges de deux à quatre pouces; les fleurs porlées sur une hampe iameuse qui part immédiatement dela racine, forment une sorte de grappe irrégulière, longue de plus d'un pied; artieulée, coudée, écailleuse. Les fleurs sont blanchâtres; et sortent de l'aisselle de petites spathes minces et membraneuses. Il leur suecède de petites capsules ovoïdes, à trois côtes obtuses, à trois loges qui contiennent cliacune plusieurs graines anguleuses. Cette espèce croît dans les lieux ombragés et humides de l'Inde, du Malabar, ete. $?$

Propriétés et usages. Nous ne possédons que trop peu de données positives, pour pouvoir décider si en effet les capsules et les graines répandues dans le commerce sous le nom de cardamomes et de grains de paradis sont produites par cette espèce. Voici les caractères de ces médieamens tels qu’ils nous sont apportés par la voie dı commerce.

On connait trois espèces de cardamome désignées sous les noms de grand, moyen et petit, qui paraissent être des variétés provenant d'une même plante, mais différentes seulement par leur grosseur. Ce sont des capsules arrondies ou allongées, à trois $\log c s$, dont chacune renferme une douzaine de graines anguleuses. Le grand cardamome est de la grosscur d'une petite noix ; il est brunâtre, rétréei a ses deux extrémités; la saveur et lodeur de ses graines est faible. Le moyen cardamome est plus court et plus effilé; enfin le petit cardamome, qui cst le plus estimé, est de la grosscur d'un pois, jaunàtre; ses graines sont brunes, d'une saveur forte et eomme térébenthacée.

Quant aux grains de paradis, seulement employés comme jarfum, à eause de leur odcur eamphrée, asscz agréable, ils sont 
ordinairement dépouillés de leur péricarpe, et sous forme dc graines triangulaires bruncs.

Tous ces médicamens jouissent de propriétés stimulantes, mais sont fort peu usitćs dans la médecine curopécnne.

$$
\text { CUR GUMA. - CURCUMA. }
$$

Calice double, l'extérieur à trois divisions courtes, l'intérieur campanulé trifide; labelle bifide; anthère double, portant deux espc̀ces d'éperons. Filament de l'étamiue pétaloïde trilobé.

Fleur's disposées en ćpi. Racine tubéreuse eharnue.

\section{Curcuma long. Curcuma longa. L. Sp. 2.}

Nom pharm. : Curcuma longa radix. Nom vulgaire : Terra merila.

Sa raeine est tubćreuse, oblongue, blanchâtre, noueuse, coudée, de la grosseur du doigt, avee quelques fibres charnues naissant des nœuds. Les fcrilles sont lanećolées, longues de plus d'un pied, glabres, offrant des nervures latérales obliques, cngaînantes à leur base. Les fleurs sont disposćes en un ćpi court, gros, sessilc, naissant du milieu des fcuilles; eet épi est imbriqué d'ćeailles, à l'aisselle de chacune desquelles se trouvent deux fleurs; chaque fleur est environnée à sa base de spathes très-eourtes. Le calice est tubuleux inférieurement, double; l'intérieur est à quatre divisions, dont une plus grande est trilobće. Les deux loges de l'anthc̀re sont adnées aux eôtćs de la fente du filet, qui est pćtaloïde; l'extrćmité supérieure de ee filet est munie d'une petite corne ou ćperon de ehaque eôlé. C'ette plantc est originaire des Indes orientalcs. $\nsucc$

Propriétés et usages. La racine du cureuma long et celle du eurcuma rond, autrc espèce du in ème genre, et qui eroît dans les mêmes lieux, ont une odeur analogue à eelle du gingembre, une saveur àcre aromatique et un peu amère. Cies raeines, peu usitćes comme médicamens, jouissent des mêmes propriétés que le gingembrc ct la zćdoaire. Elles eontiennent une maticrc eolorante jaune, fort cmployée eomme réaetif ehimique. En effet elle est très-sensiblc ̀̀ l'action des substanees alealines, qui 
la changent en rouge foncé. On l'cmploie égalcment pour colorer certains médicamens externes, surtout des eérats ou des onguents.

GINGEM BRE. - ZI N GIB ER. Roscoë.

Calice extćrieur à trois divisions courtes, l'intćrieur tubuleux à trois divisions irrćgulières; anthère fendue en deux; processus staminal simple et subulé; style reçı dans le sillon de l'ćtamiue.

Fleurs disposées en épi serré, radical et imbriqué.

Gingembre officinat. Zingiber officinale. Rosc. Lin. trans. 8, p. 348. Amomum zingiber. L.

Nom pharm. : Zingiberis communis radix.

Le Gingembrc offre une racine tubcrculcnse, irrégulièrement coudée, de la grosseur ca pouec, eoriace ct blanche à l'intérieur. Sa tige est haute d'environ 2 pieds, cylindrique, feuillue; Jes feuilles sont alterncs, distiques, lancéolées, aiguës, larges d'environ x pouce, longues de 5 à 6 , glabres, terminéesinféricu rement par une gaine longue et fendue. Ses fleurs forment un épi ovoïde, imbriqué d'ćcailles, porté sur une hampe longue de 5 à 6 pouces, uaissant à côté de la tige, ct toute recouverte d'écailles engainantes, analognes à celles de la base des feuilles. Les fleurs sont jaunâtres, les écaillcs florales ovales, arrondies, acuminées au sommct, contenant dcux fleurs yui paraissent l'unc après l'autre. Le labelle ou division interne et inférieure du calice cst pourpre, varié dẹ brun et de jaune.

Le gingembrc est originaire des Indcs oricntales. On le cultive maintcnant sur les côtes de l'Amérique méridionale, et surtout anx Antilles. Je l'ai décrit d'après des échantillons recueillis à Cayenne, par mou pèrc. $\psi$

Proprićtés ę usagres. La tacinc de gingembrc cst blanchâtre, tuberculcuse, dure, compacte, d'une odeur piquante, d'une saveur aromatiqne âcre, et en quelıue sortc brûlante, duc à unc huile volatile, plus légère quc l'eau. Elle contient de plus beaucoup d'amidon. Ce médicament cst généralcment peu enployé à cause de sa trop grande éncrgie. Mis en contact avec la membrane pitnitaire, il détermine de violens éteruumcns. Si 
on en unâche quelque temps une petite quantité dans la bouche, il donne lieu à un ćcoulement abondant de salive. S'il est ingéré dans l'estomae, il y développe un sentiment pénible de chaleur, el exeile de la manière la plus évidentc les fonctions digestives. Il peul être avanıageux, sous ce dernier rapport, aux personnes grasses et lymphatiques ehez lesquelles la digestion est lente et laborieuse, tandis qu'au eontraire son usage doit élre interdil aux lempéramens pléthoriques, aux sujets maigres, délicals, chez lesquels la susceptibilité nerveuse esı trèsdéveloppée.

Le gingembre n'agit pas seulement comme stomachique; il peul, comme tous les autrés médicamens excitans, être tour à tour emménagogue, diurétique, sialagogue, etc.

On l'unit assez souvent aux substances purgatives, qu'il rend moins désagréables et plus supporlables pour l'estomac. $O_{n}$ l'administre en poudre depuis quatre jusqu'à douze grains; en dćeoction ou en infusion, à la dose d'un gros pour deux livres d'eau; en teinture, un demi-gros à ur gros, elc. Dans les colonies on le fait confirc au sucre, afin de lui faire perdrc une partie de son âerelé.

\section{ZÉDOAIRE. - KAEIIP FERIA.}

Calice tubuleux à la base; liube à six divisions : trois exléricurres, lancéolées, égales ; trois intérieures plus larges, inégales, et comme bilabiées; une ćtamine surmonlée d'un appendice foliacé, bifide; style grêle terminé par un stiğnate évasé en entonnoir; capsule globuleuse à trois loges.

Fleurs radicales, partant de souches souterraines épaisses et charnues.

Zídoaire offrcrase. K cempferia rotunda. L. Sp. 3. Red. Lil. t. 49.

Nom phar.: Zedoaria rotundoe radix. Nom vulg. : Zédonire ronde.

Sa racine est une sorte de souche charnuc, blanchâtre, de la grosseur du pouce; ses feuilles sont lanećolées, drcssćes, entic̀res, longues de cinq à six pouces, larges d'un pouce et demi à 
deux pouces, vertes en dessus, et pourpres à leur faee in féricure. La tige est haute d'un à deux pieds.

Les fleurs sont très-grandes, unêlées de blanc et de violet. pâlc, et réunies au nombre de quatre à einq dans une espèce de spathe radieale : elles paraissent avant les feuilles; chaque fleur est environnée à sa base par unc spathe tubuleuse, minee et colorée. Le calice est pétaloïde, monosépale et irrćgulier; son tube est long et grêle; ses trois divisions extérieures sont linćaires, aiguës, au moins de la lougueur du tube; les trois intérieures sont inćgales, et a peu près disposćes en deux lèvres, l'une supérieure', formée des deux divisions les plus étroites, ct qui sont ovales, aiguës et redressées; l'autre inférieure rccourbée, formće par la troisième division, deux fois plus large que les deux autres, et profondèment bipartie.

Il n'y a qu'une seule étamine altachée au sommet ala tube du calice; son filet est. court et épais. L'anthère, qui est à deux loges, est appliquée sur sa face interne, et surmontée d'un appendicc pétaloide, bifide.

L'ovaire est terminć par un siylc grêle et capillaire qui, après avoir traversé un petit canal formé dans le filet, dcrrière l'anthère, porte un stigmate en forme de petite soueoupe creuse, dont le bord est cilié. Le fruit est une capsule globuleuse à trois loges, à trois valves, renfermant. un assez. grand nombre de graines dans chaque loge.

La zédoaire ronde est originaire de l'Inde. ₹

Propriétés et usages. Ses racines, ainsi quc celles de la zédoaire longue, que quelques anteurs lapportent au Komp. longa, et d'autres à l'amomum zedoaria Willd. ont à peu près l'odeur et la saveur du gingenbre, quoiqu'à un moindre degrć. Elles sont fort peu cmployćes aujourd'hui.

Zidoaire Gatanga. Kempferia Galanga. L. Sp. 2, Red. Lil. เ. 144 .

Nou phar.: Galange majoris radix. Nour vulg. : Galanga.

Sa raeine est fibreuse, surmontée d'uu bulbe arrondi, solide, blanc, charın, recouvert d'éeaillcs, qui sont les dé- 
bris des feuillcs précédentes. Ces fcuilles, au nombre de deux ou trois, sont ćtalées, arrondies, aiguës au sommet, ondulées sur lemrs bords, striées, largcs de trois à quatre pouces, longues de quatre à cinq : elles sont vertes et quelquefois un peu purpurines en dessous. Les fleurs, moitić plus petites que dans l'espèce précédentc, se montrent en même temps que les feuilles; les divisions internes du calice sont subcordifornes, fendnes; le labellc est composé de deux divisions semblables et aussi grandes que les deux autres divisions du calice. Cette espèce, originaire des Indes orientales, cst cultivée dans le contiuent de l'Amérique du sud ct les Antilles. $\%$

Propriétés et usages. Il cxiste une si grande analogic entre les propriétés médicales des différentes plantes de celte famille, que nous pourrions répéter ici pour le galanga ce que nous avons dit des propriétés médicales du gingembre, c'est-à-dire que c'est un excitant des plus puissans, qui peut agir tour à tour comme stomachique, sialagoguc, diu rétique, emménagogue, etc. Ccpendant en Europe on en fait assez ravement usage dans la pratique médicalc; tandis qu'au contraire dans l'Inde c'est un des aromales les plus recherchés.

Propriétés médicales et usages des Amomées. La structure des plantes de cette famille, malgré les travaux de Roscoë, de Salislury, de Roxburğ, etc., est loin d'être encorc parfaitement connue. Les différens gcures qui la composent, ct les espèces qui s'y rapportent, ont fort souvent étć confondus et pris les uns pour les antres. Celte confusion, et surtont l'éloignement des lieux où croissent les végétaux de cctte famille, originaires pour la plıpart des contrées les plus chaudes de l'Inde, sont les causes du peu de données exactes que nons possédons sur les espèces officinalcs.

Dans les plantes de cette famille, deux partics seulement sont employées, savoir : la racinc dans un grand nombre de cas; dans quelques autres, les fruits et leurs graines. Lcs. racines sous toutes plus ou moins cliarnues, blanches, presque entièrcincnt composécs de fécule amilacćc, assez pure et assez. abondaute dans quclques cspèces pour qu'on l'cn extraie, afin 
de la mettre dans le commerce. $\Lambda$ insi l'Arrorv-root, répandue depuis quelque temps dans le commerce, est une fécule que l'on retire de la racine du maranta indica et du maranta arundinacea. Elle a les mêmes caractères et s'emploie aux mêmes usages que la fécule de pommes de lerre. $\Lambda$ cet amidon, qui forme la basc des racines'dans les amomées, se trouve jointe une huilc volatile ấcre, qui leur donne alors des propriétés excilantes, fort énergiques, comme nous l'avons remarqué pour lc gingembre, la zédoaire, le galanga, etc.

Cette proprićté excitante se trouve ćgalcrnent dans les fruits et les graimes d'un grand nombre d'cspèces appartenant à cctte famille, par excmple dans les cardamomes, l'amome en grappc, etc., et confirme l'extrêmc analogic qui existe entre toutes les plantes de celte famille sous le rapport de leurs propriétés mćdicales.

VINGTI Ė IE FAMILLE.

ORCHIDÉES. - ORCHIDEA.

Les plantes de eette famille présentent un port tellement remarquable, une strueture si extraordinaire dans les différentes parties de leurs fleurs, quelles eónstituent une des familles les plus naturelles du règne végétal. Leur caliee est eoloré, pétalö̈le à six divisions, dont trois extérieures, ordinairement uniformes; trois intérieures, dont deux supérieures souvent plus petites, et une inférienre plus grande, d'une formé bizarre, colorée de différentes manières, à laçuelle on a donné le nom partieulier de labelle ou tablier. Ce calice se termine souvent à sa base par un eornet creux, plus ou moins long, 'qui porte le nom d'éperon. Une seule étamine oeeupe le centre de la fleur. Son filet est soudé avee le style et le stigmate, de manic̀re à n'eu pas ètre distinet. Cette étamine, ordinairement à deux loges, renferme du pollen, qui tombe en une ou plusieurs masses, de mème forme que les loges. L'ovaire est infère, il renferme un très-grand nombre d'ovules atta- 
chés à trois trophospermes pariétaux. Le stigmale est situé au-dessous de l'étamine, à la face antérieure du support commun. Le fruit est une capsule uniloculaire, trivalve.

Les orchidées ont une racine qui présente ordinairement deux tubercules charnus, arrondis, entiers ou découpés et palmés; quelquefois cette racine est fibreuse; leurs feuilles sont alternes, embrassantes.

\section{ORGHIS. - ORCHIS. Swartz.}

Caliee pétaloïde, double; les trois divisons extérieures à peu près égales, eonniventes ou écartées; labelle entier ou divisć, un éperon creux plus ou moins long, pollen tombant en deux masses granuleuses distinetes.

\section{Orchis male. Orchis mascula. L. Sp. 1333.}

Nom pharm, : Radix salep. v. salep. Noms vulg. Salep, Teslicule de chien, Satirion.

Les deux tuberenles que I'on remarque à la base de la tige sont ovoïdes, allongés, blanes, charnus, surmontés de fibres grểles, eylindriques, simples, qui eonstíuent la vraie raeine. La tige, haute d'environ un pied, est eylindrique, glabre, simple, tcrminée par un épi assez serré de fleurs purpurines. Les feuilles sont ovales, allongées, luisantes, glabres, assez souvent maeulées de taehes d'un pourpre noirâtre. Les fleurs sont assez grandes, purpurines, et eonstitueht un épi ovoïde, long d'environ trois pouees; elles sont situées à l'aisselle de braetées laneéolées, quelquefois eolorécs; l'éperon est à peu prìs de la longeur de l'ovaire, qui est cordu en spirale; le labelle est à trois divisons erénelées; eelle du milieu, plus longue, est bilobée. Cette plante eroît dans les bois et les pâturages. Elle fleurit en avril. $f$

Proprićtés et usages. Les tubereules charnus de eelte espèce et de toules celles qui en offrent de très-développés sont prescue uniquement formés de féeule amilaeće. C'est avee les tubereules d'espèees analogues que les Orientaux prćparent lc salep, médieament à lá fois nourrissant et analeptiquc. Celui que l'ou 
fait en France avec nos espèccs indigc̀ucs peut rcmpliccr enticrement celni que l'on tire d'Orient. On lavc ces tubercules, on les fait bouillir pendant quelque temps, on les fait sécher, et on les rćduit en poudre. Le salep sert à faire des gelées, soit avec le bouillon, soit avcc l'eau ou le lait aromatisé.

\section{VAN ILLE. $-V A N I L L A$. Swartz.}

Le calice est articulé avec l'ovairc; ses segmens tombent. après la floraison; cinq des folioles sont étalées ouvertes; le labelle cst soudé au gynostème ou support de l'anthc̀re, il est sans ćperon; l'anthc̀re est terminale et operculće : le pollen est en masses granuleuses; le fruit cst très-allongé, rempli d'une pulpe charnue.

Toutes les vanilles sont des arbrisseaux grimpans.

VANille officinale. Vanilla aromatica. Swartz. Epidendrum vanilla, L.

Nom phar. : Vanilla siliqua. Partie usitće: les fruits.

Arbrisseau sarmenteux s'ćlcvant à des liautcurs considèrables, en grimpant et s'accrochant aux vieux troncs d'arbres, au moyen de fibres radicales plus ou moins allongées. Ses feuilles sont altcrnes, sessiles, épaisses, charnues, un peu coriaces, lisses, luisantes, légèrement ondulées sur leurs bords. Ses fleurs sont grandes, formant des espèccs dc bouquets composés de cinq à six fleurs purpurines et odorantes. Les cinq divisions supćrieurcs du calice sont lancéolées, un peu ondulées'; le labclle est obovale, creusć en gouttière, un pcu sinucux sur scs bords.

Le fruit cst, long de cinq à six pouces, presque cylindrique, brunâtre, rempli dans son intćricur d'une pulpe trèsodorante et fort agréable.

La vanillc croit dans différcntes provinces de l'Amérique méridionale. On la cultivc dans un grand nombrc de 10 colonics.

Propriétés et zsages. L'odcur suave de la vanille la rend un des aromates les plus agréables et les plus rccherchés. On sait que c'est avec la julpe contcnuc dans son fruit que l'on com- 
munique au chocolat cette odeur aromatique qui le rend à la fois plus agréable ct d'une digestion plus facile. La vanille en effet excite les forces digestives de l'estomac par sa qualité stimulante. On vante beaucoup les vertus aphrodisiaques de la pulpe de vanille. On l'a mise pendant long-temps en usage comme emménagogue, antispasmodiqne, etc. Mais aujourd'hui, elle n’est guère usitée que comme aromate.

Propriétés médicales et usages des orchidées. La vanille ne devant son odeur aromatique, sa saveur agréable et sa vertu stimulante qu'à la pulpc renfermée dans l'intérieur de son fruit, et cette pulpe n'existant point dans les autres genres de la famille, on ne doit pas s'étonner de la voir former une sorte d'exception parmi les autres orchidées, dont aucune autre qu'elle ne possède cette propriété. Mais, cn revanche, une analogie frappante existe dans un autre organe de ces plantes, dans leurs tubercules souterrains. En effet dans toutes les espèces, où ils sont très-développés et chárnus, ils sont entièrement formés de fécule presque à l'état de purelé, et peuvent servir à la prćparation du salep.

Il n'y a point de plantes vénćneuses parmi les orchidées. 


\section{PLANTES DICOTYLÉDONÉES.}

I APETALÉES.

QUATRIEMME CLASSE.

APÉTALIE-SYMPHYSOGYNIE.

A. Fleurs non disposées en chatons.

VINGT-UNIÈ AIE FAMILLE.

ARISTOLOGHIÉES. - ARISTOLOCHIAE.

L'ovaire est infère; le calice monosépale, souvent irrégulier, soudé par sa base avec l'ovaire; les étamines, au nombre de six ou de douze, sont libres et distinetes, ou soudées ensemble et faisaut corps avee le style et le stigmate; le style, quand il est libre, est simple et terminé par un stigmate à six lobes. Le fruit est une capsule le plus souvent à six loges, qui eontiennent ehaeune plus sieurs graines, attaehées à l'angle internẹ.

Les Aristoloehiées sont pour l'ordinaire des plantes herbacées vivaees, ou des arbustes sarmenteux et grimpans. Leurs feuilles sont alternes.

I0 Étamines libres et distinctes.

$$
\text { AZARET. - } A Z A R U M . \text { L. J. }
$$

Calice à six angles, partagé jusqu'à son milieu en trois divisions rapprochées; dix ou douze étamines libres incluses; style à six angles arrondis, terminé par un stiggmate à six lobes; capsule à six loges.

Aźnaret d'Eunope. Asarum Europeum. L. Sp. 633. Bull. lierb. t. 69.

Nom phar. : Azari ratlix ct folia. Noms vulg. : Caluaret, orcille d'homme, rondelle, etc. Parties usitces : In racine, les feuilles.

Sa racine est horizontale, brume, de la grosscur diune 
plume à écrỉre, domnant naissance à un graud nombre de radicelles allongćes, grêles. Les tiges qui s'en élèvent sont à peine longues d'un pouce, et terminées par deux feuilles portées chacune sur un pétiole long de trois à quatre pouces : ees feuilles sont réniformes, entières, un peu échancrées au sommet, d'un vert assez foncé et luisantes. Les fleurs sont solitaires, d'un pourpre brunâtre; elles sortent ehacune de l'aisselle des deux feuilles. Le pédoncule qui les porte est long de cinq à six lignes et recourbé.

Dans chaque fleur il y a douze, rarement dix étamines, alternativement plus longues et plus eourtes.

L'azaret croît dans les lieux ombragés, sous les bois, aux environs de Paris. Ses fleurs paraissent en avril et mai. $₹$

propriétés et usages. La racine et les feuilles sont les parties que l'on met en usage; la première surtout. Elle a une saveur amère et âere, une odeur désagréable et nauséabonde: on les emploie les unes et les autrespour déterminer le vomissement. L'azaret doit en effet être compté parmi les médicamens puissamment émétiques : la dose est de quarante à einquante grains en infusion dans huit onees d'eau. Il faut avoir soin de remarquer que le vinaigre ou la dessication détruisent presque entièrement la propriété éméliquc des racines d'azaret. On doit donc les administrer fraîches. L'azaret est aussi un puissant sternutatoire; il fait la base de la poudre cle SaintAnge, que les pharmaciens administrent peut-être avec trop d'inprudence aux personnes toumentées de eéphalalgie. Des qualités aussi actives décèleut un prineipe âcre très - abondant dans l'azaret, probablement dans toutes les aristolochiées; je ne sache pourlant pas qu'on en ait tenté l'analise ehimique.

I $1^{\circ}$ Étamines soudées avec le stylc et le stigmate.

$$
\text { [Gynandrie. L.] }
$$

\section{ARISTOLOCHE. - ARISTOLOCHIA.}

Calice tubuleux à sa base, limbe irrégúlièrement eonforunó soit en orcillc d'âue, soit cn corue d'abondance; six étamines soudćes et confondues an eentre de la fleur avec le style et lc stigmate; capsule obovoüdè à six côtes et à six loges polyspermes. 
Aristoloche senpentarre. Aristolochia serpentaria. Villd. Sp. 4,p. 159 .

Nom phar. : Serpentaria: virginiana. Nom vulg. : Serpentaire de Virginie. Parlie usitée : la racinc.

Dans cette plante la racine est rampante, vivace, composéc d'un grand nombre de fibres blanchâtres, allongées, grêles, louffues, un peu rameuses, répandant une odeur aromatique, forte et camphrée. La tige est grêle, haute de huit à dix pouces, presque simple et pubesceate. Les feuilles sont alternes, péliolćes, cordiformes, aiguës, entières, légèrement ciliées sur leurs bords, un peu pubescentes.

L̀es fleurs sont petites, 'd'un rouge brunâtre; pédonculées, situées à la partie la plus inférieure de la tige, elles semblent en quelque sorte sortir de la terre. 1

L'ovaire est globuleux et couvert de poils laineux; le calice est allongé et irrégulièrement campanulé.

La capsule est presque ģlobuleuse, déprimée, à six côtes saillantes.

Cette plante croit dans les lieux montueux, dans la Caroline, la Virginie, etc. Elle fleurit pendant les mois dè juin et de juillet. 26

Propriétés médicales et usages. C'est la racine seule qui est employée. Son odeur aromatique, qui a beaucoup d'analogie avec le canıphre, sa saveur chaude et comme térébenthacée, indiquent en elle un médicancnt éuergique. Aussi emploie-t-on fréqucmment dans les fièvres ditcs ataxiques et adynamiques, et en général dans les inaladies où l'usage des stimulans est indiqué.

La serpentaire de Virginie s'administre principalement en poudre, à la dose d'un à deux serupules; en infusion dans l'eau ou le vin, à la dose de deux à quatre gros pour deux livres de liquide.

Aristomogie ronde. Aristolochia rotunda. L. Sp. 1364. Blackw. t. 256.

Partie usilée : In racine.

I.'aristoloehe ronde offre une raeine arrondie, ubcrcu- 
leuse, vivace, eharnue, à peu près de la grosseur d'une noix.

Sa tige est dressée, peı lameuse, glabre, quadrangulaire, laute d'environ un pied.

Ses feuilles sont alternes, sessiles, cordiformcs, obtuses, entières, ayant les nervures très-saillantes à leur face inférieure.

Les fleurs sont solitaires aux aisselles des feuilles supérieures, dressées, courtement pédonculées. Leur ovaire est infère, à six côtes saillantcs et à six loges.

Le calice cst monosćpale irrégulier. Il cst.tubulenx infćrieurement; d'abord globuleux an-dessus de l'ovaire, puis rétréci et allongé; il s'ćvase à sa partie supérieure; son limbe est déjeté d'un seul eôté et comme ligulé, obtus et un pcu ćchaneré à son sommet; en un mot, ce ealice rcssemble beaucoup à un demi-fleuron. Le tube offe six nervures longitudinales saillantes, qui se prolongent aussi sur le limbe.

Les ćtamines, au nombre de six, sont soudées et eonfondues avec le style ct le stigmate, et forment une masse arrondie au fond de la flenr. Sur les côtés, on voit les six anthères, formćes chacune de dcux loges; le colps charnu présente supérieurement, six mamelons saillans, vcrdâtres, glanduleux qui sont autant de stigmates qui se prolongent inférieuremcnt en une lame mince, recouvrant $c n$ parlie les anthères.

Le fruit est une capsule ovoïde, obtuse, à six angles arrondis.

Cette espèee est commune dans les ehamps, les vignes du midi de la France. Je l'ai reeueillie aux environs d'Avignon. $₹$

Propriétés et usages. Le nom d'aristoloehe, donné par les anciens aux plantes de ce genre, annonce qu'ils les regardaient comme propres à augmenter le flux menstruel. En effet, les racines de l'aristoloche longuc et ronde ont une odeur aromatique peu agréable, une savcur légèrement âere, qui déećlent. en cllcs la propriété d'agir eomnı toniques et stimulantes. Aussi les racines de ces deux plantes étaient-clles autrefois fort employées non-sculement pour acriver l'éeoulemen t des règles, mais pour combattre les fièvres intermittentes, les différentes cspèces 
de eatarrhes chroniques et une foule d'autres affeetions très différentes.

A ujour'd'hui on ne les emploie que rarement.

L'Aristoloene longue. $A$. longa. L. Sp. 1364 , qui eroit ćgalement dans les provinees méridionales de la Franee, et qui diffère de la préećdente plar sa raeine fusiforme allongée, ses feuilles réniformes, très-obtuses, et pétiolées, jouit absolument des mêmes propriétés, et était employée aux mêmes usages.

On peut en dire autant de l'aristoloehe elématite, si fréquente aux environs de Paris; mais elle paraît être beaueoup moins énergique.

\section{Propriétés médicales et usages des aristolochiées.}

La partie la plus active des plantes de eette famille est la racine. En effet, dans presque toutes ces plantes, mais plus partieulièrement dans plusieurs espèees du genre aristoloehe, la raeine est douée d'une saveur amère, aroma tique et quelquefois un peu âere. Cette âereté mêrne prédomine dans la raeine d'azaret, qui est émélique, tandis que les autres sont généralement stimulantes.

Les fruits de l'hypoeiste (cytinus hypocistus), plante parasile qui appartient à eelte famille, sont astringens. On en obtient un extrait qui jouit de propriétés toniques. Mais ce nédicament n'est plus employéà présent, si ee n'est dans le midi de la Franee. Il est un des ingrédiens de la thériaque.

Il n'y a point de plantes vénéneuses parmi les aristoloehiées.

B. Fleur's mâles disposées en chatons.

VINGT DXUXIEME FAMILLE.

\section{JUGLANDÉES. - JUGLANDEAE.}

Cette famille, qui n'est encore formée que du seul genre Juglans de Linné, présente les caractéres suivans : les fleurs sont unisexuées, monoïques; les fleurs mâles disposées en ehatons, les fleurs femelles solitaices ou réunies ou sommet des jeunes rameaux. Chacune de ces 
dernières offre un ovaire infère, à une seule loge qui contient un seul ovule dressé; cet ovaire est couronné par le limbe du calice, qui est double, et par deux stigest une drupe presque sèche, ou noix, dont l'endosperme mates très-épais. Le fruit s'ouvre en deux valves égales.

Cette famille a beancoup de rapport, d'une part avec les Térébinthacées, dont le genre Juglans faisait autrefois partie; mais elle en diffère par son ovaire infère, et ses fleurs mâles en chatons; d'autre part elle se rapproche beaucoup de la suivante (Cupuliférées), mais s'en distingue par son fruit, qui est une noix à une seule loge, à une seule graine, par ses feuilles composées, sans stipules, et par le manque de cupule.

$$
\text { NOYER. - JUGLANS. L. J. }
$$

Les fleurs sont monoïques; les mâles, en ehatons allongés, se composent de einq à six éeailles soudées ensemble, sur lesquelles sont attaehées de douze à vingt éramines; les femelles sont solitaires à l'extrémité des rameaux; elles sont formées d'un ealiee double, adhérent avee l'ovaire, qui est infère; et dont le limbe offre quatre divisions; eet ovaire qui est uniloculaire et monosperme est surmonté par deux stigmates épais divergens. Le fruit est une drupe sèelre, que l'on désigne sous le nom de noix.

Nuyer ordinaire. Juglans regia. L. Sp. i 4 r5. Blackw. t. 247 .

Le noyer est un grand et bel arbre, originaire de la Perse, pouvant s'élever jusqu’á environ soixante pieds. Il présente à peu près le port du marronier d'Inde. Il est abondamment eultivé dans toutes les provinces de la Eranee.

Ses feuilles sont alternes, articulées, pinnées, ordinairement composćes de sept à neuf folioles ovales, entières acuminées au sominet, presque sessiles. Les ehatons de fleurs mâles sont longs d'environ trois à quatre pouces, pendans, situćs à la partic supérieure des jeunes branehes de l'année préeédente. 
Les anthères, au nombre de douze à dix-lnit dans ehaque fleur, sont presque sessiles et sans filamens.

Les fleurs femelles sont rassemblées au nombre de deux ou trois à l'extrémité des jeunes pousses; ehaemne d'elles est entourée de quelques folioles étroites subulćes; le ealice est globuleux à sa base, qui est soudée avee l'ovaire infère; le limbe est double; l'extérieur très-eourt et dentieulé; l'intérieur plus long eşt à quatre divisions inégales, aiguës; l'ovaire est globuleux, il renfer'me un seul ovule dressé. Il est terminé par deux stigmates obtus, divergens, épais, eonrts, glandulenx sur leur faee interne.

Le fruit est une noix ou diupe sèehe, ovoïde, arrondie, verte, glabre, marquée d'un sillon longitudinal; son endocarpe osseux, ou noyau, s'ouvre en deux valves. L'amande est blanehe, irrégulièrement lobée et eomme eérébriforme.

Propriétés et usages. Le noyer est un arbre fort uile. En effet presque toutes ses parties sont employées dans les arts, l'éeonomie domestique ou la thérapeutique. Ainsi son bois et ses raeines sont reeherehés pour les ouvrages d'ébénisterie; il est très-dur et suseeptible d'un poli très-fin. L'écoree sert à la teinture; ses fruits sont à la fois mis en usage eomme alimens èt comme médieamens; et ses feuilles sont quelqquefois employées pour faire des lotions stimulantes et résolutives.

- La partie eharnue du périearpe de la noix est communément désignéc sons le nom de brou. Elle a une odeur forte et arouratique, une saveur amère et piquante. C'est une substanee stimulante mais fort peu employée, surtout à l'intérieur. On prépare avee elle, en la faisant macérer dans l'aleohol, une liqueur de table que l'on regarde eomme un exeellent stomaehique.

Les amandes du noyer renferment une très-grande quantité d'une huile grasse, fort employée dans eertaines provinees de la Franee, et dont les peịtres fontaussi un usage très-fréquent. Elle se raneit facilement, et dcmande, pour eette raisỏn, à être préparćc en petite quantité, afin qu'elle u'ait pas le temps de s'altérer.

- Comme toutes les parties du noyer, surtont ses feuilles, sont 
fort odorantes, on a prétendu que son émanation étail dangereuse et même qu'elle pouvait être funeste aux individus qui y restaient long-temps exposés. Ces assertions sont exagérées. I'odeur forte que ses feuilles répandent, surtout pendant les ardenr's du soleil, peut donner quelque doulenr de tête, aux personnes qui la respirent pendant long-temps; mais elle n'a point les qualités délétères que plusieurs auteurs lui attribuent.

Le brou de noix et les feuilles du noyer contiennent une assez grande quantité de lannin et d'acide gallique, pour' que quelques auteurs en aient recommandé l'usage pour le tannage des cuirs.

\section{GUPULIFÉRÉES. - CUPULIFERERE.}

Fleurs unisexuées, monoïques; fleurs mâles disposées en chatons allongés; formées de cinq à vingt étamines, portées sur une éeaille diversement eonformée; fleurs femelles environnées d'un involuere uniflore ou multiflore, qui devient une cupule éeailleuse, foliacée ou péricarpoïde; de là le nom de Cupuliferes donné aux genres de cette famille. Les fleurs femielles offrent un ovaire infère épais et charnu intérieurement, à deux. ou trois loges, qui renfernent ehaeune un ou deux ovules; il est couronné par les dents irrégulières dı limbe calycinal et par deux ou trois stigmates, quelquefois soudés à la base. Le fruit est toujours un gland, e'est-à-dire un fruit see, monosperme par avortement, indéliscent et enveloppé, en tout, on en partie, dans une eupule uniflore ou inultiflore, tantôt éeailleuse, tantôt foliacée, tantôt ayant la forme et l'apparenee d'un péricarpe. Les feuilles sout simples, aeeompagnéę à leur base de deux stipules caduques.

Cette famille est formée d'une partie des genres de la famille des Amentacées de Jussieu, distingués par la eupule de leur fruit et leur ovaire infère. Elle se eompose 
entièrement d'arbres d'une stature souvent fort élevée, portant des feuilles simples munies de stipules caduques à leur base.'

$$
\begin{aligned}
& \text { I }^{\circ} \text { Cupule éeailleuse ou foliacée. } \\
& \text { CHEN E. - Q UERCUS. L. J. }
\end{aligned}
$$

Fleurs monoïques. Les fleurs mâles disposées en longs chatons grêles, composées chacune d'une écaille calyciforme plane, lobée, et de six à huit étamines, insérées á son centre; les femelles, formées d'un ovaire infère, à trois loges, qui eontiennent chacune deux ovules, de trois stigmates spathulécs; elles sont environnées chacune d'un involucre uniflore composé d'un grand nombre de pelites écailles imbriquées; le fruit est un gland entourẹ́ à sa base d'une cupule écailleuse.

Chếne commun. Quercus robur L. Sp. i 414 Nouv. Duham. 7, t. 52 .

Noms vulgaires : Chêne rouvre, Chêne mäle, etc.

Le chêne est le roi de nos forêts. Il l'emporte sur tous lcs autres arbres indigènes par la beauté de son port, la grosseur de son tronc, la dureté et la solidité de son bois. Ses feuilles sont alternes, courtement pétiolées, obovales, sinucuses, glabres et lisses én dessus, blanchâtres'et pubescentes en dessous. A la base de leur pćtiole on trouve deux stipules linéaires trèsétroites. Les fleurs femelles au nombre de trois à quatre, sont sessiles et latéralcs sur un pédoncule axillaire, long de trois à quatre lignes. Les chatons uâles situés au-dessous dos fleurs femelles, sont filiformes, pendans : les fleurs y sont ćcartées les unes des autres, composécs d'une écaille calyciformc, arrondie, irrégulièrement lobée, laineuse cn dehors, portant à son centre de six à luuit ćtamines.

Les glands sont ovoïdes; présentant à leur sommet une petite pointe mousse et enveloppée dans leur tiers inférieur d'une cupule, forméc de petites ćcailles imbriquécs, très-courtes et très-serićes.

Lc chĉne croît eommunément dảns les forêts. Il fleurit cn mai : ses fruits sont mûrs en septembrc.

Propriétés et usages. L'ćcorce du chêne cst fort remarquable 
par son extrême astringence, due à l'acide gallique et au tannin qu'elle renferme en grande quantité. Aussi l'a-t-on désignée comme une des substances indigèncs avec lesquelles on pourrait, dans des cas urgens, remplacer le quinquina. C'est en effet un de nos meilleur's astringens. Quand on l'emploic à l'intérieur, on l'administrc en poudre, à la dose de deux ì six gros, dose que l'on répète plusieurs fois, lorsque l'on veut arréter les aceès d'une fiève iutermittentc. En faisant bouillir deux à quatre groos d'écorce de chêne concasséc dans une pintc d'eau, on prépare des lotions, avec lesquelles on lave les plaics on les ulcères atoniques, que l'on pent également saupoudrer avec cette écorce réduite en poudro très-fine.

On faisait autrefois un très-grand usage en médecine des glands et des cupules de ehêne torréfiés et pulvérisés. Celle poudre est anıère et astringente; elle s'administrait à la dose d'un demi-gros à un gros dans la diarrhée, le diabèles, l'atrophie mésentériquc des enfans, les hémorrlıagies passives, etc.

C'ẹt avce l'ćcorce de clıène ẹncassée, qui dans cet état porlc le nom de ian, que l'on tanne les différentes espèces de cuirs.

Plusienrs autres espèees de clıêne méritent encore de fixer notre attention, par quelques-uns de lenrs produits. On pent dire dc toutes en général, qu'elles jouissent des mêmes propriétés, car leur éeorce offre la même composition. Parmi les autres espèces, nous mentionnerons ici:

$I^{0}$ Lc cliêne-lićge, quercus suber, L., qui croît dans les provinees méridionales ct maritimes de la Franee, en Espagne, ele., et dont la partie externe de l'écoree fournit la substance eonnue sous le nom de liége.

Cette inatièrc, remarçuable par sa légèreté, est peu employée en médeeine. Elle sert à fabriquer plusieurs instrumens de cliirurgie et partieulièrement dcs pessaires. Cliomcl vante l'usage du liége réduit en elıarbon et ineorporć dans de l'axonge, contre les liémorrhoïdes très-donloureuses.

Lc chêne des teinturiers : quercus infectoriu Olivier. Voy. Or.1. 1/4 et 15. Celte espèce n'est qu'un arbrisseau tortueux qui eroît cu Oricnt. C'cst sur cet arlure et 'quelques autres espèces de chêne que l'on recneille les noix de galle: exernissances 
eharmues, dures, arrondies, raboteuses, de la grossen' d'une cerise, que la piqû́re d'un pelit insecte, du genre cynips, fail developper sur les pétioles des feuilles; elles lui servent de demeure pour y déposer ses oufs. Les noix de galle les plus estimées viennent d'Alep. C'est une substance éminemment astringente, dont cinq cents parties conticnnent, d'après l'analise de M. H. Davy, 185 p. de matières solubles, savoir: Tannin, 130 p.; acide gallique, uni à un pen d'extractif, 31 p.; mueilage et matière renduc insoluble par l'ćvaporation, 12 p.; carbonate de ehaux et matière saline, 12 p. Les noix de galle sont peu ou point employées à l'intéricur. Leur décoction sert à faire des lotions et des injections astringentes.

\section{NOISETIER. - CORYLUS. L. J.}

Fleurs monoïques : les mâles en chatons allongés éeailleux; clıaque fleur composée d'uue écaille trilobée sur laquelle sont insérées hnit à dix élamines; les fleurs femclles, au nombre de six à huit, forment de petits groupes entour's d'éeailles intbriquées; elles se composent d'un ovaire globulcux à deux loges, qui renferment chacune un ovule renversé, et de deux stigmates filiformes saillans.

Le gland cst osseux, envelopjé dans une cupule foliacée, irrégulièrement lobée.

Noiseter commun. Corylus Avellana. L. Sp. I4I7.

Noms vulgaires : noisetier, coudrier, arelinier, ete.

Arbrisseau touffu, s'élevant à environ douze ou quinze pieds. Ses feuilles sont eonrtement pétiolćes, cordiformes, arrundies, acnninces au sommet, doublement dentées en seie, couvertes de poils rudes et courts; à leur base on rronve deux petites stipules éeailleuses, qui tombent de très-bonne heure.

Les, fleurs sont monoïques; les mâles forment des elatons éeailleux, eylindriques, longs d'un à deux pouces, eomposés l'éeailles spatulées, aiguës, rrilobées, sur lesquuelles sont insćrćes euviron huit ćtamines, un pell harbues au sommet: les fleurs femelles sont réunies au nombre de six à Juit, dans des espèees de bourgeons eonoïdes, éenilleux; les stigmates, qui 
sont d'un rouge pourprc, sont la seule partie saillante au-dessus le ccs écailles. Chaque fleur est immćdiatement environnée d'un involncre monophylle très-court, irrégulièrement découpé; elles se composent d'un ovaire globuleux couronnć par le limbe du calice, qui offre quelques petitẹs dents irrćgulières : il est à deux loges, renfermant chacune un ovule pendant, deux stigmates très-longs, linćaires, d'un rouge pourpre partant de son sommet. Le fruit est un gland osseux, enveloppé dans une cupule foliacće plus longue que lui.

Lc noisetier est commun dans nos forêts, où il forme des buissons très-épais. Il fleurit en janvier, février et mars. Ses fruits sont murs à la fin de juillet et en août.

Propriétés et usages. L'amande, ou graine, renfermće dans le péricarpe osseux est la seule partie dont on fasse usage. Elle, est douce, agréable, nourrissante, et contient environ la moitié de son poids d'une huile fixe et grasse. On pent en faire des émulsions adoucissantes.

$$
\begin{aligned}
& 2^{\circ} \text { Cupule péricarpoïle. } \\
& \text { GHATAIGNIER - CASTANEA. T. }
\end{aligned}
$$

Éleurs monoïques : les mâles en longs chatons, se composent r'un involucre calycinal companulć, à six divisions, contenant. llouze à quinze étamines; les femelles réunies au nombre de Irois à ciuq dans un involucre écailleux et ćpineux, qui les cache jusqqu’a lcur sommet, sont situécs à la base des chiratons mâles ou à l'aissclle des feuilles supérieures: l'ovaire est rétréci à son sommet, couronné par les cinq petites dents du limbe calycinal; il offre de trois à sept loges, qui contiennent chacune deux ovules; il se termine par autant de stigmates subulés, roides, qu'il offre de loges. I,es glands sont renfermés dans l'involucre épincux qui les recouvre en totalité, et scmble former le péricarpe.

Cimataigier comnun. Castanea vulgaris. Lamk. Dict. r, p. 708. Fagus castaner. L. Sp. 1416.

Le chataignicr est. un arbre dont le tronc peut acquérix des dimensions très-considérables. Ses fcuilles sont lancéolées, ai- 
guës, glabres et luisantes en dessous, bordées de dents trèsprofondes : elles sont portées sur des pétioles assez courts; ees feuilles, larges d'environ deux pouees, atteignent quelquefois une longueur de dix à douze pouces. Les ehatons mâles sont fort longs, dressés; ils naissent dans l'aisselle des feuilles supérieures, et présentent souvent dans leur partic inférieure plu. sieur's fleurs femelles : celles-ei qui sont réunies trois à quatre en. semble dans un involuere commun pyramidal, hérissé d'éeailles roides, présentent quelquefois plusieurs étamines avortées et rudimentaires, insérées au limbe de leur caliee. Chaque ovaire offre de quatre à sept loges, renfermant chaeune deux ovules insérés ver's la partie moyenne de l'angle rentrant; tandis que le fruil à l'époque de sa maturité n'offre jamais qu'une ou deux graines, toutes les autres ayant avorté. L'involuere, ou eupule épinerse qui enveloppe les fruits, se rompt irrégulièrement lor's de la maturité des fruits; il sinule un péricarpe dont les véritables fruits seraient les graines.

Le ehataîgnier est très-commun dans nos forêts; il fleurit en juin et juillet; ses fruils sont murs eu oetobre.

Propriétés et usages. Les fruits du chataîgnier, déponillćs de leur eupule épirieuse, sont désignés sous les noms de chataígnes ou marrons. Ils sont très-farineux; quand ils sont cuits, leur saveur est légèrement suerée et agr'́able. C'est un aliment sain dont on fait un grand usage dans plusieurs provinces de la France, telles que le Limousin, le Périgord, l'île de Corse, etc.

$$
\text { HËTR. - FA GUS. }
$$

Ce genre diffère du préeédent par ses fleurs mâles en ehatons globuleux, par sa eupule péricarpoïde, qui s'ourre naturellement en quatre segmens, et ne contient que deux firuits.

Hêtre des forìts. Fagus sylvatica. I. Sp. r 4 r 6 . Nouv. Duham. 2, t. 24.

Nom vulg. : Foyard, fayard, fau, ete.

Grand et bel arbre dont les feuilles sout ovales, aiguës, un peu plissées, verles et luisantes à leur faee supérieure, pubeseentes inférieurement; aceompagnées à la base de leur péliole, qui cst court, de deux petites stipules éeailleuses ea- 


\section{CUPULIFÉRÉES.}

duques. Les fleurs mâles forment des chatons ovoïdes allongés, d'un pouce de longueur', pédonculés et pendans; ehaque fleur se compose d'une écaille caliciforme à six lobes, sur la'quelle sont insèrées environ huit étamines: les Hcurs femelles sont situées à l'aisselle des feuilles supérieures; elles sont réunies deux ensemble dans un involucre ou cupulc épineuse, fendue en quatre parties supérieurement, el qui à l’ćpoque de la maturité s'ouvre en quatre segmens, eomme les valves d'un périearpe.

Le hêtrc est un des plus beaux arbres de nos forêts. Il acquiert quelquefois une hauteur et un diamètre fort considérables. Il se plaît particulièrement dans les terrains sccs et rocailleux, sur le penehant des collines. Il fleurit en mai, et f'uclifie en septembre.

Propriétés et usages. Ses fruits, qui sont triangulaires, de la grosseur d'une petite aveline, sont désignés sous le nom de faines. L'amande qu'ils renferment est douce et agréable. Elle fournit par expressiou une huile grasse, fort avantageuse à cause de la faeilité avec laquelle on peut la conserver plusieurs années sans raneir. On l'emploic eomme assaisonnement.

Propriétés médicales etusages des Cupulifërées. Cette famille est très-naturelle sous le rapport des earaetèrcs botaniques des végétaux quila composent. Aussircmarqucrons-nous unc grande analogie dans les propriétés médicales des plantes qui appartícnnent à ee groupe. Ainsi dans tous, l'écorce est douée d'une amertume ct surtout d'une astringence extrême, c'cst ce que l'on obscrve particulièrement dans les diverses cspèces de ehène, où ces propriétćs jouissent de la plus grande ćnergie. Aussi ces éeorces sont-elles cmployées pour le tannage des cuirs. Les fruits présentent une uniformité qui n'est pas moins fraplante. Ainsi les chataignes, les faincs, les avclines sont farineuses, d'une saveur douec ct agréable, et plusicurs eonticnnent presque la moitić de lcur poids d'une huile grasse, fort employée dans l'éeonomie domestique ct les arts. Il scmblcrait a u premier coup d'ail que les fruils ou glands des chênes fissent unc execption à cettc analogic; en effet dans un grand nombrc d'espèces ccs fruits sont âpres, amer's ct for't désagréables; mais plusicurs cspèces servent à ramener le genre ehûnc à la 
r'çgle de l'analogie et de l'uniformité des propriétés, car' leurs fruits sont doux et aussi bons à manger que eeux des autres arbres de eelte famille, eomme on le remarque par exemple pour les glands du chène liége, du chêne ilex et de quelques autres espèees.

La famille des eupuliféres ne contient point de végétaux vénéneux. 


\section{APE'TALIE-ELEUTHEROGYNTF.}

A. Fleur's disposies en chatons.

VINGT-QUAT I EME FAMILLE.

CONIFÉRÉES. CONIFEREA.

Cette famille doit être comptée parıni celles dout tous les genres offrent une analogie, une ressemblance frappante, non-seulement dans leurs earactères extérieurs et leur port, mais encore dans la structure des parties qui composent leurs lleurs ct leurs fruits. Soll nom est tiré de la forme du fruit, qui est un cône laus la plupart des genres.

Les fleurs sont unisexuées, monoïques on dioïques : les mâles sont ordinairement disposées en chatons. Les étamines, dont le nombre varic, sont tantôt sessiles, tantôt portées sur des filets distincts ou soudés; les ann thères sont uniloeulaires : les fleur's lentelles' forment ordinairenıent des chatons ovoïdes ou globuleux, dont les écailles sont grandes et imbriquées; dans l'aisselle de chacune de ces écailles, on trouve une ou dleux fleurs femelles: d'autre fois ces fleurs sont réunies daus unc. sorte d'involucre qui devient eharnu, comme dans l'If', le Génévirier, ctc. Les fleurs se composent d'un ovaire conique, quclquefois à demi adhćrent, qui sc change en un akène ovoïdc ou anguleux. L'amande est fornıée par un endosperme eharnu, quelquefois oléagineux, renfermant un embiyon à denx ou à un grand nombre de cotylédons, dont la radicule est iulinement soudés avec l'endosperme, ce pui avail engagé mon père à créer pour cette famille et celle des Cycadées, qui doit en ctre rapprochéc, le nom de synothizes. 
Les coniférées sont eu général des arbres d'une haute stiture, plus rarement ce sont des arbrisseaux ou des arbustes. Leurs feuilles sont généralement étroites et subulées, tantôt solitaires, tantôt géminées on en faisceaux. Les feuilles, qui presque toujours sont persistantes, leur ont fail donner le nom d'arbres verts.

Il suinte de toutes les parties de ces végétaux des résines de différente nature qui leur domnent une odeur aromatique et térébenthacée.

PREMIÉRE SECTION.

A.rítinées ou conif Érées vrales. - Fruit, un cốne écailleux; fleurs femelles renversées.

PIN. - PINUS. Juss. Rich. Conif. t. II-I 2.

Fleurs monoïques; les mâles en ehatons éeailleux, oroïdes, rameux, dont les éeailles portent deux anthères appliquées sur toute leur faee inférieure; les femelles également en elatons éenilleux, simples, plus petites, dont les écailles portent à leur base interne deux fleurs femelles renversées : le fruil est un eône formé d'ćeailles imbriquées, ćpaisses, anguleuses et ombiliquées au sommet.

Les feuilles sont subulées, el sorınt plusieurs ensemble d'une mème gaine.

Prn rignon. Pinus pinea. L. Sp. I 4 I9. Duham. éd. 2 , t. 73 .

Noms vulgaires : Pin pinier, pin de pierre, pin cultivé.

Celle belle espéee est facile à reeonnatitre par son porl el la forme générale qu'elle affeete. Lorsqu'elle est parrvenue à un eertain âge, elle présente la forme d'm raste parasol; e'est-à-dire que son trone est simple, divisé à sa parlie supérienre on un grand nombre de branehes, qui eonstiluent nne belle tête bombée : ses feuilles sont géminées dans la mème gaine, subulćes, élroites, longucs de cinq̨ à six pouces. 
Les ehatons de fleurs mâles sont réunis plusieurs ensemble, et fornent une espèee de grappe dressée, d'une eoulenr jaune de soufre; ils sont situés vers la partie supérieure des ramifieations de la tige.

Les chatons femelles, placés au-dessous des précédens, sont ordinairement réunis deux ou trois ensemble. A l'époque de leur maturité, ils constituent des eônes ovoïdes, de la grossemr des deux poings. Leur's ćeailles très-rapproehćes les unes des autres, anguleuses et fort renflées à leur sommet, donnent attaelıe, à leur base interne, à denx fruits ovoïdes, durs, surmontés d'une aile membraneuse qui s'en détache de boune heure. Ils sont noirâlres extérieurement, et renferment une graine ou amande blanehe et eharnue. Ces fruils ne sont bien mûrs que quatre années après que les fleurs femelles, auxquelles ils unt suceédé, ont été féeondées. L'extrémité cotylédonaire de l'embryon, renfermé dans ees graines, est le plus ordinairement partagée en dix cotylédons.

Le pin pignon eroit dans les provinees méridionales et maritimes de la Franee.

Propriétés et usages. Ce sont les fruits ou amandes de cet. arbre qui sont connus et désignés sous le nom de pignons cloux. L'amande qu'ils renferment est eharmue, d'un goùt agréable, assez analogue à eelui de la noisette. Fréquemment employées autrefois par les médeeins, on en fait peu usage aujourd"lıui. Cependant elles peuvent servir à faire des émulsions qui sont adoucissantes, et qui jouissent des mêmes propriétés que celles que l'on prépare avec les amandes douees.

Dans les provinces méridionales de la France on en fait une assez grande consommation. En effet elles sont fort nourrissantes, et les enfans les recherehent avec avidité. Les confiseurs préparent avec elles des dragćes et des pralines qui sont fort agréables.

Cet arlore fournit, comme le suivant, différentes substanecs résincuses dont nous parlerons en trailant du pin maritime. 
Pin maritine. Pinus maritima. Lamarck. fl. fr. 2, p. 210. Nom vulgairc: Pin de Bordeaux.

Son tronc est élevé, raneux; ses rameaux sont ćtalés, iccouverts d'une écorce lissc d'un gris rougeâtre : ses fcuillcs sortent pax paire d'une même gaine; elles sont lisses, d'une couleur verte foncće, longues de cinq à six pouccs; clles offrent à lcur basc une écaille dont le sommet est réflćchi, leurs cônes sunt ovoïdes, allongés et comme pyramidaux, portés sur des pédoncules courts, souvent opposés deux à deux. Le sommet des ćcailles qui est renflć, se termine par une sorte de pointe ou de crochct, plus ou moins allongée. Les amandes rcnfermécs entre les ćcailles sont moins grosses, moins durcs que dans l'cspc̀ce précédentc. Leur saveur est loin d'être aussi douce. Elles ont un goût térébenthacé fort désagréable.

Lc pin maritime croît en abondance dans les provinces mćridionales de la France. Il est commun sur les bords de la Méditerranée. On le trouvc également dans lcs Pyrénées et les landes des environs dc Bayonnc ct dc Bordeaux.

Proprićtés el usages. C'est celle espc̀ce, ainsi que le pin sauvage (Pinus sylvestris $L$.), qui est si commun dans toutcs les parties montueuses de la France, et qui se distingue par ses feuiltes gćminćes d'un vert glauquc, et par ses cônes pendans, qui produisent les matières résineuses connues sous les noms de térébcnthine de Bordcaux, d'huile de tćrébenthine, de colophone, goudron, ctc., si utilement employés dans la médecine, les arts et les constructions navales. Nous allons cn peu de mots faire connaitre chacune de ces substances.

$1^{\circ}$ La térébenthine de pin, ou de Bordeaux. Elle s'obtient cn pratiquant à la base du tronc des arbres forts ct vigoureux, de larges entailles qui n'enlèvent qửune partie de l'écorce. La matic̀re résincuse cst reçue dans des vases ou des trous pratiqués au pied de l'arbrc que l'on at entaillé.

I a térébcntline est liquide, épaiss', visquense, d'une couleur jaunc-clairc. Sa saveur cst âcré et amère, sol odeur est forte et pénétrante. On emploie peu lá cérébentline à l'iutéricur, quoiqu'ellc ait été vantéc par plusieurs médecius comme un l’r. mède cfficace contre la phthisic fulmonairc. C'est surtout la 
térébenthine du Mélèze, ou térébenthine de Venise, qu'on emploie à l'intérieur. Celles du pin et du sapin sont surtout usitées dans les arts. La première sert $\dot{a}$ la préparation d'un grand nombre de médieamens externes, telles que des baumcs, des onguens, des emplàtres, etc.

La térébenthine est un médicament esscntiellenient stimulant, dont on fait assez souvent usage dans les catarrhes chroniques. C'est ainsi qu'on l'emploie fréquemment et avec assez de sueeès dans les catarrlies pulmonaires, les gonorrhées et les diarrhées ehroniques, lorsque tous les symptômes de l'irritation loeale ont entièrement cessé.

$\mathbf{2}^{\circ}$ La térébenthine que l'on laissc se sécher sur les entailles faites aux pins sc recneille en hiver, et porte dans le eommerce le nom de galipot. On purifie eelte substance en la liquéfiant par la ehaleur, et en la faisant passer à traver's un lit de paille. Elle porte alors les noms de poix cie bourgogne, de poix blanche ou poix jaune. Appliquée sur la peau, la poix de bourgogne en détermine la rubéfaction. On l'a quelquefois employée avec avantage dans eertaincs douleurs rlumatismales. Elle sert également à préparer plusieurs emplâtres.

$3^{\circ}$ L'huile ou essence de térébenthine est le prod'uit de la distillation de la térébenthinc, qui en contient environ le quart de son poids. Elle est très-limpide, fluide, d'une odeur et d'une saveur analogues à cclles de la térébenthine, inais plus fortes et plus pénétrantes. $\Lambda$ ussi agit-elle avec plus d'énergie et de promptitude quc cctte substance. Plusieur's praticiens l'ont administré avec un grand succès contre le tomia ou ver solitaire. Pour produire d'heureux résultats, elle doit ûtrc donnéc à des doses très-considérables, telles qu'une, deux, et même Irois onces. Elle occasionne àlors de légères coliques et des déjections alvines extrèmement copieuses, qui entrainent avce elles l'animal qu'on avait eu l'intention d'expulser.

On a, dans ces dernicrs temps, vauté les effets de l'essence de térébenthine, à la dose d'un à deux gros, dans unc des maladies les plus redoutables qui afligent l'especece lumaine, dans l'épilepsie. C'est surtout en Angleterre que l'on en fait plus spécialement usage dans celte cireonstanee.

Enfin on a cu souveut occision de se loucr de ce médica- 
unent administré à la dose d'un à deux gros, dans la névralgie seialique.

$4^{\circ} \mathrm{La}$ colophone ou colophane (eolophonia) est lc résidu de la distillation de la térébenthine. Elle porte eneore les noms d'arcanson et de brai sec. Réduite en poudre, on l'emploie au pansement des plaies, à la suite des opérations de ehirurgie. Elle délermine un resserrement des vaisseaux eapillaires et arrête l'effusion du sang qui a lien par les petits vaisseaux.

$5^{\circ}$ Enfin la poix noire (pix nigra), et le goudron (picea), se préparent par la eombustion du tronc et des branehes des différentes espèees de pin et de sapin. La première est plus pure que le second. Ils sont l'un et l'autre d'un grand usage dans les arts, et surtout dans la marine. On emploie lc goudron pour préserver les eordages et les bâtimens de l'aetion que l'eau excrcerait sur eux sans eelte préeaution.

L'eau de goudron (aqua picea) se prépare en faisant ınaeérer pendant plusieurs jours quatre onees de goudron dans quatre livres d'eau de fontaine; on agite le mélange de temps en temps, puis on déennte la liqueur. Cette eau, qui contient un peu d'huile volatile, d'huile empyreumatique et d'aeide acétique, est d'une couleur fauve, d'une saveur âere et résineuse, et d'une odeur forte. Elle est exeitante, et s'emploie partieulièrement dans les affeetions eutanées chroniques. Quclques auteurs l'ont prćconisée contre la plıthisie, l'astlıme, le seorbut, ete. Sa dose est d'environ une livre eoupće avec da lait ou une tisane analogue.

\section{SAPIN. - $A B I E S$. Tournef.}

Ce genre, fort rapproehé du préeédent, s'en distingue partieulièrement par ses ehatons mâles axillaires simples et par les éeailles de ses eônes qui sont planes, minces, et non renflées à leur sommet.

Le port de ees deux genres csl également fort différent : les sapins ont en géléral une forme pyramidale; leur's rancaux sont étalés horizontalement, tandis que les pins forment unc tête plus ou moins touffue. 
Strin commun. Abies pectinata. DC. fl. fr. 3. p. 276. Pinus picea. L. Sp. 1420.

Noms vulgaires : Sapin, sapin argenté.

Cet arbre aequiert une hauteur de plus de eent pieds. Son trone est nu dans sa partie inférieure, terminé supérieurement par une tête pyramidale, formée de rameaux étalés et même pendans.Ses feuilles sont subulées, étroites, planes, d'un vert glauque à leur faee inférieure, disposées sur deux rangées la térales. Les eônes, qui sont eylindriques, très-allongés, sont dressés.

Le sapin eroit naturellement dans toutes les ehaines de montagnes. Il est extrêmement commun en Auvergne, dans les Vosges, ete. Il se plait de préférenee dans les lieux pierreux, froids et découverts.

Propriétés et usages. On retire du sapin les mêmes substances résineuses que des pins maritimes et sauvages. Ainsi il fournit une térébenthine eonnue sous le nom vulgaire de térébenthine de Strasbourg.

Soumise à la distillation, on en retire également de l'essenee de térébenthine et de la eolophone, qui jouissent absolument des mêmes propriétés que eelles qu'on obtient des pins.

On fait assez souvent usage en médeeine des bourgeons du sapin, que l'on fait maećrer dans du vin ou de la bierre. On a vanté leur effieacité dans les affeetious seorbutiques.

C'est d'une autre espèce de ee genre, originaire de l'Amérique septentrionale, que l'on retire la térébentline du Canada , vulgairement désignée sous le nom de baume du Canada ou faux baune de Giléad.

\section{MÉLÈZE. - LARIX. Tournef. Rich. Conif. t. I 3.}

Ce genre, d'abord réuni au pin, puis au sapin, diffère de ces deux genres par ses eônes latéraux et non terminaux, et par ses feuilles eaduques. Il se distingue en partieulier des pins par ses ehatons mâles, simples et non réunis en grappes, par les éeailles de ses eônes femelles minees et non épaisses au sommet; des sapins, par la longue pointe que présentent les ćeailles de ses fleurs femelles. 
Médéze ordiname. Latix Europoca. DC. fl. fr. 3, p. 277. Pinus larix. L. Sp. 1 420. Abies larix. Lam. III. เ. 785. f. 2.

Le mélèze est un grínd arbre, dont le trone droil et cylindrique peut atteindre jusqu'à soixante-dix à quatre-vingts pieds d'élévation. Son bois cst rouge et compacte. Ses fcuilles sortent par faisceaux de bomrgeons ćcailleux et globuleux; elles deviennent alternes par l'allongement du jeunc rameau renfermć dans chaque bourgeon; clles sont linéaires, pointues, assez molles, et tombent de bonne heurc (caractc̀re rcmarquable qui ne s'observe parmi les conifèrcs que dans ce scul genre). Les chatons mâles sont à peu près globuleux, simples, environnés à leur base d'écaillès imbriqnées, ciliées sur leurs bords ; ils sont composés d'un très-grand nombre d'élamincs biloculaires que l'on peut considérer comme autant de fleurs mâles, formées dc dcux anthères uniloculaires. Les chatons femelles sont ovoïdes, cntourès de jcunes feuilles; ils se eomposent d'écailles imbriqućes d'un rouge pourpre, offrant unc longue pointe.

Ses eônes sont latćraux, ovoïdes allongés, formćs d'écaillcs arrondies, très-oblisises.

Le mélèze croît dans les parties élevées des $\Lambda$ lpes auprès des glaciers. On le eultive dans les jardins d'ornement.

Propriétés et usages. Le bois du mélèzc, surtout cclui des vieux troncs, est rougcâtre et veiné. Qnoique léger, il est extrêmement durable; aussi l'cmploic-t-on avee avanlage à la eonstruetion des édifiecs. L'écorce des jeunes branches est astringente et l'on s'cn scrt pour le tannage des cuirs dans cerlaines parties des Alpes.

C'est de l'écoree du méléze que suinte la résine liquide eonnue sous le nom de térébenthine de Venise. Pour facilitcr eet ćcoulement, on pratique au trone des trous et des entailles plus ou moins profondes, surtout dans la partie inférieure. Elle est liquide, assez limpide quand elle est bicn pure, d'une odeur forte et peu agréable, d'unc savcur amcre, âcre ct très-cliande. On la recueille priueipalement dans les alpes anx enrirons de Brianȩon. Elle jouit des mèmes propriétés que les autres espciees de térébenthine et s'emploie aux mêmes usages. Mais c'est de 
cette especee dont on se sert particulièrement pour l'usage interne Voyez à l'article pin maritime.

Ise mélèze fournit eneore un autre prodnit résinenx, eonnu sous le nom vulgaire dc manne de Briancon. C'est une résine qui exsnde de scs feuilles pendant l'été. Elle constitue des petits grains blanchàtres que l'on recueille et qu'on réunit en masse. Elle est fort peu employéc.

DEUX 1 Ė ME SECT TON.

Cupressiñérs. - Fruit, un cốne globulenx, fleurs femelles dressées.

\section{GENÉR IER. - JUNIPERUS.}

Les fleurs sont monoïques ou dioïques; les fleuirs mâles forment de petits chatons ovoïdes, dont les éeailles en forme de elou porlent à leur face inférieure des anthères globuleuses, scssiles; les flenrs femelles sont réunies au nombre de trois dans une espèce d'involucre eharnu, globuleux, tridenté à son sommet. Le fruit est globuleux, charnu ( c'est l'involucre qui s'est aeeru), renfcrmant trois petils noyaux triangulaires qui sont les véritables fruits.

GanévrIer conmte. Juniperus communis. L. Sp. I 470. Blackw. t. ז 87 .

Arbrisseau ordinairement dressé, rarement étalé ct couché, raneux, diffus, ponvant aequérir une hauteur de douze à quinze pieds. Ses fcuilies sont verticillées, ternées, linéaires, très-aiguës, piquanles, longues de six à lıuit lignes; gुlauques à leur face inféricure.

Les fleurs sont diö̈ques, disposées en petits chatons axillaires et solitaires; les fruits sont eharnus, noirs, de la grosseur d'un pois, renfermant dans leur inlérieur deux ou trois petits osselets triangulaires.

Le genévrier eroít sur les cotenux pien'eux et stériles.

Propriétés at usages. Les frnits du ģenévrier, eonnus sous le nom de baics rle gemiére, ont me saveur amère, ehaude ct. térébenthacée. C'est la seule partie de eet arbrisseau dont on 
fasse usage en médecine. On les emploie comme toniques et siimulans. Quand l'estomac est dans un état de débilité qui cn ralentit les fonetions; quand la sécrétion de l'urine, la menstruation, sont diminuées ou supprimées à cause de l'état de faiblesse de la vessie et de l'utérus, les baies de genièvre peuvent être avantageusement employécs comme stomachiques, diurétiques ou emménagogues.

On prépare avec ces fruits une infusion aqueuse ou vinense, après en avoir coneassé une derni-once, que l'on met dans une livre de liquide. L'extrait est une préparation fort énergique, dont la dose cst d'un scrupule à un demi-gros.

Dans ccrtains pays du nord de l'Europe on distille les baies de genic̀vre avce de l'eau-de-vie, qui prend une saveur et une odeur aromatiques et très-fortes. Cette liqueur porte le nom d'eau-de-vie de genière.

\section{Genévrter sabine. - Juniperlus sabina. L. Sp. I 472. Bull. t. I39.}

Partie usitćc : les rameaux. Nom vulg. : Sabine.

Cet arbrisscau s'ćlève, comme le précédent, à une hauteur de douze à quinze pieds. Ses feuilles sont extrêmement petites, squannniformes, dressées, rapprochées, imbriquées sur la tige, opposées, ovales, aiguës, 110n épincuses. Les fleurs sont dioïques. Les chatons sont portés sur de petits pédoncules recourbés, et écailleux.Les fruits sont pisiformes, un peu ovoïdes, clarnus, d'un bleu noirâtre, ils ne renferment qu'un ou deux petits noyaux.

Ce genévrier n'est pas rare dans les endroits secs et picrreux des provinces méridionales de la Franee.

Propriétés et usages. Les feuilles de la sabine ont une saveur âcre et amc̀re, une odcur forte, aromatique et térébenthacće. On les administre ordinairement en poudre. Elles agissent avec une extrême énergic, et déterminent, lorsque la dose cn est un peu élevée, tous les symptômes des médicamens irritans, c'est-à-dire une ardcur ineommode dans l'cstomac, des coliques violentes, dés déjections alvines mélangées de sang; l'acećlération du pouls, l'augmentation de la chaleur animale, elc. 
Quelques auteurs reeommandent l'usage de la sabine pour eombattre les vers qui s'amassent dans le eanal intestinal.

Mais e'est partieulièrement eomme exerçant une aetion stimulante spéciale sur l'utérus, que la sabine a joui d'ıne plus grande réputation. Donnée à la dose de deux à six grains, elle aetive et favorise le travail de la menstruation. Mais administrée à des doses plus fortes, elle oceasionne des aceidens extrêmement graves, telles qué l'inflammation et l'uleération des intestins, l'inflanmation de l'utérus, et par suite l'avortement et l'expulsion' du produit de la eoneeption.

On ne doit done administrer ee remède qu'avee les plus grandes préeautions, et à des doses qui permettent de n'en pas craindre les redoutables effets.

Linné, Broussonet, et un grand nombre d'auteurs, pensent que e'est une autre espèee de ce genre, le Juniperus lycia, qui fournil la gomme résine eonnue sous le nom d'oliban ou d'encens; tandis que Roxburg attribue cetle substanee à un arbre de la famille des Térébenthaeées qu'il nomme Boswellia serrata.

On brûle l'oliban dans les temples et dans les églises.

Les pharmaciens le font entrer dans plusieurs préparations offieinales, telles que divers emplâtres, la thériaque, le baume de Fioraventi, ete.

TROISIEM 5 E C TION.

TAXINÉEs. - Fruit simple, fleurs femelles solitaires.

\section{IF. - TAXUS. L. Juss. Rich. Conif, t. 2.}

Fleurs dioïques, ehatons très-petits, axillaires et solitaires, à l'aisselle des feuilles supérieures, enveloppés inférieurement d'éenilles imbriquées; les mâles sont eomposés de six à quatorze fleurs formées d'une éeaille diseoïde, peltée, porlant sous ee disque trnis à huit anthères membraneuses, également attaehées au pivot eentral. Les ehatons femelles se eomposent d'une seule fleur terminale, étroitement embrassée par des écailles imbriquées; leur ealiee est resserré à sa partie supérieure, en un petit eol très-eourt. L'ovaire paraît dépourvu de style et de stigmate. 
L'éeaille la plus intérieure de l'involucre prend un grind aceroissement, devient épaisse, eharnue et forme une sorte de cupule monophylle qui enveloppe le fruit de toutes parts.

\section{If commun. Taxus baccata. L. Sp.}

Arbre de moyenne taille, très-ramenx, portant des feuilles éparses, presque sessiles, linéaires, planes, et aiguës, elles sont dirigées des deux côtés des rameaux et tendent à s'étaler dans le même plan.

Les fleurs sont dioïques; les chatons mâles fort petits, soli taires et sessiles à l'aisselle des feuilles supérieures. Ils sont ovoüdes, environnés à leur base d'éeailles obtuses et imbriquées. Chaque ehaton, lorsçu'on enlève les ćcailles inférieures, est tout-à-fait globuleux et courtement pédieulé. Il se eompose de six à quatorize petits eorps dioseoïdes, jaunâtres dont elıeun est une fleur mâle.

Les ehatons femelles sont également solitaires ef axillaires, un peu plus petils et plus allongés que les mâles. Ils sont également formés à leur partie inférieure d'éeailles imbriquées qui embrassent étroitement une seule fleur terminale. La plus intérieure de ees écailles est monoplyylle, et en forme de godet; après la féeondation elle prend ún aceroissement considérable, s'allonge, devient épaisse, charnue, d'une bolle eouleur rouge de cerise, et enveloppe le fruit sans y adhérer par aueun point de sa surface interne.

L'if eroit dans les pays montieux. Il est eommun dans le. Jura, en Savoie, ete. Il aime les lieux froicis et ombragés. Il fleurit à Paris en mars é avril. Ses fruits śont mùrs en sepptembre.

Propriétés ét usager.s. L'if est un de ees arhres anxquels les aneicns ont attribué, un peu gratuitement, des projrriétés fort délétères, que les observations des modernes sont loin d'avoir toutes eonfirmées. C'est ainsi, disait-on, que son ombre élait mortelle pour le voyageur assez impurtudent pour s'y laisser surprendre par le sommeil. Je puis assurer un'être souvent reposé des heures entières sous des ifs dans les différentes excursions que j’ai faites daus les provinees méridiouales de la Franee, 
sans crl avoir éprouvé d'autrc aceident çu'une lćgère douleur de tête qui cessait peu dc temps après. Ses baies, qui ont également passé pour être narcotiques, sont tr'cs-visqueuses; elles ont une saveur sucrée ct agrćable. Lies enfans lcs mangent en abondance sans cn être indisposés. Il faut rejeter.le fruit que le tégument charnu cnvironne, car il a une savcur amère et désagrréable. Les feuilles de l'if, et l'cxtrait qu'on prćpare avec elles, ont déterminć quelquefois un lćger nareotismc à la dase d'environ un gros. Ils ne sont plus employés.

Quant au bois de l'if, il cst d'une bellc couleur ronge vcinć. C'est un des plus durables de iios bois indigènes. On cn prépare des poutres ẹt des planches qui sont d’un fort bon usagc.

\section{Propriétés et isages des Coniféres.}

Si l'on fait attention au nombre et a l'importance des produits fournis par les arbres de la.famille des conif'è'es, on conviendra qu'elle est un des groupes les plus intćressans du rèugne végétal. Le tronc de ces arbres majestueux, qui acquièrent une hauteur des plus considérables, est employé avec le plus grand avantage dans les coustructions civilcs et navales. Le pin rouge (pinus rubra), désigné sous le nom vulgaire de pin de Riga fournit des bois de mâture extrêmement rccherchés. L'écorce d'un grand nombre de coniféres peut être employée comme celle de nos chênes, au tannage et à la préparation des cuirs.

Les différentcs substances résineuses retirées des pins, des sapins ct des gencvriers sont ćgalcmeni rechcrchées pour l'usage pharmaceutigue et pour les arts industricls. Leur extrême analogie, leur ressemblance parfaite estunc preuve évidentc de l'affinité puissante qui unit cntre "eux les gonres de la famille des conifères, affinité que l’on remarquc égalcment dans l'organisation et la structurc singulière des différens organes de ces végétaux. ।

VINGT-CINQUI定M E A MILL E.

SALIGINEES - SALICINEXE.

Les fleurs sont diöques et forment des chatons glo- 
buleux ou allongés : les fleurs mâles se composent d'une écaille de forme variable, sur laquelle sont implantées les étamines, dont le nombre varie d'une à vingt-quatre. Le plus souvent on observe à la base des étamines une petite écaille glanduleuse, cuelquefois creuse et en forme de calice. Dans les fleurs femelles on tronve également une écaille, à la base interne de laquelle est attaché un pistil fusiforme, uniloculaire, renfermant plusieurs ovules attachés à deux trophospermes pariétaux qui occupent surtout le fond de la loge. Lestyle est très-court, sur'monté de deux stigmates, profondément bipartis. Quelquefois le pistil est environné dans sa moitié inférieure dans une sorte de calice cupuliforme trónqué.

Le fruit est une petite capsule ovoïde terminée en pointe à son sommet, s'ouvrant en deux valves, dont les bords rentrans simulent quelquefois une capsule biloculaire. Les graines qui sont fort petites sont environnées le longs poils soyeux.

Les Salicinées sont de grands arbres, des arbrisseaux ou plus rarement de petis arbustes rampans, qui se plaisent pour l'ordinaire dans les lieux humides, sur le bord des ruisseaux et dans les prairies, dont ils font l'ornement. Leurs fleurs paraissent ordinairement arant que leurs feuilles commencent à se développer. Celles-ci sont alternes, accompagnée de stipules. Leur bois est généralement blanc, tendre et peu compacte. Les Salicinées sont les végétaux que l'on multiplie le plus facilement de bouture. Ii suffit d'enfoncer dans la terre une branche de saule ou de peuplier, pour former urı nouvel individu.

$$
\text { SAULE. - SALIX. L. J. }
$$

Fleurs dioïques disposées en chatons ćeailleux : chaque fleur mâle se eompose d'ụne à cinq étamincs attachées à la base d'une écaille, qu'aecompagne me pelite languette tronquée. 
Les Aleurs femelles offrent un ovaire fusiforme pédicellé, surmonté d'un style très - court et de deux stigmates profondément bifides. Le fruit est unc capsule uniloculäire, s'ouvrant en deux valves longitudinales, et renfermant plusieurs graines recouvertes de longues soies fines et nacrćes.

\section{Saule blayc. Salix alba. L. Sp. I 449. Blackw. t. 327 .}

C'est un arbre de vingt-cinq à trente pieds d'élévation, qui se divise supérieurement en rameaux redressćs dont l'écorce est lisse et d'un vert tendre. Mais le plus souvent on l'étête, et il formc alors unc sorte de souche, dont la partie centrale se dćtruit et sc creuse, et qui est couronnće par un bouquet de branches, qui partent toutes du sommet. Ses feuilless ont allongćes, lancéolées, aiguc̈s, déntées en scie sur leurs bords. Lcur face supérieure est glabre, tandis que l'infćrieure est couverte de poils blancs et soyeux.

Les chatons se développent en même temps que les feuilles ce quí n'a pas lieu également pour toutes les espèces de ce genre, dont quelques-unes, le marcean (salix caprœa L.), par exemple, fleurissent et commencent à fructifier avant que leurs feuilles se déploient. Les fleurs mâles ont chacune deux ćtamines. Les fleurs femelles ont l'ovaire courtement pćdicellé. La capsule est allongée, renflée à sa base, terminéc en pointe à sa partie supérieure : clle est glabre.

Le saule blanc cst fréquent le long des ruisseaux, dans les prés et les bois humides. Il fleurit au commencement du printemps.

Propricétés et usages. L'ćcorce récoltéc sur les jeunes branches dc ce saule ainsi quc celle de presque toutes les autres espèces du même genrc, est douée d'une amertume et d'une astringencc très-marqućc. Aussi plusicurs auteur's ont-ils cherché à remplaccr Ic quinquina avec les ćcorces du saule blanc, du marceau et de quelques autres cspèces. Elles conticunent du taunin; un prineipc extractif ct du glulen. On les administre ordinairement en poudrc ou en décoction. Leur extrait ct lcur teinture sont moins fréquemment cmployés.

L'écorce de saule est un médicament assez émérgiqque, et qui pourrait remplacer arcc avantage lc quinquina dans les temps 
où eette écoree exotique est rare et d'un prix très-élevé. C'est en effet un de nos toniques indigènes les plus effieaees, qui détermine dans l'économic auimale des ehangemens très-notables, aussi l'a-t-on cmployé,' et souvent avce succés, dans toutes les maladies qui réelament l'usage rles toniques et du. quinquina en partieulier. Un grand nombre d'observatious ont constaté l'efficacité de l'éeoree de saule dans le traitement des fièvres intermittentes. Sa close est la même que celle de la poudre de quinquina.

$$
\text { PEUPLIER.-- POPULUS. L. J. }
$$

Fleur's diọ̈ques disposées en ehatons écailleux : les mâles offrent cle huit à vingt-quatre élamines, attachées dans un calice tronqué, situé sur une éeaille de forme variée; dans les fleurs femelles le pistil est embrassé à sa base par un ealice analogue à eelui des fleurs mâles, et surmonté de quatre stigmates.

In eapsule est à deux valves, dont les bords rentrans, si mulent une eapsule biloeulaire; les graines sont également re, eouvertes de longs poils soyeux.

Les peupliers différent des saules par leur ealiec tronqué, par leurs étamines plus nombreuses et par leur eapsule qui paraît biloculaire.

Peupler worr. Populus nigra. L. Sp. I464. Blackw.

$$
\text { t. } 248 \text {. }
$$

Le perpuier noir peut aequérir une hauteur de plus de soixante pieds lorsqu'il végète dans un sol humide et profond. Son tione se divise en ramifieations reeouvertes d'une éeoree jaune, grisâtre, fendillée. Les feuilles sont d'abord renfermées dans des bourgecons ovoïdes, allongés, aigus, enduits d'une sorle de vernis résineux et odorant. Elles sont pétiolées, trapézoïdales et présque triangnlaires, inégalement crénclées sur leurs bords, glabres et luisantes sur leurs deux faces.

Ies chatons mâles sont grêles et épars vers la partie supérieure des rameaux ie l'année précédente. Clıqque fleur présentc de doure à vingt étamines, dont les antluères sont purpurines. 
Cet arbre qui fleurit au commeneement du printemps, est commun dans les prés et les bois humides.

Propriétés et usages. Le penplier noir eroît avec rapidité. Son bois cst employé à faire des poutres et des planches. Ses bourgenns non-développés sont la seule partie dont on fasse usage en médeeine, encore cet usage est - il borné à la préparation de l'onguent eonru sous le nom dé populeum, qui doit ses proprićlés calmantes aux végćtaux nareotiques qui y entrent en plus grande quantité. Nous ne parlerons point de la teinturc alcoholique de horrgeons de peuplier que l'on employait autrefois eontre la phthisie pulmonaire. Elle est tombée dans un juste oubli.

\section{Propriétés et usages cles plantes de la famille des Salicinées.}

Peu remarquable par les proprićtés médicales des arbres qui la composent, cette famille est plus intéressante par ses usages assez multiplićs dans l'éeonomie domestique. Sans parler ici des jeunes branches des saules et de quelques espèces de peupliers qui à cause de leur sçullesse ont étć employées de temps immémorial à la fabrication des eorbeilles et dos autres olvrages de vannerie, nous dirons quc l'ćcorec des arbres de eettc famille est généralement fort astringcnte, et qu'elle peut être cmployće avec avantağe au tannage des cuirs, de même que par ses proprićtés toniques', clle est administrće avee quelque sueeès comme sueećdanée du quinquina. Quant à son bois, quoique d'un grain assez peu compacte, il est fort en usage pour les ourrages de charpente et de inenuiserie.

VIN GT-SIXIËI FAMILLE.

\section{BÉTULACÉE. - BETULACEAE.}

Les 'fleurs sont monoïques disposées en chatons écailleux; dans les chatons mâles, chaque écaille, qui souvent est composée de plusieurs écailles soudées, porte deux ou trois fleurs nues ou pourvues d'un calice à trois ou quatrc lobes; le nombre des etamines varie de deux à quatre dans chacpue fleur; les chatons femelles toujours 
situés au-dessous des mâles, et phıs petits qu'eux, sont ovoïdes ou allongés et cylindriques, formés d'écailles imbriquées, entières ou trilobées, dans l'aisselle de chaeune desquelles on trouve deux ou trois fleurs sessiles. Ces fleurs offrent un ovaire lentieulaire à deux loges, contenant chaeune un seul ovule attaehé à la partie supérieure de la cloison : deux stigmates filiformes légèrement soudés dans leur partie inférieure, plus longs que l'ovaire.

Les éeailles des chatons femelles sont caduques ou persistent, deviennent plus épaisses èt forment uneespèee de cône. Les fruits sont lenticulaires, un peu membraneux sur leurs bords, à une seule loge et à une seule graine par avortement. Ils restent indéhiseens. Cette graine renferme un très-gros embryon, dont la radieule est courte et supérieure, les cotylédons très-larges et arrondis.

Les Bétulacées sont des arbres d'une stature assez élevée ayant des feuilles alternes et pétiolées, et qui croissent dans les lienx humides ou dans les sables stériles.

Gette famille diffère de la préeédente $\mathbf{I}^{\circ}$ par ses fleurs monoïques; $2^{\circ}$ par ses étamines moins nombreuses; $3^{\circ}$ par ses deux longs stigmates filiformes; $4^{\circ}$ par son ovaire biloculaire, dont chaque loge renferme une seule graine; $5^{\circ}$ par son fruit monosperme qui reste indéliscent.

\section{BOULEAU. - BETULA. Tournef. Gœrtn.}

Fleurs monoïqucs : chatons mâles terminaux, allongćs, cylindriques; ćcailles grroupécs et soudées par six, donnant attache à six étamines à anthèrcs, dont les deux loges sont écartées et distinctcs, ct que l'on pourrait considércr comme formant trois fleurs, ainsi que cela a lieu manifestcmcnt dans l'aune; chatons femellcs allongés, cylindriqucs, beaucoup plus pclils que les mâles; chaquc écaille offre dcúx petites oreillettes à sa base, et trois fleurs qui se composent d'un ovairc mem- 
braneux sur ses bords, terminé par deux stigmates filiformes. Les fruits sont autant de petites samares membraneuses, à une seule loge et à une seulc graine, renfermćes entre les éeailles du chaton, qui sont minees et caduques.

\section{Bouleau beanc. Betula alba. L. Sp. 1393 . Duham. arbr. I. t. 39 .}

Nom vulgaire: Boulcau.

Cet arbre, qui dans les bons terrains peut acqućrir une hauteur considérable, se fait facilcment reeonnaitre à son tronc recouvert d'un ćpiderme see, blauc et naerć, s'enlevant par feuillets; à ses jeunes rameaux trc̀s-grêles, pendans à la manière des saules pleurcur's, et dont l'épiderme est rougeâtre et eouvert de petiles verrues blanches. Ses feuilles sont pćtiolćes, ovales, subtriangulaires, irrégulièrement dcntées en seie, et terminćes en pointe à leur sommet; leurs deux faees sont glabres et d'un vert clair. Les chatons mâles sont geminćs et situćs au sommct des ramifications de la tige; les chatons femelles sont solitaires et placés au-dessous des premiers. Ces chatons sont allongćs, grêles, pendans et eylindriques. Dans les chatons femelles les écailles sont trilobées.

On trouve le bouleau dans les terrains les plus sees, les plus sablonneux et les plus rocailleux. Il croit sur le penehant des collines exposées au nord, jusque dans les fentes des roehers. C'est lui que l'on trouve lc dernier en gravissant les pentes escarpées des montágnes. C'est encore lui qui s'avanee le plus loin vers les contrées du pôle glacial. Mais dans ees deux eirconstanccs ce n'est plus qu'un arbrisseau rabougri qui s'élève à peine à trois ou quatre pieds au-dessus du sol.

Propriétés et usages. Nous aurions bieu peu de ehoses à dire des propriétés médieales du boulcau, si nous ne devions parler quc de celles que l'expérience elinique a eoufirmćes. Ccpendant nous ne devons point omettre de rappeler iei que le sue et la décoetion dc ses feuilles, dont la saveur est austc̀re ct amère, ont été recommandés comme un remède vermifuge et diurétique; que son écurce, qui est astringente et amère a été quelquéfois administrée coutre les fièvres intermitlentes, 
et qn'enfin la seve limpide et aigrelette, qui s'ćeonle an printcmps des fentes que l'on pratiquc à son trone, a été préconisée eontre une foule de maladics différentes, et surtout eontre les maladics des voies urinaires, principalement celles qui sont occasionées par des caleuls arrêtés dans la vessie. Mais aujourd'hui ees diffćrentes partics ne sont que bien rarement employées par les médecins.

Dans les régions glacées du nord de l'Europe ct de l'Asie, on fait, avec l'ćcorce intérieurc du bouleau, qui est tendre, snceulente et d'une couleur rougeâtrc, des espèces de galettes qui sont, avec le poisson fumé et salé, la seule nomriturc des habitans pendant les longs hivcrs qui désolent ces contrécs.

Le bois du bouleau est blane, assez flexiblc. On en fatbrique des cerceaux et d'autrcs objets d'ćconomie domestique.

AUNE. - ALNUS. Tournef. Gœrtn.

Fleurs monoiques; chatons mâles terminaux, cylindriques et trc̀s-longs; chaque éeaille porte trois Aleurs scssiles composées d'un calice étalé à trois ou quatre divisions, et de trois ou quatre étamines; clratons f́cmelles ovoïdes, presque globuleux, formés d'ćcailles imbriquécs; dans l'aisselle de ehacune d'elles sont ordinairement deux, quelquefois trois flcurs scssiles, àccompagnécs à lcur base de dcux petiles braetées; l'ovaire est comprimé à deux loges uniovulécs, surmonté de denxstigmates filiformes; le fruit est unc sorte de pelit cône renfcrmant entre ses ćcailles, qui sont épaisses et pcrsistantes, dc petiles samarcs uniloculaircs et à une scule graine.

Ce genre, d'abord réuni au précédent, en diffère par la strueturc de ses fleurs mâles et par scs chatons femelles, dont les écaillcs persistantes et épaissies conslituent nue sorte dc petit eône.

Aune commun. Alnus vulgaris. Rich. Betulaalnus L. Sp. 1394. Ainus glutinosa. Gocrtn. fruct. 2, p. 54, t. 9o, f. 2 .

L'aune peut acquérir une haulcur de trentc-six à quarante picds. Son tronc cst.droit, cylindriquıc, divisé en rameanx 
dressés. Son bois est jaunâtre, assez tendre. Ses feuilles sont ovales, arrondies, obtuses, crénelées sur leurs bords et comme tronquées au sommet; elles sont légèrement pubeseentes, surtout lorsqu'elles sont jeunes et reeouvertes d'un enduit. visqueux et glutineux. Les fleur's se montrent peu de temps après les ferilles: lcs chatons mâles sont réunis au nombre de trois à quatre à l'extrémité ỉes jeunes rameaux; ils sont eylindriques, longs de trois à (quatre pouees; les femelles au nombre de quatre à einq sont plaeés au-dessous; ils sont: ovoïdes, longs seulement de trois à quatre lignes, formés d'éeailles ovales, obtuses, entières, au-dessus desqunelles on voit sortir les styles qqui sont de eouleur purpurine.

Les fruits qui leur sueeèdent sont des espèeeš de eônes ovoïdes de la grosseur d'une noisette.

Cế arbre est commun dans les lieux humidẹs, sur les bords des ruisseaux.

Usages et propricités : l'écoree de l'aune eontient une assez. grande quantité de tannin; aussi a-t-elle une saveur âpre et astringente. On s'est quelquefois servi de sa déeoction pous' préparer des gargarismes détersifs, employés eontre les maladies de la gorge et des amygdales. Mais eette substance est rarement mise en usage dans la pratique médieale. Les tanneurs s'en servent avee plus d'avantage pour la préparation des euirs.

Son bois, quoique tendre et léger, est employé à différens, ouvrages de tour et de menuiserie.

\section{Propriétés et usages des Bétulacćes.}

Si nous résumons les propriétés dọt jouissent les Bétulacées, nous verrons qu'elles sont presque en tous points semblables à eelles des arbres de la famille des Salieinées, e'est-àdire que leur prineipe dominant est le tannin qui existe dans leur ćeoree, prineipe qui la rend astringente el tonique. Du resle eette famille est peu intéressante sons le rapport médical. 
B. Fleurs non disposée. en chatons.

VINGT-SEPTIEMIE FAMILLE.

THY MÉLEES. - THYMELEAE.

La plupart des Thymélées sont des arbrisseaux, dont les feuilles sont ordinairement alternes, souvent persistantes.

Leur calice est monosépale, souvent coloré et corolliforme, plus rarement vert et peu apparent, tubuleux à quatre ou cinq divisions peu profondes, quelquefois persistantes, donnant attache à huit ou rarement à dix étamines` Le pistil est simple : l'ovaire est supère, uniloculaire et renferme un ovule renversé; le style est terminé par un stigmate simple. Le fruit est une petite baie monosperme ou un akène; l'embryon est renversé et épispermique.

\section{DAPHNE. - DAPHNE. L. J.}

Le ealiee est eoloré infundibuliforme, quadrifide, donnant attaehe intérieurement à huit étamines presque sessiles el ineluses, le style est eourt et surmonté d'un stigmate hémisplıérique. Le fruit est une baie globuleuse à une seule graine.

Les espèees de ee genre sont ordinairement des arbustres à feuilles alternes, qui ont les fleurs axillaires ou terminales.

\section{Daphné bois gentrl. Daphne mezereum L. Sp. 5og. Bull. t. I.}

Noms vulgaires: Lauréole gentille, bois gentil, etc.

C'est un petit arbuste de deux à trois pieds d'élévation, qui se eouvre de fleurs roses dès le mois de féviier, arant que ses feuilles eommeneent à paraître. Sa tige est rameuse, reeouverte d'une éeoree grisàtre; ses fenilles naissent toutes du sommet de ehaque rameau, an-dessus des fleurs, elle sont sessiles éparses, lanećolées très-entières, rétréeies à leur base; glabres, un peu glauques en dessous, longues d'environ deux pouces, les fleurs. 
sont roses disposées par petits groupes composés de deux à trois fleurs et dont la réunion forme une espèce d'épi ou de thyrse serré, à la partie supérieure de la tige. Chacun de ces groupes est, avant son développcment, renfermé dans un bouton squammeux, formé d'écailles imbriquées concaves.

Le calice ( 1 ) est infundibuliforme, son tube est cylindrique, son limbe est à quatre divisions étalées, obtuses, les huit étamines sont presque sessilès, attachées sur plusieurs rangs à la partie supérieure du tube.

L'ovaire est uniloculaire; contenant un serl ovule attaché à la partic supérieure de la loge. Les fruits sont un peu ovoïdes lisses, charnus, d'un rouge vif.

Le bois gentil est commun dans les bois montueux, où il fleurit dès le mois de février, avant que ses feuilles aient commencé à se développer.

Daphné ladréole. Daphne lauteola L. Sp. 5 ro. Bull. t. 37 .

Cette espèce est très-distincte de la précédente; elle a le port d'un laurier, d'où lui est venu le nom de Lauréole. Lin effet ses feuilles sont éparses, rapprochées, persistantes, coriaces, glabres, d'un ver't foncé, lancéolées, aiguës, entières, rétrécies à la base; ses fleurs sont verdâtres disposées par petits faisceaux à l'aisselle des feuilles supérieures. Lies fruits d'abord verts, finissent par devenir d'un rouge foncé et comme noirâtre. La lauréole est très-commune dans les bois humides et tourbeux.

\section{Daphné garou. Daphne gnidium. L. Sp. 5 I r.}

Partie usitée : l'ćcorce. Nom pharm.: Cortex gnidii. Nom vulgaire: Garou, sain bois, Daphné paniculé; D. à feuilles de Gniclia, etc.

Ses rameaux sont effilés, longs d'un pied et plus, chargés de

${ }^{x}$ Ce caliee se dédouble facilement en deux feuillets, ce qui semblerait donner quelque poids à l'opinion des auteurs qui considerent les périgones ou périanthes simples, comme formés par la réunion et la soudure intime du caliee et de la corolle. 
feuilles éparses, linéaircs lancéolées, aigëus, entièrcs, rétrćcies à la basc, trèz-rapprochćes, dressées. Lcs fleurs sont blanches, velues, odorantes, rapproelées au sommet des rameaux. Il leur sncećde de petités baies globuleuses, presque sèches, d'abord vertes, puis noirâtres.

Cet arbuste croît dans les provinces méridionales de la France dans les lieux secs et ineultes, sur le bord des ehcmins. Il fleurit en juin. Je l'ai trouvé abondamment près du pont du Gard; aux environs de Toulon et dans d'autres parties du midi de la France.

Proprićtés et usages. Nous rćunissons içi dans un même artiele ce que nous avons à dire touchant lcs propriétés médicales dont jonissent les différentcs espèees de Daplınés, parce qu'en effet ces propriélés sont lcs mĉmes dans toutes les espèecs de ce genre. Toutes leurs parties, mais surtout leur écorce, lcurs fcuilles et leurs fruils sont doués d'une extrêmc âcreté. Appliqnée pendant quelqquc temps sur la peau, l'écorce du garou (Daphne grnidium) ne tarde point à la rubéfier et à y déterminer une irritation vive qui occasionne le soulèvement de l'épiderme et la formation d'ampoules plus ou moins volumineuses. A ussi cmploie-t-on l'écorce de garou, et les préparations dans lesquelles elle entre, pour former des exutoires sur les différcntes parties du corps. Ce médieament doit même être prćféré aux cantharides, dans le cas où il cxiste une irritation plus ou moins vivc dans la vcssie ou les organes génitaux, sur lesqucls les cantharidcs exercent, comme l'on sait, une aetion irritante spéciale.

Prise intéricurement, l'écoree du garou dćtermine tous les aecidens des substances vćnćneuses, âcres et corrosives. Cependant quelques auteurs ont recommandé l'usage de l'éeorce et des feuilles des différentes espèces de Daphné; les uns contre les scrophules, d'au tres contre les hydropisies et la sy pliilis constitutionnelle. Celtc décoction, moins àcre que l'ćcorcc et les feuilles en nature, jouit, ainsi que les fruits des mêmes espèces, d'une vc:tu purgativc; mais il est fort rarc qu'on la prescrive arjourd'hui.

C'est en analisant l'éeorce du Daphre alpina L. que MI. Vauquelin a dćcouvert le prenier aleali organiquic. Il l'a depais re- 
trouvé en abondance daus le garou, ou écorce du Daphne gnilium. Cette base salifiable, qui est âcre et volatile, paraît être le principe aetif de ces écorces.

\section{Propriétés médicales et usages des Thymélées.}

Ce que nous venons de dire des proprićtés médieales des espèces du genre Daphné, peut s'appliquer en général à tous les autres vérgétaux qui apparlicnnent. à la famille des thymélées, qui sont plus oumoinsàcres et corrosifs. Cette âcreté paraît lépendre du principe alcalin observé par Ir. Vauquelin dans les éeorees du garou et du Daphné des Alpes. Aussi les vćgétaux de cette, famille sont-ils plus ou moins vénéneux. is .

Plusicurs sont intéressans par rapport à lenrs usages économiques. Ainsi ils fournissent un prineipe colorant jaune, assez abondant, que l'on cmploie pour teindre les laines.'

L'écorce intérieure de quelques espèces est assez dure et résistante, ponr qu'on s'en serve à fabriquer des toiles et des cordages. Mais dans aueune autre plante cette écoree n'est aussi remarquable que dans le laghctı, où elle forme un réseau composé de fils entrelaećs, qui ressemble tout-à-fait à une dentelle grossière. De là le nom de bois dentelle donné à cét arbuste.

VINGT-HUITIE MIEAMILLE.

\section{POLYGONEES. - POLYGONEAE.}

Dans les Polygonées sont réunies des plantes ordinairement herbacées, portant des feuilles alternes, engaînantes à leur base; ces gaines sont minces et membraneuses; leurs fleurs sont le plus souvent petites et verdâtres; leur calice monosépale est partagé en trois, cinq ou six divisions, souvent persistantes. Son fonds est tapissé par un disque périgyne, dont le bord est lobé. Les étamines, en' nombre variable mais défni, sont rarementau de là de quinze. L'ovaire est simple, libre, ì une seule loge, etrenfermant un seul ovule. Il est terminé 
par deux ou trois stigmates, quelquefois sessiles; d'autres fois portés sur autant de styles.

Le fruit est très-petit : c'est le plus souvent un akène triangulaire, revêtu par le calice qui quelquefois devient charnu : sa graine renferme un embryon endospermique intraire : l'endosperme est farineux.

POLYGONE. - POLYGONUM.'L. J.

Caliee pétaloïde eoloré, persistant, à quatre ou einq divisions profondes; étamines variant de einq à huit; ovaire ordinairement terminé par trois styles, que surmontent autant de stigmates eapitulés. Le fruit est un akène souvent triangulairc, reeouvert par le ealice.

Ce genre est extrêmement nombreux en espèees qui présentent, dans leur port, la disposition de leurs fleurs, des différenees assez tranchées. Aussi Tonrnefort en avait-il fait quatre genres distinets, savoir : $\mathrm{I}^{\circ}$ polygonum; $2^{\circ}$ fagopyrum; $3^{\circ}$ bistorta; $4^{\circ}$ persicaria.

Polygone sarrasin.-_Polygonum fagopyrum. L. Sp. 522. Part. usitée. Les fruits. Noms vulg. Sarrasin, blé noir, cte. Nom pharm. : Fagopyrum.

Raeine annuellc. Tige herbacée, dressée, haute d'un à deux picds, cylindrique, glabre, légèrement pubeseente à l'artieulation de chaque feuille, rameuse, rougeâtre dans sa partie inférieure.

Feuilles altermes très·éloignées, cordiformes, aiguës, un peu sinuées et eomme eiliées sur leurs bords et leurs prineipales nervures; ces feuilles sont portées sur des pétioles longs de I à 3 pouces, un peu canalieulés, ciliés sur les bords de leur gouttière, élargis inférieurement en une membrane inince et diaphane qui embrasse la tige et forme une petite gaine bifide.

Fleurs blanehes disposées en épis axillaires, eourts et serrés: les inféricurs, portés sur un pédoneule pubeseent à pen près de la longueur du pétiole; les supérieurs plus eourts formant une sorte de eorymbe terminal.

Calice péłaloïde étalé à einq divisions profondes, ovales, 
obluses, entières. Le fond du ealice est tapissé par un disque jaune étalé, sur lequel est appliqué le pistil. Ce disque forme autour du pistil huit petits mamelons ou tabereules arrondis.

Les étamines, au nombre de huil, saillantes hors du ealiee, sont insérées, savoir : einq en deliors des tuberenles du disque, et trois en dedans. Leurs filets sont grêles, dressés, glabres. Les anthères globuleuses, rougeâtres, à deux loges.

Ovaire comme pyramidal et triangulaire glabre, terminé supérieurement par trois styles eourts eylindriques, sur lesquels sont appliqués autant de stigmates eapitules. Le fruit est blanehâtre, à trois angles fort saillans.

Le sarrasin est originaire d' $\Delta$ sie. Il a été introduit en Europe vers la fin du quinzième sièele. Aujourd'hui il est naturalisé dans toutes les provinees de la Franee. On le eultive surtoul dans les terres sablonneuses. $\odot$

Propriétés et usages. C'est un végétal extrêmement préeieux. En effet, la farine que l'on obtient de ses graines est blanehe, et sans avoir les mêmes qualités que eelle du froment et du seigle, elle renferme beaueoup de prineipe nutritif; aussi en fait-on du pain dans plusieurs eontrées de la France, partieulièrement en Bretagne et dans la basse Normandie. Le grand avantage du sarrasin, c'est qu'il peut venir dans les terres les plus maigres, et que dans les terres substantielles on peut le semer après la réeolte du seigle: on obtient ses graines mûres en septembre. On fait eneore avec eette farine des galettes, des bonillies, ete.

Potygone PoIvRe d'Eau. Polygonum hydropiper. L. Sp. 5 I 7 . Bull, t. 127.

Part. usitée : les sommités. Nom plarnı. : hydropiper. Noms vulg.: curage, poivre d'eau, persicaire brulante.

Ses racines sorit fibreuses; ses tiges sont dressées, noneuses ct artieulées, hautes d'un pied, rougeâtres, portant des feuilles alternes, glabres, lancéolćes, très-aiguës, entières, sontenues par des pétioles eour'ts et eugainans à leur base. Ces feuilles n'offrent point de aches noires. les fleurs sont verdâtres, un pen rosées, disposées en épis grêles, lìches, linéaires et pendans, situés à l'aisselle des feuilles supéricures. 
Les fruits sont un peu eomprimés, obscurćment triangulaires.

Cette plante, que l'on rencontre eommunément aux environs de Paris, eroît sur le bord des ruisseaux et des étangs. -

Elle se rapproche beaneoup de la persieaire ( Polygonum persicaria, L.), dont elle diffère surtout par ses feuilles plus étroites, non maculées, ses épis plus grêles, et dont les fleurs sont beaucoup plins écartées.

Propriétés et usages. Cette plante doit son nom vulgaire de poivre d'eau à sa saveur âer'e et caustique, qui, lorsqu'on la mâehe, détermine dans la bouche un goûl piquant et comme poivré. Appliquće sur la peau, elle en détermine la rubéfaetion, ee qui la fait employer quelquefois avec avanłage pour rappeler les affeetions arthritiques vagues dans le ur siége primitif.

Polygone bistorte. Polygonum bistorta. L. Sp. 5 i 6. Bull. t. 3r 4 .

Partie usitée : la racine. Nom pharm.: bistorta. Nom vulg.: la bistorte.

Racine vivaee, eylindrique, d'un brun foncé à l'extérieur, d'une eoulemr rose intérieurement; de la grosseur du doigt; présentant des espèees d'articulations, et formant plusierurs coudures assez rapproehées. Tige herbacée, droite, cylindrique, glabre, noueuse, haute de I à 2 pieds, simple.

Les feuilles radicales sont cordifor'mes, allongées, erispées, blanchâtres et pubescentes cn dessous, portćes sur un pétiole plus long que la fcuille, triangulaire et ailé dans sa partie supćrieure, formant à sà partie inférieure une gaînc membrancuse. Les feuilles eaulinaires sont moins grandes, plus étroites, ayant la gaine très-large, surmontée d'une languctte mcmbraneuse très-allongée, aiguë; les supérieurcs sout scssiles, offrant toujours une gainc nembraneusc qui embrasse la tige.

Fleurs blanehes-rosâtres, disposćes en un épi ovoïde très-serré à l'extrémité de la lige; ehaque fleur est pédonculéc, embrassée à sa base par plusieurs bractécs scarieuses. 
Le fruit est ovoüde, à 3 angles arrondis très-saillans, lisse, glabre, contenant une seule graine dressée.

La bistoitc eroît dans les prés des montagnes. Zf

Propriétés et usages. La racine de bistorte a une saveur trèsastringente et un peu âpre, surtout lorsqu'elle est fraiehe : elle contient une grande quantité de tannin, de l'aeide gallique, beaueoup d'amidon et une petite quantité d'aeide oxaliquẹ dont Selıéele a le premier démontré l'existenee. C'est un médieament tonique et astringent que l'on met quelquefois en usage avee suceès dans les hémorrhagies ditespassives, danș la diarrhée, ete. Cullen l'a administrée à la dose de deux ou trois gros dans les fièvres intermittentes. Il y joignait souvent la poudré de Gentiane, qui en augmentait singulièrement l'effieaeité. On la donne ordinairement en poudre, à la dose d'un serupule à un demi-gros, dose que l'on porte à deux ou trois gros dans les fièvres internittentes. La déeoetion de deux à quatre gros de bistorte dans une livre d'eau, peut être employée pour faire des injeetions toniques dans les écoulemens ehroniques de l'urètre et du vagin.

\section{RUM EX. - RUMEX. L. Juss.}

Le ealiee est turbiné à sa base; a six divisions, dont trois intérieures sinueuses ou glanduleuses sur leur bord sont persistantes; six étamines insérées. au ealice : ovaire surmonté de trois stigmates rameux et glandulaires; akène triangulaire, enveloppé par le ealiee.

Les espèees sont ordinairement herbaeées. Ce genre diffère du préeédent par le nombre de ses parties, et par șes stigmates sessiles et rameux.

Rumex oseinle. Rumex acetosa. L. Sp. 481. Blackw.

$$
\text { t. } 230 \text {. }
$$

Partic usitée : les feuilles et la tige. Nom pharm. : acetosa vel oxalis. Noms vulg. oseille, surclle, ete.

Une racine vivaee rampante, brune, noirûtre, donne naissance à une tige herbacée dressée, haute d'un pied et plus, eylindrique, glabre, eannelée longitudinalement, pleine intérieurement; les feuilles radieales sont portées sur des pétioles 
canalieulés, longs de quatre à einq ponees, et garnis à leur base d'expansions minees et menbráneuses; elles sont molles, ovales, très-obtuses, sagiltées, entières; eelles de la tige sont sessiles embrassantes, très-aiguës au sommet, également sagittées ì leur base.

Les fleurs sont petites, vierdâtres, un peu rougeâtres sur les bords, disposées en panicule rameuse et ternninale : ehaeune d'elles est pédicellée, pendante, eomposée d'un ealiee turbiné à sa base, partagé en six lobes, dont trois intérieurs, ovales, obtus, un peu sinueux sur les bords : les six étanines sont ả filamens grêles et eourts, insérés sur le ealiee. Le pistil est simple et libre; l'ovaire est pyramidal et triangulaire, à une seule loge qui eontient un ovule dressé : il est surmonté de trois stigmates rameux glandulaires; le fruit est un akène à trois angles saillans, exaetement enveloppé dans les trois divisions intérieures'; aeerues et plus grandes que lui.

Cette plante eroît naturelleinent dans les prés; elle est eultivée dans les jardins potagers,' et fleurit en juin et juillet. $\dddot{x}$

Propriétés et usages. Les feuilles de l'oseille ont une saveur aigrelette et agréable, qui est due prineipalement au suroxalate de potasse qu'elles renferment; ees feuilles, qui sont surtout employées eomme alinens, sont fréquemment prescrites pour faire des bouillons rafraîehissans, que l'on ordonne dans les fièvres bilieuses ou les inflammations légères des organes digestifs, On en fait également usage pour faeiliter l'aetion des médieamens purgatifs. C'était de eelte plante el de quelques espèees voisines qu’on retirait le sel, si fréquemment employé dans les arts sous le nom de sel d'oseille; mais aujourd'hui la plus grande partie de eelui qui se débile dans le eommerce provient de l'oxalis acetosella, plante de la fanille des Oxalidées.

Les feuilles d'oseille entrent également dans la préparation des sues d'herbes. Quant à sa raeine et à ses fruits, on ne les emploie plus aujourd'hui.

Un grand nombre d'autres espèees sont eultivées dans différentes contrées, et sont employées anx mêmes usages que l'oseille : telles sont surtout les $R$. scutatus; $R$. crispus, $R$. acetosella, et plusieurs autres. 
Rumex patuence. Rumex patientia. L. Sp. 476 . Blackw. t. $48 y$.

Part. usitée : la racine. Nom pharm. : lapathum sativun. S. patientia. Noms vulg. : patience ou patience des jardins.

Cette espèce est beaucoup plus grande que la précédente; ses racines sont longues, fibreuses, épaisses, brunâtres en dehors, jaunâtres à leur intérieur; elles donneut naissance à une tige haute de quatre à cinq pieds, cylindrique, marquée de cannelures très-saillantes; cette tige, simple à sa base, se ramifie à sa partie supérieure. Les feuilles qui partent de sa base sont allongées, aiguës, sagittées; les supérieures sont ovales, allongćes, très-grandes, terminées en pointe, un.peu ondulées sur leurs bords et portées șur des pétioles assez longs, membraneux et canaliculés à leur base.

Les fleurs sont verdâtres, $\epsilon$ t forment des espèces de grappes ou de panicules à la partie supérieure des ramifications de la tige.

La patience croit dans les lieux humides en France, en Allemagne, etc. Elle fleurit en été. $\mathcal{F}$

Propriétés médicales et usages. On enploic souvent sous le nom de patience la racine de plnsicurs espèces de Rumex, et surtout celle des $R$. crispus, $R$. obtusifolius, ete. Cette substitution est sans iuconvénient, toutes ces plantes jouissant des mêmes propriétés médicales. Cette racine contient dc l'amidon ct du soufre libre. Sa saveur est âpre et amére. La décoction de racinc de patience est astringente et tonique. Son usage a quelquefois été avantageux dans le scorbut. Mais c'est principalement contre les maladies de la peau ct. surtont contre la gale, que cette racinc est plus fréquemment employce. Elle jouit inçme dans celte demière eirconstance d'une réputation en quelque sorte populaire. La dose de la racine de patienec est d'unc à deux onces pour deux livres d'eau.

Nous pourrions citcr encore ici plusicurs autres espèces de ce genre qui tou tes jouissent absolıment des mêmes propriétés; telles sont: 
Le Riarontc commun ou Rhubarbe des moines (Rumer alpinus L.), dont la raeinc, amère et légèrement purgative, agit à la manière des rhubarbes.

La Patience aguatrou ou Oseille aquatique (Rumex aquatieus L.), remarquable par la hauteur de sa tige et la longueur de ses feuilles.Elle est très-astringente; on l'a surtout recommandée dans le seorbut. Elle est désignée dans les pharmaeies sous le nom vulgaire de herba britannica.

\section{RHUBAR B E. - R HEUM. L. J.}

Calice à einq ou six divisions profondes, donnant attache à neuf étamines; ovaire surmonté de trois stigmates presque sèssiles, sinsples; akène à trois angles très-saillans et membrancux.

Ce genre diffère surtout des précédens, par le nombre de ses étamincs, et par son fruit, dontles angles sont mcmbraneux.

Toules les espèces de Rhubarbe sont herbaeées, vivaces; leurs raeines sont tubéreuses, leurs fezilles très-grandes, leurs fleurs groupées en panieules rameuses.

Rinubarbe paumée. Rheum palmatum. L. Sp. 53 r.

Part. usitée : la racine. Nom pharm. : rhubarbarum. Noms vulg. : rhubarbe, rhubarbe de la Chine ou de Moscorie.

Cette espèce offre une racine épaisse, perpendieulaire, rameuse, d'un jaune plus ou nıoins foneé, de la grosseur dı bras. Ses feuilles sont pétiolées, engaínantes à leur base, qui forme une large membrane.Le pétiole est presque cylindrique, rougeâtre; le limbe est palmé, très-grand, divisé jusqu’au milieu de sa hauteur en sept lobes très-aigus, ineisés sur leur's parties latérales, et comme pinnatifides: ees feuilles sont un peu onduleuses; à leur faee inférieure on remarque einq ou sept ncrvures très-saillantes, partant en rayonnant du sommet du pétiole, et dont les ramifications sont égolcment très-prononcées.

La tige est simple et dresséc, eylindrique, hautc de ìeux à.quatre picds, panienlée et rameuse à son sommcl.

Les fleurs sont petites, jaunattres, extrèmement nombreuses, disposées en une panieule allongéc. Chaque fleur est pédicclléc 
et se compose d'un calicc monosépale; un peu tubuleux à sa base, offrant un limbe ćtalé, à cinq divisions ovales, allongées, obtuses, plus minces et plus blanches sur leurs bords; de neuf étamines, de la longueur du calice, périgynes, ayant les filets capillaires, les anthèrcs ovoïdes, obtnscs, attachćes au filet par un point situé au-dessus de leur base.

L'ovaire est supère, libre, comme pyramidal, offrant trois faces lisses, uniloculaire, uniovulé, terminé à son sommet par trois stigmatcs arrondis, glanduleux, planes et portćs chacun par un petit style qui s'attache au milieu de sa face inférieure, en sorte qu'il parait comme pelté. Le fruit est ın petit akène triangulaire, dont les angles sont lćgèrement membraneux.

La rhubarbe palmée est originaire de la Chine et de la Tartarie. 36 ,

Propriétés et usages. La rhubarbe de Moscovic, ainsi nommée parce qu'elle nous vient de la Chine par la Sibérí et la Russie, est la plus estimée. Elle est en morceaux irréguliers, un peu aplatis, percés d'un trou; sa couleur est jaune; sa cassure est compacte, veinée de rouge; son odeur cst assez désagréable; sa saveur cst à la fois amèrc et astringente. Elle croque sous la dcnt, à cause de la grande quantité d'oxalate de chaux qu'elle renferme; sa poudre est jaune. M. Henry a trouvé dans cette racine $\mathrm{i}^{\circ}$ un principe particulier auqucl elle doit sa saveur, sa couleur et son odeur; il est jaune, insoluble dans l'eau froide; soluble dans l'eau chaude, l'alcohol et l'éther; $2^{\circ}$ une petite quantité d'une hnile fixc, douce, soluble dans l'alcohol; $3^{\circ}$ de la gomme, de l'amidon; $4^{\circ}$ plusieurs sels, tels que l'oxalate de chaux qui forme à peu pròs le tiers du poids total de la rhubarbe, du surmalate, du sulfate de chanx; $5^{\circ}$ enfin du ligneux.

M. Thomson y signale en outre, un acide libre qu'il nomme theumique. Le principe colorant de la rhubarbe était jadis cmployé dans la tcinture cn jaune; on a cessé d'en faire usage depuis qu'il a été reconnu que cette coulcur n'avait pás plus de solidité qne bcaucoup d'autrcs jauncs végétaux, qui ont l'avantage d'êtrc infinimcnt moins coùlcux.

La rhubarbe est un médicament à la fois purgatif et tonique. Sa poudre, donnée à la dose d'un gros, détermine tous Ics 
phénomènes de la purgation; landis que le même médicasnent al la dose de dix à vingt grains, agit à la manière des autres substanees astringentes et touiques. On peut administrer la rhubarbe en poudre, en infusion (deux à quatre gros pour une livre d'eau), ou en déeoction. La rhubarbe est employée quelquefois avee sueè̀s pour combattre la diarrhée; dans eetle cireonslanee c'est particulièrement la vertu tonique du médicament qui agit. On l'a également reeommandée comme vermifuge, particulièrement ehez les enfans.

Ce n'est pas seulement la raeine de la rhubarbe palmée qui jouit des propriétés que nous venons d'indiquer. Celle de plusieurs autres espèees du même genre en possède d'analogues. A insi la racine de rhapontie (rheum rhaponticum L.), celle de la rhubarbe ondulée et de la rhubarbe eompaete ( $h$. unclulatum et rh. compactum L.) peuvent être employées aux unêmes usages que la rhubarbe de la Chine; eependant elles n'ont point la même activilé.

On a eherehé à eultiver en France la rhnbarbe de la Chine; mais les raeines que l'on a obtenues par ee moyen, ont toujours été de beaueoup inférieures à eelles que l'on fait venir d'Asie. Cependant eette eulture n'est point eneore totalement abandonnée, et une partie de la rhubarbe du eommeree en provient. Mais on distingne faeilement la rhubarbe indigène de eelle de Moseovie, en ee qu'elle est moins eompaete, plus légère, moins rielse en extraetif eolorant et amer, eté.

- Propriétés médicales et usages des plantes de la famille des Polygonées.

Si l'on compare entre elles les différentes plantes de la famille des Polygonées sons le point de vue de leurs propriétés médieales, on sera frappé de la grande analogie qu'elles présentent. Ainsi dans presque toutes les espèces de ee groupe, la raeine et les jeunes feuilles ont une saveur astringente ou aeidulée, plus ou moins intense. Cette saveur que l'on doit attribuer, dans le premier de ees organes, au tannin et à l'acide gallique, et dans le seeond, à l'acide oxalique, plaec les Polygonées parmi les médieameus toniques. Cest ce que nous observons pour la bistorte, les patienees et les rhubarhes. Mais 
rcmarquons, à l'égard de ce dernier médieament, qu'il possède eneore unc propriété purgative que l'on retrouve dans un grand nombre d'cspèees de rume $x$ et entre autres dans lc rumex alpinus, nommć pour eette raison rhubarbe des moines.

Les fruits des Polygorées présentent une ressemblance xion moins frappante. Ils sont tous formés d'un endosperme farineux, d'une saveur donee et agréable, et qui scrt d'aliment dans les espèces où ces fruits, généralement très-petits, acquièrent un volume un peu plus considérable, comme dansle sarrasin.

Le poivrc d'eau (polygonum hydropiper L.) par sa saveur âere et poivréc, forme une exception frappante dans eette famille.

VI $\mathbf{N} G \mathbf{T}-\mathbf{N}$ E U VI $\mathbf{E}$ M F A M I L E.

\section{GHENOPODÉES. - CHENOPODEAE.}

ATRIPLICER. Juss.

Le ealiee des Chénopodées est monosépale, persistant, à cleux, quatre ou eing divisions profondes, et donne attache aux étamines, dont le nombre varie de quatre à dix : l'ovaire est libre, à une seule loge et à un seul ovule renversé; il est terminé par un style à deux ou quatre. divisions, portant chaeune un stignate simple, ou par: denx à quatre stigmates sessiles.

Le fruit est ordinairement minee, eomprimé et membranèx : il reste indéhiseent; plus rarement il est eharnu et sueenlent. La graine se eompose d'un embryon ordinairement roulé autour d'un endosperme farineux.

Les Chénopódées sont, ou des plantes herbacées ou des arbustes à feuilles alternes, rarement opposées, dépourvues de stipules. Leurs fleurs sont petites et peu apparentes, souvent hermaphrodites, quelquefois unisexuées.

Cette famille offre les plus grands rapports avec les Polygonées, dont elle se distingue surtont par ses feuilles privées de graiues, et par son entryon extraire. 


\section{ARROCHE. $-A T R I P L E X$.}

Fleurs femelles et fleurs mâles mélangćes : les fleurs femelles offrent un calice biparti persistant, et un ovaire surmontć d'un style bifide, et pour frnit un akène recouvert par le ealice aceru ct comprimé. Les fleurs mâles ont un calice quinquéfrdc et einq étamines; on y trouve quelquefois les rudimens d'urr pistil.

Arroche des Jardins. Atriplex hortensis. L. Sp. 1493. Blackw. t. 99 .

Noms vulg.: Bonne-Dame, Arroche, etc.

Gette plante est annuelle, et croit en abondance dans les lieux eultivés et les jardins. Sa tige dressée, rameuse, est haute d'environ deux à trois pieds; elle est glabre ct lisse : ses fcuilles sont * alternes, pétiolées, ovales, lancéolées, aiguës, molles, d'un vert glauque, quelquefois rougeâtres; les fleurs sont très-petites; elles forment cles espèces de grappes foliaeées à l'extrémité de la tige et à l'aisselle des feuilles supérieures : les fruits qui leur sucec̀dent sont minces et membraneix, formés par le calice profondément biparti et très-développé, contenant un petit akènc globuleux un peu comprimé. (

Propriétés et usciges. Les feuilles de cette plante ont une saveur douee et fade. On les mange asscz souvent cuites comme celles de l'épinard. On les faisait entrer autrefois dans les tisanes et les cataplasmes émolliens. Elles sont aujourd'hni presque inusitées. Quant aux fruits de l'arroche, ils sont, dit-on, âcres et purgatifs à la dose d'un demi-gros. Mais on cn a entièrement négligé l'usage.

\section{ÉPINARD. $-S P I N A C I A$.}

Fleurs polygames : les mâles ont un calice à quatre ou dे cinc divisions profondes, quatre ou cinq étamines; les femelles ont le calicc déeoupé en quatre ou ciriq dents: l'ovaire est surmonté de trois on quatre styles.

Le fruit est renfermé dans l'intérieur du calice très-resserré 
qui présente quelqucfois quatrc on cinq cornes saillantcs à sa partie supéricure.

\section{Épinard commur. Spinacia oleracea. L. Sp. I456.}

Plante annuelle à fleurs polygames, c'est-à-dire mâles et femclles sur deux individus distincts, et flcurs mâlcs et femelles rćunies sur le mémc individu.

Sa racine est fusiforme, allongée, blanchâtre. Sa tige dressće, simple, cylindrique, glabre, ainsi que toute la plante, lćgc̀rement striée, haute d'un pied à un pied ct demi. Ses feuilles sont pétiolées, mollcs, sagittćes : les inférieures sont entières ; les supérieures offrent à leur partie inférieure quatre divisions étroites et aiguës.

Les fleurs sont petites et verdâtres. Les fleurs mâles sont disposées en épis verticillés à l'aisselle des feuilles. Elles ont un calice très-pctit, formé de quatre sćpales dressés, un peu concaves : quatre ćtamincs saillantes, à filets dresșćs, portant des anthcres globuleuses à deux loges : point d'apparence d'organes femelles.

Les fleurs femelles forment de petits groupes scssiles anx aisselles des feuillcs. Elles ont un calice monosépale et charnu à quatre faces, très-resserrć à son orifice supćrieur, présentant quatre cornes horizontales el charnues (quelquefois une ou deux avortcnt). Le limbe est très-petit; et offre un nombre de dents dressées égal à celui des cornes.

Le pistil est renfermé dans l'intćrieur de ce ealice, qui, est immédiatement appliquć sur lui. Son pćricarpe cstglobuleux, lisse, uniloculaire, uniovulć, terminé supérieurement par qua tre stylcs saillans au-dessus du calice, portant chacun un petit sigmate.

Le fruit est cnvironné et enveloppć par le calice, qui tantôt forme cinq corncs aiguës, tantôt n'en présentc pas. Celtc dernic̀re variété, connue sous le nom d'épinard de Hollande, est considérće comme une espècc par quelques auteurs.

L'épinard est cultivé dans tous les jardins. Il flcurit ell mai et juin. Il est peu usité comme médicament, si ec n'est à l'extérieur; on l'emploic en cataplames, et il cst très-émóllicnt. 
Mais, comme aliment, son usage est très-répandu. Il parai ćtuc légèrement laxatif; il est peu nourrissant et presque insipide.

$z^{\circ}$ Fleurs hermaphrodites,

\section{A NSÉRINE.-C'HENOPODIUM. L.J.}

Fleurs hermaplrodites : calice à cinq divisions profondes; cinq étamines, rarement quatre; ovaire surmonté de deux ou trois stigmates subulés; fruit membranenx environnć par le calice, qui ne prend pas d'aecroissement, mais qui cst trèsr'esserré à sa partie supérieure. Ce genre diffère de l'arroche par ses fleurs hermaphrodites, et par son calice à cinq angies, qui ne s'aeeroît point après la fécondation.

Ansérine botrus. Chenopotium Botrys. L. Sp. 320. Blackw. t. 3 I 4 .

Part. usitée : les sommités. Nom pharm.: botryos vulgaris herba.

Noms vulg. : botrys, piment, ete.

D’unc raeise annuclle fusiforuc, blanchc, rameusc, s'élève one tige cylindrique pubescente, rameuse, haute d'un pied, qui porte des feuilles alternes allongées, pinnatifides, à lobes écartés et obtus, pubescentes, visqueuses et trés-odorantes.

Les fleurs sont petites, verdâtres, disposces en grappes allongées, à l'extrémité des ranificatious de la lige. Dans chaque fleur on trouve un calice à cinq divisions profondes, ovales, áiguës, entic̀res et pubescentes, d'abord élalćes, puis dressées et conniventes pour embrasser le fruit de toutes parts. Les étamines, au nombre de cincl, sont attachées à la base du calice; l'ovaire, presque globuleux est surnonté de deux stigmates allongés, linćailes.

Cette plante croît dius les provinces méridionales de la France. Elle fleurit anx mois de Juin et de Juillet. (-)

Propriétés médicales rt. usages. Liodenr forte et aromatique de cetle plante, sa sirveur âere et antère, décèlent en elle une aclivile donl on tient peu de compte aujourd'hui, car on l'enploic très-rarement. Cependant, ou ue peut révopucr cu 
doule l'aetion exeitanle du botrys, et les effets marqués que son usage délermine. A ussi, les anciens y avaient-ils souvent. reeours, soit dans l'hystérie, soit dans les eatarrhes ehroniques, et surtont eeux des bronehes. On employait son, infusion ou son eau distillée.

Anstírine anbroisie. Chenopodium ambrosiö̈des. L. Sp. 320.

Nom pharm. : botryos mexicana herba. Noms vnlg. : l'ambroisie, the clu Mexique.

Elle diffère de l'espèee préeédente par ses feuilles simplement dentées, aiguës, glabres; par ses fleurs entièrement sessiles. Du reste, elle en a le port et la plupart des autres earaetères. Originaire $\mathrm{du}$ nouveau monde, eette plante s'est faeilement naturalisée dlans nos jardins, d'où elle s'est r'épandue dans quelques parties des eampagnes environnantes. Elle est également annuelle.

Son odeur plus forte, mais en mème temps plus agréable, indique dans eette plante les mêmes propriétés que dans le botrys.

L'Ánsérlne anthelmintriQue, Chenopodium anthelminti-

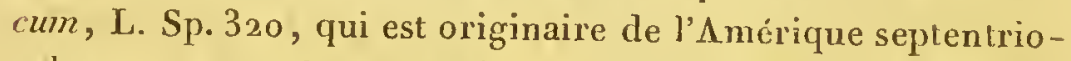
nale, est peu employée. Ses fruits sont regardés en Amérique, comme puissamment anthelmintiques.

$$
\text { SOUDE. }-\$ A L S O L A . \mathrm{L} \text {. J. }
$$

Fleurs hermaphrodites; ealiee quinquéparti, persistant; étamines au nomble de einq; ovaire portant un style bifide, le fruit est un akène renfermé dans l'intérieur du ealice, dont les divisions, conniventes à leur sommet, sont ailées, membraneuses et étalées. Les graines eontiennent un embryon roulé en spirale.

Les soudes sont tantôt herbaées el annuelles, d'autrefois vivaces et même sous-fíuteseentes.

Soude vulgaire. Salsola sodu. L. Sp. 323.

Plante ammelle, haute d'environ un jied, entièrement 
glabre, ordinairement dressée; tige herbacéc rougeâtre, ramense, portant des feuilles alternes, charnues, étroites, longues d'un à deux pouees; ses fleurs sont petites, verdâtres, axillaires, sessiles et solitaires; leur caliee est profondément quinquéparti, un peu renflé dans sa partie inférieure, resserré supérieurement; les étamines sont au nombre de cinq; l'ovaire porte un style terminé par deux stigmates subulés. Le fruit est presque globuleux, renfermé dans l'intérieur du ealiee, persistant, dont la parlie supérieure mince et membraneuse est élalée.

Cette plante est assez eommune dans les licux maritimes, sur les bords de l'Ocćan et de la IMéditerranéc; je l'ai recueillie aux environs de Marseille, de Toulon, d'Aigucmortes, etc. $\odot$

Propriétés et usages. C'est des ecndres de cette espèce et de plusicurs autres plantes ye genres et de familles différentes, mais qui eroissent toutes dans les lieux maritimes ou près des salines, que l'on retire la soude du commerce. Parmi les autres végétaux que l'on brûle pour en retirer la soude, nous citerons particulièrement les salsola kali. L. et salsala tragus L. plusieurs salicornes, entre autre les salicornia herbacea, et sal. arabica; quelques anserines, tels que le chenopodium setigerum, chenop. fruticosum, le plantago squarrosa, le mesembryanthemum nodiflorum, le fucus vesiculosus, et un grand nombre d'autres végétaux qui varient dans les différens licux où l’on s'occupe de celte préparation.

La soude la plus estimée est celle que l'on tire d'Espagne; elle est eonnue sous le nom de soude d'Alicante; on l'extrait spéeialement du chenopodium setigerum. et de quelques salsola. Elle est en masses brunâtres, très-dures, et contient de 25 a 40 pour $x$ oo de sous-earbonate de soude.

Là sonde à l'état de pureté, ou combinée avec les aeides, est employce dans les arts, et sert à la préparation de plusieurs médieamens.

$$
\text { BETTE. - BETA.L. J. }
$$

Les fleurs sont toutes hermaphrodites; le ealiee est à cinq divisions profondes; les cinq étímines sont opposées à ses segmens et insérées à leur base; l'ovairc est déprimé, surmonté 
de trois; plus rarement de denx stigmates sessiles; le fruit est un akène environné par le calice, formant einq côtes à sa partie supérieure?

Bette ondinaine. Beta vulgaris. L. Sp. 322.

Noms vulgaires : Bette bianche, poirée, carde poirée, ete. Variété : Racine tubéreuse et charnue. Vulgairement : Betterave.

Cettc plante est bisannuelle; ses feuilles inférieures sont fort grandes, d'un vert très-clair, eordiformes, entic̀res, molles, glabres, portćes sur un pétiole large, canalieulé, blane, charnu; les feuilles de la lige sont sessiles, allongées, aiguës, presque laneéolées.

La tige est haute de quatre à six pieds, dressée, irrégulièrement anguleuse et eannelée, simple inférieurement, diviséc en rameaux nombreux et paniculés à sa partic supérieure.

Les fleurs sout petites, verdâtres, sessiles, souvent rćunies et soudées deux à deux par la base sur les ramifications de la lige; elles constituent de longs ćpis grêles, dont la rćunion forme une vaste panieule. Chaque paire de fleurs est situéc à l'aisselle d'ụne bractée foliacée, plus longue qu'elles.

Le ealice est à eillq divisions profondes, égales, obluses, persistantes. Les cinq étamines opposées à cliacune des divisions du ealice, plus courtes qu'elles, sont périgynes et insérćes vers la base et an milieu de ehaque division, ̀̀ un disque qui les réunit toutes par la base.

L'ovaire est très-déprimé, à une seule loge, uniovulée, surmontć de deux stigmates courts et blanehâtres. Le fruit est un akène irrégulièrement triangulaixe, déprimé, entourré par le calice, qui n'a point pris d'accroissement.

Cette plante est cultivée dans les jardins. Fille présente deux varićtés prineipales, savoir : la carde, remarquable par ses

- Malgré l'examen le plus attentif, je n'ai pu trouver de différenee entre ce genre et l'ansérine, si ce n'est le ealice fruetifère, qui iei est ouvert à sa partie supérieure et fermé sur les ansérines. Je n'ai pu découvrir le style sur l'ovaire de ce dernier gcnre, en sorte que je pense que ces deux genres devraient être réunis. 
feuilles plus grandes, dout la côte on nervure inédianc est extrêmement laurge et charnue. On mange ces côtes, qui sourt, comme les feuilles de la poirée, un aliment assez fade.

La scconde variété est beaucoup plus intéressante, c'est elle que l'on appclle betterave on racine de diselle. Sa racine est grosse, charnuc, pivolante, simple, tantôt d'un rouge foncé, tantôt blanche ou jaune doré. Elle a, quand elle cst cuite, nne saveu douce et très-sucrée, qui la fait rechercher comme alinent. Mais e'est surtout par la quantité considérable de sucre qu'elle renferme, que eettc raeine joue un rôle important dans l'économie domestique. En cffet, pendant asscz long-temps le sucre retiré dc ees racines, a suffi à la consommation de presque toute l'Europe. Marcgraff est le premier qui ait appelé l'attention des chimistes sur l'importance de la betterave, et c'est a MM.|Achard de Berlin, et Chaptal, que l'on doit la connaissance des proećdés mis en usage pour opércr en grand.

Le sucre de betterave ne le cède en rien au sucre extrait de la canne dans les eolonies. Il eristallise parfaitement et peut entic̀rement remplacer les sucres exotiques.

\section{CAMPHRÉE. - CAMPHOROSMA.}

Le ealiee est urcéolé, à qquatre dents inégales; les étanines, au nombre de quatre, sont saillantes hors du calice; l'ovaire est surmonté d'un style bifide. Le fruit est renfcrmé dans l'intérieur du calice.

Gamphrée de Montpelaier. Camphorosma monspeliaca.

$$
\text { L. Sp. } 178 \text {. }
$$

Racine vivaee. Tige étalée, ramęuse, eylindrique (herbacée ou quel(quefois sous-frutescente) tomenteusc; rameaux florifèrcs, redressés, effilés. Feuilles faseiculées, eourtes, étroites, linéaires, aiguës, tomenteuses, au nombre de dix à touze dins l'aisselle d'une stipule subulée très-aignë, roide, plus longue que les feuilles.

Fleurs petites, disposées en épis très-scrrés, qui garnissent la moitić supérienre des raneaux florifèrcs. Ces épis sont sessiles, ovoïdes, composés d'euviron vingt flenrs serrées et comme imbriquées. Chaque fleur sessile est accompagnéce 
d'une bractée foliacẻe, ovale, aiguë, dressée, pubescente, de la grandeur du ealice, sur lequel elle est immédiatement appliquuée. Caliee ureéolé, eomprimé du côté interne, verdâtre, couvert de longs poils laineux et frisés, à quatre divisions dressées, dont deux opposées plus petites.

Les étamines, sont saillantes au nombre de quatre; leurs filets sont filiformes dressés, deux fois plus longs que le caliee.

Ovaire libre, globuleux, irrégulièrement trigone, uniloculaire, uniovulé; style simple eylindrique, stigmate très-profondément divisé en deux parties linéaires, à peu près 'de la longueur du style; le fruit est un petit akène, renfermé dans l'intérienr du calice.

Cette plante est extrêmement counmune dans les provinces inéridionales de la Franee, dans les endroits incultes et stériles. Elle fleurit pendant presque tont l'été. ₹f

Propriétés et usages. Toutes lcs parties de cette planțe exhalent une odeur forte et camphréc. Sa saveur est âcre et amère, fortement aromatique. Auirefois très - usitée, elle est presque totalement négligée par les moderncs. Cependant elle ne manque pas d'une eertaine efficacité; elle est excitante et: pourrait être employée, soit eomme sudorifique, soit comme diurétique.

\section{Propriétés médicales et usages des Chénopodées.}

Les propriétés dont jouissent les plantes de la, famille des Chénopodées peuvent aider, jusqu'à un certain point, à les distinguer des Polygonées, avce lesquclles elles ont une rcssemblance d'organisation extrêmement frappante. En cffet, dans la plupart des végétaux dc la famille précédentc on voit lrédominer des principes acides, tels que le tannin, l'acide oxalique, etc. , qui donnent aux Polygonées une vertu tonique. plus ou moins prononeéc. Toutes les Chénopodćcs, an eontraire, à très-peu d'exeeptions près, sont douces, mueilagineuses ou suerćes. Ainsi les feuilles de poirée, d'arroelıe, de earde poirée, et même celles de plusienr's espjèces de soudc, sont des alimens fades et peu reeherehés. Ccpendant quelques espèees appartenant à eette famille, contiennent souvcnt in prirncipc plus ou moins âcre el odorant, qui leur communique des 
propriétés assez aetives, ec que prouvent le Botrýs, l'Ambrosie, la Camphrée et plusieurs autres.

Mais les produils qui nous intéressent. le plus dans eette famille sont la soude que l'on retire de plusieurs plantes de genres et.même de familles différentes, et le suere, que les raeines de la Belterave contiennent en si grande quantité.

Cette famille ne renferme aueuve plante vénéneuse.

\section{LAURINEES. - LAURINEXE.}

Les Laurinées sont ordinairement des arbres ou des arbrisseaux d'un port élégant, ornés en tous temps de feuilles lisses et luisantes. Leur calice est monosépale à six, plus rarement à quatre divisions, plus ou moins profondes. Les étamines sont périgyniques; leur nombre. varie de six à neuf, quelquefois au delà; leurs filets présentent souvent à leur base deux petits appendices pédicellés et glanduleux, et leurs anthères, qui sont biloculaires, s'ouvrent au moyen de petits panneaux ou opercules, qui s'enlèvent de la base vers le sommet. I'ovaire est libre, à une seule loge, contenant un ovule pendant; le style et le stigmate sont simples.

Le fruit est une sorte de drupe, dont la base est environnée par le calice, qui est persistant. Il renfernıe une seule graine, dont l'embryon, dépourvin d'endosperne, est renversé; ses denx cotylédons sont très-épais.

Les feuilles des Laurinées sont communément alternes, plus rarement opposées; elles sont coriaces, luisantes, sonvent persistantes. Les fleurs, presque toujours unisexuées, sont tantôt monoïques, tantôt dioïques, disposées en ombelles ou en pinicnles.

$$
\text { LAURIER. - LAURUS. L. J. }
$$

Pleurs unisextcées; calice à quatre ou six divisions plus ou moins profondes; élamines de six à douze, ayant leș filets ap- 
pendieulés à la base; anthères biloculaires; obairc ovoïde; stigmate un peu ereusć en gouttière : drupe enveloppée à sa base par Ic calice persistant.

LuURIER ordinatre. Lautus nobilis. L. Sp. 529. Blackw. t. 175 .

Purties usitées : les feuilles et les'fruits. Nom pharm. : Lauri folia, baccae; noms vulg. : Le Laurier d'Apollon, ou 'Láurier franc.

Arbre très-élégạnt, toujours vert, ayant quelquefois vingtcinq ou trente pieds de haut, dioïquie comme toutcs les autres espèces de son genre. Tige dressée, rameuse. Feuilles alterncs, ovales, lancéolćes, aiguës, courtement pétiolćes, sinuées sur les bords, fermes ét luisantes, d'un vert assez vif cn-desius, plus terne à la face inférieure, ayant une seule ncrvure longitudinales et plusienr's latérales qui sont tranversales.

Fleur's mảles axillaires, disposées par petits faisceaux de deux à quatre, portés sur un pédoncule commun coürt. Chaçue faiseeau a un involucre de quatre bractées squammiformes concaves, obtnses brunes et caduques; deux extérieures son't plus pctites, ehaque involucre renferne cinq fleurs courtement pédicellćes, à pédieelles légèremcnt pubescens. Calicc monosćpale à qua tre divisions profondes, obtuses, étalées, concaves, denx extérieures opposéés plins ovales, un peu plus petiles. Douze étamines à peu près de la longucur du ealiee, quatre lui sont opposées, quatre sont alternes et quatre plus intéricures; elles sont toutes à peu près égales, èt un peu eonfluentes par leur base au fond du calice. Lcs filets sont un peu eomprimćs. Lcs qriatre plus intérieurs offrent à léur base deux appendices latéraux, claviformes stipités, jaunàtres et glanduleux. $\Lambda_{n-}$ thẻres introrses a deux loges, réunies par un eonnectif qui garnit toutc leur face externe, et forme au-dessus d'cllcs un petit appendice; les loges sont oblongucs et s'ouvrent par lontc lenr paroi antérieurc, qui se roule de la base an sommet. Le pollen cst sous forme de grains gुlobulenx jaunitires demi transparcns. Ces flours ne renferment pas de vestiges de

Fleurs frmelles disposćcs égalcment par jetits eapitules pé- 
doneulés, involucrés, renfermant ordinaircment einq fleurs, petites, sessiles, serrées, et à peu près de la longueur dcs éeailles de l'involucre; caliee turbiné, à quatre divisions, d'abord eonniventes et comme eampanulées, puis étalées, obovales, coneaves. Tube eourt et solide.

Les étamines sont remplaeées par quatre appendices alternes avee les divisions du ealiee, entourant le pistil; et eomme trilobées.

L'ovaire est ovoïde vert, uniloculaire, uniovulé; le style est épais, court, recourbé, ereusé d'un côté par un sillon longitudinal. Stigmate très-petit, glanduleux, paraissant être l'expansion du sillon du style.

Le fruil est une drupe ovoïde de la grosscur d'un pois légèrement charnue, renfermant une amande grosse, blanehâtre, entourée d'un teste assez solide.

Le laurier d'Apollon est originaire des contrées méridionales de l'Europe et de l'Asie mineure. Il eroît parfaitement en pleine terre dans le midi de la France, où il fleurit vers le mois de mai et de juin.

Propriétés et usages. Les feuilles et les fruits du laurier ont une odeur aromatique agréable, une saveur amère et piquante. Ces feuilles répandent lorsqu'on les brûle une fumée d'une odeur suave, on ne les emploie plus guère maintenant que pour aromatiscr certains alimens, et particulièrement les viandes.

Quant aux fruit ou baies de laurier, leur péricarpe contient une assez grande quantité d'une huile volatile très-odorante qui les rend un médicament puissamment exeitant, tandis que leur amande fournit par l'expression une huile grasse que l'on emploie quelquefois pour pratiquer des embrocations sur différentes parties du corps. Elle est verdâtre, d'une consistanee butyreuse, et son odeur offre faiblement eelle des feuilles de laurier; mais la plus grande quantité de l'luuile de laurier des officines cst falsifiée par les droguistes; ee n'est autre ehose que dc la graisse dc porc eolorée en vert par dc l'indigo et du cureuna, et rendue aromatiquc par la macération des feuillcs de laurier ct dc sabine grossièrcment réduites cn pulpes. C'est cc dernier onguent dont on fait un usage considérablc dans la médccine vétérinaire. 
Laurier ganfluier. Laurus cinnamomum. L, Sp. 528.

Partie usitée : L'écorce. Nom phárm.: Cinnamoni cortex.

Son tronc s'élève, dans un bon terrain, jusqu'à ringt-einq et trente pieds; il a quelquefois dix-huit pouees de diamètre. Son écoree extérieure est grisâtre en dehors et rougeâtre en dedans.

Les feuilles sont irrégulièrement opposées, courtement pétiolées, à pétiole eanalieulé, elles sont aiguës ou ovales lancéolées, longues de quatre à einq pouces, larges, d'environ deux pouees, eoriaees, lisses et vertes en dessus, glauques, eendrées en dessous, entières, à trois nervures longitudinales, partant de leur base; rarement il y en a einq; offrant un grand nombre de veines transversales.

I es fleurs sont jaunâtres, disposées en une sorte de panicule lâehe et axillaire.

Le calice est pubeseent, à six divisions profondes, ovales, obtuses dans les fleurs mâles et dans les fleurs femelles; le tube est court, turbiné.

Les fleurs mâles ont reuf étamines; disposées sur plusieurs rangs, de la longueur du ealiee.

Les fleurs femelles présentent un ovaire libre, ovoïde, terminé par un style épais, au sommet duquel se trouve un stigmate
eapitulé.

- Le fruit est une drupe ovoide, ayant la forme d'un petit gland, entourée à sa base par le ealiee. Elle a einq à six lignes de longueur; elle est violette et renferme une pulpe verlâtre et uı petit nóyau dans lequel est une amande légèrement
rougeâtre.

Le canellier habite l'île de Ceylan, où on le cultive dans̀ un espace d'environ quatorze lieues, qui s'étend cntre Matusa et Negombo, et qu'on nomme Champ de canelle. Sa eulture est également introduite dans quelques parties du nouveau Monde, aux Antilles, à Cayenne, à l'Ile de France, etc. M. Poivre assure qu'il existe à la Cochinchine une cspèce de canelle supérieure mêtme à eelle de Ceylin.

Propricités et usares. La canelle est l'écolce de l'arbre que 
nous venons de déerire, privéc de son épiderme. Elle est erz snórceaux mincés et roulés, d'une couleur roussâtre particulière, d'une odeur aromatique; d'une saveur suerće, âcre, et qui a quelque analogie, lorsqu'elle est exaltée, avcc celle des punaises. On en distingue plusicur's sortcs dans le commerce; mais la plus estimée est eelle de Ceylan; eelle qu'ou apporte de la Chine et des Antilles l'est beaucoup moins.

M. Leschenault de la Tour, dont on a lu, en avril 1822 , à l'aeadémie des seienees, unc note sur la eulture du canellier, prétend queles racines et les grosses tiges de cet arbre, fournisscni,par la distillation, une grande quantité de eamphre. C'cst au reste, une,confirmation de ce qu'avaient avancé Rhéede et Jacquin.

La cannelle est très-excitante. Elle doit cette proprićté à l'huile volatile qu'clle conticnt, de sorte que la canelle la plus riclze en,eeprineipe (qu'elle jerd aycc le temps) est celle qu'il convient le mieux d'employer. Sous ee rapport, la canelle de Ccylan doit être préférée, tantà cause de sa qualité, que de la suavité de son principe odorant. On administre souvent la poudre, à la dose de quelques grains, pour favoriscr la digestion, lorsque l'estomaç a besoin d'être stimulé, et dans ee cas op lui associe quelquefois la gentiane ou la rhubarbe. La teinture alcoholique de canelle: est après la poudre la préparation qui possède au degré le plus éminent les propriétés médịcales de cette ćcorce.

L'eau distillée de canelle est aussi un mćdicament qui ne manque pas d'énergie. On la fait entrer à la dose d'une once dans les jotions excitantes. L'infusion de demi-once de canelle coneassée, dans deux livres d'ean bonillante, forme une tisane agréable qui est diap̧horćtique et diurétique.

La eanelle cntre dans une foule de préparations officinales.

\section{Laubier sassafras. Laurus sassafras. L. Sp. 530.}

Part. usitées: la racine, le bois et l'écorce. Nom pharm. : Sassafras lignum, s. radix.

Grand arbre qui aequierl quelquefois jusqqu'à 30 et 40 pieds d'ćlévalion, ayant en fleurs lc port d'un érable. Fenilles altcrnes, pétiolées, grandes, pubescentes, eaduques, d'une forme 


\section{LAURINESES.}

très-variée, lantôt ovales, presque obtuses, atténuxées vcr's la base, cutières, mixtinerves, d'aulres, fois bi-trilobćes, prescordiformes, à deux ou trois nervures lougitudinales. Elles sont vertes ell dessus et blanchâtres en dessous. Les rameaux qui supportent les feuilles sont également pubesecns.

Les fleurs sont dioïques, jaunâtres, parlant par petites panicules du centre d'un bourgeon qui renferme égalementles feuilles. Fleur's mâles : calice à six divisions profondes, pubeseentes en dehor's, étalées, oblongues, obtuses, rétrćeies à leur base. Le fond du caliee est garni de poils.

Neuf étamines dressées, à peu près de la longueur du ealice; six opposées aux divisions du ealice; trois intérieures un peu plus grandes et d'une forme différente, stériles, et offrant à leur base deux appendices globuleux, stipités. Les six fertiles ont un filet subulć, un peu canaliculé en dedans, poilu à la base. Les anthères sont eontinues au filet, eomprimés comme quadrilatères, paraissant à quatre loges, deux supérieures et intérieures plus petites, deux inférieures et extérieures plus grandes, s'ouvrant par leur paroi antćrieure, réunies postérieurement par un eonnectif assez épais.

Le pistil est imparfait et stérile, de la longueur des étamines. L'ovaire est très-allongé.

Fleurs femelles: calice comme dans la.fleur uâle; six étamines avortées, opposćes aux divisions du calice, deux fois plus courtes que lui; filcts courls; anthères eordiformes, ne s'ouvrant pas; ovairc oblong, ovoïde, surmonté d'un style continu avec lui, canaliculć d'un côté, s'élargissant pour former le stigmate, qui est glanduleux et légèrement coneave.

Le fruit est une druje entourée par lc caliee de couleur violettc, et de la grosseur d'un pois.

I.e sassafras, originare de l'Amérique septentrionale, peut se cultiver en pleine terre sous le elimat de Paris.

Propriétés et usages. C'es̀t prineipalement la racinc de cct arbre et surlout son écorce que l'on emploie. Le commeree nous l'apporte en moreeaux de la grosscur du bras, brunâtres et comme fcrrugineux à l'extćlieur, d'unc saveur et d'une odeur aromatiques, plus développées dans l'ćeorce que dans le bois. On filit égalencut usage de l'écorce des jeunes branches. 
Le sassafras est à juste titre placé parmi lcs médicamens sudorifiqucs, et sous ce rapport on l'emploie trc̀s-fréquemment dans les affections syphilitiques constitutionnelles, les rhumatismes et les inflanmations chroniques de la peau.

Il s'administrc ordinairement en infusion; on l'emploie rarcment seul; on l'unit aux autres vćgétaux sudorifiques, tels que le gayac, la squine, la salsepareille, ete.

\section{LAURIER CAMPHRIER. Laurus camphota. L. Sp. 528 . Blackw. t. 347 .}

Part. usitće : lc Camphre. Nom pharm.: Camphora.

Le laurier camplarier est un arbre assez élevé, ayant à peu prc̀s le port d'un tilleul; il croít dans les lieux montueux des régions les plus orientales de l'Inde, et particulièrement au Japon. Son tronc est droit ct simple infćrieurement.

Ses fcuilles sont alternes, ovales, arrondies, acuminéees, entières, pétiolées; le pétiole est canaliculé plus court que les feuilles, qui sont coriaces, vertes et luisantes en dessus, glauques en dessous.

Les fleurs, disposćes cn corymbes longuement pćdonculés, sont d'abord renfermécs dans des bourgeons ćcailleux, strobiliformes, axillaires, ovoüdcs, composés d'écailles scarieuses, rousses, pubescentes, obtuses, terminées par une petite pointe et frangées sur leurs bords.

Les fruils ressemblent à ccux du carrellier, mais ils sont un peu plus petits.

Propriétés et usages. Le camphre, qui est unc huilc volatile, concrète, d'une nature particulière, cxiste cn abondance dans lontes les parties de cet arbre. Pour l'en retircr, on place lcs branches et les racines, rédnites en fragmens, dans dc grandes cucurbites de fer, surmontćes de vastes chapitaux. On chauffe. modérément, et le camphre se sublime dans la paille dont on a garni l'intérieur dcs chapitaux. Dans cet état, il est impur, en grains irréguliers, d'me coulcur grise; on lc transporte en Europe, oil on lc purific avant de l'employcr.

C'est surtout en Hollande que cette purification s'opère, en menlant le camphre avee de la chaux et le faisant sublinner dans 
un appareil convenable. M. Clémandot, pharmacien à Paris, a consigné dans le Journal de pharmacie, t. 3, p. 32 I ; les détails dc ce procédé inusité jusqu'alors en France.

Ce médicament entrc souvent dans des préparations magistrales dont l'cau est le véhicule; mais comme il n'y est que très-peu soluble, on le rend miscible à cettc eau, par l'intermède du jaune d'œuf ou d'un mucilage.

Le camphre est une substancc concrète, blanche, hyaline, cristallisable en prismes hexaëdres, d'une odeur trc̀s-pénétrante. Semblable aux huiles volatiles dans sa composition, il jouit aussi des mêmes proprićtés chimiques. Ainsi il se volatilise à l'air et disparait sans résidu. Soumis à l'action du feu, il se fond d'abord, puis se change en une vapeur dont la tension et la densité sont peu considérables; il se dissout facilement dans l'alcohol, lcs huiles et les gaz acides. L'eau le précipitc de sa solution alcoholique, mais en retient elle-même une petite portion en suspension; de sorte qu'on peut à la rigueur la considérer' comme un dissolvant du camphre. On a remarqué qu'clle en dissolvait d'autant plus, qu'ellc était plus saturée d'acide carbonique. Par l'acide nitrique, il se transforme en un acide particulier que M. Bouillon-Lagrange a nommé camphorique.

Le camphre est un médicament extrêmement prćcieux et très-ćnergique, dont il est fort-difficile de déterminer lc mode d'action d'une manière précise. Si on le donne à petite dose, commc de dcux à quatre grains, il n'occasionne aucun changcment notable; mais si la quantité en est portée subitcment à un scrupule ou au-delà, ses efféts deviennent plus manifestes : il détermine dans l'œsophage et/l'cstomac un scntiment de chaleur ct de picotement, qui se prolongc pendant plusieurs heures; lc pouls devient moins vif, plus petit et inégal; la respiration plus difficile; la face plus pâlc; le malade ressent des éblouisscmens, des pandiculations, dcs vcrtiges, en un mot se trouve dans un ćtat analoguc à l'ivressc; ces symptômes scmblent dépcndre d'unc médication sédative plutôt qu'excitantc. Mais bientôt il se montrc d'autres phénomènes qui paraissent ètrc le rćsultat de l'action inmédiate des molécules du camphre. Cé médicannent délermine secondairement les effels des suls- 
tances stimulantes, surtout si l'individu qui en fait usagc es fort, pléthoriquc ou tourmenté d'une irritation de la muqueuse gastro-intestinale; dans ce cas le pouls reprend sa force et $s a$ sa vitcsse; la chaleur animale devient plus vive, la peau se colore, etc.

Cclte variation, dans le mode d'action du camphre, a dû faire varier sur les círeonstanccs, où son emploi peut être avantageux. Ainsi quclques anteurs, comptant principalement sur ses effets sédatifs, l'administrent dans les fièvres et les inflammations; d'autres au contraire le considérant comme un remède éminemment excitant, l'emploient dans des circonstances opposćcs. Le camphre agit principalement sur le système ncrvcux: lorsqu'on le donne à petitcs doses, il calme les mouvemens ataxiques, fait cesscr les convulsions; cn un mot, agit à la manière des médicamcns sédatifs. Un grand nombre de praticiens le recommandent dans l'hystérie, la chorće et l'épilepsie; mais il s'en faut bien qu'il réussisse toujours dans ces maladies. C'est avec plus d'avantage qu'on l'emploie dans certains cas de manie, déperidant de l'hystérie. MT. le docteur Esquirol s'ers est sorivent servi avec succès.

Ce inćdicament applique à l'extéricur sous forme de liniment ou d'embrocations est génćralement fort avantageux dans les douleurs rhumatisinales et dans lcs accìs de goutte.

Un assez grand nombre de faits tendent à prouver l'action que lc camphrc excrcc sur la sécrétion du lait. Il la ralentit d'unc manière évidente, ct finit unçme par la tarir entic̀rcinent, soit qu'on en frictionne les mamelles, soit qu'on l'administre sous forme de lavcmens. Aussi s'en sert-on avantageuscment dans les engorgemens des mamelles connus sous le nom de poil. On l'emploic également dans l'érysipçle, où il agit par sa grande volatilité, qui détermine une scnsation agréable de fraicheur.

Le camphre doit être proscrit dans tous les cas oủ une irritation vive ou latente a son siége daus l'estomac ou les intestins. Il est donc extrêmement important d'étudier avec soin l'étal de ees parties avant d'cn faire usage dans les fièvres ditcs ataxiques et adynamiques. M. le professeur Hallé a remarqué qu'uni au nitre, le camphrc domé à doses réfractées cntre 
deux accc̀s de fièvre intcrmittcnte, prévient le retour du prenier stade, et qu'il agit par conséquent. comme antipériorlique.

L'expérience a souvent constaté les bons effets du camphre dans les irritations des organes de la génćration et de la sécrétion de l'urine, surtout dans celles qui résulte de l'usage des cantharides.

Le camphre s'administre tantôt en poudre, tantôt en suspension dans un liquide quelconque. Sa dose varie suivant les effets que l'on veut produire, l'âge du maladc, et surtout l'état des organes avec lesquels on le met en contact. Sa solution alcoholique, connue sous le nom d'eau-de-vie camphrée, cst très-souvent employée à l'ex térieur. Uni à l'huile, il forme des linimens, dont on fait un fréquent usage.

- Le laurier camphricr n'est pas le seul végćtal qui fournisse du camphre; cc principe existe encorc dans plusieurs autres plantes, tels quc le shorea robusta, décrit par Roxburg, et' qui produit lc camphre le plus pur et le plus estimé. Il n'cst pas répandu dans le commerce; les plantcs de la famille des Labiées en conticnnent également.

Outre les, quatrc espèces de laurier dont nous venons de donner la description détailléc, plusieurs autrcs fournissent encore des produits qui figurent dans le catalogue des médicamens empruutés au règne végẹtal; tcls sont:

Le LaUnier casse. Laurus cassia. Lin. Sp. 528 , qui, croît également aux Indes orientales, et que l'on a long-temps regardé comme une simple variété du crnellicr. Son écol'cc est connue sous les noms de cassia lignea, Xilo-cassia, canelle clu Malabar, etc. Elle est moins aromatique ct moins estiméc. que la vrạic cancllc. Ellc eultre danș plụsicurs préparations pharmacculị̣uc très-composées.

LC LAURIER a FeUlites loncues. Laurus malabathruin. Lam. originairc de l'Inde, et que l'on a confondu aussi avec le cancllicr de Ceylan. Ce sont scs feuilles qui sont appclées dans les ancicnnes pharmacopées: malabathrum ou folium Indum. Elles sont aromatiques et excitanles.

Le Launier culnawan. Laurus culilaban. L. Mant. qui se trouvc aux îles Moluques, à $\Lambda$ nboinc, ete., et dont l'ćcorce 
désignée par Rumph, sous le nom de cortex caryophylloïdes, porte dans le eommerce celui de canelle giroflée.

Le LaURier benjon. Laurus benzoin. L. Sp. 53o, qui croit darss l'Amérique septentrionale, et que l'on a regardé pendant long-temps comme produisant le benjoin.

Le LaUrier plichurim. Laurus pichurim, dont les fruits sont appelés fèves de pechurim ou pichurim.

Le Laurier avocatier. Laurus persea. L. Sp. 529. Indigène du continent dè l'Aınérique australe. Son fruit, gros coinme le poing, cst charni. Sa saveur a quelque analogie avec eelle de l'artichaut et de la noisettc. On le mange en abondance en Amérique.

Propriétés médicales et usages des Laurinées.

Il est peu de familles dans toutle règne végétal qui présentent une uniformité plus grande dans leurs propriétés, et dont les produits soient plus intéressans que eelle des Laurinées. Quelle analogie n'observe-t-on pas dans toutes les parties des végétaux qui forment ce groupe. Une huile volatile et aromatique s'y trouve répandue en abondanee, et leur donne celte odeur suave, quelquefois forte el pénétrante, eette saveur ehaude, âere, que nous olsservons dans la eanelle, le sassafras, les baies de laurier, les feuilles de malabathrum, les fèves de pichurim, en un mot, dans tous les organes de ees végétaux.

Le eamphre n'existe pas seulement dans une seule espèee du genre laurier; mais le canellier et quelques autres en eontiennent aussi, quoiqu'en moins grandé quantité. Ce n'est pas seulement dans le Laurus cinnamomum que l'ćeoree est aromatique snave, piquante, mais plusieurs autres lauriers fournissent également une eanelle tnoins estimée, il est vrai, mais qui cependant n'est pas entièrement dénuée des proprictés exeilantes que nous observons dans la eanelle de Ceylan; cu sorte quc l'on peut dire d'une manière générale que dans lit famillc des Laurinces, toutes les parties sont plus ou moins aromatiques, ct doivent ĉtre eonsilérées comme des inédicamens. exeiluns. 
MYRISTICEES. - MYRISTICE $P$. Brown.

Les plantes qui constituent cette famille nouvelle étaient d'abord réunies aux Laurinées; mais elles en diffèrent par les caractères suivans: leurs fleurs sont complétement unisexuées, tandis que dans les lauriers on trouve toujours le second sexe à l'état rudimentaire: le calice ne présente que trois divisions; les étamines, dont le nombre varie de quatre à douze, sont soudées à la fois par les filets et par les anthères, qui s'ouvrent longitudinalement; l'ovaire est surmonté de deux styles et de deux stigmates; l'ovule qu'il renferme est dressé, et dans sa maturité la graine est recouvertepar un arille charnu, ordinairement découpé.

Pour peu que l'on compare ces caractères avec ceux. que nous venons de donner des Laurinées, il sera facile d'en saisir les différences.

\section{MU SCA D I ER. - MYRISTICA. Lamk.}

Flcurs dioïques : calice à trois divisions profondes; fleurs mâles contenant de trois à doúze étamines soudées, dont les anthères s'ouvrent longitudinalement. Fleurs femelles : ovaire libre, renfermant un seul ovule dressé, surmonté de deux stylcs. Le fruit est une sorte de baie ou de drupe, qui contient une seule graine recouverte d'un arille découpé en plusieurs lanièrcs étroites.

Muscadier a romatioue. Myristica moschata. Thunberg.

Partie usitée : La graine et son arille. Nom pharm. : Nux moschata, macis. Nom vulgairc: noix muscade.

C'est un arbre d'environ trentc pieds de haut, très-touffu et ressemblant à un oranger. Il portc des feuilles alternes, orales lancéolées, entic̀rcs, accuminées, à nervures latérales régulières, longucs de deux à trois pouces, larges d'environ un 
ponee et demie, contement pétiolées, eoriaces, d'un vert foncé en dessus, blanehâtres en dessous.

Fleurs dioïques disposées en faiseeaux solitaires aux aisselles des feuilles; eluaque faiseeau très-courtement pédoneulé se eornpose d'environ qualre à six fleurs portées sur des pédieelles gréles, deux ou trois fois plus longs qu'elles.

Fleur's nâles, caliee eampanulé, ureéolé, à trois divisions ovales, aiguës, pubeseentes.

Douze étamiues, rarement neuf sympliysandres, e'est-à-dire réunies en une eolonne ereuse par les filets et les anthères; eelles-ei sont dressées et à deux loges.

Les fleurs femelles ont le ealiee ennformé de la même manière, un ovaixe ovoïde, libre, uniloenlaire, uniovulé; deux styles très - eourı́s, terminés elraeun par un sligmate petit et eapitulé.

Le fruit est une drmpe pyriforme, à peu près de la grosseur du poing, renfermant une graine grosse, ovoïde, solide, revêtue dans presque toute sor étendue, par un arille inégalement découpé, de couleur de eliair, eonnu sous le nom de macis.

La graine elle-même est très-grosse, dure et fort aromatique.

Le museadier eroît naturellement aux Moluques, et particulièrement aux iles de Benda, d'où l'on tire une énorme quanlité de museade. Il a été transporté a l'Ile de Franee en 1770 et $\mathbf{1} 772$ par M. Poivre. On le eultive aussi depnis long-temps a Cayenne et dans les Antilles.

Propriétés ct usages. La museade est la graine de l'arbre que nous venons de déerire. Elle est ovoïde, de. la grosseur d'une 'petite noix, dure, d'une eouleur brune, marbrée intérieurement. Elle est bien plus employée comme aromate que comme médieament. Quant au macis, e'est l'ax'ille ou membrane elrarnue et frangée qui reeouvre la graine; il a une saveur aromatique, piquante, fort agréable. Ces deux parties eontiennent deux sortes d'huile: l'une fixe et grasse; l'autre volatile. Dans les lieux où l'on récolte les museades, on en relire par l'expression une hnile eonnue sous le non d'huile de muscade, et qui est un unélange'des deux éspćees que nous venons d'indiquer. Elle partieipe par eonsiqquent des propriélés des liuiles grasses et des huiles volatiles. 
Ces deux substances sont stimulantes, ct font partic d'un gुrand nombre de préparations officinales.

\section{ULMACÉES. - ULMACEA.}

Cette nouvelle famille des Ulmacées a beaucoup de rapports avec celle des Urticées, auprès de laquelle elle doit être rangée dans la série des ordres naturels. Elle ne se compose que d'un petit nombre de végétaux, dont l'orme et le micoucoulier doivent être considérés comme les types.

Les fleurs sont hermaphrodites, quelquefois unisexuées par avortement; le calice est à quatre ou cinq divisions; il donne attache à un nombre égal d'étamines; l'ovaire est libre et uniloculaire, renfermant un seul ovule renversé; il est surmonté de deux stigmates sessiles, allongés, glanduleux à leur, face supérieure.

Le fruit est une samare membraneuse, on une petite drupe, renfermant une seule graine, dont l'embryon est renversé et dépourvu d'endosperme.

Les Ulmacées sont des végétaux ligneıx, pouvant s'élever à une hauteur considérable; leurs feuilles sont alternes, simples; accompagnées à leur base de deux petites stipules. Leurs fleurs sont petites, peu apparentes, solitaires ou glomérulées.

Les deux genres Celtis et Ulmus avaient été placés par M. de Jussieu dans le groupe polymorphe des Amentacées, bien qu'ils n'aient pas leurs fleurs disposées en chatons.

$$
\text { ORME.-ULMUS. }
$$

Fleurs hermaphrodites : calicc monosépale subcampanulé, un pocu comprimé, à quatre ou cinq lobes irréguliers; quatre ou cinc étamincs insćrées vers la base du calice : ovairc comprimé, librc, uniloculaire, contenant un seul ovule renvcrsé; 
surmonté de deux stigmates en forme de corne, glandulcux sur la face interne; le fruit est une samare orbiculaire, un peu échancrée en cœur à son sommct.

Orme commun. Ulinus campestris. L. Sp. 327 . Part. usitée : l'Écorce intérieure. Noms vulg. : Ormeau on Ormille, etc.

Sou tronc est dressé, cylindriquc, et peut atteindre une haúteur dc soixante à quatre-vingts pieds. Ses feuilles sont alternes, distiques, pétiolées, ovales, aiguës, dentécs en scic, d'un vert foncé, un peu rudes au toucher. Les fleurs s'épanouissent, et souvent même les fruits mûrissent avant quc les feuilles ne se développent; elles sont rapproehées, sessiles, rougeâtres, et forment des espèces de petits eapitules alternes et sessiles à la partie supérieure des ramifications de la tige. Leș ćtamines, au nombre de quatre à cinq, sont plus longues que le calice. La samare est glabre, orbiculaire, mince, un peu échancrée en cour à son sommet. Elle est à une seule loge qui contient unc seule graine.

L'orme, qui se trouve abondamment dans les forêts de l'Europe, est principalement cultivé pour planter les allées et les quinquonces dans les promenades publiques. Il fleurit dès le unois de février ou dc mars; ses fruits sont mûr's un mois après la floraison.

Propriétés et usages. L'orme présente peu d'intérêt sous le rapport de ses propriétés médicales, et de son emploi dans la thérapeutique. C'est son écor'ce intérieure qui a une saveur un peu âpre et amc̀re, que l'on a vantéc outre mesure dans le traitement des dartres et des autres affections chroniques de la peau. Quelques autcur's l'ont osé préconiser contre lcs fièvres intermittcntes, les serofules et même le cancer, mais on n'a pas tardé à reléguer dans l'oubli une substance aussi pcu digne de sa haute réputation.

I.c bois de l'orme est très-dur ct fort recherché pour les ouvrages de charonage. Il se développe souvcnt sur lc tronc de cct arbre des espèces de gibbosités dont l'intéricur cst agréablement vciné. Ellcs sont cmployécs par les ébénistes pour faire des menbles de luxe. 


\section{URTIGEES. - URTICEA.}

Les Urticées ont rarement les fleurs hermaphrodites; elles sont le plus souvent monoïques ou dioïques : le calice est tantôt monosépale, profondément divisé, tantôt il est formé de sépales distincts. Presque toujours il est persistant, et accompagne le fruit. Dans les fleurs mâles on trouve quatre ou cinq étamines alternes avec les divisions du calice, quelquefois opposées. Les fleurs femelles présentent un ovaire libre, uniloeulaire, monosperme, ordinairement surmonté de deux stigmates; cet ovaire devient un akène quelquefois accompagné du calice, qui est devenu eharnu et succulent. Les fleurs femelles forment des épis globuleux, ou sont implantées sur la paroi interne d'un réceptaele pyriforme ou évasé, qui devient ordinairement cliarnu.

Les graines sont dépourvues d'endosperme; leur embryon est tantôt droit, tantôt reeourbé:

Les Urticéés renferment des arbres à trone ligneux, comme les mûriers, les figuiers, ctc., des arbrisseaux et des plantes herbacées; leurs feuilles sont alternes, accompagnées de stipules.

On peut diviser les genres de eette famille en denx groupes suivant que leur fruit est eharnu ou sec.

Io Artocin pées ', ou Urticées à fruits charnus.

A. Fleurs réunies dans un réceptacle charnu.

$$
\text { FIGUIER.-FIGUS.L. J. }
$$

Fleurs monoïques, réunies dans un involucre pyriforme charnu, dont ellcs garnissent tonte la face intcrne : cct involucre offre à sa basc deux on trois petiles écailles, son

' Ainsi nommé, parce que l'àrbrc à pain (artocarpus) appartient ì cette section. 
sommet est pereé d'un trou bouché par des écailles nombreuses disposées sur plusieurs rangćes; les flcurs mâles, moins nombrenses occupent la partie supćrieure du réeeptacle; elles offrent un calice triparti et trois étamines saillantcs: les fleurs femelles se composent d'un calice quinquéparti, d'un ovaire uniloculaire, présentant un style latéral, terminé par deux stigmates filiformes. Le fruit se compose du réceptacle, dont les parois deviennent épaisses ct.charnues, et des ovaires qui se changent en autant de petits akc̀nes adhérens à la paroi interne du rćceptaclc.

Les figuiers sont des arbres quelquefois très-grands, ayant les feuilles alternes, d'abord enveloppćes dans unc longue stipule membraneuse.

Figuier commun. Ficus carcia. L. Sp. 15 r 3.

Part. usitée : les fruits frais ou secs. Nom pharm. : Ficus. Noms vulg. : Figues ou Figues grasses.

Le figuier est originaire d'Orient. Ce furent dit-on les Phéniciens qui l'introduisirent dans le midi de la France, lorsqu'ils vinrent, environ six cents ans avant l'ère chrétienne, jeter à Marseille les premiers fondemens de leur colonie. Sa tige peat s'élever jusqu'à vingt-cinq et même trente pieds. Ses feuilles, alternes, pétiolćes, grandcs, sont d'abord roulées et entièrement cachées dans une longue stipulé membraneuse; elles sont échanerées en cœurà leur base, palmées et ordinairement à cinq lobes arrondis et obtus; leur face supérieure est d'un vert foncé et luisante, l'infćrieure plus claire est hérissćc de poils rudes et courts. Les fleurs sont situées dans des involucres pyriformes, solitaires à l'aisselle des feuilles supérieurcs, portćs sur un pédoncule long de cinq à six lignes. Ce sont ces involucres ou rćccptacles dont les parois prerment beaucoup d'épaisseur, que l'on rcgarde comme les fruits, quoiqu'à proprement parler, les vćritables fruits soient les petits grains résistans qu'on trouve sur la surfacc internc du réceptacle, auquel clles sont attaclićes par un pédicule cliarnu.

Les fruits ou figues sont de deux sortes; les unes occupant la partie moyenne des branches, gćnéralement plus grosses 
sont mûres en juillet; on les. appelle, en Provence 'figues-fleurs; les autres, situées au sommet des branches, ne sont mûres qu'en septcmbrc. Elles sont plus petites que les précédentes, mais bien plus sucrées.

Propriétés et usages des figues. Les figues fraîches, surtout celles qu'on récolte dans les provinces méridionales de la France, sont un aliment aussi sain qu'agréable. Elles sont àduucissantes et légèremcnt laxatives. On les sert frćquemment sur nos tables. On peut les conserver pour l'hiver, aprc̀s les avoir fait. sćcher au soleil, en les exposant sur des claies. Elles sont alors beaucoup plus sucrées, mais peut-être moins faciles à digćrer. C'est dans cet état qu'on les conserve dans les pharmacies. On en fait des tisanes adoucissantes et d'un goût agréable, en coupant trois ou quatre figues par quartiers et les faisant bouillir dans une pinte d'eau. Ordinairement on les unit aux autres fruits béchiques, tels que les jujubes, les dates et les raisins secs. On prćpare encore avec les figues sèches ou fraiches, des cataplasmes ćmolliens, que l'on applique sur les tumeurs douloureuses et enflammées.

\section{DORSTÉNIA. - DORSTENIA. L. J.}

Fleurs monoïques réunies et enfoncées dans un involucre ou réceptacle plane; dans les fleurs mâles on compte une ou deux étamines, raremcnt un plus grand nombre; les fleurs femelles sont légc̀rement pédicellées êt offrent un ovaire uniloculaire et à une seule graine, portant à sa partie supérieure et externe un style filiforme terminé par deux stigmates subulés. Le fruit est unc petite capsule bivalve.

Les feuilles sont toutes radicales et pétiolćes. Ce genre diffère surlout du figuier par son involucre entièrement ouvert et plane, par ses fleurs mélangées sans ordrc, par ses fruits ou capsules bivalves.

Dorstenia contrayerva. Dorstenia contrayerva. L. Syst. plant. I. p. 342. Blackw. t. 579 .

Part. usitće : la racine. Nom pharm. : Contrayervec radix.

D’une racine allongće fusiforme, rougeâtrc, inégale, lćgè- 
rement rameuse, de la grosseur du doigt, s'élèvent trois á quatre feuilles pétiolées, larges, pennatifides, et presquc palmées, à lobes laneéolćs, irrégulièrement dentés, un peu rudes au toucher; du milieu de ces feuilles naissent deux ou trois pédoncules, de einq à six pouces de hauteúr, cylindriques, légèrement pubescens, s'évasant à leur partie supérieure en un réceptable plane, irrégulièremcnt quadrangulaire, large au moins d'un pouce dans tous ses diamètres, ayant son bord inégalement sinueux.

La face supérieure de ce réceptacle est reconverte entièrement de fleur's unisexuées mâles et femelles mélangées. Ces fleurs semblent plongées dans autant de petites eavités ou alvéoles, que l'on peut considérer eomme formécs par la soudure des enveloppes florales. Le fruit est une sorte de pelite capsnle blanche, s'ouvrant en deux valves. La Contrayerva croît dans différentes parties du Noùveau-Monde, et entre autres an Pérou et au Mexique. $\not$

Propriétés et usages. On a pendant long-lenıps ignoré l'origine de la raeine de contrayerva. Hemandez la eroyait produite par une espèee de passiflore. Bernard de Jussieu la rapportait au Psoralea pentaphylla de Linné. Miais il est certain aujourd'hui quc celle racine est cèlle du Dorstenia controyer'a et de quelques cspèces voisines. Elle est allongée, rongeâtre, terminée en pointe reenurbée à son extrémilé, donnant nasssance à quelques fibrilles cylindriques. Son odeur est aromatique, sa saveur est un pcu âere. Celte racine était bcaucoup plus employée autrefois qu'ellc ne l'est maintenant. Son nom vulgaire de Contrayersa, d'origine espugnole, ct qui signifie contrepoison, indique l'usage principal pour lequel clle était usitće. Elle doit être ensildérée comne nn médicament stimtulant, qui peut être avanlageux dans quelques cireonstinces, mais dont lẹ propriélés singulièrement exaltées jar quelques auteurs, n'ont ricn de bien remarquable.

B. Fleurs sans involucre charnu, calice devenant charnn.

MURIER. - MORUS. L. I.

Les flcurs sont unisexućes, clles forment des èpis mâles et 
femelles distincts, ovoïdcs ou presque globulenx : les fleurs mâles se composent d'un calice profondément quadriparti, et de quatre étamines alternes avec les sépales: dans les flcurs femelles, le calice offre la même structıre, mais on tronve un ovaire lenticulaire nonosperme, surmonté de dcux stigmates filiformes sessiles. Le calice devient charnu, persiste autour des ovaires, qui se changent en akènes, et tous les fruits d'un même épi finissent par se souder latéralement; et forme une sorte de baie mamelonnée.

\section{Muruer nolr. Morus nigra. L. Sp. 1398 .}

Cet arbre peut s'élever à vingt-cinq ou trcnte pieds. Son tronc est recouvert d'une écorce noirâtrc, ses feuilles sont alternes, cordiformes, aiguës, dentées en scie, pubescentes.ct rudes au touchcr. Elles sont quelquefois divisées en trois ou cinq lobes. On trouve à la base de leur pétiole denx stipules opposées, membraneuses, ovalcs, lancéalées, également pubescentes.

Les fleurs sont souvent diö̈ques, quelquefois cependant elles sont monoï ques; les épis mâles sont ovoïdes, presịue globuleux; les ćpis femelles sont pédonculés, globuleux, pendans : le calice est comprimć; les riuatrc sépales sont.connivens. Les fruits sont ovoïdes, formés d'un grand nombre de petits akc̀nes, entourés du calice devenu charnu ct sondćs par lcurs côtés. Ces fruits, de la grosseur d'une prunc de Damas, sont d'une conleur rouge vineuse, ils devicnnent presंque noirs en Inûrissant, et ressemblent. beaucoup à ceux dc la framboisc.

Le múrier noir est originairc de la Persc, d'où on l'a transplanté dans les provinces méridionales de l'Europe, où il s'est naturalisé. Suivant quelques auteurs, il proviendrait de la Chine, ct àrait été transplanté cu Persc, avant son introduction en Europlc. Il fleurit en juin; scs fruits sont mûrs cn scptembre.

Propricités el usages. L.es fruits du mûrier ou les múres, ainsi qu'on les appelle, ont une savenr sucrèe et légèrement aigrelette. Ils contienuent une grande quantité de mucilage. It est rarc yu'nu les serve sur mos liabless : ils jonisseus des mẻmens 
propriétés que les groseilles et les cerises. On peut préparer avce Ics mủres, en exprimant lc suc abondant qu'elles contiennent, des boissons rafraichissantes qui peuvent ètre utiles dans lés inflammations peu intenses des organes de la digestion ou de la bouchc. Le sirop de müres se fait avec ces fruits cueillis un peu avant l'époque déleùr maturité; en sorte qu'il cst légèrement acifle. On en fait particulièrement usage dans les maladies inflimmatoires de la bouche ou du pharynx.

$2^{\circ}$ Urticḱes vraies ou à fruits secs.

$$
\text { PARIÉTAIRE: }-P A R I E T A R I A \text {. L. J. }
$$

Fieur's polygames rassemblécs en petit nombre dans des involucres de plusieurs folioles. Chaque fleur offre un calice tubuleux, à quatre divisions persistantes: les fleurs hermaphrodites ont un ovaire libre, surmonté d'un stigmate pćnicilliforme; quatre étamines incluses : lesfleurs femelles n'en diffèrenţque par le manque d'étamincs.

Le fruit est un très-petit akène, renfermé et recouvert par le calice qui se ressère sur lui.

Pariétaire officinale. Parietaria offecinalis. L. Sp. 1492. Bull. t. I 99 .

Part. usitée : Toute la plante. Nom pharm. : Parietaria S. Helxine. Noms vulg. : Perce muraille; Casse pierre, etc.

Sa racine est vivace. Sa tige est dressée, cylindriquc, rameuse, velue, charnue, cassante, rougeâtre.

Ses feuilles sont alternes, pétiolćes, ovales, acuminées, entièrts, velues et un peu rudes sur les deux faces.

Les fleurs sont polygames, très-petites, groupées à l'aissclle des feuilles supćrieures et réunies par trois dans un petit involucre commun, formć de plusieurs petiles folioles. De ces trois fleurs, l'une est hermaphrodite; les deux autrcs sont ordinaircnent femelles.

La flcur hermaphrodite a un caliçe monosépale, tùbuleux, nince, à quatre divisions aiguës, rapprochées; un ovaire libre et central, uniloculaire renfermant 1 scul ovulc, ter-
miné par ua stigmate cn formc de pincenu; quatre ćtamiues 
attachécs sous l'ovaire et incluses. Les fleurs femclles n'en diffèrent que par l'absence des étamines qui sont avortées et rudimentaires.

Le fruit est un petit akène ov̈oüde, très-lisse ct luisant, renfermé dans le caliee, qui se ressère sur lui.

La pariétaire est très-commune aux environs de Paris; elle eroit dans les fentes des vieux murs, et à leur pied. Elle fleurit pendant tout l'été. భ

Propriétés et usages. Cctte plante a une saveur herbacée un peu salée, et renferme une assez grande quantité de nitrate de potassc; ce qui lui donne une vertu diurćtique assez prononcée. Elle est du reste émolliente et rafraîchissante. On la prescrit en décoction, ou bien on en exprimc le suc, lorsqu'elle est fraîche.

\section{CHANVRE. $-C A N N A B 1 S$. L. J.}

Fleurs dioïques; dans les fleurs mâles, calice à cinq divisions profondes; einq étamines à filamens courts; dans les fleurs femelles, ealice renflé à la base, terminé en pointe à son sommet, fendu d'un seul côté jusque près de sa base; ovaire globuleux, contenant un seul ovule renvérsé; deux stigmates filiformes saillans. Le fruit. est un akène globuleux, rccouvert par le cajice; la graine renferme un embryon amphitrope, c'est-àdire recombé en fer à cheval.

Les fleurs mâles forment de petites grappes axillaires. Les fleurs fcmclles sont sessiles, solitaires ou géminées.

Chanvre cultiví. Cannabis sativa. L. Sp. 1457 . Blackw. t. 322 .

Part. usitéc : les fruits. Nom pharm.: Cannabis semina. Nom vulg. : Chenevis.

Plante annuelle et dioïque. Tigc drcssée, droite, presque simple, effiléc, haute dc quatrc à huit picds, cylindrique, rude au toucher. Feuilles alternes, pétiolées, digitées, folioles au nombre de cinq lancéolécs étroitcs, très-aiguës, dentées en scic, rudes atu touch er, pubcsccntes, d'un vert pâle en dessous; 
les feuilles supérieures sont composécs seulement de trois folioles plus étroites.

Flenrs mâles formant de petites grappes à l'aisselle des. feuilles supérieures : elles sont courtement pédonculées, renversćes et pendantes : leur ealice est formé de einq sépalcs. étalés laneéolés étroits; et de cinq étamines rapproehécs, dressées, à filets très-courts ct eapillaires, à anthères très-grosses, et rapproehées.

Les fleur's fernelles, réunies en groupes serrés et foliaeés à l'aisșelle des feuilles supérieures, sont composées d'un calice. globuleux inférieurement, terıniné supérieurcment par un prolongement fendu dans sa longueur. L'ovairë est simple, runiloeulaire, à un seul ovule; surnonté de deux styles et de deux stigmates, subulés, glanduleux, saillans au dehor's, à travers la fente $\mathrm{dn}$ calice. Le fruit est un akène lisse et crustacé, r'eeouvert par le calice.

Lc chanvre est originaire de la Perse; mais il s'est si bien naluralisé dans toutes les contrées de l'Europe, qu'il semble en. ètre indigine.

Propriét's et usages. Toutes les parties de cette plante ont une odeur désagréable et vireuse. Aussi regarde - $\mathrm{t}$ - on le chanve eomme un végétal très-délétère. Lorsque l’on reste pendant quelque temps cxposé aux émanations qui s'élèvent d'une plantation de chanvre, on ne larde pas à éprouvcr une céplalalgie violente, des vertiges, en un mot les premiers symptômes de l'ivresse. Ces phénomènes sont d'autant plus marqués, que ce végétal est cultivé dans un pays plus inćridional; car il parait que dans le nord il perd la plus grande partie de son activité. Les orientaux emploient les feuilles de ce végétal pour préparer une boisson enivrantc, qui les jetle dans un ćtat de somnolence et d'extase.

Les fruits sont la seule partie que la médecine réclane. Ils sont composés d'une amande blanelic, louce, contenant une grande quantité d'lruile grasse; on les nomme vulgairement chenevis. Ils servent à la préparation d'émulsions, qui sont a la fois adoucissantes et Jegerencont calmantes, el dont on fait usage dans'ies inflammations du camil de lurehe.

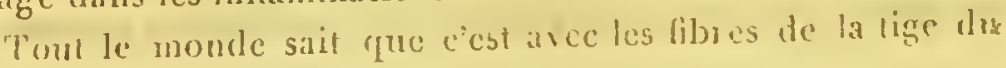


chanvre que l'on prépare la filasse ou chanve proprement dit, dont les usages sont immenses dans l'éeonomie domestique, pour la préparation des toiles et des eordages.

\section{HOUBLON. - HUMULUS. L. J.}

Fleurs dioïques. Les mâles offrent un caliee profondćment quinquéparti, cinq étamines opposées aux segınens du ealice; les fcmelles forment une espèec de capitule écailleux; entre chaque écaille on trouve deux fleurs sessiles, composées d'une braetée ovale, à bords roulés en cornet, d'un ovaire uniloeulaire, surmonté de deux longs sligmales filiformes.

Le fruit est un cône formé d'éeailles minces et membraneuses entre chacune desquelles sont deux pelils akènes.

Houblon ordiname. Humulus lupulus. L. Sp. 1457 . Bull. t. 234.

Part. usitées : les jeunes pousses et lés fruits. Noms pharm. : Lupuli turiones, fructus. S. coni.

Plantc vivaee et dioïquc, dont la lige est herbacée, légèrement anguleuse et rude, volubile de gauelic à droite autour des arbres voisins, et pouvant s'élever ainsi à une hauleur de douze or quinze pieds. Scs feuilles sont opposćes, péliolées, palmées à trois ou cincl lobes dentés, ayant à peu jrès la même forme que eellcs de la vigne, rudes an toneher; elles sont accompagnces de stipules larges, membraneuses, dressées, striées, ynclquefois bifides au sommet.

Lcs fleur's fernelles forment une espèce de capilule globuleux, de la grosseur d'un pois' solilaire, pédonculé et axillaire. II se compose d'un grand nombre d'éeailles foliaeées, légèrement velues, à l'aissclle de chacune desquelles se trouvent deux flems femclles, qui son l sessiles.

Les flcur's mâles, portées sur d'aulres individus, eonstiluent. à l'aisselle des fcuilles supérieures des grappes irrégulièrement rameuses. Les fruits sont des espićces de cônes membraneux, ovö̈les allongés, dont les écailles minces el persistantes conticment ehacume à lcur basc deux pelils akches, environnes d'une poussière granuleuse, jaunc, el de malure resineuse, que les I ravanx reens de MM. Payen ct Cihevallicr ont flímenlac étre la scule parlic active dn houblon. 
Le houblon croìt naturellement dans les haies et sur la lisière dcs bois. On le cullive cn grand dans certaines provinces du nord, particulièrement en Flandre, en $\Lambda$ lsacc, etc. Il fleurit vers le mois dc juillet, et les fruits peuvent être récoltés à la fin d'août ou au commencement dc seplembre. Ұ

Propriétés et usages. Il existe une grande analogie entre le houblon et le chanvre. Ces deux végétaux exhalcnt unc odeur assez désagrćable et nauséabonde, et participent un peu dans leur mode d'action des propriétés des plantes vireuses. Dans le houblon, on emploie spécialement les cônes écailleux et les jeunes pousses. Les premiers ont une saveur amère très-prononeée, entièrement due à la matière jaune rćsineuse. Ils sont un des ingrédiens de la bière, à laquclle ils communiquent une saveur amère qui n'a rien de désagréable. On leș emploie également en mćdccine. Le houblon estun médicament tonique assez fréquemment mis en usage : l'infusion d'une once de ces cônes séchćs, dans une livre d'cau, ou lcur décoction, forme une tisane amc̀re que l'on prescrit trìs-souvent dans les différens symptômes des scrofules, tels que le rachilis, le carreau, etc. Cette boisson ranimc les forces digestives de l'estomac. Quelques auteurs disent qu'elle agit aussi comme diaphoré.. tique, et qu'elle est très-avantageuse dans les maladies chroniques dc la peau.

Quant aux turions ou jeunes pousses, ils sont moins amers et moins aetifs, quoiqu'on les emploie dans les mêmes circonstances.

Lorsqu'on reste quelque temps exposé à l’influence des ćmanations du houblon, il détermine les mêmes accidens que le chanvre, e'est-à-dire un commencement de narcotisme.

$$
\text { OR TIE. - URTICA. L. J. }
$$

Fleurs monoïques ou dioïques. Dans les fleurs mâlcs on trouve un calice quadriparti et quatre étanines saillantes; dans les fleurs femelles, les quatre segmens du calice sont souvent inégaux, deux étant plus grands; l'ovairc cst surmonté d'un stigmate sessile, formé de poils glandulcux ct rayonnans. Le fruit cst un akène recouvert par le calice.

Les orties sont des plantes herbacécs, rccouverics de poils nombrcux, dont la piquîre est trìs-brîlante. 


\section{Ortie brulante. Urtica urens. L. Sp. 1396.}

Petite plante annuelle et monoïque, qui infeste les jardins et les ehainps cultivés. Sa tige s'ćlève à peine à un pied de haulteur; elle est presque carrée, rameuse à sa partie supérieure, et recouverte, ainsi que les feuilles, de poils dont la piqûre est extrêmement douloureuse et cuisante. Les feuilles sont opposées, ovales et profondémcnt dentées, d'un vert terne. Les fleurs sont petites, verdâtres, et forment à l'aisselle des feuilles supérieures des espc̀ces de petites grappes, composćes dc fleurs unisexuées mélangées. Cette espèee fleurit pendant presque tout l'ćté. $\odot$

Propriétés et usages. Toutes les espc̀ees d'orties sont plus ou moins à redouter à cause de la douleur qu'occasionne leur piqûre. Cette douleur dépcnd, non de la piqûre faite par les poils, mais du fluide irritant que ces poils, qui sont creux et canaliculćs, versent sous l'épiderme. L'on sait en effet que les orties dessćchées perdent la faculté de dćterminer les phénomènes de l'urtication; c'est-à-dire qu'elles n'oecasionnent plus la formation de cloches et d'empoulcs, remplies d'un fluide séreux qui soulève et détache l'ćpider'me. On em-. ployait autrefois les orties fraîches pour déterminer, à titre de révulsif, une irritation vive dans un point déterminć de la surfaee du corps. Mais ce procédé douloureux a été abandonné et remplacć par l'emploi des eantharides, du garou, ete.

$L$ 'ortie brûlante a une saveur aigrelette et légèrement rafraîehissante. Quelques auteur's, en preserivaient la décoetion dans la diarrhée et plusieurs autres maladies. Mais ce remède impuissant est depuis long-temps abandonné.

Propriétés médicales et usages des plantes de la famille des Urticées.

Les deux sections que nous avons établies dans la famille des Urticées, sous les noms d'Artocarpées et d'Urticées vraics, ne diffèrent pas moins par leurs propriétés médicales que par lcs caractères d'organisation de leurs,fruits. Tous lcs vćgélaux de la première scetion, qui sont en général plus ou moins élevés, eontiennent un sue blane ẹt laiteux, âerc et très-eaus- 
tique. Ce sue existe dans nos figuiers, et donne à quelques espèces des propriétés délétères, eomme on le voit par exemple dans le Ficus toxicaria de l'Inde. Mais de tous les arbres de ee groupe, il n'en est aueun dans lequel ee sue soit aussi abondant et arıssi vénéneux, que dans l'Antiar (Antiarris toxicaria de Leschenatalt), arbre originaire de Java, et qui fournit, dans eette île, le fameux poison, connu sous le nom d'Tpo ou Upas antiar. Ce poison est un des plus énergiques et des plus dangereux. Les. Javanais s'en servent pour empoisonner leurs. flèehes en temps de guerre. Un seul grain introduit dans le tissu cellulaire d'un ehien suffit pour le faire périr en peu de temps dans d'horribles eonvulsions. Mais toutes les $\Lambda$ rtoearpées, si remarquables par l'âereté de leur sue propre, fournissent au contraire des fruits charnus, doux et agréables, et dont quelques-uns servent presque d'unique aliment à des contrées toutes entières. Tels sont ceux de l'arbre à pain (Artocarpus incisa.), qui sont aussi gros que les deux poings et quelquefois davantage, et qui sont pour les habitans de plusieurs Arehipels de l'Oećan Pacifique une nourriture aussi salubre qu'abondante.

Les véritables Urtiećes au contraire, qui sont toutes des plantes herbaeces ou de petits arbustes, n'offrent point des proprićtés aussi énergiques. Elles sont presque toules empreintes d'un principe narcotirue, peu intense à la vérité, mais qui cependant est assez évident daus le chanvre et même le houblon. Un fait digne t'être noté, c'est que toules les Urticées ont leurs fibres souples et cepeudant résistantes; en sorte qu'on peut retirer de presque loutes les espèeés me filasse analogue a eelle du ehanvre.

TRENTE-QUATRIËM E T MILLE.

\section{EUPHORBIACÉES. - EUP IIORBIACEAE.}

Les Euphorbiacées constituent une famille cutrèmement naturelle, sous le rapport de l'uniformité de ses caractères botaniques et de ses propriétés médicales. Nous trouvons dans ces plantes des fleurs unisexuées monoïqueson dinïques, quelquefor disposéf'sen grappes, 
ou rćunies dans un involucre eommun, d'autres fois, mais plus rarement, solitaires. Leur ealiee est souvcnt donble, à cinq ou dix divisions, dont les plus intérieures sont pétaloïdes et eolorées. Dans les fleurs mâles, le nombre des étamines est très-variable; leurs filets, qui sont souvent articulés dans leur milieu, sont libres ou soudés cnsemble par leur base en un seul ou plusieurs andropliores. Les fleurs femelles offrent in caliee semblable à celui des fleurs mâles, et un pistil sessile ou pédicellé. L'ovaire est plus ou moins globuleux, à trois côtes et à trois loges, plus rarement à deux ou à un grand nombre de loges, qui renferment ehaeune un seul ovule. Trois styles bifurqués terminent ordinairement l'ovaire à sa partie supéricure, rarement on n'en observe qu'un seul, ou un plus grand nombre. Le íruit sc eompose d'autant de coques renfermant une ou deux graines qu'il y a de loges et de eôtes à l'ovaire : ees eoques sont bivalves et s'ouvrent avee élastieité.

Les graines sont recouvertes à leur partie supéricure par une erète ou earonculc de forme variée; elles renferment un embryon minee et plane, eontenu dans lintérieur d'un endospcrme eharnu.

Les Euphorbiaeées varient beaueoup par leur port. Les unes sont herbaeées; les autres sont ligneuses; leurs feuilles sont alternes, éparses ou opposées, quelquefois épaisses et sueeulentes. Presquc toutes, surtout parmi eelles qui sont herbaèées, contiennent une graude quantité d'un sue blane, laiteux et très-âcrc.

\section{EUPHORBE.-EUPHORBIA. L. J.}

Fleurs unisexuées, monoïques, quelquefois solitaires, plus souvent disposées en une sorte d'ombelle terminale, involucre monophylle (calice des autres botanistes) à huil ou dix divisions, les extérieures, de forme variće, sont arrondies, obtuses ou en croissans; les intérieures sont alternes ct dressécs. Le 
centre dc l'involucre donne attache à unc fleur femelle ordinairement pédicellée, dont l’ovaire à trois côtes, est surmonté de trois styles, souvent soudés en un scul à leur base, bifides à leur sommet; chaeune des quinze à vingt ćtamines, situées autour de la fleuŕ femelle, doit être considérće eomme une fleur mâle monandre. Elles sont entre-mêlées de petites ćcailles ordinairement fimbriées. La capsule est a trois coques monospermes. Toutes les Euphorbes ou Tithymales sont âcres ou lacteseentes.

\section{Euphorbe officinale. Euphorbia officinarum. L.}

Part. usitée : le .Suc concrelé qui s'en écoule. Nom phar. : Euphorbium. Nom vulg.': Gomme d'Euphorbe.

Cette plante ressemble toul-á-fait, pour le port, à un cierge ou cactus. Sa tige est dressée, épaisse, charnue, de Ja grosseur du bras, relevée de côtes saillantes, épineuses et longitudinales. Elle donne naissance de dislance en distance $\dot{a}$ des mamelons ovoïdes, également cannelés, et qui se changent en rameaux. Les feuilles n'existent pas, à moins qu'on ne considère comme tclles les épines plus or moins roides, dont les côtes de la tigc sont armées.

Les fleurs jaunâtres et assez petites sont solitaires et situées à la partie supérieurc des côtes de la tige; elles sont presque sessiles; leur involucre présente dix divisions, dont les cinq extérieures sont arrondies et très-obtuses.

L'Euphorbe officinale croît en Afrique et dans l'Inde. $₹$

Propriétés et usages. La substance résineuse eonnue sous le nom de suc ou gomme d'Euphorbe se retire de la plante que nous venons de décrire, et de quelques espcces qui en sont trèsrapprochées, telles que l'Euphorbia antiquorum. L. L'Eup'horbia canariensis, ctc. On l'obtient en pratiquant à eet arbrisseau des incisions peu profondes; le suc laiteux qui s'en écoule se concrète ct forme l'Euphorbium des officines.

D’aprc̀s l'analise qui en a été faite par M. Pelletier, cettc substancese compose surtout de résine $\left(\frac{60}{100}\right)$; de cire et de malate de ehaux. Elle eontient en outre unc assez grande proportion d'une huile volatile très-âcre. 
Ce médieament est d'unè ảcreté extrême. C'est un des purgatifs drastiques les plus violens: Les aneiens l'employaient très-fíćquemment, mais les modernes y ont rarement recours à cause de sa trop grande activité. Pour qu'il ne produise pas d'accidens graves, il faut.l'administrer à des doses très-faibles, telles que deux à trois grains par exemple. Appliqué sur la peau, il l'enflamme et finit par en déterminer la vésicalion.

Ce médicament, qui entre encore dans plusieurs préparations officinales, telles que l'emplâtre vésicatoirc et quelques pommades, est à peu près inusité à l'intérieur.

EupHorbe Épurge. Euphorbia lathyris. L. Sp. 655. Bull.

$$
\text { t. } 103 .
$$

Part. usitées : les graines eı les feuilles. Nom pharm.: Catapucia minor. Nom vulg. : Epurge.

Plante bisannuelle à racine pivotante, blanehe et rameuse, à tige droite, simple, haute de deux à trois pieds, glabre et d'un vert glauque; ses feuilles sont sessiles, opposées et déeussées : elles sont lancéolées, obtuses, entières, d'un vert trèsclair, surtout à leur face inférieure. Les fleurs forment une sorte de grande ombelle au sommet de la tige. Cette ombelle se compose de quatre rayons, plusieurs fois dichotomes, et aceoınpagnés à chaque bifureation de deux grandes feuilles florales, ovales, aiguës, subcordiformes.

L'involuere commun est ealyciforme, subeampanulé. Ses cinq divisions extérieures sont en forme de croissant, dont les deux cornes sont glanduleuses. Ies einq divisions intérieures sont dressées, minees et fimbrićes. Les étamines, au nombre d'enviroll quinze à vingt, sont dressćes et plus longues que l'involuere. La fleur femelle est portée sur un pédicèlle recourbé, également plus long que l'involucre.

Le fruit est gros, à trois eôtes lisses et à trois loges qui cóntiennent chacune une grosse graine jaunâtre.

On trouve assez communément cetle plante dans les lieux cultivés et sur le bord des ehemins aux environs de Paris, et dans d'autres parties de la France. Elle fleurit en juin.

Propriétés elusages. Nous pourrions répéter iei pour l'épurge, 
ce quc norss avons dit des propriétés médicales du suc d'Eupliorbe. Celte plante est en effet, ainsi que toutes lcs autres espc̀ees du même genre, un violent purgatif, mais dont les gens de la campagne font sculs usage. Ce remède n'est point sans danger à cause de l'irritation qu'il occasionne dans l'estomac et le canal ip̣tcstinal. On doit n'y recourir qu’à défaut de tout autre moyęn.

\section{Euphorbe ipt́cacuania. Euphorbia ipecacuanha. L. Sp. 653.}

Cctte Euphorbc, qui eroît naturellcment dans l'Amérique septentrionale, cn Virginic, au Canada, est vivaee; sa tige est couchéc inférieurement, où ellc est dépourvue de feuillcs, d'abord simple, puis dichotome, hautc d'environ six à huit pouces, et entièrement glabre. Scs fcuilles sont opposées, obovales, sessiles, entières, queliquefois allongées. Les deux rayons de son ombelle se divisent en un grand nombre de pédoncules grểles, termiués chacun par un seul involuerc de fleur's. Les cing appendices extérieur's de l'involucre sont arrouldis, entiers et non échrancrés en forme dc croissans. La capsule est glabre et longuement pédiccllée '

Propriétés et usages. La racine de cette płante, qui se compose de fibres cylindracées et blanchâtres, est enployée par les médccins de l'Amériquc boréale aux mêmes usages que l'ipécacuanha. Cettc propriété émétique de la racisc d'Ẽphorbe ipécaeuanha a engagé plusieurs médccins rcconmandables à rechercher si les espèces indigc̀nes de l'Europe u'en seraient pas égalcnicnt douces. D’après un grand nombre d'cssais varićs, M. le docteur Loiselcur Deslongchamps a reconnu quc la racine de toutes nos cspèces, surtont de celles qui sont vivaces, jouissail d'une vertu émétique trc̀s-prononcée, et pouvait dans plusicurs circonstances, remplacer l'ipécacuanha du Nouveau-Monde. Les 'espéces sur lcsquelles ce médecin s'est plus particuličcnient excrcé sont l'Euplot be des bois (Euph. sy.lvatica. L. Bull. t. 35.) l'Euphorbe de Gérard

- J'ai déerit cette plante d'après des échantillons recueillis par Aud. Mielıaux dans l'Amérique septentrionale. 
(Euph. gerardiana. Jacq.); l'Euphorbe eyprès (Euph.cyparis sias. L.); l'Euplsorbe pitliyuse (Euph. pithyusa. L.) Toutes ees plantes et les autres espèees eongénères jouissent des mêmes propriétés. Ces racines doivent être administrées en poudre, à la dose de 15 à 18 grains, délayés dans trois verres d'eau liède. Il est rare que l'on soit obligé d'augmenter eette dose.

L'àcreté et l'aetion vésicante des Euphorbes résident dans un prineipe volatil intimement uni à la résine, dont est priucipalement eomposé leur sne propre. Nous avons dit que la gomme résine de l'Euphorbia officinarum eontient $\frac{60}{100}$ de résine, et $\frac{\delta}{100}$ d'huile volatile et d'eau. Nos Euphorbes européennes r'enferment aussi un lait gommo-résineux, 'mais infiniment moins eauslique. On n'a pas encore d'analyse de leur sue laiteux eonerété, mais nous sommes portés à croire, que les quantités de résine et de sels étant les mêmes, il n'y existe pas une proportion aussi forte d'lunile volatile. C'est eclle-ei, dont l'action est tellement irritante qu'elle enflamme et 'eorrode les tissus animaux sur lesquels le sue laiteux, fluide ou épaissi, cst appliqué. Il est done tonjours dangercux d'administrer à l'intérieur, soit les Euphorbes elles-mêmes, soit leurs produits, parce que e'est. en déterminant une irritation plus ou moins grave daus le canal digestif qu’ils agissent comme purgatifs et émétiques.

\section{MERCURIALE. - MER CURIALIS. L. J.}

Dioïque : fleurs mẩes, calice étalé à trois divisions; dix à vingt étamines; fleurs femelles, ealiee semblable, deux filamens stériles, ovaire libre, à dcux eôtes, à deux loges, rarement à trois eôtes ct à trois loges; stigmate profondément vrant avee élasticité.

Mercuriate andeled. Mercurialis annua. L. Sp. I 465. Blackw. t. 162 .

Part. usitéc : toute la plante. Nom pharm. : Mercurialis.

Plante annuelle ct dioïque, dont la tige drcssée, rantcuse, très-glabre, ainsi que toutc la plante, anguleuse, s'ćlève à un
picd et plus. 
Les feuilles sont opposćes, pétiolées, ovales, lancéolées, aignës, dentées en scie.

Dans l'individu mâle, les neurs sont très-petitcs, rassemblćcs par petils groupes sessiles, qui forment des épis allongées, portés sur de longs pédoncules axillaircs: Le calice est étalé, a trois divisions profondes, ovales, aiguës; dix à vingt étanines dressées sont insérées au centrc du calicc.

Dans l'individu femclic, les fleurs sont un peu moins petites; les pédoncules, également axillaircs, sont beaucoup plus courts el. portcnt deux flcurs. Le cillice est à trois divisions profondes: le pistil se compose d'un ovaire arroiidi, didyme, hérissé de petitcs pointes, à deux loges, qui conticnneut chacune un scul ovulc. Le stigmate est presquc sessile, profondément partagé cn deux segmens très-divergens, couverts de papilles glandulcuses.

Le fruit est unc capsule à deux coques monospermes.

Il n'est pas rare de rencontrer des individus femclles portant des fleur's dont le pistil offićc trois côtcs, trois logcs et trois divisions au stigmate, ce qui rapprochc beaucoup la mercuriale des autres Enphorbiacées.

Il est pen de plantes plus communcs dans les jardins et les ellampscultivés, où on la trouve en fleur pendant lout l'été. (C)

Propriétés et usages. Sa saveur cst lierbaeće, fade, aqucnse, et son odeur faible, mais peu agréable. Cette plante cst cmployée comme émolliente et légèrement laxative. On donne sa décoction en lavcment. Pcu usitéc.

\section{MÉD ICIN IER.-JATROPHA. L. J.}

Fleurs monoïques; calice colorć à ciny divisions profondes, quelquiefois accompagné d'un calicule quinqréparti. Dans les flcur's mâles, dix élamincs, dont lcs filcts sont soudés par lcur base; dans les fleurs femelles, l'ovairc offre trois loges uniovulécs, et préscntc trois stylcs bifides. Le frnit est unc capsulc tricoque.

Tontes les espèces sout lactesccntes; lcurs fetilles sont lobécs ou palmées; leur's flcurs sont cn grappes. 
Médiciner manioc. Jatropha manihot. L. Sp. I429. Part. usitće : la racine et la fécule qu'elle renferme. Noms vulg. : Manioc, Pain cle cassave, Tapiolia.

Cict arbrisscau est remarquable par la grosscur de sa racine, qui est charnue, tubćreuse, blanche, pesant jusqu'à trente livres, et reinplie d'ụn suc blanc et laiteux d'une extrême âcrctć. De cetle racine part une tige dressée, haute de six à huit pieds, cylindrique, noueuse, garnie dans sa partie supérieure de feuilles alternes, longuement pétiolées, profondémcnt digitées en trois, cinq ou sept lobes, ovales, lancéolées, très-aigus, in peu onduleux sur leurs bords, d'une couleur verte foneée à leur face supérieure, glauques ct blanchâtres inférieurement. Les fleurs constituent des espćees de grappes à l'aissclle des feuilles supćrieures. Ccs grappes se composent de fleurs mâles et de fleurs femelles. Les premières offrcnt un caliee subcampanulé, à cinq divisions, d'un jaune rougeâtre, velues intérieuxement, et dix élamines; dans les fleurs femelles, les incisions du calice sont bcaucoup plus profondes; l'ovaire cst à trois côtes et se changc en une capsulc tricoque.

Lc manioc croît naturellcment dans les contrées chaudes du Nouveau-Monde. Pour se procnrer sà racine plus facilement et. arec plus d'abondance, on le eultive en. Amćriquc depuis le détroit de Magellan jusquc dans les Florides.

Propriétés et usages. La racine du manioc est presque uniquement formée d'amidon, auquel se joint un suc blanc et laileux, d'une âcrelć cxtrême, et qui est un poison des plus dangcreux. Mais ce suc ćtant fort volatil, on parvient faeilement a en priver les raeines de manioc, qui deviennent alors un aliment aussi salubre qu'abondant, et que l'on désigne sous le nom de prin cle cassave. Pour le préparer, on rape les racines lorsqu'elles sont encorc fraîches, ct l'on soumet la pâte que l'on obtient à une forte pressiou, qui en chasse le sue âerc et. vénćncux; on lave ensuite eeltc pâle dans de l'eau. C'est le résidu de la pression (que lon nomine farine de cassave. Lorsqu'on veut en faire du paim, on en forme des galettcs minces que l'on fait cuire sur des plaques de fer. La cuisson finit pas' dissiper entic̀rement le principe vénéneux. 
L'ean dians laquelle on a lavé la farine de cassave laisse déproser dans le fond des vases une assez grande quantité d'une pondre blanche. C'est de l'amidon très.pnr. On la rceneille, on la fait sćcher, el celle poudre est le tapiolia, qni est une féculc trìs-blanche et très-donec. On l'emploie comme le sagou, l'arrory-root, à faire des gelées et des potages, en la faisant cuire dans du lait, de l'cau aromatiséc, on du boullon.

Lu Cuncas (Jatropha, curcas. L.) appartient au même genre. C'est un arbrisseau également originaire de l'A.nérique néridionale. Ses graines sont connnes dans les officines sous les noms de pignons d'Tude on noix des Barbades. Elles sont violcmment jurgatives, mais anjourd'hui innsitées.

$$
\text { CROTON. - CROTON. L. J. }
$$

Les fleurs sont monoïques on dioïques : leur calice est double, l'extćricur a cinq divisions foliacées, l'intérieur' a cinq divisions pétaloüles, inanquant quelquefois. Dans les fleurs màles, on tronve de douze à vingt étamines et cinq glandes fixées au rentre; dans les fleurs femelles, l'ovaire cst à trois cồtcs, surmonté de trois slyles bifıdes. Le fruit est une capsulc tricoque, contenant trois graines.

Ce genre diffère du préeédent par son calice double, et par ses élamines plus nombreuses.

Les espèces en sont tantôt herbacécs, tantôt soufrutescentes.

Groton cascarilue. Crotori cascarilla. L. Sp. 1424.

Parl. usitéc : l'écorce. Nom pharm.: Cascarilla. S. cortex eleuthercinus. Noms vulg. : Quinquina arounatique, Faux quinquina, Chacrille.

$\Lambda$ rbrisseau s'élevant à peine à cinq on six pieds au-dessus de la surfaee du sol; sa tige est ligneuse, cylindrique, divisée en rameaux nombreux, recouverts d'unc cicorce d'un gris cendré; les jennes branches, ainsi que la surface supérienre des fenilles sont parsemées de petites écailles f́r furacćes, en forme d'éloiles, d'un blane jaunâtre. Les feuilles sont alternes, portées sur des pétioles assez eourts, clles sont lancéolćes, entières, aiguës, un peu ondulćes sur leur's bords, longues d'environ deux pouees, larges a peine de quatre à six lignes. 
Les fleurs sont verdâtres, peu apparentes, monoüques, et: constituent à la partic supérieure des rameaux, des épis allongés, dont la base sc compose de fleurs femelles, et la moitié supérieure de fleurs mâles. Cclles-ci ont un caliee à dix segmens, dont cing intéricurs sont plus minces et comme pélaloïdes, et énviron douze ou quinze étamines insérées stir le calice er soudces par la base de leurs filets. Les fleurs femclles présentent un calice semblable à celui des fleurs mâles, in ovaire à Irois côtes et à trois loges, et trois styles bifides, dont chaque division donne attaelıe à un petil stigmate.

La cascarille est originaire du Nouveau-Monde. Elle croit ualurellement au Pérou, au Paraguay, aux îles Lueayes et de Bahama : on la trouve également en abondance à Saiıt-Do. minguc.

Propriélés el usages. L'écorce de cascarille nous est trausmise en Europe sous la forme de fragnens, longs de trois a quatre pouccs, épais d'une ligne, à bords roulés; sa surface extérieure est d'un gris blanchâtre, souvent parsemée de petits lichens, sa face interne est fauve; sa cassure est compacte et résineuse. Elle possède me odeur aromatique, assez agréable, nnc savcur un peu âcre, chaude, anère et aromaticue. Elle renferme beancoup de résine et fournit a la distillation unc lıuile volatile vertc et d'une odeur suave.

Ce médicament délermine tous les phénomènes des subslances toniques cl stimulantes. Aussi plusicurs médecins le cumparent-ils au quiucquina pour son efficacić dans le traitement des fièvres intermitlentes et de la diarrhée; mais anjourd'hni on en fait assez ritrement usage. Ordinaircuscut on l'associc in 'puincquina, auquel elle communique unc odeur ct ure savenr plus iromatiques, el dont elle augmente l'cfficacité. La casca rille s'adninistre en poudre, dont la inantité varie beaueoup, suivant les effets que l'on veut produire. Lat leinture.et l'cxtrait se donnent à la dose de trente à quarante grains. Ces préparalions sont moins exployées que la poudre.

C'estsur une espèce du genic Croton (le Cincon lncifirum), et quclques aulres phintes de la famille des Fuphorbiacées que. l'on recueille dans l'Inde la matière résineuse connue sous le nom de laque. Cetle résine exsude à la suite de la piçûre 
qu'une espéce d'insccte fait aux jeunes branclies, prour y déposer ses œufs. La laque n'est plus employée en mćlccine. Elltc entre dans la fabrication de quelques vernis et de la cire i cacheter.

On cultive près de Montpellier, le Croton tinctoriun pour en obtenir le tournesol, que l'on trouve sous deux formes dans le commerce. Mais le toumesol en drapeau seulement est fabriqué en Franee. Il se prépare en imbibant à plusieurs reprises des linges du sue de celte plante et les exposant ensuite à la vapeur de l'urine putréfiće. Son principal usage est pour colorer extérieurement les fromagcs de Hollande, et pour teindre en bleu le papier à sucre.

A l'égard du tournesol en pains, on sait positivement aujourd'hui que les Hollandais nc se servent pas de Croton tinctorium, mais le fabriquent avec le roccella tinctoria espèce de lichen, qu'ils pulvérisent et mélent avcc de la mauvaise potasse, de l'urine putréfiée, et de la craie pour lui servir de laque et en augmenter le poids. La teinture de tournesol est um des rćactifs les plus sensibles pour découvrir la présence des acides libres; eeux-ci ramènent au rouge la couleur du tournesol, laquelle n'était bleue que par sa eombinaison avec les alcalis.

$$
\text { BUIS. - B UXUS. L. J. }
$$

Fleurs unisexuées monoïques : dans les fleurs mâlcs, calice quadriparti; quatre étamines saillantes attachées au-dessous d'un tubercule discoïde qui occupe le ccntre de la flcur : dans les fleurs femelles, calice composé de six écailles disposćes sur deux rangs; ovaire globuleux surmontć de trois styles écartés, creusés d'un sillon glanduleux sur leur face intcrne.

Le fruit est une capsule globuleuse à trois cornes éeartécs, à trois loges contenant chaeune deux graincs.

Toutes les espćees sont des arbres ou des arbustes à feuilles jérsislantes.

La: Burs ondinaine. Buxils sempervirchs. L. Sp. 1394.

Partie usitce: le bois et la racine.

Arbrisseau de dix à ynumze pieds de haut, d'un bois dur, 
serré, jaune, ayant l'écorec peu dislincte des couches ligncuses.

Feuilles opposécs, ovales, obluses, lisses et d'un vert foncé supérienrement; facc infère plus clairc, un peu concave. Ces feuilles, longủes d'environ un pouce, sont coriacés, persistantes, toujours vertes.

Fleurs rassemblées vers la partie supérieure des rameaux, Jans les aisselles des feuilles, en petits groupes très-serrés et rapprochés. Ces espèces de capitules se composent de fleur's mâles ct de fleur's femelles entre-mêlées, toutes égalemcul sessiles. Au centre d'un capitule d'cnviron douze fleurs, il n'y cn a qu'une femelle.

Flcurs mâles : calice squammiforme à quatre ou six divisions profondes.; les intirieures arrondies, subcordiformes; les extéricures ovales, coriaces; quatrc ćlamines saillantes, attachécs sous le pistil qui est stérile, flet cylindrique, diessé, anthère biloculaire terminale, obcordiforme.

Fleurs femelles cornme triangulaires, à angles arrondis; calice à peu pućs somblable à celui de la flemr.mâle; un ovairc libre, à trois loges, contcnant chacunedenx ovules. Cet ovaire est terminé sur ses trois angles par trois styles ćpais triangulaires divergens, a l'extrémité desquels se tnouve trois stignates disciformes recourbés, un peu concaves, apparens surtout sur la facc interne, ou ils se terminent cn pointe. Le fruit.est une capsule globulcusc, tricornc.

Propriétés et uscuges. Toutes les parties du bnis, mais principalement ses feuilles, xépandent wne odear désagréable ct comme vircusc. Leur saveur est amère et nausćabonde. La dieoction des feuilles de buis est légèrement laxative. Mais e'esi surtout colle du bois el de la racine réduite en poudre grossière, par le moyen de la rape, dout on a vanté J'action sudorifique daus le traitement de la syllibis constitutionnelle et du rhumatisnce cluosique. Ce médicanent indigène paraît avoir au inoins autant d'activite que le gayac, que nous sommes forcés d'aller comprunter au Nouvcau-Monde. Aa close de la rapure de buis est d'nuc à deux onecs pour deux livres d'can, rie l'on fril reduixe d'un tiers. Ois lui associc généralement 
lis auties végétaux sudorificues, tels que le sassafras, la salsepareille, etc.

$$
\text { RICIN. - RICINUS. L. J. }
$$

Fleur's monoïques disposées en grappes : les fleurs mâles, qui en occupent la partie inféricure, se eomposent d'un calice à cinq divisions très-profondes, et d'un très-grand nombre d'étamines, dont les filets sont soudés par la base en plusieur's faisceaux distinets. Les fleurs femelles en garnissent la parlic supérieure; leur calice est à trois ou einq divisions eaduques; l'ovaire est à trois loges monospermes, surmonté d'un style très-court, et de trois stigmates bifides et linéaires. La capsule est tricoque.

Toutes les espèees sont herbacées ou ligueuses; leurs feuilles sont alternes pétiolées, peltées, et le plus souvent palmées.

Le Ricin ordinatie. Ricinus communis. L. Sp. 1430.

Part. usitée : l'huile grasse retirée des graines. Noms pharm.:

Ricini. S. palma christis. Catapucia majoris oleum. Nom vulg. : le Palma christi.

Ce végétal, originaire de l'Inde el de l'Afrique, forme daus ces contrées un arbre, dont le trone lignenx s'élève quelquefois à trente et à quarante pieds. En Europe, au contraire, il n'est plus qu'annuel et herbacé. Cependant j'ai eu occasion, au mois de de septembre 18 I 8 , de trouver aux euvirons de Ville-Franehe, près de Nice, sur les bords de la mer, un petit bois entièrement formé de ricins en arbres. La description que je donne ici du ricin est faite d'après les individus annuels que: l'on cultive dans nos jardins.

La tige est dressée, haute de quatre à huit pieds, rancusc, cylindrique, fistuleuse, glabre, glauque et purpurescentc.

Les feuilles sont alterues, portécs sur des pétioles lougs, cylindriques et creux. Elles sont peltées, palinées, à septt ou neuf lobes ovales, lancéolés, aigus, doublement serrés, glabres et verts des deux còlés. Chacune dielles est accompiatgunée à sa base d'une stipule caluque, oppostc a la ferille, presque amplexicaule, ovale et membrancuse. 
Les flenrs sont monö̈ques, réunies sur unc mềne grappe, extra-axillaire, eomme pyramidale, garnie de fleur's femelles dans sa moitié supérienre, el de fleurs inâles inférieurement. Les fleụis mâles et femelles sont pédnneulées, et le pédoneule est arlieulé vers le nilieu de sa longueur.

Les fleurs mâles se eomposent d'un caliee à einq divisions concaves, ovales̀, aiguës et réflécliies. Les étamines sont extrêmement nombreuses, polyadelphes, c'est-à-dire que les filets sont rénnis et forment des faiseeaux grêles, rameux à leur partie supérieure, et portant des anthères très-petites, presque didymes, à une seule loge, s'ouvrant circulairement. Point de rudiment d'organes femelles.

Les fleurs femelles ont aussi un calice a cinq divisions étroites et laneéolées, caduques, quelquefois souáes ensemble par leurs bords. L'ovaire est libre, globuleux, à trois eôles ehargées de tubereules eharnus terminés par une pointe excessivement fine et acérée : il est à trois loges uniovulécs. Le style est exeessivement eourt et porte trois stigmates allongés, linéaires, très-glanduleux, bifides dans leur moitié supérieure.

Le fruit est une eapsule globuleuse à trois eòtes saillantès, arrondies, glauques, et chargées d'épines.

Propriétés et usages. L'huile grasse que l'on retire des graines de eetle plante est la seule partie dont on fasse usage. On prépare l'huile de ricin, soit par le moyen de l'expression, soit par l'eau bouillante. Par ee dernier proećdé, l'huile perd une partie de son âereté et est moius sujette à donner des coliques; e'est alors ur purgat if assez doux, el que l'on emploie trèsfréqueınment dans les différentes coliques, lit hernie élranğlée, et surtout daus le traitenent des asearides. Mais lorsqu'elle a itc préparée au moyen d'une forte pression, elle est d'unc âereté et d'une violcuce cxtraordinaires, et peut occasiomer les aecidens les plus graves. On peut la rendre plus douce en la faisant légèrement bouillir; la chaleur dissipe le principe, Âere, qui paraît très-volatil. Quelques anteur's jensent même qu'on jeut l'en priver cutièrement et la reidre propre à l'usage de la table, en la lavant a plusienrs reprises dans de l'ean aiguisćc avec de l'acide sulfurique. 
L'huile de ricin, indépentamment de sa grande viscosité, possède nue proprićté qui la distingue de toutes les autres builes grassés, c'est d'être faeilement soluble à froid dans l'aleolol. Aussi se sert-on avee suecès de eclui-ci pour savoir si elle a été étendue d'une certaine quantité d'antre huile fixe. Elle doit être limpide, ineolore, sans odear et d'une saveur fade peu marquée; elle purge alors à la dose d'une once à une once et demic, administrée dans un vélicienle approprić.

L'hnile de riein ne se rencontre pas malheurensement toujours aussi pure dans les officines. Tantôt elle est rougeàtre, tantôt elle a une odeur nausćabonde très-désagrćable, et le plus souvent sa saveur est d'une extrême âeretć. Ce sont autant de défauts qui tiennent à sa mauvaise préparatiou ou à sa véfusté. La couleur rouge des unes vicnt de ce que ponr les obtenir en plus grande quantité, on a fait chanffer les graines de ricin jusqu'à la torréfaction; telle est eelle dite d'Amérique, qui, diton, est plus purgative. L'àcreté est due à un principe volalil existant dans l'endosperme, et surtont dans l'embryon de lit graine de riein, et qui se dissout dans l'huile. On le fait dissiper à l'aide d'une ehaleur modćrée, et l'hnile qui en est ainsi priviée, cst connue sous le nom d'huile douce de riein.

L'amande des semenees de rieiu eontient une telle quanlité (le principe volatil âcre, qu'il a suffi de quelques-unes pour produire des supenpurgations très-violentes aux personnes qui en avaient mangé.

Nous aurions pu déerire enoore plusirurs autres plantes intéressantes de la fanille des Enphorbiacies, si nous n'avious pas craint d'auguenter de beaucoup le volume de eet ouvrage. Nows nons contenterons donc de Iss mentionner iei. $\Lambda$ imsi e'es! une espece de Plyyllanlic (Phyllanthus cmblica), dont les fruits sont connus dans les officines sous le nom de Mirobolans cmblics, et ru'on employait autrefois comme purgatifs. Le caontehoue ou résine ćlastigne est prodluit par le sue coagulé d'un grand arbre de cotte famille, originaire dAmérique, el (ju'Aublet a nommi Heser guynanchis. 
Propritités médicoles et usages des Euphorbiacces.

Nous relrouvons dans les propriétés inédicales des plante: de la famille des Euphorbiaeées, consiclérées d'une manière géuérale, la même analogie que nous avons préoćdemment observée dans leurs earaetères bolaniques. Toutes ees plantes sont essentiellement âeres, eaustiques et vénéneuses. Elles doivent leurs propriétés délétères au sue laiteux dont nous avons signalé l'existence dans la plupart des espèees que nous avons déeriles. Minsi dans le Mancenillier (Hippomane mancenilla), toutes les parties en sont tellement imprégnces, que l'ombrage seul de eet arbre est fatal au voyageur qui s'y repose; ses fruits, qui sont eharnus et d'un aspeet agréable, sont d'autant plus à redouter, que leur saveur, d'abord assez fade, n'avertit point du danger que l'on eourt en les mangeant. Ce sue laiteux, qui paraît être formé d'extraetif et de résine, pris intérieurement a petites doses, irrite les organes de la digestion avee lesquels on le met en eontaet, et agit dans quelques espèees eomme émétique, par exemple dans les raeines de l'Euphorbia Ipecacuanha. E. Gerardiana. E. Cyparissias, L. ete.; et dans d'autres comme nn violent pnrgatif drastique, ainsi qu'on lo remarque pour le suc d'Euphorbe. Ce suc laiteux n'est pas moins irritant, lorsqu'il est appliqné à la surface de la peau; il en détermine l'inflammation. Aussi doit-on éviter de porter la main au visage et sur les autres parties du corps où la peau est fine, et non habituellement reeouverte par les vêtemens, lorsque l'on a eueilli quelque espèee d'Eupliorbe.

Les propriétés purgatives que nous venons de signaler dans les Euphorbes, seretronvent également dans leurs gुraines. Mais il est important de remarcquer iei, d'aprés l'olservation de M. de Jussieu, que eette âcreté n'existe que dans l'embryon, ct que l'endosperme eharnu qui le revêt en tolalité, eontient an eontraire une grande rfuantité d'luile grasse el doucc. $\Lambda$ insi dans le riein, les pignons d'Inde, les graines d'épur'ge, l'action purgative réside presque exclusivencnt dans leur embryon.

Le principe délétère des Euphorbiaeces est tres-volatil et disparait asse\% facilement par la chalenr, cu sorte que lorsqu'on est parvenu à en priver les parties qui le conticnuent, ellesper- 
dent lemr action délćtére. C'est ainsi que la raciuc de manioc qui, fraîche est un vrai poison, devient, aprés quelques préparations fort simples, un aliment très-salubre.

Nous devons signaler comme une sorle d'anomalic l'odeur aromatique et agréable que l'on remarque dans quelques espèces de Croton, et specialement dans la casearille; et la saveur fade et aqueuse des espèces du genre mercuriale.

Enfin c'est un arbre de cette famille, l'Hevea Guyannensis, d'Anblet, qui fournit le Caoutchouc ou résine élastique, enıployć à la fabrieation de plusieurs instrumens de chirurgic, tels que des sondes, des bougies, des pessaires, etc. Mais cctle matic̀re existe aussi dans plusieurs autres Euphorbiaeées, et mème dans quelques espèees de figuiers, ele. 


\section{PLANTES DICOTYLÉDONEES.}

$2_{2}^{\circ}$ MONOPETALES.

SIXIÈ M CLASSE.

MONOPETALIE.ÉLEUTHÉROGYNIE.

TRRNTF-CINQUIEME FAMIIIE.

PLUMBAGINÉES. - PLUMBAGINER.

Getre petite famille se eompose seulemeńt de deux ou trois genres qui,ont entre enx une assez grande affinité, sur-tout dans la strueture de leur fruit. Leurs fleurs sont disposées en épis, en rapitules, ou en une sorte de panicule : leur calice est tubuleux et persistant: Leur eorolle est monopétale, ‘à cinq divisions, quelquefois tellement profondes qu'elle paraît polypétale(eomme dans quelques statices.) Les étamines sont au nombre de cinq, ayant souvent les filets élargis à leur base en une espèee de disque charnu et jaunâtre, sur lequel le pistil est implanté. Celui-ci présente un ovaire libre, à une seule loge contenant un senl ovule attaché au sommet d'un podosperme filiforme, qui s'élève du fond de la loge jusqu'à son sommet : les styles sont au nombre de einq, quelquefois sondés en un seul par leur base : le nombre des stigınates est égal à celui des styles ou des divisions du style. Le fruit est me capsule reeouverte par le ealice, quelquefois indéhiscente, d'autre fois s'ouvrant en un certain nombre de valves. La graine est renverséc; l'embryon est renfermé clans mo culosperme charnu.

Les Plumbaginées sont des plantes herbacées ou des 
arbustes, à feuilles alternes ou toutes radicales, souvent engaînantes à lcur base..

Observ. M. de Jussieu a placé cette faimille et les deux suivantes parmi les apétales, regardant leur calice comme un involucre et leur corolle comme un calice. Mais nous ne saurions partager l'opinion de cet illustre botaniste, et nous pensons que ces trois ordres ont infiniment plus de rapport avec les autres familles monopétales, qu'avec les apétales.

$$
\text { DENTELAIR E. - P LUMBAGO. L. J. }
$$

Calice tubuleux à cing dents; corolle infundibuliforme ou hypocratériforme à cinq divisions; cinc élamincs à filamens dilatés à la base, formant un disque annulaire autour de l'ovaire, qui est à une seule loge, contenant un seul ovule renversé et pendant au sommet d'un long podosperme filamenteux, qui part du fond de la loge et s'élève jnsqu'à son sommet. Le fruit est une capsule uniloculaire s'ouvrant en cinq valves.

Dentelaine d'europe.-Plumbago Europaca. L. Sp. 2 I 5.

Part. usitées: les fenilles, la racine. Noms pharm. : Dentarier herla et Radix. Nom vulg. : Herbe au cancer, Malherbe.

Cette plante est vivace ct présente une racinc pivolantc, blanchâtre, légèrcment rameuse; une tige dresséc, liaute d'cnviron deux pieds, ramcusc, striée; des fcuilles alternes, amplexicaules, ovales, aiguës, un peu onduleuses, rudes an toucher, offrant sur leur's bords des dentclures très-fines. Les fleur's sont violettes, rassemblées cu tête au sommet des ramifications de la tige; chacune d'elles est accompagnéc de trois ou quatre petites bractécs : le calicc est tubuleux, à cinq divisions aiguës et très-étroites, recouvert de petites glandes pédicellées : la corolle est infundibuliforme; son tube est deux fois plus long que le calice; le limbe est presque plane, à cinq lobes, ovales et obtus : les einq étamines sont saillantes audessus du tube de la corolle. L'ovaire se termine par un style quinquéfide à son sommet, đuri porte cinţ stigmates filiformes. 
La capsule est renfermée dans l'intérieur du calice, qui la reconvic en totalilé.

Ia denlelairc eroit naturellcment dans les lieux stériles des jrovinees méridionales de la Franee. Je l'ai rccueillie en Provenee, aux environs de Toulon. Elle flenrit en août ct septembre. 2

Propriétés et usages. Celte plante est d'une âcretć très-intense, surtout forsqu'elle est fraîelıe ct récentc. Sa raeinc paraîl être la prartie la plus active. On s'cn sert quelquefois comme masticatoire pour augmenter l'action des glandes salivaires. Mais c'est prineipalement dans le traitement de la grale que l'on emploie plus souvent les feuilles et la racine de dentelaire, surtout en Provence. On en fait bouillir deux à trois onees dans une livre d'huile d'olives, dont on fait ensuite des frielions sur les jarlics cxlérientes, affcclées $d u$ vice psorique. Sa racine a a ussi été répulée émétique. Mais e'est un lemède peu certain, et dont on a tolaleinent abandonné l'emploi.

- Toutcs les autres espèees du genre dentelaire jouisscnt des mèmes propriétés, c'est-à dirc qu'elles sont âeres et corrosires.

I. genrc sтатı́ qui apjartient eneore à cettc famille, et qui se distingue par sa corolle presque pentapélale, ses cinq styles distinets et sor fruit indéhiscent, diffère bcaucoup des dentelaires par ses propriétés médicales. La plupart des espèces qui le eomposen: ont une saveur astringcnte nullcment âcre, et jouissent de propriétés coniques. Aucune d'elles n'est usilée de nos jours.

TRE T T I-SIXIEM TAMIILE.

\section{NYCTAGINEES. - N YCTA GINEAE.}

Les Nyctaginées ont la tige herbacée ou ligneuse. Les ferilles opposées, souvent inégales: les fleurs axillaires ou terminales. Leur calice (involucre de Jussicu) est monosépale, à quatre ou cinq dents, plus ou moins profondes; leur corolle (calice de Jussieu) est monopétale tubuleuse, à limbe divisé : le nombre des étamines cst variable, mais il n'excède jamais dix; elles sont in- 
sérées quelquefois ì une espèce de lisque eirenlaire formé par l'épaississement et la soudure de la base de leurs filets. L'ovaire est à une seule loge, eontenant um ovile dressé : le stye est simple, terminé par un stignate capitulé. Le fruit est une coryopse renfermée dans le tube de la eorolle, dont la base est persistante. L'embryon est recourbé antour d'un endosperme eentral blane et amylaeé.

Cette famille diffère surtout de eelle qui préeède par son style et son stigmate simples; par sa graine sessile ct non portée sur un podosperme filamenteux, et par son embryon qui se roule antour de l'endosperme.

$$
\text { NYGTAGE. }-N Y C T A G O \text {. J. }
$$

Calice subcampanulé quinquéfide; corolle monopétale infundibuliforme, renflée à sa basc, qui est persistante, limbe à einq lobes; cinq étamines sondées par la base de lcurs filcts en une sortc d'urcéolc qui cnvironne l'ovaire. Le fruit est une caryopse globulcuse, reconverte par le ealice et la base de la corolle.

Nyetage Berre de nutt. - Nyctago hortensis. J. gen. pl. Mirabilis jalapa. L. Sp. 252.

Part. usitéc : la racine.

Racinc annuclle dans nos climals, tubércuse, allongéc, brunàtre.

Tige dresséc, cylindrique, glabre, rameuse, dichotome, un peu renfléc à chaque articulation, hante d'un à deux pickls.

Feuilles opposćes, pétiolécs, subcoraiformes, acuminées, molles, ciliées sur les bords, d’un vert plus foncé cu dessus.

Fleurs assez grandes de coulcur variéc, tantòt rougges, tautôt blanches on jaunes, ou enfin panachées, pédonculées, axillaires et solitares dans la partie moycnne de la lige; groupies au nombre de huit à dix à sa partic supéricure.

Claaque neur se compose d'un calice verl, partagé presque juscqu’ì sa base en cinq divisions ovales, aiguës, dressécs. 
La corolle est globuleuse à sa base, très-rétrécie au-dessus et infundibuliforme; le tube est long, grêle, et va en s'évasant insensiblement à sa partie supérieure; le limbe est un peu plane, à cinq lobes obtus, plissés et écliancrés.

Les étamines sont au nombre de cinq, plus longues que le tube de la corolle, à la base duquel elles sont soudées; leurs filcts sont grêles et déclinés; ils naissent d'un disque hypogyne qui environne lovaire et le cache en partie.

L'ovaire est simple, libre, à une seule loge, et renferme un seul ovule, attaché au fond de la loge. Le style est long, saillant hors du tube du c.alice, terminé par un stigmate simple, capitulé, formé d'un grand nombre de petites ramifications, terminées chacune par une petite glandc.

Le fruit est une caryopse, environnée et cachée par la base de la corolle, qui lui forme une enveloppe parfaitement close, et presque globuleuse, avec laquelle il finit par se souder. La graine est globuleuse; son épisperme est mince; l'embryon enveloppe l'endosperme, et le cache entièrement.

La belle de nuit, cst originaire du Pérou, où elle est vivace. On la cultive dans tous les jardins d'agrément, à causc de la variété de couleur de ses fleurs, qui ne s'épanouissent que le matin ct surtout le soir. Elle est annuelle dans notre climat.

Propriétés et usages. On a long-temps cru que c'était la racinc de cette plante qui fournissait le jalap. Mais on sait maintenant que ce médicament purgatif provient d'une espèce de liseron. La racine de belle de nuit jouit à peu près des mêmes propriétés médicales que le jalap, quoique plus faiblement. Ellc est inusitée de nos jours.

TRENTF-SEPTI它ME FAMILL :。

\section{PLANTAGINÉES. - PLANTAGINEAE.}

Dans la famille des Plantaginées, les fleur's sont hermaphroditcs, rarement unisexuées : le calice est persistant, formé de quatre divisions squammiformes; la corolle est tubuleuse, son limbe offre quatre lobes. Les étamines, an nomlire de quatre, sont dressées, attachées à 
la base du tube. Le pistil se compose d'un ovaire libre, surmonté d'un stigmate simple, subulé et poilu. Le fruit est une pyxide, ordinairement à deux loges, qui contiennent plusieurs graines. L'embryon est épispermique.

Les Plantaginées sont des plantes herbacées, dont les fleurs sont souvent disposées en épis serrés, ovoïdes ou très-allongés, portés par des pédoncules radicaux simples. Leurs feuilles sont ou toutes radicales, ou situées sur la lige.

\section{PLAN TAIN. - PLANTAGO. L.}

Les fleurs sont hermaphrodites; le caliee a' quatre divisions profondes; la corolle hypoeratériforme : l'ovaire, surmonté d'un style et d'un stigmate subulés; le fruit est une. pyxide biloeulaire, dont ehaqne loge contient une on plusieurs graines.

Pratain des sables. Plantago arenaria. D. C. fl. fr. 3 . p: 416. Bull. t.:363 (sous le nom de plant.psyllium.)

Part. nsitee : les graines. Nom vulg. : Herbe aux puces.

Sa raeine est annuelle; fusiforme, un peu rameuse. Sa tige est dressée, eylindrique, pubeșeente, rameuse, haute d'environ un pied. Ses feuilles sont opposées, sessiles très-étroites, linéaires, allongées, aiguës, pubeseentes.

Les fleurs sont trís-petites, disposées en épis eourts, trèssèrrés, ovoïdes, portés sur des pédoneules longs d'un à deux pouees, axillaires el vertieillćs, à la partie supérieure de la lige. $\Lambda$ la base de ehacun de ces épis sont quatre braetées opposées en eroix, arrondies à leur base, aeuminées au sommet. Le caliee est formé de đquatre sépales, eornme spathulés, épais et renflés à leur partie supćrienre. La eorolle est tubuleuse inférieurement; tube eylindrique de la longueur des sépales: limbe étalé à quatre divisions aiguës : elle est persistante et searieuse. Les quatre étamines sont saillantes, à filets eapillaires, a anthères biloenlaires, eourles et presque cordiformes. L'ovaire globuleux, un pen lentienlaire, est à denx loges, qui 
renferment chacune un seul ovule, attaché à la cloison. Un seul style, long, roussâtre, termine l'ovaire.

Lc fruit, très-petit, lisse, est une pyxide globuleuse, grosse environ comme un grain de millet, et renfermant deux graines, planes d'un côté, convexe de l'autre.

Cette plante est très-commune dans les lieux sablonneux de presque toute la France. $\odot$

Le Plantago psyllium L. n'en diffère que par ses épis non environnés de bractées à la base; ses feuilles un peu denticulées; et toutes ses parties moins pubescentes.

Propricétés et usages. Ce sont les graines de ces deux plantes que l'on emploie indistinctement. Elles sont émollientes et renferment une très-grande quantité de mucilage, qu'elles cèdent facilement à l'eau chaude. On en faisait autrefois des" collyres adoucissans, que l'on peut facilement remplacer avec la décoction de guimauve ou de graines de lin.

Quant au grand plantain (Plantago inajor, L.) qui est vivace, et dont toutes les feuilles sont étalées en rosette sur la terre; sa racine et ses feuilles sont légèrement astringentes. Lenr eau distillée entre quelquefois dans la composition des collyres résolutifs.

La famille des Plantaginèes ne nous offre aucune plante qui soit vénéneuse.

\section{TRENTE-HUITIEME FAMILLE.}

\section{GLOBULARIEES. - GLOBULARIE.}

Le genre globulaire, qui forme à lui seul la famille des Globulariées, établie par M. de Candolle, dans la troisième édition de la Flore française, avail été placé, par M. de Jussieu, dans la famille des Primulacées, quoique en différant beaucoup par plusieurs caractères, ainsi que ce savant l'a fait lui-même remarquer. En effet, dàns les Globulariées l'ovaire est constamment monosperme, tandis qu'il est polysperme dans les Primulacées. Dans ces dernières, les étamines sont opposées aux segmens de la corolle, tandis qu'elles sont alternes dans les Globu- 
lariées: Pir son port, cette famille a beaucoup d'analogie avec les Dipsacées, dont son ovaire libre et supère, son calice simple; la distinguent facilement. Elle a plus de rapports avec les Plumbaginées et les Nyctaginées, dont elle diffère surtout par sa graine renversée et par son fruit, qui est un akène recouvert par le calice.

\section{"1 : GLOBULAIRE. - GLOBULARIA. L. J.}

'Les fleur's sont disposées en eapitules environnés d'un involuere polyphylle : le phoranthe cst convexe, garni de pelites pailleties; chaque fleur se compose d'un calice allongé, un peu courbé, à cinq dents profondes et inégales; d'une corolle tubuleuse, dont le tube est arqué, et le limbe bilabié; la lèvre supérieure est formée dc trois lanières étroites; la lc̀vre inférieure de deux divisions plus courtes : les étamines sont saillantes, alternes avcc les segmens de la eorolle; l'ovaire se tcrmine par un style filiforme, au sommet duquel est un stigmate bifide. Le fruit est un akène renfermé et tout-à - fait clos dans liṇtérieur du ealiee, qui est persistant.

Les globilaires sont des plantes vivaces, tantôt herbacées, tantôt soufrutescentes; lcurs feuillics sont alternes, quelquefois persistántes.

Grobulane turith. Globularia alypum. L. Sp. 139 .

Part. nsitce : Les feuilles. Nom pharm.: Alypi folia.

Arbustc de deux a quatre pieds de haut, dont la tige est ligneuse, rameusé a 'rameanx dressćs, effilés, cylindriques, striés, rougéátres, un peu glauques, terminć par un capitulc de flcurs: Les feuilles sont altcrnes, obovales, lancćolées, aiguës, très-entičres , prẹsque scssiles, fermes, dressíes le long de la tigc; lics plus inférieures finissent insensiblement en un court pétiolc,

Fleurs bleucs, petites, disjosćes en capitules à l'extrémité dc chaque rameau. Ces capitules sont globuleux, scssilcs, formés d'un involucre inbriqué, dont les écailles sont brunes, scarieusés, eilicécs sur les bords. Le réccptacle ou phoranthe est convexe, spongieux intéricurement. 
Les flcurs sonl très-nombreuses $\mathrm{ct}$ très-serrées. Chacune d'elles est accompagnéce à sa basc d'une bractée un pen plus courte qu'ellc, spathulće, très-aiguẹ, chargée sur sá fáce ex tènc de poils longs et soyeur.

Le calice est monosépalc, lígèrement tubuleux', très-velu, fendue aux deux tiers de sa hauteur c̀n cinq dents sủbrilées, linéaires, aiguës.

La corolle est irrégulière, ligulée ; le tubè est un peu árqué, évasé insensiblement vers la gorgc, offrant cn devant une pelite échancrure qui sépare deux dents peu sensibles; le limbe est ligulé, allongé, roulć en dehors, fcndu au tiers de sa longueur en trois lanières étroites, obtuses. Les qualre étamines sont saillantes, dressées, ćgales, à peu près de la hauteur du limbe, inséríes au sommet du tube de la corolle.

L'ovaire est libre, ovoïde, allongé, glabie, uinloculairc, terminé par un style un peu plus çourt que les étamincs, incliné vers l'échancrure de lit corolle, grêle et filiforme, qui finit par. un stigmate fort petit, bifide.

Lu fruit cst un akène très-petit, enlouré par le calice qui le cache en entier. Il est ovoìde, jaunâtre, lisse et luisant. Le péricarpe est mince, scc et à peu près seınblable à celui . du millet.

Celte plante croît naturellement dans les provinces méridionales de la France. Je l'ai récoltée aux cnvirons de Toulon, dan's les bois rocailleux non loin de la mer.

Propriétés et usages. Les feuilles de' la Globulairc! turbith ont une saveur trc̀s-amère, légèrement àcre. Déja réputées purgatives, par. les auteurs anciens, IM. le docteur' Loiseleir Deslongchạmps a de nouvcau constatć leurs propprićtés par un grand nombre d'essais. Ce médecin ne balance pas à regarder les feuillcs de globulaire turbith comme le meilleur succédanée indigène du sćné. La dose cn est d'un gros à une dẹni-once, et mêmc unc oncc, bonillie dans huit onces d'caụ. Ce nuédicament doit être placé parmi lcs purgatives toniques. Ccpendant il est presque inusité à Paris.

On peut en dire autant des fcuilles de la globulaire vulgaire Globularia vulgaris. L., qui croît sur les pclouscs sc̀clıcs, aux environs de Paris; et qui possède à peu près les ínêmes propricités. 
SCROPHULARIEE ES. - SCROPHULARIEE.

Nous réunissons ici, à l'exemple de Robert Brown, les deux familles établies par M. de Jussieu, sous les noms de Pédiculaires et de Scrophulaires, dont les caractères distinctifs, principalement tirés de la déhiscence de la capsule, ne suffisent pas pour justifier cette séparation.

Les Scrophulariées ont le calice monosépale, persistant, ordinairement à quatre ou cinq divisions : leur corolle monopétale est toujours irrégulière : elle donne attache à deux ou quatre ćtamines didynames. L'ovaire est simple, à deux loges, terminé par un seul style, au sommet duquel se trouve un stigmate simple, bilobé. Cet ovaire est environné dans la plupart des genres par un disque hypogyne annulaire.

Le fruit est une capsule biloculaire, s'ouvrant ordinairement en deux valves, qui tantôt emportent sur le milieu de leur face interne une partie de la cloison (Pédiculaires Juss.), tantôt sont tout-à-fait nues (Scrophulaires J.); ou enfin qui s'ouvrent seulement par des pores pratiqués à la partie supérieure de chaque loge (antirrhinum, linaria). Chaque loge renferme un grand nombre de graines, attachées à un trophosperme, fixé à la partie centrale de chaque face de la cloison.

Les Scrophulariées sont des plantes herbacées, rarement soufrutescentes, dont les feuilles sont alternes ou opposées; les fleurs souvent disposées en épis. Leur tige est cylindrique ou carrée. 
$1^{\circ}$ Deux étamines fertiles.

VERONIQUE.-VERONICA. L. J.

Calice à quatré divisions proĺondes un peu inégales; cordle rotacée à quarre lobes inégaux; étamines saillanles; slyle cylindrique, terminé par un stigmale simple. Capsule biloculairc cornprimée, lenticulaire, émálginée au sommet, embrasséc par le calice persistant.

Tige herbacée, feuilles opposées, ou verticillées; fleurs axil. laires ou en épis.

Véroniqui becarunga. Veronica becabunga. I. Sp. '16. Blackw. t. 48.

Part. usitée : lesfeuilles. Nom pharm. : Becabungre herba.

Racine vivace. Tigc herbacće, charnue, rameuse, cylindrique, glabre, couchée sur la terrc, à laquellè elle s'atlache par des faisceaux de racines, partant de chacun de ses nouds. Feuilles opposées, elliptiques, obtuses, dentécs, glabres, char-. nues, inolles, finissant inférieurement en un pćtiole cour't et canaliculé.

-Fleurs violettes, courtement pédicillées, disposćes, au nombre de dix à quinze, en épis axillaires, lâchcs, portés sur des pédoncules glabres. Chaque flicur offre à sa base une bractée étroite lancéolée, un peu plus conrte que la fleur; un calicc profondément divisé en quạtre folioles qui sont ovales, aiguës, glabres; une corollc, monopélale rolacće : tube court cylindrique; limbe à quatre divisions irrćgulic̀res; trois supérieures arrondics, plus grandes, presque obluses; unc inférieure ovale , aiguë, plus étroite:

Étamincs attachécs au hant du tube de la corolle; filets subulés; anthèrcs violeltes, ovoïdes, biloculaircs.

Ovaire ovoide comprimé de derricre eridevant, biloculaire glabrc; chaque.loge renfermant un grand nombic d'ovulcs attachés à deux trophospermes saillans dans les loges. L'ovire cst parté sur un disquc hypogyne qui forme un bourclet aulour de sa base.

Style oblique cylindracć, un peu'épaissi vers son sommet, glabre, terminé par un sligmalc capilulé forl petil. 
Capsule comme didyme, éest-à-dire formée par dcux coqucs opposées, biloculaire, bivalve. Valves opposées à la cloison. Calice persistant. Graines nombreuses petites, subreniformcs.

Le Bécabunga croît dans les prairies húmides, sur'le bord des étangs et des ruisseaux. $₹$

Propriétés et usages. Cette plante est amère, un peu âere et piquante; elle est légèrement excitantc. On emploie le suc exprimé de ses feuilles fraîches comme antiscorbutique, à la manière des plantes de la famille des Crueifčres. Elle jouit arıssi d'une proprićté diurétique assez marquée.

\section{Véronique officinale. Veronica officinalis. L. Sp. 14.}

Partie usitée : les sommitès. Nom pharm. : Veronica mas. Noms vulg. : Véronique mâle, Thé d'Europe.

Racine vivace, fibreuse. Tige herbaccé, cylindrique, couchéc et diffuse, quelquefois rampantc. Feuillcs opposées, ovales, presque obtuses, dentées, molles et pubeseentes, alténuées à la base.

Fleurs disposées en épis axillaires pédoneulés; pédonculc presque de la longueur des feuilles, cylindrique, pubescent. Chaque fleur, d'une eouleur violette claire, est presque sessile, aecompagnće d'une bractée subulée.

Calice profondément quadriparti, pubescent, divisions inégुalcs ovales, allongées, aiguës, deux supérieurcs plus courtes.

Corolle rotacće; tube trc̀s-court; limbc à quatre divisions inégales; la supérieure, qui cst la plus largc, est arrondie; les deux latérales sout un pcu plus petites; l'inférieure est la plus petire. Les deux étamines sont saillantes et divergentes. L'ovairc est pubescent, eomprimé, et se change en une capsule lenticulaire émarginéc au sommet, vclue, recouvcrte par le calice.

La véronique officinale eroît abondamment dans les bois, sur lcs eotcanx. Elle fleurit en juin et juillet. 2

Propriétés et usages. Elle est un peu amère et aromatiquc. Ses feuilles, à la dosc d'une à deux pincćcs en infusion théiforıne, sont légèrement cxcitantcs. On les administrait principalemcut dans les eatarries pulmonaires chroniques. Nous me parlcrons point iei de lcur emploi daus l'ictẹrc, la gray cllc, la colique nć- 
phrétique. Il y a déjà long-tcmps qu'on les a, sous ce rapport, ensevclies dans un justc oubli.

- Plisieurs autres espcees de véroniques ont ćté employécs à peu près dans les mêmes circonstanees; telles sonı la Véronique. petit chếne (Veronica clamædrys. L.), la Véronique des prés (Véronica teucrium. L:), la Véronique en épis (Veronica spicata), qui toutes les' trois sont eommunes dans les bois aux environs de Paris.

\section{GRA'IOLE. - GRATIOLA. I. J.}

Lẹ calice est formé de cinq sépales, et aceompagné de deux bractées à sa base : la corolle est tubuleuse bilabiée; la lèvre supérieure est émarginée; la lèvre inférieure à trois divisions obtuses églaes : des quatre étamines, deux seulement sont fertiles et anthérifères : style court, terminé par un stigmale un peu oblique et eoncave.

Les gratioles sont des plantes herbacées à feuilles opposées, à fleurs axillaires, pédonculées et solitaires.

Gratiole officiname. Gratiola officinalis. L. Sp. 24. Bull. t. I3o. Orf. méd. lég. t. I.

Part. usitćes : l'herbe et la racine. Nom pharm. : Gratiola. Nom vulg. : Herbe a pauve homme.

Racine formée d'une sorle de petite souehe rampante, rameuse, émetlant des radieelles eapillaires de chacun de ses nœuds. Tige herbacée, dressée, un peu rameuse, marquée d'un sillon longitudinal, rompu à ehaque paire de feuilles. Fenilles opposécs, scssiles, deıni-embrassantes, un peu inégales, ovales lancćolées, glabres, obseurément denticulées.

Fleurs solitaires dressées, portées sur un pédoncule aplati à peu près de la longueur de la fleur, et qui offre à son sommet deux bractées laneéolées, aiguës, entières, redressćes, plus grandes que le calice, qui se compose de cinq sćpales lancẻolés, aigus, étroits, un peu inégaux; la supérieure un peu plus grande que les autres.

Corolle irrégulic̀rcment bilabiée. Tubc allongé, un peu plissé longitudinalement, quadrifide, à denx lèvres; la supérieure 
largce, légèrement échanerée, barbue à sa face interne; l'inférieıre à trois divisions égales, arrondies, très-obtuses, celle du milieu un peir redressée.

Des quatre étamines, deux sont fertiles et insérées au haut du tube; deux sont avorlćes, sous forme de filamens capillaires, un peu renflés au sommet, toutes insérées près de la partie inférieure du tube.

Ovaire simple, ovoïde, pointu, biloculaire, polysper'me. Disque hypogyne, jaune, formant un bourrelet autour de la base de l'ovairc. Style un peu oblique, cylindracé, glabre, épaissi'à son sommet. Stigmate élargi formant une espèce de petite exeavation dont l'intérieur est glanduleux, et sur monté d'une petite languette. Capsule ovoïde, glabre à deux loges polyspermes.

La gratiole croît dans les lieux humides, sur le bord des étangs, aux cnvirons de Paris. Elle fleurit en juillet. $\frac{f}{4}$

Propriétés et usciges. Cette plante a une saveur désagréable, amère, nauséabonde : elle est sans odeur, très-énergique et violemment purgative; mais employée presque exclusivement dans la médeeine populaire. Ce sont ses tiges encore chargées de feuilles et de fleurs, que l'on met ainsi en usage.

Quant à sa racine elle passe pour être émétique, à la dose de trente-six grains à un gros.

La gratiole est une plante dangereuse, que l'on ne doit mettre que rarement en usage et avec une grande circonspection. Son prineipe actif réside dans une matière amère, analogue aux résines, mais, soluble dans une grande quantité d'eau.

$2^{\circ}$ Quatre étamines didynames fertiles.

\section{SCROPHULAIRE-SCROPHULARIA. L. J.}

Caliee persistant à 'cinq lobes courts ct arrondis. Corolle' presque globuleuse, rétrécie à son sommet, à deux lèvres: la supérieure bilobée offrant à sa base internc un appendice lamelliforme : l'inférieure à trois lobes obtus, celui du milieu rabattu en dessous. Ia eapsnle cst globuleuse, tcrminéc cn 
pointe, environnée par le calice, et s'ouvre en deux valves.

La tige est earrée, les feuilles opjosées

Scrophulaine nouedse. Scrophularia nodosa L. Sp. 863.

Part. usitée : les feuilles et la racines Nom phàrm. : Scrophularia.

Raeine vivace, blanchâtre, offrant un grand nombre de nodosités. Tige dressće, carrée, rameuse, finement pubescente à angles saillans, haute d'environ deux pieds. Feuilles opposées pétiolées, eordiformes, aiguës, dentées en seie, presque glabres, d'un vert foneé.' Fleurs' petites, purpurines et verdâtres, disposées en grappe terminale, à la partie supérieure de la tige. Caliçe court, à einq lobes arrondis, presque ćgaux, persistant. Corolle monopétale irrégulière, presque globıleuse, à deux lèvres: la supérieure plus longue, plane, à deux lobes obtus, présentant à leur base interne un appendice lamelliforme : deux lobes latéraux tronqućs, un lobe inférieur arrondi rabattu en dessous, constituent la lèvre inférieure.

Les étamines sont situées ver's la base de la fleur, deux sont saillantes au dehors : les anthcres sont uniloculaires, appliqućes transversalement sur le sommet du filet.

L'ovaire est subpyriforme, assis sur un disque hypogyne qui forme autour de sa base un bourrelet cireulaire. Cet ovaire est surnonté d'un style, dont le sommet se reeourbe sur l̈e lobe moyen de la lèvre inférieure. Le stigmate est très-petit, simple.

La eapsule est globuleuse, terminée en pointe à son sommet, environnée par le calice persistant; elle offre deux loges, polyspermes, et s'ouvre naturellement en deux valves.

La scrophulaire se plaît dans les lieux ombragés des bois. Elle fleurit en juin et juillet. 4

Propriétés et usages. La serophulaire a une odeur désagréable et presque vireuse, qui a quelque analogie avec eelle du sureau. Sa savcur cst amère. Vantée pendant long - temps eoinme un remède trćs-cffieace, eette plante est peu ou point usitée aujourd'hui. On a cru ses fenilles propres à résoudre les tumeurs scrophuleuses. De lá son nom de scrophulaire. On les 
faisait également entrer dans des pommades que l’on cmployait au traitement des maladies chroniques de la peau.

Il en est de mème de la scrophulaire aquatiquc (scrophularia aquatica. L.) qui a long-temps passé pour un excellént vulnèraire.

$$
\text { DIGITALE. - DI GI TALIS. L. J. }
$$

Calice persistant à cinq divisions profondes et inégales : corolle irrégulièrement évasée, très-ouverte, à limbe oblique, offrant quatre ou cinc lobes inćgaux : style terminé par un stigmate bifide. Capsule ovoïde aeumince, s'ouvrant en deux valves.

Les digitales sont herbacćes, vivaccs; leurs feuilles sont alternes; leurs fleurs disposées en longs ćpis.

Digitale pourprée. Digitalis purpurea. L. Sp. 866. Bull. t. 2 r. Orf. méd. lég. t. 9 .

Part. usitée : les feuilles. -Nom pharm. : Digitalis. Noms vulg. Gantelée, Gants de Notre-Dame.

Cette belle plantc, qui eroît naturellement anx environs de Paris dans les bois montucux, et que l'on rencontre communémcnt dans beaucoup d'autres parties de la France, a une racine vivace ou bisannuelle, composéc d'un grand nombre de fibres brunâtres. Sa tige est simple, droite, de deux à trois pieds de hauteur; elle cst cylindrique et velue. Les feuilles radicales sont pćtiolées, ovales, aiguës, un peu onduleuses, blanchâtres et velues sur leurs denx faces. Lies fleurs, d'une couleur rouge vive sont pćdonculées, pendantes ct forment à la partie supéricurc de la tige un long épi unilatćral; chacunc d'clles est accompagnée d'une bractće, ovale, aiguë. Iıe calicc est persistant, à cing divisions profondés, ovalcs, aiguës, un peu éeartées. La corolle est irrégulic̀rcment campaniformc à cing lobes courts, inćgaux et obtus; clle est lachetéc intéricurement de pctits points noirs, garnis dc poils longs et mols. Les quatre étamincs sont plus eourtcs que la corolle. La capsule est ovoïde, acuminéc.

La digilalc pourprée fleurit vers le mois de juin. On la cul- 
live souvent dans les parterres, à canse de la bcanté de ses fleurs. "Propriétés et usages. Les fcuilles de la digitalc pourprée ont une saveur âcre, amère et désagréable. $\Lambda$ la dosc dc quelques grains, elles excitent l'action sécrétoirc des glandes salivaires, occasionnent un sentiment pćnible d'astriction dans la gorgc, et de malaise dáns l'estomac. Si cette dosc cst graduellement augmentée, il se manifeste une cxcitation générale : les mouvemens du cœur sont d'abord plus rapides et plus intenscs; la sécrétion de l'urine sensiblement angmentée; quelquefois des vomissemens ont lieu, ou les évacuations alvines deviennent plus fréquentes. Enfin si la quantité du médicament est portèe subiteınent à une dose élevée, il détermine alors tous les phénomènes de l'empoisonnement par les substanccs narcotico-âcree.

Un des effets les plus remarquables de l'administration de la digitale pourprée, c'es! l'action secondaire qu'elle exerce sur la circulation. Le pouls qui d'abord avait été accéléré par l'usage de ce médicament, finit ordinairement, chez le plus grand nombre des sujets, par devenir plus lent et moins développé, et il n'est pas rare de le voir descendre assez rapidement de soixante ou soixante - dix pulsations à quarante ct même à trente. Ce résultat, constaté par un grand nombre de pratiriens, n'a cependant pas lieu chez tous lcs sujets; il en est au contraire dont le pouls bat constamment avec plus de force et de rapidité. C'est d'après cètte action sédative de la digitale quc plusieurs auteurs en ont rccommandé l'usage dans les palpitations et les anévrysmes du cneur et des gros troncs vasculaircs.

Une des maladies conire lesquellcs on l'a cmployée avec le plus d'avanıges, c'est l'hydropisic essentielle, soit di tissu cellulaire, soit des cavilés splanchniques; l'excitation générale que cc inćdicament détermine, l'abondante sécrétion d'urine 'qu’il provoque, rendent assez bicn compte des succès que l'on a obtenus dans cette circonslance. Il n'erı est pas ainsi daus' la phthisic pulmonairc. Malgré les éloges qui lui ont ćté prodigués' par quelques auteurs, les essais de Baylc et de plusieur's médecins recommandablcs, sont loin de les a voir justifié. On a aussi eınployć la digitale avec assez de succès dans les différens syuptômes dc la maladic scropluteuse. 
Les fcuilles de digitale ponrprće s'administrent ordinairement en poudrc à la dose d'un à deux grains, dosc que l'on augmente progressivement. L'extrait aqucux est une préparation très-énergique, dont la dose est à peu près la mème que cclle de la poudre. Quant à la teinture alcnholique, sa dose cst de douze à vingt gonttes. On l'emploie quelquefois à l'extérieur pour frictionner les parties afféctées d'infiltration séreuse.

\section{EUPHRAIS E. - EUPHRASIA. L. J.}

Calice persistant quadrifide; corolle bilabiée; lèvre supérieure émarginée; lèvre inférieurc à trois lobes presque égaux; anthères rapprochées et comme soudées; capsule allongée, obtuse, comprimée, s'ouvrant en deux valves septifères par sa partie supérieure.

Feuilles alternes ou opposées; fleurs axillaires formant des épis terminaux.

Euphraise officinale. Euphrasia officinalis. L. Sp. 84x. Bull, t. 233 .

Part. usirée: toute la plante. Nom pharm.: Euphrasia.

Petite plante annuclle, dont la tige est dressée, grêlc, ramcuse, hautc de quatre à huit pouces, portant des feuilles alternes, rarement opposées, sessiles, ovales, arrondies, légèrement pubescentes, dentées sur leurs bords. Les fleurs sont purpurines, sessiles et solitaires à l'aisselle des feuilles supérieures, et formant ainsi un épi grêle; leur calice est tubůleux, à quatre dents, disposées par paires latéralement. La corolle est bilabiée; son tube est de la longueur du calice. Ia lèvre supérieure est lćgèrement bifidc; l'infćrieure est à trois lobes presque égaux; carrés et émarginés.

Les quatre ćtamines sont incluses; leurs anthères sont rapprochées et comme soudées latéralement; l'ovairc est comprimé, obtus, à dcux loges, qui contiennent plusieurs orules disposés sur deux rangées longitudinales; le slyle.est filiforme, tcrminé par un stigmate capitulé, simple; la capsule est ovoïde, comprimée, très-obtuse, recouverte par le calice, à dcux loges, 
et s'ouvrant seulement à son sommet par l'écartement des deux vinlves.

L'euphraise est eornmune sur les pelouses sèehes, dans les bois, où elle fleurit pendant les mois de juillet et d'août. -

Proprićtés et usages. La saveur de l'euphraise est amère, et son odeur légèrement aromatique. On en faisait jadis un usage très-fréquent, soit à l'intérieur, soit pour les maladies des yeux. Son eau distillée est eneore preserite quelquefois pour former des collyres, auxquels on ajoute quelque substance astringente, tels que l'extrait de saturne ou'la sulfate de zine; mais ee médicament est singulièrement déehu de la vogue 'qu'il a obtenue autrefois.

Propriétés médicales et usages des plantes de la famille des scrophularices.

Les plantes réunies dans eette famille n'offrent point une grande uniformiţé de propriétés; la plupart cependant renferment un prineipe plus ou moins âere, purgatif daus la gratiole et les différentes espèees de serophulaires, mais doué d'une énergie si grande dans la digitale pourprée, que eette plante est un véritable poison, lorsqu'on l'administre a dose un peu élevée. L'euphraise est légèrement astringente et aromalique, et ne possède point les qualités suspeetes et délétères des autres plantes de la inềue famille.

QUARANTIB M E F M I I L E.

$$
\text { A CANTHACÉE. - ACANTHACEA. }
$$

Nous observerons dans les plantés qui forment cet ordre naturel, des fleurs solitaires et axillaires ou formant des épis terminaux; chaque fleur est ordinairement accompagnée de cleux ou trois bractées, dont la forme varie singulièrement; le calice monosépale et irrégulier, présente quatre ou cinq divisions plus ou moins profondes; il est quelquefois tubuleux ou bilabié; la corolle monopétale est irrégulière, très-souvent bilabiée (la lèvre. supérieure manque quelquefois); les étamines, an nombre 
de deux ou de quatre, sont didynames, ayant les anthères à une ou à deux loges. L'ovaire est appuyé sur un disque hypogync circulaire; il présente deux logcs qui, chacune, conticnnent deıx ou un grand nombre d'ovules. Le stylc est terminé par un stigmatc trc̀s-souvent bilamellé.

Le fruit est une capsule à deux loges, rcnfcrmant deux ou un plus grand nombre de graines, portées chacunc par un podospcrme ascendant qui part de la cloison. Cctte capsule s'ouvre avec élasticitć en deux valves, qui entraînent chacune unc moitié de la cloison laquelle se détache en dcux feuillets. L'embryon est trèsgros et dépourvu d'endosperme.

Cette famille se composc d'arbustes ou de plantes herbacés, dont les feuilles sont souvent opposées, ct les fleurs axillaires. Ellc a les plus grands rapports avec les Scrophulariées, dont ellc diffèrc principalement par les bractées qui accompagnent chaque fleur; par sa corolle, presquc constamment bilabiée; par sa capsule, s'ouvrant, 'ainsi que la cloison, avec élasticité, et surtout par ses graines dépourvues d'endosperme.

\section{A CANTHE. - $A C A N T H U S$. L. J.}

Calice profondément quadriparti; divisions inégales; la supéricure très-grande el voûtée, entière, l’infćrieure un peu plus courlc, émarginée; les deux latérales beaucoup plus petites et un peu intérieures; corolle unilabiée; lèvre inférieure trilobcé ćlamines didynames, à anthćres uniloculaires; capsule bivalve et à deux loges, qui conticnnent ehacune deux graines.

Les espèces sont ordinairement herbacées, portant des feuilles opposées, élégamment et profondément découpćes ; leurs flcurs, qui formcnt un long épi tcrininal, sont chaeune aceompagnées dc trois bractécs, dont une inférieure, plus grande, est ćpineuse sur les bords. 
Agantue moree. Acanthus mollis. L. Sp. 89r. Blackw. t. 89 .

Part. usitćes: les feuilles et la racine. Nom pharm. : Acanthi folia et radix. Nom vulg. : Branc-Ursine.

Cette belle plante vivace offre une tige d'environ dcux pieds, simple, un peu anguleuse; des feuilles très-grandes presque toutes étalées en rosace à la surfacc du sol; pinnatifides, luisantes, et d'un vert foncć; leurs découpures sont très-élégamment dessinées. Les fleurs sont très-grandes, presque blanches, entièrement sessiles, et constituent un long épi, qui garnit la moitié supérieure de la tige. La corolle est unilabiée; la lèvre inférieure, qui est large et trilobće, est plus longue que les quatre étamines qui occupent la partie supérieure de la fleur. L'acanthe croît dans les provinces méridionales de la France. Je l'ai trouvé en abondance dans les ruines du château d'Hyères, en Provence: elle flcurit en juin. \&

Propriétés et usages. L'acanthc est beaucoup plus remarquable par l'élégance de ses formes, et surtout la bcauté dc scs feuilles, qui ont servi de modèle dans les ornemens du chapiteau des colonnes corinthicnnes, que par ses propriétés nuédicales. Ses feuilles et sa racine ont une saveur fadc, un peu amère. On en prépare des dćcoctions, que l'on administre surtout sous forme de lavemens adoucissans. Cetrc plante est bien rarement employće.

QUARANTE-UNIÈ ME FAMILLE.

VERBÉNACÉES. - VERBENACE AE.

Le calicc est monosépalc, tubuleux, persistant dans la plupart des genres; la corolle est irrégulic̀re, quelquefois bilabiće; les étamines, au nombrc de quatrc, sont didynames, quelquefois les dcux plus courtes avortent; l'ovaire est libre, à quatre, rarement à deux' loges, conterant chacune une seulc graine : le style est simple, terminé par un stigmate quclquefois bilobé. Le fruit esı 
une petite capsule on une baie à deux ou à quatre loges qui renferment chacune une graine.

Les Verbenacées sont des plantes herbacées ou des arbrisseaux d'un port élégant; leurs feuilles sont opposées ou verticillées : leurs fleurs forment des épis ou des grappes terminales.

Cette famille se distingue des Acanthacées par son fruit, qui ne s'ouvre point avec élasticité, et par ses loges à une seule graine; des Labiées par son fruit capsulaire ou bacciforme.

\section{VERVEINE. - VERBENA. L. J.}

Caliee tubuleux, à einq dents; eorolle tubuleuse; limbe à deux lèvres, la supérieure bilobée, l'inférieure à trois lobes; quatre étamines ineluses (rarement deux avortent); style terminé par un stigmate simple; eapsule indéhiseente, à quatre eôtes, à quatre loges monospermes.

Verveine officinale. Verbena officinalis. L. Sp. 29. Bull. t. 2 × 5 .

Part, usitée: les feuilles. Nom pharm.: Verbence folia. Noms vulgaires: Verveine, Herbe sacrée.

Raeine bisannuelle ou vivace; tige dressée, carrée, rameuse à la partie supérieure, striée, légèrement pubeseente et visqueuse, haute d'un pied à un pied et demi; feuilles opposées, les inféricures ovales, profondément ineisées, dentées, velues, rétréeies insensiblement à la base en une sorte de pétiole; les supérieures lanećolées, dentées à la base. Fleurs petites, violacées, presque blanehâtres, sessiles, alternant entre elles et formant de longs épis linéaires à la partie supérieurc des rameanx : chaeune est attaehée dans l'aisselle d'une petite braetće. I.e ealiee est tétragone, tubuleux et à cinq dents. La eorollc est. tubuleuse, bilabiée; le tube est plus long que le calice, et arqué; la lèvre supérieure est à.deux lobes obtus el égaux, l'inférieure à trois lobss également obtus et égaux. Quatre étamines trèsenurtes sont renfermćes dans l'intérieur du tube de la eorolle. 
L'ovaire est carré, tronquć au sonamct, le style court, terminé par un stigmate renflć et capitulé.

Le fruit est tétragone, tronqué au sommet, à quatre loges, renfermant chacune une seule graine, ct ne s'ouvrant pas naturellement.

La verveinc croît dans les lieux stériles, sur le bord des chemins, dans les décombres; elle fleurit en été. ₹f

Propriétés et usages. Il est peu de végétaux auxquels la superstition et la crédulité des anciens aient prêté plus de propriétés miraculeuses. $\Lambda$ utrefois employée dans l'art mystérieux des erichantemens et de la sorcellerie, long-temps en honneur chez les peuples de Rome et de la Grècc, révérée par les druides, que de titres pour accréditer le mensonge et propager l'erreur ! La verveine a long-temps ćté considérée commc l'ḥerbe à tous maux : l'ictère, l'hydropisie, la pleurésie, les ulcères, et une foule d'autres maladies n'avaient pas de remède plus efficace. Mais les modernes, réduisant à leur juste valcur les ćloges prodigués à cette plantc, l'ont reléguée parmi les substances émollientes dont l'action se borne à apportcr quelque adoucissement aux parties tourmentées d'inflammation : aussi la verveine est-elle aujourd'hui presque inusitée. Cependant lcs habitans des campagnes préparent avec ses feuilles, bouillics dans du vinaigre, des cataplasmes légèrcment irritans, qu'ils appliquenı sur lc côté douloureux dans la pleurésie. Ce moyen dérivatif est souvent assez efficace.

On a pendant.long-temps regardé le fruit du Gatrı́rer (vite $x$ agnus-castus), arbrisseau de la même famille, comme un remèdc infaillible pour émousser lcs désirs vénéricns, et pour préserver les habitans des cloîtres contré l'aiguillon de la chair. Mais la saveur chaude et aromatique de ces petites baics, dcvait certaincment produire un cffet lout contraire à celui qu'on sc proposait; aussi ce remède cst-il aujourd'hui tout-à-fail inusité.

QUARANTE-DEUXİME FAMILLE.

$$
\text { LABIEES. - LABIATAE. }
$$

Les Labiées constituent une des familles les plus naturclles et les mieux définies du règne végétal; elles 
renferment des plantes dicotylédonées, à corolle monopétale, portant les étamines et insérée sous l'ovaire.

Le calice 'est monosépale, tubuleux, à cinq divisions, quelquefois bilabié, persistant. La ccrolle monopétale irrégulière, tubıleuse, à limbe partagé en deux lèvres, l'une supérieure, l'autre inférieure. Les étamines, insérées au tube de la corolle, sont le plus souvent au nombre de quatre, deux plus grandes et deux plus petites, qui avortent quelquefois.

Le pistil se compose d'un ovaire simple, profondément quadrilobé, chaque lobe renfermant une seule graine; d'un style simple et d'un stigmate ordinairement bifide. A la base de l'ovaire on voit un bourrelet jaunâtre circulaire et saillant, formé par un disque hypogyne.

Le fruit est un tétrakène, c'est-à-dire qu'il se compose de quatre petites coques indéhiscentes, renfermant chacune une graine environnées par le calice persistant. Les graines sont épispermiquues : l'embryon a la radicule inférieure et les cotylédons planes.

Les. Labiées se distinguent très-facilement par leur port : ce sont des plantes herbacées on soufrutescentes, dont la tige est carrée, les feuilles et les rameaux opposés, les fleurs odorantes, axillaires ou verticillées.

On a partagé les genres en deux sections, suivant qu'ils présentent deux ou quatre étamines.

P R E M I Eे R E S E G T I O N.

Genres à deux étamines.

\section{ROMARIN. - ROSMARINUS. L. J.}

Calice à deux lèvres, la supérieurc comprimée, entiere, striée, l'inférieure bifide : corolle à tube renflé supérieurement, à peu près de la même longueur que le ealiec; lèvre supérieure à deux 
diqisions obtuses; l'inférieure à trois lobes, celui du milieu plus grand, concave, un peu échancrće. Étamines saillantes , filets subulés; anthères rapproehées.

\section{Romarin officinal. Rosmarinus officinalis. L. Sp. 33.} Blackw. t. 159 .

Part. usitée: les sommités fleuries ${ }^{\mathrm{I}}$.

Arbrisseau de six à huit pieds de hauteur, qui croît sur les roehers des régions maritimes; ses rameaux sont allongés, anguleux, tomenteux à l'époquc de leur premier développement.

Les feuilles sont opposées sessiles, étroites, lancéolées, obtuses, à bords entiers roulés en dessous; leur faee supérieure est glabre, l'inférieure est tomenteuse et blanehâtrc.

Ses fleurs, d'nn bleu très-pâle, sont disposées cn petits épis au sommet des jeunes ramifications de la tige.

Le ealice est à deux lc̀rres; la supérieure entière, striée, en forme de voûte; l'inférieure bifide.

La eorolle est bilabiée ; son tube est de la longueur du caliee, il offre une petite bosse à son sommet; la lèvre supérieure est bifide, ses deux divisions sont obtuses et redressées latéralement; l'inférieure est à trois lobes très-profonds, les deux latéraux sont ovales, obtus, roulés en dchors; le lobe moycn, plus grand, plus large, est arrondi, très-obtus, un peu échancré en cour à sa base et concave.

Les étamines sont au nombre de deux, plus longues quc la lèvre supéricure, redressées et infléehies, attaehées au haut $d u$ tube de la eorolle, très-rapproehées entre elles, surtout à leur parlie supérieure. Les filcts sont subulćs; les anthèrcs sont trèseomprimécs latéralement, et appliquées immédiatement l'une contre l'autre; ehacune d'elles est à unc seule loge. L'ovaire est profondément quadrilobé; lc stylc cst plus long que les étamines, subulé, et tcrminé par un stigmate simple, à pcine distinet du sommet du style. Le fruit est un tétrakc̀ne.

${ }^{x}$ Comme dans presque touies les Labiées, ce sont les sommités fleuries que l'on emploie, nous croyous inutile de le répéter pour
chacune d'elles. 
Cet arbrissean croît dans les eontrées méridionales de l'Europe, sur les bords de la Méditerranée, en Provence, etc.

Usages et propriétés. Le romarin est à juste raison placé au rang des aromatiques les plus prononcćs. On l'emploie fréquemment en fomentation à l'extérieur. On en retire une huile volatile peu usité, qui forme la base de l'eau spiritueuse connuc sous le nom d'eau de la reine de Hongrie.

\section{SAUGE. $-S A L V I A$. L. J.}

Calice tubuleux, subeampanulé, à quatrc ou einq dents, quelquefois bilabié; eorolle tubuleuse, tube dilaté et "comprimé latéralement à sa partie supérieure, plus long que le calice; lèvre supérieure comprimée, faleiforme; lèvre inférieure à trois lobes inégaux, le moyen plus grand et arrondi; étamines à filets eourts, à anthères, dont les deux loges sont éeartées l'une de l'autre par un conneetif filamentiforme placé transversalement sur le sommet du filet.

SaUGE officinatie. Salvia officinalis. L. Sp. 34. Blackw.

$$
\text { t. } 10 .
$$

Cet arbuste offre une tige quadrangulaire, pubeseente, rameuse; des feuilles opposćes, rapprochées, pubescentes, pétiolées, ovales, lancéolées, à bords denticulćs, à surface comme chagrinće, offrant souvent à sa base deux petites folioles ovales; des fleurs violaeées, disposées en une sorte d'ćpi formé de vertieilles rapprochés: chaque fleur, qui est presque sessile, est aeeompagnée d'une braetée cordiforme, aiguë, eoncave.

Calice tubulenx, strié, à cinq dents très-aiguc̈s, égales; eorolle bilabiée; lèvre supérieure plus eourte, comprimée latéralement, ćchaneréc à son somnet; lèvre inféricure à trois lobes, les deux latéraux eourts et réfléehis, le moyen très-large, lúgc̀rement ćchaneré et réfléchi. La gorge cst garnic d'une rangée de poils. Lcs deux étamincs sont incluses; leurs filets sont courts, filiformes; leur's anthères à derıx loges, séparécs par un connectif filamentiforme transversal, portant à clacunc de ses extrémitées une loge fertile.

Cetle espéce habite les provinces méridionales de la France. 
Elle fleurit en juin et juillet. On la cultive dans les jardins.

Propriétés et usages. On emploie ordinairement les feuilles et les sommités fleuries. Elles sont aromatiques, ehaudes et exeitantes. A l'intérieur on les administre en infusion théiforme; mais les modernes ont une bien mōins grande opinion de ses propriétés, que les aneiens.

Le genre sauge renferme eneore plusieurs autres espèces dont les proprićtés sont tout-à-fait analogues à eelles de la sauge offieinale. Telles sont l'orvale ou selarée (salvia sclarea L.), et la sauge des prés (salvia pratensis L.).

DEUXIEM ME SECTION.

Quatre étamines didynames.

Corolle unilabiée (la levre supérieure étant très-petite
et à peine marquée.) BUG LE. - $A J U G A$. L. J.

Caliee tubuleux, eylindrique, à einq dents : eorolle tubuleus e, renflée supérieurement; lèvre supérieure presque nulle, formée de deux petites dents; l'inférieure à trois lobes, les deux latéraux, ovales, obtus, celui du milieu plus grand et éehaneré en cour. Étamines saillantes cntre les deux dents qui
constituent la lèvre supérieure.

Bugle rampante. Ajuga reptans. L. Sp. 785 . Bull. t. 345 .

Nom pharm. : Bugula v. consolida media. Noms vulgaires: Bugle, ou petite consoude.

D'une racine vivace et fibreuse naît up e tige simple, dressée, quadrangulaire, haute de six à hui' pouees, presque glabre, émettant dè sa base un grand nombre de stolons étalés sur la terre, et s'y enracinant de distance en distanee : les feuilles sont d'une couleur bleu de eiel, garnissent la moitié supérieure de lì tige, où elles forment des verticilles rapprochiés à l'aisselle 
La bugle croit dans les bois humides et les prés, où elle fleurit dès le printemps. $\%$

Proprićtés et usages. Lorsque l'on réfléchit que la bugle est une des Labiées les moins aromatiques, on a peine à concevoir comment les aneiens ont pul lui prodiguer tant d'éloges. On l'a tour à tour employée contre l'ietère, la phthisic, les hémorrhagies, le crachement de sang, la dyssenterie, la leucorrhée, et plusieurs autres maladies très-graves; mais aujourd'hui on en a presque entièrement abandonné l'usage.

\section{GERMANDRÉE.-TE UCRIUM. L. J.}

Ce genre diffìre du précédent par la fente profonde que l'on remarque à la partie supérieure de la corolle, fente à travers laquelle les étamines sont saillantes et redressées.

Germandrée marum. Teucrium marum. L. Sp. 788.

Noms vulg.: Marum, ou Germandrée maritime.

Tige sous-frutescente, dont les rameaux sont drcssés, presque cylindriques, pulvérulens et blanchâtres, longs d'un pied et plus, grêles et effilés.

Les feuilles sont opposées, petites, ovales entières, d'un vert clair en dessus, tout-à-fait blanches en dessous, rétrécies brusquement à leur base, et formant un court pétiole.

Les fleurs sont purpurines, axillaires et solitaires a la partie supérieure des tiges; elles sont portées sur des pédoneules trèscourts.

Le caliee est tubulcux, assez large, eotonneux, à cinq dents presque ćgales.

La eorolle offre un tube redressé ; un limbe bilabić; la lèvre supérieure, à peine marquée, est profondćment fcndue, et présente deux dents saillante s ct dressćes; l'inférieure est à trois lobes, deux latéraux très-pctits, un inférieur arrondi concave.

Les quatre ćtamines sont saillantes liors de la corolle, à travers la fente qui cxiste à sa partie supéricure.

Cet arbuste cst origiuaire des eontrécs méridionales de l'Europe. Il crôtt dans lcs lieux stérilcs, aux îles d'Hyères.

Propriétés et usages. Toute la plante exlıale nue odeur très- 
agréable de citronnelle ou de mélisse. Il est peu employé, quoique assez actif. Les ehats recherchent beaucoup cette plante, et aiment à se rouler sur elle.

Germandéte Petit chêne. Teucrizum Chamcedrys. L. Sp. 790. Blackw. t. I So'.

\section{Noms vulg. : Chenette, petit chêne}

La tige est presque cylindrique, couchée, comme frutescente, articulée, pubeseente; les feuilles opposées, petites, ováles, erénelées, presque ineisées, obtuses, se terminent insensiblement à leur base en une espèce de pétiole; les fleurs sont verticillées par quatre, tournées d'un seul eôté, dressées, courtement pédoneulées, d'une eouleur rose foneée. Calice tubuleux, pubeseent, eomme à deux lèvres; la supérieure à une seule dent un peu redressée; l'inféricure à quatre dents plus petites, aiguës. Corolle unilabiée, pubescente. Tube un peu eomprimé, redressé sủitement; lèvre supérieure très-courte, profondément fendue, formant deux languettes subulćes redressées; lèvre inférieure pendante, à trois lobes, les deux latéraux fort petits, ovales, aigus, le moyen ou inférieur très-grand, dilaté et arrondi, un peu coneave.

Étamines didynames sortant, ainsi que le style, par l'échancrure de la lèvre supérieure; filets grêles, subulés, très-saillans, glabres, eoudéş au sommet; anthères ovoïdes comprimées la téralement et comme réniformes.

Le petit chêne est très-commun dans les bois, où il fleurit en juin et juillet. $₹$

Propriétés et usages. Il est très-usité, à cause du principe amer qu'il renferme en quantité beaucoup plus considérable que le prineipe aromatique, qui y est très-faible. L'infusion des sommités de petit ehêne est légèrcment tonique et stomachique; on y a souvent recours dans les scrophules, le scorbut, etc. 
Germandrér aquatique. Teucrium scordium. L. Sp. 790. Bull. t. 205.

\section{Nom vulg. : Scordium.}

Cette espèce se distingue du petit chêne par le duvet blanchâtre dont toutes ses parties sont recouvertes; par ses tiges tout-à-fait herbacées, hautes de huit à dix pouces; par ses feuilles sessiles, légc̀rement crépues et dentées; par ses flcurs pćdonculées, rougeâtres, au nombre de deux ou trois dans l'aisselle des feuilles supérieures.

Elle croît dans les lieux humides; sur le bord des ruisseaux et des étangs, aux environs de Paris. 4

Propriétés et usages. Les feuilles du scordium froissées entre les doigts, répandent une odeur aromatique un peu alliacée. Cette plante, yui ne manque pas d'une certaine ćnergie, était beaucoup plus employée autrefois qu'aujourd'hui. Comme toutes les autres Labiées elle est aromatique et stimulante. Eile entrait jadis dans une foule de préparations pharmaceutiques, entre autres dans le diascordium, auquel elle a donné son nom.

Germandrée ivette. Teucrium chamapitys. L. Sp. 787 .

\section{Nom vulg. : Irette.}

L'ivette est annuelle ; sa tige est rameuse, étalée, rougeâtre, longue de trois à cinç pouces, tétragone, poilue sur deux de ses faces qui alternent à chaque articulation.

Les feuilles sont inférieures, très-allongées comıne pétiolées, presque entières ou laciniées; les supérieures très-rapprochées, un peu poilues, à trois lobes étroits ct linéaires.

Les fleurs sont jaunes, verticillćes aux aisscllcs des feuilles supérieures.

Calice angulcux, ventru, à cinq dents, dont la supérieure ou inoyenne est très-petite, à peine visiblc. Corolle unilabiéc ; tube droit, trc̀s-renflć à sa partic inférieure; lèvrc sựérieure presque nulic, formée seulcmcnt par deux petitcs dents; l'inférieure a trois lobcs, deux latéraux ovales, allongés, obsus ; l'inférieur bcaucoup plus long, ćlargi à sa basc ct ćchancré. Etamincs didynamcs, saillantes, mais non redrcssćcs, c'est-à. 
dire suivant la direetion du ealiee et de la eorolle. Anthères uniloeulaires.

Cette espèce eroît communément dans les champs sablonıeux aux environs de Paris. Elle fleurit en juin. -

Propriétés et usages. La saveur de l'ivette est à la fois amère et aromatiqué; aussi agit-elle eomme tonique et légèrement stimulante. Son infusion chaude excite la transpiration cutanée ; de là son emploi dans la goutte, le rhumatisme, et les affeetions ehroniques de la peau.

La Germandréz museuci a ou ivette musquée (Teucrium iva. L. sp. 787 ), se distingue de la précédente par ses feuilles ovales, dentées, plus velues, et ses fleurs roses. Elle croît naturellement dans les provinees du midi de la Franee. Son odeur est plus aromatique que eelle de l'ivette ordinaire: on l'emploie dans les mêmes eirconstanees.

\section{$2^{\circ}$ Corolle manifestement bilabiée. \\ + Caliee à cinq dents, non bilabié. \\ *Étamines écartées et divergentes.}

\section{MEN THE. $-M E N T H A$. L. J.}

Calice eylindrique, à einq dents presque égales; corolle un peu plus longue que le ealice, à quatre lobes obtus presque égaux. Fleurs disposées en verticilles, très-serrées, axillaires ou en épis.

Menthe polvríe. Mentha piperita. Smith. fl. brit. 2.

$$
\text { p. } 6 \text { 工 } 3 \text {. }
$$

Tige quadrangulaire, dressée, rameuse, haule d'un à deux pieds, lćgèrement veluc, rameaux opposés, dressés. Feuilles ovales, laneéolées, aiguës, dentées en seie, un peupubeseentes, portées sur un pétiole eourt et canaliculé.

Fleurs violaeées, formant un épi court, ovoïde, très-serré à l'extrémité des rameaux. Ces fleurs, courtenıent pćdoneulécs, constitucnt des petits groupes composés d'une vinglaine de fleurs. Caliee tubuleux, presque eylindrique, régulier, à cinq dents aiguës, dont les deux supérieures uiı peı plus petites. Corolle infundibuliforme, a quatre divisions presque égales; tube 
cylindrique, évasé supćrieurement, de la longucur du calice; limbe à quarre lobes de mềne longueur, le supérieur un peu plus large, légèrement ćchancré.

Étamines didynames, écartées les unes des autres, ne dépassant pas beaucoup le tube de la corolle.

style grêle, filiforme, saillant hors de la corolle, et terminé par un stigmate bifidc.

Cctte cspèce, originaire d'Angleterre, est abondamment cultivće dans les jardins: elle fleurit à la fin de l'été. $₹$

Propriétés et usages. Sa saveur cst vive, piquante, un peu âcre, et laisse dans la bouclıe une sensation particulière de fraieheur. Son odeur est trís-aromatique el fort agréable. L'huile essentielle existe en abondance dans cette plantc. La menthe poivrée doit êtrc placée à la tête des Labićes excitantes. Elle est antispasmodique el carminative. On emploie scs sommités fleuries en infusion théiforme. On en retire une eau distillée trì́s-usitée, à la dose de trois ou quatre onces dans des potions excitantes. Son huile essentielle ne doit être administrée qu'à la dose de quatrc à cinq goultes, à cause de son extrème âcreté. On a proposé des lotions faites avce une infusion très-chargée de menthe poivrće, pour guérir la gale : ce moyen n'est pas sans cfficacité.

\section{- Menthẹ Édégante. Mentha gentilis. L. Sp. So5.}

Noms vul.: Menthe commune, baume des jardins.

La tige est dressée, rameusə, stolonifère à la base, quadrangulaire, presque glabre, liaute d'un pied.

Les feuillcs opposécs, sont pétiolées, cordiformes, aiguës, denticulécs en scie, glabres, vcrtes.

Les fleurs sont trìs-petites, disposées en ćpis, allongćs, formés de vertieillcs rapprochés à la partic supćricure des ramifications dc la tige. Le calice est strié, à cinq dcuts aiguës, allongées.

La corolle est à quatre lobcs presque égaux; le supérieur est ćchancré en cocur. Les quatrc étamincs sont incluscs et écartées les unes des autres, elles ne dépassent point la hautcur du tube de la corollc. 
Cetle menthc eroitt le long des chemins et sur le bord des champs. Elle est en fleur pendant les mois de juillet ct août. $\mathcal{F}$

Propriétés et usages. Toute la plante exhale une odeur aromatique très-agréable. Ses propriétés sont analogues à cclles de la menthe poivrće. On peut facilement lui substituer la plupart des autres espéces du même genrc, qui produiraient absolument les mêmes effetş: telles que la menthe crépue $(M$. cris$p a)$, la menthe verte ( $M$. viridis), la menthe aqualique ( $M$. aquatica), etc.

\section{HYSOPE. - H Y S SOPUS. L.J.}

Calice tubuleux, cylindriquc, à cinq dents, strié; tube de la corolle évasé, à peine dc la longueur du calice; lèvre supérieure courte et émarginée; lèvre inférieure à trois lobes; les deux latéraux petits, celui du milieu plus large et subcordiforme.

Hysoṕe officinal. Hyssopus officinalis. L. Sp. 796. Bull.

$$
\text { t. } 322 \text {. }
$$

Tige soufrutescente à la base, rameuse, à rameaux dressés, effilés, commc pulvérulens, carrés, hauts d'un pied et plus. Feuilles opposées sessiles, lancéolées, étroites, aiguës, entièrcs, un peu pulvérulentes, et garnies de petites glandes, surtout à
la face inférieure.

Les fleurs sont bleues, roses ou blanches, réunies plusieurs ensemble à l'aisselle des feuilles supérieures, toutes tournćes d'un seul côté. Le calice est tubuleux, cylindrique, un peu évasé supćrieurement, à cinq dents aiguës, un peu inégales. La corolle est tubuleuse, lc tube est grêle recourbé, dc la longueur du calice, évasé à sá partie supéricure; le limbe est bilabié; la lèvre supéricure est courte, redressée, un pen échancrée : l'infćrieure est à trois lobes, deux laléraux plus courts, entiers; celui du milieu plus grand, plus large, un pcu concave, émal'giné et subcordiforme. Lcs quatre élamines sont. ecartćes les unes des autres, et saillantcs a dehors, ainsi que lc style et lc stigruale, qui cst bificle.

L'hysope croit naturellement sur les collincs sèches des provinces inéridionales de la France; on cn formc souvent des bordures dans Ics jardins d'agrćment. Il fleurit cn juillet et aotat. $\underset{f}{f}$ 
Propriétés et usages. Les sommités d'hysope ónt unc odeur aromatique, unc saveur un peu âcre et amère. On lcs emploie spécialement dans les eatarrhes pulmonaires chroniques. L'hysope jouit même dans cette cireonstanee d'une réputation en quelque sorte populaire. L'infusion et le sirop d'hysope sont très-fréquemment employés pour faeiliter l'expectoration.

** Étamines réunies par paires.

\section{SARIETT'E. - SATUREIA. L. J.}

Caliee tubuleux, strié : corolle presque régulière, tube recourbé de la longueur du calice; lc̀vrc supćrieure redressée, plane, échancrće; l'inférieure a trois lobes, celui du milieu plus grand, un peu eoneave et émarginé.

Sariette des Jardins. Satureia hortensis. L. Sp. $79^{5}$.

Raeine annuelle : lige dressée, rameuse, à rameaux opposés, divariqués, presque cylindriques, commc pulvérulens, haute d'environ huit à douze pouces. Feuilles opposées, linéaires, laneéolées, aiguës, entièrcs, rétrécies à la base, ponctuées et glanduleuses.

Fleurs petitcs, violettes, rassemblées, au nombre de trois, à l'aisselle des fcuilles supérieures. Calice strié, à cint dents égales, profondes, très-aiguës. Tube de la corolle de la longueur du ealice, ćvasé supérieurement; lèvre supćrieure conrte, obtuse, plane, légc̀rement émarginée: lc̀vre inférieure à trois lobes obtus, cclui du milieu un peu plus grand et crcnelé.

Étamines plus eourtes que la lèvre supérieure et rapproehées sous elle.

La sarielte eroît dans les champs cultivés des provinces méridionales. On la cultive dans lcs jardins. ()

propriétés et usagres. Son odeur ct sa saveur sont à peu près les mêmes que celles du thym ordinairc. A.ussi l'cmploye-t-on plus souvent eomme ce dernicr, pour aromatiser ccrlaincs pré. parations culinaircs, qu'à titre de mćdicanıcnt. 
Sariette nes montagnes. Satureia montana. L. Sp. 794.

Tige soufrulescente à la base, rameaux dressés, effilés pubescens, presque cylindriques. Feuilles obovales, allongées, subspathulées, entières, rćtrćcies à la base, un peu acuminées au sommet. Fleur's violacées ou blanchâtres, porlées sur des pédoncules axillaires d'abord simples, puis divisés au sommet en quatrc ou cinq pédicelles, porlant ehaeun une scule fleur. Le calice est strié, tubuleux, un peu ćvasé, à cinq dents, trois redressées et deux rabattues. La corolle a un tube droit un peu comprimé latéralement, plus long que lc caliee; la lc̀vre supérieure est convexe, un peu échanérée; l'inférieure offre trois lobes obtus, eelui du milieu un peru plus grand, arrondi, presque cntier. Les étamines sont de la longueur de la lèvre supérieure, rapprochées et eachées sous eette lèvre.

La sariette des montagnes eroît dans les lieux ćlevés des provinces méridionales. Elle varie par ses fleurs, tantôt roses, tantôt cntièrement blanches. $₹$

Propriétés et usages. Son odeur est aromatique, agréable ct très-prononcée. Sa saveur est âcrc et extrêmement piquante. Elle est très-exeitante, et peut s'employer aux mêmes usages que l'hysope.

\section{CATAIRE. - NEPETA. L. J.}

Calice tubuleux à cinq dents : corolle à tube arqué, évasé supérieurement : lèvre supérieure dressée, émarginće : lèvre inférieure is trois lobes, deux latéraux courts et rabattus, celui du milieu plus grand, coneave, érénelć sur sọn bord. Étamines placéés sous la lèvre supérieure, qu'clles dépassent quelquefoís.

Cataire offrcinale. Nepeta cataria L. Sp. 797.

Racine vivace : tige herbacée, tétragone, dressće, rameuse, ferme, pubescente, haute d'un à deux pieds. Feuilles cordiformes, aiguểs, courlement pćtiolćes, crénelées, à erénelures aiguës, presque dentées, pubescentes, surtout en dessous, où elles sont blanehâtres.

Fleurs blanehâtres un peu purpurines, vertieillćes à l'ex- 
tréınité des rameaux, de wanière à former des épis terminaux. Calice tubuleux, pubescent, strié, à cinç dents aigučs, ouvertes, un peu inégales, la supérieure et les deux moycnnes plus grandes. Corolle bilabièe, tube très-ćtroit, arqué, plus court que le caliee. Limbe ouvert, à deux lčvres, la supćricure dressée à deux lobes profonds, arrondis, obtus, l'inférieure in trois divisions; les deux latérales très-petites, obtuses, réfléchies; l'infćrieure beaueoup plus grande, arrondie, coneave et crenelée sur son bord.

Étamines rapprochées sous la lèvre supérieure, qu'elles dépassent un peu.

La cataire croit dans les lieux incultes, sur le bord des chemins aux environs de Paris, où elle fleurit en juillet et a oût.

Propriétés et usages. L'odeur de cette plante est assez forte, mais peu agréable; sa saveur est un peu amère et aromatique. Son infusion est surtout employéc pour faciliter l'écouleinent des menstrues. Les chats ont une singulière prédilection pour cette plante; ils se roulent dessus avee une sorte de délices.

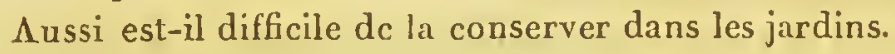

\section{LAVANDE. - LAVANDULA. L. J.}

Calice tubuleux, strié, dentć au sommet, offrant ine petite bractée arrondie, placée à sa partie supérieure. Corolle à deux lèvres: la supćrienre émargince ; l’inférieure a trois lobes obtus. Étamines renfermées dans le tube de la eorolle.

Lavañde officinale. Lavandula vera. D. G. fl. fr. éd. 3. suppl. p. 398 .

Tige soufruteseente, hautc d'environ un pied; obscurément earrée, donnant naissance à des rameaux allongés, griêles, finement pubescens, blanelâtres, carrés, foliffères inférieurement, nus à lcur partie moyenne, et florifères à leur sommcl. Feuilles opposécs, sessiles, étroitcs, lancéolées, aignüs, entières, prubescentes et blanchâtres au moment de leur dćveloppcment. Flen's violaećes, petites, verticillćes, sessiles, formant à la partie supćrieure des rameaux, des épis interrompus à lcur base. Clıaque verticille, composé d'cnviron six fleurs, cst accounpagné 
de deıx braetécs, obovales, arrondies, terminées à leur sommet par une longue pointe, striées ct prbescentes; et à la base de cliaque fleur sont une ou deux bractées extrêmement petites, linćaires. Calíe tubuleux, strié, velu, à quatre dents à peinc marqliées, avee un pctit lobe arrondi, retréci à sa base, plaeé à la partie supérieure du tube. Corolle tubuleuse, bilabiée : tube droit plus long que le calicc : lèvre supérieure obeordiforme, éclancrée, à deux lobes arrondis: lèvre inférieure à trois lobes plus petits et obtus. Étanines incluses. Le style est très-court, à peu près de la longueur du calicc, terminć par un stigmate divisé en deux lobes allongés, obtus, rapprochés l'un eontre l'autre.

La lavande est originaire des provinees méridionales de la France. On la enltive dans les jardins. $z$

L'espèee que nous venons de décrire, eonfondue jusqu'en ces derniers temps avec la lavande spie, s'en dislingue surtout par ses fenilles non spathulées, par son ealice eotonnenx, par ses bractécs ovales, etc.

Propriétés et usages. Cctte plante est extrêmement aromatique: son odcur est vive, pénétrante ct très-agréable. Sa saveur est chaude et un peu amère. C'est une des labićes les plus puissamment stimulantes. Mais cependant on l'enfploie plus souvent comme parfum que eomme médicament. C'cst de eettc plante que l'on retire l'eau spiritueuse de lavande, dont on fait souvent usage dans la toilette. Quant à l'huile essentielle d'aspic, elle est fournie par la lavande spie(Lavandula spica L.), avec laquelle la précédente a presque toujours été confondue. Cette dcrnièrc est très-commune dans les provinces méridio-
nales de la Franec.

$$
\text { GLÉCOME. - GLECOMA. L. J. }
$$

Calice eylindrique, strié : corolle à tube plus long que le caliee, ćvasć supćrieurement : lèvre supérieure bifide; lc̀vre inférienre à trois lobes; deux latćraux obtus, celui du milien plus grand et éehaneré : anthères réunies en forme de croix, 
Grícomis médénać. Glecoma hederacea. L. Sp. 807. Bull. t. 24 I.

Noms vulg. : Lierre ierrestre, Rondote, Herbe de Saint-Sean.

La tige est dressée à sa partie supérieure, rampante à sa base, simple, un peu rude et velne, haute de six à huit pouees. Les fcuilles sont opposées, pétiolées, eordiformes, arrondies, óbtuses, crénelées. Entre la base de ehaque paire de feuilles, on voit sur la tige une petite tonffe de poils, s'étendant horizontalement de l'une à l'autre.

Les flemrs sont violaećes, quelquefois roses ou même blanehâtres, légèrement pédoneulées, ari nombre de deux à trois à l'aisselle de chnque fcuille. Le ealiee est tubulenx, eylindrique, sırié longitudinalement, à einq dents très-iliģes, un peu inćgales. La corolle est bilabiée, trois fois plus longue que le ealice. Son tube va on s'évasant. La lèvre supérieure est eourte el bifide; l'inférieure plus large et plus longue, velue en dedans, est à trois lobes; les deux latéraux courts et entiers; eelni du unilieu plins large est éelraneré à son milieu. Les élamines sopnt situées sous la lèvre supérieure. Leurs anthères sont didymes et rapproelrées denx à deux, en forme de eroix. Le style est un peu plus long qúe les étamines, terminé par ur sligmate bifide.

Le lierre terrestre eroit dans les buissons, les bois ombragrís ou le long des murs. Il fleurit en avril et mai. 2 .

propriétés et usaiges. Toute la plante exhale une odenr aromatique assez agrćable. Sa saveur est un pen auère el lígìrement âere. Il est très-fréquemment usité en inf:ısion, eomme peetoral. Il eonvient plus spéeialement dans les eatarrhes pulmonaires ehroniques. Il faeilite l'expeetoration en déterminant une légère cxeitation.

\section{LAMIER. - LAMIUM. L. J.}

Calicé tubrileux à dix stries, à cinq dents inégales el trèsaiguris : tube de la eorolle plus long, évasí an sommct : lévre supéricure entière, en forme de vônle, reeouvrant les ctamines; lèvre inféricure à trois lobes, deux latéraux plus petits 
et eomme appendieulés, eelui du milieu plus grand, un peu eoncave et éehaneré.

\section{Lamier buanc. Lamizm album. L. Sp. 8og. Bull, t. 2 I 3.}

\section{Noms vulg.: Ortie blanche, Ortie morte.}

Plante vivace, dont la tige est dressée, verte; simple; icarrée, légèrement velue, ainsi que toute la plante. Elle est ereuse intérieurement et haute d'environ un pied. Les feuilles sont pétiolées, subeordiformes, aiguës, profondément dentées, à nervures saillantes à la face inférieure.

Les fleurs sont blanehes, grandes, sessiles, verticillées au nombre de quinze à seize à l'aisselle des feuilles supérieures. Le ealiee est tnbuleux; son tube va en s'évasant et offre dix stries longitudinales, il est taeheté dé noir à sa base. Son limbe est à einq dents écartées, linéaires, très-aiguës.

La eorolle offré un tube reeourbé et redressé, évasé à son sommet : la lèvre supérieure est convexe, entière, en forme de voutte, recouvrant les organes sexuels; la lèvre inférieure est à trois lobes, deux latéraux largẹs, arrondis, peu saillans, avee une petite languette étroite, eelui du milieu plus "large, arrondi, un peu eoneave, éehaneré à son sommer. Les"quatre étamines sont eaehćes sous la lèvre supérieurc. Leurs anthères sont à deux loges noirâtres, eonvertes de poils blanes, trèsćeartées a leur partie inférieure, se touehant seulement par lenr sommet. L'ovaire est profondément quadriparti. Le style est de la longueur des étamines. Il est terminé par un stigmate bifide.

Cette plante eroît abondamment dans les lieux stériles et ineultes, le long des murs, dans les déeombres. On la trouve en fleurs depuis le printemps jusqu'á la fin de l'été. $\nsucc$

Propriélés et usages. L'ortie blanche a une odeur aromatique peu agréable. Elle est légc̀rement amère. On l'a jadis reeommandée dans les serophules, la leucorrhée, ete. On employait la plante entière. Peu usitée aetuellement. 


\section{BETOINE. - BETONICA. L. J.}

Calice évasé, subcampaniforme, à cinq dents acérées: corolle à tube arqué, plus long que le calice: lèvre supéricure dresséc, obtuse, entic̀re ; l'inférieure a trois lobes, deux latéraux obtus, un inférieur plus grand, arrondi, entier on légèrement écliancré.

Bétorne officinale. Betonica officinalis. L. Sp. 8ro. Bull. t. 4 I.

Tige hcrbacée, dressée, d'un pied et plus de hauteur, simple, tćtragone, velue, ainsi que toute la plante. Feuilles opposées, les inférieures et les radicalcs longucment pétiolées, ovales, allongées, presque cordiformes, rćgulièrement crćnelées; les supérieures sónt presque scssiles, et plus étroites.

Fleurs purpnrines vcrticillées, disposées en une sorte d'épi interrompu. A la hase de chaquc verticille, qui est très-serré, se trouvent deux feuilles florales, étroites; chaque fleur est de plus accompagnée d'unépetite bractée à peu près de la hauteur du calice, très-serrée contre lui, ovale, allongće, acuminée. Le calice cst cylindrique, comme campanulé, à cinq dents acérées et presque rćgulières, glabre en dehors, poilu en dedans'ver's son orifice. La corolle est bilabiée, pubescente; le tube est allongé, cylindriquc; arqué, deux fois plus long que le calice. La lèvre supérieure est ḋressée, ovale, entière; l'inférieure est presque plane, à trois lobes, deux latéraux, arrondis et petits, un moyen plus grand, arrondi et entier. Étamines moitié plus courtes que la lèvre supćrieure qui les recouvre; filamens couverts de poils glandulcux; antlic̀res noirîtres, biloculaires. Ovaire très-profondément quadrilobé, glabre; style simple, de la longucur des étamines; stigmate bifide.

La bétoinc fleurit cn juillet ct août dans les bois, aux cnvirons de Paris, où cllc est trìs-commune. ?

Propriétés et usages. Les feuillcs de bétoine ont une odeur faible ct pcu suave, une savcur amèrc et un pcu Ácre. Réduiles eu poudre, on en faisait jadis usagc commc sternutatoires : il cn ćtait de même des fleurs, qui sont à peine odorantes. Qurant 
à la racine, cllc est faiblement émétique. L'cau distillée, la conserve, le sirop et l'emplâtre de bétoine, dont on rćservait l'usage pour les plaies de tête, sont aujonrd'hui totalement inusités.

\section{MARRUBE.-MARRUBIUM. L. J.}

Calice tubuleux cylindrique, à dix stries ct à dix dents; tube de la corolle arqué , dépassant le calice; lèvre supérieure plane, bifide; l'inférieure à trois lobes, celui du milieu ćchancré.

Marrube conmun. Marrubium vulgare. L. Sp. 8 i 6 . Bull. t. 165 .

\section{Nom vulg. : Marrube blanc.}

Une racine vivace donne naissance à des tiges dressées longues d'un à deux pieds, r'aneuses, velues et blanchâtres. Les feuilles sont pétiolées, cotonneuses, ovales, aiguës, crćnelées, crépues.

Les fleurs sont blanchcs, petites, très-serrćes, et forment des verticilles multiflores compactes, aux aisselles des feuilles, accompagnés en dehors de bractécs subulées aiguës, courtes. Le calice cst tubuleux, cylindrique, strié, offrant dix dents subulées, dont cinq alternes plus petites. La corolle est bilabiée; le tube, un peu plus long que le calice, est légc̀rement arcqué; la lèrre supéricure est dressée, plane, étroite et bifide; l'inférieure est à trois lobes inégaux, deux latéraux plus petits, ovales, obtus; celui du milieu plus grand et émarginé. Les étamines sont très-courtes, renfermées dans l'intérieur de la corolle. Le style cst également très-court, terminé par un stigmate à dcux lóbes inégaux.

Celte plante cst fort commune dans les lieux incultes, sur lc bord des routes et des fossés. Elle fleurit pendant tout l'été. Ұ Propriétés et usages. Le marrube ne manque pas d'une certaine énergic. Son odeur aromatique et comme musquée, sa saveur àcre et chaude, dénotent en lui des propriétés asse\% actives. C'est un bon stimulant, dont l'as'age peut convenir dans certains cas d'aménorrhèc et dans les calarrhes clironiques. Cette plante est un 'des nombreux ingrédiens de la thériaque; clic fait aussi partic du sirop d'armoise composé. 


\section{BALLOTE. - BALLOTA. L. J.}

Calice évasé, subcampaniforme, à cinq dents et comme à cinq faces, offrant dix stries longitudinalcs; lèvre supćrieure en forme de voûte, denticulée; lèvre inférieure à trois lobcs inégaux, celui du milieu échancré et plus grand.

Baltote noire. Ballota nigra. L. Sp. $\left(e d . x^{a}\right) 582$. Bull. t. 397 .

Noms vulg.: Marrubin, ou marrube noir.

Racine vivace; tige dressée, rameuse, carrée, pubcscente, haúlc d'un à deux pieds, rougeâtre, surtout à sa partie inférieure. Feuilles pćtiolées, ovales, subcordiformcs aiguës, crénelées, pubeseentes des dcux eôtés, un peu sinueuses et crćpues.

Fleurs purpurines disposées en un petit faisceau eourtement pédonculé, à l'aisselle dcs feuilles. Calice tubuleux subcampaniforme, évasé, à einq dents et comme à einq plis, pubescent, offrant dix stries longitudinales. Curollc bilabiéc; tubc grểle, de la longueur du calicc; lc̀vre supérieurc pctile, voûtćc, arrondie, denticulée; Jèvre inférieure à trois lobcs inégaux, le moyen échaneré. Étamines à anthères didymes, dont les loges sont.superposées. Stylc grêle, de la longucur des étamines; stigmate bifide.

Cette plante est aussi commune que la précédente, ct croit dans les mêmcs localités. $\nsucc$.

Usages et propriélés. Son odcur est moins agréable que celle du marrube blane ou commun; cependant on lcs cmploie presque indiffércmment l'une pour l'autre.

$$
\text { AGRIPAUME.- LEONURUS.L. J. }
$$

Calice à cinq dents très-aiguës et à cinq angles; corolle à lube légèerenent arqué, de la longucur du ealice; lèvre supéricure entière et dresséc, eouvcrle de poils; l'inférieure a trois lobes presque ígaux, obtus, cnlicrs : antlic̀rcs reconvertes de points blancs et brillans. 
Agripaume cardiaque. Leonurus cardiaca: L. Sp. 8 r 7. Bull. เ. 273.

Tiģe earrée, velıe, dresscée, rameuse, lıauie d'environ dcux' à trois pieds. Feuilles pétiolées, divisées en trois ou einq lobes, laciniés; elles sont molles, pubeseentes; le pétiole est eanạlieulć, pubcscent.

Fleurs purpurines, disposécs par vertieilles très-serrés aux aisselles des feuillcs. Caliec à cing angles, à cinc dents armées d'une pointe roide très-piquante; les deux inférieures sont, fortement reeourbées en bas.

Corolle bilabiée; tube gros,et ùn peu arqué; lèvre supérieure entic̀re, très-prolongée, arrondie, oblusc, en forme de voûlc couverte de longs poils blancs et soyenx; lèrre inférieure. petite, à trois lobes, deux latéraux pelits, réfléchis, l’infẹ́riçur court et obtus.

Étamines didynames, filets grểles, subulés, un peu coudćs supérieurcment; anthc̀res biloeulaires, didymcs, noirâtres, offrant des points blancs et brillans.

I a cardiaque croît dans les lieux incultes, les décombres, et fleurit en juin et juillet. $₹$

Propriétés et usages. L'odcur de ses feuilles est. asscz désatgréable. Elle a joui autr'cfois d'une grandc réputalion dans la cardialgic des cnfans; mais aujourd'hui clle est presque tout-àfait innsitće.

\section{TH Y M. - THYMUS.}

Calice tubuleux, strié, à cinq dents, trois supéricures, et deux inférieures, formant deux lèvres; gorge du calicc garnie d'un bouquet circulaire de poils qui en bouche l'cntrće; tube de la corolle de la longueur du caliee; limbe bilabié; lèvre supérieure légc̀rement échancrée; l'inférieure à trois lobes presque égaux, celui du milicu un peu plus grand et émarģiné.

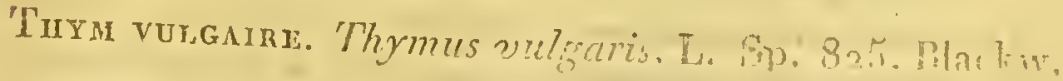


pouees, dont loules les parties sont recouvertes d'uue poussière grisâtre et enmme eendrée. Ses tiges, ligneuses à la base, herbaeées supérieurement, sont jresque eylindriques. Ses feuilles sont très-petites, ovales, laneéolées, à bords roulés en dessous, ponctuées supérieurement et blanehâtres à leur faee inférieure.

Les fleurs sont roses ou presque blanelies, pédieellées et réunies ordinairement au nombre de trois à l'aisselle des feuilles supérieures. Elles forment ainsi une sorte d'épi foliaeé au sorninet des ramifications de la tige. Le limbe du ealiee est bilabié; la lèvre supérieure a trois dents; l'inférieure a deux dents subulées; l'entrée du tube est garnie d'une rangée eireulaire de poils. La eorolle est un peu plus longue que le ealiee; la lèvre supérieure est à peine éehanerée, l'inférieure est à trois lobes égaux et obtus. Les étamines sont ineluses; le style est saillant.

Le thym eroit sur les eôteaux sees et roeailleux; on le eullive dans les jardins. $\not$

Propriétés et usages. Tout le monde eonnait l'odeur forte, pénétrante et agréable du thyın, et l'usage journalier que l'on en fait dans nos enisines pour aromatiser un grand nombre de préparations eulinaires. Mais presque jamais on ne l'emploie comme médieament, bien qu'il doive agir d'une manière fort énergique, à eause de la grande quautité d'huile essentielle qu'il eontient.

Tiny serpolete. Thymus serpillum. L. Sp. 825 .

Petite plante ćtalée, à tige sous-fruteseente à la base, rameuse, dont les rameaux sont longs de eincy à six pouces, couehés sur la terre, un pen velus, earrés, redressés dans leur yartie supérieure.

Les fenilles sont petites, opposées, ovales, obtuses, entières, rétrécies inférieurement et formant une espicee de pútiole; clles sont glabres et offrant des petits enfoneemens glauduleux à la face inférieure.

Les fleurs sont purpurines, verticillćcs, petites; les verticilles sont écartés-inférieurement, rapprocliés à lat partic supérieure, où ils forment un ćpi presque globulcux.

Le caliee est tubuleux, velu et strić inférieurement, à doux 
lèvres; la supérieure redressée, tridentée; l'inférieure à deux lents subulées plus longues; l'entrée est bouchée par une rangée eireulaire de poils blanchâtres.

La corolle offre un tube de la longueur du calice; la lèvre supérieure est evurte, un peu convexe et échanerée; l'inférieure présente trois lobes presque égaux, obtus.

Les étamines sont ineluses; le style et le stignate dépassent Ia lèvie supérieure.

Le serpollet est extrêmement eomimun dans les bois, dont il couvi'e les pelouses exposées au soleil. $\Varangle$.

Ses propriétćs sont absolumenṫ les mêmes que eelles du thym ordinaire.

\section{TI y M CAIAMent. Thymus calamintha. Scopoli. Melissa calamintha. L. Sp. 827 .}

Tige herbaeée, rameuse, dressée, tétragone, velue; feuilles cordiformcs, arrondies, pétiolées, dentées, molles et velues. Fleurs purpurines, disposées en une.petite panieule pédonculée à l'aisselle des f'euilles supérieures; ehaque fleur est elle-mêmepédicellće.

Caliee tubuleux, strié, pubescent, garni de poils intérieurement, à deux lèvres; la supérieure à trois dents redressées; l'inférieure a denx dents plus longues el subnlées. Tube de la eorolle étroit, eylindrique, renflé insensiblement. Limbe ouvert, bilabié; lèvre supéricure arrondie, échanerée, reeouvrant les organes sexuels; lèvre inférieure à trois lobes, deux latéraux, ovalcs, arrondis, obtus, eelui du milieu plus large, très-légè1 cment éehaneré.

Le ealament eroit dans les bois'aux environs de Paris.

proprićtés ct usages. Son odeur agréable a beacoup d'analogie avce celle de la mélisse; aussi l'emploie-t-on aux mêmes usages que eette plante.

$$
\text { ORIGAN. } O R I G A N U M . \text { L. J. }
$$

Calice eourt, à cinc dents, quelquefois bilabié, non garni de poils à son irtéricur; tube de la corolle plus long que le ealice. Lère supéricurc bifide; l'infírieure à trois lubes, celui du mi- 
ficu plus grand, enticr; fleurs serrées, aecompagnées elıaeune à leur basc d'une bractée ovale, souvent coloréc, formant de petits épis globuleıx, entremếlés d'écailles imbriquécs.

Origan vulgaire. Origanum vulgare. L. Sp. 824 . Bull. t. 193.

Racinc vivace, noirâtrc, presque ligneusc, rampantc. Tige obscurément quadrangulairc, dresséc, velue, rameuse à sa partic supéricure, rouggeâtre, hautc d'un pied ou environ. Fcuilles opposées, pćtiolées, velues, subcordiformes cntières, d'un vert foncé

Fleurs rosâtres disposées en petits capitules pédonculés, opposés, rapproehés cn tête à la partie supérieure des rameaux, et dont la réunion constitue une sorte de panieule serrée. Dans ces capitulcs, les fleurs sont toujours opposées et aceompagnécs à leur base d'une bractéc ovale, souven rouge, plus eourtc qu'ellcs. Lc caliee est très-court, à einq dcuts égales, non garni de poils à son intćrieur. La corolle offrc un tulse long, grêlc, cylindricue, trois fois plus long que le ealicc; la İ̀vrc supérieure cst plane, fendue; l'inférieure cst à trois lobes obtus; celui du unilieu presque rond cst plus grand. Les étamines, plus longnes que la lèvre supérieure, sont un peu écartées les unés des autres. Le style, à peu près de la mềme longueur que les ćtamincs lcs plus longucs, est tcrminé par un stigmatc bifide.

L'origan eroit dans les bois', sur les pelouscs; il fleurit en juillet et août. ł̇

Propriétés et ustges. Celte plante a unc odeur aromatique assez analogue à cclle du serpolet; sa saveur csi chaude. Il jouit des mèmes proprriétés que lcs autres labićes aromatiques. On l'emploie plus parisculičrcment à l'cxtéricur.

Origan oictame. Origamum dictamnus. L. Sp. 823 .

$$
\text { Noms vulg. : Dictaine de Créte. }
$$

Sa tige est rameuse, dressée, carrée, vcluc, haute d'environ un pied. Ses fcuilles sont opposées, périolées, ovalcs, obtuscs, arrondies, entic̀res, tomentcusés et blinchâtres sur les deux faces. 
Les fleurs sont blanches, disposées en petits épis très-serrés, pyramidaux, presque globuleux, pédonculés, opposés deux à deux et réunis plusicurs ensemble à la partic supérieure des ramifieations de la tige; ees petits épis se composent de bračtẻes foliaeées, eordiformes, arrondies, tomenteuses, disposées sur quatre rangs; à l'aisselle de eliacune de ces braetées se trouve une fleur' plus longue qu'elle. Le calice est formé d'une seule foliole 'très-obtuse, un peu roulće en cornet, évasée, pubeseentc, occupant la partie inférieure de la fleur. La corolle est bilabiée : le tube est évasé, un peu comprimé : la lèvre supérieure est courte et bifide; l'inférieure à trois lobes aigus, eelui du milieu est un peu plus grand.

- Les étamines, au nombre de quatre, saillantes hors de la corolle, sont éeartées et distantes.

Le dictame est originaire de l'île de Crète ou de Candie. On le cultive dans les jardins. $₹$

Propriétés et usages. Les poëtes et les historiens de l'antiquité ont dans leurs éerits vanté les mervcilleuses propriétés du dietame, surtout dans le traitèment des plaies oeeasionées par les javelots. et les flèehes. Mais les auteurs modernes ne font flus usage de eette plante, dont on trouve le nom inserit parmi les ingrédiens de la thériaquc, du milliridate, etc.

La Marjola1ne (Origanum marjorana. L.), que l'ou eulive fréquemment dans nos jardins à eause de l'odeur suave et pénétrante de ses fleurs, s'emploie aux nếmes usages que l'origán commun. On peut en dire autant de l'urigan de Crète, (Origanum creticum. L.), qui croit dans les provinces méridionales de la Franee.

\section{MÉLISSE. - MELISSA.}

Calice tubuleux, bilabić; lèvre supéricure à trois dents; l'inférienre à deux denıs : corolle à deux lèvres: la suppérieure en forme de voûte, éehancrée; linfúrieure à trois lohes inégaux ; eelui du milieu émarginé et cordiforne.

Ce genre diffère du thym par son calice, donl l'intérieur est nu; de l'origan, par ses fleurs non accompragnées de brictćes, ni róunies en tồte. 
Mélisse: officinale. Melissa officinalis. L. Sp. 827 . Blackw. t. 27.

La mélisse présente une tige dressée, rameuse, laaute d'un à deux pieds, poilue à ses nocuds et vers sa partie supérieure. Ses feuilles sont opposées, ovales, eordiformes, dentées, pubeseenies, courtement péliolées; ses fleurs blanches verticillées, toutes tournécs du même eôté et courtement pédoneulćes. Caliee évasé, tu. buleux, à deux lèvres très-ınarquées, la supérieure aplatie à trois clents aiguës; l'inféricure à deux dents rapprochées plus longues. Corolle bilabiée; tube grêle, eylindrique, redressé, un peu plus long que le ealice; limbe dilalé, à deux lèvres; la supérieure convexe, redresscé à son extrémité, éehancrée, oblusc; l'inférieure à trois lobes, les deux latéraux petits, ovales, obtus, l'inférieur plus grand, un peu érodé, obtus. Étañines didynames rassemblées sous la lèvre supériẹre.

La mélisse n'est pas rare dans les contrées méridionales de la Franee. Elle est eultivée dans les jardins. $₹$

Propriétés et usages. Les feuilles de mélisse, reeuellies avant l'épanouissement des fleurs, ont une odeur suave de eitron. On emploie, soit leur infusion, soit plutôt leur eau distillée, que l'on fait entrer à la dose de deux à quatre onees dans les potions ¿xeitanles. Quant à leur cau spiritueuse, connue sous les noms d'eau de mélisse ou des Carmes, il est fort rare qu'on l'adininistre intérieurement. On la fait respirer aux personnes qui tombent en défaillanee; elle fait assez souvent partie des linimens excitans.

\section{MÉLISSOT. 一 I E LITTIS. L. J.}

Caliee campanulé, évasć, eomme vésiculeux, bilabié, à trois divisions inégales : corolle très-grande, tube dilaté supérieurement: lèvre supéricure très-grande, plane, enlièze; linférieure à trois lobes obtus, celui du unilieu erénelć.

MELISSOT A FEULuES DE AluLSSL. Melitis melissophyllum.

$$
\text { I. Sp. } 8.32 \text {. }
$$

Sa racine est virace el donne naissance à une tige carré, 
dressée, haute d'un pied à un pied et demi, simple, hérissće de poils assez rudes.

Les feuilles sont opposées, pétiolées, ovales, un peu aiguës, velues, crénclées, bosselées, à nervures ramifiées et saillantes à leur face inférieure.

Les fleurs sont grandes, blanelies, un pen pédonculées, dressćes, rassemblées au nombre de deux à quatre à l'aisselle des feuilles supérieures.

Le ealiee est grand et eomme eampanulé, à trois divisions, formant deux lèvres, l'une supérieure plus grande, aiguë, quelquefois bifide; l'inférieure à deux lobes aigus, plus courts que la supérieure.

La corolle est très-grande, bilabiće : son tube est plus long et moins large qué le.caliee: son limbe est à deux lèvres : la supérieure arróndie, entière, plane : l'inférieure très-plane, à trois lobes également arrondis; celui du milieu crénelé.

Les étamines, au nombre de quatre, sont rapprocliées, plus longues que le tube de la eorolle, qu’elles dépassent.

L'ovaire est velu: le style est un peu moins long que les étamines : le stigmate est bifide.

Le mélissot eroît dans les bois ombragés, aux environs de Paris, à Meudon, Vineennes, etc. Il fleurit en mai et juin. $₹$

Propriétés et usages. Son odeur est plus forte et moins suave que celle de la unélisse, mais ses propriétés sont à pen près les inêmes.

\section{B A SILIC. - OCIMUM. I.J.}

Caliee bilabié; lèvre supérieure plane, obtuse; l'inférienre à quatre dents : eorolle semblant renversée ", à deux levves; la supérieure offraut quatre lobes obtus; l'inférienre at un seul lobe plus grand: style etétamines déclinés vers la partic inféricure de la fleur.

* Dans tontes les Labiées, les étamines sont dressées ct cachóes sous la lèvre supéricure; dans le petit nombre de cas oì les étumines sont déclinćes vers la partic inféricure de la corolle, c'est que celleci est renversée, de manière que sa lève supérienre est devenue in-
féricure. 
Basilic conmux. Ocimum basilicum. L. Sp. 833.

Lc caliec est annúcl : sa lige cst dressée, obscurémcnt tétraaiguë, pubeseentc, ramense; ses fcuilles pétiolées, cordiformes, gones, gllabres, eouvertes de points glanduleux, obscurément dentées. Pétiole canalieulé plus court quc la fcuille. Flenrs rosâtres vcrticillćes, disposćes en une sorte d'épi à l'extr'ćmité de la tige el des rameaux; chaque v.erticille; composć dẹ einq à six fleurs, est aeeompagné de dcux braetées cordiformcs, aiguës, pubeseentes, rétrćcies en pétiole. Fleurs courtcment pédonculées. Calice à cinq divisions inégalcs, pubcscentcs, disposées en deux lèvres, une supérieurc très-grande, orbiculaire, en forme de disque aplati; deux latérales ovales, aiguës, ct deux infćrieures lanećolées, très-ćtroites.

Corollc bilabiée, rcnvcrsće; tube court; limbe reuflé supérieurement, à deux lèvres : la supérieure trc̀s-large, à quatre lobes arrondis, denlieulés; les deux moyens un peu plus pelits; lèvre inférieure à un seul lobe ovale, obtus, denticulé, recouvert par les organes sexucls qui sont manifcstement dćclinés. La lèvrc inférieure est très-rétréeie à sa partie postérieure.

Le basilie est originairc des Indes Orientales, mais on lc eultive aujourd'hui dans lous les jardins, à eausc de l'odeur extrêmement suave dc ses feuilles et dc ses fleurs.

Propriétés et usages. Le basilic est, comme le thym, presque uniquement consacré à servir de condiment et d'aromalc aux préparations culinaires. Son ear distilléc est très-aromatiquc et très-suave, mais peu cmployéc.

\section{PRUNELLE. - PRUNELLA.I.J.}

Calice tubuleux, eomprimé, bilabié; lc̀vı'e supérieure planc, tronquée, tridentéc; l'inférieure bifide. Corolle à tube conrt: lìvrc supérieure concavc, obtusc, cntière; l'inféricnre à trois lobes presque égaux; eclui du inilien denticulé.

Prunele officinale. Prunclla vulgaris. L. Sp. 837. Blackw. t. 24 .

La racine, qui cst vivace, donne maissance a une tirc ra- 
- meuse, couchéc à sa base, à rameaux redressés, carrés, un peu rclus, longs de six à lunil pouces, portanl des feuilles pétiolées, ovales, subcordiformes, entières, légèrement velues : péliole long d'un pouce, canaliculé ct cilié sur ses bords.

I'lcurs violeltes, verticillées; verlicilles ordinaircment de six fleurs, très-rapprocliés les uns des autres, ct formant à la partie supérieure des ramcaux, plusienrs épis ovoüdes, très-denses, a ceompagués de deux fcuilles à lcur base. Chaque vertieille présente deux bractées très-larges, cordiformes, aiguës, striécs, rclues. Le calice cst tubuleux; comprimé, à deux lìvres. La supérieure plus largge, plane, à bords rabattus en bas, fronquéc et tridentée; l'inférieure, plus ćlroite, cst bifide. La corolle est. bilabiée: le tube de la longueur du calice: la lèvre supéricurc cst arrondie, entière ct concave : l'inférieure à trois lobes presque égaux; celui du. milieu denticulé dans son contour.

Les étamines sont cachées sous la lèvre supérieure, les filets sont subulćs, grêles, bifurciués au sommel; l'une des divisions porte l'anthère, yui est biloculaire ct didyme, l'autre cst nue.

Le style est. terminé par un stigmate profondément bifide, qui dépassc la lèvrc supérieure.

La prunelle ou brunelle est fort commune dans les bois et sur les pelouses. $₹$

Propriétés et usıges. Pcu aromatique, ct légèrement astringente, la prunelle était autrefois cmployée dans la diarrhée et ynelques autres miladies; mais elle est arjourd'lui inusitéc.

Propriétés médicules et usages des plantes de la famille des Labiées.

Ul est peu de famille dans tont le règne végétal, dont les caractères bolaniques et la physionomie particulièrc, suient plus Iranchés, et où les différens genres qui la composent, offrent une analogie plus grande que celle des Labiées. Tres-rajprochées des Antirhinées, des Verbénacées, des Solances et des Borragrinces, les Labićes se distincruent de ces trois premières familles prar leur fruit tétrakènc, ćest - àd dive à quatre. graines, tandis que dans les autres c'est unc capsule on tine baic, et des Borraginces, dout le fruit est scmblable au leur 
par leur eorolle, toujours irrćgulière, leurs'étamines, an nombre de deux on quatre, et leurs feuilles constanment opposées.

Cette analogie frappante qui existe entre les différentes plantes de la famille des Labiées se retrouve également dans les vertus dont elles sont douées. Toutes en effet sont remar'juables par leur odeur forte, pénétrante, qui leur a fait donner, et à juste raison, le nom de plantes aromatiques par exeellence. Ce principe odorant et aroınatique est dù à une hnile volatile essentielle, analogue au camphre, séerétée en abondanee par les glandes nombreuses qui existent dans presque tous les organes de ces plantes. Quelques chimistes, entre autres Cartheuser, et plus réeemment Mr. Pronst, ont pensé que, dans quelques espèees, telles que la lavande, le tlyym, la marjolaine, le romarin, ete., eette huile ćtait dn camphre; mais nous ne partageons point entièrement eette opinion. En effet, le earaetère vraiment distinetif du camphre est de pouvoir former de l'aeide eamphorique, aeide que l'on ne peut obtenir aveel'huile semi-eonerète, retirée des Labiées.

Un second prineipe existe eneore dans les plantes de eette famille : e'est une inatière gommo-résineuse qui leur donne une saveur amère, quelquefois exîêmement prononeée, eonme par exemple dans la germandrće on petit ehêne (Teucrium chamoedrys.), l'ivette, etc.

Suivant que l'un de ees deux prineipes prédomine, les proprićtés des Labiées sont différentes : si e’est l'huile essentielle, elles sont alors aromatiques, stimulantes, diffusibles, et deviennent propres à porter dans toute l'éeonomie une excitation gćnérale, une foree, et une ćnergie peu durables, à la vérité, mais qui se propagent quelquefois à tous les appareils organiques indifféremment; d'autres fois elles portent lenr aetion spéeialement sırr un appareil ou même un seul organe en partienlier. C'est ainsi qu'elles sont tour à tour emménagogues, sudorifiques, antispasmodiques, ete. Dans ee grronpe des Labiées aromatiques, se trouvent lil plupart des genres de eette nombrcuse famille, et plus partieulièrement les sauges, le. thym, le serpollet, la mćlisse, la lavande, l’origan, la sariette, le romarin, les menthes, ete. 
Si a contraire le principe aromaliquc est très-faible, landis que le principe amer estırès-dévcloppé, les proprićtés changent et les Labićes devicnnent des médieamens simplement toniques, dont l'action plus lente, moins intense, mais plus durable, se eoncentre sur l'estomac. C'est ainsi qu'agissent les différentes espèces du geure Teucrium, et surtout l'ivette ( $T$. chamepitys); le pelit chêne ( $T$. chamredrys); le scordium (T. scordium), etc.

Enfin dans un assez grand nombre de Labiées les deux principes se trouvent combinés dans des proportions à peu près égales, et leur aetion sur l'économie participe de ees deux propriétés. L'expérience a fait observer que dans ce ens ces plantes exereent une action spéeiale sur l'appareil respiratoire, auquel elles communiquent une excitation convenable. Aussi emploie-t-on souvent avee avantage l'infusion ou les autres préparations de l'hyssope, du lierre terrestre, ete. dans les catarrhes pulmonaires ehroniques, quand l'irritation a disparu, et qu'il ne reste plus qu'une toux souvent opiniâtre et fatigante, eausée par les matières muqueuses qui séjournent dans les bronehes.

En résumé, la famille des Labiées ne renferme point de plantes dangereuses : toules sont aromatiques, stimulantes, ou amères et toniqucs.

\section{QUARANTE-TROISIEMIE FAMILLE。}

\section{BORRAGINEES. - BORRAGINEA.}

Le calice est monosépale, persistant, à cinq divisions plus ou moins profondes : la corolle monopétale, le plus souvent régulière, offre quelquefois à l'orifice de son tube cinq appendices saillans et creux : les étamines sont au nombre de cinq : l'ovaire est le plus souvent profondément quadrilobé, appliqué sur tun disque hypogyne, formant un bourrelet circulaire à sa base ; le style est terminé par un stigmate simple ou bilobé : le fruit rst quelquefois une capsule ou une baie i quatre loges 
et à quatre graines; lautrefois, et le plus souvent, c'est un tétrakène.

La tige est herbacée, rarement frutescente, très-souvent roulée en crosse à sa partie supérieure et florifère; portant des feuilles alternes ordinairement couvertes de poils rudes, dont la base est rnamelonnée et persistante; de là le noin de Planta asperifolice qui leur a été donné par Linné.

ro Gorgc de la corolle garnie de cinq appendices saillans.

\section{CYNOGLOSSE. - CYNOGLOSSUM. L.J.}

Calice à cinq divisions profondes : corolle infundibuliforme; limbe concarc à cinq lobes obtus; appendices connivens et obtus : fruits hérissés dè pointes, principalement sur leurs bords.

Cynoglossẽ officinale. Cynoglossum officinale. L. Sp. r 92. Blackw. t. 249.

Racine bisannuelle pivotante : tige herbacee, dressée, velue, très-rameuse et paniculće à sa partie supérieure, haute d'environ deux pieds, striée longitudinalement. Feniiïss caulinaires, sessiles, alterncs, ovalcs, lancéolées, aiguës, entièrcs, mulles et velues, surtout à la parlie inférieurc : lcs radicales, beaucoup plus grandes et plus larges, se terminent à leur base en un péliole long de plusieurs pouces.

Lcs fleurs assez petites, de couleur rouge on violetle foncée, forment à la partie supéricurc des ramcaux, des épis allongćs, un peu roulés en crosse à leur sommet : ces fleurs sont portées sur des pédoncules d'un demi-pouce de longueur, se recourbant antour de la tigc pour se diriger tous du mềnc côté.

Le calicc est persistant, partagé en cinq divisions très-profondes, ovales, allongécs, velues en delıors.

la corolle cst monopétalc régulière, courte, infundibuliforme, dc la longueur du calice. Son limbe est concave, à cinq divisions très-obtuses; l'orifice du lube cst fcrmé par cinq̨ petits cornets, veloutés, obtus, creux à l'intérieul.

Les itamines, an nombrc de cinq, sont alterncs arec les 
appendices du tube, plus courtes qu'eux, et renfermées dans l'intérieur du tube.

L'ovaire est déprimé à quatrc côtes très-saillantes et arrondies, séparées par des enfoncemens très-profonds; il est tout couvert de poils glanduleux, et présente quatre loges renfermant chacune un seul ovule.

Le style est court et aminci en pointe à son sommet, que termine un stigmate très-petit, qui en est à peine distinct.

Le fruit est un tétrakìne aplati, hérissé de poils rudes et blanchâtres, terminć à son milieu par le style persistant.

La cynoglosse croît dans les lieux secs et sablonneux, dans les bois, aux environs de Paris.

Propriétés et usages. Toutes les parties de cette plante exhalent une odeur désagréable. Ses feuillcs cuites dans l'eau et sous forme de cataplasme sont émollientes et anodines. Son extrait entre dans les pilules de cynoglosse, dont toutes les propriétćs dépendent de l'opium, qui s'y' trouve en quantité assez considérable.

\section{BOURRACHE. - BORRAGO. L. J.}

Calice étalé à cinq divisions profondes. Corolle cn roue, ì einq lanières étroites et aiguës; appendices obtus, échancrés glabres : filamens des étamines surmontés d'une corne, située en dehors de l'anthère.

Bourrache officinale. Borrago officinalis L. Sp. rog. Blackw. t. 36 .

Part. usitée : les feuilles et les fleurs. Nom pharm. : Borraginis herba, flores.

La bourrache est une plante bisannuelle, dont la racine est allongée, noirâtre à l'extćrieur, blanche en dedans; la tigc herbacée, cylindriquc, simple inférieurement, rameuse à sa partic supérieure, charnue, dressće, couvcrte de poils très-rudes. Les feuilles radicales sont ćtalées, très-grandes, ovales, obtuscs, sinueuses sur les bords, retrécies en un long pétiole ailć, canaliculć, dilaté vers sa partie infćrieure. Les caulinaires sont sessiles, légc̀rement décurrentes, ovales, lancéolées. 
„Flcurs blenes, lisposées cu panieule lâche à l'extrémité des ramcaux : cliacune d'clles, porlée sur nn pédpncule long d'environ 111 pouce, est rúfléchic. Calice monosépale, très-profondénent quinquéfide, étalé, divisions linéaires, aignës, à unc scule nervure, glabres en dedans. Corolle rotacée, étaléc. Tube presque nul; limbe profondément quinquéparti; divisions lancéolécs, très-aiguës, offrant chacme à leur base un appendice sacciforme saillant, bifide, un peu soyeux en dedans; élamines attachées à la gorge de la corolle, saillantes, dressées, rapprochées les unes contre les autres, de manière à former une espèce de cône aigu. Filets épaissis à leur partie inférieure; leur sommet, comme tronqué, présenteà sa partic externe un appendice linguiforme bleu, dressé, atteignant le milicu de la hauteuṛ de l'ạnthère.

On rencontre fréquemment la bourrache dans les lieux cultivés. Elle fleurit pendant les mois de mai et de juin.

Propriétés et usages: La bourrache est très-acpucuse. Elle contient une petite quantité de nitrate de potasse. La décoction de ses feuilles est une de ces Loissons dont on prescrit frćquemment l'usage, peut-être par cela même quć sọn action ne se fait que faiblement sentir. Ainsi dans le, eatarrlıe pulmonaire peu intense, dans les maladies de la peau, on fait souvent usage déla bourrache. Sa décoction cst mucilaginense, lćgèrement diurétique et diaphorétique. Quant aux fleurs, elles sont insipides; leur infusion est adoucissante.

$$
\text { CONSOUDE: }-S Y M P H Y T U M \text {. L. J. }
$$

Calice à einq divisions profondes : corolle tubuleusc un peu renfléc a la pártie supériéurc, à cinq lobes courts et rapprochés; appendices lancéolés, aigñs, glandulcux.

Consoude orficinale. Symphytum officinale. L. Sp. i $9^{5}$. Part. usițée : la racine et les feuilles. Nom pluarm. : Consolidu major. Nom vulg. : Grande consoude.

- Racine vivace très-allongée, jeu rameuse, d'mn brun-noirâtre à l'extérieur, très-blanche intérieurement, d'nne sareu. l'abcrd fade et mueilagincuse, puis faiblement astringente. Tige herbacic, cliarme, anguleuse, dressée, courerte de 
poils rudes, ailée jar le prolongement des feuilles, qui sont. aliernes, ovales, lancćolćes, aiguës, un peu ondées sur leur's bords, décurrentes sur la tige à lcur base.'

Fleur's blanches ou un pcu purpurines, disposées par épis géminés à l'extrúmité des rameanx; ces épis sont recourbés en volute. Leur calice est profondément quinquéparti, à divisions étroites, lancéolées, dressées, plus courtes que le tube de la corolle; celle-ei est tubuleuse, infundibuliforme; lube gros, cylindracé, offrant à sa partie supérieure et externe cinq fentes qui sont les orifices des einq appendices de là gorge. Le limbe est ur'éolé, à einq dents réfléchies. La gorge offre einq appendices aplatis, lanérolés, gllanduleux sur leurs bords, 'I alternes avec les étamines.

La grande consoude est fort commune dans les prairies humides, sur le bord des mares et des ruisseaux, aux environs de Paris. Elle fleurit en mai et juin. $\&$

Propriétés et usages. C'est principalement la racine dont on prescrit l'usage : sat saveur est un peu astringente, mais surtoul très-inucilagineuse. On l'emploie assez souvent en décoction dans la diarrhée, le crachement de sang, les eatarrhes pulmonaires. C'est un médicament adoucissant, dont la propriéte astringente est trop faible et trop masquée par le mucilage pour pouvoir produire quelque effet..On prépare encore un sirol' de grande consoude que l'on emploie dans les mêmes circons. tances. Les feuilles de cette plante possèdent les inênies jur priétés qué eclles de la bourrache.

\section{BUGLOSSE. - $A N C H U S A$. L. J.}

Caliee à einq divisions profondes et dressées : corolle hypocratériforme; limbe presque plane à einq lobes arrondis : appendices obtus, souvent velus; stigmate bilobś.

Bugrosse officinalx. Ancluesa italica: D. C. A. fi. 3. p. 63 r.

11 parail que nous né possédons pas cu France lat vraie buglosse oflieinale décrite par Linné, qui est continće dans les. régions septentrionales de l'Turope. 
Notre espèce s'élc̀ve jusqu'à environ trois pieds; sa lige est. drcssée, très-rameuse, cylindrique, convertc de poils longs et très-rudes, ainsi que les autres parties herbacées de la plante, et porte des feuilles alternes, ovales, très-aiguës, entières, rudes au touchcr, un peu ondées sur leurs bords.

Les fleurs sont bleues, disposées en une sorte de panicule lâche à l'extrćmitć des rameaux. Leur calice est allongé, à cinq divisions profondes, linćaires, lancéolées, très-aiguc̈s, dressées.. La corolle hypocratériforme a le tube cylindrique, de la hauteur du calice; le limbe plane quinquéparti a divisions ovales très-obtuses, égales entre elles; la gorge de la corolle cst garnie de cinq appendices creux, rapprochés, bleuâtres, couverts de poils blancs, rapprochés de manièrc à cacher tout-à-fait les étamines.

La buglosse n'est pas rare dans les champs aux cnvirons de Paris, où elle fleurit au mois de juin.

Ses usages ct ses propriétés sont absolument les mêmes que ceux de la bourrache.

$2^{\circ}$ Gorge de la corolle nue, sans appendices.

\section{PULMON AIRE. - $P U L M O N A R I A$. I. J.}

Calice subcampanulé, pentagone, à cinc dents profondes; corolle hypocratériforme, à cinq lobes obtus, un peu redressés; stignate bilobé.

Polmonatre officinale. Pulmonaria officinalis. L. Sp.
r94.

Racine vivace allongée; tige dressée, presque simple, un peu charnue et épaisse, couverte de poils rudes, ainsi que les feuillcs; ccllcs qui naissent de la racine sont allongées, subcordiformes, rétrécies à la base cn un pétiole fort long; elles sont souvcnt maculées de taches blanchics; celles de la tige sont. sessiles, lancćolćcs, aiguës, un pcu décurrentes sur la tige. Les fleurs, dc couleur bleuc, guuelquefois rougeâtres, forment une sorte de corymbe à la partie supćrieurc de la tigc. Leur calice est monosépale, campanulé, à cinq angles et à cinq dents; leur corollc'est monopétale hypocratériforme; son tube est de las longueur du calicc; son limbe est campanulé à cinq lobes 
obtus; la gorge de la corolle est garnie d'une rangée circulaire de poils blanes et glanduleux. Lcs cind ćtamines ne dépassent pas le tubc de la corolle.

La pulmonaire est rrc̀s-commune dans les bois, où ellé fleurit dès les mois de mars et d'avril. 4

Propriétés et usages. Cette plante peuts'employer aux mêmes usages et dc la mème manière que la bourrache.

Propriétés et usages des plantes de la famille des Borraginées.

Les plantes de la famille des borraginées ue possèdent point les vertus bien prononeées: si elles' ne fournissent point de médicamens très-énergiques, aueune d'elles nc reè̉le de propriétés qui puissent rendre leur administration funeste.

On trouve daus toutes les borraginées une grande quantité de mueilage, assez souvent associé à une petite proportion d'un principe astringent ou amer, que l'on regarde comme narcotique. Ainsi la raeine de grande consoude (symphytuin officinale), est légèrement astringente et très-mucilaginense; la cynoglosse, au contrairc, paraît recéler un prineipe nareotique, mais peu abondant.

D'in autre côté la bourrache, la buglosse, la pulmonaire, sont très-mucilagineuses, adoucissantes et légèrement diaphorétiques. La bourrache agit de plus comme diurétique, à causé d'une cerlaine quantilé de nitrate dc potasse tout formé qu'clle r'eñferme, sel dont on soupçonne également l'existence dans la buglosse, qui décrépite légèrement quand on la brûle.

L'ćcorce de la racine de plusieurs borraginćes fournit une belle couleur rose; telles sont l'anchusa tinetoria, l'onosma echioïdes, le lithospermum tinctorium, D. C., et l'echium rubrum, dont les racines sont mêléęs et confondues dans le eommerce sous le nom d'oreanette. L'eau et l'alcohol se.chirgent ćgalement du prineipe colorant de l'orcanette.

Les fruils conuus sous le nom 'de sćbestes sont produits par nn arbrc de la famille des borraginćes appelé cordicu mixa.. Ces fruits, qui sont charnus et suerés, étaient mélangés avec les autres fruits béehiques, tels quc lcs jujubes et les dattes. Ils sont cutièrement inusités de nos jonrs. 
QUARA NTE-QUATRIEMETAMILLI.

\section{CONVOLVULACEES. - CONVOLVULACEAE.}

Nous distinguerons les Convolvulaeées ì leur ealice persistant, offrant einq divisions profondes; à leur corolle monopétale régulière, dont le limbe est entier ou à cinq lobes et donne attaehe à einq étamines; à leur ovaire libre, à deux ou à quatre loges, eontenant un petit nombre d'oviules dressés; à leur style simple ou partagé en plusieurs divisions, qui portent chaeune un stigmate. Le fruit est une eapsule recouverte par le ealice, à deux ou à quatre loges, restant quelquefois indéhiscentes. Les graines renferment un embryon, eontenu dans un endosperme charnu, et dont les deux cotylédons sont planes et plissés en différens sens.

Les plantes réunies dans la famillo des Convolvulacées sont herbacées ou soufruteseentes; leurs tiges sont grêles et volubiles; leurs feuilles sont alternes, dépourvues de stipules. Leurs fleurs sont axillaires ou terminales.

Cette famille est très-distincte des borraginées par son fruit capsulaire et la strueture de son' embryou.

$$
\text { LISERON. - CONVOLVULUS. L.J. }
$$

Caliec persistant, à cinq divisions profondes ; corollc canpanulée ou infundibuliforme, à limbc plissé; ovaire surmontí l'un style que tcrmine un stigmate bilobé. Le fruit cst une (aipsule globulcusc, mince, ordinairement à quatre loges, donı r.hacanc contient une ou deux graincs attaeliées au bas de lit rloison.

Toulcs les espèces sont herbaeécs; leur raciuc esl souvent tubéreuse et charnue; leur tigc volubilc. 
Liseron jatap. Convolvulus jalapa. L. Desfontaines An. Mus. p. 126. vol. 3. t. 40 et 41. Jpomcea macrorkiza. Mich. fl. bor. am. x. p. х4

Part. usitées: la racine. Nom pharmac. : Jalapae radix. Nom vulg. : Jalap.

Racine fusiforme, arrondie, blanche, charnue, laeteseente, dlonnant naissance à plusieurs tiges herbacées, sarmenteuscs, striées, lle la grosseur d'une plume à ćcrire, parsemées de petits tubercules, s'élevant à une hautcur dc quinze à vingt. pieds en s'entortillant autour des corps qu'elles reneontrent. Les feuilles sont alternes, pétiolćes, subeordiformes, aiguës, entières, quelquefois divisées en deux, trois ou einq lobes, glabres en dessus, velues inféricurement.

Lcs fleurs sont pédoneulćes, solitaires et axillaircs, violnećes; Icur calice est persistant, à einq divisions profondes ct un peu inégales. Leur corolle est subinfundibuliforme, régulic̀re; le tubc est eylindrique; le limbe est évasć et subcampaniforme; les cinq étamines sont rapprochćes, et nc dépassent pas le tube de la corolle. Le style est filiforme, d'une longueur égale à cclle des étamines, terminć par un stigmatc bilobé. La capsulc cst ovoïde, arrondie, minee, de la grosscur d'une noisettc, enveloppéc par le calice; ordinairement à quatre loges, contenant ehaeune une ou deux graines triangulaires, recouvertes de longs poils soyeux.

Cette plante croît prineipalement au Mexique et dans d'autres parties de l'Amérique méridionale, et jusque dans l’Amérique septentrionalc; car il est ecrtain que la plante mentionnće par Michaux sous le nom d'ipomaa macrorhiza est bien la mềnc que celle qui a été depuis déerite et figurćc par M. Desfonraincs. $z$

Proprićtés et usages du jalip. Telle qu'elle nous cst apportée (lu nouveau Monde par la voic du commeree, la raeine de jalap) est en morccaux hémisphlhériques ou en rouelics d'environ deux a trois pouces de diamètre; sa surface externe est brunc; son intéricur est moins foncé, marqué de zones ou lignes concentriques; sa cassure présente quelcques points lorillans. Son odeur est nauséabonde; sa saveru âcere el très-irrilante. Pri. Félix 
Cadet dc Gassicourt, ì qui l'on doit une dissertation fort intéressante sur le jalap, a trouvć que sur 500 parties on obtenait: résine, 50 ; eau, 24; cxtrait gommeux, 220 ; fécule, 12,5 ; albuinine, I2,5; phosph. de chaux, 4 ; muriate, de potassc, 8,1 ; s. carbon. de potasse, 2 ; s. carbon. de chaux, 2 ; carbon. de fer , $0, x$; silice, 2,7 ; perte, I 7. La partie la plus active du jalal' est sans contredit la résine, qui forme environ la dixième partie de son poids. Aussi est-il plus avantageux d'administrer cctte subsłance isolće des autres principes constituans de la racine de jalap.

Lc jalap est un mćdieament puissamment purgatif, qui, adininistré à une dose un peu élevée, pcut déterminer des superpurgations violentes, l'inflammation des intestins, et d'autres accidens trćs-graves. Son usage convient surtout aux individus chez lesquels prćdomine le système lymphatique, et à ceux dont la susceptibilité ncrveuse est presque nulle. Ainsi plusieurs praticiens ont remarqué ses bous effets dans l'hydropisie ascite esscntielle, dans les scrophules, et pour combattrc les vers intestinaux. On doit s'en abstenir lorsqu'il y a fièvre ou irritation violente dans quelque organe. La dose du jalap en poudre est d'environ trente à quarante grains pour un adulte. Il est presque toujours préférablc d'employer la résine; cette substance, toujours identique, n'est point sujette à varier dans son mode d'action. Sa dosc est de quatre à huit grains convenablement étendus dans un véhicule approprić.

\section{Liseron Scammonée. Convolvulus scammonia. L. Sp.}

Part. usitce: la gornme résine. Nom pharn.: Scammonium. Ncm vulg. : Scammonce.

Cette plante est vivace; sa racinc est allongée, ćpaisse, charnue, lactescente, produisant des tiges grêles, volubiles, un peu velucs, s'élevant à quatrc ou cinq pieds. I,cs fenillessont alterncs, pétiolées, hastćcs, aiguës, glabres ct entic̀es; les flcurs sont rougeâtres, plus pelilcs que dans l'cspc̀ce précédente; portćes, au nombrc de trois à six, sur lcs ramifications d'un pédoncule axillairc, plus long que les feuilles : les divisions du calice sont glabres, obtuses, souvent ćchancrécs et persistantes. 
On trouve ce liseron dans plusieurs contrées de l'Orient, en Syrie, etc. $\Varangle$

Propriétés et usages de la scammonée. On rencontre dans le commerce deux espèces de scanmonće, désignćcs sous les noms de scammonée d'A lep et de scammonée de Smyrne. La première, qui est la plus estimée, se retirc du liseron que nous venons de décrire. Pour l'obtenir on découvre la partie supérieure dc ses racines, on y pratique des incisions par lesquelles s'écoule un suc blanchâtre, que l'on reçoit dans de pctites coquilles où il se concrète. C'est de cette espèce seulement que nous parlerons ici. La seconde ou la scammonée de Smyrne parait provenir da periploca secamone, de la famille des apocinées.

La scammonée d'Alep est en morceaux pcu volumineux, d'un gris foncé, à cassure brillante et opaque, assez friable, d'une odeur forte et peu agréable. MM. Bonillon-Lagrange et Vogel l'ont trouvće composéc : de résine, 6o; gomme, 3 ; extrait, 2 ; débris de vćgétaux ct substances terreuses, 35. La quantité respective dc ces matériaux présente quelques variations, suivant la qualité et le choix de la substance analysće, ct suivant les racines dont on l'a retirée.

Cette gomme résine, qu'on appellc encore diagrède, est un purgatif drastique très-violent, qui ne convient qu'aux personnes fortes ou très-lymphatiqnes. Elle agit absolument de la même manic̀re que la rćsine dc jalap, et s'emploie dans les mềnes circonstances. Sa dose est dc cinq à dix ou quinze grains pour un adulte. Elle fait partie d'un grand nombre de préparations officinales, ct entre particulièremcnt dans les différentes pilules hydragogues. Pour faciliter son administration. et adoucir son action, on lui associe différentes substances mucilagineuscs ou sucrćes.

Outre les deux espćces dont nous venons de donuer la description, le genre liseron en renfermc encore plusicurs autres dignes d'être ici mentionnées. Ainsi la racine connue, dansles anciennes pharmacopécs, sous la dénomination de turbith est celle du convolvulus turpcthum L., qui croît aux Indes oricntales, à Ceylan, Java, etc. Cettc racine est en morceaux longs dc quatrc à cinq jooxces, d'cnviron un pouce d.c diamctre, dont on a quelquefois retirć la partie ccntrale; cllc est d'un 
gris-brunàtre à l'extérieur, blanche en dedans; son odeur est faible; sa saveur est nausćabonde. C'est un violent purgatif , mais innsité actuellement.

Il en est de mème du mechoacan, raeine du conwolvulus merhoacan $\mathrm{L}$., qui vient du. Mexique et de quelques autres eontrées du nouveau Monde, d'où on nous l'apporte sous forme de tranehes plus ou moins épaisses, blanehes, et eomme amilaećes, d'une saveur peu prononcée d'abord, mais qui devicnt ácrc. Il est également purgatif, mais plus faiblement que le préećdent.

La propriété purgative que nous venons de signalcr dans la racine des liserons exotiques existe également dans ceux qui croisseit naturellement dans nos climats, et surtout dans les espèees vivaees dont les raeines sont épaisses et charnues. $\Lambda$ irsi les raeines du liseron dẹs haies (convolvulus sepium. L.), du liseron soldanelle (convolvulus soldanella. L.), du liseron à feuilles de guimauve (convolvulus althaoödes. L.), jouissent, quoiqu’à un degré moins énergique, des proprićtés du jalap, de la seammouće, du turbith, ete.

Quoique le genre liseron soit un de eeux dans lequel les propriétés médieales des diverses espèees offrent la ressemblance la plus frappante, il faut eependant eonvenir que quelquesunes d'eintre elles's'en éloignent siugulièrement, el forment une. exception bien digne d'ètre remarqueée. Ainsi tandis que la majeure partie des esjèees ont dcs raeincs violemment prirgalives, nous trouvons dans eellcs de la patate (convolvalus balatas), dans celles du consolvulus edulis un aliment aussi sain qu'igréable. Dans ces deux espèees le principc résineux csl presquc uul, et. l'abondanee de la fécule amilaeée, qui compose lcurs raeines, les rend extrêmement nourrissantes.

Cetle exception cst loin de détruire l'extrême analogic offerte jar les plantes de la famille des convolvulaeées, considérćcs sous le rapport de leurs propriétés médicales. 'Toutes ces plantes peuvent être considérées comme âcres et purgatives, et leurs propriélés doivent ćtre attribuées au principe résineux qu'clles renferment. 
QUARANTE-CINQUIÉME FAMILLE.

SOLANEES. - SOLANEA.

La famille des Solanées se distingue par un caliee monosépale ordinairentent persistant, à eing divisions plus ou moins profondes; une corolle monopétale presque toujours régulière, rotaeée, infundibuliforme ou campaniforme, dont le limbe est à einq divisions; par ses einq étamines insérées à la eorolle; et son ovaire simple ì deux loges, pluriovulées, entouré à sa base d'un disque hypogyne jaunâtre. Le style est sinıple terminé par ıın stigmate çapitulé, le plus souvent bilobé.

Le fruit est tantôt une eapsule biloculaire bivalve, (rarenıent quadriloculaire, quadrivalve.(stramoinc)) septieide, ayant la cloison parallèle aux valves; tantôt une espèee de baie à deux loges, ou paraissant quelquefois à un grand nombre de loges, à eause de la saillie formée dans l'intérieur des loges par le trophosperne. Les graines, dont la surfaee est ordinairement rugueuse et chagrinée, renferment, daus l'intérieur d'un endosperme eharnu,'un embryon plus ou moins courbé ou roulé sur lui-même.

Les Solanées sont ordinairement des plantes annuelles ou.vivaees; quelquefois des arbustes ou des arbrisseaux d'un aspect triste, quil les rend suspects dans leur emploi. Leurs feuilles sont alternes; quelquefois géminées à la partie supérieure. Leurs fleurs sont solitaires ou disposées en épis ou en corymbes : assez sonvent elles naissent en dehors de l'aisselle des feuilles.

Quelques Solanées sont hérissées d'épines plus ou moins aiguës.

10 . Fruit charnu bacciforme.

$B E L L A D O N E .-A T R O P A$.

Calice campanulé, persislam, à cing divisions aiguës: rorollc 
campanulée quinquéfide, plus longue que le calice. Cinq étainines incluses à filcts subulés, portant des anthères cordiformes arrondies. Le fruit est charnu, arrondi, un pca applati supérieurement, à deux loges, renfermant un grand nombre de graines attachées à deux trophospermes situés sur la cloison.

Belladone comuune. Atropa belladona. L. Sp. 260. Bull. herb. t. 29. Orf. méd. lég. t. 5.

Part. usitées: les feuilles, la racine. Noms pharn. : Belladona S. solanum furiosum. Nom. vulg. : Belladone.

La belladone se distingue par une racine vivace, ćpaisse et charnue; par une tige dressée haute de deux à quatre pieds, cylindrique, velue, rameuse, dichotome; ses feuilles alternes ou quelquefois géminées, surtout à la partie supérieure de la tige, sont grandes, courtement pétiolées, ovales aiguës, presque entières et velues. Les fleurs sont assez grandes, solitaires, pćdonculćes, pendantes, d'un rouge tcrne; elles offrent un calice campaniforme, un peu velu, à cinc divisions ovales aiguës; une corolle monopétale, régulière, en clochc allongée, rćtrécie inférieurement en un tube court, fendue à son sommet en cinq lobes ćgaux, obtus, peu profonds. Les cinq ćtamines sont plus courtes que la corollé, à la base de laquelle elles sont insérées; les filets sont subulćs, les anthères presque globuleuses. Le pistil se compose d'un ovaire oroïde, allongé, à deux loges polyspermes, appliqué sur un disque jaunâtre; d'un style grêle et cylindrique, à peu pròs de la longueur de la corole, terminć par un stigmate applati, convexe, légèrement bilobć. Le fruit est une baie arrondie, un peu déprimé, de la grosseur d'une cerise, d'abord verte, puis rouge, et enfin presque noire; elle est environnće à sa base par le calice; elle offre dcux loges qui contiennent plusieurs graines réniformes.

La belladone est trćs-cominune aux environs de Paris; on la trouve en fleurs aux mois de juin, juillet et,d'aoùt, le long des murs, dans les décombres. Ff

Propriétés ę usages. Analysć par M. Vauquelin, lc sue de 
belladone ne lui a rien offert de bien remarquable, si ce u'est un principe résineux soluble dans l'alcohol, et que cet habile chiniste considère comme la partie active de cette plante. M. Brande dit avoir retirć du végétal qui nous occupe, une substance alcaline très-âcre et vénéneuse, et qu'il nomme Atropine.

Lcs fruits sont un poison violent, d'autant plus pernicieux que leur ressemblance avec des cerises a souvent engagé à en mangcr, et que leur saveur d'abord douceâtre n'avertit point assez tôt du danger. On trouve dans les auteurs un grand nombre de cas d'empoisonnemens occasionés par l'usage dé fruits de la belladone. On remédie aux accidens causés par cette espèce d'empoisonnement, en faisant sur-le-champ vomir le malade, et en administrant ensuite des boissons acidulées. Les feuilles, et surtout la racine, jouisscnt de propriétćs non moins ćnergiques et noll moins déletères. Elles doivent être, de même que les fruits, rangées parmi les poisons narcotico-âcres, dont ellcs développent tous les effels, lorsqu'on les donue à des doscs très-élevées. Cependant la thćrapeutique les emploie souvent et avec avantage dans plusieurs circonstances, et leur introduction dans la matière mćdicale remonte à une époque très-reculée. Ainsi les anciens faisaient usage des feuilles, appliquées sous forme de cataplasıne, dans le traitement des tumeurs cancćreuses. Plusieurs auteurs modernes en ont ćgalement recommandé l'usage interne et externe dans le cancel' des mamelles et les autres indurations squirrheuses des glandes. Mais aujourd'hui il a ćtć bien reconnu quc la belladone, ainsi que les autrcs médicamens nar'cotiques, n'cxercent aucune influence salutaire sur les tumeurs rćellement cancéreuses, mais que seulement clle peut être quelquefois avantageusc pour amener la résolution de glandes affectées d'induration simple et non squirrhcuse.

Une des maladies contre lesquelles on cmploic aujourd'hui plus fréquemment la racine et les feuilles de la bcllacione, c'est la coqueluche ou toux convulsive des cnfans. Ce sont particulic̀rement les médccins allemands qui ont donnć à la belladone unc sortc de voguc dans lc traitement de cette maladic. La dose doit en être d'abord trèsfaiblc; ainsi l'on commence par wI 
yuart ou un demi-grain de la poudre, élendu dans une cerlaine quanlité de sucre également en poửre. On augmente sueressivement cette dosc, en surveillant avee soin son action, afin d'en suspendre l'usage dans le cas où l'on s'apercevrait, de quelque trouble dans les fonctions du système nerveux. Un grand nombre d'auteurs ont constatć l'efficacité de la belladone dans eette affection. Mais, ainsi qué le remarque le docteur Mareus de Bamberg, la belladone n'est réellement avautageuse dans la coqueluche, que lorsqu'on la donne après la premic̀re période, qui est en général caractérisée par une irritation plus ou moins vive des organes respiratoircs.

On a aussi beaucoup employé la belladone dans les différentes affections du système nerveux, telles que la paralysic, les convulsions, l'épilepsic, elc.; mais fort souvent ces maladies ont résisté à son emploi. Enfin quelques anteurs lat recommandent également dans la syphilis, les scrophules, etc.; mais aujourd'hui ellc est tout-à-fait inusitée dans ces différens cas.

$\mathrm{La}$ bclladone produit constamment un effet remarquable, c'est la dilatation de la jupille. On a profité de ectte singulière propriété pour favoriser l'exécution de quelques opéralions qui se pratiquent dans l'intérieur du globe de l'œil, et surtont la eataracte. On applique sur l'ocil un calaplasme ou des compresses arrosés ou imbibés d'une solution d'extrait de belladone.

La poudre des fenilles et de la racine de belladone s'administre à Ja dose d'un demi-grain à un grain, quc l'on augmente graduellement, de'manière à la porter à uu scrupule et même au delà. Quant à son extrait, il est peu employé. On prépare aussi un sirop de belladone dont on administre depenis un jusqu'à quatre gros.

La Mandracore, atropa mandragora, L. Bull., t. 146 et 147 , autre espéce du même genre, est encore plus relorìable par ses qualités délétèr'es que la bclladone. Quoique quelques anteurs aient autrefois fait usage de sa raeine el de ses feuilles, elle est aujourd'hui entièrement innsilée. 
Calice subcampanulé à cinq divisions, persistant; corolle rotacée; tube très-court; 'limbe à cinq divisions étalées. Les anthères sont allongées, conniventes, s'ouvrent par un petit. trou pratiqué au sommet de cliaque loge, et forment une espèce de petite pyranide eentrale. Baie à denx loges, entonrée à sa base par le calice persistant.

MorelLe tubéreuse. Solanum tuberosum. L. Sp. 265.

Nom vulg. : Pomme de terre.

Racine vivace, rampante, offrant des tubercules charnus, de forme et de grosseur variables. Tige herbacée, ramerise, dressée, anguleuse et un peu ailée, charnue, presque glabre, haute d'un à deux pieds, donnant attache à des feuilles alternes, interrupté-pennées; folioles ovales, cordiformes, pubescentes, inéquilatérales, entières, un peu sinueuses sur les bords; pétiole commun canaliculé.

Fleurs violacées, roses ou blanches, en grappes pauciflores, opposées aux feuilles, au sommet des rameaux. Calice subcampanulé, poilu, à cinq divisious peu profondes, semi-ovales, aiguës. Corolle rotacée, comme étoilée, à cinq lobes planes triangulaires, dont le sommet est recourbé en-dessıs; chaque lobe plus épais à sa partie inférieure et moyenne. Tube trèscourt. Cinq étamines insérćes au sommet $d u$ tube; filamens très-courts; anthères rapprochées latéralement en forme de cône tronqué : chacune d'elles est à deux loges, qui s'ouvrent pair un petit trou a leur sommet.

L'ovaire est libre, glabre, un peu conique, offrant deux légers sillons opposés; il est à deux loges, contenant un trèsgrand nombre de petits ovules attachés à deux trophospermes saillans, qui partent du milicu de la cloison. Le style est plus long que les ćtamines; il est eylindracé, glable, et se termine par un stigmate capitulé, glandulcux, à deux lobes distincts. Le fruit cst une baie cerasiforme, noirâtre à l'époque de sat
parfaite maturité.

La pomme de terre est originaire du Pérou, ei fut intro- 
négligé e par le cultivateur, la pomme de terre est aujourd'hui eul tivée dans tous les eantons de la France. $\forall$

Propriétés et usages. Après les plantes ećréales, la pomme de terre est sans aucun donte le végétal le plus utile à l'homme pour sa subsistance. Presque uniquement composés de fécule très-purè et très-blanche, ses tubercules lui offrent un alimerit aussi abondant que salubre, qui peut dans les temps de disette remplacer entièrement l'usage du blé et des autres céréales. Lorsque l'on rape ces tubercules dans l'eau, on obtient un amidon d'une grande pureté, que l'on emploie à différens usages économiques, et avec lequel on prépare des pâtes et des bouillies. Si on les soumet à la fermentation, on cn retire une quantité eonsidérable d'aleohol, mais qui conserve toujours une odeur et une'saveur peu agréables. Enfin l'on peut, par différens procédés, ehanger en sucre la fécule qui forme la base des tubercules de la pomme de terre. Par combien de titres ee précicux végétal ne mérite-t-il point d'être soigneusement cultivé en Europe!

Moreme doucé-amène. Solanum dulcamara. L. Sp. 264. Bull. t. 23.

Partie usitée:les tiges. Nom pharm. : Dulcamara.

Sous-árbrisseau sarmentéux, dont la tige grêle, ligneuse à sả bảse, herbacée dans le reste de son étendue, est cylindracée, púbescente, et longue de plusicurs pieds. Scs feuilles sont altérnès, pétiolées, profondément trilobées. Le lobe moyen est plus grand, ovale, aigu, entier; les deux lobes latéraux sont opposés, plus petits, irréguliers. On trouve quelquefoìs des feuilles entières, d'autres fois elles sont à cinq lobcs.

Les fleurs sont violettes, disposées en grappes, pédoneulées, pauciflores, opposées aux feuilles. Le ealice est tres-petit, turbiné, à cinc lobes aigus; il est d'un violet foncé. La corolle est rótaeée, à cinc lobes profonds, étroits et aigus, marqués à leur base de deux petites taches glandulaires vertes, et luisantes. fic tube est à peine marqué. Les citanines sont rapprochées en cône. Le fruit est une petile baie ovoìde, rougeâtre, enlourée à sa base par le ealice persistarit.

Cette plante se rencontre très-communément dans les haics, 
les décombres, le long des vieux mures. Elle fleurit en juin et juillet.

Propriétés et usagres. Ce sont les jeúnes rameaux de l'année préeédente que l'on reeueille au printemps pour l'usage de la médecine. Ils sont ligneux, effilés, grêles; leur saveur, d'abord douee, est ensuite d'une amertume assez intense : de là le nom vulgaire de douce-amère donné à eette plante. La décoction des tiges de douce-amère est. la seule préparation dont on fasse usage. Elle augmente d'une manière sensible la perspiration. eutanée : aussi la preserit-on assez fréquemment dans le rhumatisme chronique, les maladies de la peau, la syphilis, ete.; sa dose est d'une à deux onees pour deux livres d'eal. Quant à ses baies elles sont fades, mais nuilement délétères, ainsi que le eroyaient les aneiens.

\section{Morelle mielongìne. Solanum melongena. L. Sp. 266. Noms vulg. : Aubergine, Méringeane, ete.}

L'aubergine présente une racine annuelle d'où s'élève une tige herbacée, rameuse, lraute d'un pied et plus, eylindrique, un peu pulvérulente, offrant des aiguillons simples, courts, assez éloignés les uns des autres. Les feuilles sont alternes, pétiolées, ovales, aiguës, sinueuses sur les bords, pubescentes; pétiole eylindrique, pulvérulent, épineux inférieurement.

Les fleurs sont très-grandes, violaeces, solitaires, pédoneulées, opposées aux feuilles, ayant souvent un eertain numbre de parties surajoutées; pédoneule d'environ un pouce, pulvérulent et épineux. Calice eampaniforme pulvérulent et épineux, offrant six ou lhuit divisions linéaires, aiguës. Corolle rotacéc, un peu plissée, divisions presque triangulaires, aiguës, en nombre égal à eclui des divisions ealieinales. Eiaminés au nombre de six à huit dans les individus eultivés.

Les fruits sont ovoïdes, allongés, ayant quclque ressemblanee avee de petits coneombres. Leur couleur est blanehé ou
violette, et marlbrée.

Cette plante est originaire de l'A mérique méridionale. On la cullive surtout dans le midi de la Franee.

Jsages. Ties habitans des provinees inéridionales de la Frane... 
font une grande consommation des fruits de l'aubergine, qu'ils mangcnl: apprêtés de différentes manic̀res Ces fruits ont une savẹur louce et agréable.

Morelte notre. Solanum nigrum. L. Sp. 266. Bull. t. 6 7.

Cette petite plante est annuelle, et croit en abondance dans les champs et les jardins. Sa tige, d'environ un pied de hauteur, est rameuse, pubescente, ainsi que les feuilles, qui sont éparses, pétiolées, presque triangulaires, et inégalement lobćes. Les fleurs sont blanches, et forment des espèces de petits bouquets composés d'environ six à huit fleurs. Les fruits qui leur succèdent sont des petites baies pisiformes, d'abord vertes, puis devenant presque noires à l'ćpoque de leur maturité. $\odot$

Propriétés et usages. La morelle noire est regardée comme suspecte par beaucoup d'auteurs, qui attribuent à ses fruits des'qualités extrêmement délétères. MT. Desfosses, pharmacien à Besançon, ayant analysé le suc reliré de ses baies, y a constaté l'existence d'un principe alcalin nouveau, combiné avcc un excès d'acide malique, et que ce chimiste a nommé solanine. Cet alcali organique, qui existe aussi dans les tiges de la douce-amère, paraît, d'après les expériences de l'auteur, être la partie aclive de ces vćgétaux. Cependant on mange dans beaucoup de contrées les feuilles de la morelle noire, bouillies dansl'eau, à la manic̀re des épinards. Ainsi à l'îlc de France et de Bourbon, et même dans les Antilles, on en fait une ćnorme consommation. Quant à ses fruits, plusieurs autcurs assurent qu'ils sont très-vénéneux, et cependant on les mange en abondance dans quelques pays, ct entre autres en Ukraine.

\section{Monelee tomate. Solanum lycopersicum. L. Sp.}

Noms vulg.: Tomate, ou Pomme d'amour.

Racine annuelle; tige herbacéc, charnnc, rameusc, cylindrique, couvcrte de poils rides, hautc d'un à dcux pieds. Feuilles alternes, interrompues pennées. Les foliolcs lcs plus grandes sont régulièrement ovales, cordiformes, aiguc̈s, un peu sinueuses à la base, pubescentes, d'un vert foncé cu 
dessus, plus claircs cn dessous; les petitcs foliolcs sont inégales et irrćgulières.

Fleurs jaunes disposées en grappes axillaires; pédonculcs - couverts de poils rudes très-rapprocliés les uns contre les autres. Ces fleurs ne sont jamais simples; elics ont toujours un certain nombre de parties surajoutées; ainsi le calice esi à six ou huit divisions très-profondes, linćaires, aignës, velıes. La corolle est rotacée, un peu campaniforme; ses divisions sont ovalcs, aiguës, en nombre égal à celles du calicc. Le tube esi. très-court.

Les étamines sont aussi au nombre de 6 à 8 , insérées au sommet du tube de la corolle; les filets sont très-courts, les anthc̀res sont lancéolées, terminées en pointe, rapprochées et. coinme soudées ensemble par les côtés, de manière à former une sorte de cône. Elles sont à deux loges, qui s'ouvrent en dedans du cône par toute la longueur de leur sillon.

Lc fruit est une baie rouge, irrégulièrement lobée. Jardins. (- o tomate est originaire du Brésil; on la cultive dans les

$\Lambda$ l'exemple dc Tournefort, M. Dunal a rétabli pour celte plante le genrc Lycopersicum, distinct des morelles par ses élamines et les divisions du calice et de la corolle plus nombrcuses, et par ses anthèrcs, qui s'ouvrent longitudinalement.

Propriétés et usages. Toute la plánte a une odeur très-pénétrante, dcsagréable; ce sont lcs fruits seulement dont on fait usage, particulièrcment dans les provinces mćridionales de la Prance, où on les connaít sous le nom de pommes d'amour. Lcur saveur est un pcu aigrcletle; on en fait des sauces, ou bien on lcs fait cuirc apprêtées de différentes manic̀res.

\section{COQUERET. - PHYSALIS. L. J.}

Calice urcéolé, vésiculeux, quinqućfide, persistant, renflé aprics la floraison, et renfermant lc fruit. Corolle rotacéc, limbc quinquéfidc, anthères allongées, rapprochées. Stylc court, terminé par un sligmatc capitulé. La baie est cerasiforme, rcn-ferméc dans l'intérieur du calice, qui esı très-reuflé: clle es biloculaire, ct conlicut des graines renilormes allachécs, id deux
trophospermes insérés à la cloison. 
Coqueret alkemenge. Physalis aukekengi. L. Sp. 262. Blackw. t. I6r.

Plante annuelle, dont la tige est herbacéc, haute d'environ un pied, un peu rameuse, velue. Les feuilles sont gćminées et pétiolécs, ovales, aiguës, sinueuses sur les bords. Les fleurs sont blanclıâtres, solitaires, cxtra-axillaires; lcur pédoncule est court et recourbć. Lé calice est urcéolé, renflé, quinquéfide, vclu. La corolle est en roue; son tube court, son limbe élalé, à cinq divisions ovales aiguës. Ies étamines, au nombre de cinq, sont courtes et conniventes au centre de la fleur.

L'ovaire est ovoüde, glabre, à deux loges; le style est court, et terminć par un stigmatc très-petit, convexe.

Le fruit est une baie rouge de la grosseur d'une petite cerise; elle est envicloppée ct cntièrcment cachée dans l'intérieur du calice, qui s'est accru et qui est devenu vésiculcux et rougeâtre.

L'alkékenge croit dans les champs cultivés, les bois. Il fleurit en juin et juillet.

Propriétés méclicales et usages. Les baies d'alkekenge sont aigrclettes, diun goût assez agréable. Elles sont légèrement diurétiques, mais fort peu usilées. Ellcs ne sont nullement vé néneuses.

$3^{\circ}$ Fruit capsulaire.

\section{MOL ENE. - VER RASCUM. L. J.}

Calice étalć, à cinđ divisiọns profọdcs: Corollẹ rotacée, à einq lobes un peu inégaux. Cinq étamincs inégales, déclinées, à filets, le plus souvcnt baribus à leur base, insérécs au sommet du tube de la corolle. Capsule ovoïdc, à deux valves. Graines très - petites, à surface tubcrculcuse et chagrinée.

Moline boulluon blanc. Verbascum thapsus. L. Sp. 252 . Blackw. t. 3.

Part. usitécs: les fleurs et les fouilles. Nom pharm. : Verbascum. Nom vulg. : bouillo'n blanc.

Plante bisanuuclle, dont la lige est simplle, droitc, effilćc, 
trés-eotonneuse, ailée, haute de deux à qualı'e pieds. Les feuilles sont grandes, ovales, aiguës, rétrécies à la base, déeurrenles, cotonneuses, blanehâtres et entières; les supérieures sont plus éłroites et lancéolées.

Les fleurs sont jaunes, grandes, disposées en longs épis simples, à l'extrémité supérieure de la tige. Le ealice est fomenteux, à eing divisions profondes, ovales, aiguës. La corolle est en roue, son tube est eourt; le limbe, presque plane, offre cinq Iobes arrondis, obtus, inégaux. Les étamines, au nombre de cinq, sont déclinées, inégales. Les filets sont subulés, eouverts de poils blanes à leur base. Les anthères sont réniformes et Iransversales. L'ovaire ovoïle subpyramidal est eotonneux, à deux loges; les ovules sont fort nombreux dans ehaque loge, attaeliés à deux trophospermes saillans sur la eloison. Le style est oblique, plus long que les étamines, tomenteux, plus gros à son sommet, sur lequel est appliqué un stigmate convexe et presque réniforme. Le fruit est une eapsule tomenteuse, ovoïde, un peu aiguë, biloculaire, septieide. Les graines sont petiles, irrégulières et chagrinées.

Le bouillon blane se trouve dans les lieux ineultes, sur'le bord des ehemins aux environs de Paris. Il fleurit pendant la plus grande parlie de l'été.

Proprićtés et usages. Ce sont les fleurs qui sont plus fréquemment employées. Elles sont adoueissantes et prectorales: On les donne en infusion théiforme dans les catarrhes pulmonaires peu intenses ${ }^{x}$.

Les feuilles sont émollientes, et peuvent être cmployées, lorsqu'elles ont été bouillies dans l'eau, à faire des eataplasmes.
adoucissans.

On peut se servir presque indistinetement des aulres espèces. de ee genre pour remplir les mêmes indications, et surtout des verbascum nigrum et verbascum lychnitis, qui sont également fort eommuns aux environs de Paris.

Il faut avoir soin de passer eette infusion à travers un linge fin pour en séparer les petits poils ludes qui eouvrent la base des filets des étamines, lesquels déterminericieut la toux par l’irritation mécam nique qu'ils exereent sur la gorge. 


\section{JUSQUIAME. - HYOSCIAMUS. L. J.}

Calice tubuleux, subcampaniforme, quinquéfide. Cornlle irrfundibuliforme; limbe oblique, à cinq lobes obtus et inégaux. Cinq étamines déclinées; stigmate capitulé simple. Lc fruit est une pyxide, c'esi-à-dire une capsule allongée, un peu ventrue à sa base, biloculaire, s'ouvrant horizontalement en 'deux valves súperposées; enveloppée par le calice, dont les dents ta dépassent. Les graines sont subréniformes tuberculeuses.

Les jusquiames sont des plantes annuelles, velues et visqueuses, a fleurs disposées en une sorte d'épi unilatéral.

Jusquiame noIne. Hyosciamus niger. L. Sp. 257 . Bull. t. 98. Orf. méd. lég. t. 4 .

Part. usitées : les feuilles et les graines. Non pharmac. : Hyosciamus.

Raeine annuelle; lige haute de dix.huit pouces à deux pieds, cylindrique, rameuse à sa partie supérieure, couverte de poils longs et visqueux; feuilles alternes, éparses el quelquefois opposces sur le nême pied; elles sont grandes, ovales, aiguës, sessiles, profondément sinueuses sur les bords, molles, velues et visqueuses. I,es fleurs presque sessiles, tournées d'un seul côté, ct disposéesfen longs épis,sont d'un jaune sale et veinées de lignes pourpres. Le ealice est à cinq dents éeartées et aiguës, visqueux. La eorolle est infundibuliforme ; son tube est eylindrique, plus étroit que le ealice; son limbe est oblique et à einq divisions inégales et obtuses.

Lc fruit est une pyxide, c'est-à-dire une capsule s'ouvrant à son sommet par une sorte de calotte ou d'opereule.

La jusquiame noire est très-commune sur lc bord des cheunins et dans les lieux incultcs.

Propriétés et usages. L'aspect de la jusquiame noire et son odeur suffiraient seuls pour. cn faire connaitre les propriétés délétères; ses feuilles d'un vert tèrne, lıćrissécs de poils visqueux; ses fleurs d'un jaune sale, parcourues de ligues rougeâlres, sont autant d'indiees de scs mauvaises qualités. En. elfet, eornme la belladone, la jusquiame noire cst un joison 
nar'cotico-âere,dont on combat les aeeidens parl'usage de l'émćlique, et ensuite par les boissons acidules. On emploic moins fréquemment la jusquiame que la belladone, quoiqne eependant leur mode d'action soit à peu près analogue. C'est prineipalement contre les affections du système nerveux que l'on en a plus souvent retiré quelque avantage; ainsi dans lc tie douloureux de la face, les névralgies seiatiques; la paralysie; plusieurs auteurs ont eélébré ses bons effets. Cependant lès praticiens modernes la preserivent moins souvent, et surtout avee moins de eonfianec. C'est ordinairement sous forme d'extrait qu'on administre la jusquiame à la dose d'un à deux graìns, dose que l'on augmente graduellement, à mesure que le málade s'y habitue.

La jusquiame blanelie (hyoscininus albus L. sp. 257 , Bull.' t. 99), et la jusquiame jaune (hyosciamus aureus), qui eroissent dans le midi de la Franee, jouissent des mêmes propriétés; la première surtout est substituée dans plusienrs préparations à la jusquiame noire.

\section{TABAC. - NICOTIANA. L. J.}

Caliee ureéolé, ventru, quinquéfide; corolle infundibuliforme; régulière; tube plus long que le ealice; limbe ouvert, plane, à einq divisions égałes; stigmate eapitulé, légèrement bilobé; eapsule ovoïde, bivalve: ehaque valve, emportant avee elle la moitié de la eloison, est bifide à son sommet. Les graines sont très-petites, irrégulièrement arrondies et rugueuses.

Les tabaes sont des plantes herbacées, dont les fleurs sont panieulées, ou rarement disposées en épi.

Tabac ordiname. Nicotiana tabacum. L. Sp. 258. Bull.

$$
\text { t. } 285 \text {. }
$$

Parties usitées: les feuilles. Nom pharm.: Nicotiana. Nonu vnlg.: Tabac, Petun, Herbe à la reine, Herbe à tous maux.

Le tabae présente une raeine annuelle, d'où s'élève une tige dressée, rameuse, eylindrique, haute de deux à quatre pieds, pubeseente et visqueuse. Les feuilles sont allernes, très-grandes, ovales, aiguës, retrécies à la base, sessiles, pubescenles et légèrement visqueuses sur les deux faees, exhalant, ainsi que 
les autres parties de la plante, une odeur vircuse très-désagréable; clles sont longues d'un picd, larges de trois à quatre pouces.

Iucs fleurs sont grandes, roses, dispośécs' en unc sorte de panieule aux extrémitćs des rameaux. Le calice cst tubuleux, ventru; quinquéfide, à divisions aiguës au sommet. La corolle est infundibuliforme, pubescente en deliors. Son tubc est cylindrique, deux fois plus long que le calice, évasć à son sommet. Le limbe est étalé, comme étoilé, a cinq divisions peu profondes, larges et aiguës. Les étamincs sont au nombre de cinq, de la longueur du tube, insérćes vers le milieu de sa hauteur. Les filets sont subulés, velus à leur partie inférieure. Les anthères sont ovoïdes, obtuses, bifides inférieurement, à deix loges opposées, s'ouvrant par un sillon longitudinal.

Le pistil se compose d'un ovaire ovoïde aigu, tronqué à sa base, appliqué sur un disque hypogyne jaune, peu distinct, sinon pàr sa couleur, de la partie inférieure de l'ovaire. Celui-ci est à deux loges, rcnfermant chacune un très-grand nombre. de petits ovules, recouvrant toute la surface de deux trophospermes très-saillans, convexès, attachés vers l'axe par un pédiculc étroit. Le style est à peu près de la longueur des ćtumines; il est glabre et cylindrique, un peu ćlargi vers son sommet, qui supporte un stigmate aplati, convexe, légèrement bilobé, Le fruit est une capsule ovoïde, un peu poinlue, s'ouvrant naturellement en deux valves.

Cetle plante nous a étć apportće du Nouveau-Monde par les Espagnols, vers le milieu du scizième siècle. Elle ne fut introduitc en France que vers 1560 ou 1565 , époque où un ạmbassadeur de Marie de Médicis à Lisbonne, en rapporta à ecttc princessc. C'cst de ce moment seulcment que date l'introduction du tabac en France, d'où il s'est ensuite répandu dans les autres contrées septentrionales de l'Europe.

Propriétés et usages. Tout lc monde connait les usages auxquels l'on emploic lc tabac, soit réduit en poudrc, soit eoupć en fragmens plus considérables. L'liabitude que s'en sont faite cerlaincs personnes, est devenuc pour clles un besoin faetice, dont ellcs ne peuvent supportcr la privation. A l'époque oì ce végétal fut apporté en Europe, le merveillcux allaché à tout ce 
qui est nouveau, fit trouver dans le tabac un rcmède universel, une sorte de panacée, proprè à guérir toutes les maladies. D'autres, au contraire, ne virent en lui qu'un remc̀de dangereux, dont on devait interdire l'usage.

Les fenilles fraiches de tabac ont une odeur vireuse et désagréable, mais lorsqu'elles ont subi un commencement de fermentation, leur odeur cst forte, piquante, et très-agrćable pour les personnes qui y sont accoutumées. Ainsi préparées, les feuilles de tabac sont d'une extrême âcreté, et en mẻme temps stupéfiantes. Quand on les mậche jiendant quelque temps, ou qu'on en introduit la fumée dans la bouche, elles augmentent d'une manière très marquće la sécrétion de la salive. Le tabac agit encore de la même manièré, lorsqu'on l'inspire par les fosses nasales; la membrane pituitaire devient le isiége d'une sécrétion plus abondante. Mais dans ces différcns cá', le tabac produit chez les individus qui n'en font pas habituellement usage, des effets qui tiennent à son action narcotique sur l'encéphale. De là les étourdissemens, la céphalalgie ; la somnolence, les nausées auxquelles sont en proie ccux qui font pour la première fois usage de ce végétal.

Introduit dans l'estomac, il l'irrite, et donne lieu à des vomissemens ou à des déjections alvines plus ou moins copieuses. $S$ 'il est administré à fortc dose, il peut occasioner les accidens les plus graves; en un mot, agir comme tous les autres poisons narcotico-âcres. $\Lambda$ ussi a-t-on tout-à-fait abandonné l'usage intérieur des feuilles de tabac. On ne l'emploie plus aujourd'hui que pour préparer des lavemens irritans, que:l'on administre dans l'apoplexie ct l'asphysie. Dans celte dernière affection, surtout lorsqu'clle est occasionée par submersion, on insuffle par des procédés divers la fumée de tabae dans les voies aériennes. Celtc fuméc, par l'irritation qu'elle y occasionn, délermine les contractions du diaphragme el tend à rétablir la respiration.

$$
\text { STRAMOINE. - DATURA. L. J. }
$$

Calice tubulcux, renflé à sa base, à cinq angles, à cinq dents profondes; caduc, à l'exception de sa parlic la plus inférieure, qui persiste et se renverse en delıors. Corolle très-grande, in- 
fundibuliformc; tubc à cinc angles; limbe offrant cinq plis, qui se terminent supérieurement paricinq lobes très-aigus. Cinq étamines incluses. Stigmate bilobé. Capsule à quatrc loges, conInuniquant deux à deux par leur sommet; à quatre valves. Graincs très-nombreuses, réniformes, chagrinćes, noires.

Lies stramoines sont tantôt des herbes annuelles, des arbustes, ou même des arbrisseáux. Elles sont rexinarquables par la grandeur de leur fleurs.

Stramoine pomme épinedse. Datura Stramonium. L. Sp. 255. Bull. t. 13. Orf. méd. lég. t, 8.

La pomme épineuse est une grande plante annuelle, dont la tigc est herbacće, cylindrique, un peu pubesccnte à sa partie supérieure; très-rameuse, haute de deux à quatre pieds et plus; dichotome. Ses feuilles sont grandes, ovales, pétiolées, aiguës, sinućes et anguleuses, un peu pubescentes.

- Les fleurs blanches ou violacćes sont très-grandes, extra-axillaires, solitaires, dressées, portćes sur un court pćdoncule pubescent. Leur calice est tubuleux, allóngé, un peu renflé à sa partie inférieure, marqué de cinq côtes très-saillantes qui aboutissent supćrieurement à cinq dents inégalcs, aiguës; il est caduc : sa.partie la plus inférieurc est la seule qui persiste avec le fruit. La corolle est ldus grande que le calice, ayant environ trois pouces de hauteur, infundibuliforme; tube à cinq angles assez uarqués; limbe allongé plus long que lc calice, ćvasé, plissé longitudinalement, sc terminant à sit partie supérieure en cinq lobes plissćs, très-acuminćs.

. Étamines inciuses, insérées au haut'dı tube de la corolle.

Ovaire presque pyramidal, couvcrt de petitcs pointes, a quatrc loges; ovules nombrcux, attachés à quatre trophospermcs saillans, partant de la cloisoṛ moyenne. Style cylindrique de la longueur des étamines, glabre, élargi à sa partic supérieure. Stigmate cu fer à clieval, étroit, glanduleux, marqué d'un léger sillon sur' toute sa face supérieurc. Le fruit est une capsulc ovoïdc, presque pyramidalc, offrant les restes du calice à sa partie inférieure; chargée de piquans lıçs-aigus, ì quatre loges incónpletes, conmuniquant entre clles deux à deux; s'ouvrant igalcuncnt cn quatre valves. 
I.es grạines sont bruuâtrcs, réniformes, et à surface clıgrinée.

La pomme épineuse est fort commune dans lcs lieux incultes, auprès des habitations. Elle flcurit en juin et juillet. $\odot$

Propriétés et usages. Les feuilles de la pomme épineuse répandent une odeur nauséabonde ct vireuse; leur saveur est âcre et amcre. Nous pourrions répéter pour cette plante ce que nous venons de dire précćdemment des propriétés délétc̀res de la jusquiame et de la belladone, en ajoutant que la pomine épineuse les possède au plus hant degré. Aussi ce végétal doitil être également placé parmi les poisons narcotico-âcres. De mème aussi que ces deux autres vćgétaux, la pomme épineuse a été introduite dans la matière médicale. Son mode d'action sur l'économie animale, et par conséquent ses propriétćs médicales, sont trop analogues à ceux de la belladone et de la jusquiame, pour qu'on ne l'ait pas employée dans les mênes circonstances. C'est surtout contre les maladies 'du système nerveux, les spasmes, les convulsions, etc. que certains anteurs prétendent avoir employé ce médicament avec succès. Mais cependant on y a rarement recours aujourd'hui. L'extrait est la préparation dont on fait usage. Sa dose doil être d'abord très-petite. Ainsi on commencera par en administrer un à deux grains dans les vingt-quatre heures, et l'on ira gradueliement en augmentant.

Remarquons ici que la plupart des cas où l'on rccommande la jusquiame, la belladone et la pomme épineuse, sont en général ceux où l'emploi de l'opium est également indiqué. Ce dernier médicament étant beaucoup mieux connu dans son mode d'action, le médecin prudent devra toujours, autant que possible, Iui accorder lạ préférence.

\section{Propriétés médicales des Solanées.}

Les plantes dc la famille des Solanćes offrent des caractères botaniqucs assez uniformes. Cependant on trouve une différence assez grande dans les propriétés médicales, ct lc mode d'action des différens végétaux qui la composent.

On peut dirc en gćnéral des Solanées, considérécs collectivement, (qu'clles sont toutcs plus ou moins dangerenscs : que 
la plupart sont des poisons narcotico-âcres des plus violéns, telles que la belladone, la mandragore, la pomme épineuse, la jusquiame, et quelques autres; tandis qu'il en est un ccrtain nombre qui sont alimentaires et adoucissantes, telles sont quelques espèces de morelle ou' Solanum et le genre molène (verbascum) tout entier.

Éludiécs d'organe à organe, les plantes de cette famille présentent ćgalement la plus grande anomalie sous le rapport de leur's qualités et des phénomènes auxquicls elles donnent maissance. Les racines sont cn général vénéneuses : c'est en elles que paraissent résider les proprićtés lcs plus actires et les plus dangereuses, dans la mandragore, la belladone, la jusquiame, tandis que les iubercules radicaux de la pomme de terre (Solanum tuberosum) et des Solanum montanum et Solanum Venezuela sont des amas de fécule amilacée presque’à l'ćlat de pureté.

Les feuilles sont en général très-âcres, très-narcotiqnes, comme le prouvent celles de la jusquiame, du tabac, de la stramoine, de la belladone, etc. Cependant celles des molènes (verbascuin) sont adoucissántes et mucilagineuses, et l'on marige dans quelques provinces les feuilles de la morelle noire, sáns qu’il en résulte le moindre accident.

Si des feuilles nous passons aux fruits, nous trouverons des différences non moins tranchées. Si l'on mange habituellement et sans inconvćnient les fr̉uits dc melongc̀ne, de tomate, d'alkekenge, de capsicum, etc., ceux de belladone, de morelie noire, dc mandragore, de pommc épineusé; etc., sont des poisons violens, que l'art, secondé par l'expérience, est parvenu à s'approprier, et emploie avec avantagc dans le traitement de certaines affections.

En résumé, la famillc des Solanées renferme des plantes en général suspectes ct dangereuses. L'on ne peut faire, sans la plus scrupuleuse attention, la substitution d'une cspèce d'un genre à un autre genre.

La propriété dominante des régétaux de cetle famille est lcur action stupéfiante, qui lcs rcnd propres à agir sur le système nerveux, surtout dans les affections sipasmodiques; telles que la manie, la paralysie ct la coqueluche, etc. 
Ce principe narcotique est ordinairement joint à un principe âcre : aussi la plupart des Solanées, telles que la jusquiane, la stramoine, le tabac, la mandragore, la bclladone sont de véritables poisons narcotico-âcres.

Quelques espèces sont émollientcs et adoucissantes, tcls sont le bouillon blanc et les autres espèces de molc̀ne.

Enfin certaines parties de quelques espèces sont alimentaires, tcls que lcs fruits de la morelle aubergine, de la tomate, des capsieum, des alkekenges; les feuilles de la morelle noire, et les tuberculès souterrains de la pomme de terre.

QUARANTE-SIXIEME FAMILLE.

\section{J A S M INÉES. - JASMINEAE.}

Cette famille forme un groupe assez bien circonscrit, et qui se distingue facilement de tous ceux qui l'avoisinent, par ses étamines, constamment au nombre de deux.

Les fleurs, dans les Jasminées, sont hermaphrodites ou unisexuées, et forment des grappes, des thyrses ou des espèces de corymbes. Leur calice présente quatre ou cinq dents, quelquefois très-longues. La corolle est monopétale, régulière; son limbe offre quatre ou cinq divisions; les étamines, au nombre de deux, sont tantôt saillantes, tantôt renfermées dans l'intérieur du tube de la corolle. L'ovaire est libre, à deux loges, qui con-. tiennent chacune deux ovules attachés vers la partie supérieure. Le style est simple, terminé par un stigmate bifide ou bilobé. Le fruit est tantôt une capsule à deux loges, renfermant chacune une ou deux graines, tantôt une baie dans laquelle on trouve d'un à quatre petits noyaux. Leur embryon est renfermé dans l'intérieur. d'un endosperme charnu.

Les Jasminées sont des arbres ou des arbrisseaux d'un port élégaut, portant des feuilles opposées, simples ou pennées, toujours ponctuées à leur face inférieure; 
-des fleurs qui répandent souvent une odeur suave et agréable.

I0 Fruit charnu.

\section{JASMIN. - $\int A S M I N U M$.}

Calice turbiné à cinq dents ou à cinq divisions étroites; corolle tubuleuse à limbc plane, offrant cinc lanières un peu obliques; étamines incluses; baie arrondie ou bilobée, à deux loges mono ou dispermes; tégument propre de la graine charnu.

\section{JASMIN OFFICINAL. Jasminum officinale. L. Sp. 9 .}

Sous arbrisseau dont la hauteur varie beaucoup. Ses rameaux sont longs et effilés, verts et glabres. Ses feuilles opposées sont profondément pinnatifides, composées ordinairement dé sept folioles ovales, aiguës, entièı'es, les trois supérieures souvent confluentes entre elles.

Fleurs blanehes, répandant un parfum très-agréable, disposées par petits bouquets axillaires et pédonculés, aecompagnés de deux braetées linéaires. Chaque fleur est elle-même pédonculée. Le calice est campanulé. Son tube est assez court. Son limbe à cinq lanières, longues et linéaires. La corolle est hypocralériforme. Son tube est très-allongé, un peu strié; son limbe à cinq divisions ovales, lancéolées, aiguës. Étamines incluses, attachées vers le milieu de la hauteur du tube. Filets courts et aplatis. Anthères biloculaires, elliptiques un peu comprimées. Pistil beaucoup plus court que le tube du calice. Ovaire presque cordifor'me à deux loges, renfermant chacune deux ovules. Style filiforme terminé par deux stigmates allongés, souvent collés ensemble. Le fruit est une baie biloculaire, dont cliaque loge contient ordinairement une seule graine.

Le jasmin est originaire de l'Asie; mais il est aujourd'luui naturalisé en Francc, et surtout dans les provinces du midi.

Propriétés et usages. Autrcfois très-cmployées commc antispasmodiques, les fleurs de jasmin sont anjourd'hui entièrement inusitces, ainsi (jur leur cau distillée, que l'on faisait entrer à la dose d'uue à deux onces daus les potions calmantes. 
Ces fleurs sont très-rccherchées des parfumeurs, qui en fixcnt l'arome par différens procédés.

\section{OLIVIER. - OLEA. L.J.}

Calice évasé à quatre dents; corolle courte ét subcampanulée, quadrifide. Ovaire à deux loges biovulées; style terminé par un sligmate bilobé : drupe charnue renfermant un noyau à une seule graine.

\section{Olivier d’Europe. Olea Eutopaza. L. Sp. r r. Blackw.

$$
\text { t. I99. }
$$

L'olivier, dans les contrécs méridionales de l'Europe, peut acquérir des dimensions assez considérables. J'en ai vu aux cnvirons de Nice dont le tronc pouvait avoir trente à trentecinq pieds d'ćlćvalion, et trois à quatre pieds de diamètre. Son fcuillage blauchâlre rćpand une teinte monotone sur les canpagnes de la Provence et du Languedoc, où on lc cultive en abondance. Ses feuilles sont opposées, persislantes, coriaces, un peu convexes, ovales, aiguës, lćgèrement dentćes, d'un vert blanchâtre.

Ses fleurs sont petites, blanchâtres, formant des espèces de pelites grappes axillaires à la partie supćrieure des rameaus. Chacune d'elles présente un calice presque plane, 'à quatre dcnts; une corolle campanulćc, courte, dont le limbe est à quatre lobes ovales, aigus. Les étanines sont un peu saillantes. L'ovaire est globuleux à deux loges biovulćes; le style est très-court; le stiginate est épais, allongć, lćgèrement bifide.

La drupe est ovoïde, allongće, d'un vert foncć. Elle renferme dans son intérieur un noyau à peu près de même forme, qui contient une seule loge et une seule graine, par l'arortcment presque constant, des trois aulres ovules. La graine est pendante, composée d'un légument mince et veiné et d'un endosperme charnu, qui contient un embryon central et rcnversé. France, est originaire d'Asie, ct a été transporté en Europe par les Phocéens, à l'époque où ils vinrent ćtablir leur colonie en Provencc. Cel arbre craint le froid; aussi ne le voit-on pas
réussir en pleine terre sous le climat de' Paris. 
Propriétés et usages. La eulture'de l'olivier est une des sources prineipales de la riehesse des provinces méridionales de la France. L'huile grasse que l'on retire du périearpe charnu de l'olive est une des plus fines et des plus employćes, soit pour l'usage de la table et dc la pharmacie, soit pour la fabrieation du șavon. Il est digne de remarquer ici que l'olivier est peut-être le seul arbre dont le péricarpe fournisse une huile grasse; ce sont généralement les graines dont on reiire les différentes autres huiles fixes.

A l'ćpoque où l'on rćcolte les olives, leur chair est dire et d'une âpreté insupportable. Aussi ne les sert-on sur les tables, qu'après les avoir laissé pendant quelque temps macćrer dans de l'eal salée; elles sont alors fort recherehées et d'un goût agréable. $\Lambda$ vant de les soumettre à la presse pour en retirer l'huile, on les met en tas jusqu'à ce qu'elles se soient ramollies, et qu'elles aient subi un eommeneement de fermentation.

L'huile d'olives peut être employée dans toutes les préparations pharmaeeutiques où l'on preserit d'ordinaire l'huile d'amandes douces. Mais c'est prineipalcment pour servir d'assaisonnement dans une foule de préparations culinaires, que sa eonsommation est immense. Dans plusieurs départemens méridionaux, on emploie exelusivement l'buile d'olives au lieu de beurre pour assaisonner une foule de mets.

Les feuilles de l'olivier ont une saveur acerbe. Quelques auscurs les regardent comme astringentes, et fẻbrifuges.

' ${ }^{\circ}$ Fruit se'c et capsulaire.

\section{LAC. $-S Y R I N G A$. L.}

Calice turbiné à quatre dents; eorolle hypócratériforme; tube un peu renfé supćrieurement; linube plane à quatre divisions un peu concaves; étamines incluses, stigmale profondćment bifide: capsule allongéc, comprimće, à deux loges, eonterant chacunc deux graines planes, et s'ouvrant en dcux valves.

Fleurs hermaphroditcs; feuilles opposćcs simples.

Lilać ondinarr. Syringa vulgaris. L. Sp. Ir.

Cet arbrisseau peut s'ćlever jusçu’à dix ou douzc picds. Scs 
feuilles sont opposées, pétiolées, cordiformes, aiguës, entières, très-glabres. Ses fleurs, d'une couleur violette tendre, forment de grandes panicules pyramidales à l'extrćmité des 'ramifications de la tige : chacune d'ellcs se compose d'un calice court, un preu glanduleux, à quatre dents; d'ure corolle, dont le tube est grêle, cýlindrique, trois à quatre fois plus long que le calice; à la partie supćrieure et interne du tube, on trouve deux étamines incluses presque sessiles; l'ovaire, qui est globuleux, offre deux loges, du sommet de chacune desquclles pendent deux ovules; le style, plus court que le tube des ćtamines, se lermine par un stigmate allongć, profondćment bifidc. La capsule est allongćc, comprimée terminée en pointe à son sommet; elle s'ouvre en deux valves carénćes, qui entraînent chacune avec elles la moitié de la cloison adhérente au milicu de leur face interne.

Le lilac est originaire d'Oricnt. Il a été introduit en Europe vers l'année 1562 . On le cultive dans tous les bosquets d'agrément.

Propriétés et usages. Jusqu'en ces derniers temps, on n'avait considéré le lilac que comme un des arbrisseaux les plus agrćables de nos jardins. Aujourd'hui, la médecine compte en lui un mćdicament qui peut devenir d'un grand intérêt. M. le docteur Cruveilhier a le premier attiré sur le lilac l'attention des praticiens. Les capsules encore vertes de cet arbrisseau ont une saveur amère très-franche, sans aucun mćlange d'âcreté. Il en a fait préparer un extrait mou, auquel il a reconnu des proprićtćs toniqués et fébrifuges très-marquées. L'anteur l'a administré à la dose d'un gros, qu'il a quelquefois continuée pendant deux ou trois jours. Les six malades qu'il a ainsi traités de fièvres intermittentes plus ou moins invćtérćes, ont tous ćlé guéris. M. Cruveillier remarque avec sagacité que six faits ne peuvent point faire loi, mais ils suffisent pour appeler l'attention des inćdecins européens sur ce nouveau remède.

$$
\text { FR Ê NE. - FRAXINUS. L. J. }
$$

Lcs fleurs, ordinairement polygames, sont quclquefois nues, c'est-à-dire sans calicc ni corollc; d'autres fois elles ont un calice sans corolle, ou enfin elles sont complc̀tes : dans re derniẹ cas, 
lẹur corolle est composée de quatre pétalés distincts. Le fruit rst une capsulc allongée, comprimce, mince et memlsraneuse sur les bords, à une seule loge, renformant une seule grainc allachée au sommet d'un podosperme filiforme, qui part de la base de la loge et s'ćlève jusqu'à son sommet.

Les frênes présentent tous des feuilles opposćes imparípennées.

Fr.êne a fleurs. Fraxinus ornus. L. Sp. 1510.

La tige de ccl arbre peut atteindre une hauteur moyenne de vingt à vingt-cinq pieds. Ses feuilles, opposćes et imparipennées, sont composćes de sept ou neuf folioles, un peu pétiolćes, ovales, acuminćes, dcntées' d'un vert clair. Les fleurs sont blanches, et s'ćpanouissent ordinaircment en même temps que les fcuilles; elles constituent une sorte de panicule rameuse à l'extrćmitć des jeuncs rameaux, et présentent un calice très-court, à quatre dents, une corolle formće de qualre pétales linéaires lancćolćs. La capsule cst très-allongće, étroite, tcrminće par une languctte planée et un peu obtuse.

Le frône à flcurs croît naturellement en Italic ; il est aujourd'hui naturalisć dans plusieurs foréls de la France.

Proprićtés et usages. C'est de cet arbre et de quelques autres espèccs du mène genre que découle le médicament connu sous łe nom de manine. Cette substance exsude naturellement a travers l'écorce dans les temps chauds; mais pour en augmenter la récolte on pratique des incisions plus ou moins nombreuses, par lesquelles la sève élaborće s'écoule et se concrèle.

On dislingue dans le commerce trois sortes de manne, savoir: $x^{\circ}$ la manne en larmes, qui est $\mathrm{c} n$ grains plus ou noins volumineux, secs, et d'une couleur presque blanche: c'est la plus pure et la plus estinéc; $2^{\circ}$ la manne en sorte, formće de larmes agglutinées par une pâte plus noire : c'cst cclle que l'on'emploie surtout dans les potions purgatives; $3^{\circ}$ cufin la manne grasse, qui est molle, gluanle et très-impure. La manne la plus estimće nous est apportćc de la Sicile et de la Calabrc. M. Thćnard l'a trouvée composće de trois principes, savoir: de sucre, qui en forme environ la dixiènc partie; dc mannite, principe doux ct cristal- 
lisable, qui eonstiluc presque uniquenent la manne en larmes, et à laquelle eile doit toutes ses propriêtés; et enfin d'une matière nauséeuse et incristallisable, d'autant plus abondante que la manne est moins purc.

La manne est un des médicamens les plus fréquemment mis. en usage. C'est un purgatif tellcment doux, suriout quand. elle est très-pure, qu'on peut l'administrer sans ineonvénient, même dans les maladies inflamnatoires; sa dose doit être portée à deux ou mème à quatre onees lopsqu'on veut qu'elle agisse arec quelque efficacitć.

Le Frêne orninatre. Fraxinus excelsior L, qui se trouve abondamment répandu dans nos forèts, présente quelque intérêt sous le rapport de ses propriélés médicales. Ses feuilles, et surtout son écorce, sont d'une astringence et d'une amcrlume assez intenses, pour que quelques autcurs aient proposć de le substituer au quinquina dans plusieurs cireonstances. Cependant il est rare qu'on l'empioie aujourd'hui.

\section{Propriétés médicales et usages.des Jasminées.}

La famille des Jasminées présente dans ses earactc̀res botaniques, des différences assez sensibles pour avoir enigagć plusieurs botanisles à la diviser en deux groupes; savair, les Jasminées vraies ct les Oléinées. Les propriétés médicalés de cette fanille n'auront donc point cette uniformilé, qui fait en:général l'apanage des groupes très-naturels. Ainsi le genre olìvier se distinguera par l'huile grasse que son péricarpe charnu fournit en abondance; les frênes, qui s'éloignent de tous les autrès genres du même ordre par leur corolle polypćtale, en différe ront aussi par leur sève douce et sucrée, qui, lorsqu'elle est conerćtée, forme le purgalif connu sous le nom de: mànne. Nous observerous plus de ressemblanee dans les propriétés des feuilles et de l'ćcoree des Jasinirées, qui est généralement amère, astringentc et tonique. Il en est de même des fleur's qụi, dans plusicurs genres, possèdent un arome suave et très-dćveloppé, comme on le remarque dans les jasmins, les lilas et ecrtaines espèces d'olivier. Il parait uréme eertain que c'est àvec les fleurs de l'olivier olnrant (olca flograns), que l'on aramatise le thé 2 la Chine et au Japon. 
QUARANTE-SEPTIÉMB FAMILLE。

\section{GENTIANEES.-GENTIANEAE.}

Dans les Gentianées, la tige est herbacée, rarement soufrutescente, et donnant attache à des feuilles opposées, sessiles ou pétiolées entières ou composées. Le calice est persistant, monosépale, à cinq divisions; la co . rolle, monopétale, régulière, tubuleuse à cinq lobes: les étamines, généralement au nombre de cinq. L'ovaire présente une ou deux loges; pluriovulées; le style est simple ou bifurqué, et le stigmate est bilobé, ou bien il en existe deux bien distincts. Le fruit est une capsule à une ou deux loges, bivalve, septicide, renfermant plusièurs graines.

$$
\text { GENTIANE. - GENTIANA. L. J. }
$$

Caliee ordinairement à cinq divisions, quelquefois membraneux, fendu et déjeté; corolle infundibuliforme, divisée en autant de lobes qu'il y a de divisions au caliee; étamines alterues a vee les lobes de la corolle, à anthères droites et non rouléés en spirale. Ovaire et eapsule fusiformes, uniloculaires, ans style distinet, mais terminés par deux stigmates roulés ex̦térieurem nt en crosse.

\section{Gentiane saune: Gentiana lutea. L. Sp. 329.}

Part. usitée : la racine. Nom pharm. : Gentiana majoris radix.

Noms vulg. : Grande gentiane; Gentianc jaune.

Cette espèee, l'une des plus remarquables du genre par sa taille èt ses usages, préscnte une racine perpendiculaire vivaee, rameuse, d'un jaune foneé à l'extérieur; elle donne naissanee a une tige droite, d'environ trois pieds de hautcur, simple et cylindrique. Ses fcuilles radieales sont rétrécies en pétiole à leur base; cellcs de la tige sont opposćes, embrassantes et soudées par leur partie inféricurc, ovales, aiguës, très-entières, d'un vert clair, marquées à leur faee inférieure de einq à sept nervures longitudinalcs très-saillantcs.

Les fleurs sont jaunes, assez grandes, pédoneulécs, et eons- 
lituent une sorte d'épi ou de grappe très-allongéc, à la partie supérieure de la lige. Cette grappe sc compose d'un grand nombre de fleurs disposées par groupes à l'aisselle des feuilles forales; les pédoncules de ces fleurs, longs d'environ un pouce, sont ordinairement simples, rarement bi ou trifurqués.

Le calice est membraneux, mince et scarieux; son orifice est extrêmement resserrć dans les boutons encore très jeunes, à cinq dents fort courtes; mais bientôt il se fend latćralement pour laisser sortir la corolle : cclle-ci est rćgulière et presque rotacée, à cinq divisions lancéolées, aiguës, très-profondes: les cinq étamines sont dressćes et altachées à la base de chaque incision. L'ovaire est ovoïde, allongé, terminé insensiblement en pointe à son sommet : il présente une seule loge contenánt un grand nombre d'ovules attáchés à deux trophospermes pariélaux : à la base de l'ovaire se trouvent cinq glandes arrondies nectarifères. Les deux stigmates sont linćaires, roulćs 'en deliors. La capsule est ovoïde allongce, uniloculaire, bivalve, reufermant des graines planes, et membraneuses sur les bords.

La grande gentiane croât dans les lieux montueux, principalement dans les terrains calcaires. On la trouve en Bourgogne, en Auvèrgne, dansles.Vosges, les Pyrénées, les Alpcs, e!c. Elle'fleurit en mai. 26

Propriétés médicales et usages. On doit a MM. Henry ct. Caventon une analise fort exacte de la racine de gentiane. Ils y ont trouvé un principe amer cristallin qu'ils supposent de nature acide, et pour lequel ils ont proposé le nom de geñtianin. Nous l'avons au contrairc signalé comme alcalin r, tant à cause de la manicre dont il se comporte, soit avec lés acides, soit avec les alcalis, qu'en raison des résultat's obtenus par MM. Henry et Caventon cux-mémes, par MM. Henry? Gruillemin et Jacquemin, dans deux précédentes änalises (Journa?
de pharm. avril I 8 I 9 ). C'est dans ce principe amer que résident
les propriélés médical les propriétés médicalcs de la gentiane. Elle contient en outre und malière résino-oléa gineuse, analogue au caoutchouc, beaucouj) de mucilage et un pcu de sucrc qui, par la fermentation, donnent une eau-de-vie assez abondant , mais désa grécíle à caús

Nonleaul Journ. de méd. t. X, p. 3iss. 
de son goût partieulier, dû sans doute à la présenee d'une petite quanilié d'huile volatile. - On prépare avee la racine de genliane un extrait et une leinture alcoholiques. Elle entre aussi dans toutes les préparations destinćes à agir comme stomachiques on toniques, dans le vin amer, le sirop antiscorbutique de Portal, etc.

La racine de gentiane est le plus puissant et le plus énergique des médicamens toniques indigènes. Son extrême amertume, dont l'eau, le vin et l'alcohol s'empareut également, lui assure un des premiers rangs parmi les médicamens qui ont la propriété de ramener lcs organes affaiblis dans l'état le plus eonvenable au libre exereiee de leurs fonctions. Quelques grains de poudre de gentiane ou une cuillerée à café de sa teinture alcoholique, étendue dans un véhicnle approprié, pris une heure avant le repas, exeitent modérément l'action contractile de l'estomae, dćveloppent l'appćtit et favorisent la digestion. Auginentez la dose du médicament, et ses effets d'abord limités à l'estomae, s'étendront bientôt à tous les autres organes de l'ćeonomie animale, et y suseiteront les symptômes de la médieation tonique. L'emploi de la gentiane eonvierdra donc dans toutes les eireonstances où il sera utile de ranimer les forces sans produire une exeitalion trop vive. Ainsi l'on en fait usage dans les fièvres intermittentes, dans le scorbut, et surtout dans les différentes affeetions scrophuleuses. L'usage de la teinture de gentiane, aidé d'un bon rćgime, d'alimens. sains, dc vêtemens chauds, et de l'habitation dans des lieux aérés et bien exposćs à l'influencc du soleil, cst un des moyens les plus effieaees, pour prćzenir et arrêtcr", chcz les enfans $d^{\prime}$ une enstitution lymphatique, les premiers symptômes des serophules. On ne doit recourir à l'usage de la gentiane dans les fic̀res intermitientes, que lorsqu'elles sont simples ou sans eomplieation dangereuse; dans le eas contraire, il serait plus prudent d'employer le quinquina.

ER Y THREE: - ERYTHRAA. Rich.

Caliee à cinq divisions linéaires profondes; corolle liypocratériforme à cinq̣ divisions; antheres roulées cn cpirale après la fécondation; oraire surmontć par un siylc bifurqué frortant 
deux stigmates distincls. Capsule très-allongée, uniloculaire, bivalve, offrant deux trophospermes Iongitudinaux, qui la font paroitre presque biloculaire.

Eníthrée petite centaunée. Erythrcea centaurium. Rich. Chironia centaurium. Lamh.

I'art. usitées: les sommités fleuries. Nom pharm. : Centaurii ininoris summitates. Noms vulg.: Petite Centaurée; Herbe au centaure; Herbe à Chiron.

Cette jolie petite plante annuelle, ešt fréqucnte dans les bois. aux environs de Paris, où elle épanouit ses fleurs roses, aux mois de juillet et d'août; sa tige, d'environ un pied de hauteur, légèrement quadrangulaire, porte de petites feuilles opposées, sessiles, ovales, aiguës, entières : les fleurs forment à la parlie supérieure des ramifications de la tige une sorte de corymbe ou de panicule. Leur calice est cylindrique, à cinq lanières étroites, subulées et dressées ; leur corolle, plus longue que le calice, est infundibuliforme; son tube est étroit et strié, terminé par un limbe à cinq divisions égales, ovales, obtuses. Les étamincs, au nombre de cinq, dépassent à peine l'orifice du tube de la corolle. L'ovaire est très-allongé, presque linéaire, marqué de deux sutures longitudinales; il est à une seule loge, "contenant un très-grand nombre de petits ovules, attachés à deux trophospermes longitudinaux, qui correspondent aux sutures, et qui sont bifurqués à leur còté libre et intérieur. Le style est. moins long que l'ovaire; il est bifurqué à son sommet, et chaque branche porte un stigmate arrondi et comme pelté. La capsule est très-allongée, enveloppée dans le calice et la corolle, qui persistent l'un et l'autre. (-)

Propriétés et usages. Les sommités fleuries de petite centaurée ont une saveur amère très-fianche, qui existe également dans les fleurs et les parties vertes, et qui devient plus intense par la dessiccation, Aussi cette plante est-elle fréqúemment prescrite, soit comme simplement tonique, soit comme fébrifuge. Mais elle ne peut avoir quclque avantage dans ce dernier cas, que lorsqu'on l'cmploie contre des fièvres intermittentes peu intenses. 


\section{MÉNYANTHE. - MENYANTHES. Tournef:}

Calice campaniforme à cinq lobes; corolle en cloche, limbe à cinq divisions égales et barbues à leur face supérieure; einq étamines saillantes; ovaire globrleux, style terminć par un stigmate bilobé. Capsule uniloculaire; graines attachćes sur plusieurs rangs à deux trophospermes, placés sur le milieu des. valves.

Ményanthe trèfle d'end. Menyanthes trifoliata. L. Sp. 208. Bull. t. 13 r.

Part. usitće : les feuilles. Nom pharm.: Menyanthes. S. trifolium. fibrinurn.

Sa tige est une souche herbacće, rameuse, horizontale, articulée, cylindrique, grosse comme le doigt, donnant naissance à des fibres radicales blanchâtres, par différens points. de sa surface inférieure. Les feuillcs sont alternes, amplexicaules et membraneuses à lęur base; le pétiole est long dc plusieurs pouces, et porte à son sommet trois folioles ovales, arrondies, très-glabres, obtuses, offrant quelques dentelures sur lcurs bords. Les flcurs blanches, lćgc̀rement lavćes de rose, courtement pédonculćes, forment un épi court et presque globuleux au sommet d'un pédoncule commun, long de cinq à six pouces, glabre, cylindrique et extraxillaire; chaque fleur est situće dans l'aisselle d'une petite écaille lancéolée, aiguë, plus courte qne le pédoncule.

Le calice est campanulć, à cinq divisions dressćcs. La coro!le est monopétale campaniforme. Son limbe est à cinq divisious lancćolées, aiguës, couvertes à leur face supérieure de longs poils glanduleux.

La capsule est ovoïde glabre, environnée par le calicc.

Cette plante croit dans lcs marécages, dans les étangs aux cnvirons de Paris : elle fleurit cn avilil ct mai. $₹$

Propriétés et usages. Lcs tiges et lcs feuilles de cetle plante sont extrêmcment amc̀res. Elles jouissent d'une propriétć $10-$ niquc bicn manifeste. On en exprime le suc, quc l'on donne à la dosc de deux à trois onces: on en préparc également une 
décoction et un extrait. C'est surtout pour combattre les scrophules, . le rachytis, etc., qu'on én fait particulièrement usage.

\section{Propriétés médicales et usages des Gentianées.}

L'amertume est une propriétć caractéristique de la famille des Gentianées. C'est à elle qu'est due l'action médicale si énergique de certaines d'entre elles, c'est son intensité qui doit faire préférer telle espèce à telle autre. Dans les plus anciẹns livres de matière médicale, nous voyons la gentiane jaune placée au premier rang. On raconte qu'elle a reçu son nom de celui d'un roi d'Illyric, qui le premier en fit connaître les vertus. La petite Centaurée et le Tréfle d'eau ont ensuịte été préconisés et employés dans les ụ̂êmes cas, c'est-à-dire dans les fièvres intermittentes et les maladies où il est nécessaire de donner du ton à la fibre musculaire. Les médecins modernes ónt confirmé les opinions des ancierıs sur ce point; ils emploient toujours avec le plus grand succès lcs Gentianćes comme toniques et fóbrifuges. Plusieurs espèces de gentiane (les $G$. cruciata et ainarella $\mathbf{L}_{\text {: }}$ ), ont été rejetécs comme possédant trop faiblement la qualité amère. La $G$. lutea a été préféréc par plusieurs motifs : elle est très-abondante dans certaines contrées d'Europe; scs racines sont très-grosses et faciles à arracher, et leur amertume est assez intense. Cependant, sous ce dernier point de vue, elle n'approche pas de quelques espèces alpines, telles que les $G$. purpurea et acaulis, qui sont franchement amères et très-peu mucilagineuses; mais leur rarelé, comparée à celle de la G. jaune, et leur exiguitć, seront peut-être toujours des motifs pour les exclure de la pharmacie.

QUARANTE-HUITIËME FAMILLE.

\section{A POCINÉES. - APOCINEEE.}

La plupart des plantes de la famille des Apocinécs sont des herbes ou des arbrisseaux lactescens, dont les feuilles sont opposées, ou verticillées, sans stipules; le calice monosépale à cinq divisions : la corolle monopétale, régulière, ayant l'entrée de leur tube nue ou gar- 
nie d'appendiees de forme variée. Les étamines, au. nombre de cinq, sont tantôt libres et distinetes, tantôt monadelphes et formant une sorte de tube eylindrique, qui reeouvre l'ovaire et se eonfond dans sa partie supérieure, avee le style et le stigmate. Le pollen, renfermé dans ehacune des deux loges des anthères, est tantốt pulvérulent, tantôt réuni en masses sólides, de même forme que les cavités, dans lesquelles elles sont contenues. Le pistil est ordinairement géminé, plus rarement on n'en trouve qu'un qui provient de la soudure des deux ovaires. Chaeun d'eux est à une seule loge, dans laquelle on trouve un assez grand nombre d'ovules, attachés à un trophosperme longitudinal, qui règne tout le long de la suture, que l'on remarque au côté interne de l'ovaire. Lorsque les deux pistils sont soudés, l'ovaire. paraît biloculaire. Le style est généralement eourt, quelquefois eependant assez allongé, et terminé par un stigmate dont la forme est très-variable.

Le fruit est un follieule simple ou double, plus rarement une baie; dans le premier eas, il est uniloenlaire, contient un grand nombre de graines imbriquées, assez souvent ornées d'une aigrette soyeuse qui part de leur biase, et s'ouvre par une suture longitudinale, qui règne sur la face interne. Les graines contiennent, dans un endosperme minee et eharnu, un embryon plane, ayant la radieule supérieure.

Les genres de eette famille peuvent être distribués en deux seetions, savoir : les Aselépiadées et les Apocinées.

$1^{\circ}$ A sclépladéEs. Étamines soudées; gorge de la corolle garuie de cinq appendices, qui forment quelquefois unc sorte de couronne; pollen réuni en masses solides.

$$
\text { CYNANQUE. - CYNANCHUM. }
$$

Cálice à cinq dents; corolle rotacéc à cinq divisions aiguës, 
vifrant à sa gorge une sorte de eouronne monophylle à cinq ou dix lobes; anthères membraneuses à leur sommet; pollen réuni en masses solidẹ, renflées et pendantes. Follieules allongés, renfermant des graines aigrettées.

Le genre eynanque, auquel nous réunissons plusieurs espèees d'aselépiades de Linné, se compose d'arbustes ordinairement sarmenteux et grimpans; dont les fleurs ensitituent des petites o mbelles simples à l'aisselle des feuilles supérieures.

Cyanque arguei., Cynanchum arguel. Delile. Cynanchum olceafolium. Nectoux.

\section{Part. usitćes : les feuillcs.}

L'arguel eroit dans les différentes contrées du nord de l'Afrique, en Nubie, es Égypte, et surtout dans les environs de Syène. Ses tiges grêles, dressées, eylindriques et entièrement glabres, s'élẹvent généralement à une hauteur de deux pieds et portent des rameaux opposés. Ses feuilles sont érgalement opposées, presque sessiles, ovales, entières, terminées en pointe à leurs deux extrémités; elles sont blanehâlres et légèrement tomenteuses. Les fleurs, qui sont blanehes, forment des espèees de eorymbes axillaires et pédoneulés. Leur cálice est régulier, à cinq divisions profondes, étroites, aiguës, étalées. Les cinq lobes de la corolle sont laneéolés, également étalés. Les einq appendices staminaux sont ereux et en forme Uie eornets. Les follieules, tantôt simples, tantôt géminés, sont renflés dans leur partie inférieure, terminés en pointe supérieurement : leur péricarpe est épais et eomme osseux; il contient une grande quantité de graines, qui sont aigrettées.

Propriétés et usages. Les feuilles de l'arguel sont fort souvent mélangées dans les dlifférentes sortes de séné, qui nous sont apportées d'Égyte, et partieulièrement dans le séné de la palte. Ce inélange n'offre aucun ineonvenient, si eomme le dit IM. Neetoux dans ses recherehes sur les sénés d'Égypte, les feuilles d'arguel possèdent absolument les mềmes propriétés que le séné, et agissent d'une manière toul-à-fait analogue. Cependart MI. le docteur Delile prétend que ee médieanent purge avee trop de violenee el eause souvent des eoliques. $\mathrm{Du}$ 
reste, le mode d'action et d'administration de l'arguel est le même que celui du séné.

Cynanque de Montpeluter. Cynanchum monspeliacum. L. Sp. 3 I $x$.

Partie usitée : le suc concret. Nom pharm. : Scammonium monspeliacum. Nom vulg. : Scammonée de Montpellier.

Cette espèce se distingue par sa tige volubile, qui s'entortille autour des corps voisins, par ses feuillcs cordiformes pétiolées, beaucoup plus grandes, d'un vert clair, et tout-à - fait glabres. Elle croît dans les provinces méditerranéennes de la France, dans les licux sablonneux; toutes ses parties sont lactescentes.

Le suc de cette plante, concrétć et mis en masse, porte le nom de scammonnée de Montpellier; il est, comme la scammonće d'Alep, violemment purgatif. Mais on en a presquentièrcment abandonné l'usage.

Cxnanque Ipécacuanha. Cynanchum ipecacuanha. Rich.

Part. usitée : la racine. Nom vulg.: Ipécacuanha de l'Ile de France.

Petit arbuste sarmenteux, dont la racine se compose d'une touffe de fibres longues et blanches; lestigcs sont sarmenteuses, efílées, glabres ou tomcnteuses, longues de deux-à trois picds ; les feuilles opposées, courtement pétiolées, cordiformes, aiguës, entières, tantôt glabres, tantôt velues; les fleurs sont petites, blanchâtres; elles formeñt des petites grappes axillaires, plus longuès quc les feuilles et pauciflorcs.

Cette plante, qui crot naturellement aux iles de France et de Bourbon, a étć décrite par M. Delamarck, sous le nom de Cynanchum vomitorium. 4

Sa racine, qui est âcre et amèrc, est employće à l'Ile de France comme succédanće de l'I pécacuanha. Elle est en effct très-émétique. 'C'est unc des espèces d'ipécacuanha blanc. (Voy. notre Histoire naturelle et médicalc des ipécacuanha du commerce, vol. in $-4^{\circ}$, fig. Paris, 18 18.) 
Cranque dompte-yenin. Cynanchum viricetoxicum. Rich.

Asclepias vincetoxicum. L. Sp. 3 r 4. Bull. t. 5 x.

Part. usitée : la racine., Noms pharm. : Vincetoxium. S. Hirudinariae radix.

Le dompte-venin est une petite plante vivace, commune dans 'les bois sablonneux, aux environs de Paris, où ses fleurs s'épanouissent vers le mois de juin. Composée d'une souche horizontale tuberculeuse, d'où partent un grand nombre de fibres allongées et cylindriques, sa racine pousse une tige d'un pied à un pied et demi de hauteur, cylindrique, très-glabre, comme tontes les autres parties de la plante, presque simple, portant des feuilles, opposées, cordiformes, aiguës, entières, pétiolées; des fleurs blanehes ou jaunâtres assez petites, qui forment des espèces de petites ombelles simples, pédoneulées dans l'aisselle des feuilles supérieures.: la corolle est rotacée à cinq lobes aigus; la couronne est charnue, à cinq lobes obtus.

Les fruits ou follicules, ordinairement géminés sont trèsallongés, terminés en pointe, glabrcs et lisses, longs d'environ deux pouees. Les graines sont planes, marginées, et portent une aigrette soyeuse et nacrée. ' f

Propriétés et usagés. La racine du dompte-venin encore réeente a une odeur un peu nausẻabonde; une saveur âcre, amère et désagréable, qui se perdent un peu par la dessiceation. C'est un médicament actif, dont la décoction provoque tantót le vomissement on des évaeulions alvines plus ou moins abondantes. Autrefois employée eomme alexipharmaque et contre un grand nombre d'affeetions différentes, cette racine est absolument inusitée à présent.

$2^{\circ}$ Apocinézs vraies. Étamines distinctes; gorge de la corolle ordinairement nue; pollen pulvérulent.

\section{PERVENCHE. $-V I N C A$. L. J.}

Calice monosépale à cinq divisions linéaires; corolle hypocia- 
térifurme, tube un peu évasé, limbe à cinq divisions obliques; entrée du tube nue; filets des étamines planes et dilatés au sommet; anthères à deux loges écartées par le filet: follicules géminés, allongés, renfermant des graines sans aigrette.

Les espèces sont presque toutes de petites plantes herbacées ou de pclits arbustes rampans.

\section{Pervenche mineure. Vinca minnt. L. Sp. 3o4. Blackw. t. 59 .}

Part. usitée : les feuilles. Nom pharm. : Vincee pervinca herba.

Cette petite plante, qui croît en abondance dans les lieux couverts et ombragés, et que l'on voit fleurir dès les mois de février et de mars, offre une racine rampante, fibreuse, blanchâtre, qui pousse plusieurs tiges, redressées, hautes de six à dix pouces, souvent beaucoup plus longues, grêles, portant des feuilles opposées, courtement pétiolćes, ovales lancéolées, très-entières, coriaces et luisantes. De l'aisselle des feuilles partent des fleurs solitiires, d'un bleu clair, pédonculées. Lenr' calice est monosépale à cinq divisions étroites, linéaircs, subulées, égales. Leur corolle est régulière et lıypocratériforme; son tube est un peu dilaté à sa partie supérieure, et le limbe est plane très-grand, à cinq divisions égales, subeunéiformes et irrégulièrement quadrilatères. Les cinq étamines sont incluses, rapprochées et cacliant entièrement le style et le stigmate. Les filets étroits et coudés à leur base, sont planes, dilatés et trèsolstus à leur partie supćrieure; les anthères sont à denx loges, séparées l'une de l'autre par le sommet du filet qui se prolonge au-dessus d'elles. Chaque loge, qui s'ouvre par un sillon longitudinal, contient une masse ovoüde de pollen, dont les particules sont peu adhérentes. L'ovaire est bilobé, accompagné de deux écailles latérales discoïdes, de la même hanteur que lui; il présente deux loges qui contiennent chacune de liuit a dix ovules: le style est allongé, élargi vers sa partie supérieure, où il offre un disque aplati, surinonté par le stigmate, qui est poilu.

Le fruit est un duuble follicule, renfermant des graines dépoirnues d'aigretle. 
Propriétés et usages. Les feuillos de la petite Pervenche, et celles de la Grande Pervinghe (Vinca major. L. Sp. 3o\%.), qui est bcaucoup plus grande dans tontes ses partics, et que I'on rencontre dans les haics des provinces unćridionales de la France, ont une saveur amère, un peu âcre et astringente. Elles sont faiblement purgatives et diaphorćtiqucs. Elles ont en quelque sortc une réputation populaire pour diminuer et suspendre la sécrétion du lait, soit à l'ćpoque de l'accouchement, soit au moment où l'on veut terminer l'alaitement. La. tisane faite avec la racine de canne et les feuilles de Pervenche est la plus fréquemment usitée dans cettc circonstance, quoique cependant son efficacité soit loin de justifier cette espèce de vogue.

\section{NÉRION.-NERIUM. L.J.}

Calice à cinq divisions profondes: corolle beaucoup plus grande, infundibuliforme rćgulic̀re, à cinq lobes obliques, à la base desquels se trouvent cinq appendices pćlaloïdes frangćs; étamincs distinctes, incluses; anthères sagittées, terminées par unc longue pointe barbue : style portant un stigmate cylindrique tronquć. Follicules allongés contenant un grand nombre de graines aigrettćes.

Nénxon laurier rose. Nerium oleander. L. Sp. 3o5. Part. employée : les feuilles. Nom pharn. : Nerion. 'Noms villg.

Laurier rose, Laurose, Rosage, etc. pieds, se divie to to six à donye chargés de feuilles terneaux trifurqués, allongćs et pubescens, aiguës, rétrćcies insnćes, scssiles, lancéolćes, roides, entičrcs, cinq pouces et plus, liblcment à la báse, longues de trois à

, larges d'environ un pouce.

de corymbe à tres-grandcs, ćlćgamment disposćes en une sorte panulé, à cinq division supérieure de la tige. Calice petit, cảmcorolle monopćtale profondes, linćaircs, a iguës, rougcâtres; tube garni de cinq a régulière, infundibuliforme; orificc du supéricure. Limbe à cindices pétaloïdes, frangés à leur parlie mines attachées à la cinq divisions obtuscs, égalcs. Cinq éta - 
cluses; filets eourts un pen renflés et arqués; anthc̀rcs biloculaires, sagittées, aminciessupérieurement, et sc tcrminant à leur sommet, par un longue pointe renflće, toute couverte de longs poils blanes et laiueux; ẹhaque loge se termine inférieurement par une pointe aiguë, assez longue. Le jistil se compose d'un ovaire double, ou de deux ovaires rapprochés, tout couverts de poils blencs; ils sont uniloculaires et contiennent un grand nombre d'ovules attachés à un trophosperine pariétal et interne. Ces deux ovaires sont surmontés d'un seul style renflé vers sa partie supćrieure, atteignant à peu près la hauteur des anthères, et terminé par un stigmate proéminent, tronqué à son sommet, et offrant à sa partie inférieure cinq petits appendices très-courts. Le fruil est un follieule double, ovoïde, trc̀sallongé, terminé en pointe à sa partie supérieure, rempli de graines aigrettées.

Le laurier rose, qui fait en automne l'orncment de nos jardins, et que nous rentrons dans la serre tempérée pendant l'hiver, végète avec vigueur dans les régions mćridionales de la France, oì il eroît dans les fentes des rochers et les lieux les plus esearpés auprès des torrens.

Propriétés et usages. Cet arbrisseau, qui flatte notre vuc par la beauté de son feuillage toujours vert, par l'éléganee de ses fleurs grandes et roses, possède eependant des propriétés extrênement dćlćtèrcs, surtout lorsquil croît au milieu dcs rochers dans les contrées méridionales de l'Europe. Son principe vénćneux est tcllement subtil, que scs émanations seules ont suffi, au rapport de quelques autenrs, pour occasioncr les aceidens les plus graves et même la mort chez les individus qui y étaient restés exposés pendant quelque temps. Il existe à la fois dans les feuilles, dans l'éeorce et jusque dans le bois luimême; mais il s'affaiblit beaucoup par la eulture. Les expériences multipliées de M. Orfila ont prouvé l'ćncrgie des propriétés de l'cxtrait du laurier rose, que cet habile expérinenta;teur place parmi les poisons narcotico-âcres. Aussi fait-on bicus rarcment usage de ee vćgćtal. Quclques auteurs emploicnt son extrait, dissout et ineorporé daus un liniment, contre les naladies chroniques de la peau, les dartres, la gale, etc. Sa dose est d'un scrupule pour un liniment de trois onces. 
Une autre espèce du même genre, le Nerium antidysentericum de l'Inde, fournit le médicament connu sous le noin de $C_{0}$ daga-pala. Cette écorce, qui est d'un rouge ferrugineux, épaisse, rugueuse, est, au rapport de Rheede, très-usitée dans l'Inde, contre la dyssenterie. Malgré les éloges qui lui ont été prodigués par Bernard de Jussieu, elle est entièrement inusitée par les médecins modernes.

\section{S TR YGHNOS. - STR YCHN.OS. J. I}

Caliee unonosépale à quatre ou cinq divisions plus ou inoins profondes; eorolle menopétale, lubuleuse, ayant le limbe à quatre ou einq découpures; étamines libres et distinetes, insérées au sommet du tube, en nombre égal aux lobes de la eorolle, dont l'entré est souvent fermée par des poils. Ovaire simple, uniloculair , surmonté par un style. Le fruit est globuleux, cliarnu, renfermant plusieurs graines, logées dans une pulpe aqueuse.

Les Strychnos sont des arbres assez élevés, non lactescens, dont les feuilles sont opposćes, entières, et les flẹurs assez petiles, disposées en eymes axillaires ou lerminales.

Str ychyos yorx vomique. Sirychnos nulx vomica. L. S. 271. Blackw. t, 3,95.

Part. usitée : les graines. Nom pharm. : Nux vomica.

C'est dans l'Inde, et partieulièrement à Ceylan, au Malabar et sur la côte de Coromandel, que crioit l'arbre long-temps ineonnu, dont les graines sont appelées noix vomiques dans le commeree. Son trone est d'une grossẹur et d'une élćvation médioeres; ses rameaux opposés sont cylindriques, glabres, d'un vert terne, chargés de feuilles opposées, eourtement pétiolées, ovales, arrondies, très-entières, lisses et glabres; ses fleurs sont petites, blanehes, formant à l'extrémité des jeunes rameaux de petits corymbes terminaux. Leur calice est

x M. de Jụssieu ot M. de Candolle ont proposé d'étahlir une famille nouvelle et distincte dẹs Apoocinées, donțt le genrc strychnos deviendrait le type; mais les caractères des genres que l'on y r'́cunirait, sont trop imparfaitement connus, pour que nous ayons cru 
beaucoup plus court que la corollc, à cinq divisions; le tứcic de la corolle est un peu renflć dans sa partie supérieure; lés cinc éla mines sont incluses. Les fruits sont ovoïdes, à pcu près de la grosseur d'une orange : leur enveloppe extérieurc est crustacée et assez fragile; leurs graines, qui semblent éparses dans une pulpe aqucuse, sont orbiculaires, déprimćes, ombiliquées sur une de leurs faces; larges de six à huit lignes, ayant de trois à quatre lignes d'épaisseur, d'une couleur brunâtre claire, un peu velues. Leur saveur est amère et désagréalule.

Propriétés et usages. Les Arabes paraissent ĉtre les premiers qui ont connu les propriétés énergiques et délétères de la noix vomique, dont on a pendant long-temps ignoré la véritable origine. Cette substance n'a guèrc élé connuc, jusqu'en ces derniers temps, que par son action pernicieuse sur l'homme et les animaux. Tous les expérimentateurs s'aceordent à considerer la noix vomique comme un poison des plus aetifs, dont les effets consistent parliculic̀rement dans unc sorte d'excitation de la moelle épinic̀re et de tous les museles qui en reẹoivent leurs nerfs. De là les contractions tétaniques que l'on observe dans les muscles des membres et ceux de la poitrine; contractions qui, s'opposant aux mouvemens de la respiration, déterminent une asphyxie complète, à laquelle on doit attribuer la mort, qui ne tarde point à survenir. En effet, on obscrve chez les in dividus qui ont succombé à l'usage de ce poison, les poumons gorgés d'un sang noir, la face violette et infiltrée; en un mot, tous les symptômes de l'asphyxie: tandis qu'en général lcs organes de la digestion ne présenten taucune trace de lésion, à moins que la noix vomique n'ait été ingérée en trop grande quantité dans l'estomac; car dans ce cas cct organe devient le siége d'une inflammation violente, ainsi que le prouve I'observation rapportée par M. Orfila. (Leçons de méd. kigg. p. 259.)

MIM. Pellctier et Caventou ont fait connaitre la composition chimique de la noix vomique. Ils y ont découvert un principe alealin nouveau, qu'ils ont nommé Strychnine. Cette matière bien purcse présentc sous la forme d'une poussière fine, blanclic, formée de petits cristanx à quatre pans, terminés par des lyramides à quatre faces; clle est presqu'insoluble dans l'ean et 
dans l'éther; nai se dissout facilemcut dans l'aleohol. Sa savcur est excessivement amc̀re. La strychnine est combinée dans lia noix vomique avec un acide particulier, observć d'ábord par oes habiles chimistes dans là fèvo de Saint-Ignace, et nommé l)ar eux Acide igasurique. On y trouve de plus une matière colorante'jaune, une huile conerète, de la gomme, de l'amidòn, de la bassorine et un peu de eire.

Des expériences multiplićes ont prouvé quc la stryclinine éait la seule partie active de la noix vomique, dè la fève SaintInnace, de l'upas tieulé et du bois de couleuvrée, dans lesqucls l'analise chimique en a démontré l'existenee. Une très-petile quantité de eet alcali, ou del'un de ses sels, détermine tous les accideus que nous avons signalés pour l'cmploi dé là noix vomique et avec une intcnsité beaucoup plus forte. Ces symptôınes se développent également, soil que la substance ait élé avalée, soit qu'on l'ait mise en eontact avec le lissu cellulaire denudé, soit enfin qu'on l'ait, injectée dans les veines ou dans le gros.intestin.

On ne sera pas surpris de voir les praliciens s'être enparć d'une substance qui a git aussi puissamment sur l'ćcononie animale, pour chercher à relirer quelqu'avantage de son adìninistration contre plusieurs affections rebclles. Ainsi les uns l'ont employće eomme un puissant j)réservatif eontre les' malidics pcstilenticlles; les autres ont vantć soñ usage dans les fièvres intermittcntes; ccux-ci l'ont reeommandée dans les affections nerveuses, telles que l'lıystćrie, la 'manie, l'hypocondrie; cte. Mais on avait presque totalement négligé l'emploi de ce mòyen éncriqique, lorsque les rccherehes de MM. Magendic et Delile, et surtout les observations eliniques de $M$. le professenir.Fouquicr, ont rappclć l'attention des mćdeeins sur cctlc substance. Cet habile praticien a su tircr un parti avantageux de l'aelion. que la noix vornique, ot surtout la strychnine, excres sur la moclle épinière, cn administrant ee médicament dans la paralysic ct surtout celle des membres infćrieurs. Les suecès quc l'on cin a réjà obtcnus dans une foule de circoustances font cspérce usuc ce múdicament pourra être d'unc graude utilitć daus le vomirgue en celte mialadie. On donne bien rarement la noix . mue en naturc; c'est principalement son cxtrait alcoho- 
lique que l'on administre, í la dose d'un à deux grains, sous forme pilulaire. La teinture s'emploie à la dose de vingt à trente gouttes. Cette quantité doit être graduellemcnt augmentée, jusqu'à ce qu'elle produise quelques effets sensibles. On doir, au contraire, la suspendre tout-à-fait, quand il se dćveloppe des phénomènes trop intenses, qui annoncent la trop grande ćnergie de son action.

La strychnine est un médicament tellement énergique, que bien peu de praticiens osent l'employer à l'intérienr. M. Magendie propose de faire des pilules de conserve dc roses, dans chacune desquelícs on ferait entrer $\frac{1}{32}$ ou $\frac{2}{8}$ de grain de strychnine, ou de préparer une teinture avec une once d'alcuhol à $36^{\circ}$, et truis grains de strychnine. La dose est de six à vingtquatre gouttes dans une potion ou une tisane appropriée.

Strrychros pìve de Sarnt-Igrace. Sirychnos Ignatia.

Ignatia amara. L. Suppl. I 49.

Part. usitée : les graines. Nom pharm. : Faba Sancti-Ignatii. s. Faba indica. Noms vulg.: Igasure, Fèse Saint-Ignace.

C'est au jésuite Camelli que l'on doit la connaissance de l'arbre dont les graines son nommées fères de Saint-Ignace. Pendant son séjour aux îles Pliilippines il en envoya des échantillons à Ray et à Petiver, qui en publièrent la description dans les Transactions philosophiques de Londres (année r669). Plus tard, Linné fils décrivit ce végétal sous le $110 \mathrm{~m}$ d'Ignatia amara (suppl. p. 149.). Enfin la plupart des moderncs le considèrent comme unc espèce du genre strychnos. Cetarbre, asscz élévé, porte des rameaux longs, cylindriques, très-glabres et conme sarmentcux, sur lescuels sont des fcuilles opposécs jpresque sessiles, ovales, acuminćcs, entic̀res, planes et très-glabres; les fleurs forment anx aisselles des feuilles des petites grappes caurtes; elles son: blanches, tubulcuses, ct. exhalent unc odeur agréable de jasmin. Les fruits, dè la grosscur d'une moycnne poire, sont ovoüdes, glabres; lcur enveloppe extéricure est sèche ct cassantc; lcurs graines, dont le nombre varic de quinze à vingt-cinq, sont éparses dans la pulpc; ellcs sont irrćgulic̀rement anguleuses, larges d'environ un porce ; leur surface, d'un 
brun pâle, est stricie et glabre; leur iṇtérieur est eorné, dur et d'une teinte verdâtre. Ces graines possèdent une saveur excessivement amère, qui se manifeste avee intensité dès qu'on en place la plus petite pareelle dans la bouehe.

Proprićtés et usages. Les fèves de Saint-Ignace sont considérécs aux îles Philippines eomme un remède des plus précieux, comme une sorte de panacée propre à la guérison de toutes les mala dies. Aussi les jésuites., qui les premiers les firent connaitre en Europe, erurent-ils devoir les décorer du nom de leur saint fondateur. C'est en eore MM. Pellelier et Caventou. qui nous ont dévoilé la nature elimique des prineipes eonstituans de la fève de Sainl-Ignaee, prineipes qui offrent la plus grande ressemblance avee eeux de la noix vomique. Ainsi on y trouve également de la strychnine eombinée avee l'aeide igasurique. Cet alcali végétal y existe même en plus grande quanlité que dans la noix vomique, puisqu'un kilogramme de fèves de Saint-Ignace leur a donné douze granmes de stryehnine pure, , landis qu'ils n'en ont retiré que quatre grammes d'une ćgale quantité de noix vomique.

Les expériences de MM. Magcndie et Delile onl démontré que eelte graine agit absolument de la même manière sur l'éeonomie animale, que la noix vomique. La mort qu'elle oceasionne lorsqu'on l'administre a liaule dose, parait également due au spasme qui s'empare des museles qui servent aux mouvemens respiratoires et à l'ásplıyxie qui en est lia suite.

Cette substance, dont on peut retirer la stryehnine, est peu. employée en médeeine, quoiqu'elle possède les mêmes propriétés que là noix vomique, et même à un degré plus intense.

Le genre strychnos est un de eeux dont toutes les espèees présentent l'uniformité la plus grande dans leur aetion sur strychnos et leurs produits sont essentiellement vénéneux, et lens. Aux exemples qne nous tirerons de la noix vomique et: de la fève de Saint-Ignaee nous pourrions ajouler eeux qui. nous sont encore offerts par le bois et la raeine de eonleuvrée,
ct surtout parl l'upas tieuté.

Le bois et la racine de coulcure ou de couleupréc sont pro- 
duits par le strychnos colubrina de Linné. Ces substanees, aujourd'hui inusitées, sont d'une amertume extraordinaire. MM. Pelletier et Caventou y ont eonstaté l'existenee de la stryehnine.

Quant à l'upis tieuté, e'est un des plus violens poisons du règne végétal. Les Javanais le retirent d'une espèee de-strychnos, et s'en servent pour empoisonner leurs flèehes. MrM. Delille et Magendie ont obtenu, par l'emploi de ee poison, les mêmes résultats de leurs expérienees sur des a nimaux vivans, que eeux qu'ils avaient déjà observés pour la noix vomique et la fève de Saint-Ignaee. Enfin MM. Pelietier et Caventou en ont également retiré de la stryehnine.

Propriétés médicales et usages dcs. Apocinées.

Le sue âere et laiteux, dont nous avons fait remarquer là présénee dans la plupart des genres de eette famille, leur eommunique des propriétés assez énergiques, et généralement délétères. Ainsi les raeines de plusieurs espèces, telles que le Cynanchum ipecacuanha, le Cynanchum monspeliacum, l'Asclepias curassavica, et quelques autres, sont émétiques et propres à remplaeer l'ipéeaeuanha đans les pays où elles eroissęnt. Ces racines et eelles de plusieurs autres Apoeinées agissent également eomme purgatives, ainsi qu'on l'observe pour eelles du $C y$ nanchum monspeliacum, qui fournit la seammonée de MIontjellier, eelles du Periploca secamone, qui produit la seammonéc de Smyrne. Dans l'éeoree du Codaga-pala, l'amertume prédomine sur le prineipe ảere, et lui donne une propriélé tonique assez marquée, que l'on retrouve également dans la raeine $d u$ dompte-venin.

Si le prineipe âcre est très-abondant, les $\Lambda$ poeinées sont alors. fort délétères. Le laurier rose, plusieurs aselépias, et surtont les espèees et les produits du genre-stryehnos, tels que la noix vomique, la fêve de Saint-Irgnaee, l'upas tieuté, la raeine de énuleuvrée, en fournissent des exemples remarquables, et sont, à juste titre, rangés au nombre des poisons narcotico-âeres.

Cependant nous trouvons quelques alimens parni les plantes de eette famille; mais ils sont toujours pris dans des espèces herbacées, à l'époque de leur premier développement, lorsque 
la sève ascendante, formée de slles açucux tiès-abondars, we s'est point encore transforméc en sucs propres par le travail de la végétation. Ainsi l'on mange dans plusicurs pays les jeunes ponsses du Periploca esculenta, de l'Apocinum indicum, de l'Asclipeas aphylla, etc.

IValgré cette anomalie beaucoup plus apparente que réelle, l'on peut dire de toutes les plantes de la famille des A pocinées, qu'elles sont âcres, purgatives ou très-rénéneuses, et que ces propriétés éncrgiques dépendent généralement d'un suc propre, blane et laiteux, que presque toutes contiennent en abondance.

QUAR ANTE-NEUVIEME FAA MLLE.

\section{DTOSPYREES - DIOSPYREAE:}

Les genres réunis par la plupart des auteurs dans cette famille n'ont point une égale affinité entre eux: 'Aussi' est-il assez difficile de rapporter rigoureusement les Diospyrées à l'une des classes de notre méthode, du moins avec tous les genres que l'on y place généralement. En effer, le calice, qui est toujour's monosépale, est tantôt entièrenent libre, tantôt soudé par sa base, ou même sa totalité, avec l'ovaire, qui dans ce cas est semi-infère ou infère; le limbe présente quatre à six dents quelquefois inégales. La corolle est monópétale, domnant attaclie à des étamines dont le nombre est déterminé ou indéterminé; ces étamines ont les filets libres, ou soudés par lcur base en un ou plusieurs faisceaux. L'ovaire est, comme nous l'avons dit, tantôt supère, tantôt infère ou seulement semi-infère; il présente ordinairement quatre loges, et dans chacune d'elles deux ou quatre ovules, dont les uns sont dressés, les autres pendans. Le style, qui est simple, se termine à son sommet par un stigmate ordinairement quadrilobé. Le fruit,

' Cette famille porte encore les noms d'Ebénacées, parce qu'une des plantes rui y sont réunies produit le bois d'ébène, de Plaquemi-
niers ou de Guaiacanćcs. 
tantôt nu, tantôt couronné par le limbe du calice, est sec on charnu; il offre quelquefois une seule loges et une seule graine, par l'avortement constant des cloisons et des autres ovules; d'autres fois il est à trois ou quatre loges, qui contiennent chacune une seule graine. L'embryon est allongé, renfermé dans l'intérieur d'un endospernie un peu dur et comme corné.

Cette famille se compose de végétaux dont la tige est ligneuse et souvent arborescente; les feuilles alternes sont simples et dépourvues de stipules; les fleurs sont axillaires.

Les Diospyrées se distinguent facilement des Apocinécs par une foule de caractères, tels que leur ovaire simple à quatre loges; la structure de leurs étamines; leurs feuilles alternes, etc.

$$
\text { STYRAX. - STYRAX }{ }^{2} \text {. L.J. }
$$

Calice un peu urcéolé, persistant, offrant à son limbc de cinq à sept dents; corolle tubulense à sa base, limbe offrant de trois à cinq lobes profonds; étamines de six à seize, insérées au tube de la corolle; filets un peni soudés par leur base. Ovaire presque entièrement libre, a quatre loges, contenant chacune deux ovules, l'un dressé, l'autre pendant; style terminé par un stigmate quadrilobé. le fruit est globuleux, sec, ordinairement à une seule loge, dont la paroi interne offre les restes des cloisons avortées, et qui contient d'une à quatre graines, tantôt insérées au fond, tautôt au sommet de la loge.

- La famille des Diospyrées ou Plaquemiers est, avec celles des Cupulifères, des Jasminées et quelques autres, une de celles daus lesquelles l'avortement presque constant de plusieurs des parties de l'ovaire masque et change le plus l'organisation primitive du fruit.

- Cè genre diffère à plusieurs égards des véritables Diospyrées, et réuni à quelques autres, tel que Halcsia, etc., il paraît constituer une famille distincte qui porterait le nom de Styracécs. 
Strrax officinat. Styrax officinale. L. Sp. 635.

'Part. usitće : le baume qui s'en écoule. Noms pharm. : Styrax calamita. Nom vulg. : Styrax ou Storax calamite.

Cet arbre, que l'on connait vulgairement sous les noms d'aliboufier ou d'aligoufier, croît națurellement en Orient et dans le midi de l'Europe. On le trouve aussi dans les provinces méridionales de la France, et surtout en Provence, dans les lieux secs et rocailleux. Il s'ćlève d'ordinaire à une hautcur de quinze à vingtacinq pieds, et se couronne de rameaux dont lcs feuilles sont alternes, ovales, entic̉res, pétiolées, molles, pubescentes des deux côtés, mais surlout inférieurement, où elles sont blanches et cotoneuses; les fleurs sont blanches, réunics, au nombre de trois à quatre à l'extrémilé dcs àrameaux. Elles sont à peu près de mème grandeur et de même forme que celles de l'oranger. Leur calice est court et prcsque cupuliforme; la corolle est à cinq ou six lobes ćtroits et très-profonds. Les étamines, variables en nombre de dix à seize, ont leurs filets monadelphes par leur base. Le fruit est globuleux, dc la grosscur d'une cerise; son péricarpe est sec et tomenteux, à une seule loge, qui contient de deux à quatre graines, dont la forme est très-variable.

C'est de cet arbre que l'on retire cn Orient la substance résineuse et balsamique connue sous le nom de Storax ou de Styrax calamite, qui est toujours solide.

Propriétés et usages du Storax. Les droguistes en distinguent deux espèces, savoir : le Storax en larmes et le Storax en pains. Le premier, composé de petits grạins transparens, est très-pur, el paraît s'écoulcr naturellemcut de l'arbre; le second est en masses rougeâtres, rćsincuses, de la grosseur du poing. On l'oblicnt'en pratiquant des incisions profondes au tronc de l'aliboufier.

Le Storax jouit, comme tous les autres bauınes, de proprićtés stimulantes. Malgré les éloges qui lui ont ćté prodigućs par Morton, les praticicns sont loin dc le considérer comme un spécifque assuré contre la phthisie pulmonaire; et aujourd'hui on ne l'emploie guère qu'á l'extćricur, soit en fumiga- 
tions, soit comme topiquc. Il entrc dans ylusieurs médicamens officinaux, entre autres dans la thériaque, le diascordiuin, le mitbridate, ctc., etc.

Une ąutre espèce de ce genre, non moins intércssante, est celle qui fournit le benjoin ", et qui a été décrite par Dryander, sous le noni de Styrax benzoe. C'est un arbre assez élevé, qui croit à Sunatra, à Java, et dans d'autres parties de l'Indc. Le benjoin, d'abord̀ liquide, s'écoule naturellcment de son écorce, ou à travers les ineisions qu'on y pratiquc. On a longteinps ignoré l'origine de ce médicament, que les uns attribuaient à un laurier, les autres à un croton, Lamarek à un badamier, elc. Dans le commerce, on en distingue deux esjèies, savoir: le benjoin amjggdaloüde, qui cst en masses solides, formées de larmes blanchâtres, réunies par une pâte presque brune; et le benjoin en sorte, inoins pur que Je précédent, et dont la cassure est uniforme et brunâtre.

I.e benjoin amygdaloïde a une eassure nette et brillante, une odeur suave, une saveur aromatique et un peu acidule; il se brise faeilement et crie sous la dent. Il brûle en répandant une fumće épaisse et blanehe, lorsqu'on le projelte sur des charbons ardens. Celte fumée cst de l'acide benzoïque, qui se sublinc, et' que l'on 'pent frilement recueillir en la recevant dans des vaisseaux froids. Cctte substance balsamique est entièrement soluble dans l'alcohol ct l'éther. L'eau la précipite de ses solutions alcoholiques, trouble la liqueur, et lui donne une teinte blanehe et laiteuse. C'est par ee moyen qu'on Irépare le lait vïrginal, cosmétique dont les dames font un grand usinge dans leur toilette, parce qu'il a la réputation d'adoucir el de tendre la jieau.

Le benjoin est un médicament stimulant, dont l'action est enlièrement analoguc à celle des autres substances résineuses et balsamiques. On l'emploie plus spécialement dans les inflamuations chroniques des organcs de la respiration, ct sur-

- On a pendant long-temps iğnoré la véritable origine dẹ ce baune. Les uns le croyaient produit par un lauricr (Laurus benzoin), les antres par un croton (L. benzoin), Lamarck par un badanier (Torminuliu benzoin): Dlarsdeu et Dryander ont prouré qu'on le tirạt d'un slytax. 
'tout dans celles de leurs membranes muqueuses. C'est ordinairement en poudre et sous forme de bols ou de pilules, que l'on fait usage da benjoin, à la dose d'un scrupule á un demigros.' D'autres fois on fait respirer au malade la fumée blanche qui se dégage lors de la combustion du benjoin. On administre encore ce médicameñt sous la forme de teinture et de sirop.

- L'acide berizoïque pur, que l'on nomme vulgaircment fieurs de benjoin, se retire par sublimation du benjoin et des anres baumes qui en renferment aussi. Il est sous forme d'aiguilles fines, blanches 'et uacrées. II n'est pas sensiblement odorant; sa saveur est àcre et piquante. Cet acide possède les mêmés propriétés quie les baumes dont on l'extrait. Il s'emploie dans les mèmes circonstances, mais à des doses plus faibles. Ainsi on en administre la poudre depuis dix jusqu'á trente grains.

Les autres genres de la famille des Diospyrées n'onl rien de remarquable par leurs propriétés médicales. Les früits, dans le genre plaqueminier (diospyros), sont des baies charnues, d'une saveur aigrelette assez agréable, ct quc l'on mange dans les pays où croissent les différentes espèces.

CINQUANTIÈME FïIILLE.

\section{ÉR I CINÉES. - E RICINEX.}

\section{Erice et Rhododendra. Juss.}

Les Éricinées sont des arbres ou des arbustes. d'une forme ćlégante et d'un aspect agréablc, dont les feuilles, sont alternes, opposées ou verticillćes; les fleurs ordinairement disposées en ćpis ou en grappes.

Le calicé est monosépale, persistant, divisć en quatre ou cinq lobes; la corolle monopétale régulic̀re est souvent persistante, quinquépartite, offrant des glandes nectarécs à sa basc internc : les ćtamines, ordinairement au nombre de huit ou dix, sont insérées à la base de la corolle, qui est périgyniquc; les anthères sont biloculaires, solıvent terminécs à leur base ou à lcur sommet par deux appendices subulés, ct s'ouvrent ordinairement par un 
simple petit trou pratiqué à la partie supérieure, plus rarement à la base de chaque loge. L'ovaire est libre et supère, ordinairement à cinq loges pluriovulées; le style et le stigmate sont simples. Le fruit est ordinairement une capsule à cinq loges et à cinq valves, lesquelles emportent, en s'écartant, tantôt une partie des cloisons sur leur face interne, tantôt ont leurs bords rentrans pour former les cloisons. Cette capsule est ordinairement accompagnée du calice. Les graines sont petites et leur embryon est dressé au centre d'un endosperme charnu.

Nous avons, à l'exemple de M. Desvaux et de la plupart des botanistes modernes, réuni les deux familles des Bruyères et des Rosages de M. de Jussieu, distinctes seulement par le mode de déhiscence de leurs fruits, qui, dans les prcmières, s'ouvrent au moyen de valves enlevant les cloisons sur leur face interne; tandis que dans les seconds les bords rentrans des valves forment les cloisons. Ce caractère assez important n'est cependant pas suffisant pour établir deux familles distinctes, d'autant plus qu'ils se rencontrent quelquefois l'un et l'antre dans certaines espèces d'un même genre, comme on l'observe par exemple dans le genre bruyère.

Nous avons retranché de cette famille des Bruyères les genres dont l'ovaire est infère, pour en former la nouvelle famille des Vacciniées, qui diffère aussi par son fruit, qui cst toujours une baie, ce qui est plus rare dans les véritables Éricinées.

$I^{0}$ Fruit charnu.

\section{ARBOUSIER. - $A R B U T U S$. L. J.}

Calice étalć, à cinq divisions profondes : corolle tubuleusc, souvent renflće, terminée supérieurement par cinq dents réflichies; dix ćtamincs incluses, dont les anthères sont appendiculées; baie à cinq loges contcnant unc ou plusieurs graines.

Les arbousiers sont des arbustes, des arbrisseaux ou méme 
des arbres, dont l'écorce est peu adhérente et s'enlìve avec facilité; leurs fleurs sont axillaires ou terminales.

\section{Arbousier busserole. Arbutus uva ursi. L. Sp. 566.}

Part. usitée : les feuilles. Nom pharm. : Uva ursi. Noms vulg.: Busserole, Buxerolle, Raisin d'ours, etc.

Petit arbuste rampant, dont la tige ligneuse, couchée à terre, est rameuse, glabre et longue d'un à deux pieds; les feuilles alternes courtement. pétiolées, ovales presque obtuses, entières, très-glabres, luiisantes et d'un vert foncé en dessus, plus claires en dessous, épaisses et très-ferınes; en un mot elles ont beaucoup de ressemblance avec celles du buis: de là les noms vulgaires de Busserole ou Buxerolle. Les fleurs, au nombre de huit à dix, sont disposées en une sorte de capitule terminal, réfléchi, accompagnées chacune de trois bractées squammiformes; deux latérales intérieures plus petites, obtuses; une moyenne plus grande, extérieure, lancéolée, aiguë. Leur calice est très-petit, étalé à plat, profondément découpé en cinq divisions, arrondies, obtuses. Leur corolle est monopétale, allongée, urcéolée, d'un blanc transparent, rétrécie de la base vers le soininet; le limbe est petit, à cinq divisions dressées, obtuses, incombentes; la base de la corolle offre dix pelites bosses arrondies, transparentes, qui sont autant d'utricules remplies d'un suc nectaré.

Les dix étamines sont attachées à la base de la corolle; plus courles que le pistil, elles n'excèdent pas la noitié de la hauteur de la corolle; filets très-gros à la base, puis terminés en pointe, poilus, aigus; anthères ovoïdes, touges, biloculaires, s'ouvrant par un trou ovale au sommet de chaque loge, portant à leur partie supérieure et postérieure deux appendices linéaires très-aigus, rougeâtres.

L'ovaire globuleux, glabre, à cinc loges multi-ovulées, se termine par un slyle gros, cylindracé, que surmonte un stigmate aplati à cinq lobes peu marqués. Le fruit est une baic de la grosseur d'un pois, d'une couleur rouge plus ou moins intense, à cing loges monospermes.

On trouve communćment ce petit arbuste dans les montagnes 
alpines et subalpines, dans les Vosges, les Alpes et les Pyacinées. Ses fleurs s'épanouissent en juillet.

Propriétés et usages. Les feuilles de la busserole ont une saveur âpre et astrigente, qui paraît être due au tanin qu'elles eontiennent. Long-temps vanté comme propre à dissoudre les conerćtions urinaires, ée végétal, qui jouit d'une action excitaute spéciale sur l'appareil séeréteur de l'urine, n'est plus eonsidéré aujourd'hui que eomme un médieament simplement diurétique, qui pent produire des effets avantageux dans la gravelle, en augmentant et favorisant la séerétion de l'urine. Sa dose est d'un à deux gros en décoction dans une livre d'eau.

Ces feuilles sont quelquefois employées dans le nord de l'Europe au tannage des euirs, et surtout à la préparation du maroquin.

Dans le midi de, la Franee, on mange les fruits de l'arbutus unedo. L., joli arbrisseau, haut de six à douze pieds, qui croît eommunément dans les bois des provinees méditerranéennes. Ces fruits, de la grossenr d'une eerise, sont eharnus, rougcâtres, mamelonnés, et ont quelque ressemblance avee une fraise : de là le noun d'arbre aux fraises, sous lequel on désigne communément eet arbrisseau.

On mange également le fruit de la plupart des autres arbousiers exotiques. $2^{\circ}$ Fruit capsulaire.

$$
\text { PYROLE. - PYROLA. }
$$

Cálice presque plane à einq divisions : eorolle monopétale, rotaeée, eoneave, à cinq lobes; dix étamines dressées, à anthères pendantes et sans appendices; style simple, terminé par un stigmate à einq lobes. Capsule à cinq loges polyspermes et à cinq valves.

Les pyroles sont des herbes vivaces, dont les fleurs forment ordinairement un épi au sonmet d'un pédoneule radieal. Elles sont rarement solitaires. 
Pxrole a feulues rondes. Prola rotundifolia.

$$
\text { L. Sp. } 567 \text {. }
$$

Part: usitéc : les feuilles. Nom pharm. : Pyrola major.

C'est une petite plantc vivace dont la racine est fibreuse et rampante; la tige, que l'on pourrait également considérer comme une sorte de hampe, est garnie infórieurement de plusieurs feuillcs trc̀s-rapprocliées, alternes, longıement pétiolées, dressées, arrondies, entières, coriaces, glabres et luisanlcs sur leur's deux faecs : la partie supérieure est đroite, simple, haute de huit à dix pouces, garnie de quelques écaillcs érartćes, et portant dans sa moitić supéricure des flcurs blanehes, pédiccllées et recourbées, qui formentun épi terminal. Cliaque fleur se compose d'un calice à cinq divisions étroites, aiguës, étalécs; d'une corolle monopétale concare, presque rotaeće, à cinç lobes oblus ct un peu inégaux; de dix ćtamines dressées, plus courtes que la corollc; d'un ovaire à cinq loges polyspermes, terminć par un style décliné. Cette plante croît dans les bois ombragés d'unc grande partie de la Franee. Elle fleurit cn mai et juin. $₹$

Propriétés et usiges. Les fenilles de la pyrole ont une saveur accrbc. On les employait jadis dans les différentes maladies qui réclament l'usage des toniques et des astringens, tels'que es eatarrhes elroniques, et surtout la diarrhée et les flueur's blanchtes. On en a également prodigué l'usage comme nédicament vulnéraire dans les coups et les contusions. Mais ce méricament est aujourd'hui tombé dans un discrédit presque
complet.

\section{CHIMOPHILE. - CHIMOPHILA. Pursch.}

Ce genre se distingue des pyroles par les filets de ses étamincs dilatés et son stignatc sessile.

Chimopinde a ombele. Chimophila umbellata. Nutt. gen. plant. am. sept. 1. p. 274.

$$
\text { Pyrola umbcllata. L. Sp. } 565 .
$$

Celtc espece est un pclit arbuste dont lit reine rampante. 
donne naissance à denx ou trois tiges liautes de quatre à einq pouees, portant vers leur partie moyenne des feuilles eunéifurmes allongées, à dentelures profondes, eoriaees, lisses et sclabres des deux eôlés. Les fleurs sont blanehes, assez grandes, pédicellées, et forment une sorte de eorymbe ou d'ombeile. simple au sommet d'un pédoneule eommun, long de deux à trois ponees, qui est la eontinuation de la tige. Chaque fleur offre un ealice étalé, à einr divisions, laneéolées, aiguës, un peu glandulcuses et eiliées sur les bords; une eorolle étalée, un peu coneave, à cinq lobes très-obtus, séparés par des ineisions extrêmement profondes; dix étamines éeartées, plus eourtes 'lue la eorolle, ayant les filets dilatés et eiliés sur les bords, et les anthères violettes, s'ouvrant par deux pores à leur sommet. Lá capsnle est globuleuse, un peu déprimée, à cinq cổes, et s'ouvre en einq valves.

On trouve eette plante dans les forêts du nord de l'Europe, de l'Asie el de l'Amérique septentrionale. $\%$

Propriétés et usagges. Les feuilles de eette plante ont une saveur à la fois donee et anère; dans la tige et les raeines il s'y joint une âpreté assez marquée, due prineipalement à une petite quantilé de lannin qui s'y trouve eontenue. Ce inédicamentest eneore fort peu employé en Europe; mais les médecins de l'Amérique septentrionale en font le plus grand eas. Il prarait que son mode d'aetion est à peu près le même que eelıi de la busserole, mais qu'il est eneore plus puissant. C'est surtoul dans la strangurie et la eolique néphrétique qu’on l'emploie eomme un remède palliatif très-avantageux, surfout quand ees inaladies sont oceasionécs par des graviers amassés dinns les reins. La propriété diurétique de eelle plante n'est pas moins utile dans les différens eas d'hydropisie, et surlout dans l'aseite. Elle paraît déterminer une exeitation spéeiale sur le systèmc absorbant. Enfin, les Anéricains l'udministrent eneore comme un stimulant externe, appliqué sous forme de topique dans les différens ulcères aloniques, et même le cancer.

Ce unédicament se dome en déeoliou, à la dose de deux gros des feuilles dans deux lives d’cau. 


\section{ROSAGE. RHODODENDRUM. L. J.}

Calice à einq dents; eorolle infundibuliformc évasée, à einq lobes; étamines uéclinées, dépourvues d'appendices; capsule à cinq loges, s'ouvrant en cinq valves, dont les bords rentrans forment les cloisons.

Toutes les espéces de ec genre sont des arbrisseaux toujours verts, d'un port élégant, dont les fleurs rouges ou jaunes sont grandes et forment des bouquets terminaux au sominct des ramifications de la tige.

Rosage rerrugineux. Rhododendrum 'ferrugineum. L. Sp. 562 .

Ce joli arbrisseau fait l'ornement des régions élevées des $\Lambda$ pes $\mathrm{cl}$ des Pyrćnées, où il croit de préfúrence dans les escarpemcns et les fentes des rochers calcaires. Sa lige peut avoir de denx à qualre pieds de hauteur: elle se divise en raucaux tortus et difformes, portant à leur. extrénité supérieure des feuilles courtement pétiolées, ovales, lancéolées, entières, persistantes, glabres, et d'un vert foneé à leur face supéricure, velues et comme ferrigineuses en dessous. Les fleurs, d'un beau rouge, mais d'une odeur désagréable, sont grandes et disposées en bouquets à l'extrémité des rameaux. Leur calice est court; leur corolle ćvasée, inclinée vers la partie inférieure; ses cinq lobes sont un peu inégaux; sa partie inférieure est marquée de petits points glanduleux.

Cette plante cst connue dans les Alpes sous les noms de rosage ou laurier-rose des Alpes. Elle fleurit vers les mois de juin et de juillet.

Propriétés et usages. En Sibérie ct dans le nord de la Russie, les liabilans cmploient fréqucmment, et avec une sorle de snecès, les feuilles et les fleur's d'une autre espèce de ce genre, originaire de ees contrées, décrite par Pallas sous le nom de Rhododendrum chrysanthum, comme très-efficace dans une foulc de maladies, et surtout contre les affections ehroniques de la peau, le rhumatismc, la syplitis, ete. Ilusicurs médceins, et surtout Villars, ont elıerehé à découv'ir si nos rosages indi- 
srines, el part irulièrement le rosage ferrugineux, ne possédaicrit. point des propriétís analognes à celles du rosage à feurs jannes. Il paraît qu'en cffet l'espèee de nos $\Lambda$ lpes agit de la môme manière que l'espèce de Sibérie, et détermine des sueurs abondantes, lorsqu'on l'administre à la dose d'uu à deux gros en infusion ou en décoction dans deux livres d'cau. Cependant ce médicament est tout-à-fait inusité dans les villes, et son usage ne s'étend pas au delà des régions montueuses où il er oît naturellement.

Propriétés médicales et usages des Éricinées.

Une saveur acerbe plus ou moins intense se fait généralement remarquer dans tous les or.ganes des végétaux qui forment la famille des Éricinces. Cette saveır, souvent âpre et astringente dans les feuilles de la Busserole, de la Pyrole, est uı peu âcre dans les Rosages. Cette âcreté prend dans le genre kalmia un léveloppement assez considérable pour en rendre les espices suspeetes et même délétères. $\Lambda$ insi, au rapport de tons les Inédeeins de l'Amérique du nord, le kalrnia latifolia, arbrisseau des plus élégans, tant par la beauté de son feuillage toujours vert, que par l'élégance et la colorotation de ses fleur's, est un végétal très-daugereux, que l'on regarde génćralement eomme un poison pour les jeunes animaux. Cependant le docTeur Bigelow ${ }^{1}$ remarque qu'il n'a jamais pu s'assurer de la vertu nareotique attribuée à ses feuilles, quoiqu'il ait tenté à eet égard un grand nombre d'expérienees; et ee célèbre professcur pense que ses effels délétères sur les jeunes animax dépendent de la grande quaritilé de résine qu’elles contiennent. Celte âereté se retrouve eneore dans quelques autres genres du inềne groupe. Ainsi un grand nombre d'auteırs, tant aneiens que modernes, ont fait eonnaitre l'action délétére du miel dont. les abeilles ont reeueilli les matériarx daus les fleu's de l'azalaen yontica. Ce fait, dont on a souvent nié l'existerice, se trouve entièrement d'aeeord aver les propriétés çue l'on a reconnues dans les kalmia, proprićtés qui existent également

I American medical botany, with coloured engravings, by. J. Bigelow. fasc: $1,2,3$. Boston. $1817,1818,181 \mathrm{~s}$ 
ERICINEES. dans plusieurs rosages, dans le ledun palustice, l'andrameda mariana, elc.

Dans les Érieinćes à fruils charnus, tels que les arbousiers, ces fruils ont en général une saveür aigrelette ct agréable, et sont fort rechcrchés dans les pays où ils parviennent à malurité. 


\title{
MONOPÉTALIE-SYMPHYSOGYNIE.
}

\author{
CINQUANTE-UNI ME FAMILLE。
}

VACCINIÉES. - VACCINIE.

FonmÉE d'une partie des genres précédèmment réunis aux Éricinées, la famille des Vacciniées ne s'en distingue essentiellement que par son ovaire constamment infère. Le calice est monosépale adhérent avec l'ovaire; son limbe offre quatre ou cinq dents; la corolle est monopétale régulière, à quatre ou cinq lobes, quelquefois assez profonds pour que la corólle paraisse polypétale, comme dans l'oxicoccus; les étamines, au nombre de huit, ont leurs anthères appendiculées, à deux lnges qui s'ouvrent par leur sommet. Le fiuit est une baie globuleuse, couronnée par les dents du calice, à quatre ou cinq loges, qui renferment plusieur's gränes.

Tous les végétaux placés dans cette famille sout des arbrisseaux ou des arbustes, à feuilles simples et alternes: leurs fleurs sont généralement axillaires.

AIRELLE. - VA C CINIUM. L. J.

Calice globuleux, à quatre ou cinq dents; corolle globuleuse, ou un peu évasée, à quatre ou cinq lobes, quelquefois trc̀s-profonds; laaie globuleuse, ombiliquée au sommet, à quatre ou cinq loges polyspermes.

\section{Arrelle myrthes. Vaccinium myrtillus. L. Sp. $49^{8}$.}

Pưrt. issitée : les fruits. Nom pharm.: Myrtilli baccee.

Pctit sous arbrisseau dont la racine est longue et rampante, la tige redressée, ramcuse, haute de huit à douze pouces, chargée de fenilles allernes, caduques, ovales, aiguës, dentées, portées sur de courts pétioles, glabres el d'un vert clair. Les 
fleurs sont blanèhes, rosécs, solitaires à l'iisselle des feuilles, et: portćes sur un pédoncule court et déeliné. Le ealice, est globuleux, petit et couromné par quatre petites dents; la eorolic cst en grelot, très-resserrée à sa partie supérieure, qui of rre quatre dents très-eourtes. Les huit étamines sont renfermées dans l'intérieur de la corolle; le style et le stignate sont légèrement saillans hors de la corolle. Le fruit est une baie noire, glauque, de la grosseur d'une petite cerise, eouronnée à son: sommet par le limbe du calice, qui est tronqué. Elle est charmis, succulente : sa ehair est violeltc : elle offre cinq loges, qui: renferment chacune huit à dix graines très-petites.

On trouve l'airelle dans les. bois ombragés et un peu humides de toutes les contrées septentrionales de l'Europe. Ses. fleurs paraissent dès les premiers jours du printemps, et ses fruits sont parfaitement mûrs en juillet et août.

Propriétés et usages. Les petites baies de cet arbuste, lorsqu'elles sont parvenues i leur ćłat de maturité, ont une savenr mucilagineuse et aigrelette, qui les rapproche beaueoup des mủres ct des groseilles. $\Lambda$ ussi ne sont-clles point négligées par les habitans des campagnes, qui les reeueillent pour s'en raffraîehir. Cet usage paraît même remonter à une très-haute antiquité, puisque nous trouvons dans lès Églogues de Virgile:

Alba ligustra cadunt, vaccinia nigra leguntur.

On peut aussi se servir de ces fruits pour préparer avec leur suc une boisson rafraichissante, utile danis les phlegmasies des organes de la digestion. Quclques auicurs ont même recommandé l'usage de ces fruits en nature pour arrêter des diarrhées ehroniques; mais on en fait rarement usage.

Ces fruits contiennent une assez grande quantité d'un prineipe colorant rouge, et sont utilement employés dans l'ar't de
la teinturc.

Quant à la tige et aux feuilles, leur savcur est ûpre et as/ringente, et dans plusieurs contrécs dis nord on les cmploie au tannare des cuirs.

La flupart des aulres especes in genre airelle jouissnl des mèmes propriétés qque le myrli!le, et cont cmployćes ârx mèmes usages. Nous citerons spécialenent iui les vaccinum oxicoccus 
ct vaccinium vilis idren, dont les loaies, possédant la saveur aigreletle que nous avons signalíe dans le nyrtille, sont fort recherelices par les peuples de l'Europe septentrionale. Nous ajouterons, à l'égard le celte dernière espèee, que ses feuilles sont assez souvent inćlangées à eelles de la busserolle (arbutus uva ursi L.), et que, selon (juelques auteurs, elles sont eomme rlles puissamment diurétiques et ulilesdans les affeelions ealculeuses de la vessie.

Nous n'insisterons pas davantage pour faire voir la grande analogie qui cxiste entre toutes les plantes de la famille des Váeiniées, lorsqu'on les eonsidère sous le point de vue de leurs proprićtís médieales.

CINQUANTE-DEUXI Ė E FAMILLE.

\section{CAM PANULACÉES.-CAMPANULACEAE.}

Cette famille se eompose en général de végétaux herbacés, aunuels ou vivacés, ayant des feuilles alternes et des fleurs solitaires ou disposées en capitules ou en épis. Leur ealiee, qui est adhérent par sa hase avee l'ovaire infère, a son limbe partagé en quatre on cinq divisions. La eorolle est toujours monopćtale; le plus sonvent elle est régulière, plus rarement elle est irrégulière ct à cinq lobes. Les étamines, dont le nombrc égale eelui des lobes de la eorolle, alternent avee eux; elles sont tantôt libres et distinctes les unes des autres, tantôt rapprochées et intimement soudćes. L'ovaire, qui est infère ou semi-infère, offre de trois à cinq loges, eontenant chacune un grand nombre d'ovules; un scul style naît du sommet de l'ovaire et se tcrmine supćrienrement par un stignate à deux, trois on cinq lobes. Le fruit est une capsule couronnée par les lobes du ealicc: elle présente de trois à cinq loges, qui s'ouvrent le plus souvent par des trous qui se pratiquent sur ses parties latérales, ou bien au moyen de valves, entrainant avec elles une partie des cloisons. Les graines, qui sont attachées à l'angle interne 
de chaque loge, contiennent, dans un endosperme charnu, un embryon axille et dressć.

10 Corolle régulière; étamines distinctes. (Cimpanulacḱts.)

\section{CAMPANULE-CAMPANULA. L. J.}

Calice à einq lobes, dout les sinus sont quelquefois membraneux et pendans; eorolle monopétale régulière, campaniforme, à rinc lobes; étamines à filamens élargis vers la base; anthèrcs linéaires, roulées en spirale après la féeondation; style tcrminé p-r un stipmate à trois ou cinc lobes; capsule à trois on cinq loges polyspermes, couronnće par les lobes du calice, ct s'puvrant ordinairement par des trous qui sc forment sur les parties latérales.

Plantes herbacées, un peu lactescentes, à feuillcs allernes, à fleurs axillaires, ou disposécs en épis.

Campanume raiponce. Campanula rapunculus. L.Sp. 232.

Sa racine est bisannuelle, perpendiculaire, un pen rameuse, très-blanchc. Sa tige est dressée, d'environ deux pieds de hautcur, divisée supérieurement en rameaux panieulés; les fenilles inférieures, étalées sur lc sol, sont allongées, tin peu sinueuses of velues; les supérieures sont étrnites, lancéolécs, aiguës, sessiles, ghlabres, un peu écartées les unes des autrcs. Les fleur's sont blenes, de moyenne grandeur, et forment une sorte dc pranicule dressée à la partie supéricure de la tige. Les divisions du caliee sont étroites, cntières ct aiguës; les lobes de la corrolle sont peu prinfonds.

Cette p'ante est fort communc dans les lieux inenltes; sur lc hord des ehemins et des fossés; elle fleurit pendant les mois de juin ct juillet.

Propriétćs et usages. On cultive ln raiponce dans nos jarcins potagers, pour recucillir sa racine au priniconps, avant 'iu'ellc n'ait ponssé la tige. Eille est assez fide, mucilagincusc, et on la mange en saladc. 
$2^{\circ}$ Corolle irrégulière; étamines soudées. (Lови́L1

$$
\text { LOBÉLIE. - LOBELIA. L. J. }
$$

Calice adhérent; limbe ạ cinq divisions; corollc irrégulière, tubuleuse, souvent fendue; limbe à cinq lobes, bilabié ; ćlainines soudées par les filets et les ánthères; style terminé par un stigmate ordinairement bilobé; capsule semi-infère, couronnée par le calice, à deux loges, qui s'ouvrent en deux vilves.

Les lobélies sont des végétaux herbacés et quelquefois ligneux et arborescens; souvent laetesccns; ayant les feuillcs allernes, ct les fleurs disposćes en épis ou en grappes.

LudÉlie sXphILITIQUe. Lobelia syphilitica. L. Sp. I320.

Part. usitée : la racine: Nom pharm. : Lobeliae radix.

Originaire des forêts de l'Amérique septentrionale, cette plante présente une tige herbacée, simple, droite, haute d'un à dcux pieds, anguleuse, velue, surlout inférieurement; dcs feuilles alternes, sesiiles, rapprochées, étalćes, lancćolées, lígèrement pubescentes, irrégulièrement denticulées et un peu sinucuses sur lenrs bords.

Scs fleurs violacées, solitaires à laisselle des feuilles, courtemcnt pédoneulées, formcut au sommet de la tige un épi trćsallongé, entrccoupé de feuilles. Leur calice est à cinq divisions trc̀s-profondes, ciliées, lancéolées, très-aiguës, se prolongenut à leur base au-dessous de leur point d'insertion sur le tubc, formant une gouttière profonde par le rapprochement de leurs bords. Le tube très-court est à peu près hémisphérique et a dix côtcs saillantes irrégulières. La corolle est monopétale, irrégulière, bilabiéc, insćrće au haut du tube du caliec : le tube est recourbé, un peu évasé supérieurement, fendu jusquu'à sa

I MI. de Jussieu et feu mon père ont séparé ce. genre des Campiamilacées pour en former une famille distincte, qu'ils ont nommere Lobéilacics; mais les earactères distinetifs de cette nonvelle fatmille ne nous ont pas paru assez trinclés pour en atutoriser la séparation d'avee les campinules. 
base à la partic supéricure : Ic limbe est bilabić. Les étamines, au nombre de einc, sont symphiisandres, e'cst-à-dirc monadelphes et synanthères à la fois, saillantes supérieurement, à travers la fente de la lẻvre supérieure, insérées, en dedans de la corolle, au sominet du tube du calice.. Filets violacés distincts et librcs dans leur tiers inférieur, réunis et soudés supérieurcment; anthères rapproehées ct soudécs en un tube court, un peu recourbé supérienrement, les supérieures étant un peu plus prolongées, les deux inférieures terminécs chacune à leur sommet par un petit bouquet de poils en forme de pinceau. L'ovaire est semi-infère, à deux loges, renfcrmant ehacune un très-grand nombre d'ovules attachés à un trophosperme saillant sur la cloison; le style est simple, eylindrique, glabre, un peu plus long que les étamines, dans le tubc desquelles il cst d'ibord contenu, puis recourbé et un peu renflé à sa partic sipérieure. Stigmate violet, formé de deux lames glandulcuses d'abord rapprochécs, ensuite étalées, offrant à leur base un eercle annulaire de petits poils blancs ct soyeux. Le fruit est une capsule anguleusc, s'ouvrant en deux valves.

Propriétés et usayes. Toute la plante est lacteseentc, et répand une odeur un peu vireise lorsqu'on la froisse entre les doigts. Sa racine, qui se compose d'une touffe de fibres grêles et blan. châtres, a une sáveur âcrc, assez analogue à cclle du tabac. Donnée à faiblc dose, sa décoetion excile la transpiration cutunće; à dose un peu plus élevée, elle angmente les déjeetions alvines, et enfin agit comme vomitive, si elle est plus rapprochéc. Celle racine jouit, auprès des médecins de l'Amérique, d'une très - grande réputation dạns le traitement de la syphilis, $\mathrm{ct}$ ils l'administrent quelquefois seulc, d'autrcs fois en y joignant l'uşagc du mercurc. On s'en sçt très-peu en Europe, malgrć les cssais tenlés il y a unè quarantainc d'années par Dupau, qui a constaté son efficacité dans un grand nombro de eas.

\section{Proprictés médicales et usages des Campanulacées.}

Presquc toutes les plantes de cctte famillc sont lactcscentes. Le suc laitcux qu'clles i'enferment offre unc amertume et souvent une ácreté fort rcmarrquables. $\Lambda$ ssez généralcuncut, dins 
le groupe des Campanulées, la présenee d'une assez grande quantité de mucilagc masque l'amertume du suc laiteux, ainsi qu'on l'observe surtont dans ces végétaux, lorsqu'ils sont encorc jeunes et qu'ils abonderit en principes aqucux; aussi dans cet état en mange - $\mathrm{t}$-on plusieurs, tels que la raiponee, les jeunes pousses du phyteuma spicata, qui plus tard deviennent. âcres et amères. Cet âereté distingủe plus spéeialement le groupe des Lobélies, où elle est assez intense pour rendre plusieurs ( $s$ ) ’̀̀ces corrosives et délétères : telles sont cn Europe le Lobelia urens et en $\Delta$ mérique les Lobelia tupa, et $L$. longiflora, qui apjliquées sur la peau en déterminent l'inflammation et produiscut cles vomissemens douloureux et l'inflammation des organes dị̣̂estifs, lorscu'üils sont donnćs à l'intérieur.

C INQUANTE-TROISI İ ME FAMILLE.

\section{CUCURBITACÉES. - CUCURBITACEAE.}

Les Cucurbitacées présentent dans plusieurs de leurs organes une structure tout-à-fait particulière, qui exige de nous quelques développemens.

Ce sont toutes des plantes herbacées, à tiges flexueuses. et souvent grimpantes, soit par leur propre torsion, soit. par le moyen des vrilles quon observe quelquefois à l'aisselle de leurs feuilles. Celles-ei sont alternes, pétiolées, simples ou divisées en lobes plus ou moins profonds, très-souveut hérissées de poils rudes et tuber'uleux. Les fleurs, unisexuées dans la plupart des genres, sont généralement monoïques et axillaires. Dans les fleurs mâles, le calice esı ordinairement subcampaniforme à cinq dents, soudé ${ }^{x}$ entièrement dans ses deux tiers inférieurs avee la base de la corolle : celle-ci, plus

- Cettc soudure di calice avec la base de la corolle a engagé M. de Jussieu à consiclérer les cucurbitacées comme apétales ou monopérianthées. II ais tous les butanistes nodernes s'itccordent avec Linnc pour reconnaitre dans ces plantes un calice et une corolle, soudés et confondus par leur basc. 
grande que lc ealice, est monopétale régnlière à cinq lobes, souvent plissée longitudinalement : les étamines sont au nombre de cinq, insérées au fond de la eorolle; quatre de ces étamines sont soudées deux à deux par les filets et les anthères, et une seule est libre et distincte; en sorte qu'il y a trois filets seulement, savoir : deux portant chacun deux anthères, et un qui est terniné par une seule. Les anthères sont uniloculaires, très-allongées, disposées en lignes flexueuses, très-rapprochées les unes des antres; plus rarement les cinq étanines sont à la fois monadelphes et synanthères. Le calice et la corolle offient dans les fleurs femclles la même forme et la mème structure que dans les mâles, avee cette exception que l'oviure, qui est infère, constitue un renflentent particulict. au-dessous du calice: on trouve assez fréquemment trois filamens stériles, qui sont les andropliöres des étamiñes avortées. Le style est simple ou-trifurqué à son sommet; qui se termine par trois stigmates épais, glanduleux et ordinairement bilobés. L'ovaire est à une seule loge, qui contient rarement une seule ovule, le plus souvent six, ou nếme un plus grand nombre, attachées aux bifurcations des lames d'un trophosperme suspendu, à trois laınes rayonnantes, qui semblent parlager la cavité de l'ovaire en trois loges, et qui ont élé considérées par' la plupart des autenrs comme tróis cloisons. Le fruit est une péponide, c'est-à-diře quill est charnu' ${ }^{\mathrm{I}}$; que son

- La structure du fruit dans la famille des Cucurluitreées est encore anjourd'hni un sujet de discussion parmi les botanistes. Ainsi la plupart des anteurs décrivent le fruit du melon, du pepon, ete. comme un péricarpe multiloculaire contenant plusieurs graines attachées à des trophospermes pariétaux. M. Auguste de Saint-Hilaire, observateur plein d'exactitude et de précision, a le premier émis sur ce sujet une opiniou que nous avons cru devoir adopter. Il considere l'ovaire comme toujours uniloeulaire; et les trois lames rayonuantes qui occupent le centre du fiuit sont pour lui un trophosperme axillaire 
intérieur est tantôt cutièrement plein ct renferme les graines nichées dans la pulpe; tantôt il s'y forme une vaste cavité accidentelle. Les graines, ordinairement comprimées, ont un tégument crustacé dans l'intérieur duquel est un embryon dépourvu d'endosperme.

\section{BRYONE. - BRYONIA.L. J.}

Fleurs monoïques ou dioïques : dans les mâles, calice à cinq dents, soudé dans ses deux tiers inférieurs avec la corolle, qui est eampanulée et à cinç lobes obtus; les cinq étamines sont triadelphes; les anthc̀res sont en lignes fluxueuses; les trois androphores sont distinets à leur base; dans les flcurs femellcs, le calice et la corolle sont lcs mêmes que dans lcs mâles, à l'éxception de l'ovaire infère, qui forme sous la fleur une saillie globuleuse : stylc surmontć de Irois stignales bifides et poilus. Fruit charnu pisiforme, renfermant ordinairement six graincs.

Bryone blanche. Byronia alba. L. Sp. I 438. Bull. t. 55. Bryonia diö̈ca. Jacq. Aust. t. I99.

Part. usitće : la racine. Nom pharm. : Bryonia. Noms vulg. : Couleuvré, Vigne blanche, Navet du diable.

Plante diöque, dont la racine est trìs-grosse, rämcuse, charnue et blanclie. Sa tige est grimpante, herbacée, rameuse, longue de lıuit à dix pieds, anguleuse et lćgèrement velıc. Le; feuilles sont alternes, pćtiolécs, échancrées en cœur à leur base, divisées cn cinq lobes anguleux, celui du milieu plus long et et plus large : les deux faccs, et surtout l'inférieure, sont couvertes de poils courts et rudes. Les vrilles sont extraxillaires, très-longues, ordinairement simples.

Les fleurs mûles sont portées sur des rameaux grèles et axil-

renversé, pendant en manière de lustrc, et portant les graines attachées horizontalcment à chacune des bifurcations qui terminent les lames de ce trophosperme. Voyez dans nos tímens de bocanigue, 2e édition, pag. 364, la définition que nons avons donnée de la jé, ponide. 
laires : elles sont au nombie d'environ dix à douze, pédonenlées : lein. ealice est eampanulé, soudé et confondu dans sa plus grande étendue avee la corolle, seulement distinct à sa partie suṕrieurê, qui offre einq divisions étroites é aiguës. La corolle est eampanulée, à einq divisions profondes, ovales, obtuses. Les étamines sont au nombre de einq, réunies en trois faisceaux par leurs filets: deux dc ees faiseeaux sont formés chacun de deux étamineś, la einquième étamine formant le troisic̀me faisceau à elle seule. Les antlières sont linéaires, uniloenlaires, et contournćes au sommet des filets. Lcs fleurs femelles, au nombre de quatre à einq, sont axillaires, portées sur des pédoncules beancoup plus courts. Leur ovaire est globuleux, infére. Le ealice et la corolle sont les mẻmes. Cet ovaire est surmonté d'un style court profondément triparti : clraeune de ses divisions, élargie vers sa partie supéricure, porte un sligmate transversal, aminei en pointe à ses deux extrémités. Le fruit rst une baie rougeâlı et globulcuse, pisiforme, contenant de trois ì six graincs.

La bryone est commune dans les haies et les lieux incultes. $\mathcal{F}$

Proprićtés et usages. La racine dc bryone est presquc entièrement formée d'amidon, auquel se joint un prineipe amer ct áere, qui lui donne une saveur désagréable et une propriété purgative très-manifestc. Cette propriété n'est pas détruite par la dessiccation. Appliquée sur la peau, la raciue de couleuvrée la rubéfic et finit par en déterminer l'inflammation. Les anciens faisaient beaucoup plus souvent usage de ce médicament quc les modernes. Ils l'employaient surtout dans les hydropisies, cer tains cas de manie, et en général dan's toutes les maladies ou I'usage des purgatifs violens était indiqué. Cette racine sèche ct réduitc en poudre s'administre à la dose de trente à quarante graines. $\Lambda$ près l'avoir rédnite en pâtc, on peut, par des lavages fréquemment répétés, enlever le principe âcre; on obtient alors une féeule trc̀s-blanche, qui peut servir d'aliment.

$$
\text { GUGUM ER E. - } \dot{C} U C U M I S . L \text {.J. }
$$

Fleurs monoïques; caliec et corolle enmpanulés, soudés cnsemble par leur hase; dans les flenrs uîles, les trois androphores sont distinets; dans les flen's f'melles, les étamiucs sont 
imparfaites; le style est surmonté de trois stigmates en forme de fer à cheval; le fruit estovoïle, ghlobulenx on allongé, lantôt charnı, lantôt see; ses graines sont lisses, et amincies sur les bord:

\section{Gucumise cologunte. - Chcumis colocynthis. L. Sp. I 435 .}

Part. usitée: les fruits. Nom pharm. : Colocynthis.

Originaire d'Orient et des îles de l'Arehipel, la eoloqn ninte présente une tige herbaeće couehée à terre, ou s'élevant sur les éorps voisins, au moyen de vrilles nombreuses extraxillaires. Cette tige est eharnue, eassante, eylindrique; couverte de poils très-rudes; ses feuilles alternes sont subréniformes, aigrıës, à cinr lobes, eelni du milieu plus marqué, dentés, pubeseens, offrant des poils rudes sur les ramifieations des nervures; le pétiole est eylindrique, présentant quelques poils rudes; il est plus long que les feuilles.

Flcurs monoïques solitaires, extraxillaires, les mâles sćparées des femelles. Fleurs mâles : ealice hérissé de poils blancs et rudes, eampanulé par sa pártie inférieure, qui est confondue a vee la eorolle : limbe à einq lanières étroites, subulées, libres. Corolle jaune-orangé, adhérente par son tiers inférieur avee le tube du ealice, campanulée, ouverte, à einq lobes ovales aigus, terminés par une petite pointe; en dedaus des filets siaminaux; le fọnd de la corolle est tapissé d'un bourrelet jaunảtre. t́tamines au nombre de cinc, dont quatre sont soudées intimement deux par deux, el la einquième senle est libre. $\Lambda$ nt tières linénires, rapprochées et formant une sorte de eône. Elles sollt uniloculaires, replićes plusieurs fois sur elles-mêmes d'une manière irrégulière.

Fleurs femelles : ovaire infère, ovoïle, eomme en massue, e’est-à-dire plus renflé à sa moitié. supérieure; limbe dn caliec el corolle comme dans la fleur mîle. Cet ovaire est uniloenlaire; il présente à sa jartie eentrale un trophosperme à trois branches trìs-saillantes clans la eavité, sur lesquelles sont attaelićs des ovules nombreux, en sorte qu'au premier eoup d'œil il paraíl 
à trois loges. Le fond de la flcur ou le sommet de l'ovaire est tapissé par nn bonrrelet eireulaire janne inégal, el dehors duquel sont trois appendiees légèrement. réflèehis, qui représentent. les étamines avortées. Le style, qui est gros, charnu, glabre, est trifide a son sommet; chaeune de ses divisions porte un stigmate bifide, irrégulier, réfléehi, se eontinuant du côté interne par un sillon glanduleux. Le fruit est globuleux, jaune, de lit grosseur d'une orange, glabrc, recouvert d'une éeorce dure, coriace, assez inince, et renfermant une pulpe blanche et spongieuse, dans laquclle on trouve des graines nombreuses, ovalcs, comprimées et blanches.

Cette plante est annuelle et eultivée dans les jardins.

Propriétés et usages. La eoloquinte du eommerce est le fruit dépouillé de son enveloppe erustaeée. Elle est en masses blanchâtres, légères, spongieuses, sèches, d'une amertume extraordinaire. La grande quantité de matic̀re résineusc qu'elle coniient la rend un des plus violens purgatifs drastiçues, dont l'usage en médleeine remonte aux ćpoques les plus reculées de l'art. En effet, les Grecs et les Romains paraissent en a voir eonnu les effets puissans, car on lit dans Dioseorides, que les lavemens préparés avee eette substance donnent lieu à des dćjeetions alvines sanguinolentes. Un tel rćsultat dénote dans la eoloquinte un médieament fort dargereux; aussi plusieurs praticiens ont-îls cherché à le faire bannir dı eatalogue des substances médieamenteuses. Cependant (quoiqu'on l'cmploie. rarement en nature, clle entre dans un grand nombre de préparations pharmacentiques, telles que les pilules ou troehisques d'Alhandal, la eonfeetion Hamech; en un not, dans presque tons les médicamens composés, qui agissent comme drastiqucs. C'est partieulièrement dans lcs liydropisies dites passives, dans l'apoplexie séreuse, la manie, ete., que l'usage de ee médica-

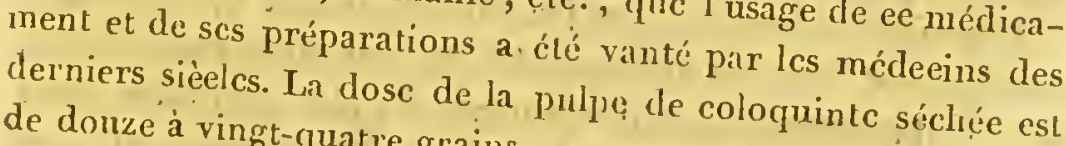
de donze a vingt-quatre grains. 
Cocumùne mexon. Cucumis melo, L. Sp. r430. Blackw. t. 329 .

Part. usitćes : les fruits et les graines.

La saveur délieieuse et le parfum de sa chair fondante et sucrie ont depuis long-temps introduit dans nos jardins potagérs ce végétal, qui a les contrécs oceidentales de l'Asie pour patrie. Une tige herbacée, eharnue, cylindrique, conchée sur la terre, ou s'élevant sur les corps environnans au moyen de vrilles extra-axillaires, et couverte de poils très-rudes, porte des fenilles alternes, pétiolées, grandes, presque eordiformes, à einq lobes inégraux; celui du milien arrondi, obtus, saillant, les deux latéraux aigus, un peu plus petits; les inférieurs très-petits: tous . sont irrégulièrement dentés et rudes. Lès fleurs sont jaunes, solitaires et monoïques. [Fleurs mâles rassemblées au nombre de quatre à einq aux aisselles des feuilles, portées sur de eourts pédoneules. Calice et eorolle subeampanulés, renfcrmant einq étamines triadelphes.Ces étamines reeouvrent le fond du ealice, qui est environné par un bourìelet verdàtre, au centre duquel est un petit tubercule.

Fleurs femelles également axillaires : ovaire infère, adhérent a vec le tube du ealice, ovoïde, allongé, couvert de poils nombreux. La partie supérieure du tube est libre; le limbe est à cinq lanières étroites. Le style est simple iuférieurement, trifide à son sommet, qui porte trois stigmates earrés, fortement échanerés. Le fruit est très-gros, ordinairement globuleux, relevé de eôtes rugueuses. Il offre souvent une vaste cavité aecidentelle. Sa ehair est roıgeâtre, quelquefois pâle, et même tout-à-fait verte. La culture a singulièrement multiplié le nombrc des variétés de ee fruit.

Propriétés e't usagres. C'est principalement sur nos tables que que l'on voit le melon figurer cn étć, épọque où sa ehair, doucc, sucréc; fondante, est un des alinens les plus agréables et les plus appropriés à la saison. En effet, clle est beancoup plus raffraielissaute que nutritive; aussi ne sert-on ce fruit que comme loors-d'oenvre, ou plus rarement au dessert ${ }^{x}$. Il convieut

r En Angleterre, le melon se mange tonjours au dessert. 
surtout aux persomnes fortes et robustes, aux tempéramens bilieux, et en général à tous ccix qui digèrent faeilcment; tandis que les individus dont l'éstomac est "paresseux le supportent assez péniblement. L'usage de cefruit a eu souvent des effets avantagcux pour les individns affeclés de maladies chroniques, surtout de dartres ou d'affections des reins et de la ves -' sie. Borelli même prétend l'avoir vu guérir des phthisies pulmónaires, résultat quc l'on'ne peut inalheureusement en espirer que fort rarement. La pulpe crue est quelquefois appliquée avec avantage sur les brûlures ou les contusions; lorsqu'elle est cuite elle constitue de fort bons cataplasmes émolliens.

Quant à ses graines, elles sont, avec celles du concombre; de la citrouille, et du potiron, désignćes dans les anciennes pharmaeopées sous les noms de semences froides majèures. Elles contiennent du muẹilage et une huile fixe, et; en les triturant dans l'ean après les avoir dépouillées de leur envelopṕé? erustacée, on en forme des émulsions adoucissantes, que l'on prescrit fréquemment dans l'ischurie, lanéplırité, l'inflanmination de l'urèthre et de la vessie.

Cucumère Gultivée. Cucumis sativus. L. Sp: $143 \%$ Blackw. t. 4 .

Part. usitées : les fruits et les graines. Nom pharm.: Cucumeris pulpa et semina. Noin vulg.: Concombre.

On ignore quellc fut la patrie du concombre, que depuis plusieurs siecles nous voyons fleurir et fruclifier dans nos jardins potagers. Plusieurs auteurs pensent que c'est des grandes Indes que nous avons retiré les premières graines de cette plante. Cctte espèce est assez facile à distinguer du melor, surtout lorsqu'elle est en fruit. Sa tigc est très-longue, anguleuse, velue ct rude au toucher, présentant des vrilles extraaxillaires. Ses feuilles sont subcordiforınes, rudes, à cinq lobes peu distinets. Ses flenrs jaunes, sont réunies plusieurs cnsemble à '’aissclle des fcuilles. Les mấles et les femcllcs sont séparées les unes des autres. Dans les fleurs fernéles, l'ovaire cst trèsallongé et hispide. Le fruit cst ovoüde, cylindrique, plús ou moins long, quclquefois un peu recourbi. Sa surface est lissc 
ou lérèrement mamęlonnéê. d'um jaune plus ou moins intensc, suivant les variétés. Ia pulpe est trc̀s-aqueuse et verdâlre; scs graines, fort nombreuses, blanches et aplaties.

Propriẹtés et usạger.s. Les eoncombres sont loin d'avoir eettc saveur, sucrée, cette chair parfuriée, quie nous savourons dans le melon is ils sont auj çontraire fades, aqueux, et même un peu nauséâhonds, 'lorsứn'ils' sont crus; aussi ne les mánge-t-on généralement qu'après les' avoir fait euire. Ils sont dans' cct. état, fort, employés pendant. l'été. C'est un aliment qque l'on peut, presque sous tous les rapports, comparer au melon, $\dot{a}$. la courge, elc.c, quant a a son mode d'alimentation, c'est-à-dire qu'il est fort peu nourrissant, et ne eonvient guère qu'aux tempéramens sanguinsiou bilieux. Sa pulpe rćeente peut être employée, de même que eelle, du melon, pour faire deș applications, raffraị̂hissantes. Elle sert à préparer une pommade fort employée dans la toilette, pour adoucir la peau et en faire disparaitre les petites/cflloréscences furfuracées. Le suc que l'on exprime de cétlespulpe, appliqué sur les dartres, en diminue la démangeaison, et calme la cuisson qu'oceasionnent fréquemment les bains sulfureux.

Lês graines du cöricdínbre joùissent dés mêmes propriétés que eelles du melon, et on les cimploic aux mêmes usagès.

On récolte souvent les fruits du coneombre lorsqu'ils sont encorc jeunes, et seulement de la grosseur du doigt. Confits au vinaigre, ils portent le nom de cornichons, et s'emploient commé condimentidans les'saucés.

$$
\text { COURGE CUCURBITA. Rich. }
$$

Ce gènre, extrêńment rapprochè du'précédent, n'cn diffère que jar sa corolle présque plane el comme rotacée, a cimu divisions très-profondes ; par son fruit ordinairement sec, contenant des gräines éehàncrées au sonımét.

ĆnvRGe cantebasse. Cucurbita lagenaria. L. Sp. 1434.

$$
\text { Partic usit. : les graines. }
$$

Cette plaulc est annuelle et préscnte une tige couchéc on grimpante, recouverte de puils mous, sillounce, arméc de 
vrilles latérales; des feuilles alternes, grandes, cordiformes, acuuninées, entières, légèrement dentées, à dents petites el éloignécs, pubcscentes, donces et inolles au touches. Licur pètiole', de la longueur. des feuilles, 'est cylindrique, 'vèln et fistulewix : Lés fleurs sont blanches; les mâles se: composent d'un' calice cain'panulé, velu, adhérent avec la corolle, à cinq divisions étroiles, courtes et subulées; d'une corolle divisce jusqu'au calice en cinq lanic̀res ouvèrtes, arrondies; acuminées, très-minces et blanches, pubescentes en dedans, surtọt vers leur base; de cinq étamines réunies en trois faisceaux. Dans les fleurs femelles, l'ovaire infère est ovoïde, ćtranglé vers'son tiers inférieur, pubescent, le calice et la corolle sont semblables à ceúx de la fleur nuâle. Trois appendices stćriles représentent lès étàmines avortées. Le style est courl, à peine trifide à son sommet, po.tant trois stigmates épais, irrégulièrèment cordiformès. Le fruit varie beauconp dans sa forme, qui est tantôt celle dune grosse poire, tantôt celle d'une massue; d'autres fởis il ést trèsallongé, cylindrique, sec, crustacé extérieurement, et rempli d'une pulpc aqueuse et jaunâtre', 'contenant les grảines:

La calebasse, primitivement originaire de l'Indè', se cultiv'e dans toutcs les parties de l'Europe. -

Própriétés ét usages. Les fruits de celte espèce sont assez. rarement employés comme alimens, quoique là pulpe ciu'ils renferment soil bonne a manger.' Leurs "graines'sont la senle partie que la médecine réclamét Leurs propriétés sont les niêmes que celles du melón, du coneombr', etc. (Voy. plus haut.)

Une autre espèce de ce genre est beaúcoup plus intéressante: c'est celle don't les fruits sont connus en Provence sous les noms

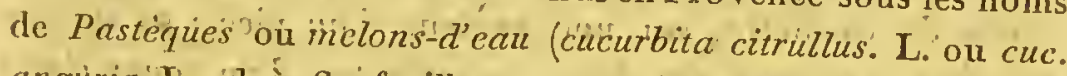
anguria. Larnk. ). Ses feuilles sont profondément découpées et commelaciniécs; scs fruits sont globuleux, lisses; leur surface est ordinairement verte; ils nc présentent point de cavité ccntrale, ct sont tout-à-fait pleins; leur chair est rongeâtre, très-fondautc: elle renferme un grand nombre de graines noirâtres, renfermćes chacune dans une petite loge particulière, crcusće au milieu de la pulpe. On fait cu Provénce nne grande consom. mation de ces fruits, qui en cffet sont fort rafraiehissans. 


\section{PÉPON:-PEPO. Rich.}

- Calice et corolle tubulenx et eampanulćs; filets des étamines monądelphes. Fruit charnu, 'très-grand, contenant des graines -planes, entourées d'un rebord un peu élevé.

i\%. Pépon a gros frútrs. Pepo macrocarpus. Rich. Cucurbita pepo. L. Sp. 1435.

.... . Partie nsit. :les'finits. Nom vulg. : Potiron, Citrouille.

Lc potiron est sans contredit une des plantes qui acquièrent dans le cours d'une année les plus grandes dimensions. En effet, sa tige, qui est herbacće, cylindrique, rude, charnue ct fistulevse, offre quelqucfois une longueur de vingt à trentc picds. Ses feuilles sont fort grandes, pétiolées, reniformes, arrondies, a cinq lobes peu marqués, obtus, couverts de poils rudes. Le jétiole a un pied de longuenr; il est cylindrique et fistuleux.

Les feurs, d'un beau jaume, sont grandes, monoïqucs et axillaircs. Les mâles ont le ealice et la corollc campaniformes, soudés par leur' base; l'un el l'autre à cinq divisions : les cinq étamines sont à la fois monadelphes ct synan!hèrcs; les anthères sont linėaires, plusieurs fois replices sur elles-mêmcs, et s'ouvraut par un sillon longitudinal. Lc écntre de la; flcur est occupé par un disque glanduleux jaune, cachẹ sous le tubc formé par les filcts staminaux. Dans les fleurs femelles, le calice et la eorolle offrent la mème forme que dans les mâles; le style est court, et porte à son sommet trois gros stigmates ćpais, glanduleux et obeordés.

Le fruit est globuleux, un peu déprimé, ayant jusqu’à deux pieds de diamètre, sur une hauteur d'm pied : sa surfaee est lisse, marquéc de eôtes peu saillantes, d'un rouge clair; sa cliair est rouge. Son intérieur prćsentc une vaste cavitć fort irrégulic̀re, formée aceidentellement au milieu du tissu eharnu, et qui offre à ses parois un grand nombre de filamens enveloppant les graines.

Cette plante est originaire de l'Iude; on la cultive abondamment dans tous les jardins potager's.

propriétes et usages. La chair du potiron est ferme el nul- 
lement fondaulc; sa saveur n'a rien de fort agréable; cependant on la wange asscz fréquemment après l'avoir fait cuire, surtout dans le lait; elle est rafraichissante et un peu lassative. On ne l'emploie point en médecine.

Les usages de ses graines sonl les mênes que eeux des graines de mclon, de concombre, etc.

\section{Propriétés médicales et usages des Cucurbiacćcs.}

Cette famille offre assez d'analogie dans son mode d'aclion sur l'ćeonornie animale, quoiqu'à plusieurs égards ellè.présente des anomalies assez grandes. La raeine de ees plantes, lorsqu'elle est vivaee, eontient, outre la féeule qui cn fait la base, un prineipc résineux âere et amcr, qui lui communique une propriété purgative et mème drastique, dont la bryone ct l'claterium (momordiea elatcrium. L.) nous offrent des ex emples. Celte propriétć énergique se retrouve ćgalcment dans la prije du fruit de la coloquinte, qui forme une exception remarquable dans eelte famille, où en génćral les fruits ont la elrair douce, sucrée, plus ou moins foridante et parfumée. Les melons, les pastèques, les courges, sont en effet fréqueimment servis sur nos tables. Remarquons, pour diminuer ce disparate dans les propriétés de la pulpe du fruit des Cuenrbitacćes, que celle dont olr fait usagc comme aliment est légèrement laxative, lorsqu'on eir mange une assez grande quantilé. Mris je serais assez porté à eroire que ee n'est pas le même principe qui leur donne cette propriété laxalive. La grande analogie qui existe entre la chair du melon, de la eitrouille et lcs fruits mucoso-sucrés, doit entraîner la similitude de leur mode d'action. Or, on sait que ces dcrniers sont souvent employés coume rafraichissans et laxatifs.

Les graines de loutes les Cueurbitacées, dont l'amande cst blanche el formée d'un gros embryon députrva d'endosperme, ont unc savcur douee et mucilagineusc. Elles eonticunent, outre le mucilage, une eertaine quantitć d'huile fixc. On lcs emploie toutes indistinctement à la préparation d'émulsions aloucissanies et calmantes, destiuces spécialement nux affections lc l'apiareil vésico-génital. En résumé, cot ordre salurel 
rentre dans lat loi générale que l'analogie de structure entrainc ạvec elle l'arralogie des propriétés.

CINQUANTE-QUATRIEME PAIIAL.

\section{SYNA NTHERES-SYNANTHEREA .}

COMPOSITEE. Auct.

Tribu la plus nombreuse dri règne végétal, puisqu'elle renferme environ la douzième partie des plantes connues. Tous les végétaux qu'elle contient ont une tige portant des feuilles âlternes, souvent découpées; des fleurs très-petitẹs réunies en tête, et formant des capitules désignés autrefois par le nom de fleurs composées : tontes ces petites fleurs sont portées sur nne espèce de plateau charnu ou réceptacle, dans la substance duquel elles sont quelquefois nichées dans autant de petites fossettes nommées alvẹ́oles; elles sont entourées à l'extérieur par une ou plusieurs rangées d'écailles, quelquefois épineuses, qui constituent un véritable involucre, nomné calice commun par les auteurs anciens. Chaque fleur se compose d'un ovaire infère à une seule loge et à un seul ovule dressé; d'une corolle monopétale, tantôt régulière, tubuleuse et infundibuliforme (ehaque fleur est alors désignée sous le nom de fleuron), tantôt. irrégnlière et déjetée en languette d'un seul côté (demifleuron); de cinq étamines synanthères, c'est-à-dire réunies et sọldées en tube par leurs anthères, les cinq filets restant distincts: l'ovaire est surmonté d'un style, qui traverse

I Les travaux récens de M. Hemri Cassini sur la famille des Synanthérées, ont fait connaitre d'une manière beaueoup plus complète l'organisation des plantes qui composent ee groupe. Cependant nous u'avons pu, dans un onviage de la nature du uòtre, adopter les cluangemens nombreux que ect habile observateur a faits daus la circonscription et les caractères des genres déja trop mulviplićs de loordse des Synanthérées. 
le tube des anthères et se termine par un stigmate bifide.

Le fruit est un akène de forme très-variée, tantôt nu à son sonmet, d'autrefoís, couronné par une aigrette, fornée d'écailles ou de poils simples ou plumeux.

Les fleurs sont tantốt hermaphrodites, tantôt ınisexées ou neutres.

Cette famille se distingue des Rubiacées par ses éțamines synanthères, et son fruit uniloculaire et monosperme, etc., des Dipsacées, par ses étamines et son fruit, dont la graine est dressée au lieu d'être renversée, et ses feuilles alternes, etc. Elle se partage naturellement en trois tribus assez distinctes: les Carduacées; les Corymbifères et les Chicoracées, que plusieurs auteurs considèrent comme autant de familles.

PREMI安 R TRIB U:

\section{GARDUACÉES. - CARDUACEAE.}

\section{CINAR OCEPHALIE. Juss.}

Toutes les fleurs sont flosenlenses", c'est-à-dirè composées de fleurons tantôt hermaplirodites, tantôt unisexuécs ou weutres; le réeeptacle est garnị de soies très-nombreuses (plusieurs pour chaque fleur), ou d'alvéoles, dans lesquelles sont inplantés les fleurons : style garni d'un bouquet cireulaire de poils au dessous de la bifureation du stigmate ${ }^{x}$.

$x^{\circ}$ Point d'aigrette.

\section{CARTHAME.-CARTHAMUS.L.J.}

Involuere renflé à sa basc; éeailles imbriquées, très-scrrées inférieurement, écartées et foliacées dans lcur partic supérieure; réceptacle soycux; fruits dépourvus d'aigr'ctle.

- Ce caractire est un des plus constans pour distinguer les Carduapées des Corymbifères flosculeuses. 
Ganthame des teinturiens. Carthamus tinciorius. L. Sp. I 162 .

1'art. usitée : les fleurs et les fruits. Nom pharm. : Carthamus. Noms vulg. : Safrain bätard, Safran d'Allemagne.

Le cartlıame offre une tige dressée, simple inférieurement, souvent un peu ranifiéc à la partie supérieure, cylindrique, glabre, un peu roide, haute d'un à deux pieds. Ses feuilles sont alternes, sessiles, ovales, aiguës, un peu piquantes, denticulées, glabres,' un peu rudes.

- Fleurs (capitules) terminales et solitaires, floseuleuses, grandes, d'un jaune doré. Involucre ovoïle arronid, composé d'écailles, dressées, roides, épineuses au sommet; les extérieures larges, épaisses, serrées daìs leur moitié inférieure, écartées, foliacées, dentieulées sur les bords dans leur moitié supérieure. Réceptacle charnu, convexe, garni de poils blanes et soyeux, qui accompagnent chaque fleur et l'environnent. Ovaire allongé, presque cylindrique, glabre, couronné par un disque épigyne jaune très-saillant. Corolle offrant un tube très-long, grếle et cylindrique, non renflé à sa partie supérieure; limbe à cinq divisions égales, lanećolées, étroilẹs. Les fruits sont ovoïdes, allongés, glabres, tronqués et nus au sommet.

Cette espèce est originaire d'Orient et dígypte. On la cultive dans plusieurs provinces méridionales de la France. Elle fleurit en juillet et août.

Propriétés ct usages. Les fruits, jadis employés, mais inusités de nos jours, sont légèrement purgatifs; on les a particulièreznent recommandés dans l'hydropisie. Ses fleurs fournissent deux prineipes colorans très-importans dans l'art de la teinture : l'un, soluble dans les alcalis, prisente toutes les teintes de rouge; l'autre est jaune et soluble dans l'eau. Le prenier est principalement employé pour donner à la, soie toutes les nuances depuis le rose clair jusqu'au rouge eerise. Il porte le nom de carthomite. Mêlé au talc finement pulvérisé, il forme le fard ou rouge régétal dont les femmes font usage pour la toilette. 
$2^{\circ}$ Aigrette poilue.

\section{CHARDON. - CARDUUS. Tourn.}

Involuere globuleux; écailles imbriquées, terminćes par une épine simple; réceptacle garni d'un grand nombre de soies; fleurons tous hermaphrodiles et fertiles; aigrette sessile et poilue.

Les feuilles et les tiges sont ordinairement épineuses.

Cirardon Marrn. Cardunes Marianus. L. Sp. $\{53$. blackw. t. 79.

Part. usit. : la racine et les feuilles. Nouns vulg. : Chardon argente", Artichaut sausage.:

Cette belle espèce est faeile à distinguer par sés fevilles très'grandes, sinnieuses, glabres, luisantes', marquées de taches blanches. Sa tige est haute de trois à quatie pieds, rameuse dans sa partie supérieure, eylindrique, glabre. Se's eapitules sont fort gros, ils terminent les ramifications "de la tige; les écailles de l'in roluere sont un peu divariquées daus leur partie supérieure; elles sont glabreș, leurs bords sont garnis de dents épiueusés; les fleurs sont de couleur purpurine. Les fruits sont surmontés d'une aigrette sessile et formée de poils simples.

On trouve eette plante dans les lieux ineultes de la. Franee. Elle fleurit en juin et juillet. (

Proprietés et usages. La raeine et les feuilles du chardon marie ont une saveur amère assez prononeée. Le sue que l'ón en exprime, lorsque ces parties sont eneore fiaiches, était employé autrefois dans le traitement de plusienrs maladies, telles que l'hydropisie, l'ictère, le rhumatisme ehronique, el même les fièvres intermittentes. Mais depuis long-teinps les médeeins en ont abandonné l'usage. Devons-nous rappeler iei que quelques auteurs n'ont pas craint de vanter les graines de ce vigétal, qui sont un peu amères et oléagineuses, eomme nu spécifique contre la rage!

Les feuilles radieales du ehardon marie, lorsquelles sont encore jeunes et rendres, se mangent dans eertains pays, après qu'on en a retranché le bord épineux; leur saven approcle. beaueoup de colle des cardons. 


\section{BARDANE. - ARCTIUM. L.}

Involucre globuleux; ćcailles imbriquées, terminées par une pointe tordue en crochet; réceptacle garni de petitcs prailletlc's subulées et nombreuses; fleurons tous hcrmaphrodiles et fert tiles; aigrette poilue, sessile trìs-courte. , it ! . ... \&. as:

Feuilles et tiges non épineuses.

Bardane officinale. Arctium lappá. 'L. Sp. í 43.

Part. usit. : la racine, les feuilles. Nom pharm.' : 'Bardana. Noms vulg. : Herbe aux teigneux, Glouteron.

Racine bisannuelle,' perpendiculaire, charnue, de la gros seur du doigt, blanchâtre en dedans, recouverte d'une épiderme d'un brun foncé. Tige presque soufrutescente, fort rameuse, haute de quatre à six pieds, cylindrique, pubescente, rougeâtre. Fcuilles cordiformes, cotonneuses, pétiolées, ondées sur lcs bords et denticulées; pétiole moins long que la feuille, canaliculé, élargi et semi-amplexicanlc à sa base.

Fleurs violettcs, flosculeuses, disposées en une sorte de paniçule à l'extrémité des rameaux, toutes fertiles, Involucre arrondi, formé par un grand nombre de petites folioles, étroites, subulées, rudes, imbriquées, dirigées dans tous lcs scns, terminées à leur sommet par un petit crochet recourbé en dedans, qui leur donne la faculté de s'attacher fortemért aux vêtemens. Réceptacle commun, plane, offrant de pelites alvéoles peu profondes, et dcs paillettes nombreuses, étrvites subulées.

Fruits presque quadrilatères surmontés d'une aigrette simple et sessile.

La bardane est très-commune dans les terrains incultes, au milieu des décombres. Elle fleurit pendant presque tout l'été.

Propriétés et usages. Sa racine a unc saveur douceatrc un peu amère. Elle renferme une asscz grande quantité d'inuline. Son action principale se porte sur la transpiration cutanée, qu'elle augincnte d'une maničre marquće; c'est donc un médicament sudorifique. On l'adıninistre plus particulièrcment en aćcoction dans les différentes maladies chroniques de la peau, les affcctions syphilitiques, rhumatismales ct arthriliques. 
Lcs feuilles de la bárdane ont une savcuv âpre et assez amère. Le suc, que l'on cu exprime, uni à l'huile, forme, selon M. Percy, un liniment fort utile dans le pansement dcs plaies et des ulcèrès atoniques, dont il favorise singulièrement la cicatrisation.

Dins les campagnes, on fait bouillir les racines de la bardane et on les mange à la manière dcs salcifis. Il en est de même de lẹurs jeunes pousses, qui ont une saveur assez agréable et semblible à celle de l'artichaut.

\section{GENTAURÉE. - CENTÁUREA. L.}

Involucre globuleux, formé d'écailles imbriquées, tantôt minces ct scarienses sur les bords, lantôt cilićes, quelquefoís terminées par une épine simple ou pectinée; fleurons de la circonférence beaucoup plus grands, inréguliers et neutres. Les fruits sont avcc ou sans aigrette.

Ce genre, très-polymorphe, a été divisé en un grand nombre de sections, que plnsieurs auteurs regardent, ct arec raison, comme autant de genres distincts.

$$
\text { I Point d'aigrettè. }
$$

Écailles de l'involucre terminées par une épine rameuse sur les còtés. (Calcithapa. Juss.)

Centauree chausise-trappe. Centaurea calcitrapa. L. Sp..$^{\dagger}$ I 297 .

Part: empl. : 'therbe entière. Nom pharm. : Carduus stellatus. - Noms vulg. : Chardon étoilé. Chausse-Trappe.

Racinc annuelle donnant naissancc à une tige dressée, trèsramcuse, roidc, striée, couverte en partie de poils laineux; feuilles sessiles, lancéolées, aiguës, dentées, incisées ou mème pinnatifides; les plus infórieures sont plus larges et comme lyrées.

Lcs capitules dc fleurs sont latéraux et scssiles. L'involucre est ovoïle, allongé, composé d'écailles imbriqućes, à basè large, dilatée, charnue; tcrminées au sommet par unc longuc épinc très-aiguë, divariquée, offrant de petitcs épines latérales à sa basc; lcs écailles les plus intérieurcs sont mutiques, et scaricuses art sommct. 
Lc réceptaele est presque plane, garni de petites écailles subulées, blanehes et naerées : toutes les fleur's, qui sont flosculeuses, s'y insèrent par un point latéral. Les fleurons extérieurs plus grands sont stériles, à trois lobes lancéolés, ne renfermant point d'organes sexuels. Les fleurons fertiles sont à cinq lobes étroits disposés eomme en deux lèvres : la supérieure a quatre lobes, l'inférieure a un seul lobe plus long que les autres.

Les fruits sont elliptiques, un peu eomprimés, latéralement glabres, lisses, sans aigrette.

La chausse-trappe est excessivement commune dans les lieux stériles, sur le bord des ehemins. Elle fleurit pendant tout l'été. (

Fropriétés et usages. Toutes les parties de ee végétal ont une saveur extrêmement amère; mais cette saveur s'affaiblit dans la racine, qui est assez douce. Cette dernière a joui au commencement du sièele dernier d'une vogue extraordinaire dans le traitement des maladies des voies urinaires, et surtout la néphrite caleuleuse. Elle formait la base du fameux remède de Baville, dont la eomposition est restée fort long-tcmps secrètc. Quant aux fcuilles, leur amertume est tellement prononeée, qu'un grand nombre d'anteurs les ont administré avee beaucoup d'avantages contre les fièvres intermittentes; ct les faits que l'on a recueillis à cet égard sont assez nombreux pour engager les mćdecins à ne pọint négliger un médicament qu'il est si facile de se procurer.

On peut donner la chausse-trappe soit en déeoction, à la dose d'une once pour deux livres d'eau, soit le suc qu'or en exprime, soit cnfin sous la forme d'extrait dont la dose cst d'une onee à une onee et demie.

$2^{\circ}$ Fruit aigretté.

Aigrette double; feuilles supérieures formant un second involucre.

(Ciricus. D. C. non L.)

Cënturén chardon béni. Cantautea benedicta. L. Sp. $1,296$.

Part. usit. : la plante entière. Nom pharm. : Carduus benedictus.

Cettc espèce, qui est annuelle, présente unc tige herbacéc, 
rameuse, courcrte, ainsi que toute la plante, de poils laineux, presque quadrangulaire, rougeâtre; des feuilles alternes semi-amplexieaules, allongćes, offrant de grandes dentelures irrégulières terminées par une petite épine. Celles qui environnent le capitule sont plus petites, dressées et serrées contre lui, s'y altaehant au moyen de longs poils eotonneux, et formant une sorte d'involuere extérieur. Les eapitules sont solitaires et terminaux, jaunes et flosculeux. L'involucre est conique, formé d'éeailles imbriquées, larges inférieurement, et terminées par une longue épine pinnatifide. Le réeeptacle est plane, chargé de poils soyeux très-nombreux.

Chaque capitule renferme vingt à vingt-cing fleurons jaunes: ceux du disque hermaphrodites et fertiles; eeux de la eireonférence neutres.

Le fruit est glabre et strié longitudinalement, attaché obliquement au phoranthe, eouronné par un petit bord à dix petites dents régulières, et par une aigrette double; l'extérieure fornée de dix soies plus eourtes que le tube de la eorolle. denticulées sur les bords ; l'intérieure formée de dix soies beaueoup plus courtes que les préeédentes, également dentieulées sur les bords.

Cette plante eroît dans les ehamps cies provinecs méridionales de la Franee, où ellè fleurit en juin et juillet. (-)

Propriétés et usages. L'amertume extrême du chardon béni indique l'aetion tonique qu'elle exeree sur l'éeonomie animale. Aussi est-ce surtout eomme fébrifuge que ee végétal a été le plus employé, principalement dans les fièvres intermittentes printannières. Son mode d'administration et ses préparations sont les mêmés que ceux de la ehausse-trappe, dont il se rapproche singulièrement par ses propriétés médicales.

Écailles de l'involucre scarieuses et ciliées sur les bords.

(Cxanus. D. C.)

Centaurée bleuet. Centaurea Cyanils. L. Sp. 1289. Blackw. t. 66.

Part. usit. : lesfleurs. Nom pharm. : Cyanus major. Noms rulg.: Barbeau, Aubifoin, Casse-Lunette.

Tige dressée, rameuse, à rameaux écartés, presque carrée, rude, velue. 
Feuilles alternes; eclles de la basc pinnatifides, les supirieurés sessiles, lancéolées, aiguës, entières, étroites, velues sur la face supérieure, marquécs ordinairement de trois nervures longitudinalcs.

Flcurs (eapitules) solitaires et terminales, composées de fleurons bleus, roses ou blanes.

Involucre ovoïde, eomposé d'éeaillés imbriquées, ovales, allongées, scarieuses et ciliées sur les bords. Réeeptacle presque plane, garni de soies qui environnent chaque fleuron.

Les fleurons de la eireonférenee sont beaueoup plus grands, irréguliers, neutres et stériles, à limbe eampanulé, oblique, divisé en six ou sẹpt lobes aigus et inégaux.

Les fleurons du centre, moins grands, sont hermaphroditcs et fertiles. Leur tube est allongé, grêle, renflé à la partie supérieure. Le limbe est à einq divisions égales et linéaires.

Le fruit est ovoïde, tronqqué à son sommet, velu, eouronné par une aigrette poilue et courte.

Le bleuet croît au milieu des inoissons et fleurit en juin. (C)

Propriétés et usages. Ce sont les fleurs que l'on emploie. Leur. saveur est légèrement amère. Autrefois employées eontre. une foule de maladies très-graves, les modernes en ont iprcsque exclu l'usage de la thérapeutique. L'eau distillée est la seule partie dont on se serve encore quelquefois. On en prépare des collyres détersifs, en y ajoutant quelque sel métallique, tels que le sulfate de zinc ou l'acćtate de plomb.

Écailles de l'inyolucre scarieusès et entières sur les bords.

(Centaurium. D. C.)

Centaurée offichare. Centaurea centaurium. L. Sp. 1286. Blackw. t. 93.

Part. usit. : la racine. Nom pharm. : Centaurium majus vel magrum. Nom vulg. : Grande Centaurcée.

La grande centaurée est une plante alpine, qui croit dans les bois et les pâturages élevés des montagnes. Sa raeine vivaee, eharnue, allongéc, ' 'ougeâtrce, et d'une odenr aromalique, pousse une tige droitc, rameusc, glabre, haule de quatrc à cinq pieds, portant de grandes fcuilles alternes et penućcs, 
dont les folioles sont lancéolées et dentées. Les fleurs, qui sont purpurines, grosses et presque globuleuses, forment une sorte de corymbe irrégulier à la partie supérieure des ramifications de la tige.

Propriétés et usages. On a aujourd'hui entic̀rement abandonné l'usage de la racine de grande centaurée, qui est amère et un pcu aromatique, è que l'on considérait jadis comme tonique et sudorifique.

Il en est de même de la J J CÉ (centaurea jacea. L.), dont la racine, légèrement astringente et amc̀re, $s^{\prime}$ employait autrefois sous forme de gargarisme dans les maladies de la bouche et du pharynx.

$3^{\circ}$ Aigrette plumeuse.

\section{CINARE. - CINARA. L. J.}

Involucre renflé à sa base, composé d'écailles épaisses, charnues inférieurement, épineuses au sommel; réceptacle charnu, concave, garni de soies nombreuses; fleurons égáux, tous hermaphrodites et fertiles; fruits couronnés par une aigrette plumcuse et sessile.

\section{Cinare artichaut. Cinara scolymus. L. Sp. i 559.}

L'artichaut, cultivé depuis si long-temps dans nos jardins comme plante potagère, est originaire du midi de l'Europe, et quoiqu’il soit depuis fort long-temps acclinaté dans les régions du nord, il ne résiste cependant point aux froids de l'hiver, lorsqu'ils sont trop rigoureux. Sa racine vivace cst épaisse;, charnue, dure, ramcuse, et donne naissance à une tige cylindrique, glabre, peu rameuse, de deux à trois pieds d'élévation, qui donne attache a des feuilles très-grandes, pinnatifides, d'un vert pâle cn dessus, blanchâtres en dessous, découpées en lobes profondément et irrégulièrement dentés. Les capitnles naissent solitaires au sommet des ramifications de la tige; 'ils sont de la grosscur des deux poings; leur rćceptacle est trèsépais, charnu, concave, garni de soies simples; les foliolcś de l'involucre sont larges, épaisscs, terminiées'en pointe épinieusè à leur sommet. Tous les fleurons sont hermaphrodites et d'une. couleur violette claire; le tube da la corolle est très-long; son 
limbe offre cing lanièxes trẹs-ćtroițes; le tube staminal est extrêmement saillant, de même couleur que la corolle. L'aigrette est sessile et plumcuse.

Propriétés et usages. La racine de l'artichaut a une saveur amère assez intenșc, que l'on rctrouve à un degré cncore plus grand dans lcs tiges. On en faisạit autrefois usage, surtout comme diurétique; mais dẹpuis long-temps ce vćgétal n'est plus cultivé que comme plante potagère. Tout le mondẹ șait que ce sont les capi tules, ou tếtes que l'on reçueille avant.l'ćpanouissement des fleur's, et dont on mange le réceptacle ct la base des feujlllcs, soit eruds, soit après les a voị fait bonillir dans l'eau. L'artichant cuit est un aliment agréable, peu nourrissant à la vérité, mais facilc à digérer, et dont on peut permettre l'usage aux convalescens. On peut conserver pour, l'hiver les réceptacles ou culs d'artichauts, en les faisant sécher après les avoir blanchișià l'eau bouillante.

Cinare cardon. Cinara carduncellus. L. Sp. ir 59 .

La patrie du cardon est la mème que celle de l'artichaut; on le trouve égalcinent dans les contrćes méridionales de l'Europe et dans le nord de l' $\Lambda$ frique. Ses feuilles découpées en lobes ćpineux, dont la côtẹ est très-saillantc, ćpaisse et charnue; ses liges plus grếles, terminćes par des têtes de fleurs trois ou quatre fois plus petites, dont le réceptacle est mince, les écailles de l'involucrc armées d'épines acérces, le distinguent faeilemęt de l'artichaut. Quelques auteurs ont cependant voulu établị que l'artichaut n'est qu'une variété du cardon. Cctte opinion nous parait fort peu fondée; car s'il en était ainși, parmi la grande quantité de cardons que l'on cultive dans les jardins, on cn verrait quelques pieds sc transformer en artichaut, ce 'ui n'est jamaị arrivé.

Dans.,cette espèce, c'est la côte ou nervure médiane des fcuilles que l'on mange. Loŕsqu'cllc est cuite, elle cst tendre ct sa sayeur offre la plus grande analogic avee celle de l'artichaut. C'est ên. général un mels assez recherché, et qu'on 11c, voit guerrargue suru la table des gens, aisés. 
CARLINE. - CARLINA. L. J.

Involucre double, l'extćrièur formé d'éeailles épineuses, ćeartées supćrieurement, l'intérieur composć d'éeailles étroites, searieuses, eolorécs et élalées en formc de rayons. Fleurons tous hermaphrodites; rćceptaclc garni de paillettes soudées par leur base : fruit surmonté d'une aigrettć plunneuse.

Carline a metilles d'acanthe. Carlina acanthifolia. Allion. fl. ped. no 57 r, t. 5 r.

Part. usit. : la racine. Nom pharm. : Carlina sive Canceleon.

Noms vulg. : Camélćon blanc, Chardouse, ete.

Cette belle plante, qui croit dans les Alpes de la Provenee, du Dauphiné et dans les Pyrénćes, offre un port tout-à-fait singulier. Ses fcuilles, qui sont grandes, ćlégamment déeoupées et épincuses, sont étalées en rosaee à la surfaec du. sol; elles sont blanchâtres et eotonneuses. Dc leur centre nait un capitule très-gros, ayant beaueoup de ressemblance avec celui dc l'artichant, et porté sur une tige tellement eourte qu'il semble sessilc. L.es fleurs sont jaunâtres; les rayons de l'involucre sont $b_{l}$ blancs, ayant en quelque sorte un brillant métallique. On trouve cette plante en fleurs pendant le mois de juillet.

Proprictés el usages. Sa raeine a une saveur amère pẹ. agréable. Les aneiens lui altribuaient des propriétés mẹrveilleuses dans le traitement des maladies pestilentielles; mais les modernes cn ont, à juste titrc, abandonné l'usage.

Dans les pays de montagnes où eroît eetle plante, les habitans des eampannes en mangent les réeeptaeles comme ceux de l'artichaut.

SECONDI TRIBU.

\section{CORYMBIFERES. - CORYMBIFERAE.} Radiées de Tournefort.

Les fleurs sont tantôt toutes flosculeuses, hermaphrodites ou unisexućes; le plus souvent elles sont radićes, c'est-à-dire que le eentre des capitules est formé de flcurons, et qu’ia la circonférence sont des demi-fleurons ordináirement femelles 
ou nentres : le réeptaele est nu ou garni de soies ou paillettes en nombre égal à eelui des fleurs; le style est dépourvu à son sommet de ee bouquet de poils dont nous avons fait remarquer l'existence dans le groupe précédent.

$I^{0}$ Réceptacle garni de paillettes ou de soies.

\section{A M O M IL LE. $-A N T H E M I S$. L. J.}

Involucre hémisphérique, composé d'éeailles imbriquées, scarieuses sur les bords; fleurs radiées; fleurons du centre herinaphrodites fertiles; demi-fleurons femelles et fertiles; réeeptacle convexe, garni de paillettes; fruit couronné par une nembrane entière ou dentće.

Gamomilue noble. Anthemis nobilis. L.Sp. 1260 . Blackw. t. 526 .

Pàrt. usit.: les capitules. Nom pharm.: Chamoemelum romanum.

' Nom vulg. : Camomille romaine.

Le nom de eamomille romaine, donné à eette espèce, semblerait indiquer une plante étrangère à la France, ee qui n'est joint; car cette espèee est fort eommune dans les allées sablonneuses et les pelouses de nos bois. Sa tige, de huit à dix pouces, est conchée, rameuse, redressée par l'extrémité de ses rameaux, qui portent ehaeun une seule fleur. Cette tige est eylindrique, striée, pubescente. Ses feuilles sont eourtes, irrégulièrement bipinnées, pubescentes, à folioles subulées, très-petites, aiguës. Ses fleurs sont solitaires; le disque est jaune, les rayonsblanes. Involucre presque plane, imbriqué, eomposé de folioles pubescentes, searieuses sur leurs bords. Réceptaele très-eonvexe et proéminent, chargé d'autant d'éeailles searieusês qu'il y a de flenrs, dont elles égalent à pen près la hauteur. Demi-fleurs de la circonférence femelles fertiles; limbe termiuć. par trois dents obtuses. Flẹrons du disque jaunes, hermaphrodites fertiles; ovaire ovoüde nn; point d'aigrette; corolle infundibuliforme, tube cylindrique; limbe eampanulé, à cinq divisions réfléchies.

$\because$ Le fruit est allongé, sur'montë d'un pétit bourrelef membiraneix. : 
On trouvc' la camomille romaine cn fleurs pendant les mois de juin ct de juillet. $₹$

Cettc espécc double facilement par la cullurc, ct c'est celtc varićté qu'on préfc̀re pour l'usage mćdical.

Propriétés et usages. Lcs capitules on fleurs de la camomille romainc r'ćpandent une odeur aromatique forte, mais agréable. Leur saveur cst extrêmement amçre et aromatique. Elles contiennent une huile volatile d'une belle couleur bleue, du. camphre, un principe gommo-rćsineux, et, une petite quantité de tannin.

L'infusion des fleurs de camomille cst une boisson à la fois touique et excitante, dont lcs praticiens font un fréquent usage. Cette infusion augmente d'une manière marquée les: forces digestives de l'eslomac, surtout quand cet organe a besoin d'être stimulé. Comme fébrifuge, on emploie fort souvent la camomille, qui réussit fort bien dans lcs fièvres intermittentes peu graves, et surtout chez les sujets faiblcs. On l'emploie aussi. comme antispasmodique, quoique moins frćqucminent. Son administration est souvent avantageuse dans certaines coliques, occasionnées par la prćsence d'une grande quantité de gaz dans les organes de la digestion. Quelques médecins prẹscrivcnt cncore ce médicament comme ver'mifnge; d'autres, poun aider: l'action des vomitifs, tels que l'émétique et l'ipćcacuanha.

L'infusion se prépare en versant deux livres d'eau bouillante sur douzc à quinze têtes de camomille : on peut les donner en poudre ou les faire macćrer dans du vin. L'eau distillée de camomillc peut entrer à la dose dc deux onces dans une potion excitante.

\section{Camomme puante. Anthemis cotula. L. Sp. $126 \mathrm{r}$.} Blackw. t. 67 .

La maroutc ou camomille puante présente une racine anmuelle, donnant naissance à plusicurs tiges rameuses, rcdressécs, cylindriques, strićes, un pcu velucs supérieurement, longues d'environ un picd; des feuillcs sessiles bipinnćes, presque glabres, à scgmens linéaircs étroits, terminés en
pointc.

Scs Reur's radićes sont terminales et solitaires au sommet 
des ranifications de la tige. Involuere hémisphérique eomposé d'éeailles imbriquées, searieuses sur leurs bords, un peu velues. Réeeptaele eonique sáillant, offrant à la base de elaque fleur une écaille subulée, étroite, à peu près de la même longueur que la fleur. Fleurons du eentre jaunes, petits, réguliers, très-sèrrés; hermaphrodites fertiles : demi-fleurons de la cireonférenee blanes, étalés, à trois dents obtuses, femelles et stériles. Frruits ovoïdes, tubereuleux.

Cette plante est extrêmement commune le long des rivières, des mares et des ruisseaux.

Propriétés et usages. Toutes les parties de la maroute répandent une odeur aromatiçue très-prononeée et très - désagréable, qui lui a fait donner le nom de camomille puante. Cette odeur indique en elle un prineipe stimulant fort intense. On l'emploic surtout dans les différentes névroses, et plus partieulièrement eontre les aeeidens de l'hystérie. On donne ses fleurs en infusion : on peut préparer des lavemens stimulans et antispasmodiques avee l'infusion de la plante entière. Du restè, seś propriétés sont fort analogues à eelles de la eanomille' romaine.

- Plusienr's autres espèees de camomille ont des proprićtés médienlës 'assez mar'quées pour pouvoir être également employées en médeeine; telle est surtout la camomille des teinturiersl(tunthemis tinctoria. L.); qui fournit une belle eonleur jaune, et que quelque auleurs disent avoir adıninistrée avec avantage eomme tonique et'stimulañte.

\section{MILLEEUILLE. - ACHILLAEA. L. J.}

Involuere ovoïde ou eylindrique, formé d'écailles imbriquées; fleurs radiées, à rayon' femelles et peu nombreux; réeeptaele plane et pailleté; fruit sans aigrette.

Millefeurle comínue." Achilleva millefolium L. Sp. I267. Blackw. t. $x 8$.

Parties usitées : les feuilles, la racine. Nom pharm. : Millefolium. Noins vulg. : Millefenille, Herbe à la coupure, Herbe au charpentier; ete.

Racine vivaee, domnant naissanee ì des tiges dressées, cylin- 
driques, simples inférieurement, un pcu striécs et velues, hautes d'un à deux pieds. Fcuilles sessiles bipinnatifides, velues; segmens très-rapproehés, allongćs, divišés en dents très-aiguës.

Fleurs radiées blanches, disposées en côrymbe d la partie supérieure des rameaux. Involucre allongé, eylindríque, cómposé d'écailles imbriquiées, obtusès, mincès et scàrieứses sự les bords. Réceptàele presqué plane', garni dé pétites écaillès lancéolées', transparentes.'Dcmi-fleurons de la eircónférence, ordirairement au nombre de einq, femelles et fertiles, trèseourts, larges, à trois dents peú marquécs. Fleurons du centre égalerient blancs, au nombre d'envirón six ; réguliers, à cinq dents, hermaphrodites ct fertiles. Fruits. ovoïdes, dépourvus d'aigrette.

La millefeuille est très-commune dans lés lieux incultes; dans les prés sees. Elle fleürit pendant la pilus grande partie dé l'été. \{

Proprićtés ét usidges. Les feuilles de cette plante ont une sáveur faiblément arccrbe et amère. Ellles ont cu jadis une trèsgrande réputation dansi le trailement des plahes récentes, à une époque où l'on eroyait utile d'aider par des applications topiques, souvent fort nuisibles, la cieatrisation des plaies simples. De là les noms vulgaires d'herbe à la coupure, herbe au charpentier; sous lesquels elle est désignée dans quelques enntrées. On les administrait aussi à l'intérieur, soit en décoetion à la ose de deux oriees pour une pinte d'eau, soil en poudre, depuis un jusqu’à deux gros. Quảnt à sa raeine, elle est égaleniènt un peu astringentc, mais elle né m'a pás paru poósséder cétle odeur de eamphre que plusieurs anteurs lui allribnent. On l'avait proposé comme un suceédané indigène de la serpentaire de Virginiè mais on en 'a abandonné l'usage ainsi cine celui des feuilles.

Mirtifieume ptarmique. Achillaca ptämica. L. Sp. I 266 .

Part. usitec: les feuilles. Nom pharm. : Ptarmica. Noms vulg. : Ptarmique, Herbe à ćtcrnuer.

Celle espècc, fort eommune dans les prés ct les lieux hu- 
mides, sc distingue de la précédente par sa tige, simplc cn bas, Cressée, pubescente à sa partie supéricurc, où elle est rameuse et paniculée; par ses feuilles lancéolées, très-ćtroites, aiguës finement dentées en scie, sessiles, glabres.

Ses flcurs radiées, à rayons blancs et à disque d'un blanc jaunâtre, sont disposécs en unc paniculc terminalc à l'extrémité des rameaux. Les demi-fleurons de la circonférence, ordinairement au nombre de dix, quelquefois douze ou treize, sont femelles fertiles, dépourvus d'aigrettes, ainsi que les fleurons du centre; leur limbe est ovale, large, comme trilobé à son sommet. Les fleurons du disque hermaphrodites et fertiles ont une corolle tubulée, dont le limbe n'est pas manifestement plus large que le tuhe, qui est un peu comprimé; le limbe est terminé par cinq lobes aigus et réflèchis.

Les fruits sont tous dépourvus d'aigrette.

Propriétés et usages. Cette plante est lćgèrement odorante; la saveur de ses feuilles est faiblcment aromatique et un peu âcre, ayant assez de ressemblance avec celle de l'estragon. Sa raciné et ses feuilles séchées et réduites en poudre sont fréquemment employées comme sternutatoires, et la racine, lorsqu'on la mâche, excitc d'une manière très-marquće l'action des glandes salivaires.

Sous le nom de genipi, lcs habitans des $\Lambda$ lpes de la Suisse et de la Savoie désignent plusieurs espc̀ces de millefeuille, telles que l'achilloea nana, $A$. moschata et $A$. atrata, qui toutes ont unc odeır aromatiquc et agréable, une saveur chaudc et excitante. On les y emploie aux mêmes usages et à peu près dansles mêmes circonstances que la camomille.

\section{HÉLIANTHE. - HELIANTHUS. L. J.}

Fleurs radićes : involucre composć d'écaillcs foliacées, écartées; demi fleurons de la circonférence neutres et très-grands; fleurons du ccntre très-serrés, hcrmaphrodites fcrtiles : réccptacle plane et pailleté. Fruits terminés par deux ćcailles lancćolées, opposćes et caduqucs. Fleurs constamnicnt jaunes. 
Hélianthe tubéreux. Helianthus tuberosus. L. Sp. iaj7.

Parl. nsitée : les racines. Noms v̈ulg. : Topinämbour, Poire de

terre.

C'est au Brésil que nous sommes rederables de cette plante, aujourd'hui si bien naturalisée dans toutes les eontrées de l'Europe, où on la eultive abondamment à cause de ses usages dans l'économie rurale et domestique. 'De gros tubereules eharnus, oblongs, rougeâtres en dehor's, blancs intérienrement, assez semblables à ceux de la pomme de terre, composent sa raeine, qui est vivaee. Il s'en élève des tiges dressées, simples, herbaeées, hautes de huit à dix picds, qui portent des feuilles alternes ou opposées, très-grandes, ovales, amincies en pointe à leurs deux extrémités, marquées sur leurs bords de petites dentelures ct un peu rudes au toucher. Les fleurs ou eapitules sont solitaires, terminalcs et jaunes, dressées, larges d'environ deux ou trois pouces. L'involuere se compose d'écailles foliacées, imbriquées, eiliées sur leurs bords.

Cette plantc fleurit vers le mois de septembre: $\Varangle$

Propriétés et usages. Les tubereules eharnus du topinambour sont un aliment sain et agréable, non-seuleıncnt pour l'homme, mais encore pour les vaehes, les boufs ct les noutons, qui en sont très-friands en hiver. Lorsqu'ils sont cuits, leur saveur cst douce et sucrée, et présente beaucoup de ressemblanee avec celle des artichauts. La culture de cette plante est Irès-avantageuse. En effet, elle réussit mêıne dans des terrains fort maigres. Cependant on la cultive beaucoup moins que la pomme de terre, qui fournit plus de matière nutritive, ct dont les usag.es sont plus inultipliés.

Une autre espèce de ee genre est encore fort remarquable, et par la grandeur étonnanle de ses capitulcs, qui ont jusqu’à huit à neuf pouces de diamètre, et par les usages de ses fruits. On la connaît généralement sous lc nom de grand soleil; c'est l'helianthus annuus, plante ánnuelle, aujourd'hui excessivement commune dans tous nos jardins, et qui nous a été apportée du Pérou. Dans quelques contrées, ses graincs torréfiées sont employées aux mèmes usages que le café. Ces graines, 
dont́ l'amandc est blanche, rcnferment une grande quantité d'huile grasse que l'on en extrait avec avantage. On cn fait aussi une sorte de bouillie employće à la nourriture des enfans, et les différentcs volailles les recherchent avce avidité.

\section{A BSIN THE. - A BSINTHIUM.}

Fleurs flosculeuses : involucre globuleux, composé d'écaillcs imbriquécs; réceptacle garni de longucs soies. Fleurons du centre hermaphrodites fertiles, à einq dents; flcurons du disque tubuleux, à deux dents, femelles. Fruits dépourvus d'aigrettc.

A в SINT н Artemisia absinthium. L. Sp. I 188. Blackw. t. I 7 .

Part. usit. : les feuilles et les sommités fléuries. Nom pharm.: Absinthium majus. Noms vulg.: Grande absinthd ou Aluine.

Raeine, vivace; tige herbacée, dresscee, un peu rameuse, couverte d'un duvet blanchâtre, très-court, qui fait paraître la plante d'un gris eendrć. Feuilles inférieures tripinnatifides, à divisions ćtroites, laneéolées, obtuses, pubescentes ct blanchâtres des deux eôtés, surtout à la face inférieure; les caulinaires bipinnatifides, puis simplement pinnatifides, et finissant vers la partie supérieure par devenir simples; allongées et obtuses. Les fleurs, qui sont floseuleuses, petiles, globulcuses, jaunâtres, pendantes, forment dcs épis axillaires simples, dont la réunion constilue une panicule très-allongée et pyramidale. Involuere semi-ovoüde, formé dc folioles ovales, obtrses, pubeseentes, scarieuses sur lenrs bords et imbriquées. Réccptacle eonvexe, garni de poils longs' et soycux. Fleurons du centre hermaphrodites fertiles; ovaire nu. Corolle tubuleuse, se terminant à son sommet par einq divisions. Fleurons de la cireonfćrenee simplement femelles, irréguliers, grèles, filiformes, terminés par deux dents qui sont dressćeś. Fruits sans aigrelte.

L'absinthe se reneontre dans les lieux pierreux et incultcs. Elle fleurit pendant les mois de juillet et d'aout. $\frac{\not 6}{6}$

Propriétés et usages. Cette plante exhale une oderir pénétrante très-prónoneée; sa saveứ est extrểmement'amc̀re et 
aromalique. C'est un médieament à la fois tonique et stimulant, auquel on a fréquemment recours, soit pour ranimer l'action languissante de l'estomae, soit dans la leueorrhée chronique oì l'aménorrhée dépendant de eauses débilitantes. Dans ces différentes eireonstanees l'absinthe produit une exeitation avantageuse. Quelques auteurs ont conseillé les préparations d'absinthe dans le traitement des fièvres intermittentes. Enfin ee médieament est assez fréquemment administré comme vermifuge.

L'absinthe se donne sous plusieurs formes : $x^{\circ}$ infusće dans l'eau bouillante à vaisseau elos, une once pour deux livres d'eau ; $2^{\circ}$ en poudre, à la dose d'un à deux serupules; $3^{\circ}$ sous for'me de vin, il est tonique et stomaehique; $4^{\circ}$ en teinture, à la dose d'un à quatre gros.

$2^{\circ}$ Phoranthe sans paillettes ni soies.

A. Point d'aigrette.

\section{ARMOISE. -ARTEMISIA.}

Fleurs flosculeuses; involucre ovoïde ou eylindrique; réceptacle nu.

Ce genre ne diffère de l'absinthe que par l'absenec des soies sur le rćceptáele.

Armorse commune. Arienisiá vulgäris. L. Sp. I 188. Blackw. t. 43 r.

Part. usitécs: les feuilles ct les sommités fleurics. No m pliarm.: Artemisia. Non vulg. : Herbe de Saint-Jean.

Tige herbacćc, droite, rameusc, liaute dè quatre à cinq picds, eylindrique, striée' longitudinalcment, rougeâtre, un peu veluc.

Tcuilles sessiles, profondément pinnatifides, larges, vertes et glabres en dessus, blanehes et cotonneuses en dessous; folioles lancéolées, aiguës, quelquefois offrant plusicurs grandes dents; les feuilles supéricures sont simples, lancéolécs; les moycnnes sont profondément trilobées.

Les fleurs sont disposécs par petits épis axillaires, allongés et 
constifuent une longue panieule étroite, effilée au bout de ehaquc rameau.

Chaque eapitule est oroïde allongé, composé d'un involuere à folioles ovales eotonnèrses, un peu searieuses sur les bords. Le réeeptacle est dépourvu de soies.

On trouve communément l'armoise dans les lieux incultes, sur le bord des chemins, où elle fleurit pendant les mois de juin et de juillet. $\&$

Propriétés et usages. Moins amère et moins aromatique que l'absinthe, l'armoise est moins énergique dans son action. C'est surtout eomme stimulante de l'utérus cque l'on prescrit eetle plante; son infusion cxcite l'éruption des menstrues, lorsqu'une cause débilitante en retarde le cours. Du reste, on l'emploie à peu près dans les mẻmes eireonstanees et sous les mêmes formes que l'absinthe, qui mérite à tous égards la prćférenee.

Armorse estragon. Artemisia dracunculus. L. Sp. i i 89 . Part.. usitée : les feuilles. Nom pharm. : Dracunculus hortensis. Nom vulg. : Estragon.

L'estragon, qui est originaire de la Sibérie, est eultivé dans les jardins. Il présente une tige lrerbacée, dressée, rameuse, eylindriqne, glabre, haute d'cnviron deux pieds; des feuilles alternes, entièr'es, sessiles, lancéolées, très-étroites, glabres et charnues. Ses fleurs sont petites, disposées en une sorte de panieule allongée, composée de petits épis axillaires. Clıaque capitule est petit, globuleux, formé de fleurons jaunâtres. L'involuere eommun est presque globuleux, formé de sept ou huit folioles eharnues, glabres, ovales, inégales. Le réceptacle est garni de soies. Les fruits sont sans aigrette.

L'estragon fleurit en août et en septembre. $\mathcal{F}$

Propriétés et usages. Les feuilles de l'estragon, quand on les mâche, ont une saveur aromatique fraìche qui pique fortement la bouche. C'est un médieament stimulant, qui agit de la même manière que les végétaux appelés vulgairement antiscorbutiques. Mais on l'emploie plus fréquemment eomme condiment dans la salade et les préparations culinaires, que comme médicament. 
Armorse de Judée. Artemisia judaïca. L. Sp.

Part. usitées : les fruits et les capitules. Noms pharın. : Santo-

lina, Serneu contra vermes. Noms vulg. : Sernen contra,

Sementine, Barbotine, etc.

C'est dans l'Arabie, la Judée et les contrées boréales de PAfrique, que croît naturellement cette armoise, qui est un arbuste d'un à deux pieds d'élćvation. Sa tige cst rameuse, comme paniculée, pubescente et d'un gris cendré; elle porte des feuilles petites, ovales, obtuses, cotonneuses, découpćes en plusieurs lobes, celui du milieu plus long que les aulres. Les fleurs sont jaunâtres, petites, presque globuleuses, pédonculćes, formant une sorte de janicule un peu resserrée, très-allongée. L'involucre est composé de petites folioles imbriquées, cotonneuses et blanchâtres. Le réceptacle est plane. Les fruits sont ovoïdes allongés, un peu striés, sans aigrette.

Propriétés et usages. Les capitules, les fruits et les ramifications supćrieures de cette plante, mélangés à ceux d'une autre espèce du même genre qui croît en Perse, et que Linné a nommé artemisia contrá, sont connus dans le commerce sous lcs noms de semen contra et de sementine. On en distingue deux variétés: le semen contra du Levant et celui de Barbarie. Le premier est le plus estimć; il est verdâtre, et se compose de capitules de fleurs enticrs ou brisés, de petits fruits ovoïdes allongés, et de pédoncules. Son odeur est assez agréable; sa saveur aromatique, chaudc, ressemble un peu à celle de l'anis. Le second, on celui de Barbarie, est beaucoup plus rćpandu dans le commerce; il est formé de petits boutons blanchâtres non développés, et de fragmens de feuilles et de pédoncules. Son odeur est plus forte, moius agréablc, et sa saveur plus âcre.

C'est principalement comme vermifuge qu'on prescrit le semen contra. La dose cst d'un scrupule pour les enfans, dose quc l'on porte à un gros pour les adultes. Ce nićdicament se donnc, soit en poudre quc l'on mêle avèc des confitures, ou dont on fait des bols afin d'en faciliter l'adıninistration, surtout pour les enfans. Le plus souvent on y associe l'nsage des purgatifs, tels que le mercure doux ou lá rhubarbe. 
Les fruits ct les eapitules de plusieurs autres espèces d'armoise jouisscnt absolument des mêmes propriétés que la sementinc, et pourraient lui être substitués. Ainsi l'absinthe eommune est un puissant anthelmentique, et l'armoise des champs possède une action nol moins ćnergiquc.

En gćnćral, la plupart des espèces du genrc armoise sont ou peuvcnt êtrc employćes en méllecine. Preșque toutes sont amc̀res et aromaliques; ainsi l'aurone des jarclins (artemisia abrotanum. L.), que l'odeur agréable de eitron exhalée par ses feuilles a fait nommer citronelle; l'armoise dos glaciers (artẹnisia glacialis. L.), ou genipi des Alpes, et plusieurs autres, peuvent dans plusieurs cas remplacer l'absinthe, bien qu'elles n’aient pas la mème intensité dans leurs proprićtés.

\section{TANAISIE. - TANACETUM. Desf.}

Involucre hémisphérique, formé d'éeailles imbriquées, scarieuscs sur les bords; flcurons du centre hermaphrodites, tubuleux, à einq lobes; ceux de la circonférence femelles et à trois lobes; fruits couronnés par une membrane circulaire entière.

Tanaisle cominune. Tanacetum wulgare. L. Sp. Ix 48 . Blackw. t. 464 .

Part. usit. : les sommités fleuries. Nom pharm. : Tanacetum sive Áthanasiá. Noms vulg. : Tanaisie, Herbe aux vers.

$\mathrm{La}$ tanaisic croît très-communément dans les lieux incultés, sur le bord des chemins. Sa racinc, qui est vivace, produit. plusieurs tiges dressćcs, fermes, cylindriques, strićes, raineuses, hautes de deux à trois pieds, sur lesquelles maissent des feuilles altcrnes, sesșiles, profondément pinuatíides, à divisions allongćes, aiguës, presquc pinnées. Les fleurs, d'un jaune doré, sont disposées ell corymbe à l'extrémité des rameaux. Leur involuere, presqne plane, se compose de deux ou trois rangs d'éeailles imbriquées, très-scrrćes, scarieuscs et sèches à leur partie supéricure; le réeeptaele est convexe et nu.

Les fruits sont ovioüles allongés, surmontés d'un rebord membraneux, circulaire ct cutier. 
Propriétés et usages. Les sommitós fleuries de la tanaisie répandent une odeur aromatique extrêmenent forte et désagréable; leur saveur est amère, âere et chaude. C'est une substancc essentiellement stimulante, et qui eontient une trèsgrande quantitć d'huile volatile. Il est peu de maladies eontre lesquelles les anciens n'aient pas eru devoir prescrire cette plante; mais les modernes ont de beaúcoup diminué sa haute réputation, et maintenant e'est presque uniquement eomme vermifuge qu'on l'çmploie. On l'administre encore quelquefois. dans l'hystérie, l'aménorrhée, mais assez rarement. Tantôt on la preserit en infusion, tantôt en poudre; quelquefois c'est sous forme de lavemcns qu'on cn fait usage, surtout dans l'hystérie. Son eau distillée et son huile éssentiẹlle sont presque tombées dans un oubli complet.

\section{BALSAMIT E.-BALSAMITA. Désf.}

Ce genre, autrefois eonfondu avec les tanaisies, s'en distingue par ses fleurons, tous quinqućfides et hermaphrodites, et par sẹs fruits, eouronnés d'ụne membrane unilatérale.

Balsamite odorante. Balsamita, suaveolens. Désf. Tanacetum Balsamita. L. Sp. I 48.

Part. usit. : les sommités fleuries. Nom plarm. : Balsamita sive Costus hortorum. Noms vulg. : Grand baume, Coq des jardins, Menthe coq, Menthe Notre-Dame, etc.

Ses tiges, qui s'élèvent d'une raeine vivaee et fibreuse, sont dressées, hautes de trois pieds et plus, très-rameuses à leur partie supérieure, blanchâtres, et eomme pulvérulentes. Les feuilles radieales sont longuement pétiolées, elliptiques, allongées, obtuses, rćgulièremcnt dentées, d'un vert elair, et pulvérulentes; eelles de la tige sont sessiles. Les eapitules sont fort nombreux, et forment par leur réunion une sorte de corymbe terminal., L'involucre est hémisphérique, cómposé d'écailles imbriquées, un peu scarieuses sur les bords; le réeeptacle ost plane et nu; les fleurons sont tous hermaphrodites, à cinq divisions et très-serrés les uns eontre les autres. Les fruils offrent à leur sommet une petite membrane mila- 
térale. On trouve eette plante dans les lieux incultes des pi'ovinces méridionales dc la France : on la cultive frćquemment dans les jardins. $f$

Propriétés et usages. Une odeur forte, aromatiquc et agréable, une savenr amère et chande, doivent faire considércr la balsamite commc un stimulant très-ćnergique. Aussi autrefois a-t-elle joui d'une grande réputation, surtout comme antispasınodiquc. En la faisant macérer dans l'huile, on préparait une huile de baume, dont l'usage était très-répandu, pour appliquer sur les plaies, et en particulier sur les contusions. Aujourd'hui les praticiens ont presque entièrement abandonné ce médicament, dont l'énergie est cependant incontestable. Sa saveur et son odeur plus agréables devraient, dans beaucoup de cas, lıi faire accorder la préférence sur la tanaisie, dont aiı reste il possède toutes les propriétćs.

\section{MATRICAIRE. - MATRICARIA. L. J.}

Involucre hémisphérique, composé d'écailles imbriquées; réceptacle conique, sans paillettes. Fleurons du centre hermaphrodites et fertiles, donnant des fuits sans aigrette.

Ce genre ne diffère des camomilles (anthemis) que par son réceptacle dépourvu de paillettes.

Matricatre officinale. Matricaria parthenium. L. Sp. I 255. Bull. t. 205 .

Part. usit. : les sommités fleuries. Nom pharm. : Matricaria. Noms vulg. : Matricaire, Espargoutte.

Cette espèce est tantôt pubescente, tantôt glabre, par l'effet de la culture. Ses tiges sout droites, ramenses et paniculćes vers leur sommet; fermes, cylindriques, striées, glabres. Ses feuilles sont ailées, larges, à folioles pinnatifides, dentées et. aiguës.

Fleurs radiées solitaires à l'extrémite d'un pédoncule assez long, dispósècs en panicule. Cell cs du disque sont jannes, celles de la circonfércnce. sont blanches. Involucre commun. presque hémisphériquc, composé d'écaillcs scaricuses sur lenrs bords et imbrinquécs. Réceptaclc nu, convexe, ponctué. Demi-fleurons 
de la circonférence femelles fertiles, à trois dents obtuses. Fleurons du disque jaunes, hermaphrodites, fertiles.

Les fruits sont sans aigrette, et surmontćs seulement d'un rebord membraneux très-court.

La matricaire croît dans les lieux cultivés et près des habitations. Elle a une odeur aromatique et forte, une sayeur chaudc et amère. On l'emploie à titre de stimulant, particulièrement dans l'aménorrhée, les fleurs blanchés, quải dćpendent de causes dćbilitantes générales ou locales. Ses usages et ses préparations sọt à peu près"les mêmes que ceux de la camomille.

Matrigaire Gamomille. Matricaria chamomilla. L. Sp. I 256. Blackw. t. 298.

Part. usit. : les sommités fleuries. Nom pharm.: Chamcemelum vulgare. Nom vulg. : Camomillè ordinaire.

C'est d'ans' les chảmps cultivés el au milieu des moissons qùe l'on trouve la camomille vulgaire. Elle offre une tige dressếe, glabre, rameuse ct comme paniculée dès sa base, haute d'environ un pied; des feuilles 'sessiles épaisses' et charnues, profondément pinnatifides, à segmens linéaires, écartés', bi ou trifides. Les fleurs sont assez petitcs;' solitaires à l'extrémité des ramificalions de la tige, qui sont allongées et un peu sillonnéés longitudinalement. Lcs rayons sont blancs et réfléchis. Les fleur's du centre sont jaunes. L’involucre' est presque 'plane', cómposé d'écailles allongées, glabres; scárieuses sur leurs bords. Le réceplacle ou phorantc est coniquc, 'saillant et nu. Les' demifleurons de la circonférence sont femelles : leur limbe off son sommet trois ' petites dents. Lies fleurons du centre sont très-petits, réguliers, hermaphrodites. Les fruits sont ovoïdes, dépourvus d'aigrette.

Propriétés et usages. La matricaire canomille, jouit des Inêmes proprićtés quc la cainomille römaine (anthemis nobilis), quoiqu'à un plus faible degré. Elle est moins 'fréqueminênt cmployce, maiss elle pcut fort bien la remplacer. Autrefóis mẹme on ha préférait gćnèralcment à cette dcrnière. Mraris son arome est. moins suavc ctison amcrtume moins intense ; 1 en sorté que les patriciens modernes prescrivènt plu's fréquein'ment la camomille romaine. Voy: Carnómille romaine. "r, il 


$$
\text { SOUCI. CALENDULA. L. J. }
$$

Involucre cylindrique, un peu renflé inférieurement, composé d'écailles unisériées; les fleurons du disque sont mâles et stériles; les demi-fleuróns sont femelles ét fertiles; réceptaclé planic; fruits irrégulier's, recourbés et hérissés en dehorș.

Soucr anficinar. Calendula officinalis. L. Sp. I3o4. Blackw. t. . 06 .

Part. usitée: les sommités fleuries. Nom pharm. : Calendula. Nom vulg. : Souci des jardins.

Nous cultivons souvent dans nos parterres cette plante à cause de la beauté de scs fleurs, qui sont d'un jaune orangé très-vif. Sa tige, dressée, est rameuse, cylindrique, un peu angl1leuse, velue, haute d'environ un pied. Ses feuilles sont alternes, sesssiles, obọales, obtuses, rétréciẹs inférieurement, entières oụ obscurément sinueuses sur leurs bords., in peu charnues , légèrement pubescentẹ des deux côtés. Au sommet des ramifications; de la tige sont des fleurs solitaires, radiées, grandes, d’une couleur jaune-orangé très-éclatante. Leur involucre est presque plane ,formé d'une seule rangée d'écalles lancéolées, linéaires, aiguệs g un peu hispides.

Le phoranthe est convexe et.nu. Les fleurons du centre sont réguliers et mâles: les demi-fleurons de la circonférence, situés sur plusieurs rangs, sont femelles et seuls fertiles.

Les fruits n'occupent que la partie exterue du capitule : ils sont irrégulièrement xecourbés, convexes en dehors ct couverts d'aspérités.

On trouve cette plante dans les lieux cultivés, les vignies, elc. $\odot$

Propriétés et usages. Toute la plante exhale une odeur aromatique peu suaye, et offre une saveur amère ct un peu ácrć. Elle possède une action! stimulante, dont on r.surtout remarqué les bons effets dans l'aménorrhée accornpagnéc de symptômes de faiblesse. Aussi est-ce principalement à titre d'cmmẹnagogue que, l'on prescrivait autrefois l'infusion des flcurs de souei des jardins. D'autres lui ont accordé une vcrtu ánti - 
spașmodique, et en ont recommandé l'usage dans les affections nerveuscs, l'hystćrie, etc. Cepcridant aújoúrd'huili és médecins ont prèsque entièremcnt banni de leur pratiquée les sommités de souci.

On a accordé à peu près les mcimes propriétés au souci dós chạmps (calendula arvensis: I.), lqui croit en' abondànce dans lcs champs et les vignes.

Fruit couronné d'une aigrette.

\section{ARNIQUE. - $A R N I C A$. L. Juss.}

Involucre un peu évasć, formé d'écailles ordinairement unisériées; réceptacle plane; fleurons du centre hermaphrodites ă cinq dents; demi-fleurons de la circonférence femelles et à trois dents; fruits allongés, tous couronnés d'une aigrette scssile et plumeuse ${ }^{\text {? }}$.

Ariege des montagnes. Arnica montana. L. Sp. 145.

Part. usit. : la racine, les fleurs. Nom pharm. Arnica. Noms vulg.: Tabac des Yosges, Betoine des inontagnes, Plantairi des Alpes, ctc.

L'arnique des' inontagnes présente une racine vivace, noirâtre, horizontale, donnait naissance à des fibres brunes et grêles. Ses feuilles sont sessiles, ovales, obtuses, entières, un peu pubescentes à leur face supćrieure, d'un vért clair, surtout inférieurement; elles forment une sorte de rosetc a la base de la tige ; celle-ci est simple, haute d'environ un pied, cylindrique, strice, pubescente, portant unc ou deux petites feuilles amplexicables, et terminée par une ou plusieurs fleurs grandes, d'un beau jaune doré, d'cnviron deux pouces de diamètre. Leur involucre est évasć, formé d'écailles lancćolées, velues, unisérićes : les fléurons du disque sont régulieṛs et hermaphrodites; les demi-fleurons de la circonférence sont très-grands et femelles. Les fruits sont allongés, pubescens, surmontćs d'une aigrette sessilc et légèrcment plumeuse.

× Tous les auteurs disent què l'aigretté est poilue; elle est "certaineinent plumeuse dans l'arnique des montagnes. 
On trouve cette plante dans les montagnes des Vosges, des $\Lambda$ lpes; de l'Auvergne et des Pyrénées. $f$

Proprićtés et usages. MIM. Lassaigne et Chevallier ont soumis à l'analyse ehimique les fleurs d'arnica, et en ont retiré: une résine odorante, une matière amère, nauséabonde; une matière colorante jaune; de l'aeide gallique;' 'de la gomme', de l'albumine et quelques sels. Lorsque la plante est récenté,' elle répand une odeur assez forte pour exeiter l'éternument ehez les individus qui la sentenit. Mais cette odenr s'affaiblit beaucoup par la dessiccation. Sa saveur, surtout celle de la racine, est amère, âcre et nauséabonde. L'arnica doit être regardée comme un médicament stimulant, mais d'un genre particulier. Ainsi, outre l'excitation qu'elle détermine dans les voies digestives, exeitation qui öccasionne souvent des vomissemens ou 'des déjections alvines abondantes, le cerveaù en reçoit une impression plus ou moins forte, qui se manifeste par une vive eéphalalgie, des mouvemens spașmodiques des membres, la difficulté de respirer, etc. Cette aetion puissante déeèle dans cetlé substance la propriété de modifier puissamment l'état aetuel de nos organes. Aussì plusieurs médecins, surtout en Allemagne, ont-ils singulièrement vanté l'usage des fleurs et de la racine d'arnica contre plusieurs maladies fort différentes. Ainsi les fièves intermittentes ont été eombattues avec suecés par ee remèdc, au rapport de Stahl et de Stool; le premier l'a également employé contre la dysenterie. D'autres l'ont preserit contre diverses affections nerveuses, telles que la parálysie, l'amaúrose, elc. Enfin, on l'a inis encore en usage contre une foule d'autres maladies très-différentes les unes des'autres.

L'infusion des fleur's d'arniea jouit en quelque sorte d'me réputation popilaire pour remédier a la commotion du celvéau, à la suile des eliutes ou des coups portés a cette partie. De la "le nom vulgaule de panaca lapsorum, sous lequel on troúve l'arniea indiquée dans quelques ouvrages.

Lés fculles, séches et réduites en pondre, sont employécs comme sternutatoires. Dans quclques pays de montagnes, on les emploie au lieu de tabae, soit pour priser, soit, mène pour fumer. 
C'est principalement en infusion que l'on preserit les fleurs ou la racine d'arniea, soit dans l'eau, soil dans le vin, ou unc bière légc̀re. La dose varic d'un gros à une onee du médicáment pour une ou deux livres de liquide, stivant l'intensilé des effets qn'on veut produire. On peut également prendre la poudre, depuis un demi-gros jusqu'à un gros, en l'incorporant dans un électuaire 'queleonque."

\section{A UNÉE. $-I N U L A$ r. L. Juss.}

Involucre imbriqué, formé d'écailles souveút appendieulées; fleurons du centre régulier's et hermaphrodites; demi-fleurons de la circonférence femelles; anthères prolongées à leur base en deux appendices filiformes; fruit couronné d'une aigrette simple et sessile.

Aunée ofpicinate. Inula helenium. L. Sp. r236.'Blackw.

t. 473 .

Part. usit. : la racine. Nom pharın. : Enula campina.

C'est une grande et belle plante vivacé; dont la racine est épaisse, d'un brun róngeấtí éxtérieurement, et presque blañ cle dans son intérieur. Elle donne naissance à une tige dressée, ferme, eylindriqué, rameuse à son sominet, couverte d'un duvet cotonneux, et hatite de quatre à six pieds.

"Les feuilles radieales sont ovales, allongées, aigues, molles, cotonneuses, 'surtout en dessoüs, "irrégulierement crénelées, finissänt insensiblement à leur pártie inferrieure en

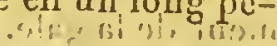

I MI. Mérat ayant remarqué quelqué différeice entre l'aúnéé offi-

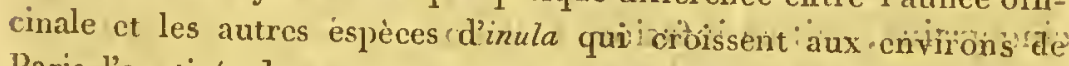
Pạris, l'a retirée de ee genre pour én former urgenre nouveau sous lë nom de Corvisartia. Mais ce changement est tout-à-fait contrairè aux règles fondamentales de la nomenclature botanique En effet, c'est l'enula campana que Linné et Jussicu ont prise pour type. de leur genre inula. Cetle plante ne peut en aucune maxière en être reticée et si l'on a trouvé entre elle et quíclques auires des 'différences suffsantes pour en former deux genres distinets ; linula helcnium devra toujours demeurer le lype du genre iniita, et les atios especes rece vront in autre nom générique. 
tholc, canaliculé. Lę̧ feuilles caulinaires, d'autaut plus petites qu'elles approchent plus du sommet de:la tige, sont scssilés ct plus arrondics.

Les fleurs sont jaunes, grandes, solitaires à l'extrémité de çraque divișion de la tige. L'invólucre est composé de plusieurs rạngs de foliolẹ hęrbacées, imbriquées, lâches, ouvertes, cordiformes, cotonneuses. Le réceptacle commun est lègèrement convexe, nu, présentant de petites alvéoles, dans lesquelles sont reçues les fleurs: Les rayons de la circonférence sont femelles.

Le fruit est allongé, presque cylindrique, surmonté d'une aigrette poilue et sessile.

L'aunée croît dans les lieux humides, les prés, aux environs de Paris, ou elle fleurit en juillet et a oût. $\nsucc$.

Propriétés et uságes. La racine d'aunée a unc odcur faiblẹ'ment aromatique, une saveur amère, âcre, et comme camphrée. Les chimistes y, ont dẹmontré l'existenee de l'albumine, d'une huile volatile, concrète, analogue au cainphre, et d'une féeule particulière, nonmée inuline par M. Thomson, et qui diffère de l'amidon, en ce qu'elle ne se prend pas en gelée par l'action dc l'eau bouillante, et qu'elle reste pulvérulente. L'enula campána est un médicament à la foiș stimulant et tonique. On le prescrit assez souvent comme emménagogue, diurétique ou sudorifique chez les individus qui ont besoin d'être excités. Quelques praticiens en font cncore usage vers la fin des catarrhes, quand tous les symptômes d'irritation ont disparu. Enfin sa dćcuction, trés-chargée, ou sa poudre incorporée dans une pommade, ont été quelquefois mises en usage dans le traitement de la gale.

Qn donne l'aunée, sột en poudre, à la dose de vingt à vingtcincquarains, soit en infusion, à la dose de demi-once pour une livre d'eau, soit enfin macérée dans du vin rouge. La dose du vin d'aunée est.d'une demi-once ou une once, répétée plusieurs fois dans la journée: $O n$ emploie aussi une autre espèce du genre aunée (inüla drsenterica); qui croit en aboudance dans les lieux humides, et qui a une saveur âcre et aromatique. Quelqucs auteurs ont loué ses boṇs cffets daus la dyscnterie. Mais on ne l'emploie plus du lout anjourd'hui, malgré les éloges que lui ont prodigués Gleditsch ct plusicurs autres uédecins de Berlin. 
TUSS ILAGE. TUSSTLAGO L Juss.

Involucre cylindriquc, formé d'écaillès tinisériées 'Tinéaires

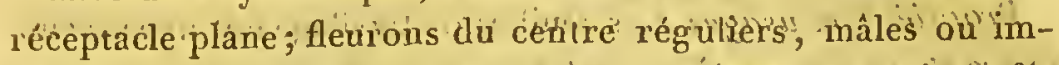
parfairement hermaplitódités; demín-fleúrôns de la circônfét-

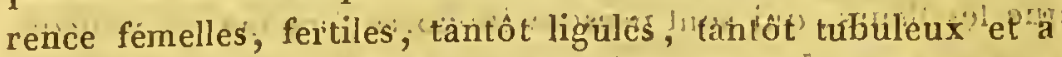

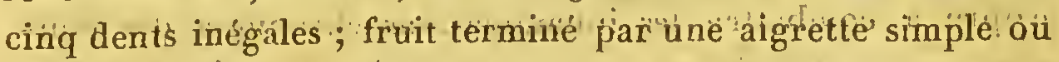
sèssilie.

Les capitules soñt tantôt sólitaires á á sommet d'une' hampe simple, tantốt dispósés en épis.

Tússidake cemmun. Tussilago farfara. L. S.p. 1274 .

\section{1. : : : Blackw. t. 204.}

Part. usitée : les fleurs et les feuilles. NYom pharm.: Tussilago; nom vulg.: Pas d'ane.

Les racines du tussilage sont vivaces, rampantes, brunâtres, de la grošseur du petit doigt; elles poussent, de distancc en distance, des hampés cylindriques, hautes de six à huit pouces, couvertes d'un duvet cotonneux et blanchâtre donnant attache à un asscz grand nombres, oint des feuiles "inortes sont des feuilles avortées et terminées a leur sommet par un seul capitule de fleurs jaurcs. Les feuilles ne commencent a se développer quapres les hampes: elles sont toutes radicales, grándes, pétiolées, cordiformes, anguleuses sur leurs bords, d'un vert clair en dessus, blanchâtres et cotonneuses a leü' face inférieure. Linvolucre est cylindrique, compose de folioles lancéolées, ctroites, accompagne a sa base de quelques écailles lâches, plus ou moins écartécs le réceptacle au pliorante est plane et nu; les fleurons du centre sont régulicrs et

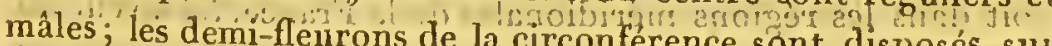
plires sur plúsieur rangs, et se terminent parrunc uanguette tres-longue, étroite, obtuse ct entic̀rc. Laigrette qui termine le fruit est sessile et formée de poils simples ${ }^{\mathrm{I}}$.

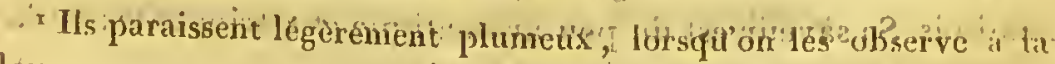
loupe.

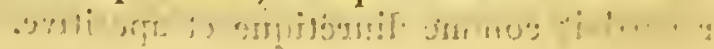


Cette plante est commune dans les lieux incultes, et surtout dans les terrains argilleúx. On la trouve en fleur dès les premiers jours du printemps. $\mathcal{F}$

Propriétés et usages. L cs feuilles du tussilage ont unc savcur amère et un peu austère; on les a de tout temps vantćes, ainsi que..les fleurs, qui sont presque inodores, comme un remède propre $_{1}$ à combattre les inflammations chroniques des poumons, accompagnées de toux; de là le nom de Tussilnge qui a été imposé à cet̀te.plante. Aujourd'hui, on n'emploie guère que les'fleurs, que l'on administre en infusion théiforme dans les irritations légères de la membrane des bronches. Quant aux feuilles, elles sont presque inusitées, malgréles éloges qui lui ont été donnés par.plusieurs auteurs, dans le träitement des scrophules. On administrait leur suc exprimé au printémps.

Le Pétasrte. Tussilago petasites; L. , dont les fleurs sont brun-rougeâtres et disposées en épis , et les feuilles plus grandes, a une odeur un peu aromátique c'est un médicament excitant toụt-à-fait abandonné aujour d'hui.

Si nous n'avions pas craint d'augmenter de beaucoup le volume de cet ouvrage, nous aurions pu décrire beaucoup d'au-" tres plantes de la tribu des Corymbifères, qui ont toutes été employées autrefois, et dont plusieurs, après avoir jouid'une réputation extraordinaire, sont tombees dans un profond oubli : nons nous contenterons d'en mentionner. ici quelquesunes."

nes.

L A cMerre. Spilanthus Acmella, L. Plante annuelle de l'Inde, dont la saveur est extremement forte et piquante, et que l'on regarde comme antiscorbutique.

"Li 'Sap̣torine. Santolina chame cyparissus "L., qui croit dans les régions méridionales de la France. Sa saveur est amere et tres-aromatique son odeur tres-pcótrante c clle cst stimulante, anthelminique, et jouit des mênes propriétés qucla'Tanaisie.

La VERGE D'On. Solidago virga auréa, très-commune dans nos boiș. Sa saycur s st un peu aromatique ct asıringente: on la fegardait comme diurćlique et apćritive. 
Le Séneçon. Senecio vulgaris, L. Petite plante annuelle, commune dans les jardins et lcs lieux cultivés. Ses feuilles ont une saveúr amère et mucilagineuse : on les prescrit encore quelquefois comme émollientes, pour l'usage externe.

L'A ya-Pana. Eupatorium Ayapana de Ventenat, qui croit au Brésil, et que l'on a naturalisé aux Iles de France et de Bourbon. Ses racines et surtout ses feuilles ont une saveur aromatique et légèrement astringente, une odeur analogue á celle de la fève ${ }_{\iota}$ Tonka. On les a, pendant quelque temps, considérées comme une panacée propre à la guérison de toutes les maladies qui affligent le corps humain; mais aujourd'hui elles sont entièremeńt inusitées.

\section{TROXSİE TR TRU. \\ CHICORACÉES.—CICHORACEZE.}

Cette tribu est très-distincte des deux autres par ses capityles entièrcment composés de demi-fleurons. Elle renferme toutes les semi-floculeuses de Tournefort.

Les Chirocacées sont des plantes ordinairement lactescentes.

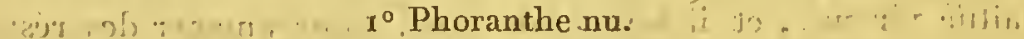

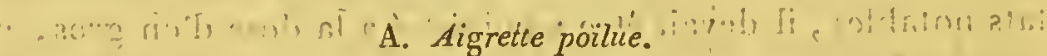

$$
\text { LAITUE - LACTUCA L J }
$$

Involuere imbriqué, cylindrique èt ùn peu rènflé à sa partie

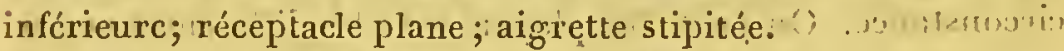

Laitue vinese. Lactica virosa. L. Sp. "Y I I 9

Part. usitće: les feuilles. Nom pharm. : Lactuca virosa. ris

La laitue vireuse présente une racine bisannuelle, d'où s'ćlève une tige dressé, rameuse dans sa partie supérieure, cylyndrique, glabre, haute de trois à quatre picds, et glauque. Cette tige donne attache $\dot{a}_{i}$ dcs feuilles semi-amplexicaulcs, les inférieures très-grandes, presque cntières, sagitteés, obtuses, denticulées, ayánt lesineivures de la fa èe'inférieure cćpineusès; les supéricures plús pietites, 'aiğuës ét pinnatifides.

Les fleurs soint jaunè, disposées' èn pánicule ramcuse'à 
l'extrémilé des branch és. L'involuere est cylindrique ;' formé d'écailles lancéolécs, imbriquécs et drcssẹes:' Le phorante est nu; plane, un peu alvéolé portant dnviron: vingt à vingtcinq fleurs hermaphrodites scmi-floscúleuses.

Le fruit est ellipsoïde', très-çomprimé, bordé d'une membrane saillante, , et:couronné par une: aigrette soieusé, śtipitée.,f formée de poils blancs nacrés et acticulés..

"Cette plahte croít dans les haies, ‘leś murailles et sưr le hord des chomins aux environs de Paŕis .: elle'. fleurit en. juillet: : . :

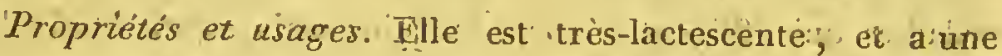
odeur désagréable et vireuse très-prononcée. G'estr' un puissant narcotique, que l'on peut comparer à la jusquiame et aux autres Solanées, sous le rapport de ses propriétés médicales et desaccidens qư'elle peut cáusèr. Oñ en prépare un extrait qui peut être substitué, dans beaucoup de circonstances, à l'ópium. La dose est de huit à dix grains : on peut l'augmenter súccèssivement, et la pörter jusqu'ä un scrupule, et même au delà. $\mathbf{M}$ : le prófesseur Orfila a tènté un grand nonibre d'expériences poùr constater les effets de l'extrait de laitue vireuse, et il a reconnu que, 'pour amener des résultats notables, il devait être administré à la dose d'un gros, et même davantage. C'est principalement contre l'hydropisie ascite que l'on a conseillé l'uságè de l’extrait de laitue vireuse ; mais cependant il s'en faut qu'il ait toujours réussi dans cette circonstance. On peut. l'employer fdars lès différentes névroses, et, en général dans toutes les maladics où l'usage de lopium est indiqué, en ayant soin de la donner à la dose de dix à douze grains, ot d'augmenter graduellement.

LAitue cútivée. Láctuca sativa. L. Sp. r i 8 . Blackw. t. $88^{\text {Li }}$

Pärt. usitée ": les feuilles.

Cclle espèce cst annuclle ; et se diștingue \}!ar une tigc dresséc, simplc infćricuremcnt, ramcuse à sọn sommet, haute d'ụ à deux pieds; glabrc, cylindriquc, à rạmcaux paniculés. Ellc 
porte des feuilles dont les inféricurcs sont ovales, arrondies, ondulées, presque entièrés, attênuécs a lá base, semi-amplexicaulcs ; les supérieures sessilcs ; cordiformes, presque auriculées, denticulées sur les bords.

Les fleurs sont jannes, disposées en paniculc, à l'extrćmité des ramcaux. Linvolucre est ovoide, allongé, imbriqué, glabrc, a folioles ovoìdés, allongécs, presque obtuscs; le rćceptacle plane, poitant environ dorze ou quinze fleurs, dont la partie inférieure est reçue dans de petites fossettes peu marquécs.

Les fruits sont ovoïes, comprimés, striés , couronnćs par unc aigrette stipitée.

On ignore quelle est positivénent la patrie de la laituc, qui èst depuis un' temps immémorial cultiyé dánt nos jardins.

Propriétés et usages. La laitue cultivée présente plusieur's variétés assez différentes les unes des autres. Les principalcs sont: la Romaine (Lactuca romana), dont les feuilles sont bcaucoup plus allongées, et la laitue pommée (Lactuca capilata). Les feuilles de laitue ont une saveur fraiche et aqueuse, dans laquelle il est difficile de saisir quelques traces d'amertume. On les mange très-souvent èn salade. Lorsqu'elles sont cuites, elles forment un aliment fade, peu nourrissant, et rafraîchissant. Les propriétés calmantes que l'on a attribuées à la laitue et à son eau distillée ne dépendent point de son principe narcotique, dont il est difficile de constater lexistcnce; on doit plutôt les attribuer à la grande quantitć. d'eau et dc mucilage que ses feuilles renferment, et qui agissent alors comme raf raîchis sañtes. On' fáit entrer l'eau distillée dè laitue à la dose de deux onces dans les potions calmantes. Ses fcuilics, bouillies danss l'eau, peuvent formcr des catáplasines ćmolliens.

\section{LAITRON. - SONCHUS. L. J.}

Involucre cylindrique, très-renflé à sà base, composé d'écailles imbriquécs et inégales. Aigrettc scssilc.

Cc genre ne diffèrc du précédent que par son aigrette, qui cst scssile et non stipitéc. 
Laitron commun. Sorichius oléraceus. L. Sp. xi16. Blackw. t. 3o et $\mathrm{x} 30$.

Plante annuelle : tige dressée, haute d'un à derux pieds, rameuse, eylindrique, glabre, un peu glauque et striće , lactescente, fistuleuse. Feuilles alternes sessiles, semi-amplexicaules de forme très-variée; tantôt presque ovales, obtuses, entic̀res ou denticulées, d'autres fois lyrées ou profondénent roncinées et subpinnatifides; elles sont toujours d'un vert clair et presque glauque.

Les fleurs sont jaunes, disposées les unes an -dessus des autres à la partie supérieurc des rameaux. L'involucre est eylindrique, renflé à sa base, formć d'écailles allongées, aiguës, inćgalcs, imbriquécs, glabres. Le rćceptaele est plane, nu.' Tous les demi-fleurons sont hermaphrodites et fertiles. La langueite est tronquée et quinquidentée à son sommet.

Le fruit "est ovoïde', strié longitudialement, couronnć par une aigrette sessile, composé de poils simples , d'un blane nacré."

'Le läitron eroît en abondanes dans lés endroits cultivés; 'et fleurit pendánt tout l'étẻ.

"Propiretés et usages. Le suc laiteux renférmé dans eéttc planle la rend àme; mais cette amertune est corrige par une assez grande quantité de inucilage. Autrefois on employait le suc épuré de laitron commc apćritif. Il est aujourd'hui inusitć. On mange dans béaúcoụ de provinees 'ses jeuñes feuilles et ses racines', comine les feuilles de laitue ct de romaine.

\section{PISSEN LIT - TARAXA C U.M.' Haller.}

Involuerc double; l'intérieur plus grand, formé d'écilllcs laneéolées dressées; l'extérieur eomposé d'ćcailles inégales, étalées ou rabattues; phoranthe eonvexe et ponctué; aigrelte simple et pédicellée.

Feuilles toutcs radieales; hampes génúralement uniflores. 
Pissenutit comnun. Taraxacum dens leonis. Hall. Leontodon taraxacum. L. Sp. 1 122. Bull. t. 217.

Part. usit. : La racine et les feuilles. Nom pharm. : Déns leonis vel Taraxacum. Noms,vulg. : Pissenlit ou Dent de lion.

Sa racine est vivace, pivotante," brune en dehors, blanche en dedans, à peu près de la girosseur du petit-doigt; elle est surmontée d'une touffe de feuilles élalées en rosace, et qui sont allongées", pinnatifides et roneinées, glabres, ayant les divisions dentées; du'centre de cét assemblage de feuilles s'ćlève une hampe uniflore, glabre, cylindrique, haute d'environ cinq ousix pouces; l'involucre extérieur est étalé; l'intérieur est dreśsé; 'le réeeptacle 'est légèrement convexé et marqué de pelites alvéolés superficiellés; l les fruits sont surmontés d'une aigrelte stipitée; êt, à l'épóque de leur parfaite maturité, 'surtóut lorsque lé temps est sec, les deüx involucres se rabattent, le réceptacle devient tout-à-fait roñd, 'les fruits's'écartent, leurs aigrettes se dilarent, et forment une sorte de boule légère, dont les diverses pièces ne'tardeut point à être entrainées par les vents.

On trouve ette plante en fleur pendant le printemps et l'étć, dans toutes les pelouses sèches', les lieux ineultes. "Propriétés et usages. Cette plante "est un 'pen läctescente; mais l'amertume de' son sue laiteux est en gránde partie mitigée et adoucie par les sues áqueux qu'elle contient èn abóndance. Aussi mange-t-on frćquemmient en sálảde lès jeunes fcuilles du pissenlit, qui ont une amertume agréable. Mais, quand la plante est plus dévelóppéce, l'amertume augmente", et e'est alors qu'on recueille l'es fcuilles et la 'racine de 'pissenlit pour l'usage médieal. On ne peut lui refuser les caraetères 'des médieamen̈s toniques. 'On fait' uságe du súe exprimé de ses

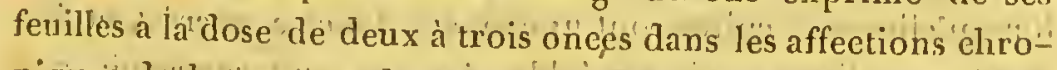

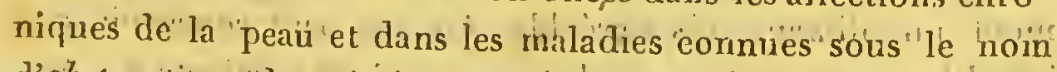
d'obstructions "des' viscères abdón'tifra ux'; din fait aussi usage

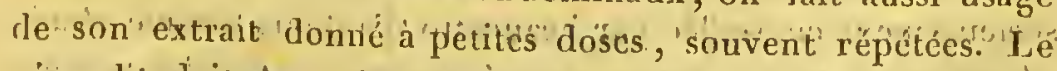
píssenlit doit être plàcé parììi 'Tës agèns dèla inédication al-

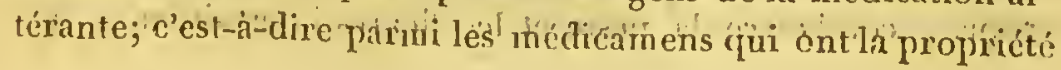


de modifier d'une manièrc en quẹlque sortc inscnsiblc l'état dé nos organes.

B. Aigretic plumense.

\section{S.GORZO NËE: - SCORZONERA. L: J.}

Involucre simplè, allongé, fornié d'écailles imbriquées, un peu mombraneuses sur lẹs bords; le réceptacle est nu; et l'aigrette est, légèrẹment știpitée et plưneuse.

\section{Scorzonère d'Espagne. Scorzonera Hispanica. L. Sp.} I 1 2. Blackw. t. 406

Part. usit. : la racine. Noms vulg. : Salsifix noir ou d'Espagne.

Sà racinc est allongée, pivotante, simple et charnue, noirâtre, extrêmemcnt blanche en dedans; ; la tịge qu'elle soutient csł dressée, rameuse.à sa partie inférieure; cylindrique, glabrç, donn̦aut attache à des feuilles alternes, sessiles.; ovales lancéolées, aiguës, rétrécies à leur.base, ẹtières.

Les fleurs sọt grandes, ,d'un jaune de 's.oufre', et termincnt les ramifications de la tige. Elles soṇt composées de demi-fleurons, tous hermaphrodites et fertiles. :

L'involucre et presque cylindrique,composé de deux rangées d'écailles, l'une extérieure, formée de quatre à cinq écailles plus courles , ovales., acuminées ; l'autre, intérieure ; beaucoup plus longue, dont les écailles au nombre de six ou environ, sont lancéolées; aiguës. Le réceptaclc est plane et nu.

Les fruits sont des akèncs terminés par une aigrette presque sessilc, plumcıse, très-ralanche.

Cette espèce, qui est bisannuelle, croít naturellement dans les prés des provinces méridionales do la France; on la cultive dạs les.jardins.

Propriétés et usages. Les racines de scorzonère, surlout lorsqu'elles sont cuites, on 'unc saveur douce et sucrée, ct forment un, aliment, trics-agrefablc. On ne peut concevoir aujourd'hui comment, une substance aussi peu active a pu ćtre sérieusement conseillée pax bcaucoup d'auteurs comme,alexipharmaque, stomachique, emmýnggoguc, ct de plus comme proprẹ à combattre la; peste ct les fievres intcrmittentes. De 


\section{SYNÀNTHÉnÉES.}

pareilles assertions', rćpétécs par des auteurs même très-modernes, font voir coinbien la matièrc médicale est restée en arrière, ct combien les propriệtẹs des plantẹ ont bespin d'être soumises à unc critiquc sévère.

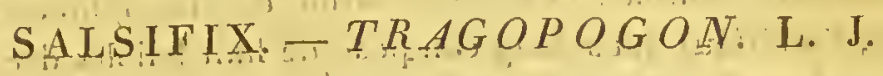

Cé genre ne'diffèrc du précédent que par son involucre simple, et composé d'une seule rangée de folioles; du reste tous les caraetères sont les mêmes:

Salsifix sauvage. Tragopogón pratense. L. Sp. i Iug.

$$
\text { Bull. t. } 2.09 \text {. }
$$

Partie usitée : la racine. 'Noms vulg: : Salsifix, Cercifix, Barbc de bouc.

Cette espèce, qui croît en abondancc dảns les prés, offre une racinc pivotante, allongée, charnue, simple, blanchâtreà l'extérieur, blanehâtre en dedans. Sa tige est ḋressée, rameuse, un peu noueusé, à rameaux allongés, eylindriques; glabres. Ses feuilles alternes sont sémi-amplexieaules, laneéolées, très-allongées, et très-aignës; entières, glabres en dessous; cotonneuses en dessus:

Les fleurs sont jaunes, grandes, solitaires et terminales. Elles sont semi-flosculeuses.

L'involuere est renflé à sa base, et comme campanulé à sa partie supérieure, composé d'écailles lancéolćes, aiguës, étroites, glabres, toutes, égales entre elles. Le phoranthe est plane et nu. Les àkènes sont très-allongés, striés longitudinalement, brunâtres et tuberculeux, couronnés par une aigrette plumeuse, longuement stipitée.

Propriétés et usages. Lcs propriétćs médieales des racines du salsifix.sauvage sont à peu près les mêmes que celles de la scorzonère, e'est-à-dire 'qu'elles sont faibles et à peine marquées. Aussi est-ce surtout comme alimens qu'on en fait'usage; ainsi que de celles d'une autre espc̀ce, que l'on cultivc trè̀sabondamment dans les jardins, et qui se distingue surtout paï ses fleurs violottes; c'est le tragopogon porrifolium de Linnt: 
$2^{\circ}$ Phorante cliargé d'écailles ou d'alvéoles.

\section{CHICOREE: - CICHORIUM. L.J.}

Involucre double; l'extérieur formé de cinq folioles réfléchies; l'intérieur plus long composé de huit folioles dressécs; réceptacle garni d'alvéoles; fruits comme tronqués, couronnés par' un rebord membraneux et frangé.

\section{Chiconée sauvage Cichorium intýluls. L. Sp. i 142. Blackw. t. 185 .}

Parties usitées : les feuilles, la racine.

La chicorée sauvage que l'on rencontre à chaque pas, le long des chemins et dans les lieux incultes, offre unc racine oblongnc, de la grosseur du doigt, pivotante, brunâtrc en dẹhors, d'où s'élève une tige herbacée, droite, presque glabre, ayant les rameaux divariqués.

- Sẹ fenilles radicales sont ovales, allongées, obtuses, rorcinćes à lobes aigus, distans, un peu velucs, finissant insensiblement en. une sorte de pétiole membraneuxisur scs bords. Les feuilles de la tige sont plus petites, à lobes plus marqués et dentés.

Les fleurs, d'un bleu clair ou blanches, sont disposées en une sorte d'épi lâche à l'extrémité des tiges.

I'involucre est double, l'extéricur a cinq divisions droites, allọngées, réfléchies, accuminées, offrant quelques..poils rudes et glanduleux à leur sommet. L'intérieur a huit divisions redressćes, de même forme, offrant aussi quelques poils glanduleux, terminées à leur sommet par une petite houppe depoils bruns. Le réceptacleiest plane, offrant dc petilcs ccllules oti est logéc la base des, ovaires.

-..Propriétés et usages. Les fcuilles ct la racine de chicoréc sauvagcont une saveur amc̀re assez intense, qui cependant s'affaiblitun peu par suite de la culture. Lcur áctioin sur: l'économic animale, et les effetsiqui cn dérivent, sont à peú près les mémes qщe,ceux que nous avons signalés pour la dentidc lion, en observant toutcfois que la chicoréc sauvage est plus activc. $\Lambda$ insi 
on prépare une décoetion ou bien on exprime le suc de ses feuilles fraîches, et l'ou obtient des médieamens qui sont légèrement toniques. On les administre dans toutes les cireonstances où les organes de la digestion ont besoin d'être excités. Quelques médeeins les prescrivent dans l'ictère et les obstructions des organes abdominaux. On prépare dans lés pharmacies un sirop de chieorée, que la rhubarbe et d'antres substances analogues rendent purgatif.

La racine de ehicorée, lorsqu'elle a été séehée et torréfiée, a une saveur très-amère, mais qui n'a rien de désagréable. On l'a conseillée comme un des meilleurs suceédanés indigènes dı eafé, et à l'époque où, par suite de la guerre, les denrées coloniales s’étaient élevées à un prix exeessif, on en faisait une énorme consommation. Mais si la racine de ehieorée torréfiée a l'amertume de la graine d'Arabie, elle ne possède point eet aroine délieieux qui forme le earactère distinetif de cette graine préeieuse.

On eultive dans les jardins une autre espèce de chicorée, que l'on connaît sous le noin d'endivé (cichorium endivia, L.), qui en differe surtout par sa raeine annuelle. C'est principalement cette espèee que l'on mange en salade et bouillie dans l'eau, sous les noms de chicorée frisée, barbe de capucin, ete.

Propriétés médicales et usages des Synanthérées.

Pour celui qui aura comparé attentivement l'aetion exerece par les plantes de la vaste famille des Synanthèrées surr l'éeonòmie animale, il sera facile de tirer cette conséquence, que cette famille est non-seulement une des plus naturelles et des plus uniformes dans la structure propre aux différens genres qui la eomposent, mais encore que cette analogie et cette uniformité existent également dans les propriétés médieales dont ces végétaux sont doués. En effet, on peut dire d'une manière générale que toutes les Synanthérées sont toriqués on stimulantes, ët que fort souvent ees deux propriélés se trouvent réunies danś les mêmes végétaux. Aussi les principes aetifs qui dominent dans ces plantes sont-ils: un prineipe amer extractif ou lactescent, eneore peu eonnu dans sa nature intime, et une liuile volatile très-odorante, qui souvent est solide, conerète, et presque identique avec le camphre. Cerpendant ehacune des trois tribus 
que nous avons élablies dans la fanille des Synanthérées, pré sente dans ses jroprićtés mćdicales quelques particularitćs propres à chacune d'clles, et qui dépendẹt surtout de la prédominance d'un des principes actifs, dont nons venons de signaler l'existeuce. Il nous paraît done nécessaire d'étudier séparément chacune de ces trois tribus.

I Les cañucées. Le principe dominant dañs les plantes dé eefte tribu est l'extractif amer. Aussi agissent-elles, pour la plupart, à la maniçre des médicamens toniques. L'huile volatile n'y existe pas, ou du moins s'y trouve dạs des proportions tellement faibles, qu'elle n'est pour ricn dans l'action que les carduaeées cxereent sur les organes de l'ćconomie aṇimale. Parmi les végétaux de eet ordre où la propriété tonique est le pluș marquée, nous citerons la elıassc-trappe, le chardon bénit, le chardon-marie, donnt l'amertume est extrêmement intense, et que l'on emploie comme toniques et comme fébrifuges. D'autres fois le principe amer cst 'moins prononé, et les carduacées agissent en augmenlant la perspiration cutanée, ou l'action sécrétoire des reins, ainsi qu'on l'observe pour les racines de bardane, de carline, ctc. Remarquons iei, conme nous l'avons déjá fait pour plusieurs autres familles, que par les soins de la eulture, on parvient à mitiger le prineipe amer, qui se trouve en quclque sorte délayé dans une grande quantité de principes aqueux et mucilagineux, et que par ce moycn plusieurs carduacées deviennent alimentaires; l'artichaut, les cardons et eertaines especes de earline c̀n sont des exemples.

$2^{\circ}$ Les corrmbįzìres. Considérćes en masse, les corymbifìres sont cn général beaucoup pliss actives que les carduacées, et fournissent à la médecine, plus d’agens tlućrapeụiques. En effet, ontre le prineipe amer que plusieurs contiennent, en abondance, l'huile volatile, le camphre, y existent encorc eu grande quantité. Anssi les végćtaux de cet ordre se font-ils rcmar(luer par-une-odeur aromatiquc et forte, une savcur amire, elraude et plus on nıons âcre, qui décèlent l'ac!ion puissance ug'elles exereent sur l'économie animale. A colte tribu appartiennent un grand nombrc de médicancos stimulans; fels que la camonillc, l'absinthe, la tanaisie, la ba!sa- 
mite, êtc. Outre les syınptômes de ła médieation stimulante, tels que l'exaltation de la sensibilité, l'accélération de lá circulation, l'augmentation de la ehaleur animale, etc. , qui

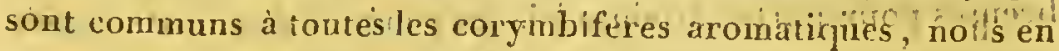
verrons d'autres produire des effels secóndaires oủ des médications spéciales, c'est-à-dire coneentrer, cn quelque sorte leur aelion sur un 'seul organe ou sur un appareil organique en partieulier. De lá les propriétés emménagogine, sultorifiçue, diurétique, antispasmodique, expectorante, sialagogue, sternutatoire, ete., ete., que l'on signalè dan's bèucoup de plantes de la tribu des corymbifères. Quand l'huile volatile est très-äbóndante, les eorymbifères sont âcres et:un peu irritantes ; on lés emploie alors comme vermifuges, ainsi qúon le fait pour la sémentine, la tanaisie, et plusieurs autres.

$3^{\circ} \mathrm{LeS}$ CHICoracérs. La plupart des chicoracées sont lactes centes; e'est il la quantité plus ou moins grande de cc, suc laiteux, qui est amer et un peu narcotique, qu'clles doivent leurs propriétés médieales. Lorsque la quantité qu'elles en renferment cst très-grande; elles sont plus ou moins suspectes, à eause de la vertu narcotique de ee sue. Ainsi la laitue vireuse et la laitue sauvage fournissent un extrait qui à une dose un peu plus forte, jouit à peu près des mêmes propriétés que l'opium. Mais ee principe laitenx n'offre pas eoristamment ce eəractère suspeet; il existe une foule: de chicoracies dáns tesquelles il est simplement amer, et qui par eonséquent sônt spécialement toniques. Nous citerons par exemple le pissenlit, la chicorée sauvage; dont toutes les partięs présentent une amertume, franche et nulleinent vireuse. Ici comme daus lés carduacées, l'influenee des soins du cultivateur n'est pas moins puissanle pón modifier les propriétés dés ehieoracées. En les étiolant, if développe les principes aqueưx, sueré et mucilagineux, et il rend douees et alibiles des plantes qui, dans l'état sauvage, sont amères et insupportables.

Si nous comparons les fruits des trois tribus de la famille des Synanthêrées, nous lenr trouverons un caráctère corhinun. L'amande ignils renferment est blanche, ordinaircment douly?

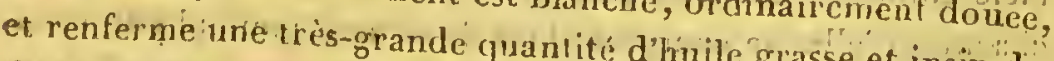
Cependant quelques genres semblent faire excepition à cette 
uniformité presque constantc; ainsi les fruits des armoises sont âcres et employés comme anthelmintiques; ceux du carthame sont purgatifs. Mais, ces exceptions sont trop peu nombrenses pour porter a atteinte à la loi générale dont celte famille tout entière ngous .offre un modèle'si parfait.

\section{CINQUANTE-CINQUIEME FAMIILE.}

\section{- Mili, DIPSACEES - DIPSACEA.}

Les Dipsacées présentent une tige ordinairement herbacée; rarement sous-fruteseente; des feuilles opposées sans stipules; des fleurs serrées et réunies en eapitules, comme dans les Synanthérées, portées sur un réceptacle commun, garni d'écailles, et entourées d'un involucre commun : ehaque fleur est immédiatement enveloppẻe dans un petit involucre propre (calice extérieur des auteurs), et se compose d'un calice adhérent par sa partie inférieure avee l'ovaire infère; d'une eorolle monopétale tubuleuse, ordinairement à quatre ou einq lóbes ; de quatre à cinq étamines, rarement moins, dont les anthères sont écartées et distịnctes; l'ovaire, qui est uniloculaire, renferme «uni seul ovule renversé; et se termine par un style et un stigmate non divisés. L'entbryon est renversé ét plaeédans un endosperme eharnu.

Les plantes de eette famille ressemblent beaueoup aux Synanthérées, surtout par leur port et la disposition de lêur'fléurs en eapitules; mais elles en diffèrent pär leurs fèuilles ópposèes, leur double ealice, leurs anthères non soudées, et leur graine qui est pendante et non dressée dans la loge.

\section{CARDIAIRE: - DIPSACUS. L."J.}

Flcurs, disposées en capitule; involucre polyphylle, réceptacle conique, garni de paillcttes, plus longues que lés fleurs; chacune d'elles sc compose d'un inrolucre monophylle tétragonc, immédialcinent appliqué sur le calice, qui est adhérent 
ávec l'ovaire infère, el tronqué supérieurement, ou il offre quatre angles; la corolle est monopétale, tubulense, à quatre lobes inégaux. Le fruit est un akène, couronné par le calice, et renfermé dans l'intćrieur de l'involucre propre.

Cardiare a foulon. Dipsacus fullonum. L. Sp. 1 亿o.

Part. usitée : la racine, les capitules: Nom pharm. Dipsacus. Nom vulg. : Chardon à foulon.

Racine blanche, bisannuelle, donnant naissance à une tige droite et dressće, roide, haute de trois à quatre pieds, épineuse, cylindrique, un peu rameuse vcrs la partie supérieure, creuse intérieurement; portant des feuilles opposées ét connées, glabres, ovales, lancćolćes, 'äiguës, enticies, un peü sinueuses et irrćgulières sur lés bords.

Les fleurs sont disposées en un eapitule trìs-dense cet ovoüde à l'cxtrćmité des rameaux. Involucre plane, formć de folioles inćgales, étroites, roides et acuminées. Phorante o voüde charnu. Chaque fleur est accompagnée d'nne ćcaille d'abord creuse et canaliculée, ð̧uis terminée par une pointe très-aiguë, recourbée par en bas, épincusc sur'les côtés. Calice double : l'extérieur (vćritable involucre), plins court, prismalique et à quatre faces, trontyué supérieurement, oü il offrc des petites dentelurès verdâtres ;' immédiatemicnt appliqué et serrć contre le calice intérieur. 'Celui-ci est soudé inférieurement avec l'ovairè infčre. Il est d'abord ovoïde, rétréci à la partic sup'ćrieure, et terminć par nn, limbe'vert, creux'et 'carré', couvert de petits poils soyeux. Corolle mónopétale, tnbuléusc, irrćgulièré. Le tube est allongć, il va en s'évasant. Lè limbe est á quatre divisions irréguličres, arrondi, presquc bilabié.' La division supérieure est lá plus grande, lcs 'trois autres à 'peu' près' égales. '́tamines, au nombre de quatre; saillantés', àtächćés au haut du tube de la corolle, alternes avec ses divisions. Filets grểles ", anthères' allongées, biloculaires', "fcridues jusqu'â 'inilieu de léur lon'gueur par la partie inféricure. Ovaire infère, ovoide, "allorig ć, uniloculairé, contenant un seul ovule pendant. Style simple à peu près de la hauteur dc la corolle, tcrininé par un stigmate allongé. 
pt latćral en forme de languețe. Fruit ovoüde, allongé, coujonué par le limbe du ealiee.

Celte espèee eroit dans les bois. On la cultive aux environs de Paris.

Propriétés el usages. La raeine de ehardon à foulon est amère et désagréable. Quelques auteurs l'ont reeommandée eonme tonique et apéritive; nais elle est tont-à-fait inusitée aujonrd' eause de ses cayituless, enployés par les bonnetiers et les fabrieans d'étoffes de laine, pour peigner leurs tissus et en tirer les poils.

\section{SCA BIEUSE. - SCA BIO SA. L. J.}

Ce genre, qui offre la même infloresceuce que le préeédent, s'en distingue surtout par son ealice, dont le lımbe est terminé parçuaire ou huit soies grêles et alḷngées.

Scabieuse des champs. Scabiosa arvensis. L. Sp. r.43. flor. dan. t. 447.

Part. usitéé : les feuilles. Nom pharm.: Scabiosá.

C'est dans les ehamps; enllivẹ́s, dans. les prés ou sur le bord des ehemins que cnait naturellement la scabieuse, dont la tige est dressée, rameuse, cylindique, poilue, hạute d'un à deux pied. Ses feuilles opposées, connées à leur base, un peu poilues en dessous, profonclément pinnatifides, finissent presque insensiblement en un pétiole ailé; ; lẹr lobe terminal est plus grand, ovale, aigu.

Lẹs fleurs, d'un violet pậle, fornent des capitules presque hémisphériques à l'extrémité des branches. Involuere régulier, eompose de dix folioles, cinq extirieures plus grandes, lanećolées, aiguës, cinq allernes plus intérieures, linéaires. Phorantẹ très-petit, presque plane, garni de ş̣ies: Caliee double: l'extérieur formant une sorte de petit godet à quatre faces, coupé horizontalement au sommet; l'intérieur soudé infé rieurement a vee l'ovaire infère, très-rétrẹ́ci au-dessus, puis ter:ming yar nn limbe coṇeave "ẹ ẹré, à lhuit dívisions subulées. l.c's corolles sont un peu irị́gulières et inégales; celles des la circonfércnce du eapitule sont plus grandes. Le tube est 
trc̀s-renflé; le limbc a quatre divisions inégales; une supérieure, c'est la plus grande; l'inférieure cst la plus petile; lcs deux latérales sont égales entre elles.

Lc fruit, environné par l'involucre, ou calice extéricur, csst tcrminé par huit soies longues et roides.

La scabieuse des champs fleurit, cn juin et juillet. $\Varangle$

Propriétés et usages. Les feuillés de cette plante ont une saveur acerbe et un peu amèrc. Elles ont joui jadis d'une trèsgiande réputatioù dans le traiteincnt dés maladiés de la peău, et particulièrcment dé lá galc. Dé là le nom de scabièusé, qui a été donné aux végćlaux de ce genrc (scabiès gálć). Cépendant M. le professeur Alibert est lón d'áccóder à la décóction des feuilles de scabieuse les avantages que plusicnrs autcurs luti ont attribués dans le traitcincnt des affections cutanécs; cn sorte qu'aujourd'hui lcs praticiens font peu de cas de cé médicar. ment.

On peut en dire aulant de la scabieusc succise; ou mors du diable (scabiosa succisa, L.), qui croît en automne dans les bois et sur les pelouses̃, et quii sẻ distinguẻ pàı'sả racine tronquće, ses feuilles entières et ses capitulcs composés de flcurs trèsserrées, et d'un violet tendre. Sa racíne ct ses feuilles sont plus astringentés que dans l'espèce précédente. On les èmplioie aux mêmes usagres et dans les mểmcs circonstaulces.

Propriétés médicales et usages des Dipsacées.

Les plantes de cetre petite fámille méritènt pcu d'intérêt: En effet, l'action qu'elles exerocnt' sur l'économie animale est bien faible; aussi sont-elles généralement pcu usitées dans la pratique inćdicalc. Une saveưr lćgèrement astringentć et amère leur donne une vertu tonique trćs-peu marquće. On ne doit pas s'étonncr qu'aucune d'clles ne soit vénćneuse.

CINQUANTE-SIXI Hี ME FATLLE:

VALERIA NEES. - VALERIANE E.

Les Valérianées sont des plantés heibacées, à feuilles oppósées; à racines très-odorantés dàns les espèces vivaces; lés fleurs sorit nues et disposées ordinairement en 
Le calice est adhérent : son limbe est denté ou roulé en dedans et formant un bourrelet circulaire. La corolle est tubuleuse, quelquefois bossue ou éperonnée à sa base; le limbe est à cinq lobes inégaux: le nombre des étamines varie de une à cinq : l'ovaire est uniloculaire, surmonté d'un style simple et d'un stigmate le plus souvent triparti.

Le fruit est un akène couronné par les dents du calice, ou par une aigrette plumeuse, formée par le déroulement du limbe du calice.

La graine renferme un embryon droit et épispermique.

Les plantes de cette famille, pendant long-temps réunies aux Dipsacées, s'en distinguent par leurs fleurs nues, sans involucre particulier, et non disposées en capitules; par leur embryon dépourvu d'endosperme.

\section{VALÉRIANE.-VALERIANA.}

Limbe du calice formant un bourrelct qui se dćroule en une aigrétte plumeuse; corolle tubuleuse un peu oblique et bossue à sa base, à cinq lobes inégaux. Trois étamines attachées au haut du tube. $\Lambda$ kène couronné par une aigrette plumeuse.

Valériane officinale. Valeriana officinalis. L. Sp. 45 . Lamk. Illust. t. 24. f. I.

Part. usitée : la racine. Nom pharm.: Yaleriana.

Sa racine est formée d'un faiseeau de fibres épaisses et blanchâtres, allongées, recouvertes de petites fibrilles grêlcs et déliées. Elle est presque inodore dans son état de fraîchcur, et aequiert en se desséchant une odcur très-pénétrante.et fétidc, et d'une nature partieulic̀re. La tige est dressće, simple inférieurement, offrant quelquefois deux ou trois rameaux dichotomes à sa partie supérieure. Elle est eylindrique, striée, vclue, surtout à sa partie inférieure, haute d'environ trois à quatre pieds. Ses feuilles sont opposćes, les inféricures pétio- 
lées, les supérieures sessilcs, 'trc̀s-profondément pinnatifides et comme pinnées, à segmens lancéolćs, étroits, aigus, presque entiers.

Les flcurs sont petites, d'un blanc rosé,' disposées en une espèce de cyne au sommet dc la tige. Les pédoncules se trifurquent trois à quatre fois avaint de porter les fleurrś. $\Lambda$ là báse de chaque trifurcation sont deux petites bractées linćaires trèsaiguës. Chaque fleur est elle-même environnée et comme embrassée par une bractée trifide à son sommet, de la mếme hauteur que le calice. Le calice est adhérent, par son tubé, a vec l'ovaire infère. Ce.tube est ovoïde; allongé, strié. Le limbe est roulé en dedans, et forme un simple bourrelct, qui, après la défloraison, 'se déroule et se déploie en une aigrette' plumeuse, qui couronne 'le fruit. La corolle est tubuleuse, presque hypocratériforme. Le tube est trìs-étroit à sa base, légèrement bossu et un peu évasé à sa partic supérieure. Le limbe cst plus ou moins étalé, à cinq divisions obtuses un peu inégales. Les étamincs, au nombre de trois, sont attachées au haut du tube de la corolle; elles sont alternes a ver, trois des. divisions qu'elles ne dépassent point. L'ovaire est infère à une loge qui contient un seul ovulc; il est surmonté" d'un slyle' filiforme, grêle, plus long que la corolle, et portant à son sommet un stigmate triparli, à divisions très-ćtroites et glanduleuses du côté intcrne: Le fruit est in akène ovoüde, allongé, strić, couronné par une aigrette plumeuse, formée par le dé. roulement du limbe du calice.

La valériane habite les bois un peu ombragés, aux cnvirons de Paris. Elle fleurit' en mai et juin. 4

Propriétés et usages. C'est la racine seule qui est employće : elle a une saveur âcre et amère; 'une odeur pénétrante et fétide. M. Tromsdorff en a retiré: un principe particulier, solnble dans l'eau; insoluble dans l'alcohol; une résine noire; une huile volatille trćs-liquide, camphrće et verdâtre; un extrait gommeux, dc la fécule et des fibres ligneuses. La valćriane augmente d'une manière marqquée l'action des différens organes de l'ćconomic animale; elle y développe tous les phćnomćnes de la médication stimulantc. C'est un médicanent très-actif et très-usilé. Ellc est puissamment. excitante et agit 
secondairement eomme antispasmodique, emménagogue, sudorificue et vermifuge: On l'administre ordinairement en pondre, à la dose de demi-gros à denx gros, dans les eas d'hystérie, ou d'épilepsie. On l'a donnée avee suceès, seule ou unie aux amers, pour eombattre les fièvres intermittentes : en un mot, elle est très-tonique et stimulante; elle parait être aussi légèrement narcotique.

Son eau distillée, son extrait, sont moins employés que la poudre.

L'odeur de la raeine de valériane, qui est pour nous sü repoussanle, exerce sur les chats une aetion tout-à-fait différẹnte. Ils la rechererch ent avee avidité.. $\Lambda$ uśsi les voit-on se rouler sur eetle plante, quỉl est fort diffieile de défendre contre leurs. atlaqués. Elle semble les jeter däns un état d'ivresse, analogue à eelui que l'opium détermine ehez les Orientaux.

On peut employer aux mêmes usages les racines de grande: valériane $(V$. phu), de petite valériane ( $V$. dioïca), et le $N$ ard cellique (racines des $V$. cellica et $V$. supina), autrefois très-employées, mais tombées en désnétude de nos jour's; parce qu'en: effet, ces raćines sont loin d'être aussi aetives que eelle de lí valériane iffieinale.

\section{$M A C H E:-V A L E R I A N E L L A$.}

Limbe du ealice à cing dents persistantes : corolle tubuleuse, eourte, à cinq lobes inégaux : deux ou trois étamines attachées an haut du tube: akène eouronné par les cinq dents du caliee. Mache cultrvée. Valerianella, olitoria. Mønch, meth.

$$
493 .
$$

Noms vulg. : Máche, Blanchette; Boursette; Clairette, Dou-

$$
\text { cette, ete. }
$$

Petite plante annuelle, à tige dressée, haute de six à dix pouees, diehotome, eylindriqué glabre, un peu canelée. Feuilles: opposées allongées, sessilles, élroites, entiéres on dentéeś; lés raclicales sont obovales très-obtuses, rélréeiès à leur base et eomme splathulées: fleur's très-petites violaeées oú blancliâlres; réunies en petirs bouquets'à la partic supérieure des ramifieations de la lige. Son fruit est arrondi, glabbre, légèrement comprimé. 
La mâche croit dans les champs, et los vignes.

Propriétés et usages: Cettc plante a peu d'odeur et de saveur. Elle n'est point d'usage en médecine. On la cultịe comme aliment dans les jardins potager's, et on la mange en salade. C'est un aliment fade.

Propriétés médicales et usagres des plantes, de la familles des

\section{Valérianées.}

Les propriétés actives des plantes de cette famille paraissent concentrées dáns lcs racines; , et n'existent d'une manic̀re marquée que dans le genre valérianc, dont toutes les espèce's' à très-peu d'exceptions près, sont vivaces. Aussi rétiouve-t-on dans un grand nombre des espèces de ce genre l'odcur forte et désagrćable, la saveur camphrée el amère que nous avons șignalées dans la valériane officinale. Quoiquue toutes les espèces jouissent à jeu près de vertus analogues, on préfère cependant cette dernic̀re, parce qu'elle est infiniment plus active que les autres espèces indigènés.

Quant aux espèces ánnuclles, elles sont pour la plipart fades, inodores et san's propriétés médicalcs màquées, comme on peut l'observer dans les diffćrentes espècés de mâche.

CINQUANTE-SEPTIEAHE FA NILLE.

RUBIACELS. - RUBIACEAE.

Les Rubiacées constituent une famille très-naturelle, extrêmement nombreuse en genres exotiques ${ }^{r}$, qui se reconnaissent aux caractères suivars : tige herbacée ou ligneuse; feuilles opposées avec des stipules intermédiaires, ou verticillées et sans stipules.

Le calice est adhérent avec l'ovaire infëre, son limbe

x La famille des Rubiacées renferme un si grand nombre de genres exotiques, que les hotanistes systématiques ont été obligés d'y établir un grand nombre de sections, afrn d'en faciliter la recherche. Ne devant traiter ici que du petit nombre de ces genres qui fournissent quelque produit'à la thérapeutique, il nous a été impossiblè d'offrir un exemple de chacune de ces sections: 
est entier ou à quatre on cinq dents. La corolle est monopétale régulière, de forme variée, à quatre ou cinq. divisions; elle est épigyne, et donne attache à quatrè ou cinq étaminies.

L'ovaire est tantôt didyme à deux loges monospernıes; son sommet est garni d'un disque épigyne jaunâtre, surmonté par un style profondément bifide, portant deux stigmates capitulés (c'est ce qui a lieu dans nos genres européens). Tantột il est à derix loges polyspermes, et surmonté d'un style et d'un stigmate simple ou bifide. D'autres fois enfin, il offre quatre, cinq ou un plus grand nombre de loges, qui contiennent chacune un ou phisieurs ovules.

Le fiuit présente beaucoup de variations : ainsi il est. quelquefois didyme, et formé de deux petites coques mónospermes sèches ou un peu charnúes; d'autres fois c'est une capsule ou une baie à deux, quatre, cinq, ou plusieurs loges, renfermant une ou plusieurs graines: dans chacune de ses loges.

Io Fruit indéhiscent à deux loges monospermes.

$$
\text { GALIET. - GALIUM. L. J. }
$$

Ovaire infère : corolle monopćlale régulic̀re, rotacée, à quatre divisions étalées : quatre étamines : un style bifide portant deux stigmates globnleux : fruit diakènc globuleux, didyme,' nu, sec, lisse, glabre ou hérissé de piquans. Fleurs quelquefois polygames.

\section{Galiet jaune. Galium verum. L. Sp. 155.}

Part. usit. : les somnités fleuries. Nom pharın. : galium lutcum. Nom vulg. : caille-lait.

Sa raeine est vivaee. Ses tiges, sont dressées, ramenses, pubescentes, lisses, earrées ct comme soufruteseentes a la base, hautes d'environ douze à dix-huit pouces: Scs feuilles sontverticillées ordinairesnent par luuit: elles sont linéaires, étroites, 
aiguës au sommet, entičres, d'un vert foncé en dessus, d'un vert clail en dessous.

Les fleurs sont jaunes, disposées en une grappe in terrompuè, allongée, terminalè. Chaque fleur offre un calice adhérent aviec l'ovaire infère; à limbe nul, non denté; une corolle rotacće, à quatre lobes.aigus, très-étalés. Quatre ćtanines dressées et saillantes. Le style est bifidc : terminé par deux stigmates capitulés. Le fruit est un diakène globuleux, didyme, glabre, non tuberculeux.

Cette plante est excessivement communc aux environs dé Paris. Elle croît dans les haies, "les prés secs, les bois, et fleurit pendant la plus grande partie de l'été. $₹$

Propriétés et usages. Le galiet jaune ou caille-lait a longtemps passé pour posséder la proprićté de cailler le lait. Mais on sait aujourd'hui à n'en plıs douter, qu'il n'a point cette proprićté. Ses sommités fleuries ont une odeur assez forte et une saveur légèrement amère et aromatique : fort en usage autrefois, comme antispasmodiques ct diaphorétiques, elles sontà peu près inusitées actuellement. Quelques auteurs n'ont pas craint de lui attribuer une propriété en quelque sorte spécificue dans le traitement de maladies, dont les moyens curatifs doivent autant varicr que lcs causcs nombreuses qui pcuvent les produire, telles que l'ictc̀re, les affections convulsivcs, l'épilepsie, etc.

\section{ASPERULE. - ASPERULA. L. J.}

Ovaire infère : corolle monopétale, "régulièrc, tubuleuse, évasće, à quatre divisions réfléchies : quatre étamines : un style bifide:.dẹx stigmates globuleux : diakène globuleux, didyme, nu, ordinairement glabre.

Áśérule herbe a r'eseunancie. Aspemulä cynanchica. L. Sp. 15 .

JPart.' usit. : toute la plante. Nom pharm. : rubia cynanchica.

Cettc pelite plante forme des tonffes aplatics. Sa racine est vivacc, et. donnc nạissance-à unc tige rameusc dès sa base, ćlalće sur la tcrrc, à ramcaux redrcssćs à lcur extrémité supćricurc, glabies, carrés ot comme géniculés, longs d'environ un 
pied. Les ferilles sont opposćes, quelquefois quaternées, allongées, élroites, linéaires, aiguës, glabres; les inférieures plus courtes sont obtuses et mucronées.

Les fleurs sont blanehes, lćgèrement lavées de rose, et disposées en petits bouquets à l'extrémité des:ramifications de la tige. Le calice est adhérent avecl'ovairc infère, son limbe est nul, non denté. La corolle est tubuleusé, 'évasée, subeampaniforme, à quatre divisions ovales, aiguës, réfléehies.

Les étamines au noubre de quatre sont attaehées et inclusè dans la corolle. Le style est simple, inférieurement plus eourt que la corolle, bifide a sa partie supérieune, et portant deux stigmates globuleux. Le fruit est un diakène globuleux, didyme, sec, nu, à surface un peu chagrinnée.

Cette aspérulc croit sur les pelouses, dans les bois, lc long des allées; clle fleurit pendant la dernière moitié de l'été. ₹

Propriétćs et usages. Cette plante lógèrement astringcnte, était autrefois très-usitée en gargarismes dans les inflammations peu intenses de la gorge. Ses racines pcuvent remplacer la garance, el fournissent comme elle une couleur rose. A ussi portet-elle dans quelques pays le nom de rubéole ou petite garance:

Aspérule odorante. Asperula odorata. L. Sp. Łọgg. Blackw. t. 60 .

Part. usit. : les sommités fleuries. Noms vulg. :: petit muguet, hépatique des bois.

Cette espèce est rivace, sa racine est rampante: sa tige dresśe, carrée, à quatre angllcs saillans, très-glabre, haute de six a huit pouces, portant des vertieilles de feuilles au nombre de huit à neuf, qui sont ovales, laneéolćes, rétréeies à la base, ciliées sur leurs bords.

Les fleurs sont blanehes, assez grandes, en bouquets terminaux, et dichotomes au sommet de la tige. Les fruits . sont hispides.

L'aspćrule odorante croít dans les bois couverts et mi peu humides aux cuvirons de Paris, dans la forét de Moninorency. Elle fleurit en mai. $2 f$

Proprités et usagres. Son odeur cst fort agréable, surtbut 
quand la plante a été desséehćc. Elle passe pour diurétique. On l'adıninistre en infusion theiforme, mais on cn fait rarcment 11sage.

$$
\text { GARANCE. - RUBIA. L.J. }
$$

Calice à qualre ou einq dents : eorolle pelite, subcampanulée à quatre ou cinq lobes : donnant attache à quatre ou einq étamines. Fruit didyırı, légèrement charnu.

Garance des temtenders. Rubia tinctomum. L. Sp. I58. 'Blackw'. t. 326.

Part. nsit. : la racine. Nom pharm. : rubia.

Une racine vivaee, horizontale, de la grosseur d'une plume de eygne, norleuse et rougeâtre, donne naissanee à plusieúrs tiges herbacées, faibles, tétragones, rancuses, arınées de petits crochets, et très-ruçes; elles porient des feuilles verticillées, sessiles, lancéolées, aiguës, fermes, hérissées de petites pointes rudes sur leurs bords, et sur la face de la nervure movenne.

Fleurs jạnes, petites, formant une sọte de panieule trèslâche à l'exlrémité des rameaux; es fleurs sont portées sur des pédoneules eourts et rameux. Caliee adhérent avee l'ovaire infère. Limbe nul. Corolle corurtement campanuléc, ia quatre divisions ovales, Irès-aiguës, réfléehies; mais le plus souvent à einq dans les individus cultivés. Quatre ou einq étamines Irès-eourtes, insérées à la base des divisions de la corollc, avee lesquelles elles alternent. Filets subulés, glabres, anthères biloeulaires, linćaires, étroites, obtuses.

Fruit diakène, lisse et golabre, un peu charnu et baceiforme: eontenant une graine dans ehaeune de srs deux loges.

La garanee croît dans les haies, lcs ehamps. Elle est culivée en grand dans quelques provinees de la France : celle du eomtát Venaisin, el surtout des environs d'Aviguou, jouit d'une grande réfulation. ₹f

Propriétés et usages. La l'ieine le garanee a unc saveur astringente. On la trouve comptée dans les aneienues pharmacopées au nombre des einq racines apéritives mineures. Mais aujourd'hui son usage est coul-à-fail banni de la praticpne médicale. Il n'en est pas ainsi dans les arts de la tcinture, où l'on 
fait une grande eonsommation de garanee, à cause de la eouleur rouge qu'elle renferme, et que l'on eniploie surtout pour la teinture des laines.

\section{$2^{\circ}$ Fruit déhiscent à deux loges polyspermes.}

\section{QUINQUINA. - CINCHONA. Pers.}

Caliee adhérent: limbe à einq dents : eorolle monopétale infundibuliforme, à einq divisions, tube eylindraeé et anguleux : einq étamines ineluses dans l'intérieur du tube : eapsule ovoïde, allongée, eouronnée par les dents du ealiee, biloeulaire, bivalve : loges renfermant plusieurs graines membraneuses sur les bords. Grands arbres à tige ligneuse, à fleurs disposées en panieules thyrsiformes.

Quingurna gris. Cinchona Condaminea. Humb et Bonpland. pl. équin. I. p. 33. t. го.

\section{C. officinalis. L. Sp. 244 .}

Noms vulg. : quinquina gris de loxa', quinquina d'uritusinga, cascarilla fina.

Cet arhre élégant, toujours orné de ses feuilles a un trone dressé, d'environ quinze à dix-huit pieds d'élévation sur un de diamètre.Son éeoree, d'où par incision déeoule un sucjaunâtre, amer et astringent, est erevassée, d'un gris eendré. Les rameaux sont droits, et opposés, disposés d'autant plus horizontalement qu'on les observe plus bas. Ils sont obseurément quadrangulaires, donnent attaehe à des feuilles opposées, glabres, ovales, laneéolées, luisantes, presque coriaces, portées sur un pétiole d'environ un pouee, latérinerves, offrant à leur faee inférieure une petite fossette (ee qui forme le earaetère distinetif de eelte espèee, à ehaque aisselle des nervures, dont le bord est garni de poils) et renferme une humeur eristalline très-astringente; le pétiole est le plus souvent eoloré en rose, ainsi que la nervure principale, et aceompagnć à sa base par deux stipules opposées, eaduques, longues de six à liuit lignes, pubeseentes en dehors.

. Fleurs blanehes ou roses, odorantes en panicule terminale, 
pédoncules cylindriques, soyeux, comme pulvérulens, le plus ordinairement trichotomes; pédicclles úniflcurs, bractéolés. Calice campanulć, long de quatre lignes, comme pulyćrulent en dehors, à cinq dents aiguës, 'étroites, dressćes, persistant. Corolle infundibiliforme, cadùque; longue d'un pouce, couverte en dehors de poils blancs et nombreux. Tube cylindrique, allongć, à cinq angles, obtus, peu saillans. Limbe étalé, à cinq divisions, ovales, aiguës. Lès cinq étaminès sónt incluses, attachées au tube de la corolle; filets courts; anthères linéaires allongées, attachées par leur base, à deux loges opposées. Pollen d'un beau jaune. L'ovaire est infère, 'ovoïdc, glabre, biloculaire, chaque loge
pluriovuléc. Disque épigyne, offrant cinq petits tubercules;'style droit, un peu plus long que le tube de. la corollc; stigmate bifide. Le fruit est une capsule ovoïde, couronnée par les dents ducalice, biloculaire, sc séparant dc la base vers le sommet, en 'deux coques, dont chacune s'ouvrc par une suture longitudinale, par sa face internc. Chaque coquc rcnferme un grand nombre de graines imbriquées, lenticulaires, à rebords membraneux, dentçes supérieurement.

Cette espèce de cinchona croit dans les Andes pćruviennes : oa la trouve auprès de Loxa et d'Ayavaca, idaus le royaume
de la Nouvelle-Grenade.

Caractère de l'ćcorcè desséchée. Elle est roulée sur ellc-mêmé en forme de tubes, depuis la grosseur d'uné plume de cigne, jusqn'à celle du doigt; épaisse d'une demi - ligne à unc ligne, sâtre, marqué de fentes transversales, interrompues et parallèles, sur lequel naisscnt des lichens de différens genres. Sa saveur' est à la fois, àmère, aromatique et légèrement astrin'-
gente.

Cette ćcorce, lorsqu'ellc est bicn choisie, est unc des mcilleures, parce qu'elle réunit les qualitćs de toutes les autres. C'est elle que les Espaznolcs désignent sous le nom de cascarilla
fina de Loxa. 
Qunguna orangè. Cinchona lancifalia. Mutis. Period. de Santa-Fé. p. 465. C.Angustifolia. R. et P. suppl. quin. 2 I. C. Tunita. Loper. C. Nitida. A. per. t. 2. "p: 5o: t. 19г. C. Lanceolata. fl. per. 't. 223. C. Roséa (fl. per. 2. p. 54: t. rǵ9.

Noms vulg, : Quinquina orange, Quina naranjada de . il Santa-Fé,

Tronc de trénte: à quaranté-ćnq pieds de hauteúr, dun ì quatre de diamètre; rameaux opposés, coưverts diunc écorcé brune ; rougeâtre, 'le plus souvent fenidllée transviersalement. - Feuilles opposéés, plus rapprochćes vers le sommet des rá m'eaux, pétiolées; ovalés, lancćolécs; aigriès, glabres', longues d'environ deux pouces.

1:Pétioles d'uhi demi-ponce de longucuŕ, un péu rildes au toucher; légèremcint canaliculés en dedans.

Stipulés très-petites, ovaless, laǹcéolécs, aiguc̈s.

- Fleurs blanehes ou roses, disposées en panicnle trichotome, ouverte, à l'extrémité des rameaux; chacque fléur éśt proùtée sur un pédieélle pubcscent, à la base duquel sont deirx petites bractées ovales, àiguës.

Calice adhérent avec l'ovaire , infère, ovoïde, jüubescent, himbe à cinq denús courtes et aiguës.

-Córole infundibuliforme, pubcscente én detrbrs.

Cirrq éramincs á pé près de la longueur du tibe dc la corolle; filets courts insérés 'vers ile milieu du tube; anthères plus Iongues, linéairés, oblongues.:

Ovaire ovoïde, biloculaire, eontenant plusienrs óvülés dans ehaque $\log \mathrm{c}$; stylc filiforme de la lonģtieur du túbé; stiğtridtc bifide.

Capsule longue d'environ un demi-ponee, 'ovoïde, 'oblonghe, noirâtre, striće, biloeulairc ', renférmant des grainés lenticülaires, à rebords membrancux et durs:

Le quinquina orangé hajite lcs pentes escarpécs des montagncs. On lc lrouvc aux cnvirous de Pampamarcha, Chacahuassi, Chuchera, etc.

Les trois espèces décrites et frgurées dans la Flore péru- 


\section{RUBLAGÉES.}

vienne de MM. Ruiz et Pavon sous les noms de Cinchona nitida, C. Lanceolata et $C$. rosea, ne sont, suivant plusieurs Luotanistes célèbres, que de simples variétés du Cinchona lancifolia de Mutis.

Caractéres dés écorces desséchées. Tues éeorces de celte espèce de quinquina sont remarquables par leur odeur et leur saveur aromatiques. Elles sont assez rares dans le commerce européen. Voiciles caractères auxquels on les reconnaît : écorces compactes, pesantes, épaisses, roulées ou planes; épiderụn sillonné de fentes transversales profondes, qui rendentisa surface externe rabotteuse; surface interne d'un fauve obscur; cassure fibreuse; saveur fortement amère et aromatique.

Quinquina rouge. Cinchona magnifolia. Ruiz et Pavon. C. oblongifolia. Mutis C. Zutescens: Ruizi: Quinologie.

Nom vulg. : Quinquina rouge.

Cet arbre a le tronc droit, élevé d'environ quatre-vingts à cent pieds; il croît très-abondamment à la Nouvelle-Grrenade et dans les forêts de Santa-Fé de Bogota'. Feuilles opposées, portées sur des pétioles d'un à deux pouces, convexes en dehors, plapes en dedans, rougeâtres; elles sọnt elliptiques-oblongues, glabres et luisantes supérieurement, offrant des veines souvent, de couleur purpurine inférieurement; elles acquièrent quelquefois un et même, dẹx pieds dellongueur, sur une largeur d'environ six pouces. Deux stipules opposées, droites, connées à la base, obovées, caduques. Fleurs blanches très-ağréablement odorantes, disposées en panicule terminale, droite., longuc d'environ un pied; pédoncules et pédicelles accompagnés de bractées lancéolées, aiguës, caduques. Calice cun paniforme, petit, pourpré; limbe quinquédenté. Corolle; en 'entonnoir, longuc d'environ un pouce, limbe ouvert, légèrement velu en dedans, à cinq divisions oblongues, obtuses...Les cinq étamines sont de la hautcur du tube. Les capsules soint oblongues, d'un ponce et demi de longueur, obluscs au sommet, qui est couronné par le limbe du calicc, atténucées à la base, légèrement striées. 
Commun dans le royaume de la Nouvclle-Grenadc, dans les forêts de Santa-Fé de Bogota, et dans plusieurs parties du Pérot1.

Caractères des écorces clesséchées. Le quinquina rouge n'est pas rare dans le commerce. Le principe astringent y est développé au suprême degré. Cette espèce a été rapportée du Pérou, et introduite en Espagne par Sébastien-Joseph LopezRuiz." Ses ćcorces sont roulćes, épaisses. de deux ì quatre lignes, lourdes et compactes; leur épiderme'd'une couleur grise, fauve ou presque blanche, est irrégulièrement fendillć ; lcur surface interne est d'un fauve rougeâtre très-intense. Leur cassurc est nette dans la moitié externe de leur épaisseur, fibreuse dans leur moilić interne; leur saveur est amc̀re, et surtout très-astringente.

L'èxtrêrme astringence de celte especce lui donnc, selon la remarque de Mutis, une action spécialc sur le système musculairc. Les recherches chimiques publiées rćcemment par MM. Pelletier et Caventou, ont prouvé que c'était le quinquina fébrifuge par excellence.

Qunnerina jaune. Cinchona cordifolia. Mutis $C$. pubescens. Vahl. C. officinalis. L. Syst. veg. C. ovata. fl. peruv. et chil. 2. t. r95. C. palescens. Ruiz. Quinologie. C. micrantha. Ret. P.

Tronc droit, haut d'environ vingt à vingt-cinq pieds. Écorce grise-noirâtre; celle des branches est pubescente et plus grise. Feuilles opposćes, tantôt ovales on ovales-lancéolées, tantôt ovales-cordiformes, portées sur un pétiole ailé, long d'un à deux pouces, conrexe en deliors, pubescentes en dessus, toinenteuses en dessous, violacées, ayant environ cincl pouccs de long, sur trois de large. Flcurs disposées en une paniculc terminale; pédoncules opposćs, pubescens; pédicelles bi ou trichotomes, unifleurs', offrant à leur base dcux petites bractées caduques. Calice, ovoïdc, violacé, limbc à cinq dents courtes; ovales, aiguës. Corolle infundibuliforme, tomenteuse cn dehors; tubc, cylindracé, renfté dans son milicu; limbe à cinq divisions ourcrtes, ovalcs, oblongnes, parscmées 
de poils sur leur face internc et sur leurs bordṣ. Étamines de la hauteur du tube de la corolle, au milieu duquel elles sont insérées. Capsule cylindracée, presque fusiforme, longue d'environ un pouce. Cette espèce croît dans les provinees de Cuença et de Loxa. En I753, 'M Santisteban l'a reneontrée aux environs de Popayan; et M. Tafalla l'a observée; en 1797 , à Playa-Grande.

- Caractéres des écorces desséchées. Le quinquina jaune est rcmarquable par l'abondanee de son prineipe amer. Aussi estil tonique par excellence: Ses écorees sont roulées de la grosseur du petit doigt à eelle du pouce, ayant diune à trois lignes d'épaisseur, sur une longueur variable; épiderme grisâtre, irrégulièrement fendillé; surface interne d'un fauvc pâle; cassure fibrense, saveur extrêmement amère et franche.

Qunquina beanc. Cinchona ovalifolia. Mutis. Hum. et Bonp. Pl. Eq. C. macrocarpa. Vahl. r. p. 65. t, r 9.

Nom vulg. : Quinquina blanc de Santa-Fë.

Cette espèce, dont le tronc ne s'élève guère que de huit à douze pieds, sur six à huit pouces de diamètre, a uue éeorce grisâtre, crevassée longitudinalement, lisse, et d'un jaunc elair intérieurement; elle donne, par incision, un suc astringent et amer de couleur jaune.

Rameaux opposés, quadrangulaires, soyeux, chargés de feuilles ovales presque obtuses, luisantes en dessus, couvertes, sur leur face inférieure, d'ın duvet soyeux, longues de quatre à six pouces, portées sur des pétioles d'environ un pouce, soyeux et légèrement eanaliculés en dedans.

Les stipules sont opposées, ovales, longùes d’ün pouce, eaduques, pubeseenies en dessous.

Fleurs blanches, petites, en panieules terminales à l'extrćmité des jeunes rameaux, accompagriées dë petites braetées linéaires eaduques; les pédoncules; qui sont également soyeux, pórtent communément trois à qualre fleurs.

Calice, long de deux à trois lignes, faisant eor'ps aveć l'ovaire dans sa moitić inférieure, renflé, et eomine eampanulé dans. sa moitié supérieure, qui est quinquédentée. 
Corolle hypocratćriforme, longue de six à huit lignes; tube allongé, cylindrique, soyeux à l'extérieur; limbe à cinq divisions linćaires égales, eouvertes de poils â leur extrémitć supériearc et interne.

Cinq étamines, de la longueur du tube, vers la partie inférieure duquel elles sont fixées; filets.eapillaires, hlancs, droits; anthères linéaires, oblongues.

Ovaire infere, couvert d'un disque vert ì cinq tubereules; style droit, un peu plus long que les étamines; stigmate bifide.

'Capsule, d'un pouce de longueur, ovoïde, fusiforme, striée longitudinalement.

Cette espèce est originaire des Andes péruviennes. On la trouve aux enviróns de Cuença, dans le royaume de la Nouvelle-Grenade, à Santa-Fé de Bogota.

Caractères des écorces. Le quinquina blanc est peu employé et assez rare dans le còmmerce; il est astringent et aromatique; ses écorces sont roulées, minces, cassantcs; son épiderme cst grisâtre; sa surface interne blanchâtre; sa cassure est fibreuse; sa savcur, d’abord faible, est amère et peu agréable.

Il est presque inusité.

Histoire, propriétès èt usages des diverses espèces de quinquina.

L'importanee du quinquina, considćré comme mćdicament, sa supériorité sur les autres substances toniques, nous ont engagé à réunir dans un même articlc l'histoire gćnćralc des espèces, Jeur analyse chimique et leur emploi thćrapeutique, et à donner à ce sujet une extension plus eonsidérable, que celle que nous avons accordće aux autres mćdieamcns dont nous avons traité dans cẹt ouvrage.

Chacune des cinq espèces dont nous, venons de faire eonnaître les caraetc̀res présente plusieurs variétés, qui peut-ûtre même appartienncnt quelquefois à dcs espèces végćtales différentes. Mais eette distinetion intéressant beaucoup plus les. droguistes et les pharmacions ehargés de la vente des quinquinas., nous eroyons ne pas devoir nous y arrèter.

Toutes les espèces de quinquina, qui sont répandues dans le commerce, sont originaires du continent de l'Amérique méri- 
dionale. C'ẹt d'abont aux euvirons de la ville de Loxa que les premiers pieds de quinquina on ćté déenuverts. Mais plus tard, quand on a mieux connu les caraotẹreș distinctifs de ces jréeieux végétaux, on cn a rencontré dans. d'autres parties de l'A mérique et particuliçrement ąu Pérou, , et dans, la royaume de la Nouvelle-Grenade.

On s’st plu à répandre șur la découverte des vertus fébrifuges de l'écoree de quinquina, des fables qui ont fini par s'aceréditer. Quelqucs-uns disent que ee fut ma Indien tourmenté par lcs ardeurs de la fièvrẹ, quị; s'étzant dẹ́saltćré avee les eaux d'un lae dans lequel plongeaient les branches d'arbres à، quinquinạ qui.l'entouraient, fut guéri dé sa fièvre et déeouvirit ainsi la merveilleuse propriétć du quinquina. D’autres: raeontcnt gu'un naturel du pays guérit ayec de la pondre de eette éeorec ụn Espagnol logć chẹz lui. Mais M. de Humboldt, quî a longtcmps résidé dans les contrćes où çroissent les quinquinas, assure gue les națrels du pays ignorent cńtièrement les propriććés des quinquinas, et par conséquenț l'usage que l'on en fait: Il eșt done éyident que ce ne sont pas. les Indiens qui iont révélé lẹs vertus de ce précieux médicament aux Luropéens::if

Ce qu'il y a de plus ecrtain, c'est que vers l'annéc 16.40 , un eorrćgidor de Loxa en fit prendre à la eomtcsșe del Cinchon, femme din viee-roi du Pérou, et qu’il la / guérit d'unc fièvre intermittente rebelle, dont elle était tourmentće depuis longfemps; A son retour en Espagne, la comlesse y rapporta du quinquina, et en distribı̣a à quelques personnés. De là le nom de poudre de la cointesse, qui lui fut d’ąorord donné. Mais ace ne fut guère que quelques années après, que les Jćsuites en ayant reçu une grande quantité à la fois, en répandirentl'usage en Italie, en Franee, en $\Lambda$ llemagne, elc., sueecssiyement dans lẹs autres parties de l'Europe.

Nous avons déjà dị que ee fụt lẹ célébre géomètre français la Condanine qui donna la première description exaete de l'arbre qui produit le quinquina. C'est aux recherehes et aux travaưx de Mutis, de MM. de Humboldt et Bonpland, Ruiz et Pavon, Tafalla, Zca et de quelques antres voyageurs iufatigables, que l'on doir la eonnaissançe, des différentes espèees qui sont anjọurd'hui répanducs dinș le eommerce. 
L'emploi du quinquiria , reneontra d'abord beaucoup d'obstaeles et de détraeteurs, avant d'être généralernent adopté par les praticiens. Son adminitration resta en France, un remède secret jusqu’à l'annće $16_{7} 6$, où Louis XIV cn acheta le secret et la recette d'un nommé Talbot, qui avait guéri avec cette poudre le dauphin fils du roi.

Depuis cette éporque, l'usage du quinquina devint plus général en Franee, et s'il s'est rencontré quelques médéeins qui aient ẻlevé des cloutes sur son efficacitć, une foule d'autres en ont constaté les merveillcux effets par'un grand nombre d'expériences.

Analyses chimiques. Nous avons jugé plus convenable de réunir dans un mèmé article les différens travaux des chimistes sur les écorees de quinquina, afin de ne pas être obligé à des répétitions pour chaeune des espèees soumises à leur examen. Les travanx de Fourcroi, de Seguin, de Vauquelin, de Lambert, de Reuss, de Gomez, ont tous fait connaitre des faits d'une haute importance, auxquels le travail récent de MM. Pelletíer et Caventou sert de complément. Aussi insisterons-nous particulièrement sur les résultats obtenús par ees jeunes chimistes.

Foureroi avait trouvé dans le quinquina une matière résinoïde partieulière. M. Vanquelin y a, de plus, signalé l'existence d'un acide, auquel il a donné le nom d'acide quinique. Cet habile chimiste a indiqué les moyens de reconnaitre la qualité fébrifuge des quinquinas par l'emploi des rćactifs chimiques, qualité qui, sauf quelqucs exceptions, est gćnéralement en rapport avec l'abondance du précipité, occasioné par la solution du tan.

M. Reuss, professeur de chimie à Moscou, en étudiant a vee soin la matière résinoïde observée par Fourcroi et Vauquelin, substance que ces ehimistes avaient toujours considérće comme complexe, en retira deux principes, l'un qu'il nomma rouge cinchonique, l'autre amer cinchonique.

Unédéeouverte non moins importante est cclle de M. Gomez de Lisbonne, qui a signalé dans les ćcorces du Pérou un principe immédiat, nouveau, äuquel il a donné le nom de cinchonin. Pour obtenir cetle substance on traite l'extrait alcoho- 
liqué di quinquina' par l'eau et la potasse, qui dissolvent successivement toute la partie extractive, et le cinchonin reste insoluble. On purifie cette substancc en' l'ćvaporant après l'àvoir fait dissoudrc dans l'alcohol. Elle est blanche, transparente cl cristállise en aiguilles allóngćcs.

C'est particulièrcmen t pour obtenir ce nouveau principe bien pur, et en ćtudier les caractères ët la nature, que MM. Pelleticr et Caventou ont soumis les quinquinas à un examen approfondi. Or, lcs résultats de leurs recherehes les ont amenés à considérer cette substance comme un nouvel alcali organique, auquel ils ont donné le nom dc cinchonine. Cette découverte est d'une haute importance, puisque l'expérience a démontré depuis que la cinchonine est le principe actif et fébrifugc des ćcorces du Pérou.

Cet alcali est $\mathrm{cn}$ aiguilles prismatiques, très-fines, peu soluble dans l'eau, 'puisqu'il exige deux mille cinq cents fois son poids d'eau bouillante pour se dissondrc. Sa saveùr est amèrc, mais assez lente à sè développer, à cause de son peu dc solubilité, tandis qu'il.s'exalte par les acides qui le rendent soluble, et le font ressembler à une forte décoction de bon quinquina. Il se dissout très - facilement dans l'alcohol, surtont à l'aide dc la chaleir. Il en est de même de l'éther, des huiles fixcs et volátiles, qui le dissolvent cependant moins facilement, surtout a froid.

Il ramène au bleu le papier de tournesol rougi par un acide. Il s'unit avec les acides, et forme avec tous des sels neutres.

C'est dans les écorces de quinquina gris ou quinquina de Loxa, que MM. Pclletier ct Caventou ont d'abord trouvć la cinchonine et qu'ils en ont ćtudié lcs caractères. Voici lc rćsultat de lcur analyse de cette espèce de quinquina :

Quinquina gris.

$1^{\circ}$ Cinchoninc unie à l'acide kinique (limate clé circhonine); $2^{\circ}$ matière grasse vcrte; $3^{\circ}$ matièrc colorante rouge très. peu soluble; $4^{\circ}$ matièrc colorante rouge soluble (tannin); $5^{\circ}$ matière colorante jaune; $6^{\circ}$ kinate de claux; $7^{\circ}$ gommc; $8^{\circ}$ amidon; $9^{\circ}$ ligncux.

Il était important de s'assurcr 'si la cinclionine éxistait dans 
toutes les autres cspèces de qụinquina. $\Lambda$ cet effet nos deux ehimistes sc sont occupés d'abord du quinquina jaunc ( $C$. Cordifulia Mut.), puis du quinquina rouge.

L'alcali relirć du quinquina jannc est en masse solide, non cristallisable, poreuse, d'un blane sale, peu soluble.dans l'cau, soluble dans l'alcohol et dans l'étlier sulfuriçue; il rétablit au blew un papier de tournesol rougi par un acide; il s'unit aux acides et forme avee cux deș sels gćnéralement solubles, ct qui eristallisent pliss facilement que cenx de cinchonine; ceș sels prćsentent aussi des différences qui lcs distinguent dc ceux à bașe de cinchonine : ces différences ont engagé MM. Pelletier et Caventou à regarder cct elcali comme tout-à-fait distinct de celni du quinquina gris, et en conséquéncc ils l'ont appclć quinine. La savcur de la quininc est très-amc̀rc, et même un peu désagrćable.

Voici les substances qui entrent dans la cornposition du quinquina jaune :

$I^{\circ}$ Kinate acide de quinine; $2^{\circ}$ rouge cinchoniquc; $3^{\circ} \mathrm{ma}-$ ticre colorante rouge soluble (tannin); $4^{\circ}$ matière grasse; $5^{\circ}$ quinate de chaux; $6^{\circ}$ amidon; $7^{\circ}$ matière colorante jaune; $8^{\circ}$ ligneux.

Le quinquina ronge a offert rćunis les deux alcalis qui existent isolćment danș le quinquina gris et lc quinquina jaune. En cffet IMM. Pellctier et Caventon sont parvenus aux résultals suivans dans l'analyse des écorces de quịquina rouge:

- ${ }^{\circ}$ ISinatc acide de cinchonine; $2^{\circ}$ kinatc acide de quininc; $3^{\circ}$ kinate de chaux; $4^{\circ}$ rougc cinchonique; $5^{\circ}$ matièrc colorante rouge solublc (tannin); $6^{\circ}$ matière grasse; $7^{\circ}$ watière colorapte jaune; $8^{\circ}$ amidon; $9^{\circ}$ ligneux.

Leș expériences pratiques dc plusieurs médccins distingués, et entrc autres de MIM. Cliomel et Doublc, on! prouvć que les alcalis organiques qui cxistent dans les écorccs de quinquina ćn étaicnt le principc véritablement actif et fébrifuge; en effet les sels de quininc et de einchoninc et en parliculicrle sulfatc, a jresque constanment réussi dans les cas oì ccs méd ceius y ont eu recours.

Quoique MM. Pelletier et Caventou n'aient point pu arriver a des rapports rigourenx ct proportionucls entre les principes 
constituans des trois espèces de quinquina, cependant ils ont remarqué que la cinchonine érail en nłọns grande quantité dans le quinquina gris, que la quinine dans le quinquina jaune. En effet, ils n'ont pu retirer que deux'grammes de cinchonine par kilogramme de quinquina gris, tandis qu'ils ont obtcnu neuf grammes de quinine d'une égale quantité de quinquina jaune. Quant au quinquina rouge de bonne qualité, il fournit une quautité beauçup plus considérable des dcux principes, puisqu'un Jilogramme produit huit grammes de cinchonine et dix-sept grammes de quinine. Il résulterait de celle connaissance importante que le quinquina rouge roulé et de bonne qualité, est le plus efficace, ;puisqu'il contient une plus grande proportion des principes actifs.

Histoire médicale. Lc quinquina doit être placé à la tête des médicamens toniques. En effet, il n'en existe aucun qui dćtermine, dans l'économie animale, des phénomc̀nes plus marqućs. Lorsqu'on donne quelques grains de poudrc de quinquina ă un individu sain, il n'occasionne aucun changement notablc; mais si cettedose est augmentée et portéc à un ou deux grós répétés plusieurs fois, il sedćveloppe alors une série de phénomènes très-remarqués. La bouclıe devicnt sèche, l'estomac est le sićge d'une sensation de pesanteur et de.gêne; bientôt la circulation devient plus active, la perspiration cutanće plus abondánte, la chaleur animale pjlus intense, la peau plus rouge; en un mot, il y a cxaltation du principe de la xie et des fonctions auxquelles il préside.

C'est en vertu du changement qu'il délermine, dans l'ćtat actuel des organcs, clicz. l'individu qui, en fait usage, que. l'on peut se rendue comptc de l'action antipériodique du quinquina, dans les fièvres, ct, en général, dans tontes les maladies intê:. mittentes. Ce n'est point, comme on l'a dit et répété, même dans les ouvrages les plus modernes, par uné action spćcifique;, agissant sur l'intermittcncc.

$I^{9}$ Comme tonique : Lc quinquina cst utile dans toutes les circonstances où l'économic animale a besoin d'être cxcitée. Ainsi, à la suite des maladies lentcs, qui ont affaibli licxcitabilité des organes, loutes les fois que les fonctions s'cxécutent difficilement, l'usage du quinquina pent étrc de la plus grandè 
utilité, en rendant aux organes le stimulus qu'ils ont perdu. C'est ainsi qu'on le dónne avee sueeès lorsque la digestion est lente et péniblc, ct qué l'csiomac a besoin d'êtré stimulé. 11 en est de mêmc dans les phlegmasics muqueuscs, passées à l'état de chronicilé. L'administration du quinquina est fort souvent suivie de sueeès, dans les catarrhes'pulmonaires chroniques, surtout eliéz les: sujets débilités par l'áge ou la lenteur de Ja maladie ; c'est' particulièrement contre les diarrhées rebelles, lorsque tous les symptômes d'irritation ont disparu, que le quinquina est d'une effieaeité remarquable.

Ön le met éneore fréquemment en usage et avec sueeès dans les hémorhagies dites passives, e’est-à-dire dans celles qui ne sont aecompagnées ni de fièvre, ni de douleurs aiguës, mais;' au eontraire, d'un état dc faiblesse et de prostration générales.

C'est par une action analogue que eette écoree est utile dans le scorbut, les serophules et quel ques autres affections générales. $2^{\circ}$ Comme fébrifuge. On emploie le quinquina soit dans les fic̀vres eontinues, soit dans les fièvres périodiques.

Il est rare que le quinquina soit nécessaire dans les fièvres continues simples, qui lc plus souvent cèdeut à des moyens hygiéniçues et à une diététique bien ordonnée. C'est surtout contre les fièvres dites adynamiques et ataxiques qu'il est plus spéeialement rceommandé. Mais l'usage de ee médicament dcmande dans eette eireonstanee les plus grandes précautions. Ainsí, an début de ees maladies, la plénitude du pouls, la langue sèche ef rouge, indiquent assez souvent un élat d'irritation qu'il faut ealmer par les antiphlogistiques, tandis que la prostration généralc, la faiblesse des pulsations dı eœur, l'ilffaiblissement du. système museulairc, la fétidité de l'haleine êt des excrétions, sont aulant dc signes qui indiquent l'emploi des préparations dc quinquina.

Mais c'est spécialement eontre lcs fic̀vrcs périodiques que le quinquina jouit d'une vertu que l'on peut a juste titre regarder commè spécifiqué.

- Lcs.fièvres intcrmittcntes on rémittentcs simples n'exigent que bien raremcut l'cmploi de ec médieament. Le rigime, la diète, quclques boissons délayantes on amères, suffiscnt dans 
le plus grand nombre des cas pour les díssiper. Ceperidant, on y a eu recours 'quelquefois quand ces moyens ont été insuffisans ou que la maladie sc prolonge trop long-temps.

Mais c'est dans lés fièvres intermittentes graves ou pernicieuses que l'aetion spécifique du quinquina produit les 'effets les plus merveilleux. Ces maladies, quelquefois si graves que le seeond aeeès, s'il n'a point été préveni à temps, 'emparte le malade, eèdent eomme par enchantement à l'éeoree du Pérou, quelles que soient d'ailleurs leur's causes et les formes sous lesquelles elles se présentent.

Cependant, l'administration de ce remède demande, pour être suivie de, succès, deśs préeautions que nous"allọns indiquer, et qui sont ćgalement applicables anx fièvres in termit-1 tentes simples, en un mot, à toutes, leśmaladies périodirịucs yui en réelament l'usage.

"Il est essentiel de combattre les complications qui pour-" raient s'opposer au suecès du quinquina.

" S'il y a embarras gastrique, il faut administrer un vomitif ou faire usage iles aeidules.

"S'il existe des signes d'embarrasintestinal, on dóit employer un purgatif, en ayant soin dé lc choișir dans la elasse des purgatifs toniques.

"Enfin, on a recours à la saignée si la fièvre intermittènte est aeeompagnée de symptômes inflammaloires très-intenses. is

On ne doit recourir à ces différens moyeus que dans le temps. de l'apyrexie, et le plus loin possible de l'aeeès qui doit se 'développer.

Ces préeautions prises, il en est encore d'autres ä observer dans l'administration même du remède, 'et qui sont spéeialement relatives à l'époque où l'on doit donner le quinquina, et quelle dose on doit en preserirc.

$1^{\circ} \mathrm{J}$ amais dans une fièvre intermittenté on ne doit administrer le quinquina pendant l'accès, car alors il en augmenterait la violcnee, loin d'y remédier.

$2^{\circ}$ Le temps le plus convenablc est de sept a huit heures avant l'accès : dans ee eaș le quinquina a le tẹmps d'opérer son aetiou avant l'heure où l'accès doit sc reproduire.

$3^{\circ} \mathrm{Si}$ c'est une fic̀vre rémittente que l'on veut eombattre, il 
faut administrer le quinquina vers lc déclin du dernier accès; par 'ce moyen' on prévient l'exaccrbation!de l'accès suivant. Doses. Elles varient suivantl'âg'e, la constitution du malade, la violence ou la durće de la.maladie : $1{ }^{\circ}$ la dose moyenne pour un adulte est 'de quatrc à 'six gros; mais' quelquefois on est obligć de porter cette dose un :enfant, la dose doit être bien moins forte : un demi-gros à un gros suffit ordinairement; $3^{\circ}$ on doit augmenter la dose eheż les vieillards, lès personnes affaiblies, ou suivant la gravitć du mal.

$\because 4^{\circ}$ La dose une fois déterminée, il ne faut pas la donner en une fois, il faut la partager en plusieurs prises que le malade doit prendre -successivement."

$5^{\circ}$ Cepcndant si la fièvre ćtait très-grave, ou que le médecin fût appelé peu de temps avant un accès, qu'il croirait devoir prévenir, on deviait donner toute la dose en une seule fois.

$6^{\circ} \mathrm{La}$ conduite à tenir est différente suivant que l'accès a été pnévenu, suivant qu'ìl a été seulement mitigć, ou enfin suivant qu'il s'est reproduit avec la même intensité.

- Dans le premier cás, quii est le ṕlus favorable et celui qui se présente le plus fréquemment, il faut,'à l'ćpoquc où l'accès devrait avoir lieu, employer encore la même dose de quinquina, puis la diminuer graduellement aux temps des accès suivans. Faute d'employer ces précautions on voit quelquefois la fièvre se reproduirc.

Si l'accc̀s n'a été que mitigé, on doit tenir la même conduite quc dans le cas précédent, c'est-à - dirc continuer à l'approche des autres accès la même dose de quinquina, que l'on pourrait inême augmenter si on le jugeait nécessaire.

Enfin, dans le cas où le quinquina n'a produit aucun effet sensible, il faut d'abord bien examiner'si l'on n'aurait point omis quelques-unes des précautions préliminaires propres à assurẹr lc succès de ce remède; on devrait dans cc cas les rentplir sans délais, ct ensuite administrer une nouvelle dose de quinquina.

Dc toutes lcs.préparations de quinquina, la poudre est celle que l'expćricnce a te plus généralcment trouvće efficacc pour combattre lcs fièvres intermittentes. Cepcudant il est des indi- 


\section{IR ÜB I ACÉES.}

vidus dont l'estomae ne peut sipporter une dose aussi considérable quc celle que l'on est obligé d'administrér à la fois', et qui le vomissènt presquile aússitôt qu'ils l'ont avalé : c'est pour prévenir cè cás fàchèx que l'on mélanğe quelquefois au quinquina la poudre de cannelle et mêrnc l'ópilum.

Les autres préparations avec lesquelles on peutremplacer la poudre, sont l'extrait alcoliolique, le sel essentiel de Lagaraic; là teintuie; et enfin les 'préparations de quinine et de cinchónine. Lorsque MM: Pelletier et Càentoú eurent découvertet isolé le prineipe actif des quinquinas, c'est-à-dire la cinchonine et la quininé, plusiturs médecins s'emparèrent de ées deux nouveaux álcalis poür èn étudièr lés'effets sur l'ćconomie animâle. MM. Chomel, Dóuble, Magendiè) Villermé; ont publié sui ce sujet des faits très-intérèssáns', èt dont les eonclusións ten-

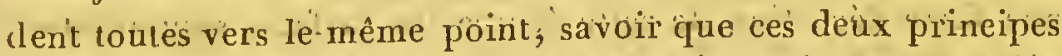
possèdent entièrement les mếmes propriếtés médieales que les

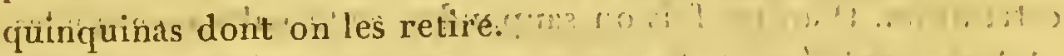

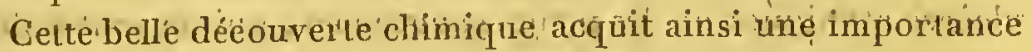
bien plus grande. En effct, s'il est une fois bien conslaté 'que la quinine ct la cinchonine possèdent les inêmes propriétés que le quinquina; quels avantagés nc devra pas en rclirer la thérapentique dáns une foule de ćrconstances? Dix ou douze grains d'rir sel de ces alcális produisant le n'ême effct que six à luai gros dé quinquiuina, il est peù de càs où ee médicament ne puisse êtire facilement administré. 'ét substitué à la poudre de quinquina. Un autreavânlage', c'est que l'on in'eśt joint toujours sủr de la qualité d'ès ćcorrés que l'on administre 'en joudre et que 'dans 'des eas très-graves on peut n'avoir insciemment à sn disposition qu'un médicamert sans effieaeité ; tandis que dans ces deux alcalis on est toujour's eertain de posséder un médicament invariable, dont les propriétés sont constament les mêmes, surtout lorsqu'ils ont ćté préparés pardes procédés convenables.

MIM. Double et Chomel ont fait l'un et l'autre eonnaîlie un grand nombie de faits qui constatent la vertu fébrifuge de la. quinine et de la cinehonine, dans le traitement. des fièvresilltermittentes ct rémittentes.

Ces deux alealis élant presque insolubles, tandis que leurs 
sels se dissolvent: fagileınent, c'cst principalement à l'etat de sulfate que l'on en fail usage.

La dose du sulfate de quinine varie de huit à quinze grains; il est rare que l'on soit obligć de. l'augmenter. On l'administre, soit directement dans une cuillerée de confilure, on de sirop, soit entre deux pains azymes, soit enfin dissous dans un liquide queleonque..

Tout ce que nous venons de dire sur l'emploi du quịquina dans les fic̀rres intermittentes et rémittentes, est applieable au traitement de ees affections'anoinales et périodiques si variées, que l'oul désigne improprement sous le noin de fièvres larvées.

Le quinquina n'est pas seulement employé à l'intérieur, les chirurgiens en font également usage dans le pansement et.lc traitement de eertaines plaies et ulcères. $\Lambda$ inși; on lave avee une forte décoction de cette écorce les surfaces suppurantes, pâles et blafárdes, afin d'y ęxeiter une rćaction utile à leur cieatrisation. D'autres fois on saupoudre celte substance sur. les ulcères atoniques ou les plaies gangrenées, qui ne sont point aecompagnées d'irritation locale.

Préparations. $1^{\circ}$ Poudre. La dose varie suivant les eirconstances où l'on fait usage de ce mćdicament. Ainsi, lorsqu'on veut l'administrer simplement comme tonique, on l'or'donne à la dose d'un scrupulc à un gr'os, que l'on dẹ́laie dans. quelques cuillerées de vin, ou dans une tasșe de tisanne ou de boullon; on peut encore l'incorporer à un sirop et en former un électuaire que l'on partage en pilules ou cn bols.

Si l'on donne le quinquina comme fébrifuge pour arrêtcr le cours d'une fièvre intermittente ou r'ćmittente, la dose doit étre bien plus considérable, et varier suivant l'àge du sujet, la durée ou le danger de la maladie. Le plus sonvent on en donne quatre, six gros ou une once, partagée en plusienrs prises que le inalade doit prendre sept à huit heures avant l'ac cès. Si eette dose ne suffit pas on l'augmenic de deux à quatre gros pour l'aecès suivant, et l'on contiuue la même dose pendant quelques jours afin de prévenir le retour des aceès suivans, en ayant toutefois le soin de diminucr grarluellement jusqu'ì ee que l'on se soit bien assuré que la fièvre a ćlé entièrement suppriniée. 
Assez souvent on mélangc la cascarillc à la poudre de quinquina pour cn augmenter l'action. Chez les sujets forts et pléthoriques, on ajoute fréquemment à la dose de quinquina un gros de crème de tartre ou dc sel de nitrc. Chez les sujets irritables, dont l'estomac supporte difficilement cette substancc, on y joint quelque préparation opiacće, ou mểmc l'opiun, à la dose d'un demi grain à un grain.

La poudre de quinquina 's'administre en suspension, dans un liquide quelconque tel que le vin, la tisane on le lait; dans ce dernier cas, il faut avoir soin de le faire prendrc au malade aussitôt que le mélange vient d'être fait, sans quoi le quinquina communiquerait son amertumc et rendrait cette boisson fort désagréable.

$2^{\circ}$ Décoction. Elle se prépare en faisant bouillir, pendant dix minutes, unc once de quinquina concassé dans deux livires d'eau, te en passánt la liqueur avant son refroidissement.

On fait usage de cette boisson, soit dans lcs fèvres contínues, simples ou graves, soit, mais plus rarement, dans les fièvres périodiques.

Cette décoction sert à préparer les injections, les lavemens dont on fait souvent tisage.

$3^{\circ} V$ in de quinquina. On lc prépare, soit en faisant macćrer de bon quinquina dans du vin blanc, ou mieux encore dans du vin de Bordeaux ou de Madère, soit par le procédé dc Parmentier, c'est-à-dire en ajoutant deux onces à dcux onces et demie de teinture de quinquina dans deux livres dc vin.

Sa dose est de deux à quatre onces. C'est surtout comme tonique, ct principalement comme stomachique, que l'on prescrit l'usage du vin de quinquina.

$4^{\circ}$ Extraits de quinquina. On en prépare piusieurs : $\mathrm{I}^{\circ} \mathrm{Par}$ la décoction dans l'eau; $2^{\circ}$ par la macération dans l'alcohol; $3^{\circ}$
par la macération dans l'eau.

L'extrait alcoholique doit être préféré, parce que les principcs actifs du quinquina sont plus solubles dans l'alcohol que dans l'eau. Sa dosc varie suivant lcs circonstances où l'on $\mathrm{cn}$ fait usage. Ainsi, comme tonique, sa dose cst d'un scrupulc; comme fébrifuge, on portc cette dose à un ou deux gros.

L'extrait préparé, en faisant évaporcr lentement la macéra- 
tion aqueuse du quinquina sur des assieltes, porte le nom de sel essenticl de Lagaraic. Sa dose eomme tonique, est de douze à vingt-quatre grains. Ces différens extraits s'administrent soit en pilules, soit dans les potions toniques.

$5^{\circ}$. Sirop cle quinquina. Cetle préparation est très-peu énergique. Aussi ne doit-on la preserire que dans les eas peu graves. On la fait entrer à la dose d'une onee dans les potionstoniques.

$6^{\circ}$ Teinture alcoholique de quinquina. Cetle préparation très-énergique peut être employée pour eonfectionner le vin de quinquina; on l'ajoute aussi aux potions toniques à la dose de ; deux à trois gros.

Après avoir donné quelques détails sur l'histoire naturelle et médieale des véritables espèces de quinquina, nous devons dire un mot des éeorees auxquelles on a également donné ce nom, mais qui n'appartiennent point au genre cinchona.

$I^{\circ}$ Les espèces'dn genre Exostemma d'abord réunies au genre cincinona en diffèrent botaniquement par leurs étamines saillantes hors du tube de la eorolle. C'est à ce genre que l'on doit rapporter le quinquina des Antilles, quinquina Péton, quinquina de Saint-Domingue, quinquina de Sainte-Lueie, etc. Leur amertume est très-considérable; mais, d'après l'analyse qui en a ćté faile par M. Pellelier, elles ne contiennent ni quinine, ni einchonine : aussi les emploie-t-on fort peu; elles possèdent en général une propriété purgative, qui n'existe point, du nooins au même degré, dans les véritables quinquinas.

$2^{\circ}$ Le quinquina de Carthagène paraît être produit par le portlandia hexandra. M. Pelletier y a démontré la présenee de la quinine el de la einchonine : eette éeoree est done préférable à la préeédente, aussi l'emploie-t-on avec sueeès anx Antilles et dans d'autres parties de l'Amérique.

-Enfin on trouve asse\% sonvent les éeorees du macrocnemum corymbosum et eelles de quelques autres Rubiacées exotiques mélangées avee les véritables espèees de quinqunina.

30 Fruit charnu renfermant deux noyaux.

GAF EIER. - COFFEA. L. J.

Calice adhérent a cinf dents : corolle tubulcuse infundibuli- 
forme, limbe plane; étamines saillantes. Baie ećrasiforme onbiliquée, eontenant deux nucules à parois minees, dont les graines offrent in sillon profond sur leur faee interne qui es I plane.

Fleurs ordinairement axillaires.

Gafeier d'Arabie. Coffea Arabica. L. Sp.

Part. usitée : les graines.

Cet arbrisseau, qui en tout temps est orné de son fenilla'ge vert et luisant, élève sa tige a une hauteur de quinze à vingt pieds. Ses rameaux portent des feuilles opposées, pétiolées ovales allongées, amineies en pointe à leurs deux extrémités, entières, glabres et.un peu sinueuses sur leurs bords; les deux stipules sont lancéolées et eaduques. Les fleurs sont blanches, presque sessiles, grouppées et réunies en grand nombre à l'aisselle des feuilles supérieures. Elles sont à peu près de la grandeur de celles du jasmin d'Espagne, et répandent comme elles une odeur extrêmement suave. Leur ealice est turbiné , terminé par einq petites dents égales; la éorolle est presque hypoeratériforme, son tube est eylindrique, plus long que le calice; son limbe est partagé en einq lobes étalés, ćgaux et laneéolés. Les étamines, au nombre de einq, sont saillantes hors diz tube de la corolle. Les anthères sont allongées, étroites et vacillantes. L'ovaire est à deux loges qui eontiennent ehaeune un seul ovule.: le style est simple, grèle, terminé par un stigmate bifide.

Le fruit est un nueulaine de la grosseur et de la couleur d'uno pelite merise, renfermant deux nueules aceolés par leur eôté interne qui est plane, et eonvexes par leur eóté externe. Dans chacun d'eux on trouve une graine carlilagineuse de même forme, ereusée d'un sillon longitudinal profond sur sa face plane.

\section{Propriétés médicales et usages du café.}

Suivant Raynal, le cafeier est originaire de la hante Éthiopie, d'où il a été transporté dạns l'Arabie vers la fin du quinzième sièele. Les environs de la ville de Moka, dans la province d'Yemen, paraissent être les lieux où le cafeier s'est le micux accli- 
maté; aussi plusieurs auteurs considèrent-ils cette partie des bords de la mer rouge comme sa véritable patric. Nons ne nous étendronș pas longuement sur l'introduction du café en Europe; tout lc monde sait que ce sont les Hollandais qui en transportèrent quelques pieds à Batavịia et de là 'à Amsterdam, où ils les cultivèrent dans leurs serres chaudes. $\Lambda u$ commencement du siècle dernier, un consul de France en envoya un individu à Louis XIV. Placé an jardin du roi, ce cafeier y prospéra et ne tarda pas à se charger de fruils qui servirent à le multiplier. $\Lambda$ cette époque l'usage du café étant devenu plus général et son commcrce plus important, les Français essayèrent d'acclimater l'arbre qui le produit, dans leurs posssessions des Antilles. Un bâtiment commandé par le capitaine Declieux, fut chargé d'ell transporter trois pieds à la Martinique. Pendant la traversée, qui fut longue et périlleuse, deux périrent en route et le troisic̀me ne dut sa conservation qu'aux soins et aux privations du capitaine, qui, pendant long-temps, partageait sa ration d'eau avec le jeune cafeier. Ce fut ce seul individn qui, peu d'années aprés, devint la souche de toutes les plantations qui s'établirent à la Martinique et dans les autres Antilles françaises. Pcu de temps après cet arbrisseau précieux fut également introduità Cayenne et à l'ílc de Bourbon; en sorte qu'aujourd'hui la majeure partie du café qui se consomme en Europe est tïrée des Antilles. Cependant celui de Moka est toujours le plus estimé et celui dont le prix est le plus élevé.

C'est la torréfaction qui communique au café la saveur suave et l'arome délicieux, qui font que tous les peuples civilisés du globe le recherchent avec autant d'avidité. Avant d'avoir subi cette opération, il est dur, et n'offrc qu'une saveur herbacée qui n'a rierı d'agréable. C'est au tannin ct à l'huile empyreumatique qui s'y développent par l'action du fcu, qu'il doit ses excellentcs qualités. L'analyse chimique a fait trouver dans le café : $x^{0}$ un acide considéré par les uns comme de l’acide gallique, par les autres, comme un acide spécial nommć cafiquc; $2^{\circ}$ unc matièrc particulière, que MM. Robiquet et Pelletier ont obtenuc bien pure, qui cst susceptible de cristalliscr, ct qui porte le nom de caffeine; $3^{\circ}$ une huilc cmpyreumatique, etc.

L'usage du café est anjourd'hui tcllcment répanclu dans 
toutes lcs classes de la société, que nous nous croyons dispensés d'entrer ảans aucun détail à ce sujct. L'infusion des graines de café, torrérifiées et réduites en poudre, lorsqu'elle a étć préparée avec soin et surtout à vaisseau clos, est une liqueur à la fois tonique ct excitante, dont l'amertume est rendue agréable par un principe aromatique et suave. Elle favorise la digestion, et exerşant une action spéciale sur l'encéphale, elle excite les fonctions de cet organe, exalte les facultés intcllectuclles ct sensitives. Beancoup d'hommes, livrćs au travail du cabinet, ne peuvent écrire que sous l'influence du café. Aussi le décore-t-on dans beaucoup d'ouvrages dı nom de boisson intellectuelle.

On fait aussi usage du café à titre de médicament, mais seulement pour les individus qui n'ont point contraclé l'habitude de cette boisson. L'infusion très-chargée de café est un mćdicament tonique, dont l'emploi a quelquefois ćté utile dans certaines a ménorrhées, ou dans la diarrhée chronique, dćpendant de causes débilitantes. Plusienrs autears ont constaté par l'expérience la vertu fébrifuge du cáf́, surtout avant la torréfaction. Le docteur Grindel l'a administré avec le' plus girand succès contre des fic̀vres intermittcntes, même trc̀s-rebelles, soit en poudre, à la dose d'un scrupule répćté plusieurs fois dans la journée; soit en décoction, à la dosc d'une once bouillie dans dix-hnit onces d'eau, que l'on faisait rćduire des deux tiers. Ce médecin rapporte que sur quatre-vingts cas de fièvres intermittentes qu'il a traitées par ce procédé, un trèspetit nombre y ont résistć.

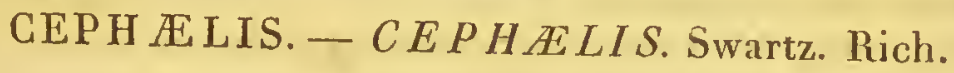

Fleurs réunies en capitule axillaire, entouré d'un involucre polyphylle. Calice à cinq dents; corollc infundibuliforme à cinq lobes. Baie ovoüde peu charnue, renfermant deux nucules qui se séparent à la maturité. 
LPécacunara annetí. Cephaelis ipecacuanha. Rich. Hist. Ipéc. p. 2 r. t. I. Callicocca ipecacuanha. Brot.

Part. usitée : la racine. Nom pharm. : Ipecacuanka grisea sivc fusca.

C'est un petit arbuste rampant ou peu élevé au-dessus de la surfaee du sol, qui croit dans les forêts épaisses et ombragćes du Brésil. On le cultive aussi dans quelques autres parties de l'Amérique inéridionale.

Les racines partent d'une tige souterrainc rampante, horizontale; ellcs sont ou fibreuse capillaires, ou bien représentent des espèces de tubereules allongés, marqués d'impressions annulaires très-rapproehées. Elles sont presque ligneuses et irrégulièrement rámeuses, ont un épiderme brun, sous lequel sc trouve un par'enchyme blane, presque eharnu dans l'état frais. Leur eentre est oecupé par un axc ligneux filiforme.

La tige, qui est d'abord souterraine, se redresse et s'élève à cnviron un pied. Elle cst fruticuleuse, simple, obseurément quadrangulaire, légèrement pubeseente dans sa partie supérieurc.

Les feuilles n'oceupent quc la partie supérieure de la tige. Au nombre de six à huit, elles sont opposées, courtement pétiolées, ovales, aeuminées, entières, rétréeies insensiblement à leur base, latérinerves, presque glabres, longues de deux à qriatre pouees.

Dcux stipules assez grandes, opposées, réunies à leur base, pubeseentes, déeoupées supérieurement en einq ou six lanières étroites, sont ințerposées aux feuilles.

Les fleurs sont petites, blanches, et forment un petit capitule tcrminal, cnvironné à sa base par nn involucrè très-grand, formé de quatre folioles pubesecntes.

Le ealice cst adhérent à cinq dents : la corolle est infundibuliforme; son tubc est eylindriquc; son limbc a cinq divisions allongées, aignës.

Cinq étamincs altachées au tube de lit corollc.

Style simple, tcrminé par deux stiguates divergens: 
Lc fruit est un nueulaine ovoïde noirâtre, contenant deux nucules blanehâtres.

C'est cettc espèce qui fournit l'ipćcacuanha lc plus répandu ct 'lc plus employé en Europe. On lc désigne sous le nom d'ipécacuanha brun ou gris. C'est celui auquel j'ai donné le: nom D'IRÉGACUANHA ANNELÉ. (Histoirc natur. et méd. des diff. csp. d'ipćcaeuanha, elc. , in-4? 1820.$)$

Cettc espèce mérite la préférencé" sur toutes les autres à calusc de sa plus grande activité, qui est due à un principe particulier désignć sous lc nom d'émétine.

Caractères de la racine. L'ipécacuanha annelć présentc les caractères suivans: racines allongées, de là grosseur d'une plume à ćcrirc, irrégulièrement contournćes ét coudées, simples òu rameuses, formćcs de petits anneaux saillans, inćgaux, trèsrapprochés, ayant environ une ligne de hautcuŕ, séparés par dcs enfoncemens moins larges; formćes de deux parties, savoir: un axc ligncux, plus ou moins grêle, ct unc couche corticalc résineuse, plus épaisse : elles sont compactcs, cassantcs, lourdes; leur cassure est brunâtrc et résineuse ; leur savcur lıcrbacéc un peu anic̀rc asscz acre; leur odeur faible, mais cependant nauséabondc, surtout celle de la poudrc.

Cctte racine, soumisc à l'analyse, nous a donné les résultats suivans: ÉmÉTINe 16; cire 1, 2; matièrc rćsincusc 1, 2 ; gomnn 2, 4; arnidon 53; matière animale 2,4 ; ligneux 12,5 ; acidc gallique des traces, total 100 partics.

L'énétine d'abord découvertc par M. Pelleitier, et que ce chiniste est parvenu à purifier, est blanche et cristallisable : c'cst lc principelactif de l'ipćcacuanha; cllc possède les mèmes. propriétés que la racinc cntic̀r'c.

\section{PSYGHOTRIE. - PSYCHOTRIA. L. J.}

Calicc à cinq dents; carolle tubulcusc, évasée, à cinq lobes dressćs; étamincs incluscs; baic grlobulcuse couronnćc par les cinq dents du calicc; ct se séparaut à la maturité en deux nucules.

Fleurs en graplues axillaires. 
Thëcacitanira stnú. Psychotria emetica. L. supl. p. I 44 . A. Rich. Hist. Ipéc. p. 27. t. 2.

Partic usitée: la racine. Nom pharm : Ipecacuanha nigra.

Petit arbuste semblable en tout pour le port au précédent, croissant dans les forèts oinbragées du. Pérou et du royaume de la Nouvelle-Grenade, etc.

La racine cst une souche presque horizontale, cylindrique, de la grosseur du pctit doigt; étranglće de distance en distance, offrant quelques radiculcs fibreuses, grĉlcs.

La tige est fruticuleuse, dricssće, haute de douze à dix-huit pouces, simple, cylindrique, finement pubescente.

Les feuilles sont opposćes, lancéolćes, aigues, finissant iṇsensiblement à leur base en un court pétiole. Elles sont entières glabres en dessus, pubescentes en dessous. Deux stipules étroites, aiguc̈s, dressées, un peu fermes et pubescentés sont interposées aux feuilles.

Les fleurs sont disposées en petites grappes axillaires et bifurquées. Le calice est adhêrent: son limbc est à cinq divisions ovales oblongues.

La corolle est infundibuliforme, évasce ; quinquéfide. Lcs cinq étamines sont incluses et attachées au tube.

- Le fruit est un nuculaine ovoïde, bleuâtre, renfermant deux nucules.

L'ipécacuanha fourni par le psychotria est très-rare dans le commerce, ct fort peu usité en Europe. On le désigne connnınément sous le nom d'ipécacuanha noir. Je lui ai doinué le

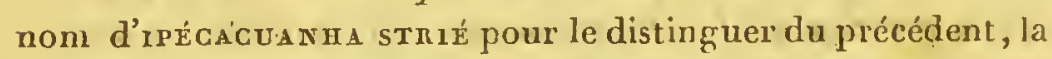
couleur ćtant extrêncment variable dans l'un et'daụs l'auire.

\section{Caractères de la racine.}

Voici quels sont ses caractères : racincs cylindracćes, le plus souvent simples, de la grosscur d'unc plume à écrirc, allongćes, pcu contournées, non rugucuses, offrant de distance cn distance des espèces d'ćtranglemens, ćloignés lcs uns des autres: Épiderme d'un brun foncé, formant dcs stries longitudinalcs; cassurc brune, noirâtre, peu rćsineuse : odeur presque uullc: șaveur fade, légèrement âcrc. 
Cette racine renfermc à jeu près les mèmes matériaux ímmićdiats que la précédente, thais elle contient la moitié moins d'émétine que l'ipćcacuanha strić.

Il est cncorc uiné áutre espècè d'ipécacuánha produite par la famille des Rubiacées. C'est l'ipécacuanha blanc fourni par le richardsonia brasiliensis nob., ou richardia brasiliensis de Gomiez.

Celte espéce, sùi laquelle M. Virey nous a donné récemment des détails ćtendus; tirés d'un mémoire de M. Gomez (Memoria sobre a ipecacuanha), n'cst ṅullement employée en Europe. Elle est originaire du Brćsil, où elle est désignée sous le norn de poia do campo.Mais elle ne uou's est point apportće par le commerce, et par consécquent on n'ein fáit point usage èn Europe.

\section{Propriétés médicales et usage de l'ipécacuantua.}

C'est à Márcgrave et Pison que l'on doit la première connaissance des proprićtés de l'ipćcacuanha. L'espćce sur laquelle ils ñous ont donné quelqués détails dans leur Histoire naturelle et médicalc du Brésil, cst le cephcelis ipecacuantıa, qui fournit l'ipécacuanha annelé. Mais lè vague qui règne dans leur descriptiou a pendant long-temps empéché les botanistes de déterminer quel pourait être lè végétal indiqué par ces aułeurs comme fournissant l'ipécacuanha. C'est ainsi que l'on a cru tour à tour que ce mćdicament ćtait la racine d'un paris, d'un chevrefeuille, d'une violette, etc. En 1 764 , le célc̀bre Mutis fit parvenir à Linné la description èt la figure du végétal qui, au Pérou et dans le royaume de la Nouvelle-Grenade, fournit l'ipécacuanha. Linné fils la publia cn $178 \mathrm{I}$; sous le nom de Psychotria emetica, ct crut qu'elle ćtait la même que celle observće au Brćsil par Marcgrave et Pison. Enfin, en I 800, M. le professeur Brotero, de Coümbre, fit connaître lá planté qui au Brésil fournit l'ipécacuanha apporté par la voie du commercc; il la noinmà Callicocca ipecacuanha. Cctte plante est bien la même que cclle de Marcgrave et Pison, mais ce geare callicocca étant le même que lc cephcelss de Swartz, j'ai nommć ce végćtal Cephatis ipécacuanha. Il résultc de ces différens travaux que l'ipécacuanha que l'on recueille au Jérou ct dans la nouvelle Grenade, est fourrii par un aurre végétal que celui du 
Brésil, quoique tous deux appartienncnt à la mêıne fanille. L'ipécacuanha du Brésil, que nous avons appelé iprécncuantia annelé, ćtant une fois plus actif que celui du Pérou, qui n'existe que fort rarement dans lc eommerce; c'est dc lui sculement que nous parlerons iei en faisant connaitre lcs propriétés médicalcs de eette racine.

La première impression de la poudre d'ipéeaeuanba sur la inembrane inuqueusc de l'estomae, est une action tonique, lorsque la dosc que l'on a donnée n'est que de quelques grains: aetion qui s'étend dans toutc l'étendue des.voies digestives. Si, au eontraire, la dose est plus considérable, il agit alors comme un irritant local et provoque le vomisserucnt. C'cst principalement comme émétique que l'on emploic l'ipćcacuanha, soit pour produire simplement le vomissement, soit pour agir comme évaeuant et dérivatif à la fois, comme lorsqu'on l'administre dans l'angine, la pncumonic, lcs oplithalmics bilieuses, etc. Donné à doses fractionnées, la poudrc d'jpécacuanla ne déIrrmine point lc yomissement, mais par les conlractions lentes qu'il fait naitre dans les organes digestifs, par-les vomituritions qu'il détermine, il fayorise et augmente la transpiration cutanée, et agit comme diaphorétique.

Un des caractères qui distinguent l'ipécacuanha des autres médicamenș ćnétiques, c'est l'action tonique qu'il exerce sur les organes digestifs: aussi tous les observateur's s'aceordent-ils à reconnaitre son efficacité dans lc traitement de la diarrhée et de la dysenterie chronique. Mais il faut bien sc garder d'en faire usage, lorsquc cette dernière maladie est encore à l'état aigu: il en aggraverait singulièrement tous les symplòmes. C'est à peu près dc lạ même manière quc cc médicament agit dans le eatarrhe pulnonaire chronique ct la coqucluche; on l'administre alors sous la forme de pastilles ou de sirop.

Enfin, des fails multipliés ont prouvé que l'ipéeaeuanlıa ćtait encore fort utile dans les péritonites qui se développent à la suitc de l'aceouclicnent.

Quant: à l'émétine, des expériences nombrenses, fiites par M. Magendie et par nous-mềne, on démontré qu'elle était le vérilablc prineipe actif de l'ipécacurah hil, el qu'elle jouissait de toulcs les propriétés qu'on a reconnue's il ce médicancul. On 
peut donc la lui substitucr dans lc plus grand nombre des cas; d'autant plus qu'elle n'a point cette odeur et celte saveur nauséeuse qui rendent ce médicament insupportablc pour beaucoup de personnes. La dose de l'émétine pour provoquer le vomissement chez un adulte est de quatre à six grains, que l'on peut augmenter ou diminuer suivant lcs circonstances.

L'ipćcacuanha s'administre ordinairement cn poudre : vingtcinq à trentc grains partagés en trois doses et suspendus dans douze onces d'eau sucrée ou d'une infusion lćgère de fleurs de camomile, suffisent pour déterminer le voinissement chez un adulte. Lorsque l'on administre cette substance dans la diarrhée, les catarrhes pulmonaires chroniques, on.la donne à la dose de deux à trois grains, plusieurs fois répćtés dans la journée. Le sirop d'ipécacuanha est principalement destinć pour les eufans: sa dose est d'une demi-once à une once. Quant aux tablettes ou pastiles, on en fait une très-grande consommation, surtout an déclin des rliumes. On prépare un sirop et des pastilles d'ćmétine qui pcuvent remplạcer les pastilles et le sirop d'ipécacuanlıa.

Propriétés médicales, et usages des plantes de la famille des Rübiacées.

Un groupe naturel de végétaux qui nous fournit à la fois les différentes espèces de quinquina et d'îpécacuanla, le café, la garance et plusieurs autres produits de cète importance, méritent de fixcr l'attention du naturaliste, du médecin et du commerçant. Aussi la famille des rubiacées doit-elle ètre comptée au nombrc des plus intéressantes, et lcs espc̀ces qư'clle renferme, parmi les plus utiles du règne végétal.

Cettc famille cst rcmarquablc par l'analogie qui existe dans lcs plantes qui la composent, sous le rapport des propriétés qu'ellcs possèdent:' Ainsiles ćcorces de la plupart des rubiacées ligncuses contiennent un principe astringent et amer, extrềmement abondant dans les différentcs espèces de quinquira ; nais qui cxistc aussi dans d'autres gcnics quoiqu'à un degré plus faiblc. Ainsi les écorces des espieces du ${ }_{\lambda}^{-}$gcnre exostcmma, ccllcs lu portandia hexcindra, du nucroc nemum iorymbosum, du peneya et de plusieurs autres végétaux exotiques apparte- 
nans à la inêmc famille, sont, dans plusieurs contrées du NYouveau Monde, substituées aux véritables espèces de quinquina. Les belles analyses chimieques de MM. Pcllctier ct Caventou ont démontré que, dans les ćcorccs du Péróu, la saveur astringente dćpendait d'un acide particulier, nommé acide kinique, tandis que l'amertume ćtait dủe àux principes immćdiats nouveaux que ces chimistes ont nommé quinine et cinchonine. Il était curieux de rechercher si cc principe n'existait point également dans les écorces des autres rubiacées; réputées fébrifuges. M. Pelletier a tenté ce nouveau travail, et il à reconnu que les écorces du portlandia liexandra, connues dans le commerce sous le nom de quinquina de Cumana, contenaient aussi de la quinine, tandis que cè principe n'a point été trouvć dans les quirquina piton et dc Sainte-Lucie, qui appartiennent au genre exostemina.

La saveur astringente dcs rubiacćes existe également dans la garance, et quelques plantes'herbacẻes indiǵèncs. Mais dans auciun autre végétal elle n'acquicrt autant d'intensité que dans le naucler gambeer de Hunter, qui croít aux Indes orientales, et dont on extrait le suc cxtractif et solide, connu sous le nom de gomme kino. Mais ici l'astringence dépend du tannin et de l'aci-de gallique, qui forment prcsqu'cn totalitć cette substance. Aussi est-ce un des mćdicamens astringens les plus puissans.

La racine de beaucoup de rubiacées fournit un principe colorant, de nuanccs varićes : tel est le principe colorant rougc de la garance; qui se retrouvc dans l'asperula tinctoria tt quelques autrcs espèces.

Plusieurs genres de cette familie produisent des racines douées d'une vertiı ćmétique : telles sont celles du cephaelis ipccacuanha.Rich, qui donncl ipćca cuanha annćlé; le psychotria emetica. L. ou ipćcacuanha simple et strić; enfin, le richardsoniı brasiliensis. Rich., qui fournit unc des cspèces d’ipécncuanlıa connuc sous le nom-d'ipecacuantua blanc.

La saveur exquise, l'arome du café nc sc retrouvent au méme degré dans les graines d'aucune autre plante de la famillc. Cependant quclques-uncs ont unc grande analogic avec elles sous plus d'un rapport : tclles sont, particulièrement, lc psychotria herbacea, à la Jámaḯuc, et dans nos climats le gre- 
lium aparine, ou grateron, qui ont élé indiqućs comme les succédanés de ce précieux végétal.

CINQUA NTE-HUITIÉME FAMILI.

CA PRIFOLIA CEE ES.-CAPRIFOLIACEAE.

Les caprifoliacées renfcrment des plantes à tịges, quelquefois sarmenteuses ct volubiles, à feuilles opposées, sans stipules.

Le calice est adhérent avec l'ovaire infère : la corolle est monopétale, régulière ou irrćgulière : les étamines, au nombre de quatre ou de cinq. L'ovairc est infère, à unc ou plusieurs loges, surmonté par un disque épigyne. Le style est simple 'on nul; dans le premier cas, il y a un senl stigmate; dan's l'autre il existe trois stigmates.

Le fruit est ordinairement charnu, à une ou plụsieurs graines ou nucules, ct couronné par les dents du calice.

Nous retirons de cette famille les genres à corolle polypétale et à feuilles alternes, pour en former un ordre distinct sous le nom d'Hédéracées.

$I^{\circ}$ Un seul style et un seul stigmate.

\section{CHEVREFEUILLE. - LONICERA.}

Le limbe du calịce est à cinq dents courtes : la corolle est tubuleuse, un peu évạsée ; son limbe est à cinq divisions inćgales et comme bilabié; leș étamines sont au nombre de cinq. Le fruiț est une baie globuleuse à trois loges polyspermès.

Ghevrefeulle commun. Lonicera caprifolium. L. Sṕ. 246. Lamk. Illustr. t. I5o. f. $\mathbf{~ . ~}$

Part. usitées : les fleurs, Nom pharm : Caprifolium.

Sous-arbrisscau grimpant, à tige sarmenteuse et volubile, s'élevant quclquefois à une très-grande kautcur, sur les arbres qui l'environnent. Ses rameaux sont allongés, cylindriques, rougeâtres, glauques. Ses feuilles opposćes, scssiles, obovales, 
arrondies, obtuses, glabres, glaucques en dessous; les supérieures soudées base à base et eonnées.

Les fleur's sont rongeâtres, disposées en ćpis eapitulés à lá sommité des rameaux : elles répandent une odeur suave; leur ealiee, globuleux, est soudé avee l'ovaire infẻre; le limbe offre einq petites dents. Leur corolle est monopétale tubuleuse, irrégulière; tube très-long, eoudé à sa base, évasé à sa partie supérieure; limbe à deux lèvres, la supérieure large plane, à quatre lobes obtus, ineombens, peu profonds; l'inférieure simple, allongée, obtuse, roulée en dessous. Etamines au nombre de einq, saillantes hor's du tube de la eorolle; filets grêles, subulés : anthères allongées, presque linéaires, jaunes; ovaire infère, globuleux, à trois loges qui renferment ehaeune quatre ovales attaehés vers l'angle interne, et disposés sur deux rangs. Le style est très-long, saillant, hors du tube de la eorolle, grêle, terminé par un stigmate évasé, convexe, ver't et glanduleux.

Les fruits sont de petites baies eharnues, suceulentes, d'un rouge elair.

Le eherrefeuille se trouve très-communémenț dans les bois, où ses fleurs répandent l'odeur la plus suave. Il fleurit en mai et juin.

Propriétés et usages. Cet arbuste attire plutôt notre attention par l'éléganee de ses fleurs et leur parfum délieieux, que par ses propriétés médieales. Une légère astringenee qui existe dans ses feuilles, a suggéré à quelques médeeins l'idée de les employer en déeoetion pour préparer des gargarismes détersifs. Ses fleurs sont mueilagineuses, et leur infusion est quelquefois preserite dans le traitement des eatarrhes pulınonaires peu intenses.

$2^{\circ}$ Style nul : trois stigmates.

\section{SUREAU. - SAMBÜUS.}

Limbe ealicinal à einq dents : eorolle réguliẻre et rotaeće, à einq lobes : einq étamines épipétálées. Le fruit est un nnenlaine à trois loges osseuses nu à trois nneules. 
Sureau voir. Sambucus nigra. L. Sp. 385. Blackw.

$$
\text { t. } 15 \text { r.fl. dan. t. } 545 \text {. }
$$

Part. usitée : l'écorce moycnne; les fleurs, les fruits. Non pharm. : Sambucus.

Arbie de moyenne grandeur, à ćcorce grise ct fendilléc, à bois blanc, mou, léger, renfermant un canal médullaire trèsdéveloppć. Feuillcs opposées, imparipinnées, d'un vert foncé, folioles opposées presquc sessiles, ovales, acuminées, un pcu échancrécs en cœur à la base, denticulẻes sur les bords. Fleurs blanches, disposées en cime au sommet des rameaux. Calice très-petit, adhérent par son tubc, qui est turbiné, avec l'ovaire infère : limbe à cinq dents étalées. Corollc monopétale rćgulière, rotacée, étalée, sans tube manifeste, à cinq lobes profonds, ovales et arrondis. Cinq étamines étalćes, plus courtcs que la corolle, alternes avec ses divisions, attachées à sa base intcrne: filets courts; anthères cordiformes. Ovairc adhérent par ses deux tiers inféricurs avec le tube du calice, à trois loges, contenant chacune une seule graine : à son sommet, cct ovaire est surmonté par un tubercule glanduleux et blanchâtre, qui supporte trois stigmates sessiles.

Le fruit est un petit nuculaine noirâtre, arrondi, couronné par les deuts du calice, ct renfermant trois nucules ou petits noyaux.

Le sureau noir croît dans les bois et les haies. Il fleurit en mai, et scs fruits sont parvenus á leur état de maturité en août et septcmbre.

Usages et propricétés. Les feuilles du surcau exhalent unc odeur un peu vircusc; ses fleurs ont unc odeur aromatique, mais peu agréable. Ce sont cllcs quc l'on emploie plus fréqucmment. Elles sont légèrement excitantcs et usitées à l'intćrieur comme diaphorétiques, et à l'extćrieur comme résolutivcs.

On prépare avoc ses fruits une conserve ou rob de sureau, cque l'on administre comme sudorilique à la dose d'un à deux gros, dans les différens cas de syphilis: si l'on auginentc la dosc, si on la porte, par cxcmplc, à quatre ou six gros, il devient purgatif. 
Cettc action purgativc existe égalcment dans l'cnveloppc verte et herbacée de la tige qui sc trouvc sous l'épiderme. Plusieurs médecins anciens, tels que Bocrhaave et Sydenham, l'ont' employée avce succès dans différens cas d'hydropisie. Sa dose est de deux à six gros en décoction dans une pinte d'cau.

On employait autrefois la racinc d'hyeble (sambucus ebulus) comme violemment purgative, proprićtć qui se retrouvc dáns les autres parties de la plante.

\section{Propriétés médicales et usages des Caprifoliacées.}

Deux principes se font remarquer dans les plantes de la famille des caprifoliacées. L'un est astringent et existe particulièrement dans les feuilles de ces végétaux, ainsi qu'on l'observe surtout dans les différentes espćces de chevrefeuille. L'autre, beaucoup plus abondant ct plus actif, peu connu dans sa nature intime, lcur communique une action purgative plus ou moins intense. Ainsi les baies des chevrefeuilles et du sureau sont laxatives, tandis que l'écorce moyenne des jcuncs rameaux de ce dernier sont un violent purgatif. Cette mème propriété existe également dans l'hyéble et surtout dans la racine, que les anciens employaient au traitement des hydropisies passives.

Les fleurs dans les caprifoliacées sont odorantes, mucilagineuses et légèrement diaphorétiques. 
BOTANIQUE MEDIGALE. 
DE L'IMPRIMERIE DE RIGNOUX, IMPRIMEUR DE L'ACADÉMIIE ROXALE DE MÉDECTNK. 


\section{BOTANIQUE MÉDICALE,}

$\mathrm{OU}$

\section{HISTOIRE NATURELLE ET MÉDICALE}

DES MÉDICAMENS, DES POISONS ET DES ALIMENS - TIRÉS D UREG NE VÉGTAL;

\section{Par Achille RICHARD,}

Docteur en Médecine, Agrégé près la Faculté de Mćdecine de Paris; Mémbre adjoint de l'Académie royale de Médccine; Professeur suppléant à la Faculté des Sciences; Membre de la Société Pliilomatique et de la Société d'Histoire Naturelle de Paris; Correspondant de la Société Linnéenne de Bordeaux, de la Société des Curieux de la Nature de Bonn, de Leipsiç, etc.
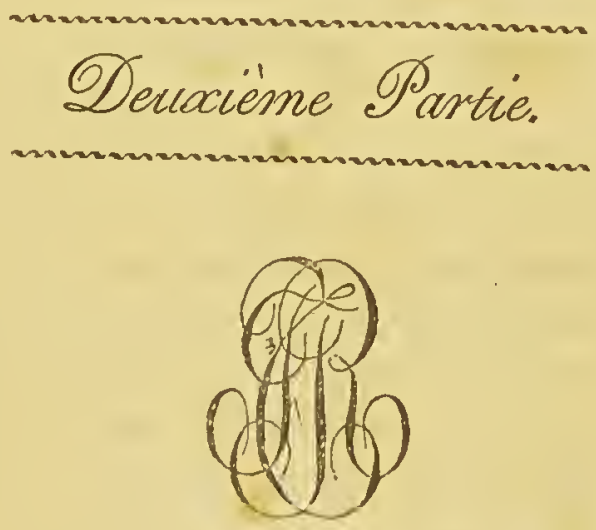

\section{A PARIS,}

\section{CHEZ BÉGET JEUNE,

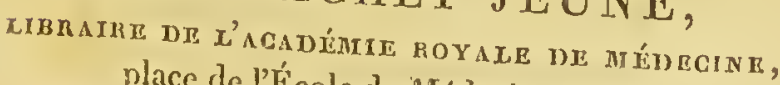 place de l'École de Médecine, n 4 .}

I 823 . 



\title{
BOTANIQUE MÉDIGALE.
}

H UITIEME CLASSE.

\section{POLYPÉTALIE SYMPHYSOGYNIE.}

\author{
CINQUANTE-NEUVIËME FAMILLE.
}

H ÉDÉRACÉES. - HEDERACEAE.

$\mathrm{N}$ ous avons séparé de la famille des Caprifoliacées les genres Hedera et Cornus, qui nous ont paru offrir des différences assez grandes pour former une famille distincte, dont voici les caractères. Ce sont des arbrisseaux ou des arbres, à feuilles ordinairement alternes, dépourvues de stipules; leurs fleurs offrent un calice adhérent, à quatre ou cinq dents; une corolle formée de quatre ou cinq pétales distincts; des étamines en nombre égal aux pétales et alternant avec eux : l'ovaire présente deux ou cinq loges, contenant chacune un seul ovule; il est surmonté d'un disque épigyne glanduleux, d'un style et d'un stigmate simples. Le fruit est charnu, couronné par les dents du calice, qui forment à son sommet une sorte d'ombilic; il renferme deux ou cinq noyaux osseux.

Les fleurs sont souvent disposées en une sorte de sertule ou d'ombelle simple.

Cctte famille se distingue surtout des Caprifoliacées, par sa corolle polypétale; ses étamines insérées sur l'ovaire, ses feuilles alternes, et ses fleurs dépourvues cie bractées; $2^{\circ}$ des Araliacées par son style simple et son fruit qui renferme de deux à cinq noyaux. 


\section{LIERRE. - HEDERA. L. J.}

Limbe du calicc à cinq dents : corolle de cinq pétales sessiles : cinc étamines épigynes : style ct stigmate simplcs: Le fruit est charnu, ombiliqué et conlient cinq nucules.

Lierre grimpant. Hedera Helix. L. Sp. 29a. Bull. t. i 33.

C'est un arbustc sarmenteux et grimpant, dont la tigc est' ligneuse, et peut asquérir lc volume du bras; il sattachc aux arbres ou aux murailles sur lesquels il croît, al moyen dc suçoirs ou petites raçines qui naissent de la tige et de ses ramifications. Ses feuilles sont alternes, pétiolées, persistantes $\vdots$ cclles des jeunes branches sont irrégulièrement ovales, aiguës, entières, Inisantes en dessus, d'un vert pâle en dessous; celles qui occupent la partie inférieure des tiges sont profondément lobées; leurs lobes, dont le nombrc, varie de trois à cinq, sont aigus et entier's.

Les fleurs sont verdâtres, pćdicellées, et forment à la partie supérieure des rameaux, des corymbes presque globuleux, dont les fleurs sont très-serrées : le calice est velu, à cinci denls courtes et écartées; la corolle est formce de cinq pétalcs à base large et tronçuée, ovales, aigus, d'abord rapprochićs cn cône, puis étalés et un peu réflćchis. Les cinq étamines, dont les filets sont courts, ont les anlhèrcs ovoïles, subcordiformes, un peu échancrées aux deux cxtrémités, et attachées au filet par le milieu de leur face postćrieure.

Les fruits sont globuleux, charnus, pisiformes, couronués par les cinq dents du calice, ils renferment cinq uucules.

Le lierre croît dans les bois ombragés, sur les vieux murs, les édifices en ruines. Il flcurit en septembre; ses fruits sont mûrs en décembre et janvier.

Propriétés médicales el usages. Les fruits du lierre, de même que ceux du sureau, possćdent une propriété purgative assez manifeste pour que plusieurs auteurs aient cri devoir en prescrire l'usage, dans l'lyydropisic, l'ictèrc, etc. Mais comme nous possćdons un grand nombre d'autrcs médicamens pnrgatifs dont ḷ'action cst plus sûre ct mieux connuc, on a banni ces fruits de la pratique moderne. Tout le monde 
connait l'usage que l'on fait des feuilles de lierre dans le pansement des cantères, des vésicatoires; elles n'exercent aucune aetion médicale sur ces exutoires, à la surfaee desquels elles entretiennent seulcment une fraîcherr agréable.

Quant à la résine de lierre ou gornme de lierre, on la retire en pratiquant dans les pays méridionaux des incisions profondes aux gros troncs du lierre; elle cst grisâtre et terne. On ne l'emploie plus aujourd'kui que pour la préparation des vernis.

Les fruits dans le genre corxorilLER, diffèrent beaucoup de ceux du lierre par leur saveur et leurs propriétés; ils sont géméralement âpres et astringens. Mais on ne les mange guère que lorsqu'ils se sont ramollis par un commencement de fermentation, ainsi qu'on l'observe pour les nèfles, les sorbes, etc. On mange, surtout en France, les fruits du cornus mas, qui croit eommunément dans les haies et les bois. D'un autre côté, l'écorce de ces arbres est très-astringente; et dans. l' $\Lambda$ mérique septentrionale on emploie celle du cornus florida et cornus sericea, comme tonique, fébrifuge et propre à remplacer le quinquina.

SOIX $\Lambda$ NTI E M FAMTLLE.

\section{ARALIACEES. - ARALIACEAE.}

Cette famille est intermédiaire entre les Hédéracées et les Ombellifères, dont elle se rapproehe singulièrement. Elle se compose de végétaùx herbacés ou ligneux, dunt les feuilles sont généralement décomposées en un grand nombre de folioles, et dont le pétiole est dilaté et membraneux à sa base: les fleurs, qui sont petites et de peu d'apparenee, sont disposées en ombelles simples, composées ou panieulées, environnées à leur base de folioles formant un involuere, leur calice adhérant avec l'ovaire infère, a son limbe entier ou denté; les pétales sont au nombre de cinq ou de six, régulicrs et insérés au pourtour du sommet de l'ovaire; les étamines sont en nombre égal, plus rarement en nombre double des 
pétales. L'ovaire offre rarement deux loges; le plus souvent il en présente cinq ou six, quelquefois dix ou douze, "contenant chacune un seul ovule. Le nombre des styles et des stigmates est égal à celui des loges de l'ovaire. Le fruit est ordinairement une baie à deux, cinq, ou un plus grand nombre de loges, couronnée par le limbe calicinal.

Les Araliacées ont les plus grands rapports avec les Ombellifères, dont elles diffèrent seulement par le nombre des loges et des styles, qui est généralement audelà de deux. Le genre Panax, qui n'a que deux loges ou deux styles; se distingue des vraies Ombellifères par son fruit charnu, qui ne se sépare point en deux à l'époque de sa maturité.

\section{GINSENG. $-P A N A X . \mathrm{L} . \mathrm{J}$.}

Limbc du calice à cinq petites dents; corolle de cinq pćtales planes; cinq étamines; deüx styles, baie à deux loges, et à deux graines.

Les espèccs de ce genre sont herbacćes; leur racine est pivotante; leur tige simple, porte trois feuilles verticillées, composées; lcurs Aleurs forment une ombelle simple ou sertule, cnvironnée d'un involucre polyphylle.

Ginseng a cine fedilles. Panax quinquefolium. Lamk. Encyc.

(Part. usit. : la racine. Nom pharm. : Ginseng ou Ginzing.

Le ginseng est une de ccs plantes merveillcuses auxquelles l'ignorance ct la crédulitć ont accordé des propriétés exiraordinaires, que l'expérience n'a pas justifićes. Sa racine, que l'on peut comparer, pour la forme et la grosseur, à cellc du panais sauvagé, est perpendiculaire, ordinaircment simplc, blanche, un peu striéc transversalement, Il s'en élève clıaquc annéc uue. tigc, simple, grêlc, cylindrique, d'un pied et plus dc hautenr, glabre et lissc, qui porte vers sa partie supéricurc trois grandes feuilles composćcs, vcrticillćes. Lcur pétiolc est lon ̧̂̀ et di- 
laté à sa base, et à son sommet on aperçoit cinq folioles diver'gentes, prescrue sessiles, ovales, dentées en scie.

Les fleurs sont blanches et forment un sertule au sommet d'un pédoneule commun qui nait du eentre des trois feuilles, et qui est la continuation de la véritable tige. A ees fleurs, dont plusieurs sont unâles et stériles, suecèdent de petites baies globuleuses, un peu eomprìmées, à deux loges, qui ehaẻune eontiennent une seule graine.

Cette plante eroit en Chine, au Japon, dans la grande Tartarie. On la trouve également dans différentes parties de l'Amérique septentrionale, telles que le Canada, la Virginie, la Pensylvanie, ete., ete. $₹$

Usages et propriétés. Les Japonais et les Chinois, auxquels nous devons la première eonnaissance de la raeine de Gin-. seng, la regardent eomme le médicament. le plus préeieux et le plus utile, que puisse fournir le règne végétal. Ils la considèrent eomme le tonique le plus puissant et le plus propre à relever les forees abattues par les fatigues, ou les excès dans les plaisirs de l'amour. Introduit en Europe vers le eommencement du dix-septième sièele, le ginseng, préeédé en quelque sorte par sa haute réputation, s'y est vendu au poids de l'or. Pendant long-temps, en effet, leś médecins. de l'Europe ont partagé a veuglém ent l'enthousiasme des Indiens et des Chinois, et ee remède a trouvé en Europe autant de dupes et de prôneurs que dans sa patrie. Mais l'expérienee clinique, qui est le' véritable ereuset où viennent s'essayer les propriétés attribućes aux substances médieamenteuses, n'a pas justifié les. ćloges prodigués au ginseng, qui aujourd'hui est à peine employé dans la. pratique des inédeeins modernes.

Telle que le commeree nous lit présente, la raeine de ginseng a subi plusieurs préparations. Après l'avoir bien lavée eldégagée des fibrilles qui naissent de sa surfaee, on la fait bonillir pendant quelques minutes, ensuite ou l'enveloppe de linge fin et on la fait séeher. C'est alors qu'on la plaee dans des boites de plomb, que l'on environne de clraux, afin de bien préserver eette racine des insectes qui pourraient l'attaquer. Ellc est dure jaunâtre, d'une consistance presquc eornée. Son odeur est faible; sa saveur, d'abord douce et sucréc, est ensuite aromin- 
tique. Elle parait composée en grandc partie de gomme et d'amidou. Laraeine de ginseng, quc l'on a tour à tour regardée eomme un spécifique eontre les maladies les plus graves, cst plaećc parmi les mćdieamens qui joaissent de la proprlété d'augmenter l'exeitabilité organique, de rendre le cours du sang plus rapide, l'excrétion de la sueur plus abondante, ete. Mais"comme nous ne manquons pas de nédicamens indigèncs propres $\grave{x}$ remplir ees divcrses indications, on fait bien rarement usage de cette racine exotique. C'était ordinairement en poudre, à la dose d'un à deux gros, ou en infusion aqueuse, à la dose d'une demie-once pour une livre d'eau bouillante que l'on adminis trait le ginseng.

La famille des Araliaeées, considérée sous le rapport de ses propriétés médieales, offre une très-grande analogie avce les ombellifères. Plusieurs espèces du genre aralie laissent suintcr un suc résineux, analogue à celui de beaueoup d'ombellifères; et leurs racines sont généralement, eomme eelles de ectte dernicre famille, d'une saveur douce et aromatique.

SOIXANTB-UNIEMT FAMILLE.

\section{OMBELLIFERES。-UMBELLIFERAE。}

Les ombellifères constituent un groupe extrêmement naturel de végétaux, dont les caraetèras sont très-tranchés et faeiles à retenir. Leur tige est lierbaeée, fistuleuse, rarementfruteseente, portant des feuilles alternes engaînantes, ordinairenıent déeoupées plus ou moins prófondémen:, ou décomposées en folioles, dont le nombre et la figure varient à l'infini. Les fleurs, qui sout très-petites, de eouleur jaune ou blanche, forment des ombelles simples ou composées, ou des eapitules plus ou moins arrondis; à la base de ces assomblages de fleurs on trouve souvent plusieurs petites folioles dispoposées symétriquement, qui constituent un involucre ou un involucelle, suivant qu'elles environnent la base des ombelles ou eelle des ombellules. 
Chaque fleur se compose d'un ovaire infère, à deux loges renfermant chacune un seul ovulc; eet ovaire est surmonté d'un disque épigyne, formant dcux mamelons, qui se confondent avec la base des deux stýles', lesquels sont terminés chacun par un stigmate trèspetit : le limbe du calice cst quelqucfois nul, ól à einq dents; la corolle est formée de einq pétales, avec lesquels alternent cinq étamines épigynes.

Lc fruit cst un diakene, de forme très-variée, se partageant à l'époquc de sa maturité en deux eoques closes ou akienes, réunis par un axe ou columelle centrale, souvent bipartible. La grainc contient un embiryon endospermique intraire.

Cctte fa millc sc distinghe des Araliacées par son ovaire. constamment à dcux logcs et surmonté de deux styles, par son fruit qui n'est jamais eharnu; tandis que dans ces dernic̀res l'ovairc est à cinq loges, surmonté de cinq stigmates, ct lc fruit est charnu lorsqu'il n'offie que deux loges.

Jusqu'à présent, la plupart des auteurs systćmatiques avaient employé la présence ou l'absence de l'involucre et des involucelles qui environnent chaquc groupc de fleurs, comme l'un des principaux caraetères, pour distinguer lcs genres ct établir entre eux quelques divisions. Mais eet organe offrc trop de variations pour que les caractères qu'il peut fournir soient de quclque importance. Nous avons prćféré, à l'exemple du eélèbre protesseur Sprengel, auquel on doit d'importans travaux sur cette famille, en diviser les genres en six seetions, dont les caractères sont spécialement tirés de la forme du fruit, qui en est l'organe le plus important. Mais nous n'avons pu adopter en entier les nombreux changcmens quo ce botaniste, et avant lui Hoffmann, ont introcluit dans la cireonscription tles genres. Il nous a paru plus utile dans cet ouvrage, uniquement destiné. 
à ceux qui se livrent à l'étude de la médecine et de la pharmacio, de donner une description exacte de la plante dont nous voulions faire connaître les propriétés. Cependant personne n'apprécie plus que nous l'importance du travail de ces deux savans.

PREMIE்E SECTION.

Pimpinelétes. Fruits ovoüdes, allongés, ordinairement striés, ou offrant des cốtes.

\section{BOUGAGE. - PIMPINELLA. L. J.}

Point d'involucre ni d'involucclles; pétales presque égaux, cordiformes; fruits ovoïdes, oblongs striés, glabres ou pubescens. Fleurs blanches.

Boucagb anis. Pimpinella anisum. L. Sp. 379. Blackw. t. 374 .

Part. usit. : les fruits. Nom pharm. : Anisum.

L'anis est une plantc annuelle, dont la racine est blanche, fusiforme, un peu rameuse. Sa tige est dressée, haute d'un pied et plus, cylindrique, rameuse, pubescente. Les feuilles radicales sont pétiolées, les unes subreniformes, arrondies, incisées, ou simplement dentées. Les autres trifoliolées, à folioles anguleuses, incisćes et dentées; les caulinaires sont découpées en lanières d'autant plus étroites, qu'elles sont plus voisincs du sommet.

Les fleurs sont blanches et petites; les ombelles sont terminales, dépourvues d'involucre et d'involucelles. Les pétales sont égaux, cordiformes, à sommet rabattu en dessus. Les ćtamines sont plus longues que les pétales; les filets sont blancs et subulés; les anthères arrondies, globuleuses. Les deux styles sont très-courts. Les fruits sont ovoïdes, striés longitudinalement, légèrement pubescens et blanchâtres.

L'anis cst originaire du Lcvant, de l'Égyptc et de l'Italie. On le cultive en grand dans certaines provinces de la France, particulièrement aux cavirons de Tours. 
Propriétés et usages. Ce sont les fruits dont on fait usage. Ils ont une saveur sucrée, aromatique, chaude, très-agréable. Ils sont stimulans, et employés principalement comne propres à réveiller les forces de l'estomae, et à expulser les gaz qui se développent dans l'intéricur du canal intestinal. Leur dose est de deux à trois pincées, en infusion dans quatre onces d'eau, ou de vin. On emploie encore l'anis comme condiment, pour faciliter la digestion de certains alimens, principalement des légumes aqueux, tels que les choux, les navets, etc.

L'on retire des fruits d'anis une huile volatile, très-excitante, dont la dose est de quelques gouttes. Leurs graines.renferment aussi une très-graude quantité d'huile grasse. On mélange assez souvent l'anis dans les apozèmes et potions purgatives. Leur saveur aromatique, et leur odeur agréable masquent celles des autres ingrédiens, qui entrent dans ces médicamens. Les confiseurs font encore avee ces fruits de petites dragées, qui sont stomachiques et carminatives.

Bougage saxifrage. Pimpinella saxifraga. L. Sp. 378. Blackw. t. 472. Jacq. Fl. austr. t. 395 .

Part. usit. : la racine, les fruits. Non pharm. : Pimpinella minor, s. nostras. Noms vulg. : Petit boucage, Persil de bouc.

Racine vivace, perpendiculaire, blanche, simple; tige dressée, cylindrique, striée, pubescente, un peu rameuse. Feuilles radicales, pétiolées, imparipennées; folioles, sessiles, subcordiformes, obtuses, dentées, glabres; les caulinaires ont les folioles plus allongées et ineisées, celles de la partie supérieure sont entières, presque linéaires.

Fleurs blanches en ombelles nues, ainsi que les ombellules, composées de douze à quinze rayons. Les pétales sont égaux, cordiformes, à sommet un peu rabattu en dessus. Le fruit est ovoïde, lisse, glabre, un peu comprimé et strié.

Cette espèce est très-commune sur les pelouses, le long des chemins, dans les bois; elle fleurit à la fun de l'étć. Ұf

propriétés et usages. Sa raeine cst un peuâcre et diurétique. 
On l'a misc en usage comme masticatoire. Ses fruits sont odorans ct légèrement excitans. Mais on fait rarcment usage de ecttc plante.

\section{CARVI.-CARUM. L. J.}

Involuere d'un à trois folioles; point d'involueelles; pétales égaux, subcordiformes; fruits ovoïdes et comme prismatiques, offrant trois eôtes sur chaqque moitié. Fleurs blanchcs.

Canvi opficinat. Carum carvi. L. Sp. 378 . Blackw. t. 529 . Fl. austr. t. 393 .

Part. usit. : les fruits. Nom pharm. : Carvi.

Sa racine est bisannuelle, allongée, charnue, blanchâtre, un peu rameuse, de la grosseur et de la longueur du doigt; clle a nne odeur à peu près analogue à eelle de la carotte. Sa tige est dressée, haute d'un à dcux pieds, eylindrique, glabre, ainsi que toute la plante; ramense vers sa partie supéricnrc. Les feuilles sont grandes, bipinnatifides, les premières divisions sont eomme vertieillées autour du pétiole commun, à segmens profondément incisés, et partagés en lanières étroites, aeuminécs. Ces feuilles sont portées sur des pétioles tiès-longs; ceux dcs feuilles radieales sont ereusés en forme dc gouttières et chlargis à leur base.

Les flenrs sont blanehes, disposées en oinbelles au sommet des rameanx. A la base de chaque ombelle, qui se composc de huit à dix rayons est un involucre formé de trois à quatre petites folioles linéaires. Il n'en existe quelqquefois qu'une seule. Il n'y a pas d'involucelles à la base des ombellules.

Les fruits sont ovoïdes, allongés et strićs.

Lc earvi habite les prairies et les lieux montueux. 4

Proprictés et usages. La racine et surtont les fruits de eeltc plante sont très-aromatiques. On les emploie comme exeitans du système digestif, on en fait également usage comme carmiuntifs.

On preserit ordinairement les fruits à la dose d'un gros $\mathrm{cn}$ infusion, dans dcux livres d'eau, ou de vin; leur poudre sc donne à la dóge d'un serupule. 
On en retirc également une lıuile volatile, avec laquelle on fait des embrocations sur l'abdomen, en la mélangeant ạvee une certain'e quantité d'huile d'olives ou d'annandes douees, dans les cas de coliques.

Dans quelques partics du nord, on emploie les fruits de carví comme condiment, cn les faisant cntrer dans les légumes, qu'ils rendeut plus faciles à digćrer.

OENANTHE. - OENANTHE. Lamkc. D. C.

Involucre nul,"ou composé de quelques folioles; involucelles polyphylles; pćtalcs inćgaux, cordiformes, ceux de la circonfércnce plus grands; fruits prismatiques striés, couronnés par les dents du ealice et les styles. Fleurs blanches.

Ce genre renferme aussi lc genre Phellandrium de Linné.

OEnanthe safranéE. OEnanthe crocata. L. Sp. 565. - Orf. Méd. lég. t. 13.

C'est dans les près humides, et sur le bord des fossés, que croît cette ombcllifère, dont il importe beaucoup de bien connaître les caractères, puisqu'elle est une des plus vénćneuses de la famille. Cinq ou six tubercules allongés, fusiformes, rapprochés en faisceau, eomposent sa racine, d'où naît une tige dresséc, hautc de deux à trois pieds, cylindriquc, cannclće, creuse intérieurement, divisée en ramealx dans sa partie supérieure; scs feuilles inférieures sont grandes, pétiolées, cngainantes à leur basc, bipinnées ou tripinnées. Ses folioles, qui sont d'un vert foncé et glabres, sont subcordiformes, incisćes profondémentà lcur sommet.

Les fleurs sont blanches, petites, très-rapprochćes. Les pćtales sont cordiformes, un pcu inégaux; les fruits sont allongćs, striés, couronnés par cinq petites dents très-aiguës, ct par les deux styles.

On trouve cette plante cn fleur, anx inois de Juin ct dc Juillet, dans les cnvirons de Paris, et plusicurs autres partics de la France. $x$

Propriétés et usages. Le suc laitncux, qui s'écoule des différentes partics de cette plante, lorsgu'on les cntame, est un 
indice certain de ses propriétés délétères. En effet, il est peu d'espèces plus dangereuses parmi toutes les ombellifères. Un grand nombre d'auteurs ont relaté les accidens, qui suivent l'emploi de l'œnanthe safranée, lorsqu'on a mćconnu son action pernicieuse. En effet, il est souvent arrivé quc des individus ont mangé la racine, ou les feuilles de celle plantc, l'ayant confondue avec quelque autre ombellifère alimentaire. On trouve dans le Journal de Pharmacie (avril r822) une observation curieuse d'empoisonnement, causé par la racinc de cette plante. Trois matelots mangèrcnt, dans les environs de Lorient, des racines de l'œnanthe safranće, qu'ils avaient proba.. blement confondues avec celles du bunium bulboccstanum, qui en effet sont douces et bonnes à manger. Peu de temps après, ils éprouvèrent de l'inflammation dans la bouche et le gosier, une douleur très-vive à l'épigastre. Ils burent abondamment de l'eau d'une fontaine, qui augmenta tous les accidens, en facilitant l'absorption du suc orangé de cette plante. L'un des trois, qui en avait mangé en plus grande quantité que les autres, mourut dans des angoisses inexprimables, quatre heures aprc̀s ce funeste repas, malgré l'émétique et les antispasmodiques, qui lui furent administrés immédiatement. Les deux autres se rétablirent au bout d'un laps de temps assez long.

Cet exemple, et beaucoup d'autres du même genre qu'on pourrait facilement y ajouter, prouvent le danger attaché à l'usage de ce pernicieux végétal. M. Godefroy, auteur de la notiee, à laquelle nous avons emprunté cette observation, dit que daus le département de la Loire-Inférieure la racine de cette plante rapée cst un remçde vulgaire contre les hémorrhoïdes. Ce remède nous parait beaucoup plus dangereux qu'utile.

OEnanthe phellandre. OEnanthe phellandrizm. D. C. F]. fr.

Phellandrium aquaticum. L. Sp. 366. Bull. t. I 4'7.

Noms vul. : Fenouil d'eau; Ciguë aquatique; Phellandre; Millefcuille aquatique.

Sa racine cst bisamnuclle, grosse, allowgéc, Llanchâtre, pi- 
votante, terminée par des fibrilles nombreuses, surmontće d'une tiğe dressée, eylindrique, grosse, rameuse, creuse intérieurement, noueuse, striée et donnant naissance, de ses nœuds inférieurs, à des fibres radicales qui partent annulairement; cette tige s'élève à quatre et mème à six pieds. Les feuilles sont décomposées, pinnées, très-grandes, formées d'un nombre considérable de folioles profondément pinnatifides, dont les lobes sont entier's : elles sont glabres et d'un vert foncé.

Les fleurs sont blanches, en ombelles terminales; sans involucre; les involucelles sont composés de six à huit folioles étalées, plus courtes que les pédoneules.

Le phellandre aquatique croít très-abondamment dans les marres et sur le bord des étangs èt des ruisseaux, aux environs de Paris. Il fleurit en juillet.

Propriétés et usages. Les feuilles, quand on les froisse entre les doigts, exhalent une odeur qui n'est point désagréable et a quelque analogie avec celle du cerfeuil. Cependant le phellandre aquatique est une plante dangereuse, ou du moins fort suspecte. Les fruits ont une odeur et une saveur aromatiques, assez semblables à eelles du cerfeuil.

On fait en Allemagne beaucoup plus usage du phellandre que chez nous. Plusieurs auteurs, entre autres Kramer et surtout Enrstringius, regardent ses graines comme un des plus puissans fébrifuges, puisque ce dernier les préfère au quinquina dans le traitement des fièvres intermittentes de tous les types. Il les preserivait à la dose d'un, deux et même quatre gros avant le paroxysme, et continuait de donner la moitić de cette dose pendant quelque temps, dans les jours d'apyrexie.

Quelques autres praticiens du nord de l'Europe les ont plus récemment préeonisées comme un remède infaillible contre la consomption tubereuleuse, la phthisie pulmonaire. Mais on sait aujourd'hui à quoi s'en tenir sur ces prétendus spécifiques.

On a également recommandé l'application des feuilles fraîches et pilćes sur les plaies, les ulcères et les contusions. 


\section{AGHE. - $A$ PIUM. L. J.}

Involucre et involucellcs composés de plusicurs foliolcs, on nuuls; pétalcs terminés à leur sommct pár une petite pointe xecourbéc cn dessus. Fruits ovoïdcs, marqqués de stries longitudinales. Fleur's d'un jaune pâle.

Ache persil. Apium petroselinum. L. Sp. 379. Blackw. t. I72.

Part. usit. : la racine, les feuilles, les fruits. Nom pharm. : P'etroselinum.

D'une racinc blanche, conique, un peu rameuse, grosse eomme le petit doigt, s'ćlc̀ve unc tige cylindrique, simple inférieurement, glabre, striće longitudinalement, non glauque, lrautc d'un pied et demi à deux pieds, un pen fistuleuse intérieurement. Les feuillcs sont décomposces, les pétioles et ses ramifications sont canaliculées, ćlargis à la base; les folioles sont. profondément ineisées en lobes aiggus, elles sont glâbres et mon luisantes.

Les fleurs sont petites, jaunâtres. Les ombelles se composent de quinze à seize rayons. L'involucre est formé de six à huit foliolcs linćaires simples, plus courtes que les rayons. $\mathrm{A}$ la base de chaque ombellulc se trouvent huit ou dix folioles linéaircs. Les fruils sont ovoïdes, un peu allongés, marqués de lignes longiludinales à peine visiblcs.

Le persil est une plante annnuelle ou bisannuelle, qui croit dans les licux un peu stérilcs. On lc cultive dans les jardins potagers, où il fleurit aux mois de juillct et août.

Propriétés médicales et usages. Il est cxtrémencnt important de ne pas confondre le persil avac la petitc ciguë, qui a avec Ini beaucoup de resscinblance, surtont quand elle est seulcment en feuilles. Cette méprise pourrait causer des accidens extrêmement graves, puisque la pelite ciguë est une des ombellifères les plus vénéncuses. En parlant de cettc dernièrc plante uous indiquerons les caractères qui la distingucnt du persil.

La racine de persil a une odeur et une saveur faiblement 
aromatiques. On la prescrit quelquefois comme diurétique. Mais c'est surtout à eauso de ses feuilles, que eettc plante est eultivée si généralement dans les jardins. En effet, on les emploie très-fréçuemment, comme eondiment, dans les diverses préparations eulinaires.

Ache odorantw. Apium graveolens. L. Sp. 379. Blackw. t. 443 .

Part. usit. : La racine, les feuilles. Nom pharm. : Apium, apium dulce. Noms vulg̣. : Ache, Céleri.

Raeine bisannuelle, eourte, piyotante, portant une tige herbaeée, ramcuse, dresscee, eylindrique, sillonnée, glabre. Feuilles inférieures ailées, à einq ou sept folioles pétiolées, portées sur un pétiole eommun fort long, eanalieulé, glabre. Ces folioles sont eomme triangulaires à trois lobes inégaux, glabres, profondément dentés: les supérieures également ailées, presque sessiles, à folioles plus petites, souvent eunéiformes et sessiles.

Fleurs disposées en ombelles nombreuses; les supérieures partant des parties latérales des inférieures, sans involuere ni involueelle; rayons ou pédoneules inćgaux; pédieelles unifloraux très-eourts.

Pétales ovales, arrondis, acuminés.

Ovaire infère, ovoïde, globuleux, offrant plu'sieurs eôtes saillantes sur ses faees, couronné par un disque épigyne blanchâtre, à deux lobes.

Diakène globuleux, ovoïde, un peu eomprimé d'avant cn arrière, offrant trois eôtes saillantes et régulières sur chaeune des deux portions dont il est composé; se rompant naturellement par la maturité en deux akènes qui laissent entre eux une eolumelle solide.

Cette plante eroit en Franee dans les marais et sur les bords des ruisseaux,

Propriétés et usages. Dans l'état sauvage, eette cspèee porte le nom spéeial d'ache : on l'appelle céleri quand elle est cultivée.

Toule la plante a une odcur aromatique, une saveur pi- 
quantc : la racine d'ache était pour les anciens une des cinq racines apéritives majeures. Elle est diurétique. On l'administre en infusion à la dose de demi-once à une once.

Quant au céleri, il est très-employé comme aliment. On le mange ordinairement cru. Il est légèrement stimulant et antiscorbutique. Il y en a une variété dans laquelle la racine acquiert unc grosseur très-considćrable, et qui porte le nom de céleri-rave; on la cultive surtout dans le nord, et on la mange cuite et apprêtée de différentes manières.

\section{MEUM. - $M E U M$. Tournef. Rich.}

Involucre et involucelles polyphylles; pétales cordiformes égaux; fruits ovoïdes allongés, marqués de trois côtes saillantes sur chacune de leurs moitiés. Fleurs blanches.

Meum officinat. Meum vulgare. Rich. cat. hort. par. Blackw. t. 525. AEthusa meum. L. Syst. vég. Athamanta meum. L. Sp. 353.

Racine vivace, allongće, rameuse, brunâtre à l'extérieur, d'une odeur et d'un goût aromatiques.

- Tige herbacée, dressée, cylindrique, rameuse dans sa partie supérieure, striće longitudinalement, glabre, ainsi que toutes les autres parties de la plante, haute d'environ un à deux pieds.

Feuilles grandes, multipinnatifides, à segmens linéaires, subulés, aigus, courts, semblables à celles du fenouíl; les radicales sont pétiolées; les caulinaires presque sessiles. Froissées entre les doigts, elles exhalent une odeur de céleri.

Fleurs blanches, disposées en ombclles à l'extrémité des ramifications de la tige. Les ombelles sont composées de douzc à vingt rayons; à leur base se voit un involucre formé de cinq à sept foliolcs étroites, linćaires, souvent fendues à leur sommet. Chaque ombellule a aussi un involucelle dc dix à douze folioles linéaires, aiguës. Des trois ou quatre ombellcs qué porte chaque tige, cclle du milieu seule est fertile; les autres sont mâles et stériles par avortemcnt du pistil. 


\section{OMBLLLFIRES.}

Les pétales sont étalés, obovales, acuminés, leur sominet. cst rabattu en dedans.

Le fruit est ovoüde, un peu comprimć d'avant en arricere, marqués sur chacune de ses partics latérales đle trois côies saillantes. Le meum croît dans les prés des montagnes, dans les Vosges les $\Lambda$ lpes, les Pyrénées, elc. $₹$

Proprićtés et usages. La racine du meum est aromalique, ct légèrement excitante. On l'employait jadis comnne diurétique et expectorantc. Très-peu usitée de nos jours, elle entre comme ingrédient daus la thériaque et quclques autres préparalions officinales très-compliquées.

\section{ANETH. - ANETHUM. L. J.}

Point d'involucre ni d'involucelles; pćtales' roulés; fruits allongés, un peu comprimés sur'les bords, et profondément striés; flcurs jaunes.

Aneth feñour.. Anethum foeniculum. L. Sp. 377. Blackw.

$$
\text { t. } 288 \text {. }
$$

Part. usit. :les fruits, la racine. Nom pharm. : Foniculum dulce.

Sa racine est vivace, allongée, de la grosseur du doigl; ses liges sont hautes de quatre à einq pieds, cylindriques, rameuses, lisses, trćs-glauques. Ses feuilles engainanles et membraneuses à leur base, sont décomposées en un grand nombre de segmens subulés et capillaires.

Les fleurs sont jaunes; les ombelles, composées d'une douzaine de rayons sont, ainsi que les ombellules, dépourvues, d'involucre èt d'involucelles. Les cinq pétales égaux entré eux, sont roulés cri dessus. Les étaminges sont étalées, plus longues que la corolle. Le fruit est glabre, ovoüde, strić longitudinalement.

Le fenouil doux habite les contrées chaudes de l'Europe. On lc trouve en France, dans les provinces inéridionales. 千

Propriétés el usages. Le fenouil repand une odcur äromatique, agríable et très-prononcéc. Sa saveur est sucrée et un per âcre. 
Sa raeine cst une des einq grandes racines apéritives : on l'cmploie le plins souvent infusée, à la dose de deux ou trois gros, dans une ehopine d'eau bouillante.

Ses fruits sont la partie la plus usitéc et la plus aetive. Les aneiens les rangeaient parmi les semences chaudes majeures. Ils sont très-excitans, et peuvent être employés avee avanıge toutes les fois qu'il s'agit de stimuler les différens appareils de l'ćconomie animale. On en retire une huile cssentielle que l'on preserit à la dose de cinq à six gouttes.

Le fenouil entre dans un grand nombre de préparations, dont les principales sont : la thériaque, le sirop d'Armoise, le sirop des cinq racines apéritives, etc.

Aneth odorant. Anethum graveolens. L. Sp. 377 . Blackw. t. 545 .

Part. usit. : les fruits. Nom pharm. : Anethum.

Plante annuelle, dont la tige, haute de deux ou trois pieds, est cylindrique, pelu rameuse, glabre, striće, glauque, creluse intérieurement. Ses feuilles sont embrassantes, déeomposées en segmens linéaires subulés, très-nombreux, souvent bifurqués à leur sommet. Les flenrs sont jaunes et petites. Les ombelles sont terminales, déponrvues d'involuere et d'involucelles. Les pétales sont égaux, petits, roulés en dedans. Les einq étamines sont saillantes cntre les pétales, et plus longues qu'eux. Les fruits sont allongés, un peu eomprimés, et offrent cinq petites eôtes longitudinales, sur ehacune de leurs dcux moitiés latćrales.

Cette plante, qui porte les noms d'anet ou aneth, de fcnouil puant, croît dans les moissons des provinees méridionales de la Franee, où elle flcurit vers la fin de l'été. $\odot$

Propriétćs et usages. Ses propriétés et ses usages sont les mêmes que ccux dı fenouil doux. Mais on l'emploie moins fréquemment, parce que sa savcur ct son odeur sont moins agréables. 
CUMIN. - CUMINUM. L. J.

Involucre et involucelles composés d'uñ petit nombre de folioles; pétales égaux, un peu échancrćs ct cordiformes; fruils ellipsoïdes, striés. Fleurs blanches ou purpurines.

Cumin officinal. Cuminum cyminum. L. Sp. 565.

Part. usit. : les fruits. Nom pharm. : Cuminum.

C'est une plante annuelle, dont la tige ramcuse et comme dichotome s'ćlève à un pied et plus; elle est glabre dans sá partie inférieure, et légèrement vịclue supęrieurement. Sés feuilles sont glabres, biternées, composćes de folioles ovalics, lancéolées, découpées en lanic̀res étroites et presque capillaïres. Les fleurs sont disposées en ounbelles terminales coniposćes d'un petit nombre de'rayons. 'L'involucre et les involucellcs sont formés de trois 'ou quatre folióles linćaires. 'Lës pétalcs sont tantôt blancs, tarintôt rougeâtres, ế lcs fruitśs sont quelquefois velus, mais plùs souvent glabres.

Le cumin est originaire d'Orient. Il croit naturellement en Égypte, en Éthiopie. On le cultive däns les jardins.

Propriétes et usages. Les semcnces du cumin ont unc savcur aromatique et agréable. Nous ne dirons rien de leurs propriétés 'médicales et de Icur emploi dans la ihẻrapeutique. En effet, elles ont un mode daction entièrcment semblable à celui de l'anis, du fenouil ct des autres ómbellifères aromatiques", c'est-à - dire qu'elles sont stimulautes, emménagognes, carminatives, etc. En Allemagne on mélange assez souvent. les graines de cumin dans la pâte avec laquelle on prépaŕc le pain, et il parait que c'est avec ses fruits que l'on aromatise les fro-
magcs en Hollandc.

DEUXI ¿̇ME SECTION.

Cicutariées. Fruils globuleux ou didymes, lisses ou offrant les côtes sirriples ou crénelées. Pétales cordiformes. Fleurs

CORIANDRE. - CORIANDRUM. L. J.

Point d'involucre; involucellcs de plusicurs folioles; pćtales 
de l'extéricur plus grands, bifilcs ; fruits globulcux, surmontés par cinq dents inégalcs. Flcurs blanches.

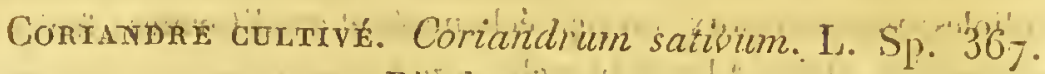
Bläkw.'t.' I 76 .

Part. usil. : les fruits. Nom pharm. : Coriandrum.

Racine annuelle fusiforme, blanche, surmantée d'une tige dressce, cylindriquc, glabre, commc noueuse, un peu ramęuse f feuilles radicales presque cutières, ou incisées et cunćiformes; les caulinaires inféricures bipinnatifides, à dćeoupurcs laciniécs; lcs supéricures à:segmens très-étroits, linéaires, écartés.

'leurs blanches rosâtres ${ }_{2:}$ disposécs en ombelle, composće d'environ cinc à six rayons inćgaux. Les fleurs de la eirconférence sont radiées à pétales plus grands. Il n'y.i pas d'involueré commun, mais chaque ombellulc offre un inyolucelle de quatre à huit folioles linćaires aiguës.

Dans les fleurs du centre, les pćtalcs sont petițs, d'abord ovales, puis rćtrćeis ęt fortement,recourbćs en dedans; en sortc que la partie infćrieure est cordiformc.

Diakene ovoïde, globuleux, eouronnć par les dents inégales du calice et les deux styles, pouvant se séparer én deux akćnes hémisphériquẹs par les progrc̀s de la maturité et de la dessieeation.

Le coriandre est originaire d'Italie, mais sa culture estısi facile en France, qu’il s'y est naturalisé. Il fleurit en juin ct juillet. (9)

Úsages et proprićtés. Lorsque eette plante est fraîche et en flcurs, elle rćpand une odeur désagréable de punaisc; de lá le nom qui lui a été imposé. Lcs fruits, quand ils sont secs, ont une odcur aromatiçue et agréable, analogue à colle de la mélisse. Ils sont earminatifs et stomachiques, et font partie des ingrédiens de l'equ de mélisse eomposée. Dans quelq̣nes contrées on les fait entrer comme condinent dans les sauces ct les ragoûls. 


\section{CIGUE. - CONIUM. L.}

Involucre de trois à cinq folioles refléchies; involucelles de trois folio!es unilatćrales; pétáles presque égäux, cordiforines; fruits globuleux, diłymes, marqués sur chaqué moitié dênq côtcs obluses, qui sont crénelées. Fleurs blanches.? Cigue Maculée. Coniuni maciiltatum. L. 'Sp. 349. Orfil. Méd: lég. t. ıo:

Part. usit. : les feuilles. Nom pharm.: : Cicuta major. Nom vuls::

\section{Grancle ciguë., ',}

in, 4. 41 "iss on

La grande ciguë offre une rạeine fusiforme, blanehe, pivotante, bisannuelle; une tige herbacéee, dresscie, irameuse, hamte de trois à six pieds, glabre, eylindrique, un peu striée, marquée de taehcs d'une couleur pourprç foncée. Scs feuilles sont alternes, très-grandes, tripinnéç, à folioless allongées, ruprofondément lentćes; les inférienres pinnatifides et presque piñneées, glabres, ct quelquẹfois maculées.

Ses fleurs sont blanches, petiles, disposées en ombelles terminales, composées d'environ dix à douzerayoris. Involucre de quatre à cinq petites fọtioles lancéolcẹs, réflćchiess et comme couchécs sur le pédoneule; involueelles de trois folioles òvales; aiguës, ćlalées et tournécs d'unłșenł ếté.

I'étales étalés, à peu près égaux, obcordiformes, sessiles. :

Diakène globulcux et comme didyme, offrant. sur eliacune de ses deux moiliés latérales einq eâtes saillantès ch́erénélées, en sorte qu'il parail lout couvert dc petịtes aspérités ou tuberculcs arrondis.

Cotle plantc croit aux environs de. Paris el dans lcs autres parties de la France, dans les licux inculıes et pierreux. Ell 'fleurit au mọis de juin et de juillet.'

Proprićtés et usages. Tontes les parties de la grande ciguë, froissées entre les doigts, exlialent nnc odeur hèjocéc ct vireuse des plus désagréables. On sait que c'est un poison violent pour l'homme el eertains animaux. Les moyens propres à combaitre l'empoisonnement par ectté substance, sont de provoquer lc vomisscment et d'adninistrè' ensuile les aeides végẹtaux étcndus, tels que le suc de cilron, le vinaigra cle.; le vin est également utilc. (Voyez Orfila, Toxic. 2. p.437.). 
Stcerck est, parmi les modernes, cclui qui a lc plus employé et prćconisé la ciguë à l'in térieur, pour combattre les affections cancéreuses rebelles. On se sert de son extrait que l'on donne à des doses gradúées, en commençant par un grain et augmentant successivement la dose jusqu'à un et deux gros.

Mais les expériences multipliées, tentécs par un grand nombre d'autres praticiens, n’ont point justifié les éloges prodigués par le médecin de Vienne à la grande ciguë. Ce médicament a toujours étć impuissant toutes les fois qu'on l'a employé contre une dégénérescenee vraiment cancćreuse. Mais on a constaté son utilité dans les engorgenens glanduleux indolens, et avant qu'aucun signe de dćgénérescence cancéreuse s'y développe.

On l'a aussi administré contre la coqueluche, les scrophules, les engorgemens des viscères abdominaux, etc. Mais c'est principalement contre les affections nerveuses qu'on l'emploie avec le plus de succès. La ciguë agit dans ce cas avec autant d'efficacité que l'opium.

C'est ordinairement la poudre des feuilles rćcemment desséchées, qui est la préparation dont on fait le plus souvent usage. On doit commencer par des doscs cxtrêmement petites, que l'on augmente ensuite graduellement. L'extrait se donne également à la dose d'un à deux grains que l'on peut porter petit à petit jusqu’à un scrupule et au delà. On prćpare aussi un emplâtre dc ciguë destiné à l'usage externe.

$$
\text { ÉTHUSE. - } A T H U S A \text {. L. J. }
$$

Point d'involucre; involucelles de quatrc à cinq folioles rabattues ct pendantes d'un seul côté, pćtales inégaux, cordiformes'; fruits presque globuleux, offrant cinq côtes simples sur chacune de scs moitiés. Fleurs blanches.

Ce genre diffčre de la ciguë par l'abscnce de l'involucre, les involucelles rabattus, ct le fruit, dont les côtes ne sont pas crćnelées.

Étudose petite cigue. AEthusa cynapizm. L. Sp. 36 \%. Bull. t. 91. Orf. Méd. lég. t. I 2.

, Noms vulg. : pelite Ciguë; Faux persil; Ciguë des jardins.

La petite ciguë est une planıc annuellc dont la racinc est 
fusiforme, allongée, blanche; lạ tige dressće, rameusc, cylindriquc, glabre, striće, glauque, rougeâtre inférieurement, creusc, portant des feuilles tripinnées, à folioles étroites, aigues, incisćes, d'un ver't foncć et luisantes.

Les fleurs sont blanehes, disposées en ombelles terminales, planes, composées d'environ une vingtaine de rayons inégaux et étalés, ceux de la circonférence plus longs. Point d'involucre. Involucelles de quatre à cinq folioles linéaires, rabattues et pendantes d'un scul côté.

La corolle se compose de cinq pétales presque égaux, étalćs, cordiformes.

Fruit globulenx, un pell comprimć, d'un vert foncé, offrant sur chacune de ses moitiés cinq côtes saillantes el arronclies.

La petite ciguë croît dans les lieux cultivćs, lcs jardins, les décombres, près des vieux murs. Elle fleurit en juillet. -

Proprictés et usages. La petite ciguë, qui jouit des mêmes propriétés délétèles que la grande, est encore plus dangereuse et plus à redouier, parce que, croissant dans les lieux cultivés, dans'les jardins potagers, elle peut facilement être prise, lorsqu'elle n'est point encore développće et en fleurs, pour le persil avcc lequel elle a beaucoup de ressemblance. Si elle était en fleurs il serait extrêmement facile dc les dislinguer : en effet, les fleurs de la petile ciguë sont Irès-blanches, cclles du persil sont jaunes-verdâtres; ses ovaires sont ovoïdes, arrondis, ceux du jersil sont allongés; sa tige est presque lisse et glauque ; celle du persil est canelée et verte.

Mais si elle n'avait poussé quc ses fenilles, on pourrait encore les distinguer quoiqu'arec moins de facilité : en effet, les feuilles du persil sont deux fois divisées; ses folioles sont larges, partagées en trois lobes subcunéiformes et denlés: la petite ciguë a les feuilles trois fois divisées; ses folioles sont. plus nombreuses, plus étroiles, aiguës, incisées et dentées; d'ailleurs, il est un excellcut caractère qu'il ne faut point négliger, c'est l'odeur, qui dans le persil est aromatique ct agréable, tandis qu'ellc est vireuse, nausćabonde dans la petitc ciguë.

Elle n'est point employćc en ınćdecinc. On remédic aux accidens qu'elle peut occasioner, par les mêmes moyens pour la grande ciguë. 


\section{CICUTAIRE. - CICUTARIA. Lamkc.}

Involuere d'une à irois folioles ou nul; involueelles polyphylles; pétales presque égaux, eordiformes; fruits globuleux, presque didymes, eouronnés par les deux styles et les einq dents du ealiee : ehaque moitié offre einq eôtes simples. Fleurs blanehes. Ce genre diffère de la eiguë par son fruit, dont les eôtes sont simples et non crénelées; de l'éthuse par ses pétales égaux, ses involucelles étalés et non réfléehis d'un seul côté.

Gicutaire aquatrque. Cicutaria aquatica. Lamkc. Encycl. Orfila. Méd. lég. t. I I bis.

Cicuta virosa. L.

Vulgairement Ciguë vireuse.

Plante vivace, dont la racine, assez gुrosse, blanchâtre et eharnue, est garnie de fibres allongées, et ercusée intérieurement de laeunes ou eavitćs remplics diun sue laitenx et jaunâtre. Sa tige est dressée, rameuse, eylindrique, erense, glabre, striée, verte, haute de deux à trois pieds. Ses fenilles, surtout les inférieures, sont très-grandes, décomposées, tripinnées; les folioles sont laneéolées, aiguës, étroites, très-profondément et irrégulièrement dentées en seie; assez souvent deux ou trois de ees folioles sont réunies et eonfluentes par leur base; les pétioles des feuilles inférieures sont eylindriques, creux, striés longitudinalement; les feuilles supérienres, moins eomposées, ont des folioles presque linéaires et dentées. Les ombelles, situées à l'extrémité des ramifications de la tige, sont eomposées de dix à quinze rayons presque égaux; l’involuere, quand il existe, est formé le plus souvent d'une seule foliole linéaire; les involueelles sont de plusieurs folioles linéaires, aussi lorgues et mênes plus longues que l'ombellule elle-mème. Les fleurs sont petites et blanelies; les pétales étalés en rose sont presque égaux entre eux; ils sont ovales, un peu eoneaves, subeordiformes, ayant le sommet relevé en dessus. Les deux styles sont assez eourts et diver'gens. Les fruits sont globuleux, presque didymes, couronnés par lesstyles et les einq dents du ealiee, et offrent sur chaeune de leurs faees convexes ot latérales, cinç eôles p̣eu saillantes et simples. 
La cicutaire aquatique croît sur le bord des mares et des ruisseaux. 2

Propriétés et usages. La eicutairc aquatique ou eignë vireuse est encore plus active et plus délétère que la grande eiguë. Les accidens qu'elle détermine sont plus graves et plus intenses, et demandent le même traitement que ceux que nous arons indiqués pour eette dernière. On ne l'emploie plus ell médecine, quoique plusieurs auteurs l'aient préeonisée eomme plus efficace que la grande eiguë. Sa racine, qui est blanche, charnuc et allongée, a été quelquefois reeucillie en guise de celle du panais, méprise qui a toujours ćté suivie des accidens les plus funestes.

TROISIËIIE SE G TIOT.

Ciucacinées. Fruits hérissés de pointes épineuses.

GAROTTE.-DAUCUS. L. J.

Involucre ec involucelles composés d'un grand nombre de folioles découpées latéralement et pinnatifides; pétales cordiformes et inégaux; fruits ovoïdes, hérissés de pointes sur loute lcur surface. Fleurs blanches. Pédoncules des ombelles dressés et rapprochés lors de la maturilé des fruits.

Carotte comiune. Dallcus carota. L. Sp. 348. Blackw.

$$
\text { เ. } 546 \text {. }
$$

Part. usit. : la racine. Nom pharm. : Daucus sylvestris et Daucus sativus.

Racine charnue, bisannuelle, eonique, allongée, pivotante, simple, rouge ou blanchâtre, donnanțnaissanee, la seeonde année de son développement, à une tige dressée, cylindrique, rameuse, hérissée de poils assez rudes, haute d'environ deux pieds, striée longitudinalement. Les feuilles sont pétiolées, tripinnatifides, lıérissées de poils, surtout sur le pétiole, les segmens sont très-petits et ineisés latéralenent.

1.es fleurs sont blanehes, disposées cn oinbelles planes, composćes d'environ une vinglaine de rayons; à la base de l'om- 
belle est un involuerc dont les folioles sont grandes, profondément pinnatifides, à segmens linéaires, lancéolés; autour de chaquc ombcllule est un involuccllc de même nature. On trouve souvent an centre de l'ombelle une fleur stćrile, d'une. couleur pourpre foncée.

Les pćtales sont cordiformes, inégaux, à sommet rabattu en dessus; ceux de la eirconférence sont beaucoup plus grands et planes. Les fruits sont ovoïdes allongćs, à cinq petites dents au sommet, hćrissés de poils blancs, très-rudes. A l'époque de la maturité les rayons se redressent et se resserrent les uns contre les autres.

La carotte est très-commune dans les prés et les pâturages. On la cultive abondamment pour les usages domestiques. Elle fleurit durant la plus grandc partie de l'ćté.

Propriétés et usages. La carolte est du nombre des végétaux dont la culture modifie ct change les proprićtés d'une manière remarquable. En effet, dans l'état sauvage, sa racine est grêle, âcre, d'une odeur forte ct aromatique, tandis que dans nos jardins elle est épaisse, eharnue, d'unc saveur douec et'suerée. On a autrefois mis en usage la racine de carotte sauvage en décoetion, comme apéritive, aujourd'hui elle nous inlćresse seulcment commc alimentaire. La carótte est mucilagineuse, sucrée et nourrissante. Maregraff en a retiré une assez grande quantité de sucre pour qu'elle devienne intćressante sous ce rapport.

On se sert quelquefois de la carotte réduite en pulpe pour appliqucr sur les geręures qui se forment au mamelon elıez les femınes qui nourrissent. Elle calme la douleur et faeilite la cicatrisation.

QUATRIE் SECTION.

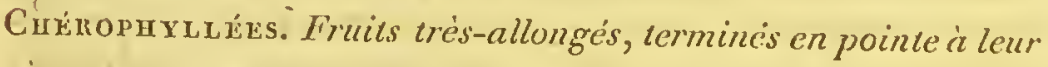
soininet.

\section{CER F EUIL. - SCA NDIX. L.}

Involuerc et involueclles formés de plusieurs folioles simples, et unilatérales; pétales égaux, eordiformes, ligulés; fruit trèsallongé el presque coniquc, tcrminć par deux petites corncs. dressćcs qui sont les styles persislans. Fleurs blanelıcs. 
Crrfeutl commun. Scandix cerefolium. L. Sp. 368. Jacq. Fl. austr. t. 3go. Blackw. t. 236.

Plante annuelle dont la racine est fusiforme, simple, blanche, la tige rameuse, dressće, glabre, cylindrique, un peu striée, haute d'à peu près deux picds, leś feùiłles radicales, longuement pétiolćes, tripinnées; à foliolès óvales, 'incisées ct'dentées, étroites, d'un vert clair; le pétiole subcanaliculé, poilu.

Les fleurs sont blanches, petites, en ombelles, souvent latérales, composćes de quatre à cinq rinons; pédoncules communs, légc̀rement pubescens; involucre composć d'un à deux folioles; involucelles de trois à quatre petites folioles. La corolle est formée de cinq pétales égaux, cordiformcs; les étamines saillantes; les deux styles sont droils. Le fruit est trèsallongé, lisse, glabre, terminé par les deux styles persistans.

Le cerfeuil croit dans les champs et se cultive dans les jardins. $\odot$

Propriétes et usages. Ce sont. les feuilles qui sont em-ployées. Elles sont légèrement excilantes et diurétiques. C'est principalement leur suc mélangé à celui d'autrcs végétaux hierbacés, qui est usité. Elles servent égalcment d'assaisonnement dans bcaucoup d'alimens. Quelques auteur's n'ont pas craint d'attribuer au ccrfcuil la propriété de guérir les affections cancércuscs; mais les modernes n'ajoutcnt aucune foi à ces suppositions mensongères.

CIN Q UIK ME SEGTION.

SÉL1NÉEs. Fruits ellipsoüdes, comprimés, membraneux. Fleurs 'jaunes ou blanches.

\section{SELIN: - SELINUM. Spreng.}

Involucre et involucelles polyphylles; pćtales ćgaux, cordiformes; fruits ellipsoïdes, comprimés, mcmbrancux sur les bords, et off'ant trois côtes saillantes sur clıaque moitić. Fleurs jaunes ou blanches. 
Sexínor Galbanum. Selimemigalbankin. Spreng. Umb. Bubon galbanum. I: .

Pirrt. usit: : la Gomme résine. Nom pharm. : Galbanum.

T'Afrique, et partieulièrement l'Éthiopie, șont la patrie de cețte ombellifère qui paraît avoir élé eonntie des̀ ancierrs. C'est un sous arbrissean de quatre à six pieds de hauteur, dónl les tiges sont cylindriques, ramenses, glabres, portant des feuilles alternes trois fois ailées; ayant leur pétiole long, dilaté et membraneux à sa base, qui embrasse la tige; les folioles qui sont très-nombreuses, cunéiformes, dentées dans leur partie supérieure, et en forme d'éventail, sont glaúques et d'un vert clair.

Les fleurs sont jaunes, et forment de grandes ombelles à la. partie supérieure des ramifięations de la tige. Leur involuere est, ainsi que les involueelles, eomposé d'un grand nombre de folioles siniples et linéairés. Les pétales sont égaux entre éux, et échanerés è cour à leur sommet. Les fruits sont ellipsoïdes, comprimés, glabres, menbraneux sur les bords, et marqués de trois eôtes peu saillantes. $\mathcal{F}$

Proprićtés et usages du Galbanum. Cette matière gommonésineuse suinte naturellement dés diverses parties de la plante, pendant les grandes ehaleurs, sous forme de petites goultelettes, rui dureissent à l'air. Mais ordinairement on se proeure ee médieanent en eoupant les branches à quelques ponees de terre; on voit alor's paraître une quantité plus eonsidérable de goultelettes, que l'on reeueille lorsqu'elles se sont eondensées à l'air. Le galbanum est en larmes jaupâtres, quelquefois réunies en masses plus ou moins volumineuses. Il est presçue translucide, à cassure grenue. Son odeur estifoste et pénétrante; sa saveur âcre et anère. Il se eompose, d'après M. Pelletier, de résine 66 , de gomme 19 , d'huile volatile 6 , d'impuretës 7 . parties.

Il entre prineipalement dans la eomposition de eertains cmplâtres, tels que le dia ehylon gommé, l'emplâire diaphorétique, ct dans eerlaines préparations trìs-eompliquécs, telles que la thériaque, le diaseordium, l'orvićlan et plusieurs antres. On l'employait autrefois très-souvent à l'intérieur. Il cst, eomme 
les autrcs gomıncs,résines; stimulant et tonique; mais on en a preșque abandonné l'usagc; et on lui préfèce généralement là gomme ammoniarque ou l'asa-f'octida.

La gomme ammoniaqué, est produitc pár une plante dc la famille des Onbellifères, qu'Olivier croyäit être une espèee de Férule, Willdenow, un heracleum; d'autres le bubon gummiferum de Jinnć ou selinum gummiferum le Sprengel. 11 cst trc̀sdifficile de se prononcer affirmativement sur l'une de ces opinions, car l'obscurité la plus profonde.cache encore l'origine des gommes résines, retirćes des plantes de la famille dẹs 0 mbellifères. Quoi qu’il en soit, voici lcs caractères que présenita la gomme ammoniaque du commeree. Elle est tantôt en masses solides, formécs de larmes jaunâtrcs, agglònerées, ou bien en larınes détachécs. Leur cassure.est blanche, oṕaque, nelte, et ne tal'de pas à prendre une zeintc jaunâtre, par le cantact dc l'air. Sa șaveur est amère, âcre et nauséeuse; son odeur forle et pćnćtrante, M. Braconnot l'a trouvée composcéside résinc 70 , gomme I 8 p. et rde ft parties d'une matière glutiniforme insoIuble.

L'action stimulante de la gomme ammoniaque a étć reconnue par tous les praticiens ct les auteurs de matière mćdicale. Lorsqu'on l'administre à faible dose ( 6 à 8 igrains), elle agit localcment sur.l'estomac, dont elle augmente: le ton et l'excitabilité, elle est alors tonique, et surtout stomachique. Mais si la dose est plus élevće, son aetion n'est plus loeale, elle s'étend au reste de l'ćconomic, et l'on voit se développer la série des 'phénomènes de la médication excitante. Aussi a-t.on prineipalèment reeours a cette sibstance, toutcs les fois que l'on veut rendre à un organe le degré d'excitabilité nécessaire à la r'ćgularité et à l'accomplisscinent de ses fonetions. Ainsi dans les eatarrhęs pulmonaires chroniques, quand il n'cxiste plus aueum signe d'iritation ni de fièvre, dans Ics leueorrhćes ou les aménorrhécs produilcs ou cnlretcnues par des causes débilitantcs, l'cmploi de ce médicament peut amener d'heureux résullals par l'cxcilation 'qu'il détcrınine; ..

Appliquée à, l'extérieur sur les tumeurs froides et indolentes, la gonme ammoniaque cst considéréc comme un des meilleur's résolutifs. 
La dose de cette substance est de 6 a 8 grains, lorsqu'ón l'adıninistre comme stomachiquc. Cette dose doit êtrc doublée ou triplée, lorsqu'on veut provoquer une médication généralc. On la donne soit dissoute dans l'alcohol, soit sous forme de pilules. Elle fait partie de la thériaque, de l'emplâtrc de cigue, du diachylon gommé, etc.

\section{PANAIS. - PASTINACA. L. J.}

Point d'involucre, ni d'involucelles'; pétales égaux, un 'peu roulćs, fruit ellipsoïde, comprimé, membraneux sur les bords, strié. Fleurs jauncs.

Panars cultivé. Pastinaca sativa. L. Sp. 376 . Blackw. t. 379 .

Le panais est une plante bisannuelle; dont la racine est fusiforme, blanche, pirotante, simple et cliarnue: La tigc dressée, cylindrique, haute de deux à trois pieds, creüsééde larges canclures longitudinales, est rameuse et glabrẹ. Lcs feuilles sont velues, composées de folioles ovales, incisćes et dentées, assez grandes.

Ses fleur's sont jaunes, disposcées en ombelles larges et ćtalćcs au nombre de trois ou quatre à l'cxtrémilé des branches, com-' posées d'une vingtaine de rayons inćgaux, ceux du centre plus petits. Point d'involuere, ni d'involucelles.

Le fruit cst elliptique, comprimé d'avant en arrière, 'légèrćment membrancux sur ses bords, offrant sur chaque face six stries, et se sćparant par la maturité, en dcux akènes, situés l'un au devant de l'autre.

Le panais croît dains les champs, et est cultivé dans les jardins polagers, à cause de sa racine.

Propriétés et usages. La racine de panais est alimentaire; clle est sueréc et aromatique. Elle a bcauconp d'analogic ct de ressemblance avec la racine de grande ciguë ct de ciguë vireurc, dont elle diffc̀re essentiellement par l'odeur ct lc goût, et surtout par lcs propriétés, puisquc cctte dernièric est essentiellement vénéncuse. On-n'en fait. point usägè en médecinc. 
Panals oroponsx. Pastinaca opopanax. L. Sp. D. C. Fl. fr. Ferula opopanax. Spreng. Umb.

Part. usit. : le suc gommo-résineux. Nom plarm. : Gummi opopanax.

Cette espèce, bcaucoup plus griande dans toutes ses parties que la précédente, en offre absolument le port; ses feuilles, qui sont longuement pétiolćes et biternécs, prćsentent des folioles très-larges, sinueuses, obliquement ćchancrées en cœur à leur base; sa tige cst haute de quatre à cinq pieds, cylindriquc, striée longitudinalemcnt, creuse dans son intérieur. Les flcurs sont jaunes, disposées en larges ombelles, plancs, occupant l'extrémité des ramifications de la tige. Les pćtales sont inégaux; les fruits sont ellipsoïdes, plancs, glabres, légc̀rement strićs.

Cette plante croít dans les provinces mćridionales de'la France, en Italie, en Grèce, en Orient, etc. $₹$

\section{Propriétés et usages de l'opopanax.}

Bien que la plante d'où l'on tire cctte substance gommo-résineuse croisse en France et dans d'autres parties de l'Europe mćridionale, cependant tout l'opopanax du commerce nous est apporté du Levant. Il est en larmes solides, sèches, irrégulièrement anguleuses, friables et opaques, d'un brun rongeâtre, marbrées de jaune à l'intćrieur'; son odeur, qui est aromatiquc, a de l'analogie avec celle de la myrrhe, ct sa saveur est âcrc, chaude et amc̀re. M. Pclletier l'a trouvć composć de résine; 42. p. gomme 33. p.; anidon 4 p.; huile volatilc 5 p., elc.

L'opopanax agit à la manière des aulres substances gommorésineuscs fournies par les plantes dc la famille dcs ombclliféres, c'est-à-dire qu'il cst stimulant: on l'emploie rarcment à l'intérieur; mais il fait partie dc plusieurs préparations pharmaceutiques.

\section{FÉRULE.-FERULA. L. J.}

Involucre et involucelles polyphylles; pélales égaux, roulćs; fruits clliptiques comprimés, marqués de trois côtres sur chaquuc moitié: Flcur's jaurics. 
Cc genre, très-voisin dn panais, en diffère par son involucre et scs involucclles; ses fruils moins comprimés, marqués dc trois côtes dorsales. M. Sprengel y réunit le pastinaca opopanax sous le nom de Ferula opopanax.

F́́RULe asa-foetida. Ferula asa-foetida. Lamk. Enc. 2. p. 638 .

Part. usit. : le suc gommo-rétineux. Nom jliarm. : Assa on Asa-Foetida.

C'est en Perse que croît ce végétal, qui fournit à la thérapentique un médicament très-précieux; sa raeine, analogue dans sa forme à celle du panais, est tantôt simple, tantôt ramcuse, recouverte d'unc ćcorce très - noire, blanche intéricurement, lactescentc et fétide; son collet est garni de filamens noirs; ses feuilles sont toutes radicales, pétiolées; le pétiole est environ de la grosseur du doigt, et long de six à huit pouces; les feuilles ont une certaine ressemblancc avec celles du pivoine, c'est-à-dire qu'elles sont triternées; que leurs folioles sont oblongues, sinueuses et presque pinnatifides, d'un vert clair, et glauqucs : elles varient beaucoup dans leur composition et la figure de leurs folioles. Du centre des feuilles radicales s'élève une tige nne, cylindrique, siriée, haute de cinq à six pieds; elle offre, de distance en distancc, des gaines membrancuses, qui ne sont que des feuillcs avortées; les fleur's sont d'un jaune pâle et forment de grandes ombelles coinposées de douze à vingt rayons; l'involucre est eaduc, et les involucelles sont polyphylies; les fruits bicn murs sont d'un brun rougeâtre èt velus. $F$

\section{propriétés et usages. de l'asa-fatidu.}

C'cst par des incisions que l'on pratique au collet de la racine de cctte plante, que s'ćcoule l'asa-foctida : elle est d'abord liquide ct jaunàtre, naais elle ne tarde pas à se concréter. Tells: qu'cllc nous est apportéc par lc cominerce, l'asa-fotida est en masses solides, d'un brun rougcâtre ì l'extérieur, offrant intéricurement des larmes grisatres et comme opalines au milien d'une pâte plus foncée; son odeur est forte, alliacće et extré- 
mement désagréable; sa saveur est âcre et amère : elle se conpose, d'après l'aṇalyse de Mr. Pellelier, de résine 65 p. bassorine I I p., gomme 19 p., huile volatile 3 p. : elle se dissout dans le vinaigre, l'alcohol faible ct le jaune d'œuf.

L'asa-fœtida, qui pour nous est sirepoussante, est pour les habitans dc la Perse un condiment extrêmemcnt recherchć, qu'ils mélangent à leurs boissons et à leurs alimens, afin de les rendre plus agréables et plus savoureux.

Tous les praticiens s'acordent à regarder l'asa - fœtida comme un médicament stimulant très'énergique : son action primitive, d'abord bornée aux organes de la digestion, dont elle auggmente la sécrétion muqueuse, ne tarde pas á réagir sur tout l'organisme, et particulièrement sur lesystème nerveux. Aussi Boerhaave considćrait-il cette substance comme le plus puissant des antispasmodiques, et recommandait-il son usage dans l'hystćrie, l'hypochondrie, l'asthme, etc. D'autres, et particulièrement Millar, l'ont employée dans la coqueluche, lorsque les phénomènes nervenx étaient très-intenses, et que la suffocation semblait imminente : ils y joignaient l'emploi de l'acćtate d'ammoniac et de l'eau distillée de menthe.

On a administrć l'asa-fœtida dans le traitement des vers intestinaux, et elle agit dans cette eirconstance avec autant d'efficacité que les autres substances excitantes trćs-odorantes, telles que la tanaisie, l'absinthe, l'ail, etc. .

En un mot, l'emploi de cette substance peut être avantageux dans toutes les circonstances où l'ćconomie animale a besoin d'être fortement stimulée.

Ce n'est guc̀re qu'en pilules et en lavemens que l'on fait usage de ce mćdicament, sa solution aquense ou alcoholiqne étant extıêmement désagrćable. Sa dose est d'un demi-scrupule à un scrupule, dose qui pent être graduellement auginentée. Lorsqu'on l'adıninistre en lavement, on en fait dissoudre un demi-gros ou un gros dans un jaune d'ouf, et on l’ajoute à une infusion excitante. On peut aussi faire usage de l'asa-foetida à l'extćrieur : appliquée sur les tuneuis indolentes, on la considère gćnćralement comme un excellent résolutif. 
A NGELIQUE. - $A N G E L I C A$. L. J.

Involuere de quelques folioles ou nul; involucelles polyphylles : pétales un peu recourbés en-dessus; fruit ovoïde, membraneux sur les bords, marqué de stries saillantes et longitudinales, surmonté par les deux styles, qui sont divergens. Fleurs blanehes.

\section{Angélique officinare. Angelica archangelica. L. Sp. 36o.} Blackw. t. 496. Fl. dan. t. 206.

La racine de l’angélique est vivaee, grosșe, allongéc, eliarnue, très-rameuse, noirâtre à l'extérieur, blanche ḍans son intérieur. Son odeur ressemble à eelle de toute la plante : elle est aromatique et très-agréable. Sa saveur est à la fois âere, ehande et un peu amère; sa tige est eylindrique, grosse, dressće, rameuse, creuse intéricurement, striće, glabre et couverte d'une poussière glauque; elle est haute de trois à quatre pieds.

Ses feuilles sont très-ģrandes, pétiolées, décomposćes, deux ou trois fois pinnées. Les fulioles sont ovales, la neéolćes, aiguës, dentées en seie. Le pétiole el ses ramifieations scint eylindriques et fistuleux; à sa base se trouvent deux grandes explansions mombraneuses, trc̀s-larges, irrégulières, qui embrassent la tige.

Les ombelles sont très-grandes et nombreuses. L'involucre est formé de quelques folioles lincéaires aiguës, qui manquent quelquefois. A la base de cliaque ombellule est un iuvolueelle d'environ huit folioles, linćaires, subulées.

Le funit est ovoïde, allongć, relevé de côtes sajillantes; et portant les deux styles qui sont plaeés presque horizontalement.

L'angćlique se trouve dans les provinces méridionales dẹe la Franee : elle croît daus les lieux montuenx et boisćs. $\%$

Propriétés et usages. Celle plante ripand une odcul donce et aromatique très-aggríable; sa savenr.est snerce, un pen âcre et aromati(jue; sa racinc est usitie ermme excilan!e dans le scorbut, les scrophules : clle est dirrétique et sucloriquc. On l'aduninistre en infusion ou en poudrc; dans le premier ens, à la dose d'une demi-once à une once, et dans lc second à celle d'un gros. 
Les tiges blanchies et confites au sucre forment une conserve très-recherehée, d'un goût fort agréable, qui esț tonique et stomaehique.

\section{PERCE-PIERRE. - CRITHMUM. L. J.}

Involucre et involucelles polyphylles; pćtales roulćs et égaux entre eux; fruits ellipsoïdes, striés, un peu comprimés. Fleurs jaunâtres.

Perce-pierre comuno. Crithmum maritimum. L. Sp. 354 .

Part. usit. : les feuilles.

Tige herbacée, eylindrique, glauque, légèrement striée, comme géniculée, rameuse, fragile, mćdullaire intérieürement.

Fenilles eharnues, engainantes, décomposćes, j folioles ovales, lancéolées, aiguës, ćpaisses et charnues, veinées, glaucpucs.

Fleurs, d'un blanc jaunâtre, disposées en petites ombelles polygames : elles sont au nombre de six à huit à l'extrémité de la tige. Celle du centre, qui est plus grande (composée d'environ (rente rayons), est hermaphrodite, fertile; loutes les autres sont mâles et stérilcs par l’absence des styles et du stigmaté; toutes ont un involucre régulier, composé de huit ì douze foioles lancéolćes, aiguës, rabattues et el arnp̣ıes. Chaque ombellule, portée sur un pédoncule strié, eylindriquie, long d'un pouee, est composée de douze à quinze fleurs couriement pédicellées, offrant un involueclle de neuf à donze folioles ovales aiguës', étalées', disposécs sur deux rangs.

Fruil elliptiçuc comprimé et strié longitudinalement. Le perce-pierre croit sur les rochers des bords de la mer; il fleurit à la fin de l'été : on le eultive dans les jardins. $¥$

Propriétés el usages. Toule la plante est odorante; sa saveur est aromatique piquante, un peu salée; elle est très-diurétique : on l'emploic beaueoup, comme assaisonnement; après lavoir fait eonfire dans le vinaigre. 
ÉRYNGLÉEs. Fleurs disposées en capitules ou ombelles simples.

$$
\text { PANICAUT. - ERYNGIUM. L. J. }
$$

Fleur's disposées en capitules et portćes sur un rćceptacle convexe, garni d'écailles. Involucre polyphylle; pétales émarginés; fruits ovoïles, strićs ou tuberculeux, surmontćs par les cinq deruts du calice.

Panica dt des champs. Eryngium campestre. L. Sp. 33 g.

Part. usit. : la racine. Nom pharm. : Eryngium. Nom vulg. : Chardon roulant ou roland.

C'est une plante de huit à dix pouces de hauteur, qui croît en abondance dans les lieux incultes, sur le bord des, champs et des chemins, et qui pour le port ressemble plutôt à un chardon qu'à une ombellifère. Sa racine est perpendiculaire, cylindrique, très-longue, brune en-dehors, blanchc en-dedans; sa tige, rameuse dìs sa base se divise en un grand nombre de ramifications dichotomes. Les feuilles radicales sont pétiolćes, divisées profondćment en trois lobes pirnatifides et épineux. Celles qui naissent sur la tige sont plus petites et moins incisées. Les capitules de fleurs sont arrondis, pédonculés, environnćs d'un involucre qui se compose de six à sept folioles linćaires, lancéolćcs, deux fois plus longues que les capitules, et épineuses. Ses fleuirs sont blanches; ses fruits sont hćrissćs de petites écailles imbriquées.

Cctte espèce est en fleurs pendant la plus grande partie de l'étć. 24

Propriétés et usages. La racinc de panicaut a unc saveur un peu amc̀re et lég c̀rement aromatique, qui se perd presque entièrement par son ćbullition dans l'eau : elle est dans ce dernier état alimentaire, ct les gcus des campagnes s'en nourrissent quelquefois. Quant à son action diurétique, on conçoit qu'clle doit être bien faible, lor'squcl'on songe au peu d'activité dc son odeur ct desa saveur : elle agit alors coimme un diurétique adoucissant, c'est-à-dire qu'elle convient particulièrcment dans les 
cas d'irritation des voies urinaires. C'est toujour's en décoction qu'elle est administrée.

Nous axons cru dcroir ne décrire ici que les espèces d'ombellifères les plus remarquables et les plus frćquemment usitées; mais nous avons éprouvé quelquie embarras dans le choix de ces espèces, à cause de l'extrème analogie qui existe entre elles, sous le rapport de leurs proprićtés médicales. Parmi les autres ombcllifères dont nous n'avons pas donné la description, nous citerons ici les suivantes comme bien moins fréquemment employćes :

$I^{\circ}$ La sanicle, Sanicula europoea, L. Plante vivace, commune dans les bois ombragés, et qui.a joui autrefois d'une très-grande vogue. Ses feuilles ont une saveur amc̀re et un pcu acerbe: on les cinployait dans les hémorrhagies, la leucorrhće, la dysenterie, etc. Inusilée.

$2^{\circ}$ L'anмi, Ammi majus, L. Ses fruits, d'une saveur un peu âcre et aromatique, étaient jadis comptés au nombre des quatre semences chaudes mineures. Inusitćs.

$3^{\circ}$ LA Liveche, Ligusticum livisticum. L., croît dans les provinces.méridionales de la France. Sa racine et ses fruits"sont aromaliques, un peu âcres et stimulans : on les emploie bien rarement.

$4^{\circ}$ L'impératoire, Imperatoria ostruthium. L. La racine de cette plante, qui croit dans les montagnes, a une saveur chaude et trćs-aromatique : elle jouit de proprićtés toniques et slimulantes fort ćnergiques, et n'est pas à dédaigner. Cependant on l'emploie assez rarement.

\section{Propriétés médicales et usages des plantes de la farnille des ombellifères.}

Cette famille doit être conıptée au nombre des plus naturelles, sous le rapport dics caracic̀res botaniques el de la ressemblance qui cxiste entre les différens genres dont elle se compose. Cependant tous les végélaux qui lui appartiennent sont loin de jouir des mêmes propriétćs, d’avoir la même action sur l'économic animale, comme le démontrent les différentes cspèces de ciguë, lé phcllandre aquatique, etc., comparées à l'anis, au cu- 
mnin, au fenouil, au persil, à la earotte, ete. Les premières, en effet, sont des poisons nareotiques très-subtils; lcs autres, au contraire, sont des médicamens et des alimens, dont l'administration ne donne jamais lieu à aucun aecident. Tâchons de donner une explication de eette anomalie plus apparente que réelle.

L'analyse chimique nous démontre dans les ombellifères deux principes de nature différente : l'un est résineux, rcnfermant une grande quantité d'huile volatile essentielle, très-odorante et très-aromatique; l'autre au contraire, est de nature extractive, peu odorant, légèrenent amer. C'est à la présence de l'un de ees principes constituaus, que les onbellifères doivent leurs propriććs. Ainsi elles seront loniques, cxcitantes, aromaliques, chaudes et diffusibles, toutes les fois que la rćsine et l'huilc volatile y prédomineront: c'est ce que l'on observe dans le fenouil, l'anis, la coriandre, l'angćlique; le cumin, le carvi, ete. Ce principe aromatique et stimulant se trouve principalement concentré dans les fruits, ainsi qu'on l'observe dans l'anis, le fenouil, le eumin, etc.; d'autres fois il existe aussi dans les tiges, tclles sont celles de l'angélique, du céleri, etc. C'est des ombellifères aromatiques que l'on relire les sues concrets gommo-résineux connus sous le nomde Gommes-résines fétides, tels que l'asa-foctida, le galbanum, l'opopanax, etc.

Si le prineipe aromatique est uni à une assez grande proportion de mucilage et de matière sucréc, les ombellifères deviennent propres à être employées comme alinens : c'est cc que démontrent les racines de carolte et de panais, le cerfeuil, le céleri, en un mot toutes les espèces eultivées dans nos jardins potagers.

Mais si au contraire la partie prćdominante est l'exıractif, si le principe aromatique ne s'y fait plus remarquer, elles auront alors des propriétés tout-à-fait différentes et devicndront de véritables poisons narcotiçues; nous en trouvous la preuve dans la grande et la pctite cignë, la cignë aquatique, différentes espèces d'venanthe, lc phellanlre aquatique, etc. Une observalion digne de remarque, c'est que lc principe aromatique est d'aulant plus développć, que les espèces vivent naturellement dans des lieux et des eontrées plus cliandes et 
plus sèches, tandis qu'au contraire on doit tonjours se défier des espèces qui croissent à l'ombre dans l'humidité, ou même dans l'eau, parce que le principe extractif et narcotique y prédomine, et qu'elles sont plus ou moins dangereuses pour l'homme et les animaux.

\section{OIXA NTE-DEUXIÈ E F MILIE.}

\section{R I B É SIÉES. - RI B E SIEAE.}

M. de Jussieu avait réuni dans eette famille les deux genres groseiller (ribes) et cierge (cactus), dont le port est tout-à-fait différent, mais dont la structure offre quelqu'analogie. Cette ressemblance n'a pas été trouvée assez grande par plusieurs auteurs modernes et par M. de Jussieu lui-ntème, èt l'on a formé du genre cierge une famille distinete sous le nom de Nopaltés. La famille des Ribésiées n'est done plus eomposée aujourd'hui que du seul genre ribes ${ }^{\mathrm{I}}$ de Linné.

Les groseillers sont de petits arbrisseaux à feuilles

I Le genre ribes, L., formant à lui seul la famille des Ribésiées, et se composant d'un grand nombre d'espèces, nous avońs cru, à l'exemple de plusieurs botanistes célèbres, pouvoir profiter des différences assez tranchées que ces espèces présentent dans leur structure et leur port, pour étahlir, dans un Mémoire inédit sur cette petite famille, plusieurs genres distincts, mais que l'on pourra à la rigueur ne eonsidérer que comme des sections naturelles d'un mênı genre. Nous avons distribué les espèces de groseillers en trois groupes, dont les types sont le groseiller à maquereau, le groseiller rouge, ou à grappes, et le cassis. Le premier de ces groupes porte le nom de Grossularia, et offre pour caractères : un॰ovaire eomplétement infère, un calice eampanulé; un style hiparti jusqu'à sa base, et des anthères cordiformes. Le second, auquel j'ai eonservé le nom de Ribes, se distingue par son ealiee presque plane, son style simplement bificle à son sommet, et ses anthères didymes. Enfin je nomme Botrycarpum le troisième, que l'on reeonnaît à son ovaire semi-infère, son style simple, ou à peine bifide à son sommet, et ses anthères cordiformes. Touter les espèces viennent se groupor daus quelqu'uu de ces genres. 
alternes et plus ou moins profondément lobées, pétiolées, souvent armées d'aiguillons simples ou divisés, que l'on peut consiclérer comme de véritables stipules qui persistent et s'endureissent. Leurs fleurs, généralement hermaphrodites, sont ou solitaires ou disposées en épis ou en grappes axillaires. Leur ealiee est monosépale, adhérent par sa base aveé l'ovaire, qui est infère ou semiinfère. Son limbe est plus ou moins eampanulé, à einq divisions égales. La eorolle se eonipose de cinq pétales en général fort petits, et alternes avec les divisions du ealice. Les étamines sont constamment au nombre de cinq, -qui alternent avee les pétales. Leurs filets sont insérés à la base des divisions ealicinales, à une sorte de bourrelet peu saillant, formé par la matière glanduleuse épanchée sur le ealiee, et constituant un disque périgyne. Les anthères sont biloculaires, tantôt cordiformes et à loges rapprochées, tantôt didymes et à loges écartées par un eonnectif. L'ovaire est infère ou simplement semi-infère; il offre une seule loge dans laquelle un grand nombre d'ovules sont insérés à deux trophospermes pariétaux et longitudinaux. Il est surmonté par un style tantôt simple ou bifide, tantôt profóndément bipartite. Au sommet de ehaque division du style on trouve un stigmate simple.

Le fruit est une baie globuleuse, polysperme, ombiliquéé à son sommet.

$$
\text { GROSEILLER.-RIBES.L. }
$$

I. Ovaire complétement infère; calice campanulé; anthères cordiformes; style profondćment biparti. Fleurs non en grappes; tiges ordinairement garnies d'aiguillons. Grossunara. Rich.

Groseiller ḱpineux. Ribes grossularia. L. Sp. 29 I. Grossularia vulgaris. Rich. monog. inéd.

C'est un petit arbuste touffu, très-rameux, qui ne s'élère 
guère au delà de trois à quatre pieds. Sa tige ligneuse et inćgale porte des feuilles d'abord disposées par petits faisceaux, à la base desquels on trouve un aiguillon à trois branches divariquées. Ces feuillcs.deviennent ensuite alternes et pćtiolées, subcordiformcs, pubescentes, divisées en cinq lobes arrondis, profondément dentćs. Les fleur's sont vertes, axillaires et solitaires. Leur pédoncule est pubescent, penché, et présente vers le milieu de sa longueur deux petites bractées squammiformes, opposées. L'ovaire, qui est complétencnt infère, est liérissé de poils rudles; le calice est campanulć, à cinq lobes étalés; les cinq pćtales sont fort petits et presque cunéiformes et dressćs. Le stylc cst velu et renflć à sa partie inféricurc. Le fruit est une baie globuleuse, de la grosseur d'une cerise, d'un rouge foncé, hérissée de poils très-rudes, et ombiliquée à son sommet.

Cet arbuste croit dans les haies et les bois. Il fleurit au printemps; ses fruils sont parfaitement mûrs au milieu de l'été.

Propriétés et usages. Les fruits de cette espèce et ceux du ribes uva crispa, L., que l'on dćsigne vulgairement șous le nom de groseilles à maquereau, ont une saveur acidule et sucrée lorsqu'ils sont parvenus à leur maturité. Cependant ils sont peu. recherchćs, et on les abandonne en génćral aux enfans. Ils sont rafraichissans et un peu relâchans. Avant leur maturité ils sont âpres et astringens, et on se sert quelquefois de leur suc comme condiment, pour assaisonner les viandes et le poisson, et particulièrement les maqueraux. Delà le nom vulgaire sous lequel ils sont généralement connus. "

II. Ovaire infère; calice presque plane; anthères didymes; style bifide à son sommet. Fleurs en grappes; tiges dépourvues d'aiguillons. Rrzes. Rich.

Groseluler rouge. Ribes rubrum. I. Sp. 290. Blackw. t. 285 .

Cctte espèce se distingue facilcment à ses tiges dressées, cylindriques, dépourvucs d'aiguillons, à ses feuilles beaucoup plus grandes que dans l'cspèce précédente; à cinq lobes pu- 
bescens et dentés. Ses flcurs, qui sont hcrmaphrodites et trc̀spetites, forment un épi on petite grappe simple, pendante, composée dc huit à douze fleurs pédicellées, portées sur un axe simple. Chaeune de ces fleurs a l'ovaire infère, glabre; le caliee presque étalé, à cinq divisions larges et trc̀s-obtuses. Les cinq pćtales sont exeessivenient petits et presque cunéiformes. Le style est terminé par deux stigmates, et le fruit est une petite baie globılcase ombiliquée, taniôt blanehe et transparente, tantôt d'un beau rouge cramoisi.

Le groseiller rouge est commun dans les haies, les bois. On le cultive en abondanee dans les jardins, où ses fruits sont mûrs en juillet et août.

Propriétés et usages. Les groseilles sont composées d'acides malique et citrique, d'albumine végétale, de matičrc colorante, dans la variété à fruits rouges, et dc sucre. On prépare avec le suc que l'ou cn exprime des tisanes, un sirop ou une gelée. Les premières se font.en écrasant les groseilles et en exprimant leur suc, que l'on ćtend d'eau, ct auquel on ajoute une quantité eonvenable de sıcre. Le sirop se prépare avec le suc clarifić, e'est-à-dire privć de l'albuimine qu'il contient. Étendu d'eau, il forme aussi une boisson extrêmcment agréable, que l'on emploie, ainsi que tous les autres ãeidules, eomme tempérante, dans les inflamınations aiguës, les fièvres bilieuses et inflammatoires. Elle modc̀re la chaléur animale, ealme l'accélération de la cireulation; en un mot, agit comme adoucissante et calmante. Quant à la gelée, c'est une préparation de table dont on permet l'usage aux convalescens.

III. Ovaire semi-infère; calice campanulé; anthères cordiformes; style simple. Fleurs en grappes. Tiges ordinairement sans aiguillons. Botrygah puar. Rich.

\section{Grosemuter nour. Ribes nigrum. L. Sp. $29 x$.} Botrycacpum nigrum. Rich. monog. inéd. Vulg. Cassis.

Pour le port, le cassis a beancoup d'analogie avee lc grosciller rouge. Sa tige est égalemcnt très raneuse. Ses fcuilles ressemblcnt beaucoup à eelles de la vigne, mais elles sont trois fois plus petites, lisses et glabres à leur face supéricure, pubes- 
centes inférieurement. Leur, pétiole est élargi et meınbraneux à sa base. Leurs fleurs forment des grappes simples, composées d'un petit nombre de fleurs pćdicellées, éeartées les unes des autres. Ces fleurs sont presque globuleuses. Leur ealiee, qui est très-renflé au-dessus de l'ovaire, et finement pubeseent à son limbe, est partagé en einq divisịons un peu rougeâtr'es. Les cinq pétales, plus courts que ees divisions, sont d'un blanc jaunâtre. Le style est simple, glabre, terminé par un stigmate bilobé. Le fruit est une baie d'un noir foneé, terne, ombiliquée à son soinmet.

Cet arbuste se reneontre assez fréquemment dans les bois à l'état sauvage. Il est dcpuis long-temps introduit dans les jardins.

Propriétés et usages. Les parois du fruit dans le eassis sont parsemées de vaisseaux propres, remplis d'un fluide aromatique très-actif, et d'une odeur peu agréable; tandis que la pulpe renfermće dans leur intérieur est légèrement aigrelette, comme celle de l'espèee précédente. La présence de ee principe odorant communique aux cassis une propriété tout-à-fait différente de celle des deux espèces dont nous venons de faire mention. Ils sont légèrement excitans. Mais comme eette saveur est peu agréable, on ne mange jresque jamais ces fruits à l'état de crudité; on cn préparc une sorte de ratafia que l'on aromatise avee la canelle, le macis, ete.

La famille des Nopaltes ou Cactíes, que l'on a, avec juste raison, séparée de celle des Riresiées, se eompose du seul genre Cierge, Cactus, L. Toutes ses espc̀ces sont des plantes grasses, qui offrent les fornies les plins bizarres et les plus variées. Leurs tiges sont tantôt eylindriques ou anguleuses et canelées, tantôt formées d'articulations superposées. Elles sont toutes dépourvues de véritables fenilles, qui sont remplacées par de petits faisceaux d'aiguillons. Quelques espèces sont tout-à-fail globuleuses, et ressemblent absolument à un mclon. Tous ces végétaux se plaisent dans les lieux les plus secs et les plus ąrides; ils s'étendent sur les rocliers de l'Amérique et de l'Asie, ou s'élèvent au milieu des sables brûlans de l'Afrique. Leurs fruits, qui sont assez gros dans quelques espèees, sont pulpeux et rafraîehissans. 
Ạucune espécc n'est employée en Europe à titre de médicament. Mais plusieurs sont administrées avec avantage dans les licux où elles croissent naturellement. Selon M. Descourtilz, on fait usage dans les Anillles, et particulièrement ả Saint-Domingue, du suc laileux que contiennent leurs parties herbacées. Ce suc est âcre et brûlanl appliquné sur la peau, il l'enflamme et agit comme tous les autres épispastiques végétaux. Aủministré à la dose de quelques gouttes, il purge violcminent, et l'on en fait un fréquent usage comme vermifuge. Mais ce remède demande Ies plus grandes précautions, à cause de sa grande activité. Les espèces cilées par M. Descourtilz sont particulièrcment le Cactus grandiflorus, L., Cactus divaricatus, Cactus flagelliformis, L. C'cst sur plusieurs espèces de Cierge, Cactus opuntia, Cactus cocciferus, etc., que l'on élève, dans différentes parties de l' $\Lambda$ mérique, le petit insecte hémiplère connu sous le nom de cochenille, qui fournit un rouge si précieux aux peintrcs et aux teinturiers, et que l'on emploie également pour colorer certaines préparations pharmaceutiques.

SOIXANTE-TROISI EME FAMIXXE.

\section{MÝRTINÉES. - MYRTINEAE}

Les genres qui composent cette famille, sont en général des arbres ou des arbrisseaux d'un port élégant, presque toujour's ornés en tout temps, ds. leurs feuilles. Celles-ci, qui sont ordinairement. opposées; sont fréquemment parsemées de points glanduleux et transparens. Leurs fleurs sont axillaires on terminales, et se composent d'un calice monosépale adhérent avec l'ovaire, présentant à son limbe quatre ou cinq divisions peu profondes. La corolle est polypétale et régulière; les étamines, généralement très-nombreuses, ont leurs fịlets libres on soudés en plusieurs fuisceaux. L'ovaire offre tantòt une seule loge, mais plus généralement plusieurs loges; il se termine par un style simple, au sommet duquel on tronve un stigmate ordinairement indivis. Le 
fruit est à une ou plusieurs loges qui contiennent chacune une seule ou plusieurs graines. Il est tantôt charnu et forme une baie ou une drupe; tantôt sec et capsulaire. Chaque graine contient un embryon épispermique, c'est-à-dire privé d'endosperme.

On ne peut confondre cette famille ni avcc les Ribésiées, qui ont les graines pariétales, les étamines définies, ni avec les Hédéracées, les Araliacées et les Ombellifères, qui, outre le port et une foule de caractères inportans, en diffèrent par leur embryon, renfermé dans un endosperme.

\section{MYRTE. -MYRTUS. L. J.}

Calice globulcux à cinq dents; corolle de cinq pétales égaux et un peu concaves; ćtamines nombreuses et à filamens libres; baie globuleuse ombiliquée à son sommet, à trois loges polyspermes.

Feuilles opposées et ponctuées.

Myrte common. Myrtus communis. L. Sp. 673 . Blackw.

$$
\text { t. } 1 \times 4 \text {. }
$$

Arbrisseau élégant, de quinze à vingt pieds de hauteur, rameux dès sa base, à feuilles toujours vertes et odorantes, portant des feuilles opposées, presque sessiles, petites et ovales, aiguës et entières, fermes, d'un vert fóncé, parsernées de petits points glanduleux, transparens; ses fleur's sont blanches, solitaires à l'aisselle des feuilles, portćes sur des pćdoncules longs et grêles, dressés; leur calicè adhérent avec l'ovaire est ovoïde, lisse et glabre; son limbe a cinq dents deni-ovales aiguës. La corolle est formée de cinq pćtales blancs, éralćs, égaux, un peu concavcs. Les ćtaminès sont très-nombreuses, ayant les filamens libres.

L'ovaire, de même forme que le calice, est à trois loges, contenant des ovules très-nombreux altachés sur deux rangs à un trophosperme central; la baie est ovoïde, presquc noire, couronnéc par le limbe du calice, à trois loges renfermant un grand nombre de graines, réniformes, dont lc 
bord externe est embrassé par une grande caroncule de méme forme que la graine. Le myrte croît naturellement dans l'టurope méridionale. Aux environs de Toulon et d'Hières, il forme avec l'arbousier et le laurier-rose, dc cliarmans bosquets. $A$ Paris, on est obligé dele rentrer en orangeric pendant l'hiver.

Propriétés et usages. Tontcs les parties de cet élégant arbrisseaı exhalent une odeur aromatique très-agrćable, qui est due à l'huile essenticlle contenue dans les petites utricules transparentes que l'on aperçoit dans la substancé des feuilles et des autres organes. Il s'y joint également un principe légèrement astringenı, surtout dans les feuilles et l'écorce, que l'on prescrivait jadis comme toniques et stimulantes dans les flux muqueux atoniques; mais aujourd'hui le myrte n'est plus considéré que comme un de nos plus jolis arl,ustes d'ornement.

Deux autres espèces exoliqucs méritent d'être mentionnécs ici. L’une myrtus caryophyllata, L., originaire d'Amérique, fournit l'ćcorce connue dans le commerce, sous les noms de canelle giroflée, bois de girofle ou bois de crabe. Celte ćcorce est en morceaux longs d'environ deux pieds, roulés les uns dans les autres, extrèmenẹnt serrés au moycn de petites cordes; sa surface externe est unie, génćralemcrt privée de son épiderme, qui est grisâtre, brunâtre intćrieurement; sa cassure est fibreuse; sa saveur aromatique, piquante, entièrement analogue à celle du gérofle, mais un peu plus faible: :

Elle peut ćtre employće comme aromate à la place dcs clous de gérofle, dont elle a la saveur et les propriétés.

La seconde est le myrtus pimenta de Linné, qui croít à la Jamaïque et dans d’autres parties de l'Amérique méridionale; ses fruits, qui sont de petites baics globuleuses, ordinaircinent à deux loges et à deux graines, portent les nouns de poive de la Jamaïque, piment des Anglais, toute épice, elc On nơis les apporte de la Jamaïque après les avoir fait sćcher. Ils sont aiors pisiformes, un peu ridés, brunâtres et olibiliqućs à leur sommet. La partie cliarnue, qui s'est desséchiée, est celle dans laquelle réside la saveur aromatique et agréablc da..ce fruit, savcur qui rappelle à la fois cclle ḋu gérofle ct de la. canelle. Ellc est due à une huile volatilc très-pesante, que l'on obtient par le moyen de la distillation, et qui joutit des mêmes 
propriétés que l'huile de gérofle. Quant aux fruits, ils sont principalement employés eomme aromate.

\section{GÉROFLIER.-CARYO PHYLLUS. Tourn. L. J.}

Calice allongé, infundibuliforme, à quatre dents; corolle de quatre pélales sessiles, étamines nombreuses et libres; ovaire uniloculaire, monosperme; style et stigmate simples; drupe seche eouronnée par les einq divisions ealicinales.

Gérúfier aromatique Caryophyllus aromaticlls. L. Sp. 735. Blackw. t. 438.

Part. usit. : les fleurs non épanouies. Nom pharm.: Caryophylli. Nom vulg. : Clous de gérofle.

Cet arbrisseau est un des plus élégans et un des plus beaux que voie naitre le soleil brûlant de l'Inde; sa forme générale est celle d'une pyramide toujours verte et toujours ornće d'une multitude innombrable de jolies fleurs roses; ses feuilles sont opposées, obovales, acurninćes, finissant insensiblement à leur base en un long pétiole canaliculé, articulé et renflé à sa partie inférieure; ces feuilles sont entic̀res, lisses, un peu connées, à nervures latérales nombreuses, partant presqu'à angle droit de la eôte moyenne; ces feuilies ont envirón qualre prouces de longueur sui denx de largenir. Les fleurs sont roses, disposées en un coxymbe terminal trichotome, et comme eomposé de plisicurs articles; à la base de chacque pićce articulée et de ehaque fleur, sont deux petites bractées sfuammiformes caduques; ces flcurs répandent une odcur aromatique des plus agréables et des plus pénćtrântes, qu'clles conservent au même degré, a près leur parfaite dessiccation. Lcul' calice est infundibuliforme, rouge, rugueux, adhérent a vec l'ovaire infère; le lube très-allongé, étroit; le limbe à quatre divisions épaisses, ovales aiguës; la corolle composée de quatre pérales arrondis, alternes avee les divisions du caliee, sessiles, un pen concaves. Étamines nómbreuses, insérćes, ainsi que la corolle, 'ai eontour du sommet de l'ovaire; filets trèsrapprochés et eonfluens : anthère ovoïdes, biloeulaires. Ovaire 
infére allongé uniloculaire, contenant un seul ovule. Style filiforme court et épais, implantć au centre d'une sortc de disque épigyne, un peu coneave. Stigmate petit, capitulć simple.

Lc fruit est une drupe sèche, ovoïde, couronnée par les divisions du calice persistant.

Le gćroflier est originaire des Moluques, d'où il a ensnite ćtć transportć dans les différentes autres parties de l'Inde, aux iles de Francc et de Bourhon, à Cayenne et aux Antilles.

Propriétéset usagres. Toutes les parties de eet arbrisseau sont extrêmement aromatiques; mais les boutons ou les fleurs, avant leur épanouissement, sont celles dars lesquelles cet arome offrc le plus de développemens et de suavité. Ce sont ces boulons que l'on recueille avec soin, et quel'on importe en Europesous le nom de clous de girofle ou de gérofle. Leur partie supérieure, forméc par les pétales rapprochés les uns contre les autres, est beaucoup plus renflée, et forme une sorte de tête, landis que le tube du calice et l'ovaire constituent un pćdieule eentral. Les gérofles doivent être lourds, d'un brun clair, d'une odeur aromatiçue agrćable, d'une-saveur âcre et piquante. Les plus estimés viennent des grandes Indes; ceux d’Amérique et de l'île đe Bourbon n'ont point une saveur aussi agrćable.

M. Tromsdorff a retiré de 1000 parties de clous de gérofle : huile volatile 180 ; matière extractive et astringente 170 ; gomme $x 30$; rćsinc 60 ; fibre végétale 280 ; cau 180 partics. L'huile volatile de gérofle, est d'une saveur brûlante, plus pesante que l'cau; d'abold incolore, elle finit par prendre une teinte brunâtre. Elle cst d'une âcreté extraoordinaire. On l'cmploie soit comme parfum, soit pour cautćriser les dents eariées et doulonreuses. Mais son emploi dans ce dernier cas demande quelques précautions, pouvant hâtệr la carie des dents roisincs.

Les clous dc gérofle sont un des aromates les plus reclicrchés et les.plus usités. Comme médicament, on les cmploir assez rarement. Cependant ils possèdent unc énergie et une activité, qui, dans bien des cas, pourraicnt être utilcment mises à contribution. Ils déterminent tous les phénomc̀nes dcs médicamens les plus excitans, ct plusieurs praticicns les ont emploýćs a vec 
avantage dans des circonstances où l'ćconornle animale avaic besoin d'étre énergiqucment stimulée. Le vin et l'alcohol se chargent également des principes actifs du gérofle, que l'on administre aussi en poudre, mêlé avec du sucre pulvérisé. Ma is ce médicament doit toujours être prescrit à des doscs très-modérées, afn de ne pas occasioner une iritation vive et souvent dangereuse dans les organes de la digestion. Ainsi cinq à six grains de la poudre, douze à vingt-quatre gouttes de la teinture alcoholiquc, otı une cuillerćc à bouche du vin de gćrofle sont les doses ordinaires auxquelles on peut administrer ses préparations.

Les fruits du gćroflier, qui sont des baies ou drupes presque sc̀ches, possédent aussi une saveur et une odeur très-aromatiques. On les emploie ćgalement commc aromates. Il en cst dc même de son écorce, que quclques auteurs pensent être celle que l'on désigne dans le commerce sous le nom de canelle giroflée, tandis que d'autres attribuent cette dernière au myrtus caryophyllata, dont nous avons parlé précćdemment.

$$
\text { GRENADIER. - PUNICA. L. J. }
$$

Calice infundibuliforme, presque campanulć, à cinq divisions; corolle de cinq pétales chiffonés; ćtamines très-nombreuses, garnissant les parois du tube calicinal; style épais à sa base; stigmate simple; fruit sec et coriace, couronné par lc tube et les dents du calice, à plusieurs loges contenant un grand nombre de graines charnues.

Grenadier commun. Punica granatum. L. Sp. 676 . Part. usit.: les fruits, les fleurs. Noms pharm. : Granati pomum et Balaustia.

Arbre de quinze à vingt picds de haut, dont le tronc est trc̀s-inégal, souvent convert dc pctites épines ou raneaux avortés, et offrant des feuillcs opposćcs courtcment pétiolées, elliptiqucs, allongécs, entic̀rcs, luisantcs, glabres; des fleurs d'un beáu rouge, solitaircs à l’cxtrémité des rameaux, presque sessilcs. Lcur calicc cst coloré, infun dibuliforme, ćpais et char'nu, adhérent par sa partic la plus inféricure avec l'ovaire infère, 
un peu dilaté au-dessus, puis étalé et à einq divisions schiti= laneéolées, offrant vers leur pointe, à la partie supérieure, ur petit turbereule eharnu et aigu.

Leur eorolle se eompose de cinq pétales insérés à la partic supérieure du tube, sessiles, arrondis, entiers, un peu en gouttière et ehiffonriés. Les étamines sont libres et très - nombreuses, atlaehées à toute la paroi interne du tube du ealice, égales entre elles, plus eourtes que les divisions ealicinales: filets:rouges, glabres, subulés. Anthères presque réniformes, jaunes, à dellx loges. Ovaire infère, adhérent avee la partie la plus inférieure du tube du ealiee, à plusieurs loges, disposées sur deux étages superposés, renfermant un grand nombre d'ovules attaehés à des trophospermes gros et saillans qui oeeupent la base et le eôté interne de ehaque loge. Style simple, ayant à: peu près la forme d'une bouteille, e'est-à-dire renflé et plus épais inférieurement, rétréei à la partie supérieure; il est lisse et glabre, terminé par un stigmate aplati, glandulaire et disciforme.

Le fruit est une eapsule globuleuse, pomiforme, de la grosseur du poing, couronnée par le tube et les dents du caliee; son périearpe, d'un jaune rougeâtre, ešt dur, eoriaee, partagé in térieurement en un grand nombre de loges disposées en deux séries superposées par des eloisons minees et membraneuses. Les graines sont nombreuses, irrégulièrement polyèdres; leur tégument propre est très-épais, elrarnu extérieurement, et renferme un embryon dépourvu d'endospernie dressé, ayant les eotylédons roulés sur eux-mèmes.

Les eôtes septentrionales de l'Afrique, baignées par la Máditerranée, paraissent être la véritable patrie du grenadier. Les Romains l'introduisirent en Italie à l'époque des guerres de Carthage, et de là il s'est répandu dans tout le midi de l'Enrope, où on le eultive asséz abondamment. Mais il eraint le froid, et dans le eentre de la Franee il ne peut être eultiré en pleine terre. Il n'y forme qu'un arbrisseau rabougri, dont les fruits ne mûrissent jamais; tandis qu'en Provence il eonstitue des arbres de moyenne taille, analogues à nos pommiers, et se couvrant eliaque années de fruits qu'on nomme grenades, et qui parviement à une parfaite maturitć. On cultive fréçucm- 
ment le grenadier dans nos orangeries, à cause de la belle eouleur rouge de ses fleurs, qui doublent avec une grande facilité.

Toutes les parties du grenadier sont inodores; aussi n'y aperçoit-on pas ces glandes vésieuleuses et transparentes qui rendent la plupart des uutres myrtacées suaves et odoriférantcs.

Propriétés et usages. Les balaustes ou fleurs du grenadicr ont une saveur extrêmement astringente, prineipalement due au tannin et à l'acide galliqque qu'elles renferment en abondanee. $\Delta$ ussi tous les observaseurs s'aecordent-ils à reeonrıâitre à ee médicamcnt une action tonique et astringente fort énergique. On emploie la décoction de balaustes, soit à l'intćrieur, soit à l'extérieur. C'est surtout contre la diarrhće ehronique que l'on en fait usage, lorsque tous les symptômes d'irritation ont disparu. On emploie alors cette déeoction; soit en tisane que l'on éduleore avee le sirop de eoings, ou tout autre, soit sous forme de lavement. Elle sert aussi à préparer des lotions et injeetions astringentes. On peut en dire à peu près autant de l'éeorce du fruit, ou dỉ péricarpe, que l'on désigne dans les pharmacies sous le nom de malicorium. Il est trc̀s-astringent, et jouit des mêmes propriétés que les fleurs; cependant on ne l'emploie gière qu'à l'extérieur. Dans les pays oì les grenadiers sont eommuns, on se sert de eette partie pour le tannage des euirs.

Les graines renfermées dans les grenades sont rougeâtres, charnucs, suceulentes et généralement d'une saveur aigrelette agréable. On les mange dans les régions mćridionales, où elles sont fort utiles pour ćtaneher la soif et rafrâehir la bouché pcndant les grandes ehaleurs de l'ćté. On peut aussi en préparer' llcs boissons rafraîchissantes, utiles dans les irritations légères des organes de la digestion, et en général dans tous les eas oì l'usage des acidules est indiqué.

Dans l'Inde, quelques pratieiens ont fait usage de l'éeorec te grenadiex en décoction conire le touia, et paraissent en avoir obtenu de grands avantages. Mais en Franec on a fort żou expérimentí ce nouveau médieament. 
Propriétés médicales et usages des Myrtinées.

Un feuillage toujours vert, des fleurs odorantes, et souvent des fruits savourcux, rendent précieux la plupart des végétaux de la famille des Myrtinées. Envisagés sous le point de vue de leur composition ehimique et de leurs propriétés médicales, ees végćtaux s'offrent à nous avec une ressemblance parfaite. En effet, deux principes s'y font surtout remarquer: l'un, beaucoup plus constant, est astringent et paraît un mélange d'acide gallique et de tannin: il existe dans les écorees, les racines, les feuilles, les fleurs et les fruits, avant ou après leur maturité. L'autre n'est point fixe de sa nature, et quclques Myrtinées en sont tout-à-fait privées : e'est une huile volatile âere et très-irritante; elle est renfermée dans de petites vésicules transparentes, qui existent dans les feuilles, les éeorees, les pétales et les fruits, cte. Assez généralement ces deux prineipes sont réunis ensemble dans le mêrme végétal; et dans des proportions à peu près égales. Ainsi dans le myrte, le géroflier, dont les feuilles et l'éeorce sont parsemées de petites vésicules pleines d'huile volatile, le prineipe astringent est assez abondant pour que dans quelques pays ees feuilles et ees écorees soient cmployćes au tannage et à la préparation des euirs?

D'autrefois, au contraire, l'un des deux principes prédomine sur l'autre. $\Lambda$ insi toutes les parties du grenadier sont cxtrêmement astringentes et nullement aromatiquies. Dans quelques autres végétaux du même ordre, on trouve au eontraire le principe volatile beaucoup plus abondant. C'est $\mathrm{d} u$ melaleuca leucortendron, L., grand arbre originaire des Indes orientales, que l'on extrait l'huile volatile de caieput, qui est d'une belle eouleur verte foncée, el d'une odeur forte ct aromatique.

Les fruits charnus des Myrtinées sont d'abord âpres et astringens; le principe aromatique n'y prédomine qu'à l'ćpoque de la maturité. Leur saveur est alors plus ou moins âcre, aromatique et eomme térébentliacée. Quelquefois, cependant, lorsque ees fruits sont très-pulpeux, il s'y développe un prineipe sueré et mucilagineux, qui, tempérant le goût aromatique, les rend d'un goût fort agréable. Les Goiaves (fruits 
MYRTINÉES.

du Psidiam pomiferum et P. prriferum, L., qui ne sont que deux variétés du même arbre), les Jamroses (fruits de l'Eugenia jambos), sont extrêmement recherchées en $\Lambda$ mérique et dans l'Inde.

La famille des Myrtinées doit donc être ajoutée au grand nombre de celles où l'on observe l'analogie entre la structure ct les propriétés médicales. Toutes, en effet, peuvent être compiées parmi les médicamens toniques ou stimulans. 


\title{
POLYPÉTALIE-ÉLEUTÉROGYNIE.
}

\author{
I. Ltamines attachées sur le calice.
}

SOIXANTE-QUATRIEMIE FAMILLE.

\section{SAXIFRAGEES. - SAXIFRAGEAE.}

LEs Saxifragées sont en général des végétaux herbacés; leur tige est rarement ligneuse; leurs feuilles sont quelquefois réunies et groupées à la base de la tige en forme de rosettes; d'autres fois elles sont alternes' ou même opposées. Les fleurs varient aussi beaueoup dans leur mode d'inflorescence. Tantôt elles sont solitaires, tantôt disposées en épis ou en corynbes. Leur ealice est toujours monosépale à quatre ou cinq divisions plus ou moins profondes, tantôt libre, tantôt soudé, dans une étendue plus ou moins considérable, avee l'ovaire. La corolle, qui manque quelquefois, se eompose de quatre ou cinq pétales, insérés au haut du tube du ealice, et alternant avec ses divisions. Les étamines, en nombre égal ou double, sont attachées au même point. L'ovaire, qui est libre, semi-adhérent ou tout-à-fait adhérent, offre une ou deux loges polyspermes: il se termine supérienrement par deux styles et deux stigmates. Le fruit est généralement eapsulaire, à une ou deux loges et à deux valves, dont les bords rentrans eonstituent la eloison. Les graines renferment un embryon placé autour d'un endosperme eharnu ou farineux.

La famille des Saxifragées sert de passage entre la classe précédente et celle à la tête de laquelle elle so trouve placée. En effet, quelques-uns des genros qui y sont réunis ont l'ovaire tout-i - fait libre; tandis que 
d'autres l'ont à moitié, ou même tout-à-fait infère. Cette particularité est -une des preuves qui attestent que la nature se joue le plus souvent de nos méthodes de classification, et fait disparaître les différenees que nous avions établies et que nous regardions comme si tranchées.

\section{S AXIFRAGE. - SAXIFRAGA.'L. J.}

Calice monosépale à einq, rarement à quatre divisions : corolle de einq ou quatre pćtales; ovaire libre ou adhérent par sa moitić inférieure avec la base du calice, à deux loges, surmonté de deux styles; ćtamines au nombre de huit à dix, insérées, ainsi que les pétales, à la paroi interne du calicc; fruit capsulaire, biloculaire, bivalve, terminé par deux cornes.

\section{Saxifrage granulé. Saxifraga granulata. L. Sp. 576 .}

Part. usit. : Les tubercules. Nom pharm. : Saxifraga alba. Noms vulg. : Perce-pierre, Rompt-pierre, Saxifrage blanc.

$\Lambda \mathrm{u}$ collet de la raeine sont rassemblés un grand nombrc de pctits tubercules rougeâtres, charnus et pisiformes. Les feuilles, qui sont presque toutcs radicales ont des pétioles d'un à deux pouces de longueur, un peu velus; elles sont rćniformes à cinq ou sept lobes très-oblus, légèrcment épaisses et velucs; les tigcs qui s'ẹn élèvent sont dressées, rameuses, hautes d'environ un pied, couvertes de petits poils eourts et rapprochés.

Les fleurs sont assez grandcs, blanches, situćes au sommet des,ramifications de la tigc.

Ie calice est subcampaniforme, à cinq divisions profondes et dressées : les cinq pétales sont ovales, subspatliulés entiers; les clix étamincs, moitić plns courtcs que la corolle, sont irrséxées vers le milieu du calicc. Le fruit est une capsule biloculaire terminée par deux corncs divergentes; elle souvre en deux valves.

Cette espècc de saxifrage est asscz eommune anx cnvirons de Paris, daus les pares de Saint-Cloud et de Boulogrie; elle fleurit au mois.de mai. 4 
Propriétés at usages. On se sert des tubcrcules de sa racine. Ils sont amers, légc̀rement Aeres et astringens, et assez fréquemment employés à la dose d'une demi-onec en déeoetion dans une pinte d'eau, eomme diurétiques. Quelques pratieiens administrent celte décoction pour combattre les petites granulations caleuleuses amassćcs dans la vessie, et aider à les en expulscr. Mais la réputation de ee remède a beaucoup diminué depuis que les médeeins n'ajoutent plus une aveuglc confiance à l'aetion des prétendus lithontriptiques, parmi lesquels on comptait jadis les tubereules de ce saxifragc.

Les autres plantes de cette famille ne nous offrent aucun intérêt.

SOIXANTE-CINQUTIS E IAMILEE.

\section{ROSACÉES.-ROSACEA.}

Les Rosacées, ainsi que l'indique leur nom, comprennent ce groupe nombreux de végétaux dont l'organisation a du rapport avec celle de la rose. Leur tige offre tous les degrés de force et de hauteur, depuis l'herbe rampante qui ne peut soutenir ses grêles ramifications, jusqu'à l'arbre fort et vigoureux dont les branches sont élancées vers les nues. Les feuilles de toutes les Rosacées sont alternes, simples, plus ou moins profondément divisées, ou enfin composées de folioles pinnées ou digitées. A la base du pétiole de ces feuilles on observe toujours deux petites stipules, qui quelquefois se soudent latéralement avec lui, ainsi qu'on l'observe surtout dans les différentes espèces de rosier. Les fleurs offrent un mode d'inflorescence extrêniement varié : elles sont tantôt solitaires et axillaires, tantôt fasciculées, tantôt en corymbes, en grappes, en épis ou en panicules. Elles sont généralement blanches, plus rarement jaunes ou rougeâtres.

Leur calice, toujours monosépale, tubuleux ou étalé, 
à cinq divisions, est accompagné quelqucfois d'un calicule cxtćricur, en partie soudé et confondu avec lui. La corolle se compose de cinq pétales ćgaux, rćguliers, étalés en rose, insérés, ainsi quc 'les étamincs, à l'cntrée du tubc du calice, ou, à la base de ses divisions, lorsqu'il est étalé. Les étamincs sont généralement en grand nombre. Celui des pistils cst très-variable. Ainsi quand lc calice est tubulcux on cn trouvc un, deux ou un grand nombre. Dans lcs deux premicrs cas, ces pistils occupent lc fond du calice; dans le dernier, ils garnissent les parois du tubc, qui souvent se resserre dans sa partie supérieure, de manic̀re à sembler former un ovaire infère. Quelquefois ces pistils restcnt distincts les uns des autrcs; d'autrcs fois ils se soudent intimcment, de manic̀re à donncr naissance à un seul et même fruit. Lorsque le calicc est étalé, lcs pistils sont rćunis sur un réceptacle central ou gynophore, souvcnt épais et charnu, commc dans le fraisier, le framboisier, etc. L'ovairc de chacun de ces pistils cst à une scule loge, qui contient un, deux ou un petit nombre d'ovules. Le style est toujours latéral, quelque fois basilaire, terminé par un stigmatc simple.

Le fruit présente dans lcs différens genres de cette famille des différcnces tellement tranchées, quc plusieurs auteurs ont cru dcvoir la partager en un asscz grand nombre de groupes distincts, dont ils ont fait autant de familles. Ainsi, tantôt le fruit est une drupe ; tantôt c'est une mélonide, ou pomme; dans quclques genres il sc composc d'un grand nombrc de petits akènes ou de petitcs ḋrupes, rćunis sur un rćccptacle commun, et environnés d'un calice étalć; dans d'autrcs, ces pctits akènes sont renfermćs dans un calicc urcćolé; enfin quelques genrcs prćsentent unc sorte de capsulc formće par la.réunion de plusieurs pistils uniloculaires, qui sc sont soudés les uns avec lcs autres. Ces modes d'organi- 
sation dans le fiuit des Rosacées ont servi de type a l'érablissement do six sections, auxquelles on a donné des noms particuliers, et que plusieurs auteurs considèrent comme des familles différentes. Nous en exposerons successivement les caractères.

PHEMI I H B SCTYON.

FrAGA R I ĆÉR. Rich.

Cette section se compose de végćtaux herbacés ou rarement frutescens ; leur calice cst étalé, persistant, à cinq divisions, quelquefois aecompagné d'un ealieule extérieur soudé avec lui. La eorolle se eompose de cinq pétales. Les étamines sont fort nombreuses. Les pistils sont groupćs au eentre de la fleur sur un gynophore, qui souvent devient eharnu. Les fruits sont des akènes ou de petites drupes monospermes rérunies en tête. Les feuilles sont toujours composées.

I Calice accompagné d'un calicule soudé ạvec lui.

$$
\text { FRAISIER. - FRAGARIA. L. J. }
$$

Cálice étalé, persistant, à dix lobes, dont einq externcs, formés par lc calicule; corolle de cinq pétales; akc̀nes légèrennent charnus, portés sur un gynophore globuleux, qui devient pulpcux, charnu, et prend beaucoup d'aceroissement. Plantes vivaccs, ì tiges étalées et stolonifères.

Fraisien commun. Fragaria vesca. L. Sp. 708.

Part. usit. : les fruits, les racines. Nom pharm.: Fragaria.

Sa raeine forme une touffe de fibres brunâtres, allongécs, grêles, un peu ramcuses, donnant naissance supérieurement ì plusieurs tiges, les unes dressées ct florifères, hautes de trois a six pouces, velues, ainsi quc les autres partics de la plantc; les autres ótalécs, formant autant de rejets ou stolons, qui s'enracinent de distance cn distance, ct constituent des faisccaux de nouvvellos tiges. Les feuilles sont radicales, pétiolées, trifo- 
liolées. Les folioles sont sessiles, ovales, un peu ondulcuses, it dentelures profondes sur leurs bords, marquées de veines tréssaillantes à' leur face inférieure. Les fleurs sont blanches, rassemblées au nombre do einq à six à l'extrémité des rameaux florifères. Le ealice est monosépale, étalé, à dix divisions profondes, einq extérieures plus étroites, et presque linéaires, appartiennent à un involucre ou ealicule soudć avec le véxitable ealice, qui est formé des cinq divisions intérieures, plus larges et aeuminées. La corolle est composée de einq pétales' étalés en sose, orbiculaires, arrondis, entiers, coneaves; offrant un onglet extrêmement eourt. Les étamines sont insérées à la base les divisions du caliee, dont la face supérieure se trouve ćpaissie par une substanee jaunâtre et glandulaire, formée par le disque périgyne: Les pistils sont rassemblés en tête hémisphérique au centre de la fleur. Ils sont portés sur un renflement - eharnu particulier, qui prend ensuite un très-grand accroissosnent, devient mou et pulpeux, et forme la partie du fruit que l'on mange. Chaque pistil se compose d'un petit ovaire ovoïde, presque réniforme, uniloculaire, uniovulé. Le style est latéral : il part du milieu d'un des eôtés de l'ovaire ; il est court et cylindrique; terminé par un petit stigmate plane à peine distinct.

Les fruits sont autant de petits akènes granuleux durs, renfermant une seule graine, réunis et portés sur un réceplacle cliarnu, rougeâtre à l'extérieur, blanc et pulpeux à l'intérieur ; l'une forme arrondie.

Le fraisier croit abondamment dans tous les bois aux envisons de Paris. On en cultive un grand nombre de variétés dans le jardins. Il fleurit et fructifie successivement pendant tout l'éé. ’̧

2ropriétés et usages. Il n'est personne qui ne connaisse les fruis du fraisier, et qui -n’ait 'appréeié leur saveur délicieuse et la szavitć dc lcur arome. Il s'en fait pendant l'ćté une énorme conscmmation sur nos tables. Saupoudrées de sucre et arrosées de vin ou de crême, les fraises sont au dessert un mcts fort recherché. Elles conviennent surtout.dans les grandes chaleurs (e l'été, et aux individus qui digèrent avec facilité; car chez:les fersonnes faibles, lymphatiques, ou dont l'cstornae ost. pixpes- 
seux, on les voit quelquefois occasioner une réritablc indigrestion. C'est dans ces circonstances qu'il est surtout utile d'y joindre du vin pur, pour en faciliter la digestion. On peut préparer, avec les fraises éerasées dans l'eau, unc boisson tempérante et rafraiehissante, propre, dans les différens cas d'inflanmation, pour diminuer la chaleur animale et l'impétuosité du cours du sang.

L'usage long-temps continué des fraises prises en grande quantilé, a souvent déterminé dans l'éeonomie animalc des ehangemens extraordinaires, et amené la guérison d'affeetions graves, qui avaient resisté à beaucoup d'autres remèdes en apparence plus aetifs. Cependant il faut se tenir en garde contre les ássertions un peu cxagérées des auteurs qui ont écrit sur ee sujet, et ne point s'en laisser imposer par l'autorité des noms. Linnć, dans une disscrtation spéciale publiée parmi ses Aménités Académiques, dit que ees fruits font disparaître en peu de. temps les eonerétions tofacées, qui se forment dans les articulations, à la suite de la goutte. Hoffmann et Sehulz assurent que l'usage des fraises a ramené promptement à la santé des individus affeetés de fic̀vre heetique et de phthisie pulmonaire trèsavancée. D'autres les ont vu apporter in soulagement réel dans la gravelle et les autres affeetions calculeuses. De pareils assertions ont bcsoin d'être de nouveau vćrifiées par l'expérienee, avant d'y ajouter pleinement foi.

La raeine de fraisier est plus fréquemment employée eomme. médieament, que les fruits. Elle a une saveur amère et sur. tout astringente. Sa déeoction est d'un rouge foncé, et contiest du tannin et de l'acide gallique. On peut en faire usage dars la diarrhée et les hemorrhagies dites passives. Mais aujorrd'hui elle est presque inusitée, après avoir joui d'une grade vogue contre plusicurs maladies différentes. Dans queljues pays les habitans des eampagnes se servent des feuilles en ?laec de thé.

\section{POTENTILLE. POTENTILLA. L. Nestl.}

Caliee étalé, à dix lobes; eorolle de cinq pétales ; akèncs rćtnis en tête sur un réecplacle qui ne prend pas l'aeeroissemeıt et ne devient pas eharnu. 
Ce genre diffère du fraisier par son gynophore, qui ne devient point pulpeux.

Potentille ansenine. Potentilla anserina. L. Sp. $7 \mathbf{r} 0$. Bull. t. 157 .

Part. usit. : les feuilles et la racine. Nom j) harm. : Anserina s.' Argentina. Nom vulg. : Argentine.

C'est sur le bord des étangs et des ruisseaux què croît cornmunément l'argentine. Ses tiges sont faibles, étalées ct stolonifères. Ses rejets, semblables à ceux du fraisier, s'enracinent de distance en distance, et donnent naissance à des touffes de feuilles. Celles-ci sont interrompu-pinnées, toutes couvertes d'un duvet blanc et soyeux, d'où la plante a tiré le noin d'ar'gentine, sous lcquel on la connait généralement; ses folioles sont ovales, aiguës et profondément dentées en scie. Ses pédonculcs sont cylindriques, soyeux, axillaires, portant à leur sommet une seule fleur assez grande et d'une belle couleur jaune de soufre. L'argentine fleurit pendant tout l'été. $₹$

Propriétés et usages. La racine et les feuilles de cette plante ont une saveur astringente. Leur décoction, qui est rougcâtre et noircit par le sulfate de fer, peut être employée comme tonique, soit dans les diffćrens cas de diarrhée chronique ou d'hémorrhagies passives, soit à l'extćrieur sous forme de lavemens, de lotions ou d'injections. Lorsque les feuilles et la racine d'argentine ont bouilli pendant quelque tcmps, elles, perdent leur saveur astringente; et dans quelques contrćes, les paysans les mangent comme herbes potagères.

Une autre espèce du genre potentille jouit absolument des mêmes propriétés, et s'emploie dans les mềnes circonstances: je veux parler de la euiNTefedilLE (potentilla reptans, L.), qui différc de la précédente par ses fcuilles, dont les foliolcs, au nombre de cinq, partent en divergeant du sommet du pétiole commun. Elle cst commune sur le bord des chcmins et des lieux incultes.

On peut en dire à peu près autant de la rormentily. (tormentilla crecta, L.), qui ne diffèrc génériquement des potentilles que par son calice à huit divisions seulcment et sa 
corolle de quatre pétales. C'est une petite plante vivace, dont les tiges sont grêles, redressées et rameuses, portant des f́euilles presque sessiles formées de trois à einq folioles digitées, profondément dentées, ovales, oblongues et velues. Leś fleurs sont jaunes, petites, pédoneulées, axillaires et solitaires.

La plupart des auteurs modernes réunissent les tormentilles au genre préeédent.

Toutes les parties de eette plante ont une saveur astringente très-prononeée. On a fait usage de sa raeine en décoction dans toutes les maladies qui réelament l'emploi des toniques astringens; et en particulier dans la leueorrhée, les hémorrhagies, la diarrhéc, lorsque tous les signes de l'irritation avaient disparu. On en prépare également des lotions, des lavemens et des injections.

\section{BEN OITE. GEUM. L. J.}

Ce genre diffère des potentilles par ses akènes, qui sont terminés par une longue pointe recourbée en erochet à son sommet, ou velue et plumeuse; du reste, sa fleur offre les mềmes earaetères.

Benoite ofriciñale. Geum urbanzm. L. Sp. 7 r 6.

Part. usit.: "la racine. Nom pharm. : Caryophyllata. Noms vulg. : Herbe de Saint-Benoît, Gariot, Récise, etc.

Sa raeine est vivaee, brunátre, lıorizontale, garnie d'un grand nombre de fibrilles capillaires. Elle donne naissance à plusieurs liges dressées, hautes d'un à deux pieds, velues et presque simples. Les feuilles radieales sont longuement pétiolées, velues, interrompu-pinnées, composées le plus souvent de neuf folioles, quatre petites et einq grandes : ees folioles sont inégales, profondément dentées et ineisées : la terıninale cst beaucoup plus grande, partagée presque jusqu'à sa base en trois lobes arrondis, subcuuéiformes, dentés et incisćs. Les feuilles eanlinaires sont presque sessiles, eomposées seulcuent de trois folioles inćgales: à la buse de leur pétiole; qui est eourt, se irourent deux stipuules foliacces, oviles-arrondies, aiguës, subcordiformes. 
Les fleurs sont assez petiies, jauncs, solitaires et terminales. Le calice est étalé â son limbe, qui est profondément jartaģé en cinq divisions lancéolées, aiguës, entre chacune desquelles se trouve une petite languette foliacée très-étroite; le tube est court et turbiné. La corolle est formée de cinq pétales elliptiques, obtus et entiers, rétrécis à. leur base, étalés, un peu plus longs que le ealice.

- Les étamines, au nombre de trente environ, moitié plus courtes que la corolle, sont, éomme elle, insérées au pourtou: du tube ealicinal:

Les pistils sont très-nombreux, et forment au centre de la fleur un eapitule serré, il's sont insérés sur un gynophore arrondi. et globuleux. Chaque pistil offre un ovaire obovoïde allongé, aminci à sa base, hérissé de longs poils : de sa partie supérieure et latérale naît un style reeourbé à son sommet et formant une sorte de petit erochet avee lequel est artieulé un stigmate allongé, grêle, un peu plus court que le style. Toutes ees parties sont persistantes, et s'accroissent même pour former le fruil, qui est un akène terminé par une longue pointe offramí un croehet en forme de hameȩon vers sa partie supérieure.

La benoite eroît dans les lietix incultes, le long des murs, et sur le bord des bois. ₹

Propriétés et usages. La raeine de benolte a joui d'une trèshaute réputation: quelques médeeins allemands et franȩais.la regardent comme un des meilleurs suceédanés indigènes $d u$ quinquina.

On trouve dans le deuxième volume du Bulletin de Pharmacie une analyse des principes que renferme eette racinc. MM. Moretti et Melandri en ont retiré du tannin, de l'extractif oxigénable, del'extractif muqueux, de l'huile volatilo ct différens sels.

Elle doit être recueillie au printemps, époque où ses principes paraisscnt être plus aetifs et plus eoneentrés. Elle se eompose d'une touffe de fibres brunâtres extérieurement, et ronges à leur intérieur. Sa saveur est légèrentent amèrc, astringente et aromatique. Son odeur, quand elle cst fraîche, approche beaucoup de eelle du gérofle : c'est pour cette raison qu'clle porte dans Ics pharmacies le nom de caryoplygliata. 
D’après ees qualités, on voit que la racine de benoite doit étre placée parni les médieamcns toniques et excitans. Aussi lcs auteurs de matière médicale signalent-ils ses heurcux résultats, lorsqu'on l'administre dans les diarrhées et les autrcs catarrhes chroniques, dans les hémorrhagies passives, surtout eelles qui ont leur siége dans l'utérus. Mais e'est spécialement eomme fébrifuge que l'on a prodigué à ce remède indigène les plus grands éloges; et l'expérience a en effèt souvent justifié l'attente des praticiens qui l'araient employé. En général, on l'administre eontre toutes les maladies qui réelament l'emploi des médieamens toniques. Quand on la donne eomme fébrifuge, sa dose est de demi-onee à deux onees dans l'intervalle des aecès, suivant le type et la nature de la fièvre. Elle mérite d'être employée.

Une secondc espèce du même genre, le geum rivale, L., qui est commune le long des ruisseaux et dans les prés du nord de la France, jouit des propriétés analogues et s'emploie dans les mêmes eirconstances.

$2_{2}^{\circ}$ Calice simple et sans calicule.

\section{RONCE. - RUBUS. L. J.}

Calice plane à dix segmens; pistils nombreux réunis sur un gynophore protubérant, qui s'aeeroît après la fécondation, et cst recouvert de petites baies monospcrmes, souvent cntregreffées les unes aree les autres.

Ronce DU mont IDA. Rubus Idceus. L. Sp. 708.

\section{Vulgairement : Framboisier.}

Arbuste de trois à six pieds d'élévation, dont les ramcaux sont allongés, très-glabres., armés de quelqucs aiguillons courts et pcu piquans. Ses fcuilles inférieures sont pétiolées, imparipinnécs, composées de cinq folioles, sessilcs, ovalcs, très-aiguës, un peu cordiformes à la base, doublement serrées, glabres en dessus, blanchics et tomenteuses en dessous. Lc pétiolc eommun présente souvent quclques aiguillons. Les feuilles supérieures sont eomposées seulement de trois folioles. 
Les fleurs sont blanchàtres, disposćes à l'aissellc des fcuilles supérieurcs ct au sommct des rameaux, en unc espèce de grappe pauciflore. Les pédoncules, qui sont grêles et glabres, sont garnis de petits "aiguillons. Le calice est presque planc à sa partie centrale; quinquéparti : ses divisions sont ovales, lancéolées, aiguc̈s, réfléchies en dessous, un peu vclues sur les bords. La corolle se compose de cinc pétalcs, petits, dressés, comme trapézoïdes, un peu obtus. Les ćtamines, très-peu nombreuses, sont dressées, serrées les unes contre les autres, un peu plus courtes que les pétales, insérées à la basc des divisions du calice, à une certaine distanice en dehors des pistils. Ceux-ci, réunis en grand noubre, forment un capitule au centre de la fleur. Ils sont, portés sur un réceptacle conique. L'ovaire est réniforme, velu, terminé latéralement par un long style grêlc, au sommet duquel est un stigmate très-petit. Le fruit, qui portc le nom de framboise, est formé d'un grand nombre de pletites drupes rouges ou blanches, trés-charnues, scrrées intimement les unes contre les autres; et réunies sur un gynophore conoïde allongé.

Cet arbuste est abondamment cultivé dans les jardins.

Propriétés et usages. Les framboises ont une saveur sucrée; un peu acidule et aromatique. On les mange ordinairement mélangées avec les fraises. Infusées dans le vinaigre, elles forıent le vinaigre-framboisć, avec lequel on prépare lc sirop de vinaigre; si fréquemment employe dans les inflammations légères du canal digcstif et de la gorge. On prépare avec le jus des framboises ct du sucre, différentes gelées ou conserves : leu'r suc fermenté forme un vin très-employé dans différentes provinces de la Pologne et de la Russie.

Les autres espéces de ce genrc présentent beaucoup: d'analogie avec le framboisier. Leurs fruits, 'en général plus fades, sont cependant assez bons à manger; et'les enfans, dans les campagnes, en consommént unc grande quantité. Les feuilles et les sommitís de la Ronce comm uve ( $R$. fruticosus. L.) et de quclques autres espèces voișines, qui sont communes dans nos bois et nos haies, sont astringentes. Leur dócoction est prescrite, à l'intéricur et extéricurcment, pour préparer des boissons ou des lotions toniques et détcrsives. Leurs fruits, auxquels quel- 
ques auteurs ont à tort attribué des qualitćs malsaincs, jouissent des mêmcs propriétés que les framboises, 'et pourraient leur être substitués dans bien des cas.

DEUXI I I B SBCION.

S SIRÉACÉES.

Celte section, esscntiellement formée du genre spiraca, a pour caractères: un calice simple, à cinq divisions ouvertes, unc corolle de cinq pétales; des ćtamincs nombrcuses, et, pour fruit, dc trois à douze capsules soudécs par leur côte intcrne, s'ouvrant en deux valves, et contenant chacune une ou plusieurs graines.

Deux espuces appartenant au genre Spiréc ont étć autrefois cmployées cn médecine, ce sont: $\mathrm{l}^{\circ}$ l'ulmaire, ou reinc des prés, spirea ulmaria, L. Sp. 702. C'est unc jolie plante vivace qui croit en abondancc dans nos prés, où elle se fait remarquer par ses grandes feuilles pinnées, d'un vert foneé en dessus, tonncnteuses et blanchâtres cn dessours, ct par ses fleurs d'un beau blane, qui forment un corymbe très-serré à la partie supérieure de la tige. Ces fleur's sont odornintes.

Sa racine, qui a une saveur astringente, ćtait jadis fort employéc comme tonique dans le traitcment des catarrhes chroniques et des hémorrhagies. passives. Ses fleurs sont légèrement excitantes. Leur infusion pent facilement remplacer celle des fleurs de sureau. On fait peu d'usagc de cette plante aujourd'hui.

$2^{\circ}$ La fulpendule, spirca. flipendula, L. Sp. 702, n'cst pas rare, au printemps, dans les bois sablonneux des environs de Paris. Sa racine, qui est vivace, se composc d'une touffc dc fibres noirâtres, qui prćsentent de distance en distance des renflcmens charnus, de forme ct de grosscur varićcs. Ses feuilles, qui sont ćtalées en rosette à la basc de la tigc, sont partagées en un trčs-grand nombre de divisions finement découpces, vertes des deux côtés. La tigć est simple ct se termine par un coryunbc ilc jolies fleurs blanchics.

Lcs tuberculcs de la filipendule sont charnus; . Blancs inlérieurement. Ceuillis au printemps, ils répandent unc légèrc 
odeur de fleur's d'oranger, qui disparait par les progrc̀s de la végétation. Ils sonit eomposés en graude partie d'amidon; et, dans quclques eas de disétte, on en a fait usage comme aliment. Lorsqu'ils sont sees, l'odeur' disparait, et on leur trouve une saveur légèrement amère et astringente, qui a engagé quelques auteurs à les preserire contre les flueurs blanehes. Inusités aujourd'hui.

TROYSI È ME SECTION.

A GRIMONIÉES.

Cette seetion est caraetérisée par un cáliee tubinleux, conte'nant un, deux ou plusieurs pistils, sur lesquels il est inımédiatement appliqué, La eorolle manquie quelquefois. Les éramines sont nombreuses, insérćes au haut du tube. Le fruit se ' compose d'un ou plusieurs akènes renfermés dans l'intérieur du ealiee. Les fleurs sont quelquefois unisexućes.

\section{A I GREMOINE. - A GRIMONIA. L.J.}

Caliee turbiné, hérisșé supérieurement de petitcs lanières çroehues, resserré dans sa partie supérieure. Etamines de quatorze ì vingt. Pistils, au nombre de deux, se changeant en deux akc̀nes mẹnbranẹux, entic̀rement enveloppés par le calice, qui est hérissé.

Plantes toutes herbacćes.

Argremoine officinale. Agrimonia eupatoria. L. Sp. 645 . Blackw. t. : 2 I.

Part. usit. : les fẹulles. Nom pharm. : Agrimonia.

D'une raeine vivaee s'ćlève une tige hcrbacée, dressée; presque simple, poilue, -ainsi que toute la plantc, : cylindrique, hautc d'environ deux pieds. Elle portc des fcuilles alternes, interrompu-pinnées, à foliolcs ovalcs, lanećolées, aiguës, profondément-dentées, entremếlées de folioles très-petites, irrégulières, et ieeompagnées de stipules foliacées, semii-cordiformes, aiguës, profondément dentécs. 
Les flcurs sont jaunes, disposćes en épi lerminal. Chacune d'elles est courtement pédonculée, munie d'une braetée trifide. Elle offre un caliee monosépale, dont le tube est turbiné; le limbe a einq divisions övales, aiguës, garnies en dehors d'un grand nombre de filamens, situés surtout à la base du limbe; le tube est recouvert de deux petites bractées poilues, profondément dentées. La eorolle est formée de cinq pétales étalés, entiers, jaunes, obovales. Les étamines, au nombre de dix-huit à vingt, sont dressées, attachées à la gorge du calice. Il y a deux pistils insérés par leur base au fond du tube du caliee, qui est reserrć sur eux.

L'ovaire est arrondi, uniloculaire et monosperme, surmonté d'un style filiforme latéral et saillant, de la hauteur des étamines, et que termine un stigmate simple et très-petit. Le fruit est eomposé de deux akènes mcmbraneux, renfermés dans l'intérieur du calice, qui est persistant et hćrissé.

L'aigremoine est très-eommune le long des chcmins, sur Ia lisière des bois, oủ elle fleurit pendant une grande partie de l'année.

Propriétés et usages. Une saveur lćgèrement âpre et astringente, est la seule qualité sensible des feuilles d'aigremoine. On emploie surtout leur décoction pour préparer des gargarismes détessifs, dont l'usage est utile dans les inflammations légc̀res de la bouche et de la gorge. Quant à leür emploi dans la diarrhée, les đlueurs blanehes, etc., il est bien moins fréquent aujourd'hui qu'autrefois, et les pratieiens n'y ont que bien rarement recours.

Deux autres petites plantes du même groupe mćritent aussi d'être mentionnées ici; ce sont: $x^{\circ}$ l'ALCHeMille, ou pied de lion, alchemilla vulgaris, $\mathrm{L}_{\text {., }}$ qui est vivaee, et eroit dans les pâturages et les prés sees; elle a des feuilles longuement pétiolées, divisées en sept ou neuf lobes arrondis et dentćs, des fleurs verdàtres et petites. Toutes ses parties sont légèrement astringentes. Les aneiens l'employaient assez fréquemment dans les cas qui demandent l'usage des légers toniques. Quelques auteurs, et entre autres Frédéric Hoffmann, lui attribuent une propriété bien propre à lui faire rendre une sorte de culte par certaines dames. Ils prétendent que sa décoction a la vertu de réparer les 
outrages du tcmps, et de rendrc à leurs eliarmes la fraîchcur et l'éclat du printemps.

$2{ }^{\circ}$ La Pimprenelle, poterium, s. sanguisorba, L. qui croit communément dansles lieux incultes sur le bord des chemins, et qui se distingue par ses fleur's rougeâtres et réunies en tête, ordinairement polygames, par ses feuilles imparipinnces, dont les folioles sont arrondies et dentées. Ces feuilles ont une saveur âcre etj aromatique. Elles sont légèrement excitantes, et maintenant on ne les emploie plus que comme assaisonnement dans certains àlimens.

Q UATAI ERI STGTION.

A MY Y A L INÉE OU DRUPACÉES.

Les caractères de cette section sont fort tranchćs, et la distinguent nettement dc toutes les autres. Elle comprend tous les genres dont le fruit est une drupe cliarnue, contenant un seul noyau, à deux graines, ou à unc seule par avortement.

\section{PRUNIER. - PRUNUS. Tourn.}

Calice campanulé, cáduc, à cinq lobes; corolle de cinq pétales; étamines nombreuses, insérćes circulairement au haut du tube calicinal. Drupe ovoïde, lisse, glauque, marquée d'un sillon longitudinal, contenant un noyau rugueux, comprimé, terminé en pointe, et creusć 'd'une gouttière sur l'une de ses deux sutures.

\section{Prunier domestique. Prunus domestica. L. Sp. 68 o.}

Cet arbre est d'une taille médiocre; ses rameaux sont ćtalés, recouverts d'un ćpidermc grisâtrc, tomenteux à leur extrémité supérieurc; son bois est rougeâtrc, plus'ou moins vciné. Ses feuilles sont alternes, pétiolées, ovales, oblongues, acuminćcs, glabres cn dessus, pubescentes en'dessous, dentécs en scie sur lcur bord. Lcs flcurs sont blanches, pédonculécs, disposćes par pctits bouqucts composés de deux, trois ou quatrc fleurs. Le'tube du calicc cst'très-court, turbiné; le limbe a. 
cinq divisions obtuses, étalécs, un peu glanduleuses, et denticulées sur les bords. La corollo est pentapćtale, blanehe, étalée. Les pétales sont arrondis, très-obtus, entiers, un peu coneaves, brusquemcnt onguiculćs. Les étanines, d'inégale graudeur, sont au noinbre de vingt à vingt-cinđ̃. Le pistil est libre, entièrement glabre ; l'ovaire est eomme pyramidal, à une seule loge qui renferme deux ovules. Le style est subulć, terminé à son sommet par un petitstigmate un peu élargi et aplati, qui se continue par un sillon glanduleux sur un des eôtés du style. Le fruit est arrondi, charnu, lisse et glabre à l'extérieur, recouvert d'un enduit résineux très-léger et très-minee, s'enlevant facilement, et que l'on désigne vulgairement sous le nom de fleur. Ces fruits présentent des variétćs innombrables sous le rapport de la forme, du volume, de la couleur, ete. Le prunier, qui est originaire des environs de Damas, se eultive dans tous les jardins. Ses fruits sont mûrs à la fin de l'étć.

Propriétés et usages. Lorsque les prunes sont parvenues à leur ćtat parfait de maturité, elles forment un des fruits les plus délicieux dc nos climats. Leur saveur douce et sucrée est rendue encore plus agréable par un arome fin ét dćlicat. En effet, existe-t-il un fruit meilleur qu'une bonne prune de ReineClaude bien mûre? Aussi en fait-on unetrès-grande consommation pendant les ehaleurs de l'été. Cepcndant les personnes faibles, ou dont l'estomae ne digc̀re que péniblement, ne doivent pas en abuser et en manger une trop grande quantité à la fois; car alors elles deviennent laxatives, et oceasionent souvent des diarrhées opiniâtres. Ces fruits ont le grand avantage de pouvoir êtrc conservés pendant l'hiver. Séchés au soleil, après avoir été passés au four, ils forment les pruncaux, qui sont à la fois un aliment et un médicament. Ceux que l'on prépare avec les grosses espc̀ces, telles quc la Saintc-Catherine, la ReineClaude, etc., ont une saveur agréable et très-sneréc, et on les sert sur nos tables au dessert. On en permet l'usage aux convalescens, lorsqu'il n'est pas encore prudent de prescrire des alimens tirćs du rc̀gne animal. Mais lorsqư'ils ont été faits avce la petile prunc de Damas, ils ont unc savcur un peu Âpre, ế acrissent comme laxatifs. On les emploic assez fréquemment pour purger lcs enfaus, ou bien leur déeoction sert d'exeipicnt pous 
des substances purgatives, dont elles masquent en grande partie la saveur désagréable.

Lcs prunes contiennent une assez grande quantité de sucre pour que plusieurs chimistes aient proposé de l'en extraire. Aussi en retire-t-on par la fermentation beaucoup d'alcool; et en $\mathrm{Alsacc}$ et une partie de l'Allemagne, c'est presque le seul dont le peuplc fasse usage.

On voit souvent suinter du tronc et des branches des vieux prunicrs une matière visqueuse, quì se durcit et se sèche, et forme une véritable gomme. Cette gomme, connue dans les pharmacies sous le nom de gummi nostras orı gomme du pays, est très-soluble dans l'eau, douce, insipide, translucide, un peu colorée en brun-rougcâtre. Elle pourrait être substituée rà là gomme arabique dans toutes les circonstances où l'on se sert de ce produit exotique:

Les amandes des pruniers contiennent une grande quantitć d'huile grasse. Dans les cnvirons de Briançon, on retire d'une variété de prunicr désignéc par Villars sous le nom dé prinus brigantiaca, une huile fixe connue sous le nom vulgaire d'huile de marmotte. Elle est douce et agréablc; on l'emploie aux mêmes usages que l'huíle d'olives et l'huile d'amandes douces.

Le prux.ÉLLier, prunus spinosa, L., autre espèce du mêne gcnre, s'en distingue par ses rameaux terminés èn pointé épineuse à leur sommet, par ses fruits dé la grosseur d'une petile cerise, et qui sont d'une âpreté extraordinaire. Cependant ils s'adoucissent un peu quand ils ont été frappés par la gelée : íls sont alors recherchés par les enfans. On préparait autrefois avec ces fruits encore verts, un extrait fort âpre et 'astringent, que l'on appelait acacia nostras, et que l'on employait comme tonique et astringent dans les différens flux atoniques. Ce médicament, que l'on tirait surtout d'Allcmagnc, est à peu prc̀s inusité aujourd'hui. L'écorce de cet arbrisscan a une savcur amèrc et astringente; elle nc manque pas d'une certainc action tonique, et. quelques auteurs l'ont inscrite parmi les nombreux succćdanćs indigènes de l'écorce du Pérou. 


\section{CERISIER. - CERASUS. 'Tourn.}

Calice eampanulé à cinq divísions courtes ct obtuses, cadue : drupe eharnue, arrondie, marquée d'un sillon longitudinal; noyau lisse, fruit non recouvert d'un vernis glauque. Ce dernier caraetère est presque ic seul qui distingue les eerisiers des pruniers, que linné avait réunis en un seul genre.

Cenisier commun. Cerasus vulgaris. Mill. dict. I. Prunus cerasus. L. Sp. 676.

Le cerisier; originaire du royaume de Pont, fut apporté á Rome, vers l'an 68o, par le fameux Lucullus.: de là il se rćpanditdans le reste de l'Europc. C'est un arbre assez élevé, qui, lorsqu'il eșı eultivé, a ses rameaux un peu élalés, de manière queleur ensemble forme unc tête arrondie. Son trone est droit ct cylindrique; son écorce lisse et luisante; son bois rouge et recher'clé pour les ouvrages de tour. Ses feuilles sont pćtiolées, pendantes, ovales, aiguës, denlćes en scie, pręqque glabres. Ses fleurs sont blanches, pédonculécs, et forment des fascicules qu bouquels cnvironnés à leur base par les ćcailles des boutons qui les renfermaient. Le ealice cst.campanulé, à cinq lobes couris et arrondis; il est caduc. La eorolle cst formée de einq pélales. I.e fruit est une drupe charnue, arrondie, d'un rouge vif, marquée d'un sillon longiludinal. Ses fruils, qui mûrissent verrs la fin de juin, sont eonnus sous les noms de ceriscs, griottes, elc.

Propriétés et usages. Les cerises, lorsqu'elles sont bien mûres, ont une savcur sucrće et légèrcment acidule. Leur chair cst jaunâtre, suceulente, molle et fondante. On cmploie asscz souvent le sue exprimć de ees fruits pour faire des boissons rafraîchissantes, que l'on administre dans lcs différentes inflammations; on l'étend d'eau, et on l'édulcore avec une quantité proportionnće de suerc. On eonserve les eerises par différens procédés, soil en les faisant sécher au soleil ou au four, soit en préparant avce elles des confiturcs, soit cufin en les confisant dans l'eau-de-vie. Les queucs de cerises sont fort cmployćcs dans la médeeine populairc comme diurétiques.

Le marasquin, liqueur de tablc fort cstiméc, et quc l'on 
prépare surtout à Zara, en Dalmatie, se fait avee une variété partieulière de eerises que l'on fait fermenter, dout on retire l'alcool, que l'on édulcore avec dusuere.

LE MERISIER, cerasus avium, M œneh., est très-commun dans nos bois, où il acquiert une hauteur de trente-six à quarante pieds. Ses feuilles sont plus étroites que dans l'espèce précédente, velues; ses rameaux redressés. Ses fruits ont la ehair plus ferme, plus suerée. C'est à celte espèce que se rapportent les variétés eonnucs à Paris sous les noms de guignes, ou eelises noires, et de bigarreaux. Elles sont moins estimées que les eerises, et sont bien moins saines.

C'est avee les ınerises noires que l'on prépare, dans les Vosges et la Forêt-Noire, l'eau de eerises, ou kirschen-wasser, qui doit son odeur forte et sa saveur un peu arnère à l'aeide hydroeyanique ( $\Lambda$. prussique.) qu'elle renferme. Ces fruits sont égale- . ment un des ingrédiens de plusieurs autres liqueur's de table, tel que le ratafia de Grenoble, ete.

Le merisier a Grappes, C. padus, D. C. Fl. fr., eroît égalemént dans nos·bois. Son éeoree, qui est légèrement amère et astringente, est tónique. Elle a été proposée comme l'un des' sueeédanés indigènes du quinquina.

Le cerisier mahaleb, ou bois de Sainte-Lueie, C. Mahaleb, Mill., se trouve en Franee dans les haies el les bois. Ses fleurs sont blanehes, petites, disposées en bouquets eorymbiformes. Ses fruits et son bois, autrefois employés, les premiers eomme lithontriptiques; le seeond eomme sudorifique, sont aujourd'hui tombés dans un juste oubli.

\section{Cerisier liaurier-Cerise. Cerasus lauro-cerasus. .} Prunus lauro-cerasus. L: Sp. 67.8 .

Vulgairement : Laurier-Cerise, Laurier-Amandier.

Arbrisseau de quinze à vingt-einq pieds d'élévation, dont le trone est rameux, assez lisse, noirâtre à l'extérieur, le bois très-dur et rougeâtre, surtont quand il a été exposé à l'air. Originaire des bords de la Mer Noire, le laurier-amandier a été transporté en Europe vers la fin du seizième sièele. Il réus- 
sit très-bien en Franee, surtout dans les provinces méridionales.

Ses feuilles, qui sont persistantes et toujours vertes, sont presque sessiles, ćtalées, et distiques sur les rameaux qui les supportent; elles sont obovales, allongées, acuminées au sommet, dentienlées sur leurs bords, vertes et luisantes en dessus, plus pâles en dessous; leur consistance est eoriace.

Leurs fleurs forment des épis axillaires, dressés, longs de trois à quatre ponees; chaque fleur est portée sur un pédicelle très-eourt; elles sont blanehes, petites, et rćpandent une odeur très-forte d'aeide hydrocyanique ( $\Lambda$. prussique.). A ces fleurs succc̀dent des drupes ovoïdes un peu allongées, ayant la forme et la eouleur de la variété de eerises 'connue sous le nom de guignes, mais plus petites. Leur saveur est douceâtre et fade.

Propriétés et usages. L'arome particulier que eontiennent les feuilles, les fleurs et les noyaux du laurier-cerise, est dù à la présence de l'acide hydroeyanique. Or, eomme eet àcide exeree une influienee très-délétère sur l'homme et les animaux', il ćtait tout naturel de soupçonner les mêmes qualités dangereuses dans le laurier-eerise. Aussi l'eau distillée de ses feuilles, et surtout leur huile esscntielle, passent-t-elles auprès de tous les médeeins pour un violent poison. La première, administrée à la dose d'un ou deux gros, a donné la mort à des chiens soumis à l'expérience, ou à des malheureux, victimes d'une imprudence ou d'une méprise funeste.

Cependant on a essayé l'emploi de l'eau distillée de lauriereerise dans la thérapentique. Quelques médecins la regardent comme très-efficaee contre les affections lentes et chroniques des viseères abdominaux, surtout chez les individus affeetés d'hypocondrie. Quelques autres paraissent en avoir retirc du sucec̀s, en l'administrant prudemment dans le eas de palpitations dn cœur.

M. le professeur Fouquier, voulant reeonnaitre les effets de l'eau distillée de lanrier-eerise sur l'éeonomie animale, afin d'appréeicr ses propriétés curatives, a fait un très-grand nombre d'expćrienees à l'hôpital de la Charité. $\Lambda$ yant reeonnm, non sans ćtonnement, que les doses indiquées pour l'administration de eclte substanee n'oeeasionaient aueun phénomènc 
appréeiable, il les a suecessivement augmentées sans jamais cn obtenir aueun effet sensible. Il a porté eelte dose à quatré, huit, douze onees, et même plus dans un seul jour, sans que les malades en éprouvassent aueun effet marqué. Croyant d'abord qu'un semblable résultat pouvail dépendre de la mauvaise préparation du médicament, il s'est ensuite servi de eette eau distillée préparée chez les meilleurs pharmaciens de Paris, et les résultats ont toujours ćté les mêmes. J'ai möi-même étć témoin de ces faits. On doit naturellement en eonelure que l'eau distillée de laurier-eerise n'est point aussi aetive qu'on lé cróit génćralement, el que son usage trop incertain doil la fäire bannir de la thẻrapeutique. On emploie quelquefois l'eaù de lairier-cerise pour' aromatiser le lait.

\section{A M A N DIER. $-A M Y G D A L U S$. Tournef.}

Ce genre offre dans l'organisation de sa fleur les mêmes earaetères que le prunier, et n'en diffère que par ses fruits recouverts d'une pellicule tomenteuse, ayant la chair peu épaisse et presque sèche, et le noyau creusć d'un grand nombre de sillons irréguliers.

Amandér curtiví. Amggdalus communis. L. Sp. 677.

Var. : a. Dulcis.

Var.: $\beta$. Amara.

L'amandier a les rameaux allongés, dressés, d'un vert elair ; ils sont très-lisses et un peu glauques. Ses feuilles sont alternes, laneéolées, dentées en scie, glabres et d'un vert clair des deux côtés. Ses fleurs sont très-grandes, extraaxillaires, au nombrc de deux ou trois au-dessous de ehaque faisceau de feuilles; chaeune d'elles est très-eourtement pédoneulće, et se compose d'un calice tubuleux, rougeâtre à l'extćrieur; le tube est turbinć ; le limbe a einc divisions étalćes, demi-ovales, lancéolées ; d'une corolle pentapétale étalée, insérće au liant du tube calieinal; les pétales sont subeordifornes, arrondis, rélrécis à leur base en un onglet court.

Les ćlamines, au nómbre de vingt-cing à trente, sont alticliées, sur plusieurs rangs, à la parlic supćrieure du tube dı. 
ealiee, au-dessus d'un disque pariétal jaunátre qui tapisse la plus grande partie de son intérieur. Les pistils sont au nombre de denx dans chaque fleur, mais un avorte presque constamment. Ils sont chargćs d'un duvet cotonneux très-abondant, exeepté la partie supćrieure du style, qui est glabre.

L'ovaire est globuleux , un peu comprimé d'avant en arrière, marqué d'un sillon du eôté interne; il est a une seule loge qui renferme deux ovules.

Le style est subulé, et se eonfond avee la partie supérieure de l'ovaire; il se termine à son sommet par un stigmate eapitulé glandulaire, lćgèrement bilobé.

Le fruit est une drupe verte, ovoïde, allongée, eomprimée, terminée en pointe à son sommet. Sa chair est peu épaisse, dure, eoriace et presque sèche. Son noyau est rugueux et erevassé. Tantôt sa coque est minee et se brise facilement, tantôt elle est ćpaisse, dure et ligneuse.

Proprićtés et usages des amandes. L'amandier présente deux varićtćs fort importantes à distinguer l'une de l'autre. La premic̀re a ses graines douces; elles sont amères dans la scconde.

C'cst des eôtes de la Barbarie et du midi de la France, que nous tirons les amandes douces: elles doivent être sèches, pesantês et rćeentes. M. Boullay a fait voir que cent parlies eontenaient : huile grasse 54 ; albumine, semblable à l'albumine du blanc d'œuf, 24 ; suere liquide 6 ; gommc 3 partics. Ces différens prineipes nous rendent parfaitement raison des effets que produisent les amandes douees sur l'économie animale. Par la grande quartité d'huile fixe et d'albumine qu'clles renferment, elles agissent à la fois comme aliment ct commc médieament. En effet, les peuples des contrées où on les réeoltc abondamment en font une grande consommation, et s'en nourrissent pcndant une partie de l'annće. Nous les voyons même figurcr sur nos tables, soit à la fin de l'étć, lor'squ'elles sont encore fraiehes, soit pendant l'hiver dans leur ćtat de dessiccation.

Considćrćes sous le rapport unédieal, les amandes douces doivent être placées parmi les médicarnens émollicus. Privées de leur pellieule extéricure, broyées et étenducs dans l'eall, elles forment; ai moyen du snere ou d'un pen de mucilage, un liquide blanc laiteux, qui porte le nom d'émulsion. Cette 
couleur blanehe est due à la suspension dans l'eau de l'huile grasse, au moyen du suere ou du mueilage.

L'émulsion forme une boisson tempérante, fort agréable, que l'on preserit fréquemment dans les irritations des organes digestifs et urinaires. On peut la rendre sédative ou diurétique par l'addition de quelques gouttes de solution aqueuse d'opium, ou de vingt à trente grains de nitrate de potasse. Le sirop d'orgeat se prépare en faisant une forte émulsion avee deux parties d'amandes douces et une partie d'amandes amères, et en y faisant fondre à une douee ehaleur trois parties de suere blane pulvérisé. Ce sirop étendu d'eau forme une tisane fort agréable, entièrement semblable dans son mode d'aetion à l'émulsion.

Le produit le plus intéressant des amandes douees est, sans contredit, l'huile grasse qu'on en retire à froid par le moyen de la presse. Elle est douee, elaire, transparente et insipide. C'est elle surtout que l'on emploie dans les différentes préparations pharmaceutiques, telles que les linimens, les embrocations, ete. Cette huile, eomme toutes les autres de la même nature, est très-adoueissante; on la preserit quelquefois à l'intérieur, dans eertaines eoliques; et, eomune l'estomae ne la digère que fort diffieilement, elle agit ordinairement comme laxative.' L'huile d'amandes douces entre à la dose de demi-onee dans le looeh blane.

Outre les différens matériaux dont nons avons signalé l'existence dans les amandes donees, les amandes amères eontiennent de plus de l'aeide prussique et une huile volatile jaune; plus pesante que l'eau. C'est à ees deux dernier's prineipes $q$ q'elles doivent leur saveur amère et l'aetion puissante et délétère 'qu'elles exereent.sur l'éeonomie animale, lorsqu'on les y introduit en grande quautité. En effet, il a été eonstaté par un grand nombre d'expérienees, que l'huile obtenue par la distillation des amandes amères, donnait lieu à des aeeidens trésgraves, et pouvait oeeasioner la mort, mênı lorsqu'elle était entièrement privée d'aeide prussique. Plusieurs médeeins, tels que Bergius, Hufeland, ete, remarquant lia foree avec laquelle les amandes amères modifient l'état de nos organes, ont proposé leur emploi eomme propre à eombattre les fièves intermittentes. Ils el préparaient des émulsions très-rapprochées, 
dont ils disent avoir obtenu quelques sueeès. Selon quelquesuns, ces anandes jouiraient de la propriété de neutraliser l'aetion des liqueurs fermentées et de dissiper l'ivresse.

Il déeoule du trone de l'amandier une gomme entièrement semblable à celle du prunier et de l'abrieotier, et confondue avee elle sous le nom de gorime du pays.

\section{PECHER. - PERSI CA. Tourn.}

Ce genre ne diffère de l'amandier, auquel Linné l'avait réuni, que par son fruit, dont la ehair est plus épaisse et plus sueeulente, et par son noyau, dont les silons sont plus profonds.

Pêcher commun. Persica vulgaris. Miller dict. n. I. Amygdalus persica. Lin. Sp. 677. Duham. arb. fruit. ed. in-8o, v. 2, p. r72. n. I-20, et 28-42. t. r-r 4 et - $20-32$.

Var.: u. Carne a nucleo secedente.

Var. : $\beta$. Carne nucleo adherene.

Var. : $\gamma$. Fructu lasi, nec tomentoso.

A bandonné à lui-même, le péehèr a le port.de ll'amandier, dont il ne diffère que par son fruit.

Ses feuilles sont alternes, lanećolées, étroites, aiguës, dentées en seie, d'un vert glauque sur les deux faces. Ses fleurs sont d'un rose pâle, alternes, et très-rapprochées les unes des autres à la partie supérieure des rameaux; elles sont sessiles. Le ealice est le même que dans l'amandier. La corolle est plus petite; les pétales sont arrondis, entiers, brusquement onguieulés à leur base; les étamines, au nombre de trente environ, sont plus longues que le pistil, et un peu plus eourtes que les pétales.

Le pistil est toujours unique. Le fruit, qui porte le nom de pêehe, est une drupé ordinairement arrondie, creusée d'une sorte de gouttière longitudinale d'un seul eôté, tomenteuse; la ehair est très-épaisse et sueeulente; le noyau est arrondi, pointu d'un eôté, marqué de sillons irréguliers et profonds.

Dans. la première variété, la ehair se détache faeilement du noyau, auquel elle tient par des filamens eharnus qui pénètrent dans les crevasses du test. La seconde variété, que llon 
désigne sous le nom de pavie ou.alberge, a la chair adhérente au noyau : elle est tantôt d'un jaune doré, eomme dans l'abrieot, d'une consistanee plus ferme: c'est presque la seule qui soit cultivée dans les provinces méridionales de la Franee; tantôt la ehair est d'un rouge pourpre.

La troisième variété, fort distincte par sa pellieule, qui est lisse et non tomenteuse, porte le noin de brugnon:- c'est une des meilleures et des plus recherchées.

Le pêcher est origináire de la Perse. On le eultive aujourd'hui dans les vignes et les jardins, soit en plein vent, soit en espalier.

Propriétés et usages. Le pêeher est bien plus intéressant par l'exeellenee des'fruits'qu'il produit, que par ses proprićtés médieales. Les pêclies sont en effet un des fruits les plus savoureux que voient mûrir nos, elimals. Comme tous les autres fruits mueoso-sucrés, elles sont rafraiehissantes et légèrement laxatives, surlout lorsqu'on en mange ell grand nombre. On peut corriger eette aetion en les saupoudrant de suere ou les trempant dảns un vin génćreux.

Les fleurs du pêcher possçdent une propriété laxative trèsdonce. Leur infusion, avee laquelle on prépare le sirop de fleurs de pêcher, purge doueement et sans. occasioner de coliques. Aussi l'emploie-t-on surtout pour les enfans en bas âge.

\section{ABRIGOTIER, - ARMENIACA. Tourn.}

Le genre abrieotier diffère du pêehcr par' son noyau non sillonné, presque rond, ayant un de ses'eôtés relevé d'un bord tranchant. Il se' distingue des pruniers par son fruit tomenteux.

Abricotier commun. Aimeniaca vulgaris. Lamík. dict. r, p. 2. Prunus armieniaca. Lin. Sp. 679. Duham. arb. fruit. ed. in- $8^{\circ}$, v. I, p. 203 , t. 5 et 6 .

L'abricotier est un arbre de grandeur moyenne: ses rameaux, dont l'épiderme cst d'un brun foncé, sont ordinaircment disposés en une tête plus ou moins large. Les fcuilles qui le eonronnent sont presque cordiformes, arrondies, aeuminées, 
dentées en scie, ollabres; eelles qui oceupent l'extrémilé đés rameaux sont rougeâtres. Les fleurs sont blanches, de grandeur moyenne, presque sessiles, disposées par petits faisceaux très-rapprochès, à la pártie supérieure des rameaux. Chacune d'elles est environnée à sa base d'un. grand nombre d'écailles imbriquées, qui la recouvraient entièrement avant son épanouissement. Le calice est tubuleux; le tube est large, ovoïde, aminci à sa' partie inférieure; le limbe est à einq divisions brusquement réfléehies, presque cordiformes arrondies, un peu coneaves et purpurines. La corolle est blanche; les cinq pétales sont arrondis, entiers, brusquement onguiculés à leur base. Les étamines sont au nombre de trente à quarante environ, un peu plus çourtes que la corolle et le pistil. Celuici est solitaire et libre au fond de la fleur; il est cotonneux, excepté dans la moitié supérieure du stỷle, qui est entièrcment glabre. L'ovaire est à une seule loge, qui renferme deux ovules: le style est subulć et se confond, insensiblement à sit base avec le sommet de l'ovaire : le stigmate cst terminal, fort petit, un peu aplati. Le fruit est une drupe arrondie, de couleur de chair, finement tomenteuse, marquée d'une sorte de gouttière : la chair est succulente, son noyau est lisse, comprimé latéralement, marqué de deux crètes saillantes sur un de ses côtés.

L'abricotier est primitivement originaire de l'Ar'ménie; Allioni prétend qu'il est sauvage aux environs de Montferrat en Piémont. On le cultive dans tous les jardins, à cause de l'excellence de son fruit.

Il-fleurit au premier printemps, avant le développement de ses feuilles.

Propriétés et usages. L'abricot est un fort bon fruit, mais qui eependant n'a' point eette délicatesse de saveur de la pêche. Il manque de ee goût acidule qui rend les pêelıes plus agréables et peut-être moins indigestes. Cependant il cst cncore très-recherehć, et on le mange, nou-seulement cru; mais euit en forme de eompote ou de gelée, ou eonservé à l'cau-de-vic. Ses amandes ont une amertume assez píononcéc : on les entploic surtout pour préparer une liquenr de table fort estimée : l'eau de noyau. 
GINQUIETE SECTION.

\section{R OS É E.}

Le genre Rosier forme à lui seul cette section, fort bien caractérisée par son calice urcéolé, rétréci à son ouverture, devenant charnu, et contenant à son intérieur plusieurs petits osselets pariétaux, qui sont les vćritables fruits.

\section{R OSIER. - ROSA. L. J.}

Le tube du calice est urcéolé, persistant; son limbe est à cinq divisions caduques : la corolle se compose de cinq pétales; les étamines sont fort nombreuses et attachées au haut du tube du calice. Les pistils sont en grand nombre, insérés à la paroi interne du calice, qui est, ainsi qu'eux, hérissée de poils rudes. Ces pistils forment autant de petits akènes osscux renfermés daus le tube du calice, qui devient charnu.

Les rosiers sont des arbustes quelquefois sarmenteux, ordinairement armés d'aiguillons, ayant lcs feuilles imparipinnées et les stipules soudées latéralement avec la base des pétioles.

\section{Rosier sauvage. Rosa canina. L. Sp. 704. Blackw. t. 8.}

Part. usit. : les fruits. Nom pharm. : Cynorhodon. Nom vulg.: Gratte-Culs.

Arbrisseau rameux, touffu, dont les branches sont armées d'aiguillons recourbés. Ses rameaux sont effilćs, glabres, cylindriques et glauques. Ses feuilles sont alternes et pinnécs avee impaire, légèrement glauques, composées de sept folioles sessiles, ovales, arrondies, obtuses, marquées de dents trc̀saiguës. Le pétiole, légèrcment canaliculé en dessus, est garni dc quelques aiguillons à sa face inféricure; les deux stipules sont soudées avec sa base. Ellcs sont semi-sagittées, denticulées sur leur bord libre. Les fleurs sont roses, grandes, rasscmblées au nombre de quatrc à six aux extrémités des ramifications de la tige et portées sur des pédoncules courts et glabres. Le calice est tubuleux, ovoïdc, allongé, glabre. Son limbe est étalé, à 
cinq divisions foliaecées, allongées, très-aignës, pinnatifides sur lcs eôtés. La corolle est pentapétale, rosacée. Chaque pétalc est scssile, eordiforme, un peu concave. Lcs étamines, en très-grand nombre (environ cent), sont insérées à la gorge du caliee, en dehors d'un disque pariétal, 'qui, après avoir tapissé l'intérieur du tube ealieinal, forme un bourrelet eirculaire à son orifiee, et le bouche presque entièrement. Elles sont beaucoup plus courtes que la corolle.

Les pistils sont au nombre d'environ douze à quinze, renfcrmés dans l'intérieur da tube du ealice, aux parois duquel ils sont attaehés. Chaque ovaire est légèrement stipité, tout hérissé de poils blanes, rudes et soyeux, ainsi que la paroi intcrne du tube, ealicinal. Il cśst surmonté d'un śtyle ǵrêle et filiforme, poilu. Ces styles, d'aboid distinets, se réunissent en isn faiseeau, qui ne s'élève pas au-dessus de l'ouverture du caliee. Chaque style est terminé par un stigmate eajpitulé, glanduleux et inégal. Le fruit se eompose du ealiee persistant, dont les parois se sont épaissies et sont devenues eharnues ct d'úne coulcur rouge foncée; dans l'intérieur de ce ealicc sont les véritables fruits, qui sont autant d'akènes eornés, durs, polyèdrcs, hérissés de poils très-rủdes, et tcrminés en poin te à leur sommet.

Cette espèec cst très-commune dans les haies et les buissons. Elle fleurit cn mai. Ses fruits sont mùrs "cn.septembre et octobrc.

Propriétés et usages. On ne fait usage en médecinc que des fruits "de cet 'arlorisscau, lorsqü'ỉls sơnt parfaitement mûrs. On sépare ávée soin la cháar, ou le ealice, des osselets ct des poils qui adhèrent ầ sá surfaee interne. Eille a me savenr astringente. C'est avéc élle que l'on prépare la cons̉erxe 'de'cynorkiodon, qui est un médićanient astringent dont on fait nsige dan's la diaríhée chronique ct plusicur's autres maladies où l'criploi des légers astringéns est indiqué. 
Rosier de France. Rosa gallica. L. Sp. 70.4. Blackw. t. 78 .

Part. usit. : lès pétales. Nom pharm. : Rosa rubra. Noms vulg. : Rose rouge ou de Provins

C'est un arbuste peu élevé, buissonneux, quii croît sur les eollines du. eentre et d'autrés partiés de la France. Ses' tiges sont dressées, rameuses, eylindriques, recouvertes de nombreux aiguillons róngeâtrè et recourbés. Leurs feuilles , "qui sont alternes et pétioléés,' se eomposent de einq ou sept folioles sessiles, ovales, cordiforines, aiguës, dentées en seic, à surfacé crépue, glabres supérièurement et d'un vert foncé, un jreu tomenteuses à leur faee inférieure. Les stipules sont adhé. rentes avétle pétiole; et un peu ciliéés sur leurs partiès latẻrales. Les flẹurs sont réunies, au nombre de deux ou trois, au sommet. des rrimeâux' elleś sont d'un beau rouge eranoisi, portant aúmónís deux póvees ét dén à trois pouces de diamètre. Leurs pćdoncules sont grêles, eylindriques, ássez longs et glandxleux. Lé tulbe de leùr calice est présque globúléux, égalèment jubesent et glanduleux; les divisions dé són limbe, pluşcourtes que les pétales", sont un peu divisées látéralenentent.

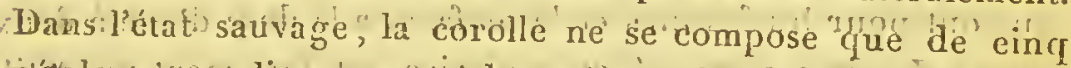

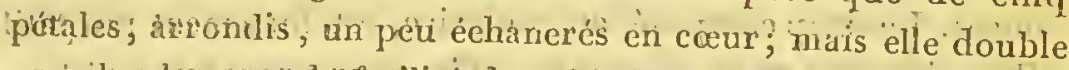
a vée la plus grainde faeilité dans les individus cultivés.

Própriétés el usages. Les pétales de ce rosier, 'qui sont la

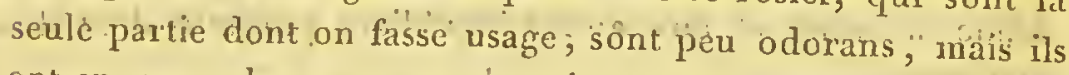
ont en revanehe une saveur' astringente très-prononcée, 'surtout lorsqüils ont ćté sécliés rapidement. Nous ne eroyons pas devoir nous étendre longuement sur leur usage dans la thérapeutique, ni rappeler les opinions erronées de quelques auteurs sur leur efficacite dans eertaines maladies, telle que là phlhisiẻ putmonnaire : on sait trop'à quoi 's'en tenir aujourd'hui sur l'effeaeité pirétendue de certains agens pliamaceutiques dans le traitement de eette eruelle maladie. Ce qu'il y a de positif relativement aux pélales de roses rouges, e’est que leur infusion èst tonique et astringente, et que l'on en préscrit'surtoutl'usage dans les ćeoulcmens dépendaus de eauses 
débilitantes. Ainsi, dans la lcucorrhéc, la blennorrhéc clıroniques, dans lit diarrhée, ctc., on l'emploie avce assez de suceès.

Ccs pétales font la base d'un assez grand nombre de préparations pharmaeeutiques. Ainsi, digérés dans le vinaigre, ils constituent le vinaigre rosat, avee lequel se prépare le miel rosat, dont on fait surtout usage dans les inflammations légères du pharynx. On fait aussi unc eonserve de roses rouges qui. jouit des mêmcs propriétés que la conserve de cynorhodon.

Le rosier des quatre saisons, ou rosc pâle, et le rosier à cent fcuillcs (Rosa bifera ct Rosa centifolic, L.) méritent également d'êtrc mentionnés iei. On connait le parfum délieieux qu'exhalent leurs belles fleurs. Ce parfum est dù à une livile essentielle, plus légère que l'eau, suseeptible de se solifidier, et que l'on désigne sous le nom d'huile eșsentielle de roses ou beurre de roses. L'eau distillée que l'on prépare avee les pétales dc ces deux espèces est odorante et à peine astringente. On en forme des collyres, que l'on rend plus aetifs par l'addition du sulfate de zinc, de l'aeétate de plop̧nb, etc. On peut éga-. lement l'employer à faire des injeetions.

C'est avee les pétales du rosier des quatre saisons, que l'on prépare daus les pharmacies les deux sirops de roses páles. Le premier, ou le sirop simple, cst faiblement laxatif, et s'emploie surtout pour les femmes et les enfans, à la dose d'une à deux onces. Le sirop composé, au contraire, est fortement purgàtif. Une demi-onee ou une once suffit pour provoquer d'abondantes évaeuations. Il doit cctte aetion éncrgique à l'agarie blane, au séné et aux autres ingrédiens purgatifs dont il se compose.

SIXIERE SIGTION.

POMACÉES. Ricl.

Lcs pistils sont aü nomb:c de dcux à einq, soudés entre eux et avec le tube du ealice, qui semble représenter un ovairc infèrc. Chaquc pistil sc enmposc d'un ovaire à unc senle $\log c$, contenant dcux ou un plus grand nombre d'ovules, d'uu style et d'un stigmate simples. Le fruit est une pomme ou mélonide, c'cst-à-dire qu'il est charnu, couronné par le limbe du ealiec, et offre deux, trois ou einq loges cartilagineuses ou osscuses. 


\section{ROSACEES.}

Cette section parait au premier abord s'éloigner considérablement des cinq autres dont nous venons d'exposer successivement les caractères, surtout si nous comparons son fruit à celui des autres sections. Mais ces différences sont plus apparentes que réelles. En effet, le fruit du pommier ne diffère dé celui du rosier, que parce que les pistils réunis dans le tubc du calice se sont soudés les uns avec les autres, tandis qu'ils restent distincts dans le rosicr. Si maintenant vous ćtalez le tube du calice des rosiers, vous aurez la structure des Fragariacécs.

\section{-POMMIER. - MALUS. Tourn.}

Calice turbiné à sa base; limbe à cinq découpurcs lancéolées, roulćes en dehors; corolle de cinq pétales velus inférieurcment; étamines rapprochécs en gerbe; cinq styles soudés par la base; nélonide globuleuse, ombiliquée à sa base et à son sommet, à ciny loges cartilagineuses, contenant chacune deux pépins.

Pommer commun. Malus communis. Lamk. D. C. Fl.

$$
\begin{gathered}
\text { fr. 4. p. } 429 . \\
\text { Pyrus malus. L. Sp. } 686 .
\end{gathered}
$$

Lc ponunier est un arbre de moyenne grandeur qui, daus nos champs, forme une tête hémisphérique, et resscmble, en quelque sorte, à un vaste parasol très-bombé. Ses feuilles sont pétiolées, alternes, obovales, subcordiformes, dentées, d'un vert foncé supćrieurement, cotonncuses et blanchâlres en dessous. Les fleurs, qui sont assez grandes et d'un rose pâlc, sont pédicéllćes et forment des espèces de petits bouquets ou sertules au somınet des jeunes ramcaux. I_eur calice est turbiné, velu, à cinq lanières lancéolćes. Lcurs pétales sont arrondis et jresque enticrs. Les cinq styles sont velus, et adhèrent entre cux par la basc. I c fruit est ordinairement globuleux, quelquefois un peu déprimé, plus rarencent allongć. Sa forme et sa grosscur diffèrent beaucoupsuivant les varićlćs, qui sont fort nombreuses. Il à quelquefois la grosseur d'une noix, commc on l'observe dans la varićté connuc sous le nom de pornmes d'apis; l'autres fois, au contraire, on cn trouve qui offrent à jeu près le volume de la têtc l'un enfunt. 
Le pommier fleurit en avril et mai. Ses fruits sont généralesnent mûrs au coninencement dc l'automne.

Usages et prapriétés. Non-seulement le pómmier est cultivé avec soin dans nos jardins fruitiers, mais cet arbre est l'objet d'unc grände eùlture dans plusieurs provinces de la France, où il eơvré une partiè des ehamps et des collinés. En cffet, il remplace la. vigne dans la plus grande partie de la Normandié, de' la Bretagne, de la Picardie, etc.; èt c'est de lui que l'ón extrait la boisson fermentée qui y tient lieu du vin. Le eidre, surtout lorsqu'il a ćté conselvé pendant quelque temps, est une boisson aussi saine qu'agréable. Il contient, en général', une moins grande quantité d'álcohol que lc vin, et fatigue moins l'estomac. Cependant il perit également eauser l'ivïésse; et avec des accidens d'autant plus intcnses, qu'il en faut unc plus grande quantité pour la détcrminer. L'aleohol que l'on retíre du cidre par le moyen de la distillation conserve tonjours une saveur peu agréable: il est moins estimé que celui que fournit le vin.

On peut rendre le cillre mćdicamenteux par l'addition de substances actives. Ainsi on en fera une boisson torique, en y laissant macérer une certaine quantité de racine de gentiane; il deviendra stimulant si l'on y ajoute un alcoholat aronalique, tel que celui de canelle, de 'gérofle, ou sil'on'y fait infuser des plantes de la famille des labiéés.

- Quant aux pommes que nous recueillons dans nos jardins, c'est. ün fruit irès-agréable et 'très-sain. Elles ne sont jamais fondảités eoonmè certaincs pnires', et leur 'chair est toujours eassaninite. Lorsqu'elles ont ćté euites et qu'òn les saupoudre de suere; on cri prescrit l'usage aux málades et aux convalescens. On prépárè aüssi avec le suc que l'on en retirc dans cet état, une confintre ou gelće cxtrênement transparente, et qui est fort recherchće. La décoction de pornme de reinelte est une tišne ràfraichissantc, 'que l'on preserit dans l'inflammation des poumbins et àcs or ợanes digestifs.

POTRIER. - PYRUS. Tourn:

Les poiricrs diffèrent des pounniers par leurs pólales ghlabres. 
leuss étamines non rapprochécs en faisceau; leurs styles libres et non soudés plar leur base. Du rcste, leur fruit présente la mềmc organisation.

\section{Pomner gommun. Pyrus communis. L. Sp. 686.}

Le poirier, abandonnć à lui-même, est un arbrc assez élevé, et dont le trone pcut acquérir des dimensions considérables. Ses feuilles, portées sur dc longs pétioles, sont ovales, obluses, finement dentécs, pubescentes à leur face inférieure dans leur jeunesse, devenant cnsuite en fièrement glabres. Dăns ses flcurs, qui sont blanches, pédonculées, et disposées en bouquets aux extrćmités des jeunes rameaux, le calice est monosépale : son tube est urcéolé, tomenteux, rempli à l'intérienr d'une substance charnuc, qui unit les pistils entre eux, de manière que la gorge du tube est entièrement boụchée. Le limbe est étalé, à cinq divisions trc̀s-aiguës. La corolle est formée de cinq pétales arrondis, un peu concaves, brusquement onguiculés à leur base. Les étamines, au nombre de vingt ou environ, sont insćrées en dedans de la corolle, au pourtour d'un disque charnu?. On trouve cinq pistils attachés au fond du calice, très-rappprochés les uns des autres : lcurs ovaires sont réunis et soudé entre enx du côté interne, et avec le tube du calice en dehors, au moyen dn disque charnu qui garnit son intérieur. Lcs styles sont grêles, rapprochés en faisceau, et presque soudés, à leur basc, distincts et libres an-dessus de la gorge du calice, terminés chacun par un pctit stigmate oblique. Le fruit est une mélonide pyriforme.

Dans l'état sauvage, les fruits du poirier, comme ceux du pommier, sont petits et d'unc âprcté intolërablc. La culture, en y développant les principes mucoso-sucrés, les rend d'une saveur douce et agréable. Le nombrc des varićtćs obtenues par les soins du cullivatcur, et quc l'on propage au moyen de la greffc, cst cxtrêmcment considérablc. On compte parmi les plus recherchées lc beurré gris, 'la crassane ou crésane, le Saint-Germain, ctc. Non-sculement le poirier cst cultivé dans nos jardins fruiticr's, soit cn (spalicrs, soit en quenouilles, mais on le cultivc en grand sur la lisic̀re des champs, dans 
beaucoup de provinces de la France, telles que la Nomnandic, l'Anjou, la Bretagne, etc. On prépare, aveci le suc qu'on en exprime, une boisson fermentée, qui porte le nom dc poiré. Cette liqucur est plus forte et plus alcoholique que celle que l'on extraiat des fruits du pommier, et son usage habituel parait être moins sain.

Pour l'usage de la table, on recherche surtout les espèces de poires qui sont fondantes, et l'on réserve pour la cuisson celles qui ont la chair ferme et cassante.

\section{COIGNASSIER. - CYDONIA. Tourn.}

Ce gcnre diffère du précédent par les loges de son fruit, qui conticnnent plusieurs graines, au lieu de deux seulement.

Coignassier cultivé. Cydonia vulgaris. Rich. Jard. med. Pyrus cydonia. L. Sp.

Arbrisscau de douze à quinze pieds, très-rameux, ses jeunes rameaux étant blanchâtres et cotonneux. Ses feuilles sont - ovales, arrondies, obtuses, larges d'un à deux pouces, longues de deux à trois, molles, douces au toucher, cotonneuses en dessous, portées sur des pétioles d'un demi-pouce de longueur, entières sur leurs bords. Les fleurs sont blanchâtres, très-grandes, solitaires à la partie supérieure des jeunes rameaux. Le tube du calice est très-cotonneux, un peu renflé à la base; le limbe est à cinq divisions rabattues, foliacées, doublement dentées. Cinq pistils sont renfermés dans le tube du calice; leur ovaire est à une seule loge, qui renferme plusieurs graines, le style est très-cotonneux à sa base. Le fruit est une mélonide pyriforme, arrondie, jaune et cotonneuse, d'une odeur trc̀s-forte, d'une saveur âpre ct désagréable. Il porte le nom de Coing.

Cet arbrisseau, qu'on cultive aujourd'hui dans tous les jardins potager's, est originairc de lîlc de Cric̀te.

Propriétés et usages. Les coings, même dans lcur ćtat parfait de maturité, ne pcuvent être mangés crus, à cause dc leur saveur âpre. Mais on prépare avec cux d'cxccllentcs marmelades, des gelćcs, des pâtes très-rechcrchées. Ccs fruits intéressent la mćdecinc, $x^{\circ}$ par le sirop que l'on prépare avcc lcur. 
julpe, lequel est légèrement astringent, et mis surtout en nsage pour édulcorer les boissons qu'on administre contre la diarrhée elronique; $2^{\circ}$ par leurs graines, qui contiemnent un mueilage très-abondant, que l'on obtient par la décoction dans l'eau. Cette décoçtion est prineipalement usitće pour préparer des collyres adoucissans.

$$
\text { NÉFLER. - ME SPILUS. L. J. }
$$

Ce genre se distingue des prćcédens par son fruit plus court, dont l'ombilie est large et ouvert, et par les cinq noyaux osseux renfermés dans son intérieur.

Néfler comadon. Mespilits germanica. L. Sp. 684.

C'est un arbre de moycnne grandeur, dont le tronc ct les branehes sont ordinairement tordus et irréguliers, et qui s'élève à douze ou quinze pieds de hauteur. Il porte des feuilles elliptiques, lancćolécs, aiguës au sommet, pubescentes, surtout en dessous; longues de einq à six pouces, larges d'environ deux pouces, presque sessiles.

Ses fleurs sont grandes, blanehes, axillaircs et terminalès. Le ealiee est turbiné, élargi, eotonneux, terminé par cinq lanières laneéolées, entières; les einq pétales sont arıondis, scssiles, un peu ondulés sur leurs bords; les étamines, au noınbre de trente à trente-six; les ciny ovaires sont pariétaux, soudés ensemble et avee la paroi interne du ealice; les cinq styles sont tordus et un peu soudés, tcrminćs chacun par un stigmate un pen évasé et laléral.

Le fruit, qui porte le nom de néfle, est turbiné, aplati supérieurement, tcrminé par les cinq lanières du calicc, qui sont divcrgentes. Il renfermc cinq nuculcs osseux, contenant chacun une grainc.

Le néllier eroît dans les forcts dé la France; on le cultive dạns les vergers, à cause de ses fruils.

Propriétés et usages. Les nèfles ne mûrissent point sur l'arbrć qui les porte. Lorsqu'on les réeoltc à la ful de l'automnc, cllcs sont cncore vcrtes à l'intéricur, dures, d'une saveur cxccssivement âpre ct insupportablc. On les élend alors sur dc la paille, ęt, vers le inilicu de l'hiver, elles s'amollissent, devienncut brunos 
en dedans, et acquic̀rent une saveur fort agréablc. Ces fruits ne sont ni malsains, ni indigestes. On les recherche peu sur les tables somptucuses. La médceine n'en fait point usagc.

\section{Propriétés inédicales des Rosqucées.}

Les six sections que nous avons ćtablies dans la vaste famille des Rosacées, et que quelques auteurs considèrent comme autant de familles distinctes les unes des autrcs, offrent entrc elles dẹs earactères communs et des différénces assez tranchées, Iorsqu'on les ćtudie sous le point de vue de lcur composition chimique, et des phénomènes que les végétaux qui y sont rćunis déterminent dans l'économie aniinale. Ainsi un caractc̀re eommun à loutes les Rosa cécs, mais quị cependant n'existe pas dans quelques-unes à toutes les époqres de leur développement, c'est leur. saveur âpre et astringente, qui est due principalement au tannin, dont on démontre fạcilement la présence par la couleur noirc que le sulfate de fer développc dans la décoction de ces végétaux. Cette saveur est surtout trc̀s-intensc dans la seetion dcs Fragariacées, et en particulier dans la racine de ees plantes. Aussi plusieurs d'entre elles sont-elles employées en médecine comme toniques, snil à l'intérieur, soit pour l'usagc externe, comme le démontrent les racines de tormentille, d'argentine, ete. Ces mèmes racines servent également, dans quelques contrées, au tannage et à la préparation des euirs.

Cette astringence existe aussi dans les Agrimoniées, et surtout dans le genre aigremoine. Cctte scction nous offre unc plante exotique qui forme une anomalie bien remarquable. Je verix parler du Brayera anthelmintica, décrit r'ćcemment par M. Kunth, et qui doit être plaeć tout près du genrẹ aigremoine. Cette plante, qui u'est eneore que fort imparfaitement eonnue, et d'après des fragmens ineomplets apportés de Constantinoplc par M. le docteur Brayer, croit en Abyssinie. Elle y est employée avec le plus grand succès an traitement du toenia, et M. le docteur Brayer a étć lni-mềme témoin do la promptitude et de l'effieącité; de cettc plante, dans le traitcment dc cettc redoutable'maladic. Unc telle propriété est hien remar- 
quable au milieu d'autres végétaux qui sont si loin de la posséder.

Plusieurs Spiréacées et ù grand nombre de rosiers nous offrent également le principe astringént des Fragariaeées. Les fruits des rosiers sauvages connus sous le nom de cyriorhaclon, les pćtales de plusieurs roses, et surtout de eelles qui ont les fleurs d'un rouge foncé; sont remarquablcs par leur saveur astringente, èt sont rangés parmi les médicamens toniques.

Dans la seetion des Amýgdalćes èt des Pomaećes, nous trouvons cricore des traces de eette saveur astringente. Les fruits, dans ces dcux sections, surtout avant l"époque de leur matnrité, ont une saveur âpre, extrềmènent désagréable. Ils contiennent, outre le tannin et l'acide gallique que nous avons renarqués dans les autres scetions, de l'ácide inalique à l'état dé liberté. Mais jar les progrès de la maturité, ils éprouvent un changement notable dans leur nature chimique: Ainsi on voit 's'y dévelopiper' en abondance les matériaux sucrés et muquenx, à mcsure que la quantité des substances aeides diminue, en sorte que parvenus à leur ćtat dé maturité parfaite, ees fruits ont une saveur douce, suerée, et nullement astringente.

Outre les substances acides dont nous venons de signaler l'existence dans toutes les sections de la famille des Fosacées, nous trouvons encore quelqucs autres prineipes dans plusieurs de ees végétaux. $\Lambda$ insi, dans la racine de benoite, et surtout dans les pétales d'un grand nombre d'espèees de rosiers, il existe ụne grande quantité d'huile volatile très-odorante, tantôt plus lourde, et tantôt plus légère que l'eau. Cette luile communique à ces végétaux uné propriété stimùlante qui, le plus souvent, se joint à leur action tonique. Mais de tous ces principcs, il n'en est pas de plus rcmarquable que l'aeide prussique (acide hydrocyanique), qui se fait remarquer dans presque lous les végétaux du groupe des $\Lambda$ mygdalées. C'cst en effet à la présence de ce prineipe délétc̀re et à eelle d'ıne huile volatile particulière, que les noyaux de pêelie, d'abricot, les feuilleș du laurier-cerisc, du pêeher, cte., doivont leur odeur forte, ct désignée vulgairement sous le noun d'odcur d'amande, lcur saveur amc̀re!, el l'action puissante ct délétère qun'ils exer- 
cent sur l'économie animale. L'aeide prussique est en effet un des poisons les plus actifs que fournit le règne végétal; il détruit presque instantanément l'irritabilité museulaire; et dans les animaux qui succombent vietimes de ses effets', ou trouve les muscles dans un ćtat de relâchement et dc flaecidité complet.

Cette propriété singulière est bien une anomalie pour la famille des Rosacées considérée en masse; mais cependant elle cesse de paraitre telle lorsque l'on songe qu'elle existe à des degrés différcns dans tous les végélaux de la section des Amygdalées ou Drupacées, qui se distinguent des autres par la structure de lcur fruit et la présence du noyau, qui est l'organe. qui en renferme la plus grande quantité.

Les graines de toutes les Amygdalées, surtout celles qui sont assez grosses, sont remarquables par la grande quantité d'huile grasse qu'elles fournissent par lc moyen de la pression. Cette huile, lorsqu'elle est pure, est douee, limpide, inodore, et jouit des propriétés adoueissantes et relâehantes de tous les agens pharmaceutiques du même genre. Cclle que l'on retire des amandes douces est la plus fine, la plus estimée, et celle dont on fait le plus fréquent usage. Assez souvent l'huile que l'on retirc des autres Drupacées contient une quantité plus ou moins eonsidérable d'acide prussique et d'huile volatile. Quand ces deux substances n'y sont qu'en petite proportion, elles lui communiquent une saveur amandée, légèrement amère, qui la rend plus sapide et plus agréable pour quelques person nes. C'est ainsi que I'on préfère, aux envilons de Briançon, l'huile exprimée des amandes du prunier, et que l'on y connait sous le nom d'huile de marmottes, à l'huile d'olive la plus fine.

Les graines, dans les Pomacées, sont remarquables par la grande quantité de mucilage contenu dans leur épisperme. C'est ainsi que la déeoction des pépins de ponmes, et surtout de coings, cst adoucissante, ct qu'on l'emploie pour préparcr des collyres émollicns.

La fanille des Rosacées est hicn plus intércssantc sous le rapport de ses usages ćconomiques, que par ses propriétés médicales. Ln effet, c'est sans eontredit la tribu naturclle de végétaux qui nous fournit le plus-grand nombre de fiuits 
savoureux et rafraichissans. Les fraises, les frambroises, les nombreuses variétés de prunes, de pêches, d'abricots, de cerises; les nèfles, les sorbes, les coings, les poires et les pommes, font l'ornement et les délices de nos tables pendant toutes les saisons de l'année. Les pommes et les poires offrent un degré d'importance encore plus grand, par la boisson fermentée qu'elles fournissent, et qui, dans une partie de la France, remplace entièrement l'usage du vin. Ces denx fruits ne sont pas les seuls que l'on puisse ainsi convertir en cidre; tous ceux des autres -Pomacées jouissent de la même proprićté; et, dans quelques cantons, les fruits du sorbier servent aussi à préparer cette boisson.

SOIXANTE-SIXISME FAMILLE.

\section{LÉGUMINEUSES. - L EGUMINOSAE.}

Papilionacées. Tourn.

La famille des Légumineuses, quoique comptéc par tous les botanistes parmi les plus naturelles, offrc ccpendant, dans leś détails de son organisation, des cliffércnces même assez tranchćes, et qui exigent de notre part des dćveloppemens plus étendus, afin de bicn faire connaître lia structure gćnérale de ces végétaux: On pcut rapportcr à trois types principaux l'organisation des fleurs dans cettc famillc. ${ }^{0}$ Tantòt elles sont irrégulières et papilionacées, c'est-à-dire qu'elles offrent un calice tubuleux, denté à son sommet; une corolle formée de cinq pétales inégaux et irréguliers, ct qui ont reçu des noms particuliers, savoir : un supćrieur, ordinairement plus grand, qu'on nomme étendard; deux latćraux, égaux et semblables, qui constitucnt les ailes; deux inféricurs, également semblal)les entre eux, quelquefois soudés ensemblc par leur bord inférieur et formant la carène; dix ćtamines, ordinaircment diadelphes, rarement libres ou monadelphes; $2^{\circ}$ tantôt la fleur cst plus ou moins 
régulière, composée d'un caliee à cinq divisions trèsprofondes, d'une corolle polypétale également régulière, et de dix étamines distinctes, dont plusieurs avortent quelquefois eonstamment dans un eertain nombre de genres; $3^{\circ}$ enfin dans le troisiène type, qui s'éloigne beaneoup des autres, le caliee est tubuleux, à einq dents, aecompagné d'un ealicule extérieur; la corolle manque; les étamines, en nombre variạble, et quelquefois, trèsconsidérable, sont mionadelphes oulibres. Ces trois divisions présentent, ainsi qu'il est faeile de le reeonnâ̂tre, une organisation assez différen te dans les parties qui eomposent leur fleur, mais elles se trouvent rapproehées et réunies par la eonformité de leur fruit, qui toujours est une'gonsse ou un légume; de là le nom qui a été donné à eette famille. Cette gousse, examinée dans les divers genres de la famille, offre des différénees fort remarquables. Ainsi elle est, ẹn général, à une seule loge, qui eontient plusieurs 'graines "et s'ouvre en deúx 'valves; d'autrés fois elle ne eontient qu’ une seule gráníle et reste indéhiseenté. Dans quélques 'genres' la gousse est par-

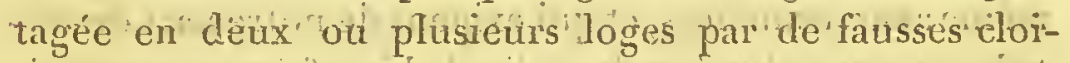
sons, ainsi qu on lobserve dans les Cásses; et mene plusieurs genres se aistinguent par leurs fiuits étranglés et comme artieulés de distancé en distance, et pourant se séparer spontanément én autant de pieces qu'il y a dariTieulations:

- La graine se coinjose d'un épisperine menbrancux quii contrent un embryon, ant les dedx eotylédons sont très-épais: Dan les génues u.corolle régulière, l'embryon est souvent reifermé dans l'intérieur d'un endosperthe mince et nonibraneux.

Les Légumineusès; de même que Jes Rósacéés diont noüs venons d'exposer les caractères, sont ot des plantes herbaećes, annuelles ou vivaces, ou des abustés, des arbiïscáux, et mêtré dés arbres d'une hante statnie. 
Leurs feuilles sont alternes, ordinairement composées, tantôt digitées, c'est-à-dire formées de folioles naissant toutes du sommet du pétiole commin, tantôt pinnées ou ayant leurs folioles diṣposées des deux côtés du pétiole commun. Dans un grand nombre d'espèces, ces feuilles sont encore plus composées, elles sọt biternées ou bipinnées; très-rarement elles sont simples. Dans tous les cas, elles s'accompagnent à leur base de deux stipules ordinairement persistantes. Les fleur's; dans ces différens genres, offrent, en quelque sórte, tous les modes d'inflorescerice, ç'est-ì-dire qu'elle's sont solitaires; en épis, en grappes, 'en panicules, etc.

Nöus diviserons les génres de la fámille des Légünìneuses en trois grandes sections qui corresponderont aux trois types principaux dont nous avons décrit l'organisation; ces trois sections porteront les noms de $\mathrm{Pa}$ pilionacées, de Cassiées et de Ilimosées.

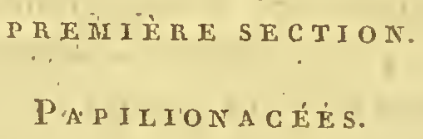

Caliee monosépale, corolle irrégulière, pentapétale, papilionacée; dix ćlamines ordinairement diadelphes.

ro Étamines diadelphes ou monadelphes.

$$
\text { GENET.-GENISTA. J. }
$$

Calice à deux lèvres; la supérieure bidentée, l'inférieure à trois dents : étendard redressé, carène abaissée, ne recouvrant pas en entier les organes sexuels. Gousse allongée, comprimée, uniloenłáire, bivalve, contenant plusieurs gुratines réniformes.

Arbustes ou arbrisscaux à feuilles généralement simples; quelquefois subulées et épyouneuses. 
Genêt des terytuniens. Genista tinctoria. L. Sp. 998 .

\section{Vulgairement : Genestrolle.}

Ce petit arbuste est commun dans nos bois et nos buissons. Ses tigcs, qui sont frutescentes à leur base, sont redressćes dans leurs deux tiers supérieurs, hautes d'environ deux pieds, cylindriques, striées, un peu angulewses, glabres. Les feuilles sont trc̀s-nombreuses, éparses, lancćolées, aiguës, glabres ou légèrement pubescentes. Ses fleurs sont jaunes, et constituent une grappe terminale à la partie supérieure des ramifications de la tige. Les fruits sont comprimés, allongćs et glabres.

Celte espèce fleurit aux mois de juin et de juillet. $\Varangle$

Proprićtés et usages. Les teinturiers emploient fréquemment la genestrolle, qui fournit une couleur jaune assez vive; et, sous ce rapport, cette plante est plis intéressante que par son emploi dans la pratique médicale. Ses fleurs sont légèrement purgatives, et ses graines émćtiques. Mais en Russie, ct surtout dans les provinces méridionales de ce vaste empire, les habitans des canpagnes ont la plus grande vénération pour cette espèce de genèt; ils considèrent sa décoction commc propre à neutraliser lcs effets du virus rabique, et à prévcnir les terribles symptômes de l'hydrophobie. Ils administrent une décoction très-rapprochće de cette plante. M. Ie docteur Tschernjajew, lecteur d'histoire naturelle à l'Universitć de Charcow en Ukraine, m'a assuré que ce remède est connu et mis cn usage par tous les habitans de l'Ukraine. Le docteur Michel Marochelti a lu, le 4 octobre 1820 , à la Socićté mćdico-physiquc de Moscou, des observations sur l'efficacitć de cette plante, qu'il, a vu mettre plusieurs fois cn usage avec succès dans lc traitement de la rage. Il dit qu'outre l'comploi de la décoction du genista tinctoria, on doit cautériscr avec une aiguille rougie au feu, lcs pctites pustules qui sc montrent suus la langue, aux cnvirons dcs glandes sublinguales. Cettc cautćrisation est sans contrcdit la partie efficace de cclte méthodc curative.

Je nc sache pas qu'cn France on ail jamais fait usagc dc cc remèdc dans celte redoulablc maladic. Un grand nombre de 
genêts jouissent dc proppriétés purgatives assez marquées, mais on les emploie bien rarement.

\section{LUPIN. - LUPINUS. L. J.}

Calice à deux lèvres; carène formée de deux pétales distincts à leur base; étamines monadelphes. Gousse épaisse, coriace; contenant plusieurs graines.

Plantes herbacćes", 'à feuilles digitées.

Lupin blanc. Lupinus albus. L. Sp. ior 5: Blackw. t. 282.

Part. usit. : les graines. Nom pharm. : Lupinus.

Plante annuelle, que l'on cultive dans les jardins, mais dont on ne sait pas positivement la patrie. Sa tige cylindrique, droite, simple, s'ćlève à environ un pied; elle est, ainsi qué les feuilles, recouverte de longs poils doux et blanchâtres. Ces feuilles sont alternes, portćes sur de longs pétioles, du sommet desquels naissent cinq ou sept folioles oblongues lancéolées, aiguës, douces au toncher, divergentes en forme d'éventail. Ses fleurs, qui sont blanches, constituentà la partie supérieure de la tige une sorte d'épi terminal. La gousse est allongée, épaisse, v'clue, contenant six à huit graines arrondies, un peu comprimées.

Propriétés et usages. Les graines du lupin ont une saveur amère peu agrćable, que l'eau bouillante leur enlève facilement: elles sont dans cet état farineuses et nutritives. Les Romains et les Grecs les maugeaient, comme nous le faisons des graines du haricot; mais aujourd'hui elles son't généralement nćgligées comme aliment. Commc mćdicament, les lupins ne méritent pas beaucoup plus d'intérèt. Quelques auteurs les ont employés, réduits en poudre, an traitement des vers intestinaux. Mais c'est principalement à l'extćrieur quu'on eu fait plus généralemcnt usage. Leur farine est placée au nombre des quatre $f a-$ rines résolutives. Or en forme des cataplasmes, auxquels on donne une plus grandc activitć, en y joignant le vinaigre, le micl, etc. Leúr décoction, qui est fort amère, a aussi été l'ecommandée contre la gale et d'autres maladies de la peau. 


\section{BUGRANE.-ONONIS. L.J.}

Calice évasé, à cinq divisions linéaires un peu inègales; étendard redressé, plus grand, strié; élamines monadelphes. Gotusse renflée, eontenant une ou deux graines.

Plantes herbacées, ou arbustes quelquefois épineux, à feuilles Irifoliolées,

\section{Bugrane x́pineuse. Ononis spinosa. L. Sp. 1006.}

Part. usit. : la racine. Nom pharm. : Ononis, s. Resta bovis. Noms vulg. : Arrêle-Bouf, Bugrande.

Sa racine est vivace, rampante, très-longue, d'une couleur brụne à l'extérieur, blanchâtre en dedans.

Les tiges sont suffrutescentes à la base, eouchćes, relevées à leur partic supérieure, rameuses, longues d'un ou plusieurs pieds, cylindriques, velnes et un peu visqueuses. Les rameaux sont le plus souvent terminés en pointe roide, et conslituent des épines simples.

Les feuilles sont alternes, courtement pétiolées, trifoliolées; les folioles sont ellipliques, denticulées ; les deux latérales un peu plins petites; ces feuilles sont quelquefois simples sur les jeunes rameaux; denx stipules ovales, aiguës, dentieulées, sont soudées ave la base du pétiole.

Ies; fleurs sont rosées, presque sessiles, axillaires, solitaires ou géminées. Leur caliee est monosépale, lubuleux à sa base, rrès-velu, à cinq divisions profondes, laneéolćes, aiguc̈s, quatre oeeupant la partie supćrieure, une seule la partie inférieure. La corolle est papilionacće : son étendard est redressé, plane, entier, strié; les ailes plus courtes, obtuses, un pen ćeartées. de la carène, qui est très-comprimée, formée de deux pétales distincis seulemert à-la base.

Jes élàmines sont monadelphes.

La gousse est nu pen plus longue que le calice, velue, renfíe, contenanlune ou deux graines.

L'arrête-hœuf est très-commun dans les champs ineultes, les lieux stóriles; il fleurit pendant les mois de juin, juillet et août. 
Propriétés et usages. C'est la racine que l'on emploic. Elle est douceâtre, ın peu amèrc et nauséabonde. On l'a surtout mise en usage pour activer la sécrétion des reins. Lcs anciens la comptaient parmi les racines apéritives. Galien et Dioscoride parlent déjà dc son action diurélique, et des avantages. de son emploi dins le traitement des affections calculeuscs de la vessie. Plusieur's auteur's modernes ont joint leur tćmoignage à celui dcs anciens. Bergịus dit l'avoir administrée avcc le plus grand succès dans l'ischurie provenant de la prićsence.de calculs retenus dans la vessie. D'autrcs. ont fait usage de sa dćcoction contre l'hydropisie de la tunique vaginale, et cufin quelques-uns, tels que Plenck, Meycr, Schncidcr, en recommandent l'usage dans l'engorgement du testicule.

La bugrane s'administre ordinairement en décoction, à la dose d'une once pour une pinte d'ear.

\section{ARACHIDE. $-A R A C H I S$. L. J.}

Calice à quatre divisions linćaires, trois supérieures et unc inférieure; élamines monadelphes; pédoncule tubuleux, contenant l'ovaire à sa base et dans son intérieur. Fruit ovoïde, pointu, presque cylindrique, indéhiscent, rćticulé extérieurement, contcnant d'une à trois grairucs.

Plante annuelle, à feuilles bijugćes.

Arachide souterraine. Arachis hypogaea. L. Sp. Io4o.

Vulgaircment : Pistache de terre.

Cctte plante, qui est annuelle, páraît appartenir à la fois aux contrées chaudes de l'ancien ct du nouveau continent, selon l'opinión la plus généralement admise. Mais, depuis la fin du siècle dernicr, on l'a cultivée avec soin, et en quelque sorte naturalisće dans le midi de l'Euroje. Sa racinc est annuclle, pivotante, garnie de fibrilles capillaires, sur lesquellcs sont dcs petits tubcrcules pisiformes. La tige, dont la hautcur varic d'un à deux picds, est d'abord couclıćc dans sa partie inférieurc, tandis que ses ramifications sout dressćes; celles-ci sont grêles, cylindriques et pubescentes. Ses fcuilles, portées sur de 
longs pćtioles pubcseens, sont composées de quatre folioles obovales, très-obtuses, ciliées et opposécs. On trouve à leur base deux stipulcs inéquilatérales, très-aiguës, un peu soudées ensemblc par leur base. A l'aisselle dc chaque feuille, il existc eommunément deux fleurs, portées chacune sur ın pédoneule pubescent, à peu près de la même longueur que les feuilles. Ces fleurs, qui sont jaunes, et dont quelques-unes sont stćrilcs par l'imperfection de leur pistil, se composent d'un calice caduc à quatre divisions linéaires, très-profondes, trois supérieures et une inférieure. L'étendard est appliqué sur les ailes, qui ne sont point étalées, et la carène est formée de deux pétales en partic libres et en partie soudés. Lcs étamines sont monadelphes.

Le pistil, dans cette plante singulic̀re, offre une organisation dont nous nc eomnaissons aucun autre exemple dans les genrcs nombreux de cette famille. Son ovaire, au lieu d'être situé au fond ducaliec, se trouve placé à la base et dans l'intérieur du pédoncule qui formc un tube grêle, pareouru intérienrcment par un long style, lequel est saillant au-dessus du tube des étamines. Lorsque la fécondation s’est opérée, la fleur se flétrit et se détache. Il ne reșle plus sur la tige que la base du pédoncule, dans l'intćrieur duquel l'ovaire est renfermé. $\mathrm{Du}$ sommet de l'ovaire, on voit poindre une petile pointe qui se recourbc vers la terre; et l'oviaire, à mesnre qu'il grossit, est élevć sur un pédicule qui s'allonge jusqu'à ce que la petite pointe ait touché la terre. Elle ne tarde pas à s'y enfoụeer, et entraine aycc clle l'ovaire, qui est dćjà assez gros, et qui va mûrir ses graines dans eette mouvelle position. Les fruits, que l’on trouve à trois ou quatre pouces sous la surface du sol, sont ovoïdes, allongés, presque cylindriques, tcrminés en pointe, d'une substance coriace, blanchătres et réticulés à l'extérieur, souvent ćtranglés vcrs lcur milieu; ils conlicnnent unc, deux ou trois graines de la grosscur d'une aveline.

Propriétés et usages. On a eherclıć, au commencement de ce sièelc, à donner à l'araehide une place impo rtantc dans notre. agricnlture. Cctte plante mérice, en effet, d'êtrc répanduc et cultivće, à causc des avautages qu'ellc peut nous procurer. En effct, les graines, lorscu'u'elles' sont fraìches et réccntes, ont 
une saveur louce, que la plupart des auteurs comparent à celle des avelines et des amandes. Cette saveur devient eneore plus agréable lorsqu'elles ont été légèrement torréfićes. Les naturels de la Nourclle-Espagne en font leur principale nourriture, et ellcs sont, pour les nc̀gres dispersćs dans toutes les parties du globc, un régal délicieux. On retice de ces amaudes une huile grasse extrémement douce, qui, selon plusieurs auteurs, ne le cède en rien à la meilleure huile d'olives. On dit qu'elle jouit de la propriétć bien prćcieuse de ne rancir janais, et d'acquérir, au contraire, plus de finesse en vieillissant. On peut préparer, avec les amandes de la pistache de terre, une pâte qui, délayée dans l'eau et éduleorće a vec suffisante quantité de suere, forme une sorte d'orgeat extrêmement agréable.

La culture de eette plante demande des soins et une cxposition particuliers. Commc elle craint le froid, elle ne peut prospérer que dáns les provinees méridionales de la France. Il lui faut une terre meuble et un peu sablonneuse, pour qu'elle puisse y enfoncer ses jeumes fruits, et lui eonfier le soin de lcur maturation.

\section{TRIGONELLE. - TRIGONELLA. L. J.}

Caliee à einq divisions égales; l'étendard et les ailes quelquefois ouverts, plus grands que la earène, qui est fort pctite. Gousse allongée, grêlé, comprimée ou cylindrique, terminée en pointe, eontenant plusieurs graines.

Plantes annuelles, à fcuilles trifoliolées.

Trigonfle henu-grec. Trigonella phonum-grcecum. L. Sp. $\operatorname{rog} 5$.

Part. usit. : les graines. Nom pharm. : Phanu-Gracum.

Sa raeine, qui est annuelle; donne naissanec à nne lige dressée, presquesimple, haute d'un pied, cylindriquc, un per veluc. Ses feuilles sont alternes, pétiolées, trifoliolées, it folioles obovales, obtuses, quelqucfois un peu échancrées; denticulées sur les bords; les stipules sont en fer de lance et cntières.

Les fleurs sont jaunes, sessiles, axillaires, géminées, quel- 
quefois solitaires, dressécs. Leur calice lubuleux, presque cylindrique, velu, est à cinq dents linéaires et égales. Leur corolle est coinprinée latćralement; l'étendard est obcordiformc comprimé, les ailes rapprochées, obtuses, la earènc trèscourte.

La gousse est très-allongée, presqne cylindrique, dressée, lerminée par une longue pointe conique, et contient plusieurs graines brunâtres, oblongues, un peu comprimées, tronquées aux deux extrémités.

Le fenu' grec croit sur le bord des champs, dans les proviness méridionales de la France. On le cultive abondamment en Alsace. $\odot$

Propriétés et usages. Les graines de fenu grec contiennent une quantité considérable de mucilage, qu'elles cèdent facilement à l'eau bouillantc. Leur décoction est employéc comme émolliente, sous forme de lotions, d'injections, etc. On fait avec leur farine des cataplasmes adoucissans et résolutifs. Toute la plante répand, lorsqu'elle est sc̀che, une odeur forte, pénétrante et très-fixe, qui pcrsiste pendant plusieurs années, même dans les ćchantillons eonservés dans les herbier's.

\section{MÉLILOT. - MELI L O TUS. Tournef.}

Calice tribuleux, persistant, à cinq dents; étendard plus long que la carène; légnme court, un peu renflé, plus Iong que le calice, strié ou chagriné, contenant unc ou deux graines.

Plantes herbacées, à feuilles trifoliolécs.

Mélilot officinal. Melilotus officinalis. Lamk.

Trifolium melilotus officinalis. L.Sp. Ioj8. Bull. t. 255.

Le mélilot est une plante annuelle dont la lige, dresséc et rameuse, s'élève à deux picds et plus; elle est glabre, cylindrique, striée, portant des feuilles alterues, pétiolées, composées de trois folioles ovales, obtuses, mucronées, dentées en scie, glabres. A. la base du pétiole, qui est élargi, on trouve deux stipules, •qui sont sondées arec ses parlics lalérales.

- Ines flcurs sont fort petites, jaunes, disposćes en petiles grap- 
pes unilatérales et très-nombrcuses à l'extrćmilé des ramifications de la tigc. Ces flcurs sont presque sessiles, légèrement pendantcs, accomıagnćes chacune d'une petite bractće linéaire.

La gousse cst petite, ovoïde, obtuse, rugueuse, embrassée à sa base par le calice persistant, 'qu'elle dćpasse de plus de moitić, contenant ordinairement une seule graine, et restant indćhiscente.

Cetle plante est commune dans les prés, les laaies, les bois, et fleurit pendant la plus grande partie de l'élé. (

Propriétés et usages. Le mćlilot répand une odeur agrćable, qui a beaucoup, d'analogie avec celle de la f'cve de Tonka. Autrefois très-frćquemment employé, soit intćrieurement, soit à l'extérieur, on ne l'administre plus guère aujourd'hui qu'en lotions ou en lavemens. Sa décoction est c doucissante, et son principe odorant est si fugace et si peu intense, qu'il n'influe presque point sur son mode d'action.

Le MÉLito' blcu, melilotus caruleus, Laın., qui est plus petit, et se distingne surtout du précédent par ses fleur's d'un bleu pâle, disposées en ćpis ovoïdes, et est beaucoup plus odorant. Aussi le connait-ori gćnćralement sous les noms de fáux baume du Pérvu, lotier odorant, elc. Son infusion thćiforme est lćgèrement aromatiquc et excitante; mais son usage est bien peu répandu.

$$
\text { HARIGO'I', - PHA SEOLUS. L. J. }
$$

Calice ćchancré supérieurement ct tridenté; étendard large et redressć; carc̀nc et étamines roulées en spirale. Gousse allongće, comprimće, contenant plusieurs graines réniformes. Plantes annuclles volubiles, à feuilles trifoliolées.

Haricot commun. Phascolus vulgaris. L. Sp. Ioi6.

Le haricot ordinaire a une tige volubile qui s'élève à une hauteur de six à dix pieds; elle est cylindrique, lćgérement pubescentc. Les fcuilles sont pétiolies, composécs de trois fo. lioles ovales, Lrincéolées, terminces pax une longuc pointe, entières; obliques, un peu pubescentes et rudes. Les deux folioles latéxales sont jresque sessiles; la foliole terminale est 
portée sur un pétiole d'un demi-pouce de longueur; lc.pétiole commun, long de trois à quatre pouccs, est canaliculé; on observe à sa base deux trc̀s-petites bractées foliacées.

Les fleurs sont blanches ou jaunâtres, disposćes en une sorte d'épi court, porté sur un pćdoncule commun, plus court que le pćtiolc; les pédicelles sont géminés. Le calice cst subcampanulé, comme tronqué à son sommet, présentanl trois petites dcnts à sa partie inférieurc; il est accompagné latéralement de deux bractécs oivertes, plus courtes que lui. La gousse est allongće, un peu comprimće, glabre, pendante, renfermant dans son intérieur des graines réniformes ordinairement blanches, quelquefois violettes, rougeâtres ou marbrées.

On croit généralenent que le haricot cst originaire de l'Inde; mais il est depuis long-temps naturalisé en Europe. Il fleurit vers lc mois de juin; ses fruits sont mûrs en septembre. $\odot$

Propriétés et usages. Les graines de liaricot sont farineuses, et contiennent une grande quantité de matière nutritive. On a peine à concevoir aujourd'hui que quelques auteurs aient pu sérieusement les prescrire, comme emmćnagogues, diurétiques, elc., et qu'une assertion aussi peu fondée ait été rćpétće par des médecins de nos jours. Mais, si ces graines sont tombées dans un juste abandon par rapport à leurs propriétés médicales, il n'en est pas de même quant à leurs usages économiques. On en fait en France une énorme consommation, soit à la fin de l'été, et lorsqu'ils sont encore frais, soit secs et pendant l'hivcr. Ils so nt fort nourrissans, mais un peu lourds pour certains estomacs, et donnent fréqucmment lieu au dégagement de beaucoup de gaz; ils né présentent pas le même inconvćnicnt lorsquc l'on mánge leurs jeunes gousses encore vertes. C'cst rin aliment aussi sain quc fácilc à digérer, et que l’on prescrit quelquefois aux convalescens.

Cctte cspécc n'est pas la scule dont on fassc usage. La graine de presque toutes les autres jouit des mêmes proprićtés.

Les cspèces du genre pouıue (dolichos), qui nc diffèrent des haricots que parce quc leur carène ct Icurs étamiues ne sont pas roulćes cn spiralc; ont, dans lcurs propriétés et leurs usages, une ressemblance frappantc avec ces dernicrs, c'estdire que leurs'graincs sont farineuscs et cmployées à la 
nourriture de l'homme. Une seule espècc mérite d'être men'tionnée à part, c'esi le dolichos pruriens, L., vulgairement appelé pois à gratter. Elle croît dans l'Inde et en Amérique. Scs gousses sont hérissées de poils courts, rudes et d'une couleur rousse, qui s'en détachent avec facilitć. Appliqués sur la peau, ils détermineut un chatouillement désagrćable, qui se change bientôt en une cuisson violente, lorsque l'on a frotté la partie sur laquelle ils avaient été placés. Quelques auteurs ont nćanmoins proposé l'emploi intérieur de ces poils, dans le traitement des vers intestinaux. Ils les administraient à des doses trc̀s-petites, après les avoir incorporés dans un électuaire ou un sirop épais, afin qu'ils n'exercent point leur action irritante sur les parois de l'estomac. Ils prćtendent que, par ce moyen, on expulse aviec la plus grande facilité les vers qui sont amassés dans le canal intestinal. Mais ce remède, qui nous parait dangereux, n'est nullement usité en France.

\section{ÁSTRAGALE. - ASTRAGALUS. 亡. J.}

Calice tubuleux oü renflé, à cinq dents; étendard couché sur les ailes et la carène, qui est obtuse. Gousse plus ou moins renflée, globuleuse ou cylindrique, partagće en deux loges par une fausse cloison longitudinale.

Plantes herbacées ou sous-frutescentes, à feuilles pinnćes, à fleurs axillaires ou en ćpis

Astragate sans tige. Astragalus exscapus. L. Mant. 275'

Part. usit. : la racine.

D'une racine épaisse, pivotante, brunâtre; s'élèvc une touffe defeuilles dont le pétiole; long dc trois à quatre pouces, est cylindriquc, un peu velu, et portc sur scs parties latérales environ une vingtaine de paires de foliolcs ovales, lancéolées, vclucs. La plante est dépourvue dc tige; les pédoncules floranx naissent de l'aisselle des feuilles radicalcs : ils sont velus, cylindriques, et portent à leur partie supérieure de trois à huit fleur's pćdicellćes, qui forment un épi lâche. Le calicc cst cylindrique; pubescent, à cinq dents un peu inégalcs. La corolle cst jaune? 
deux fois plus longue que le calice. La gousse est ovoíde, un peu comprimée, tcrminée à son sommet par une pointe allongéé, formée par)le style; elle est velue, biloculaire, et contient dans chaque loge trois ou quatre graines planes.

On trouve cette plante dans les Alpes. 4

Propriétés et usages. La racine de l'astragale sans tige a une saveur un peu amère et astringcntc. Sa décoction, qui est un peu brunâtre, n'est pas d'un goùt désagréable, et offre quelque ressemblanee avec celle de la racine de rćglisse, mais elle est moins douec. Le docteur Winterln est le premier qui ait parlé de son emploi dans le traitement de la maladie vćnérienne. Mais, depuis eelte époque, un grand nombre de praticiens, entre autres Quarin, Swediaur, Girtanner, etc., y ont joint leur témoignage. Selon eux, c'est un remède d'une grande efficacité, et qui suffit souvent seul pour faire disparaître les symptômes les plus graves de l'infeetion générale, tels que les ulcères, les exostoses, etc. Avouons eej̉endant que les niodernẹs ne partagent pas entièrcment eelte opinion avantageuse.

La racine dc l'astragale sans tige s'emploie ordinairement en déccction, à la dose d'une oncc à une onee et demie pour une pinte de liquide.

Astragale de Grètre. Astragalus Creticus. Lamk. Enc. D. C. Astrag. ig6. t. 33.

Part. usit. : la gomme adragant. Nom pharm. : Tragracunthe gummi.

Petit arbustc rabougri, dont la tige est ligneuse, et nue à sa base, divisée en rameaux courts, liérissés de longues pointes, subulées et épineuses, formécs par les pétioles des années précédentes, qui persistent et s'endureissent. Les feuilles sont rapproehıées; leur pétiole est subulé, et porte d'onze à dix-scpt petites folioles sessiles, tomentenses, ovales, aiguës. Les fleur's sont blanehes, avec des vcines pourpres; elles sont sessiles à l'aisselle des feuilles supéricures, et formcıt une sorlć d'épi très-serré.

Leur caliee, eouvert de longs poils laineux, est divisé presciue jusqu'à sa base en cinc parties linéaires. La corolle cst plus 
courte que le calice, et presque entièrement cachée par les poils dont il est revêtu. Les frruits sont renflés, un peu vésiculeux, velus et à deux loges.

Cet arbuste croit dans l'île de Crète et sur le mont Ida.

Propriétés et usagres. C'cst sur cclte espèce et sur plusieurs autres du mème genre qui croissent ćgaleinent en Orient ou en Perse, telles quc l'astragalus gummifer, L., ustragalus tragacantha, L., etc., que l'on recueillc la gomme adragant. Tournefort, dans son Voyage au Levant, dit que cette substaníce découle de l'espèce que nous venıons de décrire; d'un autre côté, M. Labillardière rapporte qu'il a vu cette gomme suinter de l'astragalus gummifer; tandis qu'Olivier prćtend qu'elle est fournie par une autre espècc qu'il nomme astr. verus, et que toute celle que le commerce apporte en Europe ne provient ni de l'ìle de Crète ni de la Syric, mais de la Pcrse septentrionale, de l'Asie mineure et de l'Arinénie. On peut, je crois, conclure de ces opinions diverses, que la gomme adragant n'est pas produite par une seule plante, mais que plusieurs éspc̀ces du genre astragale cn fournissent ćgalement. L'astragalus tragacantha, qui croît à Marseille, n'y fournit point de gomme, tandis qu'il paraît que la même plante en produit, dans des régions plus méridionales.

La gomme adragant, adraganthc ou adragante, est en lanières minces, contournćcs, ou en filamens grẻles et déliés, ou enfin en grumeaux irrćguliers. Ellè est blanche ct opaque; elle se composc de deux parties, l'une solublc dans l'eau froide, l'autre qui reste insoluble, mais s'y gonflc considérablement; on lui a donné le nom d'adragantine. Cettc dernière substance forme les $\frac{43}{200}$ du poids de la gomme adragant. Elle est soluble dans l'eau bouillante; mais elle se précipite au fond du vase par le refroidisseme nt. La gomnc adragant cst bien plus visqueuse que la gomme arabicque. D'après des expériences faites par Bucholz, une frartie d'adragant donne à l'eau autant de viscosité que vingt-cinq parties de gomme arabiquuc.

Elle cst, comme toutcs les autres substances du mème genre, adoucissantc ct nutritive. On l'emploie surtout pour donncr. aux masses pilulaires ou aux pastilles une consislance convenable; elle entre ćgalemcnt à la dose de dix à quinze graius dans les loochs et potions gommeuses. 


\section{BAGUENAUDIER. - COLUTEA. L. J.}

Calice campanulé, à cinq dents inégales; étendard large ct redressé; étamines diadelphes; gousse très-renfléc, vésiculeuse, mince, à une seule loge qui contient plusieurs graines réniformes.

Mrbrisseaux à feuilles imparipinnées et à fleurs en épis ou en grappes.

Baguenauder commun. Colutea arborescens. L. Sp. ro 45.

Part. usit. : les feuilles. Nom pharm. : Colutea vesicaria. Noms vulg. : Faux séné, Séné d'Europe.

Abrisseau de douze à quinze pieds de haut, à rameaux cylindriques, un peu pubescens dans la partie supérieure: Ses feuilles sont alternes, imparip̂innées, le plus soüvent composées de onze folioles presque sessiles, articulćes, ovales, trèsobtuses, mucronées, entières, très-finement pubescentes, surtoùt à la partie supérieure des rameaux. A la base de chaque ṕtiole sont deux stipules aiguës, petites, en partie soudées avec lui.

Les fleurs sont jaunes, pédonculées, disposées en petits bouquets-de quatre à six fleurs, portćs sur des pédoncules axillaires, plus courts que les feuilles. Ellcs offrent un calice campanulé à cinq dents inégales, les inférieures plus longucs; une corolle papilionacée; étendard très-large, rabattu en dessus; ailes étroites, obtuscs, appliquées contre la carènc, qui est grande et d'une seule pièce; étamines diadelphes.

La gousse est résiculeuse, renflée, à parois minces, devcnant translucides, et comme papyracées à l'époquc dc lcur maturité.

Cet arbrisseau croít naturcllement dans lcs régions mćridionales de la France; il est cultivé dans nos bosqucts d'ornement.

Propriétés et usages. Le nom de sćzié d'Europe, donuć par l'illustre Bocrliave aux feuilles du bagucnaudicr, prouvc que ce médccin célèbrc avait rccoinnu unc action purgalive bien réellc à cc médicancnt. Cettc propriété, déjà annoncéc par plusicurs médccins ancicns, a été de nouvcau constalée par les 
modernes. MM. Coste et Willemet surtout en ont reeommandé l'usage pour remplacer le séné. La dose est d'une, deux et même trois onees, que l'on fait infuser dans une pinte d'eau bouillante. Ces feuilles doivent être réeoltées en septembre, sćchées à l'ombrc, et conservées dans un lieu à l'abri de l'humidité. Assez souvent les droguistes mélangent les feuilles de baguenaudier avec le séné produit par le cassia obovata. Mais ccttc sophistication n'a ricn de bien fâeheux, car le baguenaudier est au moins aussi efficace que eette espèee de sénć.

\section{RÉGLISSE. - GLYCYRRHIZA. L. J.}

Calice tubuleux, bilabié, à quatre dents supérieures et inẹ́galẹs, à une seule dent linéaire inférieure; earène formée de deux pétales distincts; gousse eomprimée, oblongue, contenant de trois à six graines.

Arbustes à feuilles imparipinnées, ayant les fleurs en épis ou.en grappes.

\section{RÉguisse officinate. Glycyrhiza glabra. L. p. 1046.}

Part. usit. : la racine. Nom pharm. : Liquiritia, s. Glycyrrhiza.

La réglisse a une raeine ou tige souterraine, cylindrique, brunâtre extérieurement, jaune à son intérieur, à peu près de la grossęur du doigt, traçante et s'étendant à une grande distance a vec rapidité. Elle donne naissance à des tiges dressées, cylindriques, glabres et presque simples, dont les feuilles sont imparipinnćes, à folioles, le plus souvent au nombre de treize, ovales, entières, obtuses, légèrement échancrées à leur sommet, et recouvertes d'un enduil visqueux. A la base du pétiole commun, qui est renflée, on trouve denx stipules exeessivẹment petites, à peine visibles.

Les fleurs sont violettes, disposées en épis axillaires et pédoneulćs; leur calice est tubuleux, scabre et à deux lèvres; la earène est formée de deux pétales non soudés; les étamines sont diadclphes; les fruits sont eomprimés et glabres. Cétte plante eroît naturellement dans les contrées méridionales de la Franee. Ou la cultive dans plnsieurs provinees. $\mathcal{F}$ 
Propriétés et usages. Cette raeine a une saveur douee et suerée. La phrs estimée est eelle que l'on tire de l'Espagne ou de l'Ttalie. M. Robiquet l'a trouvée eomposée: $I^{\circ}$ d'amidon; $2^{\circ}$ d'albumine; $3^{\circ}$ de ligneux; $4^{\circ}$ de phosphate et malate de chaux et de magnésie ; $5^{\circ}$ d'une șalière résineuse un peu âere; $6^{\circ}$ d'un prineipe sueré fort différent du suere, à peine soluble dans l'eau froide, très solnble dans l'eau elıaude et dans l'alcohol, infermenteseible; $7^{\circ}$ enfin, d'une substanee particulière, suseejtibie de eristalliser en oetaèdres, et différant, par ee earaetère, de l'asparagine, dont elle se rapproehe beaueoup.

La raeine de réglisse est adoucissante: on la fait entrer fréquemment dans les tisanes, pour leur eommuniquer une saveur doneé et agréable. Séehće et réduite en poudre, on s'en sert pour rouler des pilules, ou leur donner une eonsistance eonvenáble. C'est nvee eette raeine que l'on prépare l'extrait eonnu sous le non de suc, ou jus de réglisse. Pour eela, on fait bouillir dans de grándes ehaudières de euivre la raeine eoupée en fragmens; on l'exprime fortement, et on frit évaporer jusqu'à consistanee d'extrait. On enlève ensuite eette masse avec de gràndes spatules de fer. C'est surtout en Calabre et en Espagne que l'on fait eette opération. On roule ensuite l'extrait euit, et l'on en fait des bẩons longs de einq à six prouees que l'on envelopipe aree des fenilleś de laurier. Dans eet état, il eontient toujours des pareelles de euivre que l'on a enlevées en grattant les chaudières. Il est done important de le purifier avant de s'en servir. Les gens du peuple l'emploient très-souvent dans leurs rhumes. En y mêlant de la gomme, du suere et quelques aromates; on en fait des tablettes fort agréables.

$$
\text { POIS. - PISUM. L. J. }
$$

Caliec à einq dents inégales, les deux supérieures plus eourtes; élendard très-grand, relevé; ștyle triangulaire, terminé par un stigmate velu; la gousse est allongée, et eontient plusieurs graines globuleuses.

Plantes eommunément annuclles; ayaut les fcuilles pinnées et lerminées par une vrille, et les stipules Irès-grandes. 
l'ors curavé. Pisum sativum. I. Sp. 1026. Blackw. t. 83.

La raeine est annuelle; la tige herbacće, ordinairement étalée, ou s’élevant, au moyen des villles qui tcrminent ses feuilles, autour des corps environnans: elle est glabre, glauque, et presque earrée. Les feuilles̉ sont alternes, pinnćes, bijugćes, les folioles ovales, entièrcs, mucronćes à leur sommet; le pétiole commun se prolongc et se ehange en une vrillc rameuse, dont les ramifications, roulécs en spirale, sont opposées eommc les folioles; les deux stipules que l'on remarque à la basc de ehaque pétiole sont foliaeées, plus grandes que les folioles elles-ınêtnes : elles sont irrégulièrement cordiformes, mucronées au sommet.

Les fleurs sont blanclıes, grandes, ordinairement gćminécs, axillaires et pédonculées. Le pédoncule commun, long d'un pouce ou environ, est bifurquć à sa partie supéricure. Le calice subcampaniforme est à cinq divisions profondes, ovales, lancéolées; les deux supćrieures un peu plus courtes. La eorolle a son ćıcndard redressé, très-large, ćehancrć au milieu. Les ćtanines diadelphes sont renfermćes, ainsi que le. pistil, dans l'intćriẹur de la earène. Le slyle est plane, formant un angle presque droit avee le sommet de l'ovairc, à hords rćfléchis en dessous à sa partie supérieure, dc manière à paraître triangulaire et concave en dessous, et tranchant vers son sommet; le stigmate cst, velu à sa partie supérieure. Le fruit est une gousse oblongue, un peu comprimće, terninée en pointe recourbée à son sommet, glabre, renfermant sept à huit graines arrondies, globuleuses, dont le hile est eireulaire.

Cette plante est eultivće dans toules les parties méridionales et tempćrćes de l'Europc. La varićıc que l'on eultive en grand sous le nom de pisaille, et que plusieurs auteurs appellent pisum arvense, se distingue surtout par ses fleurs violacées: sesı rames forment un exeellent fourrage pour les bestiaux. $\odot$

Proprićtés et usages. C'est seulement à titre d'alinent que celte plante est iei mentionnée; car elle ne figure plus aujourd'hui parmi les sulsstances médieamenteusqs. Les pois surtout, a vant l'ép@que de leur maturité, sont un alinnent aussi agréable yte rechenehé: Leur sareur est. dlonce et suerée, et ils ne sont 
pas alors farineux et difficiles à digérer comme les haricots. Lor'squ'ils sont secs, on les conserve pendant l'hiver. On peut en préparer deș.cataplasmes émolliens.

\section{F È E. - FABA. Tournef.}

Caliee tubuleux à einq divisions inégales; style comprimé, stigmate velu; gousse allongée, épaisse, contenant plusieurs graines réniformes.

Plantes annuelles, ayant les feuilles bijugées.

Fíve ordinaine. Faba vulgaris. D. G. Fl. fr. Vicia faba. L. Sp. Io39. Blackw. t. т9.

\section{Vulgairement Fése cle marais.}

La tige est dressée, simple, haule d'environ deux pieds, carrée, creuse, tout-à-fait glabre, à quatre angles très-saillans. Les feuilles sont alternes, bijugées, $\dot{a}$ folioles, sessiles, alternes, ovales, arrondies, entières, mucronées, glabres sur leurs deux faces. Les denx stipules qui s'observent à la base de ehaque feuille sont semi-sagittées, un peu déchiquetées, et membraneuses sur leurs bords, avee une tache bruue à leur partie supérieure.

Les fleurs forment, a11 nombre de six ordinairement, des petits épis eourts, situés à l'aisselle des feuilles supérieures, et dont les fleurs sont toutes tournées en dehors. Leur calice est tubuleux, cylindrique; son limbo est à einq divisions allongées, étroites et aiguës, dont deux supérieures manifestement plus courtes. Leur corolle est grande; l'étendard, beaucoup plus long que les antres pétales, est arrondi, enlier, plié sur lui-même suivant sa longuenr, en sorte qu'il présente une erête en dos d'ủne. Il est blanc, lavé de violet à sa partie inférieure. Les ailes sont rapprochées, offrant une grande tache noire. Lia carène est beaucoup plus courte, et caehce entre les ailes. Les étamines diadelphes sont renfermées dans la carène, ainsi que le pistil. L'ovaire est très-allongé, un peu coniprimé latéralement, terminé par un style grêle coinprimé, formant un angle droit avee lui; le stigmate est tres-petit, et offre un tonquinet de poils eourts et soyenx à sa partie inférieure. La 
gousse est́ grosse, allongće, un peu toruleuse, comme chärnue, renfermant cinq à six graines réniformes aplaties.

On ne sait pas au juste quelle est la véritable patrie de cette plante. Plusieurs auteurs la font venir d'Égypte et des confins de la Perse. Aujourd'hui clle est naturalisée dans toute l'Europe. ()

Propriétés et usages. Nous pourrions répćter pour cette plante ce que nous avons dit prćcédemment en parlant des haricots et des'pois. Les fèvcs sont un aliment ássez agréable, surtout lorsqu'elles sont jeunes et petites. On les prive en général de leur tćgument, qui est dur, épais et d'une saveur un peu âpre. Leur farine, que les anciens comptaient parmi les farines résolutives, sert à préparer des cataplasmes émollliens. Devons-nous rappeler ici que l'eau distillée des tćgumens de ccs graines a été autrefois considéréc comme diurétiqué, tandis que celle des fleurs ćtait usitéc comme cosmétique. Maí aujourd'hui leur usage est totalement abandonné.

\section{LENTIL LE. - ERV.UM. L.J.}

Calice à cinq divisions égales et profondes; corolle de la même longueur que le calice; style grêle; istigmate non velu; gousse comprimée, courte, contenant une ou deux graines comprimées ou globuleuses.

Plantes herbacées, à feuilles pinnées.

\section{Lentilue ordivaire. Ervum lens. L. Sp. 1036.}

Petite plante annuelle dont la tige rameuse et carrée est pubcscente. Ses feuilles se composent de quatre à cinq paires de petites folioles alternes, ovales, pubescentes et blanchâtres. Le pétiole comimun se prolongc en uné vrille roulée. A sa base sont deux petites stipules ovales, lancéolécs, aiguës.

Les fleurs sontblanches, réunies; au nombre de deux à trois, a l'aisselle des feuilles, et portées sur un pćdóncule commun, de même longucur quc ces dcrnicres, "ét"se terminant souven en une vrille roulće.

Le calice cst à cinq 'divisions profondes, 'égales', ćtroites, lancćolées, aiguc̈s, un peu pubciscentcs. La corollc n'cst pas 
plus longue que le calice; ses pétales sont rapprochés. Les étamines sont diadelphes. Le fruit est comprimé, court, terminé par une sorte de bec à son sommet, et contenant deux graines lenticulaires.

La lentille croit naturcllement dans les moissons du midi de la France. Elle est cultivée en abondance pour les usages domestiques; elle aime en général les terrains légers et sablonneux. $\odot$

Propriétés et usages. Tout le monde connaît l'usage que l'on fait des graines de celte plantc, qu'on ne mange en génćral quc lorsqu'elles, sont sc̀ches, fort différentcs en cela des pois, des haricots et des fèves. Bouillies et réduites cn pulpe, elles peuvent servir à préparer des cataplasmes émolliens. Quant à leur décoction, elle jouit surtout dans la médecine populaire d'une très-grande réputation pour faciliter l'éruption dans les exanthèmes, tels que la variole, la rougeole, etc.; mais les médecins n'ont pas grande confiance dans ce reméde.

$$
\text { GICHE.-CI CER. L. J. }
$$

Calice presque campanulé, à cinq divisions égales, dont quatre supérieures; corolle de la même longueur quie le calice; carène formée de deux pétales distincts. Étamines diadelphes; style filiforme; stigmate capitulé. Gousse renflée, presque cylindrique, contenant deux graines.

Plantes annuelles, à feuilles imparipinnées.

\section{Giche common. Cicer arietinum. L. Sp. 1040.}

Noms vulg. : Pois chiche, Garvance, Pesette, ctc.

La tige du pois chiche est grẻle, faible, rameuse, anguleusc, couverte de petits poils glanduleux blanchâtres, haute d'environ un pied. Ses feuilles sont alterncs, imparipinnécs, velucs, a folioles alternes, presque sessiles, assez nombrcuses, ovales, denticulées dans leur moitié supérieure. Les deux stipulcs adhérentes avec la tige sont foliacécs, profondément dentées.

Les fleurs, violettcs pâlcs, sont axillaircs, solitaires, portécs sur des péloncules grčles, recourbés, velus, lonģs d'environ 
un pouce, offrant une sorte d'articulation entourée de quatre bractées inégales très-petites, vers le milieu de sa hauteur. Leur calice est subcampanulé, à cinq divisions profondes, lancéolées, aiguës, quatre supérienres appliquées sur l'étendard, l'autre inférieure appliquée sous la carène. La corolle esl à peine plus longue que le calice. La carène est formée de deux pétales distincts. Les étamines sont diadelphes. L'ovaire est ovoïle, comprimé, très-velu, terminé supérieurement par un style grêle et filiforme, droit; glabre à sa partie supérieure; le stigmate est très-petil et capitulé.

La gousse est renflée, cylindrique où globuleuse, pubescente, contenant ordinairement deux graines presque globuleuses, trollquées d'un côté.

Cette plante, qui croît naturellement en Égypte et en Orient, est cultivée dans le midi de la France. -

Propriétés et usages. Pendant les grandes chaleurs de l'été, on,voit briller sur les feuilles et la tige de ce végétal, des gouttelettes fort petites d'un liquide visqueux et très-limpide; extrêmement acide, et que M. Deyeux a reconnu être de l'acide oxalique à l'état de pureté. Cette excrétion est, sans contredit, une des plus remarquables dont tout le règne végétal nous offre l'exemple. Les pois chiches ont servi à la nourritıre de l'lıomme dès les temps les plus reculés. Les écrits de Galien, de Plinc, etc., en font mention. On les mange surtout en Égypte, en Syrie et dans les contrées méridionales de l'Europe; mais c'est un aliment peu agréable. La décoction des feuilles 'était jadis employée comme diurétique et lithontrijjtique, et la grande quantité d'acide oxalique qu'elles contiennent explique suffisamment l'action qu'elle pouvait exercer sur' l'apparcil urinaire. Cependant ce remède est à.peu près inusité de nos jours.

\section{PTÉROCARPE. $P$ PEROCARPUS.L.J.}

Calice tubuleux, presque turbiné, à cinq dents courtes' et inégales; étendard dressé, unguiculé à sa base, plus long que les ailes et la carène; ćtamines diadelphes;"gousse très-comqrimée, plane, presque orbiculaire ou réniforme, indéhiscente et monosperme. 
Grands arbrès à feuilles imparipinnées, ayant les fleurs disposées en graplyes axillaires.

Ptérocarpe sang-dragon. Pterocarpus draco. L. Sp. -r662. Lamk. Ill. t. 6o2.

Part. usit. : le sang-dragon. Nóm pharm. : Sanguis draconis.

C'eșt un grand arbre qui croît dans l'Inde el dans différentes parties de l'Amérique méridionale. Ses feuilles alternes sont imparipinnées, composées le plus souvent de luit folioles. Leur pétiole commun est long de six à huit pouees, glabre et un peu eanalieulé. Les folioles sont alternes.,pétiolulées, ovales, acuminées, entières, tout-à-fait glabres. A la base de chaque pétiole commun on trouve deux stipules fort petites, qui se détaehent et tombent de bonne heure.

Les fleur's, qui șont jaunâtres, forment des grappes rameuses à l'aisselle des feuilles supérieures. Ces grappes sont quelquefois. ausși longues que les feuilles. Chaque fleur est pédoneulée; son ealiee est persistant, eourt, turbiné, à einq dents inégales. Ha corolle est papilionacée, formée de einq pétales distinets et onguienlés à leur base. Leses étamines sont plus courtes que la eorolle, et diadelplies.

La gousse est extrèmement eomprimée, orbieulaire, légèrement pédicellée, terminée brusquement par une petite pointe recourbée; eouyerte d'un duyet eourt et ferrugineux, restant constamment indéhiseente.

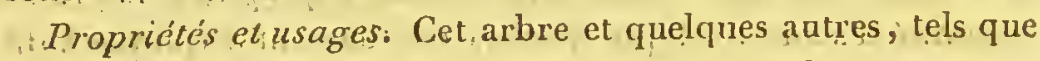
le dracena draco, de la famille des Asparaginées, le pterocarpus santalinus, etc., fọurnissent la résine eonnue sous le nom: de sang-dragon. Elle est en masses plus ou moins eonsidérables, ou en bâtons roulés; danș des feuilles de palmier, d'un brun rougeâtre, inodore, fragile; sa eassure est nette et luisante: elle eroque sous la dent; est insoluble dans l'eau;' projetée, sur des eharbons ardeus, elle brîle et répand: une fumée iere. M. Thomson a eru y découvrir une petite quantité d'acide bcizoïque, et larange parmi les baumes.

La saveur de cette résine est un pelı astringente : soll odeur 
cst nulle. Rćduite en poudrc, ellc est d'une belle couleur rouge, qu'elle communique à l'alcohol, dans lequel elle est cn grande partie šolủble:

Tous les auteurs de matière mćdicale regardent le sang-. dragon comme un médicament tonique et astringent. Mais on s'en servait plus souvent jadis que de nos jours. Les hćmorrhagies passives et la diarribée sont les mạladies contre lesquelles on en faisait surtout usage. C'est ordinairement eir poudre que l'on prescrit cetle substance, dont la dose varie d'un scrupule à un demi-gros. 'La teinture alcoholique ș'admininistre quelquefois à la dose de trente gouttes et au dclà, dans un vćhicule approprié.

Cettc résine entre ordinairement dans la préparation des. poudres dentifrices et dans certains vernis.

Il est une autre espèce de ce genre, pterocarpus santalinus, L., originaire des Indes orientales, dont le bois porte le nom de. SANTAL ROdGE. Ce bois, qui offre une couleur rouge foncée, une texture fibreụse, est très-résineux, d'une odeur et d'une. saveur faibles. 11 fournit à la teinture un principe colorant rouge assez employé dans les arts. Il ne figure plus parmi. les substances médicarienteuses.

Quelques auteurs ont cru que lc même arbre produisait la gornme lino; que l'on sait aujourd'hui être fournie par un arbre de la famille des Rubiacées, désigné sous le nom de nauclea gainbir.

$2^{\circ}$ Étamines libres et distinctes.

\section{COPAHU:- COPAIFERA. L: J. Desf.}

Calice à quatre divisions profondes et comme imbriquées. Point de corolle. Dix élamincs distinctes ct ćtalćes. Style terminé par un stigmatc simplc. Fr'uit compriné, bivalve; contcnant une ou deux graincs.

Arbres résincux à fcuilles ordinairement paripinnées, à fleurs en grappes ranneuscs. 
Copanu ofpiciral. Copaifera officinalis. Jacq. Am. p. 133. t. 86 .

Part. usit. : la résine de copahu. Nom pharm. : Oleo-resina copahu, Balsamum copaiva. Nom vulg. : Baume de copahu.

C'est un grand arbrc touffu, d'un forme ćlégante, dont les feuilles sont alternes, eomposées de einq à huit folioles ovales, acumirićes, entières, très-glabres et un peu luisantes, ponctućes et presque sessiles. Les fleurs, qui sont blanches, forment des grappes rameuses, axillaires, de la longueur des fcuilles. Lcur calice se eompose de quatre lobes un peu inégalux, étalés, que Jacquin et Linné ont décrits comme une corolle de quatre pétales, tandis que la corolle manque rćellement. Les étamines, au nombre de dix, sont libres, ćgales entre elles, toutes fertiles et étalées. Le fruit, que l'on ᄁe connaît pas eneore à son état parfait de maturité, est comprimé, orbiculaire, bivalve, et eontient ordinairement une ou deux graines.

Le eopahu croît naturellement dans l'Amérique méridionale. Jacquin dit qu'il vient pêle-mêle avee lè Myroxylum peruiferun.

Propriétés et usages de la résine de copahu.

Elle est extrêmement fluide, ineolore lorsqu'elle est récente, devenant un péu citrine en vieillissant. Son odeur est forte et pénétrante, sa saveur âcre cl très-désagrćable. On l'ubtient en pratiquant des ineisions profondes à l'écorce de l'arbre. Elle contient presqu'un ticrs de son poids d'huile volatilc, qu'elle cède facilement par le moyen de la distillation.

Cette substance rćsineuse jouit évidemment d'une aetion stimulante fort éncrgique. Donnée à fuible dose, telle que quelques goutles sur un morceau de sucre, ou dans un véliicule, elle aetive les fonctions de l'estomac et augmente l'appćtit. Son aetion proeure un rćsultat tout-à-fait différcnt quand on l'administre à plus haute dose : elle oecasione un sentiment de gêne et de pesanteur dans l'estomac, et donnc lien à des vomissemens ou à des déjeetions alvincs abondantes. On obscrve 
ces résultats lorsque la membrane muqucuse intestinale est dans son état normal, ou qu'elle est légèrement excitée; car ils sont tout-à-fait différens quand cette membrane, par suite d'une inflammation chronique, est au-dessous du ẻegré d'excitabilité 'qu'elle doit naturellement avoir. On voit alors le baume de copahu faire cesser la diarrhće, qui n'est qu'un symptôme de cet état. On en a fait également usage dans les autres catarrhes chroniques et dans la leucorrhée, quand on n'y aperçoit pas de symptômes d'inflammation.

Mais c'est spécialement contre la blennorrhagie urétrale que l'on administre aujourd'hui le, baume de copahu a vecle plus de succès Il rćussit non-seulement dans les dernières périodes de cette maladie, lor'sque tous les symptômes d'irritation ont disparu, et qu'il ne restc plus qu'un écoulement atonique, mais aussi dès son dćbut, et quand l'inflammation est très - vire. MM. Delpcch et Ribes ont surtout appelé l'attention des praticiens sur l'efficacité du baume de copahu dans cette circonstance. On doit alors l'administrer à de fortes doses, si l'on veut que ses effets soient plus certains. Ainsi on en prescrira un ou deux gros, et mĉme davantage. L'on a remarquć que cettc substance irrite beaucoup moins la surface interne des voies digestives et n'occasione plus de déjections alvines, lorsqu'on l'unit à unc cau distillće ou à une poudre aromatique, prćcaution qu'il est indispensable de prendre lorsqu'on fait usage du baume de copahu contre la blennorrhagie. On peut aussi administrer ce médicamcnt en cn versant de trente à cinquante gouttes sur un morceau de sucre, dose que l'on répète plusieurs fois dans la journée.

Cic médicament a paru apporter un soulagement réel dáns le catarrhe chronique dc la vessie. M. le professeur Delpech, de Montpcllier, a fait connaître plusieurs observations de ce genre, où il avait complétement réussi. 


\section{MYROXYLON. - MYROXYLUM:}

Myrospermum. Jacq. Juss.

Toluifera. L. J.

Calice campanulć, tronqué, à cinq dents à peine marquées; corolle de cinq pétales irrćguliers, un supérieur plus grand, onguiculć, presque cordiformc, les quatre autres étroits et linéaires. Dix étamines distirictes et un peu déclinées. Gousse allongée, très-comprimée, membraneuse, épaisse et renflće à son sommet, qui est très-oblus, et qui présente une petite loge dans laquelle; sont contenues une ou deux graines.

Arbres résineux à feuilles pinnées, ayant les fleurs en grappes simples, ou rameuses et axillaires.

Myroxylon Baumier. Myroxylum 'balsamiferum. Myroxylum peruiferum. L. Supp. 233. Toluifera balsamum. L. mat. med.

Part. usit. : le baume du Pérou et le baume de Tolu. Nom pharm. : Balsamum peruvianum. Balsamum tolutanum.

L'ćlégance et le port gracieux de cet arbre ont été remarqués par tous les voyageurs. Son tronc est recouvert d'une écorce lisse, épaisse, très-résineuse, ainsi que les autres parties du vćgćtal. Les jeunes rameaux prćsentent, dans leur partie supéricure, de petits tıbercules irréguliers; que l'on remarque également sur les pédoncules communs des fleurs. Les feuilles sont alternes, imparipinnées, composées ordinairement de huit ${ }^{\mathrm{x}}$ folioles alternes, ovales, acuminées, très-entièrcs et trc̀sglabres, presque sessilcs, et d'un vert clair. Elles sont parsc-

r Il pourrait paraître étonnant au premier abord que des feuilles eomposées de huit folioles soient imparipinnées, c'est-à-dire terminées par une foliole impaire. Mais si l'on fait mention que ces folioles sont alternes, on coneevra faeilement alors qu'il doit s'en trouver une seule qui termine le pétiole eommun. Cette observation s'appliquque également au Pterocarpus Drảeo, décrit préeédemment. 
mées de points translucides, comme dans les millepertuis. Le pétiole commun, dans les plus jerines feuilles, est pubescent; il est tout-à-fait glabre quand les feuilles sont parfaitement développées.

Les fleurs sont blanches ou roses, et forment des épis oú des grappes rameuses, pédonculées à l'aisselle des feuilles supérieures. On trouve à chaque fleur, qui cst pédicellée, l'organisation suivante : son calice est campanulé, tronqué à sa partie supérieure, qui présente quelques dents à peine marquées; les cinq pétales sont étalćs et inćgaux, plus longs que les dix étamines, dont les filets sont libres et terminés par une' anthère ovoïde et blanehe.

Les fruits sont légèrement pédicellés, allongés, fortement comprimés, membraieux et en forme d'ailes sur leurs côtés, plus renflés à leur sommet, qui offre une seule loge indéhiscente, contenant une ou deux graines. Les fruils, longs d'environ quatre à cinq pouces, ont à peu près un pouce dc largeur; ils sont tout-à-fait glabres.

Cet arbre croît dans les provinccs les plus chaudes du continent de l'Amériquc méridionale, au Pérou et dans la province de Carthagène, aux environs de la ville de Tolu.

Jusqu'à présent, on avait considéré comme deux arbres différens les végétaux qui produisent le baume du Pérou et le baume de Tolu; l'un portait le nom de myroxylum peruiferum, et l'autre celui de toluifera balsamum. Le premier avait été placé dans la famille des Légumincuses, et le sccond dans celle de Tćrébenthacées. Mais en examinant avec soin "le caractère donné par tous les auteurs du genre toluifera, j’ai remarqué que ce caractère était absolument le même que celui du $m y$ roxylon, à l'exception du fruit, que l'on décrivait seulement d'après Miller, et qui en effet scrait fort différent de cclui du genre précédent, puisqu'il serait à quatre logcs et à quatre graines. Observant ensuite, $\mathrm{x}^{\circ}$ yu'aucun naturalistc modernc n'a donné la description du toluifera; $2^{\circ}$ que cet arbrc $n^{\prime}:$ jamais été figuré; $3^{\circ}$ gu'il n'cxiste pas dans les herbiers; $4^{\circ}$ enfin que le baume de Tolu ne pcut être distingué du baume du Pérou blanc ou scc; j’avais ćté conduit à penser quc ccs deux substances balsamiques étaient rctirées d'une seule ct 
mçme espèce végétale, c'est - à-dire du myroxylum peruiferum. J'ai été confirmé dans mon opinion, $x^{\circ}$ par la lecture d'un Mémoire de don Hippolythe Ruiz, l'un des autenrs de la Flore du Pérou, qui dil que c'est le inyroxylum peruiferum, que les habitans dćsignent sous le nom de quinoquino, qui produit les deux substances résineuses apportées en Europe sous les noms de baunes du Pérou et de Tolu; que ces deux baumes ne diffèrent l'un de l'autre que par leur couleur, leur mode d'extraction, et la diffćrence des pays où on les rćcolte: le premier venant du Pérou et des pays circonvoisins; le second, au contraire, étant tiré des environs de Tolu, dans la province de Carthagène, c'est-à-dire trois cents lieues jlus au nord que le premier; $2^{\circ}$ ma conviction a étć complète, lorsque j’ài eu examiné, dans l'herbier de M. le baron de Humboldt, des échantillons de l'arbre qui fournit le baume de Tolu et le baume du Pérou, recueillis sur les lieux même par cet illustre voyageur. J'ai reconnu que ces deux arbres appartenaient à la même espèce végétale, c'est-à-dire au myroxylurn peruiferum. Il résulte de là , que le genre toluifera n'existe pas réellement, et que le fruit décrit par Miller, comme étant celui du toluifera, appartenait à un autre végétal. Dès lors les baumes. du Péron et de Tolu sont produits par un même arbre, et ne diffèrent que par leur couleur ct leur consistance, qui tienncnt surtout à la diffćrence de lcur mode d'extraction.

Du baume du Férou. On distingue, dans le commerce, deux sortes de baume du Pérou : l'un est presque sec, d'une couleur fauve claire, ordinairemcnt contenn dans de petites callcbasscs: on l'obtient en pratiquant des incisions à l'écorce de l'arbrc; l'autre cst liquide, d'un brun rougeâtre, et s'extrait en faisant bouillir dans l'eau les écorces et les jeunes rameaux; c'est le baume du Pérou noir du comınerce. Son odeur est forte, mais agréable; sa saveur cst âcrc et amèrc. Il brûle en répandant une fumée blanche, qui est produite par l'acide benzoïquc; il cst entièrement soluble dans l'alcohol : l'eau bouillante lui enlève son acidc bcnzoïquc. Le baumc du Pérou nous vient surtoul des différentes provinces du Pérou.

Du baume de Tolu. C"est aux environs de Toln, dans la province de Carthagìne, qu'our recucille ccttc substance balsa- 
mique. Le suc résineux, qui s'écoule des incisions faites au tronc de cet arbre, est reçu dans des vases où on le laisse se sécher. Il constitue alors des masses solides plus ou moins volumineuses, d'une couleur fauve, se liquéfiant avec facilité, d'une saveur âcre, mais agréable, et d'une odeur très-suave. Il se ramollit facilement sous la dent, se dissout en totalité dans l'alcohol, et cède à l'eau bouillante tout son acide benzoïque. Tantôt le baume de Tolu nous est apporté dans de grands vases de terre, qu'oun nomme potiches; tantôt on le coule, lorsqu'il est encore liquide, dans des callebasses. Il est alors fort 'difficile de le distinguer du baume sec du Pérou.

Propriétés et usages. Nous croyons devoir réunir dans un mćme article les propriétés médicales de ces deux substances, parce qu'en effet elles ont un mode d'action entièrement semblable sur l'économie animale; c'est-à-dire qu'elles déterminent une excitation vive dans les tissus, et doivent être placées parmi les médicamens stimulans. C'est surtout contre les catarrhes chroniques que l'on en fait usage, particulic̀rement du baume de Tolu. Les tablettes et le sirop dans lesquels on fait entrer cette substance sont des préparations fort agréables, et quel'on prescrit fréquemment dans la dernière période des catarrhes pulmonaires, lorsqu'il n'y a plus ni chaleur ni douleurs vives. On emploie aussi quelquefois un mélange de baume de Tolu et d'éther sulfurique, que l'on place dans un flacon terminé par un long tube recourbé. Le maladc aspire les particules qui se volatilisent, et souvent on a vu cc procédé calmer des toux opiniâtres, suivies d'expectorations muqueuses très-abondantes.

Quant au baume du Pérou, il est fort rarement usité en médecine. Les parfumeurs lc font entrer dans plusieurs essences et parfums. Du reste, ses propriétés sont les mêmes que celles du Tolu, et c'est dans les mêmes circonstances qu'il a étć prescrit par plusieurs auteurs de matière médicale.

Avant de passer à la description des plantes de la seconde section, mentionnons rapidement quelques autres papilionacées, autrefois plus ou moins en vogue, mais peu cmployćcs aujourd'hui.

${ }^{\circ}$ Le Crtise des Alpes, aubours ou faux ébćnier, Cylisus laburnum, L., joli arbre qui croît communćment dans les $\Lambda$ lpes, 
ct que nous cultivons dans nos jardins. Son écorce cst. verte ct lisse; ses feuilles trifoliolées; ses fleurs jauncs, en grappes pcndantes. Ses graines sont émétiques. Elles eontiennent un prineipe partieulier, incristallisable, d'une saveur amère ct nauséabonde, auquel MM. Lassaigne et Chevalier ont donné le nom de Cytisine. Inusité.

$2^{\circ}$ Le Spartier à balais, Spartium scoparium, L. , petit arbrisseau très-commun dans nos bois, dont les fenilles sont sinples et fort petites, les rameaux anguleux et effilés, les fleurs jaunes et grandes. Ses graines et ses sommités sont regärdées comme émétiques et purgatives. Peu usité.

$3^{\circ}$ Le GALEGA, Galega officinalis, L., plante vivaee que l'on trouve daus les prés et les bois. Ses tiges sont garnies de feuilles imparipinnées; et ses fleurs, qui sont violettes ou blanehes, forment des grappes simples et axillaires. La décoction. de cette plante, qui est légèrement amère, a été vantée autrefois comme ún remède des plus puissans. Il s'est trouvé des médecins qui l'ont regardée comme très-effieaee dans le traitement. des fièvres graves et de l'épilepsie. 'Abandonné totalement aujourd'hui.

$4^{\circ}$ L'ANAGyre fétide, ou bois puant, Anagrris fatida, L., arbrisseau des conirées méridionales de la France; dont les feuilles sont trifoliolées; les fleurs jaunes, ct naissant par petits bouquets sur les différens points de la tige. Selon Mr. le docteur-Loiscleur-Deslongehamps, ses feuilles sont émétiques et purgatives; mais elles ne sont point usitées.

$5^{n}$ L'éeoree du Geoffroya inermis de Swartz, et Geoffroya surinamensis de Murray, grands arbres originaires des Indes occidentales, mérite également d'être mentionnée ici. Les médecins américains et anglais en font grand cas. Sa saveur est amère et plus ou moins âeré, et e'est pour combattre les vers qui se développent dans lc eanal alimentaire, qu'on l'a surtout mise en usage. On emploie, soit sa décoclion, soit son cxtrait. Mais, en France, ee médicament cst tout-à-fait inusité.

$6^{\circ}$ Le genre Indrotier est un des plus intéressans de eetle famille pour l'art de la teinture. Tout lc monde sait que c'est. des feuilles de plusieurs cspèces de ce grenrc, telles que Indigoferaanil, Indigofera tinctoria, Indigofera argentea, etc., 
que l'on retire eette belle matière eolorante bleue eonnue sous le nom d'Indigo. C'est aux Iudes et en Amérique que l'on prépare eette substanee, en faisant-sueeessivement ıacérèr la plante dans plusieurs grandes euves. Dans lés pays où eroissent ees végétaux préeieux, on les emploie aussi quelquefois comme médieamens. Ils sont ámers, toniques et fébrifuges.

\section{DEUXI È M S E T T O N. \\ C A S S I É E's.}

Calice profondément divisé; eorolle de trois ou einq pétales presque égaux et réguliers; dix étamines libres ou soudées, dont quelques-unes sont souvent avortées et rudimentaires.

CASSE. - CASSIA. L. J.

Caliee eoloré, à einq divisions très-profoñdes et ea duqués; corolle pentapétale presque régulière; étamines déelinées, libres, inégales, trois inférieures plus longues, quatre latérales moyennes, trois supérieures stériles, et les plus courtes de.toutes; goursse d'une forme très-variable, tantột plane et plus ou inoins recourbée; tantôt ovoöde, allongée ou eylindrique, presque toujours indéhiseente, partagée en plusieurs loges par des eloisons transversales. Ces loges, qui eontiennent toujours une seule graine, sont quelquefois remplies de.pulpe.

Plantes herbacées ou ligneuses, a feuilles pinnées ou déeomposées; fleurs en épis ou en grappes.

ro Fruit très-comprimé ét plus on moins recourbé: SenNa.

Casse a feulldes nrgues. Cassia acutifolia. Del. Egyp.

$$
\text { t. } 27 . f \cdot \cdot \text {. }
$$

Cassia lanceolata. Nectoux Vojage (non Forsk.) Cassia senna var $\alpha$. L. Sp.

Part. usit. : les feuilles et les fruits. Nom pharm. : Senna alexandrina, Senna orientalis. Noms vulg.: Séné d'Alexandrie, Séné de la Palte, Follicules de Tipipoli, ete.

C'est un petit arbuste qui a environ deux à trois pieds d'élé- 
vation. Sa tige est ligneuse, dressée, rameuse, cylindrique! blanchâtre, un peu tomenteuse dans sa partie supérieare; elle porte deş feuilles alternes, accompagnées à leur base de deux petites stipules subulées. Chaque feuille, qui est pinnée sans impaire, sc compose de quatre à huit paires de folioles allongćes, opposées, presque sessiles, ovales, lancéolées, aiguës, entières, dépourvues de glandc à leur pétiole, qui cst trèscourt, un peu obliques et inéquilatérales à leur base, d'un vert jaunâtre, et finement pubescentes, surtout à leur face inférieure.

Les fleurs, qui sont jaunes, forment des épis pédonculés et axillaires. Chaque fleur est courtement pédicellée. Le calice est à cinq divisions profondes et inégales. Les anthères s'ouvrent chacune par ull petit trou qui se forme: au sommet de chaque loge. L'ovaire est légc̀rement pédicellé, hérissé de poils jaunes; il 'se termine pár un style grêle et recourbé. Les fruits, que 'l'on désigne improprement sous le nom dc follicules, sont planes, elliptiqucs,'obtus, non recourbés, glabres, à plusieurs loges contenant chacune une graine presque cordiforme; ils s'ouvrent en deux valves, lorsqu'ils soint parfaitement múrs.

Cette plante croît abondamment en Égypte, auprès de Syène et en Nubie.

On confond généralement cette espèce avec le Cassia lanceclata de Forskal, peiit arbuste rabougri que cet auteur a trouvé dans les déserts de l'Arabie. Mais elle en est différente, ainsi que l'a fort bien remarqué M. le profcsseur Delile, par l'absence des glandes, qui existent à la base des pćtiolules dans l'espćce de Forskal, et par ses feuilles pubescentes et moins étrọites.

Cásse a feulles obtuses. Cassia obovata. Colladon. monog. p. 92 . fol. r5. f. a.

Cassia senna var. $\beta$ L. Sp.

Cassia senna. Lamk. Ill. t. 332 . f. 2. a. b. d. f. 3. 6. 9. Part. usit. : les feuilles, les fruits. Nomś pharm.: Senna italica, Senna nostras. Noms vulg.: Séné de Tripoli, Séné d'Italie, Sćné de la Thébaide, ctc.

Cette espèce a lcs plus grands rapports avec la précédcnte, 
dans son port et dans ses caractères. Elle est généralement plus petite, et ne s'ćlève guc̀re au delà d'un pied à un pied et demi. Sa tige, frutcscente à sa base, est cylindrique, un peu pulvćrulente et rameuse dans sa partie supérieure. Ses feuilles sont alternes, paripinnćes, composées de quatre à sept paires de folioles opposées, presquue sessiles, obovales, très-obtuses, quelquefois mucronécs, amincies inférieurement, et en quelque sorte cunéiformes et inéquilatérales. Elles sont, comme dans l'espèce précédente, légc̀rement pubéscentes, d'un vert jaunầtre, et accompagnées de deux stipules subulées, entières, persistantes.

Les fleurs, qui sont d'un jaune pâle, constituent des épis axillaires pćdonculés, plus longs qué les feuilles. Il leur succède des gousses on follicules très-comprimées recourbćes en arc, et presque réniformes, plus ćtroites que dans l'espèce précédente, d'un brun verdâtre, couvertes d'un duvet très-fin et très-court, que l'on n'y aperçoit qu'avec le secour's de la loupe.

Le séné à feuilles obtuses croît spontanément dans la Thébaïde et d'autres parties de l'Égypte, nù il est vivace. Il ést annuel dans les jardins de France. On lc cultive en Italie, en Espagne, etc.

Ce sont les deux plantes que nous venons de décrire, et une troisième espèce encore mal connue, que Forskal appelle Cassia lanceolata, qui fournissent tout le séné que le commerce apporte en Europe. Voyons à étudier ce inédicament, tel qu'il nous est livrć par les droguistes.

Des diverses espéces de séné. On trouve dans le commerce trois espèces, principales de séné qui y portent les noms de séné de la Palte, séné de Tripoli et séné de Moka. Étudions successivement leurs caractères.

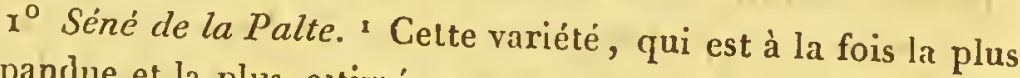
répandue et la plus estimće, nous est apportée du Caire par Alexandrie. Ellc se composc des féuilles et des fruits du cassia acutifolia, dont nous avons précédemment exposé lcs caractc̀res. Ces feuilles sont ovales, aiguës, lćgèrement pulvćru-

' Ainsi nommé à cause d'un impòt appelé palte, mis par le grand seigncur sur cette substance. 
lentes, d'un vert grisâtre, d'unc odeur assez agréable, ct d'une saveur visquense ct amèrc.

- '20. Sércé de Tripoli. Vient de la haute Égypte par Tripoli. Il est moins estimé que le précédent, et se compose des feuilles et des fruits du cassia obovata. Il est moius amcr, moins visqueux et moins employé que le séné de la palte. Les follicules de Tripoli, au contraire, que l'on trouve dans le commerce, sont certainement ceux du cassia acutifolia.

- $3^{\circ}$ Enfin le séné Moka ou de la Pique, qui provient d'Arabie, se compose de folioles lancéolées, très-étroites, entièrement glabres, et de follicules allongés, également glabres, de la 'même largeur que ceux du cassia obovata, mais n'étant pas recourbés comme eux. Je soupçonne, et je crois avec quelque fondement, que ce séné est produit par le cassia lanceolata de Forskal, observé en $\Lambda$ rabie par ce naturàliste, et que l'on a confondu jusqu'à présent avec l'espèce décrite par M. Delile, sous le nom de cassia acutifolia.

Quant au séné d'Italie, qui est produit par la casse à feuilles obtuses, il est peu estimé dans le commerce.

Les sénés sont fort souvent sophistiqués par les marchands, soit avant d'être versés dans le commerce, soit à leur arrivée en Europe. Ainsi l'on trouve souvent dáns le séné de la palte les feuilles du cynanchum argel de M. Delile, plante qui fait partie du groupe des Apocynées. Ccs feuilles sont faciles à reconnâtre à leur consistance plus ferme, leur couleur plus jaune, lcur longueur plus grande, et, en ce qu'elles ne sont pas.inéquilatérales à leur base. Du reste elleș sont âcres et purgatives. Quant au séné de Tripoli, on y mélange souvent les feuillcs du baguenandier (colutéa arboresceris, L. L.). Cette substitution offre peu d'inconvéniens, parce que d'une part cette..espćcé est peu employée et que lè baguenaudier 'à des propriétés analogucs, et que d'une autre part on peut distinguer lcs folioles de ce dernicr en ce qu'clles ne sont pas rétrêcies à leur base, 'et qu'elles manquent de cette petite pointe brusque qui existe au sommet des folioles du 'séné à feuillcs obtuses.

L'on doit à MM. Lassaigne et Feneullc uue analyse chimiquc détaillée du sénć de la paltc. Ces jeunes chimistes y ont trouvć, 
$x^{\circ}$ de la chlorophylle ou matière verte colorante; $2^{\circ}$ une huile grasse; $3^{\circ}$ unc huile volatile peu abondante; $4^{\circ}$ de l'albumine; $5^{\circ}$ un prineipc nouveau, qu'ils ont nommé cathartine; $6^{\circ}$ un prineipe colorantjaune; $7^{\circ} \mathrm{du}$ muqueux; $8^{\circ}$ de l'acide malique; $9^{\circ} \mathrm{du}$ malate et du tartrate de chaux; $10^{\circ} \mathrm{dc}$ l'acétate de potasse et quelques sels minéraux.

La cathartine, qui parait être le prineipc actif et purgatif du séné, est sous forme d'un extrait d'un jaune rougeâtre, d'une olleur particulic̀re et d'une saveur amère et nauséabonde. L'eau et l'aleohol la dissolvent facilement; mais elle est insoluble dans l'éther.

Propriétés médicales et usages. C'est aux médecins arabes que nous devons la connaissance des propriélés purgatives des șénés et leur introduction' dans la thérapcutique europẻenne. L'aetion purgativc de ee mćdicament est trop connue, et en quelque sorte trop vulgaire, pour que nous croyons nćcessaire de nous y arrêter long-temps. Le séné, administrẻ à la dose de trois à quatrc gros, donne lieu à des déjections alvines très-abondantes, qui fort souvent sont précédécs et aecompagnées de eoliques douloureuses et de nausées. C'est pour remédier à cet inconvénient, que l'on joint au séné d'autres substanees plus donees, telles que la manne, on aromatiques, comme les graines d'anis ou de coriandrc.

C'est génćralement en infusion que l'on administre le séné, à la dose de deux à quatre gros, suivant l'âge, le tempérament ct la disposition du maladc. Quelquefois on le preserit 'en dćcoetion. Mais ellc ne doit durcr quc quelques ninules, sans quoi le médicament perdrait la plus grandc partie de son activité. Quant à la poudre, c'est un médicamcntfort désagréable à prendre, parce qu'étant fort légèrc, on est foreé d'en administrer une quantité trés-volumineuse pour qu'elle produise quelque cffet. L'extrait est peu cmployé, parcc qu'il parait que sous eelte forme le séné est biell moins actif et bien moins certain dans son action.

Remarrjuons que les diverses parties de la plante, mais surtout les fruits et les pétioles, jouisscnt des mêmes propriétés que les foliolcs. On avait long-temps prélcndu que lcs coliques occasionées par le séné étaicnt dues aux pétioles des feuilles, 
qui-sont mélangés avee les fulioles. Les expériences de Bergius et de Schwilgué ont prouvé le pẹu de fondement de cette opinion.

${ }^{\circ}$ Fruit cylindrique, indéhiscent, ayant ses loges remplies de pulpe. 'Catmartocarpus.

Gasse canéricier. - Cassia fistula. L. Sp.

Part. usit. : la pulpe du fruit. Nom pharm. : Cassia fistula. Noms vulg. : Casse, Casse en bätons.

Le eanéficier est un fort bel arbre, ayant le port de notre noyer, et qui a été transporié d'Égypte et de l'Inde, sa patrie, dans les diverses parties des Antilles et de l'Amériquc méridionale, où il s'est parfaitement naturalisé. Ses feuilles sont grandes, alternes, et se composent eommunément de cinq ou six paires de folioles opposées, ovales, aiguës, un peu sinueuses, portées sur des pétiolules très-courts, glabres, longues de trois a einq pouces.

Les fleurs, qui sont jaunes et grandes, constituent de longues grappes pendantes à l'aisselle des feuilles supérieures. Chaque fleur offie, à la base du pédoneule qui la supporte, une petite braetée courte, et se compose d'un calice à einq divisions profondes, eaduques, un peu inégales et d'un vert clair; d'une corolle de einq pétales un peu inégaux, obtus, trois fois plus lonģs que le calice; de dix étanines libres, dont trois inférieures, beaucoup plus longues et déclinées, et de sept placées supérieurenent, ayant les filets beaucoup plus courts.

Le fruit est eylindriquc, long d'un pied, et quelquefois davantage, d'une couleur noire, lissc, marqué d'une sortc de bande longitudinale sur chaque suture, offrant intéricurement un grand nombrc de loges séparécs par des cloisons transversales. Chaque loge contient une seule graine, environnée d'une pulpe rougeâtre et suerée.

Propriétés et usages. Ce sout les fruits de cet arbre qu'on nous apportc du Lcvant el des Autilles, sous le nou de casse en bitons. On doit les choisir réccis, lourds et non solnuans. C'cst la pulpe qu'ils enntiennent dont on fait usage en méde- 
cine. Elle est d'un bruu rougcâtre, douce, sucrée et légc̀remcrit aigreletıe. M. Vauquelin a fait voir qu'cllc était un mélange'de gélatine, de gomme, de gluten, d'extrait de sucre et de fibres végétales. Les pharmaciens font subir diverses préparations à lá casse. Ainsi, pour la retirer des gousses qui la contiennent, on les brise et on racle leur-intérieur. La casse ainsi retirée porte le nom de casse en noyeaux. Lorsqu'on l'a fät passer à travers un tamis dc crin pour en séparer les graines .et les autres matières étrangères, c'est la casse mondée. C'est dans cet état qu'on emploie la casse pour préparer dés tisanes laxatives: deux onces de cette pulpe étendue dans, une pinte d'eau bouillante forment une boisson tempérante et laxative. Si l'on fait cuire la casse mondće avec une'certáine quàntité de sucre, on forme une préparation fort agréable, que l'on prend par cuillęrée, et qui portc le nom de cassecuite. La casse est un des purgatifs les plus doux. Son usage convient surtout aux personnes excitables qui ont le ventre paresseu.x. Il corrige cette disposition vicieuse, sans occasioner de secousses ni de coliques. Aussi faut-il s'en abstenir, pour les individus faibles et languissans, dans les hydropisies passives, etc.

La pulpe de casse entre dans l'ćlectuairc catholicum et dans le lénitif. On l'administre communément à la dose de deừ à trois onces.

\section{TAMARIN IER. - TAMARI:NDUS..L. J.}

Calice turbiné a sa base, divisé supérieurement en quatre lobes un pcu inégaux et caducs; corolle de trois péiales ondulés; trois étamincs monadelphes par.leur base. Gousse épaisse, allongée, pulpeuse intérieurement, ct contenant plusieurs graines.

Grands arbres à feuilles paripinnées et à fleurs en grappes.

TAMARINIER DE LINDE. Tamarindus indica. L. Sp. 48.

Part. risit, : La prilpe des fruits. Nom pham. : Tamarindorum pulpia: Nom 'vulg. :' T'ariarin.

Cegrandarbréa le tronc recouvert d'une écorce brune; ct 
divisé en branches vers sa partie supérieure. Ses feuilles sont alternes, élégamment pinnées, sans impaire, composées de dix à quinze paircs de folioles opposées, presque sessiles, petites, elliptiques, obtuses, très-entières, glabres, inéquilatérales à lcur base.

Du sommet des jeunes rameaux naissent des grappes un peu pendantes, composées de six à huịt fleurs assez grandes, d'un jaune verdâtre. Leur calice est turbiné à sa base, divisé supérieurement en quatre lobes un peu inćgaux et cadcus. La corolle se compose de trois pétales redressés, ondulés sur leur bord, un peu plus longs que le calice. Les étamines sont au nombre de trois seulcinent, déclinées vers la partie inférieure, soudées et monadelphes par la moitié inférieure de leurs filets, entre chacun desquels on aperçoit une petite dent aiguë. L'ovaire est allongé, étroit, falciforme, un peu velu, terminé par un style recourbé.

Le fruit est une.gousse épaisse, longue de qualre à cinq pouces, un peu recourbće, d'une couleur brune rougeâtre, prćsentant de distance en disłance des espèces d'étranglemens, remplie intérieurement d'une pulpe rougeâtre acidule, dans laquelle sont nichées des graines noircs et irrégulièremcnt cuboïdes.

Le tamarinier est originaire d'Égypte et des Indes orientales, d'où il a ensuite été transporté en Amérique et dans d'autres partics du monde.

Propriétés et usages du tamarin. Le tamarin du commerce est la pulpe du fruit de l'arbre que nous venons de clécrire. On nous l'apporte contenant encore ses semences et des fibres végétales: elle est d'un brun rougeâtre, d'une saveur açide. A près avoir ćté enlevéc des fruits qui la contiennent, elle a été évaporée à un feu doux dans de grandes bassincs de cuivre, circonstance qui explique la présence de ce métal, que l'on y rencontre quelquefois. M. Vauquelin a trouvé que cette pulpe se composait, $\mathrm{x}^{\circ}$ d'acide citrique; $2^{\circ}$ de tartrate acide de potasse; $3^{\circ}$ d'acide tartarique; $4^{\circ}$ d'acide nalique; $5^{\circ}$ de sucre; $6^{\circ}$ de gomme; $7^{\circ}$ de gelćc; $8^{\circ}$ d'amidon, qui, avec l'eau, cri forme presque les deux ticrs.

La grande quuantité de substances acides, d'awidon, de 
gomme, de suere, qui existe dans la pulpe du tamarin, place cette substance parmi les médicamens acidules et tempérans. Une tisane préparée avee une once de cette pulpe, boullie pendant einq minutes dans une pinte d'ean, passée à travers un linge fin, et suffisamment éduleorée, est une boisson rafraichissante, que l'on preserit dans les fièvres bilieuses ou les autres irritations gastriques peu intenses: elle diminue la chaleur et la fièvre. Si, au eontraire, on donble la dose de la pulpe, qu'on. la fasse bouillir pendant un quart-d'heure ou une demi-heure dans un vase de terre vernissée, on obtient alors une boisson laxative qui donne lieu à des déjections alvines plus on moins nombreuses. La pulpe du tamarin est, comme on le voit, raffraîchissante ou purgative suivant les doses auxquelles on la prescrit, et son mode de préparation.

\section{HÉMAT'OXYLON.-HAMATOXYLUM. L. J.}

Calice à einq divisions profondes et réfléehies; corolle de cinq pétales égaux et réguliers; dix étamines dressces et distinetes. Gousse très-eomprimée, presque plane, ailée sur l'une de ses sutures, contenant d'une à trois graines.

Arbres élevés, munis d'épines, de feuilles paripinnées et de fleurs en grappes axillaires.

\section{Hímatoxyló de Gampèche. Hoematoxylum campechia- num. L. Sp. 549.}

Part. usit. : le bois. Nom pharm. : Lignum campechianum. Noms vulg. : Bois de Campèche, Bois rouge, Bois de sang, Bois de Nicaragua.

La patric de eet arbre est la baie de Campèche, dans le royaume du Mexique, d'où il a tiré son nom. Mais aujourd'hui il est naturalisé dans les $\Lambda$ ntilles et la partie voisine du continent américain, où on le plante de préférence autour dics proprićtés pour en former des haies. Il peut, lorsqu'il est abandonnć à lui-mème, s'élever jusqu'à quarante ou einquıante pieds. Son ćcoree est rugueuse, son aubier.jaunâtre, tandis que la partic. eentrale de la tige est d'un rouge foneć. Les épines, 
que l'on remarque sur ses branches sont formées par de jeunes rameaux avortés. Ses fcuilles, qui sont alternes ct paripininées, se composent communćment de quatrc ou cinq paires dc folioles opposćes, pctites, obovales, presque cordiformes, entières, luisantes, coriaces, ayant les nervures latćrales parallèles.

Les fleurs sont jaunes, disposćes en épis ou grappes simples. à l'aisselle des feuilles, et rćpandent une odeur agréable, analogué à celle de la jonquille. Leur calicc est rougeâtre extćrieurement, à cinq lobes profonds et réfléchis; et un peu inégaux. Leur corolle se compose de cinq pétales étalés, égaux, allongés, rétrécis à leur base, deux foị plus longs que les lobes du calice. Les dix étamines sont saillanics, dressées, libres, à peu près de la longueur des pétales. Leurs filets sont grêles et un peu pubéscens; leurs anthèrcs subcordiformes obtuses.

La gousse, qui est allongée, très-comprimée, ensiformc, glabre, relevéc d'une'crête șur sa suture dorsale; s'ouvre en deux valves, et contient une, deux ou trois graines comprimées.

Propriétés et usages. Le bois de Campèche nous est apporté d'Amérique en grosses bû́ches, dépouillèes de leur aubier. Il est d'un brun noirâtre, trc̀s-dur, susceptible d'un beau polí. Il doṇne, par le moycn de l'eau froide, une couleur rouge funcée. Par l'ćbullition, cette coulcur devicnt plus chargée; elle s'avive par les acidcs; et passc au bleu violct par le moyen des alcalis et des oxides métalliques. Cc bois est très-usité dans la tèinture en noir et en violet. M. Chcrreul est parvenu å obtenir son principe colorant à l'état de pureté, et l'anommé hématine. Celte substance est rouge, solublc dans l'eau bouillante, et cristallise par le refroidissement.

La saveux du bois dc Campćche cst d'abord douccâtre, puis très-ästringcute. Lcs Anglais sont les premicrs qui aient introduit "celtc substance dans la thérapeutique: ' c'cst contre la diarricié chronique qu'ils ont cmployć, soit l'extrait de Camjechic, soit sa décoction. Cc remèdc jeut agir comme toutes lcs autres substances toniques et astringentes; niaris il cst à per près inusité cn trance.

Plusieurs atres arbics de la scction des Cássices doivent 
aussi être cirés, à causc de leur's usages dans l'éeonomie domestique ou l'art de guérir; tels sont :

$\Upsilon^{\circ}$ Le Caroubier, Ceratonia siliqua, L. C'esl un arbre de moyenne grandeur, qui porte de grandes feuilles paripinnées et luisantes, de petiles fleurs polygames, déponrvues de córólle, et de longues gousses épaisses, luisantes, charnues intérieurément: eet arbre eroît sur les eôtes d'Afrique, d'Espagrie è de la Provenee. L̇a chair de ses fruits à une saveur douee et sueréé; elle es: assez nourrissante et laxative : les gens du peuple et les enfans en mangent une très-grande quantité dans lis contrées où eet arbre est commun. En Égyple, on en relire une sorle de sirop dans lequel on confit d'autres fruits.

$2^{0}$ C'est du Moringa oleifera ou Guilandina moringa de Linné, arbre des Indes orientales, remarquable par són fruit triangulaire, s'ouvrant en trois valves, que l'on' retire l'HULLE DE BEN. Cette huile grasse jouit de la propriété de ne pas raneị, et de se charger avee faeilité de l'arome des flenrs. A u bout d'un temps plus ou moins long, elle se sépare en deux füartieș: l'une plus épaisse, faeilement congélable; I'autre qui resie toujours fluide. Cette dernière eșt très-employée dans les arts.

$3^{\circ}$ La Résin an ámés produite par l'Hymencea courbaril, L., grand arbre qui croît au Brésili, aux Antilles et à la Nouvelle-Espagne. Cette substaneẹ est généralement așez rare dans le commeree, où l'on vend, sous ce nom, plusieur's matières résineuses fort différentes lés uives des autres. Elle est

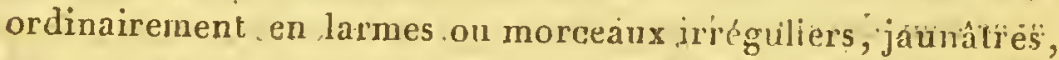
recouverts d'une sorte de poussièré 'grise, à cássúre brillanté, d'une odeur très-aromatique. Fllé n'est plus usitée en médécine, mais elle sert à la préparation des vernis.

$4^{\circ}$ J̣enx espèees du genré Cresalpinia fournissent les bois de teinture eonnus sous les noms de bois du Brésil ou de Fernumbouc et de bois de sapan. Le premier, que l'on appelle brésillą des Antilles, est produit par le Casalpinia echinnta, originaire de l'Amérique méridionale. On l'applortte en' Europe déprouillé de son aubier. Il est roage, compact, presque inodóre et insipide.; il est très-employé daus la teinture. Le second, ou brésillet des Irides, provient du Cresalpinia sapian, qui lrabite les grandes Indes : il est peu en usage en-Europe. 
THOISIBME SECTION.

Mi I OSÉEs.

Calice double; l'ex térieur à cinq dents ; l'intérieur plus grand; monosépale ${ }^{\mathrm{I}}$ régulier et tubuleux. Étamines en nombre variable, monadelphes.

Fleurs généralement pelites, disposées en épis ou en têtes globuleuses. Vógétaux herbacés ou ligneux, ayant en génćral les. feui!les décomposées.

\section{A C A CIE. - ACACIA. Willd.}

Fleurs ordinairement polygames : les mâles ont un calicule à cinq dents, un calice tubuleux à einq dents ou à einq lobes, plus ou moins profonds; des étamines très-nombreuses et monadelphes. Les fleurs hermaphrodiles ont de plus un pistil, qui devient une gousse plus ou moins comprimée, quelquefois étranglée de distance en distance, et qui s'ouvre en deux valves.

Arbres ou arbrisseaux, souvent armés d'ćpines ou d'aiguillons, ayant les feuilles décomposées 2.

${ }^{x}$ La manière dont nous traçons ici le caractère des Mineuses diffère de celle dont la plupart des auteurs décrivcnt l'organisation de ee groupc. En effet, on considère gćnćralement ces végétaux comme pourvus d'un calice à cinq dcnts et d'une corolle monopétale régulière et tubuleuse. Cependant nous sommes loin de partager cette opinion, qui attribucrait aux Mimeuses des caractères trop en opposition avec ceux des autres léguminenses, qui toutes ont la.corolle polypétale. Nous pensons qu'il est beaucoup plus rationncl de regarder le prétendu calice commè un caliculc, ct la prétendue corollc comme le véritable caliçc. Dans cette manièrc d'envisager les Mimeuscs, ces plantes scraient dépourvues de corolle, comme cela s'observe dans beaucoup d'autres genres dc la famille des Lćgumincusês, tels, par exemple, que Copaifera, Ceratonia, etc. Cettc opinion nous paraît d'uutant plus fondéc, quuc dans plusienrs cspèces, lc calicule n'exisic pas, ou consistc sculement dans une simple bractéélatéralc, commc par exemple, dans la sensitivc (Mimosa pudica, L.).

2 Dans lcs cspèces très-nombrcuses qui croissent à la NourelleHollande, les feuilles paraisscnt simples; mais ces prétcnducs feuilles ne sont quc des pétioles élargis et foliacćs, dont la véritable fcuille s'cst d̦ćtachće. 
Acacie véritaree. Acacia vera. Willd. Sp. 4. p. 1085. Mimosa nilotica. L. Sp. 1506 . Blackw. t. 377.

Parl. usit. : la gomme arabique, le suc d'acacia. Nom pharm.: Gummi arabicum; Succus acacice.

Arbre dc trente à quaranle pieds d'ćlévation, ayant les rameaux cylindriques, glabres, rougeâtres, les feuilles alternes, bipinnées; les pinnules, au nombre de dix, sont opposées, ordinairement composées de vingt paires de très-petites folioles allongées, obtuses, entières, portant une pelite glande à leur base. Il en existe unc autre entre chaque paire de pinnules. Le pétiole et ses divisions sont lćgèrement poilucs. $\mathbf{A}$ la base du premier, on trouve deux aiguillons simples très-aigus, blanchâtres, qui ne sont autre chosse que les deux stipules, persistantes, accrues et lignifiées.

Les fleurs sont jaunes, petites, et forment des capitules globuleux, pédonculés, réunis plusieurs ensemble à l'aisselle des feuilles. Leur calicule est glabre et à cinq dents, deux fois plus court que le calice, qui est tubuleux, également quinquédenté. Les étamines sont extrêmement nombreuses, deux fois plus longucs que le calice; elles sont monadelphes par lcur parlie inférieure.

Lc pédonculc commun, qui a environ un pouce de longueur, est articulć ver's son milicu, où il offre deux petiles braclées.

Les gousses sont longues de trois à quatre pouces, planes, glabres, formées de cinq à huit pièces arrondies, séparées par des étranglemens étroils. Chacune de ces pièces contient une graine.

Cet arbre élégant croît su: les bords du Nil; il est trc̀s-commún dans la haule Égyple.

De la gomme arabique. Elle découlc spontanément de l'arbre dont nous vcnons de traccr la description. Elle cst cn morceaux peu volumineux, irrégulic̀rcment arrondis, Iransparente, incolore ou légèrement jaunâtrc, solublc en tolalité dans l'eau chaudc, d'unc savcur doucc et agréablc. Ellc rend l'cau bcaucoup moins visqucuse que la gomme adraganthe. Celle subslaucc doit étrc considéréc à la fois ct commc un alimcut eE 
counme un médieament. En effet, les Arabes ct les Ėgyptieus s'cn nourrissent dans leurs courses à travers les déscrts ct les sables brûlans de lcur' pays. Comme médicament, la gomme arabique est adoucissantc; elle calne l'irritation de nos organes et fait cesser les accidens qu'elle occasionc. Ellc cst la basc de cette foule dc préparations pharmaceutiques désignées sous les nomis de pâtes, tablettes, pastilles béchiques, pectorales, télles quc la pâie de guinauve, de jujubes, etc. Une tisane faite avcc une demi-onee ou une once dc gomine arabique cn poudre, dissoute dans une pinte d'eat, cst une des boissons les plus convenables dans l'inflammation des organes respiratoires ou digestifs: Dans les toux très-opiniâtres, les malades se trouvent bien de faire fondre tans lcur bouch de petits morceaux dc gommc arabique très-pure. On l'emploie fréquemment dans la composition des loochs ses potions; elte facilite la miseibilité des huiles fixcs aved les liquides aqueux, et sert aussi à donner du lien aux masses pilulaires.

Du suc d'acaciá. C'est avcc les fruits de l'aeaeie dii Nil que l'on prẹpare cette substanee. On les reeueille lorsqu'ils sont encore verts; on en cxprime le suc, que l'on fait épaissir à une doucc chaleur jusqu'à la consistancc d'extrait. On en fait des masses dè quatre à huit onces, que l'on cnveloppe dans des morceaux de vessie: dans cel ćlat, le sue d'reacia cst solide, d'un brun rougeâtre, inodore, très-styptiquc. Il est soluble en grande partie dans l'eau, et paraît composé. d'un acidc libre, de tannin, de mucilage et d'un sel calcaire.

Ce médicament est aujourd'hui fort rare dans le commcrce, oú on lui substitue souvent le suc du prunellier. (Voy. dans la famille des Rosacees.) Il est astringent et tonique. On l'employait surtout autrefois pour combattre là diarrliéc chroniquc, les diverses hćnorrhagics passives, elc.; mais à préscnt cette substancè est à pcu prés abandonnic. 
Acacie du Sengear. Acacia senegal. Willd. Sp. 4.

$$
\text { if ri.: p. } 1077^{\circ}
$$

Mimosa senegal. L. Sp. r506. Blackw. t. 345'.

Part. usil. : la gomme sénégal. Nom pharm. : Gummi senega:

lense:

Cétte espèce a beaueoup danalogie et de ressemblanee avée la préeédente; doṇt elle se distingue par son écoree d'un gris blanelıâtre, sès 'aigúlilons, au noinbre dẹ trois, à la base de ehaque feuille, ses fleurs disposées en épis eylindricues, et sés

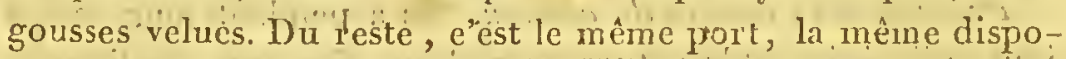
sition des feuilles'.

Elle habite les contrées brûlantes de lafrique, et est trèseommunè au Sénćgál.

De la gomme sénégal. Elle lire son nom de la eontrée áe l'Afrique oụ on la reeolte en plus grande quantité, pour limporter en Enrope. Elle differe a peine de la goume arabique, et se trónve plus abondanment dan's le eommeree que cette derniere. Les droguistes ên distinguent plusieurs varićtés ou sortes, qui tiennent à sa teinté ou à sa solubilité plus ou mons complète dans leau, qui parait dépendre en grande partie de la quantite de sel caleaire insoluble quelles contiennent. Du restè, fes proprétés éhimiques et médieales et les usages de la gomme dú Śnégal sont absolument les mêmés que eerix de la gomine arábique.

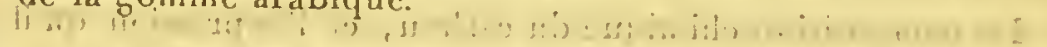

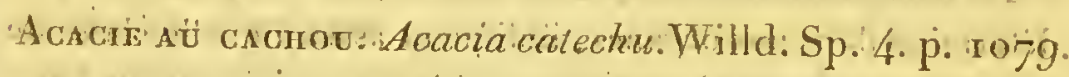
Mimosa categhu to Suppl 439. Roxbg Corom. 2

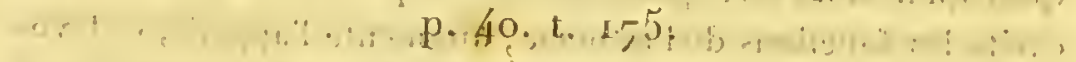

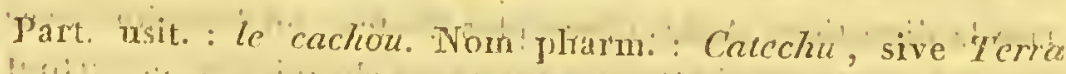

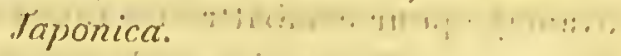

Ce "grand et bel atbre eroît dans les: Indes ioxicntáles. Ses rameaux cylindriques sout chargés do grándés feuilles bịịnnúcs, eomposées elaeuné d'environ donze paires de feuillas pinnées, qui elles-mêmes sont formées d'un nombre très-con- 
sidćrable dc paires de fulioles lancéolées, aiguës, entières, eouvertes sur leurs deux faees de poils blanehâtres, que l'on remarque aussi sur les pétioles. Entre ehaque paire de folioles, et à la base du pćtiole commun, on trouve une glande déprimée. Les aiguillons sont au nombre de deux, comprimés et un peu reeourbés.

Les fleurs constituent des épis cylindriques, longs d'un à deux ponces, portés sur des pédoncules axillaires, et réunis, au nombre de deux à trois, à l'aisselle des feuilles supéricures. Les fruits sont planes, allongés, longs de trois à quatre pouces, et contiennent de ciuq à six graines.

Propriétés et usages du cachou. On a pendant long-temps ignoré l'origine et la nature du cáchou, ainsi que l'indique le nom de terra japonica, sous lequel il était désigné. On sait aujourd'hui que e'est un ex trait prćparé avec les fruits verts et la partie centrale du bois d'une espèee d'acacie, qui croit aux grandes Indes, et particulièrement au Bengale. Cependant on retire aussi un autre extrait ä peu près semblable d'un palmier connu sous le nom d'areca catechu, mais qui n'est usité que dans l'Indc. Le cachou du conmerce est en pains aplatis, du poids de troì à quatre onces, d'un brun rougeâtre, d'unc cassure terne, sans odeur, d'une sareur dabord âpre, ensuite douce et très-agréable. On en distingue deux varićtés, nommées cachon du Bengale et cachou de Bombay. La première contient, sur deux eents parties, 97 de tannin, et 73 de matière extractive; la seconde $\mathrm{x} 09$ de tannin, et 68 d'extractif.

La composition chimique du cachou, ct l'impression qu'il détcrmine dans nos organcs, indiquent asscz à quelle classc de médicamens on doit le rapporter. C'est prarmi les agens toniques qu'il doit être placé. Donné à petite dosc, le cachou exeitc les fonctions de l'estomac, augmente l'appétit, et favorise la digestion. A des doses plus fortes, on l'emploic avec avantage pour combattre les eatarrhes clironiques, ct surtout la diarrhéc. Un demi-gros de eaehou, dissous dans une pinte d'eau de riz, forme une boisson très-utile pour lés individus faiblcs affectés de diarrhéc opiniâtrc. La ntêmc substance u'est pas moins cfficace dins les hénorrhirgies dites passives, quand il n'y a ni fièvre, ni douleurs vives. 
Tantôt on l'adininistre sous forme de pilules, à la dose dc six, donze ou vingt grains, surtout lorsque l'on veut agir localement sur l'estomac. Tantôt on le donne à celle d'un demigros, dissous daus un véhicule convenable. Cette substance s'administre aussi en tavcment ou en injection.

\section{Propriétés médlicales et usages des Légumineuses.}

Cette famille, par le grand nombre dc mćdicamens et de substances nutritives qu'elle fournit, mérite un intérêt tout particulier de la part du médecin. En exposant les caractères des divcrs genres, nous avons fait remarquer les différences souvent fort tranchées qui existent cntre eux; ces différences, nous les retrouverons également dans les propriétés médicales des 'légumineuses et dans leur mode d'action sur l'èconomie animale. Ponr mettrc de l'ordre dans l'cxposition de ces propriétés, nous les étudierons d'abord d'une manière gćnćrale dans chacun des organes qui en sont doués; nous terminerons par une récapitulation rapide des différens produits que les légumincıses fournissent à la thérapcutique, aux arts et à l'économie domestique.

Nous trouvons dans la famille des légumineuses : $I^{\circ}$ des médicamens purgatifs; $2^{\circ}$ des substances toniques et astringentes; $3^{\circ}$ des résines et des baumes $; 4^{\circ}$ des agens aromatiques et excitans; $5^{\circ}$ d'autres qui sont sucrćs; $6^{\circ}$ des principes colorans trc̀s-précieux; $7^{\circ}$ des huiles; $8^{\circ}$ des gommes; $9^{\circ}$ enfin des matières nutritives. Étudions successivement chacun de ces groupes de substances.

La proprićlć purgative cst celle que l'on observe le plus génćralement dans les légumineuses, et en même temps cellc quc l'on retrouve dans le plus grand nombre de leurs organcs. Les feuilles et les fruits des cassia obovata, cassia acutifolia et cassia lanceolata forment les espèces de séné du commcrcc. La pulpe douce et sucréc contenue dans les loges du eanéficier et du caroubier est un des laxatifs les plus doux; cclle des tamarins est légèrement acide, et agit de la mêne manière. Ne croyez pas que les espćces du genre cassc que nous avons dićcritcs soient les sculcs qui possèdent cette vertu purgative; clle 
existe égalcment dans la plupłart des autres espèces, qui toutcs sont cxotiques, et employées, dans les contrées où elles croísșcnt naturellement, aux mêmes usages que le séní ou la casse en Europe. L'analyșe chimique de MM. Lassaigne et Chevallier a fait voir que dans le séné de la palte (cassia acutifolia, Del.) l'action purgative ćtait due à un principe particulier, extractiforme, qu'ils ont nommé cathartine. Il serait curieux de rechcrcher si cette substance existe aussi dans les autres espc̀ces de casse et dans les feuillcs du baguenaudier, qui jouissent des mèmes proprićtés, et sont souvent mćlangécs parmi les séućs.

Les principes astringens ue sont pas rares dans la famille qui nous occupe. La plupart des cspèces du genre acacic, lorsque leurs gousses sont encore vertcs, fournisscnt un extrait composé en grande partie de tannin, d'uné sa veur très-astringente: tels sout le cachor' que produit l'acacia catechu, Willd.; le suc d'acacia fourni par l'acacia vera. 'C'est à cette classe qu'apparticunent encore le sang dragon, retiré de plusieurs espèces de pterocarpus et surtout du pterocarpus draco; le bois de Campèche, employć dans la teinture, mais qui, à cause de sa 'savenr astringente, a été recommandé par les médecins anglais comıne un excellent tonique. Nous pourrions également citer ici le pois chiche, à causc de l'acide oxalique qu'il exsude naturellement, s'il n'élait plus naturcl de le ranger parmi les substances nutritives.

L'ćcorce d'un grand nombre de léguminéces a une saveur anc̀re, et astringente et jouit de propriétés toniques. Lcs diverses espèces du genre Geoffroya sont dahs ce cas. On les a employées soit dans le traitement des fièvres intermittentes, soit comme antlielmintiques.

Si maintenant nous passons aux principes résinenx et balsamiques, nous les trouverons anssi dans pluścicurs végétaux dé cclte famille. Les baunes du Pírou et de Toht découlent, ainsi que nous l'aroṇs prouvé, d'unc senlc cl inểne espèce végétale, le Myroxylum balsamiferum; la résine animée est produitc par l'Hymrenea courbaril.

Plusieurs légumineniśrs soni rmarqquables par lcin oleur plus on noins forte ét lcur: savcur aromatique, et doivent ètrc classées jarmi les agrens excilans tes différentes espiçces de 
mélilot sont très-odorantes et employées surtout eomme sudorifiques et délersircs. La féve tonga ou tonka, dont l'odenir suave est due principalement à l'acide benzoïque, est la graine d'une légumineuse américaine. nommée par Aublet Coumaroun a oclora. La raeine de quelques plantes de ectle famille est employée comme diurélique et sudorifique : telles sont celles de bugrane et d'astragale sans tige, qni jouissent d'une cerlaine réputation dans le Iraitement de la syphilis.

La racice de la rćglisse, au eontraire, a une saveur douee, sucrée et inucilagineuse, que l'on retrouve aussi dans celle de l'abrus pracatorius en Amérique, qui porte le nom de réglisse des Antilles, et dont les graines, d'un beau rouge, marquées d'une taehe noire, servent à faire des collicr's, des bracelets et d'autres ornemens. Elle existe aussi dans la raeine du trèlle des̀ Alpes, dans les feuilles de l'astragalus glycjphyllos, etc. L'Hedisarum àlhaghi, qui croit en Égypte, se couvre d'une exsudation'sucrée, que l'on reeueille et qui porte le nom de manne alhaghi.

La gomme que nous avons vue déeouler de plusieurs arbres de la fainille des Rosacées (section des Drupaećes) existe aussi dans un assez grand nombre de légumineuses, des geures astragale et acaeie. Ainsi la gomme adraganihe cst produite par les astragalus gummifer, Labill.; astr. creticus, L.; et astr. verus d'Olivier. La gomme arabique et la gomme du Sénégal déconlent spontanément des acacia vera, acacia arabica, acacia senegal, Willd., et probablement de plusieurs autres espèees eneore mal connues.

Nous ferons'la mème rcmarque à l'égard de l'huile grasse, qui cxiste ćgalement dans la graine de plusieurs plantes appartenant aux deux familles des Légumineuses et des Rosacées. Nous avons indiqué Ia présenee de ce principc dans l'araclide et le moringa oleifera, qui fournit l'huile de bén.

La famille des légumineuses est riehe en prineipes colorans. Le plus précieux de tons est sans contredit l'indigo, que l'on retire surtout des especes du genre Indignfera, mais qui cxiste. aussidans d'autres plantes de la mềne famillc, ci mểre de fatmilles différentes. Nous mentionncrons ici les différens bois de ceinture, tols que le bois du Brésil.et lc bois de sapan, produits 
par le genre Cosalpinie; le bois de Campèche par l'Hématoxylon, et le santal rouge par le Pterocarpus santalinus. Ces différens genres appartiennent à la seetion des Cassiées, et fournissent un prineipe colorant rouge. Les diverses espèces de genet, au contraire, donnent une belle teinte jaune.

La famille des Légumineuses n'est pas moins importante par le grand nombre d'alimens qu'elle nous fournit. En effet, les graines de toutes les espèees de eelte fanille, qui ont les cotylédons épais et très-développés, sont remplies d'une grande quantité de féeule amilacée, et servent ulilement à la nourriture de l'homme. Qui ignore, en effet, que les pois, les harieots, les fèves, appartiennent à cette famille? Ces graines peuvent aussi être employées eomme médieamens. On en prépare des cataplasmes, qui sont adoucissans ou légèrement exeitans. Ces dernicr's sont surtout préparés avec la farine de fenugrec, de lupins, ete.

Si nous récapitulons les différens matériaux qui existent dans les Légumineuses; si nous faisons attention aux différences qu'ils présentent dans leur nature et leur mode d'aetion, nous ne pourrons nous einpêcher de eonclure que cette famille s'écarte sensiblement de la loi de l'analogie des propriétés médieales; et que, malgré des ressemblances assez grandes entre la nature de quelques-uns de ses produils, elle doit ĉtre eomptée parmi les familles qui s'éloignent de la loi générale de l’analogie.

\section{TÉRÉBENTHACÉES. - TEREBENTHACE E.}

Cette famille se compose d'arbrisseaux ou de grands arbres, ayant les feuilles alternes dépourvues de stipules, rarement simples, plus généralement trifoliolées ou pinnées. Les fleurs petites, en grappes, plus ou moins rameuses, tantôt hermaphrodites, tantôt unisexuées, monoïques ou dioïques. Leur çalice est monosépale, à trois ou cinq livisions profondes; la corolle se compose de cinq pélales ou marique entièrement. Les étamines sont en nombre égal ou double des pétales, avec lesquels 
elles alternent; elles sont insérées, ainsi que les pétales, en dehors d'un disque périgyne, qui, dans les fleurs hermaphrodites, environne l'ovaire et forme un bourrelet circulaire, et qui, dans les fleurs mâles, oceupe la place du pistil et constitue un mamelon plus ou moins irrégulier.

L'ovaire est libre et simple, tantồt à une seulè lógég', contenant un seul óvule; tantôt à plusieurs loges." Lè style est simple et souvent très-eourt, surmonté d'un stigmate trilobé ou de trois stigmates distinets. Le fruit est une drupe sèche ou succulente, contenant un seul noyau monosperme, ou plusieurs nucules. C'est quelquefois une sorte de capsule qui reste indéhiscente. Lạ graine, qui est souvent portée sur un.long podosperme plane, se compose d'un embryon renversé; dépourvu. d'endosperme.

Nous retirons de la famille des 'Térébenthaeées les genres pourvus de plusieurs pistils distincts dàns la inêmie fleur, et dont la graine est munie d'un endosperme, pour en former un ordie à part; sous le nonı de ŻíathoxxLÉES.

La famille des Térébenthacées ainsi limitée, offre de très-grands rapports avee les Légumineuses, dont il est impossible de l'éloigner. Elle s'en distingue surtout par la régularité de sa corolle (que l'on observe aussi dans quelques Légumineuses), parses étamines toujours libres, par la présence d'un disque périgyne, et par le manque
de stipules.

\section{SUIV A G. $-R H U S$. L. J.}

Flenrs souvent unisexuécs; calice à einq divisions profondes; corolle de cinq pétales; étamines au nombre de cinq; trois stigmates : drupe monospcrme.

Arbres ou arbrisseaux, à feuilles simples ou eomposées. 
Sumac vineneux. Rhils toxicodendron. L. Sp. 381.

Var. : Foliis glabris : Rhus radicans. L. Sp. 38 s.

A l'exemple des auteur's modernes, nous réunissons en une seule les deux espèces montionnées par Linnć sous les noms de Rhus radicans et de Khus toxicodendron. En effet, la seule différence qui existe entre elles, c'est que la premic̀re a ses folioles gilabres, tandis qu'elles sont pubescentes dansla seconde. C'est un arbrisseau dioïque, dont la racine est ligneuse et traçante, les rameaıx faibles et armés de petits suęoirs, au moyen desquels ils s'attachent aux corps voisins; les feuilles alternes, longueinent pćtiolécs, glabres ou pubesccntes, trifoliolćes, à folioles ovales, acuminées, entièrcs, les deux latérales sessiles; celle du milieu pétioléc. Ses fleurs, petites, verdâtres et dioïques, sont disposées en petites grappes axillaires, dressées. Les fleurs mâles sont beaucoup plus grandes que les fleurs femelles. Leur calice est petit, profondément quinquéparti, à divisions aiguës; leur corolle composée de cinq pétales ovales, lancéolés, beaucoup plus longs quc le calice, rccourbés en dehors de la nleur. Les étamines, au nombre de cinq, sont dressées et saillantes, jlus courtes que la corolle. Les filets sont épais inféricurement, amincişen pointe à leur sommet. Les anthères sont cordiformes; obtuses, introrses. Ces étamines sont insérées au pourtour d'un disque annulaire el périgyne.

- Dans les fleurs femclles, le calice ct la corolle différent peu de ceux de la fleur mâle, si ce n'est qu'ils sont trois ou quatre fois plus petits. Les cinq étamines sont rudimentaires. L'o vaire, environné d'un disque périgync, cst globuleux, à une scule loge, contenant un seul ovule portć sur un long podosperine. Le style est court et trifide; chacunc de scs divisions porte un stigmalc obtus, qui se continuc sur sa face intcrne.

Le fruit cst une petitc drupe contenant un seul noyau uniloculaire et monospcrinc.

Cet arbrisseau croît spontanément dans l'Amćrique septcntrionale. On, lc cultivc facilement elı plcin air, dans nos jardins. 
Propricités et usages. Les qualités nuisibles de cet arbrisseau sont connues depuis long-temps. On sait qu'il suffit de roucher à ses feuilles pour que la main se couvre en pcu de temps d'ampoules plus ou moins volumineuses. Ces feuilles, en effet, sont pleines d'un suc blanchâtre et résineux, d'une extrême âcreté. Les émanations qui se dégagent de cet arbrc occasionent aussi des accidens très-graves. On a vu des personnes qui, pour y être restées exposées pendant quelques instans, ont eu le corps couvert de petites pustules ou dc plaques rouges. Lc célèbre Fontana en rapporte plusieurs exemples. M. Van Mons, de Bruxelles, à qui l'on doil un travail intéressant sur ce dangereux végétal, a reconnu quc les accidens qu'il occasione sont dus à un gaz qu'il exhale pendant la nuit ou à l'ombre, plutôt qu'à son suc laiteux. Selon cet habile chimiste, ce gaz serait de l'hydrogène carboné, tenant en dissolusion un miasme délétère.

M. le professeur Orfila a fait un grand nombre d'expériences avec les feuilles du rhus toxicodendron et avec leur extrait, et il a vu qu'en général, ces substances a gissaient à la manière des poisons âcres, c'est-à-dire en déterminant une inflammation intense dans les organes de-la digestion ou toute autre partie du corps avec laquelle elles out ćté mises en contact, et qu'elles exercent une action stupéfiante sur le système ncrvcix lorsqu'elles ont été portées dans le torrent de la circulation.

Malgré les accidens occasionés par cette plante, le docicur Dufresnoy, de Valenciennes, n'a pas craint de l'introduire dans la thérapeutique, et son exemple a ensuite étć imitć par plusieurs autres médecins recommandables. C'est surtout contre les dartres invétérées et l'épilepsie qu'on en a fait usage. On administre l'extrait préparé avec les feuilles fraiches et contuses, à la dose de quinzc à vingt grains, rćpélée deux à trois fois dans la journée : cette dọse est cnsuile graducllement augmentée et portée à un ou même deux gros pour chaçue fois. Le profcsseur de Valenciennes fait les plus grands ćloges de cc médicament, et dit qu’il lui a presque constamucnt r’ćussi. Cependant quelques essais tentés récemment scmbleraicnt devoir un peu diminucr la trop grande répulation faite à celte substance. M. Ie professeur Fourquier l'a donnce sans aucun rósuliat 
avanlageux, mème en le portant à des doses Irès-considérables.

Plusieurs autres cspèces de ce genre méritent quelque attcntion. Ainsi le rhus coriaria; que l'on nomme vulgnirement vinaigrier, roure, ete., est un arbrisseau dont toutes les parties sont extrêmement astringentes, Ses jeunes rameaux serventà tanner les cuirs.

L'une des résines connues sous le nom de copal est produite, suivant plusieurs auteurs, par le rhus copallinum , 'L.; qui croît au Mexique ct dans l'Amérique septentrionale.

Le rhus vernix jouit, d'après MM. Orfila et Bigelow, des mêmes propriétćs que le rhus toxicodendron. On le cultive fréquemment dans nos jardins.

\section{PISTAGHIER. - PISTACIA. L.}

Fleurs dioïques : dans les mâles, calice à trois, rarement à cinq divisions linéaires et très- profondes; cinq étamines; corolle nulle : dans les femelles, calice comme dans la fleur mâle; ovaire à une seule loge monosperme, surmonté de trois stigmatcs épais. Drupe sèche, pouvant s'ouvrir en deux valvès, contenaut une seule graine portée sur un podosperme long et planc.

$\Lambda$ rbrisseaux à feuilles trifoliolćes, imparipinnées ou même paripinnées. Fleurs petites et en grappes.

Pistachier pranc. Pistacia vera. L. Sp. I454. Lamk. Illust. t. 8 Ix. f. I. 2 .

Part. usit. : les fruits. Nom pharm. : Pistacia vera. Nom vulg. : Pistaches.

Le pistachier est un arbrisscau dioïque, dont la tige peut s'élever à douzc ou quinze pieds. Ses feuilles sont alternes, dépourvues de stipules, composées de trois ou plus souvent de einq folioles imparipinnées, ovales, obtuses, coriaces et glabres. Les fleurs; qui sont potites et dioïques, sont portćes sur les rameaux des années précédentcs, et sor'ent d'un bourgeon formé d'écailles lanuginenscs sur leur bord. Les mâles sont disposées cn une sorte de grappe rameuse, entrceoupée d'écailles à chaquc ramification de la grappe. Cliaque fleur est légc̀rcment pédicellćc; son calice est très-petit, composé de trois folioles squan- 
niformes, dressées, linćaires, lancéolées, ou mème subulées. Il n'y a pas de corolle. Les élamines, au nombre de einq, plus longues que la corolle, ont leurs anthères presque sessiles, dressées, ovoïdes allongées, aiguẹs, à deux loges. Le,centre de la fleur nc présente aucun indice de pistil.

Les fleurs fcmelles forment des espèccs de petits épis ordinairement simples et triflores. Le calice est de même, composć de trois folioles étroites, plus rarement de quatre ou dc cinq. L'ovaire est simple, ovoïde, un peu pédicellé, à nne seule loge, qui contient un seul ovule porté sur un long podosperme, inséré au fond de la loge. Le style est à peine marqué et se termine par trois stigmates épais, obtus et réflćchis.

Le fruit est une drupe ovoïde allongée, sèche, c'est-à-dire ayant la chair très-mince, s'ouvrant en deux valves à sa parfaite maturité, de la grosseur d'une olive. La graine cst renversée et portće sur un long podosperme plane, qui naît du fond dc la cavité. L'embryon est dépourvu d'endosperme, et-se compose de deux gros cotylédons charnus, d'une belle couleur verte claire.

Cet arbrisseau, originaire d'Orient, est cultivé et naturalisé dans toutes les parties mćridionales de l'Europe.

Propriétés et usages des pistaches. L'amande-du pistachier. est trc̀s-agréable. On peut en préparer des émulsions qui s'administrent comme celles que l'on fait avec les amandes douces, dans l'irritation des organes génilaux et plusieurs autres circonstances. C'ęst une boisson extrêmement recherchée. Cés amandes sont aussi employées par les confiseurs pour faire des dragées, des glaces et d'antres friandises. Elles contiennent une assez, grande quantité d'huile grasse.

\section{Pistachmer ménebintme. Pistacia terebinthus. L. Sp. r.4505.}

Part. usil.: la térćbenthine de Chio. Nom pharm. : Terebenthina pistacina.

Cette ç̊̀ece est généralcment un peuplus petite que la précédente. Ses feuilles, qui sont alternes et pútiolées, se composent. de sept ou neuf folioles imparipinnées, ovales, lancéolćes, ai- 
suês, glabres, entières, d'un vert foncé, et luisantes en dessus, blanchàtres inférieurement. Ses fleurs, également dioïques, sont petites et en grappes rameuses. Les écailles qui accompagnent les fleurs mâles et les folioles de leur calice sont chargćes de poils roussâtres, très-épais.

Les fruits qui succèdent aux fleurs femelles sont d'une couleur violette, presque globuleux, et beáucoup plus petits que dans l'espice précédente.

Le térébin the croît spontanément en Orient, dans les îles de l'Archipel. Il est commun en Provence, dans les lieux pierreux et incultes.

Proprićtés et usages. En pratiquant au tronc de cet arbrisseau des incisiónis plus ou moins profondes, il s'en écoule un suc résinenx, ṫrès-ćplais, d'une couleur jaunâtre, d'une odeur suave, qui rappelle celte du citron ou din fenouil, et d'une sa-s veur agréable et nullement âcre. C'est la térebenthine de Chio, ainsi nommée parce que c'est surtout darns celte île que l'on en fait la récolte. Elle est assez rare dans le commerce et fréquemment sophistiquée avec la térćberthine du pin ou du mélèze, dont elle possèdc toutes les propriétés. Voyez pour ses u'sages l'article $P$ in maritime, où nous avons expos ćles propriétés médicales de la térébenthine retirée de ce bel arbre. (Prent. part., p. 138.)

Pistacher lentisqoe. Pistacia lentiscles. L. Sp. 1455.

Part. usit. : le mastic. Nom pharm. : Resina mastiche.

Encore plus petit que le précédent, cet arbrisseau croît dans les mèmes localités. Ses feuilles, dont le pétiole est plane et comme ailé, se composent de buit à douze petilcs folioles ordinairement alternes, à l'exception des deux supérieures, qui sont opposées. Elles sont ovales, lancéolécs, obtiuscs, sourcnt mucronées, entic̀res et tout-à-fait glabrcs. Les fleur's sont fort petites, en panicules axillaires, souvent géminécs, dioïqucs, cornme dans les autres cspèces.

Les fruits sont très-petits, pisiformes, rougeâttes à l'épođue de leur maturité. 
Dans l'île de Chio, ou cet arbrissèau est cultivé avee soin, on en retire, par des incisions transversales faites à son éeoree vers le mois d'août, unc matière résineuse qui se solidifie à l'air, et porte dans le commerce le nom de mastic.

Rropriélés et usages du mastic. On en connait dellx variétés; Y'une est en masses irrégulic̀res, c'est le mastic commun; l'àutre est en larmes plus ou moins grosses, souvent aplaties, d'une couleur jaune clair, couvcrtes d'une sortc de poussière blanchâtre, d'une odeur'suav c, et d'une saveur âere et aromatique. Sa cussure est brillante et vitreuse. Il se ramollit sous, la dent et $y$ dcvient ductile; c'est le mastic en larmes. Cette substanec n'est pas soluble en totalité dans l'alcohol.

C'est un usage gínéralement répandu en Grèce et dans une partie del'Orient, que les femmes et même les hommes mâehent continuellement du inastie, soit pour se fortifier les gencives et blanchir leurs dents, soit pour se parfuner l'haleine. Aussi le grand sẹgneur, s'était.il exclusivement réservé le commeree de cette substance résineuse.

Le mastic a étć jadis fort en.vogue auprès de eertains médecins, et faisait partie d'une foule de préparations pharmaceutiques, eomme lui inusitées aujourd'hui. Cependant il jouit des, mêrues propriétés que tontes les autres rćsines, e’est-à-dire qu'il est tonique et stimulant, et quc son emploi peut ayoir des résultats avanlageux dans la diarrhće chronique, et en générat. les eatarrhes anciens, quand ils ne sont ni accompagnés, ni entretenus par une cause irritante et permanente.

\section{B.AUMIER. - AMYRIS. L. J.}

Fleurs hermaphrodites : ealicc a quatre dents et persistant; cololle de quatrc pćtales; luuil ćtamines; ovaịre à. trois loges monospermes, surmonté d'un style et d'un stigmate simples; drupe légèrement charnue, contenant ordinairement un seul noyau monosperme par avortement.

Arbrisseaux exutiques, ayant les feuilles trifoliolées on inparipinnées. 
Baumier de la Mrceue. Amyris opobalsamzun. Willd. Sp. 2. p. 334 .

Part. usit. : la résine de la Mecque; les fruits; les jeunes branches. Noms pharm.: Balsamum Meccaense, sive Judaicum; Carpobnlsamum : Xylobalsamum. Nom vulg. : Baume de la Mecque ou de Juíée.

Ce petit arbrisseau peut s'élever à une hauteur de six à huit pieds. Ses rameaux sont grêles, souvcnt rabougris, et terminés en pointe épinerise; ses feuilles altcrnes, imparipinnées, composćes de cinq ou sept petites foliolcs sessiles, obovales, aiguës, 'entières, glabres et luisantes. Scs fleurs sont petites, ordinairement géminées, portées sur des pédoneulcs courts et grêles; leur calice est persistant et à quatre dents larges et peu profondes. Les fruits "sont de petites drupes obovoïdes, quelquefois terminées par un pctit mamelon conique, renfermant un seul noyau monosperme par suite de l'avortement presque constant de deux des Ioges que l'on remarque dans l'ovaire.

On trouve cominunément cet arbrisseau dans l'Arabie, et surtouit entre les villes de la Mecque et de Médine.

Propriétës et usages. Quoique lè baume on résine dela Mecque aitt été eonnu de toute antiquité, on'a pendant long-temps ignoré l'arbre dont il était retiré. Le voyageur Belon est le premier qui ait donné des renseignemens positifs à cet égard. Prosper Alpini, dans son nurrage sur lcs plantcs dé J'Égypte, publié à Venisc en 1592 , a fait une très-bonnc dissertation sur le véritable baumc de la Mecque, et donne (page 78 ) une figurc trèssatisfaisantc de l'arbrisseau dont il découlc. C'est à dater dc celte çpoque que l'on a bien connu l'arbrisscau que nous venons de déerire. C'est lui qui fournit, ainsi que nous l'avons dit précédemincnt; ${ }^{\circ}$ le baume de la Mecque; $2^{\circ}$ Ics petils fruits eonnus sous le nom de carpobalsamm; $3^{\circ} \mathrm{ctle}$ xylobalsamm.

Le baume de la Meeque ou dc Judéc est unc résinc fluide, que l'on obtient, soit en pratiquant des incisions au tronc ct aux branches de l'amyris, soit par la déeoction, daus l"cau, de scs jeunes rameaux. Le premier est plus pur et n'cxiste pas dins 
le eommerce; on le réscrve, 'dit-òn, pour le grand seigueur. C'est cclui ([u'on prépare de la sceonde manière, que l'on trouve dans le commerce. Il esi liquide, d'une tciute jaunâtre, quelquefois un peu trouble ou blanchâtre surtont lorsquíil est réeent, d'une odeur anisćc, d'une savcur a romatique. Il finit quelquefois. par devenir presque solide. Cette rćsine est souvent sophisliquée avec le baume du Canada.

On a altribué à celte substance résineuse des propriétés nuerveilleuses dans le traitement d'une foule de maladies rrop diff'ćrentes les unes des autrcs pour que le mème médicament puisse eonvenir à ehacune d'ellcs. Aussi aujourd'hui la résine de la Mecquc est-elle bien peu estimée des thérapcutistes. La plupart pensent, et avec raison, qu'elle n’a rien de supérieur à nolre térćbenthịne, qui doit Ini ćtre préfćrée eomme prodùetion indigc̀ne, et d'un prix moins élevć. Les Orientauxl'emploient surtout comme eosmétique, et les femmes Égyptiennes la regardent comme le remède le plusieffieace pour prévenir la. stérilité.

Le fruit du baumier, connu sous le nom de carpobaliamum, est une pctite drupc sèelıe, globuleuse, pisiforme, terminée en pointe à ses deux extrémités, ordinairemcnt rougeâtrc, d'unc saveur aromatirne. Il entre dans la thériaque et claus le mithridate.

Enfin l'on trouve quelquefois dans le commeree les jeunes branchés de ect.arbrisseau, qui y portent le nom de xylobalictmum. Leur saveur cst amẹ̀ etaromatique, leur odeur est suavc. En Orient, on les brûlc dans l'intérieur des temples et lc palais des sultans. Ils ne sont pas usités en inédeeine.

La résine connue sous le nom de BAUne de GILtén et ruc l'on dit produite par l'Amyris Gileadensis, qui croit spon: tanément en Arabie, cst la même ẹose que la résine dè la IrIecque:

Baumer éléminire. Amyris elemifera. Willd. 2. p. 333 . Part. usit. : la résine élémi. Nom pharm. : Elemi, sive Elcmni.

La plus grande obscurité règnc eneore, aujourd'hui.sur l'espèce végétale qui produit la résine éćmi. La plrpart ḍes auteur's 
pensent que c'est l'Amyris elemifera, mentionnée pour la première fois par Limné, dans sa Matière mnédicale. Mais, ainsi que l'a fort judicieusement remarqué l'illustre auteur de la partie botanique de l'Encyelopédie méthodique, Linné a confondu sous ce nom deux plantes fort différcntes, en réunissant celle mentionnée par Plumier, et celle que Marcgrave áppelle Icicariba. Cette dernière, en effet, qui croit au Brésil, parait apparienir au genre Icica, qui, il est vrai, diffère à peine de l'amyris. Nous manquons dc documens positifs pour éclaireir cétte question, que nous regrettons de laisser encore indćeise.

Dans le eommerce on distingue deux sortes d'élémi. La plus eommune nous est apportée de la Nouvelle Espagne et du Brésil, par caisses de deux à trois cents livres. Elle est en masses plus ou moins volumineuses, ordinairement grasse get onetueuse, surtout lorsqu'elle est récente. Sa couleur est jaunâtrc ; parsemée de points verts; son odeur'a été comparée à celle du fenouil et dépend surtout d'une livilè volatile, que l'on peut en extraire par la distillation.

La seconde sorte est beaneoup plus rare. Elle est en morceaux de trois à quatrélivres, enveloppés dans des feuilles de roseaux. Orí nous l'apporte d'Éthiopie. Il est plus quc probable qu'elle n'est pas retirée du neème arbre que la préeédente.

La résine élémi n'est guẹre employée qu’à l'extérieur. Elle entre dans la composition de plusieurs médicamens, tels que le baume de Fioraventi, les" onguens styrax et d'Arcæus.

LA MYrRHe est une gomme-résine que l'on croit généralement produite par un' arbrisseau originaire d'Arabie, et que Forskahl a décrit sous lc nom d'Amyris Kataf. Cette substance est en laimes irŕćgulières, rougeâtres et recouvcrtes d'uue sorte de poinssière blanchâtre, demi-transparente; leur cassurc est brillante, avec de petites stries blanchâtres; lcur siveur âcre et amère; leur odeur aromatique. Elle se eomposc de résine et d'huile essentiellc, 3.4; de gomme soluble, 68 parties. Aussi se dissout-elle plus faeilenent dans l'cau que dans l'alcohol.

Celte substanec cxerce une action stimulante-sur d'économie animale. Six à dix grains de niyrohe exeitent les fonctions de l'estomac et augmentent l'appćtit. A une dosc plus forte l'exciration devient généralc. On a parlé des bons cffets de cetlo 


\section{TÉRÉBENTHACÉES.}

gomme-résine dans les catarrhes chroniques, les leucorrhées ou les aménorrhćes, qui dépendent dc causes débilitantes. On l'emploie en poudre dont on forme des pilules ou un électuaire. On a également recommandé sa solution aqueuse ct ajcoholique. La myrrhe fait partie du baume de Fioraventi, de la. thériaque et de l'élixir de Garus.

Avant de passcr à l'exposition générale des propriétćs inćdicales de la famille des Térében thacées, nous devons dire quelques mots de plusieurs aritres subslances produiles par des plantes de cette famille:

$1^{\circ}$ Écorce de Fausse Aygustura, Cortex pseudoangustura, scu Angustura ferruginéa. Celte écorce nous est apportée de l'Amérique mćridionale : elle est en plaques ëpaisses, compactes, pesantes. Son ćpiderme, qui est quelquefois fongueux, est d'un gris rongeâire ; sa substance intćrieure est couleur de rouille, très-claire ou simplement grise; sa poudre est d'un blanc jaunâtre. Sa saveur est excessivement amèré et nullement âcre. Elle est inodore. Presque tous les auteur's disent, d'après le témoignage de Bı́uce, quc cette écnrce est celle d'un arbre observé par ce voyageur eu Abyssinie, et que l'Hćritier a nominé Brucea ferruginea, et qu'il figure pl. 10 de ses Stirpes. Mais une pareille assertion nous semble insoutenable. Car la fausse angusture vient du Nouveau-Monde, et l'arbre de Bruce croit en Afrique. Je partagerais plus volontiers l'opinion de M. Virey, qui perise qu'elle,provient d'un strychnos; mais je crois que cè ne peut être le strychnos colubrina, qui est un arbre des grandes Indes. Cette question a besoin d'être de nouveau éclaircie.

La fausse augusture est donc très-différente de l'écorce du brucea ferruginea, que Bruce a vu emṕloýer avec succès conıre la diarrliéc. C'est une substance extrêmement vénéneuse, qui, à des d̂̀oses même très-faibles, peut occasioncr les accidens les plus graves ét même la mort, ainsi que le.prouvent lc grand nombre d'expériences faites par plusieurs auteurs de toxicologie, et particulièrement par M. Orfila, qui cn déduit les conséquences suivantes : $x^{\circ}$ la poudre de faussc angusture et sos. diverscs préparations agissent comme la noix vornique ct les autres słxyclinos; $2^{\circ}$ la matière jaune ìmère parait être la partie la plus active. 
MM. Pelletier et Caventou ayant analysé la fausse augusture, l'ont trouvée composéc d'unc matière alcaline particulịère, analoguc à la stryehnine, et qu'ils ont nommée brucine, d'une matière grasse non vénćncuse, de bcaucoup dc gomme, 'd'une matière jaunc, soluble dans l'eau et l'aleohol, de traces de sucre et de ligneux.

$2^{0}$ Nolx D'ACajou. On appelle ainsi les fruits du cassivium occidentale de Lamarck, ou anacardium occidentale de Linné, grand arbre à feuilles simples, qui croît en Amérique et dans les Antilles. Le pćdoncule qui supporte le fruit cst rougeâtre, renflé, charnu, beaucoup plus gros que le fruit lui-même, ayant presque le volume du poing; il est astringent; on s'en sert pour préparer des boissons rafraichissantcs. Le fruit cst de,la grosseur et de la forme d'une fève, composé d'un périearpc coriace, indéluiscent, d'une ligne environ d'ćpaisscur, présentant dans ses parois un grand nombre de cellules pleines d'un suc huileux, excessivement âere, imprimant au linge des taches indélébiles. L'amande est tłoricc et bonnc à mangeṛ. Inusitće en France.

$3^{\circ}$ Anscarge, fruit de l'anacurdium orientale de Linné, oн semecarpus anacardium de Lamarck, croit aux grandes Indes. Il a la for'me d'un cœur porté sur un pédoneule renflé, plus gros que lui. Selon M. Virey, on a altribué à son amande, ainsi qu'à celle du préeédent, la singulière propriété d'exaltcr les facultés intellectuelles, de sévelopper la mćmoire, etc.

$4^{\circ}$ L'olman ou encens, que l'on eroit en général étre produit par un arbre de la famille des Conifères, est attribué par les naturalisțcs de l'Iñde à un arbre de la famille des Térébẹnthacées, nommé, par Roxburgh boswellia serrata. Mais il est important de remarqucr que cettc gomme-résine nous est apportée de l'Arabiẹ ou de l'Afrique septentrionale, d'où l'on peut eonclure que l'arbre ei-dessus mentionné donne unc matic̀re résineuse, analogue à l'oliban, mais qui en diffère cn plusieurs points. On n'cmploie gnc̀rc l'enccns cn múdccinc. On le brûle dans leṣ temples, où il rẹ́pand úne odenr suavc.

$5^{\circ}$ La rísine tracasninaca est attribućc, selon plusicurs auten's, an fagara octandra, arbre de cctte famille, ct par d'autres a l'inophyllum tacamahaca, de la famille des Gutilfùres. Inusilće. 
La famille des Térébenthaeécs produit cneore plusicurs autres matières résineuses, telles que la résine clibou, fournie par le bursera gummifera, le baume ou résine acouchi, que l'ón retire de l'icica acuchi d'Aublet, ete. Mais elles nè sont pas usitées dạns la thérapeutiquc.

\section{Propriétés médicales et usages des Térébenthacẻes.}

Le grand nombre de substanees résineuses que produisent les arbreside la famille des Térébenthacées, forme lc caractère le plus saillant de leurs propriétés médicales. En effet, c'est surtout à la classe des agens slimulans quc cette famille offre.le plus grand nombre de matériaux. Le genre amyris nous donne la résine élémi, le baume de la Mecque ou de Judée, et trc̀sprobablement la myrrhe. C'est du genre des pistachiers que déeoulent la térébenthine de Chio et le mastic. Enfin, une foulc d'autres matières résineuses sont eneore des produits de cette famille, et atlestent l'uniformité de ses propriétés.

Plusieurs Térébenthaeéès eonticnnent un prineipe astringent souvent fort développé. $\Lambda$ insi le rhus coriaria, ou roure des corroyeurs, sert au tannage des euirs. Cetle saveur astringentc existe aussi dans le schinus molle, dans le rhus glabrum, dont l'écorce est employée eomme fébrifuge. Elle se fait également scntir dans les fruits pulpeux des Térében thacées, qui sont aloris cmployés, soit à préparer des boissons rafraîehissantes, soit usités eomme alimens; tels sout eeux du mángifera indica, du spondias monbin, ete.

L'amande renferméc dans leur graine' est fort souvent douce.et agréable, coinme le prouvent celles du pistaehier; de l'anacarde, de la noix d'acajou. Elle contient généralcment une quantité plus ou moiṇs considérable d'une huile doucc et agréable.

A eôlé de cette uniformité remarquable qui existe dans la nature des prineipes des Térébenthaećes se trouvent quelques exceptions qu'il semble impossible de ramencer à la loi générale. On voil que nous voulons parler iei des effets délélères dı sumae vénéncux et de quelques autres espèees du même genrc̀. En effet' nous avons fail voir que cet arbrisscau peul occa- 
sioner des pustules et une irritation plus ou moins vive de la peau, non-seulement lorsqu'on met son suc laiteux ou scs feuilles cn contact avec quelque partic extérieure du corps, mais que cette action vénćneuse peut même avoir lieu sans contact, et uniquement par l'effet des ćmanations qu'il dégage lorsqu'il est placé à l'ombre. Il parait qu'en Amérique une espèce da genrc Amyris, d'ailleurs si remarquable par son uniformitć, possède un mode d'action analogue à celle du sumac, et a, pour celte raison, reçu le nom d'amyris toxifera. Cependant, si nous réfléchissons que tous les accidens causés par le sumac vénéneux sont dus, soit au suc laiteux qu'il renferme, soit au gaz hydrogène carbonć qu'il dégage à l'ombre, et que ce suc propre el cc gaz n'existent dans aucun antre genre de la famille, cette exception cesscra de nous étonner et n'altérera en rien la loi de l'analogie et de l'uniformité des proprićtés médicales, dont les Térćbenthacécs nous offrent un exemple.

SOIXANTE-HUITIÈME FAMILLE.

\section{RHAMNÉES. - RHAMNEAE.}

Cette famille se compose de végétaux ligneux, dont les feuilles simples sont opposées ou alternes, ordinairement accompagnées de stipules. Les fleurs sont petites, et souvent imparfaitement unisexuées. Leur calice est nınosépale, étalé ou turbiné, à quatre ou cinq divisions. La corolle, qui manque quelquefois, se compose de quatre ou cinq pétales, généralement. très-petits. Les étamines sont en même nombre que les pétales, devant lesquels elles sont ordinairement placées; elles sont insérées autọr ou quelquefois sur un disque périgyne, qui environne l'ovaire et forme un bourrelet plus ou moins saillant, ou bien tapisse le tube du calice quand celui-ci est turl)iné. L'ovaire est généralement supéricur et libre, à deux, trois ou quatre loges, contenant chacune un ou denx ovules. Le style est quelquefois 
simple, plus souvent divisé à son sommet, et portant autant de stigmates qu'il y a de loges à l'ovaire.

J se fruit cst tantôt sec ct capsulairc, tantôt charnu et renfermant un on plusieurs nucules uniloculaires et monospermes, rarement biloculaires ou dispermes. La graine, qui est quelquefois enveloppée dans un arille charnu, contient un embryon dressé, plane, renfermé dans l'intérieur d'un endosperme charnu.

Cette famille se distingue de la précédente par ses feuilles constamment simples, accompagnées de stipules; par ses graines dont l'embryon est contenu dans un endosperme charnu, ct de plus par le port des différens végétaux qui la composent.

\section{NERPRUN. - RHAMNUS. Tournef. J.}

Caliee ureéolé, subeampaniforme, à quatre ou einq divisions; corolle de quatre ou cinq pétales très-petits ct squarnmiformes; étamines en nombre égal aux pétales, au-devant desquels elles sont placées. Style terminé par trois ou quatre stigmates. Nuculaine globuleux, conterant trois ou quatre nucules monospermes.

Arbrisseaux à feuilles simples et opposées, ayant les flèurs petites et sourent dioïques.

\section{Nerprun Gathattique. Rhamnus catharticus. L. Sp. 279. Blackw. t. I35.}

Part. usit. : les fruits. Nom pharm. : Rhamni cathartici fructus.

Le nerprun est un arbrisseau dioïque, fréquent dans nos bois et nos haies, où il peut aequérir une hauteur de huit à dix pieds. Ses rameaux, souvent terminés en pointe épineuse à leur sommet, portent des feuilles opposées, pétiolées, quelquefois groupées et réunies au sommet des jeunes rameaux. Elles sont ovales, aiguës, presque cordiformes, dentées, glabres et d'un vert clair. Les fleurs sont dioïques, petites, verdâtres, pédieellées et réunies en général plusieurs ensemble. 
Xeur ealiee, tubuleux à sa base, est partaģè à son limbe en quatre lanières étalées, lanećolées, aiguës; les quatre pétales sont dressćs, extrêmement pelits, et linéaires. Dans les fleurs mâles on trouve ciualre étamines opposées aux pélales et un pistil rudimentaire. Les fleurs femelles ont l'ovaire globuleux, déprimé, à quatre loges monospermes; le style quadrifide à son sommet, et terminé par quatre stigmates obtus.

Le nueulaine est globuleux, pisiforme, glabre, eontenant ordinairement trois nueules monospermes.

Propriétés et usages. La pulpe verdâtre qui enveloppe les nueules de cet arbrisseau a une saveur amère, assez désagréable, et unc odeur nausćabonde. C'est un médieament purgatif fort énergique, mais qui a l'ineonvénient d'oecasionér des coliqués, surtout lorsqu'on l'administre en nature. On peut prévenir eet ineonvénient en buvant, après avoir fait usage de ees fruits, une tisane mueilagineuse et adoueissante: On ne doit reeourir à ee médieament que dans le eas où l'on veut opérer une sorte de révulsion énergique, eonme, par exemple, dans eertaines hydropisies, ou des dartres ehroniques. Le sirop de nerprun, que l'on preserit plus fiécquemment que les autres préparations, s'administre à la dose d'une à deux onees. Quinze à vingt fruits suffisent pour provoquer d'abondantes évaeuations. On peut aussi administrer le sue que l'on en exprime.

L'éecree moyenne de eet arbrisse:tu paraît jouir des mêmes proprićtés que les fruits. Elle détermine quelquefois le vomissement.

Le sue exprimé des friits du nerprun forme, larsqu'il a été épaissi par le moyen de la ehalcur et uni à l'alun, une matière eoloranle verte, connue dans le enmmeree sous le nom de vert de vessie.

Les fruits de la bourgène, thaimnus frangula, jouissent absolunent des mêmes propriélés. Il cn est de mềne des grains d'Avignon, fruits du rhammus infectorius, qui eroil daus le midi de la Franee. Ils sont surtout fort employés dans l'art de la teinture. 
JUJUBIER. - ZIZIPHUS. Tournef. J.

Ce genre diffère du prćcédent, auquel Linné l'avait réuni, par son calice étalć, à cinq divisions, par ses cinq étamines, insérées, ainsi que les pétales, autour d'un disque përigyne qui environne l'ovaire; par ses deux stigmates et son fruit, qui renferme un noyau biloculaire.

Jujubier officinal. Ziziphus vulgaris. Lamk. Illustr. t. $185 . \mathrm{f}$.. .

Rhamnus ziziphus. L. Sp: 282.

Part. usit. : les fruits. Nom pharm. : Jujubo.

Arbrisseau de quinze à vingt pieds d'élévation, rameux dès sa base, offrant, sur ses branches, des petits rameanx filiformes verts, qu'il'renouvelle tous les ans, et sur lesquels poussent les feuilles ct les fleurs. Ccs feuilles sont alternes, presque sessiles, ovales, obtuses, acuminées; cclles de la base presque rondes, obscurément dentées, glabres, luisantcs, marquées de trois nervures longitudinales. On trouve à leur base deux stipules subulées, très-aiguës, persistantes et se changeant en aiguillons.

Les fleu's sont petites, jaunâtres, rassemblées par petits glomerules aux aisselles des feuilles. Leur calice est ćtalé, à cinq divisions profondes, ovales, aiguës, cntières. Leur corolle se compose de cinq pétales, très - petits, ćtalés, concitves, blanchâtres, en forme"de cuiller, supportés par un onglet allongé, droit. Les cinq étamines sont de la longueur des pétales, auxquels elles sont opposées, insérćes au pourtour d'un disque périgyne, aplati, tapissant le fond du calice, et entourant le pistil dans sa partie inférieure, en formant autour de lui une espèce de bourrelet. L'ovaire est ovoïde, déprimé, biloculaire, entouré par un disque périgyne glanduleux et jaune, contenant un ovule dans chaque loge. Du sommet de l'ovaire naissent deux styles courts et charnus, terminés par dcux stigmates capitulés, qui se prolongent sur la facc inlcrne des styles.

Le fruit est une drupe ovoïdc, rougeâtrc, lisse, dc la gros- 
seur d'une olive, contcnant un noyau osseux, à deux loges monospermes.

Le jujubier, originaire d'Orient et particulièrement de la Syrie, est aujourd'hui cultivé et naturalisé dans les contrées méridionales de l'Europe.

Propriétés et usages. Lorsque les jujubes sont fraiches, leur chair est ferme, mais sucrée et assez agréable. On les mange en cet état dans les provinces inéridionales de la France, ainsi qu'en Orient. Celles que nous employons ici ont ćté séchées au soleil. Ces fruits, unis aux dattes, aux figues et aux raisins secs, constituent les fruits mucoșo-sucrés ou béchiques, dont la décoction forme une tisane adoucissante, recommandable dans les inflammations chroniques des poumons, l'ischurie, etc. Ils entrent dans plusieurs préparations dites pectorales, et entr'autrcs dans la pâte de jujubes, préparation journellement usitée, et dont la gomme arabique est certainement la partie la. plus efficace.

$$
\text { HOUX. } I L E X \text {. L. J. }
$$

Calice à quatre divisions dressćes; corolle de quatre pétales contigus par la base; quatre étamines alternes avec les pétales. Ovaire à quatre loges monospermes, surmontć de quatre stigmatcs épais et sessiles. Nuculaine contenant quatre nucules.

Arbres ou arbrisseaux à feuilles alternes, souvent persistantes et épineuses sur les bords.

Houx Éprneux. Ilex aquifolium. L. Sp. 18r. Blackw. t. 205 .

Le houx est un arbre toujours vert, dont le tronc, recouvert d'une écorce lisse et verdâtre, peut s'élever à une vingtaine de pieds, cn donnant un grand nombre de ramifications. Ses feuilles sunt alternes, presque sessiles, ovales et ondulćes sur leurs bords, dont les dents sc prolongent en pointes épineuses. Leur surface supćrieure est lisse, luisante et d'un bcau vert. Dans les individus très-gros et trc̀s-vieux, il n'est pas fort rare de trouver les fenilles dépourvnes de dents ćpineuses.

Les fleurs sont petites, blanches, polygames, groupées. a l'aisselle des fcuilles. Leur calice cst petit, a quatrc divisions 
dressées et un peu ciliées. La corolle se compose de quatre pétales très-obtus, étalés, soudés par leur base au moyen des filets staminaux, et ressemblant à une corolle monopétale rotacée. Les quatre étamines sont dressées, et alternes avec les pétales.

On trouve sur le même individư des fleurs unisexuécs, mâles ou femelles, et des fleurs hermaphrodites. L'ovaire est globuleux, déprimé, à quatre loges uniovulées. Les quatre stigmates sont sessiles. Le fruit est globuleux, déprimé et ombiliqué à son sommet, pisiforme, d'un beau rouge, et contient quatre nucules osseux.

Cet arbre est fort commun dans les bois et les haies.

Propriétés et usages. Les feuilles du houx ont une saveur amère et assez désagréable. Leur décoction ou leur extrait, pris intérieurement, augmonte la perspiratiou cutanée. Plusicurs auteurs ont signalé leurs heureux effets dans la goutte et le rhumatisme; d'autres, et particulièrement Reil, les ont administrćs contre les fićrres intermittentes. Mais aujourd'hui, on ne les emploie plus que fort rarement. Selon Dodoens, les fruils seraient, comme celıx du nerprun, purgatifs à la dose de dix à douze.

L'écorce intérieure du houx sert à préparer la glu, eimployée surlout par les oiseleurs pour lcudre des piéges aux oiseaux, mais que Chomel recommande d'appliquer sur les tumeurs artlıritiques donloureuses.

C'est au geure ilex que l'on rapporte les feuilles connues sous le nom d'apalachine. Ce sont celles de l'ilex vomitoria d'Aiton. Elles ricnnent des Florides. Les naturels du pays en préparent, aprc̀s les avoir grillées, une boisson excitaute, qu'ils prennent pour s'animcr au combat. On a remarqué qu'ellcs sont diurétiques et augmentent la perspiration cutanée; à haute dose elles provoquent le vomissement. Inusitćes.

\section{Propriétés médicales et usages des Rhiaminées.}

Il existe assez de r'csscmblance entre les végétaux cle cette famillc dont on connaît bien les propriétés médicalcs. $\Lambda$ insi la pulpe du fruit des nerpruns, du houx, a une saveur amère et nansíeusc, 
et possède une aetion purgative manifeste, qui se retrouve aussi dans leur écoree intérieure. Le genre des jujubiers forme eependant une exception bien remarquable, puisquc ses fruits sont doux, suerés et mucilagineux. Ces propriétés justifient et eonfirment la séparation de ce genre d'avee les nerpruns. Les feuilles et l'éeorce de plusieurs Rhamnées ont une saveur trèsamère, quelyuefois astringente, et sont toniques. C'est ainsi que dans l'Amérique septentrionale, on emploie avec succès celles du Ceanothusamericanus et du Prinos verticillatus, jolis arbustes qu'il serait très-faeile de naturaliser dans nos climats. L'analogie des Rhamnées se fait également remarquer dans les principes eolorans qu'ils fournissent : nous avons vu, en effet, que les fruits de beaucoup de nerpruns étaient employés avec avantage dans l'art de la teinture.

SOIXANTE-NEUVIËM FAMILLE.

\section{PORTULACÉES. - PORTULACEA.}

On distingue les plantes de cette famille aux caractèrés suivans : leur calice est libre ou semi-adhérent avec l'ovaire, partagé à son sommet en deux ou en un nombre variable de divisions. La corolle, qui manque quelquefois, èst formée de quatre à cinq pétales, insérés à la paroi interne du calice. Ces pétales sont quelquefois soudés par leur base. Les étamines varient en nombre. Il y en a quelquefois autant que de pétales; d'autres fois elles sont en nombre double de ces derniẻrs, ou même plus nombreuses. L'ovaire est. tout-à-fait supérieur ou semi-infère, à une ou à plusieurs loges, surmonté d'un style simple ou divisé, portant un ou plusieurs stigmates.

Le fruit est une capsule à une ou à plusieurs loges, monospermes ou polyspermes; c'est quelquefois une pyxide, qui s'ouvre en deux valves superposées. Les graines contiennent un embryon roulé autour d'un endosperme charnu ou farineux.

Les Portulacées sont généralement des plantes herba- 
cées ou des arbustes, ayanı les feuilles opposées ou alternes, ordinairement épaisses et charnues.

On ne peut confondre cette famille ni avec les Rhamnées, dont les feuilles sont pourvues de stipules, le fruit un nuculaine charnu, l'embryon renfermé dans l'intérieur de l'endosperme, etc.; ni avec les Térébenthacées, dont, entre autres caractères, l'embryon est dénué d'endosperme.

\section{POURPIER. -PORTULACA. L. J.}

Calice monosépale comprimé, à deux divisions profondes; corolle de einq pétales plus longs, ordinairement soudés ensemble par leur base; dix étamines ou plus, insérées à la partie inférieure du calice. Style court, surmonté de quatre ou einq stigmates; pyxide uniloeulaire, cnveloppée par le ealiee.

Plantes herbacées, pluș ou moins eharnues, à feuilles alternes.

\section{Pourpier cultivé. Portulaca oleracea. L. Sp. 638.}

Plante annuelle, dont la tige eylindrique, épaisse, eharnue, rameuse dès sá base, est étalce à telre : elle est très-glabre et rougeâtre; longue d'environ un pied, et porte des feuilles álternes, obovales, très-obtuses, eutières, épaisses, eharnues, rćtrćeies à la base, d'un vert glauque en dessous.

Fleur's jaunes axillaires, sessiles, rassemblćes plusieurs ensemble à la partie:supérieure de la tige et de ses ramifieations. Ovaire semi-infère; calice adhérent par sa base, libre et à deux divisions dans sa partie supérieure. Corolle de einq pétales, sessiles, arrondis, obtus, d'un jaune verdâtre. Étamines, environ quinze, plus courtes que la corolle, attaehées à la parlie supérieure du tube du ealice. L'ovaire est surmonté.d'un style simple inférieurcment, portant eing stigmates à sa partie
supérieure.

Le fruit est une pyxide, ou capsule circoncise, à une seule loge renfermant un grand nombre de graincs, à surface ehagrinée, attachées à un trophospermc central. 
Le pourpier habite les lieux secs et sablonneux; on le cultive dans tous les jardins potagers.

Propriétés et usages. Autrefois employé comme médicament, mais entièrement inusité aujourd'hui dans la thérapeutique, le pourpier sert seulement comme aliment. On mange ses jeunes feuilles et ses branches, ordinairement crues et en salade. Il cst rafraîchissant. On l'employait autrefois comme vermifuge et diurétique.

\section{Propriétés médicales et usages des Portulacées.}

Celte famille ne nous offre aucun intérêt sous le rapport de ses propriétés médicales. Le pourpier et diverses espèces de Claytonia, et surtout le Claytonia Cubensis, figuré par MM. de Humboldt et Bonpland dans les plantes équinoxiales, sont des légumes aqueux et rafraîchissans.

\section{Étamines insérées sous l'ovaire.}

SOIXA NTE-DIXIEM E FA MILLE.

\section{RENONCULACÉES. - RANUNCULACEAE.}

Cette famille, fort nombreuse en espèces, est trèsfacile à reconnaître, soit par le port des végétaux qui la composent, soit par la grande analogie de leurs caractères d'organisation. Leur calice est polysépale, presque toujours coloré et corolliforme, rarement persistant; leur corolle manque quelquefois, ou se compose de cinq ou d'un plus grand nombre de pétales planes ou creux et irréguliers; les étamines sont ordinairement très-nombreuses, insérées, ainsi que la corolle, au-dessous des pistils. Ceux-ci sunt tantôt réunis en forme de tête au centre de la fleur, à une senle loge, contenant une seule graine; tantôt solitaires ou groupés, et quclquefois soudés ensemble, présentant chacun une seule loge à plnsieurs graines. Le style est toujours latéral. Le stigmate est finement glanduleux, occupant le sommet du sillon 
que l'on remarque à la face interne du style; rarement il est sessile. Les fruits sont ou de petits akènes comprimés disposés en capitules; ou bien des capsules ${ }^{\mathrm{x}}$ agrégées, distinctes ou soudées, quelquefois solitaires, uniloculaires, polyspermes, s'ouvrant par leur bord ou face interne. Les graines ont leur embryon renfermé dans la base d'un endosperme charnu ou corné.

Les Renonculacées sont le plus souvent des plautes: herbacées, rarement sous-frutescentes, ayant la racine composée de fibres ou de tubercules quelquefois fasciculés, les feuilles alternes (opposées dans le seul genre Clématite), simples ou composées; les fleurs généralement grandes, et d'une belle couleur.

On peut diviser cette famille en deux sections trèsnaturelles, suivant que ses genres ont pour fruit un. akène monosperme ou une capsule polysperme.

\section{PRBIIt R I S I CTION.}

Fruit uniloculaire et monosperme. RknonculÉEs.

$1^{\circ}$ Fleurs munies d'un calice et d'une corolle.

\section{RENONGULE. $\rightarrow R A N U N C U L U S$. L. J.}

Calice de cinq sépales caducs; corolle de cinq pétales rćguliers, planes, munis, prc̀s de leur base interne, d'un petit appendicc laminé, ou simplement d'une fossette glandulifère ${ }^{2}$; étamines nombreuses. Akènes comprimés, réunis en tête, terminés par une pointe courte.

Plantes herbacées, à fleurs jaunes ou blanches, ayant les feuilles plus ou moins profondément divisées, rarement simples. Renoncule bulbeuse. Rañunculus bulbosus. L. Sp. $77^{8 .}$ Bull. t. 27.

Racine composée de fibres allongées, ramèuses, surmantée

* Le seul genre Actaca présente une baie polysperme.

2 Ce dernier caractère s'observe dans toutes les espèces à fleurs blanches. 
d'un renflement bulbiformc, arrondi, charıu, quioecupc la base de la tige. Celle-ci est dressée, rameuse, velue, haute d'un pied ou plus, cylindrique, sillonnće ỉongitudinalement dans la partie supćrieure de ses jeunes rameaux. Les feuilles radicales sont pétiolées, à pétiole velu, très-dilaté et membraneux à sa partie inférieure, qui recouvre et se confond avec'le tubercule charnu. Ces feuilles sont velues, tripartites; chaque division est elle-même partagée en trois lobes cupéiformes, trilobćs et dentés. La division du milieu est souvent pćtiolée.

Les fleurs sont jaunes, assez grandes, solitaires à l'extrémité de chaque division de la tige, qui est cannelée et leur sert de pédoncule. Leur calice est -poilu, formé de cinq sépales lancćolés, aigus, brusquement réfléchis sur le pédoncule. Les pétales sont ovales, arrondis, très-obtus, luisans et comme vernissés sur leır face interne. Les fruils sont comprimés, lisses et glabres.

Cette espc̀ce est très-commune dans les bois, les prés, les lieux humides. Elle fleurit depuis le printemps jusqu'en automne. 2

Renoncule acre. Ranunculus acris. L. Sp. 779. Orfil. Méd. lég. t. 3.

\section{Vulgairement : Grenouillette; Bouton d'or.}

Dans cette espèce, la racine est formée de longues fibres blanches, presque simples, surmontée d'une touffe de feuilles radicales, dont les pétioles sont męmbraneux à leur base, légèrcment velues. Ces feuilles sont profondément divisées en trois ou cinq lobes digités, aigus, incisés et dentés. Ceux des feuilles de la tige sont lancéolćs, entiers. La tige est dressée, simple dans sa partie inférieure, divisée supérieurement en rameaux grêles, cylindriques, nọn striés, portant les fleurs. Cclles-ci sont jaunes, nombreuses et comme paniculées. Leur calicc est poilu, ćtalé. Les pétalcs sont subcordiformes, un peu émarginćs à leur sommet.

Les fruits sont assez gros, lisses, terminés par une petite pointe courte et peu rccourbée.

Elle est fort commune dans les bois ct les licux un peu hu- 
mides. Oı en cultive dans nos jardins une belle variété à fleurs doubles, qui portc le nom de bouton d'or.

Renoncule scéLérate. Ranunculus sceleratus.L.Sp. 776. Blackw. t. 259 .

La renoncule scćlérate, ou des marais, est une plante annuelle, dont la tige est dressée, épaisse, cylindrique, striće, très-rameuse. Ses feuilles radicales sont glabres, pétiolées, orbiculaires, à trois ou cinq lobes subcunćiformes; obtus, incisćs, à dents arrondies et obtuses. Les feuilles caulinaires sont sessiles, lancćolées, irréguliè̀:ement incisées sur leurs bords ; les supérieures sont tout-à-fait entières.

Les fleurs sont jaunes, fort nombreuses, et assez petites. Les fruits, extrêmement pctits et nombreux, forment un capitule ovoïde, qui s'allonge après la floraison. Ces fruits sont subrćniformes, lisses et glabres.

Cette espèce croît sur le bord des ćtangs et des marais, où elle est extrêmement commune.

Renonctle Flammule. Ranunculus flammula. L. Sp. $77^{2}$. Bull..t. 15 .

Vulgairement : Petite douve.

Sa racine est fibreuse, fasciculée; sa tige est pleine, un peu couchée, et même quelquefois Iraçante à sa partie inférieure, redressée supćrieurement. Elle est cylindrique, rameuse, légc̀rement pubescente, haute d'environ un pied. Ses feuilles sont lancéolées, aiguc̈s, trìs-rétrécies à leur base, et formant un péz tiole allongé, membraneux et amplexicaule. Elles sont en outre glabres, légèrement denticulćes sur les bords. Les fleurs sont jaunes, solitaires et tcrminales au sommet de chaque rameau.

Les sépales sont caducs, ovales, obtus, un peu velus en dehors. Les pétalcs sont d'un jaune brillant à leur fạce interne, ołovales entiers, presque cunéiformes.

Les fruits sont glabres et lisses.

On trouvc cetlc espèce sur le bord des mares et des i'uisseaux. $\not$ 
Propriétés et usages les renoncules. Les quatrc espèces que nous venons dc décrire, et plusieurs autres du même genre, telles que les ranunculus reptans, ranunc. 'auricomus, ranunc. thora, ranunc. arvensis, etc., sont remarquables par leur extrểme âcreté. Leurs fruits, encore verts, paraissent être la partie où cette âcreté est le plus intense. Elle dépend d'un principe extrêmement volatil qui se détruit en grande partie, ou même en totalité, par la dessiccation, ou l'ćbullition dans l'eau. Ainsi, ces plantes, qui fraîches seraient extrĉmement nuisibles aux troupeaux, peuvent leur servir de nourriture lorsqu'elles ont ćtć séchées.

Si l'on applique sur une partie quelconque du corps les feuilles fraîches et pilćes de la renoncule âcre, ou de quelque autre espèce analogue, il s'y manifcste bientôt une phlogose plus ou moins vive, suivie de phlyctènes; en un mot, il se forme un véritable vésicatoirc. On pcut donc recourir à ces plantes et les employer comme vésieantes, ou lorsque l'on manque de cantharides, ou que l'on craint l'action irritante de celles-ci sur les organes urinaires. Introduit à l'intérieur, le suc ou l'extrait de renoncule âcre détermine une inflammation très-intense des organes de la digestion; et si la dosc a été un peu considérable, c'est un véritable poison ẩcre, bientôt suivi des accidens les plus graves, et de la inort. (Voyez Orfila, Toxicol., gen., et Leçons de Médecinc légale.) On s'est quelquefois servi des feuilles des renoncules fraiches pour appliquer sur les articulations tuméfićes et douloureuses par suite de la goutte; d'autres lcs ont placées sur lc poignet pour arrêter le cours d'une fièvre intcrmittente. Mais ces différens mooyens sont assez rarement employćs aujourd'hui.

L Ficaire, Ranunculus ficaria, I. Sp. 774, Bull. t. 48 , que l'on nomme aussi pctite chélidoinc, sc distingne par ses feuiles radicales, pćtiolées, entières, cordiformes; ses fleurs jaunes et grandes, dont lc calice est formé de trois sépales, et la corolle de scpt à dix pćtales. Elle cst moins âcrc que les cspèccs qui prćcèdent. Scs feuillcs sont employécs comme herbe potagc̀rc dans quelques parties de la France; mais sa racine est àcre et amc̀re. On l'a rccommandée dans les scrophules, le scorbut ct plusieurs autres maladies. Peu nsitéc de nos jours. 
$2^{\circ}$ Fleurs n'ayant qu'un calice sans corolle.

\section{ANÉMONE. - ANEMONE. L. J.}

Calice corolliforme, de cinq à quinze sépales; point de corolle ; étamines nombreuses. Akènes capitulés, terminés par une pointe qui se prolonge quelquefois en une longue queue plúmeuse.

Fleurs environnées d'un involucre de trois feuilles; tige nue; feuilles toutes radicales.

$1^{\circ}$ Fruits terminés par une pointe courte non plumeuse.

AnÉmone.

Anémone des bors. Anemone nemorosa. L. Sp. 762 .

Vulgairement : Sylvie.

Cette jolie petite plante, qui, au printemps, fait l'ornement de nos bois,' a une racine ou souche charnue, horizontale, donnant naissance à la tige et aux feuilles, par l'une de ses extrémités. Ces feuilles sont toutes radicales, pétiolées, dressées, divisées en trois folioles digitées; celle du milieu profondément partagée en trois lobes ovales, incisés et dentés; les deux latérales en deux lobes seulement, de même forme que les précédens. Ces feuilles et leurs pétioles sont légèrement velus. Les pédoneules sont radicaux, dressés, de six à huit ponces de hauteur, terminés à leur sommet par une seule fleur blanche ou légèrement purpurine, assez grande. $\Lambda u$-dessous d'elle, est un involucre formé de trois feuilles verticillées, pétiolées, semblables à celles qui naissent de la racine.

Les fruits, au nombre de quinze à vingt, sont ovoïdes, comprimés, pubescens, terminés à leur.sommet par une petite pointe recourbée.

Cette espèce se trouve alsondamment. dans les bois un peu couverts. Elle fleurit dès le premier printernps. $₹$

Propriétés et usages. La sylvie est aujourd'hui fort peu employée par les praticiens. Elle est âcre, et possède à peu près les mèmes propriétés que les espèces du genre-renoncule. Chomel 
recommande l'applicalion de cette plante sur la lête dans la teigne. Mais ce remède, qui demande des précautions à cause de son âcreté, a été abaudonné.

$2^{\circ}$ Fruits terminés par une longue queue plumeuse. Pulsatilla.

Anémone pulsatrue. Anemone pulsatilla. L. Sp. 759 .

Vulgairement: Coquelourde; Fleurs de Páques.

La pulsatille habite les bois sablonneux. Sa racine est grosse, épaisse, dıre, noirâtre et comme ligneuse. Ses feuilles radicales sont pćtiolées, soycuses, composées de folioles plusieurs fois pinnatifides, à' segmens très-étroits, linéaires, aigus el eomme subulés. La tige est haule de six à douze pouces, cylindrique, velue, portant une seule fleur un peu penchée, d'une belle couleur violette foncée. Les sépales sont dressés, velus en delıors, et constituent un ealice campaniforme.

Entre les étamines et les sépales, on trouve un certain nombre de glandes pédicellées, qui ne sont que des étamines avortées.

L'involucre est formé d'une seule feuille' sessile, embrassante, formant une sorte d'entonnoir, du centre duquel sort la fleur. Elle est découpée, dans les trois quarts de sa hauteur, en lanières étroites, linéaires, aiguës, soyeuses, presque constamment entières.

Cette espèce n'est pas rare dans les bois sablonneux, aux environs de Paris, on elle fleurit au mois d'avril. $¥$

Propriétés et usages. La pulsatille, et en général toutes less autres esjèces d'anérnone, sont d'une extrème âcretć, qui réside à la fois dans toutes leurs parties. Elle détermine, lorsqu'elle' est appliquée sur quelqu'un de nos organes, ou ingérée dans l'estomac, tous les accidens des substances âcres et corrosives; savoir, unc inflammation violente, el une action stupéfiantesur le système nerveux. Aussi MI: Orfila l'a-L-il rangće parmi les poisons âcres.

L'ean distillée que l'on prépare avec les fleur's ef les feuilles fraiches, est d'une grande âcrelé. Storchi a donné à la pulsatille une sorte de vogre. Il l'a surtout adninistréc dans l'aman- 
rose, et dit avoir ainsi gućri un grand nombre de malades affeetés de eette maladie, ou avoir apporté beaucoup de soulagement à ceux qu'il n'a point complétement guéris. Au témoignage de Storck on peut aussi ajouter eelvi de plusieurs médecins allemands. Le même auteur se loue également des sueeès qu'il a obtenus de la pulsatille, en l'employant dans la cure des symptômes conséeutifs de la syphilis, tels que les exostoses, les douleurs ostéoeopes, ete. Enfin, il l'a aussi essayée avec quelques suceès dans la paralysie, les uleères clıroniques, etc. C'était ordinairement sous la forme d'extrait que Storck employait la pulsatille. Il commençait par des doses très-faibles, telles qu'un ou deux grains, qu'il augmentait ensuite graduellement.

Malgré les éloges prodigués par le médeein de Vienne ä la pulsatille, on en a généralement abandonné l'usage.

\section{CLÉMATITE. - CLEMATIS. L.}

Caliee de quatre sépales. Fruits terminés par une queue plumeuse. Fleur's dépourvues d'involucre.

Arbustes sarmenteux; ayant les feuilles simples ou pinnées, constamment opposées.

\section{Cuématite blanche. Clematis vitalba. L. Sp. 676 .}

Vulgairement: Fiorne, Herbe aux gueux.

Sa tige est sarmenteuse ; ses rameaux, très-allongés, faibles, sont anguleux, grimpans, légèrewent pubescens. Les feuilles sont opposées, imparipinnées, leur pétiole commun est trèslong, et se roule souvent en vrille à son extrémité. Les folioles, au nombre de einq, sont pétiolulées, ovales, subcordiformes,
aiguës, entières, ou grossièrement incisées ou dentées.

Les fleurs sont blanches, disposées en une sorte de cyme pédoneulée ; c'est-à-dire qu'à l'aisselle des feuilles supérieures, il existe un pédoneule eommun, d'abord simple, qui se trifurque plusieurs fois avant de porter des fleurs. A la base de ehaque division du pédoneule, on trouve deux feuilles florales
entières, de plus en plus petites.

Le caliec est formé de quatre sépales étalés, elliptiques, allon- 
gćs, obtus, tomcnteux sur leurs deux faces, caducs, et d'un blanc terne. Les étamines sont très-nomibreuses, dressćcs, un peu plus courtes que le calice.

Les fruits sont surmontés d'nnc longue queue-plumcuse, en forme d'aigrette, chargće de poils blancs et soyeux.

Cette espèce croit dans les haies, le long des murailles; elle est cxtrêmement commune aux énvirons de Paris et dans la plus grande partie de la France. 2

Propriétés et usages. L'âcrcté que nous avons signalée dans les espèces des genres renoncule et anémone existe aussi dans le gcnre clćmatite, et y cst peut-être encore plus développée. En effet, si l'on mâche une petite parcelle des fenilles récentẹs de cette espèce, ou de la cLÉmatтite droite (clematis recta, L.), qui en est fort pen différente, on éprouve dans la bouche un sentiment d'ardelir et de cuisson, et fort solivent la langue se couvre de petites vésicules qui finissent par s'ulcćrer. Cette saveur et cettc action sont cependant beaucoup moindres dans la plante dessćchće. Si l'on applique les feuilles fraîchcs et pilécs sur quelque partie du corps, il s'y manifeste bientôt une vive inflammation, suivie de phlyctènes qui se crèvent et s'ulcèrent. Des mendians emploient souvent ce moyen pour se former sur les jambes des ulcères superficiels, et appeler sur eux la pitié des passans. Pris intćrieurement, le suc ou l'cxtrait de clćmatite peut, à certaines doses, développer tous les symptômes de l'empoisonnement par les poisons âcres, parıni lesquels elle est, à juste titre, placće.

Storck a fait avec la clćmatite droite dcs essais nombreux pour s'assurer de ses effets curatifs. Il l'a surtout mise en usage dans lc traitement des différens symptômes vénćriens consćculifs, tels que les chancres, les tumeurs osseuses et les douleurs ostéocopes. Selon lui, l'extrait donné ì la dose d'un à deux grains, a, dans le plus grand nombre des cas, ćté suivi du plus heureux succès. Le mêmc auteur dit quc ce médicament n’a pas ćté noins efficace dans la gale ancienne et rebelle, ct inême dans le cancer des mamclles déjà ulcéré. De semblablcs allégations ont besoin d'êtrc appuyécs sur de nouvcaux essais pour qu'il soit pcrmis d'y ajouter foi. Aussi ce mćdicament est-il fort négligê des morlernes. 
Celte âcreté, qui est si violente đans les parlies fraîches de la plante, disparaît en grande partie par la dessiccation, et en totalité par suite de l'ébullition dans l'eau. Aussi, dans quelques contrées de l'Italie, les, gens des campagnes mangent-ils les jeunes pousses de la clématite après les avoir fait bouillir.

\section{$2^{\circ}$ Fruits capsulaires contenant plusieurs graines.}

I ${ }^{0}$ Pétales planes et réguliers. Pienirées.

\section{P I VO I N E. - P E ONIA. L. J.}

Calice de cinq sépales concaves; corolle de cinq pétales planes et très-larges; étamines fort nombreuses; pistils, au nombre de deux à cinq, très-velus. Capsules uniloculaires polyspermes, déjetées en dehors, et s'ouvrant par une suture interne.

Plantes herbacćes vivaces, à feuilles pinnées ou décomposées, à fleurs très-grandes et rouges.

\section{Prvolne officinale. Paeonia officinalis. L. Sp. 747.}

Racine vivace, fasciculée, composée d'un grand nombre de tubercules allongés, fusiformes on globuleux, brunâtres extérieurement; surmontée d'une tige herbacée, dressée, rameuse, cylindrique, glabre et un pcu glauque; haute d'environ deux pieds. Elle porte des feuilles alternes, très-grandes, irrćgulièrement deux fois ailées, à lobes inéganx, elliptiques, lancéolés, aigus, entiers, très-glauques en dessous. Les feuilles sont légèrement pubescentes à la base de leur pétiole.

Les fleurs sont très-grandes, d'un ronge violacé, solilaires et terminales; elles se composent d'un calice à cinq sépales ar rondis, concaves, pubescens en dessous, glabres en dessus, souvent inégaux, quelques-uns se cliangeant en folioles; d'une corolle pentapétale rosacée, très-grande, dont les pétales sont ovales, très obtus, sessiles, irrćgulic̀rcment érodés à leurs bords. Les étamines très-nombrcuses (environ t oo), sont bcaucoup plus courtes que la corollc; insćrées sur plusiemrs rangs et irrégulièrement à unc sorte de bourrelet charnu (disque hypogyne) sur lequel les deux ovaires sont appliqués.

Les pistils, au nombre de deur ou de rrois, de la même 
hauteur que les étamines, sont eomposés chacun, $\mathrm{I}^{\circ} \mathrm{d}^{\prime}$ 'un ovaire libre conoïde, très-tomenteux à l'extérieur, uniloculaire, pluriovnlé; ovules en grand nombre, altachés à un trophosperme latéral et sutural; $2^{\circ}$ d'un stigmate sessile, irrégulier, en forme de erête, composé de deux lames intimement appliquées l'une eontre l'autre, hérissées de petites papilles glanduliformes sur leur bord libre; d'une eouleur pourpre foncée. Les fruits sont autant de eapsules uniloculaires, polyspermes, renflées à leur base, cotonneuses, s'ouvrant irrégulièrement du côté intérieur; les graines sont noirấtres.

Cette cspèce croît dans les régions méridionales de la France. On la eultive en abondanee dans les jardins, oủ ses fleurs doublent avee une grande faeilité.

Propriétés et usages. La raeine de pivoine, lorsqu'elle est fraiche, a une odeur forte et nauséeuse, qui se dissipe en partie par l'effet de la dessiceation. Sa saveur est d'abord douceâtre, mais ensuite amère et désagréable. Lorsque l'on compare les résultats de l'expérienee clinique avee les éloges prodigués à cette plante par les anciens, on doit éprouver plus puissaminent que jamais le besoin de soumettre leurs assertions à une critique sévère et à de nouveaux essais. La racine de pivoine a été vantée eomme un des antispasmodiques les plus puissans, et un des remèdes les plus efficaces contre l'ćpilepsie, les eonvulsions, l'lyysterie, ete. Ces éloges, dont nous trouvons la première source dans les éerits dc Galien, ont été répétés par Fernel, Willis, Vogel et plusieurs autres. Cependant des médecins non moins célèbres, et parmi lesquels nous citerons Boerhaave et Tissot, se sont plaint du peu d'efficacité de la pivoine daus les différens cas d'ćpilepsie où ils en avaient fait usage. Cette opinion a prévalu parmi les moderries, qui ont presque entièrement abandonné ee médicamcnt.

On avait attribuć aux graines et aux fleurs les mémcs propriétés; mais elles ne méritent pas plus l'attention des pratieiens que les raeines; et leurs divcrses prćparations, telles que l'ean distillée, la conserve ct le sirop, sont tonıbées dans l'oulbli.

La racine s'administrait, $\mathrm{I}^{\circ}$ sous forme d'extrait aleoholique, à la dose de dix à vingt grains, que l'on augmentait graduellemcut; $2^{\circ}$ Murray recommande, comme plus cfficace, le 
șuc exprimé de la raeine fraîche, séchće et réduite en poudre. Cette raeine entre dans les poudres dites antićpileptiques dés aneiennnes pliarmacopées.

$2^{\circ}$ Pétales creux et irréguliers. Helléion ées.

\section{HELLÉBORE.-HELLEB.ORUS. L. J.}

Calice régulier, formé de einq sépales planes et persistans; corolle composée de einq à douze pétales creux, pédieellés et en forme de eornets; eapsules au nombre de trois à six:

Plantes vivaees.

\section{Hellébore noin. Helleborus niger. L.Sp. 783. Bull. t. 33. Orfil. Méd. lég. t. 7 .}

Tige soutcrxaine horizontale, charnue, eornme artieuléc, présentant les traees évidentes de la base des feuilles qui ont servi à la former; rameuse, blanche à l'intérieur, noirâtre ì l'extérieur, donnant naissance, par son extrémité supéricure, aux feuilles, et, dans différens points de son étendue, aux fibres radieellaires, qui sont très-allongées, simples, eharnies et jaune-brunâtres, devenant noires en se déséehant, souvent pubeseentes. Les feuilles, partaut immédiatenent de la souehe, paraissent toutes radicales. Elles sont pétiolées, pédalées, à sept ou huit lobes très-profonds, obovales, laneéolćes, aleuminées, coriaees, entièrement glabres, dentées en seie dans leur partie supérieure. Les pétioles sont eylindriques, rougeâtres, longs de deux à six pouces, dilatés et membraneux sur leurs bords à
leur partie inférieure.

Les hampes sont de la même hauteur que les pétioles, eylindriques et purpureseentes comme les pétioles, portant unc ou deux fleurs roses très-grandes, pćdoneulćes et penehées; ees fleurs sout aeeompagnées d'une ou deux bractées, de figurc variable, quelquefois un peu eolorées en rose. IAc caliee jersistant est comne campanulé, un peu élalé, formé de einc a six sépales très-grands, inégaux, obovales, arrondis, trìs-obîtus. I.es eornets ou pétales, au nombre d'environ dix à douze, sont beaucoup plus courts que le ealiee; ils sont comme pédicellés, 
infundibuliformes, un peu arqućs, inégaux à leur ouvcrturc, qui est comme bilabicee. Leur couleur est jaune-verdảtre.

Les étamines sont très-nombreuses, noitié plus courles que le calice. Les pistils, au nombre de six ou huit, quelquefois davantage, sont rapprochés et réunis au centre de la fleur. Ils sont glabres; l'ovairc est oblong et comprimé, un peu courbé, se terminant supérieurement en un style allongé, recourbé à son sommet, marqué sur son côté interne d'un sillon qui s'élargit et forme le stigmate à sa partie supérieure.

Cette espècc, qui fleurit depuis le mois de décembre jusqu'en févricr, croît dans les lieux fraîs et ombragés des montagnes, dans le Daupliné, la Provence, les Vosges, etc. 7

Les jardiniers la désignent sous le nom de ruse de Noël, époque de l'année à laquelle clle est toujours en fleurs.

Propriétés et usages. Jusqu'au temps où l'illustre Tournefort publia son Voyage dans le Levant, on avait regardé notre helléborc noir comme étant celui des aneiens. Ce dernier, au rapport de Thćophraste et de Pline, croissait spontanément dans les îles d'Anticyre, dans la Bœotie, dans l'Eubćey sur le mont Hélicon et dans d'antres pays voisins. Tournefort, en visitant les mêmes contrées, y trouva une espèce différente de toutes celles qui croissent en Europe, et surtout de notre hellébore noir, et lui donria le nom d'helleborus orientalis. M. le professeur Desfontaines cn a offert la description dans les plantes du Corollaire de Tournefort, P. 58 , et l'a figurée, planche $45 \mathrm{du}$ même ouvrage. Cette déconverte de l'illustre voyageur français prouve évidemment que le faimeux.hellébore noir des aneićns, si vanté dans le traitement des maladics mentalcs, est une cspèce tout-à-fait différent e de la nôtre.

Cependant cette dernière possède des propriétés fort énerrgiques. Sa racine est âcre ct brûlantc, et lorsqu'on la laissc appliquée cuelque tcmps sur la p'eau, elle l'enflamme et y forme des vésicules plus ou moins voluminenses. Administrie intérieurement, ellc fait naitrc dans l'estomac nul scntimcnt d'ardeur et d'anxiété, qui en sollicite les contractions et donnc lieu ou â des vomissemcns abondans, ou plus fréquemment à des déjcctions alvines accompagnées de coliqucs' violentes. C'cst done un purgatif drastigne très-pnissant. $A$ unc dosc un peu éle- 
rée, cettc racine devient un véritablc poison âcre, et les malherr-• reux qui succombent victimes de son action vénéneuse présentent les organes de la digestion rouges ct souvent érodés, les poumons gorgés de sang, etc. M. Orfila rapporte un grand nombre d'observations de cettc espècc dans sa Toxicologie génćrale, ct cn tire les conchisions suivantes : $1^{\circ}$ l'effet local de la racine d'hellébore cst toujours l'inflammation de la partie sur larprolle a eu lieu son application; $2^{\circ}$ introduite à haute dose dans l'estomac, elle agit comme tous les autres poisons âcres; $3^{\circ}$ la partic soluble dans l'eau paraît être la plus active et lá plus vénéneuse.

Un grand nombre d'auteurs ont fait usage de celtc racine dans le traitement de plusienrs maladies. De même que torss les autres purgatifs drastiqques, on conçoit qu'elle a pu étre avantageuse dans certains cas de manie ou d'hydropisies passives. Les fameuses pilules de Bacher, qui ont eu unc si grande voguc contre les liydropisies, devaient toute leur cfficacité à la racine d'helléborc, qui en faisait partic. Mais aujourd'hui on ne fait que fort rarement usage de cettc plante, soit à cause des accidens qu'elle peut otcasioner, soit parce qu'il est rarc, bien qu'elle soit indigène, de la trouver en bon élit chez les pharmaciens.

\section{NIGELIE. - NIGELLA. L. J.}

Calice étalé, formé de ciơ sépales colorés et caducs, cornlle de cinq à dix pétales bilabiés, ayant la licvre supéricure bifide; étamines nombreuses; ovaíres au nombre de cịnq à dix, terminćs chacun par un long style; capsules distinctes ou sondées par leur còté interne.

Plantes herbacécs, généralcment annuelles.

\section{Nigelue cultivée. Nigella sativa. L. Sp. 753.}

\section{'Part. usit. : les graines.}

Racine annuclle, fusiforme, allongée, surmontéc d'unc tige dressée, simple inférieurement, cylindriquc, pubescentc, haute d'cnviron un picd, un pcu ramense et visqueuse a la partie supéricure. Fevilles alternes, pétiolécs, pubescentes et lígè- 
rcment visqueuses, bi ou tripinnatifides, à segmens incisés en lanières étroites et trifides.

Flcurs d'un blcu clair, et cendré, grandes, solitaires et tcrminales, non involucrécs : calice étalé, pétaloïdc, formé le cinq sépales obovales, un peu aigus, onguiculés à la basc, à bords rabattus en dessous. Corollc de huit pétales, très-petits et irréguliers, comme à deux lèvres, l'externe ou infćricure partagće en deux lobes arrondis à la base, amincis supérieurement, et portant au sommet une petite glande globuleuse, en offrant une autre vers leur base interne; la lèvre supérieurc et interne est plus courte, plus étroite, simple èt sųbulćc; ces pétalęs sont terminés infćrieurcment par un onglet recourbé à angle droit. Les étamines, au nombre d'environ quarante, sout rangées par faisceaux longitudinaux, formés chacun de cinq étamines superposées. Ils alternent avec les pétales, et sont attachés au-dessus de l'ovairc, à unc substance blanchâtre et comme glanduleuse.

Le pistil se compose d'un ovaịre à cinq côtes et à cinq loges, qui chacune renferment un assez grand nombre de graines, disposées sur deux rangées longitudinales vers l'angle rentrant. Cet ovaire est formé par cinq pistils soudés ; de la partie supérieure ẹt exterue de clıaque côte, part latéralcment un style assez gros, de la longueur de l'ovaire, un peu contourné en spirale supćrieurement, tcrminé à son sommet par un trèspetit stigmate, qui s'ćtcnd, sous la forme d'un sillon glanduleux, à la face interne du style.

Le fruit est une capsule à cinq côtes obtuses, terminée par cinq cornes latérales, à cinq logcs s'ouvrant par la suture longitudinalc et supérieure.

Cette espèce croît dans le midi de la France. $\odot$

Propriétés et usages. Lcs graines sont petites, triangulaires, un pcu comprimćes, noirâtres, et ridées transvcrsalement. L'amandc qu'cllcs coutienneut est verdâtre ct olćagincuse. Lcur savcur est âcrc et piquantc, assez analoguc à celle du poivre. On les emploie surtout comme épice, pour assaisonucr ccrtains mots; de là lc nom de toute-épice qui leur a été domné. Quclqucs antcurs les ont administrées coumc stimulautcs, emménagogrucs, etc., mais leur usagc cst tont-à-fait abandonné. La ni- 
gellc des champs ( nigella arvensis, L.), qui est très-commune dans nos moissons, jouit des mêtnes propriétés. Elle entre dans le sirop d'armoise eomposć, etc.

\section{A UP HINELLE. - DELP HINIUM. L. J.}

Caliee coloré, formé de einq sćpales inégaux, le supérieur prolongé à sa base en un éperon. Corolle de quatre pétales, quelquefois soudés ensemble; les deux supérieurs se terminant inférieurement en un appendice subulé qui. est caché dans l'éperon du sépale supérieur. Capsules distinctes, au nombre d'une à einq.

Plantes herbacées, annuelles ou vivaces, ayant les feuilles déeoupées en lobes digités; les fleurs, ordinairement bleues, en grappes terminales simples ou rameuses.

\section{Dauphinelle staphisaigre. Delphinium staphisagria. L. Sp. 750 .}

Part. usit. : les graines. Nom pharm. : Staphisagria.

La staphisaigre offre une tige dressée, rameuse, cylindrique, très-velue, d'un vert mêlé de pour̂rpre, haute d'environ deux pieds; des feuilles alternes, pćtiolées; lcs inféricures orbiculaires, éehanerées cn cour à la base, divisées en einq, sept ou neuf lobes profonds, ovales, lancéolés, aigus, entiers ou offrant quelques ineisions latćrales, d'un vert foneé et presque glabres en dessus, d'un vert pâle et velues en dessous.

Ses fleurs sont d'une couleur terne et gris de lin, disposées en épil lâche à l'extrémilć des ramifieations de la tige; chaque flenr est porlée sur un pédoneule assez eourt, velu, offrant. trois bractées linéaires, velues, eourtes, à sa partie inférieure.

Les cinq sépales sont velus en dchors et verdâtres : l'éperon est eourt et reeourbé en dessus.

Les quatre pétales sont distinets ct glabres. Les deux supćrieurs sont ovales, allongés, obtus, rapprochés, prolongés en éperon à lcur partie inférieure : les deux pétales inférieurs sont onguiculés, à limbe irrégulièrement arrondi et denticulé.

Le fruit se compose de trois capsulcs rapprochées, coton- 
neuses, ovoïdes, allongées, terminées cn pointe à leur sommet. Les graines sont gुrisûtres, irrégulièrement triangulaires, comprimées, d'une saveur à la fois trc̀s-amère et très-âcre.

La staphisaigre est originaire de l'Europe méridionale. Elle croît en Portủgal, en Provence, eté. Elle est cultivée dans beaucoup de provinces.

Propriélés et usages. L'extrême âcreté des graines de staphisaigre en forme un poison violent pour l'homme ct les animaux, lorsqu'elle cst introduite dans l'estomac. Si l'on mâche quelque particule de staphisaigre, on éprouve un sentiment de cuisson dans la bouche et une plus abondante séerétion de salive. Quelques auteurs l'ont ainsi recommandée, d'après Dioseoride, contre l'odontalgie. Mais on doit à juste titre en redonter l'usage interne, et aujourd'hui on n'emploie plus celte planie qu'à l'extérieır, pour détruire la vermine. On incorpore la poudre dans del'axonge, et l'on en forme une pommade que l'on étend sur la tête. Quelquefois on fait macérer les graines de staphisaigre dans le vinaigre, et c'est de ee dernier que l'on se sert. M. Orfila pense que la partie la plus active de cette substance est celle qui est soluble dans l'eau.

Dauphrnele consoude. Delphinium consolida. L. Sp. 748 .

\section{Vulgairement: Pied d'alouette.}

Tige dressée, cylindrique, très-lćgèrement pubescente, rainense, à rameaux divariqués, haute d'un pied et demi à deux pieds. Feuilles sessiles, découpées en segmens linéaires, écartés, bifurqués au sommet. Fleurs bleues, pédonculécs, formant des épis lâches et pauciflores à la partie supérieure des rameaux; pédoncules roides, longs d'environ un pouce, offrant dcux petites bractées alternes.

Les cinq sćpales sont un peu inégaux. Le supérieur se prolonge en éperon creux à sa base. Les quatre pétales sont réunis et soudés en un seul, qui oceupe la partie supćrieure de la fleur, et se prolonge postéricurement en un éperon plein, qui s'enfonce dans celui du caliee.

Le fruit est une seule capsule un peu velıc. 
Le picd l'aloucitc est extrèmement commun dans les moissons aux environs de Paris. $(-$

Propriétés et usages. Lcs flcurs da pied d'alouette ont une saveur amère. Leur ean distillće était autrefois employée pour faire des collyres résolutifs. D'autrcs fois on formait avec ces fleurs, bouillies dans de l'eau de roses, des cataplasmes destinés à être appliqués sur les yeux affectćs d'ophthalmie. Quelques auteurs les ont mème crues propres à expulser les calculs de la vessie, à exciter le cours des menstrues, etc. Mais aujourd'hui leur usage et celui des graines, qui jouissent à pen prc̀s des mêmes proprićtés que celle de staphisaigre, est tout-à-fait abandonné.

\section{ACONIT.-ACONITUM. L. J.}

Caliee pétaloüde, formé de cinq sépales inéganx, l'un supérieur plus grand et en forme de casquc. Corolle de cinq pétales, dont trois inférieurs très-petits ou avorlćs, et deux supériẹurs en forme de capuchon, longuement pédicellćs, renfermés dans l'intćrieur du sćpale supérieur Étamines nornbreuses. Capsules au nombre de trois ou de cinq.

Plantes herbacćes, vivaces, ayant les feuilles découpées., les fleurs violettes ou jaunes., disposées en épis ou en panicules.

Aconit napel. Aconitum napellus. L. Sp. 75 г. Orfila, Méd. lég. t. 6.

Part. usit. : la racine, les feuilles. Noms vulg.: Tue-loup, Napel, Coqueluchon, etc.

Sa racine est vieace, pivotante, napiforme, allongée, noirâtre. Sa tigc dressée, simple, haute de trois à quatre pieds, cylindriquc, glabre.

L.es feuilles sont alternes, pétiolécs, partagées jusqu'à la base en cinq ois sept lobes allongćs, subcunéiformes, profondément incisés et découpés en lanièrcs étroites et aiguës.

Les fleur's sont blcues, grandes, un peu pédonculées, disposées en un épi allongé, assez serré, à la partie supérieure de la tige. 
Leur calice cst-pétaloüle, irrégulier, formé de einq̨ sépales inégaux : un supérieur plus grand, en formc de capuchon, dressé, convexe en-dessus, coneave ćn-dessous; deux latéraux planes, inégalement arrondis, poilus en dedans; deux inférieurs un peu plus petits, ovales, entiers, ćgalement poilusà leur face interne.

La eorolle est formée de deux pétales irréguliers, longucınent onguiculés et canaliculés, terminćs supérieurement par une espècc de petit eapuchon creux, obtus et recourbé à son sommet, offrant antérieurement à son ouverture une petite languette roulée en dessus. Ces deux pétales sont dressés et eachćs sous le sépale supérieur.

Les étamines, au nombre d'environ trente, sont d'inégale grandeur, beaueoup plus conrtes que le ealice. Les filets sont planes à leur partie inférieure, subulés à leur partie supérieure; les plus externcs sont recourbés en dehors, ils sont appliquués et serrés les uns eontre les autres, et portent des anthères cordiformes obtuses.

Les pistils sont au nombre de trois, au centre des étamines; ils sont allongés, glabres, presque cylindriques, amineis en pointe au sommet.L'ovaire, qui en forme la plus grande partie, cst à une seule loge renfermant environ une vingtaine d'ovulcs disposés sur deux rangées longitudinales, et attaehés du côté externe.

Le fruit est formé de trois eapsules allongées, qui s'ouvrent par une suture longitudinale pratiquée du côté externe.

L'aconit napel croît dans les pâturages élevés des moritagncs, dans le Jura, la Suisse, etc. Il fleurit dans les mois de mai et dc juin.

Propriétés et usages. L'aconit napel est, de toutes les plantes de la famille des Renonculacécs, eellc qui paraît jouir des propriétés les plus vénéneuses. En effet, toutes ses parties, mais surtout ses feuilles et sa raeine, sont d'une extrême âcreté: Mises cn contact avee la langue, elles y excitent un scntiment doulourcux de enisson et une séerétion plus considérable dans les glandes salivaires. Le grand nombrc d'aceidens occitsionés par la rácine de l'aeonit, l'usage où l'on est dans les pays de montagnes de la mélanger à la viande avec laquelle on 
forme des appâts pour fairc périr les loups et autres animaux carnassiers, indiqucnt suffisamınent son action délétc̀re. M.Orfila a tiré d'un grand nombre d'expériences tentées par lui, pour connaître les effcts du napel, les conclusions suivantes : Le suc des feuilles, introduit dans l'estomac, le rectum ou le tissu cellulaire, détermine des accidens graves, suivis d'une mort prompte. La racinc agit encore avec plus de force. L'extrait aqueux préparć avec le suc exprimć des feuilles fraîches, et surtout l'extrait alcoholique, jouissent des mêmes propriétés vénéneuses. Ces diverses préparations sont absorbćes, agissent sur lc.système nerveux, et en particulier sur le cerveau, en détcrminant une sorte d'aliénation mentale; en outre elles exercent une irritation locale dans les organes sur lesquels elles ont été appliquées.

Storck fut le premier qui, parmi Ies modernes, chercha à introduire l'aconit dans la thćrapeutique. Il tenta sur lui-même ses premiers cssais, et n'obtint pour résultat constant qu'une augmentation de vitesse dans le cour's du sang, et par suite dans la perspiration cutanée. Dès lors il administra ce nouveau médicament dins le rhumatisme, la goutte et la syphilis chroniques, où l'èmploi des sudorifiques est en génćral avantageux. D'autres ayant remarqué l'excitation exercée par le napel sur le système nerveux, l'ont prescrit dans la paralysie, surtout celle qui se manifeste à la suite de l'apoplexie; quelques - uns en ont fait usage contre les fièvres intermittentes, l'ćpilepsie, etc. Cependant une foule d'expćriences faịtes à l'hôpital de lá Charité par M. le professeur Fouquier, avec la sagacitć qui distingue cet habile praticien, n'ont pas amené des rćsultats aussi avantageux. Le seul effct sensible remarqué dans ces essais, qui ont élé fort variés, c'èst l'augmentation évidente de la sécrétion urinaire. Mais M. Fouquier n’a reconnu au napel, ni à aucune de ses préparations, l'action stupéfixnte qui leur avait été attribuée par plusieurs auteurs. C'est contre les hydropisics passives, que le profcsseur que nous venons de citer, pense que l'aconit peut avoir d'hcureux résultats.

On peut administrer les feuilles d'aconit réduites cn poudre, ou mieux encore l'extrait préparć avee lé sue exprimé des 
feuilles fraiches, lentement évaporé. Il est nécessaire de commencer par łcs doses très-faibles, que l'on augmentcra graduellement. Airsi, l'on donnera d'abord un à deux grains de l'extrait, ou quatre à huit grains de la poudre des feuilles, en augmentant suceessivement.

Les áutres espèces du genre aconit paraissent posséder les mêmes propriétés que le napel. Ainsi l'aconitum anthora, L., l'aconitum cammarum, L., ete., qui croissent aussi dans les Alpes, sont également vénéneuses.

\section{Propriétés médicales et usages des Renonculacées.}

On peut réduire à peu de mots le résumé des propriétés générales qui distinguent les plantes de la famillc des Renonculacćes. Toutes, en effet, sont jus ou moins âcres et vénćneuses. Cette âcretć qui éxiste dans presque toutes les parties de ces végétaux paraît dépendre d'un principe fugace et volatil, qui se détruit facilement par l'effet de l'eau bouillante, ou même simplement par la dessiccation. Aussi la plupart des Renonculacćes, qui, lor'squ'elles sont fraîches, sont vénéneuses pour l'homme et les animaux, perdent-elles leurs propriétés délétères par la dessiccation ou l'ébullition. Administré à l'intćrieur, le suc ou l'extrait des Renonculacées pent, quand il est donné à haute dose, occasioner les symptômes les plus graves, et même donner la mort. Le nombre des accidens de ce genre est fort nombreux. Aussi ces végétaux sont-ils placés parmi les poisons âcres. Appliquées sur la peau, les feuilles des renoncules, des clématites, etc., en déterminent la rubéfaction, et, si l'on en prolonge l'application pendant quelque temps, il s'y formedes vésicules et des ulcères plus ou moins profouds. C'est ainsi que dans beaucoup de circonstances l'on peut substitner les feuilles des Renoncules, et surlout de la renoncule âcre, de la renoncule bulbeuse, de la renoncule scćlérate, et de plusieurs autres espèces, à la poudre de cantharides, pour éviter l'action irritante que ces dernières détẹrminent dans lcs organes urinaires.

Le principe âcre cst cneore plus développé dans la racine de ces vigélaux que dans leurs feuilles, ainsi qu'oin lo remarque 
pour les aconits. Cependant, comme il se détruit facilement, soit pas la chaleur, soit par son exposition long-temps prolongée à l'air, quelques Renonculacées pcuvent ètre employées comme alimens lorsquelles ont été bouillies dans l'eau. Nous citerons ici les jeunes pousses de la clématite blanche, que l'on mange dans le Piémont, les feuilles de. la ficaire, et même de quelques Renoncules, telles que la ranunculus auricomus, ranunculus lanuginosus, etc.

Leurs graines possèdent aussi une saveur âcre et plus ou moins amère, mais qui parait résider dans leur tégument, et nullement dans leur amande, qui souvent est douce et oléagineuse. Elles sont ordinairement employées. contre la vermine ou contre les vers.

Nous croyons inutile d'entrer dans de plus grands détails sur les Renonculacées pour faire voir l'extrême analogie qu'elles présentent entre leurs caractères d'organisation et leurs propriétés médicales.

SOIXANTE-ONZI EME FAMIILE.

\section{MAGNOLIACÉES. - MAGNOLIACEAE.}

Les végétaux qui composent la famille des Magnoliacées sont ou des arbres ou des arbrisseaux élégans, ornés de feuilles alternes, d'abord enveloppées dans deux grandes stipules foliacées. Leurs fleurs, qui sont quelquefois extrêmement grandes et répandent une odeur des plus suaves, ont un calice caduc, formé de trois à six sépales; une corolle de trois ou d'un grand nombre de pétales disposés sur plusieurs rangées. Leurs étamines sont fort nombreuses, ayant les anthères allongées et adnées sur les parties latérales des filets. Les pistils sont tantôt rapprochés et un peu unis par leur côté interne; plus souvent disposés en une sorte d'épi plus ou moins allongé. Chacun d'eux offre un ovaire à une seule loge contenant un ou plusicurs ovules, et se termine à son sommet par un style et un stigmate simples. 
Les fruits varient beaucoup. Ce sont tantồt des espèces de capsules, s'ouvrant ou en deux valves ou par une simple fente; tantôt des fruits minces, planes et indéhiscens. Dans quelques genres, ces fruits sont légèrement charnus. Leurs graines, qui sont attachées à l'angle interne de chaque loge, d'où elles pendent quelquefois suspendues à un long podosperme, se composent d'un embryon dréssé, placé dans la partie inférieure d'un endosperme charnu.

\section{TULIPIER. - L YRIODENDRON. L. Juss.}

Calice de trois sépales caducs, corolle de six pétales plus longs, dressés en forme de cloche; anthères allongées; ovaires. nombreux et imbriqués. Fruits minces, comprimés, unilocılaires, dispermes, formant une cspèce de cône imbriqué.

\section{Tulipler ordinaire. Lyriodendron tulipifera. L. Sp. 755 . Duham. éd. nou. 3. t. I8.}

Bel arbre très-ćlevć, d'un port élégant, originaire des forêts de l'Ainćrique du nord. Son tronc est cylindrique, son ćpiderme est grisâtre, peu fendillé.

Ses feuilles sont alternes, pétiolées; leur pétiolc est glabre, un peu canaliculé, renflé ä sa base et articulé : le limbe est irrégulier, quadrilatère, tronqué au sommet, à quatre lobes aigus, d'un vert peu foncé en dessus, presque blanchâlres en dessous. Dcux.stipules foliacées, très-grandes, sessiles, ovales, obtuses, cntières, glauques, cnveloppent la feuille avant son expansion.

Ses flcurs sont très-grandes, jaunes, un peu pédonculées, solitaires à l'cxtrćmité des rameaux. Le calice se compose de trois grands sépalcs étalés, ovales; obtus, un peu concaves, jamuatres, légèrement glauques et veinés. La corolle est formće de six pétales dressés, de la mème grandeur et de la mèmc forme que le calice, alternes avec les sépales, un peu recourbés cri deliors à leur partic supéricure, jaunc-verdâtres, avec ine grande tache irrégulière, coulcur de feu, à leur partic moyennc. 
Les étamines, au nombre de vingt on environ, sont dressées, un peu plus eourtes que la corolle, hypogynes; les filets sont un peu planes, élargis au sommet, se prolongeant derrière l'anthc̀rc, dont ils réunissent les loges, et formant une petite pointe au-dessus d'elle; lcs anthères sont linéaires, plus longues que les filets, extrorscs, à dcux loges, s'ouvrant par un sillon longitudinal.

Les pistils sont rassemblćs au centre de la fleur, forment un cône allongé, à peu près de la même longueur que les étamines, et se changent en autant de fruits planes et imbriqués, qui restent indéhiseens.

Propriétés et usages. L'écorce dc ee bel arbre, qui est aujourd'hui naturalisé dans tous nos jardins, a unc saveur trèsamère, ct manque entic̀rement de tannin et d'acide galliquc. Ellc jouit d'une action tonique très-évidente. Dans l'A mérique septentrionale on l'emploie avee suecćs au traitement des fièvíes intermittentes. Celte écoree peut être administrée en poudre; depuis une demi-once jusqu'à un oncé, ou mieux encore en déeoction. Nous avons fait iei mention de cet arbre, quoiqu'il soit à peine usité cn France. Mais comme il y est naturalisé et assez eommun, on pourrait tenter de nouveaux essais, pour s'assurer de son cfficacité.

Il en est de même de plusieurs espèccs du genre Magnolia, et surtout du magnolia glauca, également originaire de l'Amérique sejtentrionale, et que nous eullivons dans nos jardins, en ayant soin de le garantir pendant lcs hiver's rigoureux. Son éeorce, à laquelle on a long-temps, et à tort, rapporté la vćritable angusture s, a une saveur amère, relevée d'un goût aromatique, analogue à eelui du sassafras et du calamus aromaticus. C'est un execllent tonique aromatique, fort cn usíge dans l'Amérique septentrionale. Selon le doeteur Bigelow, on l'emploie avee le plus grand suecès dans lc traitement du rhumatisme chroniquc. Les fièvres intermiltentes cèdent aussi trèsfréquemment à son emploỉ. Ce médicament inćritcrait d'ĉtre employé en Franee.

' L'angusture est l'écorce du cuspària febrifugru de la famille des Rutacées. 


\section{DRYMIS. - DRYMIS. Forst. Juss.}

Calice à deux ou trois divisions profondes; corolle de dcux ou trois pétales (quelquefois plus nombrcux). Étamines nombreuscs, ayant les filets épaissis à lcur sommet, qui porte unc anthère à deux loges écartées. Ovaires au nombre de quatre à huit, se changeant en autant de pctites baies polyspcrmes.

Arbrcs ou arbrisseaux aromatiques, toujours verts et glabrcs.

Drymis de Winter. Drymis Wrinteri. Forst. Wintera aromatica. Murr. app. med. 4. p. $55 \%$.

Part. usit. : l'écorce. Nom pharm.: Cortex IVinterii. Nom vulg.: Ecorce de IV inter.

Cet arbre varie beaucoup dans ses proportions, et ne s'élèrc quelquefois qu'à une hauteur de six à huit pieds, tandis que quelques individus peuvent atteindre jusqu'à quarante pied. Ses feuilles sont alternes, pétiolées, ovales, allongées, obtuses, un peu coriaces et entièrement glabres, vertes en dessus, blanchâtres ct glanques inférieurement : on trouve à lcur base deux stipules foliacées et caduques.

'Les fleurs sont assez petites, tantôt solitaires, plus souvent réunies au nombre de trois à quatre all sommct d'un pédoncule commun, ayant environ un pouce de longucur, simple, ou divisé en autant de pédicelles qu'il y a de fleurs. Ces pédicelles partent tous du mêne point, et sont ariculés.

Le calice se compose de dcux à trois sépales caducs ainsi que les pétales, qui sont a nombre de six. On trouve, an centre de chaque fleur, de quarre à six pistils, qui se changent cn antant de petites baies globulcuses et glabres, de la grosscur d'un petit pois.

Cet arbre croît sur les cotcaux escarpés du détroit de Magellan. J'en ai tracé la description d'après un échantillon rapporté dc ces contrées par l'infatigảblc Commerson.

Proprićtés et usages. L'écorce de Winter, que l'on confond prcsqúc toujours avec la canclle blanchc, écorce d'un arbre de la famillc des Méliacécs, qui poric les noms de Wintcrana ca- 
nella ou canella alba, est en plaques ronlćes, d'environ un pied de longucur, épaisses de dcux à trois lignes, d'un gris rougeâtre ou couleur de chair, quelquefois brun foncć ; sa eassure est compacte et rougeâtre; sa saveur âcre, aromatique et poivrée. Elle contięnt, d'après M. Henry, de la résine, une hưile volatile, du tannin; une matière colorante ct quelques sels : la canelle blanche, an contraire, est dépourvue de tannin.

Cette écorce, qui a étć découvertc par Winter, en 157.7 , est tonique et stimulante. Cet autcur l'a d'abord employée avec succès, pendant son voyage, pour combattre les symptômes de scorbut que présentait l'équipage du vaisseau commandé par Drake. Il cn obtint de grands succès, et les fit connaitre à son arrivée en Angleterre. D'autres auteurs ont depuis fait usage de ce médicament. Ses propriétés sont les mêmes que celles de la canelle, mais moins énergiques. On l'emploie bien rarement.

L'écorce des autres espèces de ce genre a la même saveur, et peut être employée aux mémcs usages.

\section{BADIANE.-ILLICIUM. L. J.}

Son calice est formć de cinq ou six sépales écailleux ct inégaux; sa corolle d'un grand nombre de pétales étroits, disposés sur plusieurs rangs; ses étamines, an nombre de vingt à trente, sont courtes; les anthères appliquées à la facc interne des filets; le fruit est formé de huit, douze, ou d'un plus grand nombre de coques monospermes, soudées par la basc, s'ouvrant par la partie supérieure, et disposées en ćtoile:

Cc sont des arbrcs aromatiques, à feuilles alternes.

Badiane Anis étolué. Illicium anisatum. L. Sp. 664. Lam. Illust. t. 493 . f. 2.

Part. usit.; les fruits. Nom pharm.: Anisum stellatum.

C'est un arbre toujours vert, qui croît en Chine et au Japon, et qui, par son port ct son feuillage, a beaucoup de rcssemblance, avec nolrc laurier d' $\Lambda$ pollon (laurus nobilis).

Ses fenilles sont alternes, on rassemblies en bonquels à lia 
partie supérieure des rameaux; elles sont eourtement pétiolées, elliptiques, allongées, aiguës au sommet, très-entières sur leur's bords, longues d'environ trois à quatre pouces, larges d'un pouee à un pouee et demi; à la base de ees feuilles, et un pei au-dessous d'elles, on trouve sur les jeunes rameaux des stipules foliaeées, laneéolées, blanehâtres, trèseaduques.

Les fleurs sont solitaires, longuement pédoneúlées et situées dansl'aisselle des feuilles supérieures. C'es fleurs sont jaunâtres, et se composent d'un ealice eạdne, formé de cinq à șix folioles inégales, squammiforıes, dont les plus inférieur'es sont colorées et preśque pétaloïdes, d'une eorolle polypétale; les pétales sont très-nombreux, disposés sur plusieursrangs; ils sont laneéolés, aigus; les plus intérieurs sont plus étroits.

Les étamines, au nombre d'environ vingt-einy à trente, sont étalées et réfléehies en delors; leurs filets sont épảis, eourts, un peu planes. L’anthère, qui est biloeulaire, est située sur la face antérieure et à la partie supérieure du filet, dont elle est peu distinete.

Les pistils, ordinairement au nombre de huit, sont disposés en étoile et serrés latéralement les uns eontre les autres, au eentre de la fleur. Chaeın d'eux a un ovaire eomprimé, uniloculaire et uniovulé; il se termine supérieurement par un style eourt et partant de son eôté exterue : le stigınate est situé à la partie supérieure du style, sur la faee interne duquel il forme uu sillon longitudinal.

Le fruit est étoilé,.eomposé de huit coques ovoïdes; aiguës, monospermes, soudées ensemble par la base, s'ouvrant longitudinalement par leur face supérieure.

Propriétés et usages. Toutes les parties de eet arbre répandent une odeur aromatique très-suave, qui parait surtout se eoneentrer dans le fruit; qui est la seule partie employée en Europe. On le connait sous le nom de badiane ou d'anis étoilé.

L'anis étoilé a une saveur suerée, îere ê aromatique, qui a beaueoup d'analogie avee eelle de l'anis et du fenouil. On le donne en poudre, en infusion théiforme, ou l'on administre son cau distilléc. C'est un médieament puissamment stimulant. 
On prépare avec ses fruits des liqueurs de table très-agréables. L'anisette de Bordeaux doit, dit-on, son parfum délicieux aux fruits de la badiane.

\section{Propriétés médicales et usages des Magnoliacées.}

Les Magnoliacées sont remarquables non-seulement par l'élćgance de leur feuillage, la grandeur et le parfum délicieux de leurs fleurs, mais elles mëritent aussi notre attention par leurs propriétés médicales. Deux principes se montrent dans presque toutes lenrs parties. L'un cst aromatique, plus ou moins âcre et stimulant; l'autre, moins fréquent, est d'une grande amertume. Lc premier existe surtout dans l'écorce des Drymis, dans les fruits et l'ćcorce des Illicium, connus sous les noms d'anis étoilé ou de badiane, que les Chinois brûlent dans leurs temples, et que nous employons comme médicamens et comme aromates. Le second est plus abondant dans l'écorce des Magnolia et des Tulipiers, qui sont aussi un peu aromatiques, et qui, dans l'A mérique septentrionale, servent de succédanés au quinquina dans le traitement des fièrres intermittentes.

Leurs fleurs sont fort odorantes, et quelquefois extrềmement suaves. C'est avec celles du Magnolia Plumieri, L., ou TaLauma de Jussieu, que l'on aromatise les liqueurs de la: Martinique, et qu'on leur donne ce parfum exquis que nous n'avons pas encore pn imiter.

On voit, d'après ce court exposé, quc toutes les Magnoliacées sont aromatiques, toniques ou stimulantes et qu'elles offrent, sous ce rapport, une très-grande uniformité.

SOI X A N.TE-DOUZI È E FAM II I E.

\section{ME N ISPER MÉES. - MENISPERMEA.}

Des arbrisseaux sarmenteux et volubiles, portant des feuilles alternes simples, pétiolées, mueronées, sans stipules; des fleurs petites, unisexuées, et ordinairement diö̈ques, eomposent la famille des Ménispermées. Leur calice et leur eorolle sont formés de plusieurs 
pièces distinctes, assez souvent disposées sur plusicurs rangs; insérées au-dessous des pistils, et se détachant peu de temps après l'épanouissement de la flenr. Dans les fleur's mâles, le riombre des étamines varie beaucoup; elles sont en nombre égal, double ou triple des pétales; tantôt elles sont librres, plus souvent monadelphes. Dans les fleurs femelles, on trouve généralement plușieurs pistils uniloculaires, distincts ou soudés intimement, de manière à ne former qu'un seul fruit à plusieurs loges.

Le fruit, dans le plus grand nombre des genres, est une petite drupe monosperme, plus ou moins recourbée et réniforme. La graine qu'elle renferme offre absolument la même forme et se compose d'un embryon également recourbé et enveloppé dans un endosperme chairnu, mince.

"Cette famille est extrêmement distincte, et les caractères que nous en avons tracés suffisent pour la bien faire connaître. 'Tous les genres qui la composent sont exotiques.

\section{-MÉNISPERM E. - MENISPERMUM. L. J.}

Fleurs dioîques : calice de six à douze sépales; six à huit pétales. Fleur's mâles : élamines de six à vingt-quatre. Fleurs femelles: deux à quatre ovaires pédicellés, terminés par un style bifide. Fruits drupacés, réniformes arrondis, un peu compriinćs, renfermant unc seule graine.

Arbrisseaux.grimpans, à feuilles alternes et pćtiolées.

Ménisperme coque du Levant. Menispermum cocculus. L. Sp. I 468 .

'Coccuilus suberosus. De Cand. Syst. nat. veg. I. p. 5 r. Part. usit. : les fruits. Nom pharm. : Cocculi orientales. Nom vulg. : Coques du Levant.

Arbrisscau a tige grimpante, vivace, couverte d'unc ćcorce 
subéreuse et fendillće : ses feuilles sont alternes, pétiolées, cordiformes et comme tronquées à la base, épaisses, glabres et luisantes.

Les fleurs femelles sont très-petites, disposées en longues grapjes. Les fruits qui leur suecèdent sont des espèces de drupes plus grosses qu'un pois, presque réniformes, renfermant dans leur intérieur un noyau rugueux.

Cet arbuste est originaire des Indes orientales; du Malabar, ete.

Propriétés et usages. Les fruits répandus dans le commeree, et eonnus sous le nom de coques du Levant, paraissent, au rapport de Roxburgh, être particulièrement eeux de eette espèee, ainsi que de quelques autres voisines. Ils se eomposent d'une partie extérieure sèehe, minee, noirâtre et amère, et d'un noyau blane, pouvant s'ouvrir en deux valves, et renfermant une amande blanehe. Celte amande est d'une extrême amertume, qui lui est'eommuniquée par un prineipe alealin partieulier, très-vénéneux, suseeptible de eristalliser, et auquel M. Boulay a donné le nom de picrotoxine. La eoque du Levant contient en outre presque moitié de son poids d'une huile fixe eonerète, de l'albumine, quelques sels, ete.

C'est à la pierotoxine que la eoque du Levant doit l'action stupéfiante qu'elle exeree sur les poissons, les oiseaux et d'autres animaux. Tout le monde sait que dans l'Inde on s'en sert comine d'un appât, et qu'elle plonge dans une sorte de stupeur les poissons qui l'ont avalée.

Les expérienees que plusieurs médeeins ont faites a vee cette substanee démoutrent qu"elle agit eomme les poisons nareotieo-âcres, e'est-à-dire sur le système nerveux et en particulier sur le cerveau, et que le vomissement paraît être le meilleur moyen de prévenir les aecidens qu'elle développe, quand elle est eneore dans l'estomac.

La coque du Levant n'est pas employée. en médeeine. 
Ménisperme columbo.' Menispermum palmatum. Lam. Dict. 4. p. 99. Cocculus palmatus. D. C. Syst. x. p. 522 .

Part. usit. : la racine. Nom pharm.: Radix columbo. Noms vulg.: Colombo, Calumbo, Calomba, ete.

Cette espèee est, eomme la jréeédente', un arbuste dioïque, sarmenteux et grimpant. Sa racine est épaisse et eomposée de ranifieations fusiformes. Sa tige est grêle, volubile, simple, eylindrique, de la grosseur du petit doigt, eouverte, ainsi que les feuilles, de longs poils roux. Celles-ei sont alternes, pétiolées, orbieulaires, à einq.nervures qui ehaeune vont aboutir à autant de lobes éeartés, aeuminés, entiers el palmés. Les fleurs mâles sont portées et groupées sur des pédoneules simples ou rameux, plus longs que les feuilles, sur lesquels elles sont sessiles. Leur ealiee se eompose de six sépales, et la corolle est également formée de six pétales épais et subeunẻiformes. Les étamines, au nombre de six, sont plus longues que les pétales.

On ne eonnait pas eneore l'individu ni les fleurs femelles.

Le eolumbo eroît dans les forêts épaisses de l'Afrique australe, sur les rives du eanal de Mozambique. $\nsucc$

Propriétés et usages. La raeine de eolumbo nous est apportée en rouelles ou en moreeaux de trois à quatre pouees de long, sur un à deux pouees de diamètre. Son éeoree, d'un brun verdâtre, est épaisse et rngueuse ; son intérieur est à pẻu près de la même eouleur, et offre des zones eoneentriques, emboitées les unes dans les autres. Son odeur est désagrẹable, et sa saveur amère et nueilagineuse. MI. Planehe l'a trouvée eomposée du tiers environ de son poids d'amidon, d'une matière azotée très-abondaute, d'une matière jaune, amère, non préeipitable par les sels métalliques; de traees d'luuile, de quelques sels et de ligneux.

C'est ver's 1697 , que Franęois Redi a le premier larlé des proprićlćs médieales de la raeine de eolombo. Plusieurs auteurs, depuis eetle époque, l'ont suceessivement employée. C'est un médicament amer el tonique, mais qui a uu mode d'aetion 
particulier, suivant les préparations qu'on lui fait subir. Ainsi, par le inoyen de l'ébullition dans l'cau, on s'empare de toute la fćcule qu'il contient et de ses principes amers, ct l'on a un mćdicament dont l'action tonique est tempérée par la présence d'une grande quantilé d'amidon; tandis que la macération dans l'eau froide, ou l'infusion, donne un médicament simplement amer ct tonique. On a recominandé l'usage de la racine de colombo dans la diarrhće chronique. Quelques autenrs l'emploient pour augmenter les forces digestives de l'estomac. Mais en général ce médicament est fort rarement prescrit par les inédecins modernes.

- Il en est à peu près de même de la racine d'une autre plante de cette famille, le Cissampelos pareira, L., qui croît au Pérou, au Brésil et au Mexique. Cette racine porte đans le commerce le nom de Pareira-Brava. Ellc est presque inódore et d'une saveur faiblement amère. On l'a surtout vantée comme un diurćtique très-efficace dans une foúle de maladies des voies urinaires, telle que la néphrite calculeuse surtout. Elle est presque inusitée aujourd'hui.

\section{Propriétés médicales et usages des Ménispermées.}

Cettc petite famille est peu intéressante sous le rapport de ses propriétés médicales. On trouve dans la racine de plusieurs des végétaux qu'clle renfeme, un principe amer plus ou moins abondant, mais qui souvent est en grande partie mitigé et affaibli par la présence d'une grande quantité d'amidon, ainsi qu'on l'observe dans les racizues de colombo et de parëira-brava, qui sont amères et toniques.

Lc principe amer que contiennęnt les coques du Levant est bien différent dans sa nature chimique, et surtout son mode d'action sur l'économie animalc, de celui dont nous venons de signaler l'existence dans lc colombo. En effet, les expériences chimiques dc M. Boulay ont fait voir que ce principe était un alcali organiquc nouveau, susceptible de cristalliser; et les essais rqui ont été tentés par M. Goupil ct le professeur Orfila démontrent juscqu’à l'évidence lcs propriétés vćnéneuscs de cette inatière, que ce dernicr pláce parmi les poisons narcotico- 
ácres. La présence de la picrotoxinc dans les coques du Levant forme une anomalie dans celle famille, encorc généralement mal connue dans ses caractères et ses propriétés.

SOIXANTE-TREIZIÉME FA MITLE.

BERBÉRIDÉES. - BER RERIDEAE.

Les fleurs sont hermaphrodites dans les Berbéridées, qui sont des arbres, des arbrisseaux, ou nê̂ne des plantes lierbacées. Leur calice se compose de trois à six sépales caducs, quelquefois imbriqués; leurs pétales, géméralement en même nombre; sont ou ğlanduleux à leur base, ou quelquefois d'une forme tout-à-fait irrégulière : ils sont opposés aux sépales. Les étamines, dont le nombre est lè même que celui des pétales, leur sont également opposées, c'est-ä-dire placées immédiatement devant chacun d'eux ${ }^{\mathrm{I}}$. Leurs filcts sont plus ou moins allongés, portant à leur sommet une anthère dont les deux loges sont écartées, et qui s'ouvrent au moyen de deux valves qui se roulent de la base vers le somnet, comme dans les lauriers. L'ovaire est solitaire à une seule loge, qui contient un petit nombre d'ovules insérés à sa base ou sur l'une de ses sutures; il se termine par un style, qui manque quelquefois, et alors le stigmate, qui est légèrement concave, est sessile.

Le fruit est une baie, ou très-rarement me capsule uniloculaire, contenant plusieurs graines (rarement une seule par snite d'avortement), qui se composent d'un embryon axillaire, renfermé dans un endosperme charnu ou corné.

Dans les Berbéridées, les feuilles sont alternes, généralement simples, quclquefois pinnées; les fleurs sont petites, 'jaunes, en épis ou en grappes.

- Ce caractère n'est pas très-commun daus la série des familles nasurelles; on l'observe encore dans les vignes, les Primulacécs, eic. 
Cette famille est fort distincte des Ménispermées par ses fleurs hermaphrodites et son unité de pistil : ce dernier caractère la distingue très-bien des Magnoliacées, dont elle diffère encore par ses étamines opposées, en nombre déterminé, et la déhiscence particulière de ses anthères.

\section{VINETTIER. - BERBERIS. L. J.}

Calice formé dc six sćpalcs disposés sur deux rangs, accompagné extérieurement de deux ou trois petites foliolcs. Corolle de six pétales, portant deux glandes à leur base interne. Six étainines opposées aux pétales. Stigmate sessile, large, connvexe. Baie uniloculaire, contenant deux ou trois graincs.

Arbrisseanx à feuillcs alterncs, pétiolćcs, accompagnnées à lcur base d'aiguillons formés par les feuilles extćricures rudimentaires et endurcies.

\section{Vinettier commun. Berberis vulgaris. L. Sp. 472.}

Vulgairement : Épine-vinette.

C'est un arbrisseau dé quatrc à six pieds d'élévation, pouvant acquérir une plus grande hauteur' dans les contrées plus méridionales. Son écorce cst grisâtre, son bois jaune ct fragile. Ses fcuilles forment d'abord des espèces de petitcs rosettes, qui s'allongent en un ramean; elles sont alterncs, pétiolées, ovales, roides, divisées èn dents profondes et très-aiguës. Les aiguillons qui les accompagnent ne sont que des feuilles avortées.

Les fleurs sont jaunes, et constituent de petits ćpis, pendans tous d'un mêne côté; chaque fleur est pédicellée et accompagnéc d'une pelite bractće squammiforme.

Le calice se compose de six sépalcs disposés sur deux rangs, et offre fort souvent en dehor's trois antres folioles plus étroitcs el plus courtes. Les pétalcs sont aussi au nombre de six, plus longs que le calice, bifidcs à leur sommet, offrant deux petiles glandes allongées à leur base interne.

Les six élamincs sont un picu plus courtes jue los pélales, 
au-devant descuelles elles sont placées. Leurs anthères, dont les denx loges sont séparées par toute l'épaisseur du filet, s'ouvrent au moyen d'une sorte de valve, qui s'élève de la base au sommet. Ces étamines sont douées d'une irritabilité bien manifeste. Lorsqu'on les touehe avec la pointe d'une aiguille, on les voit se rapprocher avee foree.

L'ovaire est allongé, presque cylindrique, terminé par un stigmate épais, discoïde, percé à son centre d'une ouverture, qui communique directement avee sa eavité. Celle-ci contient trois ovules attachés à sa base.

Le fruit est une petite baie allongée, d'un beau rouge, ombiliquée à son sommet, contenant d'une à trois graines.

Le vinettier est commun dans les haies et les bois, où ses fleurs, qui s'épanouissent au mois de. mai, répandent une odeur fade et spermatique.

Propriétés et usages. Les petites baies de l'épine-vinette ont une saveur aigrelette très-agréable. On peut en préparer des boissons rafraîchissantes que l'on preserit dans les irritations gastriques peu intenses. Le sirop qui se fait avee ees fruits, étendu d'eau, forme une tisane fort agréable.

La racine d'épine-vinette fournit un principe colorant jaune. fort employé dans l'art de la teinture.

Du resie, cette famille ne nous offre aneun autre intérêt.

SOIXANTE-QUATORZIEME FAMTLLE

\section{PAPAVÉRACEES. - PAPAVERACEAE.}

Le calice est à deux sépales concaves et très-caducs, airsi que la corolle, qui est formée de quatre pétales plissés et comme chiffonnés avant leur développement. Lés étamines sont libres et nombreuses. L'ovaire est simple et libre, à une seule loge, dans laquelle les trophospermes forment des saillies plus ou moins nombreuses, qui constituent autant de fausses cloisons. Le stigmate est sessile, rayonné ou simplement lobé. Le fruit est une capsule polysperme, s'ouviant au moyen de valves, ou 
par de simples trous qui se forment sous les lobes du stiginate. Elle a quelquefois la forme et la structure d'une silique. Les graines contiennent un petit embryon renfermé dans la partie inférieure d'un endosperme charnu.

Les Papavéracées sont des végétaux herbacés, souvent annuels, à feuilles alternes. Leurs tiges sont remplies d'un suc propre laiteux, tantôt blanc, tantôt jaune, qui est âcre et narcotique. Leurs fleurs sont en général grandes, solitaires, terminales ou diversement groupées.

\section{PAVOT. - PAPAVER. L. J.}

Calice disépale ; corolle tétrapétale régulière. Étamines trèsnombreuses. Stigmate sessile, pelté, discoïde, rayonnć : capsule ovoïde, uniloculaire, indćhiscente, ou s'ouvrant seulement par des trous pratiqués sous le stigmate; graines trc̀s-nombreuses attachées à des trophospermes saillans et lamelliformes.

Pavot sommitine. Papaver somniferum. L. Sp. 726 . Lamk. Illust. t. 45 I.

Part. usit. : le suc et les capsules. Nom pharm. : Opium thebaicuin, Capsulce papaveris. Noms vulg. : Opium, Tétes de pavot.

Cette espèce comprend le pavot blanc et le pavot noir des auteurs, qui ne sont que dcux variétćs. Sa racine est annuelle, blanchc et fusiforme; sa tige dressée, simple inférieurement, cylindrique, glabre, glauque, hautc de deux à trois pieds, portant des feuilles sessiles, semi-amplexicaules, glabres ct glauques, allongées, aignës, subcordiformes, incisées et dentées sur les bords.

Les fleurs sont solitaires à l'extrémité dcs rameaux, qu'elles termincnt. Elles sont penchécs avant leur ćpanonisscment. Le calicc cst composé dc deux sépalcs très-caducs, ovales, concaves, glabres et glauques. La corollc offrc quatrc grands pétalcs scssiles, inéombaus sur Ics còtés, plissés el comme chif- 
fonés avant leur évolution; ils sont à peu près orbiculaires, entiers, de couleur purpurine, avec une tache brunâtre à la base ou tout-à-fait blanes.

Les étamines sont extrêmement nombreuses (environ cent); insérćes souis l'ovaire, beaucoup plus conrtes que les pétales. Les filets sont subulés; les anthères allongées, elliptiques, comprimées. Le pistil est à peu près de la même hauteur que les étamines. L'ovaire est ovoïde, subglobuleux, stipilé, glabre et glau'qu̇e, à une seule loge, à la paroi interne de laquelle sont attachés dix trophosperınes lamelleux saillans, formant de fausses cloisous incomplètes, dont les faces sont recouvertes en entier par les nombreux ovules qui s'y attachent. Le sligmale est sessile, orbiculaire, aplati, étoilć, présentant dix à douze rayons, forInés chacun de deux lạmes appliquées l'unc contre l'autre par leur face interne, qui ést glandulaire.

La capsule est arrondie, globuleuse, couronnée par lestigmate persistant, s'ouvrant par aulant de petites soupapes placées au-dessous du stigmate, que celui-ci prćsente de lobes, ou resiant indéhiscente.

Les graines sont brunâtres, très-petites.

Ce pavot est originaire de la Perse et d'Orient. On le cultive dans tous, les jardins.

Propriétés et usages. Toutes ses parties répandent une odeur vireuse et désagréable. Quand on y fait une blessure, il en déenule un sue visqueux blanchâtre, qui ne tarde point à brunir.

C'cst en pratiquant en Orient, en Perse et dans l'Inde, des incisions a ses capsules encore vertes, qu'il en découle un suc, lequel, en s'ćpaississant, constitue l'opium. Celui que l'on retire par l'ineision'des eapsules est beaucoup plus pur que celui que l'on obtient par la décoction de ses feuilles ou des capsules ellesmêmes. C'est l'opium thébaique; il est plus rare dans le commerce que ce dernier, auquel les anciens donnaient le nom de meconüum. L'opium du commeree est en gâteanx de huit à seize onces, enveloppés dans des feuilles de pavot, de tabae ou de rumex. Il doit être sec, brillant dains sa eassure, qui est brune. Son odeur est forte et vireuse, sa savemr amère, nauséense et très-désagréable. Il est soluble dans l'eau, en laissant pour résidu quelques impuretés. Il se ramollit par la claleur; 
brûle et s'enflamme lorsçu'on le projette sur des cliardons ardens.

Les travaux des chimistes modernes, et en particulier ceux de MM. Derosne, Sertnerncr, Sćguin et Robiquet, ont jeté une vive lumière sur la nature des principes constituans de l'opium, qui est composé $: \mathrm{x}^{\circ}$ de morphine; $2^{\circ}$ d'acide méconique; $3^{\circ}$ de narcotine, ou principe cristallisable de Derosnc; $4^{\circ}$ d'une matière analogue au caoutchouc; $5^{\circ}$ de mucilage; $6^{\circ}$ de fécule; $7^{\circ}$ de résine; $8^{\circ}$ d'une huile fixe; $9^{\circ}$ d'une matic̀re végéto-animale; $10^{\circ}$ d'impuretís.

De ces divcrses substances, la morphine et la narcotine sont les seules qui méritent l'attention des thérapeutistes. La.première est une substance alcaline blanche, solide, inodore, d'une amertume extrême, cristallisant en parallélipipèdes, inflammable, presque insoluble dans l'eau, soluble ì chaud dans l'alcohol. Les acides faibles, et surtout l'acétique, la dissolvent facilement. Dissonte dans un acide ou dans une huile grasse, elle agit avec phus de force que l'ex trait d'opium, et peut comme lui occasioner la mort, quand la dose a été un peu considérable.

La narcotine n’cst nullement aicaline; clle cristallise en prismes droits à base rhomboïdale. Si on la chauffe elle se fond commc un corps gras; elle est inodore et insipide. Son action sur l'ćconomie animale est moins intense que celle de la inorphine. Quclques auteurs avaient pensé que l'action irritante de l'opium dépendait de ce principe. Les expériences récentes de M. Orfila sont contraires à cette assertion. Il a vu l'npium produire une excitation ćgalement vive, lorsqu'on l'avait privé de narcotinc.

L'opium est un des médicamens les plus précieux de la thérapentique. Il exerce un empire absolu sur le systeme ricrveux; mais sa médication esĩ une des plus compliquées et une des plus obscures de la thérapeutique. A faible dosc, telle qu'un demigrain ou un grain, il calme l'excitation, apaise la douleur, et. procurc sonvent un sommeil bienfaisant ct réparateur. A dosc plus élevée, tantôt il jette dans une stupeur plus on moins profonde, ou dans un état de narcotisme cffrayaut. Tantôt il exeite, il exaltc toutes les fonctions, et amc̀ne. une sorte de 
délire el d'aliénation mentale. Enfin, il peut occasioner la mort.

Cependant l'empire de l'habitude maîtrise facilement la violente action de l'opium. Les habitans de l'Inde ct de l'Orient cn prennent des quantitćs considérables sans en ĉtre incommodés. Tout le monde sait en effet que les Orientaux et les Pcrses mâchent presque continuellement de l'opium, et qu'ils le mélangent avec leurs sorbets et leurs autres breuvages. Chez eux, cette substance a perdu, par suite de l'habitude, son action stupéfiante. Ellelcs jette seulement dans un élat de langueur voluptueuse, si bien en harmonie avcc le caractère nonchalant des peuples de l'Orient. Quand ils veulent s'excitcr au combat, ils en prennent à la foiś unc plus grande quantité, et augmentent ainsi leur ardenr guerrière.

L'opium est utile dans ces maladies si variées connues sous le nom général de nérroses. Entre les mains du praticien habile, c'est un des médicamens les plus puissans. Dernière ressource dc l'art, il calme les douleurs dont il ne peut tarir la source, et rend moins pénibles les dcrniers instans d'unc existence qu'il n'est plus au pouvoir du médecin de prolonger.

Ce mćdicament entre dans une foule de préparations pharmacentiques, auxquelles il communique ses propriétés puissantes. Telles sont : les pilules de cynoglosse, la thériaque, le laudanum liquide de Sydeuham, le sirop d'opium', les gouttes on laudanum de Rousseau, etc., etc.

L'extrait d'opium s'administre à la dose d'un quart de grain à un grain, que l'on pcut graduellement augmenter.

Les capsules sèchies du pavot blanc sont également employées en médecinc. La décoction que l'on prépare avec elles est calmante et anodinc. On l'emploie pour faire des lavemens, des lotions ou des cataplasmes, en l'ajoutant à la farine de graine dé lin.'

Les graincs du pavot ne jouissent pas de la proprićté narcotiquc, qui est si développéc dans les autres parties de celte piante. Elles contiennent unc très-grande quantité d'lunile grasse, que l'on en retire par le moyen de la presse, et que l'on brîle, sous le nom d'hnilc 'd'oillette, ou mieux olictte', (oleun on oleolum, petitc huilc).

On a cherché, dans ces dernicrs temps, à retircr des pavots 
cultivés dans nos champs une sor!̣ d'opium propre à remplaeer celui qui nous est apporté d'Orient. On a en effet obtenu un extrait analogue à l'opium, mais qui est bien loin de posséder des propriétés aussi sûres et aussi développćes, en sorte que son usage a été abandonné.

\section{Pavot coquelicot. Papaver rhaeas. L. Sp. 726. Curt. Fl. lond. 3. t. 32 .}

Part. usit.: les pétales. Nom pharm. : Rhceadis flores.

Plante annuelle, excessivement commune parmi les moissons, surtout aux environs de Paris. Tige dressée, rameuse, haulc d'un pied, hispide. Feuilles alternes, rudes, profondémẹnt pinnatifides, à lobes allongés, irrégulièrement dentés et aigus. Fleurs rouges, très-grandes au sommet des rameaux. Sépales eonvexes et hispides en dehors; les quatre pćtales sont fort grands, plissés, entiers ou irrégulièrement erénelés sur leur eontour. La capsule est obovoïde, glabre, couronnée par un stigmate étoilé, à dix ou douze lobes, quelquefois plus ou moins.

Le eoquelieot fleurit en juin et juillet. $\odot$

Propriétes et usages. Les pétales sont la seule partic de ejtte plante qui soit employée. Ils sont adoueissans et légèrement ealmans. Ils entrent dans les espèces désignées sous le nom de fleurs pectorales. On les emploie en infusion, dans les différens eatarrhes pulmonaires peu intenises.

\section{CHÉLIDOINE. - CHELIDONIUM. J.}

Calice disépale; corolle tétrapétale; étamines nombreuses; eapsule linéaire, siliquiforme, uniloeulaire, bivalve, lerninée par un stigmate bilobé; graines recouvertes supérieurement d'une erête glandulaire (arille).

Chélidoine grande téchaine. Chelidonium majus. L. Sp. 723. Blackw. t. 9 I.

Celte plante vivaee croit sur lcs, vieux murs, au milieu des déeombres. Sa tige est cylindrique, ramcusc, cassante, haule l'un à denx pieds, rougeâtre et très-velue dans sit partie infé- 
ricure. Les feuilles sont alternes, pétiolées, pinnatifides, à lobes arrondis, ineisés et dentés; ees feuilles, ainsi que la tige, contiennent en abondanee un suc laiteux et jaunâtre, qui s'en écoule lorsqu'on les entame. Les fleurs sont jaunes, rassembiées plusieurs ensemble à la partie supérieure des ramitieations de la tige. Les deux sépales sont glabres; les quatre pétales sont entiers. La capsule est linéaire, allongée, un peu toruleuse, et ressemble à une silique. La ehélidoine fleurit pendant une grande partie de la belle saison. $\%$

Propricétés et usages. Le suc laitenx et jaunâtre que contiennent les différentes parties de la ehélidoine est d'une extrême âcreté. Il peut même, lorsqu'on l'administre cn assez. grande quantité, ou qu'on l'applique sur le tissu cellulaire dénudé, causer la mort par la violence de l'inflammation qu'il y oecasione. Aussi M. le professeur Orfila range-t-il la chélidoine parmi les poisons irritans. Cependant on faisait autrefois usage, beaucoup plus fréquemment qu'aujourd'hui, de la racine de chćlidoine ou grande éelaire : le sue qu'elle renferme est un purgatif drastique très-violent, dont on a recommandé l'usage dans les hydropisies, l'ictère, et même les fièvres intermittentes. On a même conseillć d'instiller, entre le globe de l'œil et les paupières, quelques gouttes du sue de chẹlidoine, pour faire disparaitre les taches de la cornée. Ce moyen nous paraît des plus dangereux, à cause de l'inflammation violente qu'il peut développer.

Aujourd'hui on n'emploie plus guère le suc de grande chélidoine, que pour brîler les poireaux ou verrues qui se développent dans certaines parties du corps, particulièrement sur le dos et dans la paume de la main.

\section{Propriétés et usages des Papaverracées.}

Le suc laiteux blanc ou jaunâtre qui découle des différentes partics des plantes de cette famille, leur odeur vireuse et désagréable, doivcut faire soupçonner en elles des propriétés délétères et les reudre suspectes. En effet, ec suc plus ou moins âcre est doué de propriétés fort énergiques, dont la thérapeutique a su tirer un parli avantagenx. Ainsi, dans les pavots, il 
est essentiellement nareotique, et c'est d'une espèce de ee genre, du pavot somnifère, que l'on retire en Asie, le sue concret, si eonnu sous nom d'opium. Celle substance existe même, quoiqu'avec des propriétés moins puissantes, dans nos pavots eultivés. Dans la ehélidoine, au eontraire, ee-sue est jaune et très-eaustique. Appliqué sur la peau, il en détermine la rubéfaetion, et'son usage interne peut même occasioner la mort, en agissant à la manière des poisons irritans. Dans la sunguinaire du Canada (sanguinaria canadensis), le sue renfermé dans la raeine la rend émétique et drastique.

Ces qualités plus ou moins délétères des Papavéracées n'existent point dans leurs graines, qui sont remarquables par l'huile grasse qu'elles fournissent.

En général, les plantes de la famille des Papavéracées contiennent un sue laiteux et âcre, qui leur donne des propriétés très-aetives, et doit en rendre l'usage suspecl, et même sourent dangereux.

S Ó IXANTE-QUINZIÈME FAMILLE.

\section{FUMARIACÉES. - FUMARIACEAE.}

Calice disépale, très-petit, caduc; corolle irrégulière éperonnée, composée de quatre pétales inégaux, souvent réunis et soudés ensemble, de manière à représenter une corolle monopétale. Étamines, au nombre de six, diadelphes, c'est-à-dire réunis trois par trois en deux faisceaux: anthère centrale à deux loges; anthères latérales à une seule loge. L'ovaire est simple, le style grêle et filiforme; le stigmate bilamellé. Le fruit est tantốt une capsule siliquiforme, bivalve, tantôt un simple akène. Les graines sont arillées.

Les Fumeterres sont des plantes herbacées, annuelles ou vivaces, remplies d'un suc amer, aqueux, mais non laiteux.

Cette fanille, formée du seul genre fumaria, L., que les modernes ont divisé en un grand nombre de genres 
distincts, était réunic autrefois avec les Papavéracées, dont elle se rapproche en effet beaucoup, n'en différant essentiellement que par ses étamines diadelphes, sa corolle toujours irrégulière, et le suc aqueux et non laiteux de ses tiges.

\section{FUMETERRE.-FUMARIA. Tourn. D. C.}

Le ealice est très-petit : les trois pétales supérieurs sont souvent réunis, et forment un éperon à leur base; l'inférieur plus étroit, est libre. Le fruit est un akène globuleux.

Fumeterre officinale Fumaria officinalis. L. Sp. 984 . Blackw. Herb. t. 36 .

Part. usit.: toute la plante. Vulg. : Fiel de terre.

C'est une plante annuelle dont la tige est lierbacée, rameuse, coucliée, glabre, glauque, anguleuse. Elle porte des feuilles alternes, bipinnées, à folioles ćcartées, dćeoupées en lobes étroits et acuminés. Ses fleurs sont purpurines, eourtement pćdonculées (une petite braetée lancéolée cxiste à la base de chaque pédoncule), disposćes en un ćpi long et lâche. Leur calice est oblique, eomposé de deux petites folioles ovales, aiguc̈s, ćrodées dans leur eontour, attachées par leur partie moyenne et interne:

La corolle est irrégulière, eomposée de quatre pétalcs inégaux. Le supćrieur, qui est le plus grand, s'allonge à sa partie inféricure en un éperon obtus, court et rceourbé; il devicnt ensuite plane, se rétréeit, ct forme une espèce de disque arrondi, obtus, à bords un peu relevés, marqué d'unc tache verte en dessus, légèrement ereusé en gouttière cn dessous.

L'inférieur est spathulć; long, et étroit à sá basc. Les deux latéraux, qui sont semblables, d'abord onguieulís à la basc, sont ovales, allongćs, obtus, terminés subitement par une petile pointe; leur face extérieure offre une crête longitudinalc, plus saillante vers le sommet.

Étamines hypogynes au nombre de six, réunies par lcur's filcts en deux faisccaux qui supportent elıaeun trois anthères, 
celle du milieu à deux loges, les deux latćrales uniloculaires. L'ovaire est libre, ovoïde, uniloculaire, contenant un seul ovule renver'sé. Le style est filiforme, décliné, articulé avec l'ovaire, caduc, terminé par un stigmate simple capitulć.

Le fruit est un akc̀ne ovoïde, un peu comprimé d'avant en arrière, glabre.

La fumeterre est très-eommune dans les lieux cultivés, les champs, les vignes, les jardins. $\odot$

Propriétés et usages. On emploie la plante tout entière. Són annertume est très-intcnse et mélangée d'une certaine quantité de mueilage. La fumeterre est fort usitée : sa décoetion ê̂le sue retiré de son herbe fraiehe sont toniques et employés dans les affeetions scorbutiques, les éruptions chroniques de la peau, telles que les dartres, la gale, et toutes les fois qu'il faut réveiller l'aetion de l'estomae, dans la convalescence des fic̀vres de long cours, ete.

Le sue s'administre depuis une jusqu'à quatre onces : on fait une déeoction avee une poignće de fumeterre fraíchc et une chopine d'eau ou davantảge.

\section{Propriciés et usagnes des Fumariacées.}

Aueune des plantes qui appartiennent à eette famille n'est vénéneuse : toutes, au contraire, paraissent douées d'une vertu tonique, qui est due au suc amer contenu dans leurs tiges et leurs feuilles. On peut indifféremment employer les fumaria officinalis, fumaria media, fumaria spicata, ete. Toutes jouissent dcs mêmes proprićtés.

On met aussi quclquefois en usage, mais plus rarement, la fumeterre bulbeuse (corydalis bulbosa); mais elle est moins amère et moins active. Elle se distinguc par sa racine bulbeuse, ses fleur's jauncs et ses fruits allongés et polyspermes.

SOIXANTE-SEIZIE் E FAMILLE.

CRUCIFERES. - CRUCIFERAE.

Les Crucifères sont des végétaux herbacés, à feuilles alternes, dont les fleurs hermaphrodites sont composées d'un calice tétrasépale caduc, ayant deux des sépales 
quelquefois bossus à la base; de quatre pétales onguiculés et disposés en croix; de six étamines, dont deux plus petites et plus inférieures, et quatre plus grandes rapprochées en deux paires opposées; à la base des étamines, sur le réceptacle, sont plusieurs glandes, ordinairement au nombre de quatre, deux sur lesquelles sont insérées les étamines les plus courtes, deux entre les étamines les plus grandes. L'ovaire est le plus souvent à deux loges, renfermant plusieurs ovules, terminé par un style court, au sommet duquel est un stignate simple nu bilobé.

Le fruit est ou allongé, biloculaire, renfermant un grand nombre de graines attachées à deux trophospermes suturaux, s'ouvrant ordinairement en deux valves, rarement uniloculaire et indéhiscent; ou bien il est court; arrondi, elliptique ou anguleux: c'est-à-dire que c'est une silique ou une silicule.

Les graines renferment un embryon épispermique, immédiatement recouvert par le tégument propre de la graine.

Cette famille est sans contredit l'une des plus naturelles du règne végétal, et une de celles dont les caractères sont le plus tranchés. Elle forme à elle seule la tétradyhamie de Linné, ou quinzième classe du système sexuel.

Les travaux récens de M. Rob. Brown, et surtout ceux de M. de Candolle, qui a traité les Crucifères dans le second volume de son Systema vegetabilium, ont donné les notions les plus précises sur la structure des plantes de cette famille et la circonscription des différens genres qui la composent. Mais le grand nombre de divisions nouvelles quils ont établies parmi les genres, nous empêchent d'adopter leur travail. Notre ouvrage étant uniquement destiné à bien faire connaître les plantes officinales, nous ne croyons pas devoir adopter ici des 
changemens qui nous forceraient à substituer des noms nouveaux à des noms anciens et généralement connus.

Nous diviserons les Crucifères en deux sections, suivant qu'elles ont pour fruit une silique ou une silicule.

Nota. Les propriétés médicales de la plupart des Crucifères étant les mêmes, nous ne ferons que les indiquer d'une manière extrêmement brève, sans entrer dans des détails que nous serions obligés de répéter pour chacune d'elles.

P R II I RE SECT ION.

I. Crucifères siliqueuses, ou Sisymbríes.

SIS YMBRE. - SI SYMBRIUM. L. J.

Calice étalé ou connivent; pélales étalés et lćgèrement onguiculés. Silique presque cylindrique, longue, terminée en pointe, s'ouvrant en deux valves et contenant des graines globuleuses.

Sisymbre cresson de fontaine. Sisymbrium nasturtium, L. Sp. 9 I6. Flor. dan. t. 690.

Part. usit. : toute la plante. Nom pharm. : Nasturtium aquaticum.

Racine vivace, donnant naissanee à des tiges rameuses, rampantes, étalées, redressées aux extrémités des rameaux, longues d'un pied et plus, cylindriques, glabres. Feuilles alternes, imparipinnćes, glabres, à folioles ovales, arrondies, un peu inégales, la terminale plus grande, presque cordiforme : les feuilles 'les plus supérieures de la tige sont simples, cordiformes, pétiolées.

Fleurs blanches, disposées en épis lâches à la partie supéricure des rameaux; chaqua flcur est portée sur un pédoneule d'environ trois ou quatre lignes. Le calicc est formé de quatre sépales ovales, obtus, concaves, dressés. Les quatre pétales sont égaux, leurs onglets dressés, leur limbe éralé, arrondi, obtus, entier. Il n'y a que deux petiles glandes à la base des 
ćtamines les plus courtes. L'ovaire est allongć, surmonté d'un style très-court, gros, plus épais à sa partie supérieure, sur laquelle est placé un stigmate bilobć.

La silique est à peu près cylindrique, courte, ayant quatreà cinq lignes de longueur, terminée à son sommet par une pointe très-obtuse.

Le cresson de fontaine croit sur le bord des ruisseaux où l'eau cst courante. Il fleurit en juin. $F$

Propriétésetusages.C'est assurément la plante de cette famille la plus abondamment employée; on s'en sert aussi fréquemment comme aliment que comme médicament. Ce sont les feuilles que l'on met particulièrement en usage: elles sont fraiches, piquantes et légèrement amères. On les mange sans préparation, ou simplement assaisonnćes avec le vinaigre. On en exprime le sue que l'on clarifie par le repos, et que l'on donne à la dose de dcux à quatre onces.

Le cresson est un des meilleurs antiscorbutiques, à cause de la facilité que l'on a de pouvoir se le procurer frais pendant la plus grande partie de l'année. Il entre dans le sirop'et le vin antiscorbutiques.

Stsymbre officinal. Sisjmbrium officinale. D. C. Fl. fip. ed. 3. vol. 4. p. $67^{2}$. Erysimum officinale. L. Sp. 922. Blackw. t. 28 .

\section{Vulgaircment: Velur ou Herbe aux chantres.}

Sa racine annuelle porte une tige dresséc, simple inférieurement, ramcuse à sa partie supérieure, cylindrique, pubescente, effilce, haute d'environ deux pieds. Feuilles alternes; les inféricures presquc lyrécs, pubescentes; lcs smpérieures hastécs, irrégulièrement dentées, courtemcnt pétiolées.

Fleurs jaunes, petites, presque sessiles, disposées en longs épis cffilés et divariqués à l'extrémité des rameaux. Calicc de quatrc sépales demi-ouvert, pubescent; corolle cruciforme. pétales entiers, spathulés, moitié plus longs que les sépalcs; étamines tétradynames, un peu plus longues que la corolle; pistil plus court que les étamines; stigmate sessile, capitulé. 
Siliques pubescentes, dressées et appliquées eontre l'axe de la tige, un peu pédonculées, anguleuses, amineies insensiblement en pointe de la base vers le sommet, s'ouvrant'en deux valves; ayar: deux loges qui eontiennent ehaeune environ dix graines globuleuses.

Cette plante eroît dans les lieux secs et stériles, sur le bord des chemins, dans les environs de Paris. $\odot$

Propriétés et usages. Lcs feuilles du vélar ne sont ni âcres ni piquantes comme celles de la plupart des autres Civeiferes; elles sont un peu acerbes. On les emploie comme légèrement toniques, en infusion théiforme dans le eatarrhe pulmonaire ehronique, etc.

Cette crueifère jouit, parmi les chanteurs, d'une très-grande réputation, comme propre à dissiper l'enrouement; de là son nom vulgaire d'Herbe aux chantres. Le sirop d'erysimum, que l'on prépare avee eette plante, s'administre dans les mêmes circonstances.

\section{-VÉLAR. - ERYSIMUM. L. J.}

Ce genre diffère spécialentent du préećdent par sa silique, qui est tétragonc.

Vélar de Salnte-Barbe. Erysimum babarea. L. Sp. 922.

Vulgairement : Herbe au charpentier; Herbe de Ste-Barbe, etc.

Racine bisannuelle, fibreuse, blanehe et rameuse; tigc dressée, simple iuférieurement, rameuse dans sa parlie supérieurc, ct comme panieulée, marquée de canelures très-saillanies, entièrement glabre, ainsi que les autres parties de la plante.

Les feuilles sont sessiles, pinnatifides et lyrées, c'est-à-dire que le lobe terminal est beaucoup plus grand, arrondi et obtus; les latéraux sont elliptiques, obtus, presque enticrs. Les feuilles inférieures sont ordinairement d'une teintc rouge plus ou moins foncée.

Les fleurs sont jaunes, petites, courtement pédonculées, disposćes en épis allongés à la partie supéricure des ramifications de la tige. 
Le calice se compose de quatre sćpales dressés, jaunåtrcs, caducs.

Ises pétales ont leur onglet, de la même hauteur que le calice; leur limbe est obovale, obtus.

A la base des filets des étamines on observe quatre petites glandes verdâtres; deux cn dehors des deux paires des étamines les plus longues, deux plus larges, sur lesquelles sont implantćes les deux petites ćtamines.

La silique est tétragone, allongée. Cette espèce n'est pas rare dans les lieux humides et sur le bord des ruisseaux.

Propriélés et usages. Les feuilles sont lègèrement âcres; leur saveur est très-analogue à cclle du crcsson. On les emploie également comme antiscorbutiques.

Vélar aluiarre. Erysimum alliaria. L. Sp. 922. Bull. t. 338 .

Hesperis alliaria. Lamk. Alliaria officinalis. D. C. syst.

L'alliaire est une plante annuelle, hautc d'environ un ou deux pieds; sa tige est dressće, simple à la partie inférieure, cylindrique, poilue à la base, glabre et légèrement glauque vers sa partie supérieure.

Les feuilles sont cordiformcs arrondies, les inférieures obtuses, les supérieures aiguc̈s, offrant sur leurs bords de grandes dentelures. Elles sont mollcs, exhalent une odeur d'ail; lorsqu'on les froisse entre les doigts; lcur pétiole, qui cst canaliculé, long de trois à quatre pouces pour les feuilles inféricures, est très-court dans les feuilles supérieures, qui sont presque sessiles.

Les fleurs sont blanches, disposćes en ćpis très-lâches anx extrćmités des ramifications de la tige; elles sont presque scssiles. Leur calice cst formć de quatrc sćpalcs à moitić ouvcrts, blancs, très-cadncs. La corolle est dcux fois plus grande quc lc calice; lcs pétales sont un pcu ćtalćs à leur partie supéricure. Ils sont elliptiques, obtus, entiers, rétrécis en ouglet à lcur partie inféricurc.

Lcs étamincs sont incluses; à la basc de lcurs filcts on trouve quatre glandes vcrtes, unc cntre chaquc pairc des grandes 
étaınines, deux sur chaeune desquelles sont implantées les deux petites étumines. Le pistil est plus eourt que les élamines; l'ovaire est pyramidal, tétragonc, surmonté d'un style gros, eylindrique, très-court, que termine un stigmate très-petit, couvexe et glanduleux.

La silique est longue et grêle, tétragone, obtuse, striée longitudinalement sur ses faces.

Cette espèce croît dans les bois couverts et ombragés, le long des murailles, aux environs de Paris. Ellc fleurit en mai; ses fruits sont mùrs en juin et jnillet. (n)

Propriétés et usages. Toute la plante, mais les graines surtout, exhalent une odeur forte et alliacée. Autrefois on en faisait usage pour assaisonner certains alimens. La saveur des feuilles est amère ct âere, et annonce dans l'alliaire des propriétés assez énergiques. Cependant on en fait peu usage, quoiqu'elle mérite d'êtrc employée.

\section{CHOU. - BRASSICA. L. J.}

Caliee eonnivent, bossu à sa base; étamines accompaguées de quatre glandes à leur basc. Silique cylindrique, torulense, terminée par un bee plus ou moins allongé, s'ouvrant en deux valves.

\section{Grou navet. Brassica napus. L. Sp. 93 r.}

Sa racine est eharnue, blanehe, d'une forme très-variée, tantôt napiforme, tantôt plus ou moins allongée. Sa tigc est rameuse, dressée, cylindrique, glauque. Elle porte des feuilles sessiles, semi-amplexicaules, cordiformes, lancéolées, charnues et glauques; les feuilles radicales sont lyrées ct eonvertes de poils très-rudes.

Flenrs jaunes, en épis paniculés aux extrémitćs des rımeaux. Chaque fleur est pédoneulée, assez petite; le calice est à moitié ouvert, eomposé de quatre sépalcs elliptiques, lancéolés, caducs. Les pétales ont l'onglet dressé, à peu près de la hauteur du ealice; le limbe étalé, arrondi, cntier.

A la base des six étamines tétradynames, sont quatrc glandes vertes, dont deux plus petites, en dehors et cntrc les deux paires d'étamines plus longues, deux plus grosses, sur lesquelles 
sont inplantées les dcux étamincs plus courtes. L'ovaire est linéairc, comprimé, surmonté d'un stylc cylindrique que terminc un stigmate capilulé, glanduleux.

La silique est allonge, presque cylindrique, glabre, tornleuso et bosselćc, terminće à son soinmet par une pointc allongée, un peu ensiforme, et striée longitudinairement.

Le navel et ses varićtés sont cilltivés dans les jardins potagers.

Propriétés et usages. On n'emploie plus aujourd'hui le navet que comme alimcnt. Il est très-usité, surtout dans la classe indigente du peuple. C'est une substance alimentaire peu nourrissante, assez saine, mais qui a l'inconvénien de développer beaucoup de gaz dans l'estomac et les intestins.

Les graines de la navette, variétć du brassica napus, sont oléagineuses, on en retire par expression une liuile abondante, connue sous le nom d'huile de navette. Elle est employée pour I'usage des lampes.

Chou cultiví. Brassica oleracea. L. Sp. $9^{32}$.

Sa racine est bisannuelle, très-raremcnt vivace par suite de la culture, pivotante, presque simple, offrant de petites fibrilles nombreuses. La tige est dressće, glabre ct glauque, ainsi que toutes les autres parties de la plante; elle est rameuse à sa partie supérieure, et haute d'environ deux à trois pieds.

Les feuilles sont grandes, épaisses et charnues, scssiles; les inférieures, ovales, arrondies, très-obtuses, ondulcuses et bosselées; les supérieures sont ovales, allongées, inégalement denticulćes sur leurs bords: toutes sont trc̀s. glauques.

Lcs fleurs sont jaunes, assez grandes, et forment de longs épis lâches à l'extrémité des rameaux. Chaque fleur est portée sur un pédoncule d'environ un demi-pouce dc lougueur. Le calice est formé de quatrc sépales uressés, jaunâlres, dont deux sont un peu bossus a leur base; ils sont caducs. Les quatrc pélalcs ont un onglet dressć, de la longueur des sépales, un limbe étalć, arrondi, cntier.

La silique est allongée, presquc cylindriq̨uc, un peiı foı 11 leuse, tcrmince par une pointe on bec pen comprimé. 
Le chou, qui est originaire de l'Europe, est eultivé dans tous les jardins potagers. Le nombre de ses varićtés est trèsconsidérable. Cependant on peut les rapporter à einq raees principales, qui sont :

$I^{\circ}$ Le chou cavalier ou chou vert. Ses feuilles sont étalées, ne formant pas de tête. Elles sont quelquefois dćcoupées ct frangées sur les bords, suivant les variétés.

$2^{\circ}$ Le chou frisé ou chou de Milan. Scs feuilles sont réunies en tête dans les jeunes pieds; elles finissent par s'étaler, et sont. toujours crépues et bullées, caractère qui distingue cette raee de la précédente.

$3^{\circ}$ Le chou porrmé ou chou cabu est faeile à reconnaître à ses feuilles très-rapprochćes et très-serrćes les unes contre les autrcs, et formant une tête plus ou moins volumineuse. C'est une des meilleures raccs, parce que les feuilles intćrieures étant étiolées, devienncnt blanches et beaucoup plus tendres. Le chou rouge appartient surtout à eette variété.

$4^{\circ}$ Le chou-rave se distingue à sa tige, qui est renflée audessus du collet de la racine, et qui forme une tête charnue, de la grosseur des deux noings, partie qui seule est employée a la nourriture de l'homme.

$5^{\circ}$ Enfin, une dernière race est eelle que l'on connait sous les noms de choux-fleurs et de broccolis. Ici les pédoncules des fleurs s'épaississent, s'entregreffent, et sont chargés d'une multitude de fleurs qui a vortent et restent rudimentaires; clles sont rapprochćes et forment une sorte de coryıbe régulier.

Le broceoli, se distingue du chou-fleur par ses pédoneules moins épais, plus allongés, et non grouppés en eorymbe, elt sorte qu'ils ressemblent, en quelque sorte, à des jeunes turions d'asperge.

Proprićtés et usages. Les a neiens faisaient le plus grand cas du chou, auquel ils attribuaient des proprićtés merveilleuses, et l'employaient pour combattre une foule de maladics. Mais aujourd'hui ses usages sont restreints à l'ćconomie domestique. C'est un des alimens les plus fréquemment usilćs, surtout parmi les habitans des campagnes, dans le nord de la France et de la plus grande partie de l'Europe.

Les Allemands lui font subir une préparation qui lc rend 
plus faeile à digcérer et à eonserver. $\Lambda$ près l'avoir coupé menu, ils le mettent dans des tonnes avee du sel et quelques aromates, et le laissent subir un eertain degré de fermentation : ils en forment ainsi ce que l'on désigne en Franee sous le nom de chou-croúte ou sauer-kraut des Allemands. Cet aliment est fort utile pour les voyages de long cours, en ce qu'il se eonserve faeilement et qu'il agit aussi eomme antiseorbutique.

Quant aux ehoux-fleurs et aux broeeolis, ils forment un aliment reeherehé et d'une saveur très-agréable.

On a attribuć à la variété du chou à feuilles rouges de grandes propriétés médieales. Elle est suerée et très-mueilagineuse, et eonvient dans les inflammations ehroniques des organes respiratoires. On l'administre sous forme de déeoction ou de sirop. Le vulgaire regarde le ehou rouge eomme une sorte de spéeifique eontre la phthisie pulmonaire.

\section{Ghou des champs. Brassica campestris. L. Sp. 93 .}

\section{Vulgairement : Colza ou Colsat.}

Cette espèee est annuelle; sa raeine est fusiforme, quelquefois renflée; sa tige dressée, haute d'un pied à un pied et demi, cylindrique et glabre; ses feuilles inférieures sont lyrées et sinueuses, glauques, couvertes de poils rudes sur les nervures de sa faee inférieure; les feuilles supérieures sont sessiles, amplexieaules, glabres et entières. Les fleurs sont jaunes; leś siliques dressées, cylindriques, un peu anguleuses, eontenant plusieurs graines globuleuses et brunes.

Cette plante eroît spontanément dans les ehamps d'une grande partie de l'Europe : on l'y eultive aussi très-abondamment. Elle diffère du ehou eultivé par ses feuilles lyrées et hispides à leur face inférieure. Elle présente plusieurs variétés. Dans l'une d'elles, la racine est renflée, eharnue, jaunâtre extérieurement, et porte le nom de rutabaga. On l'emploie eomme aliment.

Le colza est abondamment cultivé dans les ehamps du nord de la Franee. On retire de ses graines une huile grasse, conmue sous le nom d'huile de navette ou de eolza, et qui est fort eurployée dans les arts et l'économie domestique. 


\section{ROQUE'T'TE. - ERUCA. 'Tournef. Rich.}

Ce genre, que Linné avait réuni au précćdent, s'en distingue par son style plane, ensiforme, et à peu près de la longueur de la silique, qui cst bivalve.

RoQuetre cultivée. Eruca sativa. Lamkc. Fl. fr. 2. p. 496 .

Brassica eruca. L. Sp. 932. Blackw. t. 242.

Racine annuelle, tige dressée, presque simple inférieurement, cylindrique, un peu pubescente, haute, d'un à deux picds.

Feuilles lyrées, presque glabres, un peu charnues, répandant, surtout quand on les froisse entre les doigts, une odeur forte et désagréable.

Fleurs jaunâtres, disposées en 'ćpis lâches à la partie supérieure des rameaux, agréablement odorantes : chaque fleur est dressće, courtement pédonculée. Le calice est formé de quatre sćpales dressés et connivens, dont deux sont lćgèrement bossus à la base. Les 'quatre pétales sont longuement onguiculés, les onglets dressés, le limbe ćtalé, d'un jaune pâle avec des veines rougeâtres, anastomosées. A la base des six élamines tétradynames sont quattre petites glandcs verdâtres et nectarifères; deux très-petites, en dehors des grandes étamines; deux plus larges, en dedans des étamines plus courtes. La silique est dressée, allongée, comprimée, glabre, terininée supérieurement par un appendice lamelliforme, presque de la même longueur qu'ellc, et tranchant des deux côtés : cette silique a deux loges qui contiennent chacune plusieurs graines; elle s'ouvre cn deux valves beaucoup plus courtes que la cloison, avec laquelle se continue l'appendice lamelleux.

Elle croit dans les champs cultivćs de la France. (C)

Proprićtés et usages. Toute la plante exhale une odeur forte et désagréable, unc saveur âcre et amère. C'est un stimulant assez énergique, que l'on pcut employer dans les mèmes circonstances que les autres antiscorbutiqucs. Dans plnsieurs provinces, les feuilles servent d'assaisonncment. 


\section{R AIFOR'I. - RAPHANUS. I.J.}

Calice connivent : étamines accompagnées de quatre glandes : siliques coniques, torulcuses, indćhiscentcs, comme spongieuses intérieurement.

RaIfont cultivé. Raphanus sativuls L. Sp. 935. Lamkc. Illust. t. 566 .

Vulgairement: Radis, Radis noir, Petive rave.

Sa racine est clıaruuc, tantôt arrondie, napiforme, tantôt allongée etterninéc par une longue pointe à sa partie inférieure; d'une couleur rouge, rose, noire ou blanche à l'extérieur. Sa tige cst dressée, rameuse, cylindrique, glauque, présentant quelques poils rudes et recourbés en dessous. Les feuilles sont très-profondément pinnatifidcs et lyrées, très-rudes au toucher.

Les fleurs sont roses, assez petites, pédonculćes, formant de longs épis lâches à la partie supérieure des rameaux. Le calice est composé de quatrc sépales dressés, offrant quelques poils supérieurement. Les quatre pétales sont longuement onguiculés, les onglets étroiłs ct drcssés, le limbe étalé, obovale, obtus, entier; quatrc glandes sont placées à la base des étamines tétradynames.

' L'ovaire est très-grêlc, terminé insensiblement par un stylc assez long, au sommet duquel se trouve un stigmate capitulé et glandulaire. La silique est conique, renflée $\mathrm{cl}$ bosselée à, la base, terminée en pointe allongée à son sommet, spongieusc à son intérieur, renfermant des graines qui paraissent cliacune contenue dans unc cavité particulière. Cette siliqque reste indéliscente.

Le raifort est, à ce que l'on pense généralenıcnt, originaire de la Cline et de l'Asic méridionale. D'autres lc croient provenu de l'Suropic australe: il cst depris des siècles naturalisé dans toutes les parties de l'Enropc. $\odot$

Cefte espècc présentc trois varićtés principales, savoir :

$x^{\circ}$ Le rudis. Sa rncine cst globuleuse on napiforme, tendrc. charnue, d’une eoulcur rosc ou blanche à l'cxtéricur;: 
$2^{\circ}$ La petile rave se distingue par sa racine allongće, cylinHrique on fusiformc; présentant lcs mêmes nuances que lia précédente.

$3^{\circ}$ Lc raclis noir, que l'on désigne encore sous le nom de gros raclis, et de raifort des Parisiens, est de la grosseur du poing. Son épiderme est noir et rugueux; sa chair est dure ct extrêmernent piquante. Quelques auteurs en ont fait une espèce distincte sous lc nom de raphanus niger.

Les racines de ces trois variétćs sont servies sur nos tables; les deux premicies surtont, dont la chair est moins dure et moins âcre. Le radis noir, au contraire, cst cxcessivement piquant, et doit ĉtre considérć comme un très-puissant stimulant. Les graines de cctte espèce fournissent aussi une grande quan-
lité d'lluile.

$$
\text { MOUTARDE. - SINAPIS. L. J. }
$$

Calicc étalé, pélales dressés; siliques terminées par une pointe plane on carrée.

Ce genre diffẻre surtout de la roquetle, par son calicc élalé. Moutande noire. Sinapis nigra. I. Sp. 933. Blackw.

$$
\text { t. } 416 .
$$

Racinc annuelle, domnant maissance à une tige dressée, raglabre.

Feuilles grandes, sessiles, lyrćes, glabres, un peu ćpaisses, les supérieures entières, lancéolées, aiguè̀s.

Flcurs jannes, petites, pćdonculées, disposécs en longs épis - à la partie supéricure des divisions de la tige.

Siliques grêles, dressées et a p’pliqućes contre la tige, glabres, ićtragonales, un peu toruleuses, terminécs par une pointe courte; ses graines sont brunâtres.

Cette espéce croît dans les licux un peł humides, dans les décombres, aux environs de Paris, dans les îles de la Marne : ellc fleurit en juillet et août.

Proprićtés ct usages. On emploie plus particuliercment les graines, connues sous le nom de graines de monturle usuclle. ou scincrié noir. Elles sont très-âcres et irritantes; rédnites on 
poudre, délayées dans du vinaigre, et unies à unc petite quantité de farinc de lin, elles forment les sinapismes, sorte de cataplasmes irritans, qui, appliqués pcndant quelques heures sur la surface du eorps, y déterminent la rubéfaction et même la vésication de la peau.

La farine de ces graines forme la base de la moutarde, assaisonnement stimulant, d'un usage si généralement répandu, et avec lequel ón peut préparer directement les sinapismes on les pédiluves sinapisés.

Les graines des autres espèces de ce genre sont également âcres et irritantes, mais à un plus faible degré.

\section{CARDAMIN E. - CARDAMINE. L. J.}

Caliee connivent; silique cylindrique, s'ouvrant en deux valves avee élasticitć.

Cardamine des prés. Cardamine pratensis. L. Sp. 9 I5. Vulgairement: Cresson des prés.

De sa racine, qui est vivace, s'élève une tige dressće, cylindrique, simple, glabrc, haute d'elıiroı un pied. Les feuilles radieales sont composées de folioles arrondies, obtuscs, angulcuses. Celles de la tige sont alternes, sessiles, imparipiunćes, ayant les folioles petites, allongées et étroites.

Fleurs en épi lâche à l'extrémitć de la tige, d'un blane rosé; chaque fleur est pédonculée et dressée; leur calice se compose de qualre sépales ovales, obtus, dressés, membraneux sur leurs bords, coneaves, derux opposés offrant à leur base un renflement plus rcmarquable. Les pétales 'sont trois fois plus longs que les sépales, ovales, arrondis, légèrement émarginés; étamines plus courtes quc la corolle, aecompagnces de quatre petiles glandes verdâtres, opposécs, en for'mc de godets.

Pistil de la grandeur des étamines; stigmate simple ct capitulé.

Silique allongćc, glabre, légèrement comprimée, s'ourrant avcc élasticité en dcux valves qui se roulent de la partie infesrieurc vers la supéricure. 
Cette plante est commune dans les prés humides, où elle fleurit au printemps et en été. $\mathcal{F}$

Propriétés et usages. Les feuilles de la cardamine ont une saveur analogue à celle du cresson de fontaine. Dans lc nord de l'Europe, on les emploie absolument aux mêmes usages et dans les mêmes circonstances que ce dernier. Mais en France on préfẻre généralement le eresson de fontaine.

\section{Crucifères à fruits siliculeux. Cochréarrées.}

\section{PASSERAGE. - LEPIDIUM. L. J.}

Calice étalé; pétales égaux entre eux; silicule comprimée, entière ou éehancrée au sommet, à deux loges monospermes.

\section{Passerage a feutlles rarges. Lepidium latifolium. L. Sp. 899 .}

Racine vivace, allongée, blanehâtre, rameuse; tige dressée, cylindrique, 'rameuse, glabre et d'une couleur glauque, haute d'environ deux pieds. Feuilles radicales pétiolćes, grandes, cordiformes, allongées, un peu charnues, régulièrement denticulées sur les bords, légèrement pubescentes sur les deux faces; les caulinaires sont presque sessiles, d'autant plus étroites et plus allongées qu'elles sont plus supérieures; elles sont entières, et glabres des deux côtés.

Fleur's blanches, très-petites, pédonculées, formant de petits groupes multiflores, dont l'ensemble constitue une espèce de grappe panieulée à la partie supérieure de la tige.

Le calice se compose de quatre sépales obovales, arrondis, cntiers, obtus, étalés, minces et blanchâtres,sur les bords. La corolle de quatre pétales ćtalés, arrondis, entiers, longuement onguiculés et comme spathulés; les six "étamines sont élalécs, presque égales entre elles, un peu plus conrtes que la corolle, offrant à leur base, entre les filets, six petites glandes verdâtres.

L'ovaire est comprimé, ovoïde, poilu, surmonté d'un style très-court et d'un stigmatc capitulć.

La silicule est ovoïde, compriméc, tcrmince en pointe à son sommet. 
La passerage habite les lieux humides, le bord des ruisseaux. On la trouve sur les bords de la Marne et daus les îles de Charenton. $\%$

Propriétés et usages. Les feuilles et les raeines de la passerage offrent une saveur âere et poivrée. Appliquées sur la peau, elles ne tardent pas à en déterniner la rubéfaetion. Ce inédieament est d'une grande énergie; eependant on l'emploie assez rarement : e'est un de nos antiscorbutiques les plus puissans. On pourrait mélanger avee avantage ses feuilles à eelles du eresson de fontaine ou du cresson des prés, soit pour être mangées direetement, soit pour servir à la préparation des sucs d'herbes.

Les autres espèees de ee genre ont des propriétés analogues, quoique moins énergiques. Ainsi les feuilles des lepiclum ruderale et lepidum iberis, qui l'un et l'autre eroissent sur les murailles, dans les lieux ineultes ou les déeounbres, peuvent être ınangées eomme eelles du eresson de fontaine, dont elles rappellent la saveur agréable et piquante.

\section{Passerage cresson alétots. Lepidium sativum. L. Sp. 899. Blackw. t. 23. \\ Thlaspi sativum. Desf. cat. 133.}

Noms vulg. : Cresson alénois, Cresson des jardins, Nasitort. Nom pharm. : Nasturtium hortense.

- Pelite planteranuuelle ercissant avee rapidité et offrant une tige dressée, cylindrique, glauque, raméuse, lraute d'environ un pied; des feuilles inférieures pétiolées, bipinnatifides, glabres et glauques, à segmens assez larges et ineisés; les supérieures presque simples et sessiles.

Fleur's blanehes très-petites, eourtenent pédoneulées, formant des épis enurts à l'extrémité supérieure des rameaux. Calice de quatre sépales ovales, arrondis, obtus, un peu eoncaves en dedans. Corolle de quatre pétales spathulés, un pen iralés. Ovaire lentieulaire, comprimé; stylétrès-eourt : stigmate capitulé.

Silieule lenticulaire un peu échancrée à son sommet, à denx 
loges, renfermant ehacune une graine; à deux valves earénćes, minees et membraneuses sur le dos.

Le eresson alénois eroît naturellement dans les cndroits stériles. On le eultive dans les jardins polagers. Il y en a une variété fort eommune, à feuilles sinueuses ct erépues.

Propriétés et usages. Sa savenr est ehaude, lẹgèrement âcre et piquante, très-agréable. Cettc plante est un excellent antiscorbutique, qui jouit des mênes propriétés que le eresson de fontaine, et peut, comme lui, être mangé eru et sans aueune préparation.

\section{COCHLÉAR IA. - COCHLEARIA.L. J.}

Calice formé de quatre sépales eoneaves; corolle de quatre pétales étalés. Silieules presque globuleuses, à deux valves très-convexes et à deux loges contenant plusieurs graịnes.

Cochlíaria officinal. Cochlearia officinalis. L. Sp.9o3. Lamkc. Illust. t. 558. f. r.

Nom vulg. : Herbe aux cuillers.

Cette plante bisannuelle pousse, vers la fin de l'hiver, une fouffe de feuilles radieales, cordiformes, très-obtuses, critic̀res, d'un vert foneé, luisantes, portées sur des pétioles de plusieurs pouees de longueur.

Sa racinc est fusiforme, simple, allongée, de la grosseur d'une plume à éerire.

La tige est rameuse dès sa base, à rameaux épars; cylinIrique, verte, glabre, offrant quelques eôtes longitudinales. Les fexilles sont alternes; les inférieures presque réniformes, très-obtuses, à pétiole canalieulé, entières; les supérieures allongées, sessiles, prolongées inférieurement en deux petites languettes, offrant plusieurs dents irrégulieres.

Fleur's blanches pédonculées, disposées à l'extrémité des ramcaux en ćpis eorymbiformes. Caliee de quatre sépales obtus, creux et eoncaves en dedans, convexes ext,íricureinent. Corolle de quatre pétales, dressés, blanes, moitié plus grands que le ealice, arrondis, obtus, entier's, longuement cl'subité-
ment onguieulés à Jeur base. 
Le fruit est une silicule arrondie, à deux loges contenant plusieurs graines.

Le cochléaria croît sur le rivage de la mer. On le cultive dans les jardins.

Propriétés et usages. Les feuilles du cochléaria ont une saveur âcre et légèrement amère, qui paraît dépendre d'une huile essentielle que l'on obtient par la distillation. Elle est plus lourde que l'eau, et d'une telle énergie, que, suivant Murrai, une seule goutte dissoute dans l'alcohol suffit pour communiquer l'odeur et la saveur du cochléaria à une livre de vin. Le cochléaria est, sans contredit, une des Cruciferes que l'on administre le plus fréquemment comme stimulante et antiscorbutique. On peut manger les feuilles ou en exprimer le suc. Elles entrent dans le sirop et le vin antiscorbutiques.

Cochléaria de Bretagne. Cochlearia armoracia. L. Sp. 9o4. Blackw. t. 415 .

Noms vulg. : Cranson, Raifori sauvage, ou Grand raifort.

Racine vivace, blanchâtre, allongće et rameuse, un peu charnue, de la grosseur du bras. Fenilles radicales pétiolées, trèsgrandes, elliptiques, obtuses, longues d'un pied et plus, larges de trois à quatre pouces, sinueuses et irrégulièrement dentées sur les bords ; veinées, à côte moyenue très-proẻminente. Celles de la tige sont moins grandes, étroites, lancéolées; les supérieıres presque entières.

Tige rameuse, dressée, haute de deux à trois pieds, glabre et un peu striée. Fleurs blanches, petites, pédonculées, disposées en longs épis paniculés à l'extrémité des rameaux.

Les silicules sont petites, ovoïdes, couronnées par le stigmate, qui est persistant. Elles sont à deux loges, qui renferment chacune cinq à six graines.

Cette plante croit natúrellement sır le bord des ruisseaux, dans la Bretagne et d'autres parties de la France. Elle est cultivée dans les jardins. $\mathcal{F}$

Propriétés et usages. La racine du grand raifort est la seule partie de la plante qui soit usitće. Elle est d'une odeur piquante. Sa saveur est âcre et très-forle. C'est le.plus puissant et le plus 
actif des médieamens dits antiseorbutiques. On l'emploie fraiehe, soit en infusion aqueuse, soit plutôt digérée dans le vin ou l'alcohol. Elle fait aussi partie du sirop et du vin antiscorbutiques.

\section{CAMELINE. - MYAGRUM. L. J.}

Calice un peu étalé; silicule ovoïde ou grlobuleuse, à deux valves convexes et à derix loges polyspermes, surmontéo d'une pointe formée par le style.

Ce genre est très-voisin du préeédent, dont il diffère surtout par son fruit surmonté d'une longue pointe.

Cameline ordinatre. Myagrum sativum. L. Sp. 894 .

Racine annuelle fusiforme, grêle, allongée et blanche. Tige dressée, simple inférieurement, rameuse vers sa partie supérieure, cylindrique, un peu pubescentc, surtout dı bas. Feuilles alternes, sessiles, presque glabres; les inférieures spathulées et allongées, entières ; les supérieures sagittées, glabres, un peu denticulées.

Fleurs jaunes, petites, pédoneulées, disposées en épis, paniculées à l'extrémité des rameanx. Calice de quatre sépales caducs, un peu poilus. Corolle de quarre pétales à peu près spathulés et obtus.

Silieule obovoïde, presque pyriforme, surmontée par le style persistant, à deux loges et bivalve, renfernant huit à dix graines dans ehaque loge.

Cette plante eroit dans les moissons, où elle fleurit aux mois de juin et de juillet. $\odot$

Propriétés et usages. La caneline n'est point employée en médecine: On la eultive en grand dans plusieurs provinces de la Franee, où l'on relire de ses graines une huile grasse, trèsusitée pour l'usage des lampes.

\section{Propriétés inédicales el usages' des Crucifères.}

En exposant les propriétés médicales de ehacune des plantes de eette famille, dont nous avons donné la description, nous n'avons pas eru néeessaire d'entrer dans des détails trop étendus. L'action des plantes crueifères sur l'économie animale est 
si simple, et offre une si grande analogie dans tọute la famille, qu'ayant dit pour l'une de ees plantes qu'elle était stimulante, nous n'anrions eu rigoureusement besoin, pour les antres, que d'exprimer le degré d'intensité de eette force exeitante.

C'est à une huile volatile, que les Crueifères doivent leur saveur âcre et piquante, et leur odeur plus ou moins forte et aromatique. Plusieurs auteurs les avaient attribuées à la présenee de l'ammonique dans ees végétaux; mais eette substance alealine n'y existe point toute formée. Les analyses les plus exaetes n'ont pu en démontrer l'existence dans le sue réeent ou l'eau distillée de ees plantes. Mais comme elles contiennent beaueoup d'azote, on eonçoit que, pendant la fermentation, il peut se former de l'anmoniaque par suite de la décomposition de l'cau.

Cette huile volatile existe dans toutes les Crueifères et daus tous lés orgánes de ees végétaux, mais avee des degrés variables d'intensité, en sorte qu'elle les rend ou simplement exeitans, ou plus ou moins irritans. Ainsi la raeine du eranson ou grand raifort sauvage, les feuilles de la passerage à larges fenilles, lés graines des diverses espèees de moutarde, déterminent la "rubéfaetion et même l'inflammation de la peau, lorsqa'elles ${ }^{\prime} y$ restent appliquées pendant un eertain laps de teinps. Elles agissent a vee une telle intensité lorsqu'on les administre à l'intérieur, qu'clles ne doivent être données qu'avec beaueoup de préeautions.

Il n'en est pas de même du plus grand nombre des autres Crucifèrès. Le prineipe âcre et volatil n'y existe qu'en des proportions telles, que leur saveur âcre est tempérée par une quantité d'eau ou de inucilage assez grande pour les rendre agréables. Les feuilles des diverses espèees de cresson, celles din cochléaria, du vélar, de l'lierbe de Sainte-Barbe, et en général de la plupart des autres Crueifères, servent à la fois d'alimens et de médieamens. Mais eomme leur prineipe actif est très-fugace et très-volatil, on doit toujours les employer à l'état fraís.

La médieation exereée par les Crueifères est vive et instantanée :" plle stimule fortement les différens appareils de l'éeouomie, ou agit plus spéeialement sur un seul d'entre enx. Dans 
le premier cas, les Crucifères appartienncnt aux stimulans généraux; on dit aloı's généralement qu'elles sont antiscorbutiques, parce que c'est contre le scorbut qu'on les emploie avec le plus d'avantages et lc plus fréquemment. Dans le second cas, ces végélaux peuvent ĉtre emménagogues, sudorifiques ou diurétiques, suivant qu'ils stimulent plus spécialcment l'utérus, lés organes sécréleurs de l'urinc, ou que leur action stimulante se porte ver's la périphérie du corps.

La famille des Crucifcres nous fournit rin grand nombre d'alimens sains et nourrissans. La culture, en favorisant le développemcnt dcs principes ayıeux, sucrés et mucilagineux, tend à détruire cu du moins à masquer la saveır âcre qui est propre à toutes les Clucifères dans l'étát sauvage.- C'cst ainsi que l'on mange les racines des navets, des raves, des radis, etc., les tiges du chou-rave, les feuilles des diverses espèces de choux, et les pćdonculcs ainsi que les fleurs des brocolis et des chouxfleurs.

Un caractère d'uniformitć bien remarquable cst celui que ces plantcs offrent dans la nature de leurs graines. Outre le principe volalil, qui existe dans toutes à des' degrés différens, elles contiennent une quantité plus ou moins considćrable d'huile grasse, quc l'on peut oblenir par le moyen dc la pression. Plusieurs Crucifćres sont même l'objet d'une culture spéciale pour cet objet; telles sont le colza, la navctte, la cameline, ctc.

En résumć, on peut dire de celtc famille, qu'il cxiste autant d'analogie et d'uniformilé dans ses proprićtés médicales que dans ses caractères d'organisation.

\section{CA PPA RIDÉES.-CAPPARTDEAL.}

Herbes ou arbrisscaux à feuilles alternes, simples ę avec des stipules, ou composées et sans stipules; calice de quatre sépales : corolle de quatre pétales souvent irréguliers. Étamines ordinairement en grand nombre, rarement quatre ou six seulement; oveire souvent stipité, 
uniloculaire, multiovulé; style simple ou divisé, terminé par un stigmate partagé en autant de lobes qu'il y a de divisions au style. Le fruit est allongé, charnu, bacciforme ou siliqueux, à une seule loge renfermant des graines souvent réniformes, qui contiennent un embryon recourbé, immédiatement recouvert par le tégument propre. Ces graines sont attachées à des trophospermes pariétaux, dont le nombre varie suivant les genres.

Cette famille a les plus grands rapports avec les Crucifères, surtout par le genre cleome, qui a pour fruit une véritable silique. Mais elle en diffère par ses étamines généralement en grand nombre, et jamais tétradynames, et par son fruit, qui est souvent charnu et bacciforme.

\section{CAPRIER. - CAP RARIS. L. J.}

Calice de quatre sépales caducs. Corolle de quatre pétales grands et inégaux, lcs deux inférieurs concaves et comme bossus à la base. Étamines trc̀s-nombreuses et saillantes. Ovaire longuement stipité. Le style est très-court : le fruit est une espèce de baie stipitée, obtuse et charnue, renfermant un grand nombre de graines éparses dans la pulpe.

$\Lambda$ rbrisseaux sarmenteux, ayant les feuilles simples, souvent accompagnées de deux stipules épineusęs.

CAaprier érineux. Cappatis spinosa. L. Sp. 720. Blackw. t. $4 \times 7$.

Part. usit. : les boutons cle fleurs, la racine.

Le caprier est un arbuste sarmcnteux, débilc, dont les tiges sont sous-frutescentes, étalées, cylindriques, rameuses, glabres; les rameaux effilés, glabres et herbacés. Ils portent des feuilles alternes, articulées, cordiformes, arrondies, tantôt obtuses, tantôt acuminćes, vertes, molles, offrant quclques poils courts sur leurs deux faces, très-cntières, portées sur un pétiole de deux à trois lignes, pubcscent. Deux stipules épineuses,. 
subulćes, aiguës, recourbées, existent à la base de chaque pétiole.

Les fleurs sont très-grandes, solitaires, a xillaires; le pédoncule est cylindrique, dressé, de deux à trois pouces de hauteur. Leur calice est irrégulier, composé de quatre sépales inégaux, disposés en croix, tous concaves, en forme de nacelle; l'infćrieur est lc plus grand et le plus concave, il est comme gibbeux; le supérieur est un peu moins grand; les delix latéraux sont semblables et un peu plus petits.

La corolle est irrégulière, formce de quatre pćtales inégaux, plus grands que les sépales avec lesquels ils alternent; les deux supérieurs sont dressćs, arrondis, à bords déchiquettés, onguicnlés à leur base; les deux inférieurs, un peu plus grands, sont très-irréguliers. Ils sont d'abord onguiculés et épais, présentent un appendice en forme de corne, au-devant duquel est une fossetle assez grande, verte, et couverte de poils fins et soyeux; ces deux pétales sont accolés par leur bord interne, de manière que les deux fossettes sont reçues dans la concavité du sépale inférieur.

Les étamines sont très-nombreuses, environ soixante à quatre-vingt, très-longues, hypogynes, attachées à un petit tubercule, sur lequel sont insćrés successivement les sépales, la corolle, les étamines et le pistil. Ces étamines sont les unes ascendantes, les autres descendantes, plus courtes.

Le pistil est porté sur un pédicule de la longueur des étamines. L'ovaire est ovoïde, allongé, uniloculaire, multiovulé; les ovules irrégulièrement disséminés dans la pulpe ; le style est court; le stigmate capitulé, à huit dents fort courtes et conniventes.

Le fruit est pyriforme, charnu, renfermant un grand nombre de graines nichées dans la pulpe.

Le caprier est commun en Provence; on le Irouve dans les vieilles murailles, les fentes de rochers. Il fleurit pendant tout l'étć; on le cultive avec soin dans plusieurs contrées méridionales.

Propriétés et usages. La racine est la seule partie usilée en médecine: on n'emploie que son écorce ou partic externe, qui est légérement amère, un peu âcre et acerbe. Ellc est diuró - 
lique : on la comptait autrefois au nombre des cinq racines apéritives mineurcs. Elle est peu employéc maintenant.

Mais la partie la plus rccherchée du caprier, celle pour laquelle on lc cultive en grand, daus beaucoup de cantons de lat Provence, ce sont les jemues boutons de ses fleurs, qui, confits dans lc vinaigre, sont connus sous le nóm de capres. Elles sont stimulantes, antiscorbutiques. On les emploie comme condiment et assaisonnement.

\section{Propriétés médicales et usages des Capparidées:}

On trouve dans les plantes de eette famille un principe volatil ấcre, stimulant, assez analogue à celui que l'on observe dans les , plantes crucifères, dont les Capparidées se rapprochent beaucoup par les caractères botaniques. De là on doit pressentir qu'il y aura anssi entre ces deux familles de l'analogie sous le rapport des propriétés médicales. Ainsi la racine de caprier est excitante et diurétique, comme celle de beaucoup de Crucifères: les boutons confits, et désignés sous le nom de capres, sont antiscorbutiques, à la manière de toutes les Crucifères.

SOLXANTE-DIX-HUITIEME FAMULE:

\section{HIPPOCASTANEEES - HIPPOCASTANE AE.}

Le calice est monosépale, tubuleux, à cinq lobes obtus et inégaux. La corolle se compose de quatre pétales souvent inégaux, onguiculés à leur base, insérés, ainsi que les étamines, à un disque hypogyne et circulaire. Celles-ci, généralement au nombre de sept, sont inégales et déclinées, c'est-à-dire toutes portées vers la partie inférieure de la flęur. Le pistil est simple. L'ovaire est plus ou moins globuleux, à trois loges, qui contiennent chacune deux ovules, attachés à l'angle interne; et dont l'un est dressé, tandis que l'autre est renversé. Le style est toujours simple, términé par uı stignate à peine trilobé. 
Le fruit est une capsule à une, deux ou trois loges, suivan $t$ qu'une ou deux des cloisons de l'ovaire ont avorté, s'ouvrant en trois valves : elle contient d'une à quatre et même cinq graines, recouvertes d'un tégument brun et luisant, marqué d'une grande tache blanchâtre (qui est le hile) et renfermant un embryon dont les deux cótylédons sont extrêmement gros, soudés ensemble, et dont là radicule est conique, allongée et recourbée.

Cette famille se compose du genre Esculus de Linné, ou Hippocastanum de Tournefort, et peut-être du Trigonia, qui avait été placé parmi les Malpighiacées. Ce sont des arbres ou des arbrisseaux d'un port élégant ou majestueux, ayant les fenilles opposées, sans stipules, et digitées; les fleurs disposées en grappes ou en thyrses.

Le genre Asculus avait d'abord été placé dans la famille des Acérinées ou des Érables. Il en diffère par ses fleurs hernaphrodites, par son style simple, et la forme de son fruit, qui, dans les Érables, est une samare à deux ailes et à deux loges. Une seule espèce du genre érable mérite quelque attention. C'est l'érable à sucre (Acer saccharinum, Ĺ.), originaire de l'Amérique septentrionale, et dont on retire, par des incisions pratiquées à son tronc, une matière syrupeuse, qui cristallise et forme du sucre.

\section{HIPPOCASTA NE. - $A S C U L U S$. I.J.}

Calice tubulcix, à cinq lobes arrondis; corolle de quatre pétales irrégulier's; sept étamines déclinées; capsule coriace, a trois loges (dnnt une ou deux avortent quelquefois), et quii contiennent chacune une ou deux grosses graines, brune's,
luisantes.

Arbres ou arbrissenux à feuilles opposces et digitécs 


\section{IIppocastane commun. AEsculus hippocastanum. L. Sp. 488.}

Part. usit. : l'écorce. Nom vulg. : Marronier d'Inde.

Cet arbre, qui parait originaire dc l'Inde, est eertainement le plus beau des arbres exotiques, que la culture soit parveuue a naturaliser dans nos elimats. Il élève son tronc majestueux à une hauteur eonsidérable, et se divise en une multitude de branches et de rameaux; son éeorce est fendillée et brunâtre; ses feuilles opposées, sont portées sur de très-longs pétioles, renflés et articnlés à leur base, portant à leur sommet sept grandes folioles digitées, obovales, acuminées, rétréeies inférieurement, et doublement dentées.

Les fleurs sont blanehes, marquées d'une tache rouge, formant une grappe dressée, qui termine ehaque ramifieation. Elles répandent une odeur suave; leur ealiee est tubuleux, à cinq lobes obtus et ciliés; les quatre pétales sont inégaux, onguieulés à leur base, qui est dressée, tandis que leur lame est étalée et un peu onduleuse et eiliée. Les sept étamines, plus longues que la corolle, sont déelinées; l'ovaire est eouvert de petites pointes.

Le fruit est une grosse eapsule eoriaç, globuleuse, liérissée de piquans, eontenant d'une à quatre graines diversement configurées, et s'ouvrant en trois valves inégales.

Cc bel arbre, qui fait l'ornement de nos jardins et de nos promenades, épanouit ses fleurs au eommencement de mai, et mûrit ses fruits en septembre.

Propriétés et usages. L'éeorce du marronier d'Inde a une saveur astringente et un peu amère. Elle eontient beaueoup dc tannin. Plusieurs auteurs ont pensé qu'elle pourrait remplacer le quinquina dans le traitement des fièvrcs intermittentes; mais les essais tentés à eet égard, n'out pas entièrement justifié eette assertion. Cepcndant elle ne manque pas d'une eertaine aetion tonique, et sa décoetion peut, dans plusieurs eirconstanecs, être cmployéc avec assez d'avantage.

Quant à ses graines, elles sont presque entièrement formées d'amidon, auquel se joint un prineipe amer et trc̀s-désagréa- 
ble; on peut cependant les en priver totalement, et alors on pourrait les employer à la nourriture de l'homme, ainsi que Parmentier l'a indiqué. Les chevaux, les chèvres, les vaches, les bœufs et les moutons en sont très-friands. Ordinairement on les prive de leur tégument, on les fend et on les laisse macérer dans une lessive alcaline avant de les leur donner. Par ce procédé, ils perdent une grande partie de leur amertume.

SOIXANTIE M E-DIX-NEUVI主ME FAMILLE.

\section{HYPÉRICINEEES.-HYPERICINEAE.}

Les Hypéricinées sont des plantes herbacées, des arbustes, ou même des arbres, ayant les feuilles opposées sans stipules, souvent parsemées de petites vésicules transparentes; leurs fleurs sont en général jaunes ou rougeâtres, disposées à la partie supérieure des ramifications de la tige. Leur calice est monosépale, persistant, à quatre ou cinq divisions profondes. Leur corolle se compose de quatre, ou plus souvent de cinq pétales étalés et hypogynes, ainsi que les étamines. Celles-ci sont nombreuses; leurs filamens sont généralement soudés par leur partie inférieure en plusieurs faisceaux distincts. Leurs anthères sont globuleuses ou cordiformes, vacillantes au sommet du filet qui est grêle.

L'ovaire est libre, à trois ou cinq loges, qui contiennent un grand nombre d'ovules attachés à leur angle interne. Le nombre des styles et des stigmates est le même que celui des loges de l'ovaire.

Le fruit est une capsule à trois ou cinq loges polyspermes, s'ouvrant en trois ou cinq valves, dont les bords rentrans constituent les cloisons. Les graines sont fort petites, et contiennent un embryon dressé, dépourvu d'endosperme. 


\section{MILLEPER'IUIS. - HYPERICUM. L.J.}

Calicc à cing divisions égales; corolle de cinq pélales ćtalés. Étamines nombreuses, réunies par la base de leurs filets en trois ou cinq faisceaux. Styles au nombre de trois à cinq.

Capsules s'ouvrant en trois ou cinq valves, et offrant un égal noinbre dc loges.

Plantes herbacées ou sous-frutescentes, ayant les feuilles opposées simples, marquées de points translucides ${ }^{\text {? }}$.

Millepertuis ordinaire. Hypericum perforatum. L. Sp. x поร. Blackw. t. 15 .

Racine vivace donnant vaissance à des tiges dressées, ramenses, glabres, cylindriques, avec deux lignes longitudi nales saillantes; rameaux opposés, formant unc sorte de cyme à la partie supérieure. Feuilles opposées sessiles, elliptiques, cntières, à nervures longitudinales, d'un vert foncé en dessns, d'un vert glauque en dessous, offrant, quand on les regarde entre l'œil et la lumière, un grand nombre de points transparens, qui sont autant de petites glandes.

Fleurs jaınes et terminales, disposées en une espèce de cyme à la partie supćrieure dela tige. Calice monosépale, persistant, partagć presque jusq̨u’à sa base en cinc lanières étalćes, lancéolées, aiguës. Corolle de cinq pétales étalés, ovales, obtus, sessiles, souvent glanduleux sur les bords. Étamines nombreuses, hypogynes, saillantes. Filets réunis par la base en trois faisceaux. Anthères trc̀s-petites, globuleuscs, didymes.

Ovaire libre, ovoïde, un peu allongé, à trois loges, qui r'enferment chacune un grand nombre d'ovulcs, attachés sans ordre. à l'angle interne.

Trois styles divergens naissent du sommet de l'ovaire; ils sont subulés, glabres, terminés chacun par un stigmate tréspetit, à peine distinct.

- C'est de cette particularite que ce genre a tiré son nom de millepertuis. 
Le fruit est une eapsule globuleuse, à trois loges polyspernies et s'ouvrant naturellement en trois valves.

Cette plante est fort commune dans les bois et, sur les pelousẹs. Elle fleurit en juillet. $\%$

Propriétés et usages. Le millepertuis, lorsqu'on le froisse entre les doigts, repand une odeur aromatique et résineuse. Sa saveur est légèrement âere. On en faisait autrefois un usage très-fréquent, eomme d'un médieament exeitant et anthelmintique. Il jouissait aussi d'une gránde réputation dans le traitement des plaies, à l'époque ò̀ l'usage des vulnéraires était en vogue. I'huile dans laquelle on a fait maećrer les feuilles et les fleurs de millepertuis passait pour un remède souverain très-propre à favoriser la eieatrisation des plaies simples et des uleères. Quelques autenr's ont mème employé eette plante dans le traitement des fièvies graves et de plusieurs autres maladies fort différentes. Mais l'abandon dans lequel elle est toml'un de nos jours, parle peu en faveur de son effieacilé.

Il en est de même de la toute-saine on Andosìme, Hypericum Androsamum, L., qui se distingue du millepertuis par son fruit eharnu et baceiforme. Elle jouissait autrefois d'une Irès-grande réputation dans le traitement d'une foule de maladies, ainsi que l'annonee le nom de toute-saine, sous lequel elle est vulgairement désignée. Mais elle est aujourd'hui presqụe complétement inusitée.

\section{Propriétés médicales et usages des Hypéricinées.}

L'odeur aromatique et résineuse dont nous avons signalé l'existenee dans le millepertuis eomuun, existe également dans le plus grand nombre des autres espèees de ee genre. Elle paraît due à une résine qui eommunique à l'aleohol et aux huiles, dans lesquels elle se dissout, une couleur ronge plus ou moins intense. $\Lambda$ ee prineipe résineux se tronve jointe en général une matière gommeuse plus ou moins abondante. Quelques Hypéricinées sont laeteseentes, et le sue qu'elles contiennent a beaueoup d'analogie avee eelui qui existe dans la plupart des Gutlifères, et rappelle les proprićtés âcres et purgatives de cédernier. C'est ainsi que plusienrs hypericun d'Anérique; tels 
que les hypericum bacciferum, hypericuin cayennense, ete., fournissent un suc qui se solidifie et offre une telle ressemblance avec la gomme-gutte, qu'on le connait vulgairement sous le nom de gomme-gutte d'Amérique.

On peut donc dire qu'en général les Hypéricinées sont aromatiques, résineuses, et que le suc qu'elles renferment est quelquefois purgatif.

QUATRE-VINGTIEME FAMILLE.

\section{GUTTIFÉRÉES. - GUTTIFEREA.}

Les fleurs sont quelquefois dioïques par avortement. Leur calice offre plusieurs lobes, ou se compose de plusieurs sépales distincts. Les pétales sont au nombre de quatre. Les étamines sont tantôt libres ou tantôt monadelphes. Elles sont généralement indéfinies, rarement leur nombre est rigoureusement limité; leurs anthères sont longues et adnées aux parties latérales des filets. L'ovaire est tantôt uniloculaire, tantôt à plusieurs loges qui renferment une ou plusieurs graines. Le style qui surmonte l'ovaire est toujours simple, et se termine par un stigmate également simple, qui est quelquefois sessile, par l'absence du style.

Le fruit est assez variable. Dans le plus grand nombre des genres, c'est une sorte de baie coriace, dure extérieurement, molle et pulpeuse à son intérieur, qui tantôt est uniloculaire, tantôt offre plusieurs loges contenant chacune une ou plusieurs graines. Dans quelques genres, au contraire, le fruit est une capsule renfermant une ou plusieurs graines, restant quelquefois close, ou bien s'ouvrant en plusieurs valves.

Les graines ont leur embryon dressé, immédiatement recouvert par le tégument propre.

Cette famille se compose de végétaux tous exotiques, ligneux, ordinairement très-élevés, portaut des feuilles 
opppsées, sans stipules, très-entières, coriaces, persistantes; des fleurs axillaires ou terminales.

Les plus grands rapports unissent entre elles les familles des Guttifères et des Hypéricinées. La prenière se distingue surtout par ses anthères allongées et adnées, tandis qu'elles sont vacillantes dans les Hypéricinées; par son style unique, qui est multiple dans ces dernières.

\section{MANGOSTAN. - GARCINIA.}

Caliee de quatre sépales; eorolle de quatre pétales alternes avee les divisions du ealice. : élamines au nombre de douze et au delà. Ovaire libre, à quatre ou huit loges uniovulées. Stigmate sessile et lobé.

Le fruit est une baie dure et eoriace en dehors, pulpeuse intérieurement, où elle offre plusieurs loges séparées par des cloisons minces et membraneuses. Chaque loge contient une seule graine au milieu de la pulpe.

Grands arbres lacteseens; à feuilles opposées et entières.

Gœrtner a fait voir que les genres garcinia et cambogia de Linné devaient être réunis, n’offrant pas de earactères propres à les distinguer. Il a donné à ce nouveau genre ainsi formé des deux genres de Linné, le nom de mangostana. Mais eomme le genre garcinia est plus ancien, nous avons cru qu'il était préférable d'en conserver le nom, cn prévenant que nous appelons ainsi le genre eomposć du garcinia et du cambogia de Linné.

Mangostan guttule. Garcinia cambogia. N. Cambogia gutta. L.

Mangostana cambogia. Gœrtn. 2. p. 105. t. 1o6.

Part. usit. : la gornme-gutle. Nom pharm. : Gummi-gutta.

Cet arbre, originaire des Indes orientales, peut acquérir une hauteur considérable. Son tronc se divise supérieurement en ramificatious nombrcuses, recouvertes d'un épiderme noi- 
rủtre, et portant des feuilles opposées pêtiolées, ovales, aiguës, très-entières, euriaees, ğlabres, luisantes, marquées de nervures latérales parallèles.

Les fleurs sont petites, hermaphrodites, réunies en petil nombre et sessiles à la partie supérieure des jeunes ranieaux. Leur ealiee est monosépale, eadue, à quatre lobes obtus et profonds. La eorolle est formée de quatre pétales onguieulés, également eoneaves et très-obtus.

Les étamines sont au nombre d'une quinzaine, insérćes sous l'ovaire. Celui-ei est globuleux, libre, terminé à son sommet par quatre stigmates sessiles et persistans.

Le fruit est globuleux, jaune, de la grosseur d'une orange, marqué de huit eôtes peu saillantes. Son enveloppe extérieure est dure et eoriaee, à peu près eomme celle de la grenade, et son intérieur est eharnu et pulpeux. Coupé transversalement, il offre huit loges séparées par des cloisons membraneuses et coutenant ehaeune une seule graine, au milieu de la pulpe eliarnue.

Propriétés et usages. La gormme-gutte est une gomme résine, qui déeoule soit des incisions que l'on pratique à l'écoree de l'arbre que nous venons de décrire, soit par les plaies qui résultent de l'avulsion des feuilles et des jeunes rameaux. Dans le commeree elle est en masses eylindriques ou en magdaléons, d'un brun jaunâtre, friable, ayant la eassure brillante et opaque. Son odeur est nulle; sa saveur, d'abord faible, laisse un sentiment d'âcreté dans le gosier. Elle est extrêmement soluble dans l'eau, à lacuelle elle eommunique une belle couleur jaune; elle est soluble en grande partie daus l'aleohol. Elle se eompose de vingt parties de matière gommense et de quatre-vingt parties de résine.

Tous les auteurs de matière médieale plaeent la gomme-gutte parmi les purgatifs drastiqúes. Elle exeree en effet une aetion irritante sur les organes de la digestion, laquelle donne lieu, soit à des vomissemens, soit à des déjeetions alvines abondantes, aeeompagnées de eoliques ct de tranehées. Aussi l'usage interne de ee médieament ne peut-il être avantageux que dans le eas où il est rttile d'exeiter une dérivation puissante, comme dans ccrtaincs hydropisies essentielles et passives, dans plu- 
sienrs affections chroniques de la peau. On a encore employé la gomme-gutte, comme au reste tous les autres drastiques, au traitement des vers intestinaux. Cependant il faut convenir quie maintenant on l'emploie fort rarement dans toutes ces circonstances. Elle entre néanmoins dans plusicurs préparatious pharmaceutiques peu usitées, telles que les pilules hydragogues de Bontius, l'ćlectıaire antihydropique de Charas, etc.

Lorsqu'on veut faire usage de ce médicament, c'est en poudre ou en solution, qu'on le prescrit. Sa dose est de deux à six grains, que l'on jeut répéter plusieurs fois dans la journée.

Mais c'est plus particulic̀rement dans la mćdecine vétćrinaire et dans l'art de la teinture qu'on emploie la gomme-gutte. File fournit une couleur jaune dont les peintres et lcs leinturiers se servent fréquemment.

\section{Propriétés médicales et usages des Guttiférées.}

Cette famille, uniquement composée de végćtaux exotiques, qui croissent dans les climats voisins des tropiques, offre assez d'analogie dans l'ensemble de ses propriétés médicales. Presque tous, ainsi que l'indiquc leur nom dc Guttifères, conticnnent un suc laiteux jaunâtre, plus ou moins âcrc et purgatif. La gomme-gutte, qui est produite par le garcinia cambogia el plusieurs autres arbres du même groupe, en cst l'exemple. le plus frappant ct le plis connu. Un suc analogue existe dans la plupart des autrcs Gultifèrès, et peut être cmployé aux mêmes usages.

Cependant ces végélanx, qui sont abreuvés d'un suc laiteux $\mathrm{ct}$. délétère, ont des fruits dont la pulpe acidule sert de rafrâ̂clissement daus les climats brûlans où la nature les fait croître. C'est ainsi que l'on mange ceux du mammea americana, du garcinia mangrostana et même ccux du garciria cambogia, elc. Un pareil fait est facile à expliquer par l'absence du suc laiteux dans lc fruic des Gutlifères, et ne forme pas une véritable exception dans les propriétés générales de la famille. 
QUATRE-VINGT-UNIËM FAM IULE.

\section{AURA NTI A CEES.-AURANTIACEAE.}

Gette belle farnille, dont l'oranger et le citronnier nous offrent des'modèles, se eompose d'arbres ou d'arbrisseaux élégans, conservant en tous temps leur feuillage toujours vert, et eroissant dans les régions chaudes de l'aneien et du nouveau eontinent.

Leurs feuilles sont alternes, simples ou eomposées, remplies de petites glandes vésiculeuses, qui semblent autant de points transparens, lorsqu'on les regarde entre l'œil et la lumière. Dans l'état sauvage on trouve souvent à la bạse des feuilles ou au sommet des rameaux des aiguillons ou des épines.

Les fleurs, ordinairement blanehes ou purpurines, sont groupées aux aisselles des feuilles on an sommet deś ramifieations de la tige et embaument l'air d'un parfum délieieux. Leur ealiee monosépale est plus ou moins profondément divisé en quatre ou cinq lobes. Les pétales, au nombre de quatre ou einq, sont élargis à leur base et insérés, ainsi que les étamines, au pourtour d'un disque hypogyne. Celles-ci, généralement au nombre de dix, rarement plus nombreuses, ont leurs filets libres ou soudés en plusieurs faiseeaux et polyadelphes.

L'ovaire est simple, órdinairement à plusieurs loges, contenant un, deux ou plusieurs ovules; il est surmonté d'un style et d'un stigmate simples.

Le fruit est une baie à plusieurs loges et à plusieurs graines. Celles-ei renferment un embryon droit privé d'endosperme.

Cette famille se distingue des Guttifères par ses feuilles alternes, ponetuées; par son écoree non laitense, par son fruit dont l'enveloppe externe ou épiearpe n'est point dure ni coriace, et par plusieurs autres earactères. 


\section{ORANGER.-CITRUS. L. J.}

Calice cupuloïde, pcrsistant, denté, corolle de quatre a cinq pélales sessiles et sans onglet; étamines nombreuses, ayant les filets réunis en plusieurs faisceaux. Ovaire à plusieurs loges, contenant chacune un grand nombre d'ovules attachćs à l'angle interne; style épais et cylindre; stigmate simple ct déprimé. Baie globuleuse ou allongée, recouverte d'une ćcorce épaisse et rugueuse, dont l'intérieur, qui est celluleux et charnu, peut se partager en autant de parties,; séparées par des cloisoṇs membraneuses, qu'il y a de loges à l'ovaire.

Sous la dénomination gćnérale d'orangers, ce genre comprend ceite foule innombrable d'arbres odoriférans qu'on appelle orangers, limoniers, cédraticrs, limettiers, pampelmousiers, etc., etc. La culture a exercé une telle influence sur les' espèces primitives de ce genre, ct en 'a' tellement'multiplić les variétćs, qu'on y'a élabli huit races principales, que l'on peut considérer, en quelque sorte, comme les souches de toules les variétés eultivćes en grand.

Ces huit races ont été nommées et caraetérisées de la manière suivante, par MIM. Risso et Poitenu, dans-le magnifiq̣ue ouvrage qu'ils viennent de publicr sous le titre d'Histoire naturelle' des orangers.

1 Orangers a frults dodx. Aurantia.

Leurs feuilles sont ovaies, allongécs, aiguës, quielquefois légèrement dentées, pétiolćes, à pétiole plus ou moins ailé et articulé avec la feuille. Leurs fleurs sont blanches, leurs fruits multiloculaires, arrondis ou ovoïdes, rarement terminés à lenr sommet par une pelite pointe ou un mamelon, d'un jaune d'or, légèrement lavé de rouge, et dont l'éeorce a les vésiculcs convexes.

La pulpe renfermée dans ces fruits est abondante, aqueuse, sucrée, douce, agréable ct légèrement aigrcletle.

$\Lambda$ cette première division appartiennent toutes les variétćs que nous mangeons sou's les noms d'oranges de Malte, oranges de Portugal, des Açores, etc. 


\section{$2^{\circ}$ Bigaradiers. Bigaradico.}

Les Bigaradiers ou orangers à fruit aeide et amer, s'élèvent généralement moins haut que l'oranger à fruit doux; leurs feuillcs sont plus grandes et plus larges; leurs fleurs, également plus grandes et plus odorantes, sont préférées dans les offieines pour en extraire l'huile essentielle et l'eau distillée.

Le fruit appelé bigarade a le volume et la forme de l'orange douee; mais son ćcorce est ordinairement plus rabotteuse; elle devient d'un jaune plus rongeâtre. Sa pulpe est aeide et mêlée d'amertune, ee qui empêche de l'employer, si ee n'est pour assaisonner les viandes et le poisson.

Les variétés rapportées à eette seconde section sont fréquemment eultivées par les fleuristes de Paris.

\section{Bergamottiers. Bergainia.}

Cette petite tribu se compose de végétaux qui ont les rameaux nus ou garnis de petites épines; les feuilles oblongues, aiguës ou obtuses, portées sur des pétioles ailés ou simplement marginés; leurs fleurs sont petites, blanehes, d'une odeur particulière et très-suave. Les fruits sont pyriformes ou déprimés, lisses ou toruleux, d'un jaune pâle, à vésieules concaves, à pulpe légèrement acide et d'un arome très-agréable.

Les fleurs du Bergamottier ordinaire, citrus bergamia vulgaris, sont fort recherchées pour leur odeur excellente. Il en est de même aussi de.l'écorce de leurs fruits que l'on distille pour en retirer l'huile essentielle.

\section{$4^{\circ}$ Limetifins. Limetto.}

Les Limeltiers, dit M. Risso, ont le port et les feuilles du limonier; leurs fleurs sont blanches, d'une odeur douee et parlicnlière; le fruit, plus ou moins gros, suivant les variétés, est d'un jaune pâle, ovoïde ou arrondi et terminé par ún manelon. Les vésicules d'huile essentielle de son écorce sont concaves. Sa pulpè contient une eau doueeà tre, fạde ou légèrement amère.

5 Ponpeluouses. Pompelmosei.

L.es Pompelmouses sout quclquefois épinerux, et quclques- 
uns d'entre eux ont les jeunes pousses pubescentes; ils ont des feuilles épaisses, très-grandes, portées sur des pétioles munis d'ailes assez dilatćes. Lcurs fleurs sont blanches et les plus grandes de tout le genre.

Leurs fruits sont d'une grosseur surprenante, globuleux ou pyriformes, à écorce lisse et ayant les vésicules d'huile essentielle planes ou convexes; la chair épaisse, spongieuse; la pulpe verdâtre, peu aqueuse et d'une saveur douce et peu sapide.

\section{$6^{\circ}$ Lumies. Lumia.}

Cette section comprend tous les orangers qui ont le port et les caractères des limoniers, les fleurs rouges en dehors, mais dont la pulpe est douce, plus ou moins sucrée, au lieu d'être acide.

\section{$7^{\circ}$ Lmoniers. Limonia.}

Les Limoniers sont les arbres que l'on appelle, par suite d'un usage bizarre, citronniers à Paris, tandis qu'on les nomme $\mathrm{Li}$ moniers dans le reste de l'Europc, et que c'est avec leür fruit que l'on prćpare la limonade et le sirop de limons.

Ces arbres ont leurs rameaux effilés, flexibles, quelquefois épineux, surtout dans l'état sauvage : leurs feuilles sont ovales et oblongues, dentćes, d'un vert jaunâtre, arliculées sur un pétiole dépourvu d'ailes. Leurs fleurs sont de grandeur moyenne, roses en dehors.

Le fruit, d'un jaune clair, est ovoïde, terıniné par un mamelon conique, plus ou moins long. Son écorce est tantôt lisse, tantôt rugueuse, ayant les vésicules d'huile essentielle concaves. Sa pulpe est abondante, abreuvée d'un suc d'une acidité très-agréable.

Le nombrc des varićtés rapportćes à cette section est extrêmement considćrable. Toutes se font remarquer par leur aciditć franche.

Ces arbres, sur les bords de la Méditerranéc, où on les cultive en abondance, offrent l'aspect le plus agréable. Ils sont pendant toute l'année chargés de flcur's et de fruits.

$8^{\circ}$ Cínnatiens. Ceclrce.

Ils se distinguent des Limonicrs par leurs rameaux plus 
courts et plus roides, leurs feuilles plus étroites; leurs fruits plus gros et plus verruqueux et leur pulpe moins acide.

A celte dernière section appartiennent les énormes fruits connus sous lcs noms de ponçires, et qu'on nous envoie confits dans le sucre, des différens points de l'Italie.

Telles sont les huit races principales ou espèces auxquelles on peut rapporter les variétés sans nombre que l'on cultive particulièremcnt en Italie. Nous derons ajouter qu'assez fréquemment les pépins ou graines avortent dans plusieurs de ces variétés, dont les fruits, dans quelques-unes, offrent les formes les plus bizarres et les plus anomales.

Nous allons niaintcnant tracer la description et l'histoire des dcúx cspèces les plus intéressantes, ct que nous connaissons sous les noms d'Oranger, proprement dit, et de Limonier ou Sitronnier.

Oranger ordinatre. Citrus aurantium. L. Sp. i ioo. Blackw. r. 3/49.

Part. usit. : les feuilles, les fleurs, les fruits.

Bel arbre toujours vert, à tronc lisse, cylindrique, ramifié, souvent dès sa base. Originaire de la Chine, des îles de lá mer des Indes, et de celles qui sont ćparses au milieu de l'Ocćan Pacifique, il est aujourd'hui cultivé cn grand dans les provinees méridionales de la Franee, surtout aux environs d'Hyères et de 'Toulon.

Ses feuilles sont alternes, unifolićes, ovales, subacuminées, éntières, glabres, et luisantes des deux côtés, offrant, quand on les examine entre l'œil et la lunièrc, des petits points transparens, qui sont autant de vésicules remplies d'une huile volatile d'une odeur agrćable. Ces feuilles sont articulées sur' un pétiolc long d'environ un pouce, ailé sur ses bords et comme obcordé.

Lcs fleurs sont blanches, grandes, disposées en bouquets paueiflores à l'extrémité des rameaux, ct exhalent une odeur des plus suaves et que chacun connait. Leur' calice cst extrêmement court et planc, à cinq dents larges et aiguës.

La corolle est penr:apéialc subcampanuléc. Lucs pétales sont 
elliptiques, allongćs, obtus, sessiles, un peu éjais et Ićgèrement charnus, présentant un grand nombre de glandes vésieuleuses, transparentes.

Les étamincs, au nombre d'environ vingt, moitié plus eourtes que la eorolle, sont dressćes, rapprochées latćralement les unes contre les aulres, et constituent un tube. évasé vers son sommet. Elles sont insérćes au pourtour d`un disque hypogýne, saillant, en forme de bourrelet, au-dessous de l'ovaire. Les filets sont blancs, un yeu eomprimés, souvent réunis et soudés deux ou trois ensemble, dans presque toute leur longueur. Les anthères sont introrses eordiformes, aiguës, atta ehées par leur base au sommet du filet.

Le pistil est central, à peu près de la longueur des ćlamines. L'ovaire, ovoïde, presque globuleux, à huit, neuf ou dix loges, renfermant chacune quatrc à six ovules attaehés vers l'axc. Le style est très-gros, cylindrique, terminé par un stigmate épais, jaunâtre, capitulé, globuleux, un peu concave à son sommet.

Le fruit porte le non d'orange. Il est arroudi, un peu déprimé. Sa puỉpe est douee, sucrée ct légèremcnt aigrelelte. Les oranges Ics plus estimćes sont celles qui viennenı de Malte et du Portugal.

Propriétés et usnges. L'oranger est une ressousce prćcieuse pour la thćrapeutique. Ses feuilles servent, $\mathrm{cn}$ infusion an nombre de cinq à six dans une chopine d'eau bouillanie, à faire une boisson lćgèrement diaphorétique et antispasmodique. On prépare avec les fleurs une eau distillée très-fréquemment employće dans les potions calmantes et antispasmodiques. On la donne à la dose d'une à trois onees. Elle est aussi eonnue sous le nom de naphc.

Ses fruis, on les oranges, sont également très-usités. Leur éeoree dessćchée a une saveur amc̀re et aromatique. Elle csı. exeitanle et entrc dans une foule de préparations officinales; on en fait un sirop trìs-usilé, à la dose d'une à deux onces, dans les potions toniques. Leur pulpe, qui est légèrement aeide et sucrée, sert à préparer des orangeades, sortes de boissons plus douees et moins acides que les limonades faites avec le jus de eitron. Elles sont rafraichissantes, et conviennent dans les inflamınalious légères des organcs de la digestion. On fait 
aussi avcc le suc d'orangcs clarifić un sirop trc̀s-agréablc, rafraîchissant, mais qui a l'inconvćnient de s'altérer avec facilité. Étcndu d'eau, ce sirop forme une boisson avcc laquellc on peut remplacer l'orangeade, dans la saison où l'on ne peut se procurer des oranges fraîches.

On cmploie fréquemment les oranges dans certaines maladies où il cst important de ne pas introduire une quantitć marquéc dc liquide dans les organes de la digestion, comme, par exemple, dans le cas d'engouement ou d'ćtranglement d'une hernic. Un quartier d'orange, dont le malade exprime le suc, suffit pour étancher la soif, cn rafraîchissant l'intérieur dc la bouche.

Nous n'avons pas besoin de rappeler combien les parfumeurs et les confiscurs savent tircr partie des fleurs et du fruit de l'oranger, qui contribuent à la fois à remédier à nos besoins èt à satisfaire nos jouissances. C'est avec l'écorce d'oranges quc l'on prépare la liqqueur de tablc connue sous le nom de curaçao.

Limonier ordinarre. Citrus medica. L. Sp. I 100. Blackw. t. 36 r.

\section{Vulgairement : Citronnier.}

Le limonicr croit naturellcment dans les contrćes de l'Inde situées an delà du Gange. Il a ćtć transportć dans l'Asie mincure ct l'Europe mćridionale par les califes qui, du fond de l'Asic, ćtcndirent leurs conquêtcs jusqu'aux pieds des Pyrénées.

L'et arbre cst plus ćlancé que l'oranger. Sa tige est droite, garnie dc nombreuscs ramifications anguleuses, souvent violacécs, portant des ćpincs, surtout dans l'ćtat sauvige. Les feuilles sont ovales, oblongues, acuninces, dentées, d'un vert jaunître et portćes sur des pétioles articulés, sans ailcs sur leur's partics latéralcs.

Les flcurs sont nombreuscs, dc grandeur moyenne, souvcnt disposées en grappes, lavécs de rouge-violct en deliors. Lcur calice cst court, presque plane cl à cinc dcuts. Leurs pétales, au nombre de cinc, sont scssiles, et leurs étamincs sont souvent libres et non soudécs cil firisceaux par leurs filets. 
Les fruits sont ovoïdes, d'un jaune elair, ayant la peau plus ou moins fine. Ils se terminent supérieurement par un mamelon eonique. La pulpe qu'ils renferment est pleine, d'un sue acidule et agréable.

Propriétés et usages. Le fruit du limonier est presque la seule partie dont on fasse usage en thérapeutique. Sa saveur a eidule, qui est due, eomme claeun sait, à la présence de l'acide citrique, rend ce fruit rafraichissant par exeellence. Exprimé dans une pinte d'eau, le sue d'un limon ou citron, forme une boisson tempérante extrêmement agréable, nommée limonade, et dont l'usage est très-répandı, surtout pendant les ehaleurs de l'ćtć. La limonade eonvient dans les irritations gastriques perı intenses, ainsi que nous l'avons dit préeédemment pour le sue de l'orange.

On prépare aussi avee le sue que l'on en exprime un sirop, conniz sous le nom de sirop de limons, également fort en usage dans les mêmes eireonstances que la limonade.

Quant à l'huile essentielle de limon et de bergamotte, que l'on retire par la distillation de l'ćeoree de leurs fruits; elle est extrèmement excitante, et s'administre à la dose de quelques gouttes dans une potion tonique.

\section{Propriétés médicales et usages des aurantiaccees.}

Tous les organes, dans les végétaux qui eomposent la famille des $\Lambda$ urantiacées ou Hespéridées, sont parścmés d'une multitude de petites glandes vésiculeưses, remplies d'une huilc volatile d'une odeur suave et pénćtrante. On les tronve dans l'ćpaisseur des feuilles et du caliee, dans le parenchymé des pétales et dans l'cnveloppe ćpaisse et jaunâtre qui revêt le fruit à l'extćrieur. C'est ee prineipe volatil, qui fait de ees vćgétaux des arbres éminemment odoriférans, et qui leur donncl'action stimulante que lcurs diverses parties exereent sur l'éeonomic animale.

Cettc aetion est la même pour tons les végétaux de cetle famille. Ce ne sont pas seulement les feuilles dc l'oranger, qui ont une savcur amère et aromatiquc; ses fleurs, yui ont un arome si délicicux, l'ćeoree cxtćrieure de ses fruits, 'qui es: 
amère, un peu âerce et aromatique, mais les feuilles, les fleurs et l'enveloppe du fruit dans les autres Hespéridées, possèdent des propriétés absolument semblables, et affectent nos organes de la même manière.

La famille des Aurantiacées offre eneore un caractère frappant d'analogie dansla pulpe de son fruit, qui est toujours plus ou moins acide et rafraîehissante. Dans l'orange, où eette acidité est masquée par une saveur suerée et par du mucilage, le sue exprimé de cette pulpe est susceptible de fermenter et de former une liqueur alcoholique, ou plutôt une sorte de vin, qui dans certaines eontrées de l'Inde, est employée par les naturels du pays.

\section{QUATRE-VINGT-DEUXIEMNE FAMILLE.}

\section{THÉACÉ E S. - THEACE $\not E$.}

Les genres qui composént cette petite famille avaient d'abord été placés parmi les Hespéridées ou Aurantiacées; mais ils présentent des caractères assez différens pour devoir former un ordre naturel distinct.

Les Théacées sonten général des arbrisseaux toujour's verts, portant des feuilles alternes et simples, non ponctuées, des fleurs axillaires souvent très-grandes. Leur calice est monosépale, divisé profondément en plusieurs lolos obtus et incombens par leurs parties latérales, quelquefois arcompagné en dehors d'écailles imbriquées. La corolle se compose de cinq on d'un plus grand nombre de pétales, assez souvent disposés sur plusieurs rangs, sesiles, élaryis et quelquefois soudés par leur base, de manière à représenter une corolle nıonopétale rotacée.

Les étamines sont en grand nombre, insérées sous l'ovairè. Leurs filets sont tantôt libres, phus souvent soudés en un ou plusieurs faisceaux, par leur partie in. férieure seulement. Les anthères sont arrondies et à deux loges séparées par toute l'épaisseur dụ filet.

L'ovaire est Jibre, globuleux, à trois on quatre loges, 
THÉACÉES.

qui chacune contiennent deux ovules attachés à l'angle interne. Le style qui surmonte l'ovaire est plus ou moins allongé, simplé ou divisé dans sa partie supérieure, qui porte trois ou quatre stigmates.

Le fruit est toujours une capsule dure, coriace et preśque ligneuse, à trois ou quatre côtes saillantes et à autant de loges, contenant une ou deux graines, et s'ouvrant chacune par une suture longitudinale.

Ces graines sont recouvertes d'un tégument propre, dur, corné, et renferment un embryon dont les deux cotylédons sont épais et charnus, dépourvus d'endosperme.

Deux genres seulement composent cette famille, savoir : le Thea et le Camellia. 'Tous deux sont originaires du Japon et des parties orientales de l'Asie.

La famille des Théacées se distingue de celle des Hespériclées, par ses feuilles qui ne sont point parsemées de points glanduleux, par son style divisé et son stigmate multiple, et enfin par son fruit, qui est torjours une capsule à trois ou quatre loges, et non une baie pulpeuse, comme dans les Hespéridées.

\section{THÉ. - THEA. L. J.}

Calice à cinq divisions profondes et arrondies; corolle de cinc à neuf pétales sessiles, rarement en plus grand nombre; étamines très-nombreuses. Capsules à trois coques contenant chacune une ou deux graines, et s'ouvrant par leur partie supérieure.

$\Lambda$ rbrisseaux toujours verts, ayant les feuilles alternes et les fleurs axillaires.

Thé de la Chine. Thea sinensis. N.

Thea bohea. L. Sp.

Thea viridis. I. Sp.

Arbrisseau pouvant acquéric, lorsqu'il est abandonnć à lui- 
mêtme, une hauteur de vingt-einq à trente pieds, mais qui dans l'état de eulture en dépasse rarement einq à six.

Il porte des feuilles alternes, eourtement pétiolées, trèsglabres, ovales, allongées, un peu aeuminées au sommet, longues d'environ deux à trois pouees, larges d'un pouce, roides et eoriaces, légèrement dentées en scie sur leurs bords, un peu luisantes et d'un vert foncé. Celles des jeunes pousses sont tendres et un peu pubeseentes.

Ses fleurs sont blanehes, axillaires et agglomérées, au nombre de trois à quatre à l'aisselle des fenilles; elles sont portées sur des pédoneules glabres, épaissis au sommet, et longs de quatre à einq lignes.

Le ealiee est très-eourt, à einq divisions, ovales, arrondies, obtuses, se reeouvrant latéralement; il est persistant.

La eorolle est beaueoup plus grande que le ealice, formée de einc, six nu un plus grand nombre de pétales un peu inégaux, arrondis, très-eoneaves, souvent éelıanerés à leur scmmet, étalés.

Les étamines sont extrêmement nombreuses (environ une eentaine), un pen plus eourtes que la eorolle, réunies et rapproehées vers le eenlre de la fleur, insérées au pourtour de la base de l'ovaire : les filets sont subulés, grêles et blanes; les anthères sont arrondies, didymes; les deux loges sont écartées l'une de l'autre à leur base et s'ouvrent par un sillon longitudinal.

L'ovaire est arrondi, eormme à trois eôtes, libres, à base élargie, liérissé de poils rudes et redressés; il est triloculaire; et elıaque loge renferme deux ovules attaehés à l'axe eentral.

Le style est simple dans sa moitié inférieure, triparti supérieurement et glabre; chaeune de ees divisions est terninée par un stigmate à peine distinet.

Le fruit est une eapsule à trois eoques arrondies, quelquefois à deux ou même à une seúle eoque, eontenant ehaeune une ou rarement deux graines, et s'ouvrant par une fente qui se forıne à leur partie supérieure.

Linné et la plupart des aneiens bolanistes ont distingué deux espèees du genre thé, savoir: thea bohea, qui a six pétales à sa corolle, et le thé vert, thea viridis, qui en a neuf. Mais eeltc distinetion, unirquement fondée sur le nombre des pétales, 
n'a point été adoplée par plusieurs modernes, qui regardent ces deux espèces, ct même les trois mentionnées par Loureiro dans sa Flore de la Cochinchine, commc de simples variétés produiles par suite d'une longuc culture.

L'arbre à thé est originaire des contrécs crientales de l'Asic. Il croit naturellemeut en Chine, au Japon ct dans d'autres pays voisins, où il est aussi l'objet d'unc culture extrêmement snignée. Tantôt on le plante sur la bordure des champs. Plus souvent on en formc des espéces de quinquonces sur le penchant des coteaux. Ce n'est guèrc qu'au bout de trois à quatre ans, que l'on commencc à recueillir les feuilles sur les jeunes pieds de thé, et cette récolıc cesse lorsque ces arbrisseaux ont alteint huit à dix ans. On les recèpe alors de la base, et c'est sur les jeuncs pousses développées par lcur souche, quc l'on recommence la récolte des feuilles.

En Chinc ct au Japon, cette récoltc a lieu deux fois dans l'année, au printemps etver's le mois de septembrc. Les feuilles de la première cucillette forment un thć plus fin et plus estimé. Voici le modc de préparation qu'on lcur fait subir.

On plonge ces feuilles dans de l'eau bouillante, et on les y laisse seulement pendant une demi-minute. On les retirc, on les égoutte et on lcs jette sur des poëles de fer, grandes ct platcs, qui sont placées au-dessus d'un fourneau. Ces espèces de poc̈les doivent ĉtre asscz chaudcs pour quc la main de l'ouvrier en endure la chaleur avec peine. Les feuilles doivent être continuellement remuécs. Lorsqu'on juge qu'ellcs ont été assez chauffées, on les enlève ct les étend sur de grandes tables recouvertes de nattes. D'autres s'occupent alors de les rouler avec la paumc de la main, tandis qu'un ouvrier cherclie à lcs refroidir cn agitant l'air avec de grands évcntails. Cette opération doit être continuéc jusqu’à cc que les feuilles soient complélenient refroidies sous la main de celui qui les
roule.

Cc premicr tcmps a pour objet de blanchir les feuillcs et de les priver du suc âcre et vircux qu'elles contiennent. Celle opération du grillage, sur les plaqucs de fer, doit êtrc répútće dcux ou trois fois, en ayaul soin de les chauffer dc moins cn moins, ct de rouler Ics fcuilles avec plus de soin. Pour quelques 
espèces de tliés fort estimées, chaque feuille doit être roulée isolément.

Lorsque le thé ainsi préparé a été parfaitement séclić,avant de le renfermer dans des boittes ou des eaisses, on l'aromatise avee différentes plantes odoriférantes. La connaissance de ces végétaux a long-lemps été un secret pour les Européens. Mais on sait aujourd'hui généralement que les Clinois emploient pour cet usage les fleurs de l'olea fragrans, dn camellia sasangua, arbrisseau de la mème famille que le thé, et peut-être celles de la rose à odeur de thé, que nous avons naturalisée dans noś jardins depuis quelques années.

Le nombre des valiétés ou sortes de thés du eomneree est extrêmement éonsidérable: Elles dépendent; en général, de l'état plus ou moins avaneé de développement où l'on a eueilli les feuilles, du soin avee lequel elles ont été blanchies et roulées, et surtout de leur grillage plus ou moins long-temps prolongé. Nous allons faire connaitre ces variétés principales, et surtout celles qui méritent la préférence.

On peut diviser les espèces de thés en deux sections, les thés verts et les thés noirs: Les premiers ont une couleur verte ou grisâtre. Tls sont plus âcres, plus aromatiques, que les seeond่s; dont la couleur cst plus on moins brune, et qui sont généralement plus doux et donnent une infusion d'une enuleur plus fonece.

Parmi les thés verts nous distingierons :

I' Le thé hayswen: C'est une des meilleures sortes, et eelle dont'on fait le plus d'usage en France. Il est d'une teinte vertebleuấtre. Ses feuilles sont grandes, roulées dans le sens de leur largeur. Son odeur est agréable et sa saveur astringente.

$2^{\text {o }}$ Le the perlé, ainsi numné jarce que ses feuilles sont plus roulées sur elles-unêmes, et offrent une forme presque globuleuse. Il est eomposé de feuilles plus jeunes et plus minees que le thé hayswen. Son odeur est plus agréable et sa couleur plus brunc. Cetie forme arrondie des grains du thé perlé provient de eé que les feuilles, après avoir été roulées dans le sens de leur longueur, sont replićes sur elles-mèmes dans leur largenr.

$3^{\circ}$ Le thé poudre it canon est ehoisi parmi les deux sortes 
préeédentes, et se compose des feuilles les plus petiles et les plus exaetement roulées sur clles-mémes, de manière à avoir quelque ressemblance, pour Ia grosseur, avee la poudre à eanon. Cettc espice est fort agréable, recherehée, et. d'un prix ćlcvé.

$4^{\circ}$ Le thé schulang ou'téhulun est rarc daus le commerce. If a tous les caractères $d u$ thé hayswen; mais son odenr est infiniment plus suave et plus développée.

A u nombre des thés noirs; nous mentionnerons:

$I^{\circ}$ Le ché saoutchon ou souchon. Il est d'un brun noirâtre, d'une odeur et d'une saveur plus faibles que les thés verts en général; formé de jeunes feuilles, lâehement roulées dans le sens de leur longueur. En gćnćral, on mćlange pour l'usage ordinaire un tiers de thé sonchon avec deux tiers de thé vert. L'infusion est plus colorée et moins âcre.

, $2^{\circ}$ I te thé peliao ou pelio, diffère per du précćdent. Sá couleur et. sa savenr sont lès mêmes. Son odcur' est plus suave. Il paraît formé de feuilles plus jeunes et reeouvertes d'un duvet plus abondant. On y trouve quclquefois, ainsi que dans la variété précédente, de petits fragmens de jeunes branches.

Toutes les espèces de thé doivent être soigneusement conservées à l'abri du contact de l'air et de la luinière. Pour eelá, on doit les placer dans des boîtes de bois oú de plomb, ou mieux encore dans des vases de poreelaine, hermétiquement fermés, et quc l'on ne doit jamais laisser débouclıćs.

L'analyse ehimique du thé a élé faite, il y a plusienrsannées, par Cadel de Gassicourt, qui en à retiré, par le moyen de la distillation, une eau astringentc sa uns aucune trace d'huile volatile, un extrait amer et styṕlique, composé d'acide gallique

l'endant long-temps on a atribué la couleur verte de cer. taines espèces de thé aux pláques dc cuivrc sur lesquelles on les fait sćcher; mais l'analyse chimiguc a proứ le peu de fondement de celle assertion.

Propriétés è usagès du thè. En considćrant eombien l'usage du thé est répandı dans presq́ne toules les parties de l'Europe, on s'étonnera que l'introduction de eetle substance, devenue, en quelque sorte, de première nécessité pour certains peuples, ne remonte pas au delà du milien dix-septième sièele. Ce sont. les 
IIollandais, le seul peuple de l'Europe auquel les ports de la Chine et du Japon soient ouverts, q1i Ics premiers firent eonnaître aux Européens les usages et les proprićtés du thé, el qui ont ainsi rendu l'Europe tributaire de la Cline, pour une somme qui aujourd'hui excèdc cent vingt-cinq millions de francs par année.

Nous ne répéterons point ici les éloges qui ont été prodigués au thcé, ni tous les inconvéniens et tous les maux dont on a aeeusé son usage d'être la source. C'est auprès des peuples qui en font habituellement usage, ct pour lesquels cettc boisson est devenue pun véritable besoin, qu'il faut rccueillir les faits propres à éclairer cette question. Or les Anglais, lcs Hollandais, les Belges, les Danois, les Sućdois, les Russes, les $\Lambda$ ngloAméricains, sont loin de eonsidérer le tlić comme une boisson dangcreuse. Chez li plupart de ces peuples elle a un avantage lrygiénique incontestable. Vivant dans un pays eouvert pendant une partie de l'année de brouillards, au milieu d'une atmosphc̀re froidc et humide, le thé, par la légçrc excitation qu'il développe, et'surtout par la quantité d'eau chaude qu'il introduit dans l'cstomac, entretient le corps dans un état de diaphorèsc indispcnsable au libre exerciee des fonctions et à l'entretien de la santé.

L'usage de eette boisson eommence depuis plusieurs années à se répandre plus gćnćralement en France. Il est rare daus les classes aisćes de la sociélć, qu'une soirée d'hiver se passe. sans prendrc le thé.

Cettc boisson a le grand avantagc de favoriser la digestion. Aussi est-cc toujours quelque temps après lc rcpas que l'on en fiit usage, et sou administration cst, commc ehacrin sait, un remède vulgaire contre les nauvaises diggcslions.

L'11sage habitucl du thé, surtout lorsqu'on lc boil très-fort, ne convient qu'aux personnes d'un tempéramment mou ct lynphatique; mais les loommes d'unc constitution sèche et nerveuse, les femmes faibles et excitables doivent s'en abstenir, ou en corriger la tiop grande activité en y mélaugcant une quantité suffisante de lait.

Comme substanec nédicancnleusc, l'usitgc du thé est bien anoins élendu. Conıme loutes les autres substances stimulantes, 
il active et développe les différentes fonctions. La digestion est plus prompte, plus facile, le cours du sang plus rapide, l'exhalatior cutanće plus abondante, et les facultés intellectuelles plus développées.

C'est surtout pour favoriser la digestion, le cours des urines et celui des sueurs, que les médecins prescrivent quelquefois Pusage d'une infusion de demi-gros à un gros de thé dans une pinte d'eau bouillante. Quelques auteurs ont mêrne prétendu que l'usage habituel de cette boisson empêchait les calculs urinaires de se former dans la vessie, ou du moins favorisait singulièrement l'évacuatiou des petits graviers qui s'y développent si fréquemment; inais la première de ces assertions n'est malheureusement pas aússi vraie qu'on l'a prétendu.

QUATRE-VINGT-TROISIÈME FAMILIE.

\section{MÉLIACÉES. - MELIACE E.}

Les Méliacées, qui toutes sont des végétaux exo tiques, ont leur tige ligneuse, tantôt frutescente, tantó arborescente, et ayant leurs ramifications ornées d feuilles alternes, simples ou composées, mais toujours dépourvues de stipules.

Leur calice est monosépale, à quatre ou cinq divisions plus ou moins profondes. La corolle se compose de quatre ou cinq pétales sessiles, tantôt égaux entre cux, tantôt inégaux, quelquefois légèrement soudés par
leur base, de nanière à représenter une corolle monopétale.

Les étamines sont définies, quelquefois en même nombre que les pétales, d'autres fois en nombre double. Elles sont toujours soudées et monadelphes, tantôt par leur base seulement, de manière que la plus grande partic de leurs filets est librc; tantôt elles forment un long tube, qui enveloppe le pistil dans toute son étendue et présente les anthères à sa partie supérieure in-
terne ou externe. 
Le pistil est libre, environné par un petit disque hypogyne annulaire, sous lequel sont insérés les pétales et les étamines. L'ovaire offre quatre ou cinq loges, suivant le nombre de ses pétales, et dans chaque loge existent deux ovules insérés à l'angle interne et superposés. Le style est toujours simple, et se termine par un stigmate simple ou à quatre ou cinq lobes faiblement exprimés.

Le fruit est sec, très-rarement charnu, à quatre ou cinq loges, contenant chacune une ou deux graines et s'ouvrant en quatre ou cinq valves septifères sur le milieu de leur face interne. Les graines se composent en général d'un endosperme charnu, dans lequel est placé un petit embryon renversé.

Cette famille ne peut être confondue avec celles entre lesquelles elle est placée. Ainsi elle diffère des Auran'acées et des Théacées par la présence d'un endosperme lans sa graine; et en particulier de la première, par ses tamines définies et monadelphes; de la seconde, par ses étamines peu nombreuses. Elle se distingue des'Vitiginées par ses étamines monadelphes, et le manque de stipules.

\section{AZÉDAR ACH. - MELIA. L. J.}

Calice très-petit, étalé, à cinq lobes; corolle de cinq pétales étalés; ćtamines au nombre de dix, squdées ct monadelphes, formant un long tube cylindrique, denté à son sommet, et portant les anthères à la base des dents que l'on remarque à son sommet. Style épais, simple, terminé par un stigmate petit et à cinq lobes rapprochés. Fruit charnu, contenant un noyau a cinq loges dispermes.

Tige arborescente; feuilles composées.

Azédarach commun. Melia azedarach. L. Sp. 550.

Ce grand ct bel arbre, qui de l'Inde et de la Perse sa palrie, a 
été successivement naturalisé en Orient, en Amérique, et jusque dans les provinces méridionales de la France, pcut acqućrir une très-grande hauteur. Ses feuilles sont très-grandes, alternes, bipinnées. Chaque pinnule, qui forme une feuille imparipinnée, se compose de cinq, ou plus souvent de sept folioles opposćes, lancćolées, très-aiguës, d cntćes en scie sur leur bord, entièrement glabres.

Les fleurs, de couleur violette, répandent une odeur suave, analogue à celle du lilas, et forment une grappe pćdonculée ou une sorte de panicule dressće à l'áisselle des fenilles supérieures. Ces panicules sont plus courtes que les feuilles.

Le calice est très-petit, à cinq lobes obtus et lćgèrement pubescens. Les cinq pćtales, beaucoup plus longs que le calice, sont étalés ou méme un peu rabattus, obovales, allongés obtus.

Le tube staminal est dressé, un peu plus court que les pé. tales, renflé à sa base, d'une teinte violette plus foncée, offrant à son sommet vingt petites dents et dix anthères biloculaires, fixćes à la base interne de ces dents.

L'ovaire est globuleux, surmonté d'un style épais, de la hautcur du tube staminal, et terminć par un stigmate fort petit, à cinq lobes dressés et rapproehés.

Le fruit est une drupe charnue, ovoïde, de la grosseur d'une cerise, contenant un noyau allongé, à cinq côtes et à cinq loges.

On voit assez fréquemment cet arbre dans nos jardins d'agrćment. Cependant il est sensible au froid. Ses fleurs s'ćpanouissent pendant une partie de la belle saison.

Propriétés et usages. La racine d'azédarach a une saveur amère et nauséabonde. Dans l'Amérique septentrionale, où cet arbre cst aujourd'hui fort abondant, on emploie fréquemment sa racine comme anthelmintique. Les doctcurs Barton et Valentin ont signalé les heureux rćsultats dé son administration dans celte circonstance. Mais cependant cc médicament est à peu prc̀s inusitć en France.

Quant aux fruits de l'azćdarach, lcur saveur est fade èt nauséabondc. On pensc généraleinent qu'ils sont délétèrics. M. Turpin, au contraire, assure qu'en ayant donné en irès- 
grand nombre à des chiens, ils n'en ont éprouvé aucun dérangement. Il parait même que, dans les dcux Carolines, les enfans mangent ces fruits sans en être incommodés.

Dans l'Inde on retire de la pulpe de ccs fruits et de ceux d'une autre espèee de ce genre, nommée melia azedirachta, L., une huile grasse, employéc à divers usages ćconomiques, et particulièrement pour les lampes.

Cet exemple du périearpe fournissant une huile grasse, est, a vee l'olivier, le seeond que l'on connaisse. L'on sait, en effet, que e'est de la graine que l'on retire ce principe immédiat dans tous les autres végétaux.

\section{WINTÉRANIE.-WINTERANIA. L. J.}

Calice à trois lobes trc̀s-obtus; corolle de cinq pćtales. Dix étamines monadelphes formant un tube, sur les parois externes duquel sont insćrées dix anthères cordiformes, biloculaires. Style terminé par un stigmate à trois lobes. Baie contenant une, deux ou trois graines.

Tige ligneuse, feuilles simples.

Wintéranie canelle blanche. Winterania canella. L. Sp. 636.

Canella alba Murrai.

Part. usit.: l'écorce. Nom pharm. : Canella alba. Noms vulg. : Canelle blanche, Fausse écorce de Winter.

Cet, arbre peut s'élever à une hauteur de vingt à trente pieds. Ses ramifications sont couvertes d'une écorce grisâtre, presque blanche, et portent des feuilles alternes simples, presque sessiles, obovales, obtuses, entières, rétrécies en pointe à leur partie inférieure, d'un vert clair, entièrement glabres et luisantes à leur face supérieurc.

Ses fleurs forment des espèces de grappes terminales. Leur calice est coneave, à trois divisions très-larges et trc̀s-obtuses, se recouvrant un peu par leur partie latćralc. Leur corolle se compose de pétales élargis à leur base, un peu épais.

Les étamines sont au nombre de dix, entièrement mona- 
dclphes. Leurs filets forment un tube ouvert et rétréci dans sa partie supérieure, qui est entière et non dentée; portant les dix anthères appliquées sur les dcux tiers supérieur's de sa faec externe. Ces anthères sont allongćes eordiformes, à deux loges, immédiatement contiguës par leur's parties latérales.

L'ovaire cst ovoïde, allongć, à trois loges. Le style est épais et court, et se termine par un stigmate légèrement irilobé.

Le fruit est une baie globuleuse, eontenant une, deux ou trois graincs noires et luisantes.

Cet arbre croît naturellement à la Jamaïque et dans d'autres Iles du golfe du Mexique.

Propriétés et usages. Après avoir enlevé l'écoree des jeunes ramcaux avee un instrument de fcr, on la fait sécher à l'ombre. Cette éeorce est en plaques roulées, de cinq à six ponces de longueur, de deux à trois lignes d'ćpaisseur, d'une eouleur. grise-blanchâtre, légèrement rosée; d'une saveur amère, âcre et aromatique. Analysée par M. Henri, elle ne lui a présenté ni tannin, ni sulfate de polasse, ni oxide de fer, caractères qui la distinguent chimiquement de l'écorce de Winter, avee laquelle on la confond souvent dans le commerce. De la le nom de fausse écorce de Winter, qui lui a été donné par Cartheuser. L'ćeorce de'canelle blanche est, en gćnéral, d'une couleur plus pâle et d'un tissu plıs lâche que la vćritable écorce de Winter.

Commc elle, e'est un médicanent toniquc et stimulant assez. énergique, mais cependant peu employé. On lui prćfère, en général, la canelle de la Chine, comme infiniment plus active et plus suave. Dans les Antilles on emploie comınunément la eanelle blanchc eomme condiment.

Quelques auteurs prétendent qué la résine alouchi dćeoule naturellemcnt dc ect arbre, assertion qui est loin d'êtrc prouvée.

\section{Propriétés médicales et usages des Méliacées.}

On eonnaît peu les propriétés médicales des plantes qui forment la fanillc des Mćliacées. A en juger par celles qui nous sont mieux eounues, ces propriélés offrent per d'analogie. Ainsi tandis que l'écoree dc la canelle blanchc est aromatique 
et stimulante, celle de l'azédarach est nauséeuse, et celle du Srvieteniafebrifuga amère et fébrifuge. On a d'abord rapporté à eette famille le cusparia febrifuga, 'jui fournit l'éeorce d'anguslure vraie; mais cet arbre est beaucoup mieux placé dans la famille des Rutacées, où nous en traiterons prochainement.

Le bois d'acajou, si recherché en Europe pour les ouvrages d'ébénisterie, est celui d'un arbre de cette fámille, originaire des Indes, et qui porte le nom de Sirietenia Mahagoni.

QUATRE-VINGT-QUATRIËME FAMILLE.

\section{VINIFÉRÉES. VINIFEREAE.}

Cette famille, composée d'un très-petit nombre de genres, a la vigne pour type. Elle est formée de végétaux sarmenteux, s'enlaçant autour des corps voisins par la torsion de leur tige, s'y maintenant par le moyen des cirrhes ou vrilles dont elle est mmnie. Les feuilles sont alternes, simples ou digitées, accompagnées de deux stipules à leur base. Les vrilles sont toujours opposées aux feuilles, et sont généralement rameuses et tordues en spirales.

Les fleurs sont petites, verdâtres, disposées en grappes opposées aux feuilles. Leur calice est extrêmement court, sinueux; leur corollc est formée de quatre à six pétales sessiles, quelquefois soudés par leur partie supérieure, dc manière que la corolle s'enlc̀ve d'une seule pièce, en formant une sorte de petit capuchon. Les étamines sont opposćes aux pétales.

L'ovaire est accompagné d'un disquie hypogyne et annulaire, sinueux et comme lobé sur son bord libre. Cet ovaire est à deux $\log c s$, contenant chacune deux ovules dressés. Le style est court et épais, terminé par un stigmatc peu distinct, légèrement bilobé.

Le fruit est une baie ovoïde on globuleuse, contenant d' une à quatre graines. Celles-ci se composent d'un tégn• 
ment épais, dur et coriace, d'un endosperme cartilagineux, qui renferme à sa partie inférieure un ëmbryón dressé.

Cette famille est extrêmement distincte par le port tout particulier des végétaux qui la composent. On ne peut la confondre ni avec les Viéliacées, qui ont les étamines monadelphes en nombre double des pétales, et qui sont dépourvues de stipules; ni avec les Géraniacées, qui ont l'ovaire à cinq loges, dix étamines, dont cinq avortent quelquefois, et un fruit sec composé de trois à cinq coques monospermes.

$$
\text { VIGNE.-FITIS. L.J. }
$$

Calice trc̀s-court et sinueux, ou légèrement denté; corolle de cinq pétales adhèrens par leur partie supérieure, et s'enlevant comme une sorte de coiffe. Cinq étamines opposées aux pétales. Style très-court ou nul. Baie à deux loges, contcriant chacune deux graines dressées, dont uné ávorte assez souvent.

Arbustcs sarmenteux ayant les feuillès alternss; lćs vrillés et les grappes de fleurs opposées aux feuilles.

Vigne cultivée. Vitis vinifera. L: Sp. 293. Blackw.

$$
\text { t. } 155 \text {. }
$$

Arbrisseau sarmenteux, qui peut acqućrir unc hauteur considérable en s'enroulent autour des arbres voisins, et dont l'écorce est fibreuse et peu adhérente au bois.

Feuilles alternes, péliolées, ćchancrées à la base, presque arronáies, à cinq lobes aigus, doublement dentés, velus ou tómenteux à leur face inférieure. Pétiole cylindrique, strié, renflé à sa basc. Vrillcs tournées en spirales, rameuses, opposées aux feuilles, servant à élever et à fixer les rameaux aux corps environnans.

Fleurs trc̀s-petites, verdâtres, disposées en gráppes opposéeś aux feuillcs. Calice monosépale très-pétit, étalć, cupuliformé; et persistant, à limbe un peu sinueux. Carolle de cinq.pétales 
verts, libres par leur partie inférieure, réunis ct soudés supérieurement, soulevés d'une scule pièce cn formc de petite cloche par les élamines. Cclles-ci sont au nombre de cinq, opposćes aux pélales, attachées à la base de l'ovaire. Filcts grêles et subulés : anthères cordiformes, biloculaircs, jaunes, attachées par le milieu du dos.

Pistil pyriforme, nn peu plus court que les étamines. Ovaire libre; ovoïde, acuminé à son sommet, à deux loges, contenant chacune deux ovules dressés. Le stigmate est presquc sessile, capitulé, un peu bilobé. Autour de l'ovaire on trouve un disque annulaire.

Le fruit, que l'on appelle raisin, est une baie à une ou deux loges, et renferme d'une à quatre graines.

Dans notre climat, cet arbuste fleurit an mois de juin, et quelquefois même de juillet, et ses fruits sont parfaitement mûrs en septernbre et octobre.

La vigne est originairc de l'Asie, d'où elle passa successivement en Grèce et en Italie. Ce furent les Phéniciens, à ce que l'on croit généralement, qui la transportèrent dans les Gaules, à l'époque où ils vinrent établir leur colonie sur lcs bords de la Méditerranée, aux environs de Marseille. Aujourd'hui la vigne est culiivée dans toutes les contrées tcmpérées de l'Europe. On en rencontre beaucoup de pieds à l'état sauvage dans les haies et sur les rochers de plusieurs provinces de la France. Elle porte généralement dans cet érat le nom de lambrousque. Le nombre des variétés de vignes culivées en grand est extrêmement considćrable. On sait que les raisins sont tantôt d'un vert jaunâtre, tantôt d'un rouge violet, plus ou moins foncé. La grosseur des grains varie également beauconp. Ainsi, dans quelques variétés, ils acquièrent le volume du poucc, et dans d'autres ne dépassent pas la grosseur d'un pois. Dans le raisin de Corinthe, toules les graines avortent.

Propriétés et usages. Qucl sujet inépuisable quc la vignc, si nous voulions entrer ici dans des détails étendus sur les produits varićs qu'elle fournit aux arts, à la thćrapeutique ct à l'économie domestique. Mais forcć de nous circonscrirc dans des limites étroiles, nous ne dirons que quclques mots de chacune de ses utiles productions. 
Lorsqu'au retour du printemps on retranche de la vigne ses rameaux inutiles, on voit s'écouler en abondancc, des plaies qui en rćsultent, des goutteleltes d'un liquidc aqueux, fout-àfait incolore, d'une saveur à peinc aigrelette. C'cst la sève, qui déjà s'était mise en mouvement. La médecine populaire emploie fréquemınent ce liquide dans les ophthalmics chroniques. On l'a même regardć commc diurćtique, incisif, etc. Analysé par M. Deyeux, il s'est montré composé d'une matière vćgétoanimale, d'acide acétique et d'acćtatc de chaux. C'est un remc̀de à peu prc̀s inerte, qui ne mérite pas d'être employé.

Les feuilles de la vigne ont une savcur âpre et astringente. Elles sont fort recherchées par les animaux herbivores. Quclques aateurs en ont recommandé l'usage dans le traitement de la diarrhée, et en gćnćral des catarrhes chroniques.

Avant leur parfaite maturité, les grains de raisins ont une saveur astringente. Le suc que l'on en extrait est fort acide. Sous le nom de verjus, on l'emploie pour assaisonnèr les viandes ou certains légumes. Mais c'est à l'époque où les raisins sont parfaitement mûrs, qu'ils forment un des fruits les plus agréables et les plus savoureux. La pulpe qu'ils rcnferment est extrêmement succulente, douce et sucrée. Ils sont rafraîchissans, légèment laxatifs, surtout lorsqu'on en mangc beaucoup à la fois. On a vu leur usage long-tcmps continuć amener des changemens favorables dans certaines maladies chroniques, tclles que des engorgemens des viscères abdominaux, dans les dartres ou d'autres affections cutanćes, dans la phthisie, la fièvre hcctique, etc.

Les raisins secs ne.sont pas moins utiles ni d'un goût moins agréable. Ils sont généralement plus sucrés. On les prćpare en lcs faisant sćcher au four, après les avoir trempé dans unc lessive alcaline. Les plus estimés sont ceux qui vicnnent de la Syrie, des îles de la Grc̀cc et des contrées méridionalcs de l'Europe. On les sert fréquemment sur nos tables, surtout pcnỏant l'hiver, ct la médecine les comptc, a vec lcs figucs, les daltes, lcs jujubes, parmi les fruits adoucissans et béchiques.

Le suc que l'on extrait par expression des raisins frais ct bien mûrs, porte le noin de moût. C'est un liquidc ćpais, wiı pcu tronblc, d'unc savcur douce et très-sucréc. Il cst fort nour- 
rissant. On peut l'employcr conme le miel pour édulcorer plusicurs préparations. Il sert également à préparer des gelées, des confitures, etc.

Le vin est, sans contredit, le principe le plus intéressant que fournisse la vignc. Tout lc monde sait qu’on le prépare en soumettant le raisin à la fermcntation. Dans les premiers jours de celle opération il a d'abord une saveur très-sucrée; mais pctit à petit cette saveur sucrée diminue, à mesure que la fermentation s'opère, parce que la plus grande partie du sucre se change en alcohol. Le vin préparé aver du raisin noir, dont on a laissé l'enveloppe dans la cuve où il a bouilli, a une tcinte violacée plus on moins intense, el forme lc vin rouge. 'Lc vin blanc, an contraire, se fait avec du raisin blanc, ou bien du raisin noir, que l'on a privé de son enveloppe pendant la fcrmentation.

Il est peu de substances qui offient autant de variations que le vin. Quclle ćnorme diffćrence n'existe-t-il pas, pour la saveur, entre les vins spiritueux qu'on retirc dans les íles de la Grèce, l'Espagne, l'Italie, et ceux des coteaux de la Champagne ou des bords du Rhin! Les premiers sont alcoholiques, spiritueux, excitans et sucrés, les autres sont aigrclets et rafraîchissans. Cés différences de saveur, d'arome et de qualité se font également remarquer dans les vins recueillis en des lieux voisins les uns des autres. Elles tiennent non pas à des variétés spécifiques entre les arbustes qui les fournissent, mais à la différence dans leur exposilion, dans la nature du terrain qui les nourrit et dans les soins apportés à la fabrication de cette liqueur.

Cependant ces. différences, si appréciables au goût, échappent fréquemment à l'analyse chimique. Les seules que l'on observe dans les diverses espèces de vins tiennent à la proportion variable de leurs principes constituans, ct non à la présence de nouveaux élémens.

Tous les vins sont formés d'eau, d'alcohol, dont la quantité varic dc 9 à 26 parlies sur cent, suivant les espèces ct les qualitẻs; de mucilagge ct d'une matic̀re végéto-animale; d'un principc colorant bleu, passant au rouge par son mélange avec les acides (ce principe n'existe que dans les vins ronges); d'acide acétiquc; de lartratc acide de polassc; de tartrate de chaux; 
d'hydrochlorate de soudc; de sulfatc de potasse; d'un atome de tannin, elc.

On peut diviser les vins en trois classes, savoir : $x^{0}$ les vins spiritueux; $2^{\circ}$ les vins âpres; $3^{\circ}$ et les vins acidules.

$I^{\circ}$ Les vins spiritueux sont ceux qui se font remarquer par la grande proportion d'alcohol qu'ils renferment. Leur saveur est chaude et spiritueuse. On peut les sous-diviser en trois sections, savoir : les vins spiritueux sucrés : cc sont ceux que l'on n'a pas laissé fermenter assez long - temps pour que lous les principes sucrés se convcrtissent en alcohol. Tels sont les vins de Frontignan, de Lunel, de Malvoisie, etc. Les vins spiritueux cuits ne diffìrent des prćcédens, que parce que la fermentation a étć arrêtće par lc moyen du calorique; en sorte que ces vins sont aussi plus ou moins sucrés; tels sont les vins de Grenache, d'Alicante, et en général la plupart des vins d'Espagne. Enfin les vins spirilueux ct secs sont ccux dont tout le sucre a étć converti en alcohol, comme les vins de Madère, de Xères, etc.

En général, lcs vins contiennent d'autant plus d'alcohol, qu'on les récolte dans des pays plus méridionaux. Lcs vins spiritueux sont plus excitans que tous les autres, surtout ceux qui sont sccs.

$2^{\circ}$ Parmi les vins äpres nous comprenons les vins dc Bordeaux, de Bourgngne, des bords du Rhône, ctc. Ils contiennent moins d'alcohol que les précédens. Leur saveur cst plus ou moins âpre, surtout lorsqu'ils ne sont point encore faits. Ils sont nourrissans et toniques.

$3^{\circ}$ Quant aux vins aigrelcts, ils sont ordinairement blancs, et leur saveur est plus ou moins acidule. Ils sont mousseux, lorsqu'ils ont ćté mis en bouteilles avant que la fcrmentation soit achevće. L'acide carbonique, qui continue à se former, se combine avec lc vin et tend à se dégager avec rapiditć quand on enlćve l'obstacle qui s'opposait à son expansion : tcls sont surtont les vins de Clyampagne. On peut rcindrc mousseux toute espécc de vin blanc, en y ajoulant une certaine quantilé dc sucre, lorsfu'on le met cn bouteilles. Parmi les vins aigrelets non moussenx, dous citcrons surtout les vins du Khhin. Xls sont en général plus on inoirıs diurćti quics. 
Nious ne parlerons point des usages du vin conme boisson diétćtique ou médicamenteuse. Nous n'agitcrons pas de nouveau la question oiseuse, de savoir si la eonnaissancc de cette liqueur fut plus funeste qu'utile à l'espèce humaine. Nous dirons simplement que l'usage modéré du vin, surtout lorsqu'il est vicux et de bonne qualité, ranime les forces épuisées, développe les faeultés intellectuelles, rend l'homme plus gai et. plus confant, tandis que son abus lc jette dans une exaltation, bientôt suivie d'une sorte de stupeur, d'hébêtement des facultés des sens et de l'esprit, et le plonge dans un état voisin du cuma et l'apoplexie. Si des poëtes et des artistes célc̀bres ont puisé dans cette liqueur les inspirations heureuses de leur génie, un plus grand nombre y ont ćteint le flambeau créateur que la nature s'ćtait plu à allumer en eux.

Comme médicament, le vin doit être placć à la tête des toniques. Mais pour qu'il produise d'heureux effets, il doit être administré à des individus qui n'en font pas habitucllement usage. On doit alors choisir l'espèee et la qualité du vin, suivant l'effet qu'on vcut produirc, et se rappeler quc les vins spiritueux sont cxeitans et diffusibles; lcs vins rouges et âprcs toniques, et les vins blancs et acidules diurétiques. On doit choisir, autant que possible, des vins vieux et de bonne qualité pour l'usage médieal.

On rend les vins médicamenteux par l'addition de subslances plus ou moins actives. Ils se préparent de deux manièrcs priṇeipales, savoir : en faisant macérer direetement les substances dans le vin, ou en les faisant digérer dans l'alcohol, que l'on ajoule ensuite à ce liquide. Ce dcrnier procédé, que l'on doit à Parmentier, est surtout préférable lorsquc l'on veut préparer les vins médicamcnteux cn petilc quantitć et extemporanćment. Préparćs de cette manière ils se conservent plus faeilement, et sont moins sujets à s'altércr.

Enfin c'cst avec le vin que l'on forme l'aleolol et le vinaigre. Par la distillation, on obticnt l'aleohol ou eau-de-vic, yui, outre l'eau qu'clle rcnfcrine, contient aussi plusicurs autres substances étrangères. $A$ combien d'usages n'cst pas curployé ce nouveau produit de la vigne? Dans l'art pharmaccutique, l'alcohol cst le dissolvant d'unc foule de sulstances, inalta- 
yuables par l'enu, telles que les résines, les baumes, les huiles essentielles, le canphre, lcs gommes-résines, etc. Il sert à la préparation des teintures, des éthers, ete. Dans l'éeonomie domestique, il est le menstrue des résines avcc lesquelles on prépare les vernis; il est cmployé à préparer les ratafias et toutes les liqueurs de table.

Si l'on abandonne le vin au contact de l'air, la fermentation acéteuse s'en empare et il se change en vincigre. Ce nouveau liquide diffère du vin par sa composition et son mode d'action sur l'écononie animale. Il sert à une foule d'usages dans les arts et l'éeonomie domestique, et forme la base d'un grand nombre de préparations pharmaceutiques. Rectifié et privé des substances étrangères qu'il renferme il forme l'acide acétique ou vinaigre radical.

C'est a vec le tartre qui se dépose sur les parois des bariques, quel'on prépare le tartrate a eide de potasse, l'aeide tartarique, et tous les médicamens dans la composition desquels ils entrent.

\section{Q́UATRE-VINGT-GINQUIÈME FAMILLE.}

\section{GE R A NIACÉES. - GERANI ACEA.}

Les genres qui composent la famille des Géraniacées ont entre eux la plus grande analogie dans leurs formes extérieures et leur organisation interne. Ce sont, en général, des végétaux herbacés, rarement sous-frutescens, portant des feuilles simples ou composées, alternes ou plus communément opposées, avec deux stipules entre chaque paire de feuilles.

Les fleurs sont souvent grandes et d'une couleur trèséclatante, et offrent différens modes d'inflorescence. Le plus souvent elles sont axillaires. Chaque fleur présente un calice monosépale, souvent persistant, à cinq divisions très-profondes, quelquefois un peu irrégulier, et prolongé à sa base en un éperon creux, plus ou moins long. La corolle, qui est formée de cinq pétales, est tantôt régulière, tantôt irrégulière. 
Le nombre des étanines varie de einq à dix. Leurs filets sont quelquefois tous libres et distinets; d'autres fois ils sont soudés et monadelphes par leur base; tantôt les filets sont tous anthérifères, tantôt un eertain nombre sont nus et dépourvus d'anthères. Ainsi, dans le genre Geranium proprement dit, les filets des dix étamines sont munis de leur anthère; trois sont nus, et sept anthérifères dans le genre Pelargonium; et enfin on en trouve cinq qui sont stériles, et einq qui sont terminés par une anthère, dans toutes les espèees du genre Erodium.

L'ovaire est tout-à-fait libre, à trois oll einq eôtes très-saillantes, présentant un égal nombre de loges, dans chaeune desquelles un ou deux ovules sont attaehés vers l'angle interne. Le style est long, simple et terminé par trois ou einq stigmates linéaires et divergens.

Le fruit se eompose de trois ou einq eoques uniloeulaires indéhiseentes, eontenant ordinairement une seule graine et réunies par un axe eentral. A l'époque de la parfaite maturité, ees eoques se détachent et se sépárent les unes des autres, entraînant quelquefois avee elles une partie de leur axe eentral et du style, qui forme à leur sommet une pointe plus ou moins longue.

Les graines eontiennent un embryon renversé qui est dépourvu d'endosperme.

Cette petite famille est extrêmement distinete, et par son port, et par ses earaetères. Elle se distingue des Viniférées par ses feuilles opposées, l'absenee des vrilles, son stigmate multiple, son fruit see, et ses graines dépourvues d'endosperme; des Malvaećes par ses feuilles généralement opposées, ses étamines toujours définies, son embryou, dont les deux cotylédons ne sont pas roulés, ete. 
Calice persistant, à cinq divisions profondes, corolle de cinq pétales égaux ou inégaux; dix ètamines monadelphes par la basc, libres dans leurs deux tiers supérieurs, ayant assez souvent trois ou cinq de leurs anthères qui avortent.

Fruit à cinq coques monospermes, rćunies sur un axe ccntral et se dćtachant de la base vers le sommet.

Plantes herbacćes, ou sous - frutescentes, ayant lcs feuilles opposées munies de stipules; lcs fleurs axillaircs.

Ainsi caractérisé, le genre géranion est un des plus nombreux en espc̀ces dans tout le règne végétal. Aussi les auleurs moderues l'ont-ils divisć en trois genres, que l'on peut, à la rigueur, ne considćrer que comme de simples sections d'un même genre. Toutes les espèces qui ont le calice ct la corolle réguliers, leurs dix ćtamines fertiles et anthćrifères, constituent le genre Geranium proprement dit. Les espèces en sont toutes herbacćes, assez nombreuses. Le genre.Erodium comprend toutes les espc̀ces dont la corolle est régulière, mais qui ont cinq de leurs filets dépourvus d'anthères. Elles sont herbacćes et peu nombreuees.

Enfin on a formé le genre Pelargonium du grand nombre d'espèces, souvent sous-frutescentes, qui ont la corolle plus ou moins irrégulic̀re, et trois de leurs ćtamines privées d'anthères. Tous les Pelargonium sont exotiques, et la plupart originaircs du Cap de Bonne-Espérancc. C'est à ce genre qu'appartiennent les grandes et bclles espèces que l'on cultive dans les orangeries, telles que pelargonium zonale, pelargonium roseum, pelarigonium formosum, etc. Aucune des espèces de ce dernier groupe n'est en ployée en médecine.

$1^{\circ}$ Corollc irrégulière, dix étamines anthérifères. Geranium.

Géranion a robert. Geranium robertianum. L. Sp. 955. Part. usit. : toute la plante. Noms vulg : Herbe à Robert, Herbe ìl'esquinancie.

Sa racine est vivacc, et donnc naissance à des tiges dressées, 
rameuses, dichotomes, génieulćes et artieulćes, renflées à chaquc articulation, poilues, eylindriques et rougeâtres. Les feuilles sont opposées, pétiolées, profondément partagées en trois folioles pinnatifides, à segmens ovalcs, incisés, à dents arrondies et mucronées. Ces feuillcs sont rougcâtres et un peu poilues. Les stipules sont très-petites, aiguës et foliacćes.

Lcs fleurs sont rouges, géminćes, portćes sur des pédoncules axillaires plus longs que les feuilles, et bifurqués à leur sommet. Le calice est tubuleux, renflé à sa base, composé de cinq sépales ovales, laneéolés, mucronés au sommet, offrant deux ou trois côtes saillantes. La corolle est formée de cinq pétales obovales, arrondis, obtus, cntiers, longuement onguiculés à la base, le double plus longs que le ealice. Les étamines sont au nombre de dix, toutes anthérifères et fertiles.

Le fruit est globuleux, à einq côtes et à cinq coques à sa base, à surfaee ehagrinée et un peu velue; surmonté par un appendiee pyramidal, pentagone et glabre, terminé par une pointe plus ou moins longuc.

Cette plante croît trc̀s-abondamment le long des murailles, dans les déeombres et les lieux ineultes. ₹f

Proprićtés et usages. L'herbe à Robert exhale une odeur forte et très-dćsagréable. Sa saveur est manifestement astringente. On faisait autrefois un plus fréquent usage de eette plante que maintenant. Sa décoction ćtait employée sous forme de gargarisme dans le traitcment des affeetions des amygdales, $\mathrm{du}$ voile du palais et du gosier. Quelques auteurs ont prescrit le sue que l'on en exprime, dans les caleuls de la vessie, et même contrc les hémorrhagies. Mais cette plante est à peu près inusitée aujourd'hui, dans toutes ces eirconstances. La médeeine populaire cn fait seule usage.

Plusieurs autres espèces de ee genre ont ćté jadis employées danss les mêmes circonstances, tels sont les Geranium gruinum, ou bee de grue, Geranium sanguineum, Geraìium pratense, etc. 
$2^{\circ}$ Cinq des filets sont privés d'anthère. Enovrux.

Érodion Musqué. Erodilim moschatum. Willd. Sp. 3. p. $63 \mathrm{r}$.

Geranium moschatum. L. Sp. 95 r.

Cette petite plante est annuelle ou 'quelquefois bisannuelle. Sa tige est étalée, rameuse, diffuse, herbacée, velue, coudće, cylindrique.

Les feuilles sont opposćes, imparipinnées, pétiolées, velues, à folioles alternes, ovales, obtuses, incisćes et dentées; la foliole? terminale plus grande et tripartite. A la base de chaque paire de feuilles sont trois stipulcs scaricuses, très-minces, obtuses, deux d'un côté, une seule de l'autre.

Les fleurs sont petites, violacées, redrcssées, disposćes au nombre de luit à dix en sertule ou ombelle simple, portće sur un pćdoncule commun, axillaire, dressć, velu, quelquefois un peu plus long que les feuilles; chaque fleur est supportée par un pédicelle horizontal, redressé seulement à son sommet.

Le calice est pentasćpalc persistant, ćtalé; les sépalcs sont ovales, lancéolés, acuminés, concaves, glabres en dessus, veJus et striés cn dessous. La corolle est pcntapćtale; les pétales sont dc la longueur des sépales, elliptiques, entiers, obtus, terminćs inférieurement par un onglet court. lls sont. trćs-caducs. Les étamines sont au nombre de cinq, dressées contre le pistil; leurs filets sont grêles ct alternent avec cing ćcailles minccs, larges, plus courles, souvcnt fendues, qui sont cinq étanines avortécs. Les anthères sont violetles, didymes, arrondies, attachées par le milieu du dos. En dehors et à la base des cinq étamincs fertilcs, sont cinq petites glandes vertes, qui constituent une sorte de disque extérieur.

Le pistil estdc la hanteur des ćtamines; l'ovaire globulcux, के cinq côtes saillantes, couvertes de soies blancliâtrcs, à cin प loges, renfermant chacune un seul ovule; le style gros et pyraınidal, à cinq faces, terminć à son sommet par cinq stigmates, linéaires, recourbés cn dehors à leur partie supćricurc.

- Le fruit est formć d'un axe ccntral, prismatique, très-allongé, aigu, qui est le style persistant et rlćrcloppé, à la base duque! 
sont cinq coques ou akènes, terminćs supérieurcment par une arête longue grêle, velıe en dcdans, qui s'attaclic' au sommet de l'axc. Ces coques sont velues en dehors.

Cette espèce croît dans plusieurs provinces de la Francc, en Langucdoc, en Bretagne, en Picardie, etc. Elle fleurit en mai.

Propriétés et usages: ICette plante répand une odeur de musc très-prononcée. Son infusion théiforme est légèrement excitante et antispasmodique. On l'employait autrefois coinme diaphorétiquc. Mais aujourd'hui son usage est à peu prèsabandonnć.

\section{GAPUCINE. - TROP OE OLUM. L. J.}

Calice monosćpale éperonné à sa base, à cinq divisions profondes; corolle de cinq pétales, dont trois sont ciliés sur les bords; huit étamincs libres. Style terminé par trois stigmates. Fruit a trois coqucs monospermes et indéliiscenles.

Les feuilles sont alternes, déponrvues de stipules, et les flcurs sont axillaires.

\section{Capucine ordinarre. Tropoeolum majus. L. Sp. 490.}

Plante annuelle dans nos climats, dont la tige trcs-rameuse est couchée, glauq̨ue, légèrement pubescente vers ses extrémités, longue d'un à deux pieds.

Les feuilles sont éparses, sạs stipules, longucment pc̉tiolées, peltées, orbiculaires, un peı anguleuses; leurs nervures partent en rayonnant dı point d'insertion du pétiole, qui est un pẹ latéral; la face supérieure cst glabre, d'un vert foncé; l'inférieure cst lćgèrement pubescentc et d'un vert clair.

Les fleurs sont très-grandes, d'un rougc dc feu très-éclalant, elles sont portćes sur des pédoncules axillaires, cylindriques, glabres, longs de quatrc à six pouces.

Lc calice est irrégulier, coloré, monosépale à cinq divisions profondes, ovales, lancćolées, aiguës; les trois supérieures sont plus larges et sc prolongent en arricre du point d'attachc en un épcron allongé, grêlc, ercux, pointı, plus lonğ quc les divisions lu calice. 
La corolle est pcutapétale, irrégulière: les deux pélales supćrieurs sont obovales, obtus, rétrécis insensiblement en onglct à lcur base : les trois inférieurs plus longs, ovales, arrondis, entiers, sont portés sur des onglets très-étroits, ayant presque la mêmc longueur que le pćtale lui-mèmc, qui cst frangé et comme cilié sur ses bords à sa partie inférieure; ces pétales sont attachés sur le calice, les deux supérieur's, au dessus de l'ouverture de l'éperon; les trois inférieurs autour $\mathrm{du}$ pistil.

Les élamines, au nombre de huit, sont courtes, déclinćes vers la partie inférieure de la fleur.

L'ovaire cst eomme globuleux, à trois côtes très-saillantes et arrondies, striées longitudinalement, à trois loges qui renferment chacune un seul ovule.

Le style est dressé, triangulaire, trifide à son sommet; chaquc division porte un stigmate très-petit, à peine distinct. Le pistil paraît être formć de trois pistils réunis et sondés du côté intcrne.

Le fruit est un triakène: chacun des trois akc̀nes, convexe d'un côté et rccouvert de côtes irrégulières, offre deux faces planes du côté interne.

La eapucine est originairc du Pérou, où elle est vivace : on Ia cultive en France dans tous les jardins. Elle fleurit pendant la plus grande partie de l'été, et y est annuelle.

Propriétés et usages. Les différentes parties de cette plante ont une odeur vive et piquante, une saveur chaude, analogue en tout à celles des plantes Crucifc̀res, à côté desquelles clle vient se ranger par ses propriétés stimulantes, qui la rendent très-efficace dans lc scorbut, les scrophules, eic. Ses fruitslet scs flcurs confits dans lc vinaigre. scrvent d'assaisonnement.

L'usage médical de cctte plante n'cst pas aussi répandu qu'il mériterait de l'ćtrc. C'est un stimulant extrêmement éncrgoique, et qui pcut être comparé aux meilleurs antiscorbutiques produits par la famille des Crucifères.

Propriëtés médicales et usagres des Géraniacées.

Quoiqu'un grand nombre de plantes de la famille des Géraniacées fasse l'ornement $\mathrm{dc}$ nos jarriins et de nos serres, un 
très-petit nombre d'entre elles eependant méritent quelqu'intérêt sous le point de vue médieal. L'astringence que nous avons signalée dans l'herbe à Robert se retrouve dans un grand nombre d'espèces du mème genre, et leur eommunique. une aetion tonique, mais peu intense. Dans quelques autres Géraniaeées, il existe un principe aromatique et stimulant, comme, par exemple, dans la eapueine, en sorte que presque toutes les plantes de ee groupe exereent une action exeitante sur l'économie animale.

\section{QUATRE-VINGT-SIXI ĖMIE FAMILLE。 \\ OXALIDEES. - OXALIDEAE.}

Le genre Oxalis avait été placé à la suite des Géraniacées par M. de Jussieı. Ce genre oflire, en effet, plusieurs caractères communs avec cette familie, mais cependant il en diffère tellement sous d'autres points essentiels, que les modernes ont cru devoir en former le type d'un nouvel ordre naturel sous le nom d'Oxalidées. Voici quels sont ses caractères:

Il se compose de plantes herbacées, annuelles ou vivaces, généralement dépourvues de tiges, ou ayant quelquefois cet organe réduit à la forme d'un ou de plusieurs tubercules charnus et souterrains, d'où naissent les feuilles et les hampes qui supportent les fleurs. Ces feuilles sont portées sur des pétioles plus ou moins longs, et se composent de trois folioles sessiles, sourent obcordiformes, qui naissent en divergeant du sommet du pétiole commun; très-raremént on ne trouve qu'une seule foliole, ou bien plus de trois au sommet du pétiole.

Les pédoncules qui portent les fleurs partent tantùt de la racine ou tige souterraine, ou de l'aisselle des feuilles caulinaires, dans les especes pourrues d'nne tige. Chaque fleur a un calice monosépale, persistant, à cinq divisions profondes; une corolle régulière, formice 
de cinq pétales, quelquefois. soudés ensemble par leur base, de manière à sembler constituer une corolle monopétale campanulée; dix étamines monadelphes, par la moitié inférieure de leurs filets, dont cinq sont plus courts et cinq, alternant avec les précédens, sont plus longs.

L'ovaire est libre, à cinq loges, contenant chacune de quatre à huit ovules, attachés à l'angle interne. Cet ovaire est surmonté de cinq styles, terminés chacun par un stigmate.

Le fruit est une capsule à cinq loges, environnée à sa base par le calice; chaque loge renferme plusieurs graines (rarement une seule par suite de l'arortement des autres); cette capsule s'ouvre en cinq valves, qui chacune se séparent longitudinalement en deux parties.

Les graines sont renversées, enveloppées dans un arille charnu, qui les recouvre en totalité, et s'ouvre avec élasticité par une suture longitudinale. L'embryon a la même direction que la graine, et se trouve renfermé au centre d'un endosperme charnu.

Cette famille se distingue des Géraniacées par ses graines enveloppées d'un arille, son embryon placé au centre d'un endosperme charnu, et par son fruit qui est une capsule, s'ouvrant en cinq valves, et contenant plusieurs graines.

\section{SURELLE. - OXALIS. L. J.}

Calice persistant à cinq divisions profondes; corolle de cinq pétales égaux, quelquefois soudés par leur base. Dix él, monadelphes; cinq styles et cinf stigmates. Capsule a cinc loges et à cincr valves, contenant ordinairement plusieurs graines arillées.

Plantes herbacces, annuclles on vivaces, ayant, on gínúral, les fenillcs irifoliolées. 
Suretre ache. Oxalis acetosella. L. Sp. 620. Part. nsit. : les feuilles. Noin vulg. Alléluia, Pain de coucou, cte.

Racine composée de petites fibrilles blanehâtres. Tige souterraine, horizontale, eylindrique, offrant de distanee en distanee des renflemens formés par des granulations squammiformes, eharnues, épaisses, de l'aisselle desquelles partent les raeines, les feuilles et les fleurs. Les feuilles sont radieales, et naissent au nombre de einq à six de l'extrémité de la souehe. Chaeune d'elles est pétiolée, eomposée de trois folioles arrondies, obeordées, pliées en deux suivant leur longueur, et souvent ehaeune de leur moitić s'applique l'une eontre l'autre: elles sont pubeseentes. Le pétiole est eylindrique, dressé, pubeseent, haut de trois à quatre pouees.

Les fleurs sont solitaires, pédoneulées, blanehes, au nombre de deux à trois. Les pédoneules, semblables aux pétioles, offrent au dessus du milieu de leur longueur deux braetées extrêmement petites, soudées à leur base.

Le ealice est monosépale, eampanulé, beaucoup plus eourt que la corolle.

La corolle est eampanulée, formée de cinq pétales obovales, obtus, très-minees, présentant à leur base trois appendiees; celui du milieu forme l'onglet, les deux latéraux sont obtus et appliqués eontre eeux des pétales voisins.

Étamines, au nombre de dix, hypogynes; einq alternes plus grandes, einq plus pétites; filets subulés, ģrêles, réunis inférieurement dans la longueur d'une demi- ligne. Les plus grands. sont plus eourts que les pétales; les plus eourts dépassent.le milieu de la hauteur des premiers; anthères didymes, trèspetites, pendantes, biloeulaires.

Ovaire allongé, à einq loges, eontenant ehaeune deux ovules: cinq styles divergens, terminés chacun par un stigmate simple, surmontent l'ovaire. La eapsule est à cinq angles et à einq loges.

Cetre petite plante eroît dans les bois ombragés et humides, aux environs de Paris, où elle fleurit en mars et avril.

Propriétés et usages. Les feuilles de la surclle ont une saveur 
acide et agréable, qui a unc analogic frapljantc avec celle de l'oseille. Cette saveur est duc, dans ces deux plantes, à la présence du mêtne principe, l'oxalate de potasse. Aussi ces fẻuilles sont-elles rafraîchissantes et légèrement diurétiques.: On fait quelquefois usage du suc quc l'on en exprime.

Mais c'est particulièrement à cause du scl qu'elle renfermc, que cette petite plante offre de l'intérct. Cet oxalate de potasse, que l'on connait sous le nom vulgaire de sel d'oseille, parce qu'on lc retire également de la plante qui porte cc nom, peut servir à préparer des limonades rafraîchissantes et agrćablcs. La dose est d'un à deux gros pour deux livres d'eau. C'est de lui que l'on retire l'acide oxalique, employć en chimie comıne un des meilleurs réactifs pour reconnaitre la présence de la chaux.

Le sel d'oseille est aussi fort en usagc pour enlever les taches d'encre sur le linge blanc, le bois, elc. Cctte saveur acidc, qui est si prononcće dans cette plante, existe aussi dans la plupart des autres espèces de ce genre, et forme le caractc̀re distinctif de cette petite famille, qui n'est encore composée que du seul genre oxalis.

QUATRE-VIVGT-SIPTI ĖME FAMILI, E。

\section{MALVACÉES. - MALVACEAE.}

Les plantes de cette famille ont ordinairement une tige herbaeée ou ligneuse, des feuilles alternes simples ou eomposées, accompagnées de stipules. Les fleurs offrent différens modes d'inflorescenee. Elles sont axillaires ou terminales.

Leur ealiee est monosépale à cinq divisions, le plus souvent environné d'un second ealice extérieur', ou calicule, divisé en un nombre variable de segmens. La corolle est for'mée de einq pétales, ordinairenıent soudés et confluens par leur base avee la substanee qui forme les filets des étamines, en sorte que la eorolle tombe fréquemment d'une seule pièee, emportant avec elle les étamines. Celles-ci sont ou fort nombreuses, réunies en 
tube par lcurs filets et monadelphes, ou seulement au nombre de cinq à dix, dont quclques-unes avortent quelquefois, ou ont leurs filets privés d'anthères. L'ovaire est le plus-souvent simple, formé d'un grand nombre de côtes saillantes, qui correspondent chacune à une loge; d'autres frois il est globuleux et à cinq loges, qui contiennent un ou plusieurs ovules.

Le style est quelquefois simple; d'autre fois il est partagé en un grand nombre de dirisions, portant chacune un stigmate. Le fruit est ordinairement composé d'un grand nombre de petites capsules indéhiscentes, uniloculaires, monospermes, disposées en cercle et très-serrées les unes contre les autres; d'autres fois, c'est une capsule à cinq loges polyspermes, ou cnfin un fruit coriace, charnu intérieurement et restant indéhiscent.

Les graincs sont dépourvues d'endosperme et contiennent un embryon qui a la même direction qu'elles, et dont les cotylédons sont en général plissés.

I. Étamines nombreuses. Fruits composés de petites coques rapprochées circulairement.

\section{- GUIMAUVE.-ALTHAEA. L. J.}

Calice monosépale à cinq divisions; calicule offrant de $\operatorname{cin} q$ a neuf lobes aigus. Pétales échancrés ou entiers. Étamincs nombreuses. Capsules monospermes inđéhiscentes, réunies eu cercle à la base du style.

Goimaúve officinale. Althaca officinalis. L. Sp. 966 .

Part. usit. : La racine, les feuilles.

Racine fusiforme pivotante, charnue, blanche, dc la grosseur du doigt indicatcur, longue d'environ un pied, simplc ou quelqquefois rameusc, donnant naissance à une lige herbacéc, dressée, cylindrique, tomenteusc, ainsi que toutes les partics herbacćcs de la plante.

Les fenilles sont alternes, pćtiolécs, molles, douces an tou- 
cher, eordiformes, à trois ou einq lobes peu marqués, aigus, créıelés; deux stipules membraneuses, eaduques, pubeseentes, divisées profondément en deux ou trois lanières étroites, existent à la base de ehaque feuille.

Fleur's blanehâtres, ou légèrement lavées de rose, presque sessiles, axillaires, formant une espèee de panieule à l'extrémité de la tige. Caliee double; l'extérieur a neuf divisions étroites, aiguës, plus eourtes que l'intérieur qui en offre einq, ovales, aeuminées, très-aiguës. Corolle de einq pétales subeordiformes, entiers, rétréeis inférieurement, où ils sont unis avee la substanee des filets anthérifères, de manière à reeouvrir et eaeher entièrement le pistil.

Étamines en nombre indéterıniné, monadelphes; filets subulés et distinets vers leur partie supérieure, réunis dans leurs deux tiers inférieurs en un tube traversé par le style. Anthères réniformes transversales, attaehées par le milieu de la faee inférieure, uniloeulaires.

Ovaire libre, très-déprimé, arrondi, pubeseent, diseoïde, marqué dans son eontour d'un grand nombre de eôtes, présentant intérieurement un grand nombre de loges monospermes, qui dans le fruit sont autant d'akènes eomplets, offrant un axe eentral très-épais, auquel ils sont attachés.

Style plus eourt que le tube des étamines, glabre, eylindrique, fendu supérieurentent en huit ou neuf divisions étroites; ehaeune d'elles est terminée par un stigmate eapitulé, très-petit.

Fruit orbienlaire très-déprimé, tomentenx, relevé de eôtes, qui sont ehaeune autant de petites eoques mouospermes, et enveloppé par le ealice persistant.

La guimauve eroit dans les ehamps eultivés : elle fleurit en juin et juillet. $z$

Propriétés et usages. Sa raeine est peut-être ull des médieamens les plus fréquemment usités. Elle donne par son ćbullition dans l'eau un mueilage très-abondant. Elle est employée avee succès pour eombaitre l'inflammation.

Ses feuilles et ses tiges peuvent être employées aux mẻmes usages. Ce médieament est surtout preserit pour l'usage externc. 
Guimauve roșé tremière. Althcea rosea. Cavan.

Dissert. 2. t. 28 . f. $x$.

Alceea rosea. L. Sp. 966 .

Part. usit. : les feuilles.

Plante annuelle, dont la tige dressée, droite, simple, cylindrique, pubeseente, s'élève quelquefois à quatre ou huit pieds.

Ses feuilles sont grandes, alternes, pétiolćes, subcordiformes, légèrement quinquélobées, à lobes obtus, elles sont tomenteuses, et un peu rudes, surtout en dessous. A la base du pétiole sout deux stipules déeoupées en lanières étroites.

Les fleurs sont extrêmement grandes, roses, blanches ou rouges, eourtement pédonculées à l'aissclle d'une bractće incisée en dćeoupurcs linéaires; elles constituent un long épi qui occupe le quart supćrieur de la tige.

Le calieule, ou ealice extérieur, est monosépale, très-tomenteux, à six divisions ovales aiguës.

Le calice, plus grand, est à cinq divisions de mềme forme, et opposées à cclles $d n$ ealiculc; tous deux sont persistans.

La corolle est très-grande, subcampanulée, formée de cinq pétales obovales très-obtus, très-larges supćrieurement, rétrécis et subeunćiformes à la base, où ils sont réunis et confluens avec la matière des filets staminifères; en sorte qu'ils tombent tous d'une seule pièee, emportant avec eux les étamines, et que la eorolle parait monopétale.

Les étamines sont tr'c̀-nombreuses (environ eent), réunies par leurs filets et monadelphes.

Les fruits sont formćs par un grand nombre d'akc̀nes eontigus par lcurs côtćs, et rapprochés eireulairement au centre du ealice.

La rose tremièrc est cultivće dans tous les jardins et partcrres d'agrément, à cause de l'éclat, de la varićté et de la grandeur de ses fleurs. $₹$

Propriétés et usages. On peut l'cmployer aux mêmes usages . 
que la guimave. Elle fournit un mucilage abondant. Scs fleurs, dans la variété rouge, sont un pcu astringentes, et ont la réputation d'être vulnćraires. Mais cette proprićtć astringente est tellement masquée par l'abondarice dı mucilage, que son action est presque nulle.

\section{MAUVE. $M A L V A$.}

Calice intérieur monosépale à cinq divisions : calicule dẹ trois - petites folioles étroites; pétales échancrés au sommet et subcordiformes : éfamines nombreuses, capsules monospermes indéhiscentes, réunies en cercle à la base et autour du style.

Mauve sauvage. Malva sylvestrits. L. Sp. 969. Blackw. t. 22.

Part. usit. : les fleurs et les feuilles. Nom vulg. : Grande mauve.

Sa racine est pivotante, blanche, charnue, presque simple; il s'en élc̀vc plusieurs tiges dressées, rameuses, cylindriques, couvertes de poils rudes, assez rares, hautes d'un pied et plus.

Les feuilles sont alternes, très-longuement pćtiolćes, comme articulées, réniformes, arrondies, à cinq ou sept lobes peu profonds, trćs-obtus, crénclés; deux stipules ovales aiguc̈s, cilićes, presqu'entic̀res, sont placées à la base de chaque feuille.

Fleurs purpurines, au nombre de trois à cinq aux aisselles des feuilles, portćes sur un pćdoncule long, grểle et cylindriquc. Lcur calice est double. L'extćrieur à trois divisions étroites, l'intérieur campanulć, demi quinquéfide à lobes aigus. Leur corolle cst composćc de cinq pétales obcordiformcs échancrés supćricuremcnt, terminés inférieuremeut par un onglet, unis avccla substance du tube anthćrifère.

Fruit composé d'un grand nombre de petites coques monospermes, réunies circulaircment autour d'un axe central commun.

On trouve communémcnt la grande manve le long des haies, dans les bois : cllc fleurit en juin ct juillct. $\frac{F}{*}$ 
Propriétés et usages. Les flenr's de mauve sont très-fréquemment employées eomme adoueissantes dans les inflammations des bronches, de la trachée-artère, ete. On les donne en infusion théiformc.

Les feuilles et les tiges sont usitées eomme adoueissantes, à l'extérieur.

Mauve a feumles nondes. Malva rotundifolia. L. Sp.
969.

\section{Vulgairement: Petite mauve.}

Raeine allongée, très-blanehe, eharnue. Tige rameuse, étalée, eylindrique, un peu pubeseente, rameaux longs d'un pied, aseendans ou redressés à leur extrémilé.

Feuilleś alternes portées sur de longs pétioles subeanalieulés, un peư velus, présentant à leur base deux stipules sessiles, velues, aiguës, entières ou dentieulées : ees feuilles sont arrondies, pubeseentes, subréniformes à einq ou sept lobes obtus et dentés.

Les fleurs sont petites, axillaires, pédoneulées, blanehâtres ou purpurines, au nombre de trois ou quatre, à l'aisselle des feuilles. Le ealieule se compose de trois petites folioles subulées, étroites, distinetes à lenr base. Le ealiee est monosépale, tubuleux, à einq divisions aiguës. Les einq pétales sont elliptiques, émarginés au sommet et subeordiformes.

La pelitemauve est très-fréquente sur le bord des chemins, dans les ehamps. Elle fleurit pendant presciue tout l'élé. ()

Propriétés et usages. Elle jouit absolnment des mẻmes propriétés que la grande mauve, mais elle est moins usitée, paree qu'elle est plus petite dans toutes ses parties.

II. Étamines au nombre de cinq à dix. Capsule multiloculaire indéhiscente.

GACAOIER. - THEOBROMA. Juss.

Calice cadue, à einq divisions très-profondes; eorolle de 
cinq pétales irréguliers ereusés en goutlière à leur base, rétréeis au milieu et terminés par une lame plane à leur somınet; dix étamines monadelphics par leur partie infćrieure, où elles forment un tube, libres dans leur moitié supérieure, où einq alternes sont dćpourvues d'anthères. Style surmonté de cinq stigmatcs. Le fruit est gros, sec, allongé, marqué de dix sillons, ćpais, et contient un grand nombre de graines, dont le tégument est charnu.

Arbres à feuilles alternes et entières, ayant les fleurs groupées par petits bouquets.

\section{Cacaoier ordinaine. Theobroina cacao. L. Sp.}

Part. usit. : les graines. Nom pharm.: Semina cacao. Nom vulg, : Faba mexicana.

Le cacaoïer peut s'élever à trente ou même quarante pieds : son trone, dont le bois est tendre et léger, se divise en un grand nombre de ramifications grćles et allongćes, sur lesquclles il existe des feuilles altcrnes, entières, eourtement pétiolécs, obovales, acnininćes, lisses et glabrcs. Les deux stipules, que l'on remarque à la base des pétioles, sont linéaires, entières et caduq̨ucs.

Les fleurs sont rougeâtres, portées sur des pćdicelles grêlcs et réunics en pelits faisceaux, placćes un peu au-dessus de l'aisselle des feuilles; quelques-uns de ces groupes ou faisceanx de fleurs, naissent sur le tronc et les grosses branches, et ce sont les seuls dont les fleursisoient fćcondes et donnent des fruits, tandis que toutes les fleurs qui se développent sur les jeunes rameaux sont stćriles.

Le calice est à cinq divisions très-profondes, d'un rougre foneć, lancéolécs, aiguës, entières, eaduques. La corolle est formće de cinq pétales diessés, et connivens par leur sommet. Ils sont clargis, creusés en gouttière à leur partie inférieure, trc̀s-rétrécis dans leur parlie moyenne, élargis de nouveau à lewr sommet.

L'ovaire est libre, ovoïde, allongé, tomenteux, marquué de dix sillons longitudinaux; il offre cinq loges inultiovulées. I, o 
style est long, grêle, lígèrement quinquétide à son 'sommet, qui porte einci stigmates aigus.

Le fruit est ovoïde, allongé, quelquefois manselonné à son sommet, marqué de dix sillons longitudinaux, ayant sa surfaee inégale et rabotteuse, tantôt jaune, tantôt rouge, suivant les variétés. Le périearpe est épais, dur et indéhiscent; sa cavité intérieure est simple, par' suite de l'avortement des eloisons qui existaient dans l'ovaire, en sorte que les graines sont groupées au eentre du fruit et enveloppées dans une julpe aqueuse et aigrelette. Elles se eomposent d'un légument propre erustaeé, reeouvrant un gros embryon, dont les deux eotylédons sont découpés en un grand nombre de lobes irrégulièrement plissés.

Cet arbre intéressant est originaire du Nouveau-Monde. Il eroît spontanément au Mexique et dans d'autres partics de l'Amérique méridionale. Sa eulture s'est introduite dans les $\Lambda$ ntilles et d'autres eontrées du continent américain. Ce ne fut guère que vers le milieu du dix-septième siècle que les Français s'adonnèrent à la eulture du eacaoïer dans leur's eolonies.

Lorsque l'on a eueilli ees fruits à leur parfaite maturité, on les brise pour en retirer les graines. Avant de les verser dans le eommeree, on leur fait subir l'un des deux modes de préparation que nous allons indiquer. Tantôt on les dépouille de la pulpe qui les reeouvre et on les fait simplement séeher, en les exposant au soleil pendant un temps plus ou moins long; tantôt on les enfouit en terre et on les y laisse jusqu'à ee que la fermentation en ait détaehé la partie pulpeuse. C'est au eaeao préparé de celte dernière manière que l'on donne le nom de cacao terré.

Dans le commeree, on distingue plusieurs sortes de eaeao, savoir : $\mathrm{I}^{\mathrm{O}}$ Le cacao caraque, que l'on reeueille sur la eòte de Caraeas. On le distingue en gros et en petit, suivant le volume de ses graines. Il est généralement terrć. C'est l'espèee la plus reeherehée. Ses graines sont plus arrondies et plus grosses que dans le eaeao dcs îles. Lenr eouleur intćricure est d'un lnuu violaeć. Leur tégumentent s'enlève avee faeilité. La saveur du eacao earariue est douee et agréable.

$2^{\circ}$ Sous le nom de eneao desîles on comprend généraleınent 
rout celui qui est liré des $\Lambda$ ntilles et même des fles de France et de Bourbon. Les grains en sont moins gros et plus aplatis, d'unc saveur amère et austère. Cette sorte contient plus de matière butyreuse que la précédente, et porte lés noms de cıcao berbiche, cacao'de Surinam, elc., suivant les lieux où on la récolte.

- Propriétés et usages clu cacao. Dans l'état frais, ces graines ont une saveur âpre et amère qui n'a rien d'agréable. Elles la perdent en grande partie par le terrage, et surtout lorsqu'elles ont été grillées dans des poêles de fer ou des cylindres nommés vulgairement brúloirs. Elles acquièrent alors une saveur agréable, douce, onctueuse. C'est avec ces graines, ainsi torréfiées, que l'on prépare le chocolat. Pour cela, on les prive de leur enveloppe crustacée, et on les pile dans un mortier de fer que l'on a préalablement chauffé. Après en avoir fait une pâte grossière on y mélange une égale quantité de sucre en poudre et on broie de nouveau la pâtc sur des pierres de liais, au moyen de cylindres de fer. On coule ensuite cctte pâte encore molle dans des moules. Ainsi préparé, le chocolat porte le nom de chocolat de santé; mais généralement on $\mathrm{y}$ ajoute quelques aromates, tels que la vanille et la cannelle, qui relèvent sa saveur et en facilitent la digestion.

On peut rendre le chocolat plus ou noins amer ou excitant, suivant le degré de torréfaction qu'on lui fait subir. Les Italiens et les Espagnols torréfient le caeao beaucoup plus que. les Français. Aussi leur chocolat est-il plus foncé en couleur et plus amer.

L'usage du chocolat est trop universellement répandu, pour ๆu'il soit nécessaire d'entrer dans de longs délails à cet égard. On le mange soit cru, soit après l'avoir délayé et fait bouillir dans de l'eau ou du lait. C'est un aliment très-nourrissant, mais que beaucoup de persornes ne digèrent que péniblement. Il est analeptique et convient aux individus épuisés par de longues maladies oudes excès vénériens. Chez ceux qui le digèrent, il produit promplement une amélioration sensible et ranime les forces. On a vu quelquefois l'usage lnng-lemps coutinué du chocolat devenir irés-favorablc à des personnes affectées de phthisie ou d'antres malndies chroniques. Cetlc substance 
agréable est quelquefois employée pour masquer le goût de eertains médicanens désagréables. C'est ainsi qu’on préprare un ehoeolat à la mousse de eorse, qui est anthelmintique; un choeolat au quinçuina, qui est tonique et fébrifuge, ete.

Le enea eontient une très-grande quantité d'une huile grasse et solide, connne généralement sous le rom de beurre de cacao. Elle est blanehe, jaunâtre, d'une saveur douee et agréable. . C'est un des eorps gras les plus adoucissans que l'on eonnaisse. On l'emploie beaueoup eomme eosmétique et eomme médieament. Il a le préeieux avantage d'avoir une odeur agréable et de se séeher avee rapidité. On en fait des pommades, que l'on applique sur les geręures qui se forment aux mamelles ou dans d'autres parties du eorps. Le beurre de eaeao trouve eneore uñ emploi fréquent dans la préparation des suppositoires adoueissans, dont l'usage est extrêmement avantageux dans un grand nombre de eireonstanees.

Enfin l'enveloppe erustaeće qui recouvre la graine n'est pas à dédaigner. Sa saveur est acerbe, et quelques auteurs en regardent la déeoetion comme toniçue.

Parmi les autres végétaux exotiques de la famille des Malvaeées, nous pouvons encore mentionner les suivans:

$z^{\circ}$ Le Banвa (Adansonia digitata', L.), le plus grand et le plus gros des arbres eonnus. Ses feuilles sont eomposees de sept à neuf folioles digitées au sommet d'un pétiole commun. Ses fleurs, qui sont extrêmement grandes, sont remplaeées par des fruits ovoïdes, allongés, tomenteux, verd̂atres, trèsgros, ayant leur éeoree épaisse et presque ligneuse, et offrant intérieurement une substance rougeâtre, spongiense, remplie d'mn sue aeidule très-agrćable. Au rapport d' $\Lambda$ danson et dn doeteur Louis Franek, les lrabitans du Sénégal, de l'Égypte, de la Nubie, ete., regardent eelte pulpe rougeâtre, que l'on apportait autrefois sons le nom de terre sigillée de Lemnos, comme un des remèdes les plus effieaees eontre la dyssenteric, affeetion si rcdoutable dans ees régions brûlantes, par la rapidité de sa marelıe. Mais eette substanee est tout-à-fait inusilćt: en Europe.

$2^{\circ}$ L'anвrette (Hibiscus abclmoschus, L.), petite plante originaire de l'Inde, mais qui s'cst naturalisée cn Égypte ct 
jusque daus les Antilles. Ce sont ses graines qui sont connues sous les noms d'ambrette, abel mosch, ou graines cle musc, à causc de leur odeur musquće. Autrefois employées en médecine comme stimulantes et antispasmodiques, les parfumeurs seuls en font usage aujourd'hui.

$3^{\circ}$ Le Cotonnier (Gossipium herbaceum). Celte espèce, et - plusieurs autres du même genre, méritent le plus grand intérêt sous le rapport de l'économie domestique et politique. Leurs fruits sont des capsules contenant plusieurs graines, dont le tégument propre est chargć de longs filameıs blancs ou roussâtres, doux, soyeux, que l'on connaît sous le nom de colon. Cette subslanee exolique est cerlainement un des produits les plus importans du commerce des deux. Indes avec l'Europe. On le eultive dans l'Inde, l'Afriqque, les deux $\Lambda$ mériques, les Antilles, etc. On a cherché à introduire cette culture dans les provinces méridionales de la France, mais elle y a peu réussi, et les essais à cet égard n'ont pas été assez multiplićs.

Propriétés médicales et usages des plantes de la famille des Malvacées.

Si les Malvacées ne sont point remarquables par l'énergie de leurs proprićtés médicales, elles sont fort intéressantes sous le rapport de l'uniformité parfaite que ees propriétés présentent clarss toute la familie. Toutes lcs Malvacées contiennent, dans lcurs différentes parties, une quantité eonsidérable de mucilage. Aussi sont-elles essentiellement adoucissantes et émollientes, et peuvent-elles être employées indifféremment les unes pour les autres sans le moindre ineonvćnient. Dans quelques eontrées même elles servent à la nourriture de l'homme. Ainsi, dans diverses parties de l'Europe, on mange les jeunes feuilles de nos mauves, après les avoir fait bouillir. Dans les deux Indes et l'Äfrique on cultive pour le même usage lè Gombo ou Hibiscus esculentus de Linné.

Les Malvacées exotiques nous intéressent anssi sous d'autres rapports. Ainsi ee sont les graines torréfiées du Theobroma cacao qui, convenablement préparées, forment le chocolat. On trouve,sur les graines de plusieurs espèces de gossipium, une 
espèce de bourre, formée de filamens longs et soycux, qui forment lc coton, substanee de première nécessité, et qui lient un des premiers rangs dans la balance du commerce de l'Europe arec les deux Indes.

Enfin, c'est à la famille des Malvacées qu'appartiennent les colosses du règne végćtal, les plus grands arbres connus, les Вловавs (Adansonia digitata), dont le tronc a quelquefois soixante à quatre-vingts pieds de eirconférencc.

Tous ees végétaux, tant indigc̀nes qu'exotiques, peuvent indiffćremment être cmployés comme émolliens. On ne connait aueune plante vénćneuse parmi lcs Malvacées.

\section{QUATRE-VINGT-HUITIËIIE FAMILLE.}

\section{TILIACEES. - T I L IACEAE.}

Cette famille a beaucoup de rapports avce eelle que nous venons d'étıdier prócédemment. Elle se compose d'arbres, d'arbustes ou de plantes herbacées, ayant les feuilles alternes, simples, aceompagnées de stipules; les fleurs axillaires ou terminales. Lcur ealice est coloré, à quatrc ou eing divisions profondes et eaduques. Les pétales alternant avee lcs divisions calycinales, sont géuéralement en nonbre ćgal; rarenient la eorolle manquc.

Les étamines sont nombreuses et ont leurs filamens librcs et distincts; leurs anthères à deux loges.

L'ovaire est simple, librc, sessilc ou stipité, ayaut de deux à einqloges, qui contiennent eliaeune un, dcux óu plusicurs ovules attachćs à l'angle interne. Le style est simple et se termine par un stigmate à deux, trois ou einq lobes.

Le fruit est sec ou eharnu, à deux ou plusieurs loges, indéhiscent ou s'ouvrant en plusieurs valves. Chaque loge eontient une ou plusicurs graines, dont l'cndosperme est eharnu et les cotylédons plancs.

Ijes Tiliaeées se distinguent des Malvacées par leurs 
étamines, dont les flets sont entièrement libres, par leur style simple; leur fruit, qui est quelquefois charnu, et leurs cotyledons planes et non lobés.

\section{TIL L E U L. - TILIA. L. J.}

Calice caduc à cinq divisions profondes; corolle de cinq pćtales ${ }^{\mathrm{r}}$. Étamines nombreuses et distinctés, ovaire à cin loges biovulćes; style simple terminć par un stigmate à cinq lobes rapprochćs. Capsule globuleule à cinq logcs, contenant chacune une ou deux graines.

Arbres a feuilles simples et cordiformes; ayant leur's pédon cules soudés avec la bractée qui les accompagne.

Tilleur d'Europe. Tilia Europaea. L. Sp. 773.

Part. usit. : les fleurs. Nom pharm. : Tilia hortensis.

Les autcurs modernes, à l'excmple de Ventenat et de Desfontaines, ont distinguć dans le Tilia Europaca de Linné deux espèces distinctes, mais qui ne nous paraissent être, comme à l'immortel Suédois, que deux variétés d'une même espèce.

L'une, quc Ventenat nomme Tilia microphylla, ou Tilleul à petites feuilles, croít communément dans nos bois, où il peut acquérir unc hauteur de cinquante à soixante pieds. Son écorce est épaisse, rugucuse, fendillée dans sa partie infćrieure, lisse supérieurement. Ses feuilles sont alternes, cordiformes, arrondies, acuminées, dentées en scie, presque glabres et un peu fermes, assez pctites, présentant à leur face inférienre, des pctits poils ferrugincux disposés par touffes, à l'aisselle des nervurcs principales. Ses fleurs sont plus petites. Son fruit est globuleux et pubescent.

Cette variélé est fort commune dans les forêts de prcsque toutc la France. On la designe sous lcs noms de tilleul sauvage,
tillaux, etc.

${ }^{1}$ Les espèces de ce genre qui croissent cn Amérique présentent en face de chaque pétale une écalfe colorée, et qui semble former un second pétale intérieur. Ce caractère n'existe pas dans les cspèces
européennes. 
La seconde rariété, ou lc tilleul à larges feuilles, Tilia platyphyllos de Ventenat, se distinguc surtout par son tronc moins élevé, ses feuilles beaucoup plus grandes, plus molles et vclues; ses fleurs, également plus grandcs, et son fruit pyriforme, relevé de einq côtes. On le eultive généralement dans les pares et les jardins, sous le noin de Tilleul de Hollande, et ses fleurs s'épanouissent un mois plus tôt que eelles de l'espèee précédente.

Les cara etères que nous venons d'énoncer suffisent pour faire voir que ces deux espèces peuvent n'être considérées que comme de simples variétés.

Propriétés et usages. Les feuilles, et en général toutes les parties herbacées du tilleul ont une saveur fade ct contiernent une quantité considérable de mucilage, caractère qui les rapproehe singulièrement des Malvaećes. Aussi ces feuilles et la partie intéricure de l'éeoree peuvent-elles être employées avee avantage, pour préparer des décoctions émollientes, dont l'einploi est le mène que eelui des plantes de la fumille des Malvaeées.

Mais ce sont particulièrement les fleurs du tilleul que la thérapeutique réclame. Elles répandent une odeur suave. C'est généralement en infusion théiforme qu'on lcs administre. On en prćpare aussi une eau distillée. On ne peut nier l'action qu'elles exercent sur le système nerveux; elles sont antispasmodiques, calınantes, légèrement diaphorétiques. Mais peuton eroire à leur prétendue efficacité dans le traitement de l'épilepsie, aujuurd'hui que la nature de celte maladie nous est mieux connue. Cependint on trouve dans plusienrs auteurs les fleurs de tilleul vantćes comme une sorte de spécifique dans eette redoutable affection.

Les graines du tilleul contiennent une eertaine quantité d'une huile grasse et douee. Quelqucs auteurs en ont préparé une pâte analogue à celle que forme le caeao, mais qui lui est de beaucoup inférieure.

C'est à la suite de cette famille que l'on a plaeé lc Rocouren, (Bixa orellana, L.), bel arberiginaire des forèts de l'Amérique méridionale. Ses graines, lorsqu'elles sont parfaitement mûres, fournissent, par l'infusion ou la macération dans l'eau, 
unc patte linctoriale, connue sous le nom de rocou ou roucou, et que les teinturiers emploient pour communiquer aux étoffes une couleur rougeâtre. Celle pâte a une saveur aromatique. Les Indiens la dissolvent dans l'huile et s'cn frottent toutes les parties extćrieures du corps.

\section{Propriétés médlicales et usages des Tiliacées.}

Le tilleul est à peu près le seul vćgétal de toute cettc famille, cependant assez nombreuse, qui soit employé en médecine. Nous y avons remarqué surtout un principe fade et mucilagi- neux trcs-abondant, qui exisie dans les feuilles et les autres parties herbacćes de cet arbre, ct que d'autres Tiliacées nous présentent égalencnt. C'cst ainsi qu'en Égypte on mange le Corchorus olitorius, comme plante potagère.

L'odeur suave des fleurs dc tilleul sc retrouve aussi dans plusieurs aulres vćgćlaux de cette famille, qui tous sont remarquables par la ténacitć dcs fibrcs qui compiosent leur ćcorce, avec laquelle on fabrique des toiles et des cordages dans certaines contrées.

\section{QUATRE-VINGT-NEUVILME FAMILLE.}

\section{CISTEES.-CISTEA.}

Le genre Cistus de Linné, que les auteurs nodernes ont divisé en deux genres sous les noms de Cistus et d'Helianthemum, eonstitue à lui seul eette petitefamille, dont voici les earaetères : le ealiee est monosépale, à cinq divisions profondes; la eorolle est formée de einq pétales réguliers. Les étamines sont en grand nombre et ont leurs filets parfaitement libres et distincts. Le pistil est simple et libre; l'ovaire est globuleux, à trois ou cinq loges. Il est surmonté d'un style indivis, au sommet duquel est un stigmate simple. I e fruit est see; tantôt il offre trois loges et s'ouvre en trois valves; tantôt il en préseute einq, s'ouvrant seulement à leur partio supérieure, par l'écartement des valves, qui restent soudées par leur base. 
Les graines renfermées dans cette capsule sont attachées à des trophospermes qui règnent à l'angle interne de chaque loge, sur les bords de la cloison. L'embryon est placé dans un endosperme charnu. Il a sa radicule repliée sur les cotylédons.

Cette famille se compose de petits arbustes ou d'arbrisseaux ayant généralement les feuilles opposées, simples, munies ou dépourvues de stipules; les fleurs, tantôt axillaires, tantôt terminales. Elle offre beaucoup d'analogie avec les Tiliacées, dont elle diffère surtout par ses feuilles opposées et ses graines attachées à l'angle interne des cloisons.

Le genre violette d'abord placé à la suite des cistes, forme aujourd'hui une famille différeute nommée VıoLARIÉES.

CIS TE. - CISTUS. Tournef. Juss.

Calice régulier, persistant, à cinq divisions très-profondes; corolle rosaeée, formée de einq pélales égaux. Étamines nombreuses. Style et stigmate simples. Capsule à einq ou dix loges, contenant chacune plusieurs graines.

Arbustes, portant des feuilles opposées et entic̀res, des fleurs assez grandes, très-fugaces, dont les pétales tombent avee la plus grande faeilité.

\section{Giste de Crète. Cistus creticus. L. Sp. 738.}

Part. usit. : le Ladanum. Nom pharm. : Labdanum.

Cet arbuste élégant eroît dans lés lieux sees et pierreux de l'île de Crète ou de Candie, en Syrie et dans plusieurs îles de l'Arehipel.Ses tiges, dressćes, rameuses, pubeseentes, portent des feuilles opposées, ovales aiguës, sinueuses sur les bords, pubeseentes et terminćes inférieurement par un pétiole large et membraneux.

Les fleurs sont pédoneulées, grandes et d'un beau rouge 
ponceau : elles sont ordinairement réunies au nombre de trois au sonmet des ramifications de la lige. Comme tontes les autres espèces de cctte famille, ccs fleurs s'ćpanouissent aux premicrs rayons dı soleil levant, suivent cet astre dans sa course, et le soir du jomr qui les a vu naître les voit se flétrir, ct leurs pétales se délacher et tombcr.

Le calice persistant est à cinc divisions très-profondes, ovalcs aiguës, pubcscentes. Lcs cinq pétales, qui forment la corolle, sont étalćs en rose, beaucoup plus grands que le calicc, ils sont minces et un peu crépus. Les étamines sont fort nombreuscs, d'une belle couIcur jaune dorć, beaucoup plus courtes que la corolle.

Le fruit est une capsule globulcusc, pubescente, recouverte par les lobes du calice; clle offre cing loges contenant chacune plusieurs graines, et s'ouvre en cinq valves cmportant chacune une partie des cloisons sur le milieu de leur facc interne.

C'est sur cet arbuste et plusieurs antres espćces du même genre, telles quc Cistus ladanifer, Cistas laurifolius, elc. , que l'on recueille en Orient la substance résineuse connue dans le commercc sous le nom de ladanum. Pour cela, ou se sert d'instrumens particuliers ayant la forme d'un ratcau, qui, au lieu de dents en fer, sont armés de lanières de cuir. On promène ces lanièrcs sur les cistcs; elles se chargent dc la matière rćsineuse dont leurs feuillcs sont enduitcs. On racle ensuite ces lanières pour en retirer le ladanum.

Autrefois la récolte du ladanum sc faisait d'une toute autre manière. Selon Dioscorides, on le j'etirait de la barbe des chèvres qui allaient au milieu des ladaniers brouter l'hcrbe des inontagnes.

Propricités et usages du Ladanum. Dans le commerce, on distinguc deux sortes de ladanum. L'un est cn masses plus ou moins volumineuses, d'un brun moirâtre, poisseuses, enveloppées dans des morccaux de vessic, c'est le ladanum en pain. L'autre est en inorccaux roulés ct tordus, plus sces, durs ct cassans, et conslitue le laclanum in tortis. Cctte substance résincuse, quand cllc est pure, exlialc une odeur balsamique et très-agréablc; sa savenr cst un pcu anc̀re et aromatique; insoluble dans l'cau, elle sc dissout presqu'er totalité dans l'al- 
cohol. Projetúe sur des eharbons ardens, elle brûle et rípand unc fumée blanche et ćpaissc.

Mais il est bien rare, ou, pour ainsí dire, impossible d'avoir dans le commerce du ladanum bien pur. Ce n'est, le plus souvent, qu'un mélange d'une très - petite quantité de ladanum, de matières résineuses, et surtout d'un sable fin et ferrugineux. Aussi les praticiens onl-ils presqu'entièrement abandonné l'emploi d'un médicament sur lequel il est, en quelque sorte, impossible de pouvoir compter, et qui ne possède qu’à un degré assez faible les propriétés eommunes à toutes les autres substances résineuses. Cependant les pharmaciens le font encore entrer dans certaines préparations officinales, pour la plupart inusitées.

Les parfumeurs l'emploient plus fréquemment dans plusieurs de leurs préparations cosmétiques.

\section{Propriétés médicales et usages des Ciștées.}

Celte famille n'étant formée, ainsi que nous l'avons dit précédemment, que du seul genre Crste, il est facile de conceroir qu'elle offre peu d'intérêt sous le point de vue médical. En effet, le ladanum est le seul produit qu'elle offre à la thérapentique. Il est important de remarquer qu'outre les espèces dont nous avons parlé, la plupart des autres Cistes qui croissent dans les contrées méridionales de l'Europe, et qui sont frutescentes, fournissent une matière résineuse analogue au ladanum,

QUATRE-VINGT-DIXIEME FAMILLE.

\section{VIOLARIE்ES.VIOLARIAE.}

Autrefois réuni à la famille qui précède, le genre VioLETT⿱s est devenu letype d'un nouvel ordre assez distinct, et dont voici les caractères : calice à cinc divisions profondes, quelquefois prolongées au-dessous de lenr point d'attache; corolle irrégulière, formée de cinq pétales inégaux, dont linféricur, en génćral pliss grand, st 
termine quelquefois à sa base par un éperon creux, plus ou moins allongé.

Les étamines, au nombre de cinq, alternent avec les pétales, et sont, ainsi qu'eux, insérées au pourtour de la base cle l'ovaire. Les filets sont généralement très-courts; les anthères à deux loges, terminées. supérieurement par un appendice membraneux, sont rapprochées au centre de la fleur, contigıës par leurs côtés, et forment un cône qui recouvre le pistil : les deux anthères, placées devant le pétale inférieur, offrent à leur partie externe une corne plus ou moins allongée, qui s'enfonce dans l'éperon de ce pétale. L'existence de cette corne est subordonnée à celle de l'éperon.

L'ovaire est libre et simple, à une seule loge, contenant plusieurs ovules attachés à trois trophospermes longitudinaux qui règnent sur les parois. Le style est tantôt droit, tantôt recourbé en crochet, et se termine par un stigmate tantôt simple, tantôt renflé et creusé en une cavité semi-circulaire.

Le fruit est une capsule revêtue par le calice : il offre une seule loge, s'ouvre en trois valves, sur chacune desquelles sont attachées les graines. Celles-ci contiennent au centre d'un cndosperme charnu un enbryon dressé ayant les cotylédons plancs et la radicule cylindrique.

Les Violariées sont herhacées ou sous-frutescentes. Leurs feuilles sont simples, opposées, rirement alternes, accompagnées à leur base de deux stipules. Leurs fleurs sont axillaires, tantôt droites, tantût renversées au sommet du pédoncule.

Cette famille a beaucoup de rapport avec les Cistées, mais elle s'en distingue par sa corolle constamment irrégnlièrc, souvent éperonnée; par ses étamines, an nombre de cinq seulement; par son fruit nilocu- 
laire $r$, dont les graines sont pariétales; par son embryon droit et non recourbé ni roulé en spirale.

$$
\text { VIOLET'TE. - VIOLA. Ventenat. }
$$

Calice à einc divisions très-profondes, prolongées à leur base au-dessous de leur point d'attache; corolle étalće, de cinq pétales inégaux, dont l'inférieur est ereusé à sa base en éperon. Style reeourbé. Étamines presque sessiles, ayant les anthères rapprochées en forme de eône au centre de la fleur.

Plantes herbaeées, annuelles ou vivaces.

Vrolette odorante. Viola odorata. I. Sp.

Part. usit. : les fleurs, la racine. Nom pharm. : Viola hortensis.

Sa tigc forme une souehe souterraine horizontale, inégale et éeailleuse, d'un blane sale, de la grosseur d'une plume à écrire, donnant naissanee à un grand nombre dc radieelles rameuses ct ehevelues. Cette souehe, que l'on eonsidère eommunémènt eomme la raeine, se compose d'un axe blane et eel-

r Tous les auteurs déerivent le fruit du genre Helianthomun, qui n'cst, ainsi quz nous l'avons dit, qu'un démembrement du genre Cistus, eomme une capsule à une seule loge, dont les graines sont attachées an milieu de la face internc de chacune des trois valres, et par eonséquent il n'existerait aucune différence entre lc fruit des Héliantlièmes et celui des Violariées. Ce caractère est entièrement faux. L'nvaire, dans toutes les espèces d'Hélianthèmcs, est constaminent à trois loges, et ses ovules sont attaehés à l'angle rentrant de chaque loge. Mais il arrive assez souvent que, dans plusieurs espèees, les cloisons qui sont minces, se détaclıeut du eóté interne avant la maturité, en sortc qu'au moment où la eapsule s'ouvre, les cloisons n'étant plus unies ensemble par leur côté interne, et ayant entrainé avec elles les graines contre les valves, la capsule parait uniloeulaire, ét les graines semblent êtrc attaelıées anx valves; ee qui n'a réellement pas lieu. Plusieurs espèces eonservent jusqu'à leur parfaite maturitć une eapsulc à trois loges et des graines manifestement. axillaires. 
luleux et d'unc couche charnue qui- l'environne. Les feuilles naissent par touffes du sommet de la tige et de ses ramifications. Elles sont aceompagnées à leur base d'éeailles ou stipules minees, ovales aiguës, eiliées sur leurs bords. Leur pétiole est long de trois à quatre pouees et creusé d'ıne gouttière du eôté interne : les feuilles sont cordiformes, obtuses, crénelćes sur leurs bords, légc̀rement pubescentes.

Les fleurs sont solitaires, portées sur des pédoneules axillaires, grêles, à peu près de la longueur des pétioles, réfléehis à leur sommet; elles sont d'une belle eouleur violettc et répandent une odeur extrèmcment agréable. Le calice est formé de cinq sćpales, dont la base se prolonge au-dessous de leur point d’attache. La corolle est irrégulière, pentapétale. Les deux pétales supérieurs sont redressés : l'inférieur, qui cst lc plus grand, se termine à sa base par un éperon eourt et obtus.

Les einq étamines, qui sont presque sessiles, ont les anthères biloculaires, rapproehées les unes eontre les autres et formant une espèee de cône au-dessus du pistil; ehaque anthère est surmontée d'une pelite languette mince, terminée en pointe, d'une couleur jaune plus foneée. Du milieu de la faee externe de ehaenne des deux étamines qui regardent le pétale inférieur, part une eorne planc ct tranchante qui s'enfonce dans l'éperon. L'ovaire est globuleux et surmonté d'uu style reeourbé en forme d'S, plus gros dans sa moitié supér'ieure, et terminé par un stigmate très-petit et creux.

Le fruit est une eapsule uniloenlaire trivalve.

La violette odorante eroît dans les bois ombragés, où elle fleurit en février, mars et avril. On la eultive dans les jardins. zf

Propriétés médicales et usages. Les fleurs sont, dans la violette, la partie la plus recherelice ct celle que l'on prescrit le plus fréquemment. Leur odeur suave est connue de tout le monde. On l'a aeeuséc, fort injustement à notre avis, d'avoir été la cause d'aeeidens graves, tels que de migraines, de convulsions, de l'apoplexie et même de la mort. Il nous parait diffieile d'aceorder à un arome aussi peu développé que celui des fleurs de violette, une action aussi puissante et aussi funeste. Quelques auteurs prescrivent l'infusion de ccs flcurs récentes, 
ou leur eau distillée, comme antispasmodique et légèrement ealmante dans plusieurs affections nerveuses. Mais c'est principalement comme adoucissantes, à eause du mueilage qu'elles contiennent, que l'on administre l'infusion des fleurs de violette, dans l'inflammation des organes de la respiration. On prépare avee ces fleurs un sirop très-agréable, d'une belle couleur violetĩe, qui sert à éduleorer certaines tisanes, et dont les chimistes font usage eomme réaclif ehimique, pour reconnaître la présence des acides ou des alealis.

La racine, ou pour parler plus exactement, la tige souterraine de la violette est d'un blane sale à l'extérieur. Son odeur est peu marquée, surtout lorsqu'elle est sèehe; sa saveur est un pcu âcre, amère et nauséabonde. Des expériences assez multipliées ont prouvé qu'á la dose d'un demi-gros à un gros elle provoquait le vomissement et plusieurs déjeetions alvines. Mais celtc propriété est beaueoup moins développée que dans un autre végétal de la inême famille, l'Ionidium ipecacuanha, que pendant long-temps on a considéré comme fournissant le véritable ipécacuanha du commerce.

Quant aux graines de cette plante, quclques auteurs, entre autres Sehultz, leur ont attribué beaucoup d'efficacité dans le traitement de la gravellc, ponr faeiliter l'expulsion des petites conerétions caleuleuses qui se fornent dans les organes séeréteurs de l'urine. Mais leur usage est aujourd'hui lombé dans l'oubli.

Vrolette des champs. Viola arvensis. D. G. Fl. fr. 4. p. 808 .

Part. 'usit. : toute la planite. Nom pharm. : Viola syluestris. Nom vulg. : Pensée saurage.

Celte petile plante annuelle a sa tigedressée, angulense, glabre, rameuse, haute de six à dix pouecs. Ses fenilles sont altcrues, pétiolées, ovales obtuses, erénelées sur' leurs bords et accompagnécs à leur base de dẹx stipules déeoupées et pinnalifides.

Ses flenrs sont petites, d'un jaune mélé de violet, portées 
sur des pćdoncules axillaircs et solitaires, plus longs que les feuilles, dans l'aisselle desquelles ils sont situés. Les divisions calicinales sont égales, lancéolćes, prolongées au-dessous de leur point d'atlache en un petit appendice obtus et denticulć. Les pétales sont à peine plus longs quc le calice. L’ćperon du pétale inférieur est conique et redressé.

Les cinq étamines ont leurs antlières presque sessiles et légèrement soudées entre elles par leurs pariies latérales. Les deux qui correspondent au pétale inférieur offrent sur le milicu de leur dos un appendice recourbé, qui s'enfonce dans l'éperon de ce pétale.

L'ovaire est globulcnx, scssile, glabre, à nne seule loge, qui contient un grand nombre d'ovules atlachćs à trois trophospermes pariétaux. Le style est coudé à sa base, épaissi dans sa parlic supérieurc, où il se termine par un stigmale capitulé, un peu oblique, globuleux, offrant à sa partie inférieure une petite excavation asscz profonde.

La capsule est globulcuse, glabre, recouverte par le calice, et s'ouvre cn trois valves.

La pensće sauvage est très-commune dans les champs cultivés, où clle fleurit aux mois de mai et de juin.

Propriétés et usages. Toutes les parties de cetle plante ont une savcur amère et désagréable. Beaucoup d'auteurs s'accordent à reconnaitre son eflicacité dans le traitcment des maladies chroniques de la peau. C'est, ponr me servir d'une expression populaire trop fréquemment usilće dans le langage médical, un excellent dépuratif. Cependant plusieurs médecins modcrues, et en parliculier lc profcsseur Alibert, n'en ont pas retirć les mêmes avantages; en sorte que la pensće sauvage est un mćdicament sur lequel on doit peu compter. On l'administre en décoction, à la dose d'une à deux onces pour une livre d'eau; son exlrait se donne à la dosc d'un scrupule et au delà.

Sa racine est ćmétiquc, mais assez faiblement; en sorte qu'il faut la prescrire à la dose d'un demi-gros, pour en retirer quelqu'ivantage. 
IONIDE. - IONIDIUM. Ventenat. Pombalia. Vandelli.

Ce genrc diffère du précédent, auqucl il avait étć réuni, par sou calice, dont les divisions ne sont pas prolongćes audessous dc leur point d'attache; par sa corolle non étalée, ni éperonnée; par ses anthc̀res non rapprochées en cône.

Il se compose de végćtaux exotiques, herbacés ou sous-frutescens.

IonIde IPÉg.ACUnNHa. Ionidium ipecacuanha. Vent. Viola ipecacuanha. L. Suppl. 397.

Viola calceolaria. L. Sp. 1327 .

Viola itoubou. Aublet Guy. t. 3 I 8.

Pombalia ipecacuanha. Vand. fasc. I, p. 7. t. I.

Nous regardons comme unc seule et même espèce, d'après l'observation de M. Auguste Saint-Hilaire, les viola ipecacuanha et viola calceolaria de Linné, et la viola Itoubou d'Aublet. Cettc dernic̀rc, en effet, ne diffère des denx autres que par sa tige couvcrte d'un duvet jaunâtre et très-long; du reste, ces divcrscs plantes offrent absolument les mêmes caractc̀res. Lcur racine est vivace, blanchâtre, rameuse, cylindrique. Ics tiges sont dressćes ou étalées à terrc, cylindriques, légèrcment rameuses, glabres ou poilues.

Lcs feuilles sont alternes, obovales aiguës, dentées, rétrécies inscnsiblcment à leur base en un pétiole court; elles sont tantôt chargées de poils mous très-abondans, tantôt entièr'cment glabres. A leur base existent dcux stipules linéaires et entières, couvertes de poils nombreux.

Lcs fleurs sont pédicellćes, solitaires à l'aisselle des feuilles, qui garnissent la partic supérieurc de la tige. A la basc de chaque pédoncule existent deux ou trois petites bractées linćaircs, très-courtes. Lc calice est renflé à sa base, formé de cinq sépales lancéolćs, aiggus, rapproclıés supćrieuremcnt, hérissés cxtéricurement de poils nombreux, dont un grand nombre sont plus épais, ct glandulcux à lcur sommct.

La corolle cst irrégulièrc, composćc de cinq pétalcs; lcs 
deux supérieur's sont étroits, lancéolćs, aigus, et ne dépassent pas la hauteur du ealice; lcs deux latéraux sont plus larges et denx fois plus lonģs; l'inférieur, qui n'est point éperonné à sa base, est le plus long de tous; il est étroit et eoneave inférieuremont, très-large et presque carré dans sa moitié supérieure.

Les cinq ćtamines ont leurs filets libres et lcurs anthères distinctes, terninćes, cliacune à son sommet, par un appendice membraneux.

La capsule est presque triangulaire, à une seule loge, et s'ouvrc en trois valves.

Cette espècc croît dans les terrains sablonneux des bords de la mer, au Brésil, à la Guyane et dans leș Antilles. Ұf

Propriétés et usages. On a cru pendant fort long-tcmps que l’ipécacuanha du Brésil, apporté en Europc par Ia voie du eommeree, était uniquement fourni par ce végélal. Mais l'on sait aujourd'hui, d'une manière positive, que c'est à unc plante de la famillc des Rubiacées, le, cephoelis ipecacuanha, que l'on doit attribuer le véritable i] ćcacuanlıa du eommerce, quc nous avons désigné sous le nom d'ipécacuanta annelé. Ccpendant commc on y mélange quelquefois la racine de l'ionidium ipecacuanỉa, et que d'ailleurs cette racine possède des propriétés très-manifestes, nous avons cru devoir en parler dans eet onvragc. Elle est généralemcnt désignée sous le nom d'ipécacuanha blanc, à eause de sa couleur qui est blanchâtrc. Voici les carnetères physiqucs de la racine dessćehće : elle est d'un blanc sale, ramcuse, cylindrique, de la grosseur d'une plume à écrire, un peu tortucuse, offrant quelquefois des ćtranglemens ou des intersections peu marqućes. L'axe central est plus épais et plus jaune que la couche eorticale; sa cassurc est assez nette, pcu résineuse; son odeur est herbacée ct nauséeuse; sa saveur est eomme amilacće, d'abord peu sapide, mais bientôt un peu amère ct d'une âereté remarquable.

J'ai fait lc premicr l'analyse chimique dc cette raeine (Hist. nat. des ipécac., p. 44). Ellc contient plus de la moitié de son poids d'amidon, un peu d'ćmćline, quelques sels et matières grasses, etc. Le prineipe cristallisable que nous y avons observć, et que nous n’avons ju éludier avcc assez de soin, ne scrait-il pas de l'érnétine? A l'époçue oì nous avons publić 
notre travail, on n'était pas eneore parvenu à obtenir cette substance cristallisće; depuis lors, M. Pelletier, auquel on en doit la connaissance, l'a dégagéc des matières étrangères qui y étaient unies, ct se l'est procurée pure ct cristallisće. Nous soupçonnons avec quelque fondement que c'était de l'émétine aussi cristallisce que nous avons relirće des raeines de l'ionidium ipecacuanka. Au Brésil, on les emploie assez fréquemment à la dose d'un à deux scrupules. Il est rare qu'on en fasse usage en Europe; mais du reste leur mode d'action est tout-à-fait analogue à celui des autres ipécacuanhas. $V o y$. pag. $44 \mathrm{I}$.

\section{Propriétés inédicales et usages des Violariées.}

Nous avons peu dc choses à dire tuuchant les proprićtés mćdicales des plantes de ceite famille, considérées d'une inanière générale. Les fleurs de la violette ordinaire (viola odorata, L.), sont remarquables par le parfum suave qu'elles répandent et le mucilage qu'elles contiennent. $\Lambda$ ussi les emploie-t-on parliculièrement eomme adoucissantes ct légc̀rement calmantes. Mais c'est surtout les racines des violariées qui offrent quelqu'intérêt et une analogie parfaite. Dans presque toutes, en effet, surtout dans celles qui sont vivaces, elles ont une saveur âcre et nauséabonde, et possc̀dent une jpropriétć émétique plus ou moins intense. Ainsi dans les espèces exotiques, nous trouvons l'ionidium ipecacuanka, qui croit au Brésil, an Pérou ct dans la Guyane; et l'ionidium parviflorum, originaire du Pćrou, dont les racines sont quelquefois apporiées sous le nom d'ipécacuanha blanc, ou sont mélangées aux ipécacuanhas gris.

Cette propriété se retrouve aussi, quoiqu'à un plus faible degré, dans la racine de plusieurs espèces indigènes, et en particulier dans cclles des viola odorata, viola canina, viola tricolor et viola arwensis. 


\section{POLYGALEES. -POLYGALER.}

On disting'ue les plantes de cette petite famille à leur caliee, offrant trois, quatre ou cinq divisions, plus on moins profondes, tantôt égales et régulières, tantôt irré gulières et inégales. Leur corolle est formée de trois à cinq pétales libres ou soudés par leur base, au moyen des filets staminaux et semblant eonstituer une eorolle monopétale irrégulière, diviséé dans sa partie supérieure en lobes qui forment deux lèvres.

Les étamines sont communément au nombre de huit, soudées par leurs filets, et diadelphes: quelquefois ii n'en existe que deux ou trois, qui sont libres; clans les deux cas, elles sont insérées sur les pétales. Leurs anthères s'ouvrent généralement par un trou qui se pratique à leur sommet : elles sont uniloeulaires.

L'ovaire est libre et supère, à deux ou à une seule loge, contenant chacune in oa deux ovules. Le style est simple et se termine par un stigmate dont la forme est extrêınement variable dans les différens genres.

Le fruit est une petite capsule, quelquefois légèrement charnue, à une ou deux loges, qui chacune renferment une graine. Cette eapsule souvre en deux valves, emportant ehaenne la moitié de la cloison sur leur faee interne.

La graine est suspendue, souvent aecompagnée à sa base d'ün arille charuu et lobé. L'embryon est renversé, placé au centre d'un endosperme charnu, qui manque dans le genre krameria.

Les Polygalées sont des plantes herbaeées, ou des arbustes d'un aspeet agréable et d'un port élégant. Leurs feuilles sont'alternes et dépourvues de stipules. Leur's llenrs, qui ont en général quelque ressemblanee exté- 
rieure avec celles des Légumineuses, sont quelquefois axillaires et solitaires, mais plus souvent terminales et en épis, accompagnées à leur base de deux bractées latérales.

Les raractères que nous venons d'énumérer suffisent pour distinguer eette famille de celles dont nious l'avons rapprochée.

$$
\text { POLYGALA. - POLYGALA. L. J. }
$$

Caliee à einq divisions profondes et inégales, dont deux latérales plus grandes et souvent colorées. Corolle irrígulière, dc cinq pćtalcs soudés par leur base et disposćs en deux lèvres; huit ćtamincs diadelphes. Capsule comprimée, à deux loges monospermes, s'ouvrant en deux valves. Graines arillćes, contenant un embryon endospermique.

Plantes herbacćes ou frutescentes, ayant les feuilles älternes et entières, les fleurs cn épis terminaux.

Polygala a Mier. Polygala amara. L. Sp. $9^{8}$.

Part. usit. : la racine. Nom pharm. : Polygala amara.

C'est sur les pelouses sèches, dans les lieux ineultes, que croît cette jolic petite plante, qui 'épanouit ses fleurs d'un beau bleu d’azur pendant une partie de l'été. Sa raeine est vivace, rameuse, blanchàtre; elle développe plusieurs tiges de quatre à cinc pouces de hauteur, ordinairement eouehées dans leur partie inféricure, redrcssées supérieurement et glabres. Ses feuilles sont alternes, lcs inférieures sont obtuses et eommc spathulées; les supérieures lancéolćes, étroites, aiguës et sessiles.

Les fleurs forment un épi, qui tcrmine la partic supćricure de la tige. Chacune d'elles est pćdicellée, accompagnée à la base de son pédieelle de deux petites bractées linéaires, très-eourtes. Le ealiee est à cinq divisions trc̀s-profondes ct inégales; deux sont latérales, colorées, beaucoup plus grandes quc les autres, obovales aiguc̈s, entic̀res; les trois autres sont linćaires, étroites ct bcaucoup plus courtes.

La corolle est à peu près de la même longueur quc les deux grandes divisions du calice; clle se compose de einq pétales unis intimement par leur base, au moyen des filets des ćta- 
mines. Deux de ces pétales sont égaux et fórment une sorte de lèvre supérienre; l'inférieure est eoncave et composée d'un pétale qui est déeoupé en lanières ex trêmement étroites. Les deux autres pétales sont latéranx.

Les étamines, au nombrc de huit, sont soudées en deux faisceaux et diadclphes, renfermées dans une sorte de carène très-eoncave, qui rćsulte de la soudure des deux pétales latéraux. L’insertion des pétales est hypogynique.

L’ovaire est allongé, très-eomprimé, à deux loges, qui eontiennent chacune un seul ovule. Le style est dilaté, terminé par un sligmate concave et comme à deux lèvres, dont la supéricure est dressée et beaueoup plus grande.

La eapsnle cst comprimée, eordiforme, glabre, à deux loges, et s'ouvrc en deux valves; les graines sont arillćes et velues.

Propriétés et usages. Toutes les parties de cette plante, mais surtout sa racine, sont d'une amertume très-intense. C'est un médicament toniquc, mais qui en même temps provoque presque constamment la purgation. Sous ec rapport, il peut être ntile dans certaines hydropisies qui nc sont pas liées à l'état d'inflammation du péritoine ou des organes revêtus par eette membrane.

Mais que penser des ćloges qui lihi ont été prodigués dans le traitement des maladies inflammatoires des poumons, telles que la pneumonic, la pleurćsie, la phthisie pulmonaire et le erachement de sang. Collin, Van Swićten, et plus récemment MM. Coste et Villemet, prétendent l'avoir employé avec avantage dans ces différens cas. Mais si l'on fait altention qu'ils associaicnt le polygala amer à l'usage du lait et des mueilagineux, et que souvent même ils faisaient préećder son administration de l'emploi de la saignée, les médeeins vraiment physiologistes sauront faire la part de ce médieament, ct attribucront ccrtainement les lieureux résultats obtenus par les pratieiens que nous venons de nommer, à la saignće, au lait et anx mucilagineux.

On peut administrer le polygala amer à la dosc d'une once. pour deux livres d'eau; on préparc avee sa poudre des bols ou ın électuaire dont la dose est d'un sermpule à un gros. Son extrait est moins fréquemment prescrit. 
Porygata sínéga. Polygala senega. L. Sp. 990.

Part. usit. : la racine. Nom plarm. : Radix seneka. Nom vulg.: Polygala de Virginie.

Le polygala de Virginie offre une racine vivaee, rameuse, grisâtre extérieurement, blanche à son intérieur. Il s'en élève chaque année plusieurs tiges herbaeées, trc̀s-simples, hautes de huit à dix pouces. Ses feuilles sont sessiles, assez grandes, ovales, lancćolées, aiguës, cntières, glabres, d'un vert clair.

Les fleurs sont petiles et constituent un épi terminal. Les deux ailes du calice sont obtuses et veinées. La corolle est trèscourte et close.

Les capsules sont petites, très-comprimées, échancrées en cour à leur sommet, à deux loges et à deux valves. Les graines sont noires, ovoüdes allongées, terminées en pointe à l'une de leurs extrémités.

Cette plante croît spontanément dans différentes parties de l'Amérique septentrionale. $\&$

Propriétés et usages. La racine du polygala de Virginie, telle qu'elle nous est fournie par le commerce, varie de la grosseur d'une plume à celle du petit doigt. Elle est irrégulièrement contournée, un peu rameuse, épaisse supérieurement ; elle présente une sorte de côte saillante qui règnc sur l'un de ses côtés. Son ćcorce est grisâtre et comme résineuse; son axe est blanchâtre. Son odeur est faible el nausćeuse; sa saveur, d'abord douceâtre et mucilagineuse, est un peu âcre, amère et irritante. Introduite dans la bouche, elle angmentc la sécrétion des glandes salivaires; sa poudre, mise en contact avec la membrane pituitaire, détermine l'éleruuenent.

La parlic externe de cette racine est la plus active. Son infusion aqueuse est plus âcre que sa teinture alcolıolique.

En Amérique, la racine récente du sénélia jonit d'une trèsgrande répulation dans le traitement de la morsure des serpens. Mais en Europe, c'est particulièrement à titre d'excitant que l'on en fait usage. $A$ faible dose, celte racine augmente la perspiration entanće el prilinonaire; à dose plus élcrée, elle peut 
être énétiçue el purgative. La préparation la plus convcnable est une déeoetion que l'on prćpare avee une onee de raeine, bouillie dans trois livres d'eau jusqu'à réduetion d'un tiers.

Les éloges qui ont élć prodigués à ce médieament dans les maladies de poitrine, même à l'état inflammatoire, nous for ceront à lui appliquer les observations que nous venons de faire à ee sujet, en parlant du polygala amer. En effet, ee n'est point à son emploi que doivent être exelusivement rapportés les sueeès obtenus, puisqu'en génćral on le fait prćeéder de la saignće, et qu'on y associe l'usage du laỉ, de la gomme et des adoucissans. Dans le catarrhe pulnonaire ehronique, où sur la fin du eatarrhc pulmonairc aigu, quand les symptônes d'irritation ont disparu, la décoction de polygala peut être fort avantageuse : en facilitant l'expeetoration, elle fait souvent disparaître l'oppression dont les malades semblaient ĉtre aeealblćs.

On a aussi reeommandć l'usage de ee médieament dans l'asthme, le croup, le rliumatisme ehronique, l'amćnorrhće et les hydropisies. Dans cc dernier eas, il doit être administrć à haute dose, afin que son aetion se porte plus spćeialement sur le canal digestif ct détermine la purgalion. Mais en général il est, je crois, important de s'abstenir de cette substance ćminemment tonique et excitante, toutes les fois qu'il y a une irritation manifeste de quelque organe important; tandis qu'au eontraire son usage peut être d'une grande utilitć chez les sujets faibles, lorsqu'il y a débilité, et que l'ćeonomie a besoin d'être slimulée.

Outre la décoction, on peut eneore employer la poudre de sćnéka, à la dose de viugt à quarante grains. On peut aussi préparer un vin de polygala, en faisant maećrer quatre onees de cette racine dans une livre de vin.

\section{KRAMÉRIE. - KRAMERIA. L. Juss.}

Caliee à quatre divisions profondés et régulières; eorolle de quatre à cinq pétales, inćgaux et irréguliers, dont dcux ou trois, qui sont supérieurs, sont plus longs et onguiculés, et deux inférieur's sessiles et plus courts. Étaminç au nombre de trois à 
quatre. Ovaire à une seule loge; fruit globuleux, indéhiscent, hérissć de pointes. Graines dépourvues d'arille et d'endosperme.

Kramérie truande. Krameria triandra. Ruiz et Pavon. Fl. Per.

Part. usit. : la racine. Nom pharm. : Radix ratanhice. Nom vulg.: Ratanhia.

Arbuste dont la raeine est rameuse et rampante horizontalement sous la terre: la tige dressée, divisée en ramifications nombreuses, velues et blanehâtres. Les feuillcs sont alternes, très-rapprochćes à la par tie supérieure des jeunes rameaux; elles sont assez petites, ovales, oblongues, aiguës; dures et coriaces.

Les fleurs sont placćes à l'aisselle des feuilles supérieures. Chaque fleur est portée sur un pédonculc très-court et accompagnée de deux bractées, rapprochées du ealice : eelui-ci est à quatre divisions profondes, ovales, allongées, aiguës, glabres en dedans, velues extćrieurement.

La corolle se composc de quatre pétales irréguliers et inégaux; deux supérieurs redressés, élroits, onguieulés à leur base, presque lancéolés dans leur partie supćrieure; deux infćrieurs sessiles, presque orbiculaires, très-obtus, appliqućs contre l'ovaire.

Les étamines sont au nombre de trois, entièrement libres, et ascendantes. Leurs filets sont épais, cylindriques, articulés supćrieurement au-dessous de l'anthère, qui est terminale, conique, à une seule loge, et s'ouvre parun trou, qui se forme a son sommet. Ces étamines sont liypogynes, airsi que les pétales.

L'ovaire est ovoïde, trc̀s-velu, à une scule lóge, eontcuảnt deux ovules suspendus. Le style est long et recourbé, et se terinine par un stigmate très-petit, arrondi et bilobé.

Lc fruit est globuleux, pisiforme, lhérissé de pointes raides. Il reste indéhiscent et renferme deux, quelquefois une seule grainc, par suite d'avortement. Ces graincs eonliennent ur gros embryon dressé, dépourvu d'endosperme. 
Cet arbuste est originaire du Pérou.

Propriétés et usages. Le nom de ratanhia, donné par les Péruviens à cet arbuste, est tiré de la forme de sa racine, qui est rampante. C'est à Ruiz, botaniste espagnol, l'un des auteurs de la Flore du Pérou et du Chili, que l'on doit la connaissance de la plante qui fournit la racine de ratanhia et celle de ses usages dans la thérapeutique. Voici les caractères de cette racine. Elle est composée de ramifications cylindriques de la grosseur d'unc plume à celle du petit doigt; d'un brun rougeâtre extérieurement. Elle est formée de deux parties, l'une corticale plus foncée, un peu fibreuse, d'une saveur extrêmement astringente sans mélange d'amertume ; l'autre centrale, est plus dure, d'un jaune rougeâtre, d'une saveur plus. foible. C'est de la première seulement dont on doit faire usage; il est important de choisir les racines de ratanhia de grosseur moyenne; car celles qui sont trop grosses ont la partie centrale plus épaisse et la corticale plus mince.

M. Vogel a trouvé dans la racine de ratanhia un principe. résinoïde, rouge, d'une trc̀s-grande astringence, de l'amidon, de la gomme et quelques sels. M. Peschier, pharmacien à Genève, y a découvert uu acide qu'il regarde comme nouveau, et qu'il nomme acide kramérique. Il forme avec lcs alcalis des sels cristallisables, qui, en général, ne s'altèrent point à l'air.

Pendant son séjour au Pérou, M. Ruiz a vu très-fréquemment employer la racine de ratanhia, et en ayant lui-mème. fait usage, il a pu s'assurer de son efficacité. L'extrême astringence de cette racine on fait un tonique très-énergique. C'est surtout contre les diarrhées chroniques et les hémorrhagies. passives, c'cst-à-dire dans des maladies exemptes d'inflammation aiguë, que l'efficacité du ratanhia est vraiment merveilleuse. Les cssais que plusieurs praticiens européens ont faits à cet égard, justifient parfaitement la confiance que les Pćrnviens lui accordent dans cette circonstance. Mr. Je docteur Hurtado, médecin espagnol, qui a résidé à Paris, a publić plusieurs obscrvations détaillées sur l'emploi de cette racine exotiquc. Son usage peut aussi être avantageux dans l'aménorrhéc, la leucorrhéc ct la blennorrhagie chroniques, en 111 
mot, dans toutcs les maladies oủ l'emploi des toniques et particulicrement des astringens est réclamć.

C'est généralement en déeoction que l'on administre le ratanhia. Une demi-once à une once bouillie dans une livre d'eau for'mc une boisson astringente fort ćnernique. Son extrait, que l'on nous envoie souvent tout préparé du Nouveau-Monde, se donne à la dose d'un serupule à un demi-gros.

\section{Propriétés médicales et usages des Polygalées.}

Cette petite famille qui, à l'exception du gcnre polygala, ne se compose que de genres exotiqucs, présente en génćral une assez grande uniformité dans lcs qualités sensibles et la manière dont les unćdicamens qu'elle renferme influencent les différens organes avec lesquels on les met en eontact. En effet, ees médieamens, qui sont en pctit nombre, appartiennent ious à la classé des toniques. Les uns sont spécialcment amers ou lćgćrement âcres, tels sont lc polygala amer et le polygala sénéka. Ce ne sont pas seulement ces deux espèccs qui jouissent de ces proprićtés; le polygala vulgaire, le polygala d'Autriche et plusieurs auires parmi les cspèces indigèncs, et le polygala rosea de Michaux, et quelques autres espc̀ces exotiques, possèdent des propriétés entic̀rement analugues.

Les espèces du genre kramćrie ont, au contraire, dcs racines . qui sont d'une très-grande astringence. Outre le krameria triandra, qui eroît au Pćrou, et fournit spćcialement le ratanhia, plusicurs autres espćccs, et en particulier le krameria ixina, que l'on trouvè à Saint-Doningue et dans lcs áutres Antillcs, jouissent de propriciés tellcment semblablcs, que lcur racine peut être facilement substituće au ratanhia du Pérou.

QUATRE-VINGT-DOUZIÉME FAMILLE.

SI M A ROUBEES. - SIMARUBEA.

Cette famille, qui se compose des genres Quassis et Simardia ז, n'est probablement, ainsi que les Ochnacées,

1 Je genre SrasRuba d'Aublet est une véritable espèce de quassia. 
de M. de Candolle, qu'une seetion de la famille des Rutacées, avec laquelle elle offre une foule de earaetères communs. Ses fleurs sont hermaphrodites ou quelquefois unisexuées par avortement. Leur calice est eourt, persistant, à quatre ou cinq lobes. Les pétales, au nombre de cinq, sont dressés, incombans par leurs parties latérales, et caducs.

Ghaque fleur contient de cinq à dix étamines libres, attaehées à un disque hypogyne très-épais, souvent plus large que la base du pistil, au-dessous duquel il est placé. Les filets des étamines présentent à leur faee interne et inférieure une écaille ordinairement velue, avec lạquelle ils sont solidés dans une étendue plus ou moins considérable.

Le pistil est simple et appliqué sur le disque, dont nous venons de parler. L'ovaire est un peu déprimé, à cinq côtes saillantes, qui forment autant de loges libres clu côté interne et unies seulement à leur sommet par la base du style. On trouve dans chaque loge un ovule suspendu à l'angle interne et supérieur. Le style est simple, terminé par un stigmate qui offre autant de lobes qu'iliy a de loges à l'ovaire.

Le fruit se eompose d'autant de petites drupes qu'il y avait de loges à l'ovaire. Elles sont ovoïdes allongées, portées sur le disque elıarnu, tout-à-fait distinetes les unes des autres, contenant chacune un noyau monosperme, dans lequel est une graine qui renferme un embryon sans endosperme. Ces fruits, qui sont à peine charnus, peuvent s'ouvrir en deux valves, à l'époque de leur parfaite maturité.

- Les Simaroubées sont des árbres très-élevés ou de simples arbrisseaux, qui croissent dans l'Amérique méridionale. Leurs feuilles sont alternes, imparipinnées, dépourvues de stipules, et leurs fleurs forment des grappes ou des panieules terminales. 


\section{QUASSIE. - QUASSIA. Rich. D. C.}

Fleurs hermaphrodites : ealiee eourt, persistant, étalé, à einq divisions profondes; eorolle de einq pétales dressés, beaucoup plus longs que le ealiee. Dix étamines munies à leur base d'une écaille velue. Style simple, terminé par un stigmate à einq lobes peu marqués.

Arbrisseaux à feuilles imparipinnées, ayant les folioles eonstamment opposées.

Quassie amèbe. Quassia amara. L. suppl. 235. Lamk. Illust. t. 343. f. I.

Part. usit. : la racine. Nom pharm. : Radix quassice amara. Noms vulg. : Quassia amara; Bois de Surinam.

Arbrisseau de six à dix pieds d'élévation, droit, irrégulièrement rameux; à éeoree eendrée très-amère.

Feuilles éparses, oeeupant ordinairement le sommet des rameaux, très-glabres, quino-pinnées, rarement trifoliées. Pétiole commun rougeâtre, épais à sa base, ailé et membraneux dans le reste de son étendue, obtus et eomme tronqué à l'insertion des folioles. Celles-ei sont sessiles, obovales, oblongues, acuminées, rétrécies à la base, presque entières, à nervures rougeâtres, saillantes. Leurs bords et eeux du pétiole sont légèrement enroulés.

Fleur's en épi terminal multiflore, d'environ huit à dix pouees de longueur; fleurs dressées, eourtement pédieellées, ayant à leur base une braetée petile, spathulée, reeourbée; toutes sont hermaphrodites, inodores, rouges, ainsi que le rachis et les pédicelles.

Caliee très-petit; tube eourt, turbiné, solide; limbe étalé, plat, à einc divisions ovales, eiliées.

Corolle de einq pétales ineombans, dressés, formant une espèee de tube allongé, eylindrique; ees pétales sont linéaires, oblongs, légèrement eanaliculés, se rétrćeissant insensiblement de la base vers le sommet, insérés au pourtaur d'un disque hypogyne. 
Dix ćtamines à peine saillantes hors de la eorolle, cinq alternes un peu plus courtes, hors de l'anthère; mais peu de temps après les filets s'allongent considérablement, et les anthc̀res tombent. Ces filets sont filiformes et offrent à leur base un appendice obovale arrondi, glabre en dedans, chargé de poils en dehors, qui se rétrćcit subitement à sa base en un petit onglet. Le filet semblc naitre du milieu de cet appendice, lequel s'attache à là base du disquc. Les anthc̀res sont ovoïdes, oblongues, bifides à la base, attaehées au filet par le milieu du dos.

Le disque, plus large que les ovaires, est eylindrique, tronqué supćrieuremcnt, et offre dix petites fossettes pour l'insertion des étamines.

L'ovaire est globulcux, à cinq côtes, à cinq loges uniovulćes, soudées par leur sommet, mais distinctes par leur côte interne.

Le style naît đcs sommets réunis des cinq partics de l'ovaire; il est filiforme, à cinq sillons légers, un peu plus long que les étamincs : le stigmate est globuleux, capité à cinq dents rapprochées.

Le disque devient un rćceptacle charnu, rougeâtre, supportant les cinq parties de l'ovaire, qui se sont tout-à-fait écartées ct isolées les unes des autrcs, en sorte qu'il y a cinq fruits distincts, noirs, obovoïdes, constituant chacun une drupe renfermant une noix de même forme, qui est uniloculaire, et monosperme.

Cet arbrisseau croît spontanément à Surinam. On le cultive ì Caycnne et dans d'autres partics de la Guyannẹ.

Propriétés et usages. La racine du quassia amara est cylindrique, d'une grosseur variable, grisâtre et lachetéc cxtéricurement, blanchâtre en dedans, inodore. Sa saveur est excessivement amère, surtout celle de la partic corticale. Le principe amer du quassia est ćgalement soluble dans l'eau ct dans l'alcohol. Il est d'un jaune-brunâtre un peu transparent. M. Thomson lui a donné le noin de quassine.

Ce médicament est cértainement un de ceux dans lesquels la saveur amcre est la plus intcnse et la plus pure. Aussi doit-il être eonsidéré eomme cssentiellement tonique. La grande répu- 
tation dont celte racine a joui pendant quelque temps est aujourd'hui dc beaueoup diminuéc. On l'administre cncore quelquefois pour activer les forees digcstives dc l'cstomac, à la suite des maladies longues et chroniques qui ont jetć dans un état de faiblesse la plupart des organes de l'économie animale. Quelques auteurs l'ont également reeommandé dans les fic̀vres intermittentcs, la.goutte et les eatarrhes ehroniques. Mais en général on fait pen usage aujourd'hui de ee médicament exotique, que la gentiane et les autres amers indigènes peuvent faeilement remplacer.

C'cst ordinairement en infusion que le quassia amara est prescrit. Cetle infusion se prépare avee un gros de cette rácine que l'on fait infuser pendant six à douze heurcs dans une livre d'eau. Celte boisson cst d'une amertume excessive. On peut aussi préparer un vin, une teinture et un extrait de quassia; mais on les emploie très-rarcment.

$$
\text { SIMAROUBA. - SIMARUBA. Rich. D. C. }
$$

Fleur's unisexuées : calice concavc, à cinq lobes; corolle dc cinq pétales dressćs : ćtamines au nombre de cinq à dix.

Arbres à feuilles imparipinnées, ayant les folioles quelquefois alterncs.

Simarouba de Cayenne. Simaruba Guyannensis. Quassia simaruba. L. suppl. 234. Lamk. III. t. 343. f. 2.

Parl. usit. : écorce de la racine. Nom pharm. : Cortex simarubre.

Trćs-grand arbre dioïque, atteignant soixante à soixante-dix picds d'ćlćvation, ayant à peu pròs le port d'un frêne. Tronc droit, de deux picds de diamètre.

Feuilles alternes, plus rapproehćes vers le sommet des branelics, pinnćes, glabres. Pétiole commun d'un pied à un pied et demi cle longueur, un peu eanaliculé, surtout vers son sommet. Folioles allernes au nombre de dix à seize, courtement pćliolées, oblongues, arrondies, très-obluses, un peu échancrées, ou offrant une pointe très-eourte, cntières, glabres., épaisses el coriaces, sans nervures latérales apparentes. 
Fleur's dioïques petites, disposícs en unc trés-grande panicule ramifiée; chaque ramification est accompagnée par une feuille florale spatliulće, longuement pétiolćc. Les fleurs sont blanchůtrcs, très-courtcment pédicellées.

Fleurs mâles : caliee courtement campanulé, pubeseent, à cinq dents inégales, dressées.

Corolle de cinq pétales, bcaucoup plus longrs que lc calice, dressés, incombans, terminés par unc petite pointe, elliptiques, un peu canaliculés, insérćs autolir de la base du disque.

Dix étamines, un peu moins longues que les pétales. Filets dressés, filiformes, glabrcs, offrant en dedans dc leur partie inférieurc un appendice obovale, hćrissé dc poils. Anthères introrses, oblongues, fixécs par le milieu du dos.

Le disque oceupe lc fond de la fleur; il est charnu, tronqué et aplati supćrieurement.

Pas vestiges de pistil.

Fleurs femellcs : dix ćtamines avortées, très-courtes, dont les filets sont tout hérissés de poils dans la partie inférieure.

Pistil un peu plus court que la corolle : ovaire arrondi, a cinq coques, implanté sur le milien du disque. Chaque coque cst ovoïde, sailiante, réınie, aux autres seulement par le sommet, distincte du côté dc l'axe. Lc stylc est épais, plus court quc l'ovaire, à cinq sillons. Stigmate épais, capitulé, ombiliqué à son centre, à cinq divisions réfléchics, oblongues, lignlécs, obtuscs. Chaque coquc est rniloculaire, cóntenant un ovule attaché par la moitié supérieure de son bord internc.

Le fruit est commc dans le quassia anara.

Cet arbrc croît naturellement dans les lieux sablonneux, à la Guyanc, à Saint-Domingue ct à la Jamaïque.

Proprićtés et usages. Le simarouba du commerec est l'ćcorce de la racine de l'arbre que nous venons de décrire. Ellc cst en plaques souvent très-longues, repliées ou roulées sur cllesmèmes, d'un gxis jaunâlrc, d'unc tcxtıre fibrcuse ct lâche. Son odeur cst nulle ct sa saveur trćs-amcie. M. Morin, pharmaeien a Ploucn, s'cst occupé de l'analyse du simarouba. Il l'a trouvé composé d'une matière résincusc, d'unc huilc volatile, ayant l'odeur du bcnjoin, de quassinc, ou principc amcr du grassia amara, d'acétulc le polassc, d'acidc malique et de 
quelques sels. La quassine en est eertainement le prineipe aetif.

Le simarouba est un des médicamens que l'on a le plus préeonisés eontre les flux de ventre. Mais la réputation dont il jouit auprès d'ın grand nombre de pralieiens est-elle justement méritće? On serait tenté de le eroire, s'il fallait s'en xapporter aveuglément au témoignage de plusieurs auteurs eélèbres, et repousser les lumic̀res que la physiologie et l'expérienee elinique tendent à jeter sur ect objet. Nul doute que toutes les fois que la diarrhée, les fleurs blanches, la dyspepsie, etc., contre lesquelles on en fait usage, ne sout pas dues à une inflammation des intestins, des organes génitaux et de la muqueuse de l'estomae, le simarouba n'ait pu, en réveillant l'exeitabilité affaiblic, procurer un soulagement prompt ct effieace. Mais par son action essentiellement tonique, ee médieament doit être nuisible dans tous les eas où il y a doulẹur ou inflammation vive dans quelque organe important.

On a fait aussi usage du simarouba dans les fièvres intermittentes veruales, qui cèdent en rénéral faeilement aux soins hyģiéniques et à l'emploi cies amers; dans le scorbut, les scrophules, la eblorose, ete. On lui a aussi attribué la propriété d'arrêter le vomissement. Mais pour produire ect effet, il faut nécessairement que ee phénomène morbide ne dépende pas de l'inflammation de l'estomae.

C'est ordinairement en dćeoction que l'on prescrit l'éeorce de simarouba, à la dose d'ine onec pour une pinte d'eau. On peut aussi l'administrer en poudre, sous la forme de bols ou d'éleetuaire, ou enfin en préparer un extrait.

\section{Propriétés médicales et usages des Simaroubées.}

Les Simaroubées se eomposent d'un très-petit nombre de végélaux, qui tous sont exotiques. Sous le rapport de leur composition ehimique et de leurs propriétés médicales, ils offrent entre cux une ressemblanee parfiitc. Ell effet, le principe aner nommé quassine par les elimistes, et dont nous avons signalé l'existcnce dans la racine du quassia amara et dn simarouba, se retrouve non-seulenent dans les autres partics de ecs végétanx, telles que le bois, les feuilles, l'éeorce, 
la graine, mais dans les trois ou quatre autres espèces qui forment avec ellcs toutc la famille des Simaroubécs. Sous ce rapport, ce petit groupe s'ćloignc beaucoup dcś Rutacées, qui sont âcres, aromatiques ct cxcitantes, tandis qu'il s'en rapproche si intimement par ses caractères d'organisation.

QUATRI-VINGT-TREIZIÈ FAMILXE.

RUTACÉES. - RUTACEAE.

Végétaux herbacés, sous-frutescens ou même ligneux, à feuilles alternes, ou opposées, simples ou composéespinnées. Leur calice est monosépale, à ciuq divisions profondes; la corolle, composée de quatre ou cinq pétales quelquefois inégaux : les étamines, au nombre de huit ou dix, sont attachées à un clisque hypogyne, qui élève l'ovaire et lui forme une espèce de stipes; l'ovaire est à quatre ou cinq côtes, à autant de loges, contenant chacune un ou plusieurs ovules renversés; le style est simple, terminé par un stigmate simple ou à cinq lobes.

Le fruit est globuleux ou comprimé, à deux, trois on cinq côtes plus ou moins saillantes, et quelquefois en forme d'ailes. Il se partage souvent en autant de petites capsules, s'ouvrant par le sommet et la partie interne, qu'il y a cle loges. Les graines contiennent un embryou ręnfermé dans un endosperme charnu.

$$
\text { RUE. - RUTA. L. Juss. }
$$

Calice plane, étalé, persistant, à quatre divisions aiguës; corolle de quatrc ou cinq pétalcs concaves, onguiculés; huit à dix étamines : ovaire à quatro ou cinq côtes rugueuses; slyle et slignate simples; capsulc à quatrc ou cinq loges, polyspermes, s'ouvrant seulement par la partic supérieure et in-
ternc.

Végétaux herbacés ou sous-frutescens, à feuilles alternes et pimnécs. 
Rue odorante. Rula graveolens. L. Sp. 548. Blackw. t. 7.

Part. usit. : les feuilles.

Arbuste de trois à quatre pieds de hauteur, ramcux dès sa base. Les branches inféricures sont presque ligneuses et persistantes; les supérieures herbacées, cylindriques, sont très-glauques, et présentent, ainsi que le reste de la plantc, nn grand nombre de petitcs glandes, contenant une huile volatile d'une odeur extrêmement fortc et pénétrante.

Fcuilles ćparses, composées, glauqucs; pétiole commun, très-grand, cylindrique; divisions secondaires, canaliculées; foliolcs cunéiformes, un pcu épaisses et charnues.

Fleurs jaunes, disposées en une espèce de corymbe paniculé, rameux dès sa partie inférieurc. Les fleurs, courtement pédonculées, sont disposées altcrnativement le long des rameaux $d u$ corymbe; au-deșsous de chacune d'elles et latéralement, est une bractéc très petite et linćairc.

Calice ćtalé, pelit, à quatre ou cinq divisions aignës, sessiles, persistantes. Corolle de quatre ou cinq pétales onguiculés, cn forme de cueiller, un peu sinueux sur les bords.

Étamines au nombre de huit à dix, dressées, saillantes, de la longueur de la corolle, attachées à la base d'un disque hypogyne, très-épais, jaunâtrce, offrant dans son pourtour autant de glandes arroudies qu'il y a d'étamines. Les filets sont subulés; les anthères biloculaires, ovoïdes, arrondies, aftachées par la base.

J'ovaire est fendu jusqu'à son milieu cn quatre ou cinq partics; il csì très-rngueux à causc du grand nombre de glandes qu'offre sa surface; il présenic quatre ou cinq loges, contenant cinq à six ovules comme réniformes, atlachés vers le milicu de son axe.

Le style est central, plus court que les élamines, terminé par un stigmate sinple, tr'c̀-petit.

Le fruit est à quatrc ou cinç côtes saillantcs et rugacuscs, a autant de loges s'ouvraut seulement par leur partic supćricurc et internc. 
La rue offieinale croit dans les lieux secs et pierreux du midi de la France. $\not 4$

Propriétés et usages. L'odeur répandue par toutes les parties de cette plante cst extrêmement forte, aromatique, peu agréable. Elle est due à l'huile volatile, sécrétée par les glandes nombreuscs que l'on renarque dans toutes les parties de la r'ue. Sa saveur est âere, un peu amère, aromatique et trèschaude.

On emploie les feuilies, qui sont stimulantes et mêmc irritantes, pour activer le eours des menstrues, retardées par une cause débilitante. On les donne aussi dans la chlorose : elles sont fréquenment usitćes comme vermifrges. On les administre en infusion à la dose de demi-gros à un gros pour une chopine d'eau, ou en poudre à la dose de huit à dlouze grains sous forme de pilules. Appliquées sur la peau, elles peuvent en déterminer la rubéfaction.

C'est un remède qu'il ne faut prescrire qu'avec beauconp de eireonspection, surtout aux femmes d'un tempérament irritable; il agit avec beaucoup d'activité sur l'utérus, et pcut produire l'inflammation de cet organe, une hémorrhagie inquiétante, et, dans quelques circonstanees, l'avortement.

\section{DICTAMNE.-DICTAMNUS.}

Calice profondément partagé en cinq lanières lancéolées; corolle de cinq pétales inégaux; quatre supérieurs dressés et un inférieur; dix étamines déelinées; style et stigmate simples. Le fruit est à einq loges ct à einq côtes saillantes, ct comme étoilé; chaqune loge renferme deux à trois graines.

\section{Dictame peanc. Dictamnlés albus. L. Sp. 548.}

Part. usit. : la racine. Nom pharm.: Radix fraxinello, s. Dicsamni albi. Nom vulg. : Fraxinelle.

Racine vivace, formée dc fibres allongées et assez grosses. Tige dressée, simple, 'roide, cylindriquc, hante d'un pied et
lemi à deux pieds.

Feuilles alternes, imparipinnćes, longues de six à huit pou- 
ces, eomposées de sept à onze folioles sessiles, ovales aiguës, dentieulées, inéquilatères. Le pétiole eommun est ailé entre chaque paire de folioles.

Les fleurs sont grandes, rouges ou blanehes, pédoneulées, disposées en un long épi lâche, qui oeeupe le tiers supérieur de la tige.

Les pédoneules, la partie supérieure de la tige, le ealiee, la face externe des pétales, sont eouverts d'un nombre infini de petites glandes rougeâtres, globuleuses, qui séerètent une huile volatile abondante, d'une odeur forte et peu agréable.

Chaque fleur est portée sur un pédoneule long d'environ un pouce, aecompagné d'une ou de deux petites braetées linéaires; toujour's ee pédoncule est recourbé à son sommet.

Le ealiee est monosépale étalé, profondément partagé en einq lanières étroites, linéaires, aiguës, de eouleur purpurine.

La eorolle est pentapétale, irrégulière, étalée; quatre des pétales oeeupent la partie supérieure de la fleur, ils sont dressés, ovales aigus, rétréeis en onglet à leur base. Le cinquième est inférieur et pendant, rétréei supérieurement et à sa base.

Les étamines sont au nombre de dix, déelinées vers la partie inférieure de la fleır et à peu près de la longueur de la eorolle; les filets sont allongés, subulés, reeourbés à leur partie supérieure, et garnis de petites glandes rougeâtres, légèrement poilus dans leur partie inférieure; les anthères sont à quatre faees, obtuses, attaehées au filet par leur base.

Le pistil est libre et eentral, élevé sur un stipe plus étroit que la base de l'ovaire, et dont la substanee se confond avee eelle dı pistil, sans diseontinuité. L'ovaire est globuleux, à cinq eôtés arrondis, tout eouvert de poils et de glandes d'un rouge très-foneć; il présente einq loges, qui eontiennent ehacune trois ovules attaehès vers l'axe, et alternes entre eux. Le style est plus cour't que les étamines, mais également déeliné, terminé par un stigmate exeessivement petit, et à peine distinet dis sommet du style.

Le fruit est à einq côtes saillantes et étoilées, s'ouvrant par le eôté interne.

Lil fraxinelle eroit dans les beis en Alsace et dans les provinees méridionales de la France. $\%$ 
Propriétés et usages. Toute la plante exhale une odeur aromatique très-forte, due à son huile volatile. Sa racine, qui est amère et aromatique, était jadis employée eommc sudorifique et vermifuge; mais aujourd'hui les mćdecins en ont abandonné l'usage à la médecine populaire.

Dans les grandes chaleurs de l'été, l'huile volatile, qui s'échappe dc la plante, forme autour d'elle une atmosphère que l'on peut enflammer en y plongeant une bougie allumée.

\section{GAIAC. $\neg U A I A C U M$. L. J.}

Calice à einq divisions profondcs, un peu inégales; corolle de cinq pétalcs réguliers, planes et étalés; dix étamines; ovaire pédieellé, à einq loges; style simple; capsule un pcu charnne extérieurement, à deux, trois ou cinq loges, formant autant d'angles saillans.

Arbres à feuilles opposées, paripinnées, à fleurs axillaires et pédonculées.

Gä̈ac opficinat. Guaiacum officinale. L. Sp. 546. Blackw. t. 35o. f. I. 2.

Part. usit.: le bois, la résine. Noms pharm.: Guaiacum, s. Lignum sanctum.

Cet arbre, assez élevé, a le bois jaunâtre, très-dúr et trèscompact. Ses rameaux sont recouverts d'un épiderme grisâtre et rugueux; ils sont eomme artieulés et ornés de feuilles opposées, paripinuées, eomposées dc deux ou trois paires de folioles opposées, sessiles, ovales, obtuses, entières, glabres, longues d'un pouce à un pouce et demi.

Les flcurs sont bleucs, portécs. sur des pédoneules d'un pouee et plus de longucur, réunies au nombrc de huit à dix à l'aisselle des feuilles supérieures. Ces pédoncules sont finement pubeseens. Le caliee cst à einq divisions tr ćs-profondes, un peu inégales, obtuses, légèrcment vclues en dchors. La eorolle est formée de einq pétales ćtalés, obovales obtus, rétrćcis à leur base.

Les dix étamines sont dressées; leurs filets sont grêles, sim- 
ples, terminés par une anthère allongée, qui se roule après lo féeondation.

L'ovaire est obovoïde, eomprimé, pédicellé à sa base. Le style qui le termine est simple. Le fruit est une sorte de eapsule lćgèrement eharnue en dehors, tantôt globuleuse, à einq côtes et à einq loges, mais plus fréquemment comprimée, presque eordiforme, comme à deux ailes et à deix loges.

Le gaïae eroit naturellement en Amérique. On le trouve à la Jamaïque, à Saint-Domingue, ete.

Propriétés et usages. Le bois de gaïae du commerce est en bûehes plus ou moins volumineuses, reeouvertes d'une écorce grisâtre et eompaete, dont la face interne présente des efflorescences blanehes, qui sont probablement, ainsi que l'observe M. Guibourt, de l'acide benzoï (jue. Ce bois est très.compacte, pesant, presqu'inodore, d'un brun verdatre au centre, jaunâtre dạs ses eonches externes. Il est très-résineux. Sa saveur est excessivement âcre et aromatique.

On. le râpe en général avant de l'employer en médeeine. Cette sciure prend, lorsqu'elle est exposée à la lumière, une coulenr verte plus on moins intense, qui paraît due à l'action de l'air et de la lunière sur la résine qu'elle eontient.

La résine de gaïae dćcoule de l'arbre déerit ei-dessus, par les incisions que l'on pratiquè à son éeoree. Elle est en masses irrégulic̀res, à enssure brillante, d'une enulenr brune verdâtre, d'une odeur assez agréable, qui rappelle celle de l'aciıle benzoïque: sa saveur, d’abord faible, devient âcre, ę̆ prond fortement à la gorge. Celle résine, exposée à la lunière, prend une teinte verle plus ou moins vive. Les aeides lui font ćprouver divers changemens de eouleur, que l'on altribue génćralement aux différens degrés d'oxigénalion que subit eetle résine; ct, eomme clle offre des earactères qui ne se remarquent pas dans les autres subsiances résineuses, M. Brandes a proposé d'en faire un principe immédiat nouveau. Elle est soluble dans l'alcohol et l'élhcr, mais presque inatlaquable par l'eau.

Le gaïae, ct surțout sa résine, possèdent une action ćminemment stimulante. Leur usage détermine lous les plićnomènes d'une excitation puissante qui se porte en ginćral vers la périphŕrie du coipss, et augmente dime manière sensible la 
perspiration culanće: aussi est-ce surtout comme sudurifique: que l'on emploie ce médicament. C'cst vers le commencemeut du seizième siècle, c'est-à-dire peu dc temps aprc̀s l'apparition de la syphilis en Europe, que l'on a commencé à en faire usage. Il fut d'abord considéré comme un remède infaillible, une sorte de spécifique, propre à triompher des symptômcs qui a vaient résisté à l'usage du mercure. En effct, le gaïac n'a 'jainais guéri d'une manière radicale, que des individus ciont les symptômes avaient ćté cntrctenus et souvent exaspérés par l'emploi peu méthodique des inédicamens mercuriels. Mais, dans aucun cas, cette substance n'a guéri scule les symptômes d'une infection générale. Comme tous les autres sudorifiques exotiques, auxqiuels on l'associe presque constaminent, le gaïac peut être d'un grand secours dans le traitement de la maladie vénériemne constitutionnelle; mais il ne suffit pas poúr la guérir.

L'enıploi de ce remède a aussi été recommandé par beaucoup de médccins dans le traitement de la goutte ct du rhumatisme chroniques, des dartres et de quelques autres maladics de la peau. Mais il faut observer d'une manière générale, que ce médicament ne pent ètre a vantagcux, dans ces différens cas, que chez les individus affaiblis, et quand ces affcctions n'offrent plus les signes d'une inflammation aigı̈̈; car alors il serait plus nuisible qu'utile.

On adninistre le bois de gaïac en décoction, soit seul, soit mêlé avec les autres bois et racines suclorifiques, tels que le sassafras, la salseparcille et la sçuinc. Lorsqu'on l'emploie seul, on prépare cette décoction avec une à deux onces de gaïac râph́, 'que l'on fait bouillir dans deux livres d'cau jusqu'à réduction d'un tiers. Cettc tisane, convenablement édulcorée, doit être prise par verrées d'heurc en heure.

Quant à la résine, on la prescrit assez fréqucmment sous la forme de pilules ou d'électuaire, ou suspendue au moyen de l'alcolol dans un véhicuie aţucux. On peut aussi l'avoir en suspension dans l'eau, cn mêlant enscmble une partie de la résinc en pondre avec vingt parties de sucre et une demi-jartic de gonme adragant, que l'on ćleud dans cent partics d'eau. Li dose cst d'un à deux scruprulcs, que l'on peut graduellement augmenter. 


\section{CUS PARIE. - CUSPARIA. Humboldt.}

Calice campanulé à cinq divisions; corolle de cinq pétales soudés ensemble par leur basc, et formant une corollc monopćtale tubuleuse; cinq ou six ćtamines, dont deux seulement sont anthćrifc̀res. Ovaire à cinq loges uniovulées; style simple, stigmate à cinq lobes rapprochés; cinq capsules monospermes, bivalves, réunies à un axe central.

Arbres exotiques, à feuilles trifoliées, à fleurs en grappes axillaires.

\section{Cusparie fébrifuge. Cusparia febrifuga. Humb.} Boriplandia trifoliata. Willd.

Part. usit. : l'écorce d'angusture. Noms pharm. : Cortex angustura. s. Angosturae. Noms vulg. : angusture vraic, Cusparé.

Cet arbrc peut s'ćlever à une hauteur considérable. Son écorcc cst. grisâtre. Ses jcunes rameaux sont cylindriques, verts, avec des petits points gris; ils portent des feuillcs éparses, rćunies en plus grand nombre vers leur partie supérieure. Leur pćtiole est long de huit à dix pouces ct canaliculé; il se terınine par trois foliolcs, sessiles, digitćes, minces, glabres et luisantes, ovalcs, allongćes, aigü̈s, entières; cclle du milieu cst un peu plus grande que les deux latérales. Il n'y a pas de stipules.

Les fleurs sont blanehes, et forment à l'aisselle des feuilles supérieures, des grappes dressées, cylindriques, pédonculées, à peu prc̀s de la même longueur que les feuilles.

Leur calice est subcampanulé, à cinq divisions assez profondes, ovales aiguës. La corolle, qui est trois fois plus longue que le calice, se compose de cinq pétales, soudés cnsemble par lenr base au moyen des filets staminaux, de manière à ressembler à unc corolle monopétale, tubuleuse par sa base, à cinq divisions profondes ct obtuses. Le calice et la corolle sont couverts de poils fasciculés.

Ics ćtamines sont au noubrc de cinq à six, dont deux seulement sont anthérifères; les autres sont stériles et un peu plus longues; toutes ont leurs fileis dilatćs ct membrnneux à lcur 
base, et servant ainsi de moyen d'union enire les pétales. Les anthères sont allongées, obtuses, à deux loges, et se terminent inférieurement par un petit appendiee membraneux.

L'ovaire est sessile au fond de la fleur, à einç eôtes obtuses et saillantes, à cinq loges contenant elacune un seul ovule attaclé vers l'angle interne et supérieur. Cet ovaire est environné et en partie caché par un disque saillant, eoneave, dont la hauteur dépasse un peu eelle de l'ovaire. Le style est simple, et se termine par un stigmate à einç lobes rapproehés.

Le fruit se eompose de einq eapsules, rétunies sur un axe commun, et qui chacune sont uniloculaires, monospermes et bivalves.

Cet arbre est originaire des bords del'Orénoque, dans l' $A$ mérique méridionale, où MM. de Humboldt et Bonpland l'ont vu. former d'inménses forêts. Il croît aussi dans d'autres parties du eontinent et des îles de l'Amérique.

Propriétés ct usages. L'angusture vraie, que l'on a longtemps eru provenir du magnolia glauca, est l'éeoree de l'arbre dont nous venons de traeer la deseription. C'est à MM. de Humboldt et Bonpland que l'on doit eette importante découverte. Cette éeorce est en plaques dont la longueur varie de deux à quinze pouees; elles sont peu roulées, minees sur les bords. Leur épiderıne est d'un gris jaunâtre, quelquefois épais et fongueux, et scmble formé par une espèce de lichen. Leur eassure est eompaete, résincuse, d'une teinte brune-jaunâtre : leur face interne est fauve, quelquefois légèrement rosée; leur saveur. est amc̀re, un peu nauséense, et laisse dans la bouehe, surtout à la pointe de la langue, un sentiment d'âcreté et de pieotement.

Măgré les travaux importans de MiM. Vauquelin et Planelie, on ne connait pas eneore bien positivement la nature des principes eonstituans de cette éeorce. On sait qu'elle ne eontient ni tannin, ni acide gallique, mais quelques sels, une matière amère très-abondante et un prineipe azoté.

Ce n'est guèrè que vers la fin du dernier sièele que l'on a connu en Europe les propriétés médieales de l'éeoree d'angusture. Les anglais furent les premiers qui tentèrent des essais à cet égard. Lc succès que les médecins américains retiraient de 
l'usage de ce médicament dars la dyssenterie et les fièvres intermittentes, dut engager à en faire usage contrc ces deux maladies; MM. Ewers et Williams l'ont employć avec lc plus gland succès contre ces affcctions. Mais il est essentiel de n'en fairc usage dans la dyssenteric, que quand celte in aladie a pcrdu son carastcre inflammaloire; car, dans le cas contraire, elle en augmenterait infailliblement tous les symptômes. Quclques praticicns l'ont aussi recommandć contre la fièvre jaune. M. de Humboldt assure que plusieurs mćdecins, dans la patrie même des quinquinas, ont plus de confiance dans la vertu fébrifuge de l'angusture. Cependant, d'autres praticiens ne partagent point cette haute opinion sur l'efficacité dc l'angusture, qui a souvent échouć dans des cas très-simples. Aussi, de nos jours, emploie-t-on fort rarement ce médicament exotique, moins certain dans ses effets quc l'écorce du Pérou.

C'est ordinairement en poudre, à la dose de vingt à vingtquatre grains, répétće plusieur's fois, que l'on administre l'angusture. $\Lambda$ dose plus élevéc, elle détcrmine presque constamment la purgation. On prescrit ausis l'infusion ou la décoction d'un à deux gros de cette écorce dans deux livres d'eau. Sa teinture alcoholique est une préjiaration très-efficace.

\section{Propriétés médicales et usages des plantes de la famille des Rutacées.}

La saveur ànèrc, âcre, aromalique de la rue officinale se retrouve dans la p'upart des antres plantes de la famille des Rutacécs, quijouissent toutes de proprićtés excilanlcs, comme Ic prouve la fraxinelle ou dictamnc blanc, et les diffírcntes espéces du genre Rutı, qui peuvent toutes êtrc einployées les unes pour les autres. Le bois el i'écorcc de gaïlc, qui sont un peu âcres et amères, et si fréqueinment employés coınme sudorifiques, l'ćcorce d'angusture, qui est an ère et tonique, confirment cette analogie cn l'élayant de nouvcaux faits.

Ainsi l'on peut dire qu'en général toutes les planles de la fámille des Rutacées sont âcres, aronatiques, un pen amères, et jouissent d'une vertu tonique ou excitante tris-mariprcic. 
QUATRE-VINGT-QUATORZIEME FAMILLE.

\section{CARYOPHYLLËES.-CAKYOPHYLLE $E$.}

Plantes herbacées, rarement sous-frutescentes, à feuilles opposées, sessiles; à fleurs en épis ou en bouquet à la partie supérieure de la tige; le calice est tantôt monosépale, tủbuleux, à cinq dents, persistant ; d'autres fois il est formé de cinq sépales distinctś : la corolle est de cinq pétales longuement ouguiculés, rarement sans onglet : les étamines varient en nombre, de quatre, cinq à dix, dans ce dernier cas cinq sont unies avec les pétales, les cinq autres sont libres et attachées sous l'ovaire.

L'ovaire est libre, à une ou plusieurs loges, terminé par un à cinq styles et autant de stigmates.

Le fruit est une capsule à une ou plusieurs loges, s'ouvrant en plusieurs valves, ou seulement par l'écartement de dents placées à sa partie supérieure; rarement ce fruit est charnu et bacciforme.

L'émbryon est endospernique extraire, roulé autour d'un endosperme farineux.

$$
\text { OEILI,ET. - DIANTHUS. L. J. }
$$

Cálice tubuleux, à cinç dents, entourć à sa base d'un calicule formé de plusicur's écailles impriquécs : corolle de cinq pétales longuement onguiculés; dix étamines; deux słyles : eapsule s'ouvrant par le sommet seulement, et à une seule loge.

OEillet nes sandins. Dianthus caryophyllus. L. Sp. 587. Blackw. t. 85 .

Part. usit. : les pétales. Nom pharm. : Caryophyllus hortensis.

L'oxillet, qui fait l'ornement de nos jardins par la variété et. l'éclat de ses fleurs, est unc plante vivace, dont la tige est couchée inféricurement, redressćc dans sá parlic supériemre, 
haute de deux á trois pieds, rameuse, cylindrique, noueuse et eomme artieulée, glabre et glauque, ainsi que les autres parties de la plante.

De elaque nœud de la tige et de ses ramifieations partent deux feuilles opposées, sessiles, semi-amplexienules, linéaires, allongées, aiguës, entières, ercusées en gouttières, reeourbées dans leur extrémité supérieure. Les fleurs naissent au sonınet des rameaux. Elles sont solitaires on réunies au nombre de deux ou trois. Leur ealice est tubuleux, cylindrique, à einq dents, aeeompagné à sa base de quelques éeailles imbriquées. La eorolle est formée de einq pétales d'un rouge poneeau, denticulés à leur sommet, qui est tronqué.

Le fruit est une capsule ovoïde très-allongée, s'ouvrant seulement par des dents qui existent à son sommet.

Cette plante eroit naturellement dans les lieux pierreux des provinees méridionales. $₹$

Propriétćset usages. Les fleurs de l'œillet ont une odeur extrêmement agréable, aromalique, piquante, ayant beaueoup de ressemblanee avec eclle du girofle. Elles sont légèrement excitantes. Leur infusion passe pour diaphorétique, mais comme leur principe aromalique est très-fugaee, cette boisson est bien peu eflieace. Aussi l'emploie-t-on fort rarement. On prépare un sirop et un ratafia d'œillet, qui sont des préparations beaueoup plıs agréables qu'uliles.

\section{SAPONAIRE. $-S A P O N A R I A$. L. J.}

Calice tubuleux, eylindrique, à einq dents, nu à sa base: einet pétales onguieulés, appendieulés : dix étamines : deux styles : eapsule à une senle loge, s'ouvrant par le sommet.

Saponaire officitale. Saponaria officinalis. L. Sp. 584. Blackw. t. I 3 .

Part. usit.: les sommilés fleuries. Nom pharm. : Saponaria.

Raeine vivace, poussant plusieurs tiges dressces, rameuses, fermes, cylindriques et nouenses.

f'euilles opposées, glabres, sessiles, ovales aiguës, entières, 
rétréeies à la base, marquées de einq nervures longitudinales, dont les trois moyennes sont plus apparentes.

Fleurs gुrandes, roses pâles, disposées en une sorte de panicule terminale.

Calice monosépalc, tubuleux, renflé à sa partie moyemne, pubeseent et à cinq dents aigü̈s.

Corollc de cinq pétales très-longuement onguiculćs, à onglets très-droits, plus longs que le calicc, offrant sur leur face interne une lame longitudinale saillante, donble, terminée supćrieurement par deux petites pointes : lirnbe étalé, eunéiforme, un peu échancré.

Étamines au nombre de dix, saillantes hors de la corolle, ayant les filets longs, grêles et subulés, glabres, réunis à leur base, cinq alternes plus renflés que les einq autres, tous soudés avec la partie inférieure de l'ovaire. Celui-ci est ovoïdc, très-allongé, lisse et glabre, rétréci à sa base et à soṇ sommet, uniloeulaire, contenant un grand nombre d'ovules, attachés à un trophosperme central. Du sommet de l'ovaire naissent deux styles articulés, slalırcs, subulés, aplatis du côté interne, un peu recourbés au sominet.Stigmates très-pctits, se prolongeant sur la faee interne des styles en un sillon glanduleux.

Capsule uniloeulaire, s'ouvrant par la partie supérienre.

La saponaire eroìt naturellement dans lcs champs cultivés aux environs de Paris. Elle flcurit en juin et juillct. $f$

Propriétés et usages. Les différenies parties de la saponaire sont légèrement amères et mucilagineuscs. On les emploic fréquemment en décoetion, eomme sudorifiques, dans la syphilis constitutionnelle, les inaladies cutanées; la goutte. Le suc extrait de la plante fraîche est employć aux mêmes usagcs. Mais c'est un médicament peu effieace, et dont on a beaucoup trop exalté les propriétés.

Propriétés médicales et usages des Caryophyllées.

Cette famille, qui est si nombrcuse cu genres et en espc̀ces, rioffre aucun intérêt sous lc point dc vuc médical. En effet, si rous en exeeptons la saponairc, qui a une saveur amc̀re, les 
fleurs de l'œillet, qui sont légèrement aromatiques, nous ne trouvons dans les Caryophyllées, dont́ la plus grande partie appartient à la Flore européenne, que des herbes insipides et sans utilité.

\section{QUATRE-VINGT-QUINZILIME FAMILLE.}

\section{LINACÉES. - LINACEAE.}

La famille des Linacées, dont le genre lin est le type, offre pour caractères: un calice de cinq sípales; une corolle de cinq pétales, sans onglets; cinq à dix étamines monadelphes, seulement par la hase de leurs filets. L'ovaire est à cinq ou à dix loges, contenant chacune un seul ovule attaché à la partie supérieure de l'angle interne de chaque loge; cinc styles et autant de stignates partent du sommet de l'ovaire.

Le fruit est une capsule globuleuse à huit ou dix logges monospermes; les cloisons sont formées par les bords rentrans des valves, dont le nombre égale celui des loges. I es graines sont lisses : elles reuferment un embryon dépourvu d'endosperme et ayant les cotylédons planes.

Cette petite fanille a beaucoup de rapports avec la précédente. Elle en diffère par la structure de son fruit, et par ses graines dépourvues d'endosperule.

$$
\text { LIN. - I.I } \wedge^{\top} U \text { IH. L. J. }
$$

Calice de cinq sépales, persistant; corollc campanulée, formée de cinq pétales très-caducs; dis ćlamines, dont cinq avortent souvent, ct. sont remplacées par autant de petiles écailles. Cinq slyles. Capsule à dix loges monospermes, environnée. par le calice. 
Lin vsder. Linum usitatissimum. L. Sp. 397. Blackw. t. 160 .

Part. usif.: les graines.

Racine annucllc, poussant une tige dressće, simple inférieurement, un peu ramifiée à sá partie supcrícure, effilée, grêle, cylindrique, entièrcment glabrc, ainsi que les autres parties de la plantc.

Feuilles ćparses, sessiles, lancéolćes aiguës, entièrcs, d'un vert glauque, marqućes à leur face inféricure de trois nervures longitudinales et parallèles.

Fleurs bleues, terninales au sommet des ramifieations de la tige. Calice pontasépale, subcampanulé, persistant; sépales ovales, lancéolés, aigus, membrancux sur les bords. Cololle pentapélale, subcarnjaniforme, très-caduque; pélalcs deux fois plus longs que le calice, obovales arrondis, très-obtus et entiers, rétrécis à leur basc.

Cinq ćtamines beaucoup plus courtes que la corolle : flets réunis ct monadel phes à leur base, présentant cntre chacun d'eux une petite pointe qui cst une élamine avortée. Les anthicres sont cordiformes, allongies, extrorses.

Ovaire ovoülle, terıniné en pointe à son sommet, lissc, luisant ct glabre; à dix loges renfermant clracunc un seul ovule.

Cinı slyles grêles, se confondant à leur partie supérieure avec les stigmates, qui sont obtus.

Le fruit est une capsule globulcuse cnvironnće par le calice, ordinairement à dix valves, dont les bords rentrans forment les cloisons; chaquc loge renferme une seule graine brune, ovale, comprinće, très-lisse et luisante.

Le lin croit naturclicmcnt dans les champs. On le cultive en grand dans plusieurs provinces dc la France. (C)

Proprićtés et usages. On fait en inćdecine un usage trèsfréquent et une énoŕme consommation des graincs du lin. En effet, outı e l'huile grasse qu'clles contiennent cn abondance, ellcs renferment anssi une quantité trćs-considćrable de mucilage. Aussi ces graines sont-clles adoucissantes et émollientes 
par cxcellence. Leur décoction dans l'eau est épaisse et visqueuse. Elle est peu agréable à boire, à moins qu'on ne l'ait faite très-lćgère. Cette décoction peut être employée avecle plus grand succès dans tous les cas d'inflainmation, soit de l'estomac et des intestins, soit de la vessie, des reins, du canal de l'urètre, etc. On prćpare avec elle des gargarismes, des collyres; des injections, des fomentations, des lavemens adoucissans.

La farine préparée avec ces graines est d'un usage extrêmement fréquent dans la thérapeutique chirnrgicale. On cn forme des cataplasmes que l'on applique sur les tumeurs, les plaies, les ulcèr's enflammés. Arrosés avcc une solution aqueuse d'opium, ou préparés avec la décoction des têtes du pavôt blanc, ces cataplasmes deviennent sédatifs.

L'huile grasse quc l'on retire des graines de ce végétal est fort employée dans les arts, et surtout dans la peinture. Comme toutes les autres substances de la même nature, elle est relâchante el peut agir comme purgative.

Nous n'avons pas besoin de rappelcr ici que c'est arec les fibres de la tige de cette plante, que l'on prépare le fil de lin, dont on fait des éloffes très-recherchées.

Une seconde espèce de ce genrc en diffère beaucoup par ses propriétés; c'estle lux cathartieue (Linum catharticum, L.), petite plante annuelle, très-commune sur les pelouses un peu humides, et qui se distingue à sa tige grêle et dicholomé, à ses fcuilles ovales, et à ses fleurs blanches. Elle parait posséder une propriété purgative, mais à un si faible degré, que depuis long-temps on en a abandonué l'usage.

Cette propriété purgative du lin cathartique forme une exception assez notable dans le groupe des plantes qui composent la famille des Linacées, qui toutcs sc rapprochent du lin usucl par le mucilage abondant que renferment leurs graines, et la tćnacitć dcs fibres de leur tige. 


\title{
TABLE MÉTHODIQUE
}

\author{
DES FAMILLES ET DES GENRES.
}

Préface.

Introduction. Division des végétaux en Acotylédons, Monocotylédons et Dicotylédons; leur subdivision en neuf classes.

PLANTES ACOTYLÉDONÉES.

Iro Classe.

I $^{\text {re Famille. }}$

2e Famille.

30 Famille.

4. Famille.
ACOTYLÉDONIE.

Algues. Algà.

Varec. Fucus.

Champignons. Fungi.

Agaric. Agraricus.

Amanite. Amanita.

Bolet. Boletus.

Mérule. Merulius.

Clavaire. Clavaria.

Morille. Morchella.

Helvelle. Helvella.

Truffe. Tuber.

LICHÉNÉEs. Lichenes.

Lichen d'Islande. Cetraria.

Fougìres. Filices.

Polypode. Polypodium.

Néphrode. Nephrodium.

Doradille. Asplenium.

Adianthe. Adianthum.

Osmonde. Osmunda: 
II Classe. MONO-ÉLEUTHÉROGYNIE.

$\S$ I. Fleurs nues ou simplement enveloppées d'écailles. $5^{\circ}$ Famille. Aroïdérs. Aroidece.

Gouet. Arum.

Acore. Acorus.

6* Famille. Piṕrinées. Piperinea.

Poivrier. Piper.

7e Famille. Cýpéracées. Cyperacece.

Souchet. Cyperus.

Laiche. Carex.

8- Famille. Graminées. Gramineo.

Froment. Triticum.

Ivraie. Lolium.

Seigle. Secale.

Orge. Hordeum.

Avoinc. Avena.

Roseau. Arundo.

Canne à sucre. Saccharum.

Riz..Oryza.

Maïs. Zea.

\$II. Fleurs munies d'un calice pétaloñde.

9e Famille. Alisnacées. Alismacéa.

Fluteau. Alisma.

10'Famille. Colchicḱes: Colchicece.

Colchique. Colchicum.

- Vératre. Veratrum.

í Famille. Palmiers. Palma.

Datiier. Phonix.

ix Famille. Asparacivies Asparaginea.

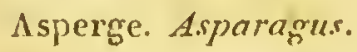


DES FAMILLES IT DES GENRES.

Muguet. Convallaria.

Smilax. Smilax.

Fragon. Ruscus.

I $3^{\mathrm{e}}$ Famille. Limaćes. Liliaceœ.

Lis. Lilium.

Ail. Alluum.

Scille. Scilla.

Aloès. Aloe.

I $4^{e}$ Famille. Nrmpнíacies. Nympleacea.

Nénuphar. Nymplicea.

III Classe. MONO-SYMPHYSOGYNIE.

I5 Famille. Diosconées Dioscorea.

Taminier. Tamus.

$16^{\text {e }}$ Famille. Broméliackes. Bromeliacea.

Aranas. Bromelia.

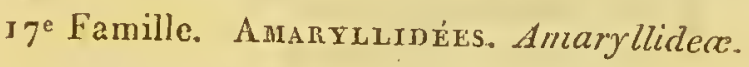

Narcissc. Narcissus.

I 8 e Famille. IRInÉE. Iriclea.

Iris. Iris.

Safran. Crocus.

19 l'amille. Amonḱ. Amornere.

Amome. Ainoinum.

Curcuma. Curcuina.

Gingembre. Zingiber.

Zédoaire. Koempferia.

20. Funille. Orenters. Orchiclea.

Orchis. Orchis.

Vanille. Vanilla. 
IV" Classe. APÉTALIE-SYMPHYSOGYNIE.

A. Fleurs non disposées en chatons.

$21^{-}$Famille. Aristolochises. Aristolochice.

Azaret. Asarum.

Aristoloche. Aristolochia.

B. Fleurs mâles disposées en chatons.

22. Famille. JuglandÉEs. Juglandea.

Noyer. Juglans.

23. Famille. Cupuliférézs. Cupuliferce.

Chêne. Quercus.

Noisetier. Corylus.

Châtaignier. Castanea.

Hêtre. Fagus.

$V$ Classe.

APÉTALIE-ÉLEUTHEROGYNIE.

A. Fleur's disposies en chatons.

$24^{\circ}$ Hamille. Coñárḱes. Coniferece.

Pin. Pinus.

Sapin. Abies.

Mélèze. Larix.

Genévrier. Juniperus.

If. Taxus.

$25^{\circ}$ Famille. Salicinézs. Salicinced.

Saule. Salix.

Peuplier. Populus.

$26^{\circ}$ Famille. Bétulacírs. Betulacec.

Bouleau. Betula.

Aune. Alnu.s.

B. Fleurs non disposées en chatons.

$27^{\circ}$ Famille.

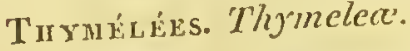

Daphné. Daphne. 
DES FAMILLES ET DES GENRES,

28. Famille. Polyconés Polygonea.

Polygone. Polygonum.

Rumex. Rumex.

Rhubarbe. Rheum.

$29^{\circ}$ Famille. Chéropodées. Chenopodece.

Arroche. Airiplex.

Épinard. Spinacia.

Ansérine. Chenopodium.

Soude. Salsola.

Rette. Beta.

Camphrée. Camphorosma.

30. Famille. Launzwées. Laurinece.

Laurier. Laurus.

3re Fanille. MYristucéEs. Mýristicea.

Miuscadier. Mrtistica.

$32^{\circ}$ Famille. Uimázír Ulmacé.

Orme. Ulmus.

33. Famille. URticḱs. Urticę.

Figuier. Ficus.

Dorsténia, Dorstenia

Mûrier. Morus.

Pariétaire: Parietaria.

Chanvre. Cannabis.

Tloublon. Humulus.

Orlie. Urlica.

34 Famille. Euphor biacḱr. Euphorbiacea.

Euphorbe. Euphorbia.

Mercuriale. Mercurialis.

Mćdicinier. Jatroplia.

Croton. Croton.

Buis. Buxus.

Ricin. Ricinus. 
$2^{\circ}$ Monopétales.

VIe Classe. MONOPETALIE-ÉLEUTHÉROGYNIE.

35e Famille. Plumbaginées. Plumbagineoe.

Dentelaire. Plumbago.

36e Famille. Nyctáméses. Nyctaginece.

Nyctage. Nyctago.

$37^{\mathrm{e}}$ Famille. Puantaginézs. Plantaginece.

Plantain. Plantago.

38 Famille. Globulariées. Globulatioe.

Globulaire. Globularia.

$39_{e}$ Famille. Scrophulartées. Scrophulario.

Véronique. Veronica.

Gratiole. Grotiola.

Serophulaire. Scrophularia.

Digitale. Digitalis.

Euphraise. Euphrasia.

$40^{\circ}$ Famille. Aganthacḱs. Acanthacece.

Acanthe. Acanthus.

$4_{1} I^{e}$ Famille. Verbenactes. Verbenacece.

Verveine. Verbena.

G $2^{\mathrm{e}}$ Famille. LabIÉEs. Labiatoe.

Romarin. Rosmarinus.

Sauge. Salvia.

Bugle. Ajuga.

Ger'mandrée. Teucrium

Menthe. Mentha.

Hyssope. Hyssopus.

Sarielte. Satureia.

Cataire. Nepeta.

Lavande. Lavandula. 
DES FAMITLES ET DES GENRES.

Gléchome. Glechoma:

Lamier. Lamium.

Bétoine. Betonica.

Marrube. Marrubium.

Ballote. Ballota.

Agripaume. Leonurus.

Thym. Thymus.

Origan. Origanum.

Mélisse. Melissa.

Mélissot. Melittis.

Basilic. Ocymum.

Prunelle. Prunella.

43. Famille. Borraginézs. Borraginea.

Cynoglosse. Cynoglossum.

Bourrache. Borrago.

Consou'de. Symphytum.

Buglosse. Anchusa.

Pulmonaire. Pulmonaria.

44 Famille. Corvolvulacḱes. Convolualacea.

Eiseron. Convolvulus.

$45^{\mathrm{e}}$ Famille. Solantes. Solanece.

Belladone. Atropa.

Morelle. Solanum.

Coqueret. Physalis.

Molène. Verbascum.

Jusquiame. Hyosciamus.

Tabac. Nicotiana.

Stramoine. Datura.

46: Famille. Jasminkes. Jasminer.

Jasmin. Sasminum.

Olivier. Olea.

Lilas. Syringa.

Frêne. Fraxinus. 
$47^{\circ}$ Famille. Grantankélentianeo.

Gentiane. Gentiana.

Erythrée. Erythraea.

Ményanthe. Menyanthes.

$48^{\mathrm{e}}$ Famille. Apocinézs. Apocinece.

Cynanque. Cynanchum.

Pervenche. Vinca.

Nérion. Nerium.

Strychnos. Strychnos.

$49^{\circ}$ Famille. Drospyréss. Diospyrece.

Styrax. Styrax.

$50^{\mathrm{e}}$ Famille. Ėricinézs. Ericinea.

Arbousier. Arbutus,

Pyrole. Pyrola.

Chimophile. Chinophila.

Rosage. Rhododendrum.

VIr Classe. IMONOPÉTALIE-SYMPHYSOGYNIE:

5I- Famille. VacGrintées. Vaccinice.

Airelle. Vaccinium.

$52^{\mathrm{e}}$ Famille. Campanulacées. Campanulaceo.

Campanule. Campanula. .

Lobélie. Lobelia.

53e Famille. Cucurbitacḱes. Cucurbïtacece.

Bryone. Bryonia.

Cucumère. Cucumis.

Courge. Cucurbita.

Pépon. Pepo.

$54^{\circ}$ Famille. Sxnanthéríes. Synantherce.

re Tribu. Carduacées. Carduacece.

Carthame. Carthamns. 
DES FAMULELS LT DES GENRES.

Chardon. Carduus.

Bardane. Arctiurn.

Centaurée. Centaurea.

Cynare. Cynara.

Carline. Carlina.

2. Tribu. Con mabifines. Corymbifera.

Camomille. Anthemis.

Millefeuille. Achillaea.

Hélianthe. Helianthus.

Absinthe. Absinthium.

Armoisc. Artemisia.

Tanaisie. Tanacetum.

Balsamitc. Balsamita.

Matricaire. Matricaria.

Souci. Calendula.

Arnique. Arnica.

Aunée. Inula.

Tussilage. Tussilago.

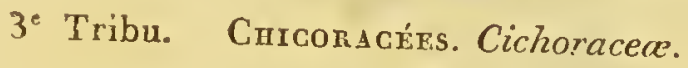

Laitue. Lactuca.

Laitron. Sonchus.

Pissenlit. Taraxacum.

Scorzonère. Scorzonera.

Salsifix. Tragopogon.

Chicorée. Cichorium.

55 Famille. Dipsácér. Dipsacea.

Cardiairc. Dipsacus.

Scabieuse. Scabiosa.

56 Famille. Valérianées. Valerianeo.

Valériane. Valeriana.

Mache. Valerianclla.

$57^{\circ}$ Famille. Rubiacées. Rubiace $a$.

Fallet. Galium. 
Aspérule. Asperula.

Garanee. Rubia.

Quinquina. Cinchona.

Caféier. Coffea.

Céphoelis. Cephoelis.

Psychotrie. Psychotria.

58e Famille. Caprifoliackes. Caprifuliacea.

Chèvrefeuille. Lonicera.

Sureau. Sambucus.

VIII Classe. POLYPÉTALIE-SYMPHYSOGYNIE-

$59^{\mathrm{e}}$ Famille. Hédéracḱes. Hederacece.

Lierre. Hedera.

$60^{e}$ Famille. Araumacées. Araliacea.

Ginseng. Pana.x.

6re Famille. Ombelurìnes. Ombelliferce.

Boucage. Pimpinella.

Carvi. Carum.

OEnanthe. OEnanthe.

Ache. Apium.

Méum. Meum.

Aneth. Ancthum.

Cumin. Cuminum.

Coriandie. Coriandrum.

Ciguë. Conium.

Éthuse. Ethusa.

Cicutaire. Cicuria.

Carotte. Daucus.

Cerfeuil. Scandix.

Selin. Selinum.

Panais. Pastinaca.

Férule. Ferula.

Angélique. Angelica.

Peree-pierre. Chrithmur.

Panicaut. Eryngium. 
62 Famille. RıвÉstées. Rïbesioe.

Groseiller. Ribes.

63e Famille. MrrtinÉ. Myrtinea.

Myrle. Myrtus.

Géroflier. Caryophyllus.

Grenadier. Punica.

IX Classe. POLYPÉTALIE-ÉLEUTHÉROGYNIE.

§ I. Étamines attachées sur le calice.

$64^{\mathrm{e}}$ Famille. SaxirnaGÉEs. Saxifragea.

Saxifrage. Saxifraga

65 Famille. Rosacŕes. Rosacece.

$1^{\text {re }}$ Sect. Fragariźes.

Fraisier. Fragaria.

Potentille. Potentilla.

Benoite. Geum.

Ronce. Rubus.

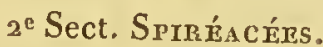

Spirée. Spiraea.

3e Sect. Agrimoniées.

Aigremoine. Agrimonia.

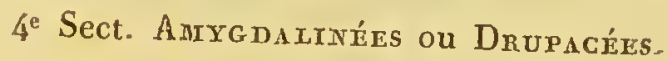

Prunier. Prunus.

- Cerisier. Cerasus.

Amandier. Amygdalus.

Pécher. Persica.

Abricotier. Armeniaca.

5e Sect. RosḱEs.

Rosicr Rosa.

6e Sect. Ponacíes.

Pommicx. Malus. 
Poirier. Pyrus.

Coignassier. Cyclonia.

Néflier. Mespilus.

$66^{e}$ Famille. Lécumineuses. Leguminosa.

I Sect. Papilionacées.

Genêt. Genista.

Lupin. Lupinus.

Bugrane. Ononis.

Arachide. Aractis.

Trigonelle. Trigonella.

Mélilot. Melilotus.

Haricot. Phaseolus.

Astragale. Astragalus.

Baguenaudier. Colutea.

Réglisse. Glycyrrhiza.

Pois. Pisum.

Fève. Faba.

Lentille. Ervum.

Ciche. Cicer.

Ptérocarpe. Pterocarpus.

Copahu. Copaïfera.

Myroxylon. Myroxylum.

$2^{\mathrm{e}}$ Sect. Cassiźes.

Casse. Cassia.

Tamarinier. Tamarindus.

Hématoxylon. Hocmatoxylum.

$3^{\text {e }}$ Sect. MriroséEs.

Acacic. Acacia.

$67^{\circ}$ Famille. Térébinthacér.s. Terebinthacece.

Sumac. Rhus.

Pistachicr. Pistacia.

Baumier. Amyris. 


\section{DES FÁMILLES ET DES GENRES.}

68 Famille. Rhannérs. Rhamnea.

Nerprun. Rharnnus.

Jujubier. Ziziphus.

Houx. Ilex.

$69^{e}$ Famille Pontulacées. Portulacece.

Pourpier. Portulaca.

$70^{\mathrm{e}}$ Famille Rexoxctuacées. Renunculaceo.

Ire Sect. Renonculées.

Renoncule. Ranunculus.

Anémone. Anemone.

Clématite. Clematis.

2 Sect. Péoníkes.

Pivoine. Pceonia.

$3^{e}$ Sect. HeLLÉBoRÉEs.

Hellébore. Helleborus.

Nigelle. Nigella.

Dauphinelle. Delphinium.

Aeonit. Aconitum.

$71^{\mathrm{e}}$ Famille. MacnoliacÉrs. Magnoliacea.

Tulipier. Lyriodendron.

Drymis. Drymis.

Badiane. Illicium.

$72^{\circ}$ Famille. Ménispermúes. Menispermece.

Ménisperme Menispernum.

$73^{\mathrm{e}}$ Famille. Bernéridées. Berberidec.

Vinettier. Berberis.

$74^{e}$ Famille. Papavéracḱes. Papaveracea.

Pavot. Papaver.

Chélidoine. Chelidonium. 
$75^{\circ}$ Famille. Fumantacées. Fumariacere.

Fumeterre. Fumaria.

76 $6^{\circ}$ Famille. Crucifìnes. Cruciferce. కre Sect. Sisymbriées.

Sisymbre. Sisymbrium. Vélar. Erysimum.

Chour. Brassica.

Roquette. Lruca.

Raifort. Raplianus.

Moutarde. Sinapis.

Cardamine. Cardamine.

ge Sect. Cochlé.lotées.

Passerage. Lepidium.

Cochléaria. Cochlearia.

Caméline. Myagrum.

$77^{\mathrm{e}}$ Famille. Capparidérs. Capparidea.

Caprier. Capparis.

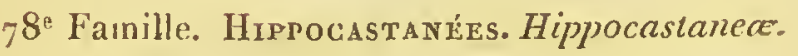

Ilippocastane. Esculus.

$79^{\mathrm{e}}$ Famille. Hyfericinét. Hypericinece.

Millepertuis. Hypericum.

80 Famille. Guttiférées. Guttifereo.

Mangostan. Garcinia.

$81^{\mathrm{e}}$ Famille. Aurantracées. Aurantiacea.

Oranger. Citrus.

82 Famille. ThÉać́es. Theacece.

Thé. Thea.

83e Fanille. Mǘnacées. Meliace

Azédarach. Melia.

Wintéranic. Winteranion. 
DES FAMILLES ET DES GENRES.

84 Famille. Viñférées. Venifera.

Vigue. Vitis.

85" Famille. Géranıáés. Geranincea.

Géranion. Geranium.

Érodion. Erodium.

Capucine. Tropaeolum.

86 Famille. OxalidéEs. Oxaliclea.

- Surelle. Oxalis.

87e Famille. Malvacées. Malvacece.

Guimauve. Althoa.

Mauve. Malva.

Cacaoier. Theobroma.

$88^{e}$ Famille TiliacéEs. Tiliacec..

Tilleul. Tilia.

89e Famille. Cistées. Cistere.

Ciste. Cistus.

$90^{\mathrm{e}}$ Famille. Vrolariées. Violaria.

Violelte. Viola.

Ionide. Ionidium.

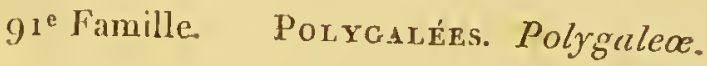

Polygala. Polygala.

Kramérie. Krameria.

$92^{\mathrm{e}}$ Famille. Simaroubées. Simarubea.

Quassie. Quassia.

Simarouba. Simarub̌a.

$9^{3}$ Famille. Rutacéss. Rutacea.

Rue. Ruta.

Dietamne. Dictamnus.

Gaïae. Guaiacum.

Cusparie. Cusparia. 
TABIE MÉTHODIQUE

$94^{\circ}$ Famille. Caryophyluées. Caryophyllece.

OEillet. Dianthus.

Saponaire. Saponaria.

- $9^{5}$ Famille. Linacées. Linacea.

Lin. Linum.

FIN DI LA TABLK METHODIQUK. 


\section{TABLE ALPHABETIQUE}

\section{DES MATIÈRES.}

A

Abiétintés.

Abricotinr.

commun.

Absinthe.

commune.

Acacia nostras.

AcaciE.

véritable.

au cachou.

du Sénégal.

Acajou, noix ( $\left.d^{\prime}\right)$.

ACANTHACÉES.

Acantur.

molle.

Ache.

odorante.

persil.

Acmelle

Aconit.

$$
\text { napel. }
$$

ACORE.

aromatique.

* ACOTylédonées, tran-

\section{TFS.}

* ACOTYLÉDONIE.

Adranthe.

capillaire clu Canada de Montpellier.

Adragant. Voy. gomme.

Adragantine.

Aganic.

$$
\text { annulaire. }
$$

Pages.

i 36 Agaric.

527 blanc.

id. brûlant.

$37^{8}$ caustique.

id. dechêne.

5 rg comestible.

584

585

587

id.

604

239

240

$24 \mathrm{I}$

462

463

46

392

$63 \mathrm{x}$

délícieux.

élevé.

faux mousseron.

da houx.

mẹurtrier.

mousseron.

de l'ulivier.

oreillette.

styptique.

* AGRIMONIÉES.

Agripaune.

cardiaque.

IGREMOINR.

$i d$ officinale.

48 Ait.

id.

15

id. Airelle.

commun.

ognon.

poireau.

ir myrtille.

42 Alchemille.

id. ALGUES.

1 ALISMACÉES.

555 Alkékenge.

r9 Alliaire.

20 AloEs.
Pages.

I9

29

23

24

29

I 9

23

20

22

id.

24

2 r

22

2 I

24

5 ×5

262

263

5.5

id.

89

id.

yx

go

342

id

$5 \times 6$

I5

73

294

$66 i_{2}$

94 
800

Aloùs.

perfolié.

en épi.

caballin.

hépatique.

lucide.

sucotrin.

AMander.

cultivé.

Aninite.

bulbeuse.

oronge.

fausse orollge.

sulfurine.

tête lisse.

venéneuse.

verdätre.

AMARYLLIDÉES.

Ainbrette.

Amini.

AMOMÉES.

Anome.

en grappe.

Amygdalées.

Anagyre.

Anavas.

comestible.

Androsème.

AnénIont.

des bois.

pulsatilie.

Aneth.

fenouil.

odorant.

Angéligue.

officinale.

Angusture fausse.

vraie.

Anis.

étoilé.

Ansérine.
TABLE AIPHABETTQUE

Pages.

94

$i d$.

id.

49

94

id. * APÉTALIE - ÉLEUTHÉRO-

id. GYNIE.

I 35

id. * APÉTALIE-SYMPHYSOGY-

523 NLE.

id. APOCINÉES.

I 20

25 ArACHID

3 I 5

${ }_{2} 6$ souterraine.

547

id.

$i d$. ARALIACEES.

$45 \mathrm{r}$

id. Anbousizr.

334

id. busserole.

335

27 Argentine.

509

26 Arguel.

3 I 7

id. ARISTOLOCHIÉES.

120

IO2 ARIstoloche. I 2 I

$736 \quad$ longue. I24

485 ronde. 122

rog serpentaire. id.

id. Anmolse.

379

id. commune. id.

5 I7 estragon. 38o

572 de Judée. . 38r

ior Arique. $\quad 387$

$i d$ des montagues. - $i d$.

685 AROIDÉES. 46

6 I9 Ав коснв.

id. des jardins. id.

620 Artichaut. 369

465 * ARTOCARPÉES.

icl. Asa fotida.

480

466 ASPARAGINÉES. 82

482 Asparagine. 84

id. Asrenge. $\delta_{2}$

603 officinale. 83

774 Aspérule. $4 \mathrm{I} 3$

456 à l'esquinancie. id.

639 odorante. $\quad$ iा 4

ijz Astragnix. 553 
DES MATIERES.

8 or

Pages.

Astragate.

554 Aunér.

Pages.

de Crète.

sans tige.

ATRIPLICÉES.

id.

officinale.

389

553 AURANTIACÉES.

id.

r69 Ara pana.

690

Avorne.

cultivée.

AU NE.

Aunéz.

commun.

65 Azaret.

393

id.

I 20

I54 AzÉDarach.

id.

commun.

id.

706

389

id.

B

Baobab.

BaDIANE.

étoilé.

Bagurnaudir. commun.

Ballote.

noire.

Balsamite.

odorante.

Barbotine,

Bardane.

officinale.

BaSILIC.

commun.

Baume de Gilead.

de copahr.

du Pérou.

de Tolu.

de la Mecque.

BAUMIER.

élémifère.

de la Mecque.

Beccabunga.

Belradone.

commune.

Belle-de-nuit.

Berr.

Benjoin.

BENOITB.

736 BenorTh.

639 officinale.

510

id. BERBERIDÉES.

id.

556 Bergumotier.

id. Bítorne.

262 officinale.

$69^{2}$

260

id. Betel.

id.

383 BrtTe.

id. ordinaire.

381 Betterave.

364 Bois.

id. du Brésil.

269

270

$14 \mathrm{I}$

566

569 BÉTULACÉES.

de Campêche.

de couleuvrée.

53

174

175

id.

337

583

580

337

572

583

570 Blé de Turquie.

I 5 r

600 Blenet.

599 Bigarndier.

60 I Bistorte.

600 boLet.

23 I

285

286

amadouvier.

comestible.

224 BORRAGINÉES.

583 Botrys.

$33_{2}$ Boucage.

5 ro anis.

70

367

692

I62

28

29

28

29

273

I 72

456

id. 
Boucage.

saxifrage.

Bouillon blanc.

Bouleau.

blanc.

Bourrache. officinale.

Brayera.

BROMELIACÉES.

Brucine.

Bryone.
Pages.

456 Bryonx.

407 blanche.

294 Bugle.

I 52

I 53

275

id. Bugrane.

538 épineuse.

100 Buis.

604 ordinaire.

350 Busserole.
Pages.

350

id.

247

id.

277

id.

546

id.

$21 \dot{4}$

id.

335

\section{$-\mathrm{C}$}

I20 Canne à sucre.

733 Canelle.

67

r $8 \mathrm{r}$

$7^{32} \quad$ girofléc. $\quad 494$

$7^{33}$ blanche.

587 Caoutchouc.

708

2 I 8

435 Capillaihe du Canada.

42

434 de Montpellier.

435 nōir.

436 CAPPARIDÉES.

38 GAPRIER.

265 épinenx.

48 CAPRIFOLIACÉES.

675 Capucine.

id. ordinaire.

372 Cardamine.

id. Cardamome.

385 grand.

373 moyen.

372 petit.

344 Cardiatri.

345 à foulon.

id. Cardon.

I84 Carnuacrirs.

I76 CARYOPHYLI,ÉES

id. Carltir.

578 Ga notrr. id.

4 I

677

678

id.

445

722

id.

670

I 10

id.

id.

id. 
DES MATIÈRES.

Caroubier.

Carpobalsainum.

Carthane.

des teinturiers.

Pages.

Carthamite.

Caryt.

$$
\text { officinal. }
$$

Casse.

canéficier.

à feuilles aiguës.

583

Chanver.

Pages.

6 r

cultivé.

I99

36r Charinon.

362

id. béni.

marie.

id.

363

id.

458 Chataignier.

366

id.

commun,

$13 x$

id.

à feuilles obtuses. $\quad 574$

* Cassiées. en bấtons.

Cassis.

Cataire.

officinale.

Cathartine.

* Caucaliónes.

Cédracier.

Céleri.

Centaurtét.

$$
\begin{aligned}
& \text { bleuet. } \\
& \text { chardon béni. } \\
& \text { chausse trappe. } \\
& \text { officinale. } \\
& \text { petite. }
\end{aligned}
$$

Celpe.

Céphelis.

Cerreutu.

ipécacuanha.

Cerister.

commun.

commun,

à grappes.

laurier-cerise.

mahaleb.

Cétérach.

Cévadille.

CHAMPIGNONS.

Champignons vénéneux.

Clianterelle.

573 Chausse-trappe.

578 Chk̂ne.

573

578

573

490

255

id.

CENOPODEES

577 CHÉROPHXLLÉES.

473 Chìvrefruilue.

693

463

365

367

366

365

368

$3 \times 3$

28

437

438

474

$47^{5}$

520

id.

$52 \mathrm{I}$

id.

Cliendent.

commun.

* CHICORACÉES.

Chicorée.

commun.

liége.

des teinturiers.

peiti.

365

$\times 28$

id.

I 29

id.

249

653

id.

769

474

445

id.

393

400

402

400

60

337

$i d$.

663

666

664

663

562

id.

472

id.

467

469

id.

id.

$47^{\circ}$

425

742 
So4

Crstr.

CISTEEES.

de Grète.

ladanifere.

Citron.

Citronnier.

Civetce.

Clatima. coralloïde.

Cuématitr.

blanche.

Cocotier.

Cocléaria.

de Bretagne. officinal.

Cocos.

Codaga-pale.

Cotgrassier. cultivé.

Coin.

COLCHICÉES.

Colchipur. d'automne.

Colombo.

Colophone.

Coloquinte.

Colza.

Concombre. CONIFÉRÉES.

Consoudr.

$$
\text { officinale. }
$$

Contrayerva. CONVOLVULACÉES.

Copahu. officinal.

Coque du Levant. Coquelicot. Coquelourde. Coguenet. allkélkeuge.
TABLE ALPITABÉTIQUE

Pages.

742 Coriandrt.

id. cultivée.

Pages.

467

468

$45 \mathrm{I}$

$37 x$

737

356

id.. Courge.

g2 callebasse.

id.

3o Cresson alénois.

672

id. de fontaine.

659

670

657

52

$35 \mathrm{I}$

352

355

354

$\begin{array}{lll}323 & \text { CUCURBITACÉES. } & 348 \\ 536 & \text { CunIN. } & 467\end{array}$

id. officinal. $\quad i d$.

id. CUPRESSINÉES. 143

75 CUPULIFĖKES. I 27

id. Curcuma. II

76 long. id.

644 rond. id.

140 Cusparie. 774

352 fébrifuge. $i d$.

666 CyMARE. $36 y$

355 artichaut. id.

I 35 cardon. 3 \%

276 Cymaneue. 3 if

id. arguel. 317

rg4 dompte-venim. 3 ro

280 ipéeacuanha. 318

565 de Montpellier. id.

566 Cynoglosse. 274

642 officinale. id.

653 Crnorhodon. 530

620 CYPÉRACEES. 5 í

293 Cytise. $\quad 57 \mathrm{I}$

294 
Daphá.

bois gentil.

garou.

lauréole.

DATTIER.

cultivé.

Dauphinexte.

consoude.

Dratecatre. staphysaigrè.

d'Europe.

DICOTYLÉDONÉES, PLANTES.

Dictajane.

de Crète.

blanc.

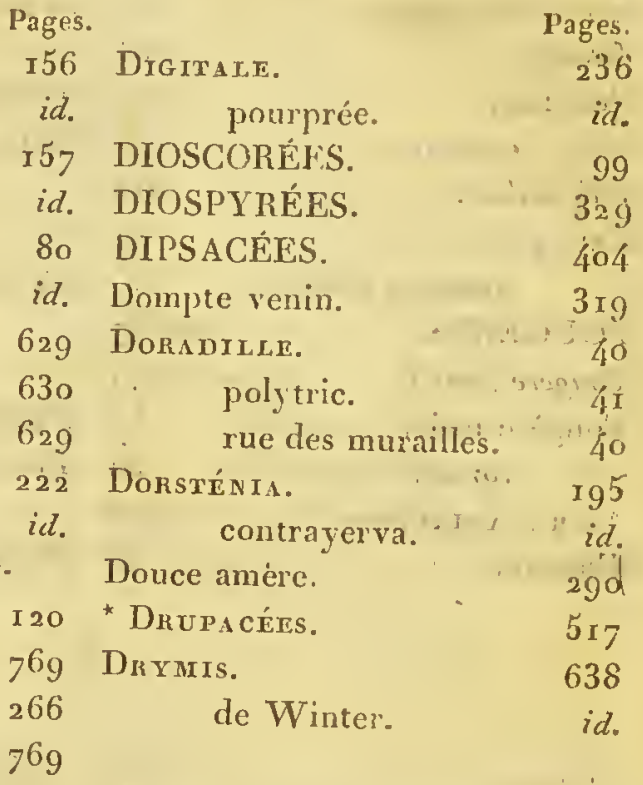

E.

İ́chalotte.

Écorce de Winter.

Ellébore blanc.

Émétine.

Encens.

Enula campana.

ÉPINARD.

commun.

Épine-vinette.

Equisétacées.

ÉRICINÉES.

Éronion.

musqué.
92 * ÉRYNGIÉES.

638 Érythrít.

77

$4^{3}$ × $45-60$

389

I 70

$\mathrm{r} 7 \mathrm{r}$

647

45

333

$72 \mathrm{r}$

id.

9 Exhuse.

Euphraist. petite centaurée. $\quad 3$ I 3

484

32

470

id.

204

205

épurge.

, 208

206

238

officinale.

id.

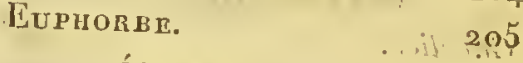

$\therefore 207$

\section{F.}

Frnouta.

Fenu grec.

465 Firule.

549 asa foctida.

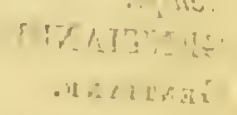

‥14s i

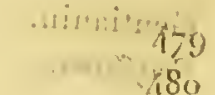


806

Fìve.

ordinaire.

Fève Saint.Ignace.

Ficairc.

Figuier.

commun.

Filipendule.

Fiuteau.

plantain d'eau.

FOUGERES.

Fougère femelle.

Fougère mâle.

rojale.

* Fragariactís.

Fragon.
TABLE ALPHABITIQUL

Pages.

560 FAGON.

id. piquant.

326 Fraisiter.

618 commun.

I93 Framboisier.

194 Frîne.

514

74

à fleurs.

id. Froment.

ordinaire.

37 cultivé.

43 rampant.

39 FUMARIACEES.

42 Funeterre.

506

officinale.

86 Fungine.

Pages.

86

id.

506

id.

$5 \times 2^{\circ}$

307

308

309

58

59

60

655

656

id.

32

G

Gä̈AC. officinal.

Galanga.

Galbanum.

Galéga.

Galiet.

jaune.

Galipot.

$$
\text { jaune. }
$$

Garance.

des teinturiers.

Gattilier.

Gexît.

des teinturiers.

Grifévriter.

commun. sabine.

Genipi.

GENTIANEES.

Gentiane.

jaune.

Gentianin.

Geoffroia.
771 GÉRANIACÉES.

717

id. Geranion.

719

II $4^{\circ}$ musqué.

$73 I$

573 Germandrée.

$4 \mathrm{I}^{2}$

id.

I 39

415

id.

243

543

544

I 43

id.

144

376

3 ro

aquatique.

ivette.

marum.

musquée.

petit chêne.

Géroflier.

aromatique.

Gingtambre.

officinal.

Ginseng.

à cinq feuilles.

Gléchome.

hédéracé.

id. GLOBULARIÉES.

id. Globulairu.

3I I turbith.

$57 x$

vulgairc.
476 lierbe à Robert. 7 I9
248

250

id.

248

$25 \mathrm{I}$

249

$49^{5}$

id.

I 12

id.

452

id.

257

258

227

22.8

id.

229 
Goiave.

Gomme adragant. ammoniaque. arabique. du Sénégal. gutte.

kino. de lierre.

Goudron.

Gouet.

ordinaire.

Graines d'Avignoin. de paradis.

Gratiole.
DES MATIÉRES.

Pages.

500 Gratrole.

554 officinale.

477 Grenade.

585 Grenadrer.

587 commun.

687 Grosextler.

444 épineux.

$45 \mathrm{r}$

I 40

46

47

608

I 10

57

233 Gutrmères.
So7

Pages.

233

id.

499

497

id.

488

id.

490

489

66

728

id.

730

686

H

HARYCOT.

HÉDÉRACÉES.

commun.

HéLIANTHE.

tubéreux.

Hellébiore.

blanc.

noir.

Helminthocorton.

Helvelle.

ordinaire.

HÉma Toxylon. de Campêche.

Hépathiques.

HêtrR.

55. HÊTRE.

id. des forêts.

$\times 32$

449 Hrppocastiane.

id

$68 \mathrm{r}$

$376 \quad$ commun. $\quad 682$

377 HIPPOGASTANÉES. 680

625 Houblon. 2 $20 \mathrm{I}$

77 ordinaire. id.

625 Houx. 6 ro

r6 épineux. id.

$3 \mathrm{r}$ petit. 86

id. HYPÉRICINÉES. 683

$58 \mathrm{r}$ IIjpociste. $\quad \mathrm{24}$

id. * HYPOXYLÉEs. 44

44 Hrssope. 253

132 officinal. id.

I

Is.

cominuil.

Impératoirc.

Indigo.

145 Indigotier.

146 lode.

572

485 IONIDE.

573 Ipecacuanha.

17

750

id. 
Pages.

Ipécacuanha annclé.

438
blanc. gris.

noir.

IRIDÉES. strié.

IrIs.

d'Allemagne.

75 I IRIS.

438

440 Ivelle.

de Florence.

Pages.

ฯ 05

ro6

des marais.

105

il. musquée.

250

ro4 IvRaIE.

ro5 enivrante.

$25 \mathrm{r}$

6 I

id.

г 06

\section{$\mathrm{J}$}

Jalap.

28 JUJUBter.

ramiose.

JASMINÉES.

J ASMIN.

officinal.

JUGLANDÉES.

Jujube.

$\begin{array}{rc}28 \text { I } & \text { JUJUBIER. } \\ 50 \text { I } & \text { officinal. } \\ 303 & \text { JUSQUIAME. } \\ 304 & \text { noire. } \\ i d . & \text { blanche. } \\ 124 & \text { jaune. } \\ 609 & \end{array}$

$6 \circ 9$

$i d$.

296

id.

297

id.

K.

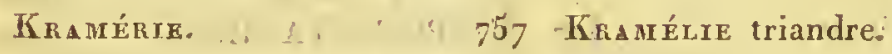

\section{L}

LABIEES.

Ladanum.

Laiche. des sables.

LATRON.

cominun.

Latue.

cultivéc.

vireuse.

Laminer.

blanc.

Laque.

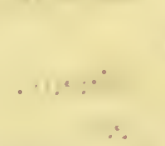

$\therefore \quad \therefore \frac{743}{55}$

'LAURIER.

178

43 amandier. .51

55

avocatier.

$r 88$

305

$39^{6}$

393

394

393

258

259

213

LAURINEES.

$x 78$

LaUnien.

id.

benjoin.

id.

camphrier. ... $\quad 184$

cannellier. I $8 \mathrm{I}$

casse.

$\mathrm{x} 8_{7}$

cerise.

$52 \mathrm{I}$

culilawan.

$\mathrm{r} 87$

à feuilles longues. id.

pichurim. $\quad$ I8S

rose. , $32 \mathrm{r}$

ordinaire. $\quad 179$

sassafras. $\quad$ I 82 
LVANDR.

officinale. spic.

IÉGUMINEUSES.

bentille.

ordinaire.

ICHENEES.

ichen aphiheux.

d'Islande.

pulinonaire.

pyxidé.

LIERRE.

grimpant.

terrestre.

Lilss.

LILIACÉES.

ordinaire.

Limettier.

Limonier.

LIN.
DES MATIERES.

Pages.

256 LIN.

id. cathartique.

257 usuel.

54 I LINACÉES.

56 I LIs.

id.

34

36

34

36

36

450

id.

258

306

id.

88

$6 y^{2}$

$693 .-696$

780 Lycopodrackés.
809

Pages.

780

$7^{82}$

$78 \mathrm{x}$

780

88

id.

280

284 .

28 I

284

284

282

283

485

346

id.

$69^{3}$

545

id.

44

M

$\mathrm{MACHF}_{\mathrm{A}}$

$$
\text { cultivée. }
$$

Maïs.

cultivé.

MACNOLIACÉES.

MAL, VACEES.

Mandiagrire.

Mangosin.

Maniguette.

$$
\text { guttier. }
$$

Manue.

Manne de Briancon.

Mannite.

Masjolaine.

Marmonier d'Inds.

Marrube.

cummun.

4 ro Marum.

id. Mastic.

7o Matricarre.

id. camomille.

635 officinale.

727 Mauve.

288

687

id. Méchnacen.

I

$3 \cup 8$

$\times 43$

308

267

682

MIIACÉES.

26 . Mélilox.

bleu.
248

598

384

385

384

$73 \mathrm{r}$

$73 \mathrm{r}$

732

284

210

2 I 2

2 II

If 1

142

705

550

$55 x$ 
810

MÉLILOT.

officinal.

MíxIsse.

officinale.

MÉLIssot.

Melon.

à feuilles de mélisse.

Melongène.

MENISPERMÉES.

Ḿ́nisframe.

columbo.

Menthe.

coque du Levant.

crépue.

élégante.

poivrée.

verte.

Ményanthe.

trèfle d'eau.

Mercuriale.

annuelle.

Merisier.

Mérule.

chanterelle.

MEUM.

officinal.

MILLEFEUILLE.

commune.

plarmique.

MiLLePERTUIs.

ordinaire.

* Mrmosées.

Mirobolans emblics.

MoLÈn B.

bouillon blanc.

TAELE ALPHABÉTIQUE

Pages.

550 NONOCOTYLEDDONÉES

$550 \quad$ TES.

267 MONO.ELEUTHEROGYNIE. 1.

268 MONOPÉTALES.

2 I

id. * MONOPÉTALIE-ÉLEUTH]-

id. ROGYNIE.

354 * MONOPÉTALIE-SYMPHY.

357 SOGYNIE.

$3 / 4$

29 I MONO-SYMPHYSOGYNIE. 9 ?

64 I Morelle.

642 douce-amère.

644 mélongène.

$28 \mathrm{~s}$

noire.

$2 y \mathrm{C}$

642

251

253

Morille.

tubéreuse.

252

ordinaire.

$29 \mathrm{I}$

2,42

289

30

25 r Moussis.

3 I

253 Mousse de Corse.

44

3 I 4 Moutarde.

id. noire.

669

209 Muguet.

id.

id. de mai. id.

52 I Muritr.

${ }_{96}$

3o noir. $\quad$ I97

id. Muscadier.

464 aromatique.

I 89

id. MYRISTICÉES.

id.

374 Mrnoxylon.

I 89

568

id. baumier. id.

375 Myrrhe. 602

684 MчRте. 494

id. carrophyllé. id.

584 commun. 493

218 piment. . 494

294 Myrtille. 342

id. MYRTINÉES. $49^{2}$

$\mathbf{N}$

NARCISSE.

Io3 Navet.

663

des prés.

id. Níflitr.

$53-$ 
DES MATIÉRES.

Néflier.

Pages.

NÉNUPHAR.

commun.

537 Nigende cultivée.

Pages.

id. Norsexrek.

627

97 commun.

13 o

98 Noix de Galles.

blanc.

jaune.

Néphrodr.

id. Noix vomique.

39 Noyer.

Nérion.

fougère mâle.

Ner PRUN.

laurier-rose.

Nigelie.

cathratique.

321 Nyctagr.

id. belle de nuit.

607 NYCTAGINÉES.

id. Nympher.

627 NYMPHÉACÉES.

id.

I 29

323

ז 25

id.

224

id.

223

98

97

O

OEillet.

des jardins.

OEtanthe.

phellandre.

safranée.

Ognon coininun.

dc lis.

de scille.

Oliban.

Olivier.

d'Europe.

OMBELLIFE'RES.

Opium.

Opopanax.

Oranger.

ordinaire:

ORCHIDÉES.

Orchis.

mâle.

Onge.

cultivé.

mondé.

perle.

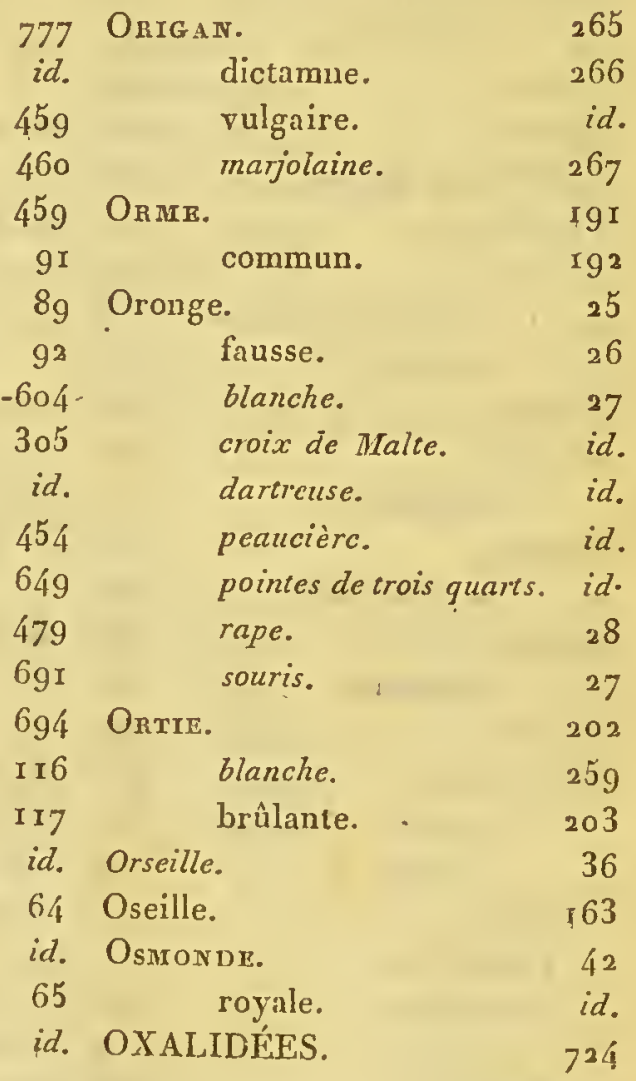


Pain de cassave. PALMIERS.

Panais.

cultivé.

opopanax.

Panicaut.

des champs.

PAPAVÉKACÉES.

* Papilionacées.

Pareira-brava.

Pariétaire.

officinale.

Palate.

Patience.

Palience aqualique.

Passeragr.

Pavot.

$$
\text { coquelicot. }
$$

somnifère.

Pastèque.

Pêcher.

commun.

Pípon.

à gros fruits.

Perch-pierre.

Persil.

commun.

Pervenche.

grande.

petite.

\section{Pétasite.}

Petil chênc.

Peuplien.

noir.

Phellandie.

Pignons doux.

d' Inde.

- Prapintalérs.
$\mathrm{P}$

Pages.

2 I I Pimprenelle.

79 PIN.

478 maritime.

id. pignon.

479 sauvage.

484 Piperin.

id. PIPERINÉES.

648 Pissentit.

543 commun.

645 Pistachiek.

I98। franc.

id. lentisque.

284 térébinthe.

r65 Pryorne.

I66 officinale.

67 I PLANTAGINÉES.

649 Plantain.

653

649

357

$5_{2} 6$ PLUMBAGINÉES.

id. Poircan.

358 PoIrier.

id. commoun.

483 Pors.

id.

462

3 I

$3 \% \mathrm{I}$

$3_{20}$

392

233

r5o

id. Poix blanchc.

4 Go jaune.

${ }^{3} 37$ noire.

¿12 Polycroïte.

POLYGALÉES.
Pages.

5 I 6

r 36

I38

r36

I38

52

49

396

397

596

id.

598

597

623

id.

225

226

id.

74

227

22 I

90

534

535

558

562

559

50

52

$5 \mathrm{r}$

$5 \mathrm{I}$

r6I

$5 \mathrm{r}$

I39

id.

I 40

ros

$7^{53}$ 


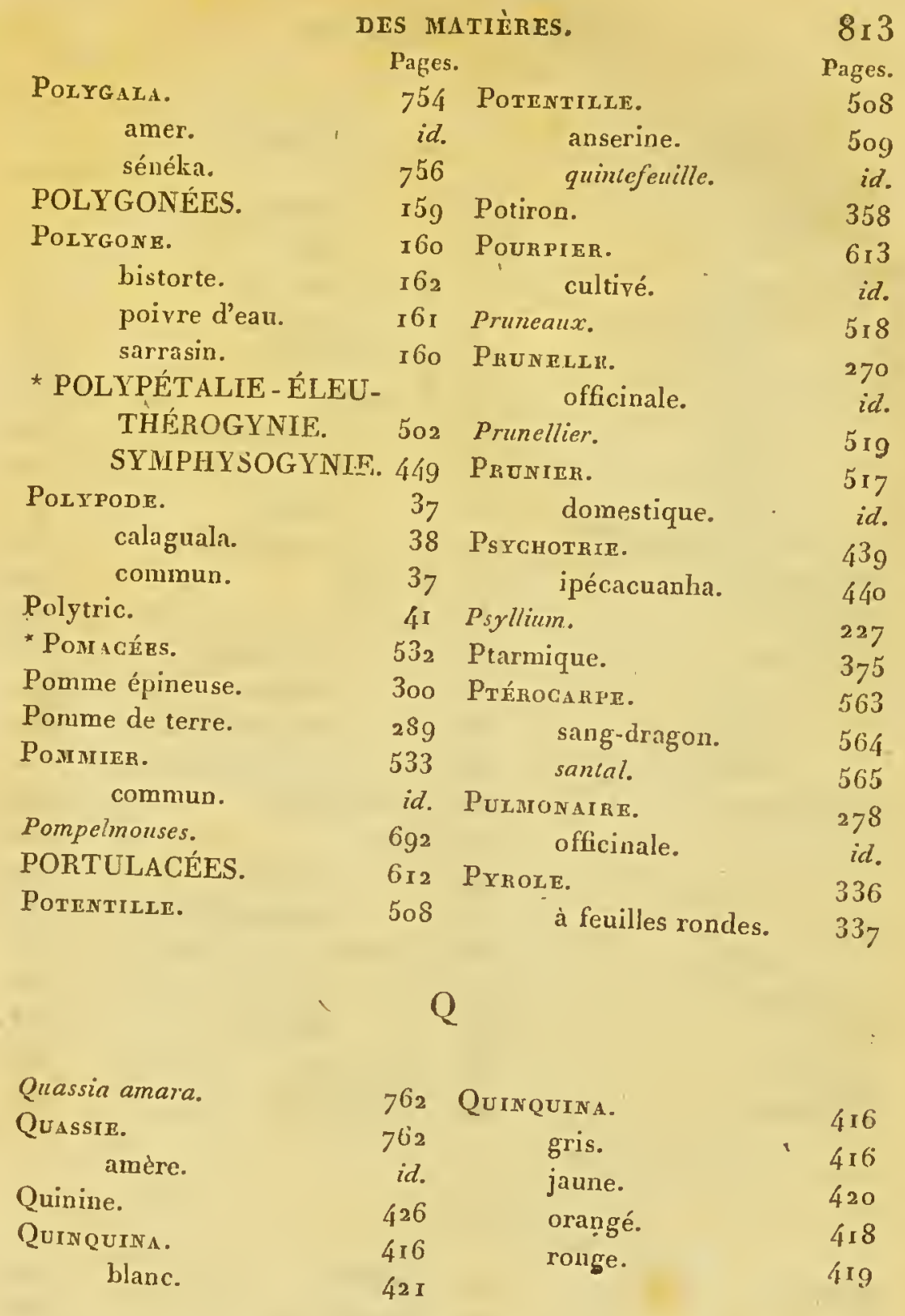

\section{R}

radis.

Raifort.

$$
\text { noir. }
$$

cultivé. 
814

Réglisst.

officinale.

RENONCULACÉES.

Renoncule.

âcre.

bulbeuse.

flammule.

scćlérate.

Résine aconchi.

animée.

chibou.

élémi.

tacamahaca.

RHAMNÉES.

\section{Rhapontic.}

RHUBARBE.

palmée.

de la Chine.

de Moscovie.

RIBÉSIEEES.

Ricin.

or dinaire.

Riz.

cultivé.

Rocambolle.

Rocout.

Rocouyer.

Romarin.

TABI,E ALPMABÉTYQUE

Pages.

557 Ronianin.

Pages.

id. officinal.

244

6 I4 Roncr.

6 r5 du mont Ida.

245

5 I 2

616 comenune.

6 r5 RoQuette.

$5 \times 7$

culiivéc.

id.

514

667

id. ROSACÉES.

id.

605 Posage.

504

583

605 Roseav.

ferrugineux.

339

$60 x$ àbalais.

id.

604

à quenouilles.

66

606 Rosízs.

67

I66 Rosier.

57

ז66

de France.

529

id.

id.

id. des quatre saisons. $\quad 532$

id. à cent feuilles.

id.

487 RUBIACÉES.

$4 \mathrm{Ix}$

2 I6 Rus.

id.

odorantc.

767

768

69 desmurailles. 40

id. Rumex.

г 63

92 oseille. id.

741 patience. $\quad$ 665

740 Rutabaga.

666

244 RUTACÉES.

S

Sabine.

Satran. cultivé.

Sagou.

Salep.

SALICINEES.

Salsepareille.

Satsifix.

sauvage.

I 44 Sanicle.

485

I07 Sang dragon.

id. Sanial ronge.

565

8I Santolinc.

$39^{2}$

II SAPIN.

147 commun.

ז 40

I $4 \mathrm{I}$

85 Saponatre.

$77^{8}$

399

officinale.

id. Sarrietti.

id. 254 
DES MITIÉRES.

Sarkiette.

des jardins.

Sarrasin.

des montagnes.

Sassafias.

Sivge.

officinale.

Sa Ule.

blanc.

Saxifrage.

granulé.

SAXIFRAGÉES.

ScaBIIUSE.

des champs.

Succise.

Scammonée d'Alep. de Smyrne.

Sceau de Salomon.

Scille.

Scillitine.

officinale.

Scolopendre.

Scordium.

Scorzonire.

d'Espagne.

SCROPHULARIÉES

Scrophulatre.

aquaiture.

noucuse.

SEIGLE.

Seltar.

cultivé.

ergoté.

galbanum.

gummifere.

SÉLINŔES.

Seinen contra.

Sementine.

Sené.

Seneçon.

Seneka.
Pages.

254 Serpentaire de Virginie.

Pages.

id. Serpollet.

I 22

264

255 Sévadille. Voy. Cévadille.

r6o Simatrouba. $\quad 764$

r8 a de Cayenne. id.

246 ' SIMAROUBÉES. $\quad 760$

id. Srsyabre. 659

r 48 cresson de fontaine. 659

I 48 officinal. 660

503 SISYMBRIÉES. - 659

id. Smilax. 85

5оa Salsepareille. id.

$406 \quad$ Squine. 86

id. SOLANÉES. 285

407 Soucher. 54

283 comescible 55

id. long. $\quad 54$

85 rand. 55

92 Soucr. 386

id. officinal. id.

$9^{3}$ Soude. $\quad 7^{3}$

43 vulgaire. id.

250 Spartier. 572

398 SPIRÉaĆES. 5 ז4

id. Squine. 86

23o Staphysaigre. 629

234 Statice. 223

236 Storax. 33 I

235 Sríanorne.

$62 \quad 299$

id Strychine.

pomme épineuse. 300

63 Struchios. 324

$47^{5}$ fève St.-Ignace. $\quad 326$

476 noix vomique. $\quad 323$

477 StrRax. 330

475 benjoin. $33_{2}$

38 r officinal. 33 I

38 r Sucre. 68

575 Sunrac. $\quad 593$

$\begin{array}{ll}39^{3} & \text { vénéneux. } \\ 756 & \text { Sunkau. }\end{array}$

446 
Sureau.

Pages.

446 SURvile.

Pages.

4 in

725 SYNANTHËRÉES.

SURRLLE.

\section{$\mathrm{T}$}

Tabac. ordinaire.

Tamarin.

Tamarimier. de l'Inde.

Taminier. cornmun.

Tapioka.

* 'IAXINÉES.

TEREBEN'THACEES

Térébenthine du pin. de Chio. essence de de Strasbourg. de Venise.

ТнЕ́.

de la Chine.

'THÉACÉES.

Tuxm.

calament.

297 Тнута.

263

id. serpollet.

580 - vulgaire.

263

57.9 THYMELEES.

156

id. TLIIACEES.

738

99 Tilleul.

$7^{3} 9$

id.

d'Eturope.

id.

2 I2 Topinambur.

377

145 Tormentille.

509

$59^{2}$ Tournesol.

$2 \pi 4$

I38 Trèfie d'eau.

$3 \mathrm{I} / 4$

597 Trigonille.

549

I59 fenu grec.

I 4 I Tauré.

id.

3 I

$3_{2}$

142 blanche.

$3 \mathrm{I}$

699 noire.

636

id. Tulipien.

id.

698 ordinaire.

$3 g$ I

263 Tussilage.

265

commun.

id.

\section{U}

ULMACÉES.

Ulmaire.

Ig Upas lieuté.

328

514 URTICÉES.

\section{V}

VACCINIÉES.

VALÉRIANR. officinale.

VALERIANÉES.

VANILIE.

342 officinale.

id.

408 Varee vermifugc.

I6

id. Varce vésiculeux.

17

407 V'́LAR.

$66 \mathrm{r}$

I 8 alliaire.

662 
DES MATIÉRES.

Pages.

VÉLAR.

de Sainte-Barbe.

V'ERATRE.

blanc.

cévadille.

Vératrine.

VERBENACÉES.

Verge d'or.

Verjus.

VéroNiqú.

beccabunga.

officinale.

petit chêne.

VERVEINE.

66 r Vrefeine.

id. officinale.

77 Vigne.

id. cultivée.

$i d$ Vinteter.

78 commun.

$24 \mathrm{I}$ Vin.

$39_{2}$ Vinaigre.

7I3 VINIFÉREES.

23 I VIOLARIÉES.

id. Violftre.

${ }_{2} 32$

233

242

des champs.

ipécacuanha.

odorante.

\section{W X}

708 XYlobalsamum.

id.

Wintéranie.
canelle blanclie.

\section{$\cdot \mathrm{Z}$}

Ż́DOAIRE.

galanga.

longue.

\section{3 Z'́doAIRE.}

I 13

I 4 officinale.

id.

id.
$60 \mathrm{I}$

817

Pages.

242

id.

7 II

id.

647

id.

7 I 2

7 I 7

7 ro

744

746

748

750

746

FIN DE LA TABLE DES MATIĖRES.

Nola. Dans eette Table, les noms de elasses ou de familles sont éerits en capitales; ecux de genres en petites eapitales; ceux des médieamens ou des éerit en ilalique les synonymes, les tion eomplète, en romain; enfin on des fait mention sans en donner uue deseriptionens ou les espèees dout il est 


\section{CORR I GENDA.}

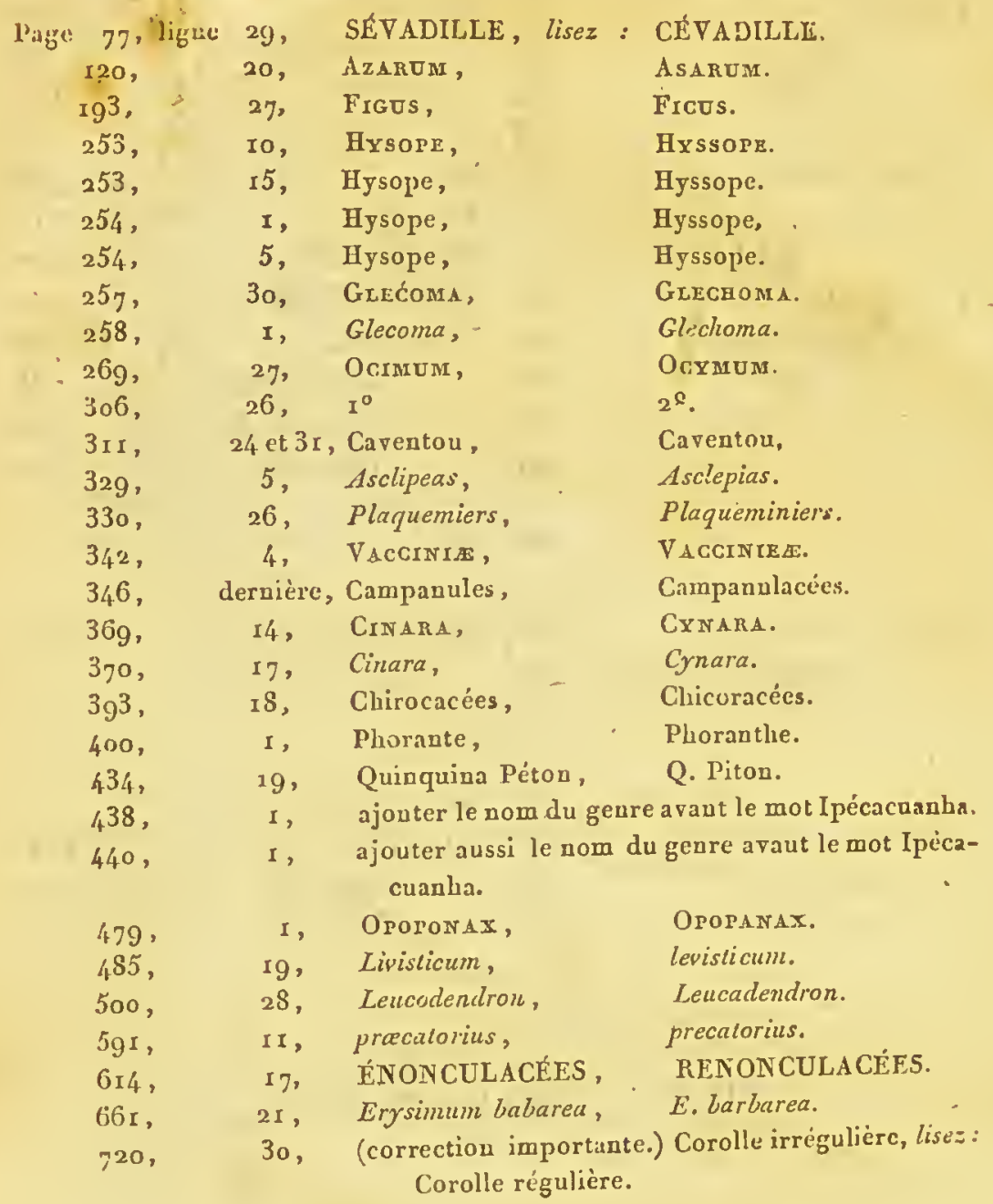




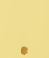
- 
, 


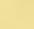




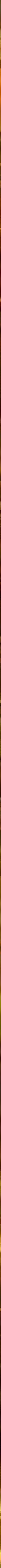

